\title{
Ecological Evaluation of Proposed Dredged Material from Richmond Harbor Deepening Project and the Intensive Study of the Turning Basin
}
M. R. Pinzá
P. J. White
H. L. Mayhew
J. Q. Word
E. M. Karle
L. L. Michaels
N. P. Kohn

June 1995

Battelle/Marine Sciences Laboratôry

Sequim, Washington

Prepared for the

U.S. Army Corps of Engineers -'San Francisco District under a Related Services Agreement with

the U.S. Department of Energy

under Contract DE-AC06-76RLO 1830

Pacific Northwest Laboratory

Operated for the U.S. Department of Energy

by Battelle Memorial Institute 


\section{DISCLAIMER}

This report was prepared as an account of work sponsored by an agency of the United States Government. Neither the United States Government nor any agency thereof, nor any of their employees, make any warranty, express or implied, or assumes any legal liability or responsibility for the accuracy, completeness, or usefulness of any information, apparatus, product, or process disclosed, or represents that its use would not infringe privately owned rights. Reference herein to any specific commercial product, process, or service by trade name, trademark, manufacturer, or otherwise does not necessarily constitute or imply its endorsement, recommendation, or favoring by the United States Government or any agency thereof. The views and opinions of authors expressed herein do not necessarily state or reflect those of the United States Government or any agency thereof. 


\section{DISCLAIMER}

Portions of this document may be illegible in electronic image products. Images are produced from the best available original document. 
PNL-10627

UC-600

\section{ECOLOGICAL EVALUATION OF} PROPOSED DREDGED MATERIAL FROM RICHMOND HARBOR DEEPENING PROJECT AND THE INTENSIVE STUDY OF THE TURNING BASIN
M. R. Pinza
H. L. Mayhew
L. M. Karle
N. P. Kohn
P. J. White
J. Q. Word
L. L. Michaels

Battelle/Marine Sciences Laboratory

Sequim, Washington

June 1995

Prepared for the U.S. Army Corps of Engineers - San Francisco District under a Related Services Agreement with

the U.S. Department of Energy

Contract DE-AC06-76RLO 1830

Pacific Northwest Laboratory

Richland, Washington 99352 



\section{SUMMARY}

Richmond Harbor is located on the eastern shoreline of central San Francisco Bay in Richmond, California. The Richmond Harbor access channels and several of the shipping berths are no longer wide or deep enough to accommodate modern deeper-draft vessels. The Water Resources Development Act of 1986 (Public Law 99-662) authorized the U.S. Army Corps of Engineers (USACE), San Francisco District to deepen and widen the navigation channels in Richmond Harbor. Several options for disposal of the material from this dredging project are under consideration by USACE, as follows: disposal within San Francisco Bay, at open-ocean disposal-sites, or at uplands disposal sites.

The purpose of this study was to conduct comprehensive evaluations, including chemical, biological, and bioaccumulation testing of sediments in the selected areas of Richmond Harbor. This information was required by the Environmental Protection Agency (EPA) and the USACE in order to evaluate the suitability of sediments in these areas for unconfined aquatic disposal.

Battelle/Marine Sciences Laboratory (MSL) collected 20 core samples, both 4-in. and 12-in., to a project depth of $-40 \mathrm{ft}$ mean lower low water (MLLW) ( $-38 \mathrm{ft}$ MLLW plus $2 \mathrm{ft}$ of overdepth) using a vibratory-hammer core. These 20 field samples were combined in the laboratory to form five test composites plus an older bay mud (OBM) composite that were analyzed for physical/chemical parameters, biological toxicity, and tissue chemistry parameters following the EPAUSACE guidelines called Evaluation of Dredged Material Proposed for Ocean Disposal (Testing Manual). Solid-phase tests were conducted with the amphipod, Rhepoxynius abronius, the clam, Macoma nasuta; and the polychaete worm, Nephtys caecoides. Suspendedparticulate-phase (SPP) tests were conducted with the sanddab, Citharichthys stigmaeus, the mysid, Holmesimysis costata; and the bivalve, Mytilus galloprovincialis. Bioaccumulation of contaminants was measured in tissues of Macoma nasuta and Nereis virens.

Sediments from one ocean reference sediment, the Deep Off-Shelf Reference Area (R-OS), and two in-bay reference sediments, the Bay Farm Borrow Area (R-BF) and the Alcatraz Environs Reference Area (R-AM), were tested concurrently. Results from analysis of the five test treatments were statistically compared with the reference sediment R-OS in the first five sections of this report. Appendixes $Q$ and $R$ contain the comparisons of the test treatments with reference sediments R-BF and R-AM, respectively.

The solid-phase tests for Richmond Harbor sediments show acute toxicity to $R$. abronius exposed to test treatment TB Lower COMP when compared with effects from the reference sediment R-OS. Test treatments SF COMP, SFW COMP, and OBM COMP were acutely toxic to $N$. caecoides relative to the reference sediment $R-O S$. The Richmond Harbor test treatments UIH COMP and TB Upper COMP were not acutely toxic to any of the solid-phase test species. 
The results of the $C$. stigmaeus and $H$. costata SPP tests showed no statistically significant difference between the $0 \%$ and $100 \%$ SPP for any test treatment. The results of the M. galloprovincialis SPP test showed no statistically significant difference (as defined by embryo survival) between the $0 \%$ and $100 \%$ SPP for test treatments SFW COMP and TB Upper COMP. None of the survival results for $M$. galloprovincialis was below $50 \%$; therefore, $L C_{50}$ values could not be calculated. Analysis of normal larval development for M. galloprovincialis showed statistically significant toxicity in the 100\% SPP of test treatments SFW COMP, UIH COMP, TB Upper COMP, and TB Lower COMP relative to the $0 \%$ SPP. The $\mathrm{EC}_{50}$ values that were below $100 \%$ SPP were as follows: $80 \%$ SPP for SFW COMP, $57.6 \%$ SPP for UIH COMP, $74.8 \%$ SPP for TB Upper COMP, and $69.7 \%$ SPP for TB Lower COMP. Inhibition of normal larval development could have been largely attributed to ammonia released from the sediment into the SPP of the SFW COMP, UIH COMP, and the TB Lower COMP. The mean percentage of normal larvae for these composites is within the range of expected effects caused by ammonia. This is not the case for TB Lower COMP; the $E_{50}$ value is below the $95 \%$ confidence interval for ammonia, suggesting that contaminants other than ammonia could have been responsible for the reduction in the percentage of normal larvae present in the $100 \%$ SPP of this composite.

M. nasuta and $N$. virens tissue contaminant concentrations were one to five orders of magnitude below the Food and Drug Administration action limits for fish and shellfish after exposure to Richmond Harbor sediments. However, specific contaminants in tissues exposed to the test treatments were statistically significantly elevated when compared with the concentrations in the tissues exposed to the reference treatment R-OS.

Nine high molecular weight polyaromatic hydrocarbons (HPAHs), at least one pesticide (4,4'-DDD, 4,4'-DDE, 4,4'-DDT, and dieldrin), and one metal (lead) showed statistically significant bioaccumulation in M. nasuta tissues exposed to SF COMP, SFW COMP, UIH COMP, and TB Upper COMP relative to that in tissues exposed to R-OS. The pesticides found in $M$. nasuta tissues exposed to SF COMP, SFW COMP, and UIH COMP were elevated at levels ranging from $<2$ to 470 times those in the $M$. nasuta tissues exposed to reference treatment R-OS. M. nasuta tissues exposed to three test composites, SF COMP, SFW COMP, and UIH COMP, had HPAH concentrations that were elevated to levels greater than 10 times and up to 78 times higher than those found in the tissues exposed to R-OS.

Similarly, in N. virens tissues, the same groups of compounds bioaccumulated with statistically significant elevations relative to those exposed to R-OS. The HPAHs and at least one pesticide (4,4'-DDT, 4,4'-DDD, 4,4'-DDE, and dieldrin or aldrin) were the most prevalent contaminants in $N$. virens tissues exposed to SF COMP, SFW COMP, and UIH COMP, relative 
to those in tissues exposed to the reference treatment R-OS. In tests using these three composites, 4,4'-DDD was elevated in $N$. virens tissues to levels greater than 10 times and up to 110 times higher than those in $N$. virens tissues exposed to R-OS.

The results from the 10-day acute toxicity test with $R$. abronius showed acute toxicity to sediments from TB Lower COMP. A review of the sediment chemistry data showed that most of the contaminants were associated with station TB-4. Because the Turning Basin represents a large quantity of dredged material, approximately 333,500 cubic yards of sediment, the USACE and EPA decided that more definitive testing was necessary to characterize the extent of contamination in this area. This testing will be referred to throughout the report as the Intensive Study of the Tuming Basin. MSL staff collected nine cores from the Turning Basin; these nine cores consist of the seven stations originally tested plus two additional stations, TB-8 and TB-9, located to the northeast and southwest of station TB-4. For comparison purposes, sediment was also collected and tested from the three reference areas (R-OS, R-BF, and R-AM) and two control areas (C-WB and C-SB).

Solid-phase toxicity tests were conducted with the amphipod $R$. abronius in three separate experiments: a standard 10-day test, an ammonia reduction to $<20 \mathrm{mg} / \mathrm{L}$ test, and an ammonia reduction to $<15 \mathrm{mg} / \mathrm{L}$ test. The results from the standard 10-day test showed that six test treatments were acutely toxic to $R$. abronius relative to $R-O S$. These test treatments are TB-2 Lower, TB-3 Lower, TB-5 Lower, TB-7 Lower, TB-8 Lower, and TB-9 Lower. The results for the ammonia reduction to $<20 \mathrm{mg} / \mathrm{L}$ tested showed only one test treatment, TB-3 Lower, was acutely toxic to $R$. abronius when compared with R-OS. The results of the ammonia reduction to $<15 \mathrm{mg} / \mathrm{L}$ showed that TB-3 Lower, TB-7 Lower, TB-8 Lower, and TB-9 Lower were not acutely toxic to $R$. abronius when compared with R-OS. Once the ammonia was reduced to $<20 \mathrm{mg} / \mathrm{L}$ or $<15 \mathrm{mg} / \mathrm{L}$ in all test treatments, no acute toxicity to $R$. abronius was observed when compared with the effects to $R$. abronius exposed to R-OS. These results suggest that ammonia could have contributed to the observed toxicity of the test sediments. Ammonia is considered to be a nonpersistent compound and is not a chemical of concern for evaluation of sediment for disposal at R-OS. If the results of all three experiments are used to evaluate suitability of Tuming Basin sediments, then none of the Tuming Basin stations are acutely toxic to $R$. abronius relative to R-OS. 


\section{CONTENTS}

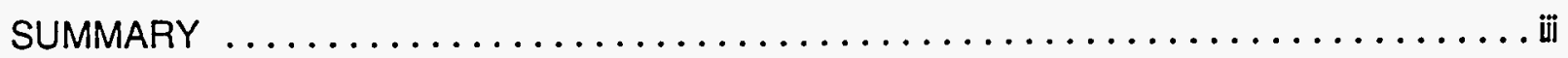

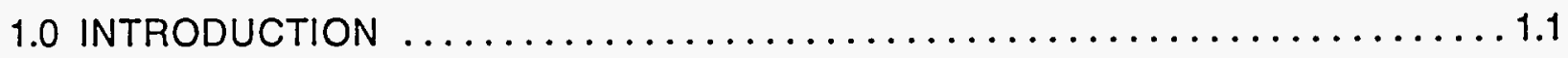

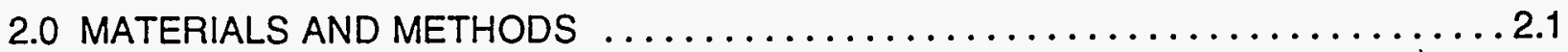

2.1 SEDIMENT AND TEST ORGANISM COLLECTION $\ldots \ldots \ldots \ldots \ldots \ldots \ldots 2.1$

2.1.1 Richmond Harbor Core Samples $\ldots \ldots \ldots \ldots \ldots \ldots \ldots \ldots \ldots \ldots \ldots \ldots \ldots \ldots$

2.1.2 Reference and Control Samples . . . . . . . . . . . . . . . . . 2.4

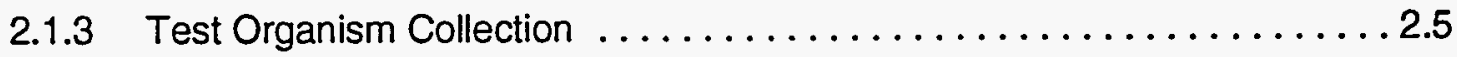

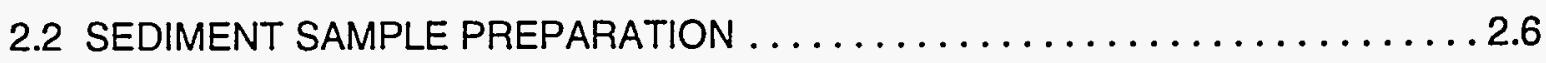

2.2.1 Laboratory Glassware and Equipment Preparation ............. 2.6

2.2.2 Geologic Description of Cores ........................

2.3 SEDIMENT AND TISSUE CHEMISTRY PROCEDURES $\ldots \ldots \ldots \ldots \ldots \ldots 2.7$

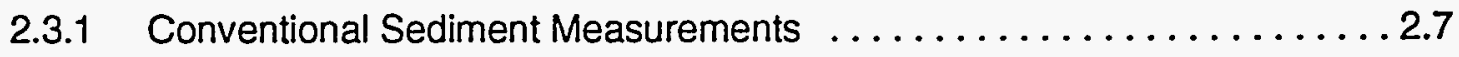

2.3.2 Semivolatile Organic Compounds ...................... 2.11

2.3.3 Chlorinated Pesticides and PCBs $\ldots \ldots \ldots \ldots \ldots \ldots \ldots \ldots \ldots \ldots \ldots \ldots \ldots \ldots$

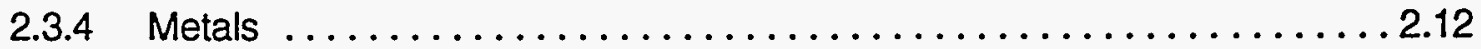

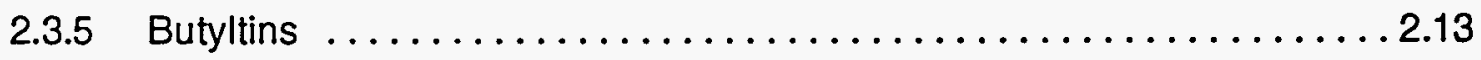

2.3.6 California Waste Extraction Test (WET), Soluble Threshold Limit Concentration (STLC), Metals, Hexavalent Chromium and STLC, Pesticides, and PCBs ...................................

2.3.7 Preparation of Solid-Phase Samples $\ldots \ldots \ldots \ldots \ldots \ldots \ldots \ldots \ldots .2 .14$

2.3.8 Preparation of Suspended-Particulate-Phase Samples $\ldots \ldots \ldots \ldots \ldots 2.14$

2.4 TOXICOLOGICAL TESTING PROCEDURES $\ldots \ldots \ldots \ldots \ldots \ldots \ldots \ldots \ldots \ldots \ldots \ldots \ldots$

2.4.1 10-Day Solid-Phase Static Test with $R$. abronius $\ldots \ldots \ldots \ldots \ldots \ldots .16$

2.4.2 10-Day Solid-Phase Flow-Through Test with N. caecoides and $M$. nasuta . .......................... 18

2.4.3 28-Day Solid-Phase Flow-Through Test with

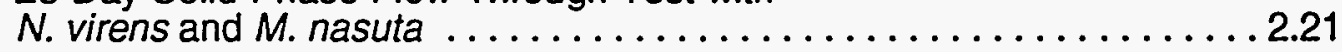

2.4.4 96-Hour Suspended-Particulate-Phase Test with $C$. stigmaeus $\ldots \ldots \ldots 2.21$

2.4.5 96-Hour Suspended-Particulate-Phase Test with $H$. costata . . . . . . . 2.22 


\section{CONTENTS (contd)}

2.3.6 48-Hour Suspended-Particulate-Phase Test with Larval M. galloprovincialis . . . . . . . . . . . . . . . . . . . . . 2.24

2.5 DATA ANALYSIS AND INTERPRETATION $\ldots \ldots \ldots \ldots \ldots \ldots \ldots \ldots \ldots \ldots$

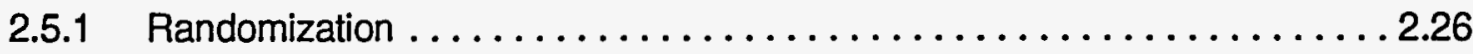

2.5.2 Statistical Analysis of Solid-Phase Tests . . . . . . . . . . . . 2.26

2.5.3 Statistical Analysis of Suspended-Particulate-Phase Tests . . . . . . . 2.26

2.5.4 Statistical Analysis of Bioaccumulation $\ldots \ldots \ldots \ldots \ldots \ldots \ldots \ldots \ldots .27$

2.6 QUALITY ASSURANCE/QUALITY CONTROL PROCEDURES $\ldots \ldots \ldots \ldots .27$

2.6.1 Sample Tracking and Storage $\ldots \ldots \ldots \ldots \ldots \ldots \ldots \ldots \ldots \ldots \ldots \ldots \ldots \ldots$

2.6.2 Sediment and Tissue Chemistry Quality Control Procedures . . . . . . . 2.28

2.6.3 Toxicological Testing Quality Control Procedures . . . . . . . . . . . 2.29

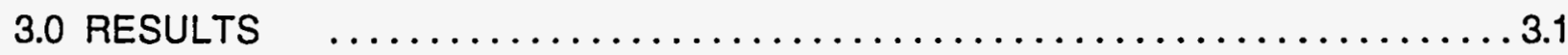

3.1 SEDIMENT COLLECTION AND SAMPLE PREPARATION $\ldots \ldots \ldots \ldots \ldots .1$

3.1.1 Richmond Harbor Deepening Project Core Sampling ... . . . . . . 3.1

3.1.2 Reference and Control Sediment Sampling ................ 3.1

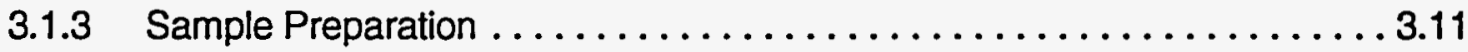

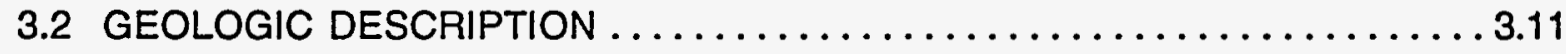

3.2.1 Santa Fe and Inner Harbor Channels ..................... 3.13

3.2.2 Proposed Turning Basin . . . . . . . . . . . . . . . . .

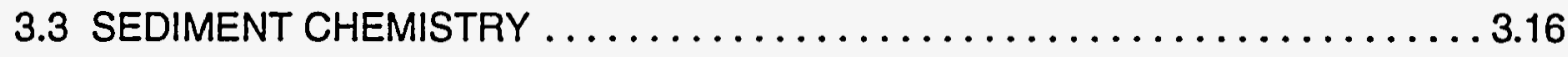

3.3.1 Sediment Conventional Measurements $\ldots \ldots \ldots \ldots \ldots \ldots \ldots \ldots . \ldots \ldots$

3.3.2 Polynuclear Aromatic Hydrocarbons and Phthalate Esters . . . . . . . . 3.22

3.3.3 Chlorinated Pesticides and Polychlorinated Biphenyls (PCBs) . . . . . 3.22

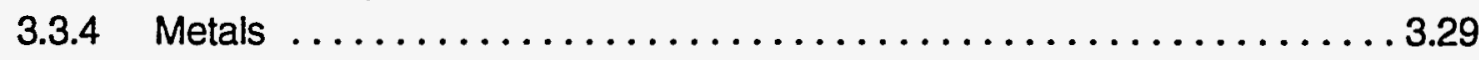

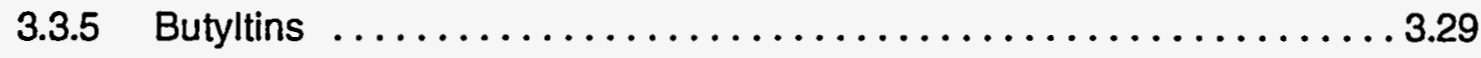

3.3.6 California Waste Extraction Test (WET) and Soluble Threshold Limit Concentrations (STLC) for 17 California Assessment Metals (CAM), Hexavalent Chromium and Selected Pesticides and PCBs by Method 8080 


\section{CONTENTS (contd)}

3.4 TOXICOLOGICAL TESTING RESULTS $\ldots \ldots \ldots \ldots \ldots \ldots \ldots \ldots \ldots \ldots .38$

3.4.1 10-Day Solid-Phase Static Test with $R$. abronius ...............40

3.4.2 10-Day Solid-Phase Flow-Through Test with M. nasuta and $N$. caecoides .................................... 31

3.4.3 28-Day Solid-Phase Flow-Through Test with M. nasuta and

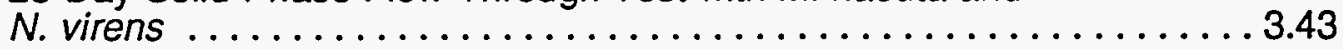

3.4.4 96-Hour Suspended-Particulate-Phase Static Test with C. stigmaeus ..3.43

3.4.5 96-Hour Suspended-Particulate-Phase Static Test with H. costata . . . . . 3.44

3.4.6 48-Hour Suspended-Particulate-Phase Static Test with M. galloprovincilias ................................. 3.47

3.5 TISSUE BIOACCUMULATION $\ldots \ldots \ldots \ldots \ldots \ldots \ldots \ldots \ldots \ldots \ldots \ldots \ldots \ldots \ldots \ldots \ldots \ldots \ldots$

3.5.1 Statistical Analyses of Bioaccumulation Results ............... 3.51

3.5.2 Bioaccumulation Results for $M$. nasuta and $N$. virens ...............51

4.0 RESULTS OF THE ANALYSIS OF THE INTENSIVE STUDY OF THE

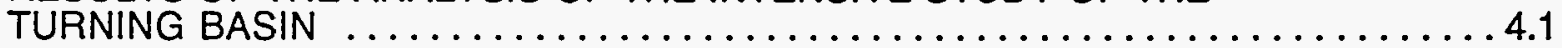

4.1 SEDIMENT COLLECTION AND SAMPLE PREPARATION $\ldots \ldots \ldots \ldots \ldots .3$

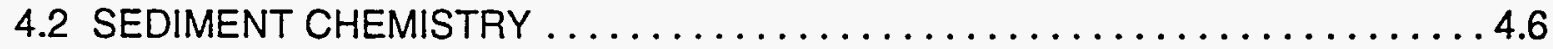

4.2.1 Sediment Conventional Measurements $\ldots \ldots \ldots \ldots \ldots \ldots \ldots \ldots .6$

4.2.2 Polynuclear Aromatic Hydrocarbons $\ldots \ldots \ldots \ldots \ldots \ldots \ldots \ldots . . .4 .11$

4.2.3 Chlorinated Pesticides and Polychlorinated Biphenyls (PCBs) . . . . . 4.11

4.2.4 Metals $\ldots \ldots \ldots \ldots \ldots \ldots \ldots \ldots \ldots \ldots \ldots \ldots \ldots \ldots \ldots \ldots .13$

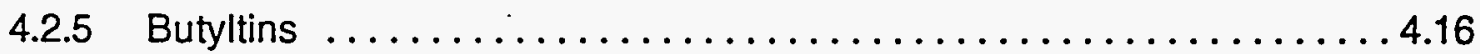

4.3 TOXICOLOGICAL TESTING RESULTS $\ldots \ldots \ldots \ldots \ldots \ldots \ldots \ldots \ldots \ldots \ldots . \ldots \ldots \ldots \ldots$

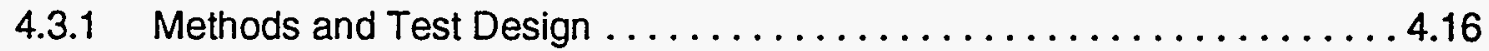

4.3.2 The Standard 10-day Test with $R$. abronius $\ldots \ldots \ldots \ldots \ldots \ldots \ldots .24$

4.3.3 Ammonia Reduction to $<20 \mathrm{mg} / L$ Test with $R$. abronius ............27

4.3.4 Ammonia Reduction to $<15 \mathrm{mg} / L$ Test with $R$. abronius $\ldots \ldots \ldots \ldots 4.28$ 


\section{CONTENTS (contd)}

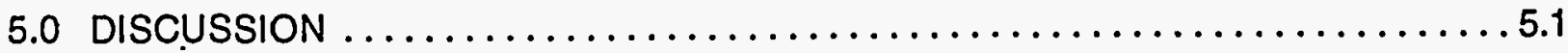

5.1 SEDIMENT CHARACTERISTICS $\ldots \ldots \ldots \ldots \ldots \ldots \ldots \ldots \ldots \ldots \ldots .1$

5.2 TIER III EVALUATIONS $\ldots \ldots \ldots \ldots \ldots \ldots \ldots \ldots \ldots \ldots \ldots \ldots \ldots \ldots \ldots \ldots \ldots \ldots \ldots \ldots .2$

5.2.1 Deposited Sediment (Solid-Phase) Acute Toxicity ............. 5.2

5.2.2 Water Column Effects . . . . . . . . . . . . . . . . . . . . . . 5.4

5.2.3 Deposited Sediment Bioaccumulation ................... 5.5

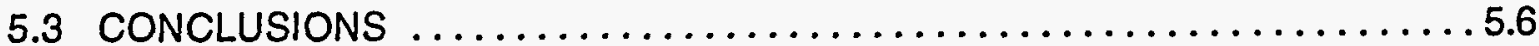

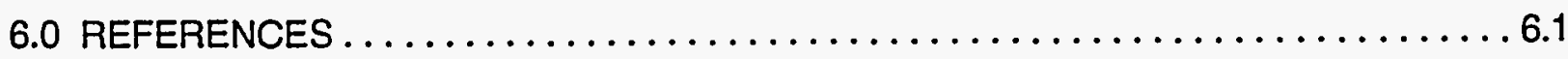

APPENDIX A MATERIALS AND METHODS USED FOR THE DESCRIPTION OF SEDIMENT CORES $\ldots \ldots \ldots \ldots \ldots \ldots \ldots \ldots \ldots \ldots \ldots \ldots \ldots . \ldots \ldots$

APPENDIXB CORE DATA LOGS $\ldots \ldots \ldots \ldots \ldots \ldots \ldots \ldots \ldots \ldots \ldots \ldots \ldots \ldots \ldots \ldots \ldots \ldots \ldots .1$

APPENDIX C SEDIMENT CHEMISTRY AND QUALITY ASSURANCE DATA ....... C.i

APPENDIX D INTENSIVE STUDY OF THE TURNING BASIN SEDIMENT CHEMISTRY AND QUALITY ASSURANCE DATA $\ldots \ldots \ldots \ldots \ldots \ldots \ldots \ldots \ldots \ldots$ D. $i$

APPENDIXE BIOASSAY RESULTS FOR 10-DAY SOLID-PHASE, STATIC TEST AND 96-HOUR REFERENCE TOXICANT T.EST FOR RHEPOXYNIUS abronius

APPENDIXF INTENSIVE STUDY OF THE TURNING BASIN BIOASSAY RESULTS FOR 10-DAY SOLID-PHASE, STATIC TEST AND 96-HOUR REFERENCE TOXICANT TEST FOR RHEPOXYNIUS abronius ......... F.i

APPENDIX G INTENSIVE STUDY OF THE TURNING BASIN BIOASSAY RESULTS FOR 10-DAY SOLID-PHASE, AMMONIA REDUCTION TO $<20 \mathrm{mg} / \mathrm{L}$

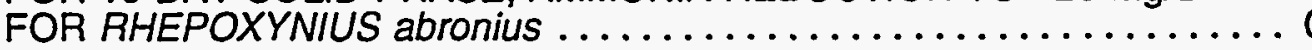

APPENDIXH INTENSIVE STUDY OF THE TURNING BASIN BIOASSAY RESULTS FOR 10-DAY SOLID-PHASE, AMMONIA REDUCTION TO <15 mg/L TEST AND 96-HOUR REFERENCE TOXICANT TEST FOR RHEPOXYNIUS abronius

APPENDIXI BIOASSAY RESULTS FOR 10-DAY SOLID-PHASE, FLOW-THROUGH TEST WITH MACOMA nasuta AND NEPHTYS caecoides ............ l.i

APPENDIX J BIOASSAY RESULTS FOR 28-DAY SOLID-PHASE, FLOW-THROUGH

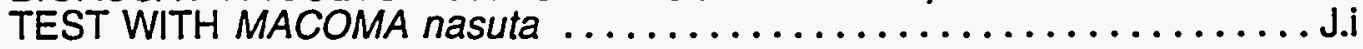

APPENDIXK BIOASSAY RESULTS FOR 28-DAY SOLID-PHASE, FLOW-THROUGH

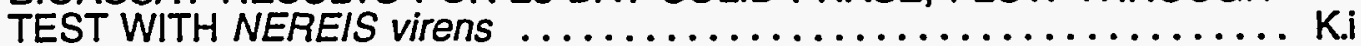


CONTENTS (contd)

APPENDIXL BIOASSAY RESULTS FOR 96-HOUR SUSPENDED-PARTICULATEPHASE TEST AND 96-HOUR REFERENCE TOXICANT TESTS FOR CITHARICHTHYS stigmaeus .......................... L.

APPENDIXM BIOASSAY RESULTS FOR 96-HOUR SUSPENDED-PARTICULATEPHASE TEST AND 96-HOUR REFERENCE TOXICANT TESTS FOR HOLMESIMYSIS costata ........................... M.

APPENDIXN BIOASSAY RESULTS FOR 48-HOUR SUSPENDED-PARTICULATEPHASE TEST AND 48-HOUR REFERENCE TOXICANT TESTS FOR MYTILUS galloprovincialis N.i

APPENDIX O TISSUE CHEMISTRY AND QUALITY ASSURANCE DATA FOR

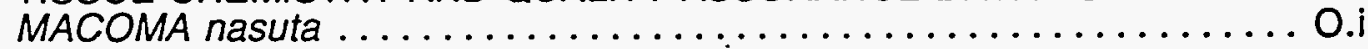

APPENDIXP TISSUE CHEMISTRY AND QUALITY ASSURANCE DATA FOR NEREIS virens P. $\mathbf{i}$

APPENDIX Q POTENTIAL EFFECTS OF DISPOSAL OF RICHMOND HARBOR DEEPENING SEDIMENTS AND THE INTENSIVE STUDY OF THE TURNING BASIN SEDIMENTS AT THE BAY FARM BORROW AREA

APPENDIXR POTENTIAL EFFECTS OF DISPOSAL OF RICHMOND HARBOR DEEPENING SEDIMENTS AND TURNING BASIN AT THE ALCATRAZ DISPOSAL SITE AND AT ALCATRAZ ENVIRONS REFERENCE AREA . . R.1 


\section{FIGURES}

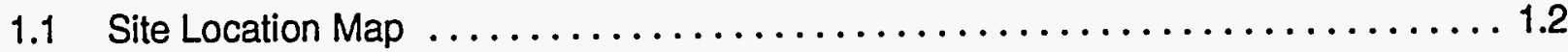

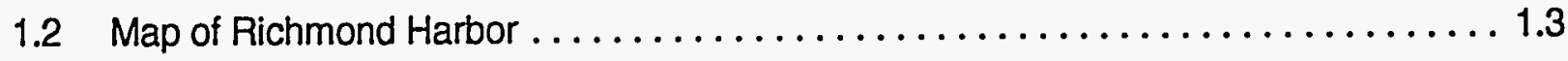

2.1 Components of the 4-in. and 12-in. Vibratory-Hammer Coring Devices . . . . . . 2.2

2.2 Static Mason Jar for $R$. abronius Toxicity Test $\ldots \ldots \ldots \ldots \ldots \ldots \ldots \ldots \ldots \ldots \ldots \ldots \ldots \ldots$

2.3 Flow-through Aquaria for 10-Day M. nasuta/N. caecoides Toxicity Test and $28-D a y$ M. nasuta and $N$. virens Tests ......................... 2.19

3.1. Sampling Stations and Compositing Scheme for the Richmond Harbor

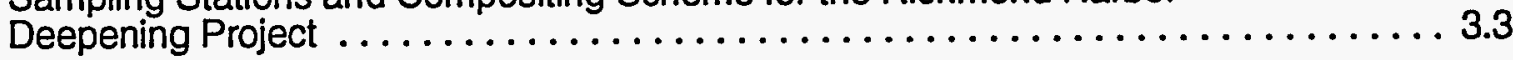

3.2 Location of Deep Off-Shelf Reference Area (R-OS) $\ldots \ldots \ldots \ldots \ldots \ldots \ldots . \ldots . \ldots$

3.3 Location of Bay Farm Reference Area (R-BF) $\ldots \ldots \ldots \ldots \ldots \ldots \ldots \ldots \ldots \ldots \ldots \ldots \ldots$

3.4 Location of Alcatraz Environs Reference Area (R-AM) $\ldots \ldots \ldots \ldots \ldots \ldots \ldots .7$

3.5 Location of M. nasuta Control (C-SB), Sequim Bay, Washington ........... 3.8

3.6 Location of $R$. abronius Control (C-WB), West Beach, Whidbey Island,

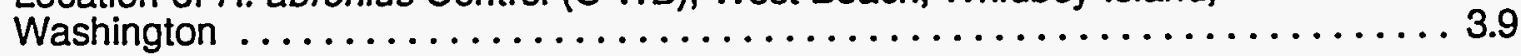

3.7 Location of N. caecoides Control (C-NE), Tomales Bay, California ............ 3.10

3.8 Geologic Cross-Sections of the Santa Fe Channel and Upper Inner Harbor Channel of Richmond Harbor . . . . . . . . . . . . . . . . . . . . . . . . . . . . . . . .

3.9 Geologic Cross-Sections of the Turning Basin in Richmond Harbor . . . . . . . . 3.15

3.10 Grain Size Distribution in Sediment Treatments $\ldots \ldots \ldots \ldots \ldots \ldots \ldots \ldots \ldots .18$

3.11 Percentages of TOC in Sediment Treatments ......................... 3.19

3.12 Percentages of TVS in Sediment Treatments ......................... 3.19

3.13 Concentrations of Oil and Grease in Sediment Treatments $\ldots \ldots \ldots \ldots \ldots \ldots . . .20$

3.14 Concentrations of TPH in Sediment Treatments $\ldots \ldots \ldots \ldots \ldots \ldots \ldots \ldots \ldots . .20$

3.15 Concentration of Oil and Grease vs. TPH $\ldots \ldots \ldots \ldots \ldots \ldots \ldots \ldots \ldots \ldots \ldots \ldots \ldots \ldots \ldots \ldots .21$

3.16 Concentrations of Total PAH in Sediment Treatments . . . . . . . . . . . . 3.25

3.17 Concentrations of Aldrin in Sediment Treatments $\ldots \ldots \ldots \ldots \ldots \ldots \ldots \ldots .26$

3.18 Concentrations of 4,4'-DDD in Sediment Treatments $\ldots \ldots \ldots \ldots \ldots \ldots \ldots \ldots .26$

3.19 Concentrations of $4,4^{\prime}$-DDE in Sediment Treatments $\ldots \ldots \ldots \ldots \ldots \ldots \ldots \ldots .27$

3.20 Concentrations of $4,4^{\prime}$-DDT in Sediment Treatments $\ldots \ldots \ldots \ldots \ldots \ldots \ldots \ldots .27$

BH-DEEPENING $\quad x i$ 
3.21 Concentrations of Dieldrin in Sediment Treatments $\ldots \ldots \ldots \ldots \ldots \ldots \ldots \ldots .28$

3.22 Concentrations of Aroclor-1254 in Sediment Treatments . . . . . . . . . . . . 3.28

3.23 Concentrations of Silver in Sediment Treatments $\ldots \ldots \ldots \ldots \ldots \ldots \ldots \ldots \ldots .32$

3.24 Concentrations of Arsenic in Sediment Treatments . . . . . . . . . . . . . . 3.32

3.25 Concentrations of Cadmium in Sediment Treatments $\ldots \ldots \ldots \ldots \ldots \ldots \ldots \ldots .33$

3.26 Concentrations of Chromium in Sediment Treatments $\ldots \ldots \ldots \ldots \ldots \ldots \ldots \ldots .33$

3.27 Concentrations of Copper in Sediment Treatments $\ldots \ldots \ldots \ldots \ldots \ldots \ldots \ldots .34$

3.28 Concentrations of Mercury in Sediment Treatments $\ldots \ldots \ldots \ldots \ldots \ldots \ldots \ldots .3 .34$

3.29 Concentrations of Nickel in Sediment Treatments . . . . . . . . . . . . . . 3.35

3.30 Concentrations of Lead in Sediment Treatments . . . . . . . . . . . . . . . 3.35

3.31 Concentrations of Selenium in Sediment Treatments $\ldots \ldots \ldots \ldots \ldots \ldots \ldots . .36$

3.32 Concentrations of Zinc in Sediment Treatments $\ldots \ldots \ldots \ldots \ldots \ldots \ldots \ldots . . . \ldots \ldots$

3.33 Concentrations of Tributyltin in Sediment Treatments . . . . . . . . . . . . 3.37

3.34 Concentrations of Dibutyltin in Sediment Treatments . . . . . . . . . . . . . 3.37

3.35 Response of R. abronius to Porewater Ammonia Concentrations in Richmond Harbor Deepening Sediments Relative to Water-Only Mean Response and

$95 \%$ Confidence Interval . . . . . . . . . . . . . . . . . . . . . . . . .

3.36 Response of $M$. galloprovincialis to Ammonia in 100\% SPP from the Test

Treatments (Test 1) Relative to the Water-Only Mean Response for Test $1 \ldots \ldots .50$

3.37 Response of M. galloprovincialis to Ammonia in 100\% SPP from the Test

Treatments (Test 2) Relative to the Water-Only Mean Response for Test $2 \ldots \ldots 3.50$

4.1 Sampling Stations for the Richmond Harbor Deepening Project-Intensive Study

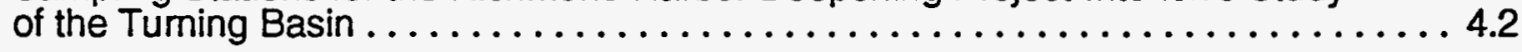

4.2 Grain Size Distribution in Sediment Treatments, Richmond Harbor Deepening Project-Intensive Study of the Tuming Basin $\ldots \ldots \ldots \ldots \ldots \ldots \ldots \ldots \ldots \ldots \ldots .8$

4.3 Percentage of TOC in Sediment Treatments, Richmond Harbor Deepening Project-Intensive Study of the Turning Basin $\ldots \ldots \ldots \ldots \ldots \ldots \ldots \ldots \ldots \ldots .9 . \ldots \ldots$

4.4 Percentage of TVS in Sediment Treatments, Richmond Harbor Deepening Project-Intensive Study of the Turning Basin $\ldots \ldots \ldots \ldots \ldots \ldots \ldots \ldots \ldots \ldots .9 . \ldots \ldots$

4.5 Concentrations of Oil and Grease in Sediment Treatments, Richmond Harbor Deepening Project-Intensive Study of the Turning Basin 
FIGURES (contd)

4.6 Concentrations of TPH in Sediment Treatments, Richmond Harbor Deepening

Project-Intensive Study of the Tuming Basin

4.7 Concentrations of Total PAH in Sediment Treatments, Richmond Harbor Deepening

Project-Intensive Study of the Turning Basin $\ldots \ldots \ldots \ldots \ldots \ldots \ldots \ldots \ldots \ldots . .12$

4.8 Concentrations of Aldrin in Sediment Treatments, Richmond Harbor Deepening

Project-Intensive Study of the Turning Basin $\ldots \ldots \ldots \ldots \ldots \ldots \ldots \ldots \ldots \ldots \ldots .13$

4.9 Concentrations of 4,4'-DDD in Sediment Treatments, Richmond Harbor Deepening

Project-Intensive Study of the Turning Basin $\ldots \ldots \ldots \ldots \ldots \ldots \ldots \ldots \ldots \ldots, \ldots \ldots \ldots, 14$

4.10 Concentrations of 4,4'-DDE in Sediment Treatments, Richmond Harbor Deepening

Project-Intensive Study of the Turning Basin $\ldots \ldots \ldots \ldots \ldots \ldots \ldots \ldots \ldots \ldots .14$

4.11 Concentrations of 4,4'-DDT in Sediment Treatments, Richmond Harbor Deepening

Project-Intensive Study of the Tuming Basin $\ldots \ldots \ldots \ldots \ldots \ldots \ldots \ldots \ldots \ldots \ldots \ldots .15$

4.12 Concentrations of Aroclor 1254 in Sediment Treatments, Richmond Harbor Deepening

Project-Intensive Study of the Turning Basin $\ldots \ldots \ldots \ldots \ldots \ldots \ldots \ldots \ldots \ldots \ldots .15$

4.13 Concentrations of Silver in Sediment Treatments, Richmond Harbor Deepening

Project-Intensive Study of the Tuming Basin $\ldots \ldots \ldots \ldots \ldots \ldots \ldots \ldots \ldots \ldots .18$

4.14 Concentrations of Arsenic in Sediment Treatments, Richmond Harbor Deepening Project-Intensive Study of the Tuming Basin $\ldots \ldots \ldots \ldots \ldots \ldots \ldots \ldots \ldots \ldots \ldots .18$

4.15 Concentrations of Cadmium in Sediment Treatments, Richmond Harbor Deepening Project-Intensive Study of the Tuming Basin $\ldots \ldots \ldots \ldots \ldots \ldots \ldots \ldots \ldots \ldots . .19$

4.16 Concentrations of Chromium in Sediment Treatments, Richmond Harbor Deepening Project-Intensive Study of the Tuming Basin $\ldots \ldots \ldots \ldots \ldots \ldots \ldots \ldots \ldots \ldots .19$

4.17 Concentrations of Copper in Sediment Treatments, Richmond Harbor Deepening Project-Intensive Study of the Turning Basin $\ldots \ldots \ldots \ldots \ldots \ldots \ldots \ldots \ldots \ldots . \ldots \ldots .20$

4.18 Concentrations of Mercury in Sediment Treatments, Richmond Harbor Deepening Project-Intensive Study of the Tuming Basin $\ldots \ldots \ldots \ldots \ldots \ldots \ldots \ldots \ldots . \ldots .20$

4.19 Concentrations of Nickel in Sediment Treatments, Richmond Harbor Deepening Project-Intensive Study of the Tuming Basin $\ldots \ldots \ldots \ldots \ldots \ldots \ldots \ldots \ldots \ldots .21$

4.20 Concentrations of Lead in Sediment Treatments, Richmond Harbor Deepening Project-Intensive Study of the Tuming Basin

4.21 Concentrations of Selenium in Sediment Treatments, Richmond Harbor Deepening Project-Intensive Study of the Turning Basin

4.22 Concentrations of Zinc in Sediment Treatments, Richmond Harbor Deepening Project-Intensive Study of the Turning Basin

4.23 Concentrations of Tributyltin in Sediment Treatments, Richmond Harbor Deepening Project-Intensive Study of the Turning Basin

BH-DEEPENING 


\section{FIGURES (contd)}

4.24 Concentrations of Dibutyltin in Sediment Treatments, Richmond Harbor Deepening

Project-Intensive Study of the Turning Basin

4.25 Response of $R$. abronius to Porewater Ammonia Concentrations in the Intensive Study of the Turning Basin Sediments from the Standard 10-Day Test Relative to the Ammonia Reference Toxicant Dose-Response Curve . . . . . . . . 4.26

4.26 Response of $R$. abronius to Porewater Ammonia Concentrations in the Intensive Study of the Turning Basin Sediments from the Ammonia Reduction to $<20 \mathrm{mg} / \mathrm{L}$ Test Relative to the Ammonia Reference Toxicant Dose-Response Curve

4.27 Response of $R$. abronius to Porewater Ammonia Concentrations in the Intensive Study of the Turning Basin Sediments from the Ammonia Reduction to $<15 \mathrm{mg} / \mathrm{L}$ Test Relative to the Ammonia Reference Toxicant Dose-Response Curve

5.1 Matrix of Sediment Chemistry, Significant Acute Toxicity, and Bioaccumulation for Richmond Harbor Deepening Sediment Treatments Relative to the Deep Off-Shelf Reference Sediment, R-OS. 


\section{TABLES}

2.1 Analytical Chemistry Requirements for Richmond Harbor. Sediment Treatments . . . 2.8

2.2 Analytical Chemistry Requirements for Richmond Harbor Tissue Samples . . . . . . 2.9

2.3 Grain Size Fractions Measured $\ldots \ldots \ldots \ldots \ldots \ldots \ldots \ldots \ldots \ldots \ldots \ldots \ldots \ldots \ldots \ldots \ldots \ldots$

2.4 Analytical Method and Corresponding Metal for Each Sample Matrix $\ldots \ldots \ldots \ldots \ldots 2.12$

3.1 Sampling Information for Sediment Composites, Richmond Harbor

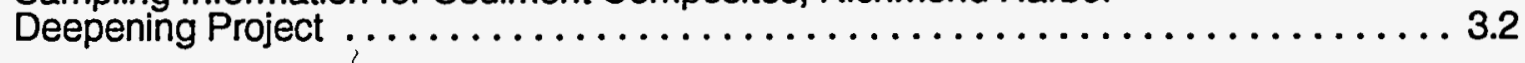

3.2 Reference and Control Sediment Sampling Data $\ldots \ldots \ldots \ldots \ldots \ldots \ldots \ldots .4$

3.3 Sediment Samples and Testing Strategy, Richmond Harbor Deepening Project . . . 3.12

3.4 Conventional Sediment Measurement Results for the Richmond Harbor Deepening

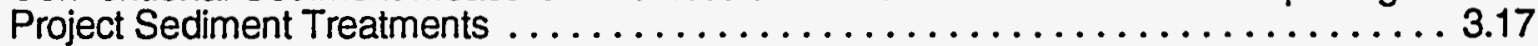

3.5 Detected PAHs, Pesticides, and PCBs in Richmond Harbor Deepening Project Sediment Treatments . . . . . . . . . . . . . . . . . . . . . . . . . . . . 3.23

3.6 Metal and Butyltin Concentrations in Richmond Harbor Deepening Project

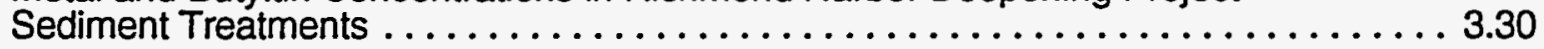

3.7 Summary of Detected Metals Analyzed by the California Waste Extraction Test . . . 3.38

3.8 Summary of 10-Day Solid-Phase Toxicity Tests, Richmond Harbor Deepening

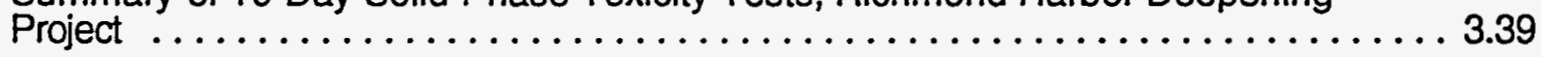

3.9 ANOVA Results for the 10-Day Solid-Phase Toxicity Tests, Richmond Harbor Deepening Project

3.10 Ammonia Monitoring Summary for the 10-Day R. abronius Solid-Phase Static Test, Richmond Harbor Deepening Project

3.11 Results of the 28-Day Solid-Phase Flow-Through Test with M. nasuta and $N$. virens, Richmond Harbor Deepening Project

3.12 Summary of Mean Proportion Surviving 96-Hour C.stigmaeus SuspendedParticulate-Phase Test, Richmond Harbor Deepening Project .

3.13 Summary of Ammonia Concentrations Measured in the Suspended-ParticulatePhase of Sediments from the Richmond Harbor Deepening Project ............. 3.46

3.14 Summary of Mean Proportion Surviving 96-Hour H. costata SuspendedParticulate-Phase Test, Richmond Harbor Deepening Project

3.15 Results of 48-Hour Suspended-Particulate-Phase Test with M. galloprovincialis . . . 3.48

3.16 Mean Values of Contaminants Detected in Tissues of $M$. nasuta Exposed to Richmond Harbor Deepening Composites 


\section{TABLES (contd)}

3.17 Mean Values of Contaminants Detected in Tissues of N. virens Exposed to Richmond Harbor Deepening Composites

3.18 Summary of Test Treatments with Statistically Significant Elevations in the Tissues of Either M. nasuta or $N$. virens at Levels Greater than Five Times Those of the Reference Treatment R-OS

4.1 Sampling Information for Richmond Harbor Tuming Basin, Intensive Study of the

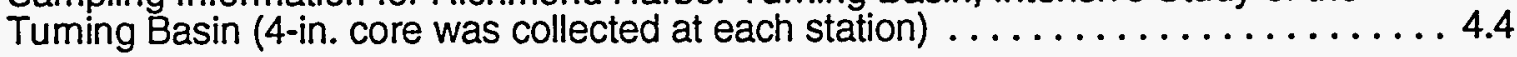

4.2 Reference and Control Sediment Sampling Data $\ldots \ldots \ldots \ldots \ldots \ldots \ldots \ldots . .5$

4.3 Conventional Sediment Measurement Results for the Sediment Treatments, Richmond Harbor Deepening Project-Intensive Study of the Turning Basin $\ldots \ldots .4$

4.4 Detected Total PAHs, Pesticides, and PCBs in Sediment Treatments, Richmond Harbor Deepening Project-Intensive Study of the Turning Basin . . . . . 4.11

4.5 Metal and Butyltin Concentrations in Sediment Treatments, Richmond Harbor Deepening Project-Intensive Study of the Turning Basin ................. 4.17

4.6 Ammonia Monitoring Summary for the 10-Day R. abronius Solid-Phase Static Test, Richmond Harbor Deepening Project-Intensive Study of the Tuming Basin . . . . 4.25

4.7 Ammonia Monitoring Summary for the 10-Day R. abronius Solid-Phase, Ammonia Reduction to $<20 \mathrm{mg} / \mathrm{L}$ Test, Richmond Harbor Deepening Project-Intensive Study

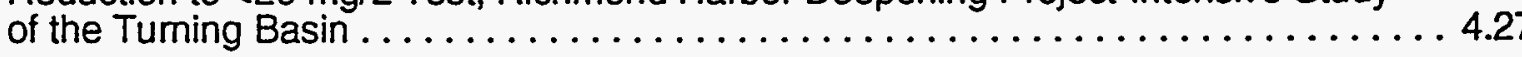

4.8 Ammonia Monitoring Summary for the 10-Day R. abronius Solid-Phase, Ammonia Reduction to $<15 \mathrm{mg} / \mathrm{L}$ Test, Richmond Harbor Deepening Project-Intensive Study

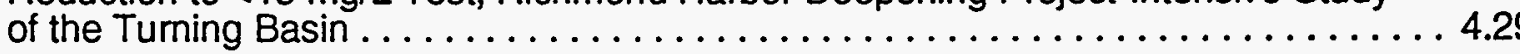

5.1 Comparison of Richmond Harbor Solid-Phase Acute Toxicity to that of the Deep Off-Shelf Reference Sediment R-OS ........................... 5.3

5.2 Comparison of Richmond Harbor Solid-Phase Acute Toxicity to that of the Deep Off-Shelf Reference R-OS, Intensive Study of the Turning Basin $\ldots \ldots \ldots \ldots . .3$

5.3 Summary of Suspended-Particulate-Phase Toxicity Tests,

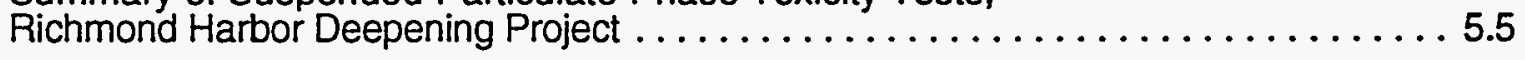

5.4 Comparison of FDA Action Levels With Contaminant Levels in M. nasuta and N. virens Exposed to Richmond Harbor Sediments . . . . . . . . . . . . . . . . 5.7

5.5 Summary of Statistically Significant Acute Toxicity and Bioaccumulation for Richmond Harbor Deepening Project Sediment Treatments Relative to the Reference Sediment R-OS 


\subsection{INTRODUCTION}

Richmond Harbor, a major West Coast port for shipping and petroleum refining, is located on the eastem shoreline of central San Francisco Bay near San Francisco, California (Figure 1.1). Improvements are required in Richmond Harbor (Figure 1.2) and its access channels to accommodate modern deeper-draft vessels. The Water Resources Development Act of 1986 (Public Law 99-662) authorized the U.S. Army Corps of Engineers (USACE), San Francisco District, to deepen and widen the navigation channels to $-40 \mathrm{ft}$ mean lower low water (MLLW) ( $-38 \mathrm{ft}$ MLLW plus $2 \mathrm{ft}$ of overdraft) in Richmond Harbor. Several options for disposal of the material from this dredging project are under consideration by USACE as follows: disposal within San Francisco Bay, at open-ocean sites, or at upland disposal sites. The deepening and widening of areas of Richmond Harbor evaluated in this report will remove an estimated 602,000 cubic yards of dredged material.

Section 103 of the Marine Protection, Research, and Sanctuaries Act of 1972 (MPRSA), Public Law 92-532, specifies that all proposed disposal of dredged material into open water be evaluated to determine the potential environmental impacts of these activities. Potential impacts to ocean waters are determined by evaluation of dredged material through the 40 CFR 227 guidelines. Similarly, disposal of dredged material into waters of the United States must be evaluated for potential environmental impacts through guidelines (40 CFR 230) developed under Section 404 of the Federal Water Pollution Control Act Amendments of 1972, also called the CWA. The testing reported in this report complies with requirements of the MPRSA and CWA in determining suitability of dredged material for open water disposal.

Battelle/Marine Sciences Laboratony (MSL)(a), operating under contract to USACE, conducted earlier evaluations of the Richmond Harbor Channels (Ecological Evaluation of Proposed Dredged Material from Richmond Harbor [Pinza et al. 1992] and Environmental Evaluations for Deepening of Richmond Harbor and Santa Fe Channels [Brown et al. 1990]).

As a follow-up to these evaluations, more intensive sampling and analyses were planned for the Richmond Harbor Deepening Project. The study area for the Richmond Harbor Deepening Project includes 20 stations: 5 in the Upper Inner Harbor (UIH), 4 in the Santa Fe Channel (SF), 4 in the National Gypsum-GATX berth area called Santa Fe widening stations (SFW), and 7 in the Tuming Circle that were separated into upper and lower sections to produce TB Upper and TB Lower composites. Sediments from these stations were collected with a vibratory-hammer corer to a depth of $-42 \mathrm{ft}$ MLLW and then separated into two segments, mudline to $-40 \mathrm{ft} \mathrm{MLLW,}$ and $-40 \mathrm{ft} \mathrm{MLLW}$ to $-42 \mathrm{ft}$ MLLW. The sediments from mudline to the project depth of $-40 \mathrm{ft} \mathrm{MLLW}$

(a) The Battelle/Marine Sciences Laboratory is part of the Pacific Northwest Laboratory, which is operated for the U.S. Department of Energy by Battelle Memorial Institute. 


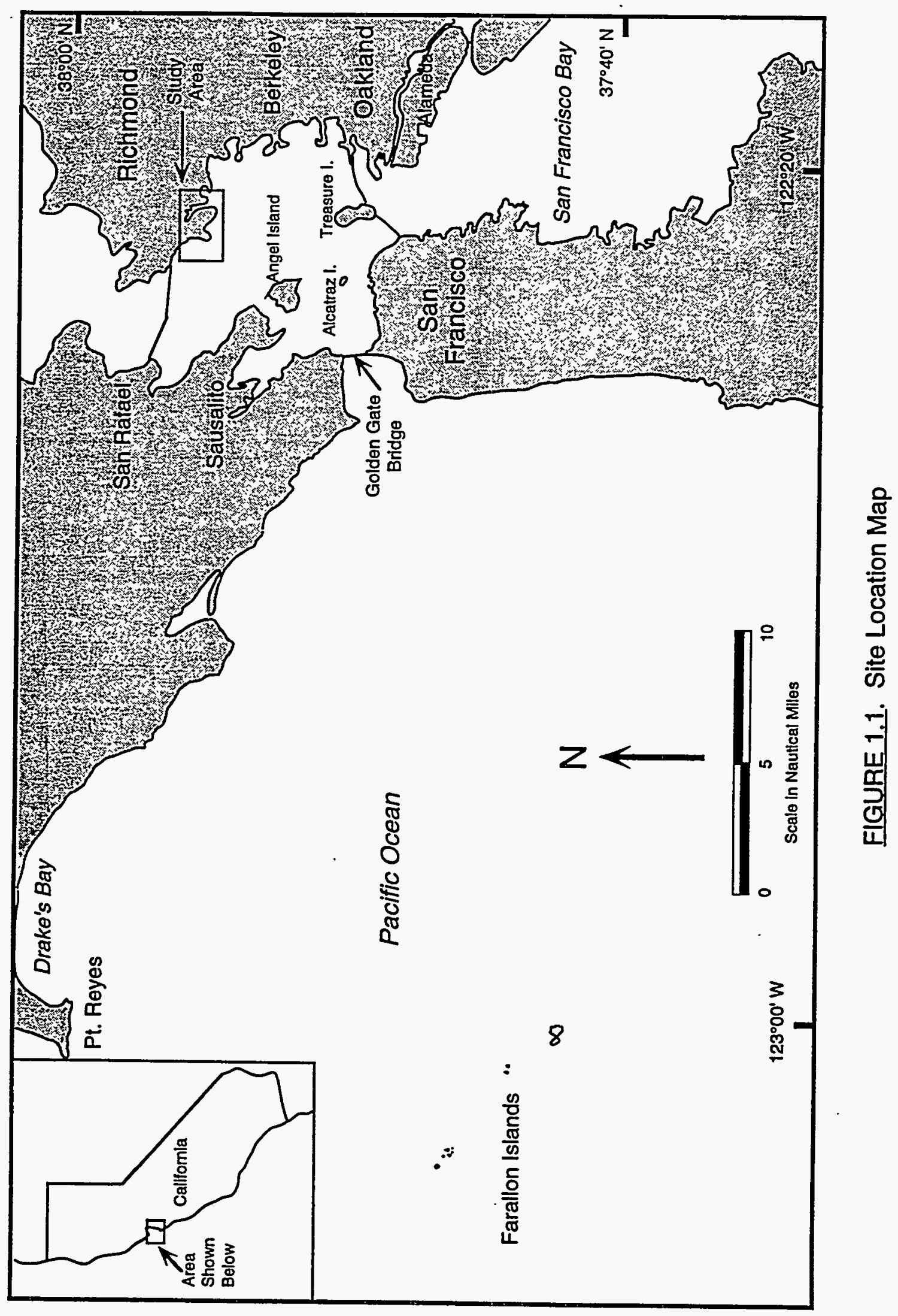




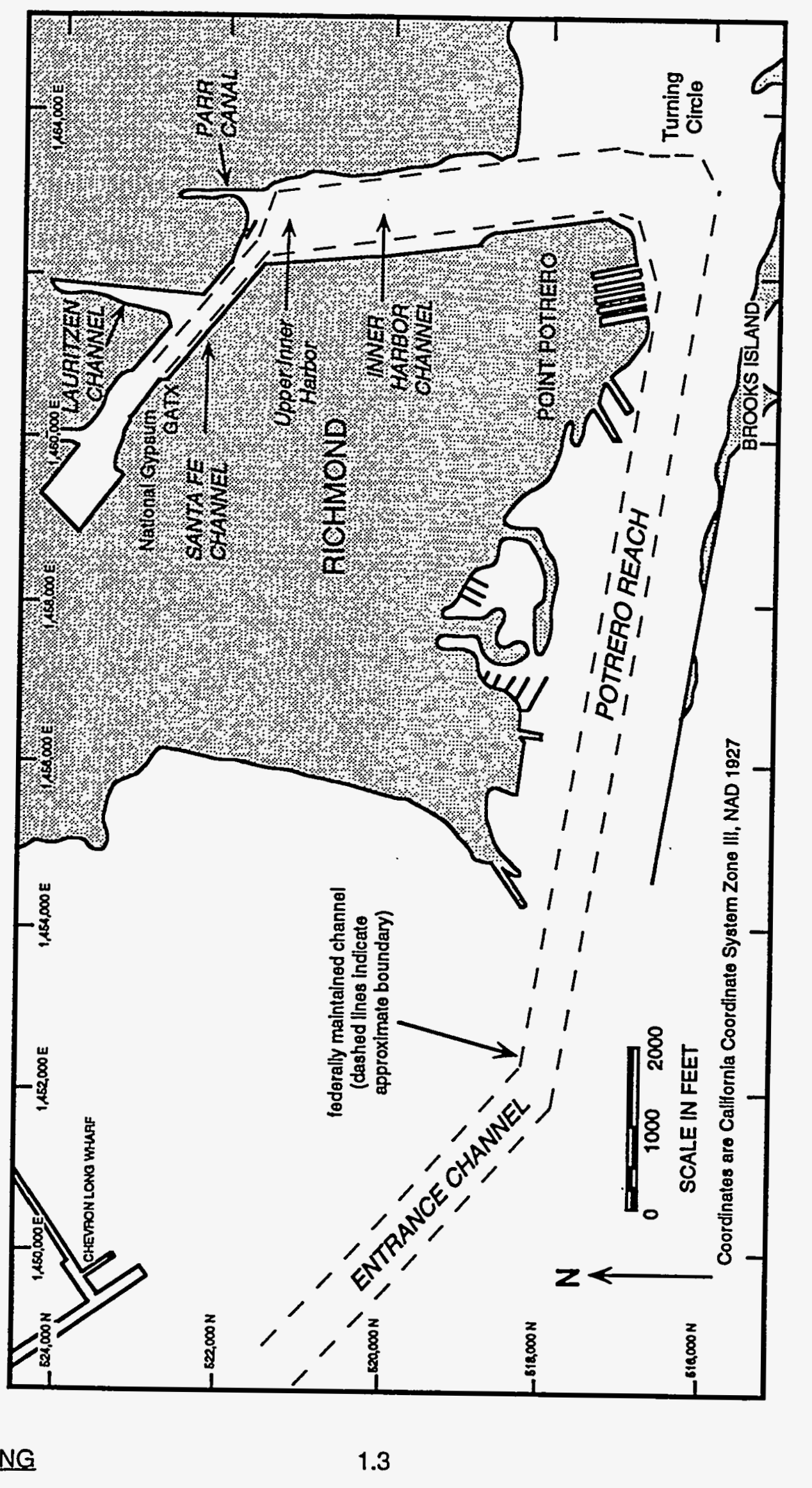

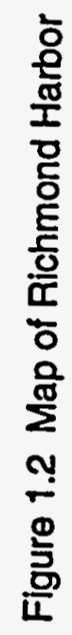


were used to form five test composites. If old bay mud (OBM) was present in any of the field stations from $-40 \mathrm{ft}$ MLLW to $-42 \mathrm{ft}$ MLLW, it was combined to make an OBM composite (COMP). The 4-in. core samples collected at each of the 20 field stations were subjected to geologic analysis and subsampled for physical/chemical parameters.

The five test composites and the OBM composite were subjected to chemical analysis, biological testing, and tissue chemistry analysis following the guidelines in the Evaluation of Dredged Material Proposed for Ocean Disposal (Testing Manual) (EPAUUSACE 1991), hereinafter referred to as the 1991 Implementation Manual. The guidelines require that reference and control sediment samples be evaluated in the same manner as the test sediments. The purpose of the reference sediment is to compare the biological responses and contaminant levels of a proposed dredged sediment sample with those of a potential disposal area that is "...substantially free of contaminants and which...reflects conditions that would exist in the vicinity of the disposal site had no dredged-material disposal ever occurred...." The control sediment allows validation of test results through evaluation of the health and normal response of test organisms.

In August 1993, the Environmental Protection Agency (EPA) released the Final Environmental Impact Statement (EIS) for Designation of a Deep Water Ocean Dredged Material Disposal Site off San Francisco, California. The preferred alternative site (Alternative Site 5) is located off the continental shelf, approximately 50 nautical miles from the Golden Gate in 2500 to $3000 \mathrm{~m}$ of water. The EPAVCorps Deep Water Ocean Reference Site (R-OS) is located approximately 16 miles south of Site 5 .

The focus of this report is the comparison of the five test composites from the Richmond Harbor Study Area and the OBM COMP with the sediment from the Deep Off-Shelf Reference Area (R-OS). These test composites are also compared with sediment from two in-bay reference sites, the Bay Farm Borrow Area and the Alcatraz Environs Reference Area. The latter two comparisons are presented in Appendixes $Q$ and $R$, respectively.

Geologic examination of the 20 Richmond Harbor field samples included descriptions of sediment layers and other notable features of the sediment. Chemical analyses were performed on sediment from the individual stations plus the composites and includes measurements of conventional parameters (grain size, total organic carbon [TOC], total volatile solids [TVS], oil and grease, and total petroleum hydrocarbons [TPH]), EPA priority pollutant organics (polynuclear aromatic hydrocarbons [PAHs], phthalate esters, polychlorinated biphenyls [PCBs], and chlorinated pesticides), metals, and butyltins. The five Richmond Harbor test composites (SF COMP, SFW COMP, UIH COMP, TB Upper COMP, and TB Lower COMP) were analyzed using the California Waste Extraction Test (WET), using Method 8080 for the soluble 
threshold limit concentrations (STLC) of selected chlorinated pesticides, and PCBs. The 17 Califomia Assessment Metals (CAM17) and hexavalent $\mathrm{Cr}$ were also analyzed using WET.

Biological toxicity tests included controlled laboratory exposures of sensitive marine organisms to the solid phase and suspended-particulate phase (SPP) of the dredged material. Solid-phase acute toxicity and bioaccumulation tests compare the effects of the dredged sediment on sensitive benthic organisms with those of a reference sediment representing a potential disposal site. Four species were used for the solid-phase tests: the amphipod, Rhepoxynius abronius; the bentnose clam, Macoma nasuta; and the polychaetes, Nephtys caecoides and Nereis virens. The SPP toxicity tests are designed to test for acute toxicity or sublethal effects of dissolved contaminants and those associated with the suspended particulates in the water column. Evaluations of SPP effects are then made, after allowing for initial mixing of the dredged material. Three species were exposed to the various concentrations of SPP: the juvenile speckled sanddab, Citharichthys stigmaeus; the mysid, Holmesimysis costata; and larvae of the bay mussel, Mytilus galloprovincialis.

Potential for bioaccumulation of contaminants from sediment is determined after a 28-day exposure of $M$. nasuta and $N$. virens to the solid-phase of the proposed dredged material, followed by chemical analyses of the tissues for the EPA priority pollutant organics, metals, and butyltins. Contaminant levels in the tissues of the organisms exposed to the test treatments were statistically compared with the contaminant levels in the tissues exposed to the reference treatments and to U.S. Food and Drug Administration (FDA) limits. The purpose of these analyses is to provide data to address potential mobility of contaminants from sediment proposed for ocean disposal.

The results in Section 3 of this report show that the TB Lower COMP was acutely toxic to $R$. abronius. Because the Turning Basin represents approximately 333,500 cubic yards of dredged material, the USACE and EPA decided that further investigations of this area were necessary to more clearly define the nature and extent of sediment contamination and acute toxicity in the Tuming Basin. Sediment was collected from nine stations in the Tuming Basin. These stations consist of the seven stations sampled during the January 1994 field effort, plus two new stations located to the northeast and southwest of station TB-4.

The Tuming Basin sediments were collected to $-40 \mathrm{ft}$ MLLW using the 4-in. vibratory hammer core. The core from each station, with the exception of TB-4, was then split into two samples: one sample consisted of sediment from mudline to $5 \mathrm{ft}$ below mudline and the other sample consisted of sediment from $5 \mathrm{ft}$ below mudline to $-40 \mathrm{ft}$ MLLW. In the core from station TB-4, sediment from $-33.4 \mathrm{ft}$ to $-38.8 \mathrm{ft}$ MLLW, representing the middle section of the core, was composited separately from the upper and lower segments because of its disrupted appearance and hydrocarbon odor. The sediment from mudline to $5 \mathrm{ft}$ below mudline from each core was 
archived in a $1-\mathrm{L}$ glass container in the event that further analysis would be required. The sediment from $5 \mathrm{ft}$ below mudline to $-40 \mathrm{ft}$ MLLW and the TB-4 Middle section were thoroughly mixed, subsampled for chemistry, and used in three separate 10-day $R$. abronius tests. Three reference sediments (R-OS, R-BF, and R-AM) and control sediments (C-WB and C-SB) were also collected for this study and used for comparison purposes and to validate the test results.

The methods used for the Intensive Study of the Turning Basin were the same as those used in the January 1994 study and are described in Section 2 and 4 of this report. The Intensive Study of the Turning Basin results compared to the reference R-OS are located in Section 4 of this report. The results of these test treatments were also compared with those from testing sediment from two in-bay reference sites, the Bay Farm Borrow Area and the Alcatraz Environs Reference Area. Those two comparisons are presented in Appendixes $Q$ and $R$, respectively.

The results of the January 1994 study also showed that OBM COMP was acutely toxic to $N$. caecoides. The sediment chemistry results for that composite showed that no contaminants of concern were elevated above reference levels. Discussions among MSL, USACE, and EPA staff concluded that this composite should be tested again to determine the reason for the acute toxicity. Four sampling stations, $\mathrm{UIH}-2, \mathrm{UIH}-4, \mathrm{SFW}-1$ and SFW-3, were resampled, and the sediment was composited into one OBM COMP that was chemically analyzed and used in a 10-day N. caecoides feeding study. The results from that study are presented in a separate report, The Older Bay Mud Study (a).

This report is divided into five sections. Section 1.0 is the introduction containing a brief overview. Section 2.0 describes the methods and materials used for sample collection and processing, biological testing, physical and chemical analyses of sediments and tissues, data analysis, and quality assurance requirements. Section 3.0 presents the results of geologic descriptions, biological testing, and physical and chemical analyses. Section 4.0 presents the results of the Intensive Study of the Turning Basin. Section 5.0 is the discussion and conclusions. Section 6 lists the literature cited in support of this document. A series of appendixes contain detailed data listings for the following areas:

Appendix A Materials and Methods Used for the Description of Sediment Cores

Appendix B Core Data Logs

Appendix C-D Sediment Chemistry and Quality Control Data

Appendix E-N Toxicity Test Data

Appendix O-P Tissue Chemistry and Quality Assurance Data

(a) 1995 draft report, Pacific Northwest Laboratory, Richland, Washington. 
Appendix Q Potential Effects of Disposal of Richmond Harbor Sediments and the Intensive Study of the Turning Basin Sediments at the Bay Farm Borrow Area

Appendix R Potential Effects of Disposal of Richmond Harbor Deepening and Turning Basin Sediments at Alcatraz Island Disposal Site and at Alcatraz Environs Reference Area. 


\subsection{MATERIALS AND METHODS}

\subsection{SEDIMENT AND TEST ORGANISM COLLECTION}

Sediment core samples were collected using either a 4-in. or 12-in. vibratory-hammer corer at 20 stations in Richmond Harbor. The sediment samples were collected to $-42 \mathrm{ft} \mathrm{MLLW}$ (project depth $-40 \mathrm{ft}$ plus $2 \mathrm{ft}$ for potential OBM composite). Specific locations of sediment sampling stations are presented with the sampling results in Section 3.1. Four-inch core samples were collected at each station and used for geologic description and sediment chemistry. Twelve-inch core samples were also taken at each of the 20 stations and combined to form 6 sediment COMPs. These six sediment composites were submitted for chemical analyses and used for biological testing of the sediments. In addition to the sediment composites, sediments from three reference areas were also collected and consisted of sediment from four stations at the Bay Farm Borrow Area, eight stations at the Alcatraz Environs Reference Area, and one station at the Deep Off-Shelf Reference Area; henceforth, these reference sediments will be called R-BF, R-AM, and R-OS, respectively. Sediment was also collected from the four control stations and was used to validate the toxicity tests. Biological testing required the collection of seven species of marine organisms; four of the species were collected in California ( $N$. caecoides, C. stigmaeus, H. costata and M. galloprovincialis ), two species were collected in western Washington (R. abronius, $M$. nasuta), and one species ( $N$. virens) was collected from Maine.

\subsubsection{Richmond Harbor Core Samples}

Navigation support for locating the sampling stations in Richmond Harbor was provided by Towill, Inc., of Concord, California, and included a survey vessel and operator. The surveyors used a laser/range azimuth positioning system (EDM-Geodimeter AGA-120, Wild T-2 1-s theodolite). Towill provided corrected water depths at each station by measuring the actual depth with a recording fathometer (DE719-E), measuring the water surface elevation, and calculating the difference between the water surface elevation and $0 \mathrm{ft}$ MLLW. All stations were sampled to $-42 \mathrm{ft}$ MLLW (-40 ft project depth and $2 \mathrm{ft}$ for OBM COMP) using a 12-in. vibratory-hammer split corer and a 4-in. vibratory-hammer corer. Both samplers were designed by the MSL and Manson Construction (Figure 2.1). The 12-in. corer was used to collect the large volume of sediment needed for biological testing and chemical characterization, while minimizing contamination caused by contact with core tool or excessive sample handling. The 4-in. cores were used to collect sediment for geologic descriptions and chemical characterizations at each station. The 4-in. cores were collected and stored in noncontaminating Lexan polycamonate tubes, which maintain the stratigraphic integrity of sediments and allow a geologist to describe the vertical stratigraphy and types of sediment present at each station. 


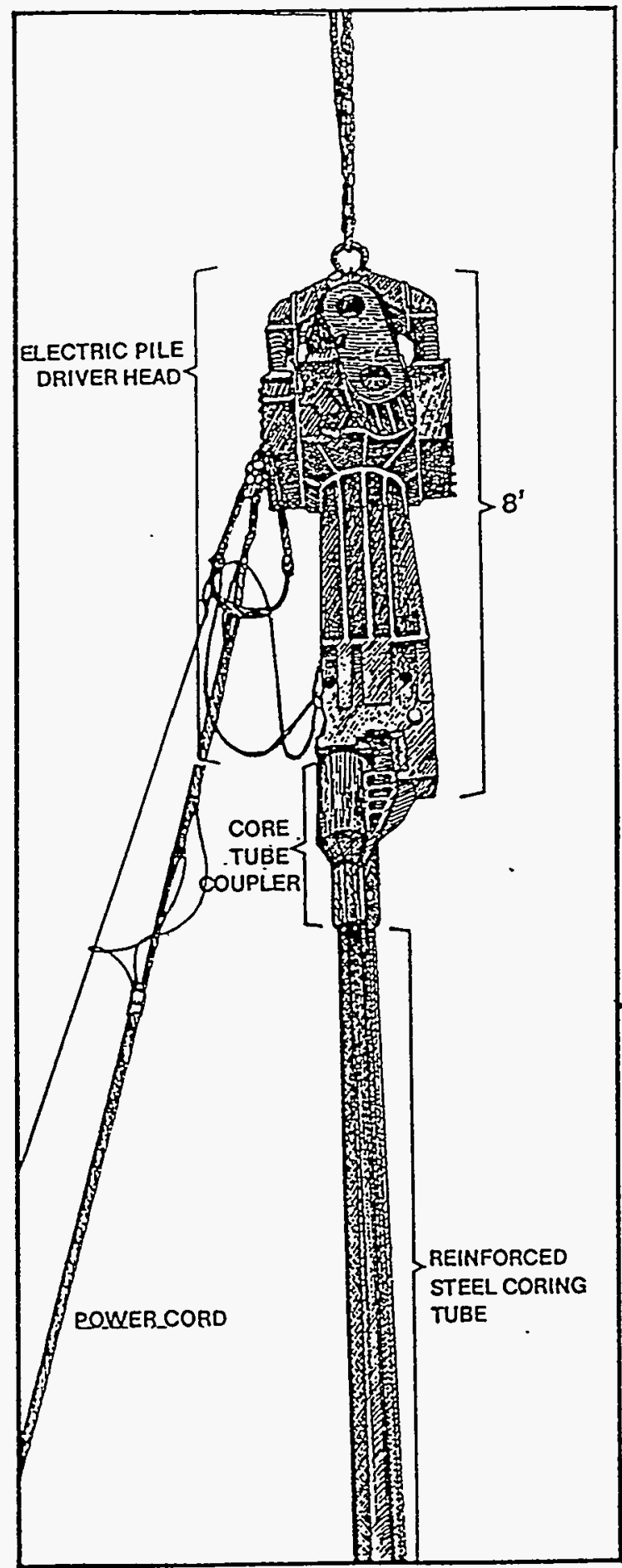

Vibratory-hammer Core
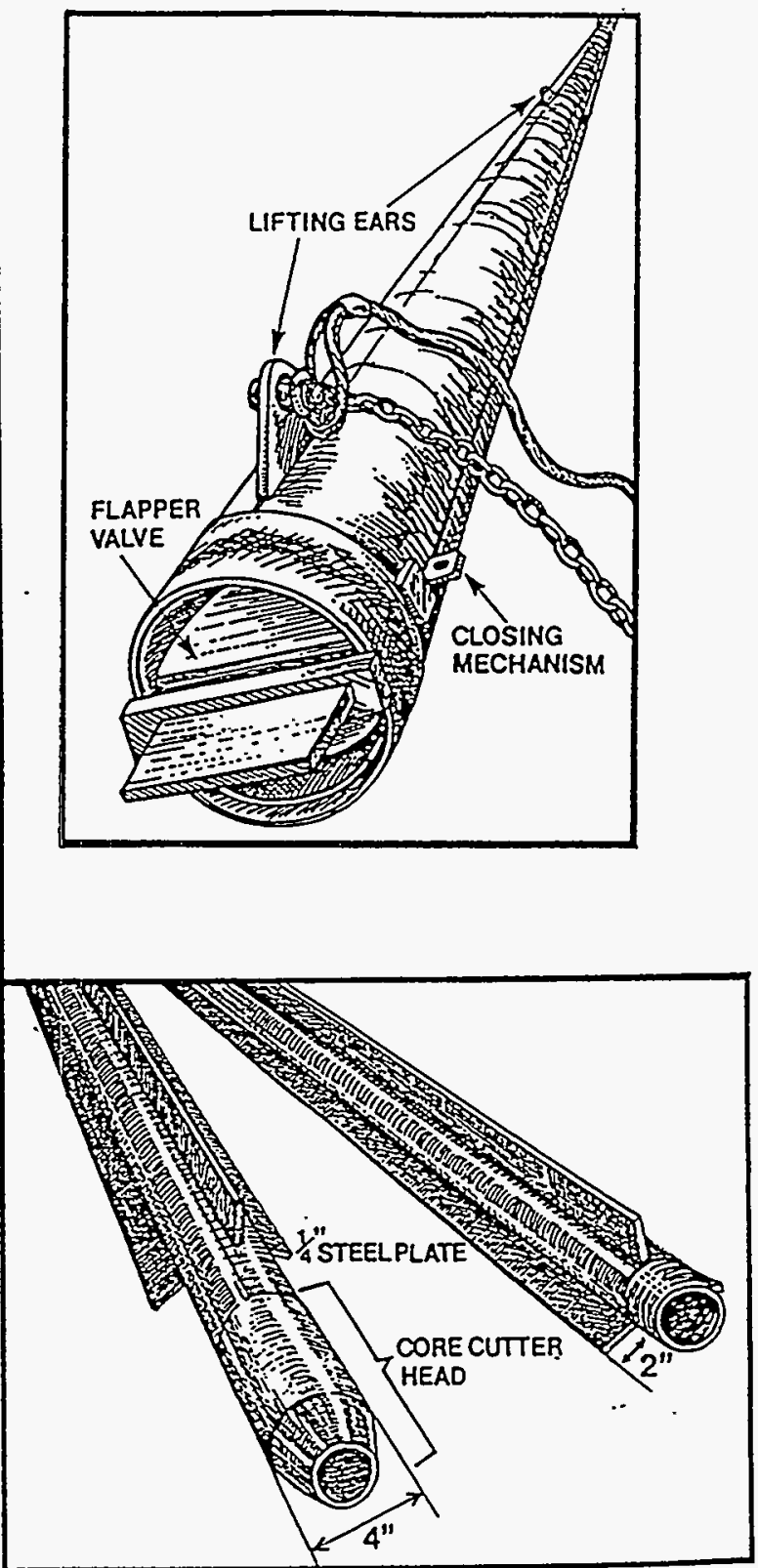

Core Cutter Head Assembly

FIGURE 2.1. Components of the 4-in. and 12-in. Vibratory-Hammer Coring Devices 
Both the 12-in.- and 4-in.- core samplers were deployed from Manson Construction's derrick barge, Hagar. The two sizes of cores were collected in a similar manner, but the sediment samples were handled differently. For both sizes of core, the coring apparatus was attached to an electric vibratory hammer. The corer and the vibratory hammer were suspended by the crane on the derrick barge. When the coring apparatus was directly above the sampling station, the core was lowered through the water to the sediment surface. Then, for harder-packed sediments, the vibratory hammer was started and the corer penetrated down through the sediment to a project depth of $-40 \mathrm{ft}$ MLLW, as indicated by the water surface level relative to marks on the outside of the core barrel. For soft sediment, the weight of the coring apparatus often caused penetration through the sediment without vibration; once harder material was reached, the hammer was tumed on and the corer was allowed to penetrate to project depth. The coring apparatus was then pulled from the sediment, detached from the vibratory hammer, and lowered onto the barge deck.

As each 12- in. core was brought on board the barge platform, the hinged door of the core barrel was opened and the sediment was measured from the mudline downward to ensure that appropriate depth was reached. If the required core length was not achieved, the sediment in the core barrel was emptied and rinsed with seawater to prepare for a second core attempt. Once the required core length was achieved, the sediment was marked at $-42 \mathrm{ft}$ MLLW.

After the core segments were measured, the appropriate amount of sediment (calculation of volume to be removed was based on the amount of sediment needed for chemical and biological analyses) was transferred, using a stainless steel spade, from the core barrel to an epoxycoated 5-gal bucket. Each sample container was labeled with the project name, station or composite designation, contributing station(s), and the sampling date(s). The containers were sealed and kept $\operatorname{cool}\left(\sim 4^{\circ} \mathrm{C}\right)$ in a freezer on board the sampling vessel until loaded into a refrigerated van at the end of the sampling day.

Sediment was also collected to $-42 \mathrm{ft} \mathrm{MLLW}$ using the 4-in.-diameter vibratory-hammer corer sampler, one core was collected per station. The core barrel was lined with a 3.125-in. (inner diameter) steam-cleaned Lexan core liner. When each core was brought on board, the liner was pulled from the barrel and the sediment measured from the mudline downward to determine whether appropriate depth was reached. If not, the liner was replaced, and another core sample was taken until project depth was reached. Then the Lexan liner was carefully carried to the cutting stand where it was capped, sealed, labeled, and if necessary, cut into shorter sections to fit in the freezer. Each core label included an arrow pointing to the top of the core, the station designation, core section indicator (e.g., Section 1 of 2 and Section 2 of 2), length interval from the mudline (e.g., 0-3 ft), and sampling date. When each 4-in. core was labeled and sealed, it was kept in a freezer on board the sampling vessel at $-4^{\circ} \mathrm{C}$. 
Detailed sampling records were maintained at each station and consisted of the following: station name, date, type of core (12-in. or 4-in.), replicate number, uncorrected water depth, tide height, corrected water depth, required core length, sampling time, total core collected, and comments. At the end of each sampling day, cores were off-loaded from the barge and stored in a refrigerated van at the staging area. When sampling was completed, the inventory of the samples was confirmed and recorded on the MSL chain-of-custody forms. The custody forms were signed by the field leader, who kept one copy and sealed the others with the core samples. The interior of the refrigerated van was maintained at $4^{\circ} \mathrm{C}$ while the core samples were transported to the MSL in Sequim, Washington.

Richmond Harbor site water was also collected using a peristaltic pump and $25 \mathrm{ft}$ on noncontaminating Lexan C-flex tubing. Water was pumped from approximately $15 \mathrm{ft}$ below the surface into solvent-rinsed 5-gal polypropylene carboys. This site water was used to prepare the SPP (Section 2.2.4).

\subsubsection{Reference and Control Samples}

Reference sediment samples R-AM, R-BF and R-OS were collected using a pipe dredge deployed from the FV Cobra, a charter boat owned and operated by Bob Smith Sportfishing. Sampling locations were determined by LORAN $\mathrm{C}$ and variable fix and range radar systems aboard the vessel and by a Raytheon Global Positioning System (GPS). The vessel navigation systems were verified at known fixed locations, such as the Golden Gate channel pilot buoy. Reference sampling records were maintained in a log book, and consisted of station position, date, time, replicate, water depth, sediment type, and comments. All reference samples were kept in labeled coolers on board the sampling vessel until they were off-loaded to the refrigerated van.

The control sediment sampling stations were located in Sequim Bay, Washington (C-SB); West Beach, Whidbey Island, Washington (C-WB); Dillon Beach/Tomales Bay, California (C-NE); and Newcastle, Maine (C-NV). The control sediment from Sequim Bay was collected with a modified van Veen grab sampler $\left(0.1 \mathrm{~m}^{2}\right)$ deployed from an MSL research vessel. West Beach sediment was collected with a small, MSL-designed, anchor-dredge sampler that also obtains sufficient quantities of Rhepoxynius abronius for test purposes. The dredge was deployed from the MSL's 17-ft Boston Whaler in approximately $15 \mathrm{ft}$ of water at the sampling location as determined by reference to shoreline features. The control sediment, C-NE, was collected by Brezina and Associates, using a shovel, and was collected concurrently with the test organisms $N$. caecoides and $C$. stigmaeus. This control sediment and the test organisms were shipped overnight to the MSL. The sediment was stored at $4^{\circ} \mathrm{C} \pm 2^{\circ} \mathrm{C}$ and the test organisms were maintained at proper holding conditions. The New England sediment was collected concurrently with the test organism, N. virens, by Aquatic Research Organisms, Newcastle. 


\subsubsection{Test Organism Collection}

Seven species of marine organisms were used in Richmond Harbor toxicity tests:

- bentnose clam, Macoma nasuta

- polychaete, Nephtys caecoides

- polychaete, Nereis virens

- phoxocephalid amphipod, Rhepoxynius abronius

- juvenile flattish speckled (sanddab), Citharichthys stigmaeus

- juvenile mysid shrimp, Holmesimysis costata

- larvae of bay mussel, Mytilus galloprovincialis.

All of the organisms were wild-captured individuals collected either by a commercial supplier or by the MSL. M. nasuta were collected from intertidal zones in Discovery Bay near Gardiner, Washington, by a commercial supplier, using a shovel, sieve, and bucket. In the field, clams were kept cool in large containers filled with sediment and seawater from the collection station. R. abronius were collected by the. MSL off West Beach, Whidbey Island, using the specially designed anchor dredge deployed from a 17-ft Boston Whaler. Sediment brought up with the dredge was sieved through a 2-mm mesh screen to remove large debris and predatory species. During sampling, the amphipods were kept in coolers partially filled with their native sediment and seawater until delivery to a holding tank at the MSL.

Brezina and Associates (Dillon Beach, California) supplied N. caecoides, C. stigmaeus, and $H$. costata individuals for toxicity testing. N. caecoides were collected from mud flats in Tomales Bay using a shovel, bucket, and sieve. $N$. caecoides were placed into clean coolers containing sediment and seawater from the collection station. Prior to ovemight shipment to the MSL, the seawater in each cooler was supersaturated with oxygen (22 ppm). The C. stigmaeus were collected from Tomales Bay in $12 \mathrm{ft}$ to $15 \mathrm{ft}$ of water. C. stigmaeus were captured with a small trawl with a 0.25 -in. mesh net. The trawl was held close to the work boat so a dip net could be used to transfer $C$. stigmaeus into double plastic bags containing oxygen-saturated seawater. $H$. costata were collected with a plankton dip net and transferred to a holding container aboard the work boat, where they were sorted by appropriate age and size class and then shipped to the MSL in bags containing oxygen-saturated water. Adult bay mussels ( $M$. galloprovincialis) were obtained from the intertidal zones of Long Beach, Califomia, by Marinus Incorporated. $N$. virens were collected from intertidal regions of Newcastle using a bucket and shovel, and were transported via overnight mail in moist mats of seaweed packed in coolers. 


\subsection{SEDIMENT SAMPLE PREPARATION}

According to the 1991 Implementation Manual, sediment must be initiated into biological tests within 6-weeks of sample collection, although 2 weeks is the recommended holding time. In the 6-week holding period the core samples were received at the MSL and inventoried against the chain of custody, processed for solid-phase and SPP testing, and initiated into the appropriate biological tests. The following sections describe equipment preparation, geologic descriptions of core samples, and preparation of sediment for solid-phase and SPP tests.

\subsubsection{Laboratory Glassware and Equipment Preparation}

The cleaning of glassware, stainless steel utensils, plastic, laboratory containers and equipment was done according to stringent procedures to avoid contamination of sediment samples. Glassware, including test containers, aquaria, and sediment transfer equipment, was washed with warm, soapy water, rinsed five times with deionized water, then soaked in a $5 \%$ reagent- grade nitric acid bath for a minimum of $4 \mathrm{~h}$. After soaking, glassware was rinsed with deionized water five times and allowed to dry. Titanium tools, polyvinyl chloride (PVC), Nalgene, and other plastic items, such as funnels, were washed and soaked in acid baths in the same manner as glassware.

Stainless steel bowls, spoons, spatulas, and other utensils were washed with warm, soapy water, rinsed five times with deionized water, and allowed to air dry. They were then rinsed with methylene chloride under a fume hood and the methylene chloride was allowed to evaporate under the hood before use.

Rubber stoppers and other porous materials were washed with warm, soapy water and rinsed five times with deionized water. These items were then "seasoned" by continuous soaking in $0.45-\mu \mathrm{m}$-filtered seawater for at least 2 days prior to use.

Large pieces of laboratory equipment, such as the epoxy-coated (TNEMEC Epoxy converter 83-83B) mixer used to mix sediment and epoxy-coated boards used to hold cores for geologic descriptions, were washed with mild soap solution and thoroughly rinsed with tap water followed by deionized water.

Equipment used to measure water quality, such as $\mathrm{pH}$, dissolved oxygen (DO), temperature, ammonia, and salinity, were calibrated according to manufactures' guidelines or as specified in MSL standard operating procedures (SOPS).

\subsubsection{Geologic Description of Cores}

A geologic characterization of each Richmond Harbor sampling station was conducted by an MSL geologist. The description was performed on each 4-in. core. All core sections from one station were removed from storage and scored longitudinally with a circular saw. A linoleum knife 
was used to split the core open to expose the sediment stratigraphy. The geologist measured and described the core from top to bottom, recording data on a core data log. The geologic characterization protocol (Appendix $A$ ) was consistent with the American Society of Testing and Materials (ASTM) Method D2488-84 (ASTM 1984).

\subsection{SEDIMENT AND TISSUE CHEMISTRY PROCEDURES}

Richmond Harbor sediment treatments were analyzed for conventional and chemical parameters. Conventional parameters consisted of the following: grain size, TOC, TVS, oil and grease, TPH, and percentage of solids. Chemical parameters consisted of PAHs, chlorinated pesticides, PCBs, phthalate esters, metals, and butyltins. Metals, pesticides, and PCBs were also analyzed using WET. Table 2.1 lists the parameters for which the Richmond Harbor sediment treatments were analyzed and shows the quality assurance ranges and detection limits for each parameter. Richmond Harbor tissues of $N$. virens and $M$. nasuta were analyzed for the set of PAHs, chlorinated pesticides, PCBs, phthalate esters, metals, and butyltins (Table 2.2).

The following sections briefly describe the methods used for analysis of sediments and tissues for the required physical and chemical parameters. Analyses followed established procedures where applicable. Quality control samples when appropriate, included method blanks, matrix spike (MS) analyses, standard reference materials (SRMs), and analytical replicates. The MS and SRM were used as a measurement of analytical accuracy. The analytical replicates were used to evaluate analytical precision.

Prior to subsampling for chemistry, all sediment composites were thoroughly homogenized (Section 2.3.7) to provide a uniform consistency. Sample aliquots for chemical analyses were placed in cleaned and labeled containers appropriate for the parameters to be measured. Sediment treatments not used immediately were returned to the labeled, epoxy-coated metal buckets and stored at $4^{\circ} \mathrm{C}$.

\subsubsection{Conventional Sediment Measurements}

Grain size analysis was conducted by Soil Technology, Inc., of Bainbridge Island, Washington. Sixteen grain size fractions were determined by a combination of sieve and pipette techniques from the Puget Sound Estuary Program (PSEP) Protocols for Measuring Selected Environmental Variables in Puget Sound (PSEP 1986). These methods are consistent with ASTM D2217 (ASTM 1985) and D422 (ASTM 1972) (with the substitution of a No. t00 sieve for a No. 140 sieve). An additional measurement for salt content was performed, and each grain size fraction was corrected for this salt measurement. Table 2.3 presents the fractions measured. 
IABLE 2.1. Analytical Chemistry Requirements for Richmond Harbor Sediment Treatments

\begin{tabular}{|c|c|c|c|c|}
\hline Parameters & $\begin{array}{l}\text { Detection } \\
\text { Limits (a) } \\
\text { (mg/kg dry wt) }\end{array}$ & $\begin{array}{l}\text { Number of } \\
\text { Samples }\end{array}$ & $\begin{array}{c}\text { Range of } \\
\text { Recovery (\%) }\end{array}$ & $\begin{array}{c}\text { Relative } \\
\text { Precision (\%) }\end{array}$ \\
\hline
\end{tabular}

Sediment

Conventional Parameters

TOC

Oil and Grease

TPH

Grain Size

Total Solids

TVS

$\begin{array}{cc}0.1 \% & 36 \\ 20 & 36 \\ 20 & 36 \\ 1.0 \% & 36 \\ 1.0 \% & 36 \\ 0.1 \% & 36\end{array}$

$\begin{array}{cc}\text { NA (b) } & 10 \\ 50-150 & 20 \\ 50-150 & 20 \\ \text { NA } & 20 \\ \text { NA } & 20 \\ \text { NA } & 20\end{array}$

Metals

Silver (Ag)

Arsenic (As)

Cadmium (Cd)

Chromium (Cr)

Copper (Cu)

Mercury $(\mathrm{Hg})$

Nickel (Ni)

Lead $(\mathrm{Pb})$

Selenium (Se)

Zinc (Zn)

$\begin{array}{cc}0.1 & 36 \\ 2.5 & 36 \\ 0.1 & 36 \\ 33 & 36 \\ 5.5 & 36 \\ 0.02 & 36 \\ 7.5 & 36 \\ 6.2 & 36 \\ 0.1 & 36 \\ 7.8 & 36\end{array}$

$\begin{array}{cc}75-125 & 20 \\ \text { NA } & 20 \\ 75-125 & 20 \\ \text { NA } & 20 \\ \text { NA } & 20 \\ 75-125 & 20 \\ \text { NA } & 20 \\ \text { NA } & 20 \\ 75-125 & 20 \\ \text { NA } & 20\end{array}$

\section{Organic}

Compounds

$\begin{array}{lllll}\text { Butyltins } & 0.001 & 36 & 40-120 & 30 \\ \text { PCBs(c) } & 0.02 & 36 & 40-120 & 30 \\ \text { PAHs(d) } & 0.02 & 37 & 40-120 & 30 \\ \text { Pesticides(e) } & 0.002-0.03 & 36 & 40-120 & 30 \\ \text { Phthalate Esters } & 0.02 & 36 & 40-120 & 30\end{array}$

(a) Target detection limits; all efforts were made to reach lowest practical detection limits.

(b) Not applicable. Spiking for specific method is not feasible.

(c) Reported as Aroclor equivalents 1242, 1248, 1254, and 1260 and total PCB. Analyzed using EPA Method 8080.

(d All compounds on EPA Method 610 list. Analyzed using Method 8270 in selected ion mode.

(e) All compounds on EPA Method 608 list. Analyzed using Method 8080. 
IABLE 2.2. Analytical Chemistry Requirements for Richmond Harbor Tissue Samples

\begin{tabular}{llccc}
\hline \hline Parameters & $\begin{array}{c}\text { Detection } \\
\text { Limits (a) } \\
\text { (mg/kg wet wt) }\end{array}$ & $\begin{array}{c}\text { Number of } \\
\text { Samples }\end{array}$ & $\begin{array}{c}\text { Range of } \\
\text { Recovery (\%) }\end{array}$ & $\begin{array}{c}\text { Relative } \\
\text { Precision (\%) }\end{array}$ \\
\hline Metals & 0.1 & & & \\
$\mathrm{Ag}$ & 2.0 & 90 & $75-125$ & 20 \\
$\mathrm{As}$ & 0.1 & 90 & $\mathrm{NA}(\mathrm{b})$ & 20 \\
$\mathrm{Cd}$ & 1.0 & 90 & $75-125$ & 20 \\
$\mathrm{Cr}$ & 4.3 & 90 & $75-125$ & 20 \\
$\mathrm{Cu}$ & 0.02 & 90 & $\mathrm{NA}$ & 20 \\
$\mathrm{Hg}$ & 1.0 & 90 & $75-125$ & 20 \\
$\mathrm{Ni}$ & 1.0 & 90 & $75-125$ & 20 \\
Pb & 1.0 & 90 & $75-115$ & 20 \\
$\mathrm{Se}$ & 35 & 90 & $\mathrm{NA}$ & 20 \\
$\mathrm{Zn}$ & & & $\mathrm{NA}$ & 20 \\
Organic & & & & \\
Compounds & 0.001 & 90 & $40-120$ & 30 \\
Butyltins & 0.02 & 90 & $40-120$ & 30 \\
PCBs (c) & 0.02 & 90 & $40-120$ & 30 \\
PAHs (d) & 0.003 & 90 & $40-120$ & 30 \\
Pesticides(e) & 0.02 & 90 & $\mathrm{NA}$ & $\mathrm{NA}$ \\
Phthalate Esters & & & &
\end{tabular}

(a) Target detection limits; all efforts were made to reach lowest practical detection limits.

(b) Not applicable, Spiking for XRF analysis not feasible.

(c) Reported as Aroclor equivalents 1242, 1248, 1254, and 1260 and total PCB, EPA Method 8080.

(d) All compounds on EPA.Method 610 list. Analyzed using Method 8270 in SIM.

(e) All compounds on EPA Method 608 list. Analyzed using Method 8080.

TABLE 2.3. Grain Size Fractions Measured

\begin{tabular}{ccc}
\hline \hline Grain Size $(\mu \mathrm{m})$ & Phi & Screen Number \\
\hline \hline 3350 & -2 & 6 \\
2000 & -1 & 10 \\
1000 & 0 & 18 \\
250 & 2 & 60 \\
125 & 3 & 120 \\
62.5 & 4 & 230 \\
48 & 4.5 & NAla) \\
31.2 & 5 & NA \\
23 & 5.5 & NA \\
15.6 & 6 & NA \\
7.8 & 7 & NA \\
3.9 & 8 & NA \\
1.9 & 9 & NA \\
0.9 & 10 & NA \\
$<0.4$ & 11 & NA
\end{tabular}

(a) Not applicable. 
Approximately $25 \mathrm{~g}$ of each sediment sample was analyzed for total solids, and another $10-\mathrm{g}$ to $100 \mathrm{~g}$ aliquot was weighed for grain size analysis. To separate the coarser sand and gravel fraction from the silt/clay fraction, sediment was washed with distilled water through a $63.5-\mu \mathrm{m}$ (4.0 phi) sieve into a $1-\mathrm{L}$ graduated cylinder. The coarse fraction was dried, weighed, and shaken through a nest of sieves to yield the required seven coarse subfractions. Any material still passing through the final $63.5-\mu \mathrm{m}$ sieve was added to the previous fines in the $1-L$ graduated cylinder. The silt/clay fraction was then subdivided by a pipette technique based on Stoke's Law of differential settling velocities for different sized particles. The silt/clay fraction was disassociated by adding a dispersant (sodium hexametaphosphate) to distilled water contained in a $1-L$ graduated cylinder. At specified time intervals and specified depths below the surface, $20-\mathrm{mL}$ aliquots were withdrawn from the graduated cylinder, delivered to a preweighed container, and dried at $90^{\circ} \mathrm{C} \pm 2^{\circ} \mathrm{C}$ to a constant weight. Triplicate analysis of three samples was performed as a quality control measure. Other quality control measures, such as spikes, SRMs, or minimum detection limits, do not apply to grain size analysis.

Analysis of total volatile solids was performed at Analytical Resources Inc. (ARI) in Seattle, Washington. Total volatile solids are a measure of the fraction of total solids that are lost on ignition. The TVS measurements are used as an estimate for the amount of organic matter in the total solids. Operationally, TVS are defined by the combustion temperature and do not always represent the organic content of a sample because some of the more volatile organic material may be lost during drying and some inorganic material may be lost during combustion. To perform TVS analysis, ARI follows PSEP (1986), which first oven dries the sample to constant weight, and then the sample is removed and combusted at $550^{\circ} \mathrm{C}$. The sample was cooled in a desiccator and then reweighed. The amount of sample lost during ignition was then defined as the volatile solids fraction. Quality control measures included one method blank and three sets of triplicate analysis.

Analysis of TOC was performed by Global Geochem, in Canoga Park, California. The TOC is the amount of nonvolatile, partially volatile, volatile, and particulate organic carbon compounds in a sample. Each sediment treatment was dried and ball milled to a fine powder. Before combustion, inorganic carbon in the sample was removed by acidification. The TOC in sediment was then determined by measuring the quantity of carbon dioxide released during combustion of the sample (EPA 1986a) and reporting the release as percentage of dry weight. Quality control measures included six method blanks and one triplicate analysis per batch.

Total oil and grease and TPH were performed by ARI. Total oil and grease includes vegetable oils, animal fats, soaps, waxes, and any other carbon-hydrogen material extractable by the solvent Freon. The TPH comprises the nonpolar mineral fraction of total oil and grease that is not removed by silica gel absorption. Infrared spectrophotometry (IR) was used to determine 
concentrations of oil and grease (Method 413.2, EPA 1979) and petroleum hydrocarbons (Method 418.1, EPA 1979). A 20-g aliquot of sample was dried with anhydrous sodium sulfate, then extracted with Freon. For total oil and grease, sample extracts were scanned from 4000 to $600 \mathrm{~cm}^{-1}$ on an infrared spectrophotometer, and the peak height was measured at $2930 \mathrm{~cm}^{-1}$. Since this wavelength represents the $-\mathrm{CH}_{2}$ configurations of hydrocarbons, it was the standard used to determine oil and grease. For TPH, silica gel was added to the extract to remove the more polar animal-and vegetable-based oils. The extract was then shaken and allowed to settle. An aliquot was then removed and scanned the same way as was the oil and grease sample. The relationship of peak height to oil concentration was determined by regressing the peak height versus a known concentration of fuel oil and vegetable oil for TPH and oil and grease, respectively. Quality control measures include one blank, a matrix spike, and one analytical triplicate per batch.

\subsubsection{Semivolatile Organic Compounds}

Analyses for semivolatile organic compounds (PAHs and phthalate esters) in the Richmond Harbor sediment treatments and $M$. nasuta and $N$. virens tissues were performed by the MSL in Sequim, Washington. The semivolatile organic compounds analyzed in sediments were the 16 PAHs listed in EPA Method 610. These compounds were extracted by the National Oceanic Atmospheric Administration (NOAA) status and trends method (Krahn et al. 1988), which involves multiple extractions on an ambient roller using methylene chloride as the extraction solvent. A portion of the extract was used for $\mathrm{PAH}$ and phthalate ester analysis by gas chromatography/mass spectroscopy (GC/MS) in the selective ion mode (SIM) following EPA SW-846 Method 8270 (EPA 1986b). Tissue extracts were run through gel permeation chromatography (GPC) prior to analysis to remove any additional interferences.

Quality control measures included at least one method blank per batch. A matrix spike solution consisting of all $16 \mathrm{PAH}$ compounds was added to each sample of both sediment and tissue to assess the accuracy of the measurement. One matrix spike was performed for each batch. National Institute of Science and Technology (NIST) SRM 1941 was used to assess the accuracy of the sediment measurement and NIST SRM 1974 was used to assess the accuracy of the tissue measurement. One sample in each batch was analyzed in triplicate to assess precision.

\subsubsection{Chlorinated Pesticides and PCBs}

Pesticide and PCB analyses for Richmond Harbor sediments and $M$. nasuta and $N$. virens tissue samples were performed by the MSL. Chlorinated pesticides and PCBs in sediments and tissues were quantified by gas chromatography/electron capture detection (GC/ECD) following EPA SW-846 Method 8080 (EPA 1986b). 
Chlorinated pesticides and PCBs were extracted simultaneously with the PAH compounds, using the ambient roller technique described for PAHs. The procedure involved multiple methylene chloride extractions. A portion of the methylene chloride extract was solventexchanged to hexane, and interferences were removed by passing the extract through a column packed with deactivated alumina and silica by the NOAA status and trends method (Krahn et al. 1988). The samples then require an additional cleanup treatment using HPLC to remove other interferences. Analytical quantification was performed using GC/ECD analysis. Surrogates were added to each sample before extraction to assess extraction efficiency.

Quality control measures included a method blank with each batch. A matrix spiking solution, consisting of either a subset of pesticides or one Aroclor, was also added to the appropriate samples before extraction. The matrix spike analyses were conducted with each batch to assess accuracy of the measurements. One sample in each batch was analyzed in triplicate to assess precision.

\subsubsection{Metals}

Sediment and tissue metals analyses were performed by Pacific Northwest Laboratory (PNL). Ten metals were measured in sediments and tissues: silver (Ag), arsenic (As), Cd, chromium ( $\mathrm{Cr}$ ), $\mathrm{Cu}$, mercury $(\mathrm{Hg})$, nickel (Ni), lead ( $\mathrm{Pb})$, selenium (Se), and zinc ( $\mathrm{Zn})$. Samples of sediment, $M$. nasuta tissue, and $N$. virens tissue were analyzed using a combination of four different methods: 1) energy-diffusive $x$-ray fluorescence (XRF), following a PNL standard operating procedure; 2) Zeeman graphite-furnace atomic absorption spectroscopy (GFAA), following modified EPA 200.9 (EPA 1991); 3) cold-vapor atomic absorption spectroscopy (CVAA), according to the method of Bloom and Crecelius (1983); and 4) inductively coupled plasma mass spectrometry (ICP/MS), following modified EPA 200.8 (EPA 1991). The analytical methods for each sample matrix and corresponding metals for which each method was used are presented in Table 2.4.

TABLE 2.4. Analytical Method and Corresponding Metal for Each Sample Matrix

\begin{tabular}{|c|c|c|c|c|c|c|c|c|c|}
\hline \multicolumn{4}{|c|}{ Sediment } & \multicolumn{3}{|c|}{ N. virens Tissue } & \multicolumn{3}{|c|}{ M. nasuta Tissue } \\
\hline XRF & GFAA & CVAA & ICP/MS & XRF & CVAA & ICP-MS & XRF & CVAA & ICP-MS \\
\hline $\begin{array}{l}\mathrm{As} \\
\mathrm{Cr} \\
\mathrm{Cu} \\
\mathrm{Ni} \\
\mathrm{Pb} \\
\mathrm{Zn}\end{array}$ & $\begin{array}{l}\mathrm{Ag} \\
\mathrm{Se}\end{array}$ & $\mathrm{Hg}$ & $\mathrm{Cd}$ & $\begin{array}{l}\mathrm{As} \\
\mathrm{Cu} \\
\mathrm{Se} \\
\mathrm{Zn}\end{array}$ & $\mathrm{Hg}$ & $\begin{array}{l}\mathrm{Cr} \\
\mathrm{Ag} \\
\mathrm{Cd} \\
\mathrm{Pb} \\
\mathrm{Ni}\end{array}$ & $\begin{array}{l}\text { As } \\
\text { Cu } \\
\mathrm{Se} \\
\mathrm{Zn}\end{array}$ & $\mathrm{Hg}$ & $\begin{array}{l}\mathrm{Cr} \\
\mathrm{Ag} \\
\mathrm{Cd} \\
\mathrm{Pb} \\
\mathrm{Ni}\end{array}$ \\
\hline
\end{tabular}


To prepare sediment and tissues for analysis, samples were freeze-dried, then blended in a Spex mixer-mill. Approximately $5 \mathrm{~g}$ of this mixed sample was then ground in a ceramic ball mill. The XRF analysis was performed on a $0.5-\mathrm{g}$ aliquot of dried, ground material pressed into a pellet with a diameter of $2 \mathrm{~cm}$. For GFAA, CVAA, and ICP/MS analyses, $0.2-\mathrm{g}$ aliquots of dried homogenous sample went through an acid digestion process to separate and isolate the metals from the matrix.

Quality control measures for metals analyses included analysis of blanks (not applicable to XRF technique), matrix spike, and triplicate analyses for each batch of up to 20 samples, and analysis of at least 1 SRM sample per 20 samples. The SRMs for sediment were SRM 1646, obtained from NIST, and BEST-1 obtained from the National Research Council of Canada (NRCC). The tissue SRM consisted of an oyster tissue, 1566a, obtained from NRCC.

\subsubsection{Butyltins}

Butyltins in sediment and $M$. nasuta and N. virens tissue were analyzed at the MSL. Butyltin compounds in sediment and tissues were analyzed using gas chromatography/ flame photometric detection (GC/FPD) following the methods of Unger et al. (1986).

Wet samples were extracted with methylene chloride and tropolone. Tripentyltin was added before extraction as a surrogate compound to assess extraction efficiency. The mono-, di-, and tributyltin compounds extracted from the sediment and tissues were derivatized to a less volatile, more thermally stable form (nonionic n-hexyl/or n-pentyl derivatives). The extracts were passed through a Florisil liquid chromatography column for cleanup, and the butyltins were quantified by GC/FPD. Concentrations were reported in $\mu \mathrm{g} / \mathrm{kg}$ dry weight of mono-, di-, and tributyltin species as tin. The recently certified reference material for butyltins, NRCC SRM PACS-1, was analyzed with the sediment. Selected sediment and tissue samples were spiked with di- and tributyltins prior to extraction to assess the accuracy of the procedure. Method blanks, three sets of matrix spikes and three sets of triplicates were analyzed as quality control measures.

\subsubsection{California Waste Extraction Test (WET). Soluble Threshold Limit Concentration (STLC). Metals. Hexavalent Chromium and STLC. Pesticides, and PCBS}

Califomia State Title 22 WET and subsequent analyses for soluble threshold limit concentration (STLC) of metals, pesticides, and PCBs were conducted by Clayton Environmental Consultants of Pleasanton, Califomia. The WET extracts (membrane-filtered liquid portion of sediment sample) were measured for metals by either EPA Method 6010 (inductivelycoupled plasma [ICP]) or by atomic absorption (AA). Extracts were prepared and measured for pesticides and PCBs following EPA Methods 3510 and 8080 . Two surrogate internal standards were added prior to extraction: decachlorobiphenyl and tetrachloro-m-xylene. Quality control 
samples for both metals and organics analyses included a method blank, matrix spike, and matrix spike duplicate.

\subsubsection{Preparation of Solid-Phase Samples}

Solid phase, also called bulk sediment or whole sediment, refers to the sediment itself, as opposed to suspended or dissolved phases. In biological tests, the solid phase of sediments can be from the test sediment (represents dredged material once it has settled at an aquatic disposal site), the reference sediment (the existing environment of a disposal site without dredged material), or the control sediment (environment of a benthic test organism).

All of the Richmond Harbor sediment used for biological testing came from stations that were combined to yield the six sediment composites. The compositing scheme was provided by USACE prior to field sampling. Individual stations were sampled with the 12-in. vibratory-hammer corer, and specific and appropriate volumes from each station were removed and placed in a corresponding labeled bucket. The labeled buckets with the appropriate composite name were then sent back to the MSL for processing. The procedure for homogenizing Richmond Harbor test sediment composites involved placing the sediment in a mixer coated with a epoxy paint and mixing the sediment with minimal amounts of $0.45-\mu \mathrm{m}$-filtered seawater to achieve a homogeneous consistency. Once a sediment composite was thoroughly homogenized, it was referred to as a sediment treatment, indicating that all the necessary sample processing was completed and the sediment could be used in testing. The term sediment treatment will be used to describe all three sediment types, test, reference and control prepared in this manner.

The reference and control sediment sample processing involved sieving prior to compositing. To perform the sieving process, sediments were placed on screens having mesh diameters of 0.5 or $1.0 \mathrm{~mm}$, depending on sediment type, and press sieved into clean epoxycoated buckets. Depending on the sediment consistency, minimal amounts of $0.45-\mu \mathrm{m}$ filtered seawater was added to ensure thorough mixing. Any sediment or organism remaining on the $0.5 \mathrm{~mm}$ sieve was removed and discarded. After sieving the sediment treatments were stored at approximately $4^{\circ} \mathrm{C}$ until needed for testing. Between sieving of different reference sediments, all equipment was thoroughly rinsed with $0.45-\mu \mathrm{m}$-filtered seawater to avoid potential crosscontamination of samples.

\subsubsection{Preparation of Suspended-Particulate-Phase Samples}

The SPP of sediment composites was used to evaluate water column effects of open-water dredged material disposal. The SPP is the liquid supernatant that remains after mixing sediment with seawater and allowing heavier particles to settle to the bottom. Because SPP preparation does not involve filtration, this phase contains suspended particles as well as 
dissolved constituents. The SPP tests evaluate effects caused by both the physical presence of the suspended particles and the chemical toxicity of contaminants associated with the particles or dissolved fractions. The process is intended to approximate exposure conditions created as a result of material discharged through the water column during dredge-disposal operations.

The first step of SPP preparation was creating a 4:1 (volume:volume) water to sediment slurry in $1-\mathrm{L}$ glass jars with Teflon-lined lids. The jars were marked at $200 \mathrm{~mL}$ and $400 \mathrm{~mL}$ and filled to the 200-mL mark with brine-adjusted Richmond Harbor site water. The brine was prepared by freezing and thawing filtered Sequim Bay seawater, and decanting the liquid to reach a salinity of $100 \%$. Homogenized sediment was added until the water was displaced to the 400-mL mark. The jar was shaken vigorously by hand and then filled to $1 \mathrm{~L}$ with the brineadjusted Richmond Harbor seawater. Twelve jars of sediment and water were placed on a shaker table and agitated for $30 \mathrm{~min}$ at a shaking rate of 120 to $150 \mathrm{cycles} / \mathrm{min}$. After shaking, the slurry was poured into $500-\mathrm{mL}$ Teflon containers with tightly-fitted lids. These containers were placed in a centrifuge and spun for 10 to $15 \mathrm{~min}$ at a g-force of 777 (equivalent to a 24-h settling period). The 10-min centrifugation was necessary to ensure that test organisms would be visible at the first observation after exposure to SPP test treatments. After centrifugation, the supernatant was poured into clean.10-gal aquaria; and the sediment remaining in the Teflon jar was discarded. If SPP was not used immediately, it was stored at $4^{\circ} \mathrm{C}$. The Teflon jars were rinsed after each use, and the above process was continued until an adequate amount of SPP was produced for each test treatment. Between sediment SPP preparations, all glass and Teflon containers were appropriately cleaned according to procedures described in Section 2.2.1.

For each SPP treatment, there were five replicates of each of the four SPP concentrations: $0 \%$ (MSL filtered seawater), 10\%,50\%, and 100\% SPP. The brine-adjusted Richmond Harbor sitewater was used to prepare the SPP, as noted above, and $0.45-\mu \mathrm{m}$ filtered Sequim Bay seawater was used to prepare the dilution series.

\subsection{IOXICOLOGICAL TESTING PROCEDURES}

Biological tests including solid-phase, and bioaccumulation were performed at the MSL. The solid-phase tests were used to assess the acute toxicity potential of dredged material after it had settled at an aquatic disposal site. Three species of marine organisms were exposed to the test treatments from Richmond Harbor, reference area sediment, and control sediment.

Two acute toxicity tests were conducted: 1) a 10-day solid-phase static test using the burrowing amphipod, $R$. abronius, and 2) a 10-day solid-phase flow-through acute toxicity test exposure using the polychaete, $N$. caecoides and the clam, M. nasuta. 
The SPP tests evaluate effects caused by the physical presence of suspended particles and the toxicity of chemical contaminants associated with the particles or dissolved into the water after disposal. Three marine species were used in these tests: juvenile sanddabs (C. stigmaeus), mysids ( $H$. costata), and larvae of the bay mussel ( $M$. galloprovincialis). The SPP treatments were prepared as described in Section 2.2.4.

The bioaccumulation test was a 28-day exposure of $M$. nasuta and $N$. virens, tested in separate test containers. The purpose of the bioaccumulation test was to assess the potential for bioaccumulation of contaminants from the sediment into the tissues of the organisms. The sediment treatments and procedures were similar to those of the 10-day test, except they involved a longer exposure period, larger test population, larger species of polychaete, and depuration process for surviving $M$. nasuta and $N$. virens.

The MSL facilities provided the required conditions for flow-through solid-phase tests, static solid-phase tests, and static SPP tests. Laboratory equipment providing these testing conditions included a controlled-temperature environment, flow-through filtered seawater supply, lighting control, and air supply.

\subsubsection{0-Day Solid-Phase Static Test with $R$. abronius}

The amphipods were kept in a large holding tank containing their native sediment with flowing $15^{\circ} \mathrm{C}$ seawater. Organisms were not fed during the holding period, which was less than 2 weeks before test initiation.

The $R$. abronius test was conducted in 1-L glass jars (Figure 2.2) placed in random positions on a water table maintained at $15^{\circ} \mathrm{C}$. Prior to test initiation, test sediment was added to the jars to a depth of $2 \mathrm{~cm}$, and then $0.45-\mu \mathrm{m}$-filtered seawater was added to a volume of $750 \mathrm{~mL}$. The jars were aerated and placed on the water table overnight to stabilize temperature to test conditions. After settling, initial water quality parameters were measured in each container and recorded on water quality forms.

The amphipods were gently sieved from the holding tank into clean seawater and counted into small transfer containers. The number of organisms was then confirmed by a second observer before the amphipods were transferred into the test container. Initiation of testing began by adding $20 R$. abronius to each test container. The date and time of initiation were recorded on data forms. $R$. abronius were observed daily during the test, and the number of organisms floating on the surface, swimming in the jar, or on the sediment surface was recorded on observation forms. Amphipods that were floating on the surface were gently pushed below the water surface with a pipette tip and observed as they either buried or did not rebury into the sediment. Two replicates of each sediment treatment in dummy jars were also prepared in the same manner as the test containers, with the exception that no organisms were added. These 


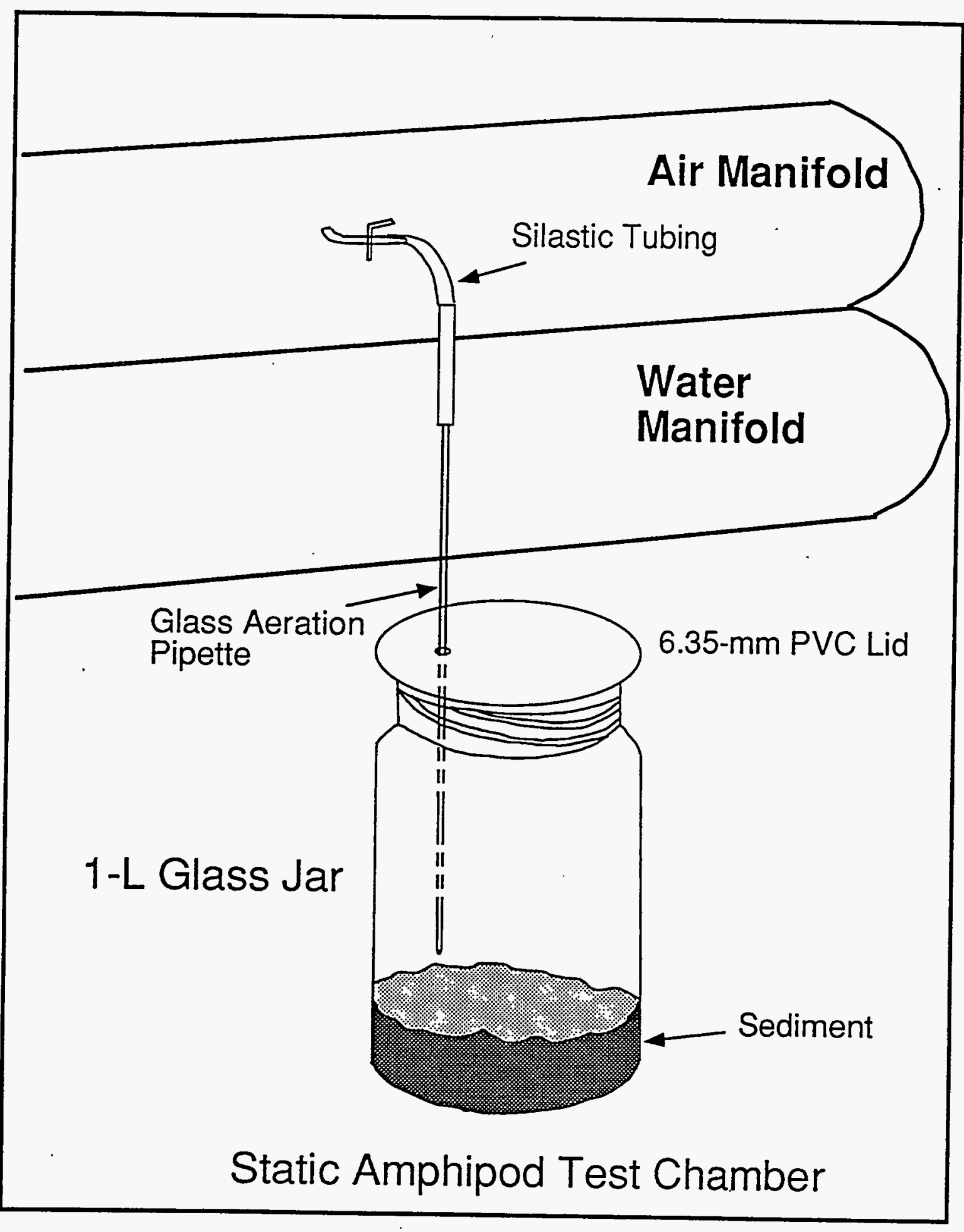

FIGURE 2.2. Static Mason Jar for $R$. abronius Toxicity Test 
dummy jars were used to measure the interstitial porewater ammonia of the sediment treatments prior to initiation of the organisms and on Day 10 (termination).

Water temperature, salinity, $\mathrm{pH}$, and $\mathrm{DO}$ were measured daily in one replicate of each sediment treatment, and in all containers at initiation and termination of the bioassay. Ammonia in the overlying water was measured on Days $0,1,3,7$, and 10 . Porewater ammonia was measured in dummy jars on Days 0 and 10. Acceptable ranges for water quality parameters during the experiment were as follows:

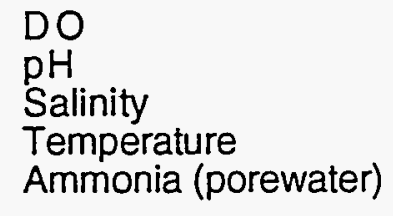

At the end of the test (Day 10), the contents of each jar were sieved through a $0.5-\mathrm{mm}$ Nytex screen to collect the $R$. abronius. The organisms were placed in clean seawater in a glass dish labeled with the sediment treatment and replicate number. The number of live and dead organisms was counted and examined under a dissecting microscope. The presence or absence of body parts recovered at the end of the test was also noted. If an individual organism did not respond to gentle probing it was considered dead. At least $10 \%$ of the mortality counts were confirmed by a second observer.

A 96-h reference toxicant test with cadmium chloride was conducted to have a basis for comparison with the health and expected response of the test organisms to a known toxicant. The reference toxicant test was conducted in the same manner as the 10-day solid-phase test. R. abronius were exposed to a seawater control plus four concentrations of cadmium chloride $(0.38,0.75,1.5$ and $3.0 \mathrm{mg} / \mathrm{L}$ as cadmium [Cd]). There were three replicates of each concentration.

\subsubsection{0-Day Solid-Phase Flow-Through Test with N. caecoides and M. nasuta}

Prior to testing, N. caecoides were held in their native sediment in shallow trays covered with well-aerated $15^{\circ} \mathrm{C}$ seawater from a gravity-fed flow-through system. M. nasuta were held in large water tables or holding tanks containing clean sediment with flow-through $15^{\circ} \mathrm{C}$ seawater. Temperature, $\mathrm{pH}, \mathrm{DO}$, and salinity of water in each holding tank were monitored daily. The organisms were not fed during the holding period.

The flow-through tests with M. nasuta and N. caecoides were conducted in a 10-gal aquaria placed in random positions on water tables. Figure 2.3 shows the system used for flowthrough tests. Approximately $8 \mathrm{~L}$ of sand-filtered seawater was added to each aquarium via the flow-through system. Then, sediment was added to a depth of $3 \mathrm{~cm}$, by measuring the required amount $(3870 \mathrm{~mL})$ into a glass container and pouring it into the aquarium while washing it with 


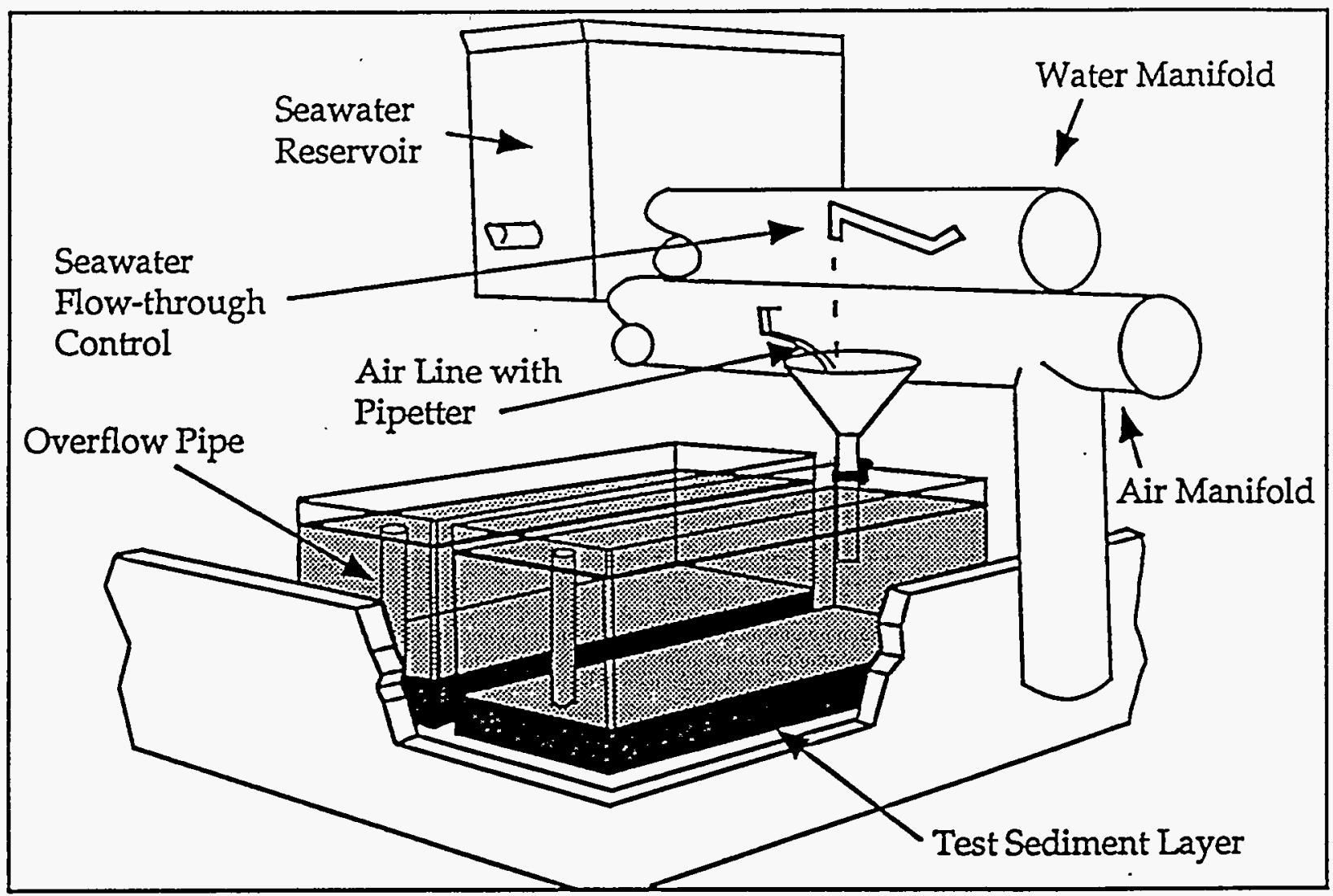

FIGURE 2.3. Flow-through Aquaria for 10-Day M. nasuta/N. caecoides Toxicity Test and 28-Day $M$. nasuta and $N$. virens Tests 
seawater to help distribute the sediment evenly over the bottom. The flow-through system was initiated, and aquaria were allowed to fill to a total volume of approximately $36 \mathrm{~L}$. For $4 \mathrm{~h}$, the sediments in the aquaria were allowed to settle in the absence of flowing seawater. Then the flow-through system was adjusted and calibrated to deliver $125 \pm 10 \mathrm{~mL} / \mathrm{min}$ of seawater flow to each aquarium. The system was allowed to operate overnight before the addition of test organisms.

To initiate the test, 20 or $25 \mathrm{M}$. nasuta and $20 \mathrm{~N}$. caecoides were collected from the holding tanks and placed in each aquarium. Each test aquarium was labeled with initiation time/date and the initials of the examiner who placed the organisms in each chamber. Water quality parameters (below) were measured daily in at least one replicate of each sediment treatment and recorded on water quality data sheets. A replicate of each sediment treatment dummy jar was used to measure the interstitial porewater ammonia of the sediment treatments prior to initiation and termination of the test organisms. (Water quality data are provided in Appendix E). The water quality parameters and ranges established for the tests were as follows:

$\begin{array}{ll}\mathrm{DO} & \geq 6.0 \mathrm{mg} / \mathrm{L} \\ \mathrm{pH} & 7.30 \text { to } 8.30 \\ \text { Salinity } & 30 \pm 2.0 \% \\ \text { Temperature } & 15.0^{\circ} \mathrm{C} \pm 2.0^{\circ} \mathrm{C} \\ \text { Flow Rates } & 125 \pm 10 \mathrm{~mL} / \mathrm{min} \\ \text { Ammonia } & \text { measured but presently not established. }\end{array}$

Daily observations of test organism behavior were made and recorded on data forms. The number of $M$. nasuta on the sediment surface and the number of those with their siphons exposed were noted, as well as the number of $N$. caecoides on the sediment surface and the number of those with only their heads exposed. In addition, the number of dead organisms in each aquarium was recorded on daily observation forms. Dead organisms were removed from the aquaria and incinerated; no replacement of dead organisms occurred during testing. If a dead N. caecoides was removed, it was identified as a whole animal, a head, or a tail portion.

At the end of the 10-day test, water quality measurements were performed in all replicates and the contents of each aquarium were gently passed through a 1.0-mm Nytex screen to recover the $N$. caecoides and $M$. nasuta. The organisms were placed in glass dishes and labeled with the sediment treatment number. At this time, the number of dead and live organisms of each species was counted. Death was determined by observing whether the $N$. caecoides reacted to gentle probing; if there was no movement, the organism was considered dead. Death of $M$. nasuta was determined by the presence of gaping shells. The mortality data were recorded on the termination forms. At least $10 \%$ of the mortality counts were confirmed by a second observer. 


\subsubsection{8-Day Solid-Phase Flow-Through Test with N. virens and M. nasuta}

The procedure for conducting the 28-day solid-phase flow-through test with $N$. virens and $M$. nasuta was identical to that of the 10-day test, with five exceptions: 1) the number of organisms in each aquarium was $25 \mathrm{M}$. nasuta and $25 \mathrm{~N}$. virens because more individuals were needed to produce enough tissue for chemical analysis; 2) $N$. virens replaced $N$. caecoides because it is a much larger species and can provide a greater quantity of tissue for chemical analysis; 3 ) the exposure period was increased from 10 to 28 days; 4) the surviving test organisms were depurated, and tissues were sampled for chemical analysis; and 5) the M. nasuta and $N$. virens were tested separately. The ranges for water quality parameters, as well as the test conditions, such as temperature and flow rate, were the same for the 28-day test as for the 10-day test. Water quality parameters were measured, and mortality of the test organisms monitored at the same frequency for both tests.

When the 28-day test was terminated, the living $M$. nasuta and $N$. virens were collected for chemical evaluation of bioaccumulation. To ensure that tissue chemistry results would not be biased by contaminants associated with sediment grains in the digestive tract, the test organisms were allowed to depurate, or void the digestive tract, for $48 \mathrm{~h}$ following the 28-day exposure. The surviving $N$. virens from one test aquarium were placed in another flow-through 10-gal aquarium with flowing seawater and no sediment. The animals were not fed during the depuration period. The surviving $M$. nasuta were contained in a glass baking dish (without sediment), and placed in an aquarium with flowing seawater. After $48 \mathrm{~h}$ of depuration, the $M$. nasuta shells were cleaned with a scrub brush prior to the removal of tissues using titanium knives. The tissues were placed into clean jars and submitted for chemical analysis. The $N$. virens were gently washed in clean seawater to remove extemal sediment grains and put in containers for chemical analyses.

\subsubsection{6-Hour Suspended-Particulate-Phase Test with C. stigmaeus}

The test chambers for the SPP test with $C$. stigmaeus were 10-gal static aquaria randomly positioned on the water tables, with 20 to 24 aquaria per table. Test temperature was maintained by a circulating water bath on the water table. Aeration was provided through a glass pipette connected by silastic tubing to an overhead air manifold. Aquaria were labeled with a sediment treatment code, concentration, and replicate number. The volume of test material in each aquarium was $10 \mathrm{~L}$. To obtain the $100 \%$ SPP treatment, $10 \mathrm{~L}$ of $100 \%$ SPP was added directly to the aquarium; the $0 \%$ SPP treatment consisted of $10 \mathrm{~L}$ of Sequim Bay filled seawater. To prepare the $10 \%$ and $50 \%$, SPP concentrations appropriate volumes of $100 \%$ SPP and $0.45 \mu \mathrm{m}$-filtered Sequim Bay dilution water were mixed directly in a test aquarium.

After SPP preparation and placement of containers on the water table, aeration was started and initial water quality parameters were measured in all replicates. Ten $C$. stigmaeus 
were removed from the holding tanks, using a net, and added to each test container. The test population for each concentration was 50 individuals (200 individuals per SPP treatment). Initiation time and date were documented on test containers and data forms.

C. stigmaeus were not fed during the 96 -h exposure. After initiation, $\mathrm{DO}, \mathrm{pH}$, salinity, and temperature were measured daily in at least one replicate. Ammonia was measured in at least one replicate of the $100 \%$ SPP prior to the introduction of test organisms and at the end of the 96-h test. Acceptable ranges for the water quality parameters during the experiment were as follows:

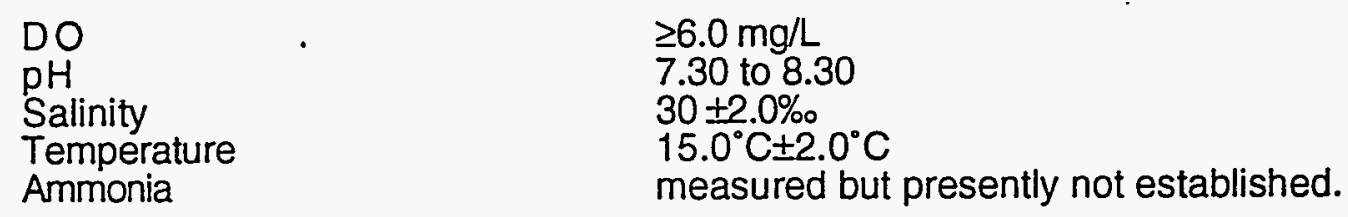

Observations of $C$. stigmaeus activity and behavior in each test container were made at test initiation and at $4,24,48$, and $72 \mathrm{~h}$. An organism was considered dead if it did not respond to gentle probing.

Before termination of the test at $96 \mathrm{~h}$, water quality parameters were measured in all replicates. At $96 \mathrm{~h}$, the number of live and dead organisms was counted in each test container. As a quality control check, a second observer confirmed at least $10 \%$ of the mortality counts.

A 96-h Cu reference toxicant test was also conducted to establish the health and expected response of the test organisms. The reference toxicant test was conducted in the same manner as the SPP tests. C. stigmaeus were exposed to a seawater control plus four concentrations of copper sulfate $(0.5,1.0,1.5$, and $2.0 \mathrm{mg} / \mathrm{L}$ as $\mathrm{Cu})$. There were three replicates of each treatment.

A 96-h ammonia reference toxicant test was conducted to establish the expected response of the test organisms to ammonia. The ammonia reference toxicant test was conducted in the same manner as the SPP tests. C. stigmaeus were exposed to a seawater control plus four concentrations of ammonia $(15,20,25$, and $30 \mathrm{mg} / \mathrm{L}$ as ammonium chloride). The actual concentrations of ammonia were measured in this experiment and are reported in Section 3.0 of this report. There were three replicates of each concentration.

\subsubsection{6-Hour Suspended-Particulate-Phase Test with H. costata}

Prior to testing, $H$. costata were held for at least $48 \mathrm{~h}$ in flow-through aquaria maintained at test temperature $\left(15^{\circ} \mathrm{C}\right)$. In the holding tanks, $H$. costata were fed brine shrimp twice a day, and water quality parameters were monitored daily. 
The test containers for the $H$. costata test were 400-mL glass jars placed in random positions on water tables. Test temperature was maintained by immersing these containers in a circulating water bath. Aeration was provided through a pipette connected by silastic tubing to an overhead air manifold. Appropriate volumes of $100 \%$ SPP and $0.45-\mu \mathrm{m}$-filtered Sequim Bay dilution water were added to 1 -gal jars to make $0 \%, 10 \%, 50 \%$, and $100 \%$ SPP concentrations for the $H$. costata test. A total of $1500 \mathrm{~mL}$ was prepared for each dilution to provide the test volume of $300 \mathrm{~mL}$ in each of five replicates. The test containers were labeled with a sediment treatment code, concentration, and replicate number.

After the SPP concentrations were prepared and placed on the water table, gentle aeration was started and water quality was measured in all replicates. H. costata were then removed from the holding tanks, using a wide-bore pipette. To initiate the test, 10 individuals were added to each container to produce a test population of 50 individuals per concentration (200 individuals per treatment). The test initiation time and date were documented on data forms. After test initiation, water quality parameters were measured in one replicate. Ammonia was measured in at least one replicate of the 100\% SPP prior to initiation of the organisms and at the end of the $96-h$ test. The parameters for this test were as follows:

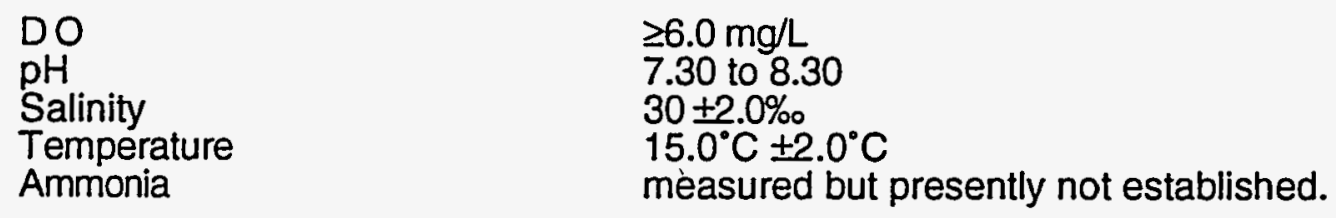

Observations of test organisms were made at test initiation and at $4,24,48$, and $72 \mathrm{~h}$, using a light table to enhance visibility of the $H$. costata. During the $96-\mathrm{h}$ exposure, $H$. costata were fed brine shrimp daily. Excess food was removed with a small pipette before daily observations, using extra caution not to disturb test animals. Molted exoskeletons and any particulates that had settled from the SPP solution were also removed.

Prior to test termination, water quality parameters were measured in all replicates. At $96 \mathrm{~h}$, the number of live and dead animals was counted in each test container. An organism was considered dead if it did not respond to gentle probing. As a quality control check, a second observer confirmed surviving test organisms in at least $10 \%$ of the mortality counts.

A 96-h Cu reference toxicant test was conducted to establish the health and expected response of the test organisms. The reference toxicant test was conducted in the same manner as the SPP tests. H. costata were exposed to a seawater control plus four concentrations of copper sulfate $(50,100,150$ and $200 \mu \mathrm{g} / \mathrm{L}$ as $\mathrm{Cu}$ ). There were three replicates of each treatment.

A 96-h ammonia reference toxicant test was also conducted to establish the expected response of the test organisms to concentrations of ammonia. The ammonia reference toxicant 
test was conducted in the same manner as the SPP tests. H. costata were exposed to a seawater control plus 11 concentrations of ammonia $(0.25,0.5,1,2,5,10,20,40,60$, 80, and $100 \mathrm{mg} / \mathrm{L}$ as ammonium chloride). Actual ammonia measurements were determined for this experiment and are reported in Section 3.0 of this report. There were three replicates of each concentration.

\subsubsection{8-Hour Suspended-Particulate-Phase Test with Larval M. galloprovincialis}

Mussels were held in flowing, unfiltered Sequim Bay seawater at ambient temperatures for approximately five days. Chambers for the bivalve-larvae test were $500-\mathrm{mL}$ glass jars, labeled with sediment treatment code, concentration, position number, and replicate number. Dilutions of SPP $(0 \%, 10 \%, 50 \%$, and $100 \%)$ were prepared with Sequim Bay seawater in a 2,000-mL graduated cylinder, then $300 \mathrm{~mL}$ of test solution was poured directly into each of five replicate test chambers. After all chambers reached testing temperatures $\left(16^{\circ} \mathrm{C} \pm 2^{\circ} \mathrm{C}\right)$, initial water quality parameters were measured in all replicates. Test chambers were placed in random positions on a water table and provided with gentle aeration.

Spawning was induced by placing adult $M$. galloprovincialis into $15^{\circ} \mathrm{C}$, filtered Sequim Bay seawater and then rapidly raising the holding water temperature to $20^{\circ} \mathrm{C}$. Spawning generally occurred within $1 \mathrm{~h}$ of temperature elevation. Spawning males and females were isolated in individual jars with filtered Sequim Bay seawater and allowed to shed gametes for approximately $45 \mathrm{~min}$. Eggs from each female were then filtered into separate jars through a $75 \mu \mathrm{m}$ Nytex screen to remove feces, detritus, and byssal fibers. Sperm from at least three males were pooled and $10 \mathrm{~mL}$ of sperm solution was then added to the individual egg stocks. Egg-sperm solutions were mixed every $10 \mathrm{~min}$ with a perforated plunger. Fertilization proceeded for $1 \mathrm{~h}$, then the fertilization rate (percentage fertilized) was determined by removing a subsample and observing the number of multi-cell stage embryos. Fertilization was considered successful if greater than $90 \%$ of the embryos were in the multi-cell stage. To prevent polyspermy, egg stocks with greater than $90 \%$ fertilization were rinsed on a $20 \mu \mathrm{m}$ Nytex screen to remove excess sperm. Embryo stock-solution density was estimated by removing a $0.1 \mathrm{~mL}$ subsample and counting all multi-cell embryos, then multiplying by 10 to yield embryo density (embryos $/ \mathrm{mL}$ ). Stock solution was diluted or concentrated to yield 7500 to 9000 embryos $/ \mathrm{mL}$. The test was initiated by introducing $1 \mathrm{~mL}$ of stock solution into each test chamber to produce embryo densities of 25 to 30 embryos $/ \mathrm{mL}$. Test initiation date and time were recorded on data sheets. Following initiation, $10 \mathrm{~mL}$ stocking density subsamples were removed from each container and preserved in $10 \%$ formaldehyde to determine actual stocking density. Water quality parameters were measured in one replicate per treatment daily throughout the test. Acceptable ranges for water quality parameters were as follows: 


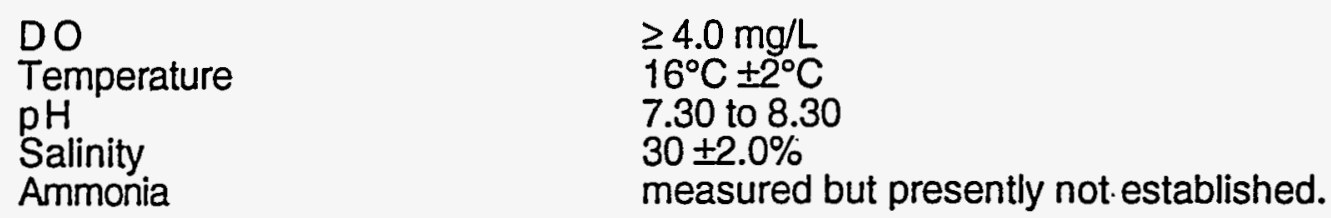

The bivalve test was terminated after $48 \mathrm{~h}$, when greater than $90 \%$ of the larvae in the controls had reached the D-cell stage (prodissoconch I). Final water quality parameters were recorded for all replicates. In addition, ammonia concentrations were measured in one replicate of all $0 \%$ SPP and $100 \%$ SPP treatments.

Each chamber was then homogenized with a perforated plunger, and a 10-mL subsample was removed and placed into $20-\mathrm{mL}$ scintillation vial. The subsample was then fixed with $1 \mathrm{~mL}$ of $50 \%$ formaldehyde in seawater. Samples were scored for the appearance of normal D-shaped larvae (prodissoconch 1), abnormal prodissoconch I larvae, developmentally delayed/developmentally delayed-abnormal larvae (categorized as "other" in Appendix J), and total number of larvae. At least $10 \%$ of the counts were confirmed by a second observer.

A 48-h Cu reference toxicant test was conducted with each batch of test lavae to establish the health and expected response of the test organisms. The reference toxicant test was set up and conducted in the same manner as the SPP tests. M. galloprovincialis larvae were exposed to a filtered Sequim Bay seawater control plus copper sulfate concentrations of $1 \mu \mathrm{g} / \mathrm{L}, 4 \mu \mathrm{g} / \mathrm{L}, 16 \mu \mathrm{g} / \mathrm{L}$, and $64 \mu \mathrm{g} / \mathrm{L}$ as $\mathrm{Cu}$, with three replicates per concentration. Because not all treatments could be tested concurrently, a separate reference test was performed with each round of tests to compare gamete sensitivity to a known toxicant.

A 48-h ammonia reference toxicant test was also conducted to establish the sensitivity of test organisms to ammonia. The ammonia reference toxicant test was conducted in the same manner as the SPP tests. M. galloprovincialis were exposed to a seawater control plus four concentrations of ammonia (1,10,20,40,80, and $100 \mathrm{mg} / \mathrm{L}$ as ammonium chloride). Actual ammonia concentrations were measured for this experiment and are reported in Section 3.0 of this report. There were three replicates of each concentration.

\subsection{DATA ANALYSIS AND INTERPRETATION}

The geologic characteristics, sediment chemistry, acute toxicity, and bioaccumulation potential of Richmond Harbor dredged material samples were compared with data from the analysis of the reference sediment R-OS. The geologic evaluations and sediment chemistry data are not analyzed statistically, but are presented in both graphical and tabular formats to assist with interpretation. These portray the differences in physical and chemical characteristics between the dredged material and the reference sediment R-OS. 


\subsubsection{Randomization}

All solid-phase and SPP toxicity tests were designed as completely random tests using the discrete uniform random number generator in LOTUS 123 spreadsheet. Organisms were randomly allocated to treatments, and treatments were randomly positioned on water tables. Special care was taken with $C$. stigmaeus individuals in order to eliminate bias caused by variable mobility of the fish (otherwise, easily caught fish would be used earlier than more mobile fish).

\subsubsection{Statistical Analysis of Solid-Phase Tests}

Solid-phase acute toxicity data are compared only with data for one reference treatment, using a one-tailed Dunnett's test (Dunnett 1964) with an experiment-wise error rate $\alpha=0.05$. This test identifies, with $95 \%$ confidence, test treatments with greater acute toxicity (mortality) than the reference. The Dunnett's test is the recommended statistical method to apply to assessment of dredged material for open-water disposal (EPA/USACE 1991). Dunnett's test approach is environmentally more conservative because it results in the identification of potentially a greater number of stations that are unacceptable for unconfined aquatic disposal. However, when Dunnett's test is applied to nonindependent data sets, there is increased probability of Type II statistical error (a chance that a difference between treatment and reference means will be identified as statistically significant when it is not). Dunnett's test results are used in conjunction with the criterion that mortality between test and reference treatments must be greater than $20 \%$ for a sediment to be considered acutely toxic.

\subsubsection{Statistical Analysis of Suspended-Particulate-Phase Tests}

Two statistical tests are presented in the 1991 Implementation Manual for the interpretation of SPP tests. The first test is a one-sided t-test between survival in control replicates and survival in the 100\% SPP replicates. This test is performed only when survival in the $100 \%$ SPP is less than control ( $0 \%$ SPP) survival and when control survival is greater than $90 \%$ (indicating test validity). Prior to conducting the t-test, angular transformation (arcsine of the square root) of the proportion surviving in test replicates is performed to reduce possible heterogeneity of variance between control and $100 \%$ SPP mean survivals. The second test required by the 1991 Implementation Manual is an $L_{50}$ calculation, the concentration of SPP that is lethal to $50 \%$ of the individuals tested. The $L C_{50}$ values for these tests were calculated using the Trimmed Spearman-Karber Method (Finney 1971). The Spearman Karber estimator is appropriate only if there is increasing mortality with increasing concentration and if $50 \%$ or greater mortality is observed in test solutions when normalized to control survival. If $50 \%$ mortality does not occur in the $100 \%$ SPP dilutions for any treatments, then $L_{50}$ values are reported as $>100 \%$ SPP. The same method was used to calculate $\mathrm{EC}_{50}$ values (the concentration at which $50 \%$ of 
the test individuals show a developmental effect) for the bivalve SPP test and $L_{C_{50}}$ values for all reference toxicant tests.

\subsubsection{Statistical Analysis of Bioaccumulation}

Before statistical analysis of $M$. nasuta and $N$. virens tissue concentrations, a visual inspection of the tissue chemistry data was performed. If visual inspection showed that a compound was undetected in the replicate samples in test treatments, or that the mean tissue concentration in the reference treatments was greater than that in the test treatments, no further analysis was performed. If the detected concentration of a compound for at least one replicate exceeded that of any reference treatment, statistical analysis was performed. In all cases, detection limits were used in numerical calculations when a compound was undetected.

Contaminant levels in tissues of $M$. nasuta and $N$. virens exposed to potential dredged material test treatments were compared with those exposed to sediment from the Deep Off-Shelf reference area. Like the solid-phase toxicity data, bioaccumulation data were statistically analyzed using Dunnett's test $(\alpha=0.05)$. In contrast to a multiple comparison test, the result of using the Dunnett's test is the identification of Type II errors, which detect a greater number of statistically significant differences between treatment and reference. Any statistically significant bioaccumulation was reported along with the magnitude of the difference between mean contaminant concentrations found in the test treatment tissues and the mean concentration found in the tissues exposed to the reference sediment R-OS.

\subsection{QUALITY ASSURANCE/QUALITY CONTROL PROCEDURES}

The quality assurance/quality control (QAQC) procedures followed for these studies were consistent with the 1991 Implementation Manual and the EPA protocols (PSEP 1986). The procedures were documented by the PNL Quality Engineering Division in a QA plan (QAP). Data accumulation notebooks were assigned to each portion of the study and served as records of day-to-day activities during the research. All entries in the notebooks were signed, dated, and reviewed by both the project manager and the quality assurance engineer. The following discussion summarizes QAVC procedures followed for the three main portions of this study: sediment sampling, biological testing, and chemical testing.

\subsubsection{Sample Tracking and Storage}

All sediment samples were accompanied by chain-of-custody forms from the time of collection to receipt at the MSL. After sample collection and compositing, a new set of custody forms was initiated for the sediment subsamples requiring chemical analyses. These accompanied the samples to the appropriate laboratory where the forms were signed and returned to the MSL project manager. Custody forms were also initiated for all tissue samples 
upon completion of the biological testing. These forms accompanied the samples to the appropriate laboratory for chemical analyses.

All sediment collected for these studies was stored in glass, cellulose acetate butyrate containers, or steel drums lined with 9-C-4-A-phenolic epoxy, a noncontaminating coating. Sediment cores and grab samples were stored at $4^{\circ} \mathrm{C}$ prior to biological testing. Subsamples for chemical analyses were obtained prior to biological testing. These subsamples were stored frozen (except those for grain size analysis, which were held at $4^{\circ} \mathrm{C}$ ) until chemical analyses were performed. Samples for organic analyses were stored frozen for up to 2 months (PSEP 1986). Samples for metals were freeze-dried upon receipt at the laboratory and held for up to 6 months (EPAUSACE 1991; PSEP 1986).

Tissue samples were frozen immediately upon completion of the bioaccumulation tests. Samples for organic analyses and metals were stored in precleaned glass jars with Teflon-lined lids and samples for metals analyses were stored in precleaned plastic jars. Prior to analyses, samples for organic analyses were held for up to 2 months.

\subsubsection{Sediment and Tissue Chemistry Quality Control Procedures}

Chemical testing procedures require that specific QAVC protocols be followed. The QAVC guidelines specific to this project are provided in the PNL Quality Assurance Division as a QAP. These guidelines include the following:

- $\quad$ analysis of a method blank with each batch of samples

- $\quad$ replicate analysis on at least $5 \%$ of the samples (triplicate analyses where possible) to assess analytical precision

- analysis of matrix spikes on $5 \%$ of the samples (where applicable) with appropriate compounds to assess accuracy

- analysis of SRMs at a frequency of $5 \%$, if available for the analytes of interest and sample matrix

- $\quad$ archiving of all instrument printouts (e.g., raw data and chromatograms from AA and GC analyses) for future review.

In actual practice, some of the specific guidelines listed in the QAP for analytical precision and accuracy were modified to apply to the most current methods employed by laboratories. The guidelines for detection limits, range of recovery, and relative precision are listed in Table 2.1 for sediments and in Table 2.2 for tissues.

Measurements of accuracy can be determined by analyzing matrix spikes of known concentrations, as well as SRMs that have been certified for the presence of specific parameters. Matrix spikes were analyzed for organic parameters, including oil and grease, TPH, PAHs, pesticides, PCBs, metals, and butyltins. Spikes generally are made up of a subset of the 
analytes of interest. Spike recoveries were calculated based on the difference between the amount spiked and the amount recovered in the sample, taking into account the amounts already present in the spiked sample. Spikes for organic compounds and metals were analyzed at a frequency of $5 \%$. Surrogate compounds were added in known amounts to samples analyzed for PAHs, pesticides, PCBs, and butyltins. Surrogate compounds are added to samples prior to extraction, and their recoveries are a measurement of the efficiency or procedural accuracy of the analysis. Sediment SRMs were analyzed for metals and for organic compounds and metals. Tissue SRMs were analyzed for PAHs and metals. The SRMs for pesticide and PCBs in tissue were not available for this study. The SRMs are not associated with analysis of TOC, oil and grease, TPH, TVS, or grain size.

Measurements of precision were obtained through replicate analysis of selected sediment treatments. Analysis of replicates shows the precision or repeatability of the results. The measurement of precision is the industrial statistic "I," relative percentage of difference (RPD) for duplicate analyses, and the relative standard deviation (RSD) for triplicate analyses. The "l" statistic is defined as the absolute value of the difference between duplicate measurements, divided by the sum of the duplicates. The RPD is defined as the absolute value of the difference between two duplicate measurements, divided by the mean of the duplicates, multiplied by 100 . The RSD is defined as the sample standard deviation divided by the mean, multiplied by 100 . All instrument printouts and other raw data generated using the MSL's analytical instruments are filed at the MSL for future reference. Raw data generated by offsite analytical facilities are retained at those facilities, but can be made available for inspection.

\subsubsection{Toxicological Testing Quality Control Procedures}

Test organisms were handled carefully during collection and transfer to test containers. Organisms shipped to the MSL were gradually equilibrated to test conditions, and kept in their native sediment whenever possible. Animals were fed, if necessary, before biological testing. Information on the collecting and handling of each test species is included in Section 2.1.3.

Selection of species was consistent with the 1991 Implementation Manual and involved the use of juvenile forms, burrowing invertebrates, deposit-feeding organisms, and a larval (planktonic) form. Representatives of all test organisms were taxonomically identified by qualified experts at the MSL before use in bioassays.

Water quality parameters were measured to ensure that acceptable experimental conditions were maintained during testing. Conditions consisted of a stable temperature $\left( \pm 2.0^{\circ} \mathrm{C}\right)$, minimum DO of $4.0 \mathrm{mg} / \mathrm{L}$, and $16 \mathrm{~h}$ of light per day. Salinity and $\mathrm{pH}$ could vary within each test container using the following ranges: salinity $\pm 2.0 \%$, and $\mathrm{pH} \pm 0.5$ units. These limits and values are consistent with those outlined in the 1991 Implementation Manual. Water quality instruments were calibrated according to the manufacturers' specification or PNL protocols. 


\subsection{RESULTS}

\subsection{SEDIMENT COLLECTION AND SAMPLE PREPARATION}

Sediment samples were collected between January 28 and February 2, 1994, from selected field locations in Richmond Harbor. The reference sediment from Bay Fam Borrow Area, Alcatraz Environs Reference Area, and Deep Off-Shelf Reference Area were collected between January 24 and 26, 1994. Control sediment from Sequim Bay, West Beach, Tomales Bay, and New England were collected between February 1 and February 18, 1994. All sediment samples were stored in noncontaminating containers, epoxy-lined 5-gal buckets or seasoned coolers at approximately $4^{\circ} \mathrm{C}$ until ready for processing at the MSL. Richmond Harbor and reference sediment samples were shipped via refrigerated van to the MSL upon completion of the sampling effort. Core samples were geologically described at the laboratory before being homogenized into samples for sediment chemistry. Composites of the test, reference and control treatments were homogenized for sediment chemistry and biological toxicity testing. The SPP of each sediment composite was also prepared for biological testing.

\subsubsection{Bichmond Harbor Deepening Project Core Sampling}

Sediment core samples were collected to $-42 \mathrm{ft}$ MLLW (-38 ft MLLW project depth plus $2 \mathrm{ft}$ overdepth plus up to $2 \mathrm{ft}$ of OBM) from a total of 20 stations in Richmond Harbor: 5 in the Upper Inner Harbor (UIH COMP), 4 in the Santa Fe Channel (SF COMP), 4 in the National Gypsum-GATX berths called Santa Fe Widening stations (SFW COMP), and 7 in the Turning Circle that were separated into upper and lower stations (TB Upper and TB Lower COMP). Stations containing OBM from $-40 \mathrm{ft}$ to $-42 \mathrm{ft}$ MLLW were subsampled to make an OBM composite. One 4-in. core and one 12-in. core were collected at each station as described in Section 2.1.1. Sampling information for 4-in.- and 12-in.- core samples is listed in Table 3.1. Station locations and compositing information are shown in Figure 3.1.

\subsubsection{Reference and Control Sediment Sampling}

Sampling information for reference and control sediment collection is presented in Table 3.2. The Deep Off-Shelf Reference Area is located approximately 50 nautical miles southwest of the Golden Gate Bridge (Figure 3.2), off the continental shelf, in about $3000 \mathrm{~m}$ of water. Sediment samples from this area were collected using a pipe dredge deployed from the FV Cobra as described in Section 2.1.2. The R-BF and R-AM sediments were also collected using the FV Cobra. The Bay Farm Borrow Area, located in San Francisco Bay (Figure 3.3), was sampled at four locations and the sediments were combined to form one R-BF composite, representative of this area. 


\begin{tabular}{|c|c|c|c|c|c|c|c|c|}
\hline \multirow{2}{*}{ Station } & \multicolumn{2}{|c|}{$\begin{array}{l}\text { Califomia State Plane } \\
\text { coerdinates (Zone lll) }\end{array}$} & \multirow[b]{2}{*}{ Latitude (N) } & \multirow{2}{*}{ Longitude $(\mathrm{m})$} & \multirow[t]{2}{*}{$\begin{array}{c}\text { Top of } \\
\text { Core } \\
\text { (-At MLLW) }\end{array}$} & \multirow[t]{2}{*}{$\begin{array}{c}\text { Core } \\
\text { Required } \\
\text { to }-40 \mathrm{ft} \text { (ft) }\end{array}$} & \multirow{2}{*}{\multicolumn{2}{|c|}{$\begin{array}{l}\text { Volume } \\
\text { Contribution } \\
\text { to COMP (gai) }\end{array}$}} \\
\hline & North & East & & & & & & \\
\hline $\begin{array}{l}\text { SF-1 } \\
\text { SF-2 } \\
\text { SF-3 } \\
\text { SF-4 }\end{array}$ & $\begin{array}{l}521,738.32 \\
522,057.12 \\
522,387.11 \\
522,712.99\end{array}$ & $\begin{array}{l}1,462,203.74 \\
1,461,809.50 \\
1,461,406.62 \\
1,461,015.29\end{array}$ & $\begin{array}{l}37^{\circ} 55^{\prime} 05.618^{n} \\
37^{\circ} 55^{\prime} 08.691^{\prime \prime} \\
37^{\circ} 55^{\prime} 11.874^{\prime \prime} \\
37^{\circ} 55^{\prime} 15.018^{n}\end{array}$ & $\begin{array}{l}122^{\circ} 21^{\prime} 51.913^{n} \\
122^{\circ} 21^{\prime} 56.912^{n} \\
122^{\circ} 22^{\prime} 02.021^{n} \\
122^{\circ} 22^{\prime} 06.985^{n}\end{array}$ & $\begin{array}{l}38.5 \\
37.8 \\
37.0 \\
35.9\end{array}$ & $\begin{array}{l}1.5 \\
2.2 \\
3.0 \\
4.1\end{array}$ & $\begin{array}{r}5 \\
7 \\
9 \\
13\end{array}$ & $\begin{array}{l}\text { to SF COMP } \\
\text { to SF COMP } \\
\text { to SF COMP } \\
\text { to SF COMP }\end{array}$ \\
\hline $\begin{array}{l}\text { SFW-1 } \\
\text { SFW-2 } \\
\text { SFW-3 } \\
\text { SFW-4 }\end{array}$ & $\begin{array}{l}522,099.85 \\
521,903.55 \\
521,710.62 \\
521,523.35\end{array}$ & $\begin{array}{l}1,461,571.48 \\
1,461,795.44 \\
1,462,018.23 \\
1,462,256.88\end{array}$ & $\begin{array}{l}37^{\circ} 55^{\prime} 09.067^{n} \\
37^{\circ} 55^{\prime} 07.171^{n} \\
37^{\circ} 55^{\prime} 05.307^{n} \\
37^{\circ} 55^{\prime} 03.503^{n}\end{array}$ & $\begin{array}{l}122^{\circ} 21^{\prime} 59.892^{\prime \prime} \\
122^{\circ} 21^{\prime} 57.049^{\prime \prime} \\
122^{\circ} 21^{\prime} 54.221^{\prime \prime} \\
122^{\circ} 21^{\prime} 51.197^{\prime \prime}\end{array}$ & $\begin{array}{l}32.9 \\
34.1 \\
28.0 \\
30.8\end{array}$ & $\begin{array}{r}7.1 \\
5.9 \\
12.0 \\
9.2\end{array}$ & $\begin{array}{l}5 \\
4 \\
8 \\
7\end{array}$ & $\begin{array}{l}\text { to SFW COMP } \\
\text { to SFW COMP } \\
\text { to SFW COMP } \\
\text { to SFW COMP }\end{array}$ \\
\hline $\begin{array}{l}\text { UIH-1 } \\
\text { UIH-2 } \\
\text { UIH-3 } \\
\text { UIH-4 } \\
\text { UIH-5 }\end{array}$ & $\begin{array}{l}520,784.24 \\
521,007.25 \\
521,065.41 \\
521,265.09 \\
521,289.00\end{array}$ & $\begin{array}{l}1,462,517.29 \\
1,463,021.53 \\
1,462,701.82 \\
1,462,446.79 \\
1,462,695.23\end{array}$ & $\begin{array}{l}37^{\circ} 54^{\prime} 56.249^{\prime \prime} \\
37^{\circ} 54^{\prime} 58.552^{n} \\
37^{\circ} 54^{\prime} 59.064^{\prime \prime} \\
37^{\circ} 55^{\prime} 00.988^{\prime \prime} \\
37^{\circ} 55^{\prime} 01.273^{n}\end{array}$ & $\begin{array}{l}122^{\circ} 21^{\prime} 47.764^{\prime \prime} \\
122^{\circ} 21^{\prime} 41.528^{\prime \prime} \\
122^{\circ} 21^{\prime} 45.532^{\prime \prime} \\
122^{\circ} 21^{\prime} 48.763^{\prime \prime} \\
122^{\circ} 21^{\prime} 45.669^{n}\end{array}$ & $\begin{array}{l}36.9 \\
35.3 \\
37.3 \\
34.4 \\
36.0\end{array}$ & $\begin{array}{l}3.1 \\
4.7 \\
2.7 \\
5.6 \\
4.0\end{array}$ & $\begin{array}{l}6 \\
8.5 \\
5 \\
10 \\
7\end{array}$ & $\begin{array}{l}\text { to UIH COMP } \\
\text { to UIH COMP } \\
\text { to UIH COMP } \\
\text { to UIH COMP } \\
\text { to UIH COMP }\end{array}$ \\
\hline $\begin{array}{l}\text { TB-1 } \\
\text { TB-2 } \\
\text { TB-3 } \\
\text { TB-4 } \\
\text { TB-5 } \\
\text { TB-6 } \\
\text { TB-7 }\end{array}$ & $\begin{array}{l}515,998.97 \\
515,872.52 \\
516,138.25 \\
516,410.09 \\
516,618.50 \\
516,685.17 \\
516,872.49\end{array}$ & $\begin{array}{l}1,463,059.03 \\
1,463,413.44 \\
1,463,701.22 \\
1,463,489.51 \\
1,463,878.13 \\
1,463,510.37 \\
1,463,674.47\end{array}$ & $\begin{array}{l}37^{\circ} 54^{\prime} 09.054^{\prime \prime} \\
37^{\circ} 54^{\prime} 07.873^{\prime \prime} \\
37^{\circ} 54^{\prime} 10.557^{\prime \prime} \\
37^{\circ} 54^{\prime} 13.202^{n} \\
37^{\circ} 54^{\prime} 15.338^{\prime \prime} \\
37^{\circ} 54^{\prime} 15.925^{n} \\
37^{\circ} 54^{\prime} 17.809^{\prime \prime}\end{array}$ & $\begin{array}{l}122^{\circ} 21^{\prime} 39.817^{\prime \prime} \\
122^{\circ} 21^{\prime} 35.365^{\prime \prime} \\
122^{\circ} 21^{\prime} 31.841^{\prime \prime} \\
122^{\circ} 21^{\prime} 34.549^{\prime \prime} \\
122^{\circ} 21^{\prime} 29.753^{\prime \prime} \\
122^{\circ} 21^{\prime} 34.357^{\prime \prime} \\
122^{\circ} 21^{\prime} 32.357^{\prime \prime}\end{array}$ & $\begin{array}{r}30.2 \\
5.2 \\
4.6 \\
28.3 \\
6.3 \\
30.9 \\
8.6\end{array}$ & $\begin{array}{l}5.0(a) \\
5.0 \\
5.0 \\
5.0 \\
5.0 \\
5.0 \\
5.0\end{array}$ & $\begin{array}{l}5 \\
5 \\
5 \\
5 \\
5 \\
5 \\
5\end{array}$ & $\begin{array}{l}\text { to Upper COMP } \\
\text { to Upper COMP } \\
\text { to Upper COMP } \\
\text { to Upper COMP } \\
\text { to Upper COMP } \\
\text { to Upper COMP } \\
\text { to Upper COMP }\end{array}$ \\
\hline $\begin{array}{l}\text { TB-1 } \\
\text { TB-2 } \\
\text { TB-3 } \\
\text { TB-4 } \\
\text { TB-5 } \\
\text { TB-6 } \\
\text { TB-7 }\end{array}$ & $\begin{array}{l}515,998.97 \\
515,872.52 \\
516,138.25 \\
516,410.09 \\
516,618.50 \\
516,685.17 \\
516,872.49\end{array}$ & $\begin{array}{l}1,463,059.03 \\
1,463,413.44 \\
1,463,701.22 \\
1,463,489.51 \\
1,463,878.13 \\
1,463,510.37 \\
1,463,674.47\end{array}$ & $\begin{array}{l}37^{\circ} 54^{\prime} 09.054^{n} \\
37^{\circ} 54^{\prime} 07.873^{n} \\
37^{\circ} 54^{\prime} 10.557^{n} \\
37^{\circ} 54^{\prime} 13.202^{n} \\
37^{\circ} 54^{\prime} 15.338^{n} \\
37^{\circ} 54^{\prime} 15.925^{n} \\
37^{\circ} 54^{\prime} 17.809^{\prime \prime}\end{array}$ & $\begin{array}{l}122^{\circ} 21^{\prime} 39.817^{\prime \prime} \\
122^{\circ} 21^{\prime} 35.365^{\prime \prime} \\
122^{\circ} 21^{\prime} 31.841^{\prime \prime} \\
122^{\circ} 21^{\prime} 34.549^{\prime \prime} \\
122^{\circ} 21^{\prime} 29.753^{\prime \prime} \\
122^{\circ} 21^{\prime} 34.357^{\prime \prime} \\
122^{\circ} 21^{\prime} 32.357^{\prime \prime}\end{array}$ & $\begin{array}{r}35.2 \\
10.2 \\
9.6 \\
33.3 \\
11.3 \\
35.9 \\
13.6\end{array}$ & $\begin{array}{r}4.2 \\
29.8 \\
30.4 \\
6.7 \\
28.7 \\
4.1 \\
26.4\end{array}$ & $\begin{array}{r}3 \\
15 \\
15 \\
4 \\
14 \\
2 \\
13\end{array}$ & $\begin{array}{l}\text { to Lower COMP } \\
\text { to Lower COMP } \\
\text { to Lower COMP } \\
\text { to Lower COMP } \\
\text { to Lower COMP } \\
\text { to Lower COMP } \\
\text { to Lower COMP }\end{array}$ \\
\hline
\end{tabular}

(a) TB Upper COMP was representative of TB stations from mudline to $5 \mathrm{ft}$ below mudline. 


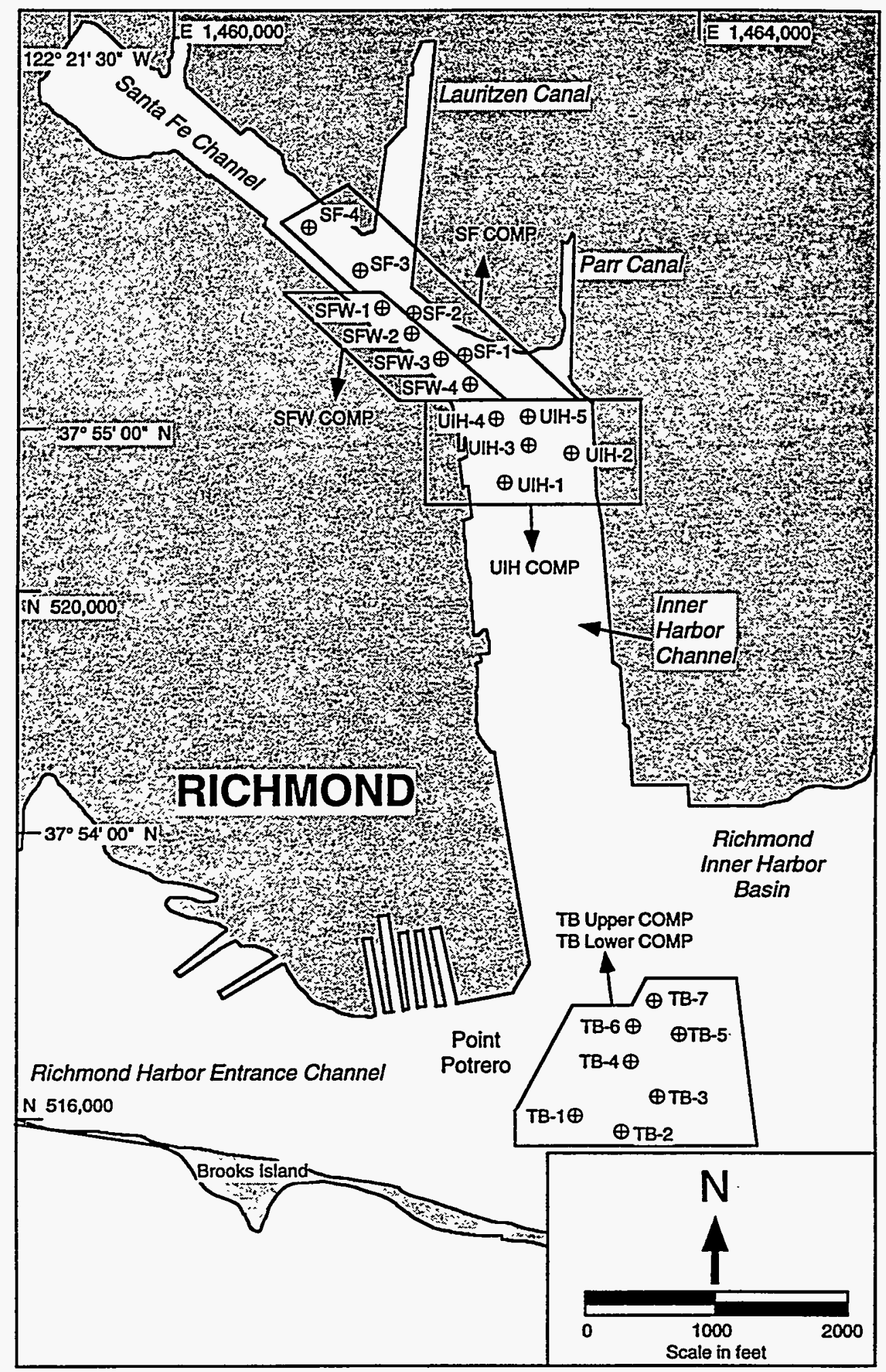

FIGURE 3.1. Sampling Stations and Compositing Scheme for the Richmond Harbor Deepening Project 
TABLE 3.2. Reference and Control Sediment Sampling Data

\begin{tabular}{|c|c|c|c|c|c|}
\hline \multirow[b]{2}{*}{ Reference Area } & \multirow[b]{2}{*}{ Station } & \multicolumn{2}{|c|}{ Station Location } & \multirow[b]{2}{*}{ Depth (ft) } & \multirow[b]{2}{*}{ Volume (gal) } \\
\hline & & Latitude (N) & Longitude $(W)$ & & \\
\hline Bay Farm & $\begin{array}{l}\text { R-BF } 2 \\
\text { R-BF } 3 \\
\text { R-BF } 4 \\
\text { R-BF } 5 \\
\text { TOTAL R-BF }\end{array}$ & $\begin{array}{l}37^{\circ} 44.60^{\prime} \\
37^{\circ} 44.34^{\prime} \\
37^{\circ} 44.38^{\prime} \\
37^{\circ} 44.50^{\prime}\end{array}$ & $\begin{array}{l}122^{\circ} 16.75^{\prime} \\
122^{\circ} 16.75^{\prime} \\
122^{\circ} 16.60^{\prime} \\
122^{\circ} 16.60^{\prime}\end{array}$ & $\begin{array}{l}20 \\
31 \\
31 \\
32\end{array}$ & $\begin{array}{l}10 \\
10 \\
10 \\
\frac{10}{40}\end{array}$ \\
\hline Alcatraz Environs & $\begin{array}{l}\text { R-AM A } \\
\text { R-AM B } \\
\text { R-AM C } \\
\text { R-AM D } \\
\text { R-AM F } \\
\text { R-AM G } \\
\text { R-AMH } \\
\text { R-AMI } \\
\text { TOTAL R-AM }\end{array}$ & $\begin{array}{l}37^{\circ} 49.75^{\prime} \\
37^{\circ} 49.75^{\prime} \\
37^{\circ} 49.75^{\prime} \\
37^{\circ} 49.27^{\prime} \\
37^{\circ} 49.27^{\prime} \\
37^{\circ} 48.83^{\prime} \\
37^{\circ} 48.83^{\prime} \\
37^{\circ} 48.78^{\prime}\end{array}$ & $\begin{array}{l}122^{\circ} 25.88^{\prime} \\
122^{\circ} 25.57^{\prime} \\
122^{\circ} 24.90^{\prime} \\
122^{\circ} 25.88^{\prime} \\
122^{\circ} 24.90^{\prime} \\
122^{\circ} 25.88^{\prime} \\
122^{\circ} 25.57^{\prime} \\
122^{\circ} 24.95^{\prime}\end{array}$ & $\begin{array}{l}65 \\
71 \\
58 \\
61 \\
85 \\
59 \\
46 \\
50\end{array}$ & $\begin{array}{r}5 \\
5 \\
5 \\
5 \\
5 \\
5 \\
5 \\
5 \\
40\end{array}$ \\
\hline Deep Off-Shelf Area & R-OS & $37^{\circ} 24.71^{\prime}$ & $123^{\circ} 14.74^{\prime}$ & 4000 & 40 \\
\hline Sequim Bay Control & C-SB & $48^{\circ} 03.70^{\prime}$ & $123^{\circ} 01.50^{\prime}$ & $25-30$ & 50 \\
\hline Tomales Bay Control & C-NE & $38^{\circ} 13.83^{\prime}$ & $122^{\circ} 57.67^{\prime}$ & intertidal & 40 \\
\hline West Beach Control & C-WB & $48^{\circ} 23.83^{\prime}$ & $122^{\circ} 40.00^{\prime}$ & $15-20$ & 10 \\
\hline New England Control & C-NV & $N D(a)$ & ND & ND & 5 \\
\hline
\end{tabular}

(a) ND Not Determined.

The Alcatraz Environs Reference Area surrounding Alcatraz Island (Figure 3.4) consisted of eight field locations that were individually sampled for sediment chemistry parameters and then composited to form one R-AM test treatment, representative of the area. This composite was also sampled for sediment chemistry. Four control sediments for use in solid-phase toxicity tests were collected from Sequim Bay (Figure 3.5), West Beach (Figure 3.6), Tomales Bay (Figure 3.7), and New England, as described in Section 2.1.2. Sequim Bay sediment (C-SB) was used in all solid-phase tests as an experimental control as well as for the native control for the clam, $M$. nasuta. West Beach control sediment (C-WB) was used as the native control for the amphipod, $R$. abronius. Tomales Bay is the source of native sediment for the polychaete, $N$. caecoides, and was used in the 10-day toxicity test. Native sediment for the polychaete, $N$. virens, was collected from a site in Maine for use in the $N$. virens 28-day bioaccumulation test. 


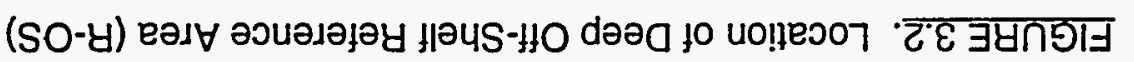

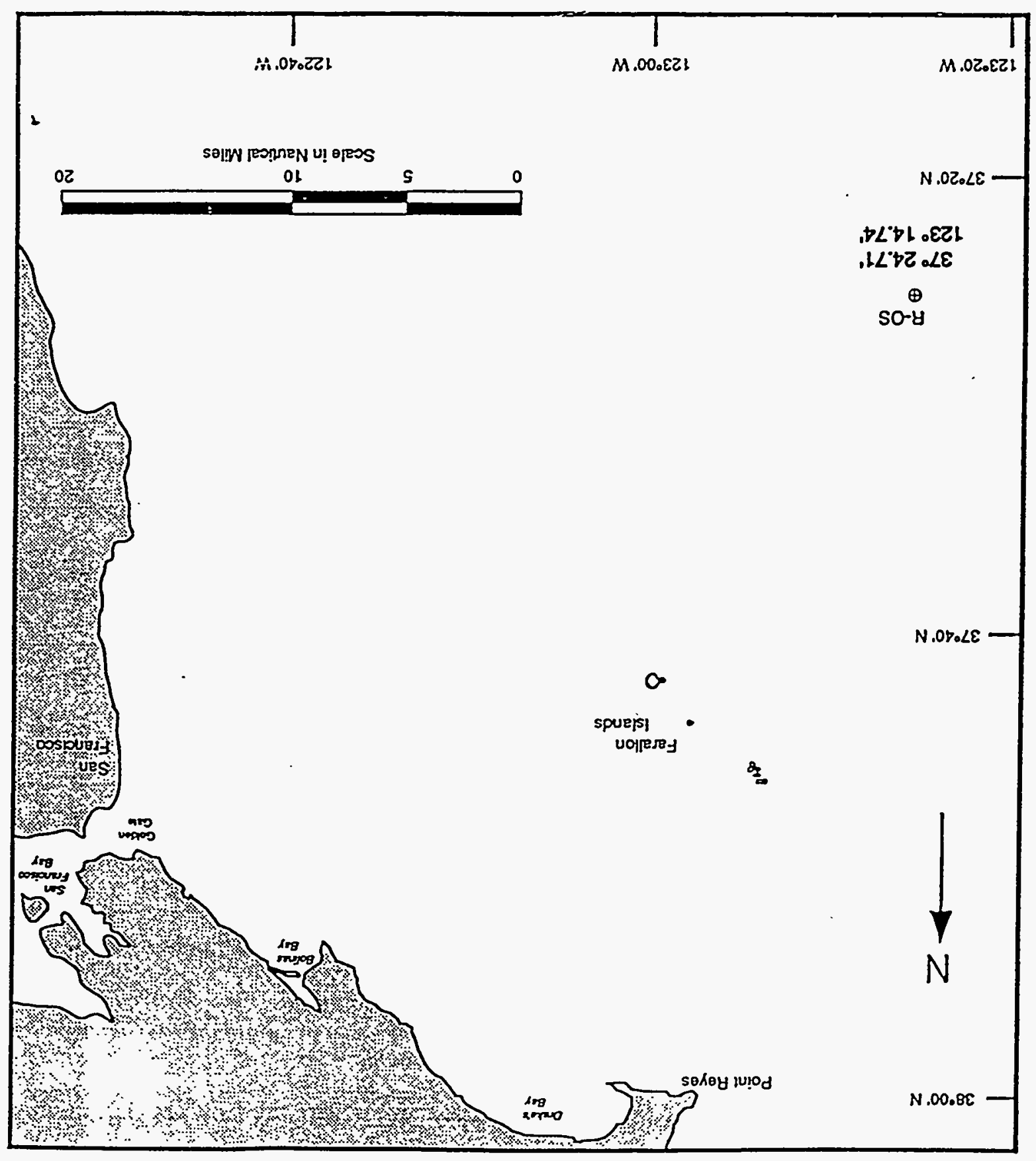




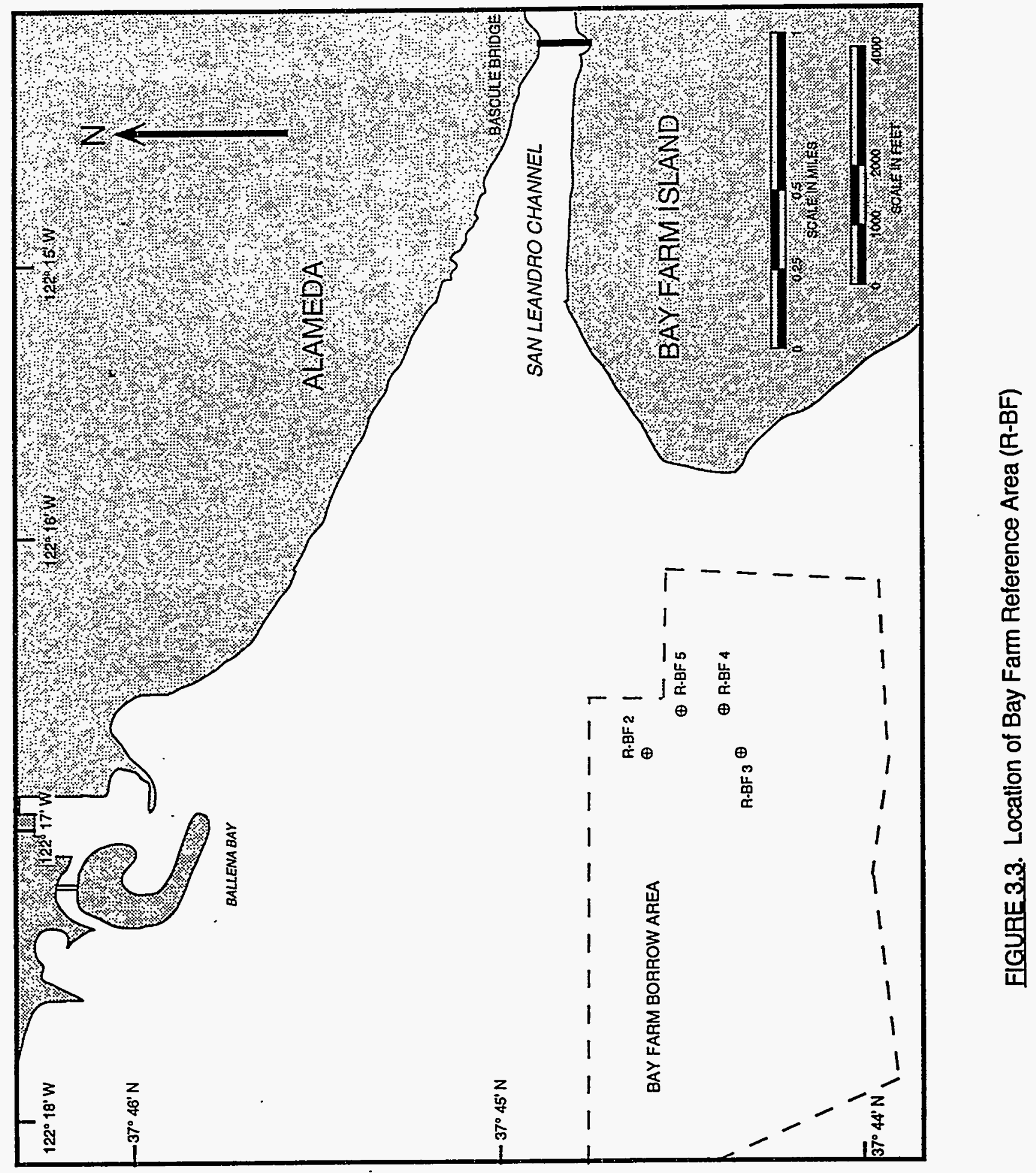




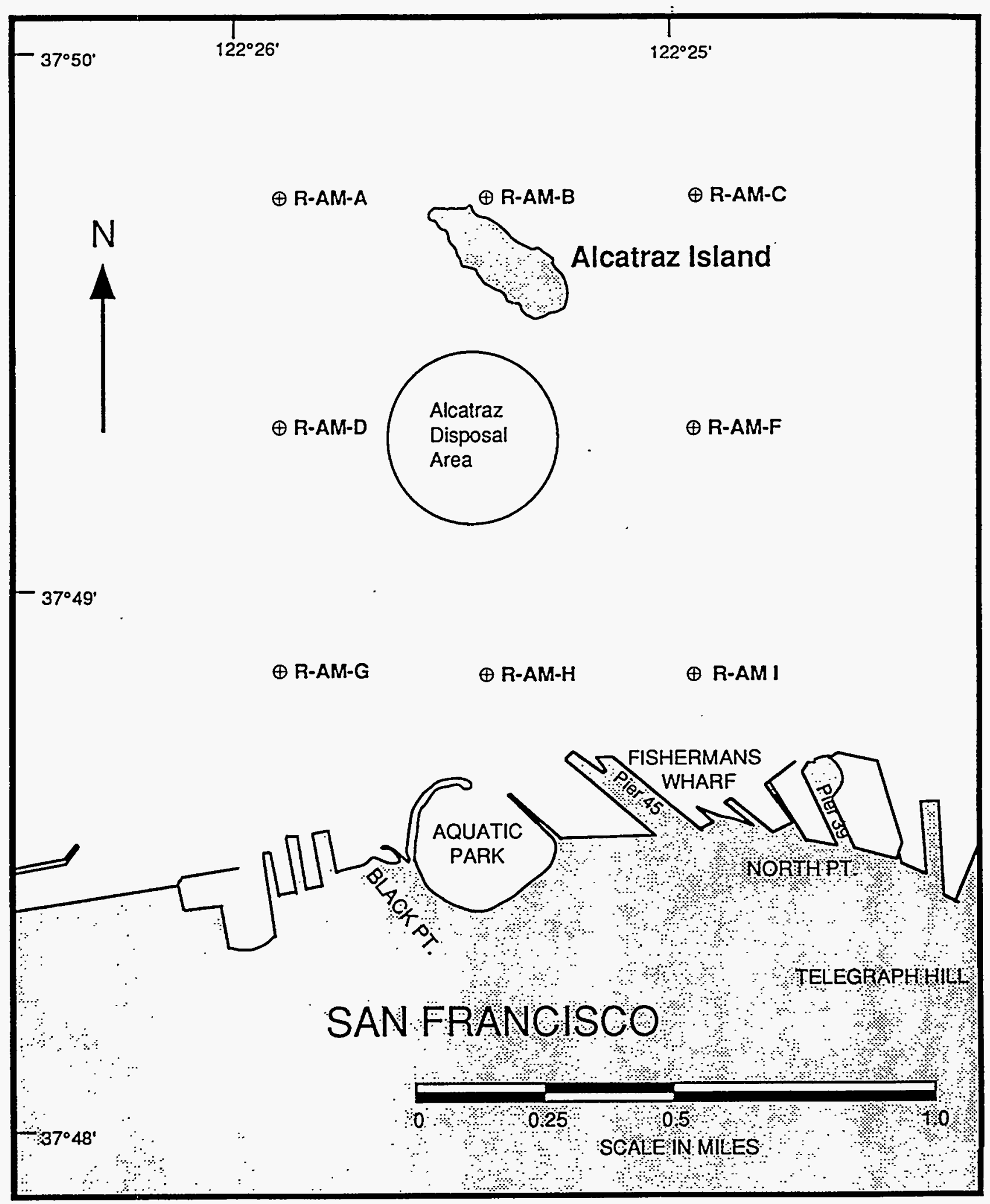

FIGURE 3.4. Location of Alcatraz Environs Reference Area (R-AM) 


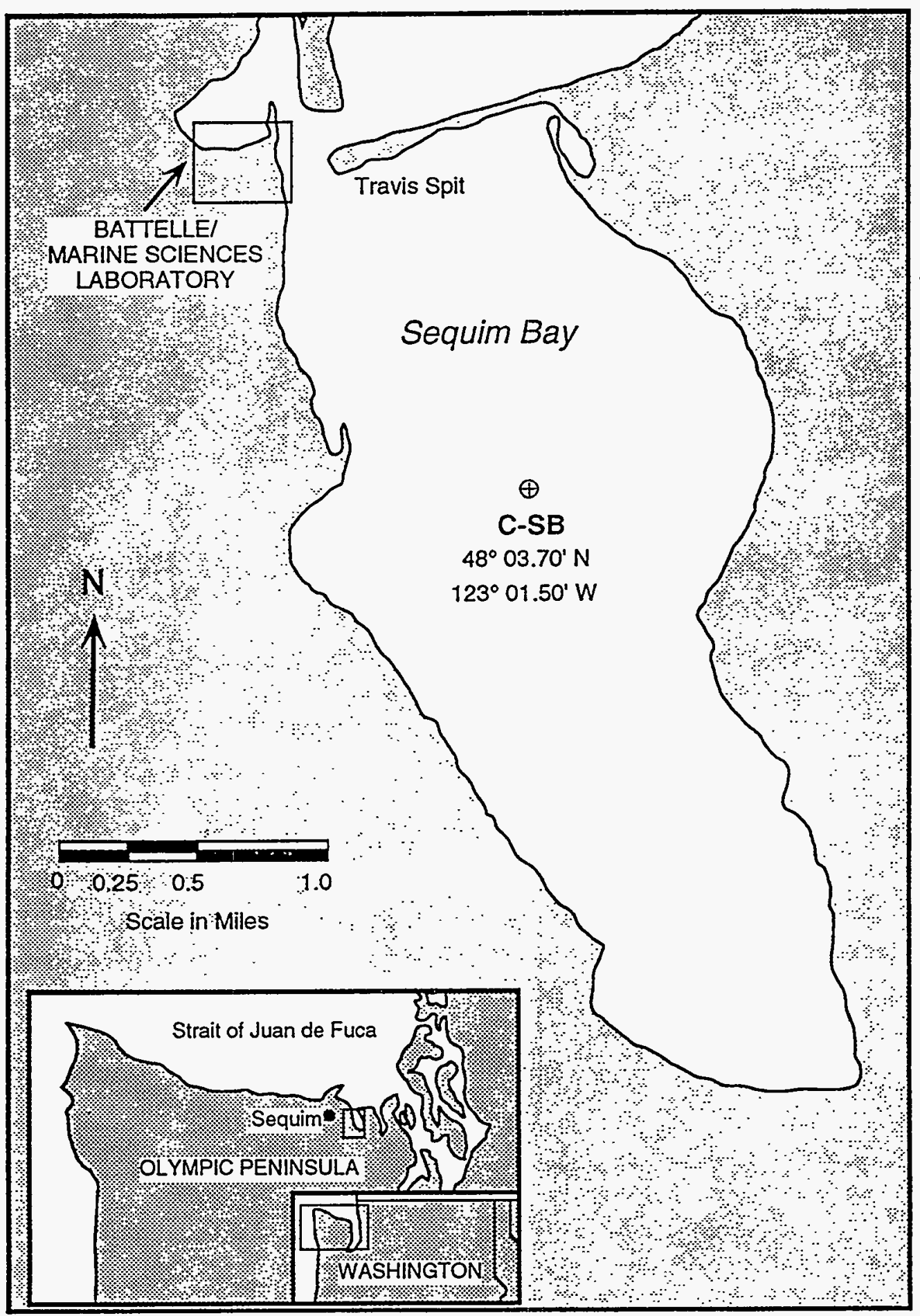

FIGURE 3.5. Location of M. nasuta Control (C-SB), Sequim Bay, Washington 


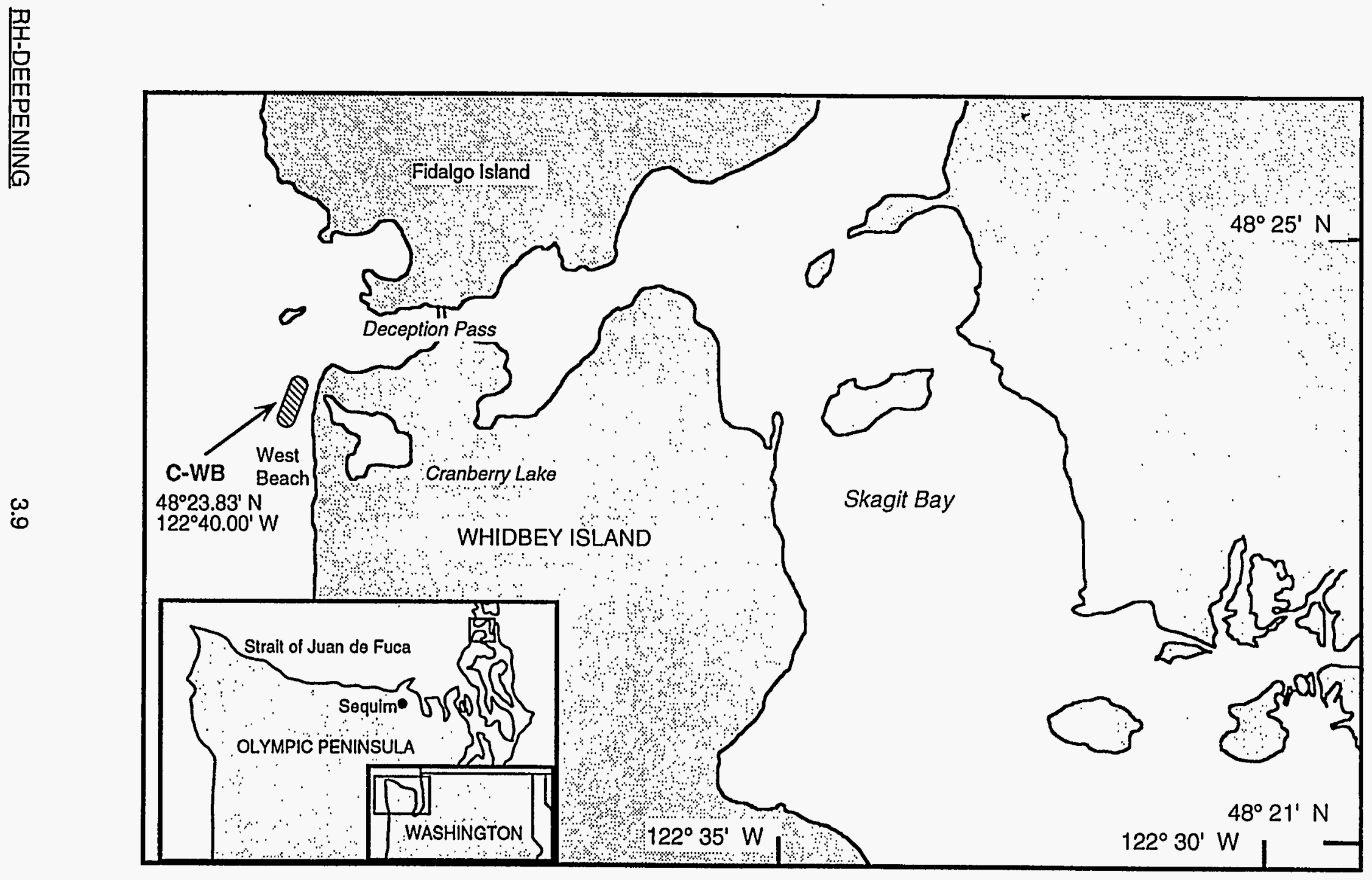

EIGUAE 3.6. Location of $R$. abronius Control (C-WB), West Beach, Whidbey Island, Washington 


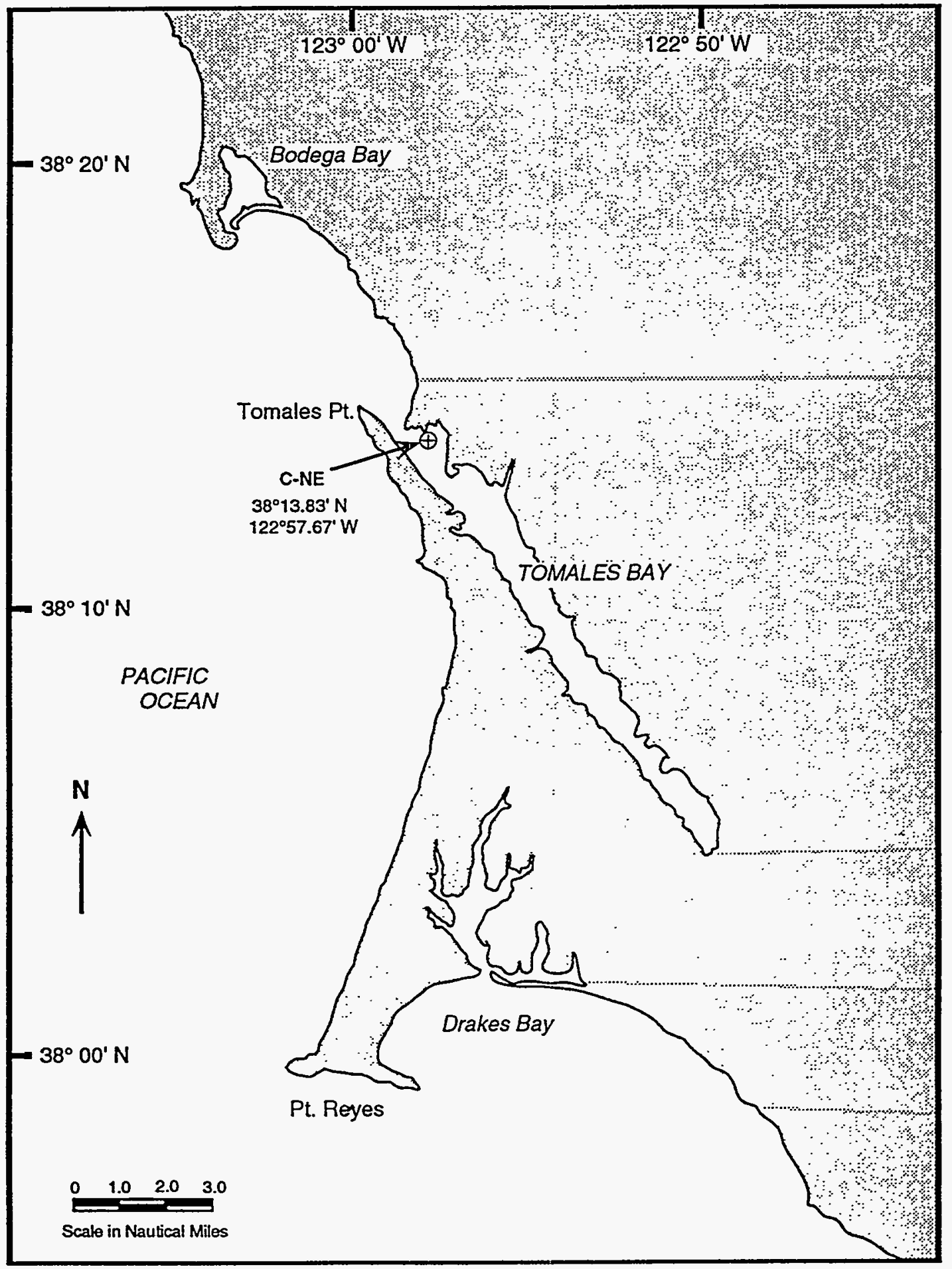

FIGURE 3.7. Location of N. caecoides Control (C-NE), Tomales Bay, Califomia 


\subsubsection{Sample Preparation}

Richmond Harbor sediment composites, 4-in. cores, reference sediments, and control sediments were processed as soon as they were received at the MSL. The composites, consisting of the material between the mudline and $-40 \mathrm{ft}$ MLLW from each contributing station for a total of approximately $30 \mathrm{gal}$ of sediment, were thoroughly homogenized before biological and chemical testing. The 4-in. cores were described by a geologist (Section 2.2.2) before the sediment between the mudline and $-40 \mathrm{ft}$ MLLW was removed and homogenized for sediment chemistry. Reference and control sediments were press-sieved through $0.5-$ or $1.0-\mathrm{mm}$ mesh to remove organisms, and then were thoroughly homogenized before testing. Table 3.3 summarizes the chemical and biological testing strategy for all Richmond Harbor samples.

\subsection{GEOLOGIC DESCRIPTION}

In this section, the characteristics of the marine sediments in Richmond Harbor are described based on the 4-in. cores collected during the field study. The cores were logged according to ASTM Procedure D2488-84 (ASTM 1984). Sediment characteristics described are dilatancy of silt/clay, toughness of silt/clay, plasticity of silt/clay, sediment type (i.e. engineering classification), color, consistency (i.e. firmness), cementation, sedimentary structure, reaction with hydrochloric acid, maximum particle size and odor. In addition, other features such as root traces, mollusk shells, or other detritus were noted. A detailed description of the materials and methods used for describing the cores is provided in Appendix A.

Marine sediment throughout Inner Richmond Harbor consists of two geologic units: the younger bay mud (YBM) and the underlying OBM (Goldman 1969). The YBM is typically composed of black or dark gray, very soft to soft clay, silt, and fine-grained sand with a high water content. The YBM has been accumulating in an estuarine environment since the last retreat of glacial ice (from about 15,000 to 18,000 years ago). The YBM is up to $130 \mathrm{ft}$ thick in San Francisco Bay (Goldman 1969). The underlying OBM consists of relatively dry, firm to hard silts and clays with variable amounts of sand. The marine portions of the OBM are finer-grained and generally olive or gray in color. It is believed that the OBM was deposited in shallow marine and terrestrial environments during the interglacial epoch immediately preceding the formation of the Wisconsin ice sheet, and was exposed and subjected to erosion during the first Wisconsonian glacial advance (Goldman 1969). While exposed, the OBM sediments desiccated and consolidated. The OBM is up to $200 \mathrm{ft}$ thick, and appears to be about $50 \mathrm{ft}$ thick in the Richmond area. The OBM in Richmond Harbor is underlain by interbedded sandstone and shale bedrock of the Franciscan Formation, which outcrops at Point Potrero (Helley and Lajoie 1979). 
TABLE 3.3. Sediment Samples and Testing Strategy, Richmond Harbor Deepening Project

\begin{tabular}{|c|c|c|c|c|c|c|c|}
\hline $\begin{array}{l}\text { Sediment } \\
\text { Treatment }\end{array}$ & $\begin{array}{c}\text { Core } \\
\text { Size (in.) }\end{array}$ & Vertical Segment & $\begin{array}{c}\text { Mudline } \\
(-\mathrm{ft} \text { MLLW) }\end{array}$ & $\begin{array}{l}\text { Sediment } \\
\text { Chemistry }\end{array}$ & $\begin{array}{l}\text { SPP } \\
\text { Testing }\end{array}$ & $\begin{array}{l}\text { Solid- } E \\
\text { Phase } r \\
\text { Testing }\end{array}$ & $\begin{array}{l}\text { Bioaccu- } \\
\text { mulation } \\
\text { Testing } \\
\end{array}$ \\
\hline SF COMP & 12 & Mudline to $-40 \mathrm{ft}$ MLLW(a) & $N A(b)$ & YES & YES & YES & YES \\
\hline SF-1 & 4 & Mudline to $-40 \mathrm{ft} \mathrm{MLLW}$ & 38.5 & YES & NO & NO & NO \\
\hline SF-2 & 4 & Mudline to $-40 \mathrm{ft}$ MLLW & 37.8 & YES & NO & NO & NO \\
\hline SF-3 & 4 & Mudline to $-40 \mathrm{ft}$ MLLW & 37.0 & YES & NO & NO & NO \\
\hline$S F-4$ & 4 & Mudline to $-40 \mathrm{ft}$ MLLW & 35.9 & YES & NO & NO & NO \\
\hline SFW COMP & 12 & Mudline to $-40 \mathrm{ft}$ MLLW & NA & YES & YES & YES & YES \\
\hline SFW-1 & 4 & Mudline to $-40 \mathrm{ft} \mathrm{MLLW}$ & 32.9 & YES & NO & NO & NO \\
\hline SFW-2 & 4 & Mudline to $-40 \mathrm{ft} \mathrm{MLLW}$ & 34.1 & YES & NO & NO & NO \\
\hline SFW-3 & 4 & Mudline to $-40 \mathrm{ft} \mathrm{MLLW}$ & 28.0 & YES & NO & NO & NO \\
\hline SFW-4 & 4 & Mudline to $-40 \mathrm{ft} \mathrm{MLLW}$ & 30.8 & YES & NO & NO & NO \\
\hline UIH COMP & 12 & Mudline to $-40 \mathrm{ft}$ MLLW & NA & YES & YES & YES & YES \\
\hline $\mathrm{UIH-1}$ & 4 & Mudline to $-40 \mathrm{ft}$ MLLW & 36.9 & YES & NO & NO & NO \\
\hline$U \mathrm{UH}-2$ & 4 & Mudline to $-40 \mathrm{ft} \mathrm{MLLW}$ & 35.3 & YES & NO & NO & NO \\
\hline UIH-3 & 4 & Mudline to $-40 \mathrm{ft} \mathrm{MLLW}$ & 37.3 & YES & NO & NO & NO \\
\hline $\mathrm{UIH}-4$ & 4 & Mudline to $-40 \mathrm{ft} \mathrm{MLLW}$ & 34.4 & YES & NO & NO & NO \\
\hline UIH-5 & 4 & Mudline to $-40 \mathrm{ft} \mathrm{MLLW}$ & 36.0 & YES & NO & NO & NO \\
\hline TB Upper COMP & 12 & Mudline to $5 \mathrm{ft}$ below mudline & NA & YES & YES & YES & YES \\
\hline TB-1 Upper & 4 & Mudline to $5 \mathrm{ft}$ below mudline & 30.2 & YES & NO & NO & NO \\
\hline TB-2 Upper & 4 & Mudline to $5 \mathrm{ft}$ below mudline & 5.2 & YES & NO & NO & NO \\
\hline TB-3 Upper & 4 & Mudline to $5 \mathrm{ft}$ below mudline & 4.6 & YES & NO & NO & NO \\
\hline TB-4 Upper & 4 & Mudline to $5 \mathrm{ft}$ below mudline & 28.3 & YES & NO & NO & NO \\
\hline TB-5 Upper & 4 & Mudline to $5 \mathrm{ft}$ below mudline & 6.3 & YES & NO & NO & NO \\
\hline TB-6 Upper & 4 & Mudline to $5 \mathrm{ft}$ below mudline & 29.5 & YES & NO & NO & NO \\
\hline TB-7 Upper & 4 & Mudline to $5 \mathrm{ft}$ below mudline & 8.6 & YES & NO & NO & NO \\
\hline TB Lower COMP & 12 & \multirow{2}{*}{\multicolumn{2}{|c|}{$\begin{array}{l}5 \mathrm{ft} \text { below mudline to }-40 \mathrm{ft} \text { MLLW NA } \\
35.2 \mathrm{ft} \text { to }-40 \mathrm{ft} M L L W\end{array}$}} & YES & YES & YES & YES \\
\hline TB-1 Lower & 4 & & & YES & NO & NO & NO \\
\hline TB-2 Lower & 4 & $10.2 \mathrm{ft}$ to $-40 \mathrm{ft} \mathrm{MLLW}$ & NA & YES & NO & NO & NO \\
\hline TB-3 Lower & 4 & $9.6 \mathrm{ft}$ to $-40 \mathrm{ft} \mathrm{MLLW}$ & NA & YES & NO & NO & NO \\
\hline TB-4 Lower & 4 & $33.3 \mathrm{ft}$ to $-40 \mathrm{ft}$ MLLW & NA & YES & NO & NO & NO \\
\hline TB-5 Lower & 4 & $11.3 \mathrm{ft}$ to $-40 \mathrm{ft} \mathrm{MLLW}$ & NA & YES & NO & NO & NO \\
\hline TB-6 Lower & 4 & $35.9 \mathrm{ft}$ to $.40 \mathrm{ft} \mathrm{MLLW}$ & NA & YES & NO & NO & NO \\
\hline TB-7 Lower & 4 & $13.6 \mathrm{ft}$ to $-40 \mathrm{ft}$ MLLW & NA & YES & NO & NO & NO \\
\hline OBM COMP & 12 & $-40 \mathrm{ft}$ to $-42 \mathrm{ft} \mathrm{MLLW}$ & NA & YES & YES & YES & YES \\
\hline R-OS & grab & NA & NA & YES & NO & YES & YES \\
\hline R-BF & grab & NA & NA & YES & NO & YES & YES \\
\hline R-AM & grab & NA & NA & YES & NO & YES & YES \\
\hline C-SB & grab & NA & NA & NO & NO & YES & YES \\
\hline C-NE & grab & NA & NA & NO & NO & YES & YES \\
\hline C-WB & grab & NA & NA & NO & NO & YES & No \\
\hline $\begin{array}{l}\text { (a) Compositec } \\
\text { mudline to - } \\
\text { (b) NA Not app }\end{array}$ & $\begin{array}{l}\text { d samp } \\
-40 \mathrm{ft} \mathrm{M} \\
\text { oplicable }\end{array}$ & $\begin{array}{l}\text { les consisted of equal perce } \\
\text { LLLW. } \\
\text { e. }\end{array}$ & jes of $c c$ & (i.e. 20 & & volume & \\
\hline
\end{tabular}


The Santa Fe and Inner Harbor Channels have been dredged to a maintenance depth of $-35 \mathrm{ft} \mathrm{MLLW}$. The proposed turning basin east of Point Potrero has never been dredged. The characteristics of the YBM and OBM in the Santa Fe Channel, upper Inner Harbor Channel, and proposed turning basin are described below.

\subsubsection{Santa Fe and Inner Harbor Channels}

Eight cores were collected from the Santa Fe Channel: four from the center (SF-1 through SF-4), and four along the southern edge of the channel (SFW-1 through SFW-4). Five cores were collected from the Inner Harbor Channel (UIH-1 through $\mathrm{UIH}-5)$. Core locations are shown in Figure 3.1. Geologic cross-sections of the Santa Fe Channel and Upper Inner Harbor Channel are presented in Figure 3.8. The elevation of the YBM/OBM contact was approximately $-40 \mathrm{ft} \mathrm{MLLW}$ in the center of the channels, and as shallow as $-35.2 \mathrm{ft}$ MLLW along the southem edge of the Santa Fe Channel (SFW-3). The contact probably represents the dredged surface of the OBM, and the YBM in the channels has accumulated since dredging began. The YBM ranged in thickness from $0.7 \mathrm{ft}$ (SF-1) to $7.2 \mathrm{ft}$ (SFW-3). The YBM consisted of very dark gray to black, very soft to soft silty clay with few mussel shells and wood fibers. The OBM was olive gray or brown where present above $-40 \mathrm{ft} \mathrm{MLLW} \mathrm{(Stations} \mathrm{SFW-1,} \mathrm{SFW-3,} \mathrm{and} \mathrm{SFW-4).} \mathrm{A} \mathrm{2-ft}$ thick layer of well-graded, very coarse sand was present at the top of the OBM at SFW-1.

\subsubsection{Proposed Turning Basin}

Seven cores were collected in the proposed turning basin east of Point Potrero (TB-1 through TB-7). Core locations are shown in Figure 3.1. Geologic cross-sections of the turning basin are presented in Figure 3.9. The YBM was much thicker in the proposed turning basin than in the Richmond Harbor channels, ranging from $2.2 \mathrm{ft}$ to greater than $35.5 \mathrm{ft}$. The OBM was encountered at only one station in the tuming basin (TB-1). The YBM was composed primarily of dark gray, very soft to soft clay. The clay commonly contained whole and fragmented clam shells (Macoma sp.). Gas holes and a sulfur smell were common in the sediment, probably as a result of decomposing organic matter. A layer of shell hash $2 \mathrm{ft}$ thick was found from about $4 . \mathrm{ft}$ to $6 \mathrm{ft}$ below the mudline at stations TB-2 and TB-3. A layer of clayey sand with rounded pebbles was found approximately $25 \mathrm{ft}$ below the mudline at stations TB-2, TB-3, TB-5, and TB-7. Vertical root traces were found in the uppermost $3 \mathrm{ft}$ of YBM at Station TB-6. Because this area has never been dredged, some of these sediments may have been deposited in preindustrial times.

The OBM at Station TB-1 consisted of firm to hard interbedded clayey gravel and silt. The OBM sediments were olive gray, olive, or olive brown in color. The pebbles in the gravel were well-rounded and up to 1.5 in. 

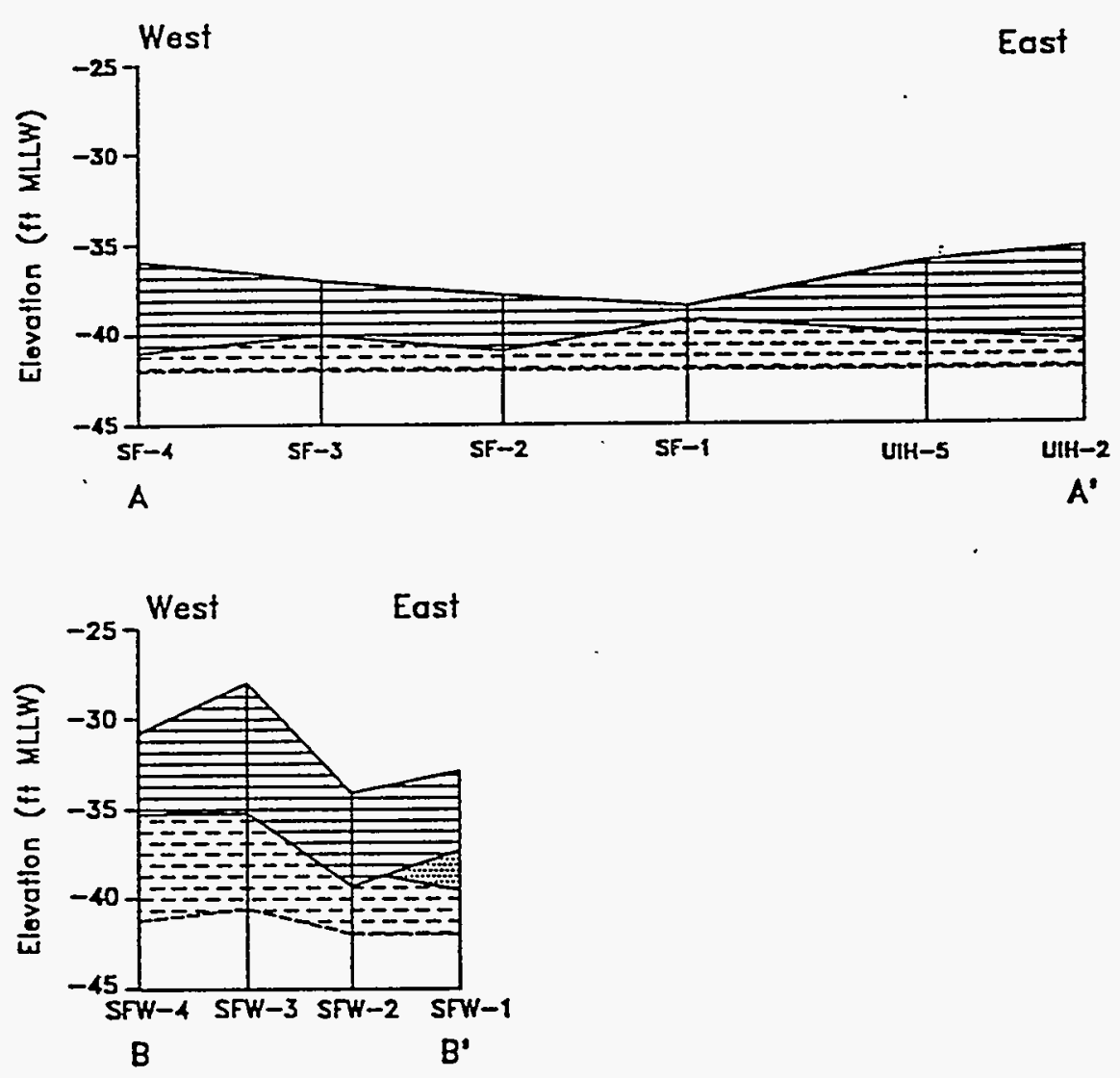

LEGEND

Younger Boy Mud, sllty clay

$E==-$ Older Bay Mud, sllt

Older Bay Mud, sand

- Bottom of coro

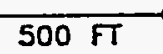

Vertical Exaggeration $=50 x$

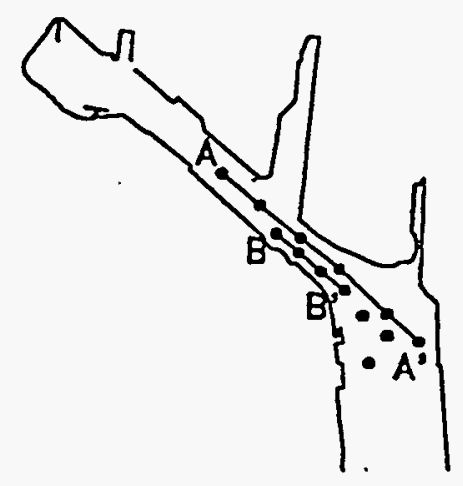

EIGURE 3.8. Geologic Cross-Sections of the Santa Fe Channel and Upper Inner Harbor Channel of Richmond Harbor 


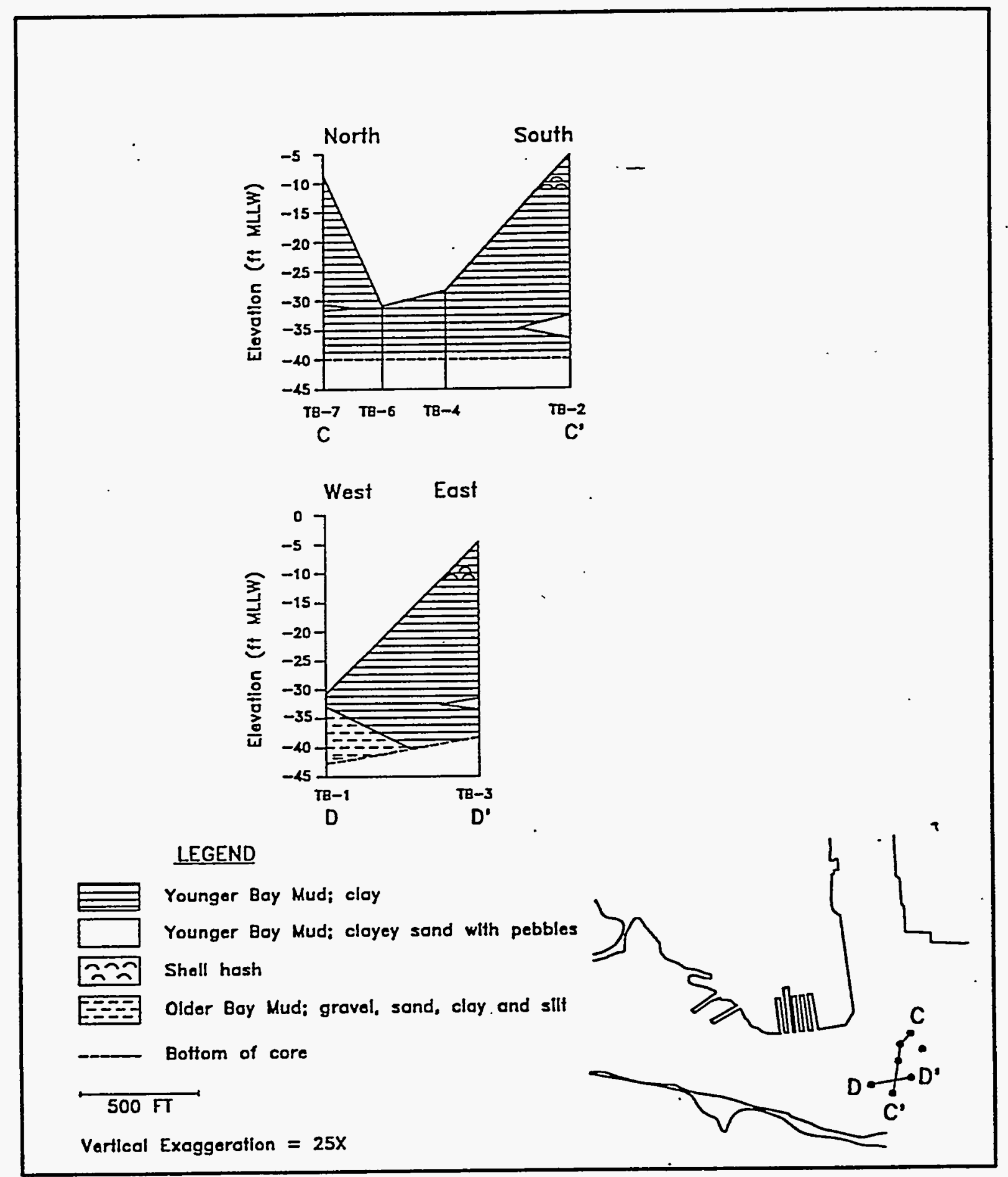

FIGURE 3.9. Geologic Cross-Sections of the Tuming Basin in Richmond Harbor 


\subsection{SEDIMENT CHEMISTRY}

\subsubsection{Sediment Conventional Measurements}

Sediment conventional measurements are grain size,TOC, TVS, oil and grease, and TPH. Grain size, TOC, and TVS are expressed as percentage of dry weight of the sample. Oil and grease and TPH concentrations are expressed as $\mathrm{mg} / \mathrm{kg}$ dry weight. A summary of the Richmond Harbor Deepening Project conventional measurements is presented in Table 3.4. The complete results, including quality assurance/quality control summaries and results, are presented in Appendix C, Tables C.1 through C.7. The conventional parameters are also depicted graphically for all sediment treatments in Figures 3.10 to 3.14. The OBM COMP was analyzed for PAHs, pesticides, PCBs and butyltins. The results of these analyses are reported in the appropriate sections.

The Richmond Harbor test treatments were predominantly fine-grained, with $45 \%$ to $98 \%$ of the sediment in the silt and clay categories. Only two treatments, TB-1 Upper and TB-1 Lower, had greater percentage of gravel and sand. The reference sediment R-OS was also fine-grained ( $66 \%$ silt and clay).

Percentages of TOC in the test treatments ranged from $0.05 \%$ in TB-1 Lower to $1.37 \%$ in SF-4. Typically, the reference sediment R-OS (1.35\%) and R-BF (1.24\%) had among the highest percentages of TOC of any sediments analyzed during this project. Only the sediment from SF-4 (1.37\%) had a higher TOC content than that of R-OS. The higher percentages of TOC were associated with the fine-grained sediments. All sediment treatments with TOC percentages $\geq 1.0 \%$ were predominantly silt and clay. The percentages of TVS ranged from $1.73 \%$ in TB-1 Lower to $3.25 \%$ to TB-2 Upper in the test treatments. Thirteen of the test sediments had TVS values greater than that of R-OS $(2.49 \%)$.

Oil and grease concentrations were detected in most test treatments and ranged from $27 \mathrm{mg} / \mathrm{kg}$ in SFW-4 to $232 \mathrm{mg} / \mathrm{kg}$ in SFW COMP. The concentrations in 18 of the test treatments were higher than in R-OS sediments ( $39 \mathrm{mg} / \mathrm{kg}$ ). The detected TPH concentrations ranged from $32 \mathrm{mg} / \mathrm{kg}$ in TB-6 Upper to $104 \mathrm{mg} / \mathrm{kg}$ in SFW COMP. The TPH concentration was undetected in R-OS sediments. The TPH concentrations followed a pattern similar to that of the oil and grease concentrations. Those stations with the higher oil and grease values also had the highest TPH values. The fractional percentage of TPH to the oil and grease total ranged from $34 \%$ to $87 \%$, indicating that most of the oil and grease present in these sediments can be attributed to petroleum sources. Sediment from stations in the Santa Fe channel (SF-3, SF-4, SFW-2, SFW-3, and SFW COMP) and Upper Inner Harbor (UIH COMP, UIH-4, and UIH-5) contain relatively more TPH than predicted based on the concentrations of oil and grease in the samples. This relationship is illustrated in Figure 3.15 . 
TABLE 3.4. Conventional Sediment Measurement Results for the Richmond Harbor Deepening Project Sediment Treatments

\begin{tabular}{|c|c|c|c|c|c|c|c|c|}
\hline \multirow[b]{2}{*}{$\begin{array}{l}\text { Sediment } \\
\text { Treatment }\end{array}$} & \multicolumn{6}{|c|}{ Percent Dry Weight } & \multicolumn{2}{|c|}{$\mathrm{ma} / \mathrm{kg}$ Dry Weight } \\
\hline & $\begin{array}{l}\text { Gravel } \\
>2000 \mu \mathrm{m} \\
\end{array}$ & $\begin{array}{c}\text { Sand } \\
62.5- \\
2000 \mu \mathrm{m} \\
\end{array}$ & $\begin{array}{c}\text { Silt } \\
3.9- \\
62.5 \mu \mathrm{m} \\
\end{array}$ & $\begin{array}{l}\text { Clay } \\
<3.9 \mu \mathrm{m} \\
\end{array}$ & TOC & TVS & $\begin{array}{c}\text { ma/kg D } \\
\text { Oil and } \\
\text { Grease }\end{array}$ & Jeight \\
\hline R-OS & 0 & 34 & 45 & 21 & 1.35 & 2.49 & 39 & $29 U(a)$ \\
\hline $\begin{array}{l}\text { SF COMP } \\
\text { SF-1 } \\
\text { SF-2 } \\
\text { SF-3 } \\
\text { SF-4 }\end{array}$ & $\begin{array}{l}1 \\
1 \\
6 \\
0 \\
0\end{array}$ & $\begin{array}{r}29 \\
29 \\
18 \\
9 \\
5\end{array}$ & $\begin{array}{l}35 \\
42 \\
34 \\
32 \\
32\end{array}$ & $\begin{array}{l}35 \\
28 \\
42 \\
59 \\
63\end{array}$ & $\begin{array}{l}0.71 \\
0.33 \\
0.98 \\
1.27(b) \\
1.37\end{array}$ & $\begin{array}{l}2.32 \\
2.27 \\
2.62 \\
2.67 \\
2.70\end{array}$ & $\begin{array}{l}29 U \\
36 \\
66 \\
136 \\
98\end{array}$ & $\begin{array}{l}29 \mathrm{U} \\
23 \mathrm{U} \\
34 \\
67 \\
57\end{array}$ \\
\hline $\begin{array}{l}\text { SFW COMP } \\
\text { SFW COMP(c) } \\
\text { SFW-1 } \\
\text { SFW-2 } \\
\text { SFW-3 } \\
\text { SFW-4 }\end{array}$ & $\begin{array}{l}5 \\
\text { NA(d) } \\
13 \\
8 \\
2 \\
3\end{array}$ & $\begin{array}{l}23 \\
\text { NA } \\
35 \\
15 \\
18 \\
27\end{array}$ & $\begin{array}{l}37 \\
\text { NA } \\
21 \\
35 \\
47 \\
45\end{array}$ & $\begin{array}{l}35 \\
\text { NA } \\
31 \\
42 \\
33 \\
25\end{array}$ & $\begin{array}{l}0.76(b) \\
N A \\
1.00 \\
1.09 \\
0.49 \\
0.32\end{array}$ & $\begin{array}{r}2.26 \\
\text { NA } \\
2.21 \\
2.84 \\
2.32 \\
2.01\end{array}$ & $\begin{array}{l}102(b) \\
232 \\
44 \\
79 \\
117 \\
27\end{array}$ & $\begin{array}{l}68(b) \\
104 \\
35 \\
69 \\
84 \\
22 U\end{array}$ \\
\hline $\begin{array}{l}\text { UHH COMP } \\
\text { UIH-1 } \\
\text { UIH-2 } \\
\text { UIH-3 } \\
\text { UIH-4 } \\
\text { UIH-5 }\end{array}$ & $\begin{array}{l}0 \\
0 \\
0 \\
0 \\
1 \\
0\end{array}$ & $\begin{array}{r}6 \\
5 \\
2 \\
7 \\
13 \\
7\end{array}$ & $\begin{array}{l}33 \\
35 \\
33 \\
35 \\
35 \\
39\end{array}$ & $\begin{array}{l}61 \\
60 \\
65 \\
58 \\
51 \\
54\end{array}$ & $\begin{array}{l}1.23 \\
1.17 \\
1.20 \\
1.12 \\
0.87 \\
0.97\end{array}$ & $\begin{array}{l}2.69 \\
2.80 \\
2.73 \\
2.81 \\
2.83 \\
2.74\end{array}$ & $\begin{array}{r}91 \\
204 \\
97 \\
80 \\
142 \\
139\end{array}$ & $\begin{array}{l}65 \\
75 \\
38 U \\
34 U \\
72 \\
70\end{array}$ \\
\hline $\begin{array}{l}\text { TB Upper COMP } \\
\text { TB-1 Upper } \\
\text { TB-2.Upper } \\
\text { TB-3 Upper } \\
\text { TB-4 Upper } \\
\text { TB-5 Upper } \\
\text { TB-6 Upper } \\
\text { TB-7 Upper } \\
\text { TB-7 Upper(c) }\end{array}$ & $\begin{array}{c}8 \\
22 \\
5 \\
1 \\
0 \\
1 \\
0 \\
0 \\
\mathrm{NA}\end{array}$ & $\begin{array}{r}14 \\
33 \\
20 \\
13 \\
3 \\
7 \\
3 \\
5 \\
\text { NA }\end{array}$ & $\begin{array}{l}45 \\
24 \\
41 \\
48 \\
46 \\
58 \\
49 \\
66 \\
\text { NA }\end{array}$ & $\begin{array}{l}33 \\
21 \\
34 \\
38 \\
51 \\
34 \\
48 \\
29 \\
\text { NA }\end{array}$ & $\begin{array}{l}0.85 \\
0.50 \\
0.73 \\
0.78 \\
1.09 \\
0.79 \\
0.66 \\
0.63 \\
\text { NA }\end{array}$ & $\begin{array}{l}2.48 \\
2.45 \\
3.25 \\
2.47 \\
2.63 \\
2.44 \\
2.43 \\
2.38 \\
\text { NA }\end{array}$ & $\begin{array}{l}47 \\
36 \\
36 \\
28 U \\
169 \\
26 U \\
83 \\
29(b) \\
20 U\end{array}$ & $\begin{array}{l}30 U \\
23 U \\
25 U \\
28 U \\
57 \\
26 U \\
32 \\
25 U(D) \\
20 U\end{array}$ \\
\hline $\begin{array}{l}\text { TB Lower COMP } \\
\text { TB-1 Lower } \\
\text { TB-2 Lower } \\
\text { TB-3 Lower } \\
\text { TB-4 Lower } \\
\text { TB-5 Lower } \\
\text { TB-6 Lower } \\
\text { TB-7 Lower }\end{array}$ & $\begin{array}{l}3(b) \\
9 \\
1 \\
0(b) \\
0 \\
0 \\
0(b) \\
1\end{array}$ & $\begin{array}{l}15(b) \\
53 \\
23 \\
13(b) \\
4 \\
12 \\
7(b) \\
3\end{array}$ & $\begin{array}{l}46(b) \\
23 \\
43 \\
52(0) \\
47 \\
55 \\
50(b) \\
55\end{array}$ & $\begin{array}{l}36(\mathrm{~b}) \\
15 \\
33 \\
36(\mathrm{~b}) \\
49 \\
33 \\
43(\mathrm{~b}) \\
41\end{array}$ & $\begin{array}{l}0.69 \\
0.05 \\
0.62 \\
0.70 \\
0.93 \\
0.70 \\
0.55 \\
0.72\end{array}$ & $\begin{array}{l}2.15 \\
1.73 \\
2.08 \\
2.21 \\
2.88 \\
2.27 \\
2.27 \\
2.43\end{array}$ & $\begin{array}{l}35 \\
19 U \\
29 \\
30 \\
58 \\
25 U \\
26 U \\
26 U\end{array}$ & $\begin{array}{l}26 U \\
19 U \\
24 U \\
25 U \\
30 U \\
25 U \\
26 U \\
26 U\end{array}$ \\
\hline $\begin{array}{l}\text { (a) U Undetecte } \\
\text { (b) Value is mea } \\
\text { (c) Sample rean } \\
\text { matrix spike } \\
\text { (d) NA Not appli }\end{array}$ & $\begin{array}{l}\text { at or above th } \\
\text { of replicate a } \\
\text { lyzed approxin } \\
\text { ata. } \\
\text { able. }\end{array}$ & $\begin{array}{l}\text { he detection } \\
\text { nalysis. } \\
\text { nately one m }\end{array}$ & $\begin{array}{l}\text { limit. } \\
\text { nonth after o }\end{array}$ & riginal oil a & d grea & TPH & sis to $\mathrm{pr}$ & epropriate \\
\hline
\end{tabular}

BH-DEEPENING 
Grain Size (percent dry weight)

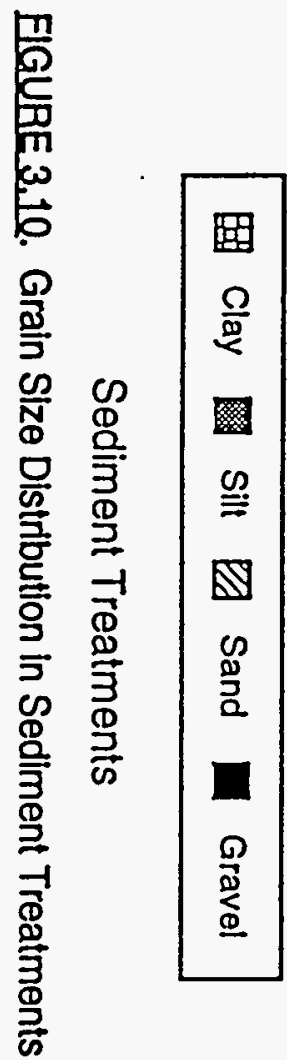

TB Upper COMP In

TB-1 Upper f 1 -

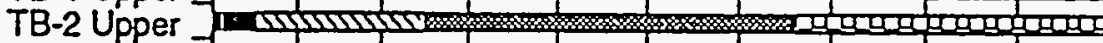

TB-3 Upper 1100

TB-4 Upper

TB-5 Upper

TB-6 Upper Tr

TB.7 Upper

TB Lower COMP

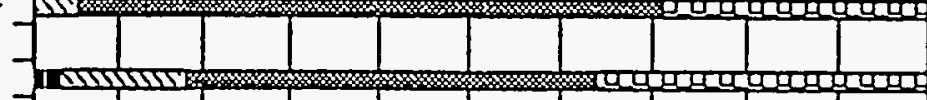

TB-1 Lower to .

TB-2 Lower

TB-3 Lower -

TB-4 Lower

TB-5 Lower

TB-6 Lower -

TB-7 Lower or

R-AM -A A

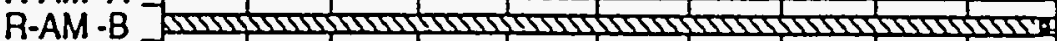

R-AM -C -

R-AM-D - D

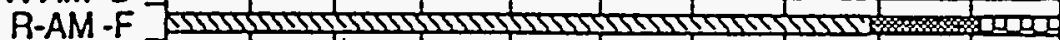

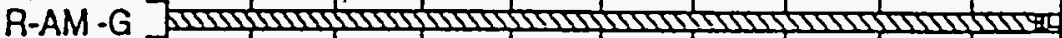

R-AM -H DSWM

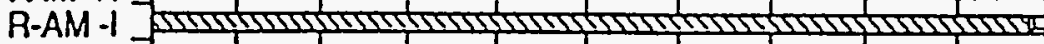

R-OS Am (1)

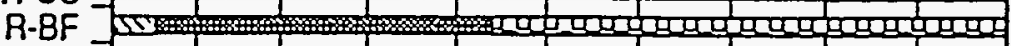

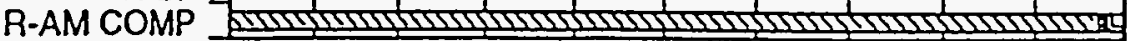




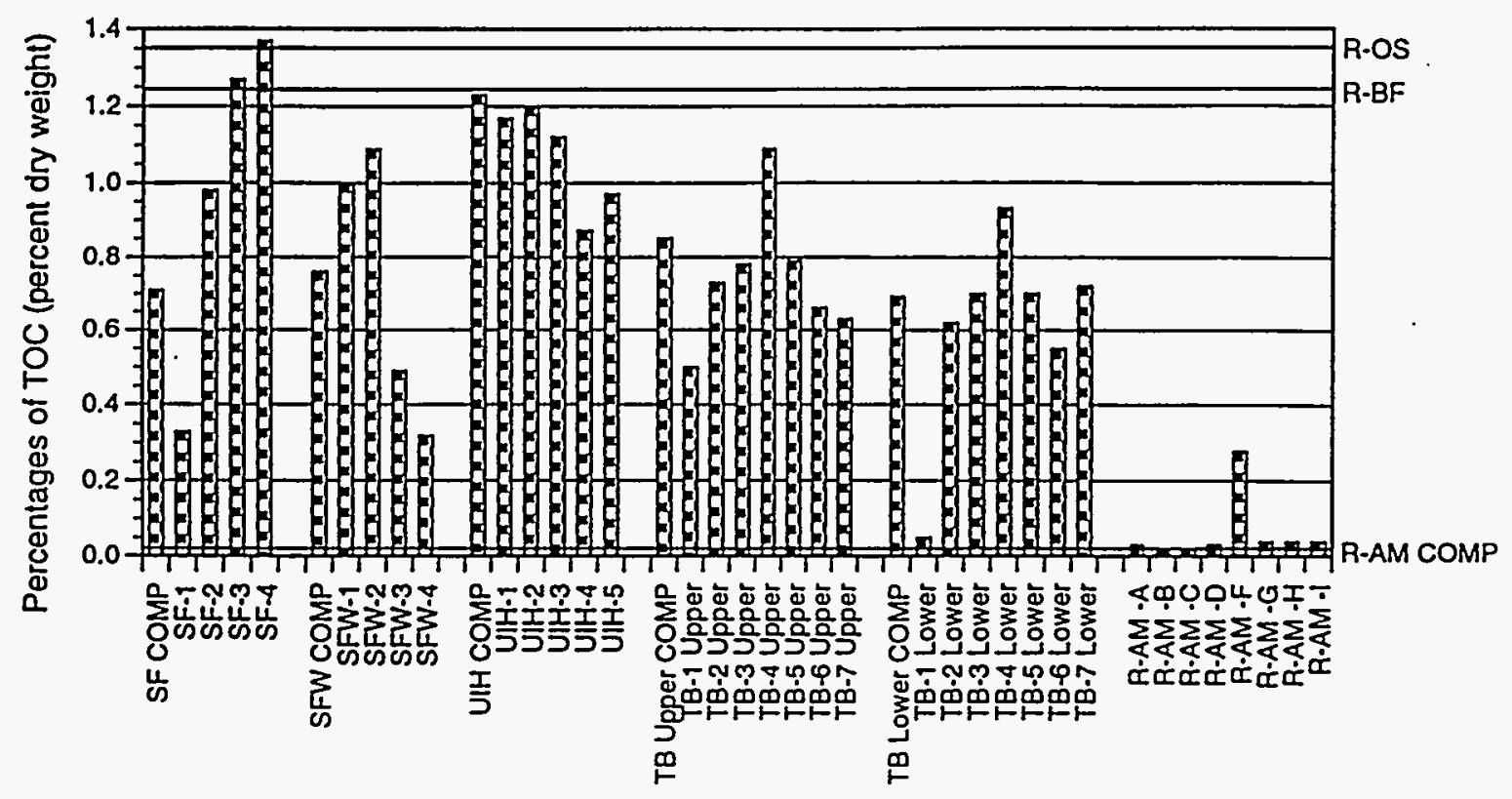

Sediment Treatments

FIGURE 3.11. Percentages of TOC in Sediment Treatments

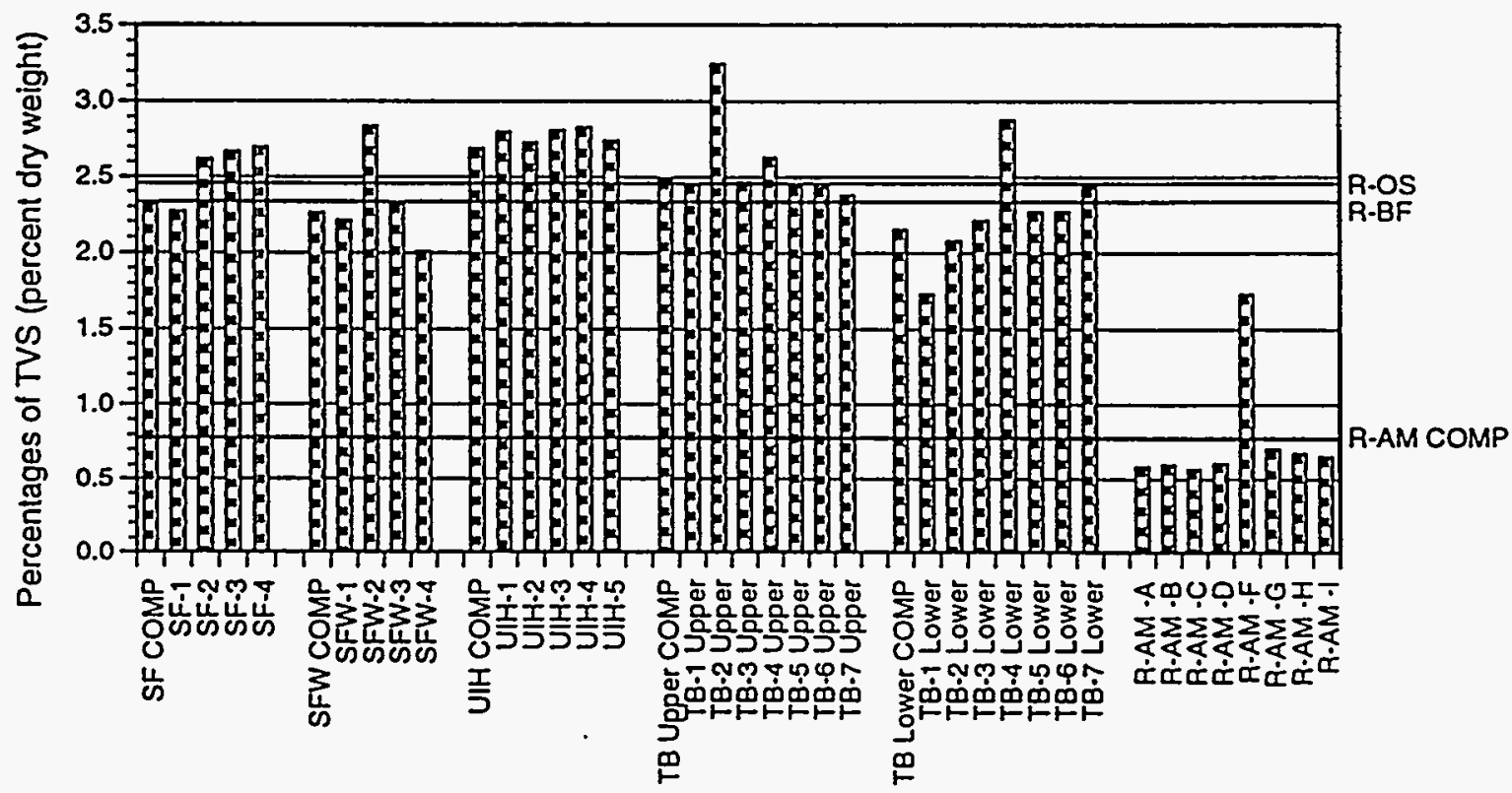

Sediment Treatments

FIGURE 3.12. Percentages of TVS in Sediment Treatments 

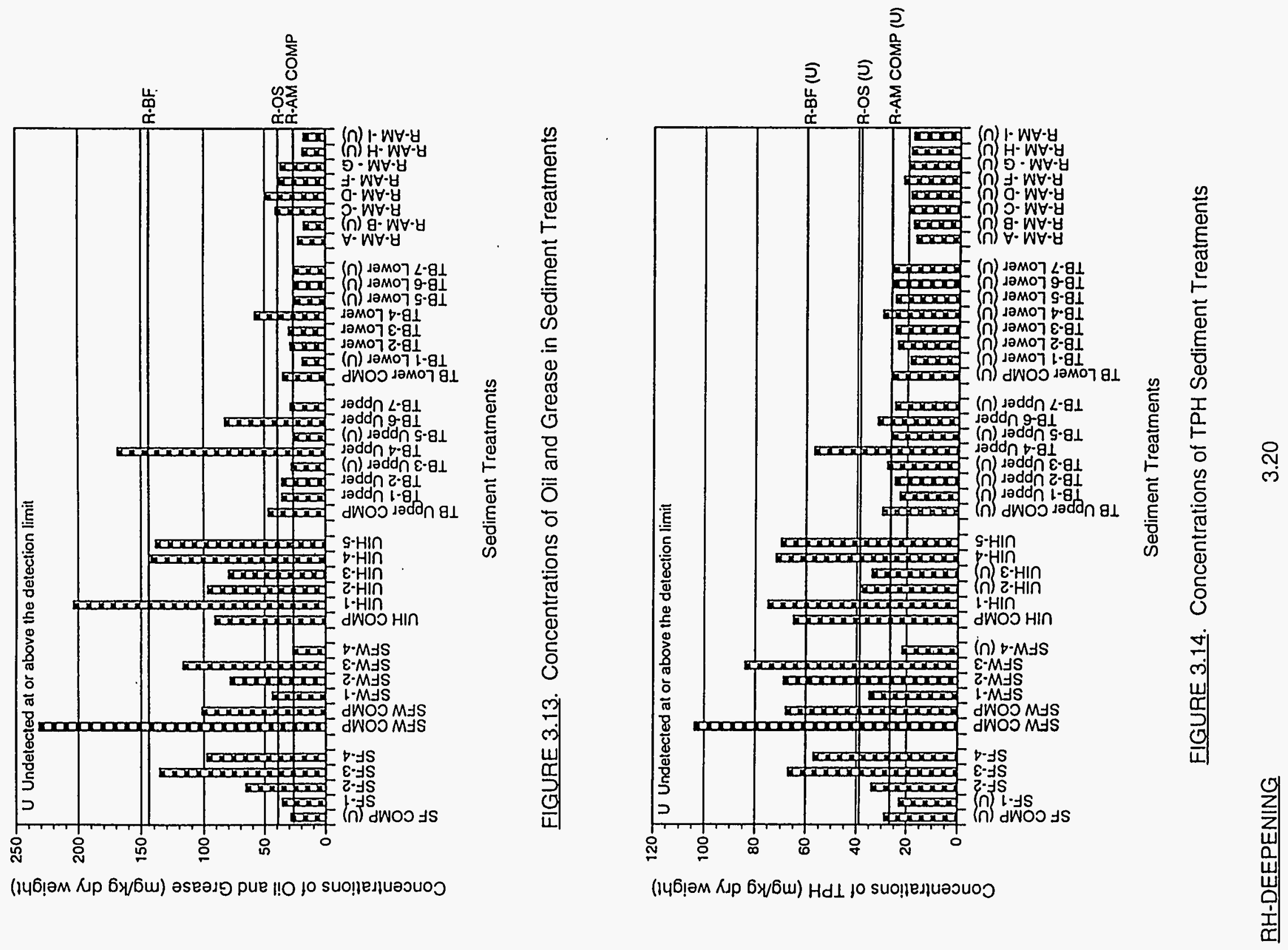


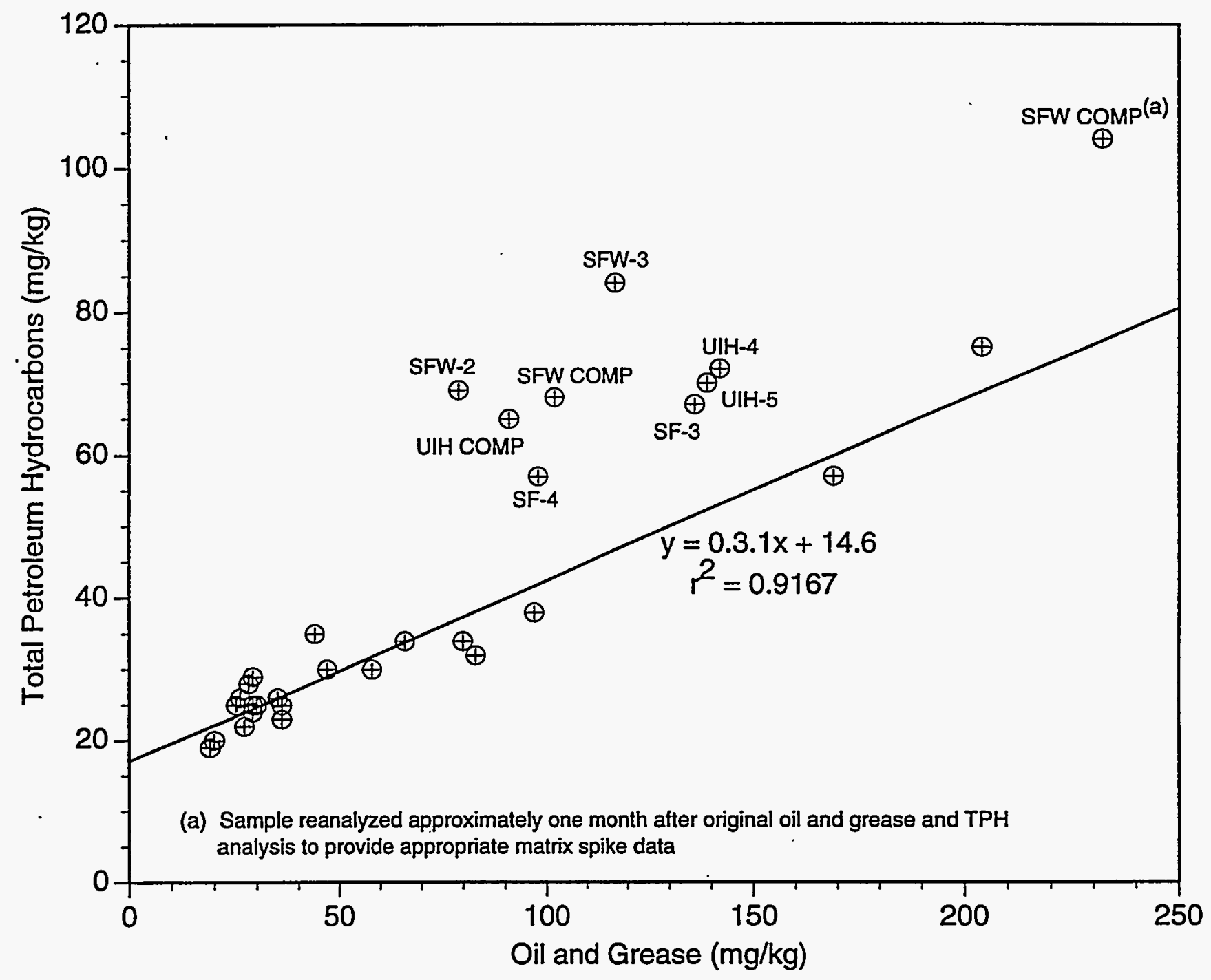

FIGURE 3.15. Concentration of Oil and Grease vs. TPH 


\subsubsection{Polynuclear Aromatic Hydrocarbons and Phthalate Esters}

The Richmond Harbor sediment treatments were analyzed for the 16 priority pollutant PAHs listed in the 1991 Implementation Manual. The complete results of PAH and phthalate esters analysis, including $Q C$ data and QA/QC summaries, are presented in Appendix C, Tables C.8 through C.15. Table 3.5 is a summary of total PAHs, pesticides, and PCB concentrations for the test treatments and the reference treatment R-OS. The test treatments with higher organic concentrations relative to the reference R-OS were delineated by shading the test treatment values.

Concentrations of low-molecular-weight PAHs (LPAHs) in the test treatments ranged from undetected in TB-1 Lower to $3897 \mu \mathrm{g} / \mathrm{kg}$ in SFW COMP. The concentrations of high-molecularweight PAH (HPAH) ranged from $2 \mu \mathrm{g} / \mathrm{kg}$ in TB-1 Lower to $3390 \mu \mathrm{g} / \mathrm{kg}$ in SFW-2. The five test treatments with the highest overall total PAH concentrations were SFW COMP, SFW-2, SFW-3, SF-3, and SF-4, with concentrations of $5703 \mu \mathrm{g} / \mathrm{kg}, 3776 \mu \mathrm{g} / \mathrm{kg}, 3293 \mu \mathrm{g} / \mathrm{kg}, 3745 \mu \mathrm{g} / \mathrm{kg}$, and $3763 \mu \mathrm{g} / \mathrm{kg}$, respectively. Twenty-four test treatments had levels of total PAHs (TPAH) that were higher than those of the reference treatment R-OS (Figure 3.16). Naphthalene was found in the highest concentration in SFW COMP and SFW-3, and pyrene and benzo(b)fluoranthene were found in the highest concentrations in SFW-2 and SF-4. The LPAH compounds were much higher in concentration than HPAH at SFW COMP and SFW-3 representing approximately $67 \%$ of the TPAH.

Six phthalate esters were analyzed in the Richmond Harbor sediment treatments. The results of the phthalate esters are presented in Appendix C, Tables C.13 and C.14. One compound, bis(2-ethylhexyl)phthalate ester was detected in 20 of the test treatments, ranging from $104 \mu \mathrm{g} / \mathrm{kg}$ in SFW-3 to $473 \mu \mathrm{g} / \mathrm{kg}$ in SF-4. The only other detected phthalate ester was butyl benzyl found in UIH-5 at $58 \mu \mathrm{g} / \mathrm{kg}$. The reference treatment $R-O S$ had no detectable levels of any phthalate ester.

\subsubsection{Chlorinated Pesticides and Polychlorinated Biphenyls (PCBs)}

The Richmond Harbor sediment treatments were analyzed for 18 chlorinated pesticides and 4 PCBs. Eight pesticides were detected in the sediment of at least one test treatment. The compound DDT and its chemical analogues, as well as dieldrin and aldrin, were prevalent in a majority of the test treatments and are summarized in Table 3.5 The compound 4,4'-DDD, was found in the sediments at the highest concentrations ranging from $0.75 \mu \mathrm{g} / \mathrm{kg}$ in TB-5 Upper to $288 \mathrm{D} \mu \mathrm{g} / \mathrm{kg}$ ( $\mathrm{D}$ indicates that the sample required dilution in order to remain within the calibration level of the GC) in SF-4. One compound, 4,4'-DDE, was detected in the sediment from R-OS at a concentration of $0.94 \mu \mathrm{g} / \mathrm{kg}$. All of the detected pesticides (except 4,4'-DDE) were found at higher levels in the test treatments relative to the sediment from R-OS (Figures 3.17 to 3.21 ). 


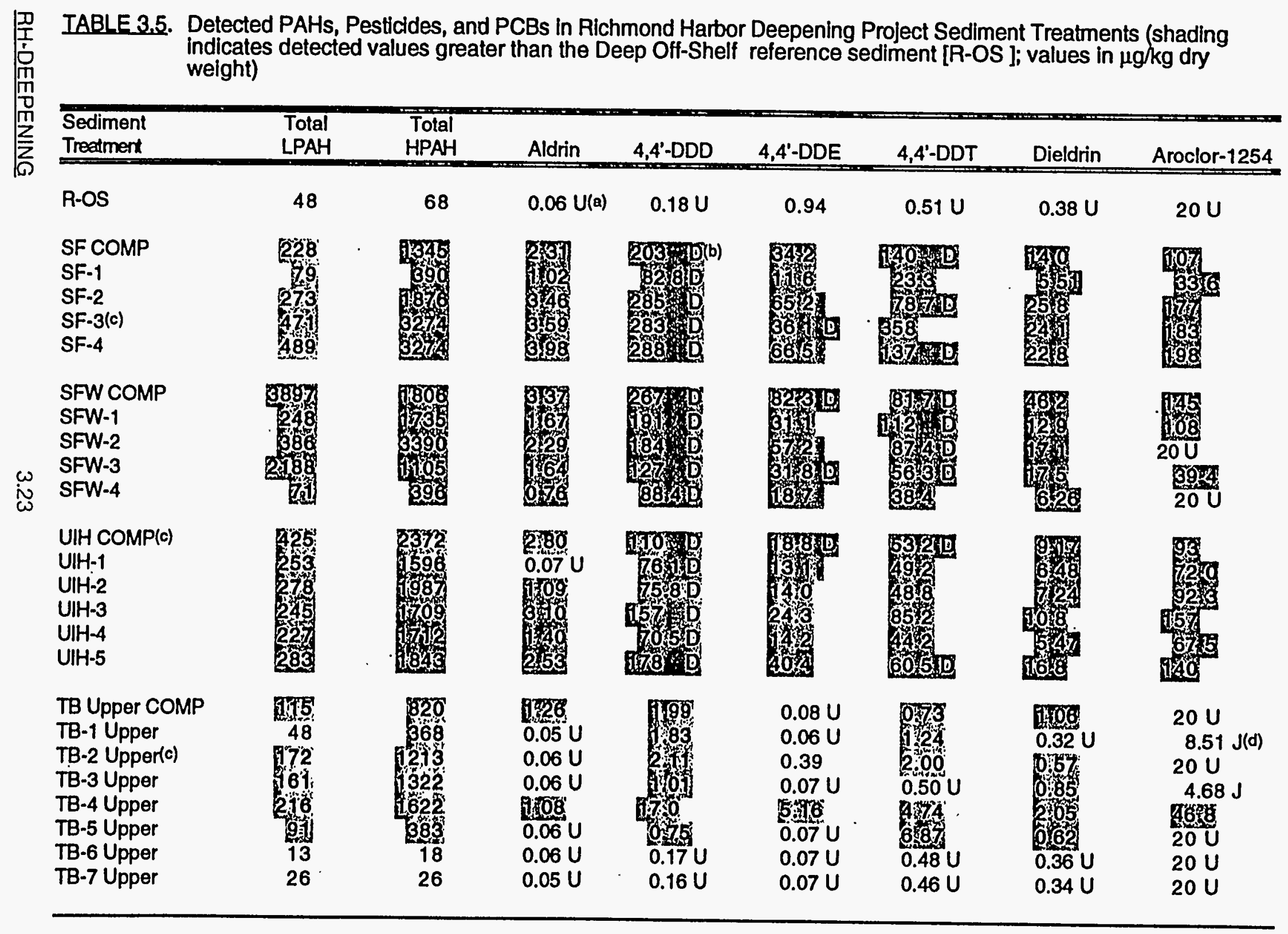




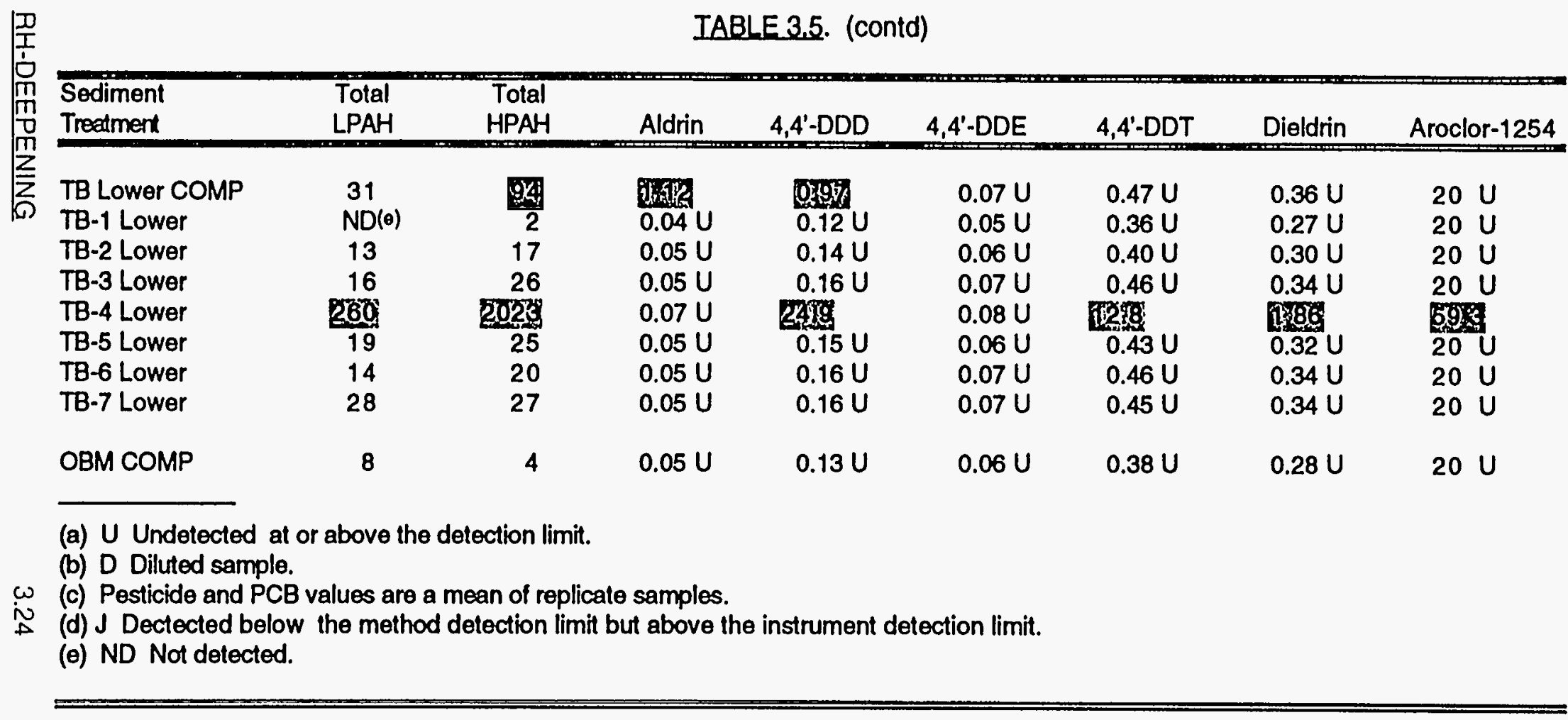


Concentrations of total LPAH and total HPAH ( $\mu \mathrm{g} / \mathrm{kg}$ dry weight)

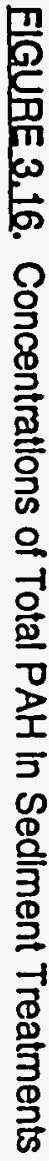

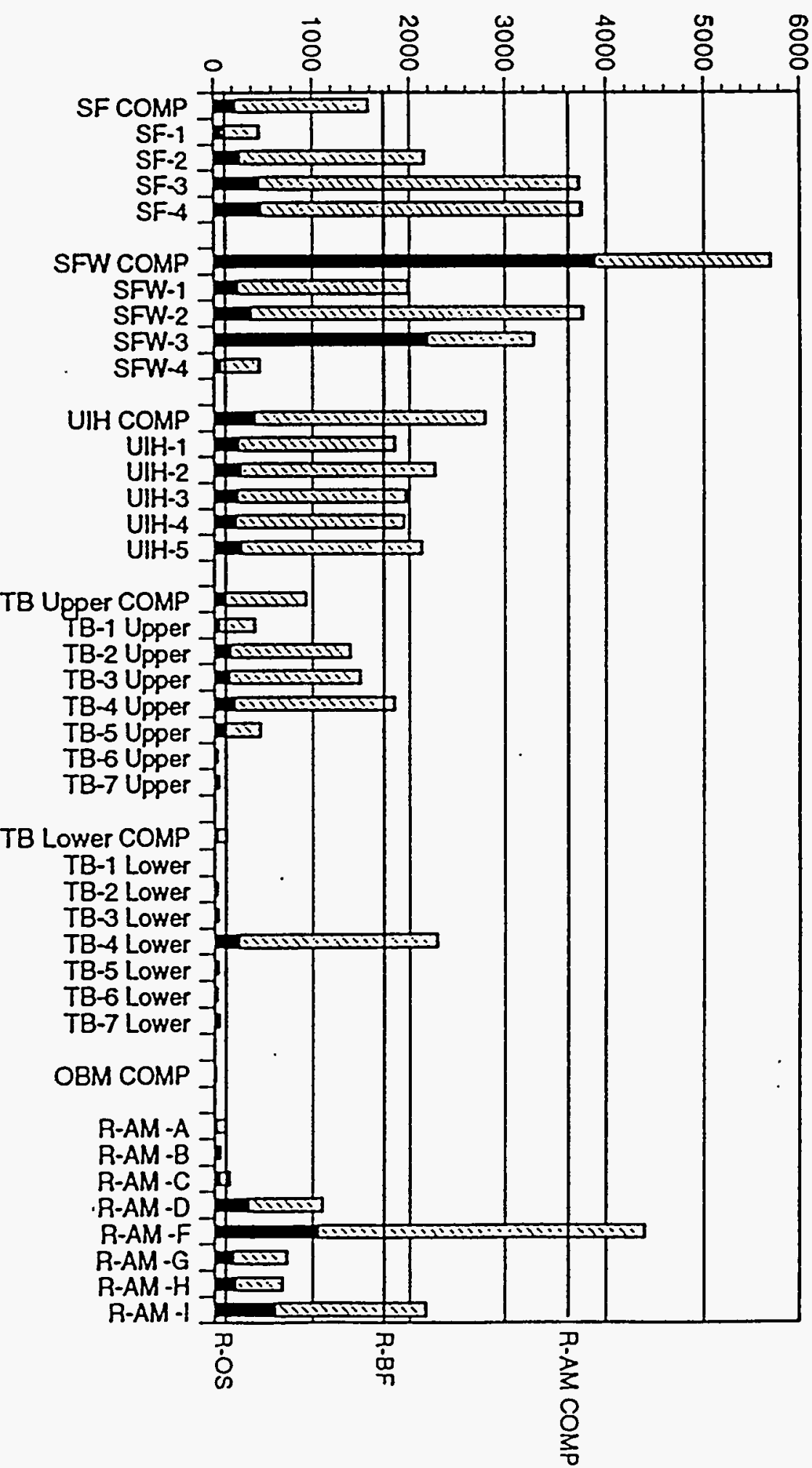




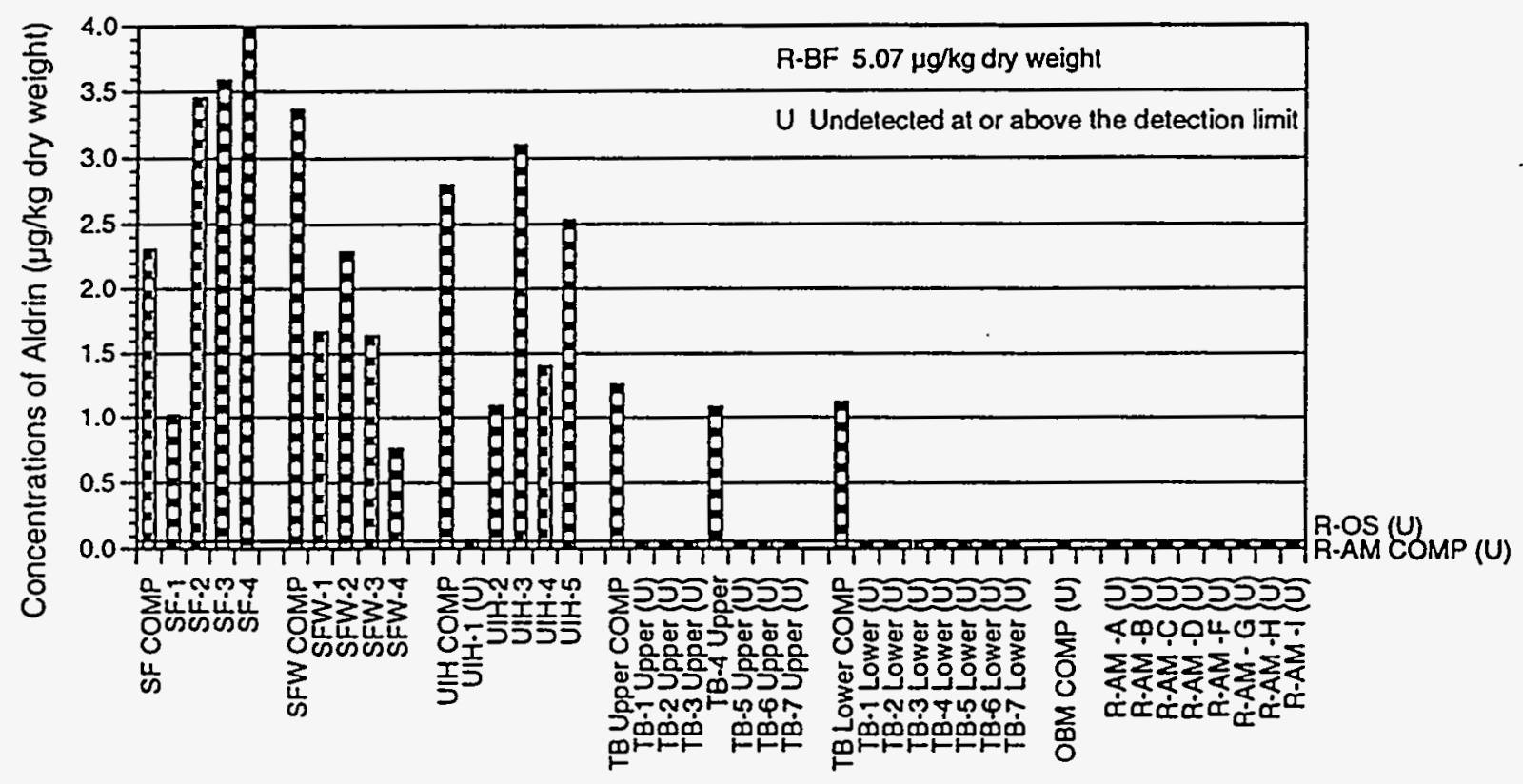

Sediment Treatments

FIGURE 3.17. Concentrations of Aldrin in Sediment Treatments

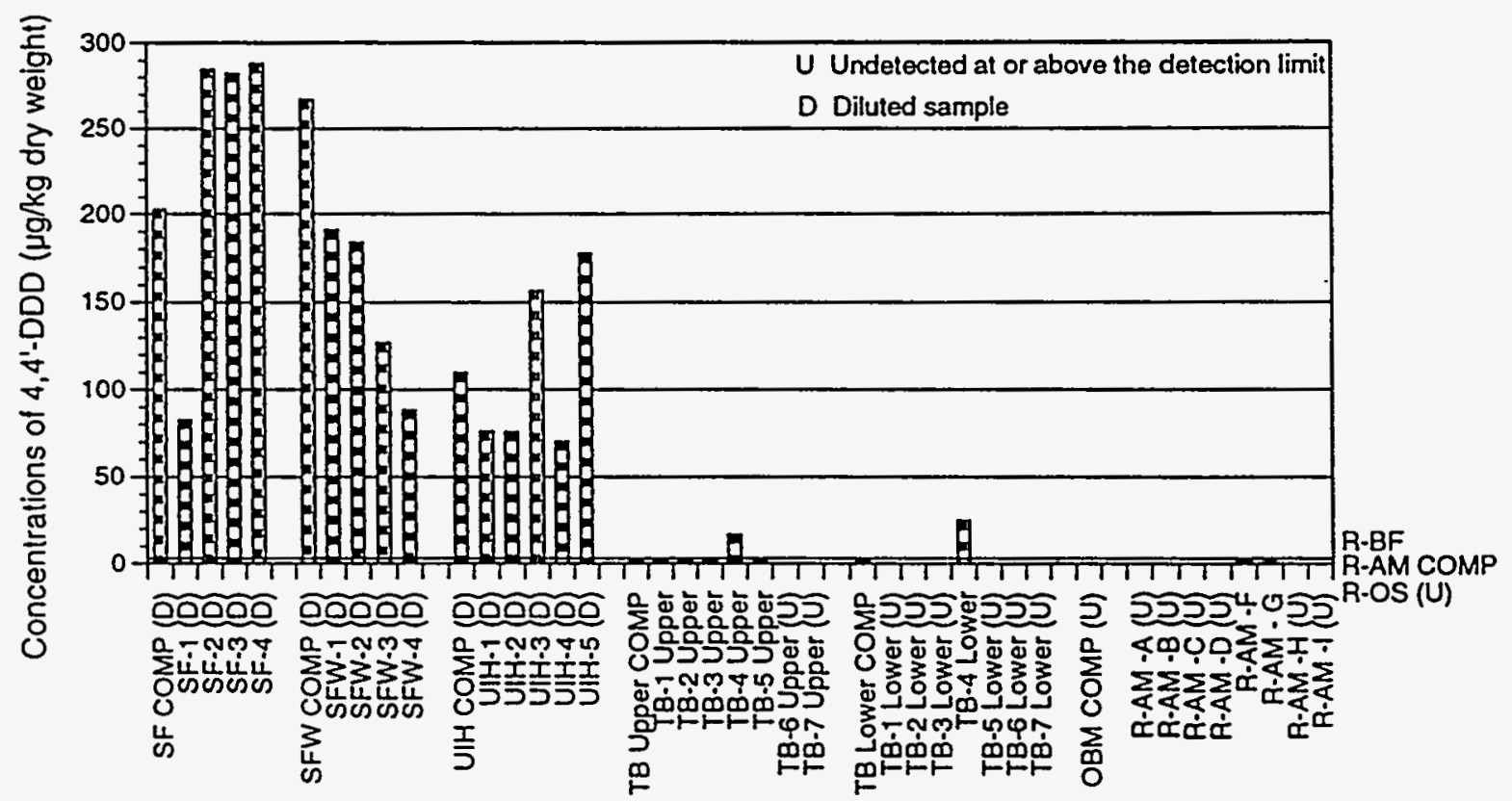

Sediment Treatments

FIGURE 3.18. Concentrations of 4,4'-DDD in Sediment Treatments 

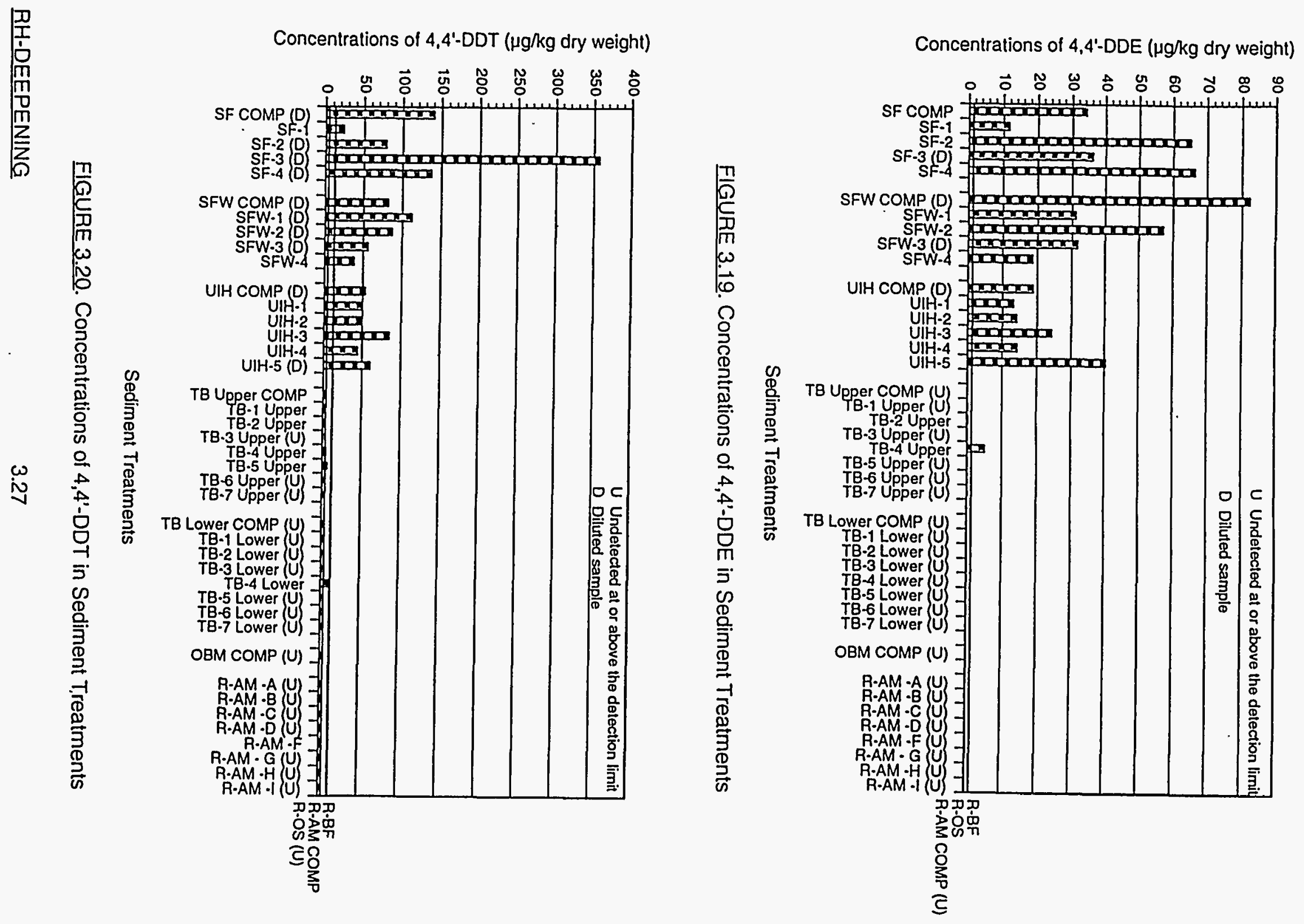


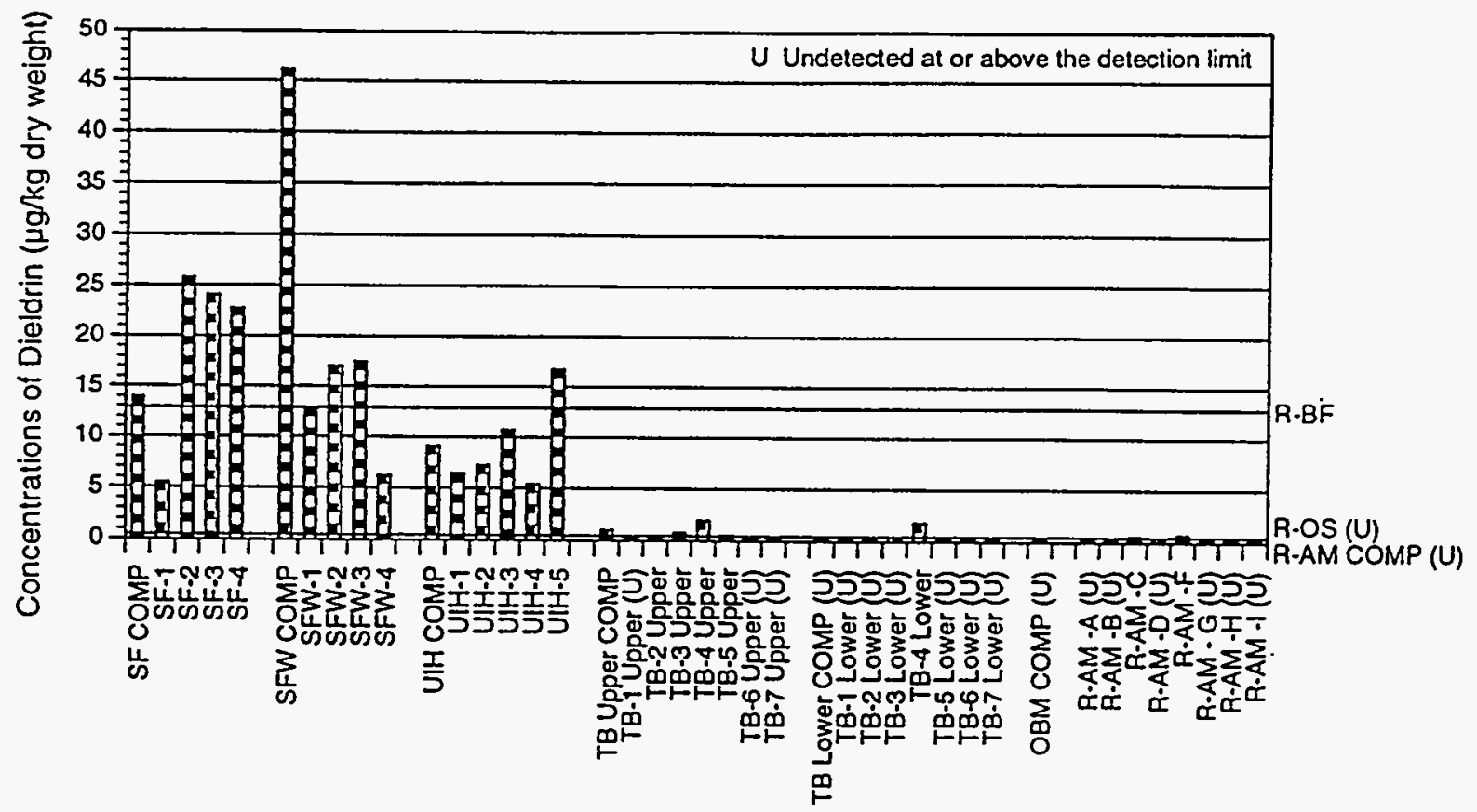

Sediment Treatments

FIGURE 3.21. Concentrations of Dieldrin in Sediment Treatments

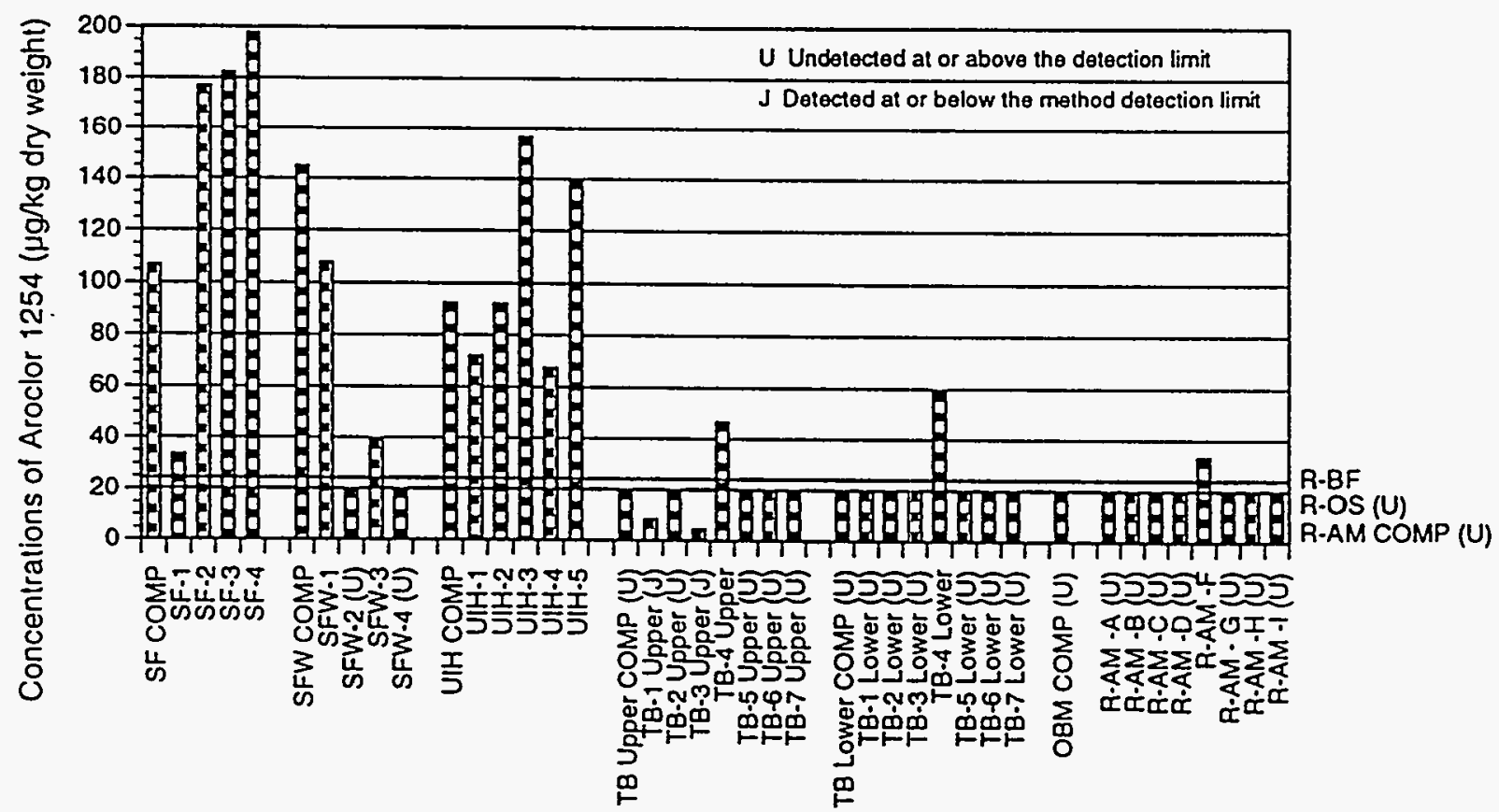

Sediment Treatments

FIGURE 3.22. Concentrations of Aroclor-1254 in Sediment Treatments 
Aroclor 1254 was the only PCB found in the majority of the test treatments ranging from $4.68 \mathrm{~J} \mu \mathrm{g} / \mathrm{kg}$ ( $\mathrm{J}$ indicates detected below the method detection limit, but above the instrument detection limit) in TB-3 Upper to $198 \mu \mathrm{g} / \mathrm{kg}$ in SF-4. The reference sediment R-OS had no detectable levels of any of the Aroclor compounds (Figure 3.22).

\subsubsection{Metals}

Ten metals were analyzed in the Richmond Harbor sediment treatments. Table 3.6 shows shaded values for those test treatments with higher concentrations of metals than were found in R-OS. Seven metals, $\mathrm{As}, \mathrm{Cr}, \mathrm{Cu}, \mathrm{Hg}, \mathrm{Ni}, \mathrm{Pb}$, and $\mathrm{Zn}$, were found at higher levels in the majority of the test treatments relative to R-OS. Selenium concentrations were higher in R-OS $(1.25 \mathrm{mg} / \mathrm{kg})$ than in all of the test treatments. The remaining two metals, $\mathrm{Ag}$ and $\mathrm{Cd}$, had elevated concentrations in less than half of the test treatments relative to the reference treatment. Sediments from test treatment SF-4, had the greatest number of metals $(\mathrm{Cr}, \mathrm{Cu}, \mathrm{Pb}$, and $\mathrm{Zn})$ at the highest concentrations among all test treatments. Test treatment TB-1 Lower had five metals $(\mathrm{Cd}, \mathrm{Cu}, \mathrm{Ni}, \mathrm{Pb}$, and $\mathrm{Zn})$ at the lowest concentrations of any test treatment.

Sediments from the Santa Fe Channel and the Upper Inner Harbor area appear to have the greatest concentration of metals, whereas sediment from the Turning Basin appears to be less enriched with metals (Figures 3.23 to 3.32 ).

\subsubsection{Butyltins}

Three organotins (mono-, di-, and tributyltin) were measured in the Richmond Harbor sediment treatments. A summary of the dibutyltin (DBT) and tributyltin (TBT) analyses are shown in Table 3.6 and Figures 3.33 and 3.34. The TBT concentrations were detected in 18 test treatments and ranged from $1.05 \mu \mathrm{g} / \mathrm{kg}$ in SFW-4 to $30.6 \mu \mathrm{g} / \mathrm{kg}$ in SF-3. Eighteen of the test treatments had detectable values of DBT. The DBT concentrations in the test treatments ranged from $1.13 \mu \mathrm{g} / \mathrm{kg}$ in TB-1 Upper to $33.1 \mu \mathrm{g} / \mathrm{kg}$ in SF-4. The reference sediment R-OS had concentrations of TBT and DBT that were detected below the method detection limit.

\subsubsection{Califomia Waste Extraction Test (WET) and Soluble Threshold Limit Concentrations \\ (STLC) for 17 California Assessment Metals (CAM). Hexavalent Chromium and Selected Pesticides and PCBs by Method 8080}

Five Richmond Harbor test treatments were analyzed for 17 metals, hexavalent chromium, and selected pesticides and PCBs using the WET. The detection limits set forth for analysis were approximately one-tenth of the STLC values listed in Title 22 of the California Code of Regulations (Health and Safety Code §25205.7). 


\begin{tabular}{|c|c|c|c|c|c|c|c|c|c|c|c|c|}
\hline \multirow{2}{*}{$\begin{array}{l}\text { Sediment } \\
\text { Treatment }\end{array}$} & \multirow[b]{2}{*}{$\mathrm{Ag}$} & \multirow[b]{2}{*}{ As } & \multirow[b]{2}{*}{$\mathrm{Cd}$} & \multicolumn{3}{|c|}{ Motals } & \multirow[b]{2}{*}{$\mathrm{Ni}$} & \multirow[b]{2}{*}{$\mathrm{Pb}$} & \multirow[b]{2}{*}{$\mathrm{Se}$} & \multirow[b]{2}{*}{$\mathrm{Zn}$} & \multicolumn{2}{|c|}{ Butution } \\
\hline & & & & $\mathrm{G}$ & $\mathrm{Cu}$ & $\mathrm{Hg}$ & & & & & TBT & DBT \\
\hline R-OS & 0.556 & $2.19 \mathrm{~J}(\mathrm{a})$ & 0.489 & 171 & 23.5 & 0.084 & 68.1 & 10.8 & 1.25 & 84.3 & $0.40 \cup(0)$ & $0.65 U$ \\
\hline $\begin{array}{l}\text { SF } D O M P \\
\text { SF-1 } \\
\text { SF-2 } \\
\text { SF-3 } \\
\text { SF-4 }\end{array}$ & $\begin{array}{l}0.391 \\
0.303 \\
0.566 \\
0.628 \\
0.684\end{array}$ & $\begin{array}{r}94 \\
14 \% \\
134\end{array}$ & $\begin{array}{l}0.51 \\
0.922 \\
0.654 \\
0.474 \\
0564\end{array}$ & $\begin{array}{l}189 \\
178 \\
202 \\
214\end{array}$ & $\begin{array}{r}550 \\
368 \\
78 \% \\
92: 8 \\
107\end{array}$ & $\begin{array}{l}0360 \\
0.815 \\
0.490 \\
0.628 \\
0.689\end{array}$ & $\begin{array}{r}80.3 \\
93 \% \\
110 \\
109\end{array}$ & $\begin{array}{l}35 \% \\
48.9 \\
66.6 \\
848\end{array}$ & $\begin{array}{l}0.235 \\
0.128 \mathrm{U} \\
0.418 \\
0.336 \\
0.412\end{array}$ & $\begin{array}{c}130 \\
83.5 \\
178 \\
204 \\
208\end{array}$ & $\begin{array}{l}852 \\
687 \\
80.6 \\
270\end{array}$ & $\begin{array}{r}798 \\
9659 \\
98.25 \\
33.1\end{array}$ \\
\hline $\begin{array}{l}\text { SFW COMP } \\
\text { SFW-1 } \\
\text { SFW-2 } \\
\text { SFW-3 } \\
\text { SFW-4 }\end{array}$ & $\begin{array}{l}0.603 \\
0.438 \\
0.615 \\
0.537 \\
0.268\end{array}$ & $\begin{array}{c}124 \\
94 \\
9.48 \\
9.6 \\
93.4\end{array}$ & $\begin{array}{l}0.880 \\
0.482 \\
0.855 \\
0.782 \\
0.628\end{array}$ & $\begin{array}{l}192 \\
169 \\
158 \\
168 \\
183\end{array}$ & $\begin{array}{l}65.3 \\
68.5 \\
343 \\
55.6 \\
69.6\end{array}$ & $\begin{array}{l}0843 \\
0.377 \\
0.857 \\
0.465 \\
0.158\end{array}$ & $\begin{array}{l}928 \\
82.6 \\
67.6 \\
8686 \\
86 \%\end{array}$ & $\begin{array}{l}45 \% 8 \\
65 \% \\
20 \\
30.4 \\
4.4 .3\end{array}$ & $\begin{array}{l}0.522 \\
0.235 \\
0.421 \\
0.796 \\
0.243\end{array}$ & $\begin{array}{l}157 \\
867 \\
119 \\
153\end{array}$ & $\begin{array}{l}2.85 \\
5.78 \\
4.79 \\
0.40 \mathrm{U} \\
1.06:\end{array}$ & $\begin{array}{l}673 \\
988 \\
8.86 \\
0.850 \\
206\end{array}$ \\
\hline $\begin{array}{l}\text { UIH COMP } \\
\text { UIH-1 } \\
\text { UIH-2 } \\
\text { UIH-3 } \\
\text { UIH-4 } \\
\text { UIH-5 }\end{array}$ & $\begin{array}{l}0.639 \\
0.698 \\
06670 \\
00719 \\
0.491 \\
0.663\end{array}$ & $\begin{array}{l}136: \\
432 \\
1968 \\
10 \%\end{array}$ & $\begin{array}{l}0.613 \\
0.484 \\
0.465 \\
0.596 \\
0.733 \\
0.570\end{array}$ & $\begin{array}{l}203 \\
192 \\
103 \\
189 \\
168 \\
202\end{array}$ & $\begin{array}{l}86: \\
58.8 \\
83.9 \\
85 \% \\
68.0 \\
82.1\end{array}$ & $\begin{array}{l}0.508 \\
0.807 \\
0.618 \\
0.648 \\
0.31 \% \\
0.518\end{array}$ & $\begin{array}{l}12 \\
15 \\
117 \\
10 \\
114\end{array}$ & $\begin{array}{l}62.5 \\
53.6 \\
63 \% \\
59.5 \\
373 \\
582\end{array}$ & $\begin{array}{l}0.334 \\
0.507 \\
0.434 \\
0.331 \\
0.150 \\
0.413\end{array}$ & $\begin{array}{l}102 \\
180 \\
183 \\
180 \\
192\end{array}$ & $\begin{array}{l}858 \\
5.88 \\
6.6 \\
466 \\
8.2 \\
811\end{array}$ & $\begin{array}{l}9338 \\
795 \\
967 \\
6868 \\
6.02 \\
700\end{array}$ \\
\hline $\begin{array}{l}\text { TB Upper COMP } \\
\text { TB-1 Upper } \\
\text { TB-2 Upper } \\
\text { TB-3 Upper } \\
\text { TB-4 Upper } \\
\text { TB-5 Upper } \\
\text { TB-6 Upper } \\
\text { TB-7 Upper }\end{array}$ & $\begin{array}{l}0.223 \\
0.163 \\
0.214 \\
0.275 \\
0.501 \\
0.145 \\
0.135 \\
0.102\end{array}$ & $\begin{array}{l}10 \% \\
12 \% \\
12 \% \\
146 \\
96 \\
9.8 \\
9.2\end{array}$ & $\begin{array}{l}0.249 \\
0.159 \\
0.300 \\
0.306 \\
0.352 \\
0.299 \\
0.224 \\
0.288\end{array}$ & $\begin{array}{l}166 \\
210 \\
173 \\
169 \\
164 \\
171 \\
184 \\
212\end{array}$ & $\begin{array}{l}40 \% 5 \\
33: 6 \\
42.6 \\
46 \% \\
68 \% \\
34.0 \\
47 \% \\
26: 0\end{array}$ & $\begin{array}{l}0239 \\
0.200 \\
0.373 \\
0.532 \\
0.401 \\
0.075 \\
0.00 \\
0.066\end{array}$ & $\begin{array}{l}869 \\
717 \\
8 \% 8 \\
105 \\
84 \% \\
108 \\
749\end{array}$ & $\begin{array}{r}174 \\
21 \% 2 \\
272 \\
38.6 \\
13.8 \\
10.3 \\
9.4\end{array}$ & $\begin{array}{l}0.240 \\
0.128 \mathrm{U} \\
0.240 \\
0.337 \\
0.420 \\
0.426 \\
0.340 \\
0.243\end{array}$ & $\begin{array}{l}100 \\
73.4 \\
968 \\
19 \\
165 \\
90 \% 0 \\
972 \\
85.0\end{array}$ & $\begin{array}{l}167 \\
0.40 \mathrm{U} \\
136 \\
0.40 \mathrm{U} \\
2.18 \\
0.40 \mathrm{U} \\
0.40 \mathrm{U} \\
0.40 \mathrm{U}\end{array}$ & $\begin{array}{l}0.65 U \\
.10 \\
0.65 U \\
0.65 U \\
2.38 \\
0.65 U \\
0.65 U \\
0.65 U\end{array}$ \\
\hline
\end{tabular}




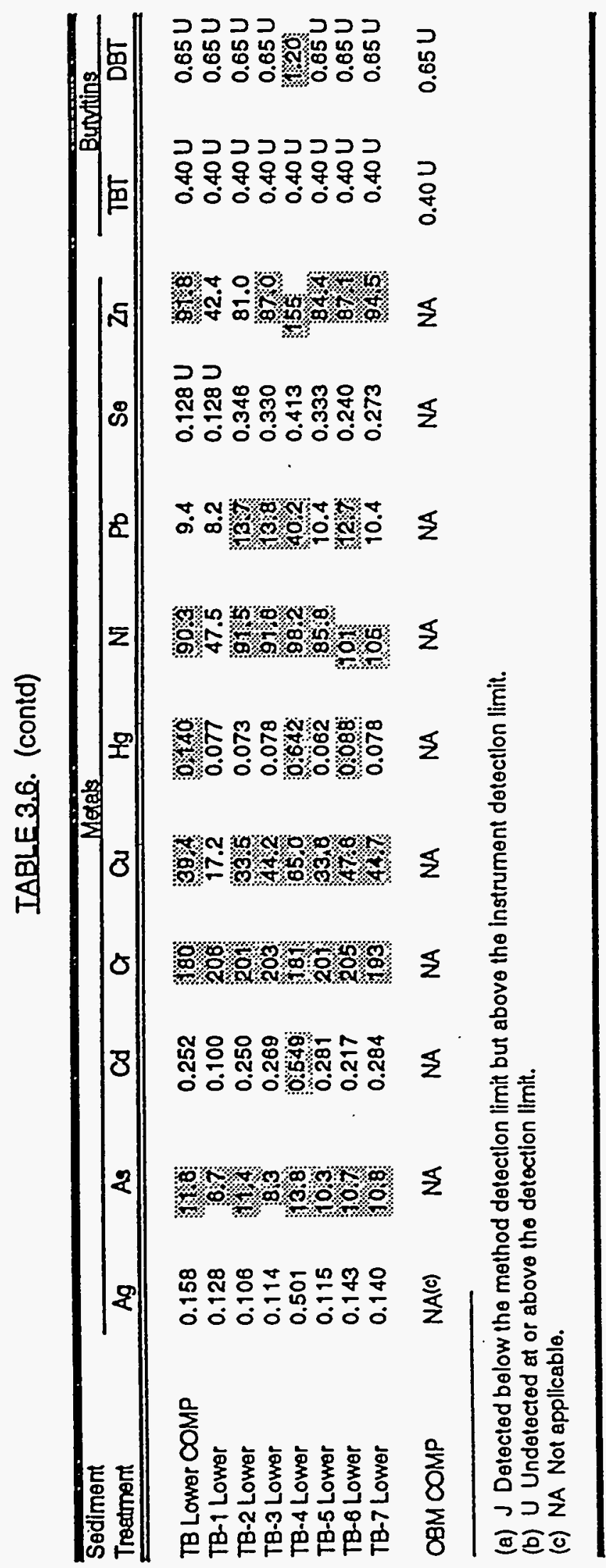

DRAFT RH-DEEPENING 

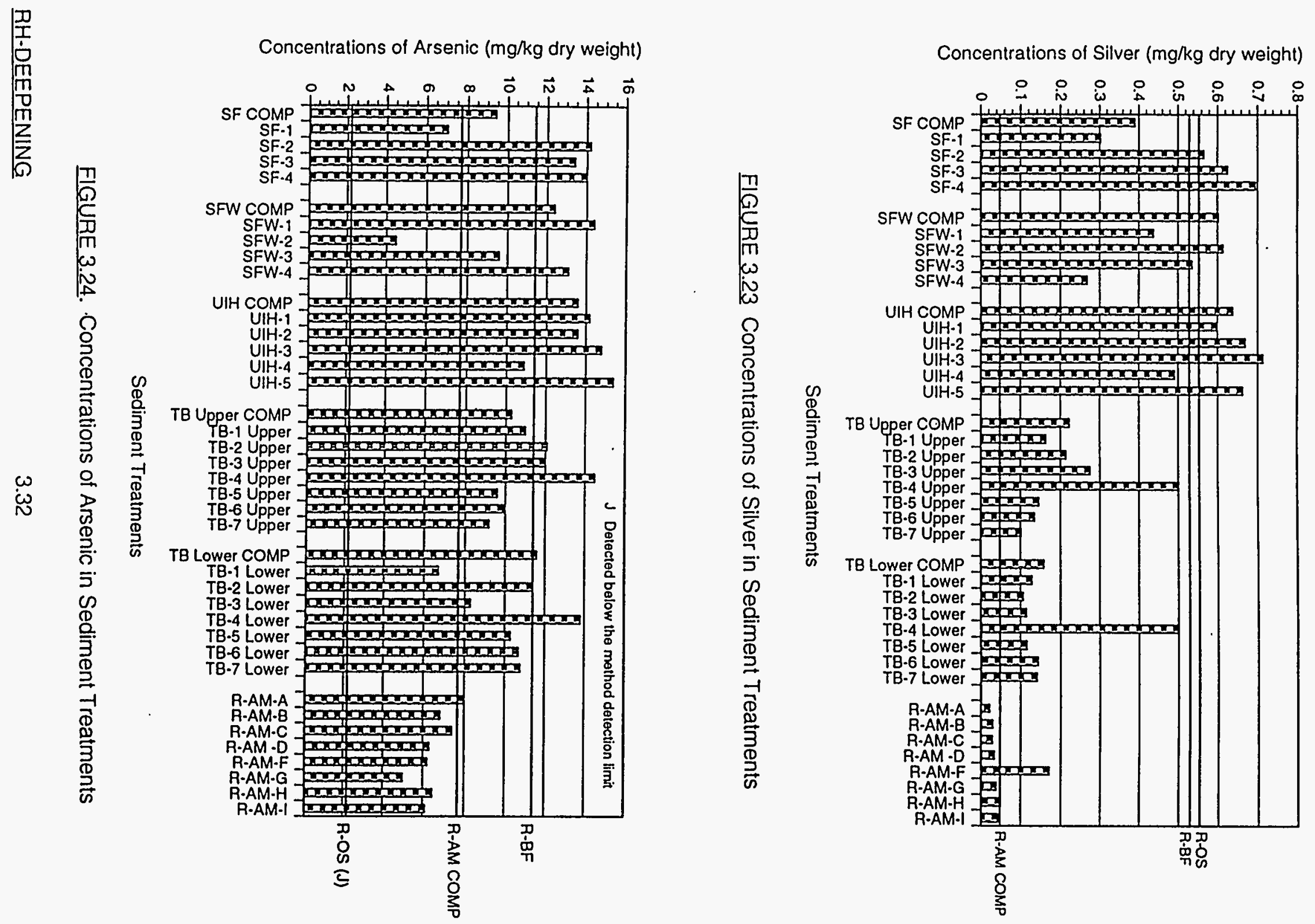

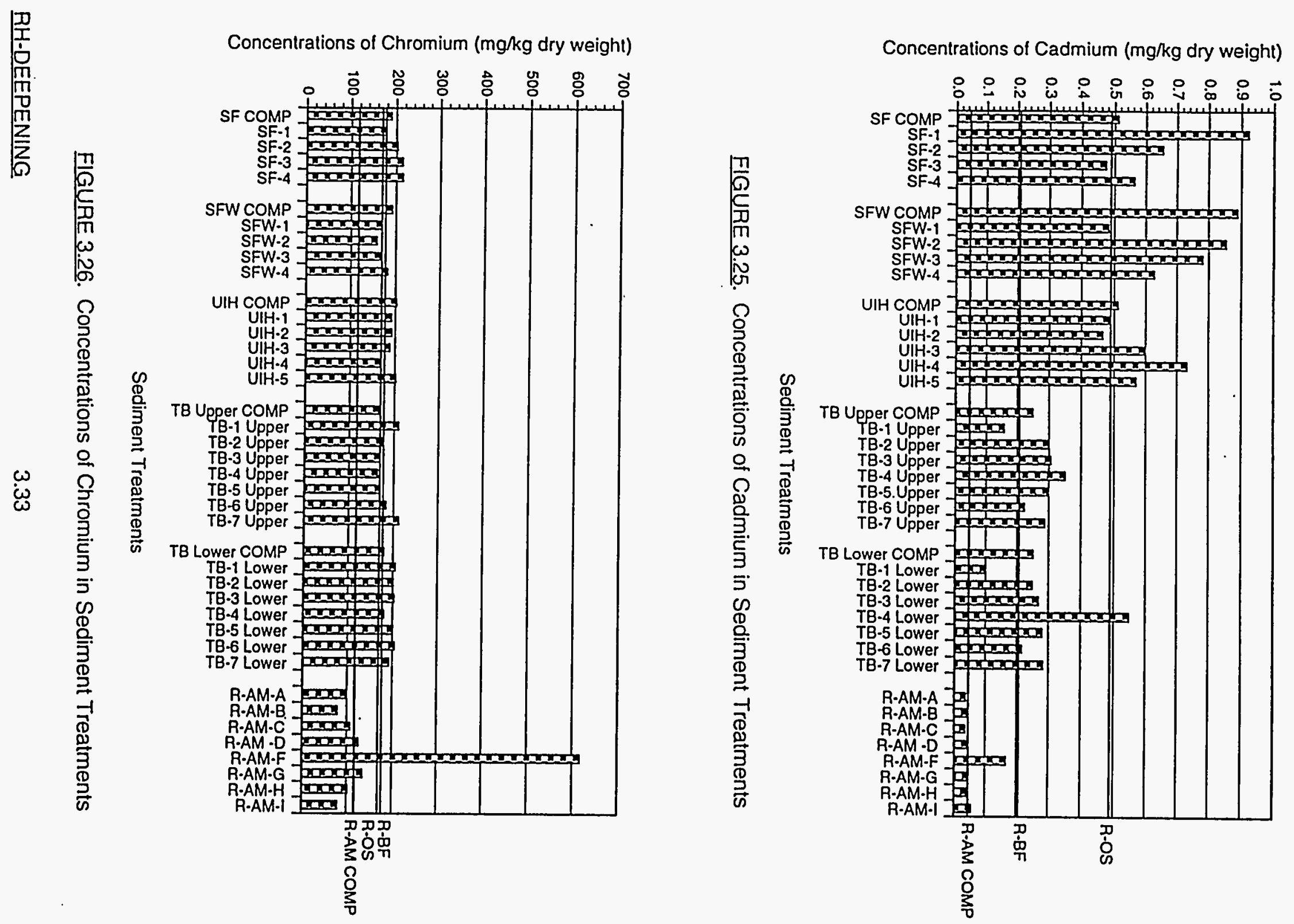

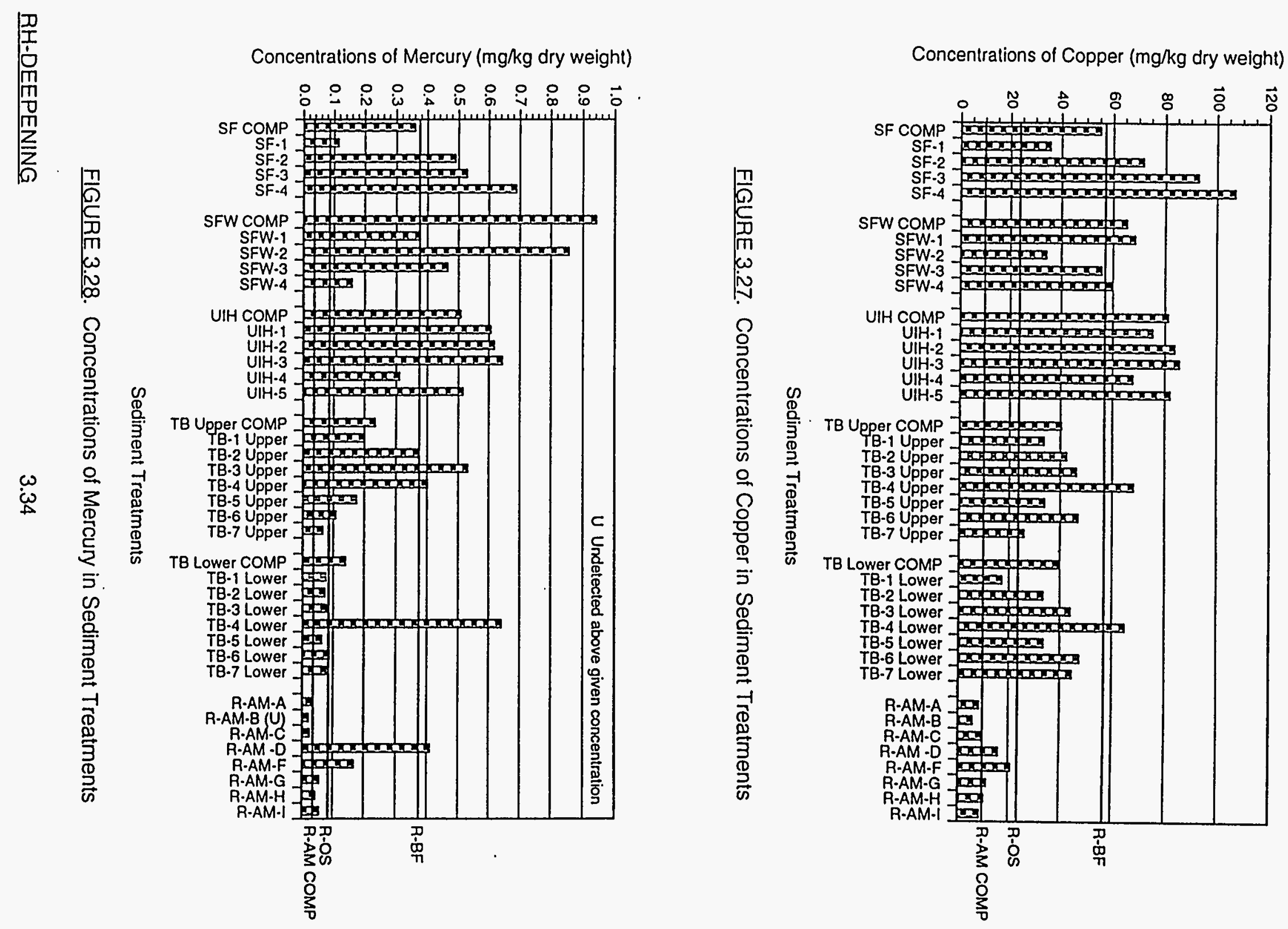


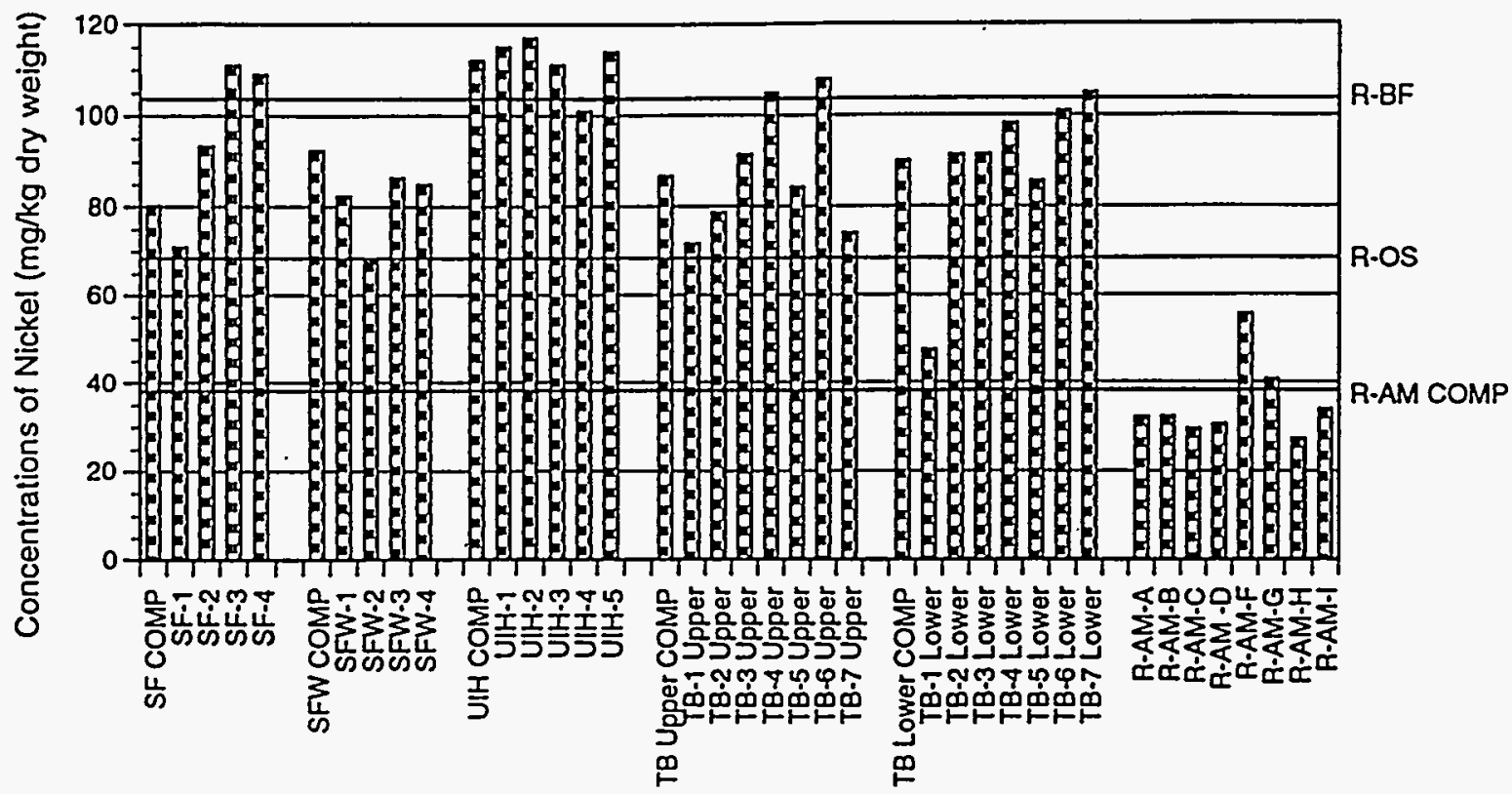

Sediment Treatments

FIGURE 3.29. Concentrations of Nickel in Sediment Treatments

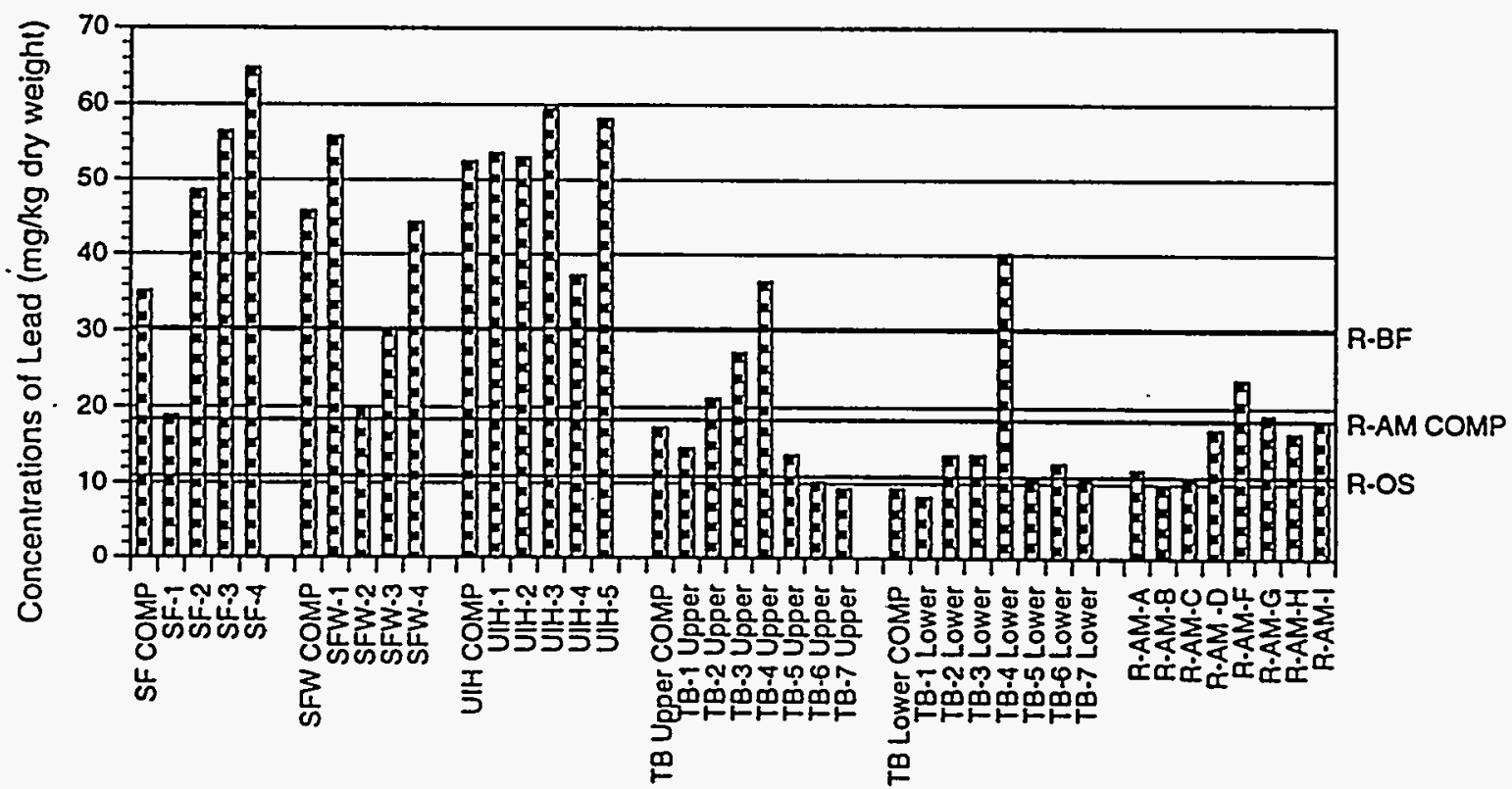

Sediment Treatments

FIGURE 3.30. Concentrations of Lead in Sediment Treatments 


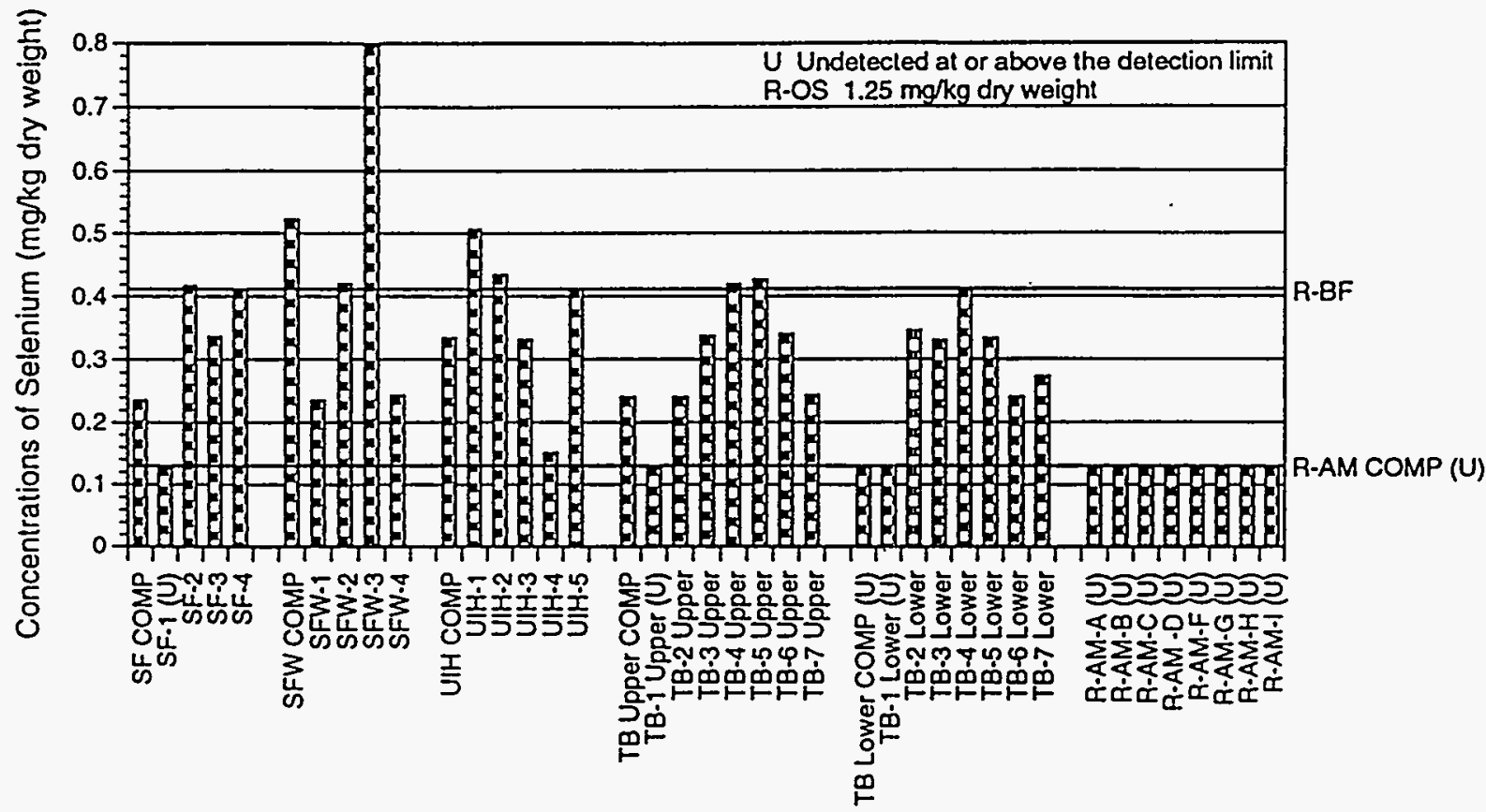

Sediment Treatments

FIGURE 3.31. Concentrations of Selenium in Sediment Treatments

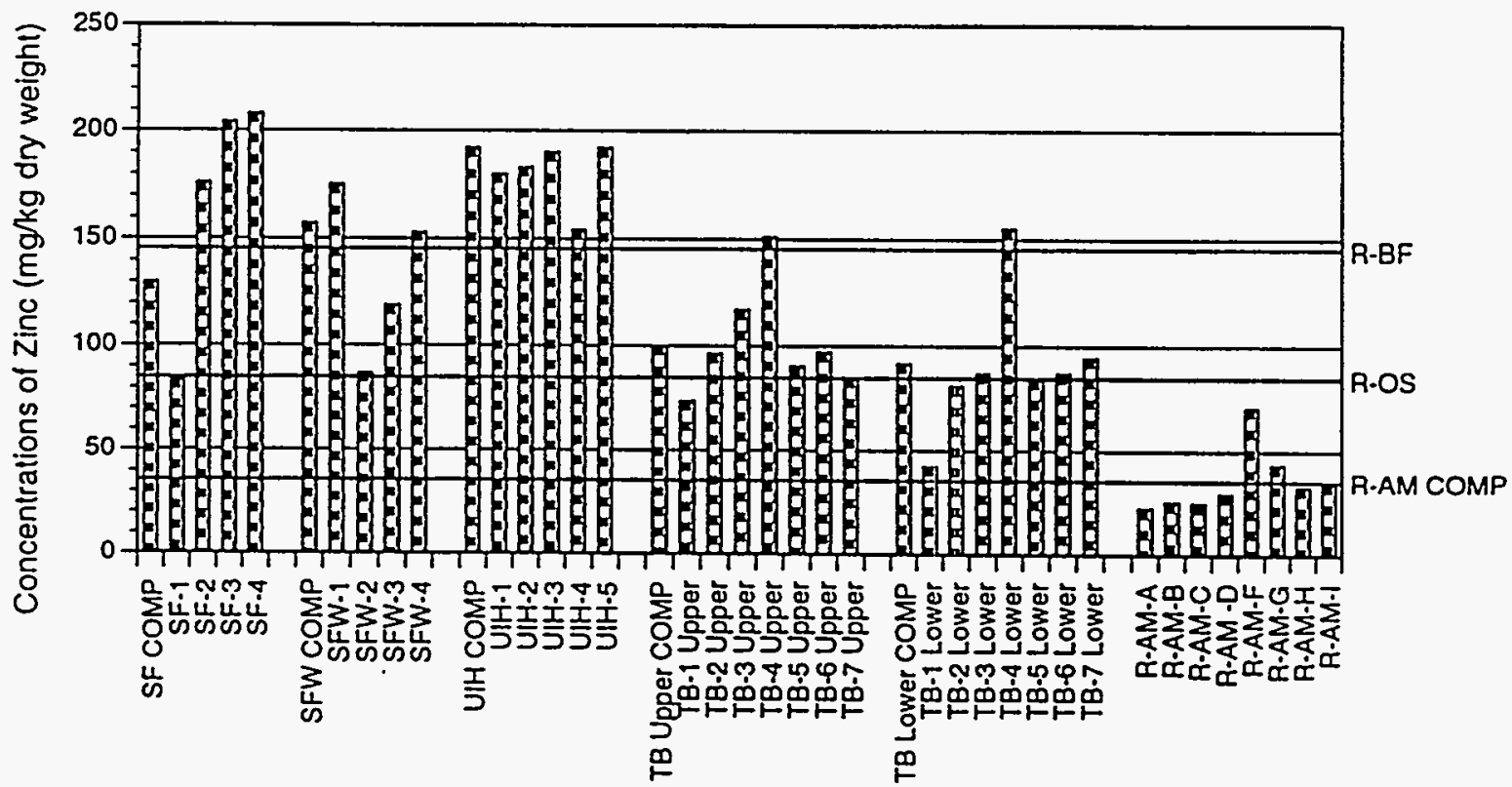

Sediment Treatments

FIGURE 3.32. Concentrations of Zinc in Sediment Treatments 


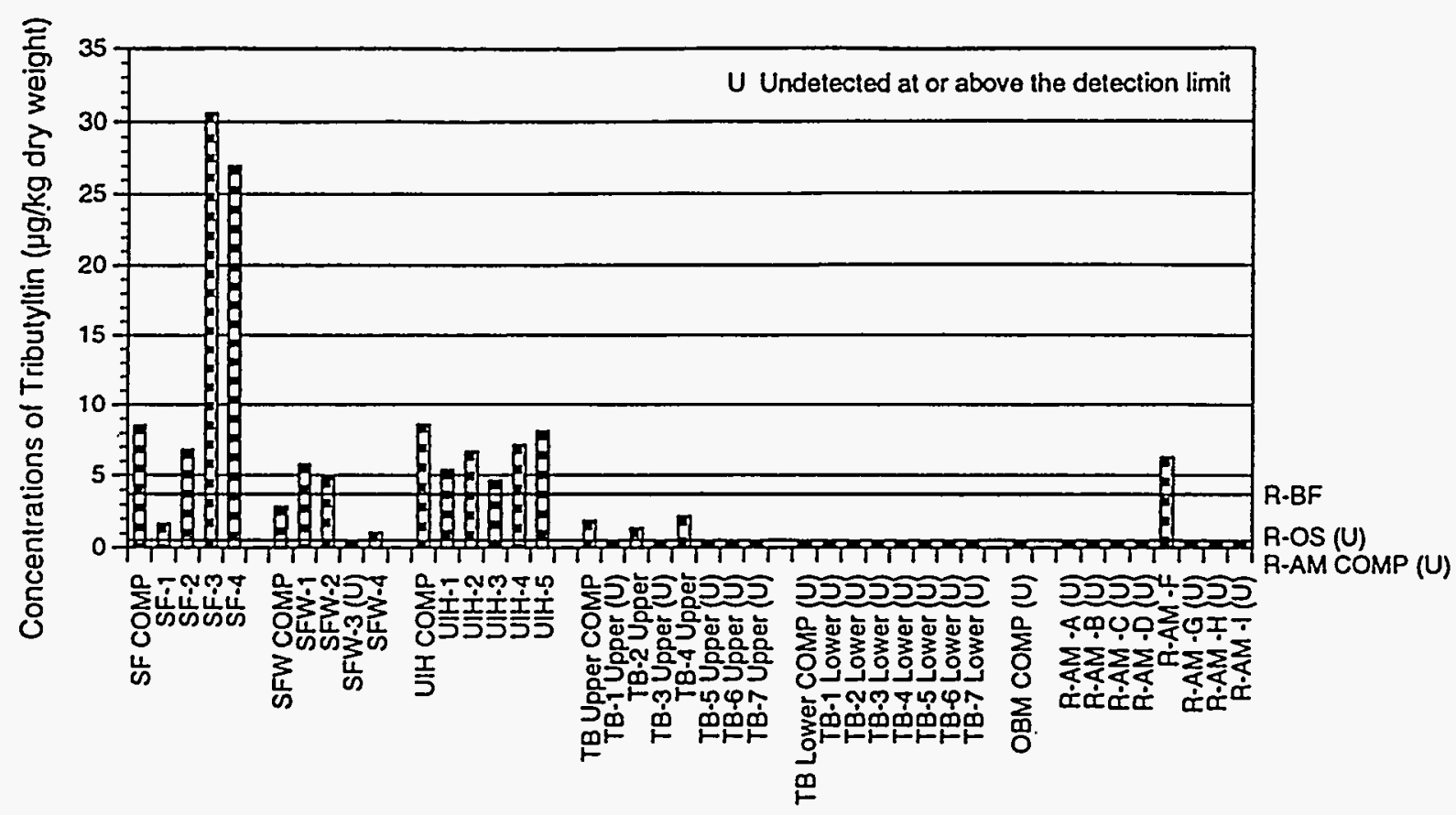

Sediment Treatments

FIGURE 3.33. Concentrations of Tributyltin in Sediment Treatments

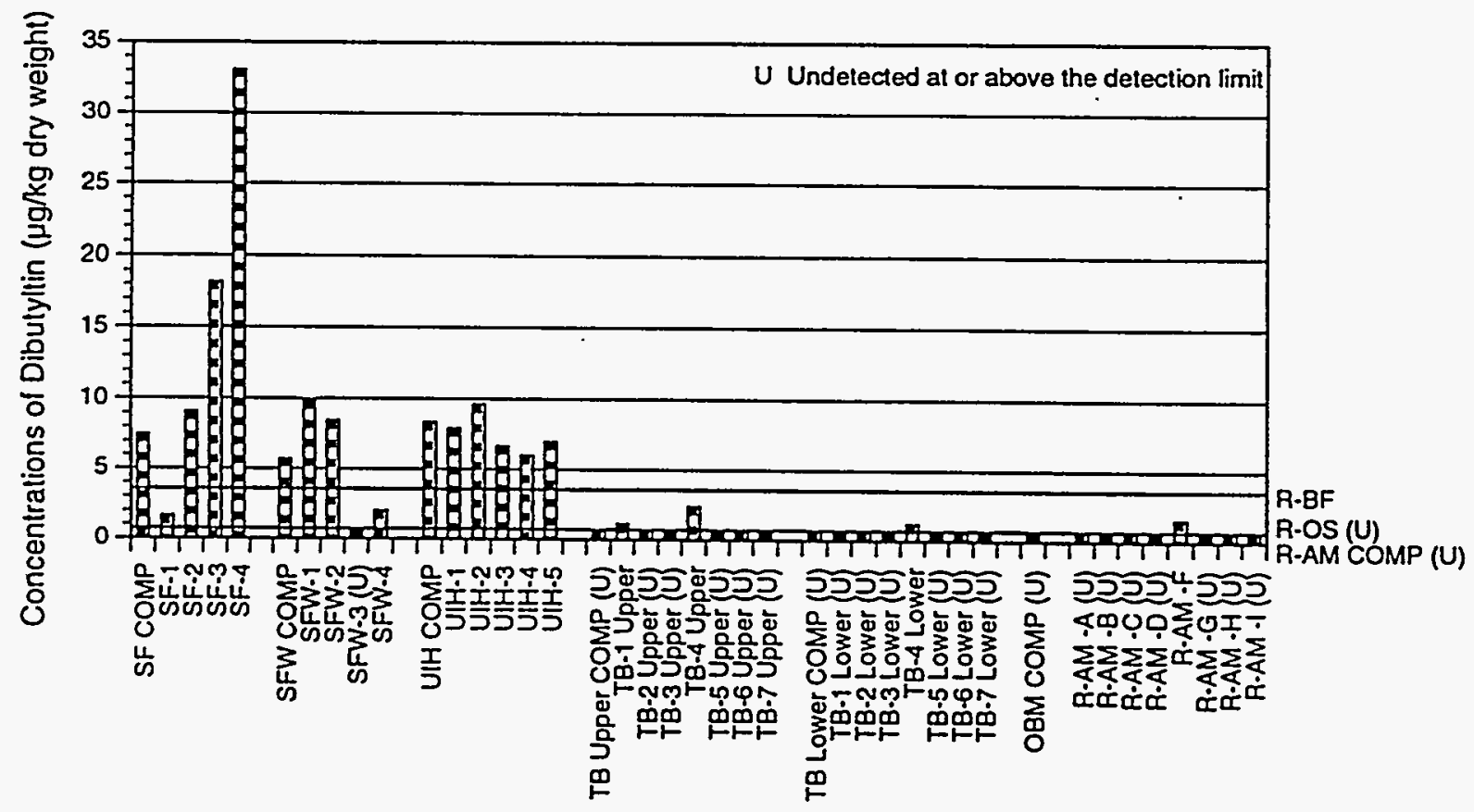

Sediment Treatments

FIGURE 3.34. Concentrations of Dibutyltin in Sediment Treatments 
The results of the metals analysis are shown in Tables C.27 through C.29. Nine of the 17 metals analyzed were undetected in all five test treatments. Five metals, $\mathrm{As}$, barium (Ba), $\mathrm{Cr}$, vanadium $(\mathrm{V})$, and $\mathrm{Ni}$, were detected in all five test treatments (Table 3.7). Hexavalent $\mathrm{Cr}$ was undetected in all test treatments. Nineteen pesticides and seven Aroclors were extracted using the WET and analyzed by Method 8080 . None of these pesticides or Aroclors was detected in any of the five test treatments.

\subsection{TOXICOLOGICAL TESTING RESULTS}

Six toxicological tests were conducted to assess the biological toxicity and bioaccumulation potential of contaminants from Richmond Harbor Deepening Project sediments. The complete data for water quality monitoring, test results, and the reference toxicant tests, are contained in Appendixes $E$ through $N$. The QAVC summaries are located at the front of each appendix and provide information related to organism source, holding and acclimation, water quality parameters, reference toxicant information, and test validity.

Solid-phase toxicity tests were conducted on the five Richmond Harbor test treatments, the OBM COMP, and the appropriate "native" control sediment for each species. Three species of marine invertebrates were exposed for 10-days to the solid-phase treatments: $R$. abronius, $M$. nasuta, and $N$. caecoides. Survival data for these organisms are summarized in Table 3.8. A 28-day exposure of $M$. nasuta and $N$. virens to the five Richmond Harbor test treatments and the OBM COMP was conducted to assess bioaccumulation of contaminants in test organism tissues. The results of each solid-phase test were examined to ensure that the test was validated by $90 \%$ survival in the native control sediment. The data from the 10 -day solid-phase acute toxicity tests were then evaluated by analysis of variance (ANOVA) and Dunnett's test to determine whether statistically significant differences occurred between the test and reference treatments (Table 3.9).

TABLE 3.7. Summary of Detected Metals Analyzed by the California Waste Extraction Test

\begin{tabular}{lccccc}
\hline \hline Sediment & \multicolumn{3}{c}{$(\mathrm{mg} / \mathrm{L})$} & & \\
\cline { 2 - 6 } Treatment & Arsenic & Barium & Chromium & Nickel & Vanadium \\
\hline \hline SF COMP & 0.05 & 1.5 & 0.2 & 0.2 & 0.5 \\
SFW COMP & 0.08 & 2.5 & 0.3 & 0.2 & 0.6 \\
UIH COMP & 0.06 & 0.8 & 0.4 & 0.3 & 0.7 \\
TB Upper COMP & 0.08 & 1.1 & 0.1 & 0.2 & 0.6 \\
TB Lower COMP & 0.08 & 1.9 & 0.1 & 0.3 & 0.5 \\
\hline \hline
\end{tabular}


TABLE 3.8. Summary of 10-Day Solid-Phase Toxicity Tests, Richmond Harbor Deepening Project

\begin{tabular}{|c|c|c|c|c|c|c|}
\hline \multirow[b]{2}{*}{$\begin{array}{l}\text { Sediment } \\
\text { Treatment } \\
\end{array}$} & \multicolumn{2}{|c|}{ A. abronius } & \multicolumn{2}{|c|}{ M. nasuta } & \multicolumn{2}{|c|}{ N. caecoides } \\
\hline & $\begin{array}{l}\text { Percent } \\
\text { Survival }\end{array}$ & $\begin{array}{l}\text { Acute } \\
\text { Toxicity }\end{array}$ & $\begin{array}{l}\text { Percent } \\
\text { Survival }\end{array}$ & $\begin{array}{l}\text { Acute } \\
\text { Toxicity }\end{array}$ & $\begin{array}{l}\text { Percent } \\
\text { Survival }\end{array}$ & $\begin{array}{l}\text { Acute } \\
\text { Toxicity }\end{array}$ \\
\hline R-OS & 89 & NA(a) & 100 & NA & 96 & NA \\
\hline SF COMP & 89 & $\mathrm{NO}(\mathrm{b})$ & 100 & NO & 79 & YES(c) \\
\hline SFW COMP & 77 & NO & 98 & NO & 81 & YES \\
\hline UIH COMP & 77 & NO & 100 & NO & 88 & NO \\
\hline TB Upper COMP & 70 & NO & 99 & NO & 86 & NO \\
\hline TB Lower COMP & 50 & YES & 98 & NO & 96 & NO \\
\hline OBM COMP & 72 & NO & 98 & NO & 38 & YES \\
\hline C-SB & 93 & NA & 100 & NA & 96 & NA \\
\hline$C-W B$ & 98 & NA & NA & NA & NA & NA \\
\hline C-NE & NA & NA & 100 & NA & 94 & NA \\
\hline
\end{tabular}

(a) NA Not applicable.

(b) NO Indicates that test treatment was not statistically significantly different from the reference sediment R-OS at $\alpha=0.05$.

(c) YES Indicates that test treatment was statistically significantly different from the reference sediment R-OS at $\alpha=0.05$ and $>10 \%$ lower in survival than R-OS $(20 \%$ for R. abronius).

TABLE 3.9. ANOVA Results for the 10-Day Solid-Phase Toxicity Tests, Richmond Harbor Deepening Project

\begin{tabular}{lccccc}
\hline \hline $\begin{array}{l}\text { Source of } \\
\text { Variation }\end{array}$ & $\begin{array}{c}\text { Sum } \\
\text { Squares }\end{array}$ & d.f. & $\begin{array}{c}\text { Mean } \\
\text { Square }\end{array}$ & F-Ratio & $\begin{array}{c}\text { Significance } \\
\text { Level }\end{array}$ \\
\hline \hline R. abronius & & & & & \\
$\begin{array}{l}\text { Treatment } \\
\text { Residual }\end{array}$ & 0.736 & 6 & 0.123 & 9.728 & 0.0001 \\
& 0.353 & 28 & 0.013 & & \\
M. nasuta & & & & & \\
Treatment & 0.042 & 6 & 0.007 & 0.959 & 0.4702 \\
Residual & 0.204 & 28 & 0.007 & & \\
& & & & & \\
N. caecoides & 1.998 & 6 & 0.333 & 17.151 & 0.0001 \\
$\begin{array}{l}\text { Treatment } \\
\text { Residual }\end{array}$ & 0.544 & 28 & 0.019 & & \\
& & & & & \\
\hline \hline
\end{tabular}


A test treatment was considered acutely toxic if it was statistically significantly different from the reference sediment and if the survival of the test organisms exposed to the test treatment was $\geq 10 \%$ lower than survival in the reference sediment ( $\geq 20 \%$ lower than reference for $R$. abronius).

Suspended-particulate-phase toxicity tests were conducted with the five Richmond Harbor test treatments and the OBM COMP. Three concentrations of SPP $(10 \%, 50 \%$, and $100 \%$ ), were prepared and tested concurrently with a seawater control (0\% SPP). Three species of marine organisms were exposed to the test treatments prepared as SPP: C. stigmaeus, $H$. costata, and $M$. galloprovincialis. Control survival was used to validate the tests. The data for the $0 \%$ (control) and the $100 \%$ SPP treatments were statistically compared using a two-sample t-test. If the result was statistically significant at an experiment-wide error rate of $\alpha=0.05$ and there was at least $50 \%$ reduction in response relative to the control, an $L_{50}$ or $E_{50}$ estimate was made using the Trimmed Spearman-Karber method.

\subsubsection{0-Day Solid-Phase Static Test with $R$. abronius}

Tables 3.8 and 3.9 contain summaries of the solid-phase toxicity testing results for $R$. abronius. The test was validated by $98 \%$ survival of $R$. abronius in their native control sediment, C-WB. The fine-grained control sediment, C-SB also had an acceptable $R$. abronius survival of $93 \%$. Survival in the test treatments ranged from $50 \%$ in TB Lower COMP to $89 \%$ in SF COMP. Only one test treatment, TB Lower COMP, was acutely toxic to $R$. abronius relative to R-OS, which had $89 \%$ survival. The population of amphipods used for this project was assessed using a $C d$ reference toxicant test. The resultant $L C_{50}$ was $0.90 \mathrm{mg} / \mathrm{L} \mathrm{Cd}$ (confidence interval $=0.77 \mathrm{mg} / \mathrm{L}$ to $1.06 \mathrm{mg} / \mathrm{L} \mathrm{Cd}$ ). This $L C_{50}$ is within the range of $0.68 \mathrm{mg} / \mathrm{L}$ to $1.25 \mathrm{mg} / \mathrm{L} \mathrm{Cd}$ established for measuring the sensitivity of $R$. abronius (ASTM 1990).

Ammonia concentrations were monitored in overlying water (Days $0,1,3,7$, and 10) and in porewater (Days 0 and 10 ) of each sediment treatment during the $R$. abronius solid-phase static test (Table 3.10). Ammonia measurements were taken from dummy jars that were set up and run concurrently with the test treatments. Total ammonia in sediment porewater ranged from $2.53 \mathrm{mg} / \mathrm{L}$ to $24.9 \mathrm{mg} / \mathrm{L}$ at test initiation, and from $<1 \mathrm{mg} / \mathrm{L}$ to $13.8 \mathrm{mg} / \mathrm{L}$ by test termination. The highest levels of porewater ammonia occurred in TB Lower COMP $(24.9 \mathrm{mg} / \mathrm{L}$ on Day 0 and $13.8 \mathrm{mg} / \mathrm{L}$ on Day 10). The lowest levels of porewater ammonia were found in the reference and control sediments, as well as in the OBM COMP.

In a 96-h water-only ammonia reference toxicant test with $R$. abronius collected from the same location but tested at a later date (May 1994), $R$. abronius responded to total ammonia concentrations between $20 \mathrm{mg} / \mathrm{L}$ and $200 \mathrm{mg} / \mathrm{L}$, with an $L C_{50}$ value of $72.18 \mathrm{mg} / \mathrm{L}$ total ammonia. 
TABLE 3.10. Ammonia Monitoring Summary for the 10-Day R. abronius Solid-Phase Static Test, Richmond Harbor Deepening Project

\begin{tabular}{|c|c|c|c|c|c|c|c|}
\hline \multirow{2}{*}{$\begin{array}{l}\text { Sediment } \\
\text { Treatment }\end{array}$} & \multicolumn{5}{|c|}{ Overlying Water Ammonia (mg/) } & \multicolumn{2}{|c|}{ Porewater Ammonia (moL) } \\
\hline & Day 0 & Day 1 & Day 3 & Day 7 & Day 10 & Day 0 & Day 10 \\
\hline TB Upper COMP & 3.33 & 9.35 & 9.70 & 9.45 & 1.80 & 12.3 & 1.70 \\
\hline TB Lower COMP & 12.6 & 20.8 & 26.5 & 25.7 & 5.49 & 24.9 & 13.8 \\
\hline SF COMP & 1.81 & 3.80 & 1.94 & 5.13 & 1.43 & 6.64 & 2.62 \\
\hline UIH COMP & 8.47 & 10.7 & 13.1 & 11.7 & 1.76 & 13.7 & 3.00 \\
\hline SFW COMP & 4.55 & 8.79 & 8.95 & 9.99 & 1.84 & 9.64 & 3.08 \\
\hline OBM COMP & 1.11 & 1.96 & 2.14 & 3.34 & 1.32 & 2.53 & 2.49 \\
\hline R-AM & 0.419 & 0.493 & 0.261 & 0.896 & 1.19 & 3.25 & 1.03 \\
\hline R-BF & 0.779 & 1.43 & 1.74 & 0.700 & 1.23 & 3.38 & 0.663 \\
\hline R-OS & 0.649 & 1.09 & 0.272 & 1.48 & .1 .42 & 3.61 & 1.05 \\
\hline C-SB & 0.756 & 1.94 & 0.844 & 1.14 & 1.30 & 4.22 & 1.07 \\
\hline$C-W B$ & 0.815 & 0.947 & 0.802 & 1.31 & 1.45 & 4.99 & $N D(a)$ \\
\hline
\end{tabular}

(a) ND No data; sediment was too sandy to extract an adequate quantity of interstitial water for ammonia measurement.

Figure 3.35 shows the average dose-response of $R$. abronius to ammonia that was established from five independent studies conducted in 1994. R. abronius survival in the test treatments and the measured porewater ammonia concentrations for each treatment were plotted on the . dose-response curve. The test treatment SF COMP had $R$. abronius survival that fell within the $95 \%$ confidence interval of the dose-response curve. However, four of the remaining test treatments (UIH COMP, SFW COMP, OBM COMP, and TB Upper COMP) that fell below the dose-response curve were not considered acutely toxic to $R$. abronius when compared with sediment from R-OS.

The test treatment TB Lower COMP falls well below the dose-response line, indicating that toxicity of this treatment cannot be attributed entirely to ammonia. This composite was further evaluated in October 1994 and the results of this evaluation are presented in Section 4.0 of this report.

\subsubsection{0-Day Solid-Phase Flow-Through Test with M. nasuta and N. caecoides}

The results of the 10-day solid-phase flow-through test with $M$. nasuta and $N$. caecoides are presented in Table 3.8 and Table 3.9. The $M$. nasuta test was validated by $100 \%$ survival in the native control sediment C-SB. M. nasuta survival for the Richmond Harbor test treatments was at least $98 \%$, whereas survival of organisms in sediment from the reference treatment R-OS 


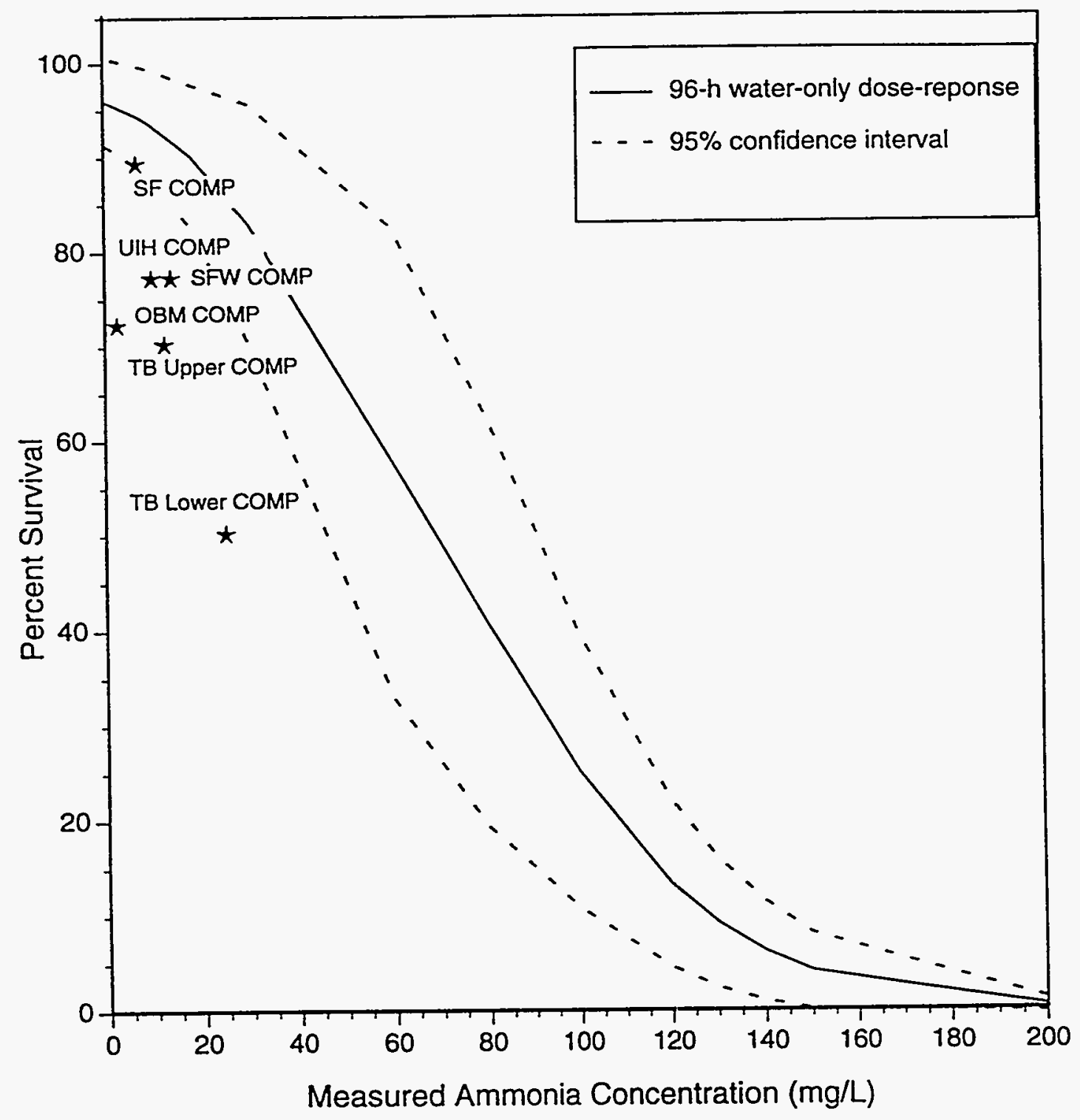

FIGURE 3.35. Response of $R$. abronius to Porewater Ammonia Concentrations in Richmond Harbor Deepening Sediments Relative to Water-Only Mean Response and 95\% Confidence Interval 
was $100 \%$. Statistical analysis was performed on the data to compare the test treatments with R-OS. These results showed no statistically significant differences between organism survival in the test treatment when compared with survival in the reference treatment R-OS.

The toxicity test with $N$. caecoides was validated by $94 \%$ survival in their native control sediment C-NE. Survival of $N$. caecoides in the test treatments ranged from $38 \%$ in the OBM COMP to $96 \%$ in the TB Lower COMP. Statistical analysis of the survival results showed that sediment from three test treatments, SF COMP, SFW COMP, and OBM COMP, were acutely toxic to $N$. caecoides relative to the sediments from the reference treatment R-OS.

Ammonia concentrations were monitored in the overlying water of each sediment treatment on Days $0,1,3,7$, and 10 during the $M$. nasuta/ $N$. caecoides solid-phase, flow-through test. Total ammonia values were generally the same or lower than the incoming flow-through seawater ( $\leqslant 0.45 \mathrm{mg} / \mathrm{L}$ ). Unpublished data at the MSL show that $N$. caecoides survival was not affected when exposed to $90 \mathrm{mg} / \mathrm{L}$ ammonia in a 4-day test using ammonia spiked in seawater and then mixed with C-NE control sediment. Although porewater ammonia was not measured during this test because of the difficulty of removing sediment from the flow-through system, it can be inferred from other porewater ammonia data for the same sediment treatments (Table 3.10) that the sediment ammonia levels were not as high as $90 \mathrm{mg} / \mathrm{L}$.

- Sediment from SF COMP, SFW COMP, and OBM COMP had greater mortality than would be predicted based on the interstitial water ammonia concentrations. Therefore, some other contaminant in addition to or in place of ammonia is responsible for the mortality of $N$. caecoides to these sediment treatments.

\subsubsection{8-Day Solid-Phase Flow-Through Test with M. nasuta and N. virens}

Table 3.11 contains the results of the toxicity tests for the 28-day M. nasuta and N. virens tests. These tests were validated by $91 \%$ and $95 \%$ survival in the $M$. nasuta (C-SB) and N. virens (C-NE) native control sediments, respectively. The test treatment survival range for M. nasuta was $90 \%$ in the TB Lower COMP to $96 \%$ in the UIH COMP. The test treatment survival for the $N$. virens test ranged from $93 \%$ in SF COMP to $98 \%$ in the TB Lower COMP. Sediments from the reference treatment R-OS had $96 \%$ survival of $M$. nasuta and $98 \%$ survival of $N$. virens. Statistical analysis was not conducted on this data, since the purpose of the 28-day test was to provide results of the bioaccumulation potential of specific test treatments.

\subsubsection{6-Hour Suspended-Particulate-Phase Static Test with C. stigmaeus}

The results of the 96-h SPP static test with C. stigmaeus are presented in Table 3.12. The test was validated by $99 \%$ survival of $C$. stigmaeus in the $0 \%$ SPP. The survival of C. stigmaeus in any concentration of SPP for each test treatment was never below $98 \%$. Results of the t-tests showed no statistically significant differences between the 100\% SPP and 
TABLE 3.11. Results of the 28-Day Solid-Phase Flow-Through Test with $M$. nasuta and N. virens, Richmond Harbor Deepening Project

\begin{tabular}{lcc}
\hline Sediment & $\begin{array}{c}\text { M. nasuta } \\
\text { Preatment }\end{array}$ & $\begin{array}{c}\text { N. virens } \\
\text { Percent Survival }\end{array}$ \\
\hline \hline R-OS & 96 & 98 \\
SF COMP & 95 & 93 \\
SFW COMP & 94 & 94 \\
UIH COMP & 96 & 96 \\
TB Upper COMP & 94 & 96 \\
TB Lower COMP & 90 & 98 \\
OBM COMP & 94 & NA(a) \\
C-SB & 91 & NA \\
C-NV & NA & 95 \\
& & \\
(a) NA Not applicable. & & \\
\hline \hline
\end{tabular}

the $0 \%$ control for any test treatment. The $L_{50}$ values were not calculated because there was not a $50 \%$ reduction in survival of $C$. stigmaeus. The $L_{50}$ for copper was $0.88 \mathrm{mg} / \mathrm{L} \mathrm{Cu}(95 \%$ confidence interval $[\mathrm{Cl}]=0.77$ to $1.00 \mathrm{mg} / \mathrm{L} \mathrm{Cu}$ ). These results are slightly below the $\mathrm{LC}_{50}$ range established from previous MSL studies ( 1.2 to $1.6 \mathrm{mg} / \mathrm{L} \mathrm{Cu}$ ) indicating that the test organisms were slightly more sensitive than species used in previous studies. This does not appear to have effected the results, based on the high survival of $C$. stigmaeus in all concentrations of SPP. The $L C_{50}$ from the ammonia reference toxicant exposure was $23.9 \mathrm{mg} / \mathrm{L}$. One other study has been conducted at the MSL with ammonia and C. stigmaeus; it resulted in an $L_{50}$ of $30.9 \mathrm{mg} / \mathrm{L}$ ammonia. Ammonia concentrations were measured in the $100 \%$ SPP of each sediment treatment on the day of initiation and again at the termination of each SPP test (Table 3.13). The total ammonia concentrations in SPP treatments were below the ammonia-effects ranges for C. stigmaeus derived from the two reference toxicant tests conducted at the MSL.

\subsubsection{6-Hour Suspended-Particulate-Phase Static Test with H. costata}

Table 3.14 shows the results of the toxicity test and statistical analysis for the $H$. costata test. This test was valid by a mean percent survival of $97 \%$ in the control (0\% SPP) treatment. Survival in the test treatments ranged from $86 \%$ in the $100 \%$ SPP of SF COMP to $100 \%$ survival in the 50\% SPP of TB Lower COMP. Results of the t-tests showed no statistically significant differences between the $100 \%$ SPP and the $0 \%$ control for any test treatment. The $L_{50}$ values were not calculated because there was not a $50 \%$ reduction in survival of $H$. costata. 
TABLE 3.12. Summary of Mean Proportion Surviving 96-Hour C. stigmaeus SuspendedParticulate-Phase Test, Richmond Harbor Deepening Project

\begin{tabular}{|c|c|c|c|c|}
\hline $\begin{array}{l}\text { Sediment } \\
\text { Treatment }\end{array}$ & $\begin{array}{l}\text { Concentration } \\
\text { (Percent SPP) }\end{array}$ & $\begin{array}{c}\text { Mean } \\
\text { Percent } \\
\text { Surviving }\end{array}$ & $\begin{array}{l}\text { Survival in } 100 \% \text { SPP } \\
\text { Significantly Lower Than } \\
\text { Survival in } 0 \% \text { SPP }\end{array}$ & $\begin{array}{c}96-h \\
\text { LC } 50 \\
\text { (Percent SPP) }\end{array}$ \\
\hline $\begin{array}{l}\text { SF COMP } \\
\text { SF COMP } \\
\text { SF COMP } \\
\text { SF COMP }\end{array}$ & $\begin{array}{r}0 \\
10 \\
50 \\
100\end{array}$ & $\begin{array}{l}100 \\
100 \\
100 \\
100\end{array}$ & NO & $>100$ \\
\hline $\begin{array}{l}\text { SFW COMP } \\
\text { SFW COMP } \\
\text { SFW COMP } \\
\text { SFW COMP }\end{array}$ & $\begin{array}{r}0 \\
10 \\
50 \\
100\end{array}$ & $\begin{array}{r}98 \\
100 \\
100 \\
100\end{array}$ & NO & $>100$ \\
\hline $\begin{array}{l}\text { UIH COMP } \\
\text { UIH COMP } \\
\text { UIH COMP } \\
\text { UIH COMP }\end{array}$ & $\begin{array}{r}0 \\
10 \\
50 \\
100\end{array}$ & $\begin{array}{r}98 \\
100 \\
100 \\
98\end{array}$ & NO & $>100$ \\
\hline $\begin{array}{l}\text { TB Upper COMF } \\
\text { TB Upper COMF } \\
\text { TB Upper COMF } \\
\text { TB Upper COMF }\end{array}$ & $\begin{array}{r}0 \\
10 \\
50 \\
100\end{array}$ & $\begin{array}{r}100 \\
98 \\
100 \\
100\end{array}$ & NO & $>100$ \\
\hline $\begin{array}{l}\text { TB Lower COMP } \\
\text { TB Lower COMP } \\
\text { TB Lower COMP } \\
\text { TB Lower COMP }\end{array}$ & $\begin{array}{r}0 \\
10 \\
50 \\
100\end{array}$ & $\begin{array}{r}98 \\
100 \\
100 \\
100\end{array}$ & NO & $>100$ \\
\hline $\begin{array}{l}\text { OBM COMP } \\
\text { OBM COMP } \\
\text { OBM COMP } \\
\text { OBM COMP }\end{array}$ & $\begin{array}{r}0 \\
10 \\
50 \\
100\end{array}$ & $\begin{array}{r}100 \\
100 \\
98 \\
100\end{array}$ & NO & $>100$ \\
\hline
\end{tabular}


IABLE 3.13. Summary of Ammonia Concentrations Measured in the Suspended-ParticulatePhase of Sediments from the Richmond Harbor Deepening Project (all values are a mean of two replicate measurements)

\begin{tabular}{lcccc}
\hline \hline Sediment & \multicolumn{3}{c}{ Total Ammonia in $100 \%$ SPP (mg/L) } \\
\cline { 2 - 5 } Treatment & $\begin{array}{c}\text { 100\% SPP } \\
\text { 0-hour }\end{array}$ & $\begin{array}{c}\text { C. stigmaeus } \\
\text { 96-hour }\end{array}$ & $\begin{array}{c}\text { H.costata } \\
\text { 96-hour }\end{array}$ & $\begin{array}{c}\text { M. galloprovincialis } \\
\text { 48-hour }\end{array}$ \\
\hline & & & & \\
SF COMP & 2.20 & 4.02 & 4.04 & 2.00 \\
SFW COMP & 5.82 & 2.38 & 8.08 & 4.35 \\
UIH COMP & 10.2 & 3.02 & 11.4 & 5.50 \\
TB Upper COMP & 3.34 & 3.31 & 11.3 & 3.60 \\
TB Lower COMP & 7.33 & 4.75 & 11.4 & 5.50 \\
OBM COMP & 2.65 & 1.00 & 2.22 & 1.25 \\
\hline
\end{tabular}

TABLE 3.14. Summary of Mean Proportion Surviving 96-Hour H. costata SuspendedParticulate-Phase Test, Richmond Harbor Deepening Project

\begin{tabular}{|c|c|c|c|c|}
\hline $\begin{array}{l}\text { Mean } \\
\text { Sediment } \\
\text { Treatment }\end{array}$ & $\begin{array}{l}\text { Concentration } \\
\text { (Percent SPP) } \\
\end{array}$ & $\begin{array}{l}\text { Mean } \\
\text { Percent } \\
\text { Surviving } \\
\end{array}$ & $\begin{array}{l}\text { Survival in 100\% SPP } \\
\text { Significantly Lower Than } \\
\text { Survival in 0\% SPP } \\
\end{array}$ & $\begin{array}{c}96-h \\
\text { LC }_{50} \\
\text { (Percent SPP) } \\
\end{array}$ \\
\hline $\begin{array}{l}\text { SF COMP } \\
\text { SF COMP } \\
\text { SF COMP } \\
\text { SF COMP }\end{array}$ & $\begin{array}{r}0 \\
10 \\
50 \\
100\end{array}$ & $\begin{array}{l}94 \\
98 \\
96 \\
86\end{array}$ & No & $>100$ \\
\hline $\begin{array}{l}\text { SFW COMP } \\
\text { SFW COMP } \\
\text { SFW COMP } \\
\text { SFW COMP }\end{array}$ & $\begin{array}{r}0 \\
10 \\
50 \\
100\end{array}$ & $\begin{array}{l}98 \\
96 \\
96 \\
88\end{array}$ & No & $>100$ \\
\hline $\begin{array}{l}\text { UIH COMP } \\
\text { UIH COMP } \\
\text { UIH COMP } \\
\text { UIH COMP }\end{array}$ & $\begin{array}{r}0 \\
10 \\
50 \\
100\end{array}$ & $\begin{array}{r}100 \\
96 \\
94 \\
90\end{array}$ & No & $>100$ \\
\hline $\begin{array}{l}\text { TB Upper COMP } \\
\text { TB Upper COMP } \\
\text { TB Upper COMP } \\
\text { TB Upper COMP }\end{array}$ & $\begin{array}{r}0 \\
10 \\
50 \\
100\end{array}$ & $\begin{array}{l}96 \\
98 \\
96 \\
96\end{array}$ & No & $>100$ \\
\hline $\begin{array}{l}\text { TB Lower COMP } \\
\text { TB Lower COMP } \\
\text { TB Lower COMP } \\
\text { TB Lower COMP }\end{array}$ & $\begin{array}{r}0 \\
10 \\
50 \\
100\end{array}$ & $\begin{array}{r}98 \\
94 \\
100 \\
94\end{array}$ & No & $>100$ \\
\hline $\begin{array}{l}\text { OBM COMP } \\
\text { OBM COMP } \\
\text { OBM COMP } \\
\text { OBM COMP } \\
\end{array}$ & $\begin{array}{r}0 \\
10 \\
50 \\
100 \\
\end{array}$ & $\begin{array}{l}98 \\
94 \\
98 \\
96\end{array}$ & No & $>100$ \\
\hline
\end{tabular}

BH-DEEPENING 
Two reference toxicant tests were used to assess $H$. costata sensitivity. The $\mathrm{Cu}$ reference toxicant test produced an $\mathrm{LC}_{50}$ of $70.7 \mu \mathrm{g} / \mathrm{L} \mathrm{Cu}(95 \% \mathrm{Cl}=67.1 \mu \mathrm{g} / \mathrm{L}$ to $74.5 \mu \mathrm{g} / \mathrm{L} \mathrm{Cu})$. This result is similar to that from a previous study conducted at the MSL ( $L C_{50}$ of $68.3 \mu \mathrm{g} / \mathrm{L} \mathrm{Cu}$ ). The reference toxicant test with ammonia had an $\mathrm{LC}_{50}$ of $39.8 \mathrm{mg} / \mathrm{L}$ ammonia $(\mathrm{Cl}=32.3 \mathrm{mg} / \mathrm{L}$ to $49.0 \mathrm{mg} / \mathrm{L}$ ). Currently no other ammonia data are known for $H$. costata. A database of $H$. costata sensitivity to ammonia will be developed for future projects. Ammonia concentrations were measured in the 100\% SPP of each sediment treatment on the day of test initiation and again at the termination of each SPP test (Table 3.13). The total ammonia concentrations in SPP treatments were below the observed $\mathrm{LC}_{50}$ for ammonia, suggesting that ammonia is not likely to have affected the survival rate of $H$. costata.

\subsubsection{8-Hour Suspended-Particulate-Phase Static Test with M. galloprovincialis}

The results of the 48-h suspended-particulate-phase test with M. galloprovincialis are presented in Table 3.15. The M. galloprovincialis test was validated by the high percentage of survival ( $90 \%$ or greater) in all the 0\% SPP. The mean percentage of survival was calculated by dividing the total number of surviving lavae (sum of the normal D-shaped, the abnormal lavae, and the larval stages) by the mean of the initial stocking density of 253 embryos $/ 10 \mathrm{~mL}$ for Test 1 (UIH COMP, TB Lower COMP, and SFW COMP) and 238 embryos $/ 10 \mathrm{~mL}$ for Test 2 (TB Upper COMP, OBM COMP, and SF COMP). Survival of the bivalve larvae ranged from $80 \%$ in the $100 \%$ SPP of TB Upper COMP to $99 \%$ in the $50 \%$ SPP of SF COMP. Two test treatments, SFW COMP and TB Upper COMP showed statistically significant differences in larval survival between the 0\% SPP and the 100\% SPP. The LC 50 could not be calculated in the test treatments because survival was always above $50 \%$.

Normal development of the lanae to the D-shaped stage is more useful for assessing larval toxicity because abnormal or delayed development prior to this stage is suspected to lead to mortality under natural conditions. The percentage of normal embryos was calculated by dividing the number of nomal D-shaped larvae at termination by the mean stocking density for each test. The percentage of normally developed larvae in the test treatments ranged from $0 \%$ in the $100 \%$ SPPs of both UIH and TB Lower COMPs to $>96 \%$ in the $50 \%$ SPP of SF COMP and the $100 \%$ SPP of OBM COMP. Normal development of M. galloprovincialis was compared in the $0 \%$ SPP and the $100 \%$ SPP of each test treatment using a t-test. The difference in the percentage of normal lavae between the $0 \%$ and $100 \%$ SPP was statistically significantly different for four test treatments, SFW COMP, UIH COMP, TB Upper COMP, and TB Lower COMP. The $\mathrm{EC}_{50}$ values ranged from $57.6 \%$ SPP in UIH COMP to $80.0 \%$ SPP in SFW COMP.

Two reference toxicants, copper and ammonia, were used to assess the sensitivity of the bivalve larvae relative to that found in previous studies. Results for the copper sulfate test had 
Table 3.15 Results of 48-Hour Suspended-Particulate-Phase Test with M. galloprovincialis

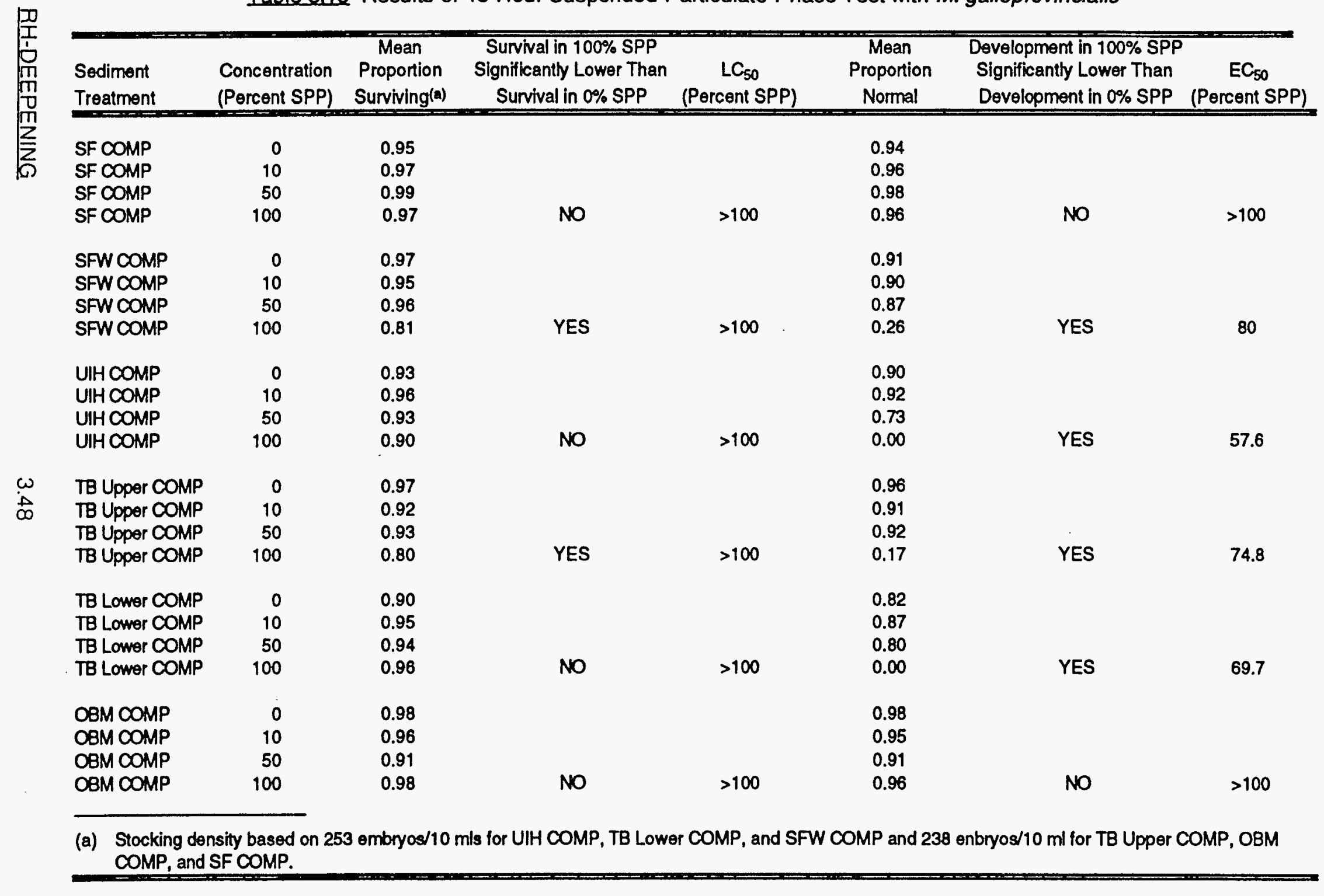


$\mathrm{LC}_{50}$ of $24.5 \mu \mathrm{g} / \mathrm{L}$ (95\% Cl=17.2 $\mu \mathrm{g} / \mathrm{L}$ to $\left.26.0 \mu \mathrm{g} / \mathrm{L}\right)$ and $12.1 \mu \mathrm{g} / \mathrm{L}(95 \% \mathrm{Cl}=11.1 \mu \mathrm{g} / \mathrm{L}$ to 13.3 $\mu \mathrm{g} / \mathrm{L})$ for Tests 1 and 2, respectively. The $\mathrm{EC}_{50}$ results were $6.7 \mu \mathrm{g} / \mathrm{L}(95 \% \mathrm{Cl}=6.4 \mu \mathrm{g} / \mathrm{L}$ to $7.1 \mu \mathrm{g} / \mathrm{L})$ for Test 1 and $8.0 \mu \mathrm{g} / \mathrm{L}(95 \% \mathrm{Cl}=7.86 \mu \mathrm{g} / \mathrm{L}$ to $8.04 \mu \mathrm{g} / \mathrm{L})$ for Test 2 . These values are within the range of responses $\left(\mathrm{LC}_{50}\right.$ values ranging from $5.8 \mu \mathrm{g} / \mathrm{L}$ to $35.0 \mu \mathrm{g} / \mathrm{L} \mathrm{Cu} ; \mathrm{EC}_{50}$ values ranging from $5.7 \mu \mathrm{g} / \mathrm{L}$ to $21.0 \mu \mathrm{g} / \mathrm{L} \mathrm{Cu}$ ) previously reported both by the $\mathrm{MSL}$ and by other scientists (Dinnel et al. 1983; EPA 1985).

The $L_{50}$ results from the two ammonia reference toxicant tests were $63.0 \mathrm{mg} / \mathrm{L}$ ( $95 \% \mathrm{Cl}=59.2 \mathrm{mg} / \mathrm{L}$ to $67.1 \mathrm{mg} / \mathrm{L}$ ) for Test 1 and $43.2 \mathrm{mg} / \mathrm{L}$ total ammonia $(95 \% \mathrm{Cl}=40.8 \mathrm{mg} / \mathrm{L}$ to $45.9 \mathrm{mg} / \mathrm{L}$ ) for Test 2. The $\mathrm{EC}_{50}$ results for the ammonia reference toxicant tests were $2.23 \mathrm{mg} / \mathrm{L}$ $(95 \% \mathrm{Cl}=2.11 \mathrm{mg} / \mathrm{L}$ to $2.36 \mathrm{mg} / \mathrm{L}$ ) and $2.76 \mathrm{mg} / \mathrm{L}(95 \% \mathrm{Cl}=2.71 \mathrm{mg} / \mathrm{L}$ to $2.80 \mathrm{mg} / \mathrm{L})$, for Tests 1 and 2 , respectively.

Ammonia concentrations were measured in the 100\% SPP of each sediment treatment on the day of test initiation and again at the termination of each SPP test (Table 3.13). Ammonia cannot be ruled out as a factor affecting normal development in bivalve larvae exposed to Richmond Harbor SPP treatments. The two ammonia reference toxicant tests were conducted using the same M. galloprovincialis larvae that were exposed in the SPP tests. In these ammonia-only tests, a reduced number of normally developed larvae was observed at low total ammonia concentrations (estimated $\mathrm{EC}_{50}$ values of $2.23 \mathrm{mg} / \mathrm{L}$ and $2.76 \mathrm{mg} / \mathrm{L}$ ). The doseresponse curve for the ammonia exposures as well as the mean percentage of normal larvae in the $100 \%$ SPP of each treatment plotted against the ammonia concentration in that $100 \%$ SPP is presented in Figures 3.36 and 3.37. Normal larval development of $M$. galloprovincialis in SF, SFW, UIH, and TB Lower COMPs is within the $95 \%$ confidence limits of the ammonia-only doseresponse; this suggests that the reduced normal development of larvae in those treatments could have been largely attributed to ammonia. Normal development of $M$. galloprovincialis lanae exposed to SPP from SF COMP, TB Upper COMP, and OBM COMP falls below the lower $95 \%$ confidence limit; this suggests that the reduced normal development cannot be positively attributed to ammonia alone.

\subsection{TISSUE BIOACCUMULATION}

$M$. nasuta and $N$. virens were used in a 28-day bioaccumulation test in which they were exposed to test, reference, and control sediment treatments. The tissues of $M$. nasuta and $N$. virens exposed to the test and reference sediments were analyzed for PAHs, phthalate esters, chlorinated pesticides, $\mathrm{PCBs}$, metals, and organotins. Complete tissue chemistry results in wet and dry weight, and $Q C$ data for these analyses are presented in Appendixes $O$ and $P$. The appendixes also contain QAQC summaries for each chemical parameter and contain 


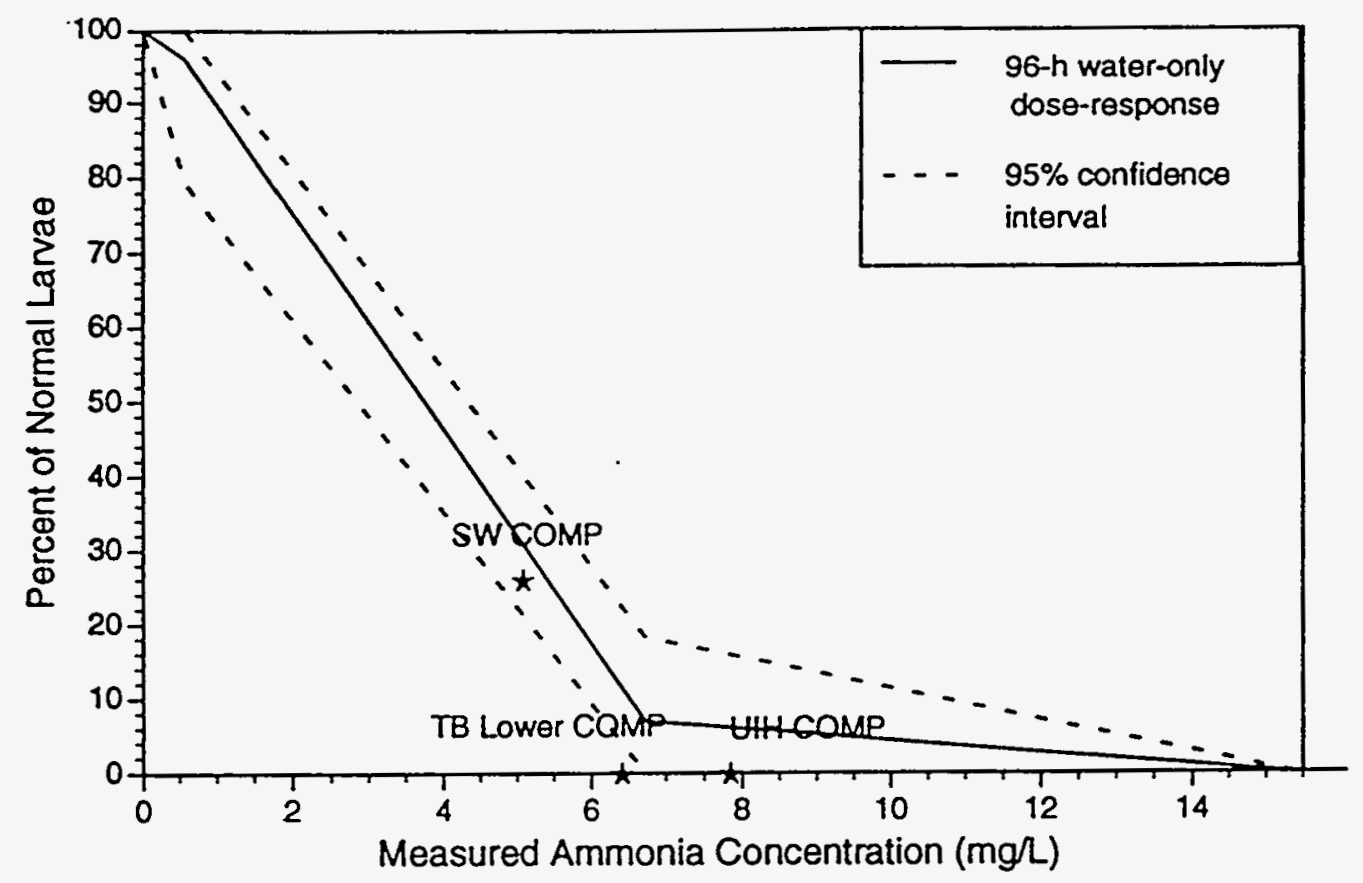

FIGURE 3.36. Response of M. galloprovincialis to Ammonia in 100\% SPP from the Test Treatments Relative to the Water-Only Mean Response for Test 1

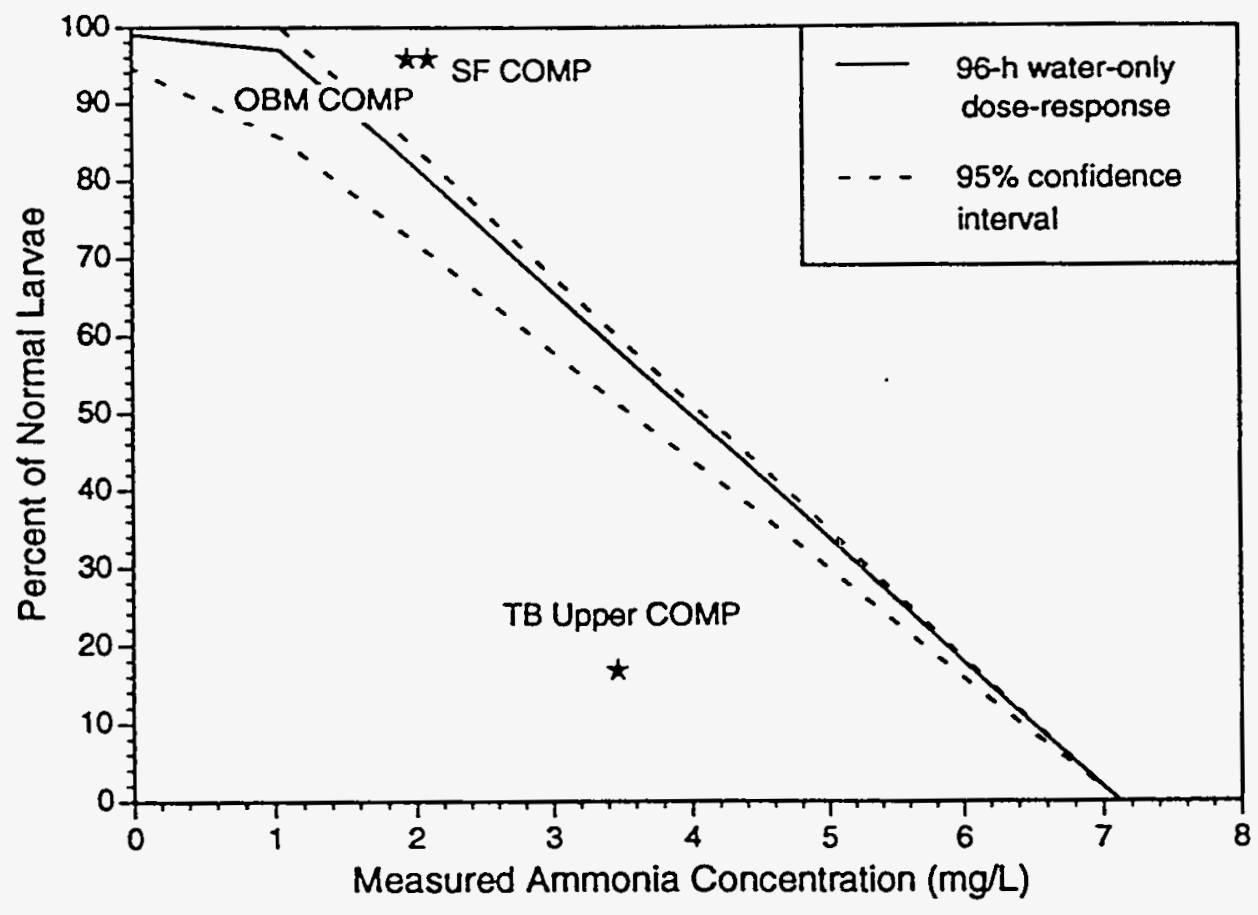

FIGURE 3.37. Response of M. galloprovincialis to Ammonia in 100\% SPP from the Test Treatments Relative to the Water-Only Mean Response for Test 2 
information regarding analytical laboratory, holding times, detection limits, dates of analysis, matrix spike data, replicate analysis, and SRM results.

\subsubsection{Statistical Analyses of Bioaccumulation Results}

The tissue chemistry results summarized in the following section were analyzed using Dunnett's test ( $\alpha=0.05$ ) for statistical comparison of all test treatments to the reference treatment R-OS. If a contaminant was detected (no $U$ or $J$ qualifier) in tissues exposed to any replicate test treatment and if the mean tissue concentration of the test replicates was greater than the mean tissue value of the reference treatment, a statistical comparison between test treatment and reference treatment concentrations was made. Reference treatments were used regardless of whether the values were detected or undetected. If a value was undetected ( $U$ flag), the detection limit value was used in the statistical analysis. If a compound was detected below the method detection limit ( $\mathrm{J}$ flag), then the associated value was used for statistical analysis. When all five replicate values of a test treatment were either undetected or detected below the method detection limit ( $U$ or $\mathrm{J}$ qualifier), then the test treatment was not statistically compared with the reference sediment. The background tissues were taken from $M$. nasuta and $N$. virens that were held in clean sediment and then allowed to depurate prior to subsampling for chemical analysis. The purpose of the background tissues was to determine whether $M$. nasuta and $N$. virens were exposed to contaminants prior to biological testing. Background (preexposure) concentrations and control concentrations were not included in the statistical analysis. Mean contaminant concentrations and the results of the statistical comparisons are presented in the following sections.

\subsubsection{Bioaccumulation Results for M. nasuta and N. virens}

The mean values of contaminants detected in the tissues of $M$. nasuta and $N$. virens are summarized in Tables 3.16 and 3.17, respectively, for the 28-day bioaccumulation tests. The complete results are reported in Appendix 0 , Tables 0.1 through 0.27 for $M$. nasuta and Appendix P, Tables P.1 through P.27, for $N$. virens. In the appendixes, the data are reported in both wet and dry weight.

Concentrations of contaminants were compared in $M$. nasuta and $N$. virens tissues exposed to the test treatment and those exposed to the reference sediment R-OS. Table 3.18 is a summary organized by test treatment showing those compounds that were statistically significantly elevated at levels of five times or greater when compared with concentrations in the reference R-OS.

Bioaccumulation of PAHs was seen primarily in test-treated $M$. nasuta tissues and was predominantly from the HPAH compounds. Four of these HPAHs, pyrene, benzo(b)fluoranthene, benzo(k)fluoranthene, and benzo(a)pyrene, were elevated in $M$. nasuta tissues exposed to 


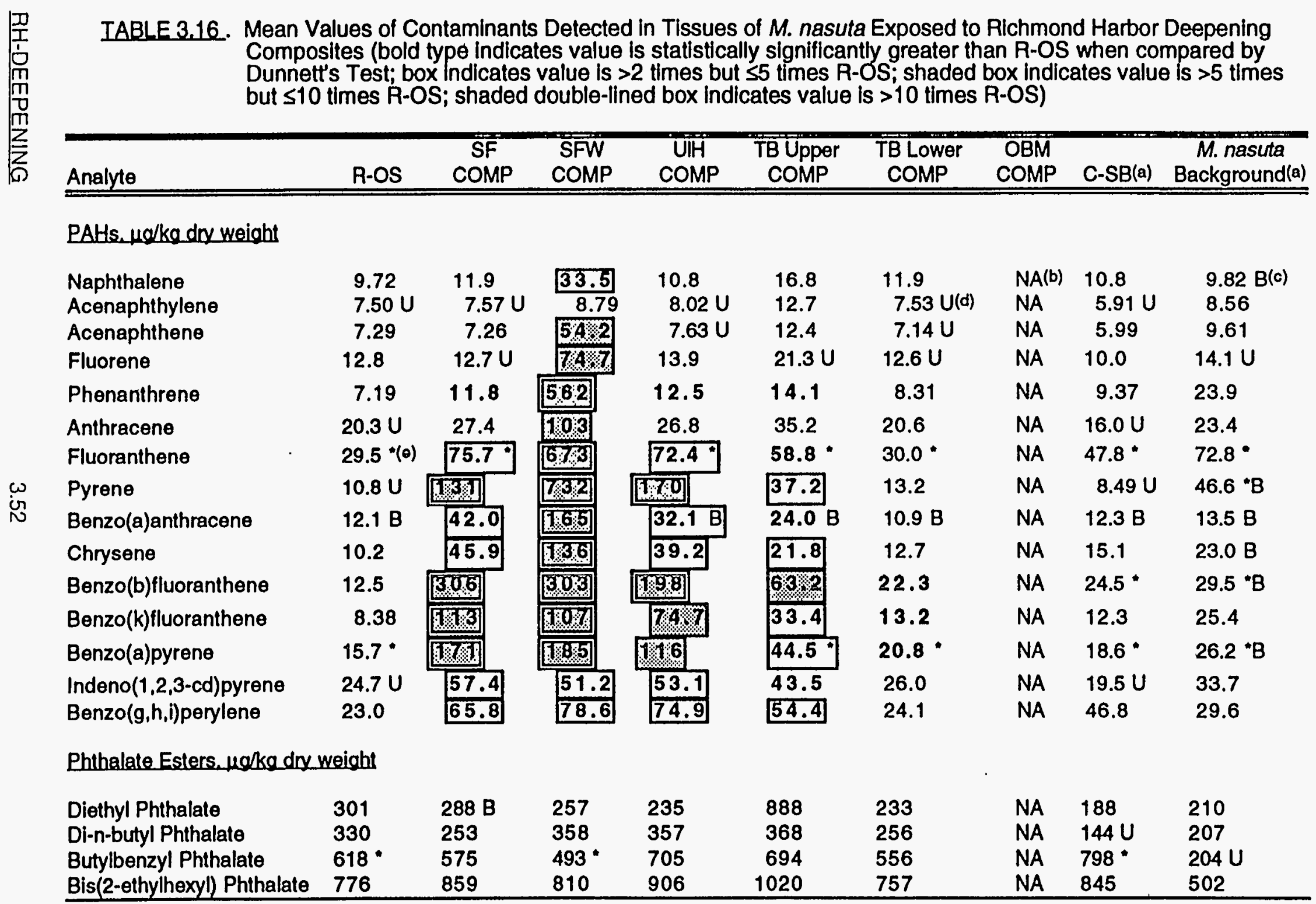


IABLE 3.16. (contd)

\begin{tabular}{|c|c|c|c|c|c|c|c|c|c|}
\hline Analyte & R-OS & $\begin{array}{c}\text { SF } \\
\text { COMP }\end{array}$ & $\begin{array}{l}\text { SFW } \\
\text { COMP }\end{array}$ & $\begin{array}{c}\text { UIH } \\
\text { COMP }\end{array}$ & $\begin{array}{l}\text { TB Upper } \\
\text { COMP }\end{array}$ & $\begin{array}{l}\text { TB Lower } \\
\text { COMP }\end{array}$ & $\begin{array}{l}\text { OBM } \\
\text { COMP }\end{array}$ & C-SB(a) & $\begin{array}{c}\text { M. nasuta } \\
\text { Background(a) }\end{array}$ \\
\hline \multicolumn{10}{|c|}{ Pesticides/PCBs. $\mu \mathrm{g} / \mathrm{kg}$ dry weight } \\
\hline $\begin{array}{l}\text { beta BHC } \\
\text { delta BHC } \\
\text { gamma BHC }\end{array}$ & $\begin{array}{l}2.3 U \\
2.3 U \\
1.1\end{array}$ & $\begin{array}{l}2.3 U \\
2.3 U \\
1.1 U\end{array}$ & $\begin{array}{l}2.6 \mathrm{U} \\
2.6 \\
1.7\end{array}$ & $\begin{array}{l}2.7 \\
2.4 U \\
1.2 U\end{array}$ & $\begin{array}{l}3.8 U \\
3.8 U \\
1.8 U\end{array}$ & $\begin{array}{l}2.7 U \\
2.7 U \\
1.3 U\end{array}$ & $\begin{array}{l}3.6 U \\
3.6 U \\
1.8 U\end{array}$ & $\begin{array}{l}1.8 U \\
1.8 U \\
0.94\end{array}$ & $\begin{array}{l}2.6 U \\
2.6 U \\
1.2 U\end{array}$ \\
\hline $4,4^{\prime}-D D D$ & $2.1 \mathrm{U}$ & 489 & $5 \%$ & 182 & $3.6 \mathrm{U}$ & $2.5 \mathrm{U}$ & $3.4 \mathrm{U}$ & $1.7 \mathrm{U}$ & $2.4 U$ \\
\hline 4,4'-DDE & $0.7 U$ & 912 & 329 & $0.7 U$ & 2.68 & $0.6 \mathrm{U}$ & $1.0 \mathrm{U}$ & $0.5 \mathrm{U}$ & 2.9 \\
\hline $4,4^{\prime}-$ DDT & $1.6 \mathrm{U}$ & $1.6 \mathrm{U}$ & $1.8 \mathrm{U}$ & $1.7 \mathrm{U}$ & 3.5 & $1.9 \mathrm{U}$ & $2.6 \mathrm{U}$ & $1.3 \mathrm{U}$ & 17 \\
\hline Dieldrin & $1.5 \mathrm{U}$ & $51 \% 0$ & 118 & 29.5 & $2.5 U$ & $1.7 \mathrm{U}$ & $2.3 \mathrm{U}$ & $1.2 \mathrm{U}$ & $1.6 \mathrm{U}$ \\
\hline $\begin{array}{l}\text { Endosulfan I } \\
\text { Aroclor } 1254\end{array}$ & $\begin{array}{c}2.3 U \\
160 U\end{array}$ & $\begin{array}{r}2.5 \\
160 U\end{array}$ & 210 & $\begin{array}{l}2.7 \\
140\end{array}$ & $\begin{array}{l}3.8 U \\
140 U\end{array}$ & $\begin{array}{r}2.7 U^{\circ} \\
150 U^{\circ}\end{array}$ & $\begin{array}{c}3.6 U \\
150 U\end{array}$ & $\begin{array}{c}1.8 U \\
150 U\end{array}$ & $\begin{array}{c}2.6 \mathrm{U} \\
140 \mathrm{U}\end{array}$ \\
\hline \multicolumn{10}{|c|}{ Metals mo/kg do weight } \\
\hline $\begin{array}{l}\text { Silver } \\
\text { Arsenic } \\
\text { Cadmium } \\
\text { Chromium } \\
\text { Copper } \\
\text { Mercury } \\
\text { Nickel }\end{array}$ & $\begin{array}{c}0.249 \\
23.2 \\
0.183 \\
2.31 \\
12.4 \\
0.069 \\
4.85\end{array}$ & $\begin{array}{c}0.216 \\
24.7 \\
0.202 \\
1.99 \\
12.8 \\
0.060 \\
3.86\end{array}$ & $\begin{array}{c}0.192 \\
27.1 \\
0.199 \\
2.10 \\
11.3 \\
0.076 \\
3.68\end{array}$ & $\begin{array}{c}0.183 \\
20.8 \\
0.183 \\
2.05 \\
12.4 \\
0.063 \\
3.66\end{array}$ & $\begin{array}{c}0.196 \\
22.8 \\
0.200 \\
2.21 \\
15.1 \\
0.084 \\
4.09\end{array}$ & $\begin{array}{c}0.197 \\
23.4 \\
0.210 \\
2.04 \\
11.5 \\
0.062 \\
4.90\end{array}$ & $\begin{array}{c}\text { NA(b) } \\
\text { NA } \\
\text { NA } \\
\text { NA } \\
\text { NA } \\
\text { NA } \\
\text { NA }\end{array}$ & $\begin{array}{c}0.183 \\
24.2 \\
0.178 \\
1.54 \\
12.4 \\
0.051 \\
3.02\end{array}$ & $\begin{array}{c}0.492 \\
31.2 \\
0.254 \\
1.12 \\
15.1 \\
0.063 \\
2.62\end{array}$ \\
\hline Lead & 1.11 & 2.11 & 2.30 & 2.11 & 1.57 & 1.24 & NA. & 1.34 & 1.34 \\
\hline Selenium & 1.84 & 1.69 & 1.79 & 1.66 & 1.65 & 1.57 & NA & 1.65 & 1.79 \\
\hline Zinc & 97.0 & 107 & 110 & 93.9 & 105 & 96.6 & NA & 89.4 & 107 \\
\hline \multicolumn{10}{|c|}{ Butyltins. $\mu \mathrm{g} / \mathrm{kg}$ dry weight } \\
\hline $\begin{array}{l}\text { Tributyltin } \\
\text { Dibutyltin }\end{array}$ & $\begin{array}{l}13.8 \\
12.3\end{array}$ & $\begin{array}{l}23.5 \\
11.8\end{array}$ & $\begin{array}{c}11.5 \\
9.30\end{array}$ & $\begin{array}{l}17.2 \\
10.4\end{array}$ & $\begin{array}{l}8.73 \\
9.44 U(c)\end{array}$ & $\begin{array}{l}9.05 \\
12.0\end{array}$ & $\begin{array}{l}13.6 \\
10.9\end{array}$ & $\begin{array}{l}10.8 \\
10.1\end{array}$ & $\begin{array}{l}4.3 .1 \\
10.3\end{array}$ \\
\hline \multicolumn{10}{|c|}{$\begin{array}{l}\text { (a) Treatment not included in Dunnett's Test data set. } \\
\text { (b) NA Not applicable. } \\
\text { (c) B All replicate values are < } 5 \text { times the amount detected in the associated method blank. } \\
\text { (d) U Undetected in all replicates; value is mean of dry weight detection limits. } \\
\text { (e) Ion Ratio out or confimation ion not detected in all replicates. }\end{array}$} \\
\hline
\end{tabular}




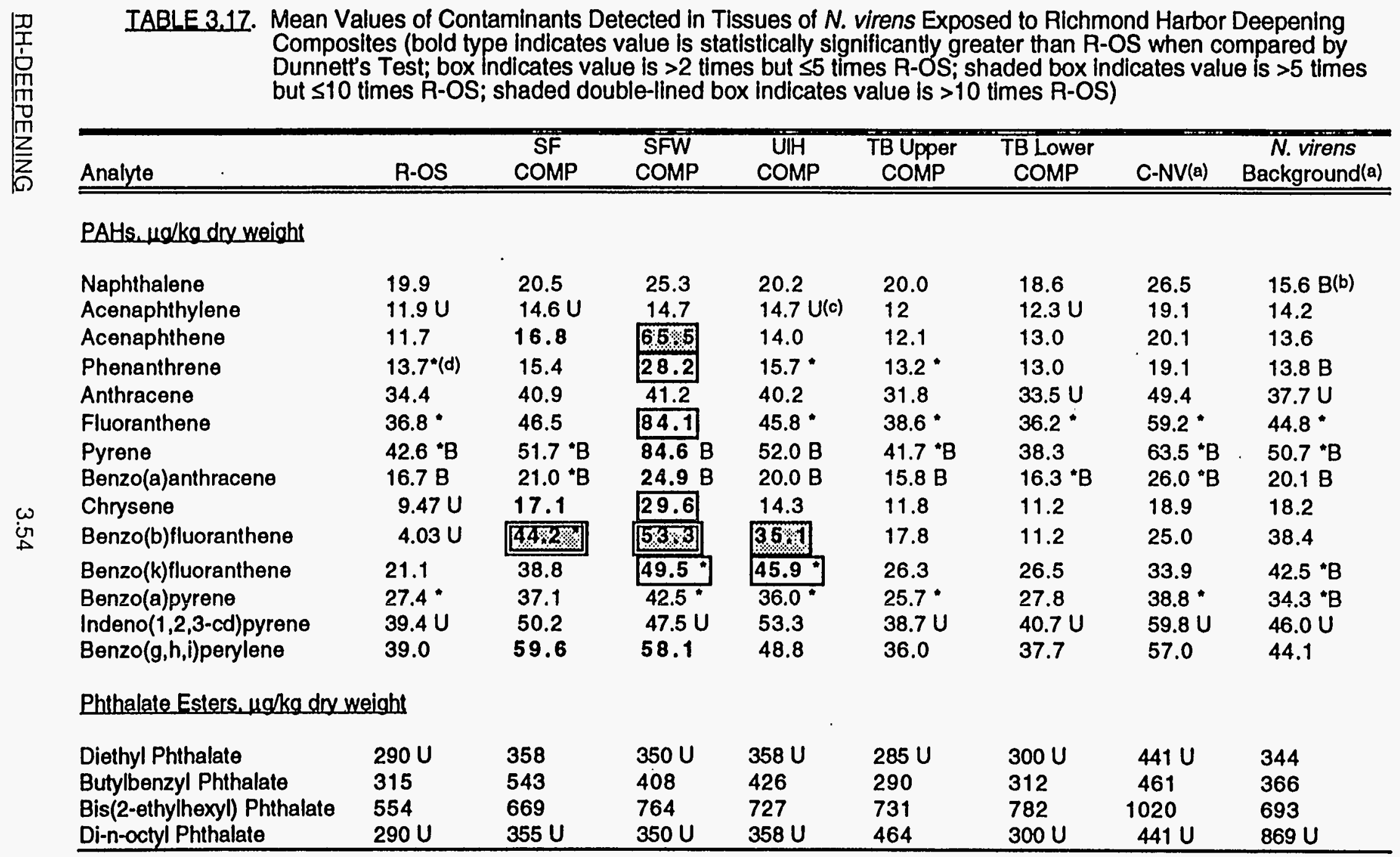




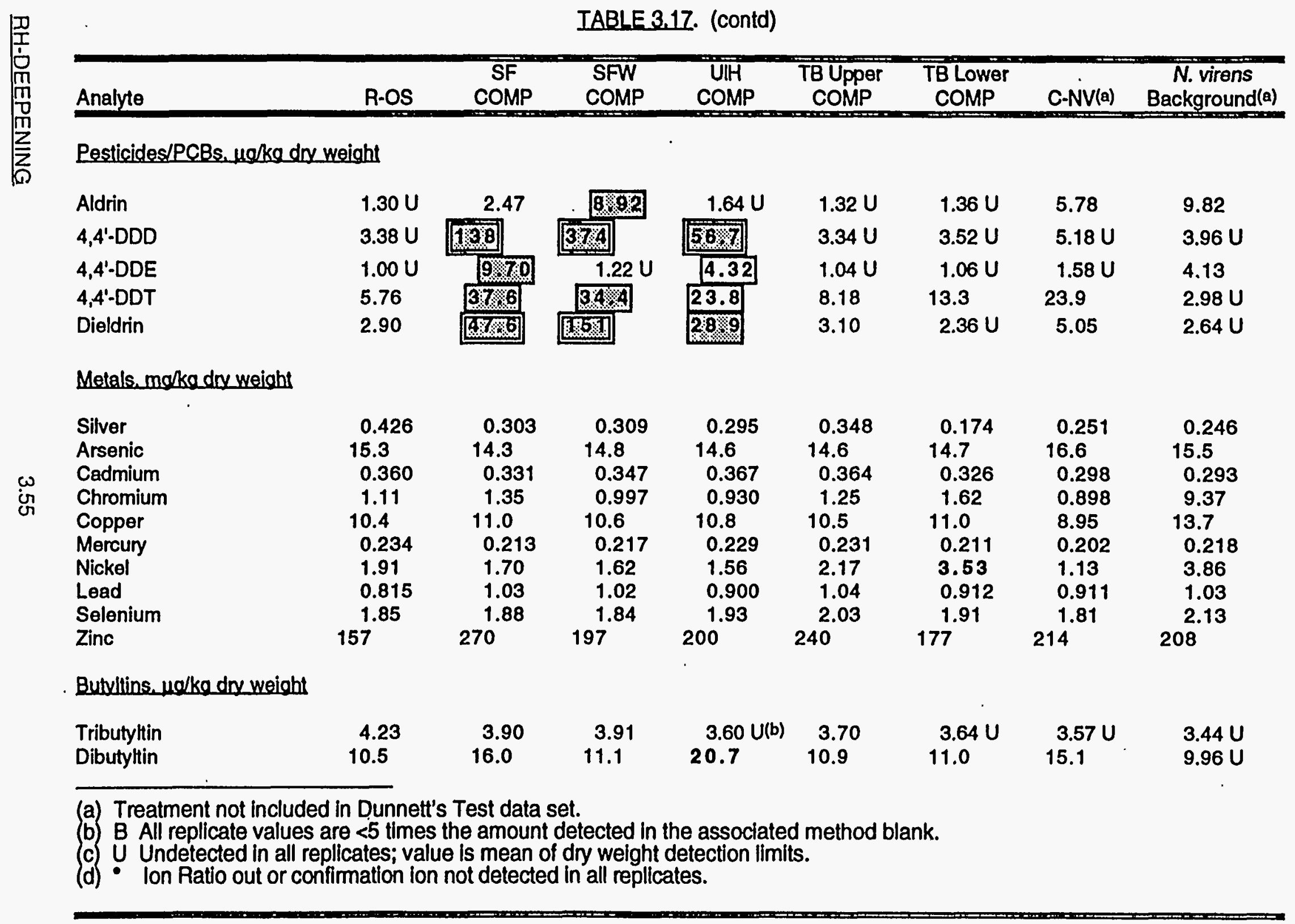


IABLE 3.18. Summary of Test Treatments with Statistically Significant Elevations in the Tissues of Either M. nasuta or N. virens at Levels Greater than Five Times Those of the Reference Treatment R-OS (number shown is the magnitude above the reference treatment R-OS).

\begin{tabular}{|c|c|c|c|}
\hline $\begin{array}{l}\text { Sediment } \\
\text { Treatment }\end{array}$ & Analyte & M. nasuta & N. virens \\
\hline SF COMP & $\begin{array}{l}\text { Pyrene } \\
\text { Benzo(b)fluoranthene } \\
\text { Benzo(k)fluoranthene } \\
\text { Benzo(a)pyrene } \\
4,4^{\prime}-\mathrm{DDD} \\
4,4^{\prime}-\mathrm{DDE} \\
4,4^{\prime}-\mathrm{DDT} \\
\text { Dieldrin }\end{array}$ & $\begin{array}{c}12 \\
24 \\
13 \\
10 \\
232 \\
160 \\
- \\
34\end{array}$ & $\begin{array}{c}-- \text { (a) } \\
10 \\
- \\
- \\
40 \\
9 \\
6 \\
16\end{array}$ \\
\hline SFW COMP & $\begin{array}{l}\text { Acenaphthene } \\
\text { Fluorene } \\
\text { Phenanthrene } \\
\text { Anthracene } \\
\text { Fluoranthene } \\
\text { Pyrene } \\
\text { Benzo(a)anthracene } \\
\text { Chrysene } \\
\text { Benzo(b)fluoranthene } \\
\text { Benzo(k)fluoranthene } \\
\text { Benzo(a)pyrene } \\
\text { 4,4'-DDD } \\
4,4^{\prime} \text {-DDE } \\
4,4^{\prime}-\text {-DDT } \\
\text { Dieldrin } \\
\text { Aldrin }\end{array}$ & $\begin{array}{l}7 \\
5 \\
78 \\
5 \\
22 \\
67 \\
13 \\
13 \\
24 \\
12 \\
11 \\
258 \\
470 \\
- \\
78 \\
-\end{array}$ & $\begin{array}{l}5 \\
- \\
- \\
- \\
- \\
- \\
\overline{13} \\
- \\
\overline{10} \\
6 \\
5 \\
52 \\
6\end{array}$ \\
\hline UIH COMP & $\begin{array}{l}\text { Pyrene } \\
\text { Benzo(b)fluoranthene } \\
\text { Benzo(k)fluoranthene } \\
\text { Benzo(a)pyrene } \\
\text { 4,4'-DDD } \\
\text { Dieldrin }\end{array}$ & $\begin{array}{c}15 \\
15 \\
8 \\
7 \\
86 \\
19\end{array}$ & $\frac{\overline{8}}{\overline{16}}$ \\
\hline TB Upper COMP & Benzo(b)fluoranthene & $5^{\circ}$ & - \\
\hline
\end{tabular}

TB Lower COMP Compounds were not statistically significant at levels 5 times or greater than R-OS. OBM COMP Compounds were not statistically significant at levels 5 times or greater than R-OS.

(a) - Analyte was not statistically significantly elevated at levels five times or greater than levels in the tissue of R-OS. 
SF COMP, SFW COMP, and UIH COMP at levels ranging from 7 times up to 67 times those in tissues exposed to the reference sediments, henceforth called reference levels. The HPAH benzo(b)fluoranthene was also elevated in $N$. virens tissues exposed to SF COMP, SFW COMP, and UIH COMP at levels up to 13 times those of the reference levels. Phthalate esters were not statistically significantly bioaccumulated in the tissues of either species.

At least one of the five pesticides, (4,4'-DDD, 4,4'-DDE, 4,4'-DDT, dieldrin, or aldrin), among the 18 analyzed, bioaccumulated in one or both species exposed to sediment from SF COMP, SFW COMP, and UIH COMP. These compounds were elevated between 5 times and up to 470 times over the reference levels.

$M$. nasuta and N.virens tissues exposed to most test treatments did not bioaccumulate metals or butylins at levels $\geq 5$ times over the reference levels. Relative to concentrations found in tissues exposed to R-OS, there was a statistically significant difference in the concentration of each of the following: $\mathrm{Pb}$ in $M$. nasuta tissue exposed to SF COMP, SFW COMP, UIH COMP, and TB Upper COMP; Ni in N. virens tissues exposed to TB Lower COMP; TBT in $M$. nasuta tissues exposed to SF COMP; and DBT in N. virens tissues exposed to UIH COMP.

Concentrations of pesticides, PCBs, and butyltins were compared in M. nasuta tissues exposed to test treatment OBM COMP and those exposed to the reference sediment R-OS. Relative to concentrations found in tissues exposed to R-OS, there was no statistically significant elevation of any of the contaminants analyzed. 


\subsection{RESULTS OF THE ANALYSIS OF THE INTENSIVE STUDY OF THE TURNING BASIN}

The results presented in Section 3.0 of this report showed that TB Lower COMP was acutely toxic to the amphipod, $R$. abronius, when compared with the survival of $R$. abronius exposed to R-OS. The larvae of the bivalve, M. galloprovincialis, also showed acute toxicity when exposed to the SPP from this sediment treatment. Porewater and overlying ammonia concentrations were monitored, as appropriate, for both toxicity tests. Figure 3.35 shows the dose-response of $R$. abronius survival plotted against the initial porewater ammonia concentrations measured in each sediment treatment. Survival of $R$. abronius exposed to TB Lower sediments is less than expected based upon the 4-day dose-response curve and $95 \%$ confidence limits. This reduced survival suggests that the toxicity of this sediment treatment cannot be attributed entirely to ammonia. Figure 3.36 shows the dose-response of the number of normally developed larvae of $M$. galloprovincialis plotted against the measured porewater ammonia concentrations in the $100 \%$ SPP of each sediment treatment. This figure suggests that the reduction in normal development of bivalve larvae exposed to the $100 \%$ SPP of TB Lower COMP is closely related to the concentration of ammonia.

An examination of sediment chemistry data from the Turning Basin samples showed that most contaminants of concern were located at one station, TB-4. Since the Turning Basin represents approximately 333,500 cubic yards of potential dredged material, higher resolution testing of this area was requested by USACE and EPA and conducted in October 1994. The Turning Basin was originally characterized by seven field stations. Two additional stations, TB-8 and TB-9, located to the northeast and southwest of station TB-4, were sampled in an effort to determine contaminant concentrations and effects in this area (Figure 4.1). Each core representing TB-1 through TB-9 was subjected to a geological description, chemical analysis, and a 10-day R. abronius test. By treating each core separately, more conclusive information was obtained concerning the nature and extent of chemical contamination and potential toxicity in Turning Basin sediment. This study will be referred to as the Intensive Study of the Turning Basin.

In addition to sampling in the Tuming Basin, sediment was also collected from four other Richmond Harbor stations (UIH-2, UIH-4, SFW-1 and SFW-3). The older bay mud portion of cores from these stations were combined into an OBM COMP (Figure 4.1). The OBM COMP was analyzed for sediment chemical parameters and used in a standard 10-day $R$. abronius toxicity test.

The methods used in the Intensive Study of the Turning Basin, including those specific to collecting test, reference, and control samples; obtaining test organisms; preparing sediment samples; conducting chemical analysis; performing toxicity tests; interpreting and analyzing data; and following QAQC procedures, were previously described in Sections 2.1 through 2.6 of this 


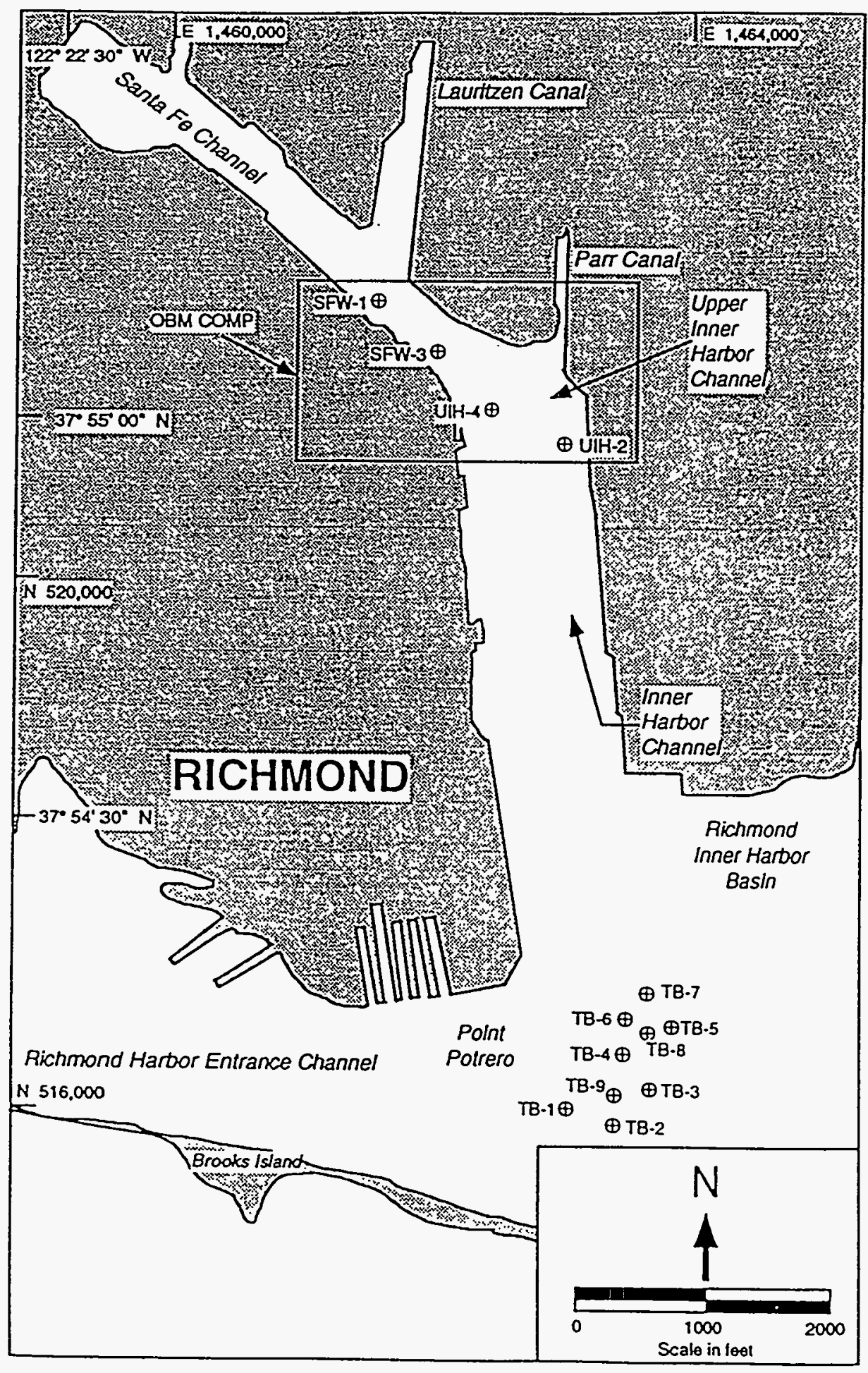

FIGURE 4.1. Sampling Stations for the Richmond Harbor Deepening Project-Intensive Study of the Turning Basin 
report. The only difference in these methods was that TOC analyses for the Turning Basin sediments and the OBM COMP were performed by ARI rather than by Global Geochemistry. Briefly, ARI used the method described in Plumb 1981, which involves direct combustion at $850^{\circ} \mathrm{C}$ in a resistance furnace. Combustion products are carried in the oxygen stream through a catalytic converter (to assure complete oxidation to $\mathrm{CO}_{2}$ ) and into the IR machine. Prior to analysis, samples are purged of inorganic carbon by acidification, dried at $70^{\circ} \mathrm{C}$, and then ground to pass through a $120-\mu \mathrm{m}$ mesh sieve. The methods used by ARI and Global Geochemistry are comparable in performing TOC analysis.

\subsection{SEDIMENT COLLECTION AND SAMPLE PREPARATION}

The field sampling effort occurred over a 2-day period on October 11 and 12, 1994. Sediment core samples were collected to $-40 \mathrm{ft}$ MLLW from the nine Turning Basin stations and to $-42 \mathrm{ft}$ MLLW from the four stations composited to form the OBM COMP. Either the 4-in. and 12-in. core barrels were used to collect these sediments. Sediments were also collected from the three reference areas (R-OS, R-BF, and R-AM) and two control areas (C-WB and C-SB). Table 4.1 summarizes the field sampling information. Table 4.2 contains field collection information for the reference and control treatments.

The reference sediments were collected with a pipe dredge deployed from the FN Cobra as described in Section 2.1.2. One station was sampled to represent R-OS (Figure 3.2), four stations were sampled to represent R-BF (Figure 3.3), and seven stations were sampled to represent R-AM. Station R-AM-F was omitted from the R-AM composite because when the individual stations surrounding Alcatraz Island were chemically analyzed in January 1994, R-AM-F had much higher levels of LPAHs and HPAHs relative to the other stations (Appendix C, Tables C.8 and C.9). Consequently, USACE decided to omit R-AM-F from the R-AM composite. Sediment was collected from C-SB, the experimental grain size control, using a van Veen grab sampler, and from C-WB, the native control sediment for the $R$. abronius test (Figures 3.5 and 3.6) using the amphipod dredge sampler.

Navigation support was provided by Sea Surveyors of Benicia, California. A laser/range azimuth positioning system was used to position the barge at the correct sampling locations. Water depths were checked and recorded at each station by measuring the actual depth with a recording fathometer, measuring the water surface elevation, and calculating the difference between the water surface elevation and $0 \mathrm{ft}$ MLLW.

The characteristics of the Richmond Harbor Turning Basin sediments were geologically described from mudline to $-40 \mathrm{ft}$.MLLW using the 4 -in. core samples. The cores were logged according to ASTM Procedure D2488-84 (ASTM 1984) as previously described in Section 3.2 of 


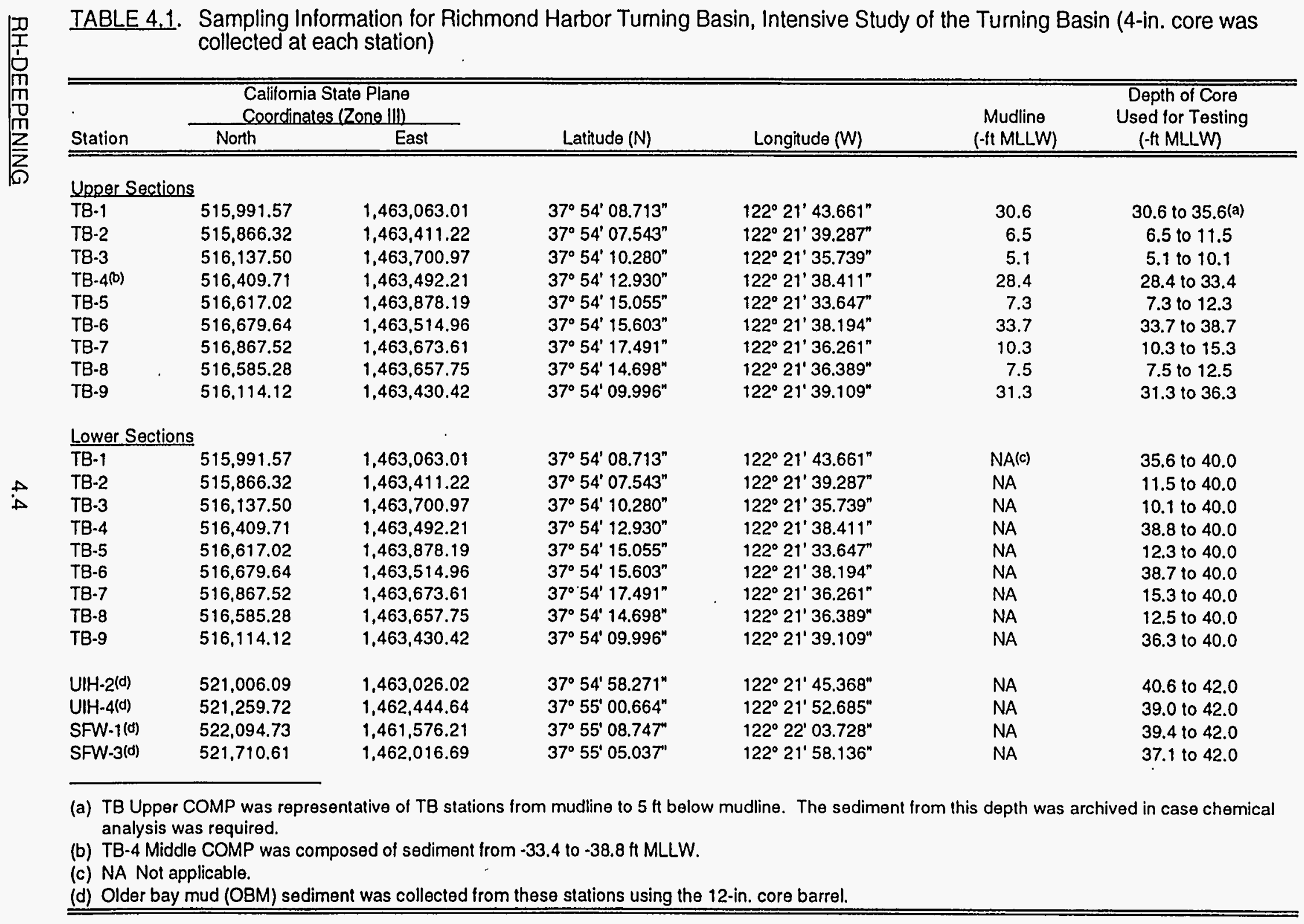


TABLE 4.2. Reference and Control Sediment Sampling Data

\begin{tabular}{|c|c|c|c|c|c|}
\hline \multirow[b]{2}{*}{ Reference Area } & \multirow[b]{2}{*}{ Station } & \multicolumn{2}{|c|}{ Statiōn Location } & \multirow[b]{2}{*}{ Depth $(\mathrm{ft})$} & \multirow[b]{2}{*}{ Volume (gal) } \\
\hline & & Latitude $(\mathrm{N})$ & Longitude $(\mathrm{W})$ & & \\
\hline Bay Farm & $\begin{array}{l}\text { R-BF } 2 \\
\text { R-BF } 3 \\
\text { R-BF } 4 \\
\text { R-BF } 5 \\
\text { TOTAL R-BF }\end{array}$ & $\begin{array}{l}37^{\circ} 44.63^{\prime} \\
37^{\circ} 44.34^{\prime} \\
37^{\circ} 44.38^{\prime} \\
37^{\circ} 44.54^{\prime} \\
\end{array}$ & $\begin{array}{l}122^{\circ} 16.75^{\prime} \\
122^{\circ} 16.74^{\prime} \\
122^{\circ} 16.60^{\prime} \\
122^{\circ} 16.60^{\prime}\end{array}$ & $\begin{array}{l}20 \\
28 \\
31 \\
31 \\
\end{array}$ & $\begin{array}{r}5 \\
5 \\
5 \\
5 \\
20\end{array}$ \\
\hline Alcatraz Environs & $\begin{array}{l}\text { R-AM A } \\
\text { R-AM B } \\
\text { R-AM C } \\
\text { R-AMD } \\
\text { R-AM G } \\
\text { R-AMH } \\
\text { R-AMI } \\
\text { TOTAL R-AM }\end{array}$ & $\begin{array}{l}37^{\circ} 49.75^{\prime} \\
37^{\circ} 49.79^{\prime} \\
37^{\circ} 49.76^{\prime} \\
37^{\circ} 49.27^{\prime} \\
37^{\circ} 48.80^{\prime} \\
37^{\circ} 48.82^{\prime} \\
37^{\circ} 48.83^{\prime} \\
\end{array}$ & $\begin{array}{l}122^{\circ} 25.88^{\prime} \\
122^{\circ} 25.40^{\prime} \\
122^{\circ} 24.89^{\prime} \\
122^{\circ} 25.82^{\prime} \\
122^{\circ} 25.84^{\prime} \\
122^{\circ} 25.57^{\prime} \\
122^{\circ} 24.90^{\prime}\end{array}$ & $\begin{array}{l}62 \\
45 \\
69 \\
70 \\
45 \\
50 \\
50\end{array}$ & $\begin{array}{r}3 \\
3 \\
3 \\
3 \\
3 \\
3 \\
3 \\
21\end{array}$ \\
\hline Deep Off-Shelf Area & R-OS & $37^{\circ} 24.86^{\prime}$ & $123^{\circ} 14.38^{\prime}$ & 4400 & 8 \\
\hline Sequim Bay Control & C-SB & $48^{\circ} 03.70^{\prime}$ & $123^{\circ} 01.50^{\prime}$ & $25-30$ & 10 \\
\hline Tomales Bay Control & C-NE & $38^{\circ} 13.83^{\prime}$ & $122^{\circ} 57.67^{\prime}$ & intertidal & 10 \\
\hline West Beach Control & C-WB & $48^{\circ} 23.83^{\prime}$ & $122^{\circ} 40.00^{\prime}$ & $15-20$ & 5 \\
\hline
\end{tabular}

this report. A detailed description of the methods used to describe each core is presented in Appendix A. Appendix B contains the core logs for both the January and October 1994 field sampling efforts.

Nine cores were collected in the proposed turning basin east of Point Potrero (TB-1 through TB-9). Core locations are shown in Figure 4.1. Sediment characteristics were similar to those observed in the January 1994 cores collected from the same locations. The YBM ranged in thickness from $3.8 \mathrm{ft}$ at station TB-1 to greater than $33.5 \mathrm{ft}$ at station TB-2.

The OBM was encountered at three stations: TB-1, TB-7, and TB-8. The elevation of the YBM/OBM contact at these stations was $-34.4 \mathrm{ft} \mathrm{MLLW,}-33.6 \mathrm{ft} \mathrm{MLLW}$, and $-37.2 \mathrm{ft}$ MLLW, respectively. The OBM at station TB-1 consisted of olive gray and olive brown, soft to firm interbedded clayey gravel and silt. The OBM at stations TB-7 and TB-8 consisted of dark gray firm clayey silt.

The YBM was composed primarily of dark gray, very soft to soft clay containing numerous whole and fragmented clam shells (Macoma sp.). At stations TB-6, TB-7, and TB-9, 
the uppermost $3 \mathrm{ft}$ to $5 \mathrm{ft}$ of sediment had a disrupted texture characterized by a mixture of the dark gray clay found at the other stations and oily, black silty clay with shreds of wood and a hydrocarbon odor. At station TB-4, the disrupted layer extended to $10.4 \mathrm{ft}$ below the mudline.

The sediment from each 4-in. core was split into two composite samples except for TB-4, which was split into three composite samples. One sample consisted of sediment from mudline to $5 \mathrm{ft}$ below the mudline, and the other consisted of sediment from $5 \mathrm{ft}$ below the mudline to the project depth of $-40 \mathrm{ft}$ MLLW. In the core from station TB-4, sediment from $-33.4 \mathrm{ft}$ to $-38.8 \mathrm{ft}$ MLLW, representing the middle section, was composited separately because of its disrupted appearance and hydrocarbon odor. An aliquot of the sediment from mudline to $5 \mathrm{ft}$ below mudline from each core was archived in 1-IL glass containers in the event that additional analyses would be required.

The sediment from $5 \mathrm{ft}$ below mudline to $-40 \mathrm{ft}$ MLLW was thoroughly mixed for each station, subsampled for chemistry, and used for biological testing. The OBM COMP sediment was collected using the 12-in. core barrel. The OBM sediment was taken from depths ranging from $-37 \mathrm{ft}$ to $-40.6 \mathrm{ft}$ MLLW from the four stations contributing to the OBM COMP (UIH-2, UIH-4, SFW-1, and SFW-3). These sediments were thoroughly mixed to create the OBM COMP that was submitted for chemical analysis and biological testing.

Sediments from the reference and control treatments were processed in the same manner as the test treatments with one exception. The reference and control sediments were presssieved through 0.5 or $1.0-\mathrm{mm}$ mesh to remove organisms, and then homogenized and subsampled for chemical analysis.

\subsection{SEDIMENT CHEMISTRY}

\subsubsection{Sediment Conventional Measurements}

The sediment conventional measurements analyzed in the turning basin sediments are grain size, TOC, TVS, oil and grease, and TPH. Grain size, TOC, and TVS are expressed as percentages of dry weight of sample. Oil and grease and TPH are expressed as $\mathrm{mg} / \mathrm{kg} \mathrm{dry}$ weight. Table 4.3.summarizes the results of these analyses. The complete results, including QAVQC summaries, are presented in Appendix D, Tables D.1 through D. 6 . The results of the conventional analysis of the sediment treatments are also graphically illustrated in Figures 4.2 through 4.6. The chemical analyses of the OBM COMP are also reported in the appropriate sections. The grain size results from the Richmond Harbor Intensive Study of the Tuming Basin were similar to those obtained during the January 1994 study. The Turning Basin test treatments, TB-2 Lower through TB-9 Lower, the reference treatment, R-OS, the OBM COMP, and the control treatment, C-SB, were all predominantly fine-grained with $74 \%$ to $96 \%$ of these 
TABLE 4.3. Conventional Sediment Measurement Results for the Sediment Treatments, Richmond Harbor Deepening Project-Intensive Study of the Turning Basin

\begin{tabular}{|c|c|c|c|c|c|c|c|c|}
\hline \multirow[b]{2}{*}{$\begin{array}{l}\text { Sediment } \\
\text { Treatment }\end{array}$} & \multicolumn{6}{|c|}{ Percent Dry Weight } & \\
\hline & $\begin{array}{c}\text { Gravel } \\
>2000 \mu \mathrm{m} \\
\end{array}$ & $\begin{array}{c}\text { Sand } \\
62.5- \\
2000 \mu \mathrm{m} \\
\end{array}$ & $\begin{array}{c}\text { Silt } \\
3.9- \\
62.5 \mu \mathrm{m}\end{array}$ & $\begin{array}{l}\text { Clay } \\
<3.9 \mu \mathrm{m}\end{array}$ & TOC & TVS & $\begin{array}{l}\mathrm{mg} / \mathrm{kg} \mathrm{D} \\
\text { Oil and } \\
\text { Grease }\end{array}$ & y Weight \\
\hline R-OS & 0 & 26 & 53 & 21 & 1.0 & 2.4 & 100 & 77 \\
\hline $\begin{array}{l}\text { TB-1 Lower } \\
\text { TB-2 Lower } \\
\text { TB-3 Lower } \\
\text { TB-4 Middle } \\
\text { TB-4 Lower } \\
\text { TB-5 Lower } \\
\text { TB-6 Lower } \\
\text { TB-7 Lower } \\
\text { TB-8 Lower } \\
\text { TB-9 Lower }\end{array}$ & $\begin{array}{r}13 \\
3 \\
1 \\
0(b) \\
0 \\
0 \\
1 \\
1 \\
0 \\
0\end{array}$ & $\begin{array}{r}49 \\
18 \\
15 \\
4(\mathrm{~b}) \\
10 \\
7 \\
5 \\
7 \\
6 \\
15\end{array}$ & $\begin{array}{r}23 \\
47 \\
50 \\
48(b) \\
44 \\
54 \\
40 \\
53 \\
55 \\
44\end{array}$ & $\begin{array}{r}15 \\
32 \\
34 \\
48(b) \\
46 \\
39 \\
54 \\
39 \\
39 \\
41\end{array}$ & $\begin{array}{l}0.11 \\
0.67 \\
0.67 \\
1.1 \\
0.58 \\
0.90 \\
0.81 \\
0.70 \\
0.76 \\
0.59\end{array}$ & $\begin{array}{l}0.79 \\
2.3 \\
2.1 \\
2.6 \\
2.1 \\
2.2 \\
2.6 \\
2.4 \\
2.6 \\
2.1\end{array}$ & $\begin{array}{l}14 \\
50 \\
40 \\
18 U \\
16 U \\
56 \\
17 U \\
15 U \\
43 \\
20\end{array}$ & $\begin{array}{l}9.9 U(\mathrm{a}) \\
27 \\
16 U \\
18 U \\
16 U \\
58 \\
17 U \\
15 U \\
16 U \\
16 U\end{array}$ \\
\hline OBM COMP & 0 & 18 & 56 & 26 & 0.16 & 1.9 & $11 \mathrm{U}$ & $11 \mathrm{U}$ \\
\hline
\end{tabular}

sediments in the silt and clay categories. Sediments from test treatment TB-1 Lower and C-WB were predominantly sand.

Percentages of TOC ranged from $0.11 \%$ to $1.1 \%$. The level of TOC in the R-OS sediments $(1.0 \%)$ was only exceeded by that in sediment from TB-4 Middle. The percentage of TOC in OBM COMP was $0.16 \%$. The percentages of TVS in the test treatments ranged from $0.79 \%$ to $2.6 \%$; the percentage of TVS in the reference treatment was $2.4 \%$. Sediment from TB-4 Middle, TB-6 Lower, and TB-8 Lower had higher concentrations of total volatile solids than that in R-OS. The OBM COMP had a TVS value of $1.9 \%$. These results were comparable to those found during the January 1994 effort.

Oil and grease concentrations were above detection limits in most of the test treatments, ranging from $14 \mathrm{mg} / \mathrm{kg}$ to $56 \mathrm{mg} / \mathrm{kg}$. The concentration of oil and grease in the reference sediment $\mathrm{R}$-OS was twice the detected concentrations in the test treatments. Only two test treatments, TB-2 Lower (27 mg/kg) and TB-5 Lower (58 mg/kg), had detectable concentrations of TPH. Again, the reference treatment R-OS had higher concentrations of TPH $(77 \mathrm{mg} / \mathrm{kg})$. The oil and grease and TPH concentrations for test treatments TB-4 Middle and TB-5 Lower do not concur with the concentrations of other organics found in these sediments and should be considered suspect. 


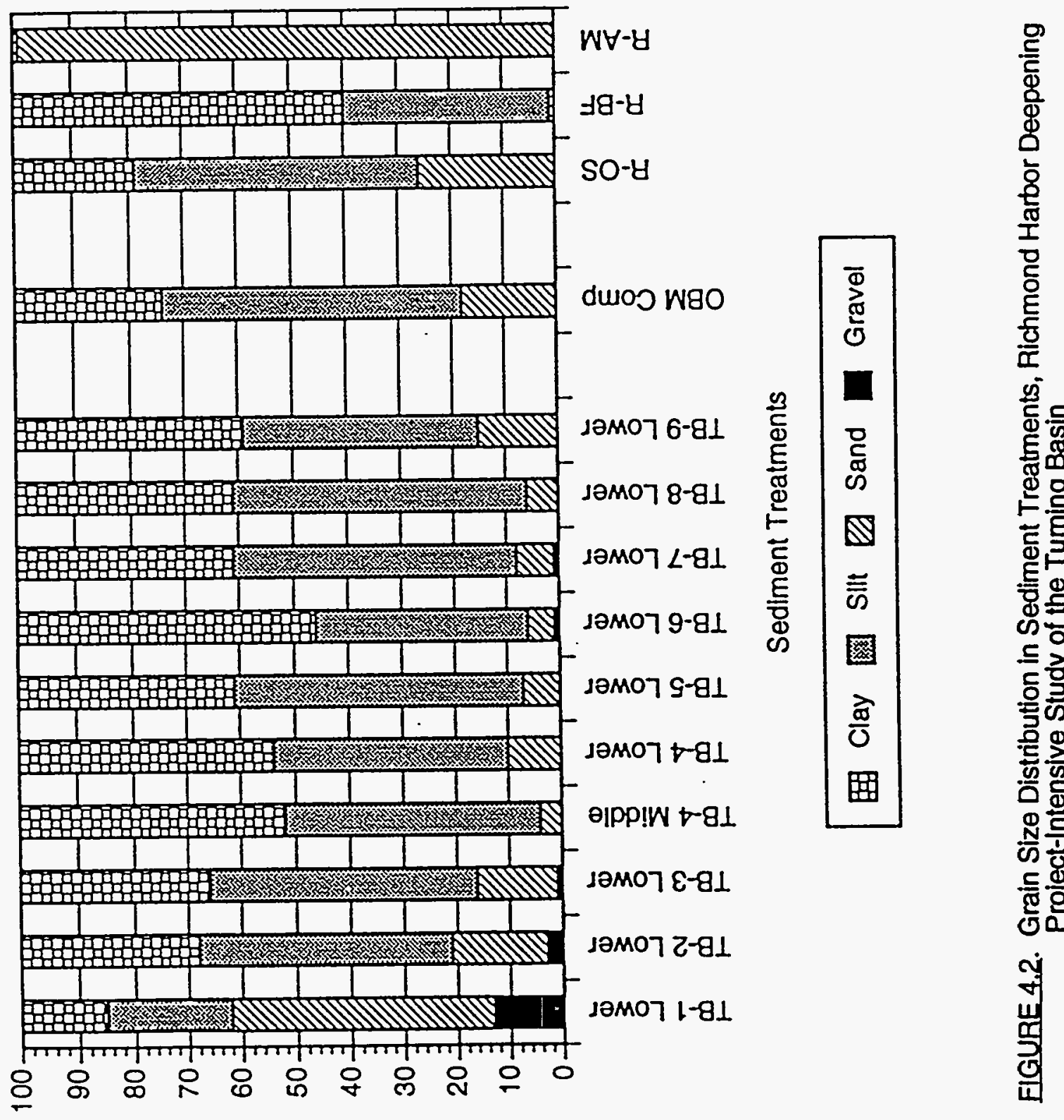

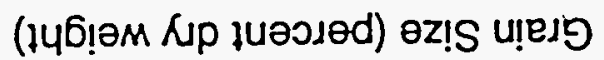



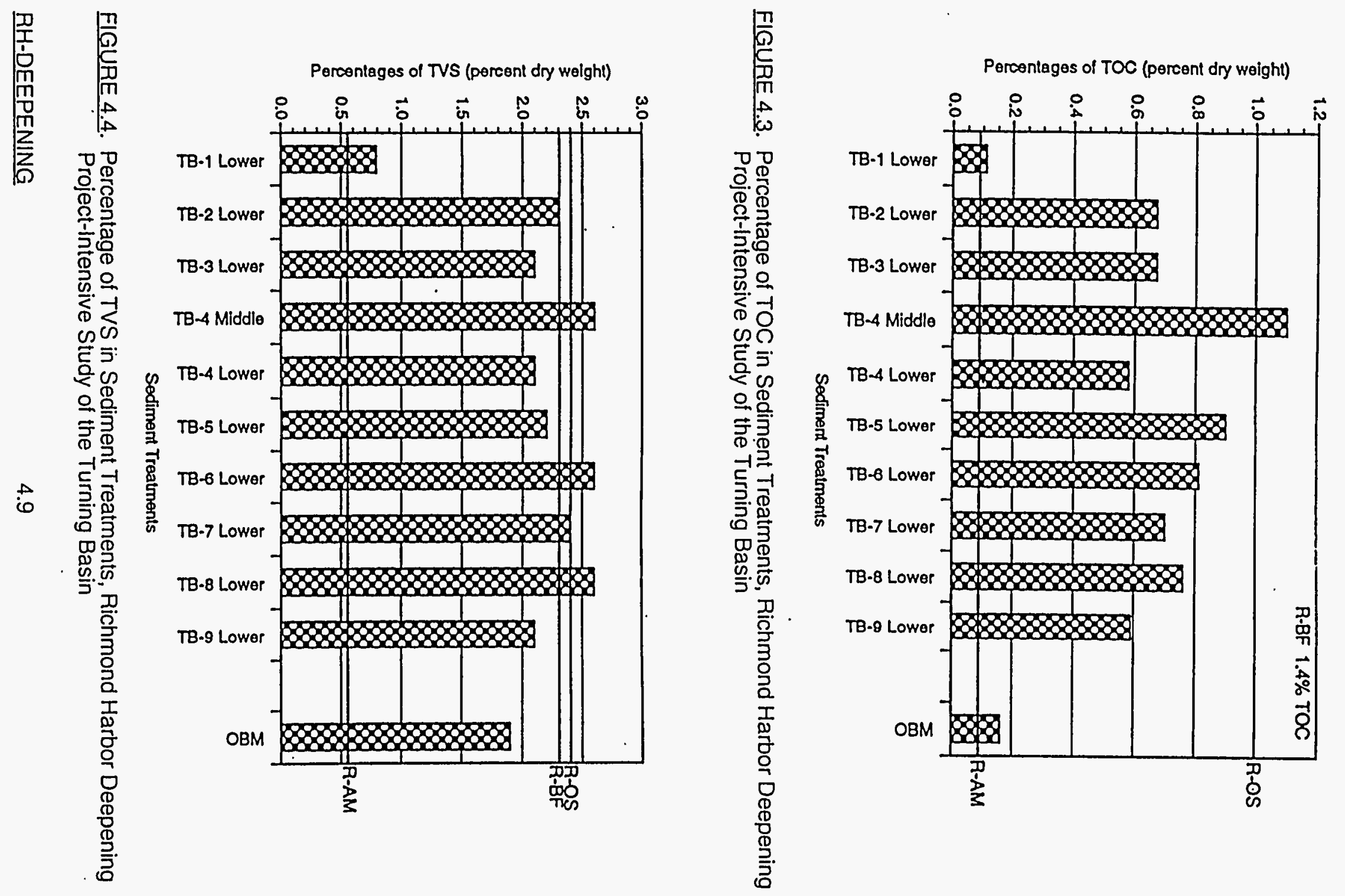


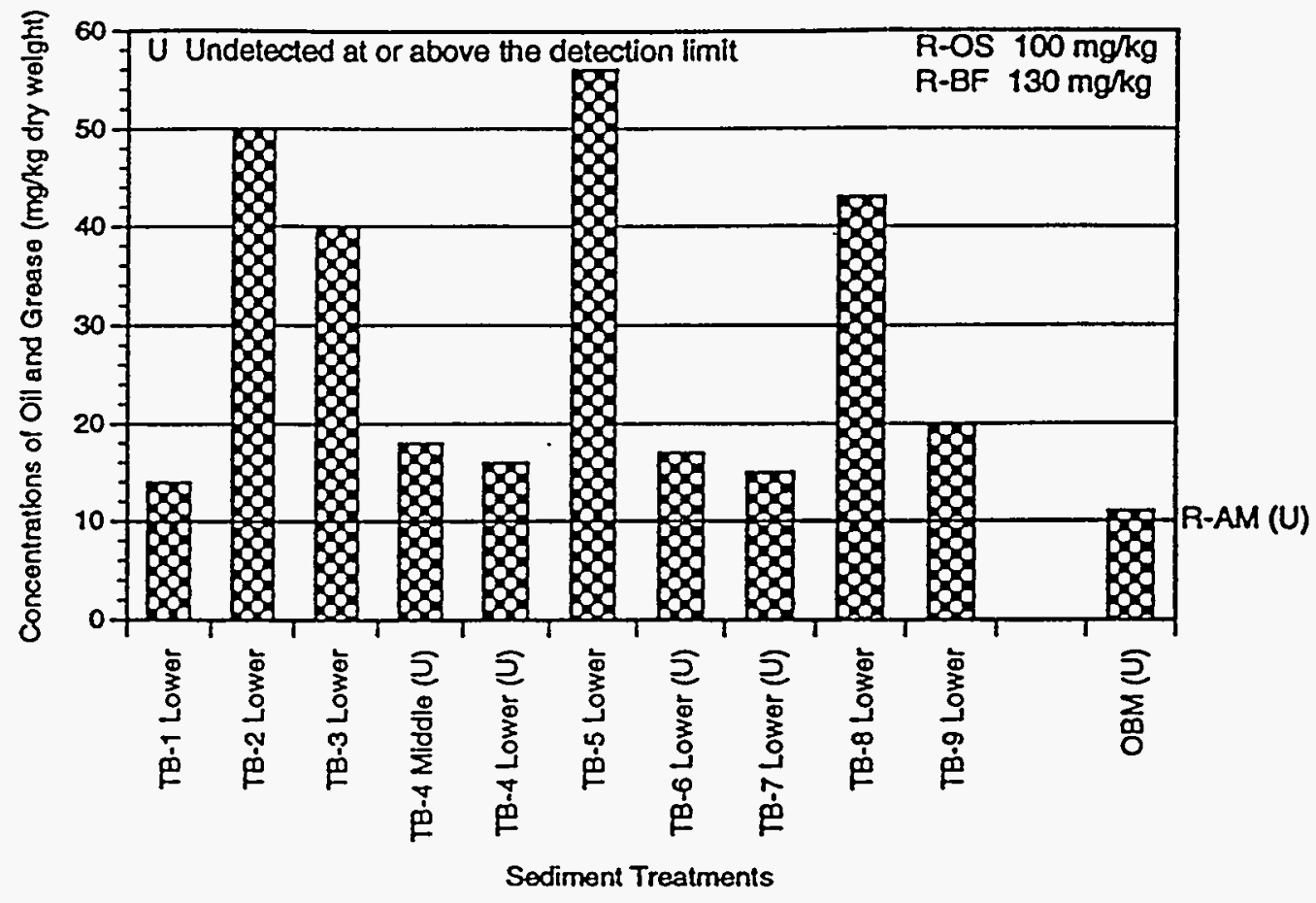

FIGURE 4.5. Concentrations of Oil and Grease in Sediment Treatments, Richmond Harbor Deepening Project-Intensive Study of the Turning Basin

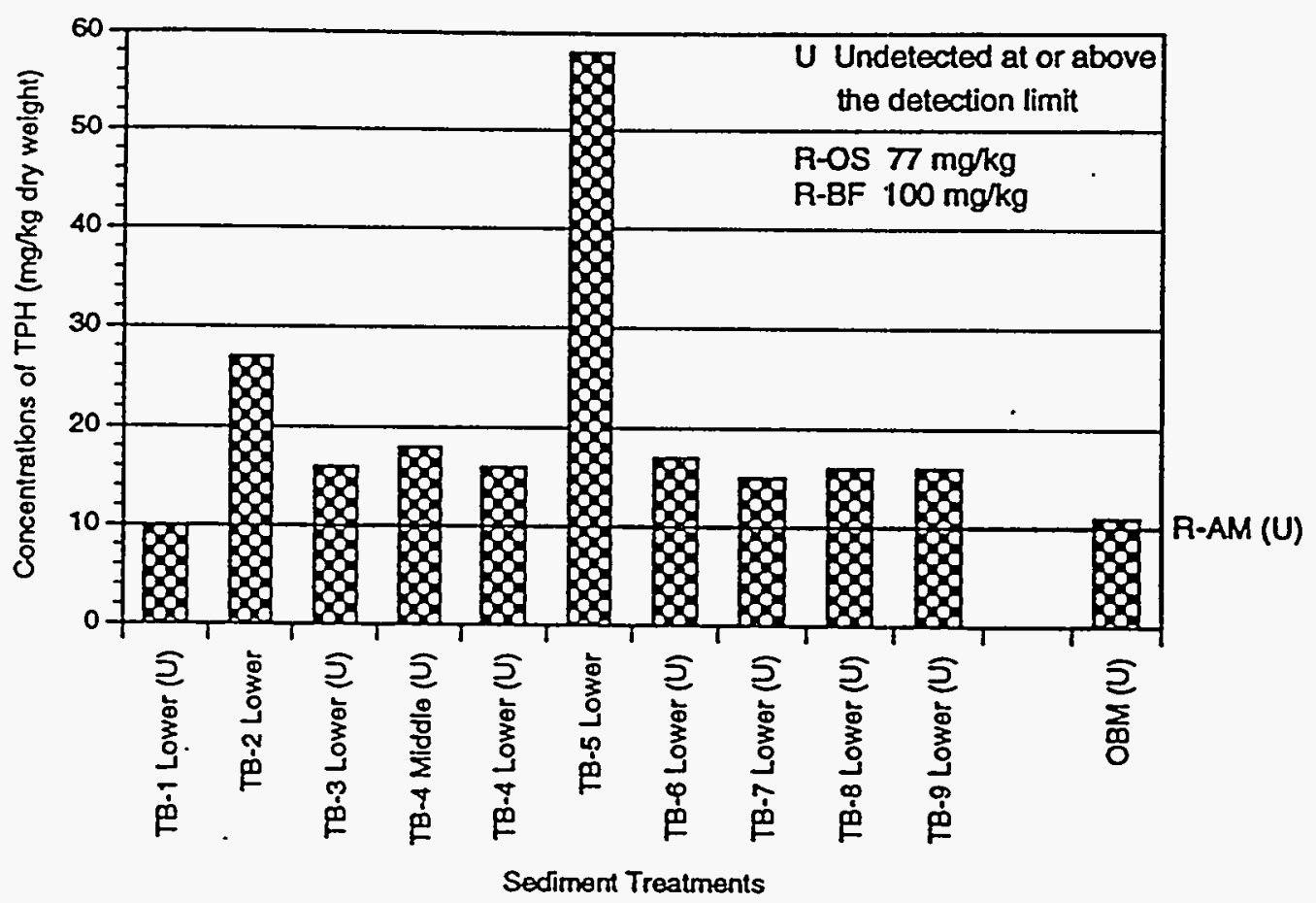

FIGURE 4.6. Concentrations of TPH in Sediment Treatments, Richmond Harbor Deepening Project-Intensive Study of the Turning Basin 


\subsubsection{Polynuclear Aromatic Hydrocarbons}

The Richmond Harbor Intensive Study of the Turning Basin sediment treatments were analyzed for 16 PAHs as listed in the 1991 Implementation Manual. The complete results including QAVQC results are reported in Appendix D, Tables D.7 through D.12.

Table 4.4 is a summary of those organic compounds that were detected in at least one of the test treatments. Figure 4.7 is a graph showing the concentrations of PAHs in the test treatments relative to $\mathrm{PAH}$ concentrations in the reference sediments. The concentrations of LPAHs and HPAHs in the reference sediment R-OS were higher than those of the test treatments, with the exception of the TB-4 Middle stations. The sediment concentrations of LPAHs and HPAHs in the TB-4 Middle sediment were $339 \mu \mathrm{g} / \mathrm{kg}$ and $2355 \mu \mathrm{g} / \mathrm{kg}$, respectively. The OBM COMP had a total LPAH concentration of $29 \mu \mathrm{g} / \mathrm{kg}$ and a total HPAH concentration of $28 \mu \mathrm{g} / \mathrm{kg}$.

\subsubsection{Chlorinated Pesticides and Polychlorinated Biphenyls (PCBs)}

Eighteen pesticides and four PCB congeners were analyzed in the sediments from the Richmond Harbor Intensive Study of the Turning Basin. The complete results including QAVQ results are reported in Appendix D, Tables D.13 through D.19. Four pesticides and one Aroclor congener were detected in at least one sediment treatment (Table 4.4). Detected concentrations

TABLE 4.4. Detected Total PAHs, Pesticides, and PCBs in Sediment Treatments, Richmond Harbor Deepening Project-Intensive Study of the Turning Basin (values in $\mu \mathrm{g} / \mathrm{kg}$ dry weight)

\begin{tabular}{|c|c|c|c|c|c|c|c|}
\hline $\begin{array}{l}\text { Sediment } \\
\text { Treatment } \\
\end{array}$ & $\begin{array}{l}\text { Total } \\
\text { LPAHs } \\
\end{array}$ & $\begin{array}{l}\text { Total } \\
\text { HPAHs }\end{array}$ & Aldrin & 4, $4^{\prime}-D D D$ & 4,4'-DDE & 4,4'-DDT & $\begin{array}{c}\text { Aroclor } \\
1254 \\
\end{array}$ \\
\hline $\begin{array}{l}R \cdot O S \\
R \cdot B F \\
\text { R-AM }\end{array}$ & $\begin{array}{r}65 \\
355 \\
538\end{array}$ & $\begin{array}{r}124 \\
2116 \\
1055\end{array}$ & $\begin{array}{l}0.25 \text { U(a) } \\
2.15 \\
1.32\end{array}$ & $\begin{array}{l}0.31 U \\
5.19 \\
0.21 U\end{array}$ & $\begin{array}{l}1.29 \\
2.61 \\
0.11 U\end{array}$ & $\begin{array}{l}0.87 U \\
1.19 U \\
0.58 U\end{array}$ & $\begin{array}{l}20 \mathrm{U} \\
46.8 \\
20 \mathrm{U}\end{array}$ \\
\hline $\begin{array}{l}\text { TB-1 Lower } \\
\text { TB-2 Lower } \\
\text { TB-3 Lower } \\
\text { TB-4 Middle } \\
\text { TB-4 Lower } \\
\text { TB-5 Lower } \\
\text { TB-6 Lower } \\
\text { TB-7 Lower } \\
\text { TB-8 Lower } \\
\text { TB-9 Lower }\end{array}$ & $\begin{array}{r}17 \\
22 \\
38 \\
339 \\
47 \\
51 \\
52 \\
35 \\
38 \\
43\end{array}$ & $\begin{array}{r}37 \\
36 \\
58 \\
2355 \\
66 \\
62 \\
67 \\
69 \\
67 \\
62\end{array}$ & $\begin{array}{l}0.17 \cup \\
0.66 \\
0.21 U \\
1.15 \\
0.21 \cup \\
0.22 U \\
1.17 \\
1.69 \\
0.97 \\
0.35 \cup\end{array}$ & $\begin{array}{c}0.21 U \\
0.17 \cup \\
0.26 \cup \\
19.3 \\
0.26 \cup \\
0.27 \cup \\
0.29 \cup \\
0.27 \cup \\
0.27 U \\
0.43 U\end{array}$ & $\begin{array}{c}0.11 U \\
0.09 U \\
0.14 U \\
-15.1 \\
0.14 U \\
0.15 U \\
0.16 U \\
0.15 \cup \\
0.15 U \\
0.24 U\end{array}$ & $\begin{array}{l}0.58 U \\
0.47 U \\
0.74 U \\
9.3 \\
0.72 U \\
0.76 U \\
0.83 U \\
0.77 U \\
0.76 U \\
1.21 U\end{array}$ & $\begin{array}{l}20 U \\
20 U \\
20 U \\
101 \\
20 U \\
20 U \\
20 U \\
20 U \\
20 U \\
20 U\end{array}$ \\
\hline OBM COMP & 29 & 28 & $0.18 U$ & $0.22 U$ & $0.12 U$ & $0.63 \mathrm{U}$ & $20 \mathrm{U}$ \\
\hline
\end{tabular}




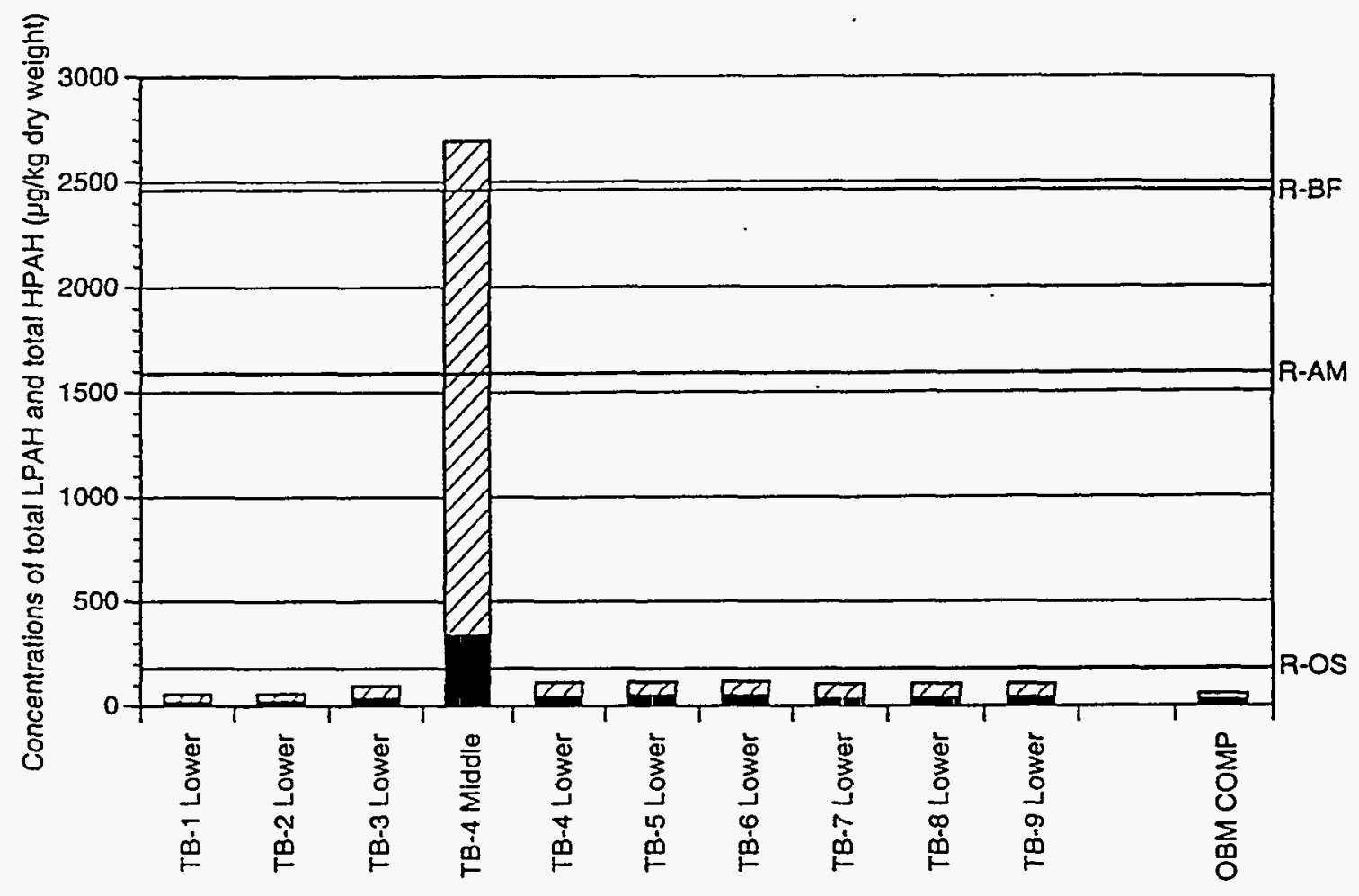

Sediment Treatments

Q Total HPAHs $\square$ Total LPAHs

FIGURE 4.7. Concentrations of Total PAH in Sediment Treatments, Richmond Harbor Deepening Project-Intensive Study of the Turning Basin 


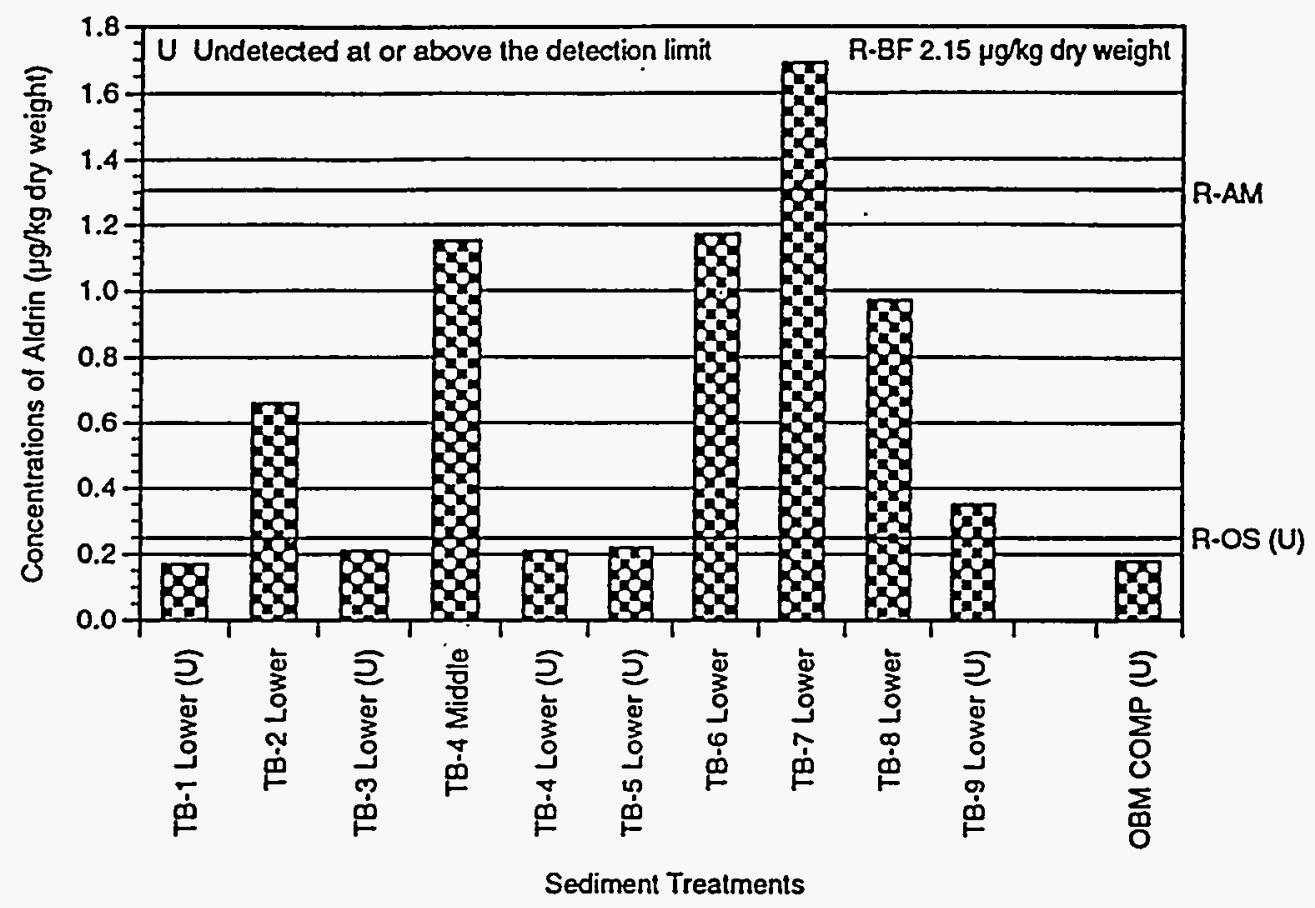

FIGURE 4.8. Concentrations of Aldrin in Sediment Treatments, Richmond Harbor Deepening Project-Intensive Study of the Turning Basin

of aldrin ranged from $0.66 \mu \mathrm{g} / \mathrm{kg}$ to $1.69 \mu \mathrm{g} / \mathrm{kg}$ in the test treatments; aldrin was undetected in R-OS sediments. The test treatment TB-4 Middle had detectable concentrations of 4,4'-DDD, 4,4'-DDE, 4,4'-DDT, and Aroclor 1254. The concentrations of these pesticides and Aroclor 1254 were at least five times higher than concentrations in the reference treatment R-OS. Pesticides and PCBs were not detected in sediments from the OBM COMP. Figures 4.8 through 4.12 show the relationship between concentrations of pesticides and Aroclor 1254 in the test treatments plotted against those found in the reference treatments.

\subsubsection{Metals}

Ten metals were analyzed in the Richmond Harbor Intensive Study of the Turning Basin sediments (Table 4.5). The complete results including QAVC reśults are reported in Appendix D, Tables D.20 and D.21. Each of these metals was detected in all of the test treatments, with the exception of selenium, which had detectable concentrations for three test treatments (TB-4 Middle, TB-7 and TB-8). Test treatment TB-4 Middle had the highest concentrations of eight metals ( $\mathrm{Ag}, \mathrm{As}, \mathrm{Cd}, \mathrm{Cu}, \mathrm{Hg}, \mathrm{Pb}, \mathrm{Se}$, and $\mathrm{Zn}$ ). The concentrations of $\mathrm{Ag}$, $\mathrm{Cd}, \mathrm{Hg}$, and Se at R-OS were higher than those in all sediment treatments except TB-4 Middle. Metals concentrations of the OBM COMP were within the range observed for the reference treatments, with the exception of cadmium, the concentration of which was higher than those 


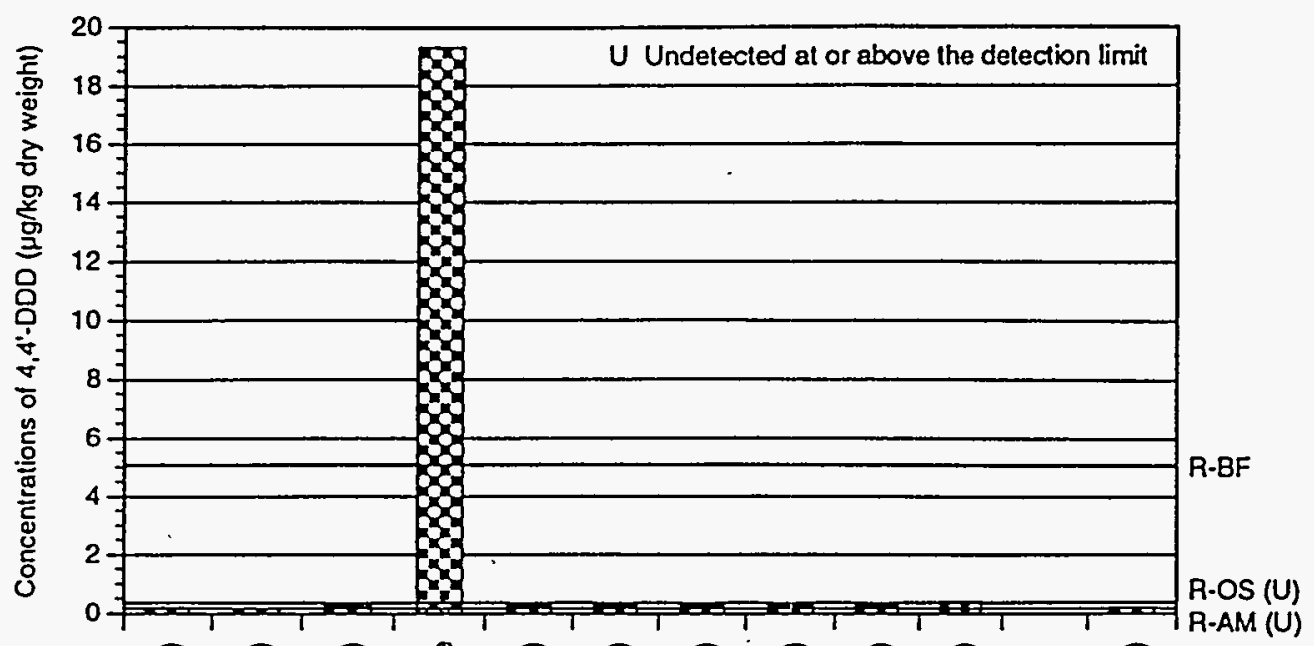

\begin{tabular}{|c|c|c|c|c|c|c|c|c|c|c|}
\hline & 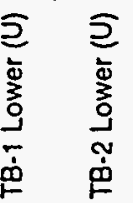 & 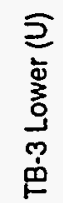 & 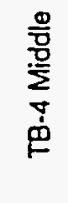 & 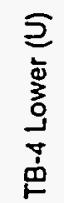 & 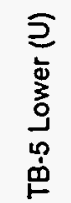 & 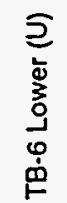 & 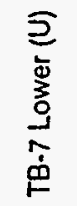 & 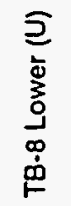 & 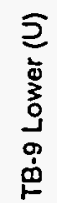 \\
\hline
\end{tabular}

FIGURE 4.9. Concentrations of 4,4'-DDD in Sediment Treatments, Richmond Harbor Deepening Project-Intensive Study of the Turning Basin

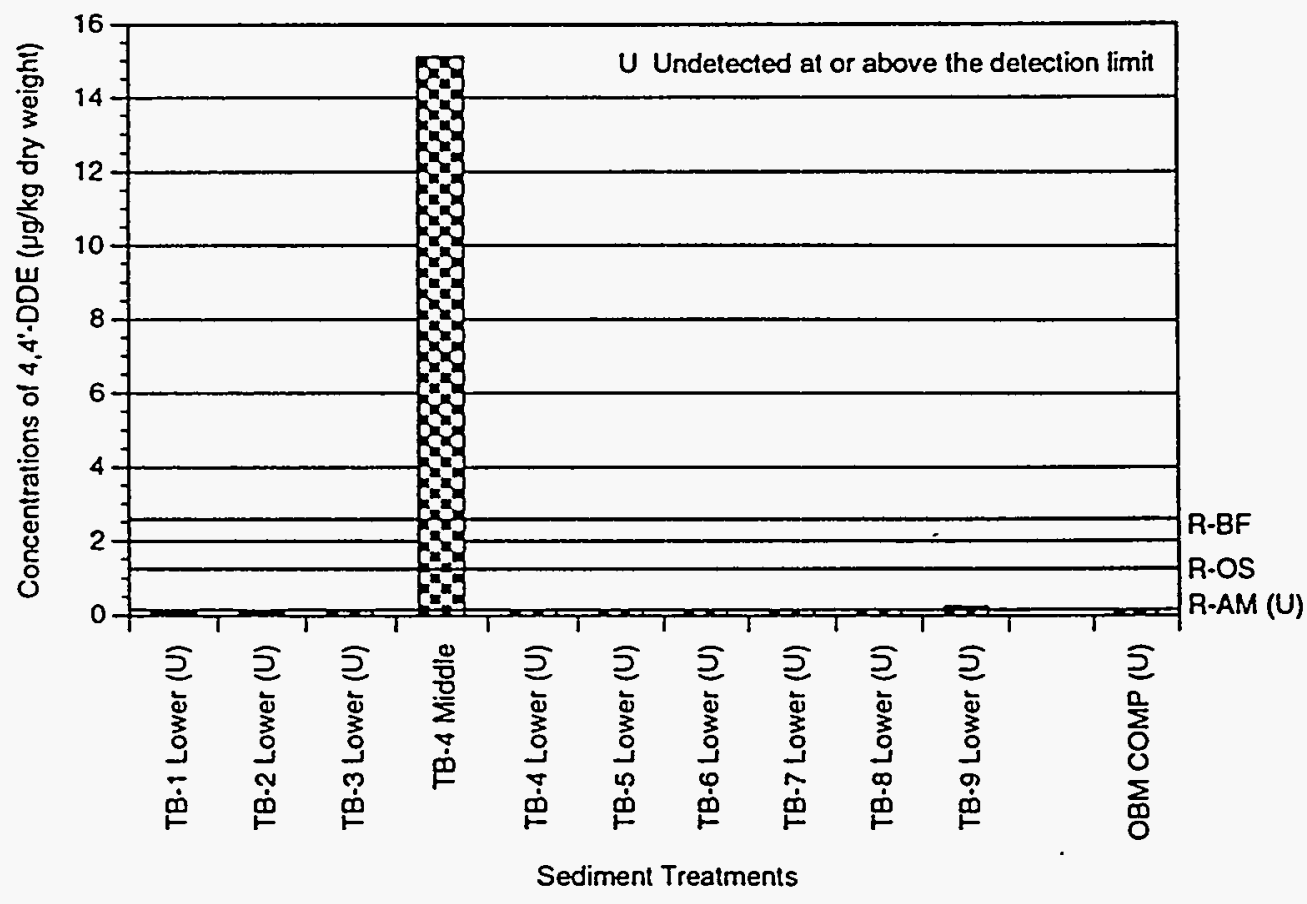

FIGURE 4.10. Concentrations of 4,4'-DDE in Sediment Treatments, Richmond Harbor Deepening Project-Intensive Study of the Turning Basin 


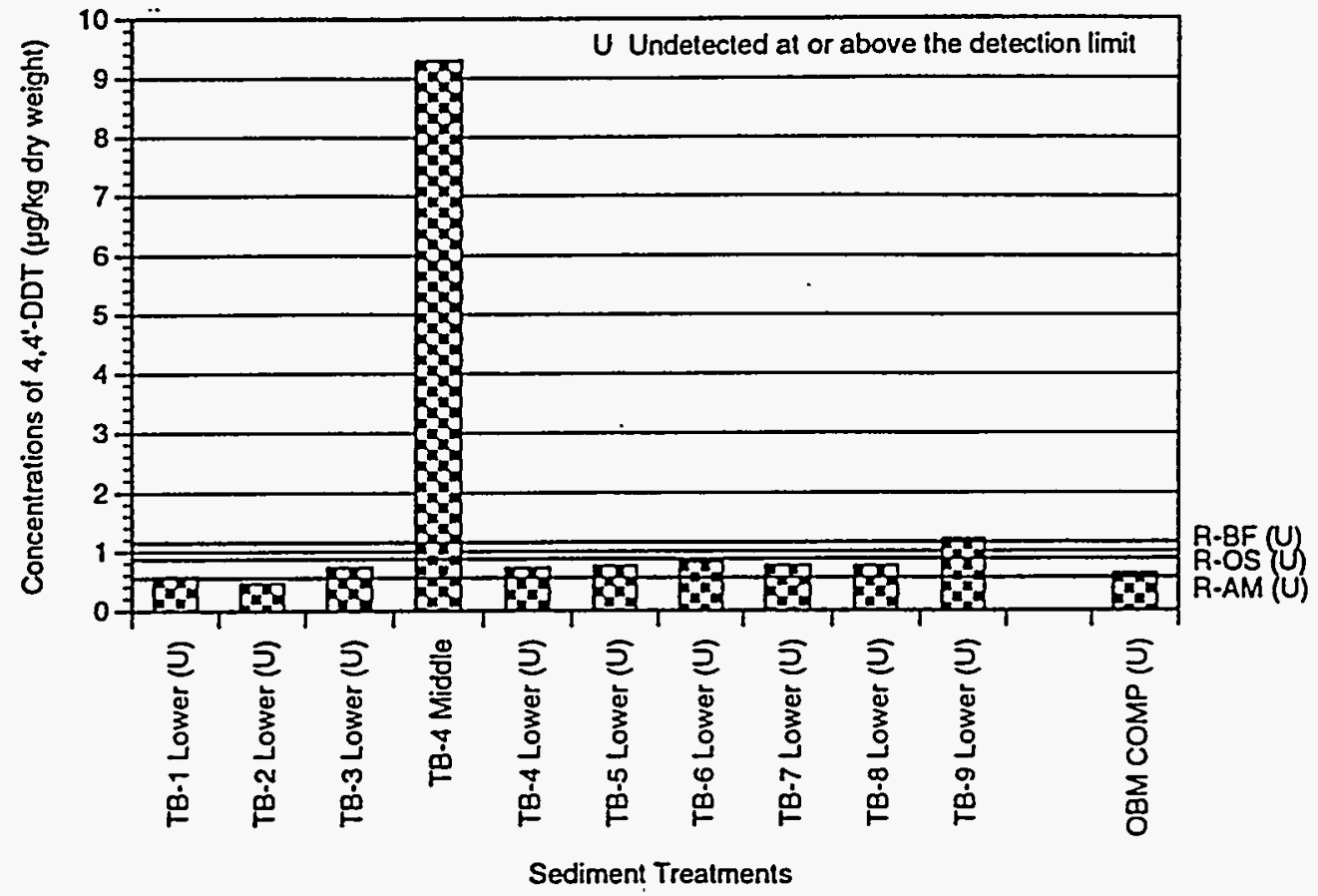

EIGURE 4.11. Concentrations of 4,4'-DDT in Sediment Treatments, Richmond Harbor Deepening Project-Intensive Study of the Turning Basin

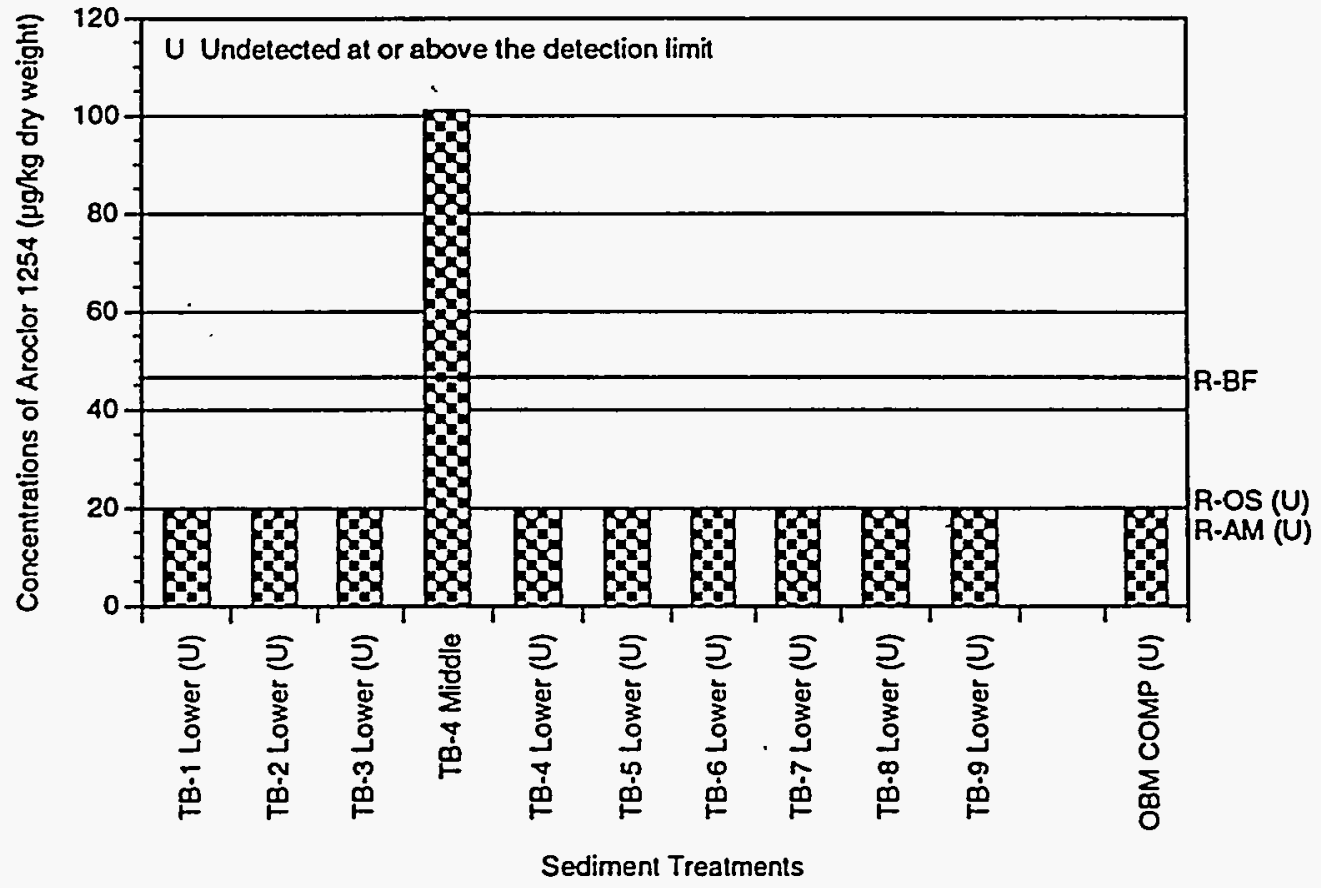

FIGURE 4.12. Concentrations of Aroclor 1254 in Sediment Treatments, Richmond Harbor Deepening Project-Intensive Study of the Turning Basin 
observed in sediment from all treatments except TB-4 Middle $(0.56 \mathrm{mg} / \mathrm{kg})$. Figures 4.13 through 4.22 illustrate the trends of metals enrichment for the Richmond Harbor Intensive Study of the Turning Basin sediments.

\subsubsection{Butyltins}

Three organotin compounds were analyzed in the sediments for this study. The complete results including QAVQC results are reported in Appendix D, Tables D.22 and D.23. Table 4.5 summarizes the results for the TBT and DBT analysis, and Figures 4.23 and 4.24 graphically depict these results. Monobutyltin was not detected in any of the sediment treatments. Detectable concentrations of TBT ranged from $0.49 \mu \mathrm{g} / \mathrm{kg}$ to $3.66 \mu \mathrm{g} / \mathrm{kg}$. TB-4 Middle was the only test treatment with a TBT concentration that was higher than that of the reference treatment R-OS. Detectable concentrations of DBT in the test treatments ranged from $0.76 \mu \mathrm{g} / \mathrm{kg}$ to $1.05 \mu \mathrm{g} / \mathrm{kg}$. DBT was not detected in the sediments from R-OS. The OBM COMP had no detectable concentrations of either TBT or DBT.

\subsection{TOXICOLOGICAL TESTING RESULTS}

The 10-day $R$. abronius solid-phase test was conducted on the nine test treatments, the OBM COMP, the three reference treatments, and the two control treatments. The complete data, including test results, observations, water quality monitoring, and reference toxicant tests, are contained in Appendixes F, G, and H. The QAVQC summaries are located at the front of each appendix and provide information related to organism collection, holding and acclimation, water quality, reference toxicant information, and test validation. The results of the comparison with the reference treatment $R-B F$ is in Appendix $Q$, and the comparison with the reference treatment $\mathrm{R}-\mathrm{AM}$ is in Appendix $\mathrm{R}$.

$R$. abronius test results were evaluated by ANOVA and Dunnett's test to determine whether statistically significant differences occurred between test and reference treatments. $A$ test treatment was considered acutely toxic if it was statistically significantly different from the reference treatment and if survival of the test organisms exposed to the test treatment was $\geq 20 \%$ lower than survival in the reference treatment.

\subsubsection{Methods and Test Design}

The standard 10-day $R$. abronius test was performed on 10 test treatments, three reference treatments and two control treatments. Six test treatments, TB-2 Lower, TB-3 Lower, TB-4 Middle, TB-4 Lower, TB-5 Lower, and TB-9 Lower, had initial porewater ammonia concentrations that were greater than $20 \mathrm{mg} / \mathrm{L}$, which is considered the no-observable-effects concentration (NOEC) for $R$. abronius based on Methods for Assessing the Toxicity of SedimentAssociated Contaminants with Estuarine and Marine Amphipods (EPA 1994). Therefore, in addition to the standard 10-day test, a second 10-day test was conducted using sediments from 


\begin{tabular}{|c|c|c|c|c|c|c|c|c|c|c|c|c|}
\hline \multirow{2}{*}{$\begin{array}{l}\text { Sediment } \\
\text { Treatment }\end{array}$} & \multicolumn{10}{|c|}{ Metals. } & \multicolumn{2}{|c|}{ B̈utylins } \\
\hline & $\mathrm{Ag}$ & As & Cd & $\mathrm{Cr}$ & $\mathrm{Cu}$ & $\mathrm{Hg}$ & $\mathrm{NI}$ & $\mathrm{Pb}$ & $\mathrm{Se}$ & $\mathrm{Zn}$ & TBT & DBT \\
\hline R-OS & 0.44 & 5.39 & 0.35 & 186 & 31.8 & 0.123 & 77.3 & 8.0 & 1.34 & 94.7 & 0.62 & $0.56 \cup(B)$ \\
\hline $\begin{array}{l}\text { TB-1 Lower } \\
\text { TB-2 Lower } \\
\text { TB-3 Lower } \\
\text { TB-4 Mlddle } \\
\text { TB-4 Lower } \\
\text { TB-5 Lower } \\
\text { TB-6 Lower } \\
\text { TB-7 Lower } \\
\text { TB-8 Lower } \\
\text { TB-9 Lower }\end{array}$ & $\begin{array}{l}0.10 \\
0.11 \\
0.11 \\
0.65 \\
0.11 \\
0.10(b) \\
0.12 \\
0.11 \\
0.10 \\
0.10\end{array}$ & $\begin{array}{c}6.07 \\
10.2 \\
9.2 \\
16.5 \\
9.7 \\
10.1 \text { (b) } \\
12.4 \\
9.8 \\
10.7 \\
7.8\end{array}$ & $\begin{array}{l}0.25 \\
0.21 \\
0.20 \\
0.54 \\
0.17 \\
0.21 \text { (b) } \\
0.20 \\
0.20 \\
0.21 \\
0.15\end{array}$ & $\begin{array}{l}231 \\
221 \\
184 \\
182 \\
181 \\
192(b) \\
173 \\
188 \\
182 \\
196\end{array}$ & $\begin{array}{l}20.9 \\
39.8 \\
36.1 \\
74.0 \\
44.3 \\
41.2(b) \\
53.4 \\
42.4 \\
45.8 \\
41.2\end{array}$ & $\begin{array}{l}0.059 \\
0.071 \\
0.058 \\
0.734 \\
0.076 \\
0.058(b) \\
0.037 \\
0.038 \\
0.066 \\
0.068\end{array}$ & $\begin{array}{c}55.3 \\
84.4 \\
85.1 \\
94.6 \\
93.6 \\
97.6(b) \\
113 \\
92.7 \\
101 \\
87.9\end{array}$ & $\begin{array}{l}11.1 \\
11.8 \\
9.3 \\
43.9 \\
12.1 \\
10.6(b) \\
8.4 \\
11.1 \\
10.3 \\
14.1\end{array}$ & $\begin{array}{l}0.17 U \\
0.17 U \\
0.17 U \\
0.39 \\
0.17 U \\
0.17 U(b) \\
0.17 U \\
0.19 \\
0.19 \\
0.17 U\end{array}$ & $\begin{array}{c}51.2 \\
88.6 \\
85.4 \\
185 \\
90.7 \\
94.3(\mathrm{~b}) \\
105 \\
95.8 \\
97.2 \\
82.7\end{array}$ & $\begin{array}{l}0.57 \\
0.53 \\
0.49 \\
3.66 \\
0.61 \\
0.48 U \\
0.54 \\
0.52 \\
0.48 U \\
0.48 U\end{array}$ & $\begin{array}{l}0.56 U \\
1.05 \\
0.56 U \\
0.82 \\
0.56 U \\
0.76 \\
0.56 U \\
0.56 U \\
0.56 U \\
0.56 U\end{array}$ \\
\hline OBM COMP & 0.11 & 3.28 & 0.56 & 142 & 27.4 & $0: 044$ & 62.7 & 10.6 & $0.17 \mathrm{U}$ & 68.3 & $0.48 U$ & $0.56 U$ \\
\hline $\begin{array}{l}\text { (a) Undet } \\
\text { (b) Values is }\end{array}$ & & le a & $\begin{array}{l}\text { on lir } \\
\text { is. }\end{array}$ & & & & & & & & & \\
\hline
\end{tabular}




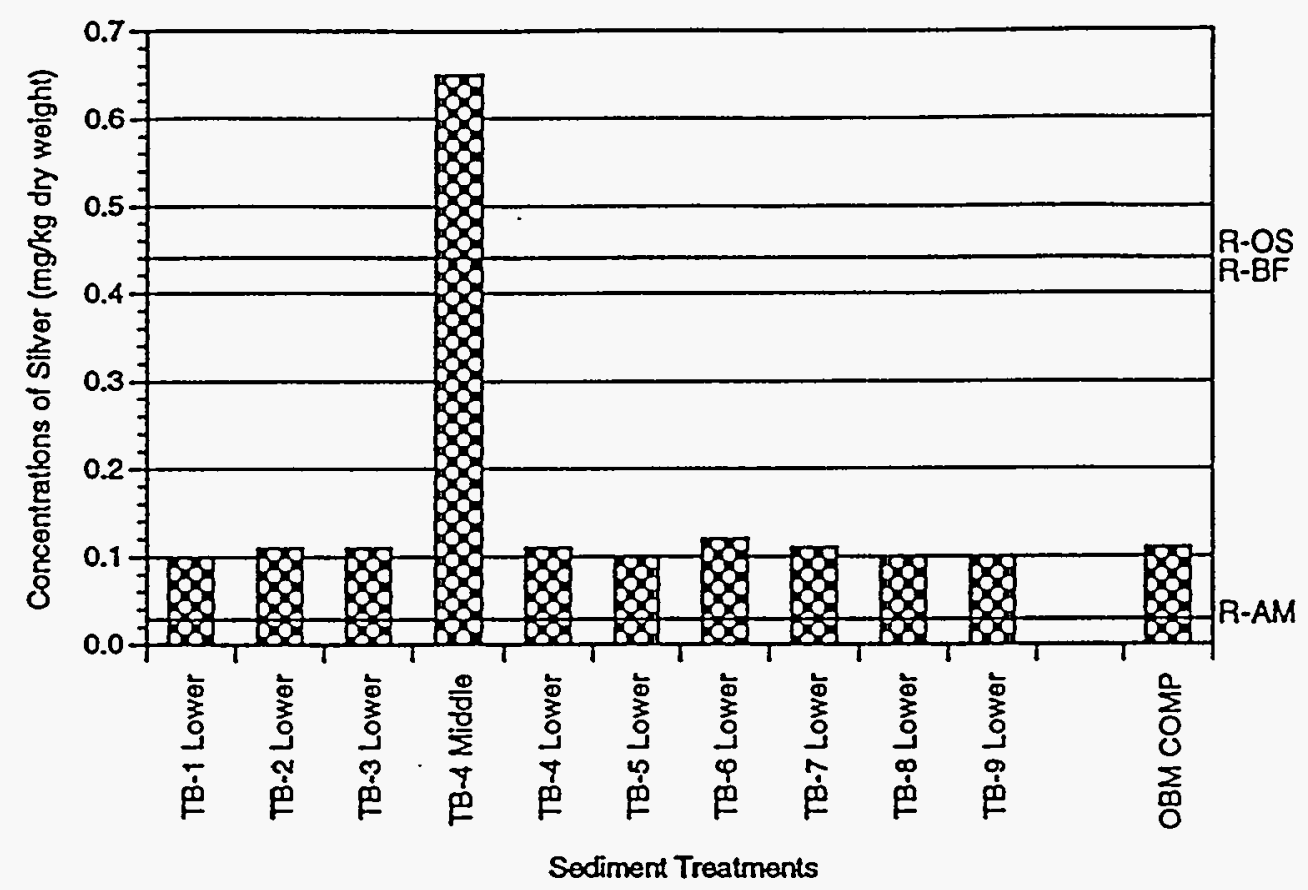

FIGURE 4.13. Concentrations of Silver in Sediment Treatments, Richmond Harbor Deepening Project-Intensive Study of the Turning Basin

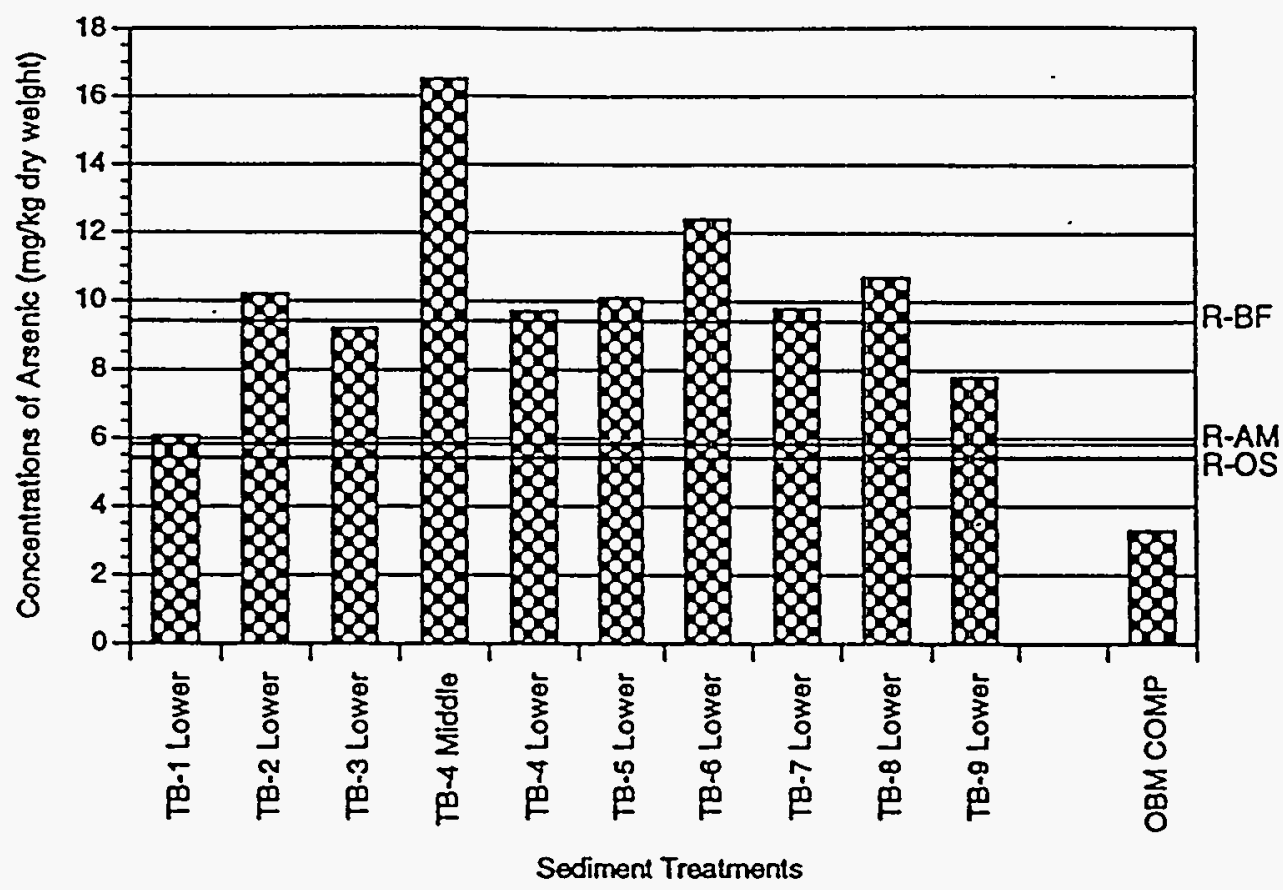

FIGURE 4.14. Concentrations of Arsenic in Sediment Treatments, Richmond Harbor Deepening Project-Intensive Study of the Turning Basin 


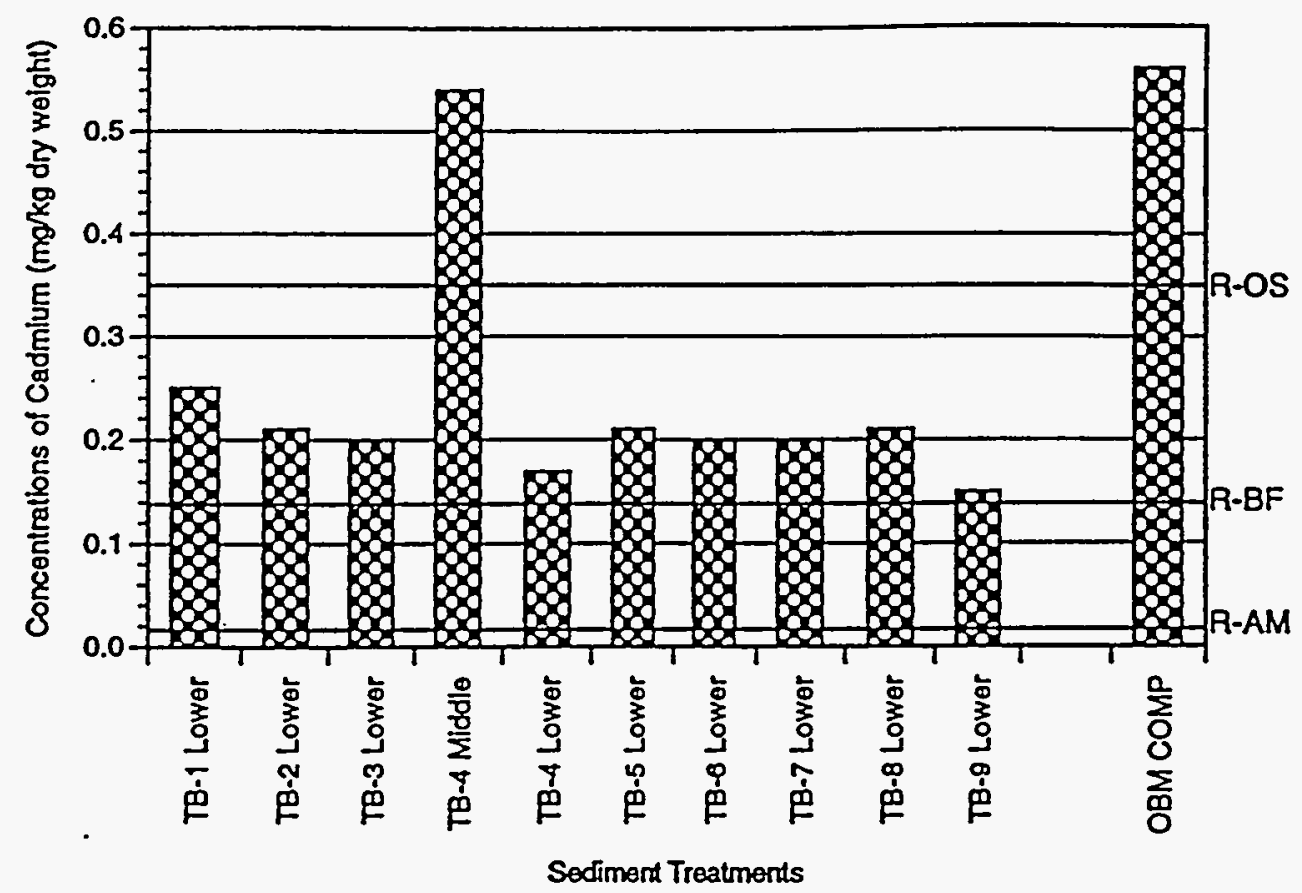

FIGURE 4.15. Concentrations of Cadmium in Sediment Treatments, Richmond Harbor Deepening Project-Intensive Study of the Turning Basin

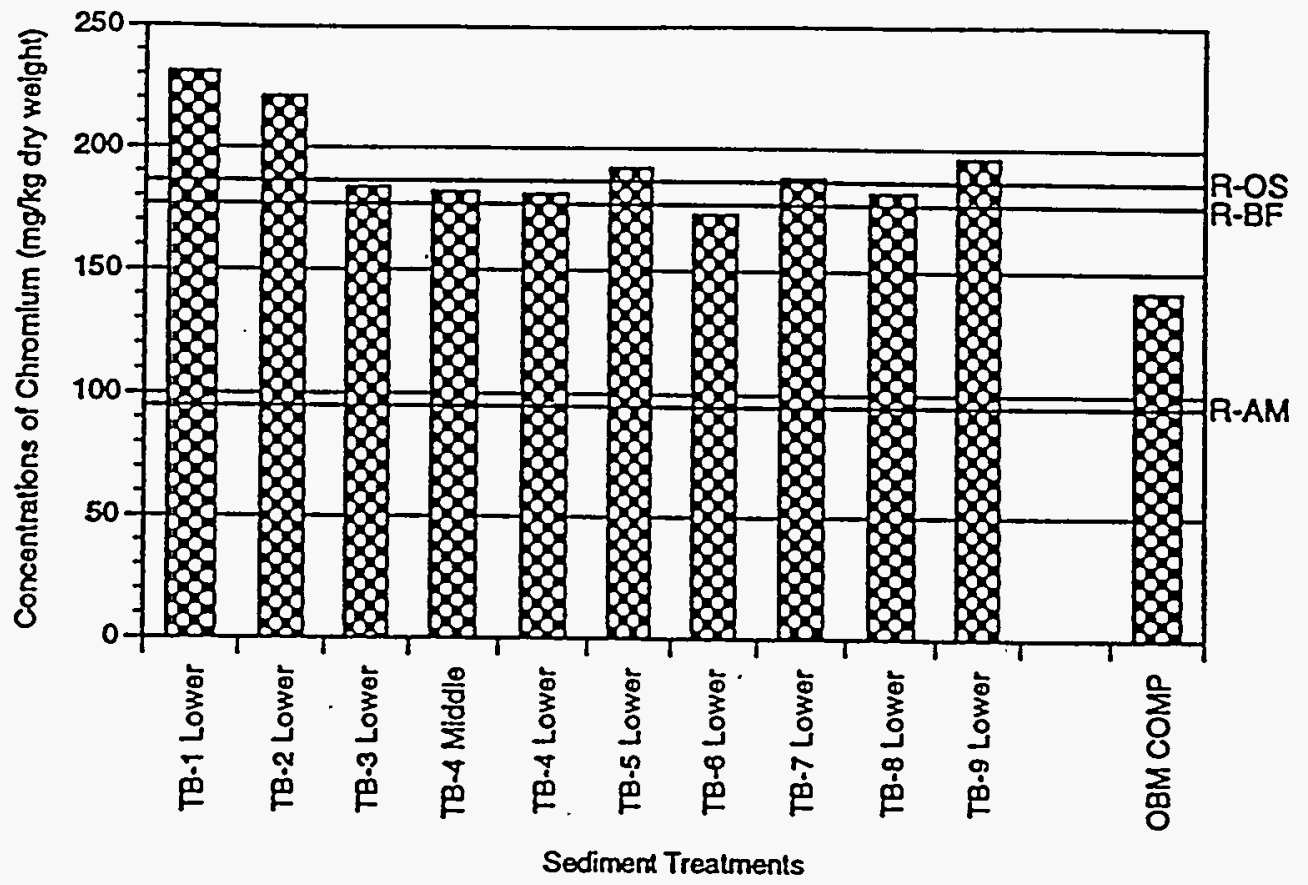

FIGURE 4.16. Concentrations of Chromium in Sediment Treatments, Richmond Harbor Deepening Project-Intensive Study of the Turning Basin 


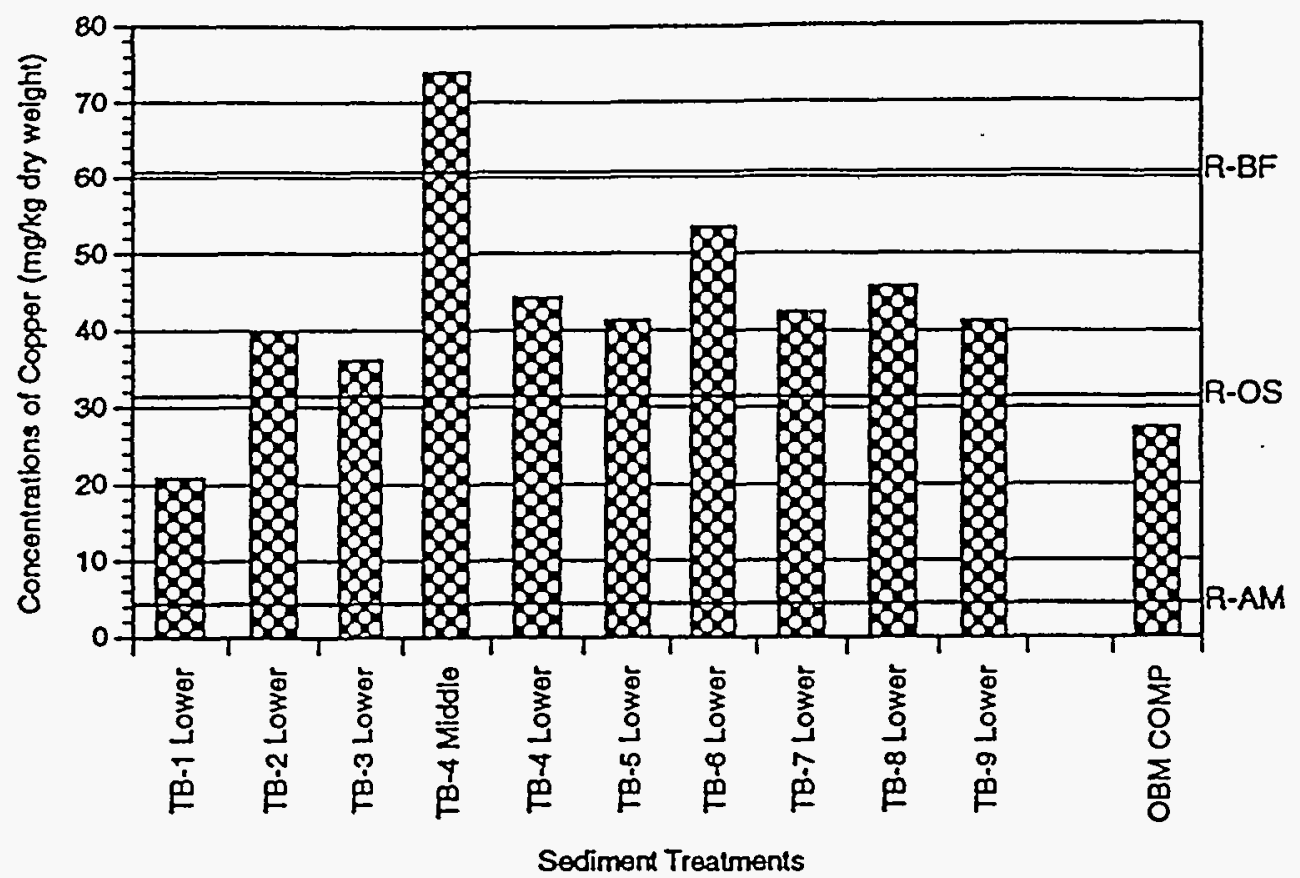

FIGURE 4.17. Concentrations of Copper in Sediment Treatments, Richmond Harbor Deepening Project-Intensive Study of the Turning Basin

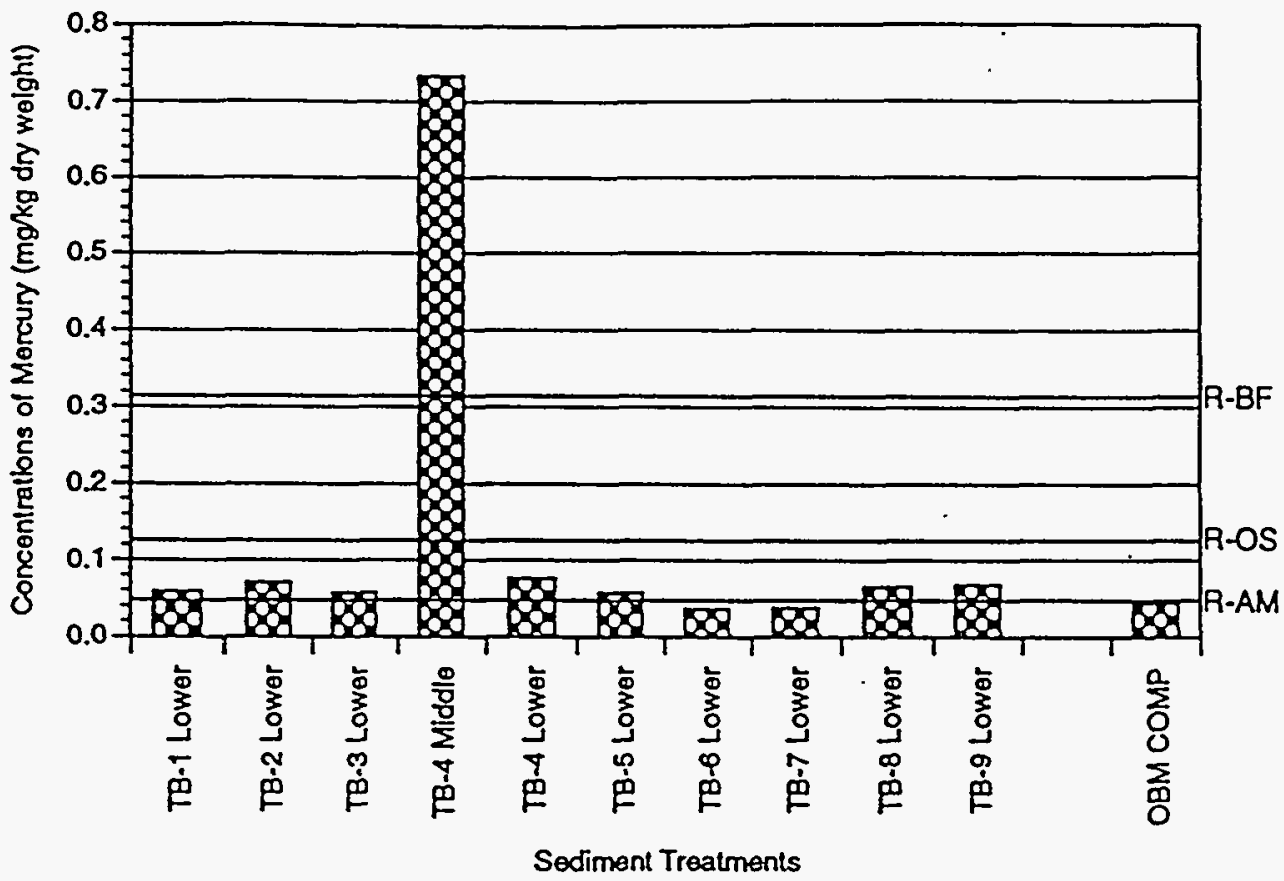

FIGURE 4.18. Concentrations of Mercury in Sediment Treatments, Richmond Harbor Deepening Project-Intensive Study of the Turning Basin 
u!seg bu!uנn

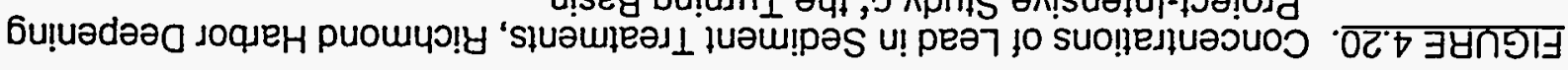
spounges 1 nowipos

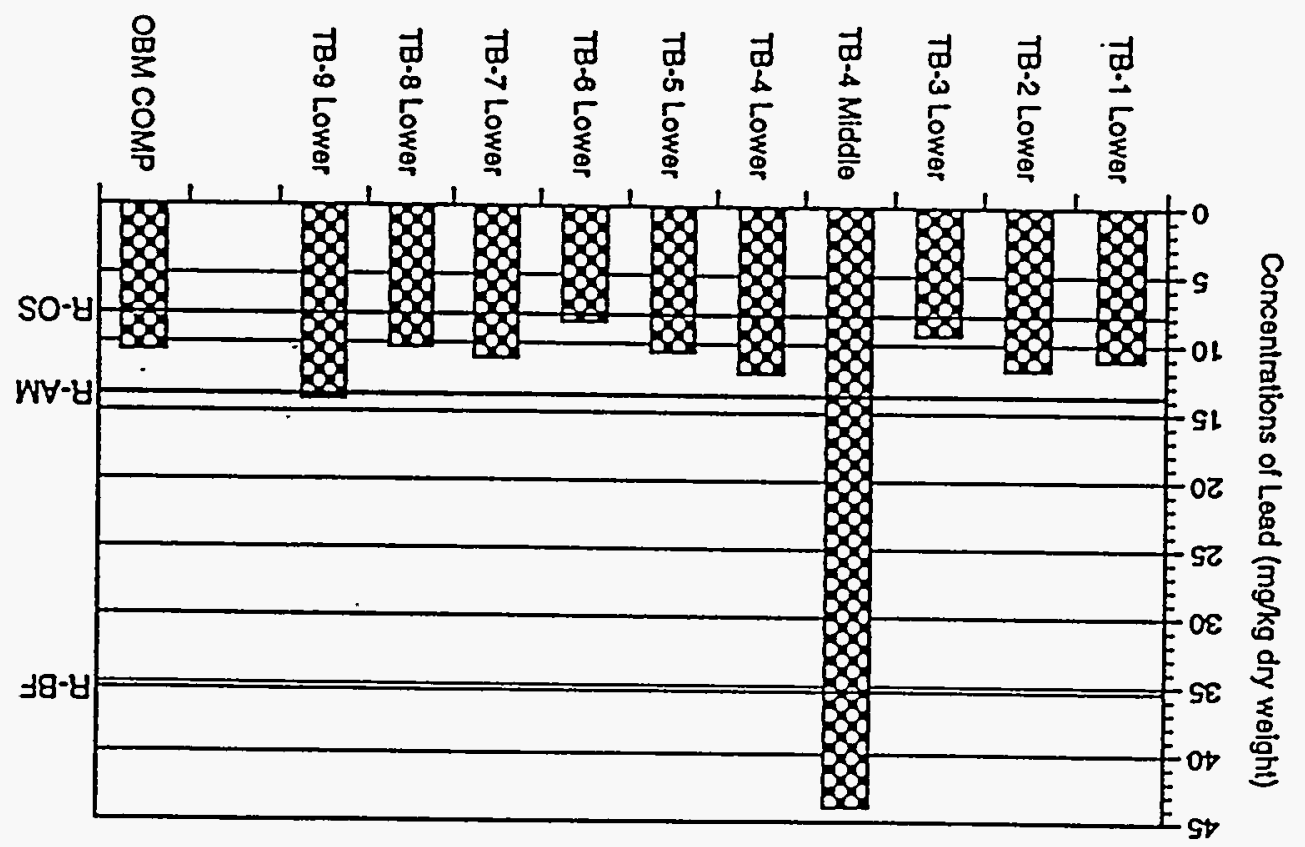

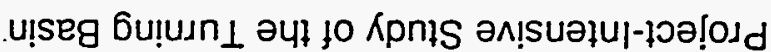

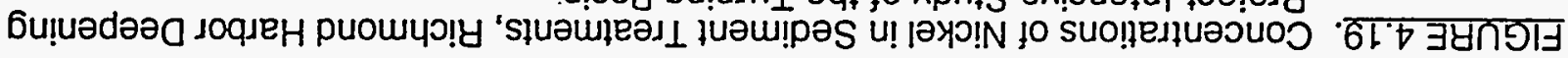

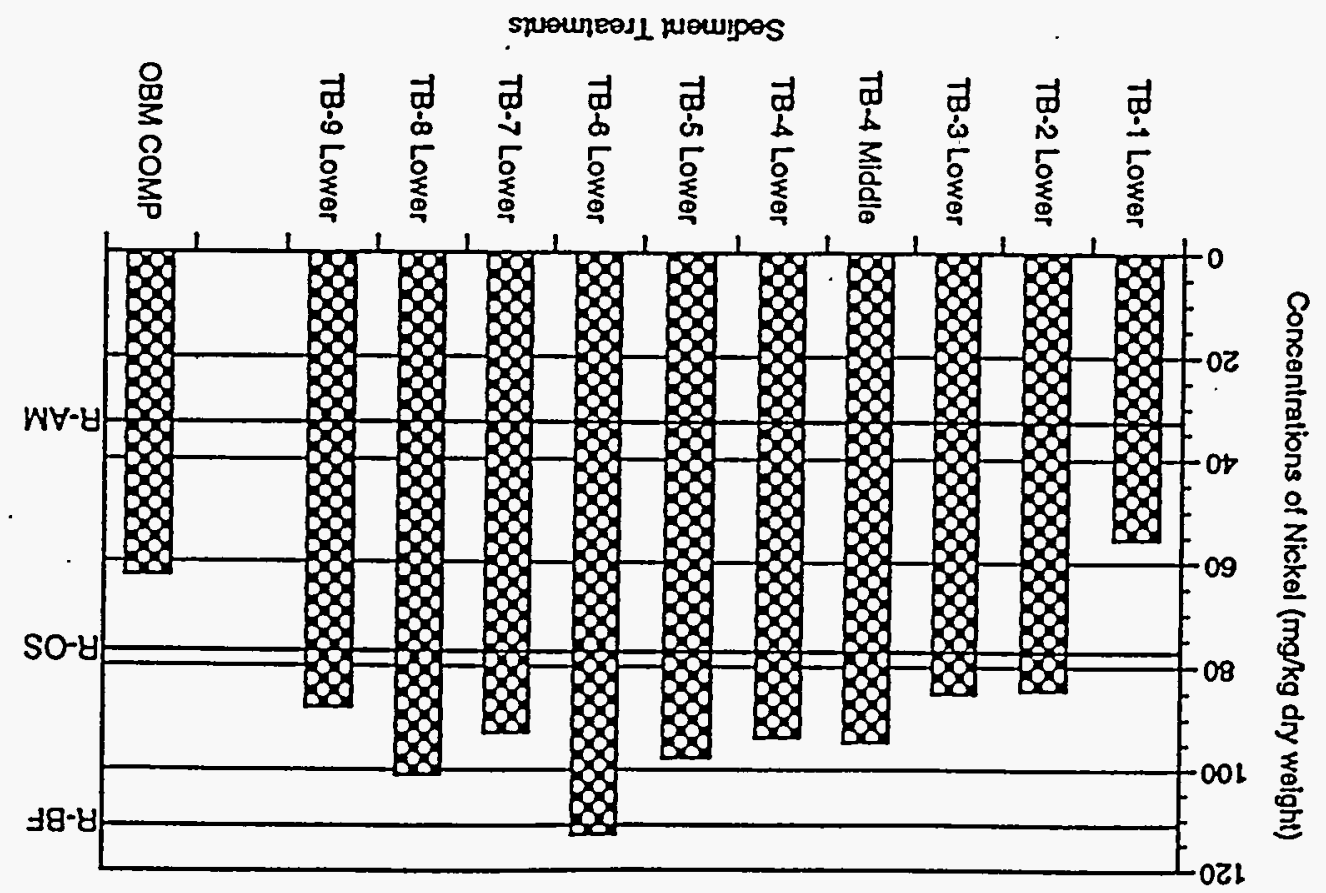




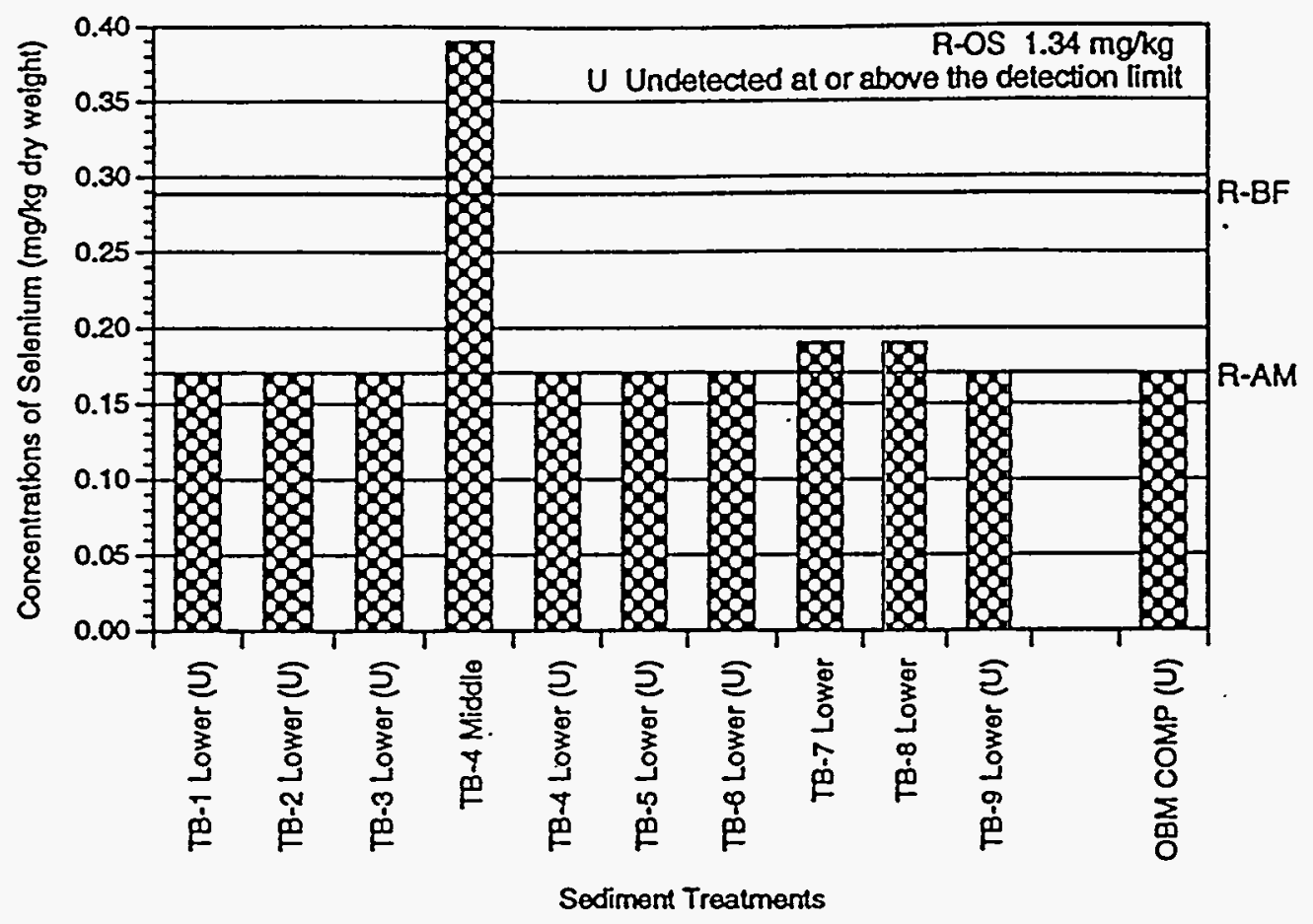

FIGURE 4.21. Concentrations of Selenium in Sediment Treatments, Richmond Harbor Deepening Project-Intensive Study of the Turning Basin

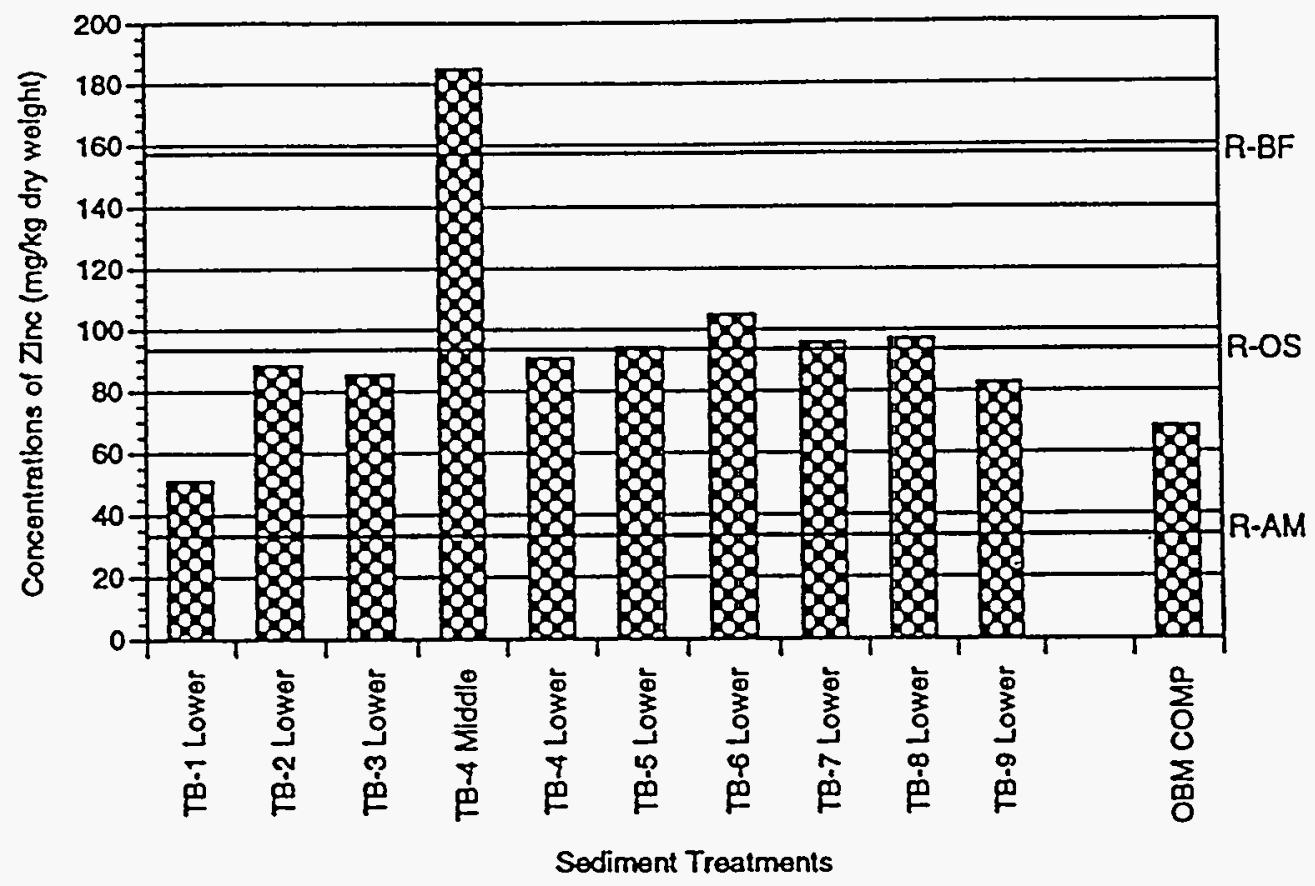

FIGURE 4.22. Concentrations of Zinc in Sediment Treatments, Richmond Harbor Deepening Project-Intensive Study of the Turning Basin 


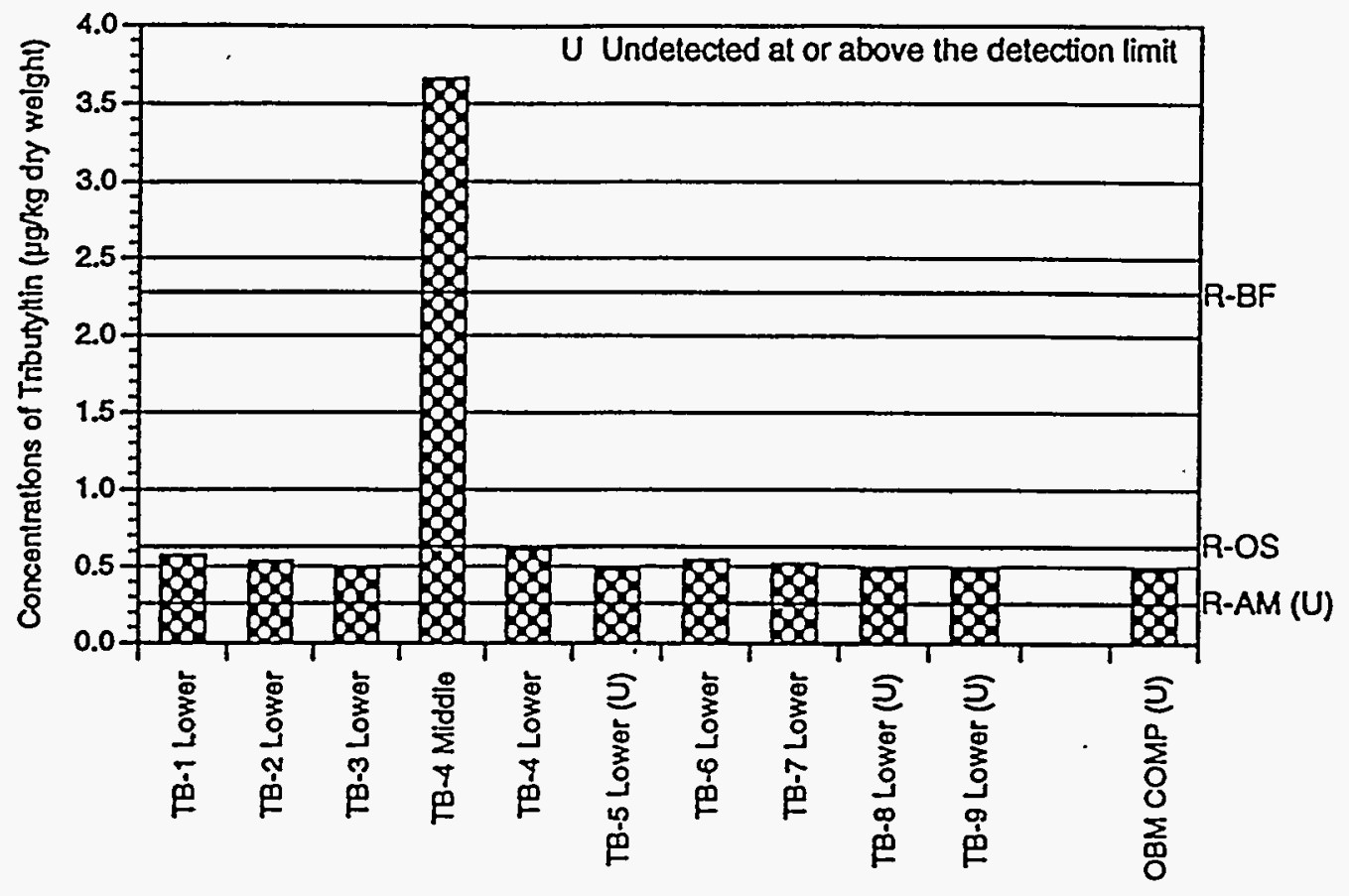

Sediment Treatments

FIGURE 4.23. Concentrations of Tributyltin in Sediment Treatments, Richmond Harbor Deepening Project-Intensive Study of the Turning Basin

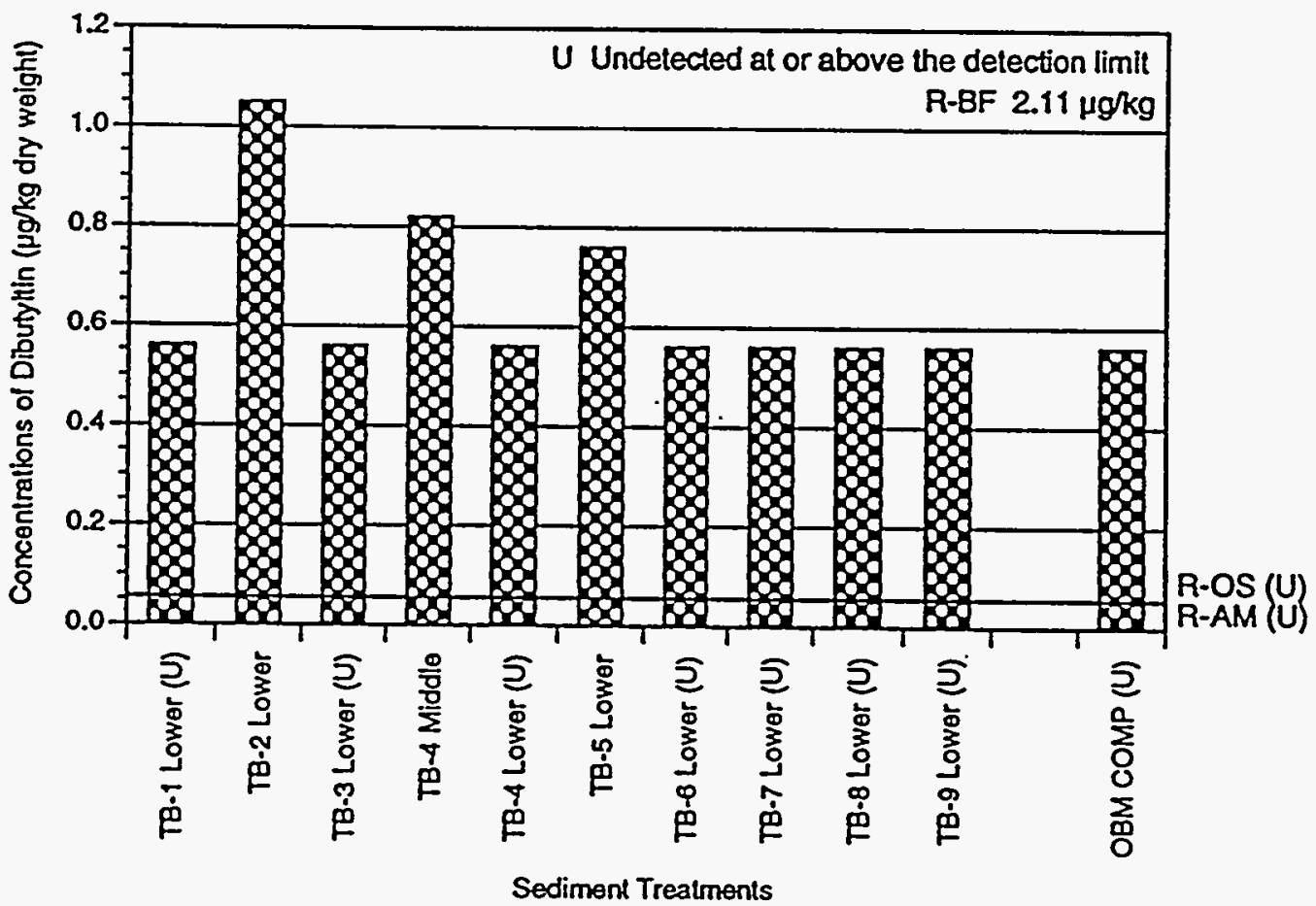

FIGURE 4.24. Concentrations of Dibutyltin in Sediment Treatments, Richmond Harbor Deepening Project-Intensive Study of the Turning Basin 
the six test treatments with porewater ammonia concentrations that were greater than $20 \mathrm{mg} / \mathrm{L}$. This second test, called the ammonia reduction to $<20 \mathrm{mg} / \mathrm{L}$ test, followed the procedures outlined in EPA 1994. To reduce the levels of ammonia in the test containers, the overlying water was exchanged from the test containers by running the system under flow-through conditions for $30 \mathrm{~min}$ twice a day. It took approximately seven days or 14 exchanges for the porewater ammonia concentrations to reach $<20 \mathrm{mg} / \mathrm{L}$. When the ammonia levels were $<20 \mathrm{mg} / \mathrm{L}$ in all test treatments, the test organisms were added to the test containers, and the test proceeded as a static 10-day test. The same batch of test organisms was used for the standard 10-day test and the ammonia reduction to $<20 \mathrm{mg} / \mathrm{L}$ test. Consequently, the reference toxicant test results apply to both tests.

Current research conducted at the MSL indicates that at $20 \mathrm{mg} / \mathrm{L}$ acute toxicity effects could be observed and that this concentration, therefore, could be an inappropriate NOEC for $R$. abronius. Our research suggests that $15 \mathrm{mg} / \mathrm{L}$ could be a more appropriate NOEC for ammonia toxicity to $R$. abronius. To test this hypothesis, a third $R$. abronius test was performed following the same procedures as the ammonia reduction to $<20 \mathrm{mg} / \mathrm{L}$ test, with the exception that all ammonia concentrations were lowered to $<15 \mathrm{mg} / \mathrm{L}$ prior to the addition of test organisms. Prior to testing, the sediments were held in the cold room at $4^{\circ} \mathrm{C}$. Four test treatments were used for this experiment, TB-3 Lower, TB-7 Lower, TB-8 Lower, and TB-9 Lower. These test treatments were chosen because of their reduced survival of $R$. abronius in either the standard 10-day or ammonia reduction to $<20 \mathrm{mg} / \mathrm{L}$ tests. The sediments for this test were layered into the test containers and the overlying water was exchanged from the test containers 26 times (this process took 13 days) before ammonia level were $<15 \mathrm{mg} / \mathrm{L}$. When the ammonia levels were $<15 \mathrm{mg} / \mathrm{L}$ in all test treatments, the test organisms were added to the test containers, and the test proceeded as a static 10-day test. A new batch of test organisms was required for the ammonia reduction to $<15 \mathrm{mg} / \mathrm{L}$ test. Consequently, a second reference toxicant test results was conducted with this experiment. The results of all three tests, the standard 10-day static test, the ammonia reduction to $<20 \mathrm{mg} / \mathrm{L}$ test, and the ammonia reduction to $<15 \mathrm{mg} / \mathrm{L}$ test, are described below.

\subsubsection{The Standard 10-day Test with $R$. abronius}

Ammonia concentrations in the standard 10-day test were monitored in the overlying water (Days $0,1,3,7$, and 10) and in the porewater (Days 0 and 10) of each sediment treatment (Table 4.6). Porewater ammonia measurements were taken from dummy jars that were set up and run concurrently with the test containers. Total ammonia concentrations in the porewater were highest for test treatment TB-9 Lower with a concentration of $39.4 \mathrm{mg} / \mathrm{L}$ on Day 10 of the test. The reference treatment $\mathrm{R}-\mathrm{OS}$ and control treatments had porewater ammonia concentrations $<2.46 \mathrm{mg} / \mathrm{L}$. 
TABLE 4.6. Ammonia Monitoring Summary for the 10-Day $R$. abronius Solid-Phase Static Test, Richmond Harbor Deepening Project-Intensive Study of the Tuming Basin

\begin{tabular}{|c|c|c|c|c|c|c|c|c|c|}
\hline \multirow{3}{*}{$\begin{array}{l}\text { Sediment } \\
\text { Treatment }\end{array}$} & \multirow{2}{*}{\multicolumn{5}{|c|}{ Overlying Water Ammonia (mg/L) }} & \multirow{2}{*}{\multicolumn{2}{|c|}{$\begin{array}{c}\text { Porewater } \\
\text { Ammonia (mg/) }\end{array}$}} & \multicolumn{2}{|c|}{ Static Test } \\
\hline & & & & & & & & \multirow{2}{*}{$\begin{array}{l}\text { Percent } \\
\text { Survival }\end{array}$} & \multirow{2}{*}{$\begin{array}{l}\text { Acute } \\
\text { Toxicity }\end{array}$} \\
\hline & Day 0 & Day 1 & Day 3 & Day 7 & Day 10 & Day 0 & Day 10 & & \\
\hline R-OS & 0.447 & 0.396 & 0.579 & 1.12 & 0.566 & 1.18 & 1.01 & 94 & NA(a) \\
\hline TB-1 Lower & 3.10 & 3.06 & 2.55 & 4.94 & 2.42 & 8.18 & 5.61 & 87 & NO \\
\hline TB-2 Lower & 13.4 & 16.1 & 14.3 & 19.0 & 15.8 & 31.4 & 23.7 & 52 & YES \\
\hline TB-3 Lower & 11.7 & 12.3 & 14.4 & 19.3 & 14.7 & 24.7 & 21.9 & 25 & YES \\
\hline TB-4 Middle & 12.5 & 13.0 & 14.2 & 21.0 & 15.9 & 33.4 & 24.9 & 82 & NO \\
\hline TB-4 Lower & 10.6 & 14.2 & 14.0 & 19.7 & 16.3 & 32.9 & 23.6 & 76 & NO \\
\hline TB-5 Lower & 11.6 & 10.2 & 12.7 & 16.4 & 13.6 & 22.4 & 19.2 & 62 & YES \\
\hline TB-6 Lower & 7.82 & 10.9 & 11.4 & 12.5 & 11.7 & 20.0 & 15.6 & 76 & NO \\
\hline TB-7 Lower & 8.38 & 11.3 & 12.1 & 13.7 & 12.0 & 17.9 & 14.9 & 55 & YES \\
\hline TB-8 Lower & 7.46 & 5.57 & 8.12 & 11.5 & 9.63 & 16.2 & 14.9 & 64 & YES \\
\hline TB-9 Lower & 25.3 & 18.5 & 27.7 & 28.3 & 32.1 & 38.5 & 39.4 & 28 & YES \\
\hline OBM COMP & 0.734 & 0.639 & 0.723 & 1.13 & 0.380 & 1.14 & 0.637 & 68 & NA \\
\hline C-SB & 1.67 & 1.61 & 1.23 & 1.08 & 0.597 & 2.46 & 1.08 & 89 & NA \\
\hline$C-W B$ & 0.347 & 0.330 & 0.778 & 1.39 & 0.564 & 2.20 & 2.71 & 98 & NA \\
\hline
\end{tabular}

(a) NA Not applicable.

Reference toxicant tests using $\mathrm{Cd}$ and ammonia were conducted to assess the sensitivity of the test organisms used in the standard 10-day test. The $\mathrm{LC}_{50}$ for the $\mathrm{Cd}$ reference toxicant test was $0.81 \mathrm{mg} / \mathrm{L} \mathrm{Cd}$ (confidence interval $=0.57 \mathrm{mg} / \mathrm{L}$ to $1.17 \mathrm{mg} / \mathrm{L} \mathrm{Cd}$ ). This $L C_{50}$ is within the range of $0.68 \mathrm{mg} / \mathrm{L}$ to $1.25 \mathrm{mg} / \mathrm{L} \mathrm{Cd}$ established for $R$. abronius (ASTM 1990), indicating that the response of this batch of test organisms was similar to that of organisms used in past studies and that these data can be used to compare with other data sets. The results of a 96-h ammonia reference toxicant test indicate that the $L C_{50}$ for this batch of test organisms was $80.57 \mathrm{mg} / \mathrm{L}$ total ammonia (confidence interval $=69.10 \mathrm{mg} / \mathrm{L}$ to $93.95 \mathrm{mg} / \mathrm{L}$ total ammonia).

The standard 10-day test was validated by $98 \%$ survival of $R$. abronius in the native control sediment C-WB. The experimental grain size control sediment (C-SB) also had adequate control survival of $89 \%$. R. abronius survival in the standard 10 -day test ranged from $25 \%$ for TB-3 Lower to $87 \%$ for TB-1 Lower. A statistical comparison of the standard 10-day test results showed that six test treatments were acutely toxic relative to the reference treatment $R$-OS (Table 4.6). The survival of $R$. abronius exposed to OBM COMP was 68\%. Ammonia concentrations in the porewater of OBM COMP prior to test initiation was $1.1 \mathrm{mg} / \mathrm{L}$, indicating that ammonia was not responsible for reduced toxicity in this composite. 
Figure 4.25 is a dose-response curve of $R$. abronius survival to ammonia in a 96-h reference toxicant test plotted against the survival and corresponding.porewater ammonia measurements for the test treatments. The dose-response line is shown along with a difference of $10 \%$ or $20 \%$ from the dose-response line to give a range of ammonia response used for comparison. These values were chosen based on their applicability from the 1991 Implementation Manual, which states that a given teșt sediment is acutely toxic if mortality is statistically significant and exceeds mortality in a reference sediment by difference of $10 \%$ or $20 \%$ (for amphipods). The figure shows that eight test treatments are below the dose-response line for ammonia. Six of these eight treatments were also considered acutely toxic to $R$. abronius relative to survival of $R$. abronius exposed to sediment from R-OS.

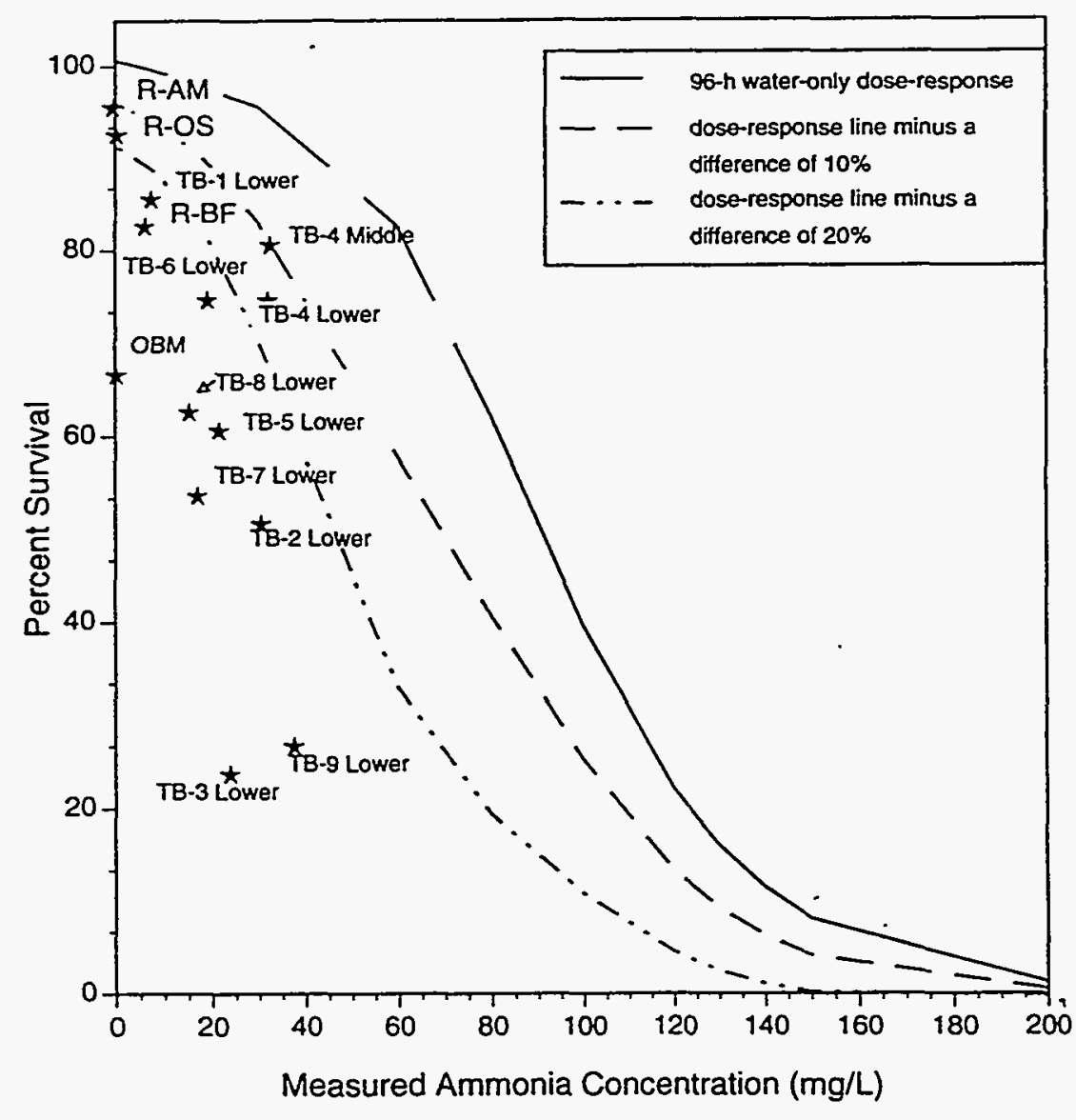

FIGURE 4.25. Response of $R$. abronius to Porewater Ammonia Concentrations in the Intensive Study of the Turning Basin Sediments from the Standard 10-Day Test Relative to the Ammonia Reterence Toxicant Dose-Response Curve 


\subsubsection{Ammonia Reduction to $<20 \mathrm{mg} / \mathrm{L}$ Test with $R$. abronius}

Ammonia concentrations in the ammonia reduction to $<20 \mathrm{mg} / \mathrm{L}$ test were monitored in the overlying water and porewater of each sediment treatment following the same protocols as those for the standard 10-day test. Table 4.7 is a summary of the ammonia measurements taken during this test. The highest porewater ammonia concentration $(18 \mathrm{mg} / \mathrm{L})$ was observed for test treatment TB-9 Lower.

The population of amphipods used for the ammonia reduction to $<20 \mathrm{mg} / \mathrm{L}$ was the same as that used for the standard 10-day test. The reference toxicant results for this test are reported in the preceding section.

The ammonia reduction to $<20 \mathrm{mg} / \mathrm{L}$ was performed on the six test treatments that had porewater ammonia concentrations greater than $20 \mathrm{mg} / \mathrm{L}$. The test results for the ammonia reduction to $<20 \mathrm{mg} / \mathrm{L}$ test ranged from $70 \%$ for TB-3 Lower to $89 \%$ for TB-4 Middle. Statistical analysis showed that one test treatment, TB-3 Lower, was acutely toxic relative to the reference treatment R-OS (Table 4.7).

The survival results from this test and the corresponding porewater ammonia measurements were plotted against the dose-response curve for this batch of test organisms. Figure 4.26 shows that when the porewater ammonia levels in the test treatments were brought down to the theoretical NOEC for ammonia, the results for three additional test treatments, TB-5 Lower, TB-2 Lower and TB-4 Lower, fell within the dose-response curve and corresponding $20 \%$ response. This finding suggest that ammonia could have been the primary reason for the acute toxicity of these sediments to $R$. abronius.

TABLE 4.7. Ammonia Monitoring Summary for the 10-Day $R$. abronius Solid-Phase, Ammonia Reduction to $<20 \mathrm{mg} / \mathrm{L}$ Test, Richmond Harbor Deepening Project-Intensive Study of the Tuming Basin

\begin{tabular}{|c|c|c|c|c|c|c|c|c|c|c|}
\hline \multirow{3}{*}{$\begin{array}{l}\text { Sediment } \\
\text { Treatment }\end{array}$} & \multirow{2}{*}{\multicolumn{5}{|c|}{ Overlying Water Ammonia (mg/) }} & \multirow{2}{*}{\multicolumn{2}{|c|}{$\begin{array}{c}\text { Porewater } \\
\text { Ammonia (mg/) }\end{array}$}} & & \multicolumn{2}{|c|}{$\begin{array}{c}\text { Ammonia Reduction } \\
\text { to }<20 \mathrm{mg} L\end{array}$} \\
\hline & & & & & & & & & \multirow{2}{*}{$\begin{array}{l}\text { Percent } \\
\text { Survival }\end{array}$} & \multirow{2}{*}{$\begin{array}{l}\text { Acute } \\
\text { Toxicity }\end{array}$} \\
\hline & Day 0 & Day 1 & Day 3 & Day 6 & Day 10 & Day 0 & Day 10 & 1 & & \\
\hline R-OS & 0.447 & 0.396 & 0.579 & 1.12 & 0.566 & 1.18 & 1.01 & & 94 & NA(a) \\
\hline TB-2 Lower & 1.23 & 1.15 & 2.18 & 4.75 & 8.87 & 14.2 & 10.3 & & 79 & NO \\
\hline TB-3 Lower & 0.733 & 1.23 & 2.51 & 3.56 & 4.97 & 9.87 & 12.6 & & 70 & YES \\
\hline TB-4 Middle & 1.07 & 1.14 & 2.89 & 4.63 & 9.01 & 15.1 & 9.49 & & 89 & NO \\
\hline TB-4 Lower & ND(a) & 0.991 & 1.92 & 4.16 & 8.30 & $N$ & 13.9 & & 81 & NO \\
\hline TB-5 Lower & 0.915 & 1.20 & 2.81 & 4.94 & 6.08 & 11.7 & 12.5 & & 82 & NO \\
\hline TB-9 Lower & 3.79 & 1.72 & 4.24 & 8.64 & 7.28 & 18.0 & 15.6 & & 74 & NO \\
\hline
\end{tabular}




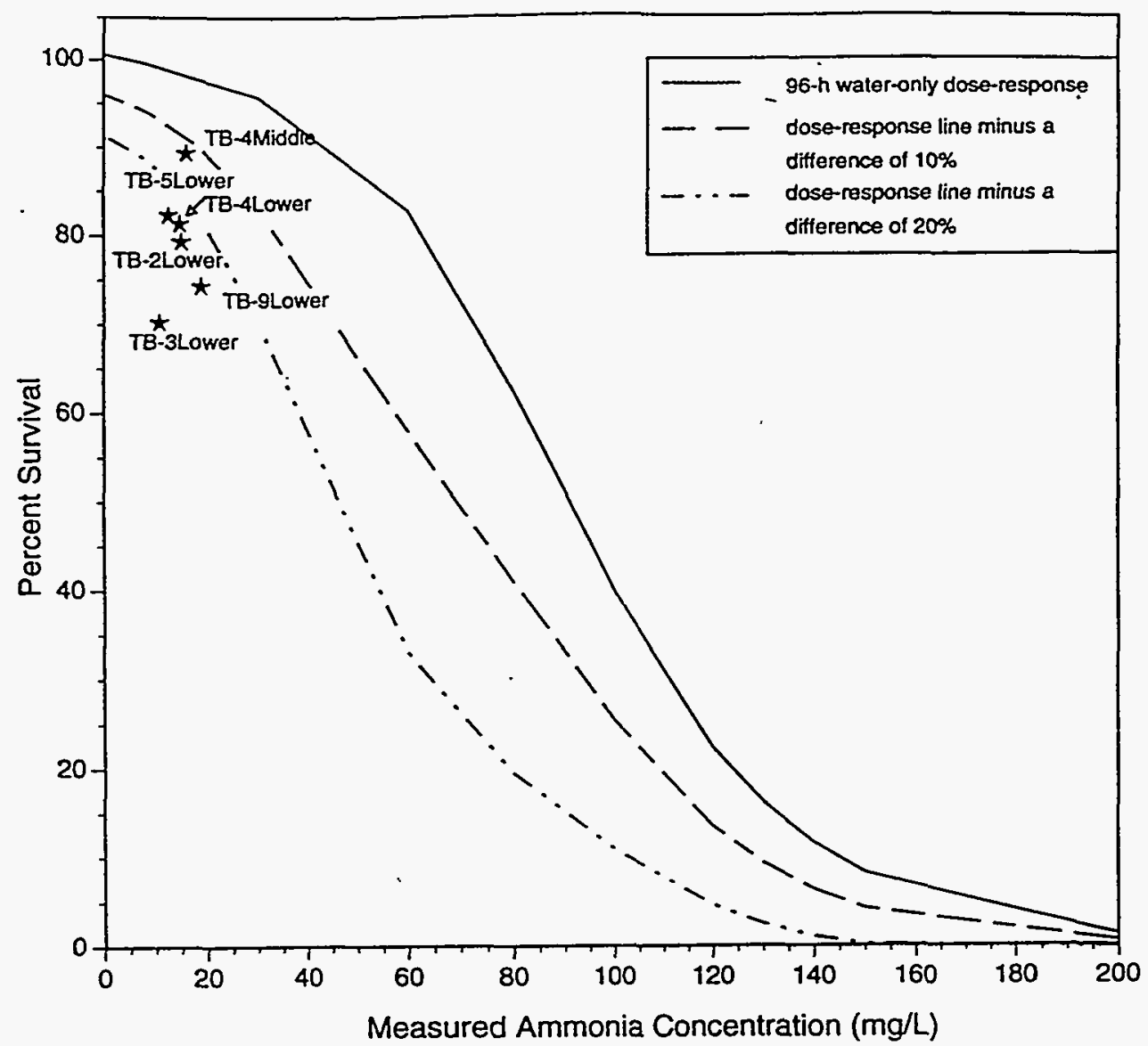

FIGURE 4.26. Response of $R$. abronius to Porewater Ammonia Concentrations in the Intensive Study of the Turning Basin Sediments from the Ammonia Reduction to $<20 \mathrm{mg} / \mathrm{L}$. Test Relative to the Ammonia Reference Toxicant Dose-Response Curve

\subsubsection{Ammonia reduction to $<15 \mathrm{mg} / \mathrm{L}$ Test with $R$. abronius}

Ammonia measurements were monitored in the overlying water and porewater of each test treatment following the same procedures previously outlined. Total ammonia in the sediment porewater ranged from $1.34 \mathrm{mg} / \mathrm{L}$ (C-WB) to $14.7 \mathrm{mg} / \mathrm{L}$ (TB-9 Lower) at test initiation and from $4.42 \mathrm{mg} / \mathrm{L}$ (TB-8 Lower) to $12.8 \mathrm{mg} / \mathrm{L}$ (TB- 9 Lower) at test termination (Table 4.8).

The sensitivity of amphipods used for the ammonia reduction to $<15 \mathrm{mg} / \mathrm{L}$ test was assessed using $\mathrm{Cd}$ and ammonia. The resultant $L_{50}$ was $0.27 \mathrm{mg} / \mathrm{L} \mathrm{Cd}$ (confidence interval = $0.14 \mathrm{mg} / \mathrm{L}$ to $0.52 \mathrm{mg} / \mathrm{L} \mathrm{Cd}$ ). This $L_{50}$ is below the range of sensitivity $(0.68 \mathrm{mg} / \mathrm{L}$ to $1.25 \mathrm{mg} / \mathrm{L}$ Cd) reported in ASTM 1990 and studies performed previously at the MSL, suggesting that this particular population could have been more sensitive to stresses such as contaminant load or temperature fluctuations compared with the batch used for the standard 10-day test and the ammonia reduction to $<20 \mathrm{mg} / \mathrm{L}$ test. Because of the acceptable survival of $R$. abronius in the native control sediment, the results of this test were used to assess the acute toxicity of $A$. abronius to Turning Basin sediments. The results of the $96-\mathrm{h}$ ammonia reference toxicant test 
TABLE 4.8. Ammonia Monitoring Summary for the 10-Day R. abronius Solid-Phase, Ammonia Reduction to $<15 \mathrm{mg} / \mathrm{L}$ Test, Richmond Harbor Deepening Project-Intensive Study of the Turning Basin

\begin{tabular}{|c|c|c|c|c|c|c|c|c|c|}
\hline \multirow{3}{*}{$\begin{array}{l}\text { Sediment } \\
\text { Treatment }\end{array}$} & \multirow{2}{*}{\multicolumn{5}{|c|}{ Overlying Water Ammonia (mg/) }} & \multirow{2}{*}{\multicolumn{2}{|c|}{$\begin{array}{c}\text { Porewater } \\
\text { Ammonia (mgl) }\end{array}$}} & \multicolumn{2}{|c|}{$\begin{array}{c}\text { Ammonia Reduction } \\
\text { to }<15 \mathrm{mg} \text {. }\end{array}$} \\
\hline & & & & & & & & \multirow{2}{*}{$\begin{array}{l}\text { Percent } \\
\text { Survival }\end{array}$} & \multirow{2}{*}{$\begin{array}{l}\text { Acute } \\
\text { Toxicity }\end{array}$} \\
\hline & Day 0 & Day 1 & Day 3 & Day 7 & Day 10 & Day 0 & Day 10 & & \\
\hline TB-3 Lower & 0.135 & 0.944 & 2.45 & 2.55 & 1.66 & 4.71 & 7.14 & 83 & NO \\
\hline TB-7 Lower & 0.189 & 3.28 & 3.27 & 4.17 & 2.13 & 7.79 & 7.75 & 75 & NO \\
\hline TB-8 Lower & 0.121 & 0.706 & 2.18 & 2.81 & 1.01 & 8.18 & 4.42 & 81 & NO \\
\hline TB-9 Lower & 0.356 & 1.76 & 4.41 & 7.43 & 6.56 & .14 .7 & 12.8 & 80 & NO \\
\hline C-WB & 0.038 & 0.133 & 0.211 & 0.124 & 0.051 & 1.34 & $N D(a)$ & 100 & NA(b) \\
\hline
\end{tabular}

(a) ND No data.

(b) NA Not applicable.

using $R$. abronius had an $L C_{50}$ of $30.9 \mathrm{mg} / \mathrm{L}$ ammonia (confidence interval $=25.9$ to $36.9 \mathrm{mg} / \mathrm{L}$ of total ammonia). This result also indicates a test population that was more sensitive than those documented in past data sets.

The ammonia reduction to $<15 \mathrm{mg} / \mathrm{L}$ test was validated by $100 \%$ survival of $R$. abronius in the native control sediment $C$-WB. Survival of $R$. abronius in the test treatments ranged from 75\% for TB-7 Lower to $83 \%$ for TB-3 Lower (Table 4.6). None of the test treatments was acutely toxic to $R$. abronius when compared with R-OS.

Figure 4.27 shows the results of the ammonia reference toxicant test conducted with the ammonia $<15 \mathrm{mg} / \mathrm{L}$ test plotted against the survival and porewater measurements for the test treatments. Again, the dose-response curve was fitted with a difference of $10 \%$ or $20 \%$ from the dose-response line. This figure shows that once the ammonia concentrations were reduced to. $<15 \mathrm{mg} / \mathrm{L}$, survival in all four test treatments increased significantly until none of the test treatments was acutely toxic compared with R-OS. 


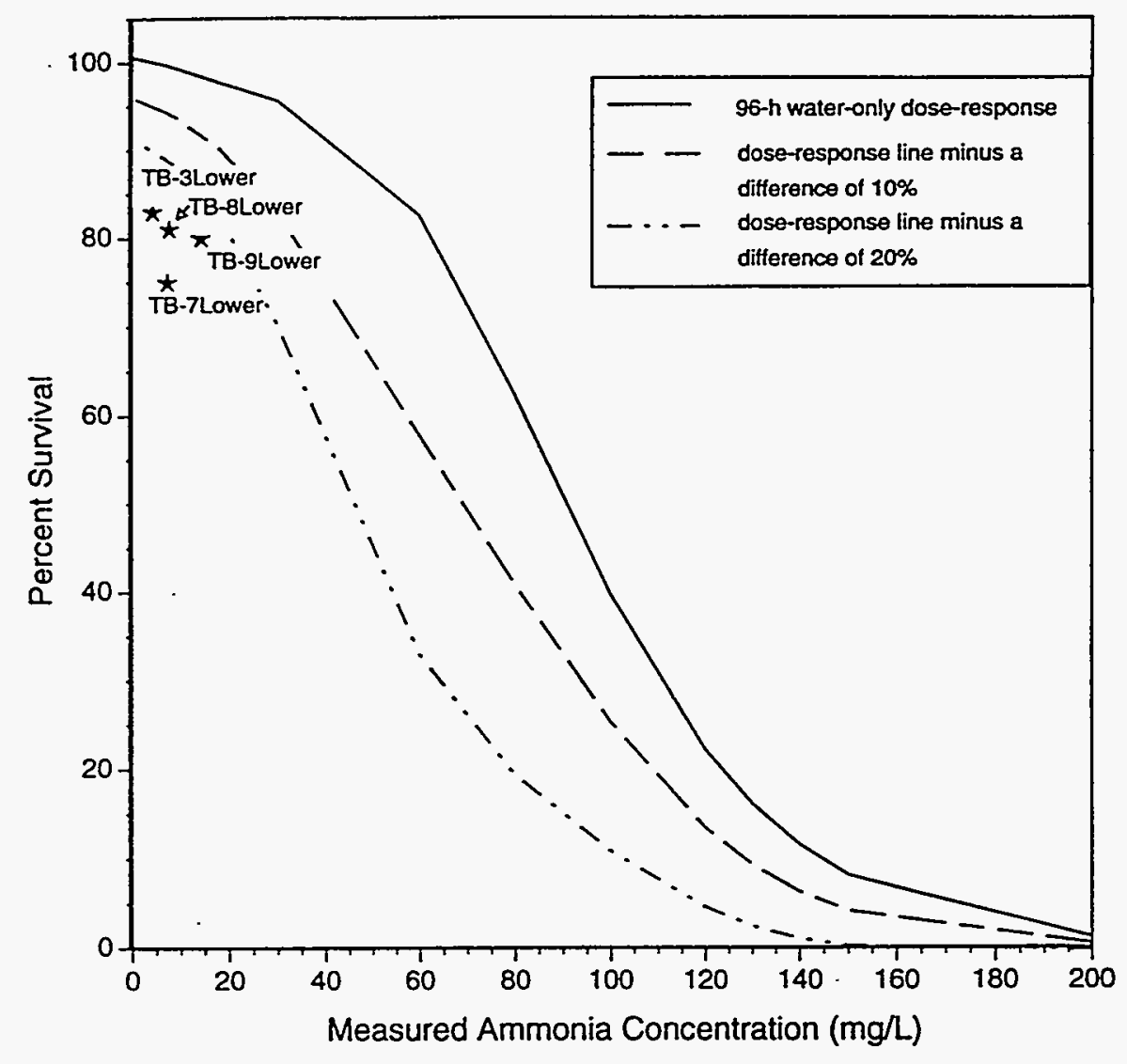

FIGURE 4.27. Response of $R$. abronius to Porewater Ammonia Concentrations in the Intensive Study of the Turning Basin Sediments from the Ammonia Reduction to $<15 \mathrm{mg} / \mathrm{L}$ Test Relative to the Ammonia Reference Toxicant Dose-Response Curve 


\subsection{DISCUSSION}

In this section, the analyses of sediments from the Richmond Harbor Program and the Intensive Study of the Turning Basin are compared with sediment from the reference station R-OS and discussed in the context of the Tier II and Tier III guidelines in the 1991 Implementation Manual. Potential water column effects of dredged material disposal are evaluated for compliance with the limiting permissible concentration (LPC) set forth under Tier II. According to the 1991 Implementation Manual, "the pumose of Tier II is to provide a reliable, rapid screen for potential impact and thereby eliminate the need for further testing." Tier III guidelines for determination of compliance with criteria for ocean disposal, defined under CFR 40, Section 227.13(c), Appendix A of the 1991 Implementation Manual, include assessments of water column toxicity, deposited sediment (solid-phase) toxicity, and deposited sediment bioaccumulation. Physical characterization and sediment chemistry analysis of Richmond Harbor and the Tuming Basin sediments are used in support of toxicity tests and bioaccumulation results to evaluate appropriate disposal options.

\subsection{SEDIMENT CHARACTERISTICS}

Mudline elevations of the 20 Richmond Harbor sampling stations ranged from $-30.4 \mathrm{ft}$ to $-41.4 \mathrm{ft}$ MLLW. Geologic evaluations of the 4-in. cores show that sediment from the Richmond Harbor Deepening Project is composed primarily of unconsolidated YBM. The homogenous finegrained nature of the Richmond Harbor sediments indicate that they were deposited in an environment with low current speed.

Physical and chemical analyses were performed on the Richmond Harbor test sediments from mudline to $-40 \mathrm{ft}$ MLLW. The reference treatment $R-O S$ had a higher percentage of TOC than was found in any test treatment. The sediments from the stations comprising SF COMP, SFW COMP, and UIH COMP generally had the highest levels of TVS, oil and grease, TPH, PAHs, and pesticides. The pesticides, 4,4'-DDD, 4,4'-DDE, 4,4'-DDT, and dieldrin, were considerably elevated in SF COMP, SFW COMP, and UIH COMPS, and the individual stations comprising these composites, over levels found in R-OS. The primary source of these pesticides is the former United Heckathorn property on the eastern shore of the Lauritzen Canal (Figure 3.1), which is now a federal Superfund site (White et al. 1994).

Mudline elevations for the Turning Basin sediments ranged from $-5.1 \mathrm{ft}$ to $-33.7 \mathrm{ft}$ MLLW and were composed of unconsolidated YBM with numerous whole or fragmented clam shells. Three stations, TB-1 Lower, TB-7 Lower, and TB-8 Lower contained segments of OBM sediment. All of the test treatments and the reference treatment R-OS were fine-grained sediments except for TB-1 Lower, which was predominantly sand. Concentrations of TOC and 
TVS in both the test and reference treatments were typical of fine-grained sediments. The reference treatment R-OS had the highest concentrations of oil and grease, TPH and PAHs of any sediment treatment except for TB-4 Middle, which had higher concentrations of both LPAHs and HPAHs. TB-4 Middle also had the highest detectable concentrations of 4,4'-DDD, 4,4-DDE, 4,4-DDT, Aroclor 1254, 8 of the 10 metals, and TBT.

\subsection{TIER III EVALUATIONS}

\subsubsection{Deposited Sediment (Solid-Phase) Acute Toxicity}

Deposited sediment toxicity was determined by exposing three species of marine organisms ( $R$. abronius, $M$. nasuta, and $N$. caecoides) to test sediment treatments in 10-day solid-phase tests. If the difference between survival in proposed dredged material (test treatments) and in the reference treatment is statistically significant and exceeds $10 \%(20 \%$ for R. abronius), then the test material does not meet the criteria for open ocean disposal as stated in Appendix A of the 1991 Implementation Manual. The Richmond Harbor test treatments UIH COMP and TB Upper COMP were not acutely toxic to any of the solid-phase test species (Table 5.1). Acute toxicity to $R$. abronius exposed to test treatment TB Lower COMP was observed when compared with those exposed to the reference sediment R-OS. The mortality of $R$. abronius in this sediment is greater than the average dose-response curve for ammonia, as shown in Figure 3.35, indicating that other contaminants or factors are potentially responsible for the sensitivity of $R$. abronius to TB Lower COMP. This composite was evaluated more extensively in the Intensive Study of the Turning Basin, and the results are reported below.

The Intensive Study of the Tuming Basin (Table 5.2) evaluated the toxicity at nine Tuming Basin locations, the OBM COMP, reference sediments, and control sediments using the standard 10-day $R$. abronius test. Sediment from station TB-1 Lower did not show a statistically significant increase in toxicity relative to reference or control sediments. Test treatments TB-4 Middle, TB-4 Lower, TB-6 Lower, and the OBM COMP were not acutely toxic to R. abronius relative to R-OS. The remaining six test treatments (TB-2 Lower, TB-3 Lower, TB-5 Lower, TB-7 Lower, TB-8 Lower, and TB-9 Lower) were acutely toxic to $R$. abronius, with survival ranging from $25 \%$ to $64 \%$.

The sediment from these six test treatments came from core sections that were buried by $5 \mathrm{ft}$ of Richmond Harbor sediment. Using these sediments could have enhanced the quantity and influence of ammonia in acute toxicity tests with $R$. abronius. Consequently, those test treatments with a porewater ammonia concentration greater than $20 \mathrm{mg} / \mathrm{L}$ of ammonia were subjected to an ammonia reduction protocol, whereas test treatments with less than $20 \mathrm{mg} / \mathrm{L}$ ammonia were not. In all cases where ammonia was reduced to $<20 \mathrm{mg} / \mathrm{L}$ prior to test initiation, 
TABLE 5.1. Comparison of Richmond Harbor Solid-Phase Acute Toxicity to that of the Deep Off-Shelf Reference R-OS (shading indicates mean survival statistically significantly lower than the reference based on Dunnett's test and $\geq 10 \%$ difference between treatment and reference and for $M$. nasuta and $N$. caecoides, $\geq 20 \%$ difference for $R$. abronius)

\begin{tabular}{lccc}
\hline $\begin{array}{l}\text { Sediment } \\
\text { Treatment }\end{array}$ & $\begin{array}{c}\text { R. abronius } \\
\text { Percent } \\
\text { Survival }\end{array}$ & $\begin{array}{c}\text { M.nasuta } \\
\text { Percent } \\
\text { Survival }\end{array}$ & $\begin{array}{c}\text { N. caecoides } \\
\text { Percent } \\
\text { Survival }\end{array}$ \\
\hline \hline R-OS & 89 & 100 & 96 \\
SF COMP & & & 79 \\
SFW COMP & 89 & 100 & 81 \\
UIH COMP & 77 & 98 & 88 \\
TB Upper COMP & 77 & 100 & 86 \\
TB Lower COMP(a) & 70 & 99 & 96 \\
OBM COMP & 50 & 98 & 38 \\
\end{tabular}

(a) Evaluation of $R$. abronius toxicity to TB Lower COMP is based on the results from the three tests performed in the Intensive Study of the Turning Basin in October 1994.

TABLE 5.2. Comparison of Richmond Harbor Solid-Phase Acute Toxicity to that of the Deep OffShelf Reference R-OS, Intensive Study of the Turning Basin (bold type indicates mean survival statistically significantly lower than the reference based on Dunnett's test and $\geq 20 \%$ difference for $R$. abronius)

\begin{tabular}{lccc}
\hline \hline \multirow{2}{*}{$\begin{array}{l}\text { Sediment } \\
\text { Treatment }\end{array}$} & $\begin{array}{c}\text { Average Percent Survival } \\
\text { static 10-day test }\end{array}$ & $\begin{array}{c}R \text {. abronius ammonia } \\
\text { reduction to <20 mg/L }\end{array}$ & $\begin{array}{c}R \text {. abronius ammonia } \\
\text { reduction to <15 mg/L }\end{array}$ \\
\hline \hline R-OS & 94 & 94 & 94 \\
TB-1 Lower & 87 & NA(a) & NA \\
TB-2 Lower & 52 & 79 & NA \\
TB-3 Lower & 25 & 70 & 83 \\
TB-4 Middle & 82 & 89 & NA \\
TB-4 Lower & 76 & 81 & NA \\
TB-5 Lower & 62 & 82 & NA \\
TB-6 Lower & 76 & NA & 75 \\
TB-7 Lower & 55 & NA & 81 \\
TB-8 Lower & 64 & NA & 80 \\
TB-9 Lower & 28 & 74 & NA \\
OBM COMP & 68 & NA & 100 \\
C-WB & 98 & & NA
\end{tabular}

(a) NA Not applicable. 
the survival of $R$. abronius increased to at least $70 \%(70 \%-89 \%)$. As a result of the ammonia reduction to $<20 \mathrm{mg} / L$ test, five test treatments were not acutely toxic to $R$. abronius and only one test treatment, TB-3 Lower, was still considered acutely toxic. Further examination of this data set plus data from other studies previously conducted at the MSL showed that a porewater ammonia concentration of $15 \mathrm{mg} / \mathrm{L}$ could be a more appropriate level to use as the ammonia NOEC. Based on this new ammonia level, an ammonia reduction to $<15 \mathrm{mg} / L$ test was performed on four test treatments, TB-3 Lower, TB-7 Lower, TB-8 Lower, and TB-9 Lower. In all cases, the survival of $R$. abronius increased above $75 \%$ and none of the test treatments was acutely toxic to $R$. abronius when compared with R-OS.

The results from the three tests, combined with numerous data sets previously established at the MSL, suggest that sediments taken from core sections below the influence of native flora and fauna have high concentrations of interstitial porewater ammonia. This could be due to the lack of nitrifying bacterial populations that convert ammonia to nitrite and ultimately to nitrate. As bacterial populations are established in the test containers (current research shows this process can take up to 38 days), the ammonia levels decrease and the effects caused by ammonia are either diminished or removed.

Test treatments SF COMP, SFW COMP, and OBM COMP were acutely toxic to $N$. caecoides relative to the reference sediment $R$-OS. Known response to ammonia indicates that $>90 \mathrm{mg} / \mathrm{L}$ of ammonia are required to produce an $L C_{50}$ value. None of the porewater levels exceeded $25 \mathrm{mg} / \mathrm{L}$; therefore, contributors other than ammonia must be present to cause the observed response. A study on the importance of food concentrations in sediments to the survival of $N$. caecoides was implemented and is reported in The Older Bay Mud Study (a).

\subsubsection{Water Column Effects}

Estimates of toxicity in the water column were also evaluated by exposing three sensitive marine species (C. stigmaeus, $H$. costata, and $M$. galloprovincialis) to three concentrations of SPP and a control ( $0 \%$ SPP). The results for $C$. stigmaeus and $H$. costata showed that none of the test treatments was statistically significantly different between the $0 \%$ and $100 \%$ SPP (Table 5.3). The percentage of $M$. galloprovincialis survival was statistically significantly different between the $0 \%$ and $100 \%$ SPP for two test treatments, SFW COMP and TB Upper COMP. None of the percent survival results for $M$. galloprovincialis was below $50 \%$; therefore, LC $_{50}$ values could not be calculated. The results for normal development with $M$. galloprovincialis showed statistically significant response to test treatments SFW COMP, UIH COMP, TB Upper COMP, and TB Lower COMP relative to the control. The $\mathrm{EC}_{50}$ values that could be calculated were as follows: $80 \%$ SPP for SFW COMP, $57.6 \%$ SPP for UIH COMP, $74.8 \%$ SPP for

(a) 1995 draft report, Pacific Northwest Laboratory, Richland, Washington. 
TABLE 5.3. Summary of Suspended-Particulate-Phase Toxicity Tests, Richmond Harbor Deepening Project (bold type indicates mean survival in 100\% SPP significantly lower than control in 2-sample T-test, $\alpha 0.05$ )

\begin{tabular}{|c|c|c|c|c|c|c|c|c|c|}
\hline \multirow[b]{3}{*}{ Treatment } & \multicolumn{3}{|c|}{ Mysid H. costata } & \multicolumn{3}{|c|}{ Bivalve $M$, galloprovincialis } & \multicolumn{3}{|c|}{ Sanddab $C$. stigmaeus } \\
\hline & \multicolumn{2}{|c|}{ Mesan Survival (\%) } & \multirow{2}{*}{$\begin{array}{r}\mathrm{LC}_{50} \text { as } \\
\% \text { SPP }\end{array}$} & \multicolumn{2}{|c|}{ Mean Normal D $(\%)$} & \multirow{2}{*}{$\begin{array}{r}E C_{50} \text { as } \\
\% \text { SPP }\end{array}$} & \multirow{2}{*}{\multicolumn{2}{|c|}{$\begin{array}{l}\text { Mean Survival (\%) } \\
0 \% \text { SPP } 100 \% \text { SPP }\end{array}$}} & \multirow{2}{*}{$\begin{array}{l}\mathrm{LC}_{50} \text { as } \\
\% \text { SPP }\end{array}$} \\
\hline & $0 \% \mathrm{SPP}$ & $100 \%$ SPP & & $0 \%$ SPP & $100 \%$ SPP & & & & \\
\hline SF COMP & 94 & 86 & $>100$ & 94 & 96 & $>100$ & 100 & 100 & $>100$ \\
\hline SFW COMP & 98 & 88 & $>100$ & 91 & 26 & 80.0 & 98 & 100 & $>100$ \\
\hline UIH COMP & 100 & 90 & $>100$ & 90 & $\mathbf{0}$ & 57.6 & $\cdot 98$ & 98 & $>100$ \\
\hline TB Upper COMP & 96 & 96 & $>100$ & 96 & 17 & 74.8 & 100 & 100 & $>100$ \\
\hline TB Lower COMP & 98 & 94 & $>100$ & 82 & $\mathbf{0}$ & 69.7 & 98 & 100 & $>100$ \\
\hline OBM COMP & 98 & 96 & $>100$ & 98 & 96 & $>100$ & 100 & 100 & $>100$ \\
\hline
\end{tabular}

TB Upper COMP, and 69.7\% SPP for TB Lower COMP. Normal development could have been affected by ammonia released from the sediment into the SPP of the SFW COMP, UIH COMP, and the TB Lower COMP (Figure 3.36). The $\mathrm{EC}_{50}$ values for these composites are within the range of expected effects caused by ammonia. This is not the case for TB Lower COMP; the response exceeds the $95 \%$ confidence interval for ammonia, suggesting that additional contaminants or factors combined with ammonia could be responsible for the lower percentage of development to normal larvae in the $100 \%$ SPP of this composite.

Under 1991 Implementation Manual guidelines, LPC of dissolved plus suspended contaminants cannot exceed 0.01 of the acutely toxic concentration $\left(L C_{50}\right)$ at the boundaries of the disposal site, after allowing $4 \mathrm{~h}$ for initial mixing. However, the LPC values cannot be obtained using $L C_{50}$ values, since none could be calculated.

In the bivalve test, the percentage of larvae normality is probably more indicative of the test treatment toxicity than the percentage of survival because only normal developed larvae at $48 \mathrm{~h}$ are likely to survive to adulthood. Therefore, the most environmentally protective approach would be to base the LPC on the $\mathrm{EC}_{50}$ results for $M$. galloprovincialis larvae. As with the LPC calculations using $L C_{50}$ values, the $E_{50}$ for $M$. galloprovincialis lanval abnormality requires application of the Addams model (Schroeder and Palermo 1990) to predict contaminant concentrations at the edge of the mixing zone. The concentration of SPP for the Richmond Harbor test sediments at the edge of the mixing zone would have to be less than $0.57 \%$ to meet the requirements in the 1991 Implementation Manual.

\subsubsection{Deposited Sediment Bioaccumulation}

The potential for bioaccumulation of contaminants was evaluated through 28-day solidphase exposures of $M$. nasuta and $N$. virens to Richmond Harbor sediments, followed by chemical analysis of the tissues. The tissue contaminant concentrations were compared with 
existing FDA limits and were statistically compared with the tissues exposed to the reference sediment R-OS. Compliance criteria for bioaccumulation are not as well-defined as for water column or deposited sediment toxicity. If any statistically significant bioaccumulation is detected, then other considerations are examined, such as the number of elevated compounds, the number of species showing elevated contaminant levels, the magnitude of increase in contaminant concentrations, the degree or magnitude of the elevations relative to tissues exposed to reference sediment, and related sediment toxicity.

M. nasuta and $N$. virens tissue contaminant concentrations were one to five orders of magnitude below the FDA action levels for fish and shellfish after exposure to Richmond Harbor sediments (Table 5.4). There were, however, tissue contaminant concentrations in the test treatments that were statistically significantly elevated when compared with concentrations in the tissues exposed to the reference treatment R-OS. Table 5.5 is a summary of this comparison.

Nine HPAHs, up to three pesticides (4,4'-DDD, 4,4'-DDE, and dieldrin), and one metal, $(\mathrm{Pb})$ showed statistically significant bioaccumulation in $M$. nasuta tissues exposed to SF COMP, SFW COMP, UIH COMP, and TB Upper COMP relative to bioaccumulation in tissues exposed to R-OS. In all cases, the pesticides found in tissues exposed to SF COMP, SFW COMP and UIH COMP were elevated at levels greater than 10 times (from 20 to 259 times) those found in $M$. nasuta tissues exposed to reference treatment R-OS. Three test treatments, SF COMP, SFW COMP, and UIH COMP, had HPAH concentrations that were elevated at levels greater than 10 times (from 13 to 68 times) levels found in the tissues exposed to R-OS. Elevated levels of PAHs in tissues of $M$. nasuta exposed to the TB Lower COMP were always less than two times the concentration in tissues exposed to the reference site R-OS.

The bioaccumulation results for test-treated $N$. virens tissues are similar to those for M. nasuta for the following compounds, relative to those found in tissues exposed to R-OS: the HPAHs and four pesticides (4,4'-DDT, 4,4'-DDD, 4,4'-DDE and dieldrin or aldrin) were the most prevalent contaminants in $N$. virens tissues exposed to SF COMP, SFW COMP, and UIH COMP. In tests using these composites, 4,4'-DDD and benzo(b)fluoranthene were elevated in $N$. virens tissues at a level or at levels greater than 10 times (from 10 to 111 times) higher than in $N$. virens tissues exposed to R-OS.

\subsection{CONCLUSIONS}

Sediment chemistry, acute toxicity and bioaccumulation data for each Richmond Harbor test treatment and Tuming Basin test treatment are summarized in the following paragraphs. Test sediments from Richmond Harbor was evaluated based on four criteria where applicable: 
IABLE 5.4. Comparison of FDA Action Levels With Contaminant Levels in M. nasuta and N. virens Exposed to Richmond Harbor Sediments

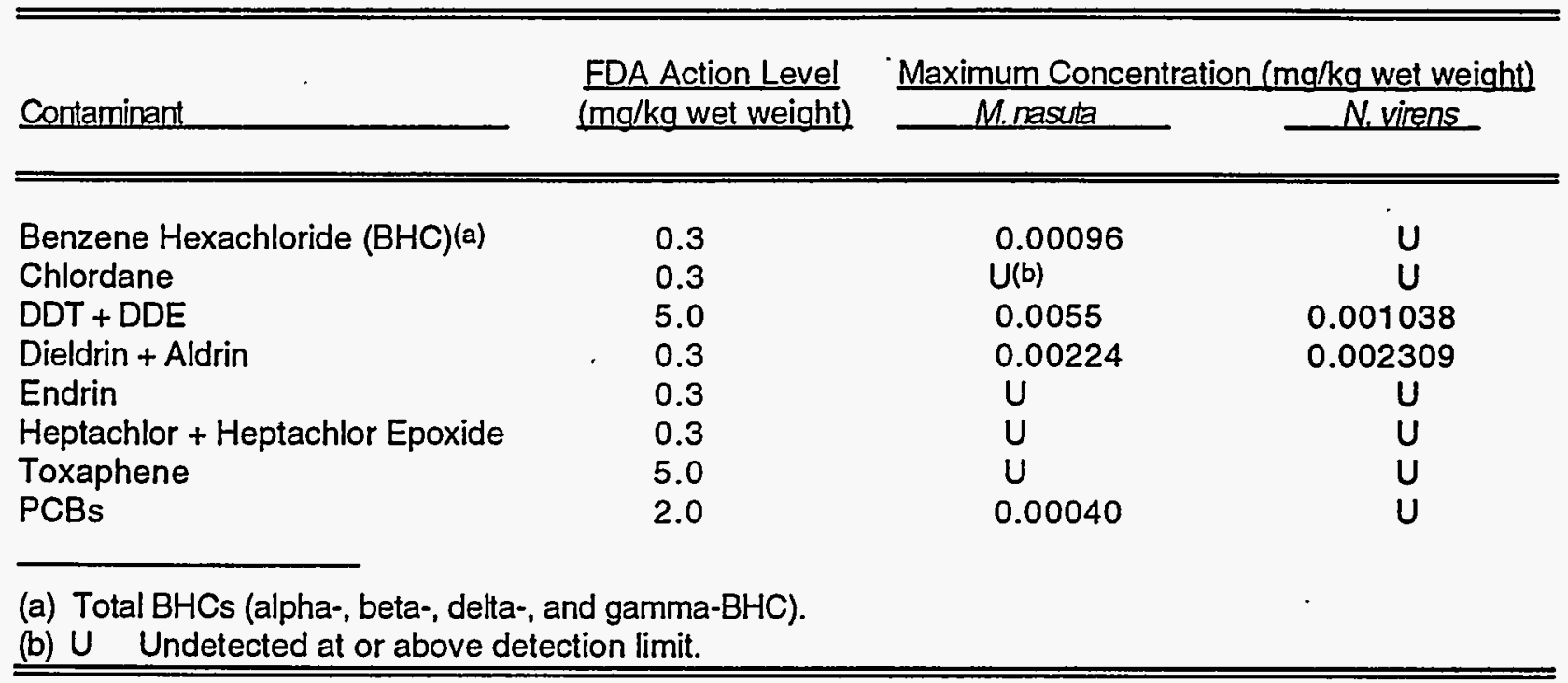

1) concentrations and magnifications of contaminants in the test sediment treatments relative to the reference sediment; 2) calculable $L_{50}$ or $E_{50}$ values for organisms exposed to dissolved and suspended material in the water column relative to a control ( $0 \%$ SPP); 3) solid-phase acute toxicity of the test treatments compared with the reference sediment; and 4) 'concentrations and magnifications of contaminants in the tissues of both $M$. nasuta and $N$. virens exposed to the test treatments relative to those in tissues exposed to the reference sediment. The matrix in Figure 5.1 presents the results of these evaluations.

Figure 5.1 also shows the acute toxicity of the test treatments relative to that of reference sediment R-OS, the number of contaminants in $M$. nasuta and $N$. virens that were elevated above levels found in the reference sediment $R-O S$, and the range of magnitudes (2-, 5- 10-times R-OS) of contaminant accumulation, and cases in which similar classes of contaminants were accumulated for both species. The following paragraphs present an overview of the results for each test treatment relative to the reference sediment R-OS to assist the USACE, EPA, and other resource agencies in evaluating suitable disposal options for the Richmond Harbor sediments.

SF COMP is located in the center of Santa Fe Channel and represents approximately 23,000 cubic yards of dredged material. Mudline depths range from $-35.9 \mathrm{ft}$ MLLW to $-38.5 \mathrm{ft}$ MLLW. Sediment from this composite are predominantly silt and clay with lower concentrations of TOC, TVS, oil and grease, and TPH than in the R-OS sediments. The detectable concentrations of PAHs, pesticides, PCBs, metals, and butyltins were higher in 


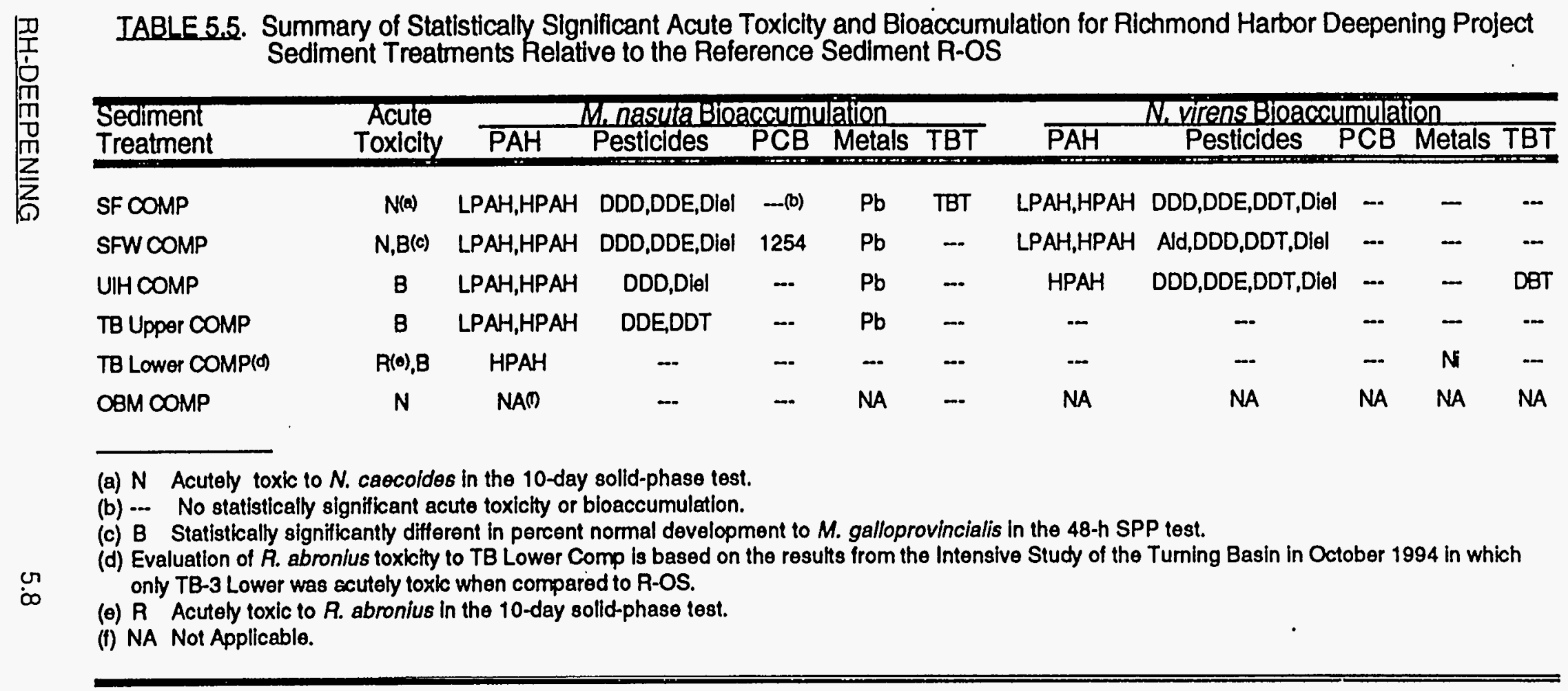




\begin{tabular}{|c|c|c|c|c|c|c|c|}
\hline 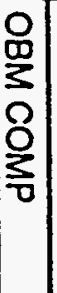 & 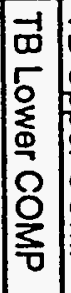 & 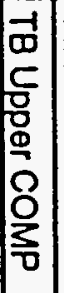 & & & & 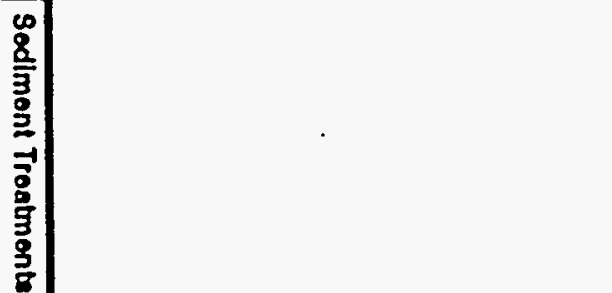 & \\
\hline & & $<$ & $<1$ & $<1$ & $<$ & sediment LPAH > R-OS & \multirow{5}{*}{ 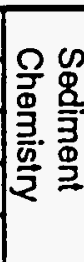 } \\
\hline & $<1$ & $<$ & $<$ & $<1$ & $<$ & sodiment HPAH > R-OS & \\
\hline & $\rightarrow$ & $\omega$ & or & on & or & \# of sediment Pesticide and PCB > R-OS & \\
\hline \multirow[t]{3}{*}{$\frac{2}{2}$} & $\infty$ & $\infty$ & $\infty$ & $\infty$ & $\infty$ & $\#$ of sediment Metals > R-OS & \\
\hline & & -1 & $N$ & N & $n$ & \# of sediment Butyitins > R-OS & \\
\hline & $\infty$ & $\boldsymbol{\omega}$ & $\infty$ & $\Phi$ & & species associated with SPP toxicity & \multirow{2}{*}{$\begin{array}{l}\vec{a} \\
\text { z. } \\
\text { a. }\end{array}$} \\
\hline$z$ & 7 & & & 7 & $z$ & species with solid-phase acute toxicity & \\
\hline$\sum$ & & & & & - & \# of LPAH compounds (6 possible) & \multirow{6}{*}{ 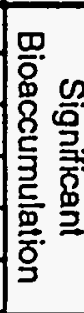 } \\
\hline \multirow[t]{3}{*}{$z$} & & & & & & \# of HPAH compounds (10 possible) & \\
\hline & & & & & 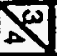 & \# of Pesticide compounds (19 possible) & \\
\hline & & & & & & \# of PCB compounds (4 possible) & \\
\hline \multirow[t]{20}{*}{$\bar{z}$} & & & & & & \# of Metals compounds (10 possible) & \\
\hline & & & & & & \# of Butyltin compounds (3 possible) & \\
\hline & & & & & & \# of LPAH compounds (6 possible) & \multirow{6}{*}{ 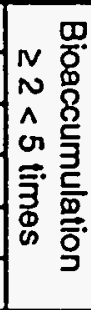 } \\
\hline & & & & & & \# of HPAH compounds (10 possible) & \\
\hline & & & & & & \# of Pesticide compounds (19 possible) & \\
\hline & & & & & & \# of PCB compounds (4 possible) & \\
\hline & & & & & & \# of Metals compounds (10 possible) & \\
\hline & & & & & & \# of Butyltin compounds (3 possible) & \\
\hline & & & & & & \# of LPAH compounds (6 possible) & \multirow{6}{*}{ 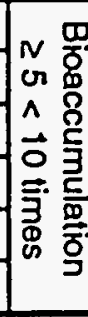 } \\
\hline & & $<$ & $x^{N}$ & & & \# of HPAH compounds (10 possible) & \\
\hline & & & & & & \# of Pesticide compounds (19 possible) & \\
\hline & & & & & & \# of PCB compounds (4 possible) & \\
\hline & & & & & & \# of Metals compounds (10 possible) & \\
\hline & & & & & & \# of Butyltin compounds (3 possible) & \\
\hline & & & & & & \# of LPAH compounds (6 possible) & \multirow{6}{*}{ 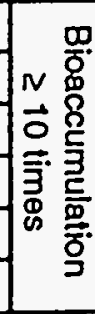 } \\
\hline & & & & & & \# of HPAH compounds (10 possible) & \\
\hline & & & & & & \# of Pesticide compounds (19 possible) & \\
\hline & & & & & & \# of PCB compounds (4 possible) & \\
\hline & & & & & & \# of Metals compounds (10 possible) & \\
\hline & & & & & & \# of Butytin compounds ( 3 possible) & \\
\hline
\end{tabular}


sediments from this composite than from the reference treatment R-OS. SF COMP was acutely toxic to $N$. caecoides. Bioaccumulation of nine HPAHs and four pesticides occurred in the tissues of $M$. nasuta and $N$. virens relative to that found in tissues exposed to R-OS. In most cases, the elevations of pesticides in tissues of both test-treated species was greater than 10 times (from 16 to 233 times) higher than in tissues exposed to R-OS sediments. Metals and butyltins concentrations were also statistically significantly higher in $M$. nasuta tissues exposed to test sediment.

Test treatment SFW COMP is located in the berthing area for National Gypsum and GATX and represents approximately 19,000 cubic yards of dredged material. Mudlines in this area range from $-28 \mathrm{ft} \mathrm{MLLW} \mathrm{to}-34.1 \mathrm{ft}$ MLLW. The grain size fractionation in this composite is similar to that in the reference sediment R.OS, with similar contributions to the sand (23\%), silt $(37 \%)$, and clay $(35 \%)$ categories. Concentrations of TOC and TVS were lower than in the reference R-OS. The oil and grease, TPH, total PAH, detectable pesticides (except for $4,4^{\prime}-\mathrm{DDT}$ ), and Aroclor concentrations were higher in this composite than in any of the other test treatments or in the reference treatment. This composite also had higher concentrations of nine metals and butyltins relative to the reference sediment, R-OS. Sediment from SFW COMP was acutely toxic to $N$. caecoides in the 10-day solid-phase test. The SPP test with M. galloprovincialis was statistically significantly different in percentage of nomal development to a D-cell stage relative to the results in $0 \%$ SPP. The $\mathrm{EC}_{50}$ for this composite was $80 \%$ SPP. Normal development could have been affected by ammonia released from sediment into SPP (Section 3.4.7, Figure 3.36). The $\mathrm{EC}_{50}$ falls within the dose-response curve generated from M. galloprovincialis, suggesting that ammonia could be responsible for the reduction in the number of larvae that developed nomally to the D-cell stage. Bioaccumulation of at least nine of the PAHs and three pesticides (4,4'-DDD, 4,4'-DDE and dieldrin) were statistically significantly elevated in both the $M$. nasuta and $N$. virens tissues exposed to sediment from SFW COMP relative to levels found in the tissues exposed to R-OS. In many cases, the bioaccumulation of PAHs and pesticides in the tissues of M. nasuta (11 PAHs and 3 pesticides) or $N$. virens (2 PAHs and 4 pesticides) exposed to this composite were found at levels at least five times greater than in tissues exposed to R-OS. Eight of the PAHs that bioaccumulated in M. nasuta tissues were also elevated at greater than 10 times the concentrations found in the $M$. nasuta tissues exposed to R-OS.

The UIH COMP is located in the Upper Inner Harbor Channel and represents approximately 60,000 cubic yards of dredged material. Mudlines in this channel range from $-34.4 \mathrm{ft}$ MLLW to $-37.3 \mathrm{ft}$ MLLW. Sediments from this composite are a fine-grained silt-clay mixture. Percentages of TOC and TVS in this composite are similar to those in reference sediment R-OS. The oil and grease, TPH, total PAH, detectable pesticides and PCBs, 9 of the 10 metals, and butyltins were higher in this sediment relative to what was found in sediment from 
R-OS. Acute toxicity was observed in the percentage of normal development of the M. galloprovincialis. An $\mathrm{EC}_{50}$ of $57.6 \%$ SPP was calculated for this composite. Again, ammonia could be the cause of the reduction in percentage of normally developed larvae to the D-cell stage (Figure 3.36). At least two HPAHs (benzo[b and k]fluoranthenes), and two pesticides (4,4'-DDD and dieldrin) were statistically significantly elevated in both $M$. nasuta and $N$. virens tissues exposed to sediments from this composite relative to concentration in tissues exposed to R-OS. Seven other HPAHs were also elevated in M. nasuta tissues exposed to this composite relative to those in $M$. nasuta tissues exposed to R-OS.

The TB Upper COMP is located in the Turning Basin, which sits at the entrance to the Inner Harbor and Santa Fe Channels. The Turning Basin represents 500,000 cubic yards of sediment. The sediments from this composite are predominantly fine-grained silts and clays. Percentages of TOC and TVS are similar in this composite to the reference sediment R-OS. Oil and grease, total PAHs, six metals, and TBT were higher in sediments from TB Upper COMP than in sediments from R-OS. The percentage of normally developed $M$. galloprovincialis larvae exposed to the $100 \%$ SPP of this composite was statistically significantly different from that of normally developed larvae exposed to the 0\% SPP. An EC 50 of $74.8 \%$ SPP was calculated for this composite. Normal development of M. galloprovincialis larvae of this composite falls below the $95 \%$ confidence limit, suggesting that ammonia cannot fully account for this affect. Bioaccumulation of nine HPAHs and two pesticides (4,4'-DDT and 4,4'-DDE) occurred in $M$. nasuta tissues exposed to this composite relative to $M$. nasuta tissues exposed to the sediment from R-OS.

Test treatment TB Lower COMP is composed of seven stations from $5 \mathrm{ft}$ below the mudline to $-40 \mathrm{ft} \mathrm{MLLW.} \mathrm{Sediments} \mathrm{are} \mathrm{predominantly} \mathrm{fine-grained} \mathrm{silts} \mathrm{and} \mathrm{clays} \mathrm{with} \mathrm{lower}$ concentfations of TOC, TVS, and oil and grease than are found in sediments from R-OS. The concentrations of HPAHs and six metals were higher in this sediment composite than sediment from R-OS. TB Lower COMP was acutely toxic to $R$. abronius. Since the observed toxicity appeared to be related to ammonia, additional testing during the Intensive Study of the Tuming Basin was performed to verify this relationship. The results from the additional testing are described below. There was a statistically significant difference between the $0 \%$ and $100 \%$ SPP of this composite in the percentage of $M$. galloprovincialis that reached the normal D-cell stage. An $E_{50}$ of $69.7 \%$ SPP was calculated for TB Lower COMP. This EC $\mathrm{E}_{50}$ provides an ammonia concentration that falls within the ammonia dose-response curve generated for $M$. galloprovincialis (Figure 3.36), suggesting that the reduced normal development of larvae exposed to the SPP from this composite may be largely due to ammonia. The elevations of three HPAHs in M. nasuta exposed to TB Lower COMP was statistically significant but $\leq 2$ times the concentrations found in $M$. nasuta tissues exposed to R-OS. Of the contaminants measured in $N$. virens tissues 
exposed to TB Lower COMP, only Ni showed any elevation that was statistically significant, but less than two times the level in tissues exposed to R-OS.

The TB Lower COMP was split into 10 individual stations during the Intensive Study of the Turning Basin. These stations were tested independent of the composite to provide more definitive data for the evaluation of the suitability of Turning Basin sediments. The results of each Turning Basin station are presented below.

The depth of the core tested for the TB-1 Lower station ranged from $-35.6 \mathrm{ft}$ to $-40 \mathrm{ft}$ MLLW. Sediment from this station was primarily sand with overall lower concentrations of contaminants of interest relative to the other stations and the reference sediment R-OS. The results of the standard 10-day $R$. abronius test showed that TB-1 Lower sediments were not acutely toxic to $R$. abronius relative to R-OS.

TB-2 Lower sediments were tested between $-11.5 \mathrm{ft}$ to $-40 \mathrm{ft} \mathrm{MLLW.} \mathrm{The} \mathrm{sediments} \mathrm{from}$ this station were fine-grained and had lower concentrations of the conventional and organic parameters and five metals relative to R-OS. TB-2 Lower was tested in both the standard 10-day test and the ammonia reduction to $<20 \mathrm{mg} / \mathrm{L}$ test. . The results showed that TB-2 Lower was acutely toxic for the standard test but was not acutely toxic for the ammonia reduction to $<20 \mathrm{mg} / \mathrm{L}$ test when compared to R-OS.

The depths of the core tested for station TB-3 Lower ranged from $-10.1 \mathrm{ft}$ to $-40 \mathrm{ft} \mathrm{MLLW.}$ TB-3 Lower sediments were fine-grained with lower concentrations of detectable conventional, organic, six metals, and butyltin parameters relative to sediment from R-OS. The sediment from TB-3 Lower was tested during all three $R$. abronius tests with the following results: acutely toxic to $R$. abronius for both the standard 10-day test and the ammonia reduction to $<20 \mathrm{mg} / \mathrm{L}$ test; not acutely toxic to $R$. abronius for the ammonia reduction to $<15 \mathrm{mg} / \mathrm{L}$ test.

TB-4 Middle was tested using sediment ranging from -33.4 to $-38.8 \mathrm{ft}$ MLLW. Sediments from this station were fine-grained and had the highest concentrations of PAHs, some pesticides; PCBs, eight metals, and butyltins relative to any sediment treatment including the reference R-OS. The station TB-4 Middle was tested during the standard 10-day test and the ammonia reduction to $<20 \mathrm{mg} / \mathrm{L}$ test and was not acutely toxic to $R$. abronius in either test relative to R-OS.

The testing depths for TB-4 Lower ranged from -38.8 to $-40 \mathrm{ft}$ MLLW. The sediments from this station were fine-grained and had lower concentrations of oil and grease, TPH, organics, six metals, and tributyltin when compared to sediment from R-OS. The $R$. abronius results for the standard test and the ammonia reduction to $<20 \mathrm{mg} / \mathrm{L}$ test showed that TB-4 Lower was not acutely toxic when compared with R-OS.

TB-5 Lower sediments used for testing ranged from -12.3 to $-40 \mathrm{ft}$ MLLW. This sediment was also fine-grained and had lower concentrations of organics, five metals, and tributyltin when

\author{
RH-DEEPENING $\quad 5.12$
}


compared with sediment from R-OS. Sediments from TB-5 Lower had the highest concentrations of oil and grease and TPH when compared with the other test treatments. The results of the $R$. abronius test showed that TB-5 Lower was acutely toxic to $R$. abronius during the standard 10-day test but not acutely toxic to $R$. abronius during the ammonia reduction to $<20 \mathrm{mg} / \mathrm{L}$ test.

The depth of the core tested for the TB- 6 Lower station ranged from $-38.7 \mathrm{ft}$ to $-40 \mathrm{ft}$ MLLW. Sediment from this station was primarily fine-grained with higher concentrations of aldrin, $\mathrm{As}, \mathrm{Cu}, \mathrm{Ni}, \mathrm{Pb}$, and $\mathrm{Zn}$ than the reference sediment $\mathrm{R}-\mathrm{OS}$. The station TB-6 Lower was tested during the standard 10-day test and was not acutely toxic to $R$. abronius relative to R-OS.

The sediments used for testing station TB-7 ranged from -15.3 to $-40 \mathrm{ft}$ MLLW. TB-7 Lower was fine-grained and had higher concentrations of aldrin and six metals when compared with sediment from R-OS. Sediment from TB-7 Lower was acutely toxic to $R$ abronius for the standard test but not acutely toxic to $R$. abronius for the ammonia reduction to $<15 \mathrm{mg} / \mathrm{L}$ test.

Station TB-8 was tested from depths ranging from -12.5 to $-40 \mathrm{ft}$ MLLW. TB-8 Lower sediments were fine-grained and had higher concentrations of oil and grease and five metals relative to R-OS. Sediments from TB-8 Lower were acutely toxic to $R$. abronius for the standard test but not acutely toxic to $R$. abronius for the ammonia reduction to $<15 \mathrm{mg} / \mathrm{L}$ test.

The depth of the core tested for the TB-9 Lower station ranged from - 36.3 to $-40 \mathrm{ft} \mathrm{MLLW.}$ Sediments from this station were fine-grained and had higher concentrations of oil and grease and five metals relative to the reference sediment R-OS. Sediments from TB-9 Lower were tested during all three $R$. abronius tests and the results of the comparison with R-OS provided the following results: acutely toxic to $R$. abronius during the standard 10-day test but not acutely toxic to $R$. abronius for either the ammonia reduction to $<20 \mathrm{mg} / \mathrm{L}$ test or the ammonia reduction $<15 \mathrm{mg} / \mathrm{L}$ test.

The OBM COMP was created using samples taken from the $-40 \mathrm{ft}$ to $-42 \mathrm{ft}$ MLLW sections of any field cores that contained OBM. The sediment from this composite was analyzed for PAHs, pesticides, and butyltins. None of these contaminants was elevated in the OBM sediment over levels found in sediment from R-OS. Sediments from OBM were acutely toxic to N. caecoides in a 10-day test. Pesticides, PCBs, and butyltins were examined in M. nasuta tissues. None of these parameters was elevated in $M$. nasuta tissues exposed to OBM COMP relative to levels found in tissues exposed to sediment from R-OS.

The OBM COMP sediments were further evaluated during the Intensive Study of the Tuming Basin. The sediment results from that study confirmed those reported in January 1994 that none of the contaminants of interest were above levels reported in the reference sediment 
R-OS. The acute toxicity of OBM sediments to $N$. caecoides was included in a more definitive study called The Older Bay Mud Study (Pinza et al. 1995) published in a separate report. 


\subsection{REFERENCES}

40 CFR 227. 1977. U.S. Environmental Protection Agency (EPA), "Criteria for the Evaluation of Permit Applications for Ocean Dumping of Materials." U.S. Code of Federal Regulations.

ASTM (American Society for Testing and Materials). 1972. Determination of Soil Constants and Standard Method for Particle-Size Analysis of Soils (16 fractions). Method D-422. American Society for Testing and Materials, Philadelphia, Pennsylvania.

ASTM (American Society for Testing and Materials). 1984. Standard Practice for Description and Identification of Soils. D2488-84, American Society for Testing and Materials, Philadelphia, Pennsylvania.

ASTM (American Society for Testing and Materials). 1985. Standard Method for Wet Preparation of Soil Samples for Particle-Size Analysis. Method D-2217. American Society for Testing and Materials, Philadelphia, Pennsylvania.

ASTM (American Society for Testing and Materials). 1990. Standard Guide for Conducting 10-day Static Sediment Toxicity Tests with Marine and Estuarine Amphipods. E 1367-90. American Society for Testing and Materials, Philadelphia, Pennsylvania.

Bloom, N.S., and E.A. Crecelius. 1983. "Determination of Mercury in Seawater at Sub-Nanogram per Liter Levels." Marine Chemistry 21:337-390.

Brown, B.N., N.P. Kohn, J.A. Ward, and B.N. Bjornstad. 1990. Environmental Evaluations for Deepening of Richmond Harbor and Santa Fe Channels. PNL-7614, Pacific Northwest Laboratory, Richland, Washington.

Dinnel, P., Q. Stober, J. Link, M. Letourneau, W. Roberts, S. Felton, and R. Nakatani. 1983. Methodology and Validation of a Sperm Cell Toxicity Test for Testing Toxic Substances in Marine Waters. Final Report FRLI-UW-8306, Fisheries Research Institute, University of Washington, Seattle, Washington.

Dunnett, C.W. 1964. "New Tables for Multiple Comparisons with a Control." Biometrics 20:482-491.

EPA (U.S. Environmental Protection Agency). 1979. Methods for Chemical Analysis of Water and Wastes. EPA-600 4-79-020 Methods 160.4, 413.2, 418.1, Environmental Monitoring and Support Laboratory, Cincinnati, Ohio.

EPA (U.S. Environmental Protection Agency). 1985. Ambient Water Quality Criteria for Copper, 1984. EPA 440/5-84-031. January 1985. Office of Water Regulations and Standards, Criteria and Standards Division, Washington, D.C.

EPA (U.S. Environmental Protection Agency). 1986a. Determination of Total Organic Carbon in Sediment. Environmental Protection Agency Region 11, Environmental Services Division, Monitoring Management Branch, Edison, New Jersey.

EPA (U.S. Environmental Protection Agency). 1986b. Test Methods for Evaluating Solid Waste: Physical/Chemical Methods. SW-846. EPA-955-001-00000, U.S. Government Printing Office, Washington, D.C.

EPA (U.S. Environmental Protection Agency). 1991. Methods for the Determination of Metals in Environmental Samples. EPA-600/4-91-010 Methods 200.8, 200.9, Environmental Services Division, Monitoring Management Branch, Cincinnati, Ohio. 
EPA (U.S. Environmental Protection Agency). 1994. Methods for Assessing the Toxicity of Sediment-Associated Contaminants with Estuarine and Marine Amphipods. EPA 600/R-94/025. U.S. Environmental Protection Agency, Office of Research and Development, Washington, D.C.

EPAUSACE (U.S. Environmental Protection Agency/U.S. Army Corps of Engineers). 1991. Evaluation of Dredged Material Proposed for Ocean Disposal (Testing Manual).

EPA-68-C8-0105, U.S. Environmental Protection Agency, Office of Marine and Estuarine Protection, Washington, D.C.

EPAUSACE (U. S. Environmental Protection Agency/U. S. Army Corps of Engineers) . 1993. "Technical Panel Recommendations Conceming Use of Acute Amphipod Tests in Evaluation of Dredged Material." Memorandum addressed to EPA Regional Ocean Dumping Coordinators, EPA Regional Wetlands Coordinators, and U.S. Corps of Engineers Regulatory and Civil Works Elements: U.S. Environmental Protection Agency, Office of Water, Washington, D.C.

Finney, D.J. 1971. Probit Analysis. 3rd Ed. Cambridge University Press, Boston, Massachusetts.

Goldman, H.B. 1969. "Geology of San Francisco Bay." In Geologic and Engineering Aspects of San Francisco Bay Fill, Report 97, pp. 9-30. California Division of Mines and Geology, San Francisco, Califomia.

Helley, E.J., and K.R. Lajoie. 1979. Flatland Deposits - Their Geology and Engineering Properties and Their Importance to Comprehensive Planning. U.S. Geological Survey Professional Paper 943, Washington, D.C.

Krahn, M.M., C.A. Wigren, R.W. Pearce, L.K. Moore., R.G. Bogar, W.D. MacLeod, Jr., S.L. Chan, and D.W. Brown. 1988. "New HPLC Cleanup and Revised Extraction Procedures for Organic Contaminants." NOAA Technical Memorandum NMFS f/NWC-153. NOAANNMFS/NWFSC, Seattle, Washington.

PSEP (Puget Sound Estuary Program). 1986. Recommended Protocols for Measuring Selected Environmental Variables in Puget Sound. Vols. 1 and 2. Prepared by Tetra Tech, Inc. for the Puget Sound Estuary Program, Bellevue, Washington.

Pinza, M.R., J.A. Ward, H.L. Mayhew, J.Q. Word, D.K. Niyogi, and N.P. Kohn. 1992. Ecological Evaluation of Proposed Dredged Material from Richmond Harbor. PNL-8389, Pacific Northwest Laboratory, Richland, Washington.

Plumb, R. H. 1981. Procedures for Handling and Chemical Analysis of Sediment and Water Samples. U.S. Army Engineer Waterways Experiment Station, Vicksburg, Mississippi.

Schroeder, P.R., and M.R. Palermo. 1990. Automated Dredging and Disposal Alternatives Management System, User's Guide. Technical Note EEDP-06-12, U.S. Army Engineer Waterways Experiment Station, Vicksburg, Mississippi.

Unger, M.A., W.G. Maclntyre, J. Greaves, and R.J. Huggett. 1986. "GC Determination of Butyltins in Natural Waters by Flame Photometric Detection of Hexyl Derivatives with Mass Spectrometric Confimation." Chemosphere 15(4):461-470.

White, P.J., N.P. Kohn, W.W. Gardiner, and J.Q. Word. 1994. The Remedial Investigation of Marine Sediment at the United Heckathom Superfund Site. PNL-9383, Pacific Northwest Laboratory, Richland, Washington. 
APPENDIX A

MATERIALS AND METHODS USED FOB IHE DESCRIPTION OF SEDIMENT CORES 


\section{APPENDIX A}

\section{MATERIALS AND METHODS USED FOR \\ IHE DESCRIPTION OF SEDIMENT CORES}

\section{A.1 MATERIALS}

The following is a checklist of items and materials useful for the examination and description of sediment cores.

- $\quad$ ASTM Procedure D 2488-84

- $\quad$ Stainless-steel knife

- Hand lens (10X magnification)

- $10 \mathrm{~N}$ Hydrochloric acid $(\mathrm{HCl})$

- Ruler (scaled in 0.1-foot increments)

- Blank log forms (see Figure A.1)

- Clipboard

- AGI Data Sheets

- Munsell Color Charts

In addition, the charts and/or reference materials listed in Table A.1, and included in this appendix, are useful in the description of specific sediment characteristics.

\section{A.2 METHODS}

Descriptions of the physical, chemical, and biological features preserved in sediments aid in the interpretation of the types of geologic processes active both during and after the sediment was deposited. A total of 17 sediment characteristics, outlined in ASTM (1984), are commonly used to describe inorganic soils. These are listed in Table A.2.

Moisture condition was not routinely logged because of the saturated nature of the sediments. Furthermore, since particles were rarely larger than coarse sand, neither were angularity, particle shape, range in particle size, nor hardness logged. For this reason, these sediment characteristics were not included in the log form used for the description of the sediments (Figure A.1). However, in the few instances where these characteristics did apply, they were described under the "COMMENTS" column.

The definition of "soil" from the engineers standpoint (ASTM, 1984), includes any unconsolidated sediment. The geologic definition of soil is slightly different and restricts soils to those sedimentary deposits that have undergone alteration near the land's surface by either physical, chemical, and/or biological processes; therefore, in a strict sense, not all sediments are soils. For the purposes of this discussion, however, "soils" and "sediments" will be used synonymously. 


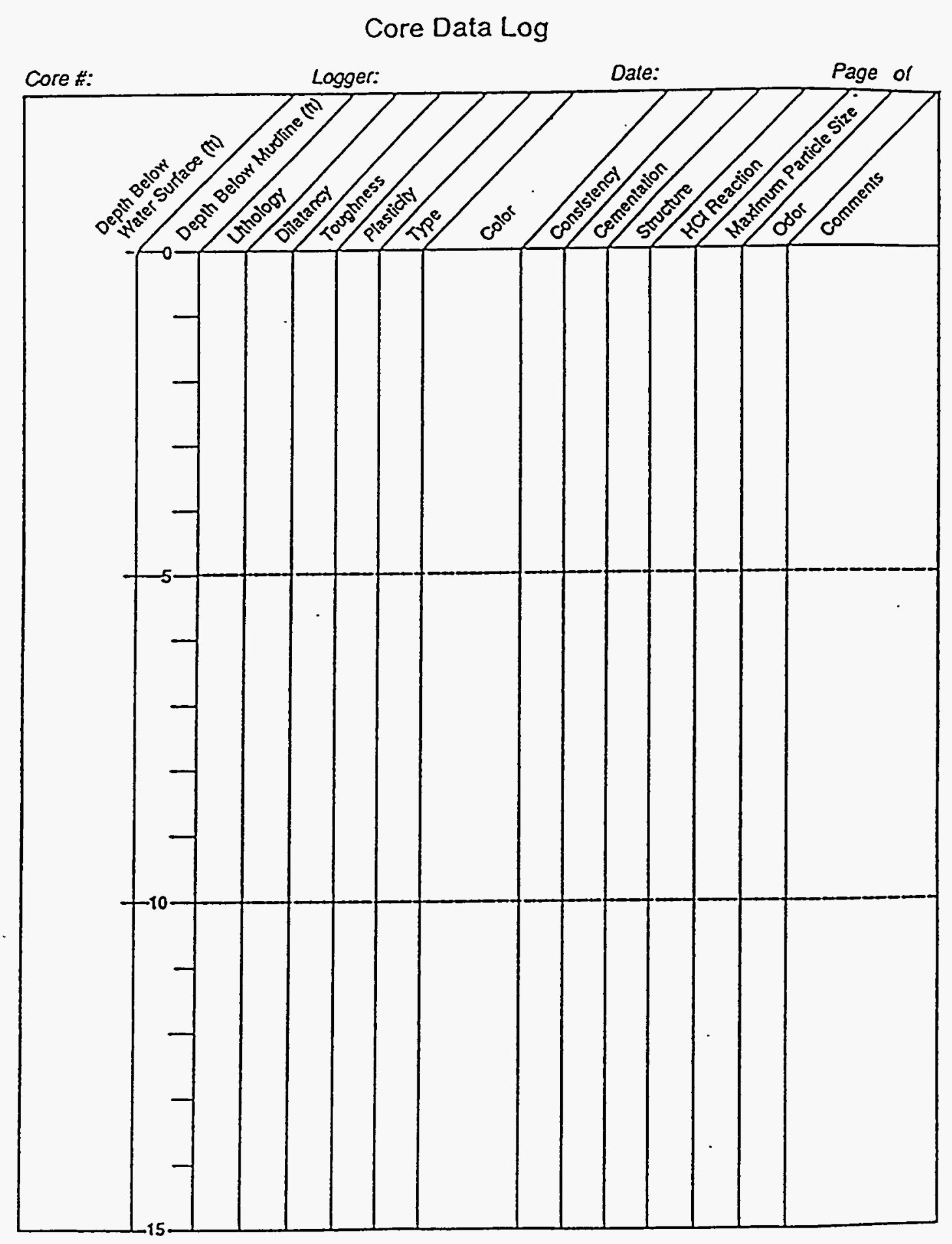

FlGURE A.1. Log Form Used to Record Sediment Descriptions 
IABLEA.1. Charts and Other Reference Materials Used to Provide Standardized Descriptions of Sediment Characteristics.

\section{CHART/REFERENCE}

- Percentage

Estimate Chart

- Roundness Scale

- Sorting Chart

- Particle Shape

- Munsell Soil Color Charts

- Unified Soil Classification System

- Grain-size Scales

- Lithologic Symbols
PURPOSE

Estimate percentage of individual particles or constituents

Roundness of sand and coarser particles

Estimate of grading

Reference to describe particle shape

Soil color

Method for designating sediment type

Range of particle sizes; maximum particle size

Graphic pattems for lithologic log
FIGURE\#

A.2

A.3A

A.3B

A.4

A.5

A.6, A.7

A.8, A.9 •

A.10, A.11

IABLEA.2. Sediment characteristics identified in ASTM Procedure D2488-84.
1) angularity(a)
2) particle shape(a)
3 color
4 odor
5) moisture condition
6) $\mathrm{HCl}$ reaction
7 consistency (i.e., firmness)
8 cementation(a)
9) structure

10) sediment classification type

(i.e., lithology)

11) range of particle sizes ${ }^{(\mathrm{a})}$

12) maximum particle size

13) hardness(a)

14) dry strength(b)

15) dilatancy(b)

16) toughness(b)

17) plasticity(b)

(a) Applies to coarse-grained sediment (sand and larger particles).

(b) Applies to fine-grained sediment of mostly silt and/or clay. Features not generally logged for this study are undertined. 
It is sometimes helpful to provide an estimate of the relative proportions of different constituents in sediments (e.g. light- versus dark-colored minerals). This is made easier and more accurate by using a percentage estimate chart, which provides a graphic reference with varying concentrations of a particular constituent (Figure A.2).

The criteria used to describe each of the 17 sediment characteristics identified in ASTM (1984) are discussed below.
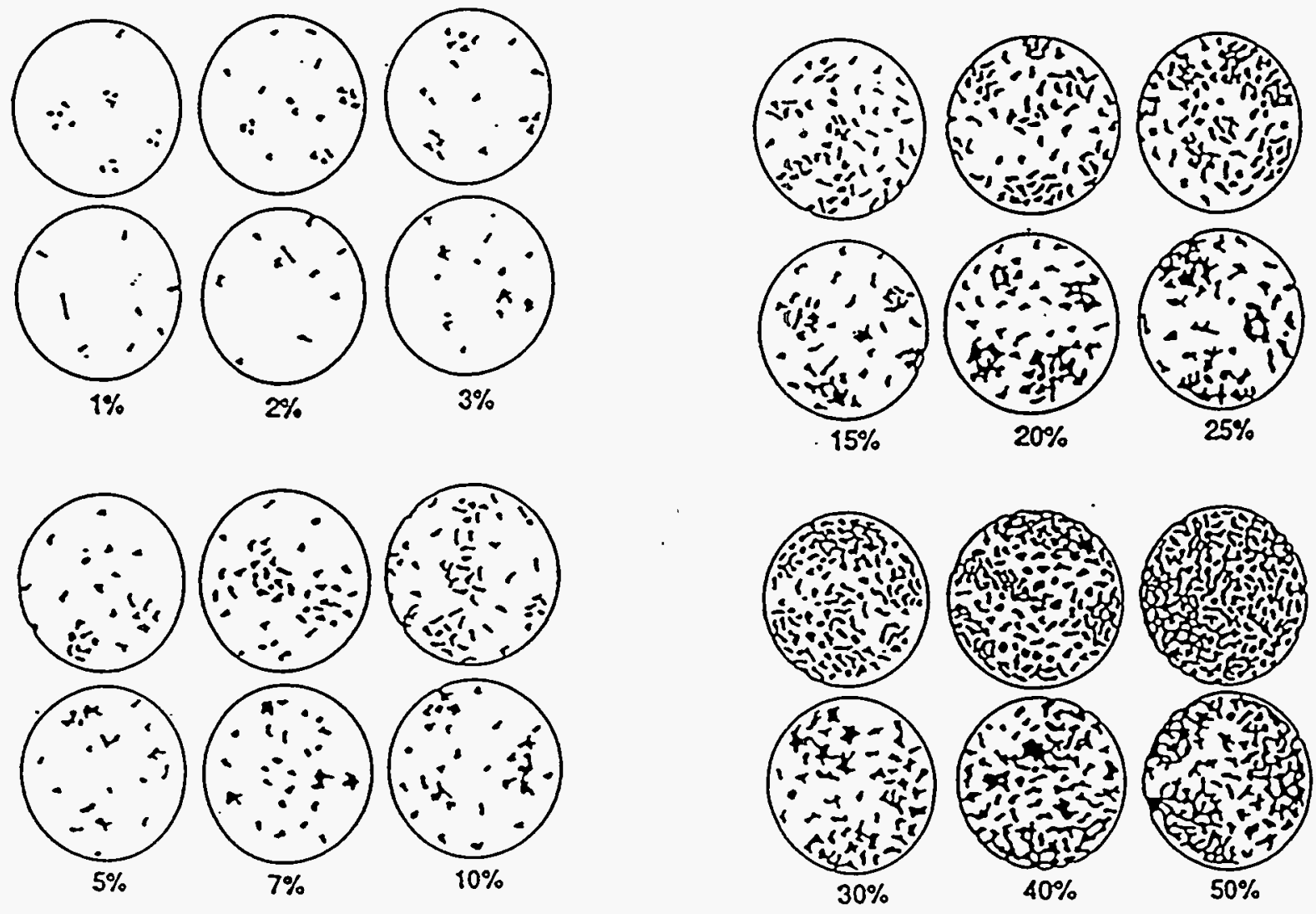

EIGUREA.2. Comparison Chart Used to Estimate the Percentages of Constituents (from AGI 1982) . 


\section{A.2.1 Anqularity}

The angularity of sedimentary particles is a reflection of the sedimentary environment and the amount of time that has elapsed before deposition and burial. A chart showing how to classify the angularity of sedimentary particles is presented in Figure A.3A. A range of angularity may be stated, such as, subrounded to rounded.

A

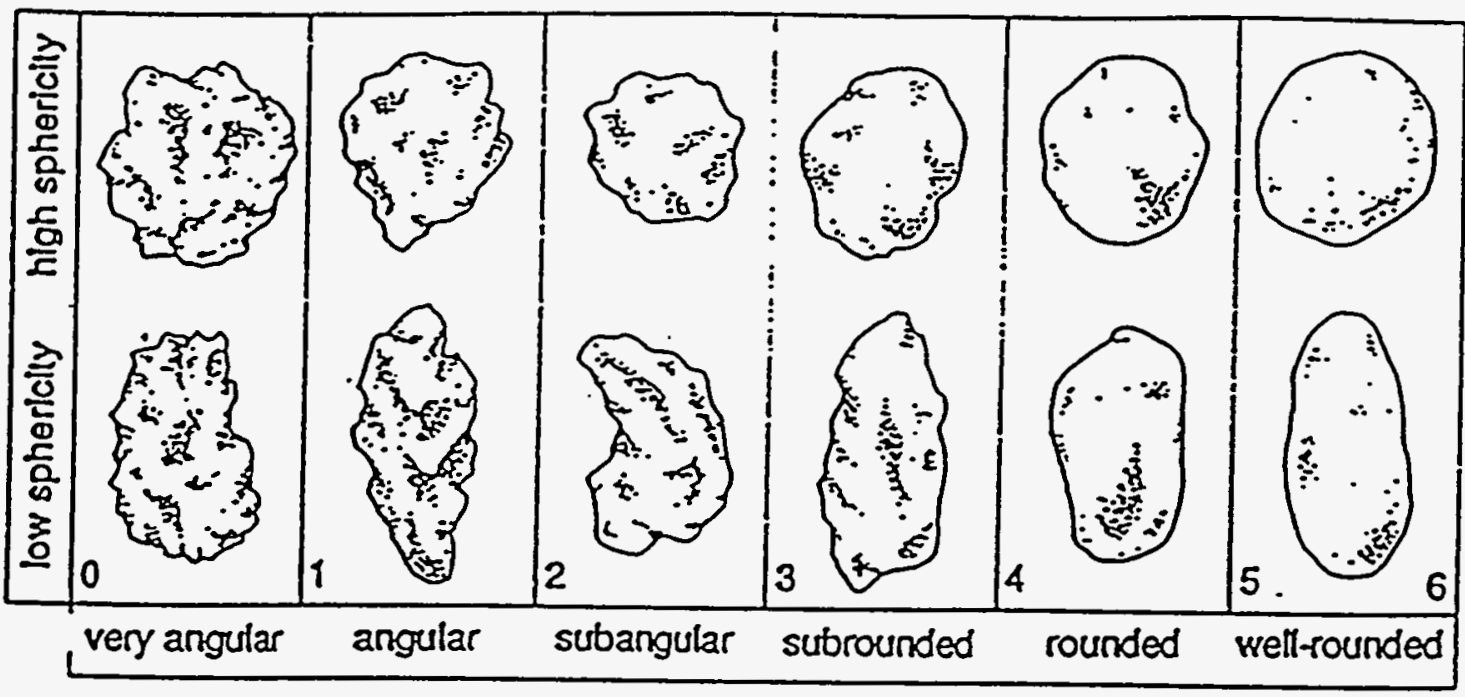

$B$

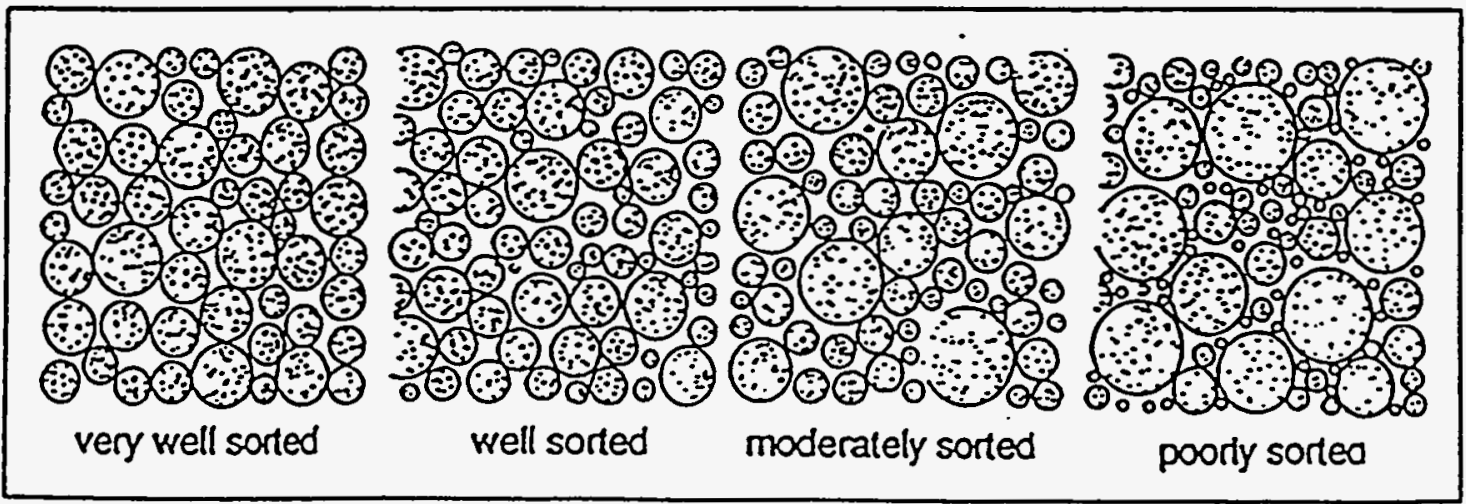

Poonly Graded

Well Graded

FlGURE A.3. Charts Used to Visually Estimate (A) Roundness/Sphericity and (B) Sorting/Grading 


\section{A.2.2 Shape}

Shapes of sedimentary particles often reflect the intemal characteristics (e.g., preferential parting) of the material or sometimes the type of sedimentary environment. For example gravel clasts deposited in high-energy environments, such as beaches and river bottoms, are often $X$ wom flat.

According to Figure A.4, gravel-sized clasts may be described in one of four ways. First, if the ratio of the clast's width to thickness is $>3$, it is classified as flat. Second, if the ratio of the clast's length to width is $>3$, the clast is elongate. Third, if both criteria apply the clast is both flat and elongate. And last, if none of the criteria apply, then shape is not mentioned. Indicate the fraction of the clasts that have the shape, such as, one-third of gravel clasts are flat. Particle shape did not apply to most of the sediments logged during this project and the few pebbles that were observed were neither flat nor elongate.

$W=$ Width

$T=$ Thickness

$L=$ Length

Flat: $W / T>3$

Elongated: $L W>3$

Flat and Elongated: meets both criteria

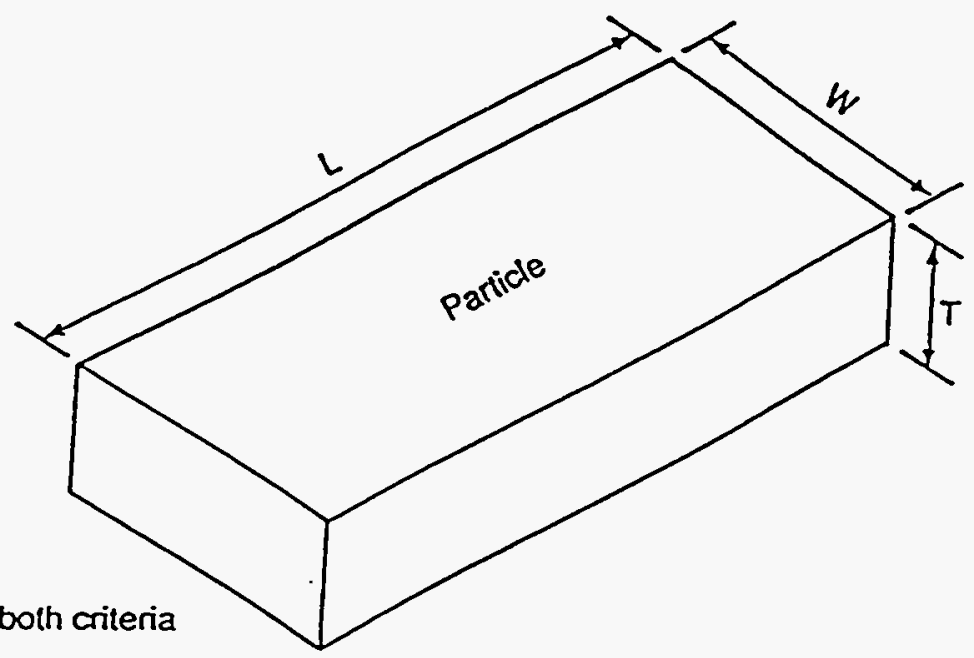

ElGURE A.4. Criteria Used to Describe Particle Shape of Pebbles and Large Gravels (From ASTM 1984) 


\section{A.2.3 Color}

Color may be useful in identifying materials of similar geologic origin. For example, color was often a useful criteria for differentiating younger bay mud from older bay mud. Sediment color was determined by comparing the wet sediment with standard sediment colors given in Munsell (1975). The advantage to using the Munsell soil color system is that it provides a consistent, standardized method for describing color and subjectivity is minimized.

The Munsell color notation consists of three simple variables that combine to describe all colors known in the Munsell soil color system. The three variables are: hue, value, and chroma (Figure A.5). The hue notation indicates the relation of the sediment color with respect to red, yellow, green, blue and purple; the value notation indicates its lightness, and the chroma notation indicates its strength (i.e., intensity).

Color can be described either by the Munsell notation (e.g. 5 YR 5/3; hue $=5 Y R$, value $=5$, chroma $=3$ ) or by its equivalent color name (e.g., reddish brown). Both the color name and Munsell notation were recorded on core logs (see Appendix B). Only rarely was there not a reasonable match between the true color of the core sediment and one of the colors on a Munsell color chart.

\section{A.2.4 Oder}

Odors may indicate the presence of contaminants or be the result of the geochemical environment. Odors most frequently noted were that of petroleum hydrocarbons and the smell of rotten eggs (an indication of the presence of hydrogen sulfide). Both of these odors were restricted to the younger bay mud unit. Petroleum odors may be the result of contamination of the sediments by shipping spills or industrial waste, or perhaps is derived from the abundant decaying organic matter present in these sediments. Hydrogen sulfide is a common natural by-product in chemically reducing environments such as the Richmond Harbor estuary.

\section{A.2.5 Moisture Condition}

Moisture condition is described as either dry, moist, or wet according to the following criteria:

DRY Absence of moisture, dry to the touch

MOIST Damp but no visible water

WET Visible free water, usually soil is below water table (i.e., saturated)

All the sediments logged for this project were taken from below sea level and did not lose any significant moisture between the time they were drilled and logged. Therefore, they are all classified as wet. 
$\frac{\pi}{2}$

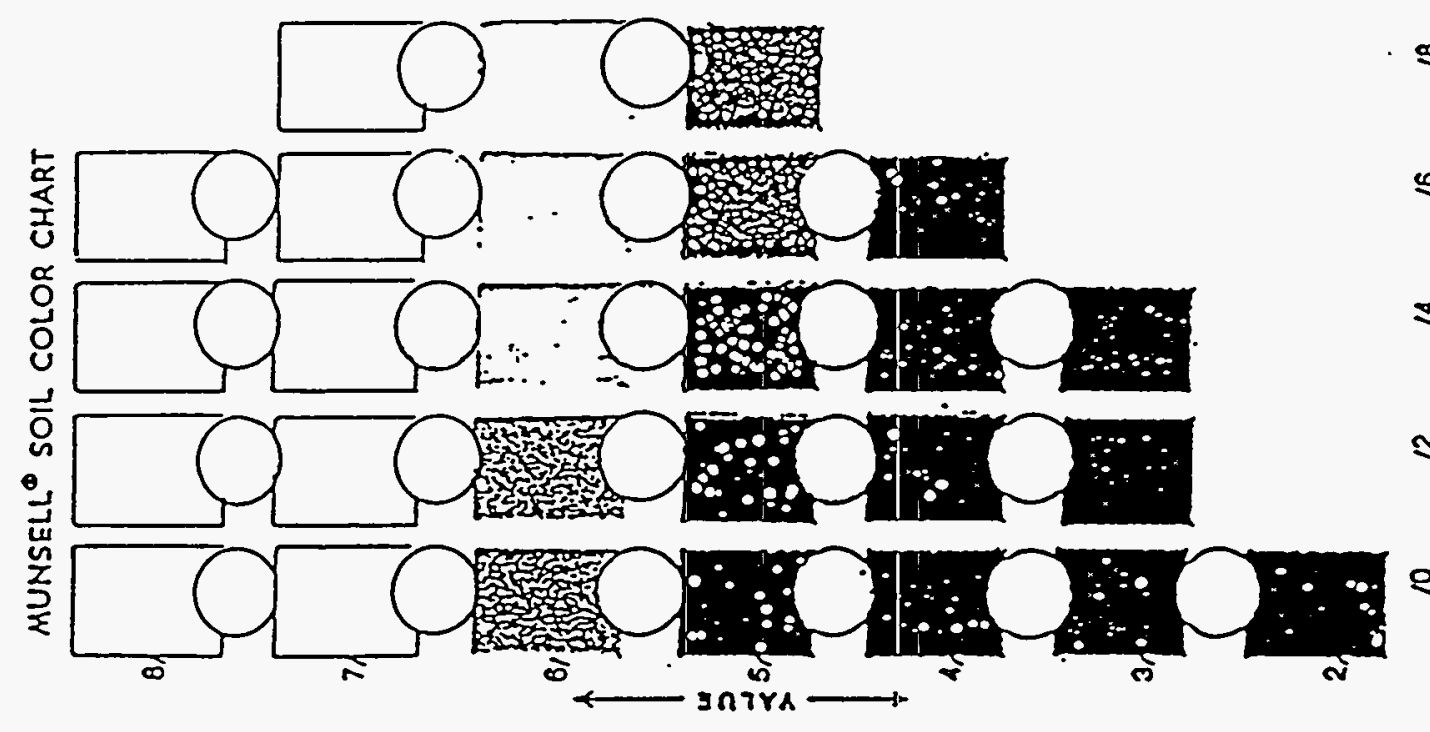

q

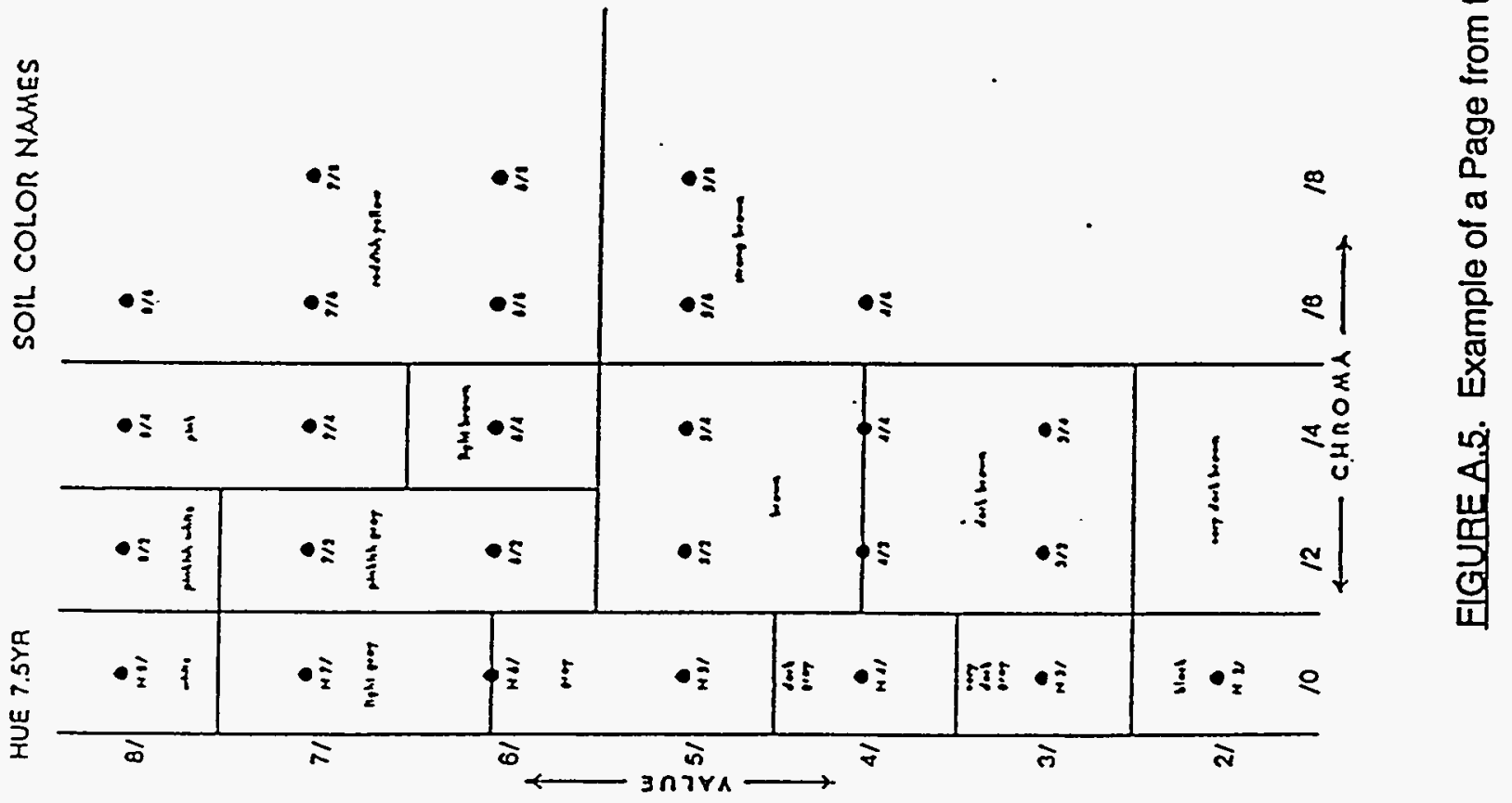




\section{A.2.6 $\mathrm{HCl}$ Reaction}

The reaction (i.e., effervescence) of sedimentary material, as a result of adding dilute hydrochloric acid, is an indication of the presence of calcium carbonate. Calcium carbonate in sediments may be derived from a variety of sources including: 1) physical disintegration of preexisting carbonate rocks (e.g., limestone, marble), 2) biogenic precipitation (e.g., shell, bone), and, 3) soil development. In the last example, calcium carbonate concentrations, often referred to as caliche or calcrete, may accumulate over time near the land's surface in arid climates. Where calcium carbonate concentrations occur in combination with other evidence for soil development, such as root traces and oxidation, then a pedogenic (soil forming) origin is favored. Criteria for describing the reaction with $10 \mathrm{~N} \mathrm{HCl}$ are as follows:

NONE No visible reaction

WEAK Some reaction, with bubbles forming slowly

STRONG Violent reaction, with bubbles forming immediately

A solution of $10 \mathrm{~N} \mathrm{HCl}$ is obtained by slowly adding one part of concentrated hydrochloric acid to three parts of distilled water. (To avoid a violent exothermic reaction never add water to acid.)

\section{A.2.7 Consistency}

Consistency is a measure of the firmness or consolidation of sedimentary material. In general, there is a direct relationship between consistency and age of the deposit (i.e., older deposits are usually more firm because of compaction and/or cementation). Consistency is most applicable to fine-grained sediments and least applicable on sediments that contain significant amounts of gravel. The criteria used to determine consistency are as follows:

VERY SOFT Penetrometer penetrates soil greater than $4 \mathrm{~cm}$

SOFT Penetrometer penetrates soil 2.0 to $4.0 \mathrm{~cm}$

FIRM Penetrometer penetrates soil 0.25 to $2.0 \mathrm{~cm}$

HARD Penetrometer penetrates soil less than $0.25 \mathrm{~cm}$.

The penetrometer used for sediment core descriptions consists of a 6-in. nail spike attached to a clay brick for a total mass of $2.0 \mathrm{~kg}$; the nail spike is marked in centimeter increments to quantify the.amount of soil penetration. 


\section{A.2.8 Cementation}

Often sedimentary particles are held together with a binding cement. Three common natural cements are calcium carbonate (lime), silica, and iron-oxide compounds. Particles cemented with calcium carbonate effervesce in the presence of hydrochloric acid (see Section A.2.6 above). Sediments cemented with iron oxide are usually some shade of red, yellow, or brown. Usually there is a relationship between consistency (Section A.2.7) and cementation, in that strongly cemented deposits are also hard to very hard. Criteria used to describe the degree of cementation are:

WEAK Crumbles or breaks with handling or light finger pressure

MODERATE Crumbles or breaks with considerable finger pressure

STRONG Will not crumble or break with finger pressure.

\section{A.2.9 Structure}

Structures are features that originate within the layers of sediment or at the sediment/water interface in response to various physical, biologic and/or chemical processes. Structures may be classified into two categories: primary and secondary. Primary structures form as the sediment is being deposited (e.g., lamination, stratification). Secondary structures form after deposition, often as a result of compaction or other stresses (e.g., fissured, slickensided), biologic activity (e.g., root traces, mottling), and soil development (e.g., homogeneous, blocky, mottled). The following are some common structures observed in sedimentary deposits.

\section{PRIMARY STRUCTURES}

STRATIFIED Altemating layers of varying material or color with layers at least $6 \mathrm{~mm}$ thick

LAMINATED Altemating layers of varying material or color with the layers less than 6 mm thick

LENSED Inclusion of small pockets of different sediment type, such as small lenses of sand scattered through a mass of clay. (This type of structure may also be secondary).

\section{SECONDARY STRUCTURES}

FISSURED Breaks along definite planes of fracture with little resistance to fracturing

SLICKENSIDED Fracture planes appear polished or glossy, sometimes striated

BLOCKY

Cohesive soil that can be broken down into small angular lumps which resist further breakdown

MOTTLED Variation in color of sediments as represented by localized spots or blotches of color or shades of color

HOMOGENEOUS Same color and appearance throughout. 


\section{A.2.10 Sediment Classification Type}

The classification method used in this study is the Unified Soil Classification System, which consists of a two-letter designation for most soils (i.e., unconsolidated sediments). A simplified version of the Unified Soil Classification System is presented in Figure A.6, whereas a more-detailed breakdown is presented in Figure A.7.

According to the Unified Soil Classification System, coarse-grained sediments are classified based on grain-size distribution and grading (i.e., sorting), while fine-grained sediments are classified on the basis of grain size and liquid limit vs. plasticity.

Particle-size distribution may be determined with precision using laboratory methods (e.g., sieving of sand and coarser particles; pipette or hydrometer analysis of silt and clay). Because these methods are expensive and time-consuming, it is more desirable to estimate grain size using rapid visual-manual techniques described below. For example, sand and coarser particles are most easily identified via comparison with standard charts of grain size (Figures A.8 and A.9). Fine-grained soils, consisting of mostly silt and/or clay, on the other hand, are identified based on manual tests of their dry strength, dilatancy, toughness, and plasticity (Figure A.10).

In the Unified Soil Classification System, the first letter of the sediment-type symbol represents the predominant grain-size interval, be it gravel $(G)$, sand $(S)$, silt $(M)$, or clay (C). For coarse-grained sediments, the first letter (i.e., $G$ or $S$ ) may be followed by a descriptor of grading, either $W$ (well graded) or $P$ (poorty graded), or a secondary grain-size descriptor ( $M$ or C). The definition of grading is opposite that of sorting, a common geologic term. For example, a clean, well-sorted sand, consisting of particles over a narrow range in grain size, is referred to as poorly graded in the Unified Soil Classification System and would receive the designation "SP". The relationship between grading and sorting is shown graphically in Figure A.3B. The second letter in the fine-grained soil designation consists of either $L$ (low liquid limit) or $H$ (high liquid limit).

The lithology column on the geologic log (Figure A.1) essentially represents a graphic display of sediment type, which can be utilized for quick easy reference and comparison between different cores and thus make interpretations easier. Examples of lithologic symbols in common use are presented in Figure A.11. Additional symbols may be used as long as they are graphically representative of the feature and are specifically defined and identified in a key that accompanies lithologic logs. 


\begin{tabular}{|c|c|c|c|c|}
\hline \multicolumn{3}{|c|}{ Major Divisions } & \multirow{2}{*}{\begin{tabular}{|c|} 
Group \\
Symbols
\end{tabular}} & \multirow{2}{*}{$\begin{array}{l}\text { Description } \\
\begin{array}{l}\text { Well-graded (i.e., poorly sorted) gravels, } \\
\text { gravel-sand mixtures, little or no fines }\end{array}\end{array}$} \\
\hline \multirow{8}{*}{ 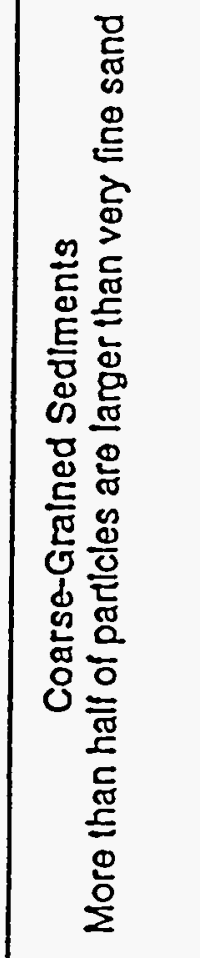 } & \multirow{4}{*}{$250 \%$ Gravel } & \multirow{2}{*}{$\begin{array}{l}\text { Clean } \\
\text { Gravels }\end{array}$} & & \\
\hline & & & GP & $\begin{array}{l}\text { Poorty graded (i.e., well sorted) gravels. } \\
\text { gravel-sand moxtures, ritlle or no fines }\end{array}$ \\
\hline & & \multirow{2}{*}{$\begin{array}{c}\text { Gravels } \\
\text { with } \\
\text { Fines }\end{array}$} & GM & Silty gravels, gravel-sand-silt moxtures \\
\hline & & & GC & Clayey gravels, gravel-sand-clay mixtures \\
\hline & \multirow{4}{*}{$250 \%$ Sands } & \multirow{2}{*}{$\begin{array}{l}\text { Clean } \\
\text { Sands }\end{array}$} & SW & Well-graded sands, gravelly sands, little or no fines \\
\hline & & & $S P$ & Poorty graded sands, gravelly sands, little or no fines \\
\hline & & Sands & SM & Sitty sands, sand-silt mixtures \\
\hline & & Fines & SC & Clayey sands, sand-clay moxtures \\
\hline$\stackrel{\infty}{C_{\mathcal{J}}} \stackrel{\grave{\Xi}}{=}$ & & Low & $M L$ & $\begin{array}{l}\text { Silts and very fine sands, sitty or clayey fine sands, } \\
\text { or clayey sitts, with sight plasticity }\end{array}$ \\
\hline 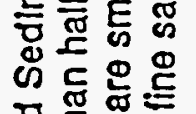 & Silts and & Limit & $C L$ & $\begin{array}{l}\text { Clays of low to medium plasticity, gravelly clays, } \\
\text { sandy clays, silty clays, lean clays }\end{array}$ \\
\hline 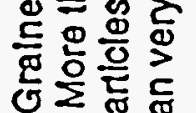 & Clays & High & MH & Silts or fine sandy silts with moderate plasticily \\
\hline$\frac{\mathbb{C}}{u} \div=$ & & Limit & $\mathrm{CH}$ & Clays of high plasticity, fat clays \\
\hline
\end{tabular}

\$9012061.1

FIGURE A.6. Abbreviated Form of the Unified Soil Classification System (From AGI 1982) 


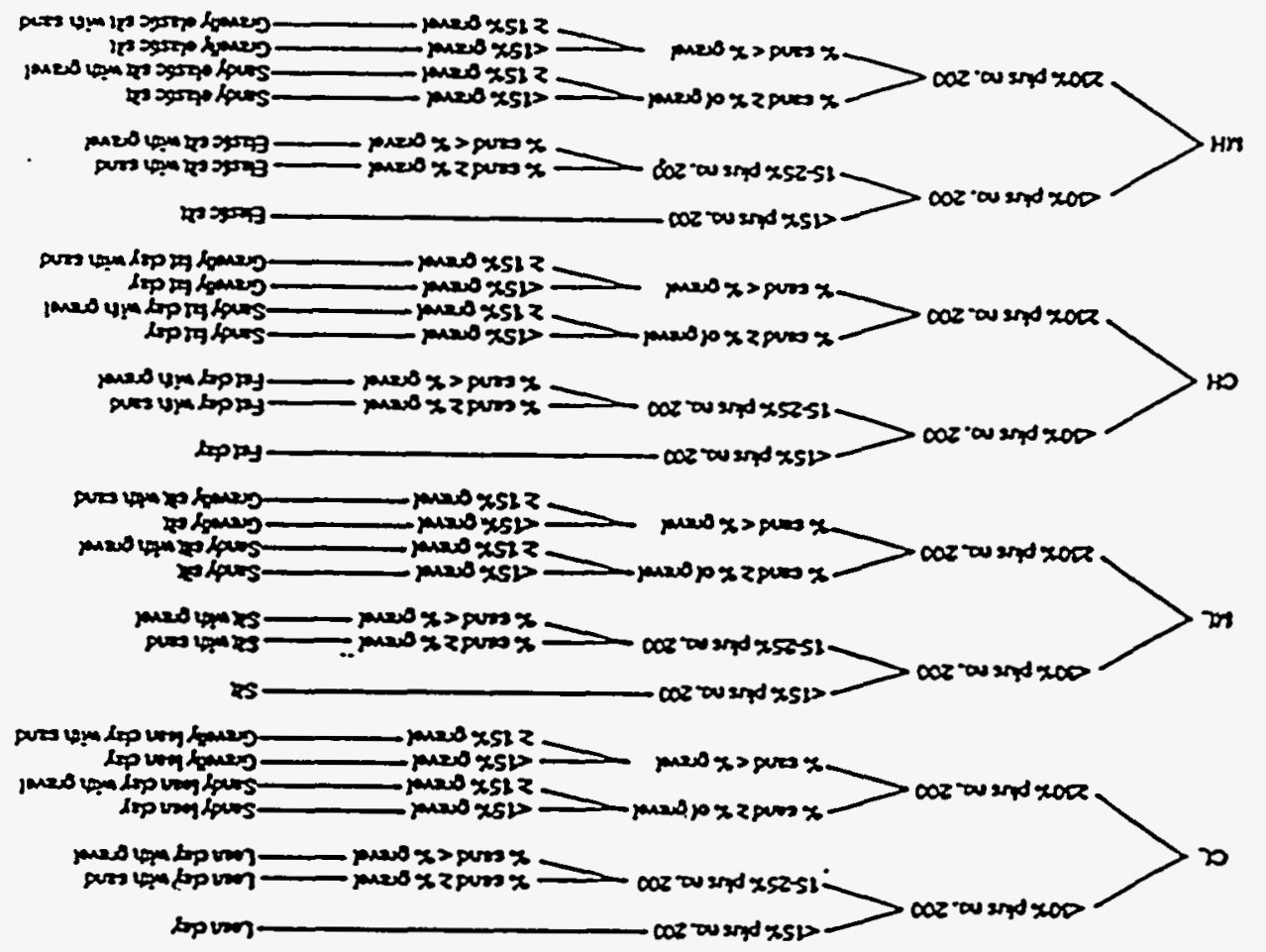

nent doas

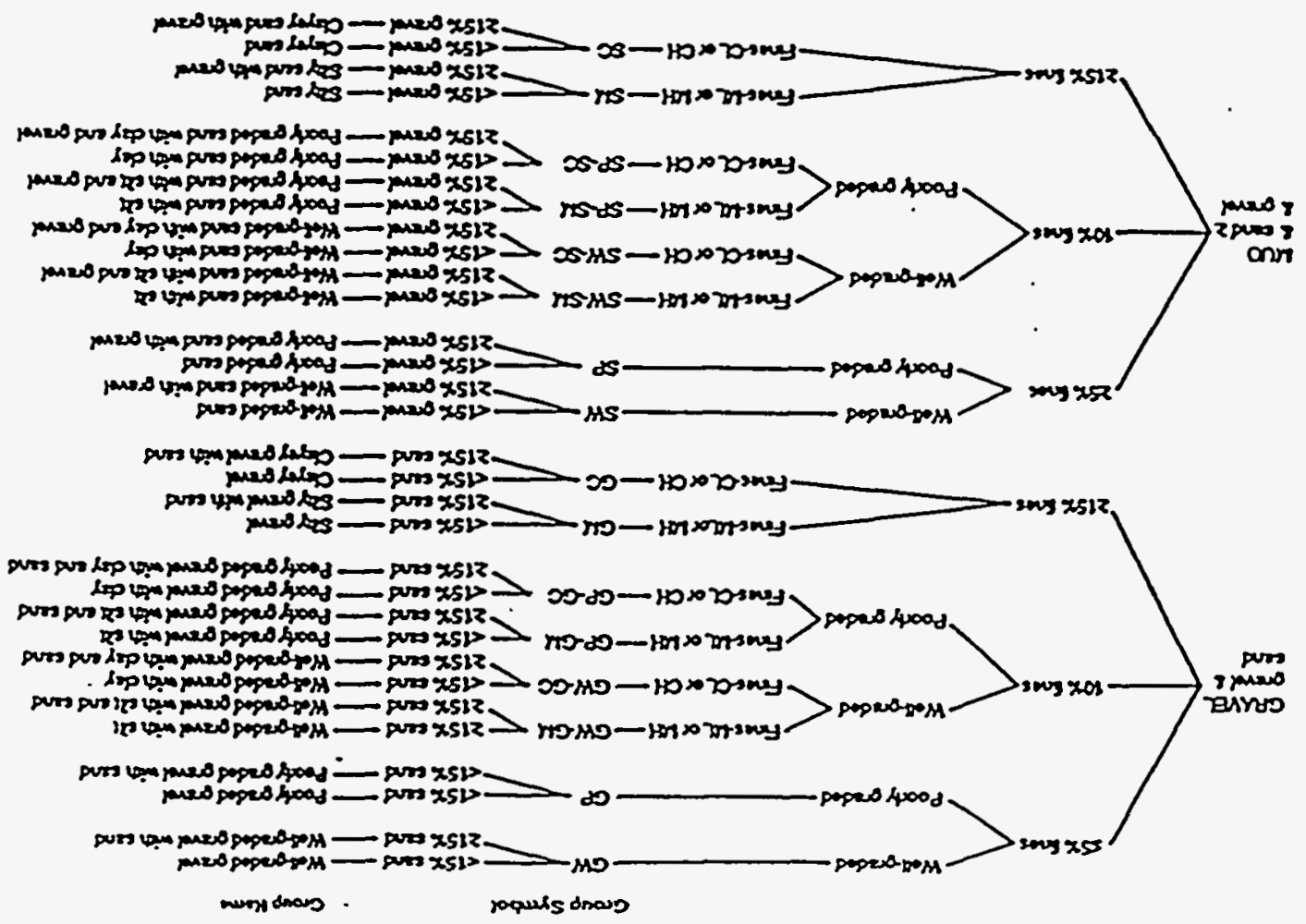




\begin{tabular}{|c|c|c|c|c|c|c|c|}
\hline \multicolumn{3}{|c|}{ Grade Limids } & \multirow[b]{2}{*}{ inches } & \multirow{2}{*}{$\begin{array}{c}\text { U.S. } \\
\text { Slandard } \\
\text { Sieve Series }\end{array}$} & \multirow{2}{*}{\multicolumn{3}{|c|}{ Grade Name }} \\
\hline phi & $\mathrm{mm}$ & $\mathbf{m m}$ & & & & & \\
\hline-12 & $4096-$ & $-\quad-\quad-$ & 1613 & $-\quad-$ & $-\overline{-}--$ & & \multirow{11}{*}{ GRAVEL } \\
\hline-11 & $2048-$ & $-\quad-\quad-$ & 80.6 & -- & $\overline{\text { lange }}-\overline{-}-$ & & \\
\hline-10 & $1024-$ & $-\quad-\quad-$ & 40.3 & $-\quad-$ & $\overline{\text { modium }}$ & Boublers & \\
\hline-9 & $512-$ & $-\quad--$ & 202 & $-\quad-$ & $\overline{\text { small }}^{-}-$ & & \\
\hline-8 & $256-$ & --- & 10.1 & -- & large & & \\
\hline-7 & $128-$ & $-\quad--$ & 5.0 & $-\quad-$ & $-\overline{\text { smail }}--$ & Cobbles & \\
\hline-6 & $64-$ & $-\quad-$ & 252 & $63 \mathrm{~mm}-$ & very coarse & \multirow{5}{*}{ Peboles } & \\
\hline-5 & $32-$ & & 1.26 & $31.5 \mathrm{~mm}$ & $--\overline{-}-$ & & \\
\hline-4 & $16-$ & $-\quad-\quad-$ & 0.63 & $16 \mathrm{~mm}-$ & $\overline{\text { medium }}^{-}-$ & & \\
\hline-3 & $8-$ & $-\quad--$ & 0.32 & $8 \mathrm{~mm}-$ & $\overline{l i n}^{-}--$ & & \\
\hline-2 & $4-$ & -- & 0.16 & No.5 - & ${ }_{\text {very fine }}^{-}-$ & & \\
\hline \multicolumn{3}{|l|}{$-1-$} & 0.08 & No. 10 & very coarse & \multirow{5}{*}{ Sand } & \multirow{5}{*}{ SAND } \\
\hline 0 & $1-$ & $-\quad--$ & 0.04 & No. 18 - & $-{ }_{\text {coarse }}-$ & & \\
\hline+1 & $1 / 2-$ & $0.500-$ & $-\quad-$ & No. 35 - & - $\overline{\text { medium }}-$ & & \\
\hline+2 . & $1 / 4-$ & $0.250-$ & - & No. 60 - & $\overline{f i n e}^{-}--$ & & \\
\hline+3 & $1 / 8-$ & $0.125-$ & $-\quad-$ & No. 120 & very fino & & \\
\hline $4-$ & $-1 / 16-$ & 0.062 & & $-\mathrm{No} .230-$ & coarse & \multirow{4}{*}{ Sit } & \multirow{8}{*}{ MUD } \\
\hline+5 & $1 / 32-$ & $0.031-$ & $-\quad-$ & $-\quad-$ & $\overline{\text { medium }}^{-}-$ & & \\
\hline+6 & $1 / 54-$ & $0.016-$ & - & $-\quad-$ & $\overline{r i n e}^{-}--$ & & \\
\hline+7 & $1 / 128-$ & $0.008-$ & - & $-\quad-$ & $-\overline{\text { very fine }}-\overline{-}$ & & \\
\hline+8 & $1255-$ & $0.004-$ & $-\quad-$ & $-\quad-$ & coarse & \multirow{4}{*}{ Clay Size } & \\
\hline+9 & $1512-$ & $0.002-$ & $-\quad-$ & $-\quad-$ & $\overline{\text { modium }}^{-}-$ & & \\
\hline+10 & $1 / 1024$ & $0.001-$ & -- & $-\quad-$ & $-{ }_{\text {fine }}^{-}--$ & & \\
\hline+11 & $1 / 2048$ & $0.0005-$ & $-\quad-$ & $-\quad-$ & ${ }_{\text {very fine }}^{-}-$ & & \\
\hline$-+12-$ & $-1 / 4096-$ & $-0.00025-$ & & & & & \\
\hline
\end{tabular}

FlGURE A.8. Grain-size Scale Used to Detemine Sedimentary Particle Size 


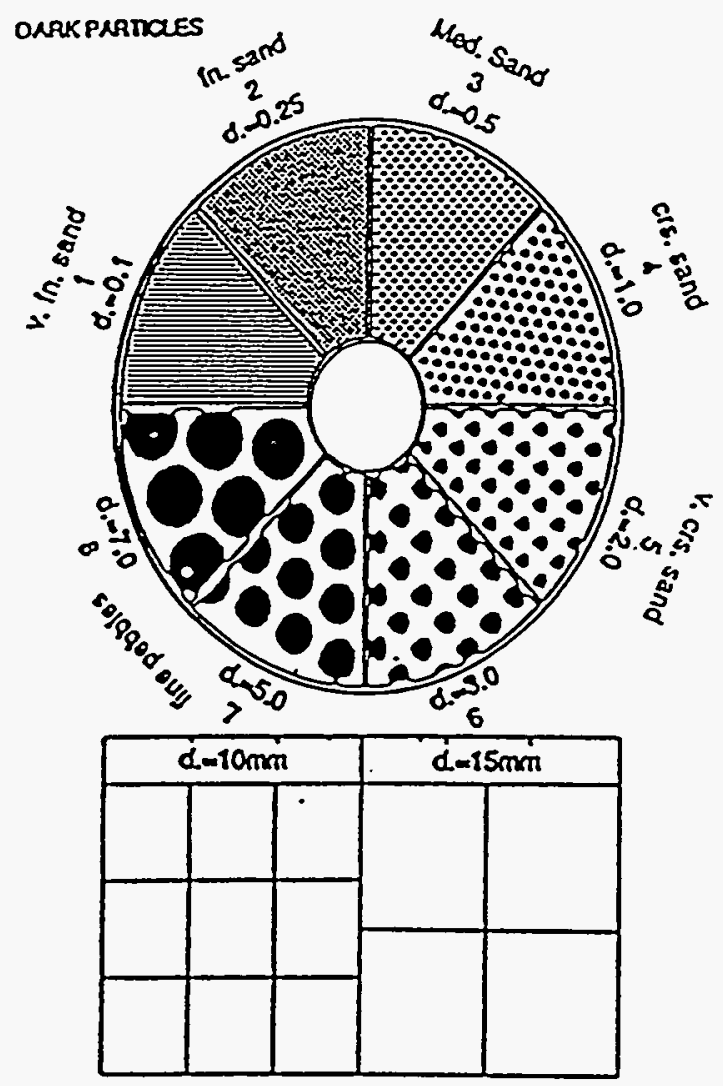

ElGURE A.2. Comparison Chart Used to Distinguish Among Sand to Pebble-size Particles (From AGI 1982). For larger particles, refer to Figure A.8; for smaller particles, refer to Sections A.2.13 and A.2.16 in this Appendix

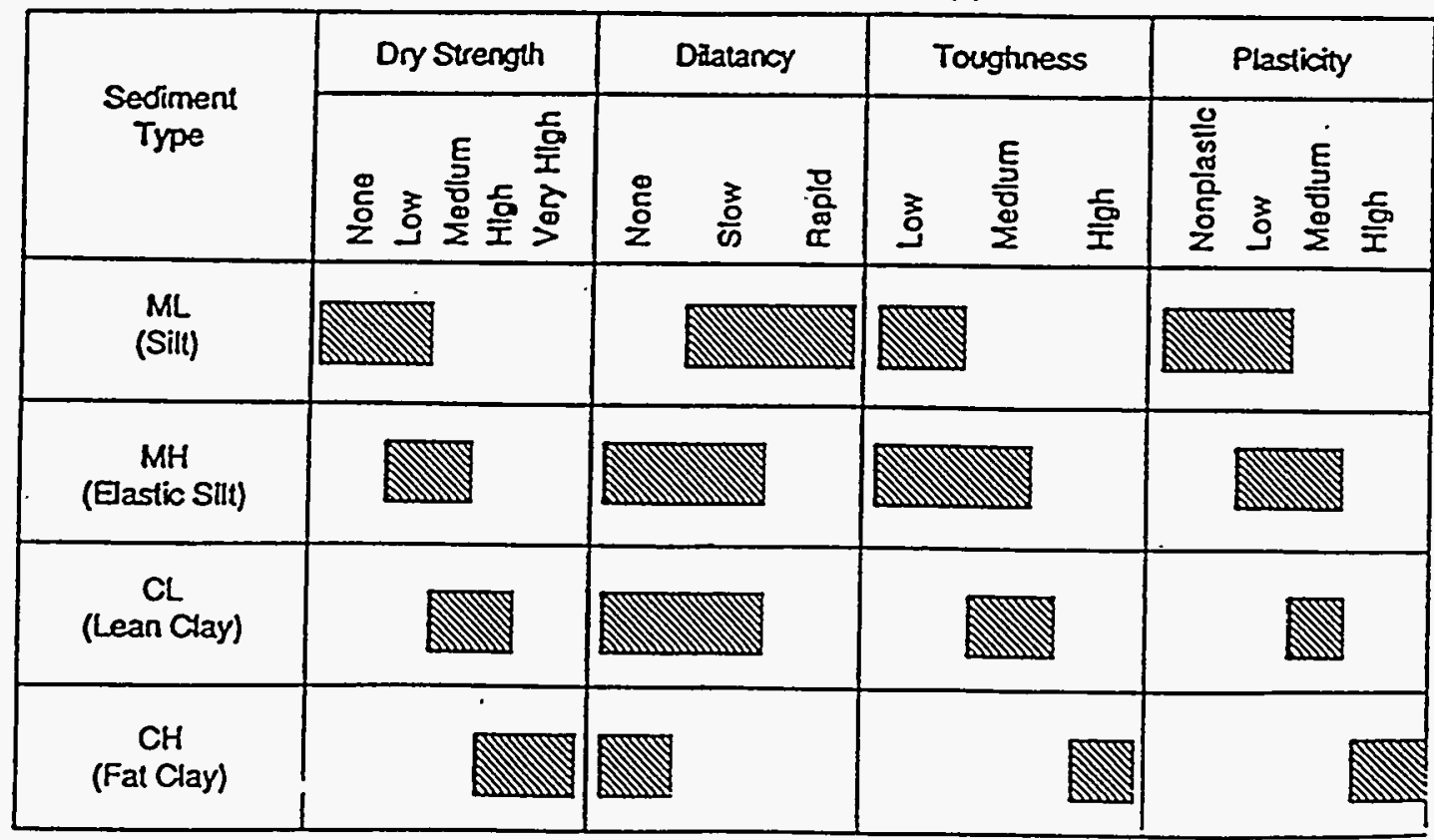

FIGURE A.10. Identification of Inorganic Fine-grained Soils From Manual Tests 


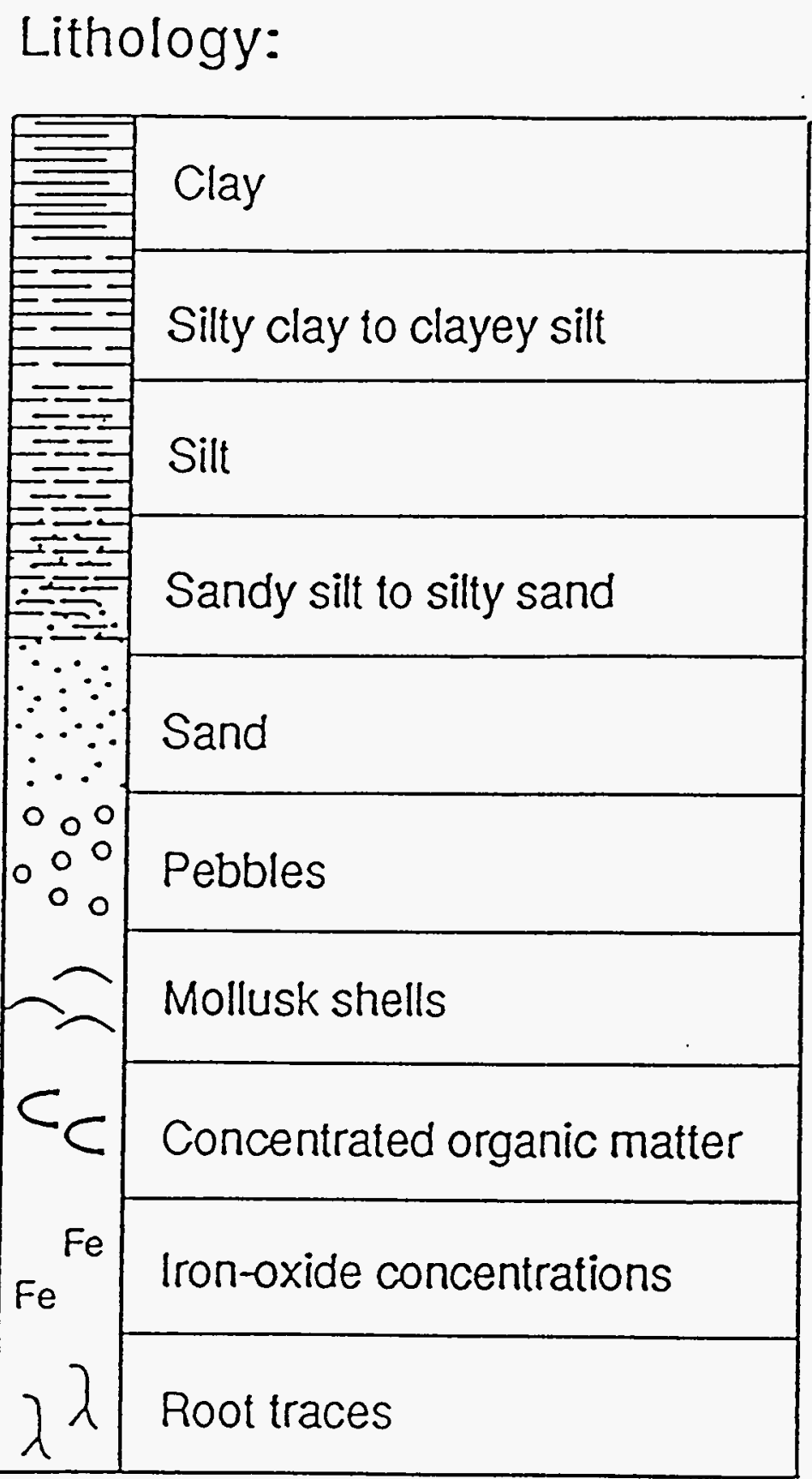

FIGURE A.11. Lithologic Symbols Used on Core Log Forms 


\section{A.2.11 Range of Particle Sizes}

For gravel-and sand-sized particles, the range of particle sizes within each component is defined. For example, $20 \%$ fine to coarse gravel, $40 \%$ fine to coarse sand. The sizes of particles corresponding to the different size components are presented in Figures A.8 and A.9.

\section{A.2.12 Maximum Particle Size}

Maximum particle size is significant because it gives a general indication of the amount of turbulence or energy associated with deposition. If the maximum particle size is sand, it should be described as either fine, medium, or coarse sand. If the maximum particle size is in the gravel range, the largest particle is measured and its width recorded along the narrowest axis. The sizes of particles corresponding to the different size components are presented in Figures A.8 and A.9.

The maximum grain size observed for the younger bay muds ranged from silt to medium sand, while the older bay mud usually ranged from fine sand to coarse sand. The largest particles observed anywhere were fine pebbles in the older bay mud unit.

\section{A.2.13 Dry Strength}

Dry strength, along with dilatancy, toughness, and plasticity are physical characteristics used to distinguish fine-grained inorganic soils, consisting of mostly silt and/or clay. Basically, the more clay present in a soil the greater its dry strength (Figure A.10). To perform a manual test of dry strength enough material must be selected in order to mold into a ball about 1 in. in diameter. Mold the material until it has the consistency of putty, adding water if necessary. From the molded material, make at least three test specimens each about $1 / 2$ in. in diameter. Allow the test specimens to dry in air, sun or by artificial means, as long as the temperature does not exceed $60^{\circ} \mathrm{C}$ (ASTM, 1984). The criteria for determining dry strength are as follows:

NONE The dry specimen crumbles into powder with mere pressure of handling

LOW The dry specimen crumbles into powder with light finger pressure

MEDIUM The dry specimen breaks into pieces or crumbles with considerable finger pressure

HIGH The dry specimen cannot be broken with finger pressure. Specimen will break into pieces between thumb and a hard surface

VERY HIGH The dry specimen cannot be broken between the thumb and a hard surface.

Dry strength was determined from the cores by sampling selected intervals and allowing the samples to air dry ovemight. Dry strength was determined the next day and noted in the comments column of the geologic log. 


\section{A.2.14 Dilatancy}

Dilatancy is a measure of how easily a soil gives up water when shaken. For example, some clays have the ability to absorb and retain large amounts of water into their crystal lattice. "Fat" clays tend to retain their water even under stress whereas "lean" clays and silt tend to release water when shaken.

To test for dilatancy select enough material to mold into a ball about 1/2 in. in diameter. Mold the material, adding water if necessary, unitil it has a soft, but not sticky consistency. Smooth the soil ball in the palm of the hand with a blade of a knife or small spatula. Shake horizontally, striking the side of the hand vigorously against the other several times. Note the reaction of water appearing on the surface of the soil. Squeeze the sample by closing the hand or pinching the soil between the fingers, and note the reaction. Specimens with high dilatancy will quickly yield water when shaken and absorb water when squeezed. The criteria for describing dilatancy are:

NONE No visible change in the specimen

SLOW Water appears slowty on the surface of the specimen during shaking and does not disappear or disappears slowiy upon squeezing

RAPID Water appears quickty on the surface of the specimen during shaking and disappears quickly upon squeezing.

The range of dilatancy for the different fine-grained sediment types is shown in Figure A.10. From this figure it is apparent that dilatancy decreases with decreasing grain size.

\section{A.2.15 Toughness}

After completion of the dilatancy test, shape the same specimen into an elongated pat and roll by hand on a smooth surface or between the palms into a thread about $1 / 8 \mathrm{in}$. $(3 \mathrm{~mm}$ ) in diameter. (If the sample is too wet to roll easily, it should be spread into a thin layer and allowed to lose some water by evaporation.) Fold the sample threads and reroll repeatedly until the thread crumbles at a diameter of about $1 / 8$ in. The thread will crumble at a diameter of $1 / 8$ in. when the soil is near the plastic limit. Note the pressure required to roll the thread near the plastic limit. Also, note the strength of the thread. After the thread crumbles, the pieces should be lumped together and kneaded until the lump crumbles. Note the toughness of the material during kneading and classify into one of the following categories. 
LOW Only slight pressure is required to roll the thread near the plastic limit. The thread and lump are weak and soft

MEDIUM Medium pressure is required to roll the thread to near the plastic limit. The thread and lump have medium stiffness.

$\mathrm{HIGH}$ Considerable pressure is required to roll the thread to near the plastic limit. The thread and the lump have very high stiffness.

The range of toughness for the different fine-grained sediment types is shown in Figure A.10. From this figure it is apparent that toughness increases with a decrease in particle size.

\section{A.2.16 Plasticity}

On the basis of observations made during the toughness test, describe the plasticity of the material according to the following criteria:

NONPLASTIC A 1/8 in. thread cannot be rolled at any water content

LOW The thread can barely be rolled and the lump cannot be formed when drier than the plastic limit.

MEDIUM The thread is easy to roll and not much time is required to reach the plastic limit. The thread cannot be rerolled after reaching the plastic limit. The lump crumbles when drier than the plastic limit.

HIGH It takes considerable time rolling and kneading to reach the plastic limit. The thread can be rerolled several times after reaching the plastic limit. The lump can be formed without crumbling when drier than the plastic limit.

The range of plasticity for the different fine-grained sediment types is shown in Figure A.10. From this figure it is apparent that an increase in plasticity accompanies a decrease in grain size. 


\section{A.3 REFERENCES}

American Geological Institute (AGI). 1982. AGI Data Sheets for Geology in the Field, Laboratory, and Office: American Geological Institute. Falls Church, Virginia.

American Society for Testing and Materials (ASTM). 1984. Standard Practice for Description and Identification of Soils (Visual-manual procedure): Procedure D 2488-84. p. 293-302. American Society for Testing and Materials, Ptiladelphia, Pennsytvania.

Compton, R. R. 1962. Manual of Field Geology. John Wiley and Sons, New York, p. 378.

Last, G.V., and T.L. Likala. 1987. A Field Guide for Well-site Geologists: Cable-tool Drilling.

PNL-6392, Battelle, Pacific Northwest Laboratory, Richland, Washington.

Munsell. 1975. Munsell Soil Color Charts. Macbeth, a Division of Kollmorgen Co., Baltimore, Maryland, 7 charts.

Tucker, M. E. 1982. The Field Description of Sedimentary Rocks. John Wiley and Sons, New York, p. 112. 
APPENDIX B

CORE DATA LOGS 


\section{Core Data Log}

Project: Richmond Harbor Intensive Study

Core \#: TB-1 Logger: PJ White

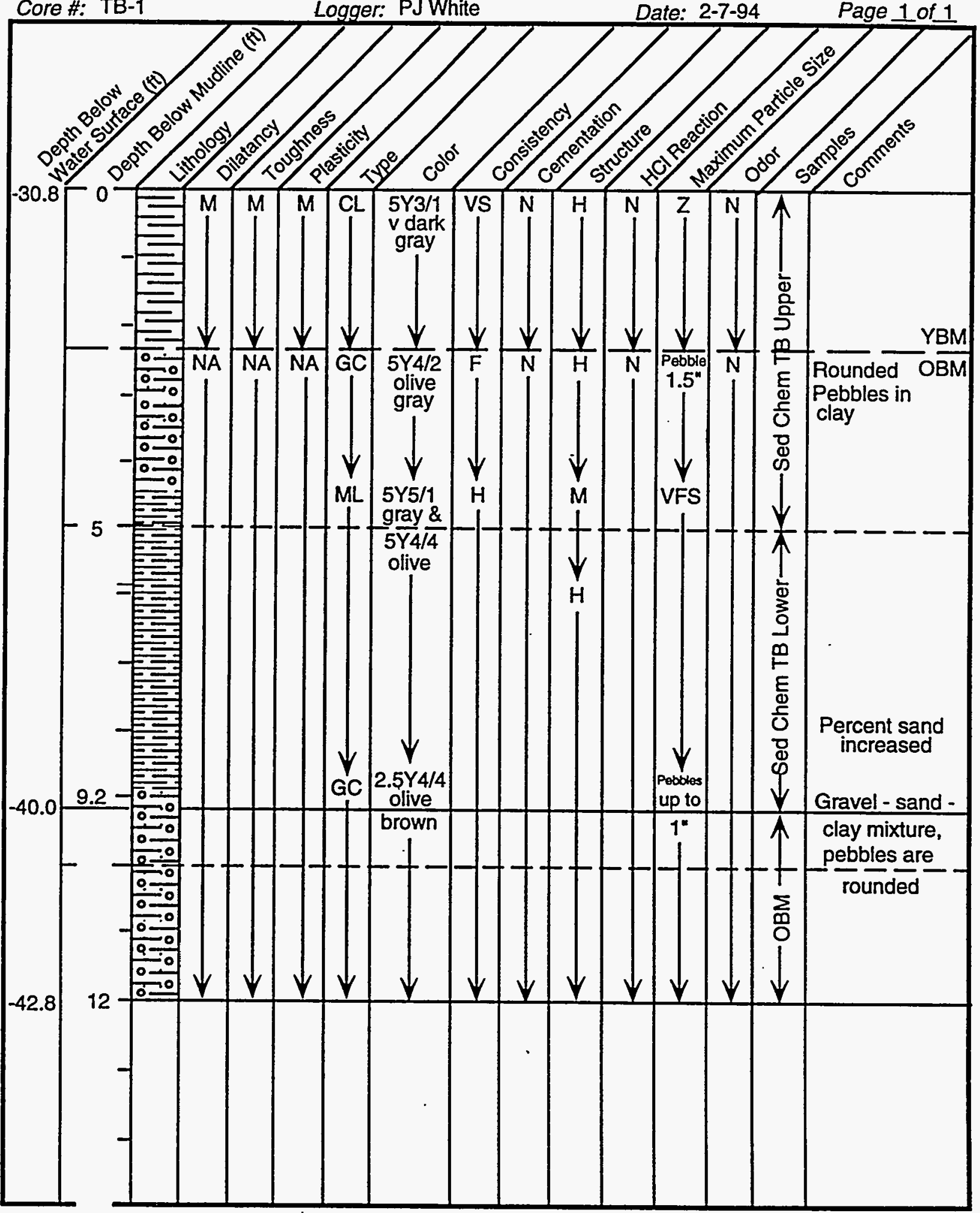


Core Data Log

Project: Richmond Harbor Intensive Study

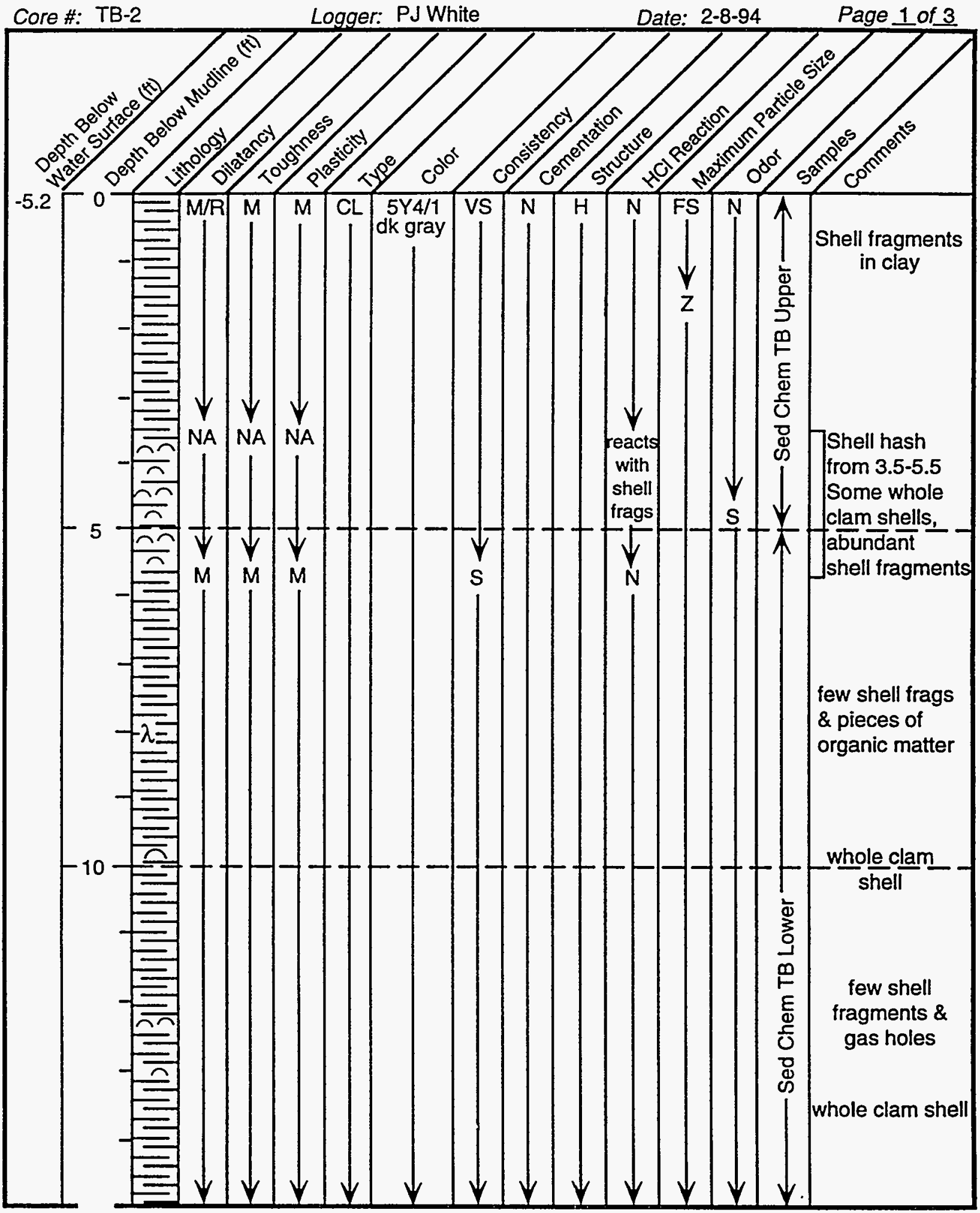


Project: Richmond Harbor Intensive Study

\section{Core Data Log}

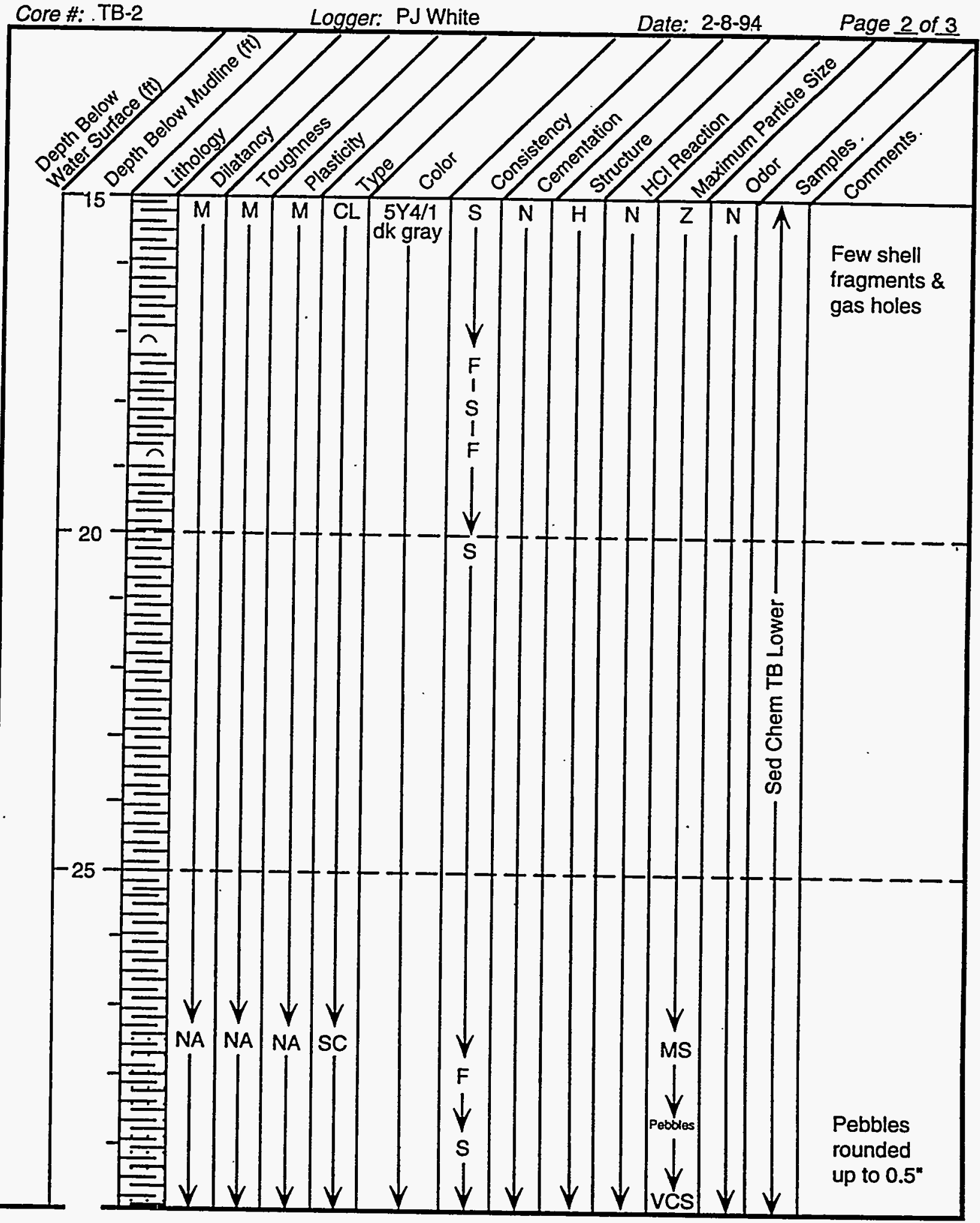




\section{Core Data Log}

Project: Richmond Harbor Intensive Study

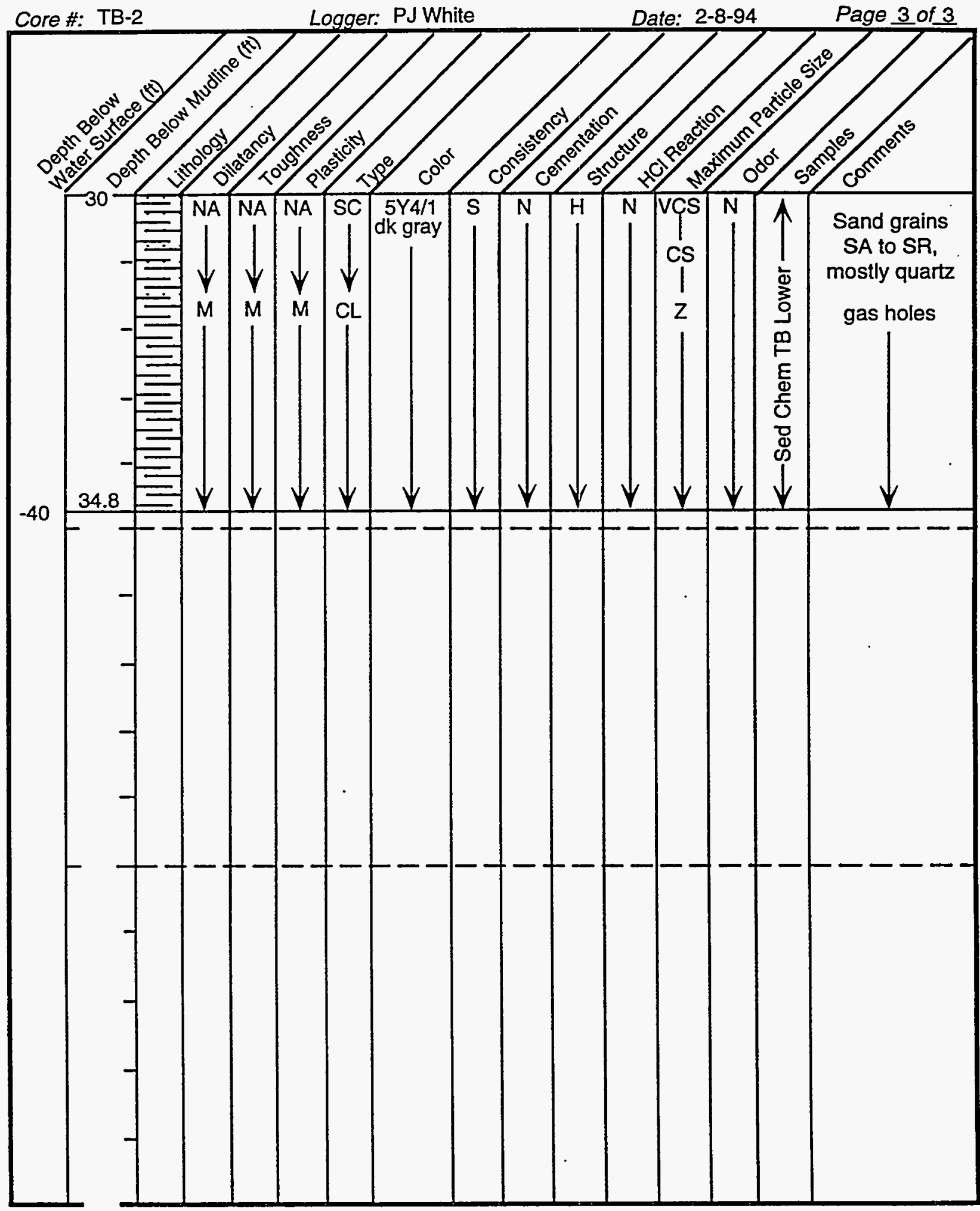


Core Data Log

Project: Richmond Harbor Intensive Study

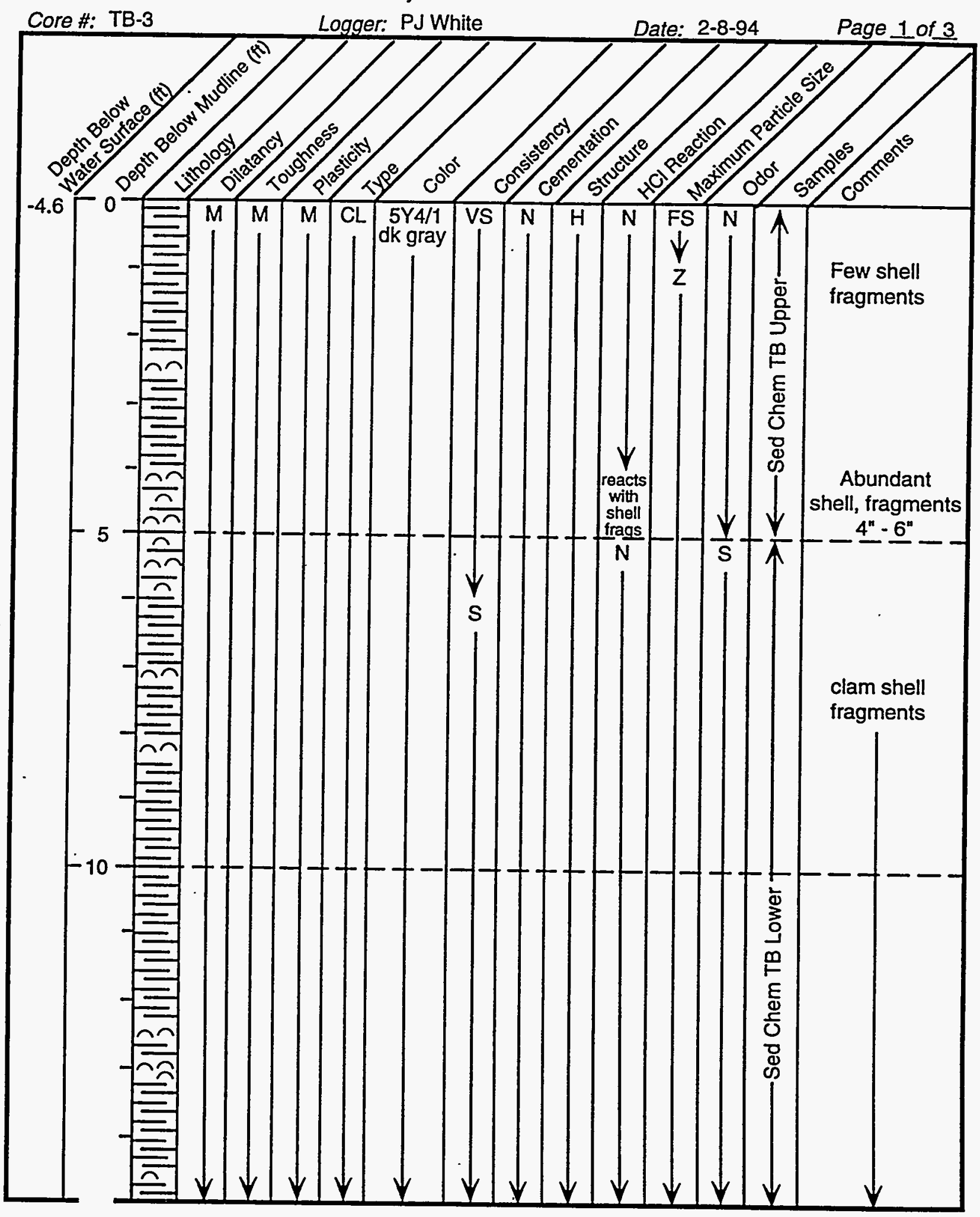


Core Data Log

Project: Richmond Harbor Intensive Study

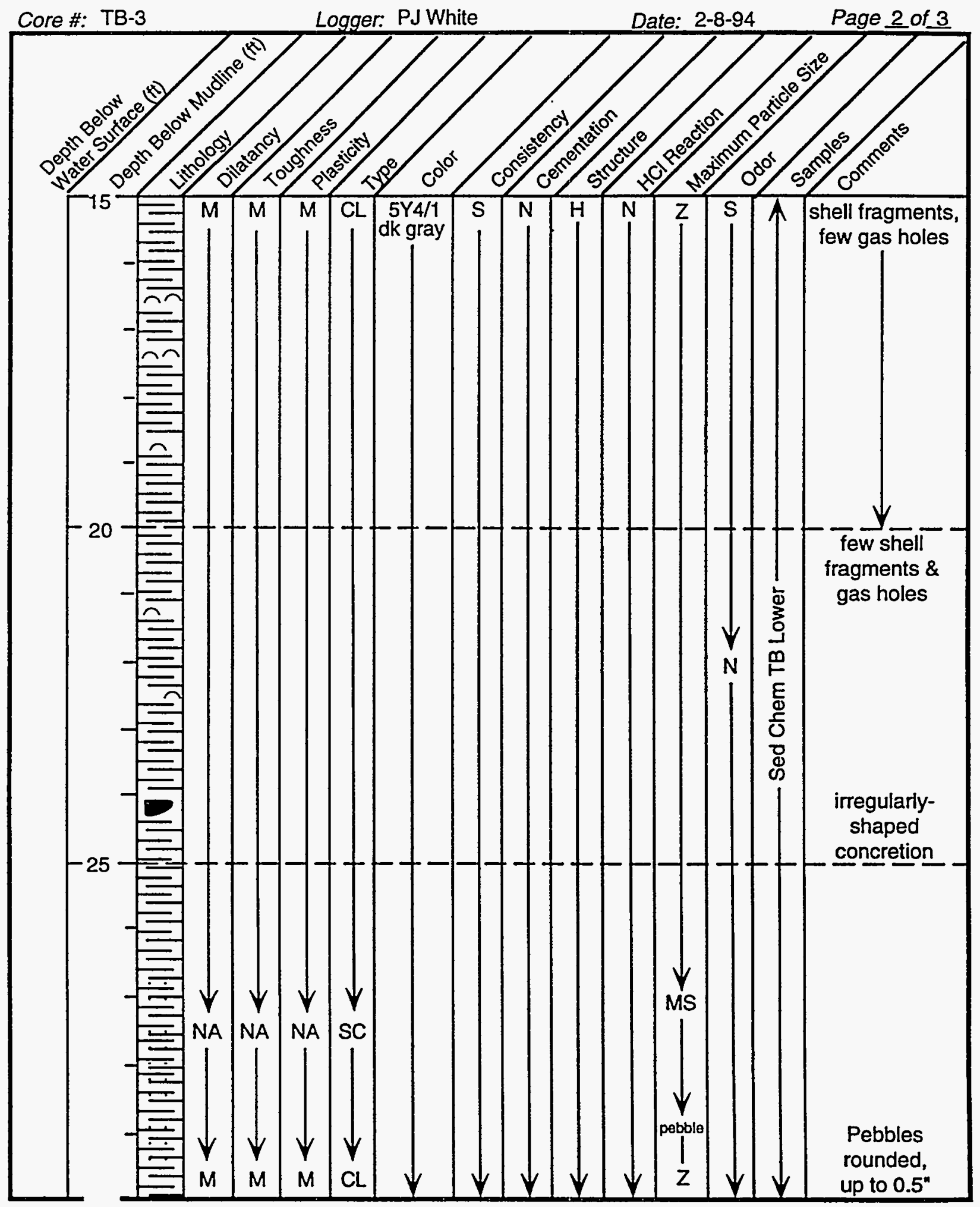




\section{Core Data Log}

Project: Richmond Harbor Intensive Study

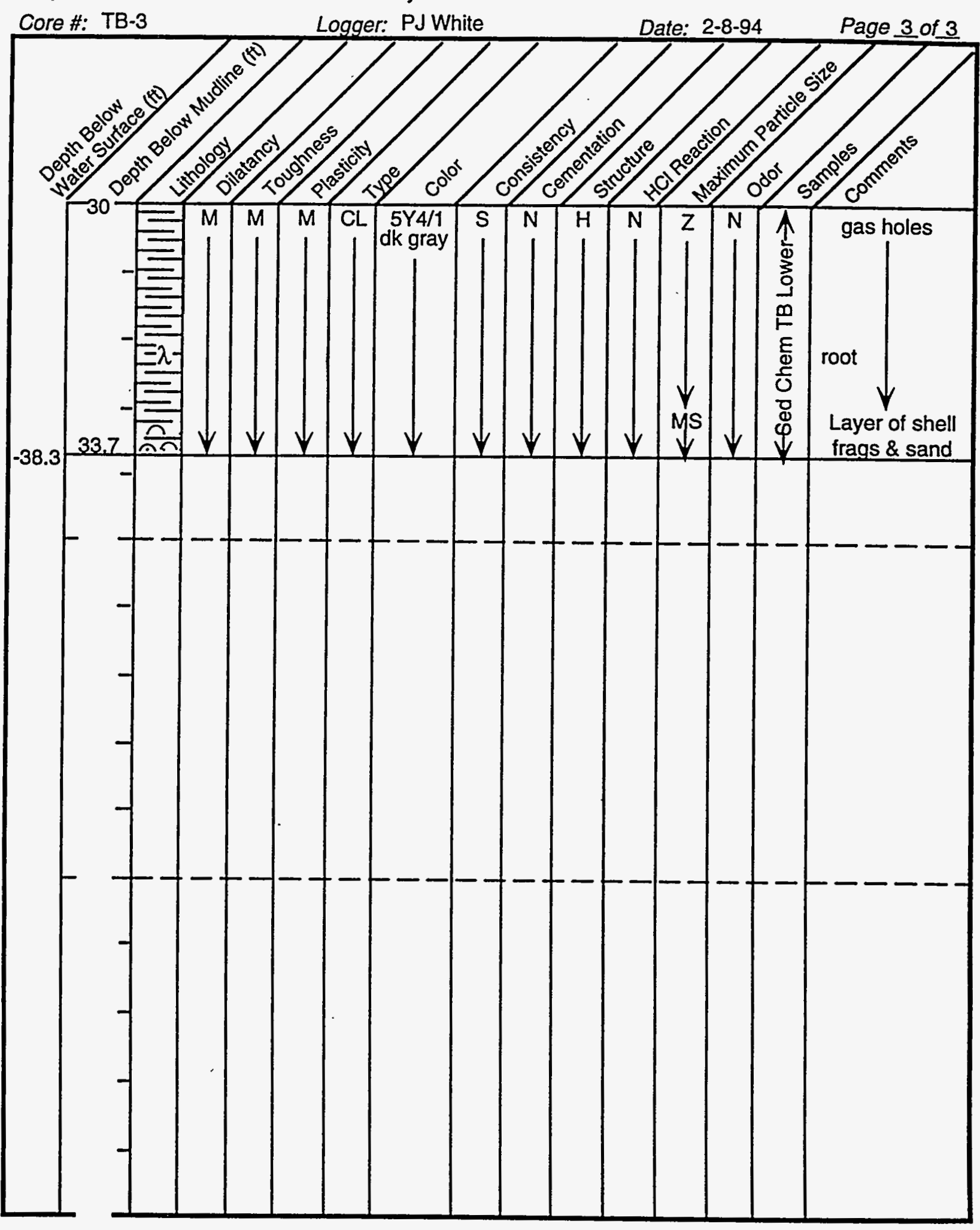


Core Data Log

Project: Richmond Harbor Intensive Study

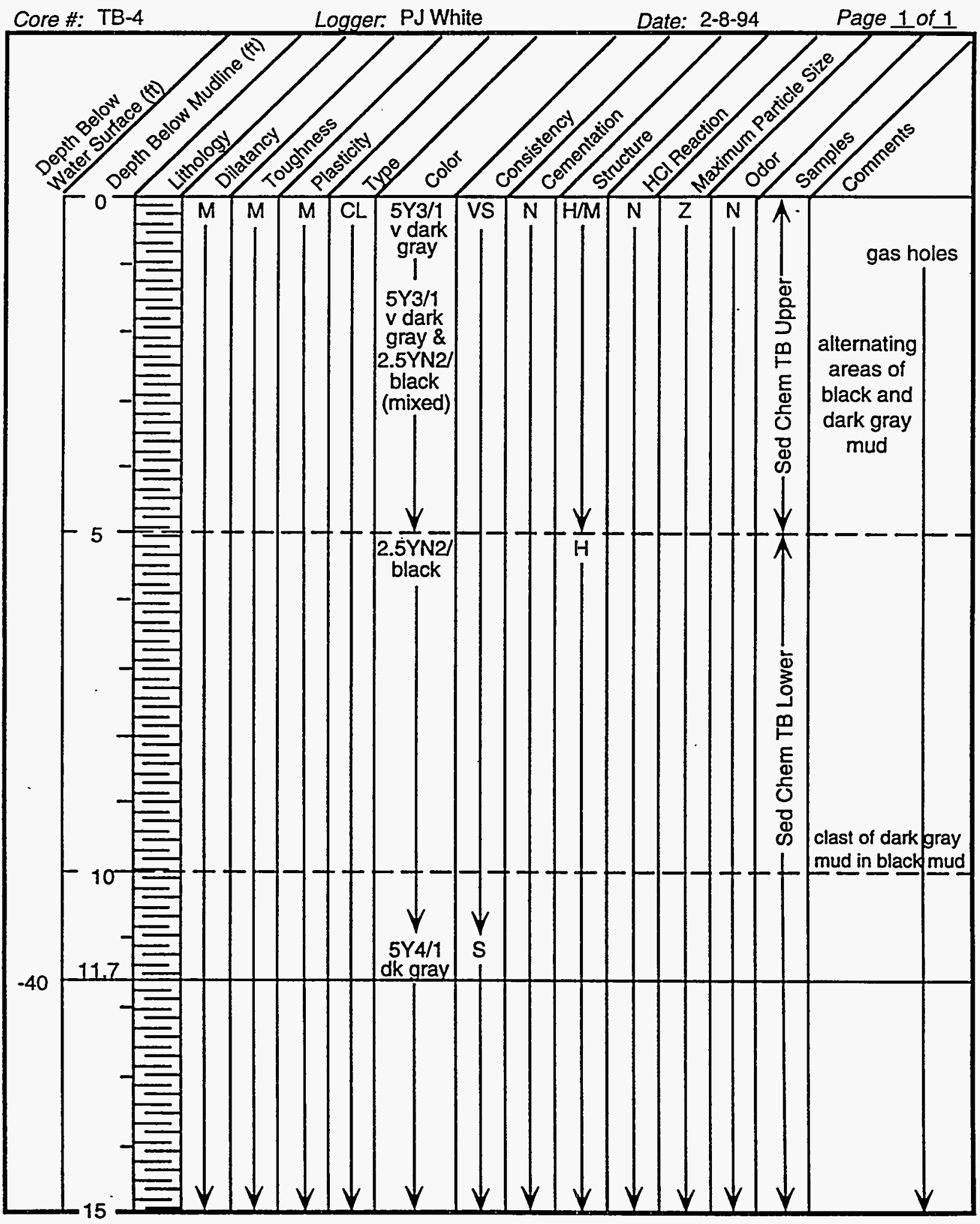




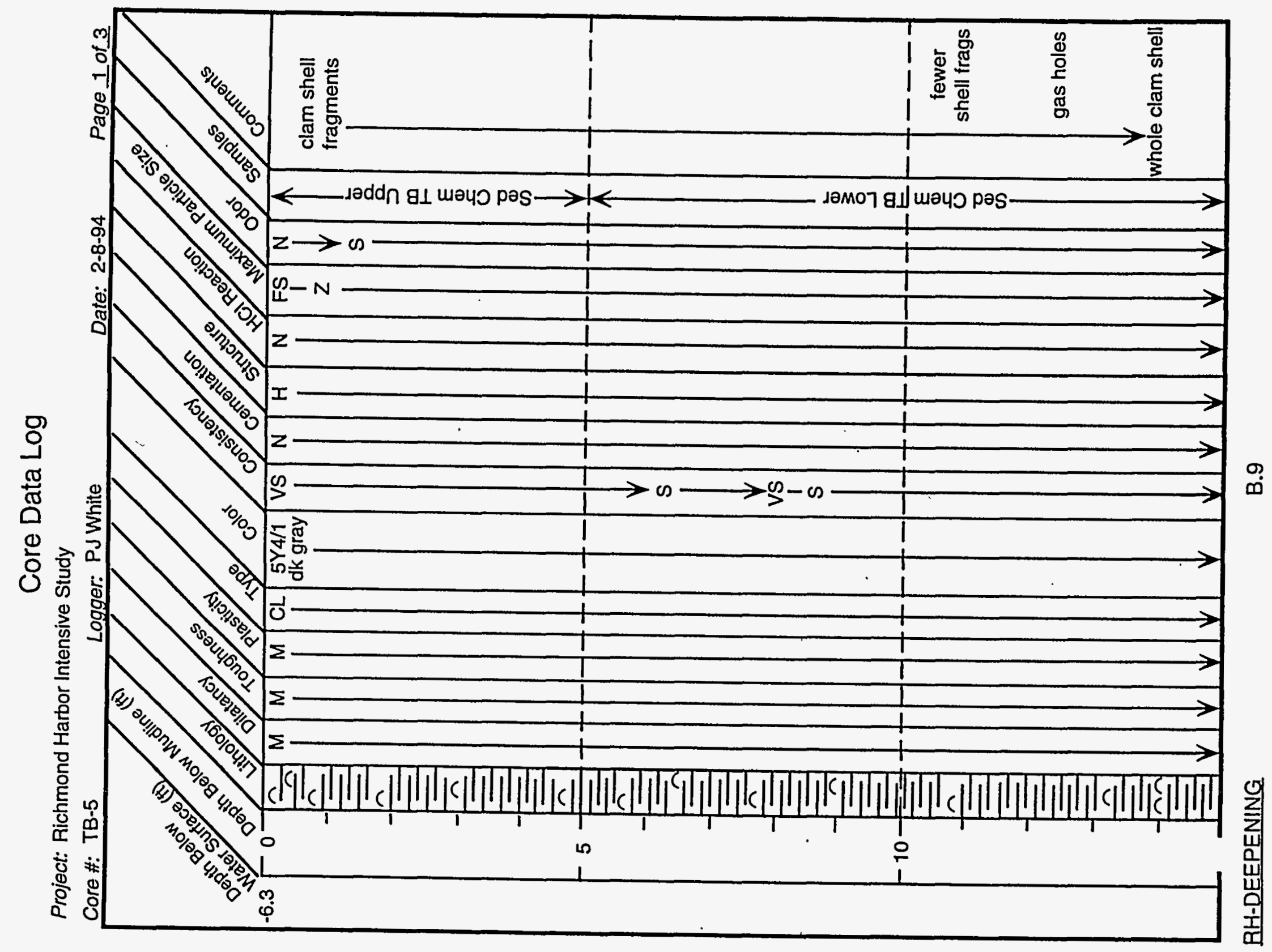




\section{Core Data Log}

Project: Richmond Harbor Intensive Study

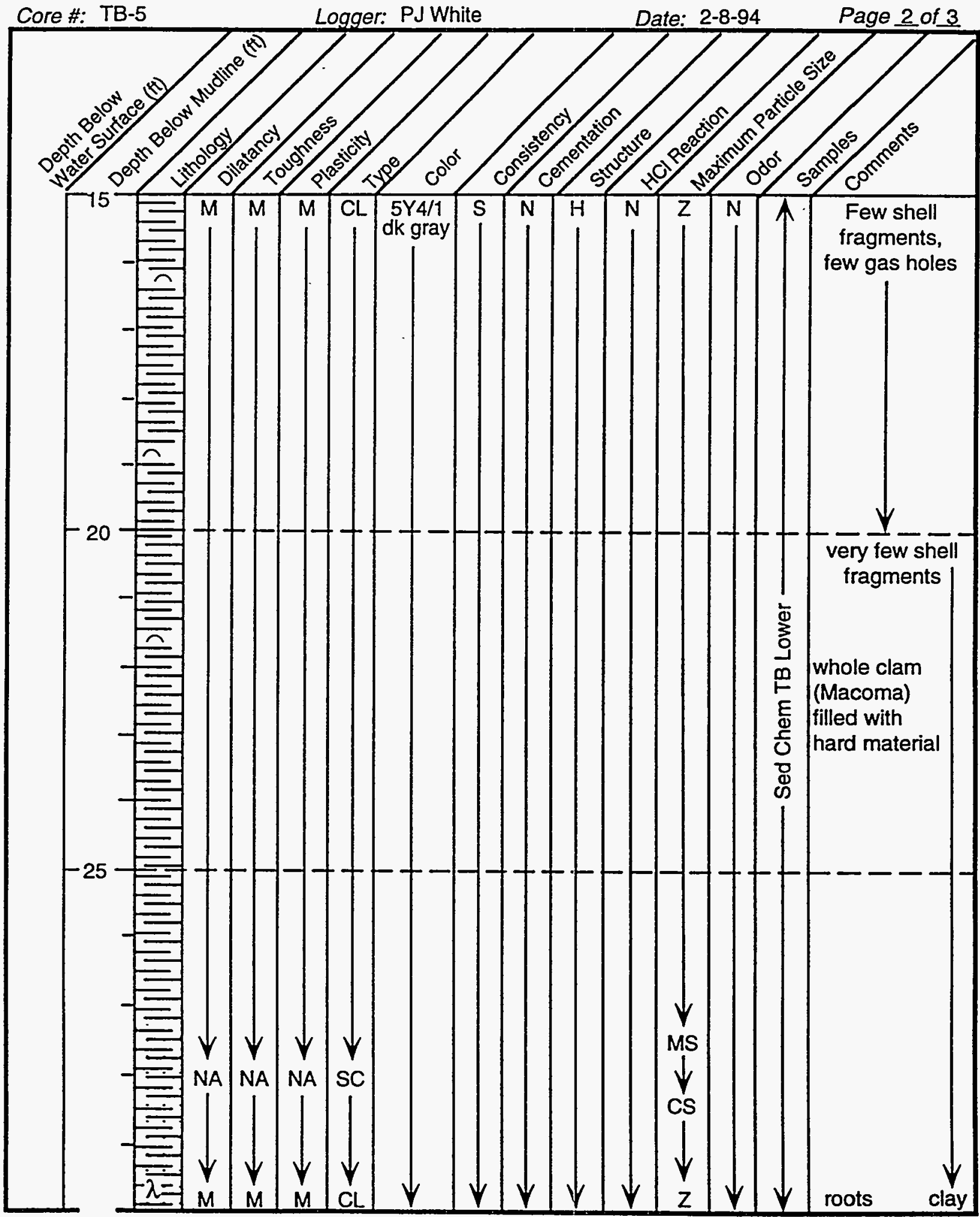


Core Data Log

Project: Richmond Harbor Intensive Study

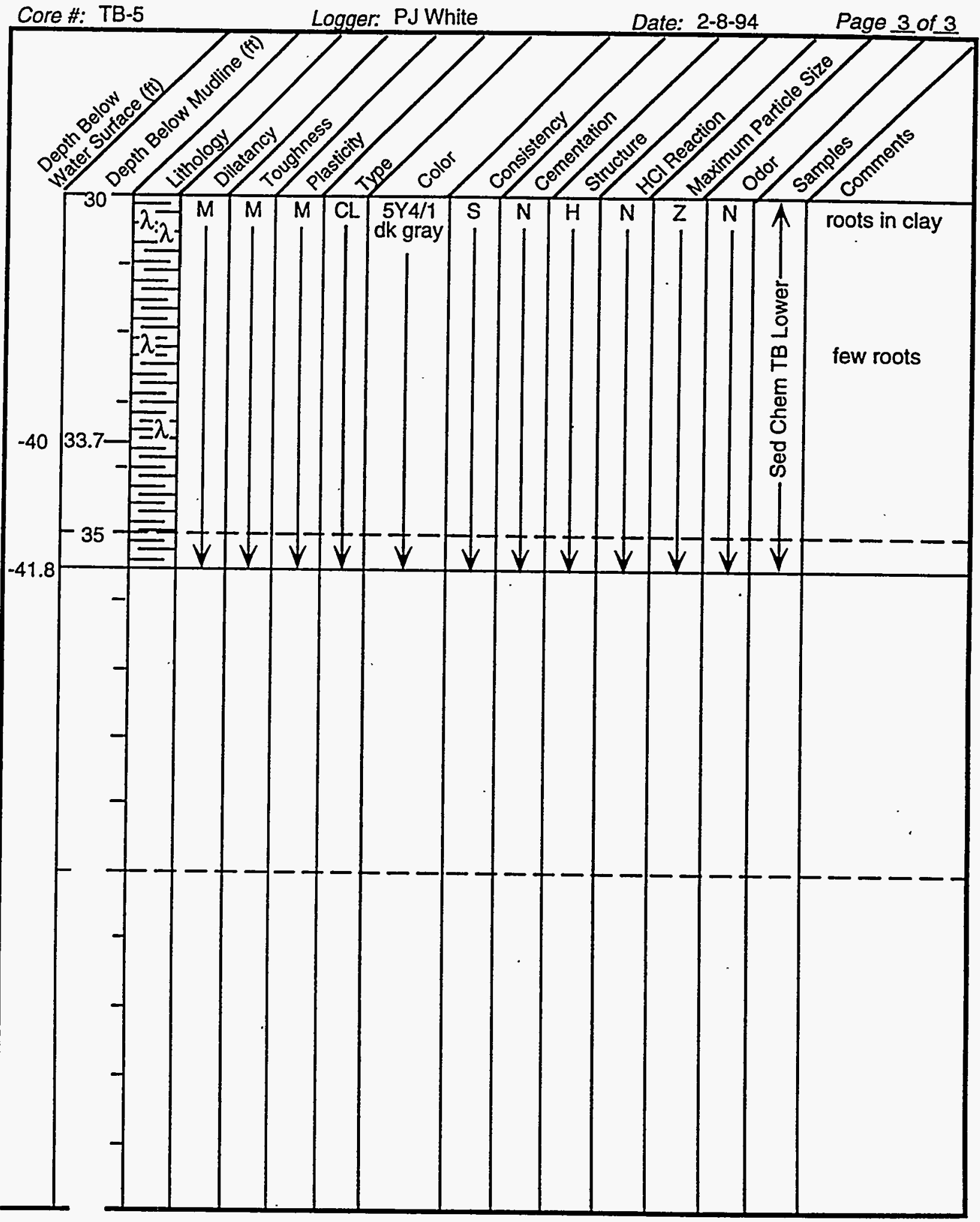


Core Data Log

Project: Richmond Harbor Intensive Study

Core \#: TB-6 Logger: PJ White

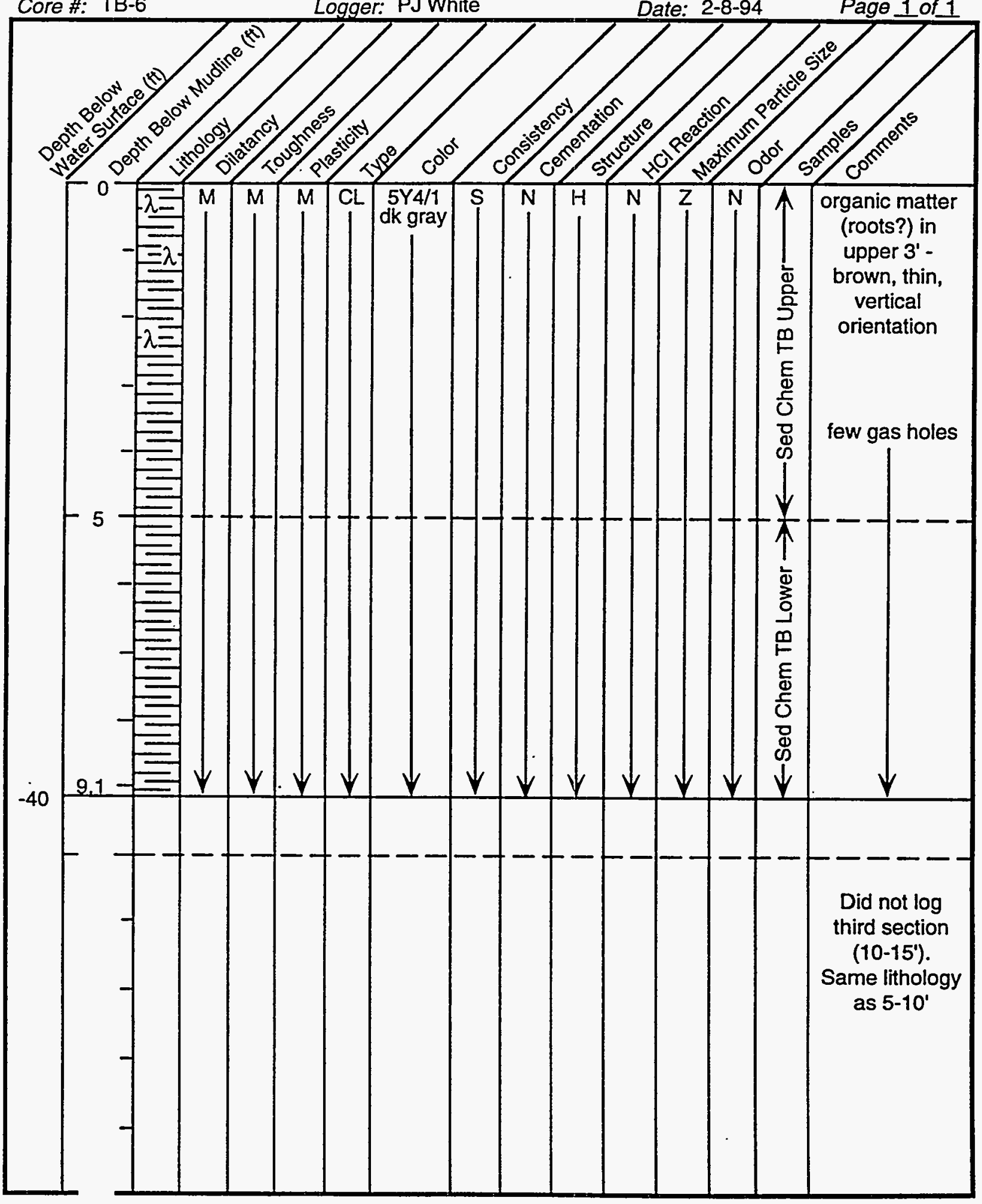

RH-DEEPENING

B.12 
Core Data Log

Project: Richmond Harbor Intensive Study

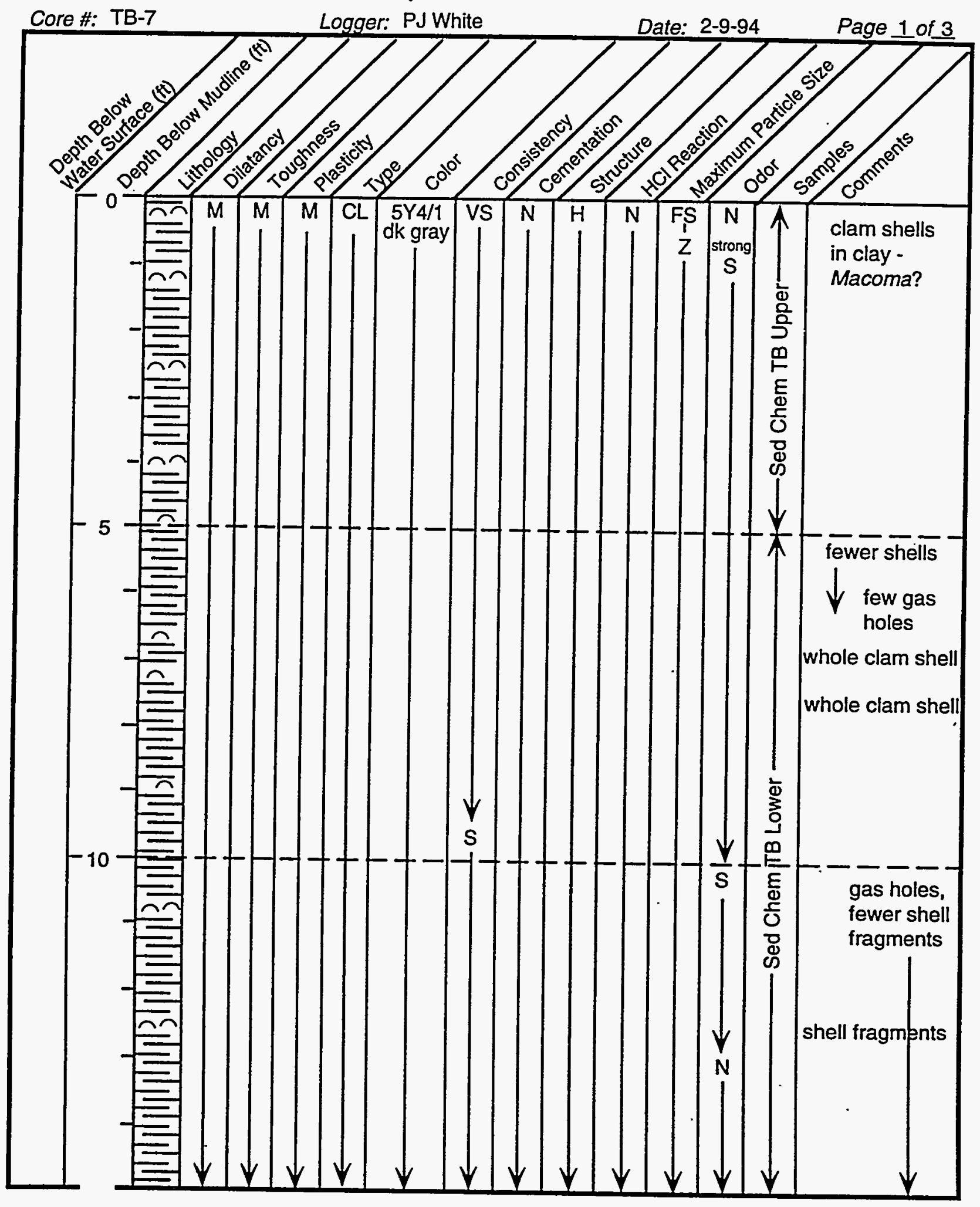


Core Data Log

Project: Richmond Harbor Intensive Study

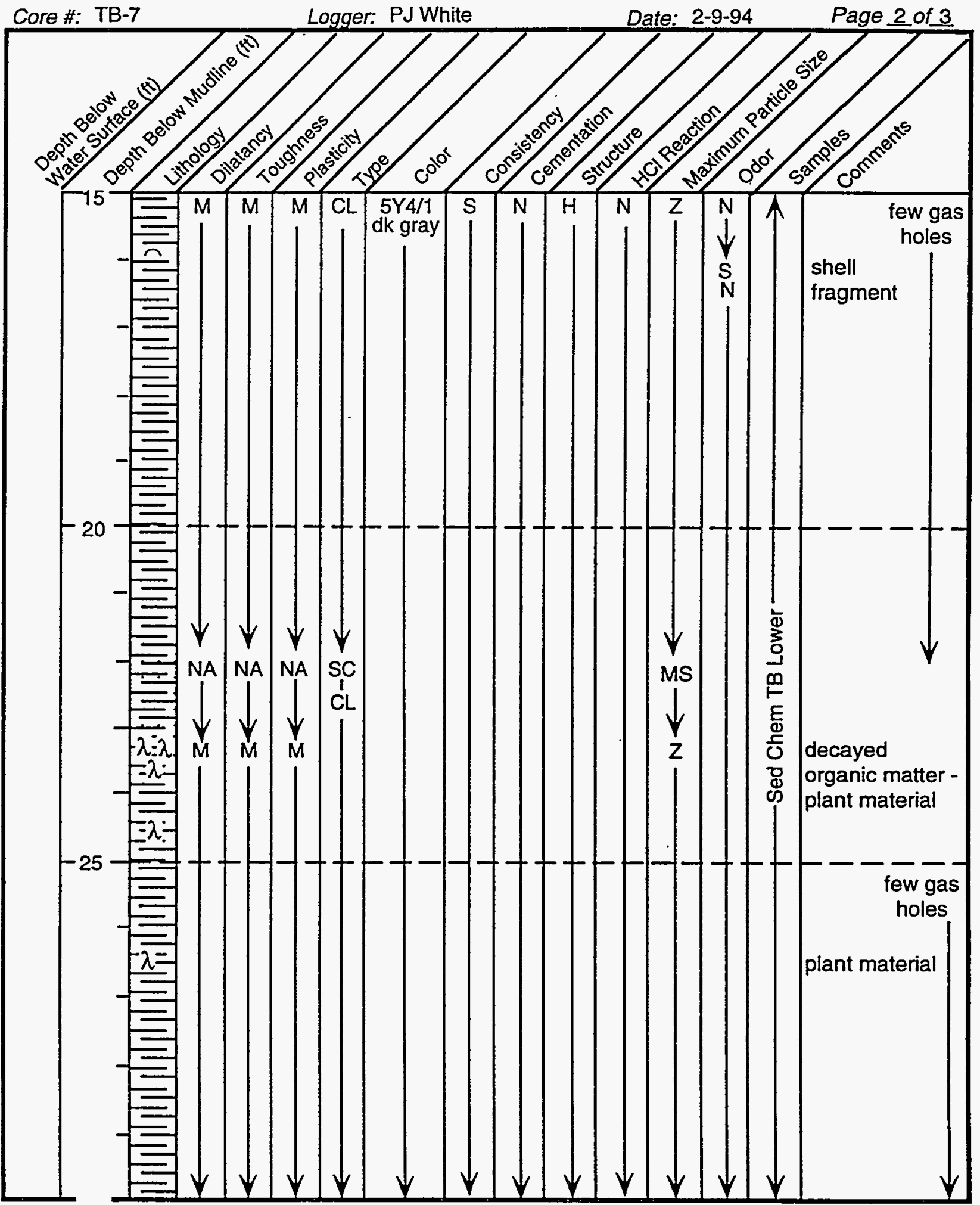


Project: Richmond Harbor Intensive Study

Core Data Log

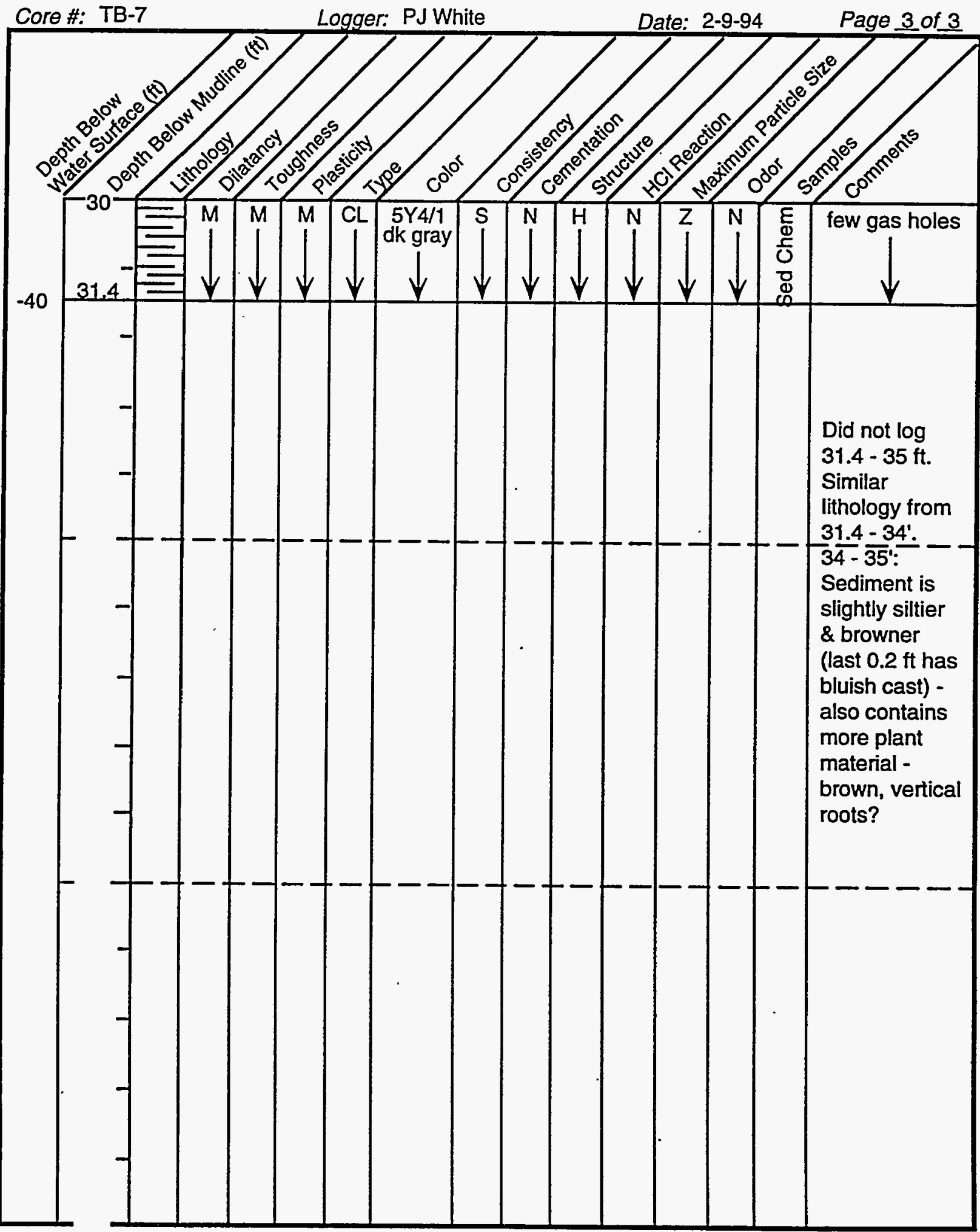


Core Data Log

Project: Richmond Harbor Intensive Study

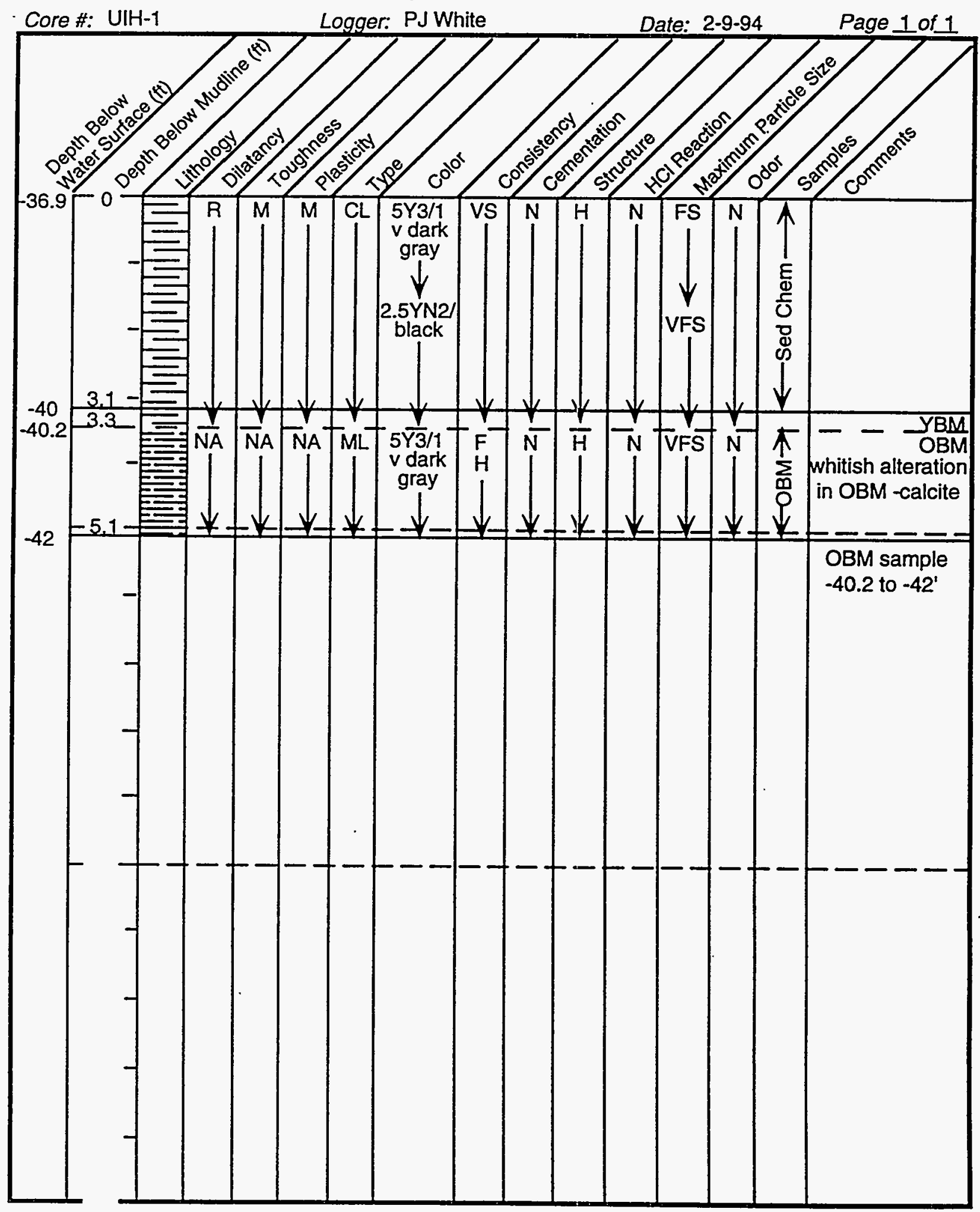


Core Data Log

Project: Richmond Harbor Intensive Study

Core \#: UIH-2

Logger: PJ White

Date: 2-9-94 Page 1 of 1

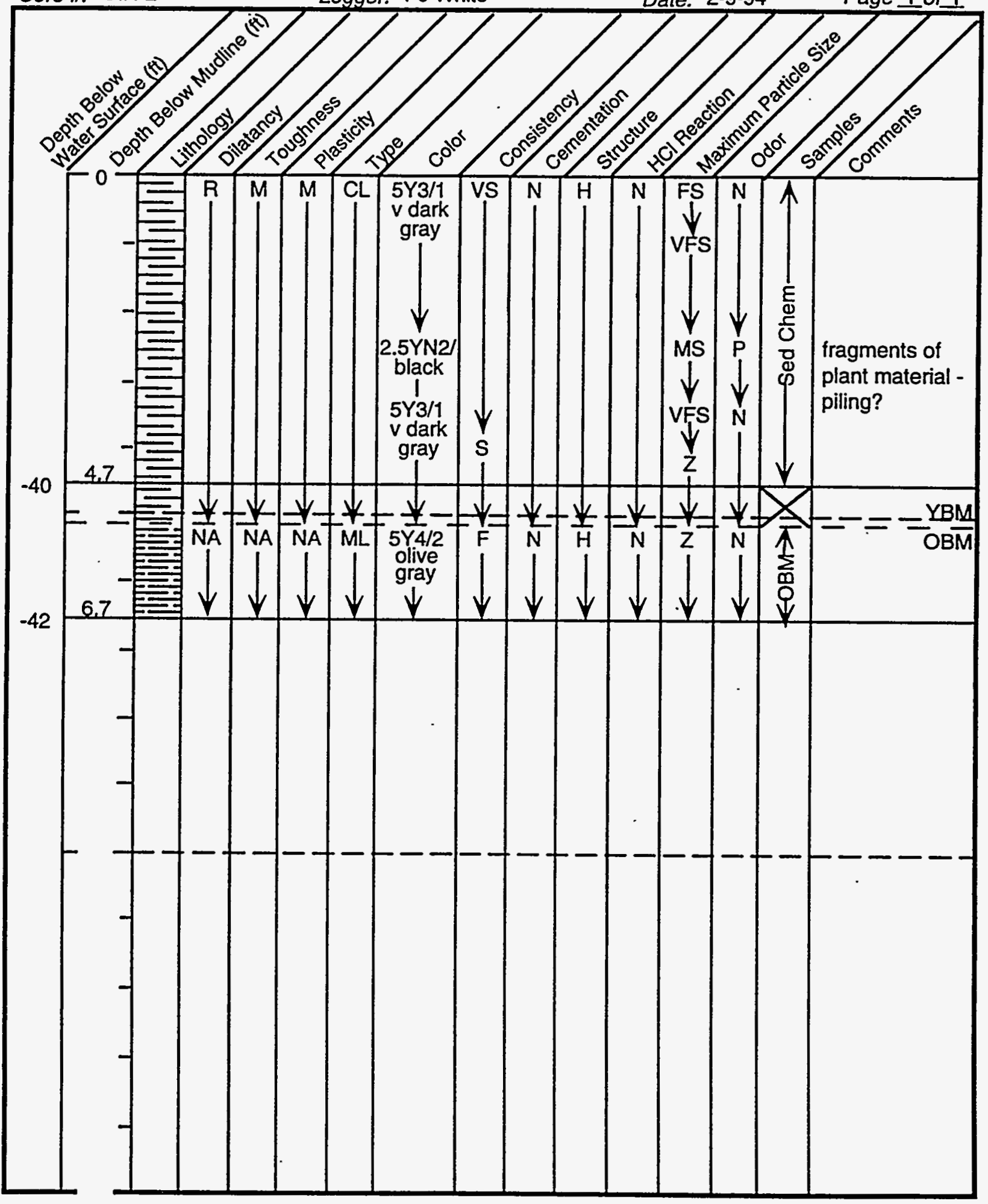

RH-DEEPENING

B.17 
Core Data Log

Project: Richmond Harbor Intensive Study

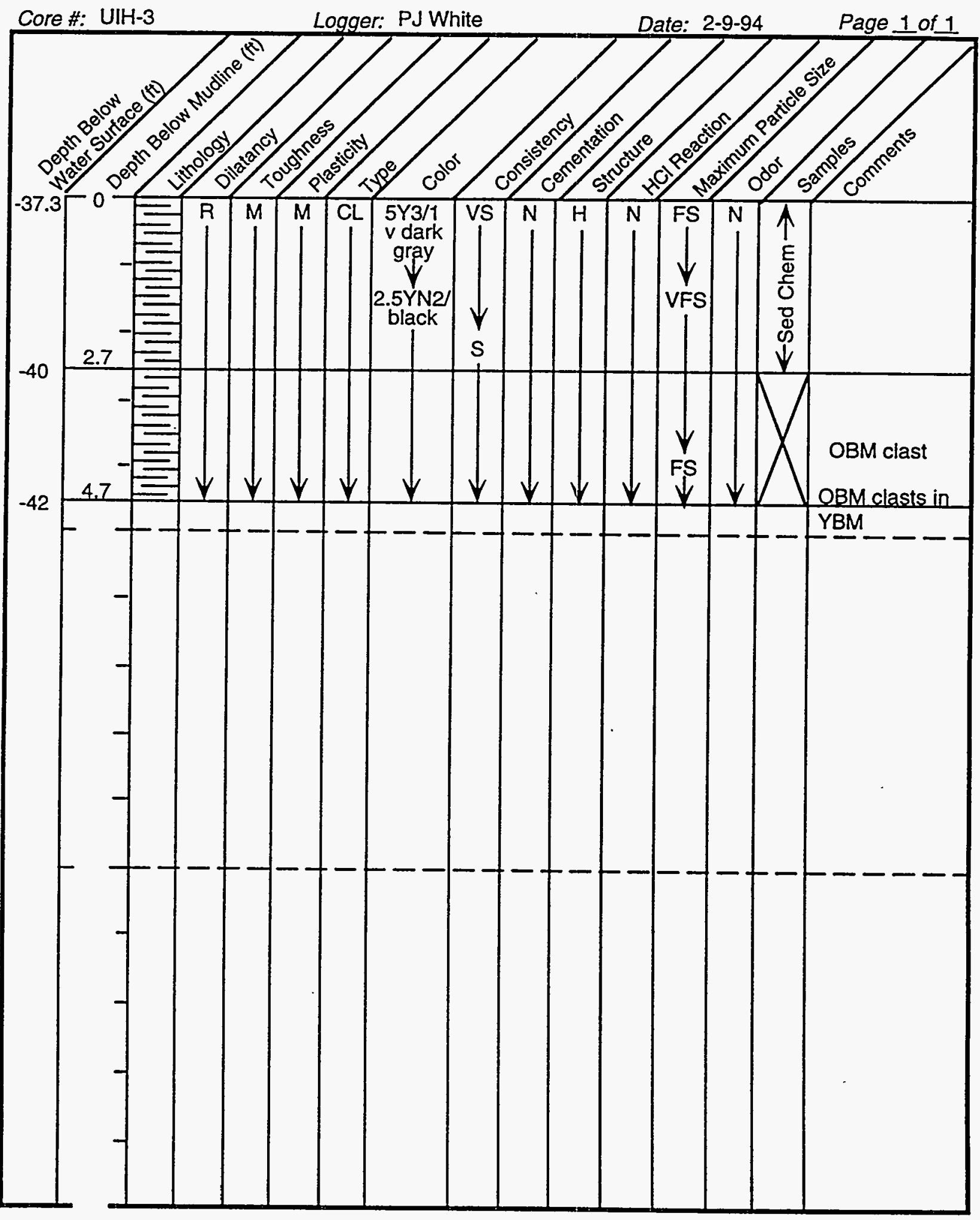


Core Data Log

Project: Richmond Harbor Intensive Study

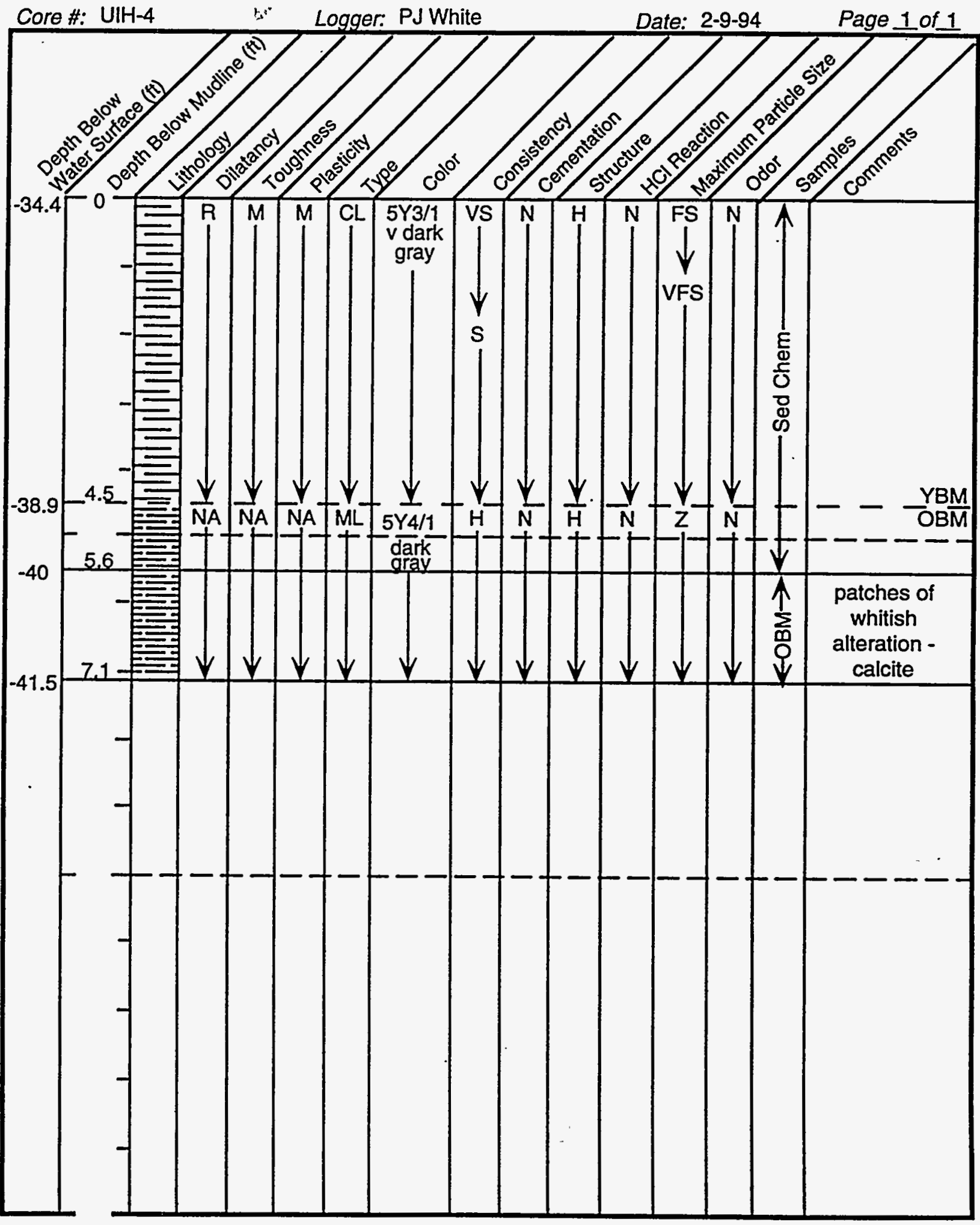

RH-DEEPENING

B.19 


\section{Core Data Log}

Project: Richmond Harbor Intensive Study

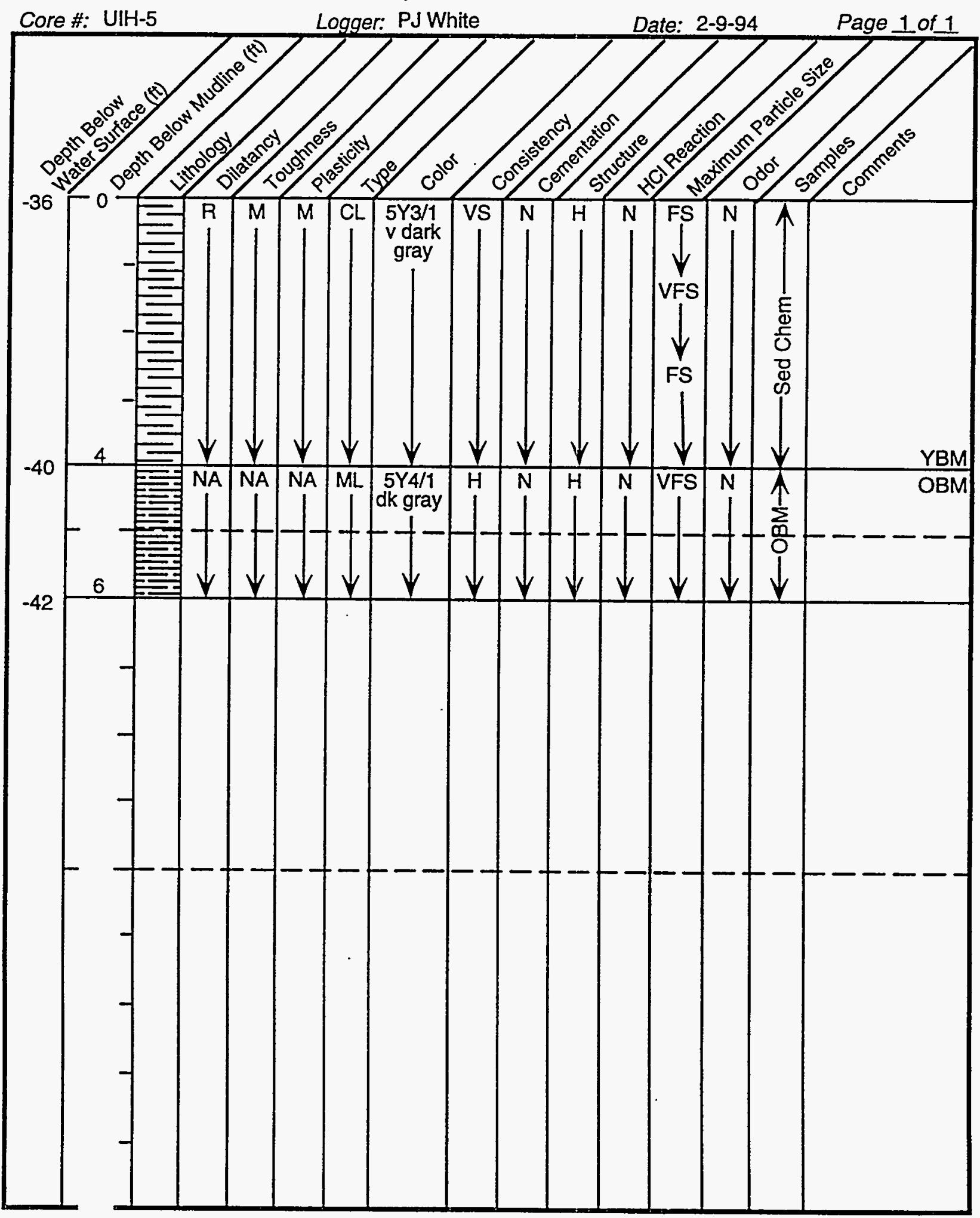




\section{Core Data Log}

Project: Richmond Harbor Intensive Study

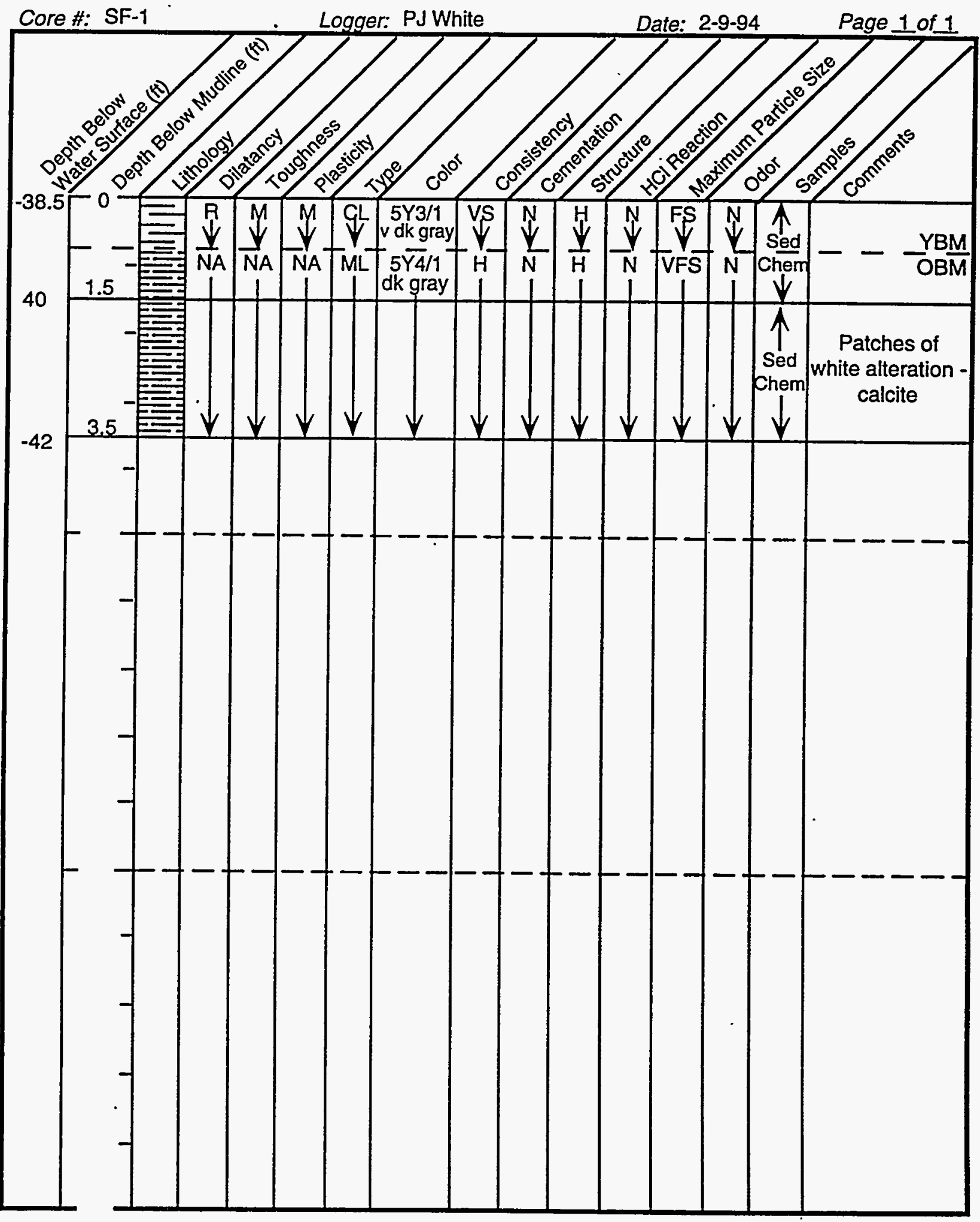

RH-DEEPENING

B.21 
Project: Richmond Harbor Intensive Study

Core Data Log

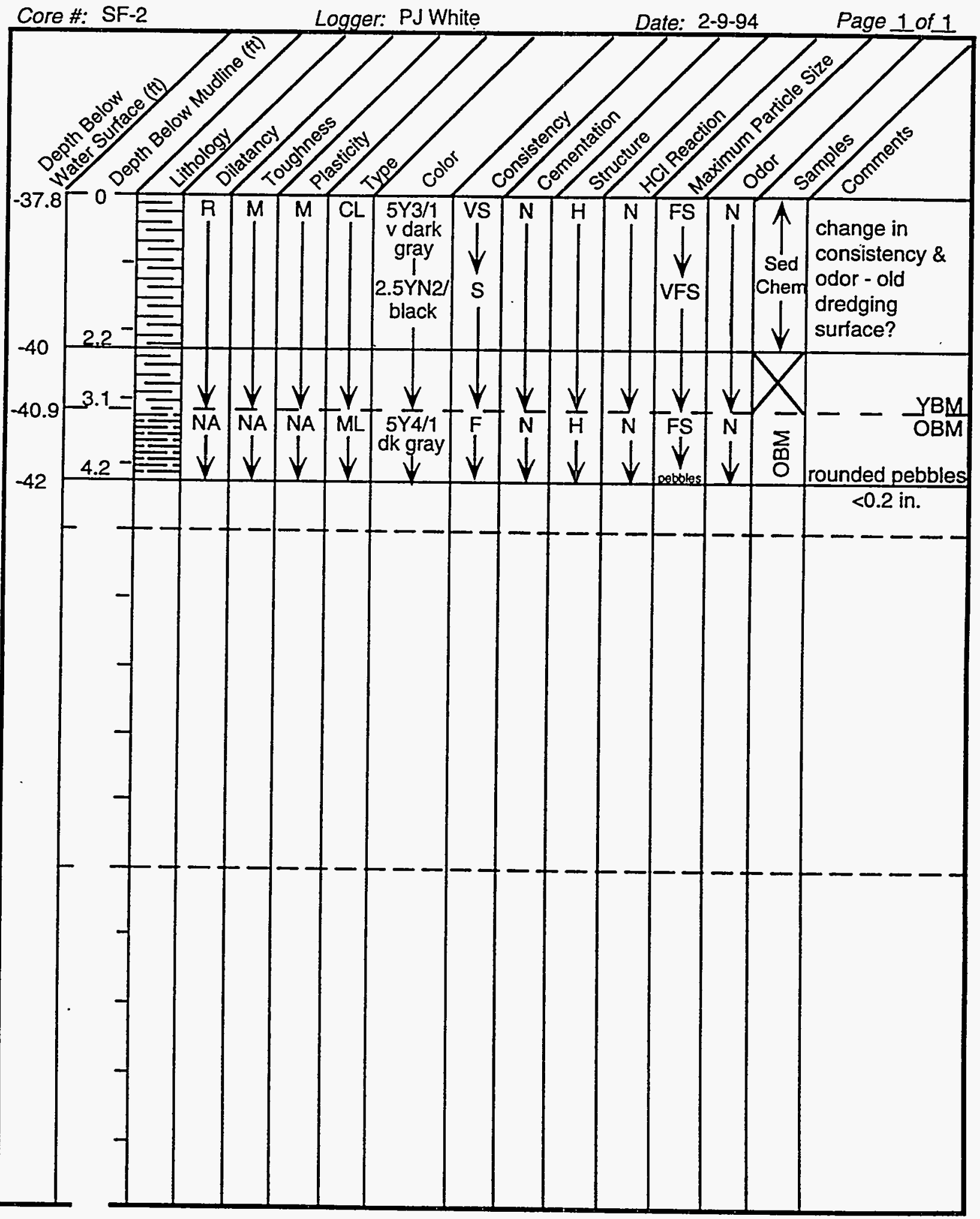


Core Data Log

Project: Richmond Harbor Intensive Study

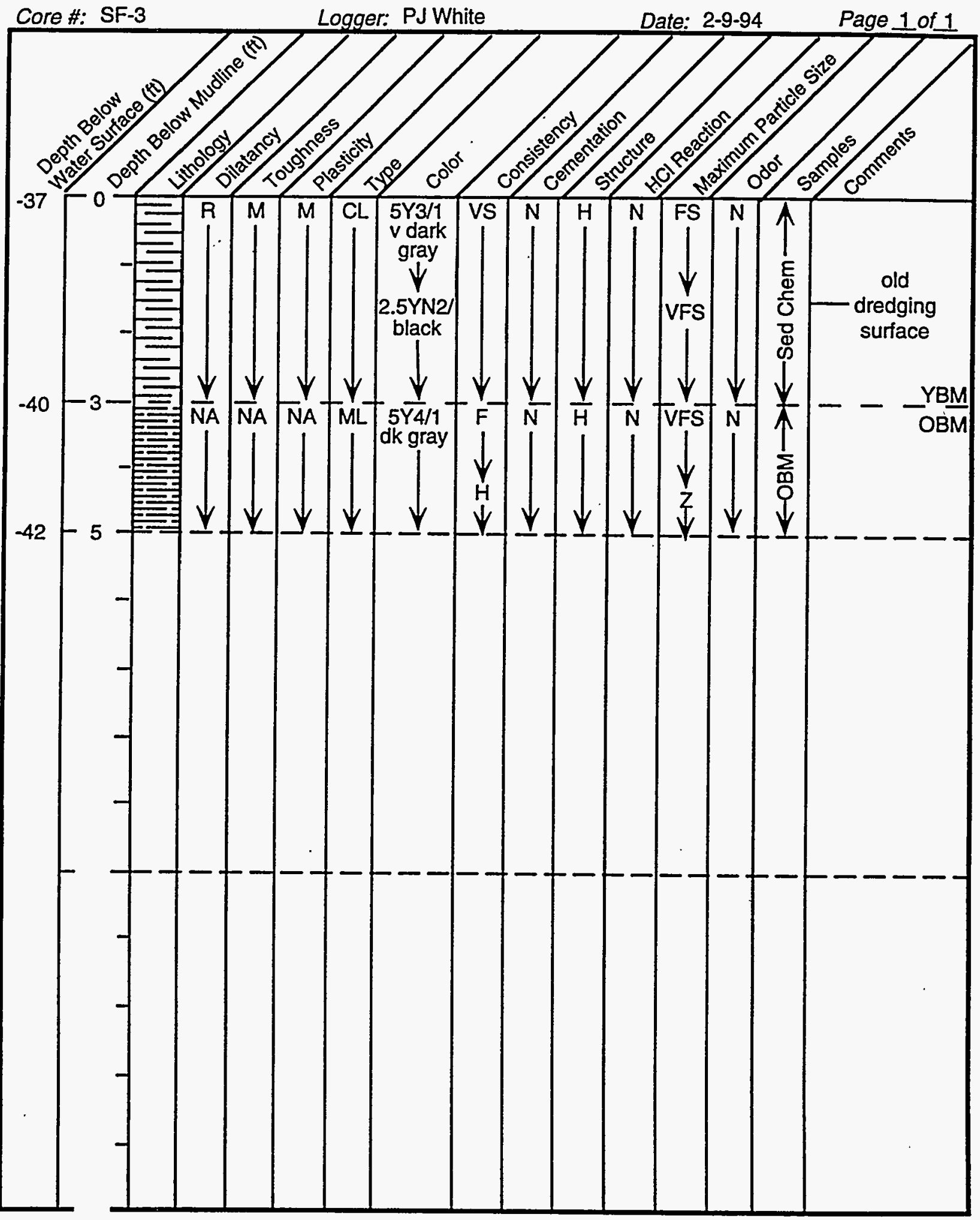




\section{Core Data Log}

Project: Richmond Harbor Intensive Study

Core \#: SF-4 Logger: PJ White

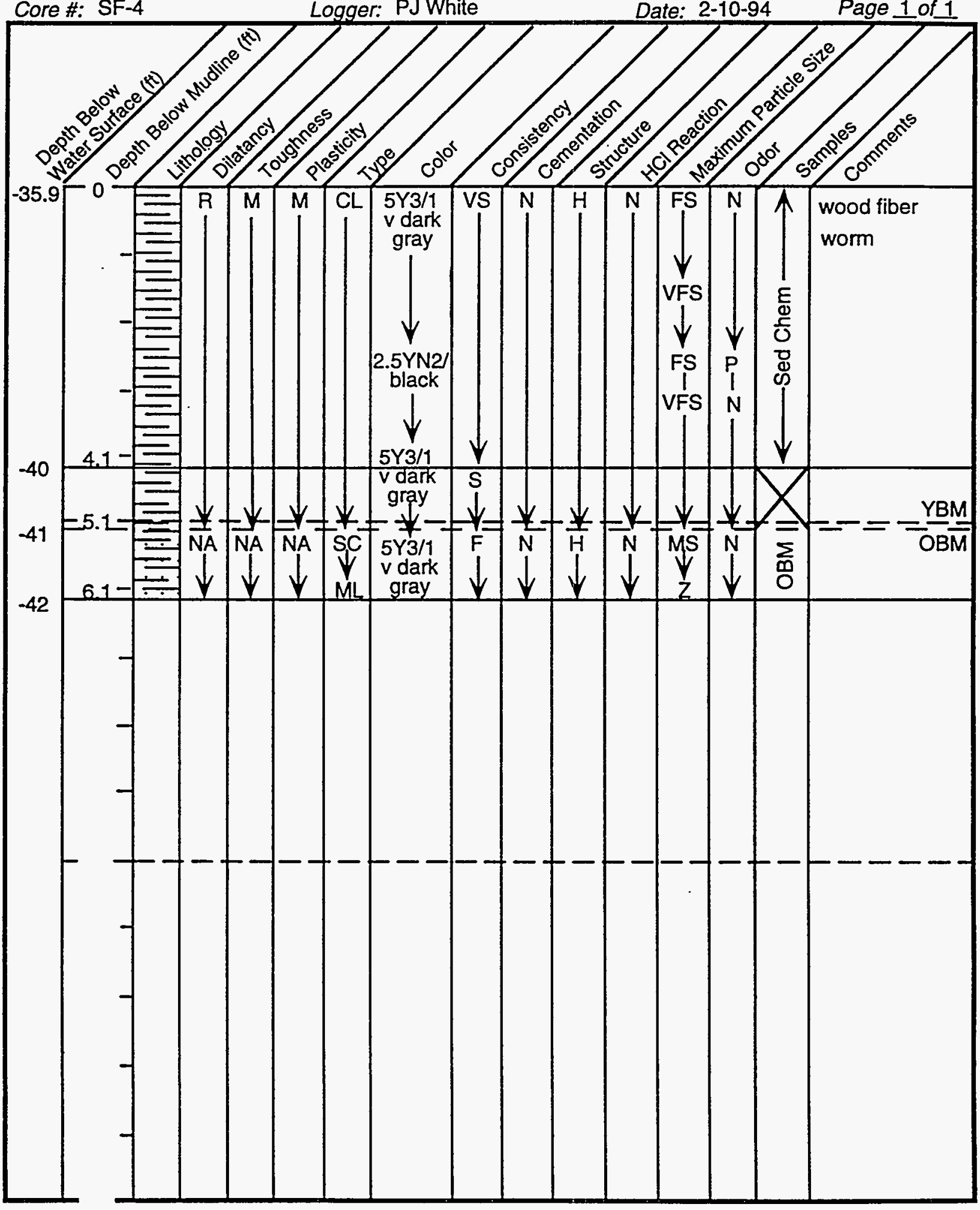

RH-DEEPENING 
Project: Richmond Harbor Intensive Study

\section{Core Data Log}

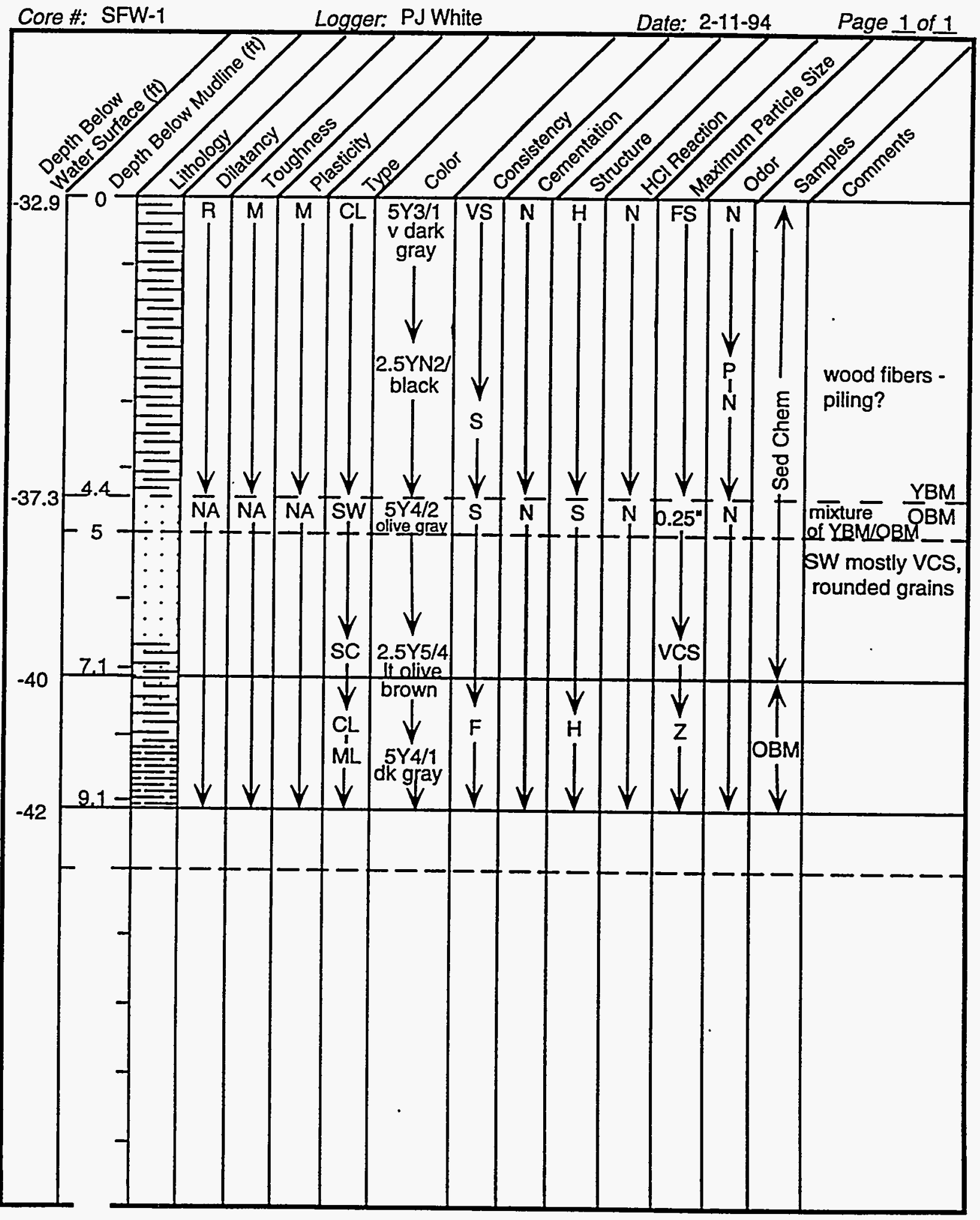


Core Data Log

Project: Richmond Harbor Intensive Study

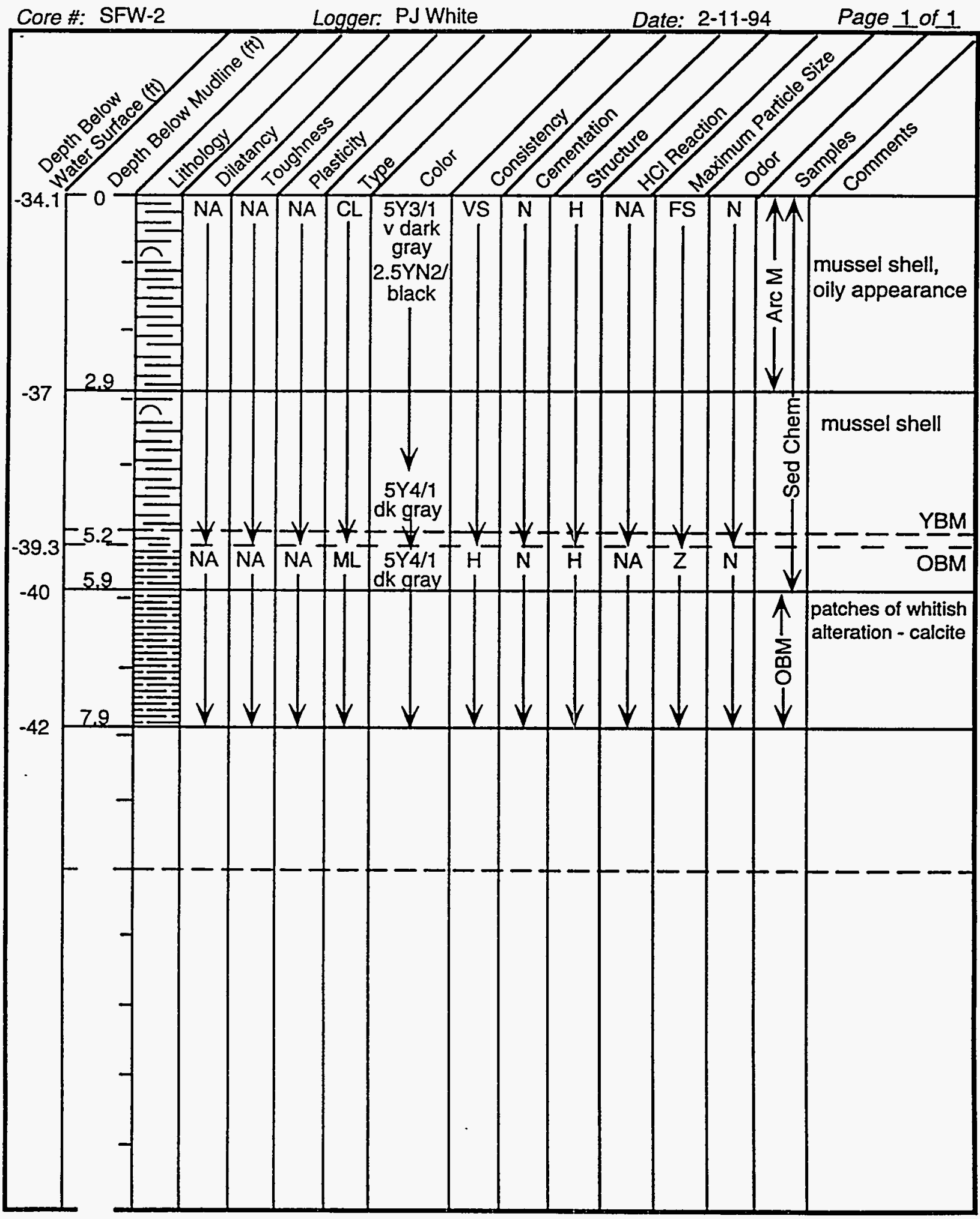




\section{Core Data Log}

Project: Richmond Harbor Intensive Study

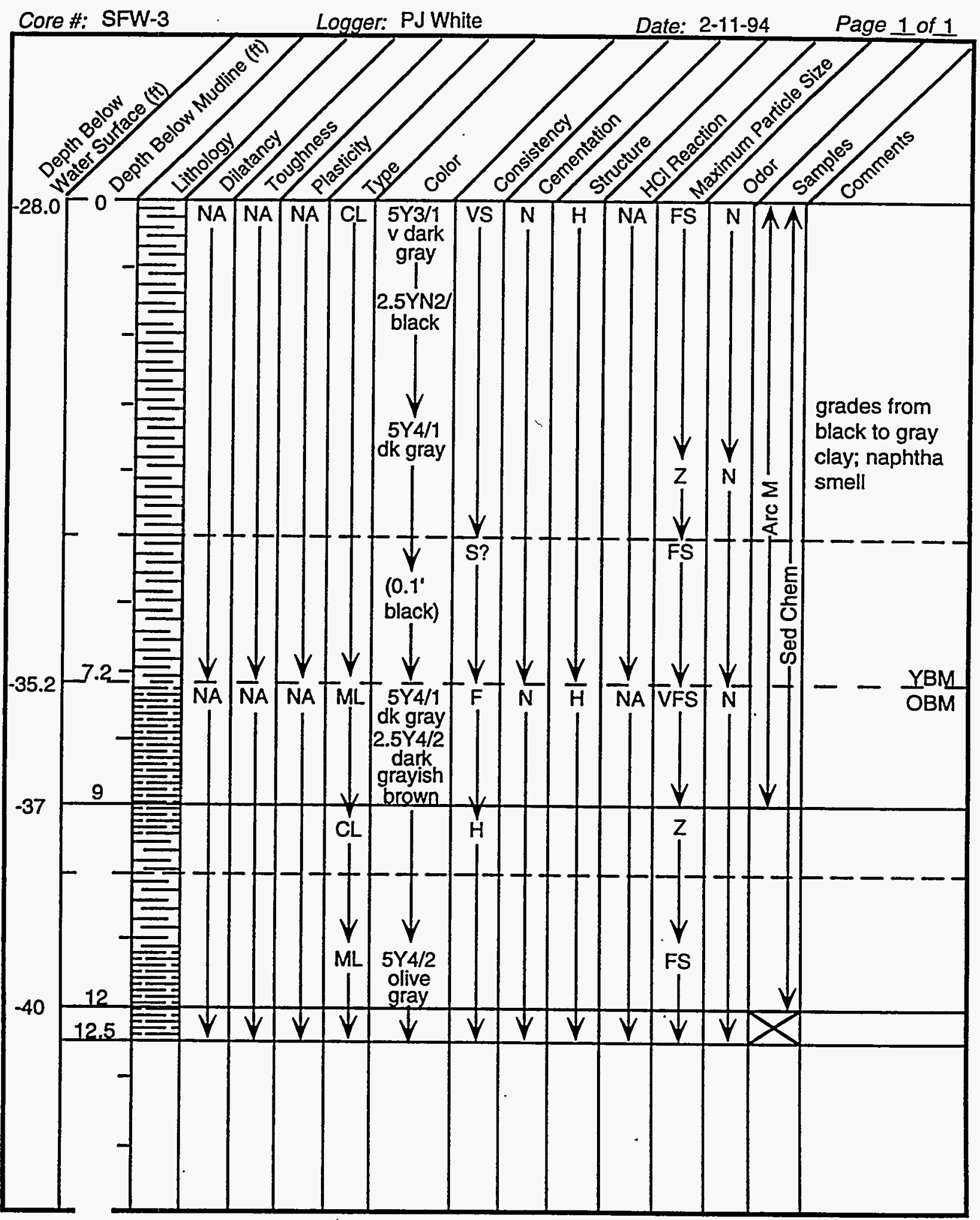


Core Data Log

Project: Richmond Harbor Intensive Study

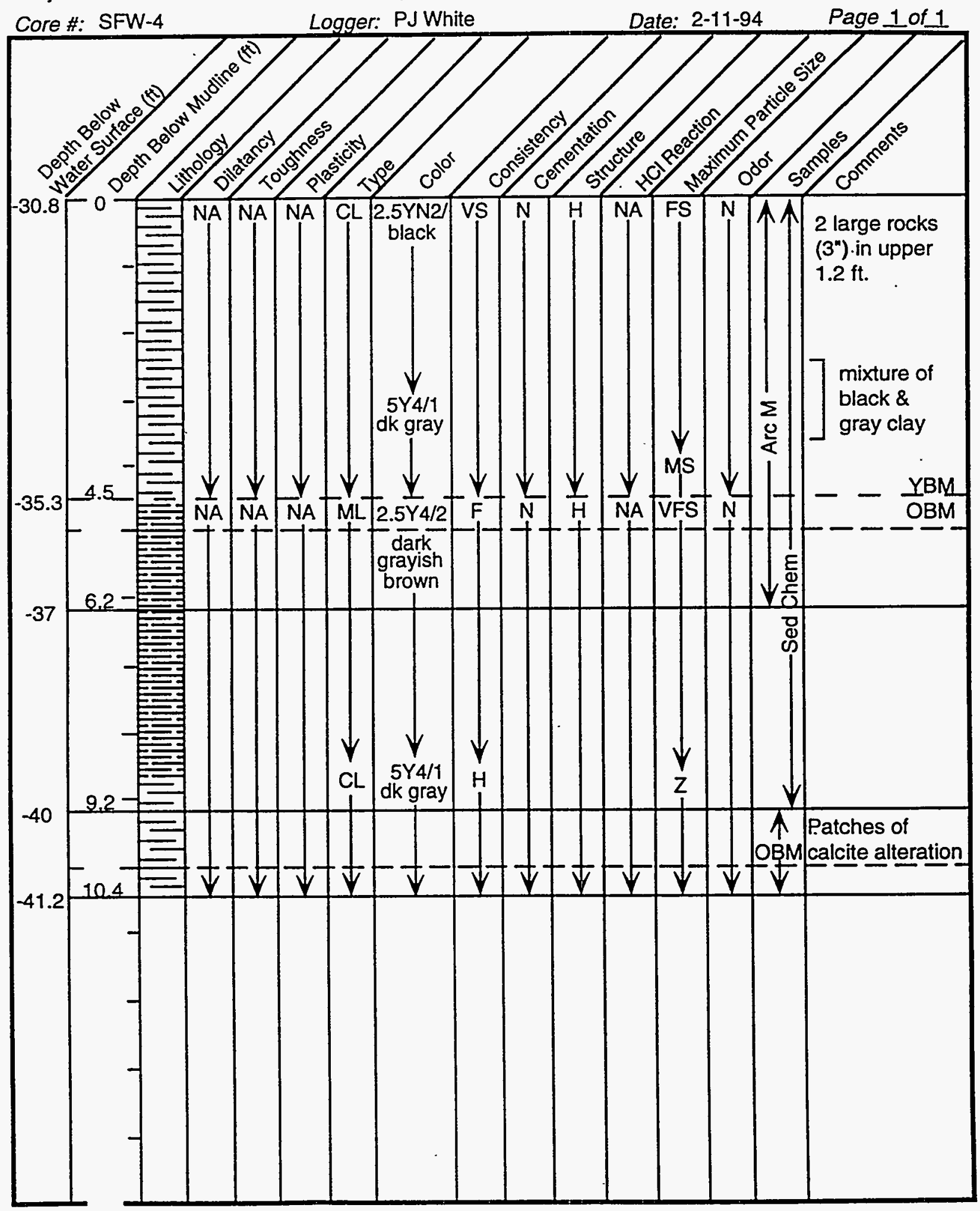


Core Data Log

Project: Richmond Harbor Intensive Study of the Tuming Basin

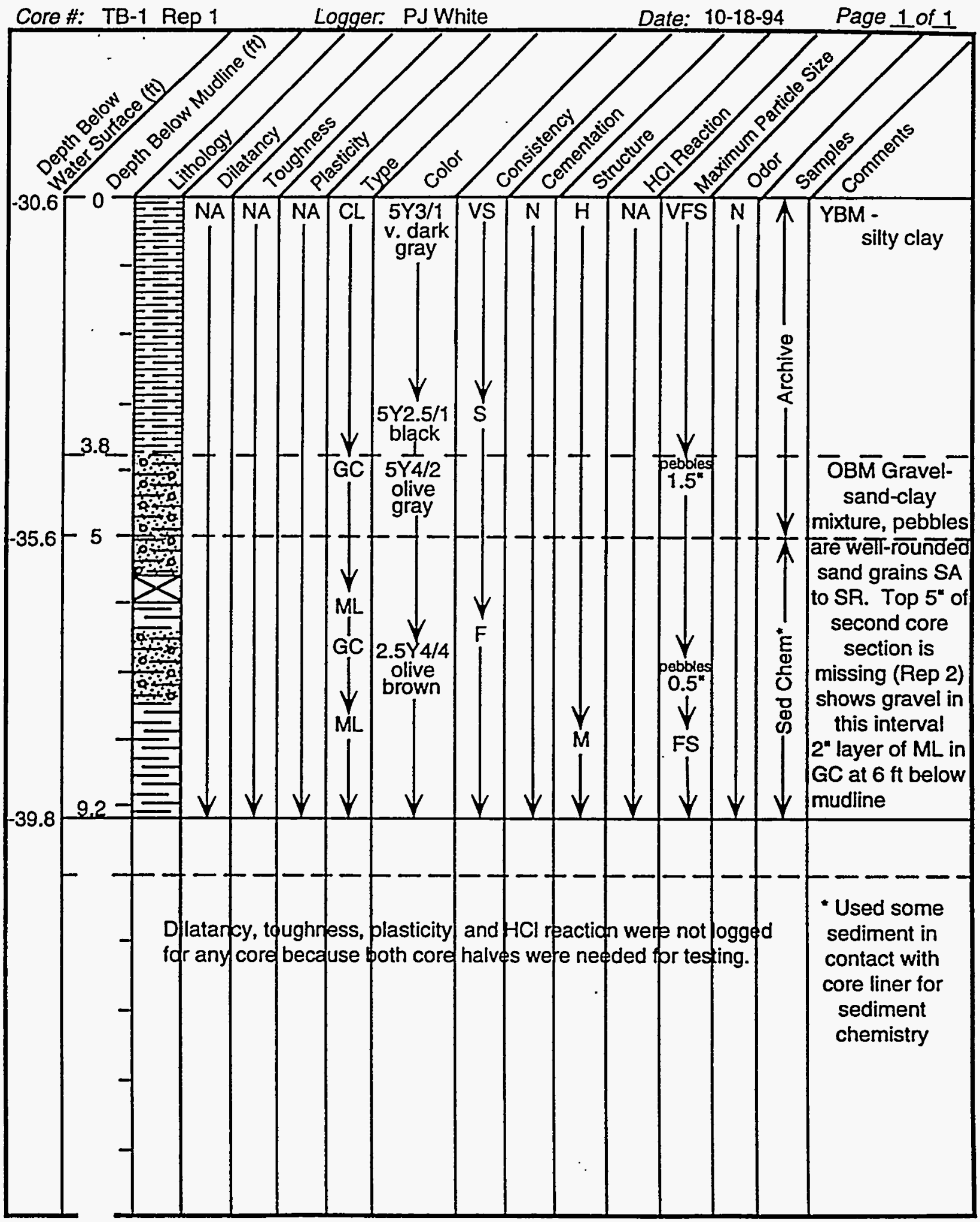


Core Data Log

Project: Richmond Harbor Intensive Study of the Tuming Basin

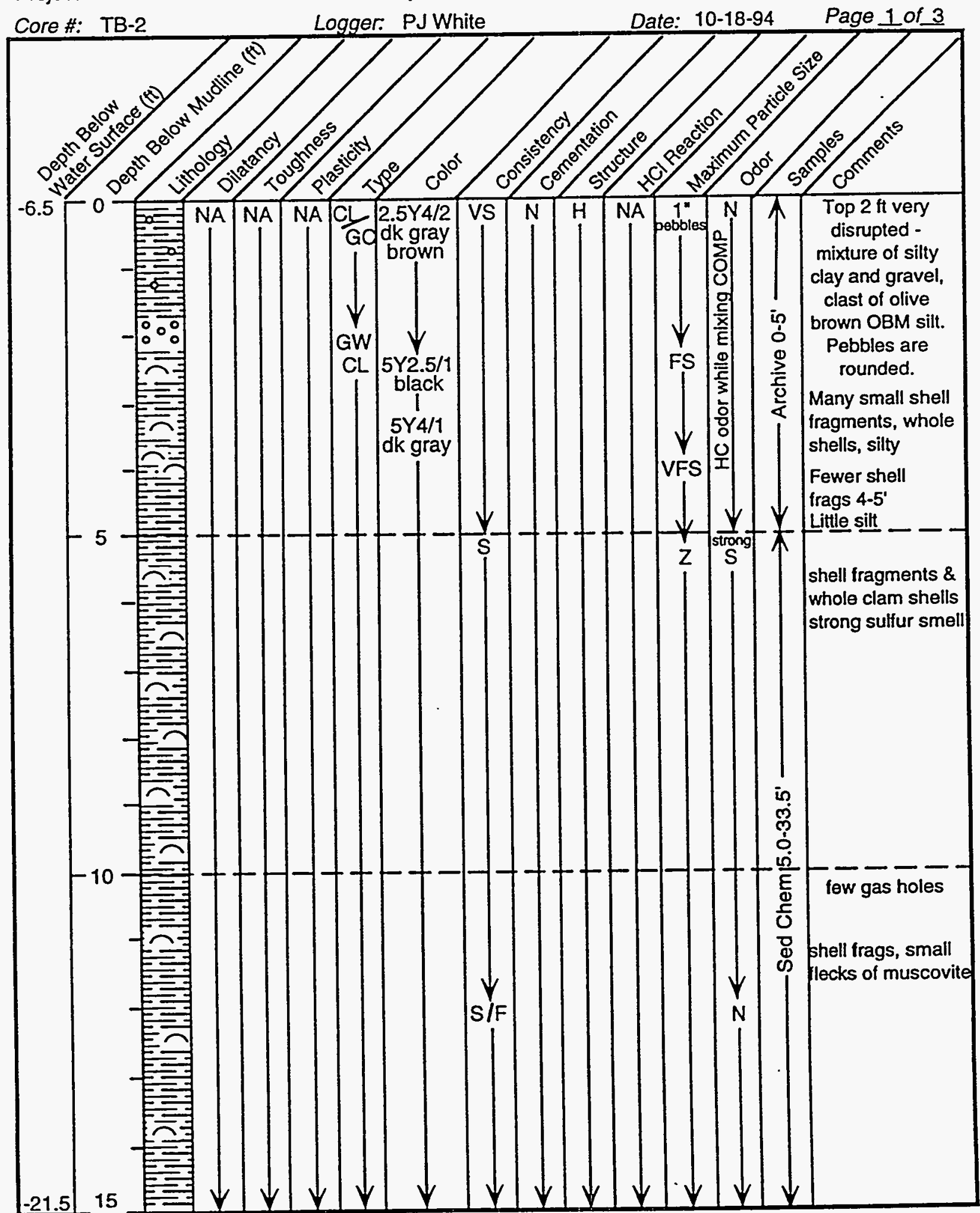


Core Data Log

Project: Richmond Harbor Intensive Study of the Tuming Basin

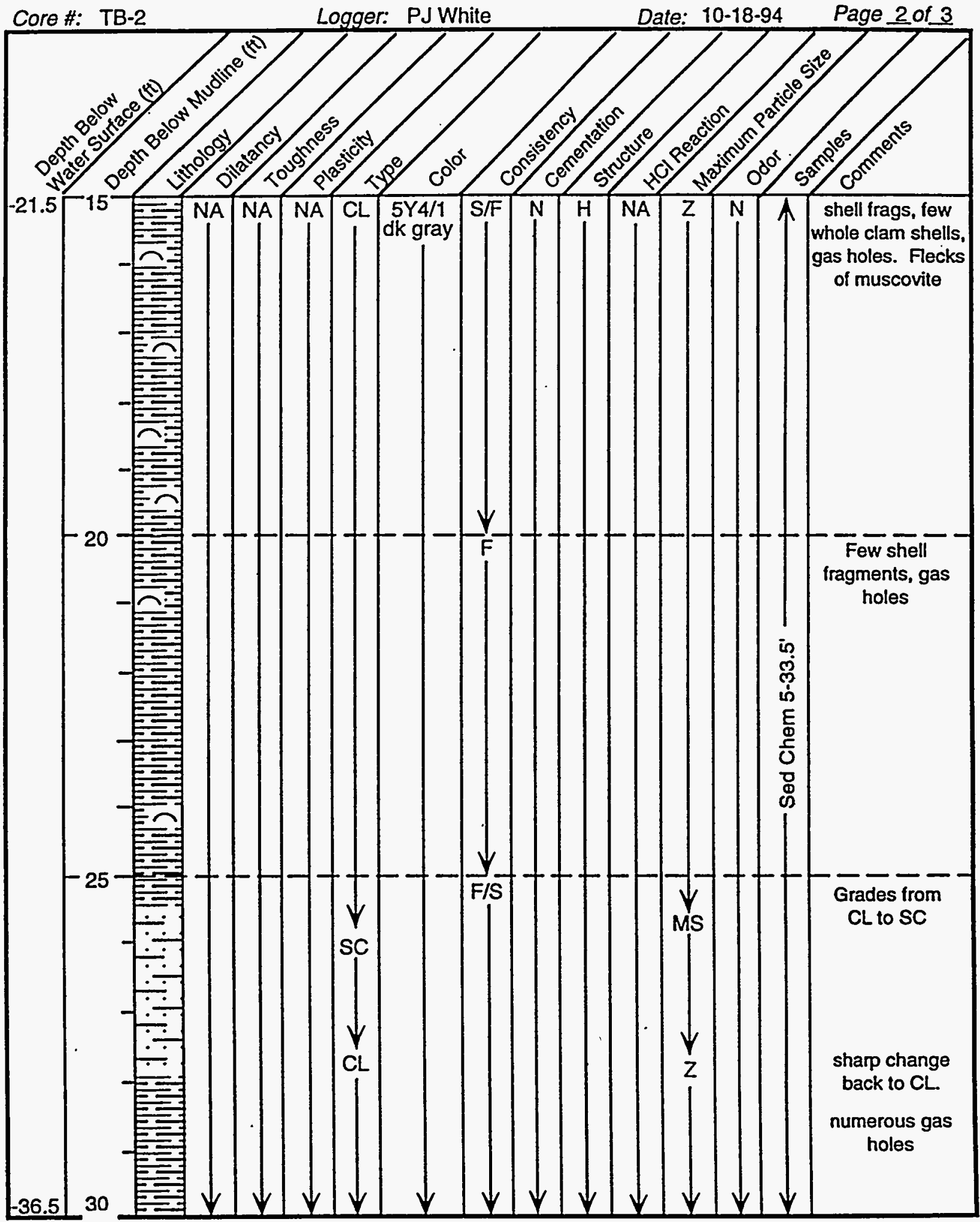




\section{Core Data Log}

Project: Richmond Harbor Intensive Study of the Tuming Basin

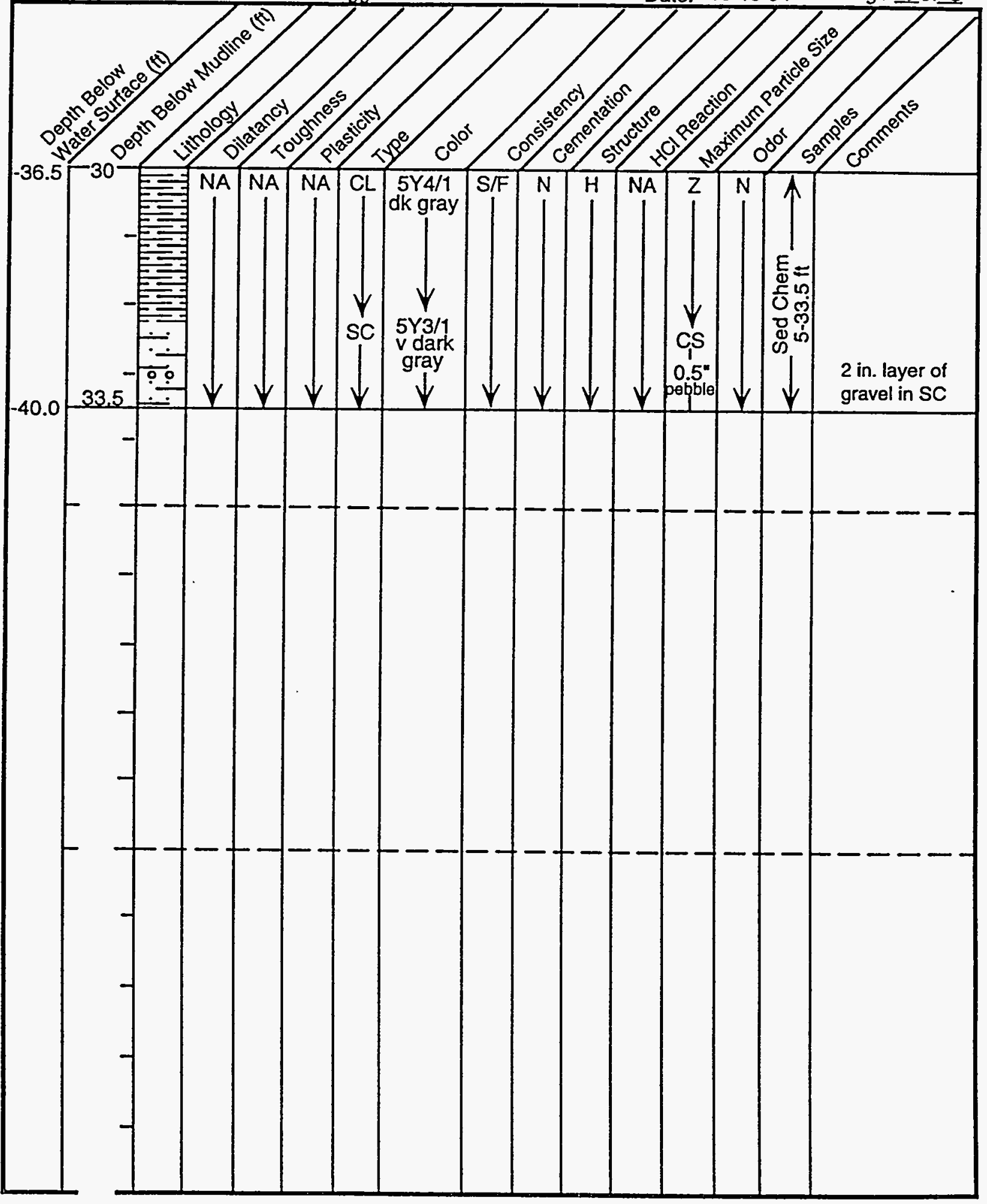




\section{Core Data Log}

Project: Richmond Harbor Intensive Study of the Turning Basin

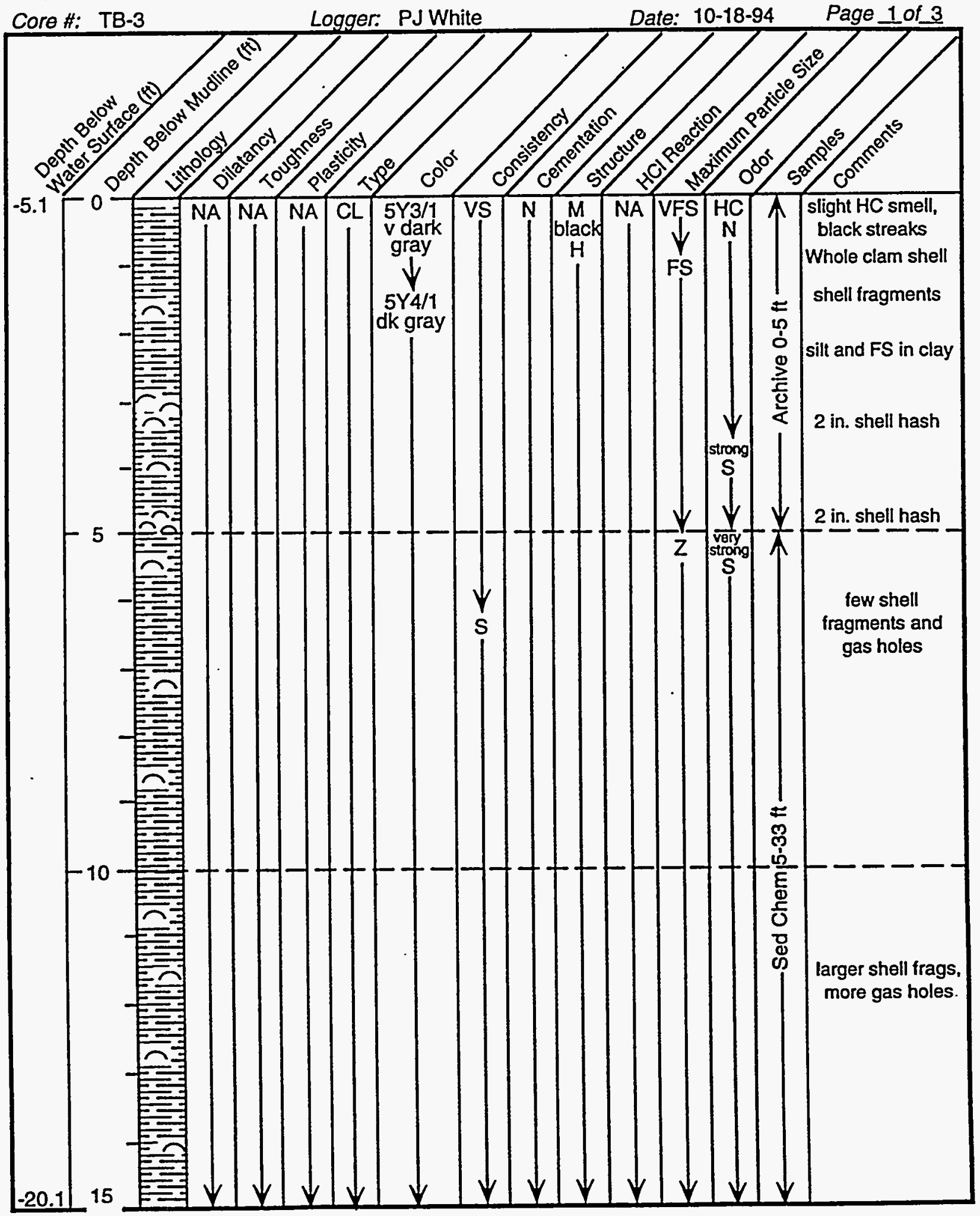




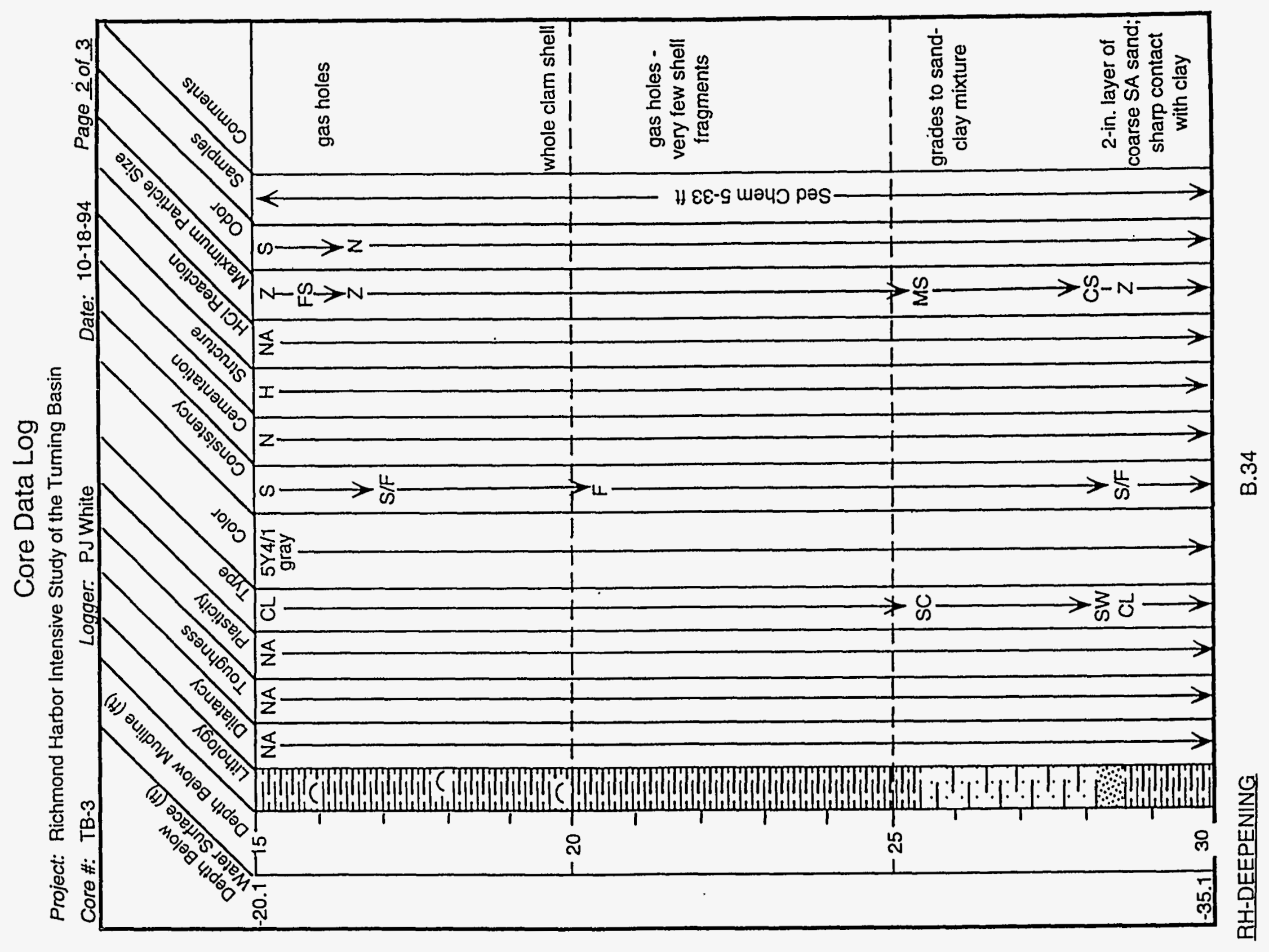




\section{Core Data Log}

Project: Richmond Harbor Intensive Study of the Turning Basin

Core \#: TB-3

Logger. PJWhite

Date: $10-18-94$

Page 3 of 3

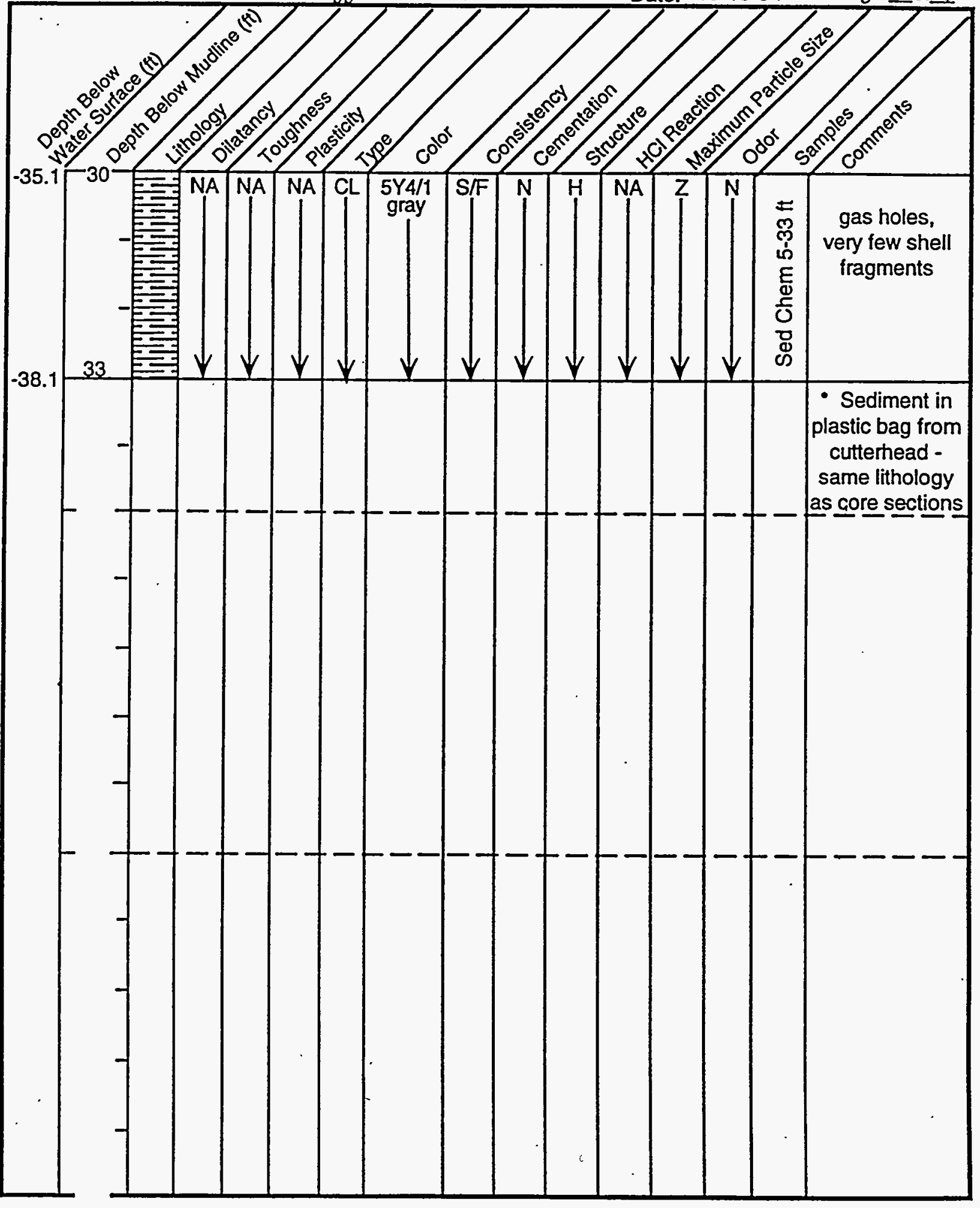

RH-DEEPENING

B.35 


\section{Core Data Log .}

Project: Richmond Harbor Intensive Study of the Tuming Basin

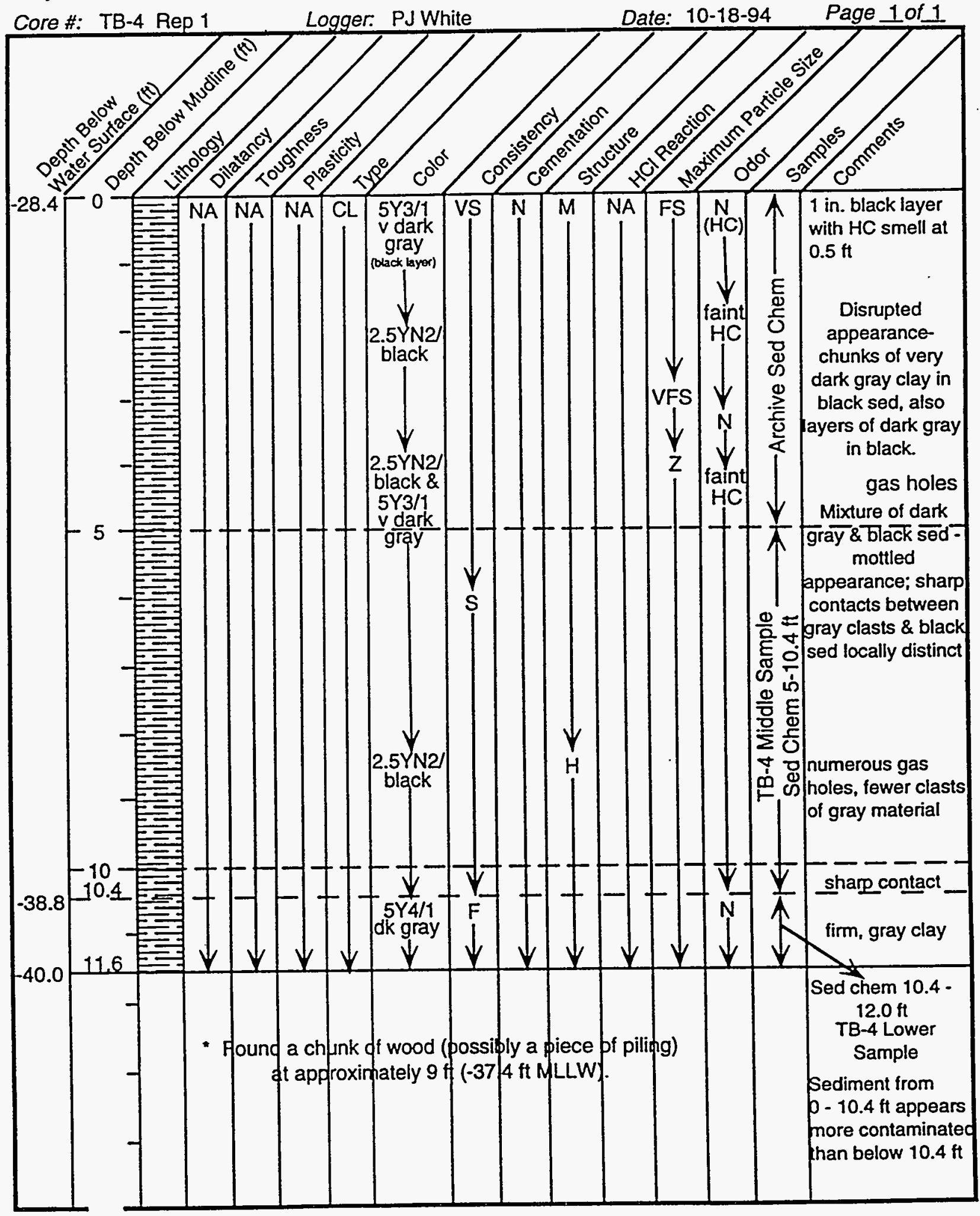




\section{Core Data Log}

Project: Richmond Harbor Intensive Study of the Tuming Basin

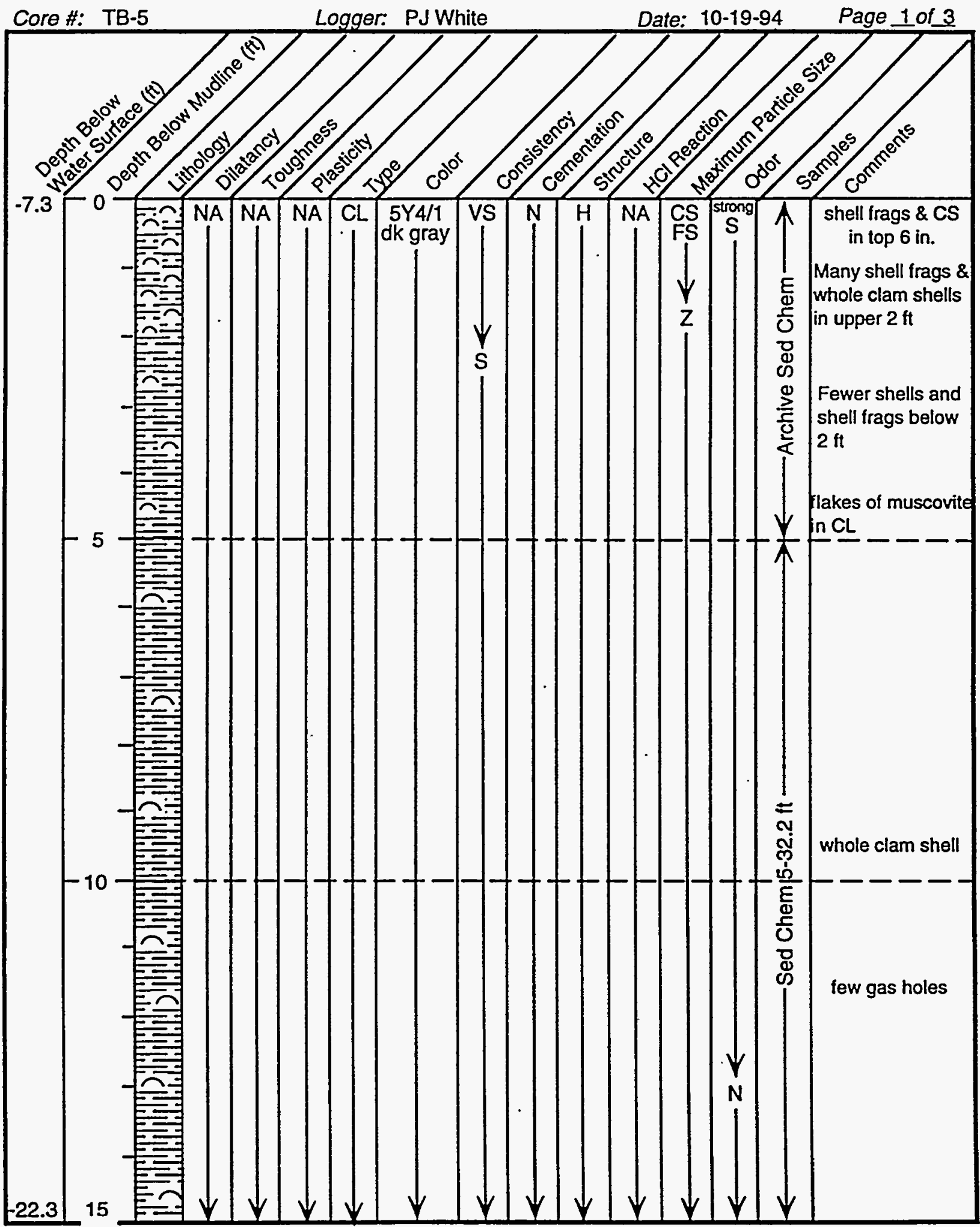




\section{Core Data Log}

Project: Richmond Harbor Intensive Study of the Tuming Basin

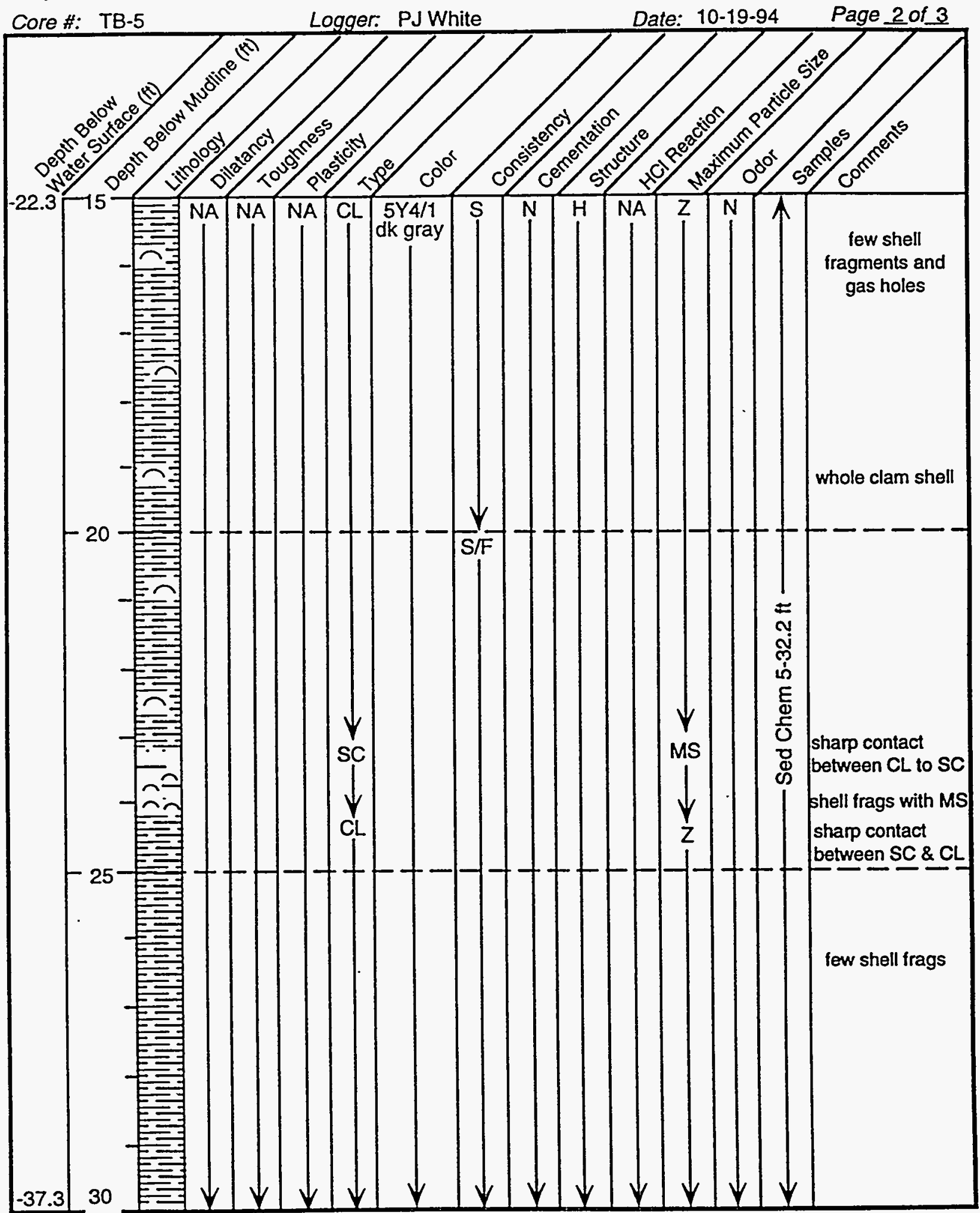


Core Data Log

Project: Richmond Harbor Intensive Study of the Tuming Basin

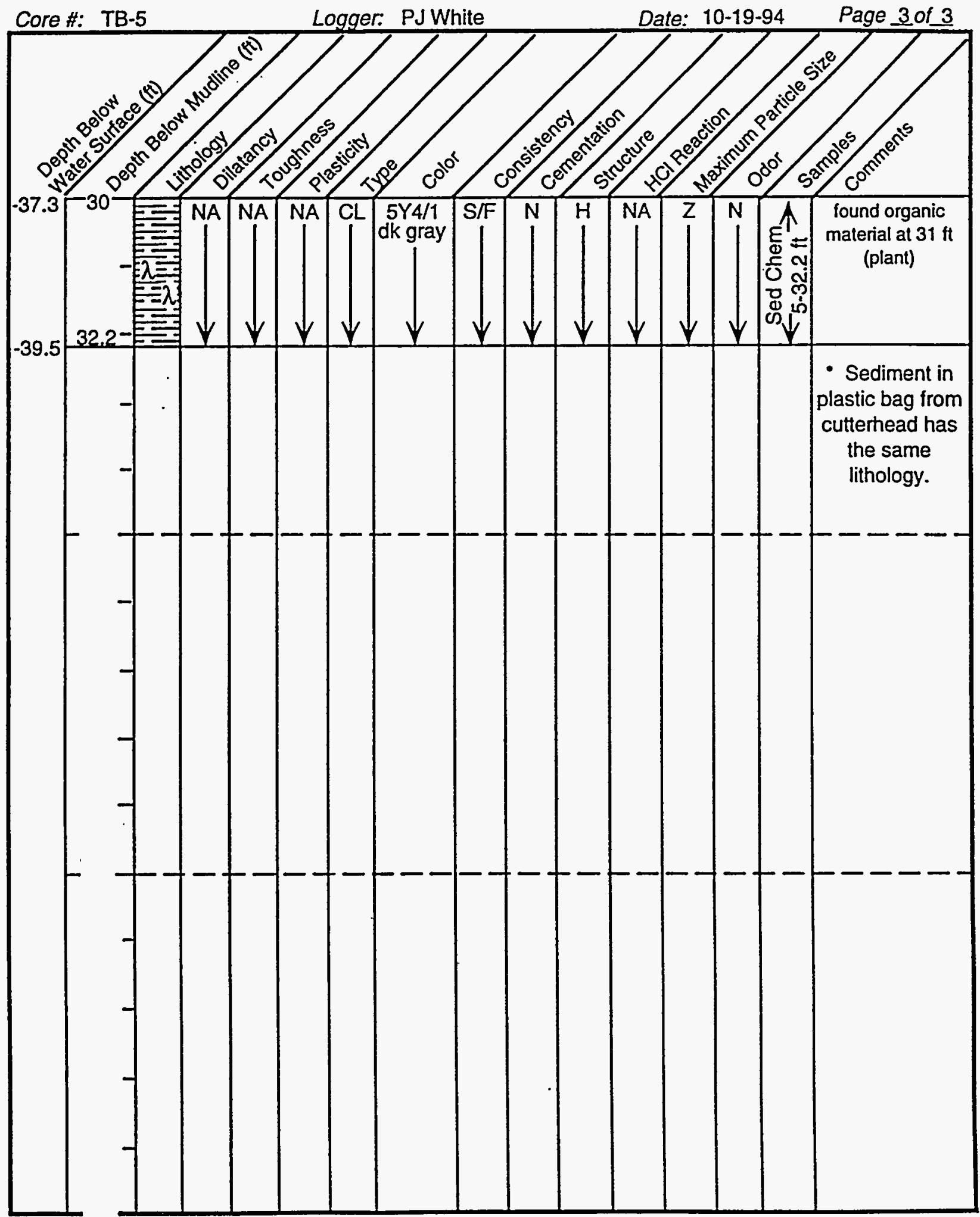


Core Data Log

Project: Richmond Harbor Intensive Study of the Turning Basin

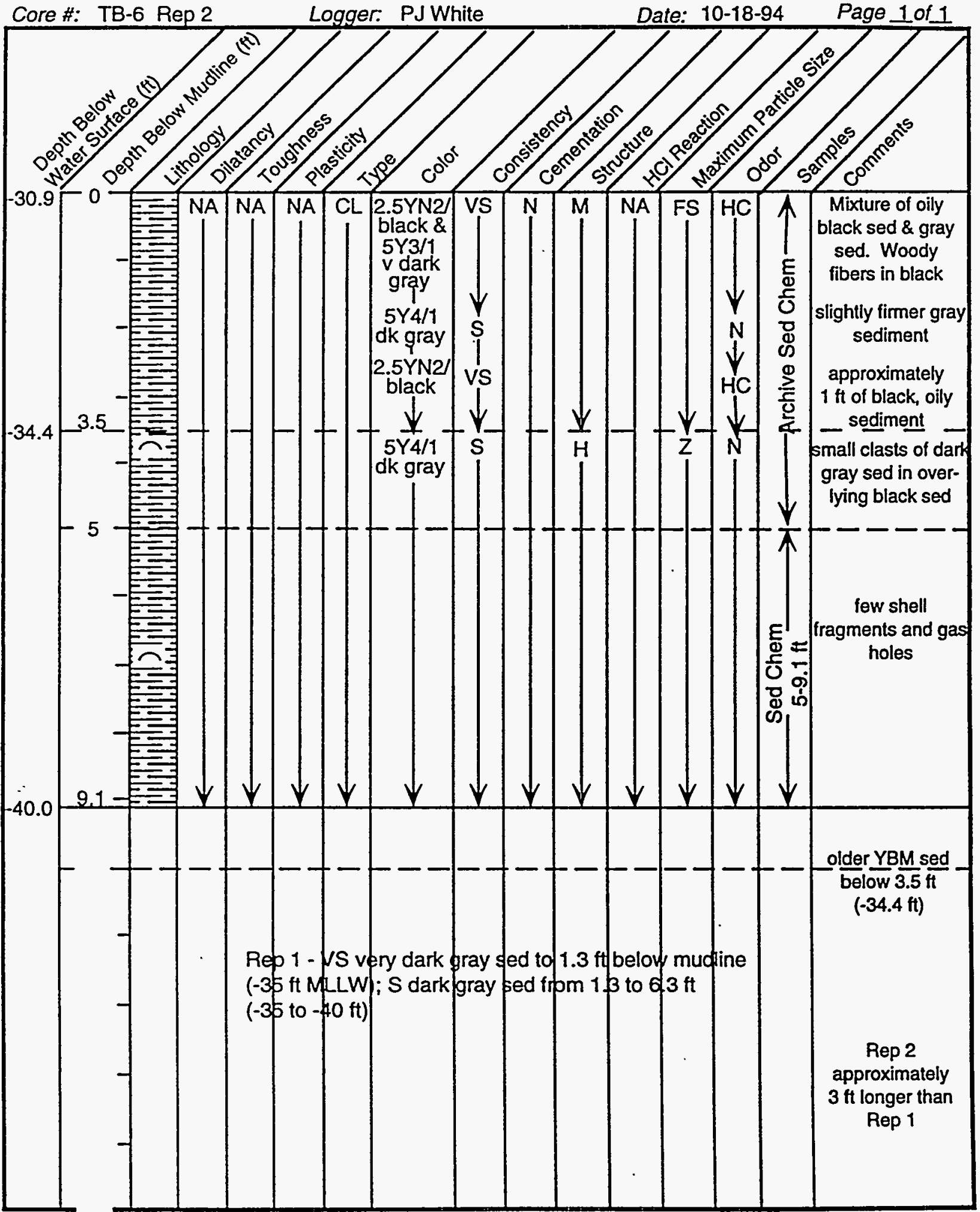


Core Data Log

Project: Richmond Harbor Intensive Study of the Tuming Basin

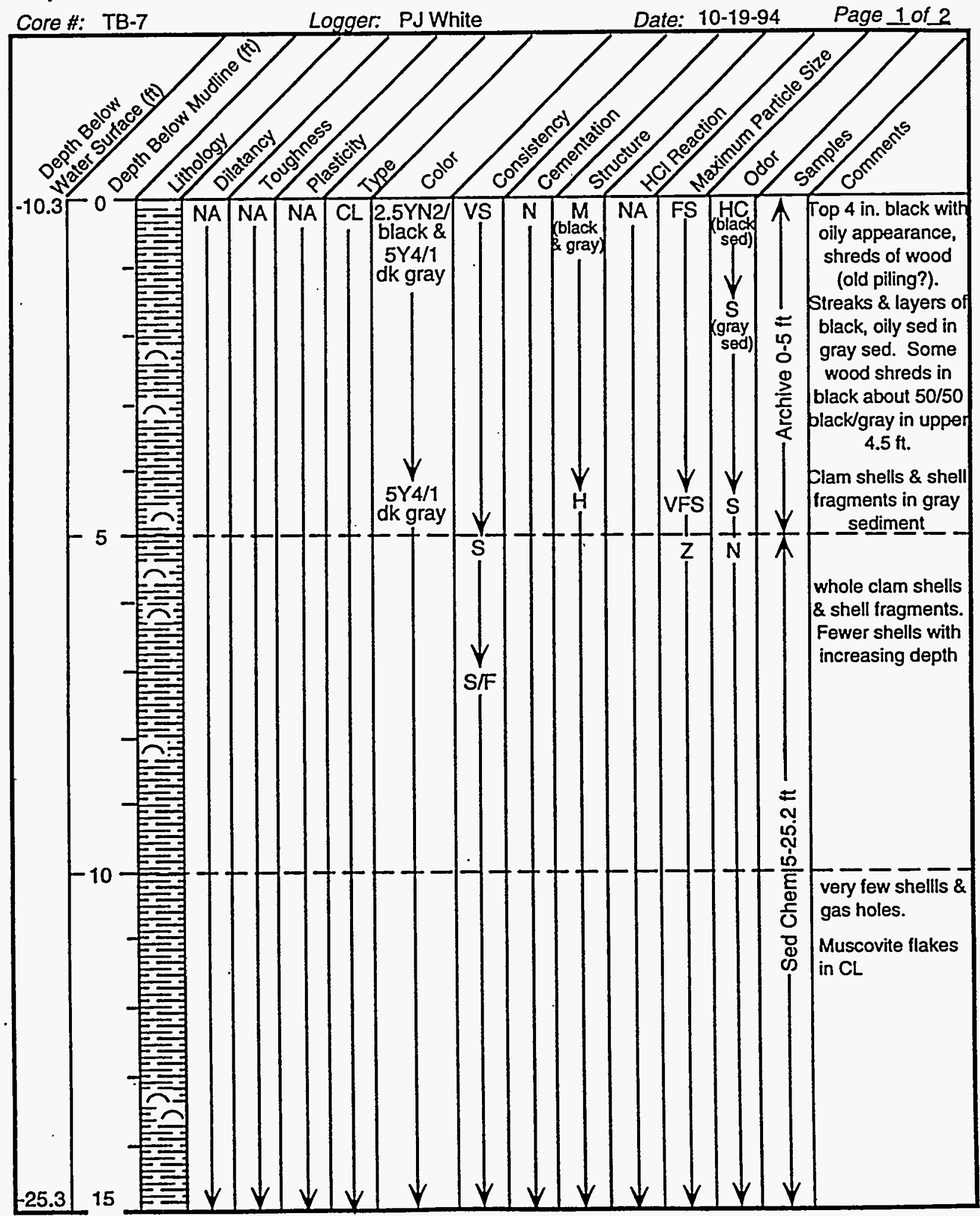

RH-DEEPENING

B.41 
Core Data Log

Project: Richmond Harbor Intensive Study of the Tuming Basin

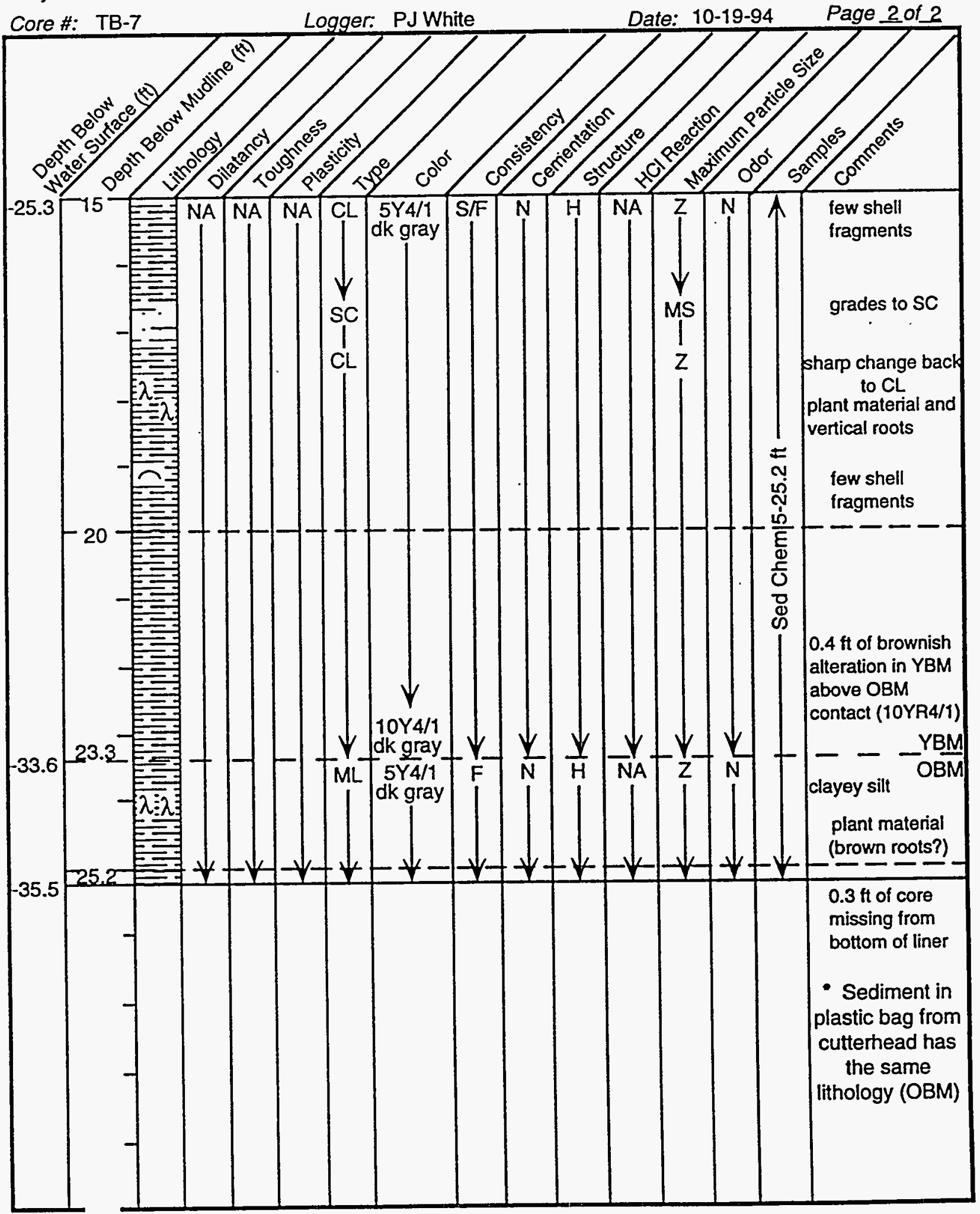




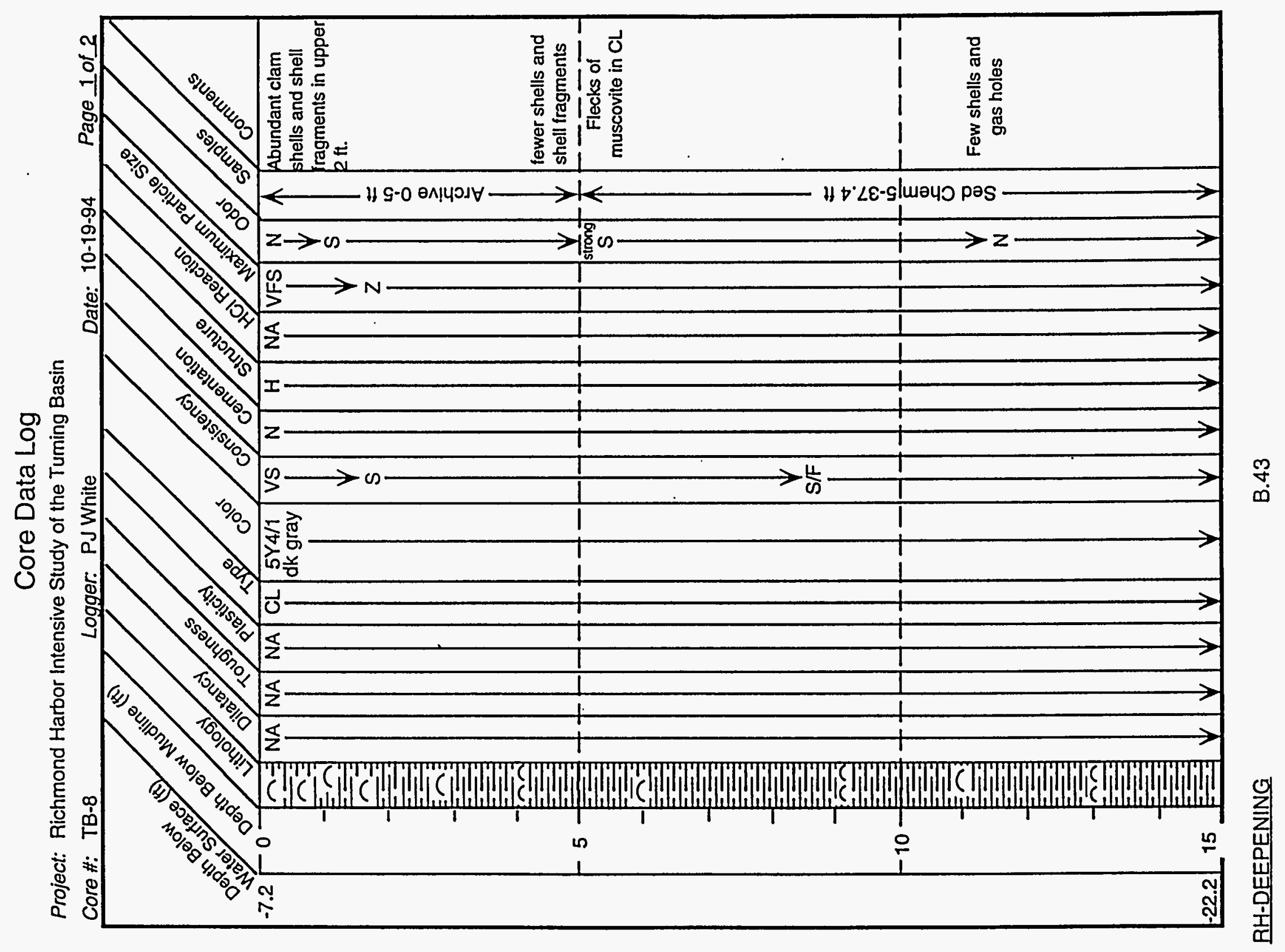




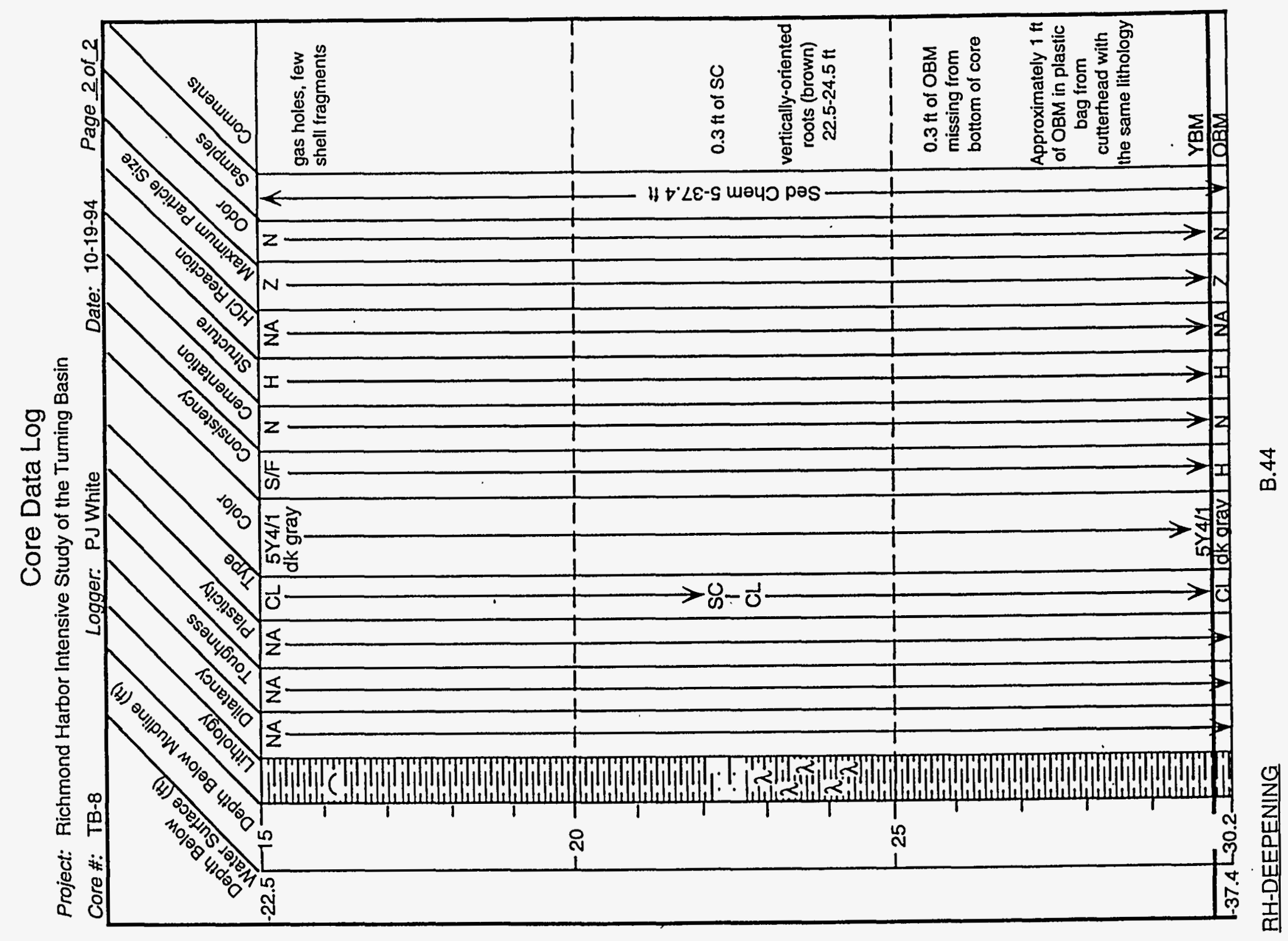


Core Data Log

Project: Richmond Harbor Intensive Study of the Tuming Basin

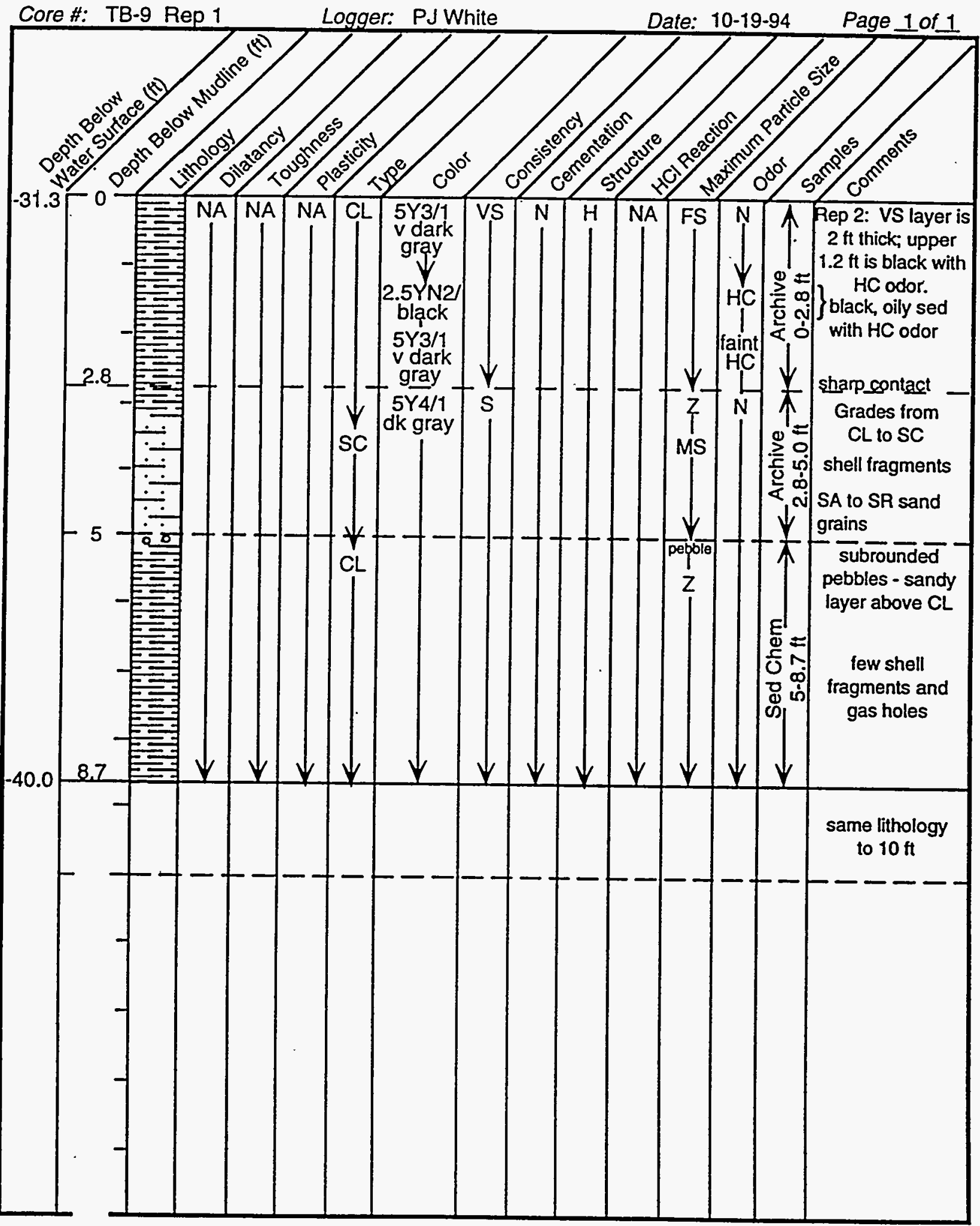

RH-DEEPENING 
APPENDIX C

SEDIMENT CHEMISTRY AND QUALITY ASSURANCE DATA 


\section{QA/QC SUMMARY}

PROGRAM: $\quad$ Richmond Harbor Deepening Project

PARAMETER: Grain Size

LABORATORY: Soil Technology

MATRIX:

Sediment

\section{SAMPLE CUSTODY}

Forty-three samples were received at Soil Technology on 2/15/94 in good condition. Samples were analyzed in two batches.

\section{QA/QC DATA QUALITY OBJECTIVES}

Reference Method

PSEP 1986

\section{Range of \\ Recovery}

Not applicable

\section{Relative Precision}

$\leq 20 \%$ for fractions

greater than $5 \%$

\section{Detection Limit}

$$
1.0 \%
$$

\section{METHOD}

Sixteen grain size fractions were determined by a combination of sieve and pipette techniques. An additional measurement for salt content was performed and each grain size fraction was corrected for this salt measurement.

\section{HOLDING TIME}

The holding time of 6 months was met for all grain size analyses.

\section{REPLICATES}

Three sets of triplicates were analyzed with the samples. The precision criteria was exceeded in one grain size fraction in one set of triplicates, with a relative standard deviation of $22 \%$. 


\title{
QA/QC SUMMARY
}

\author{
PROGRAM: Richmond Harbor Deepening Project \\ PARAMETER: Total Organic Carbon (TOC) \\ LABORATORY: Global Geochemistry \\ MATRIX: \\ Sediment
}

\section{SAMPLE CUSTODY}

Forty-three samples were received at Global Geochemistry on 2/15/94 in good condition.

Samples were analyzed in four batches.

\section{QA/QC DATA QUALITY OBJECTIVES}

\begin{tabular}{|c|c|c|c|}
\hline Reference Method & $\begin{array}{l}\text { Range of } \\
\text { Recovery }\end{array}$ & Relative Precision & Detection Limit \\
\hline EPA 1986 & $\leq 20 \%$ & $\leq 10 \%$ & $0.1 \%$ \\
\hline
\end{tabular}

\section{METHOD}

Total organic carbon is the amount of non-volatile, partially volatile, volatile, and particulate organic carbon compounds in a sample. Each sample was dried and ball milled to a fine powder. Before combustion, inorganic carbon in the sample was removed by acidification. The TOC was then determined by measuring the carbon dioxide released during combustion of the sample.

\section{HOLDING TIMES}

The holding time of 6 months was met for all TOC analyses.

\section{METHOD BLANKS}

Six method blanks were analyzed with the samples. All procedural blanks contained less than $0.005 \%$ TOC. No QC criteria are designated for TOC method blanks.

\section{REPLICATES}

Two sets of duplicates and three sets of triplicates were analyzed with the samples. The relative percent difference for one set of duplicates was $100 \%$; however, the TOC content in these samples was less than $0.05 \%$. The relative standard deviation for one set of triplicates was $13 \%$; these samples also contained $\leq 0.05 \%$ TOC.

\section{DETECTION LIMITS}

The achieved detection limit was lower than the target detection limit of $0.1 \%$ TOC. 


\section{QAVQC SUMMARY}

\section{PROGRAM: Richmond Harbor Deepening Project \\ PARAMETER: Total Volatile Solids (TVS) \\ LABORATORY: ARI \\ MATRIX: \\ Sediment \\ SAMPLE CUSTODY}

Forty-three samples were received at ARI on 2/15/94 in good condition. Samples were analyzed in three batches.

\section{QAVQC DATA QUALITY OBJECTIVES}

Reference Method

160.4
Range of
Recovery

NA

\section{Relative Precision}

$\leq 20 \%$

\section{Detection Limit}

$0.1 \%$

\section{METHOD}

Total volatile solids are a measure of the fraction of total solids that are lost on ignition at higher temperature. First, the sample was oven dried to constant weight and then removed, weighed, and ignited at $550^{\circ} \mathrm{C}$. The sample was cooled in a desiccator and then reweighed. The amount of sample lost during ignition was defined as the volatile solids fraction.

\section{HOLDING TIMES}

A holding time is not specified for TVS analyses.

\section{METHOD BLANKS}

One method blank was analyzed with the samples. No TVS were detected.

\section{REPLICATES}

Three sets of triplicates were analyzed with the samples. The relative standard deviation for each set of triplicates was within the QC criteria of $\leq 20 \%$.

\section{DETECTION LIMITS}

The achieved detection limit was lower than the target detection limit of $0.1 \%$ TVS. 


\section{QA/QC SUMMARY}

PROGRAM: Richmond Harbor Deepening Project

PARAMETER: Total Solids

LABORATORY: ARI

MATRIX: Sediment

\section{SAMPLE CUSTODY}

Forty-three samples were received at ARI on 2/15/94 in good condition. Samples were analyzed in three batches.

QA/QC DATA QUALITY OBJECTIVES

$\begin{array}{cccc}\text { Reference Method } & \begin{array}{c}\text { Range of } \\ \text { Recovery }\end{array} & \text { Relative Precision } & \text { Detection Limit } \\ \text { EPA } 160.3 & \text { NA } & \leq 20 \% & 1 \%\end{array}$

METHOD

HOLDING TIMES

A holding time is not specified for Total Solids analyses.

METHOD BLANKS

One method blank was analyzed with the samples. No solids were detected.

\section{REPLICATES}

Three sets of triplicates were analyzed with the samples. The relative standard deviation for each set of triplicates was within the QC criteria of $\leq 20 \%$.

DETECTION LIMITS

The achieved detection limit met the target detection limit of $1 \%$ solids. 


\title{
QA/QC SUMMARY
}

\author{
PROGRAM: Richmond Harbor Deepening Project \\ PARAMETER: Oil and Grease \\ LABORATORY: Analytical Resources, Inc. \\ MATRIX: Sediment
}

\section{SAMPLE CUSTODY}

Forty-three samples were received at ARI on 2/15/94 in good condition. Samples were analyzed in three batches.

\section{QA/QC DATA QUALITY OBJECTIVES}

$\begin{array}{llcc}\text { Reference Method } & \begin{array}{c}\text { Range of } \\ \text { Recovery }\end{array} & \text { Relative Precision } & \text { Detection Limit } \\ 418.1 & 50 \%-150 \% & \leq 20 \% & 20 \mathrm{mg} / \mathrm{kg} \mathrm{dry} \\ \text { METHOD } & & & \end{array}$

Total oil and grease includes vegetable oils, animal fats, soaps, waxes, and any other carbonhydrogen material extractable by the solvent Freon. An aliquot of sample material was dried with anhydrous sodium sulfate and extracted with Freon. The extract was shaken, allowed to settle, removed, and scanned from 4000 to $600 \mathrm{~cm}^{-1}$ by infrared spectrophotometry (IR). The peak height measured at $2930 \mathrm{~cm}^{-1}$ was used to quantify the concentration of oil and grease in the sample.

\section{HOLDING TIMES}

The samples were analyzed from $2 / 28$ through $3 / 3 / 94$, which is within the holding time of 28 days.

\section{METHOD BLANKS}

One procedural blank was processed with each batch of samples. No hydrocarbons were detected in the method blanks at concentrations above the detection limit.

\section{MATRIX SPIKES}

One matrix spike (MS) was analyzed with each batch of samples. Percent recoveries ranged from $97 \%$ to $106 \%$.

\section{REPLICATES}

One set of triplicates was analyzed with each batch of samples. The relative standard deviation exceeded the QC criteria of $\leq 20 \%$ in the triplicates for Batch $1(23 \%)$.

\section{DETECTION LIMITS}

Achieved detection limits ranged from 18 to $29 \mathrm{mg} / \mathrm{kg}$, some of which are higher than the $20 \mathrm{mg} / \mathrm{kg}$ target detection limit. 


\section{QA/QC SUMMARY}

PROGRAM: $\quad$ Richmond Harbor Deepening Project

PARAMETER: Total Petroleum Hydrocarbons (TPH)

LABORATORY: Analytical Resources, Inc.

MATRIX:

Sediment

\section{SAMPLE CUSTODY}

Forty-three samples were received at ARI on 2/15/94 in good condition. Samples were analyzed in three batches.

\section{QAVQC DATA QUALITY OBJECTIVES}

\section{Reference Method}

418.1
Range of

Recovery

$50 \%-150 \%$
Relative Precision

$\leq 20 \%$
Detection Limit

$20 \mathrm{mg} / \mathrm{kg}$ dry

\section{METHOD}

Total petroleum hydrocarbons comprise the nonpolar mineral fraction of total oil and grease that is not removed by silica gel absorption. An aliquot of sample material was dried with anhydrous sodium sulfate and extracted with Freon. Silica gel was added to the extract to remove the more polar animal and vegetable based oils. The extract was shaken, allowed to settle, removed, and scanned from 4000 to $600 \mathrm{~cm}^{-1}$ by infrared spectrophotometry (IR). The peak height measured at $2930 \mathrm{~cm}^{-1}$ was used to quantify the concentration of hydrocarbons in the sample.

\section{HOLDING TIMES}

Samples were analyzed from $2 / 28 / 94$ through $3 / 3 / 94$. The samples were analyzed within the holding time of 28 days.

\section{METHOD BLANKS}

One procedural blank was processed with each batch of samples. No hydrocarbons were detected in the method blanks at concentrations above the detection limit.

\section{MATRIX SPIKES}

One matrix spike (MS) was analyzed with each batch of samples. Percent recoveries ranged from $93 \%$ to $104 \%$.

\section{REPLICATES}

One set of triplicates was analyzed with each batch of samples. The relative standard deviation was $15 \%$ for the one set of triplicates that contained TPH in all three samples.

\section{DETECTION LIMITS}

Achieved detection limits ranged from 17 to $38 \mathrm{mg} / \mathrm{kg}$, some of which are higher than the $20 \mathrm{mg} / \mathrm{kg}$ target detection limit. 


\section{QA/QC SUMMARY}

$\begin{array}{ll}\text { PROGRAM: } & \text { Richmond Harbor Deepening Project } \\ \text { PARAMETER: } & \text { Polynuclear Aromatic Hydrocarbons (PAH) and Phthalates } \\ \text { LABORATORY: } & \text { Battelle/Marine Sciences Laboratory, Sequim, Washington } \\ \text { MATRIX: } & \text { Sediment }\end{array}$

QA/QC DATA QUALITY OBJECTIVES

$\begin{array}{ccccc}\begin{array}{c}\text { Reference } \\ \text { Method }\end{array} & \begin{array}{c}\text { Range of } \\ \text { Recovery }\end{array} & \begin{array}{c}\text { SRM } \\ \text { Accuracy }\end{array} & \begin{array}{c}\text { Relative } \\ \text { Precision }\end{array} & \begin{array}{c}\text { Detection } \\ \text { Limit (dry wt) }\end{array} \\ \text { GC/MS } & 40-120 \% & \leq 30 \% & \leq 30 \% & 20 \mu \mathrm{g} / \mathrm{kg}\end{array}$

METHOD

HOLDING TIMES

Sediment samples were extracted with methylene chloride using a roller under ambient conditions following SOP MSL-042, Extraction and Clean-up of Sediment and Tissue for Semivolatile Organics which is based on methods used by the National Oceanic and Atmospheric Administration for their Status and Trends Program (Krahn et al. 1988). Samples were then cleaned using Silica/Alumina ( $5 \%$ deactivated) chromatography followed by HPLC cleanup. Modifications in the clean-up method were required to adequately recover the phthalate compounds. In the first batch of samples, the Si column clean-up step was eliminated. In the second and third batches of samples, extracts were eluted through silica and alumina per the SOP, but twice the usual amount of methylene chloride was used.

Extracts were quantified using gas chromatography/mass spectrometry (GC/MS) in the selected ion mode (SIM) following SOP MSL-M-043, Identification and Quantification of Polynuclear Aromatic Hydrocarbons by GC/MS which is based on EPA method 8270 (EPA 1986).

Forty four (44) samples were received on 2/15/94 in good condition. Samples were logged into Battelle's log-in system and stored at approximately $-20^{\circ} \mathrm{C}$ until extraction. The following summarizes the extraction dates and GC/MS/SIM analysis dates:

$\begin{array}{lll}\text { Batch } & \text { Extraction } & \text { Analysis } \\ \text { Batch 1 } & 3 / 2 / 94 & 3 / 12 / 94 \\ \text { Batch 2 } & 3 / 10 / 94 & 3 / 19 / 94 \\ \text { Batch 3 } & 3 / 23 / 94 & 3 / 31-4 / 1 / 94\end{array}$

DETECTION LIMITS Target detection limits of $20 \mu \mathrm{g} / \mathrm{kg}$ dry wt were met for all PAH compounds. Achieved detection limits for PAHs were determined by multiplying the standard deviation of 7 spiked replicates by the student $t$ value. Target detection limits of $20 \mu \mathrm{g} / \mathrm{kg}$ for phthalates were exceeded. Limits of quantitation (LOQ) for phthalates were determined by multiplying the standard deviation of 7 spiked replicates by 10 . LOQs were higher than MDLs because phthalates were detected in the background blank sample. The LOQs ranged from $22.7 \mu \mathrm{g} / \mathrm{kg}$ to $163 \mu \mathrm{g} / \mathrm{kg}$ dry weight depending on the sample weight and percent moisture. 


\section{QAVQC SUMMARY (continued)}

METHOD BLANKS One method blank was extracted with each extraction batch. Any sample values that were less than 5 times the value in the associated method blank were flagged with a "B." Other analytes detected in the method blanks were either unconfirmed or detected at less than the QC criteria of 5 times the MDL.

\section{SURROGATES}

MATRIX SPIKES

REPLICATES

Five isotopically labelled compounds were added prior to extraction to assess the efficiency of the method. These were d8-Naphthalene, d8Acenaphthene, d12-Chrysene, d10-Pyrene and d14-Dibenzo(a,h) Anthracene. Recoveries of all surrogates were within the quality control limits of $40-120 \%$. Two samples in Batch 2 (SF-3 and SFW-3) had low surrogate recoveries because of extraction problems; these samples were re-extracted and reanalyzed with Batch 3. Surrogate recoveries were within QC limits for the reanalyses.

One sample from each batch was spiked with all PAH and phthalate compounds in Batches 1 and 3 , and with PAH compounds only in Batch 2. Matrix spike recoveries for 13 of the $22 \mathrm{PAH}$ compounds in Batch 1 and 12 of $16 \mathrm{PAH}$ compounds in Batch 2 were above the upper control limit. In Batch 3, recoveries of 2 PAH compounds exceeded the acceptable range, and recoveries of 2 phthalate compounds were below the minimum acceptable recovery of $40 \%$. The high recoveries of PAH compounds in the matrix spikes for Batches 1 and 2 appear to be due to sample inhomogeneity. Recoveries of spiked compounds in blank spikes analyzed with each batch of samples were within QC limits, and results for SRMs are generally good. The Batch 2 matrix spike was analyzed in triplicate with Batch 3 to test sample homogeneity; RSDs for 17 of 18 compounds exceeded $30 \%$ (these results are not reported with the sample data).

One sample from each batch was extracted and analyzed in triplicate. Precision was measured by calculating the relative standard deviation (RSD) between the replicate results. The RSDs were $\leq 30 \%$ for analytes greater than 10 times the MDL except for phenanthrene in Batch 1 (RSD of $31 \%$ ), and 9 compounds in Batch 2. The 9 compounds in Batch 2 had RSDs between $32 \%$ and $37 \%$. In Batch 3, 6 of 17 compounds greater than 10 times the MDL had RSDs exceeding $30 \%$.

SRMS

One SRM,1941a, a marine sediment obtained by the National Institute for Science and Technology was analyzed with each batch. Fourteen of the sixteen PAH compounds analyzed are certified. All PAHs were detected within $30 \%$ of the certified mean with the exception of chrysene, benzo(b)fluoranthene, and dibenzo(a,h)anthracene in Batches 1 and 2 , and benzo(b)fluoranthene and dibenzo(a,h)anthracene in Batch 3. 


\section{QAVC SUMMARY (continued)}

MISC

Some of the compounds are flagged to indicate that the ion ratio for that compound was outside of the $\mathrm{QC}$ range. This is due primarily to low levels of the compound of interest. Because the confirmation ion is present at only a fraction of the level of the parent ion, when the native level of the compound is low, the amount of error in the concentration measurement of the confirmation ion goes up. The compound is actually quantified from the parent ion only so most likely this will not affect the quality of the data. For sample values that are relatively high (>5 times the MDL) it may be an indication of some sort of interference.

\section{REFERENCES}

Krahn, M. M., C. A. Wigren, R. W. Pearch, L. K. Moore, R. G. Bogar, W. D. MacLeod, Jr., S. L. Chan, and D. W. Brown. 1988. "A Rapid High-Performance Liquid Chromatographic Method for Isolating Organic Contaminants from Tissue and Sediment Extracts." NOAA Technical Memorandum NMFS F/NWC-153, Silver Spring, Maryland.

U.S. Environmental Protection Agency (EPA). 1986. Test Methods for Evaluating Solid Waste: Physical/Chemical Methods. SW-846. U.S. Document No. 955-001-00000, U.S.E.P.A., Washington D.C. 


\section{QA/QC SUMMARY}

$\begin{array}{ll}\text { PROGRAM: } & \text { Richmond Harbor Deepening Project } \\ \text { PARAMETER: } & \text { Chlorinated Pesticides and PCBS } \\ \text { LABORATORY: } & \text { Battelle/Marine Sciences Laboratory, Sequim, Washington } \\ \text { MATRIX: } & \text { Sediment }\end{array}$

QAVQC DATA QUALITY OBJECTIVES

$\begin{array}{ccccc}\begin{array}{c}\text { Reference } \\ \text { Method }\end{array} & \begin{array}{c}\text { Range of } \\ \text { Recovery }\end{array} & \begin{array}{c}\text { SRM } \\ \text { Accuracy }\end{array} & \begin{array}{c}\text { Relative } \\ \text { Precision }\end{array} & \begin{array}{c}\text { Detection } \\ \text { Limit (dry wt) }\end{array} \\ \text { GC/ECD } & 40-120 \% & \leq 30 \% & \leq 30 \% & 2.0-30 \mu \mathrm{g} / \mathrm{kg}\end{array}$

METHOD

HOLDING TIMES

DETECTION LIMITS

METHOD BLANKS
Sediment samples were extracted with methylene chloride using a roller under ambient conditions following SOP MSL-M-079, "Extraction and Clean-up of Sediment and Tissue for Semivolatile Organics following the Surrogate Internal Standard Method" based on EPA Methods 3510 and 8080 (EPA 1986) and NOAA status and trends methods (Krahn et al. 1988). Samples were then cleaned using silica/alumina (5\% deactivated) chromatography followed by HPLC cleanup (Krahn et al. 1988). Modifications in the clean-up method were required to adequately recover the phthalate compounds. In the first batch of samples, the Si column clean-up step was eliminated. In the second and third batches of samples, extracts were eluted through silica and alumina per the SOP, but twice the usual amount of methylene chloride was used. Extracts were analyzed using Gas Chromatography/ Electron Capture Detection (GC/ECD) following SOP MSL-M-044, "Analysis of PCBs and Chlorinated Pesticides by GC/ECD" based on EPA method 8080 (1986). The column used was a J\&W DB-17 and the confirmatory column was a DB-1701, both capillary columns (30 $\mathrm{m} \times 0.25 \mathrm{~mm}$ I.D.).

Forty-four (44) samples were received on 2/15/94 in good condition. Samples were logged into Battelle's log-in system and stored at approximately $-20^{\circ} \mathrm{C}$ until extraction. The following summarizes the extraction dates and GC/ECD analysis dates:

\begin{tabular}{|c|c|c|}
\hline Batch & Extraction & Analysis \\
\hline $\begin{array}{l}\text { Batch 1 } \\
\text { Batch 2 }\end{array}$ & $\begin{array}{l}3 / 2 / 94 \\
3 / 10 / 94 \\
3 / 23 / 94\end{array}$ & $\begin{array}{l}3 / 14-19 / 94 \\
3 / 21-25 / 94 \\
4 / 2-4 / 94\end{array}$ \\
\hline
\end{tabular}

Target detection limits were met for all samples. Detection limits reported are based on an MDL study involving low level spikes of 7 replicate extractions. MDLs are defined as $3 x$ the standard deviation of the mean recovery.

One method blank was extracted with the extraction batch. No pesticides or PCBs were detected in the blanks. 


\section{QAVC SUMMARY (continued)}

SURROGATES

MATRIX SPIKES

REPLICATES

SRMS
Two compounds, PCB congeners 103 and 198, were added to all samples prior to extraction to assess the efficiency of the analysis. These compounds are also used to correct all sample results and are considered surrogate internal standards (SIS). Recoveries of these compounds were within the QC guidelines of $40-120 \%$ for all samples analyzed.

One sample from each batch was spiked with a subset of 6 pesticides and Aroclor 1254. Matrix spike recoveries were within the laboratory QC recovery limit (40-120\%) for all pesticides and for Aroclor 1254 with the exception of $\mathrm{g}-\mathrm{BHC}$, Aldrin, and Endrin in Batch 1. One of the phthalate compounds spiked into the solution interfered with the recovery of Aldrin.

One sample from each batch was extracted in triplicate. Precision was measured by calculating the relative standard deviation (RSD) between the replicate results. Only one pesticide was detected in all 3 replicates in Batches 1 and 2; the RSD was less than $30 \%$. Six pesticides were detected in all 3 replicates in Batch 3; RSDs were less than $30 \%$.

One SRM, 1941a, a marine sediment sample obtained from the National Institute of Science and Technology (NIST) was analyzed with each batch. Only two pesticides are certified, 4,4-DDE and 4,4DDD. The recovery of $4,4^{\prime}-\mathrm{DDD}$ was higher than the certified value in the SRMs from Batches 1 and 2. The modified cleanup procedures for these samples resulted in a very complex chromatogram for the SRM, and interferences may have affected the recovery of this compound. The recoveries of both compounds were within QC criteria for the Batch 3 SRM.

Misc. - All pesticide detections are confirmed on a secondary column. The RPD criteria is $67 \%$.

\section{REFERENCES}

Krahn, M. M., C. A. Wigren, R. W. Pearch, L. K. Moore, R: G. Bogar, W. D. MacLeod, Jr., S. L. Chan, and D. W. Brown. 1988. "A Rapid High-Performance Liquid Chromatographic Method for Isolating Organic Contaminants from Tissue and Sediment Extracts." NOAA Technical Memorandum NMFS FINWC-153, Silver Spring, Maryland.

U.S. Environmental Protection Agency (EPA). 1986. Test Methods for Evaluating Solid Waste: Physical/Chemical Methods. SW-846. U.S. Document No. 955-001-00000, USEPA, Washington D.C. 


\section{QA/QC SUMMARY}

PROGRAM: Richmond Harbor Deepening Project

\section{PARAMETER: Butyltins}

LABORATORY: Battelle/Marine Sciences Laboratory, Sequim, Washington

MATRIX:

Sediment

\section{QA/QC DATA QUALITY OBJECTIVES}

$\begin{array}{ccccc}\begin{array}{c}\text { Reference } \\ \text { Method }\end{array} & \begin{array}{c}\text { Range of } \\ \text { Recovery }\end{array} & \begin{array}{c}\text { SRM } \\ \text { Accuracy }\end{array} & \begin{array}{c}\text { Relative } \\ \text { Precision }\end{array} & \begin{array}{c}\text { Detection } \\ \text { Limit (dry weight) }\end{array} \\ \text { Unger et al. } & 40-120 \% & \leq 30 \% & \leq 30 \% & 1 \mu \mathrm{g} / \mathrm{kg}\end{array}$

METHOD

HOLDING TIMES

DETECTION LIMITS

METHOD BLANKS

SURROGATES
Butyltin analyses were performed according to MSL-SOP-M-004 following the method of Unger et al. (1986). Sediment samples were extracted with methylene chloride using a roller under ambient conditions followed by derivitization using a Grignard reagent to change to a form compatible with gas chromatography. Sample extracts were then cleaned by passing through a florisil column. Extracts were analyzed using Gas Chromatography/Flame Photometric Detection (GC/FPD).

Forty-four (44) samples were received on 2/15/94 in good condition. Samples were logged into Battelle's log-in system and stored at approximately $-20^{\circ} \mathrm{C}$ until extraction. Samples were extracted in three batches. Holding times were met for all extractions and analyses. The following table summarizes the extraction dates and GC/FPD analysis dates:

\begin{tabular}{|c|c|c|}
\hline Batch & Extraction & Analysis \\
\hline $\begin{array}{l}\text { Batch } 1 \\
\text { Batch } 2 \\
\text { Batch } 3\end{array}$ & $\begin{array}{l}2 / 25 / 94 \\
3 / 7 / 94 \\
3 / 11 / 94\end{array}$ & $\begin{array}{l}3 / 2-3 / 94 \\
3 / 9-10 / 94 \\
3 / 16-17 / 94\end{array}$ \\
\hline
\end{tabular}

Target detection limits of $1 \mu \mathrm{g} / \mathrm{kg}$ dry wt. were met for all butyltin compounds. These detection limits represent the method detection limit defined as roughly 3 times the standard deviation of results from 7 replicate low level matrix spikes.

One method blank was extracted with each extraction batch. No butyltins were detected in the blanks.

One compound, Tripentyltin chloride, was added to all samples prior to extraction to assess the efficiency of the method. This compound is also used as an internal standard as all data is corrected for the recovery of the compound. Surrogate recoveries were within the QC limits of $40-120 \%$ for all samples. 


\section{QA/QC SUMMARY (continued)}

MATRIX SPIKES One sample from each batch was spiked with tri- and dibutyltin. Matrix spike recoveries for tri- and dibutyltin ranged from 83 to $128 \%$. Tributyltin in the matrix spike for batch 3 exceeded the QC limits of 40-120\%; however, the SRM for the corresponding batch was within QC limits.

REPLICATES One sample in each batch was extracted in triplicate. Precision was measured by calculating the relative standard deviation (RSD) between the replicate results. No butyltins were detected in the replicates from batches 1 and 2 . RSDs for Batch 3 were within the QC criteria of $\leq 30 \%$.

SRMs

PACS-1, an estuarine sediment obtained from the National Canadian Research Council (NRCC) was analyzed along with the samples from each batch. The results for tri- and dibutyltin were within $30 \%$ of the certified mean value for all batches with the exception of dibutyltin in batch 2, which was below the lower control limit. The recovery of dibutyltin in the matrix spike for batch 2 was $103 \%$, which is within the control limits.

\section{REFERENCES}

Unger, M.A., W.G. Macintyre, J. Reaves and R.J. Huggett. 1986. "GC Determination of Butyltins in Natural Waters by Flame Photometric Detection of Hexyl Derivatives with Mass Spectrometric Confirmation." Chemosphere. 15:461-470. 


\section{QA/QC SUMMARY}

PROGRAM:

PARAMETER:

LABORATORY:

MATRIX:

SAMPLE CUSTODY
Richmond Harbor Deepening Project

Waste Extraction Test (WET) and STLC of metals

Clayton Environmental Consultants, Pleasanton, California Sediment

Five sediment samples were received at Clayton Environmental Consultants on $2 / 15 / 94$, in good condition.

\section{QAVC DATA QUALITY OBJECTIVES}

Reference Method

$N A(a)$

METHOD

HOLDING TIMES

METHOD BLANKS

MATRIX SPIKES

REPLICATES

\section{Range of \\ Recovery}

NA

\section{Relative Precision}

NA
Detection Limit

NA

The WET extracts (membrane-filtered liquid portion of sediment sample) were measured for metals by either EPA Method 6010 (inductively-coupled plasma or ICP) or by atomic absorption (AA).

The holding time of 6 months was met for all WET test analysis.

One method blank was analyzed with the samples. No metals were detected in the blank.

Two matrix spikes were analyzed with the samples. The percent recoveries ranged from $85 \%$ to $106 \%$.

Precision was measured by calculating the RPD between the matrix spike and matrix spike duplicate recoveries. The RPD values ranged from $0 \%$ to $8 \%$.

DETECTION LIMITS The achieved detection limits were approximately one-tenth of the soluble threshold limit concentration (STLC) values.

(a) Data Quality Objectives not established prior to analysis of sediment samples. 


\title{
QA/QC SUMMARY
}

\author{
PROGRAM: Richmond Harbor Deepening Project \\ PARAMETER: Waste Extraction Test (WET) and STLC of pesticides and PCBs \\ LABORATORY: Clayton Environmental Consultants, Pleasanton, California \\ MATRIX: \\ Sediment
}

SAMPLE CUSTODY Five sediment samples and one water sample were received at Clayton Environmental Consultants on 2/15/94, in good condition.

QAVQC DATA QUALITY OBJECTIVES

Reference Method $N A(a)$

METHOD

HOLDING TIMES

METHOD BLANKS

MATRIX SPIKES

REPLICATES

SURROGATES

DETECTION LIMITS

\section{Range of} Recovery

NA

\section{Relative Precision}

NA

\section{Detection Limit}

NA The WET extracts (membrane-filtered liquid portion of sediment sample) were measured for pesticides and PCBs following EPA Methods 3510 and 8080 .

The holding time of 6 months was met for all WET test analysis.

One method blank was analyzed with the samples. No PAHs, pesticides, or PCBs were detected in the blank.

Two matrix spikes were analyzed with the samples. The percent recoveries ranged from $73 \%$ to $119 \%$.

Precision was measured by calculating the RPD between the matrix spike and matrix spike duplicate recoveries. The RPD values ranged from $0 \%$ to $7 \%$.

Two surrogate internal standards (decachorobiphenyl and tetrachloro-m-xylene) were added prior to extraction. The percent recovery of these surrogates ranged from $104 \%$ to $110 \%$.

The achieved detection limits were approximately one-tenth of the soluble threshold limit concentration (STLC) values.

(a) Data Quality Objectives not established prior to analysis of sediment samples. 
TABLE C.1. Summary of Sediment Grain Size Including Quality Control Data, Richmond Harbor Deepening Project

\begin{tabular}{|c|c|c|c|c|c|}
\hline \multirow[b]{2}{*}{$\begin{array}{l}\text { Sediment } \\
\text { Treatment }\end{array}$} & \multirow[b]{2}{*}{$\begin{array}{l}\text { Analytical } \\
\text { Batch } \\
\end{array}$} & \multicolumn{4}{|c|}{ Total Percent (dry weight) } \\
\hline & & $\begin{array}{c}\text { Gravel } \\
\geq 2000 \mu \mathrm{m} \\
\end{array}$ & $\begin{array}{l}\text { Sand } \\
62.5- \\
2000 \mu \mathrm{m} \\
\end{array}$ & $\begin{array}{c}\text { Silt } \\
3.9- \\
62.5 \mu \mathrm{m} \\
\end{array}$ & $\begin{array}{r}\text { Clay } \\
\leq 3.9 \mu \mathrm{m} \\
\end{array}$ \\
\hline $\begin{array}{l}\text { SF COMP } \\
\text { SF-1 } \\
\text { SF-2 } \\
\text { SF-3 } \\
\text { SF-4 }\end{array}$ & $\begin{array}{l}1 \\
2 \\
1 \\
1 \\
1\end{array}$ & $\begin{array}{l}1 \\
1 \\
6 \\
0 \\
0\end{array}$ & $\begin{array}{r}29 \\
29 \\
18 \\
9 \\
5\end{array}$ & $\begin{array}{l}35 \\
42 \\
34 \\
32 \\
32\end{array}$ & $\begin{array}{l}35 \\
28 \\
42 \\
59 \\
63\end{array}$ \\
\hline $\begin{array}{l}\text { SFW COMP } \\
\text { SFW-1 } \\
\text { SFW-2 } \\
\text { SFW-3 } \\
\text { SFW-4 }\end{array}$ & $\begin{array}{l}1 \\
2 \\
2 \\
2 \\
2\end{array}$ & $\begin{array}{r}5 \\
13 \\
8 \\
2 \\
3\end{array}$ & $\begin{array}{l}23 \\
35 \\
15 \\
18 \\
27\end{array}$ & $\begin{array}{l}37 \\
21 \\
35 \\
47 \\
45\end{array}$ & $\begin{array}{l}35 \\
31 \\
42 \\
33 \\
25\end{array}$ \\
\hline $\begin{array}{l}\text { UIH COMP } \\
\text { UIH-1 } \\
\text { UIH-2 } \\
\text { UIH-3 } \\
\text { UIH-4 } \\
\text { UIH-5 }\end{array}$ & $\begin{array}{l}1 \\
1 \\
1 \\
2 \\
2 \\
1\end{array}$ & $\begin{array}{l}0 \\
0 \\
0 \\
0 \\
1 \\
0\end{array}$ & $\begin{array}{r}6 \\
5 \\
2 \\
7 \\
13 \\
7\end{array}$ & $\begin{array}{l}33 \\
35 \\
33 \\
35 \\
35 \\
39\end{array}$ & $\begin{array}{l}61 \\
60 \\
65 \\
58 \\
51 \\
54\end{array}$ \\
\hline $\begin{array}{l}\text { TB Upper COMP } \\
\text { TB-1 Upper } \\
\text { TB-2 Upper } \\
\text { TB-3 Upper } \\
\text { TB-4 Upper } \\
\text { TB-5 Upper } \\
\text { TB-6 Upper } \\
\text { TB-7 Upper }\end{array}$ & $\begin{array}{l}1 \\
1 \\
2 \\
2 \\
1 \\
1 \\
1 \\
1\end{array}$ & $\begin{array}{r}8 \\
22 \\
5 \\
1 \\
0 \\
1 \\
0 \\
0\end{array}$ & $\begin{array}{r}14 \\
33 \\
20 \\
13 \\
3 \\
7 \\
3 \\
5\end{array}$ & $\begin{array}{l}45 \\
24 \\
41 \\
48 \\
46 \\
58 \\
49 \\
66\end{array}$ & $\begin{array}{l}33 \\
21 \\
34 \\
38 \\
51 \\
34 \\
48 \\
29\end{array}$ \\
\hline $\begin{array}{l}\text { TB Lower COMP, Replicate } 1 \\
\text { TB Lower COMP, Replicate } 2 \\
\text { TB Lower COMP, Replicate } 3 \\
\text { TB-1 Lower } \\
\text { TB-2 Lower } \\
\text { TB-3 Lower, Replicate } 1 \\
\text { TB-3 Lower, Replicate } 2 \\
\text { TB-3 Lower, Replicate } 3 \\
\text { TB-4 Lower } \\
\text { TB-5 Lower }\end{array}$ & $\begin{array}{l}1 \\
1 \\
1 \\
1 \\
1 \\
2 \\
2 \\
2 \\
1 \\
2\end{array}$ & $\begin{array}{l}6 \\
2 \\
1 \\
9 \\
1 \\
0 \\
1 \\
0 \\
0 \\
0\end{array}$ & $\begin{array}{r}14 \\
15 \\
15 \\
53 \\
23 \\
13 \\
12 \\
14 \\
4 \\
12\end{array}$ & $\begin{array}{l}46 \\
46 \\
47 \\
23 \\
43 \\
51 \\
53 \\
53 \\
47 \\
55\end{array}$ & $\begin{array}{l}34 \\
37 \\
37 \\
15 \\
33 \\
36 \\
34 \\
33 \\
49 \\
33\end{array}$ \\
\hline
\end{tabular}


TABLE C.1. (contd)

Sediment

Treatment

TB-6 Lower, Replicate 1

TB-6 Lower, Rep 1 icate 2

TB-6 Lower, Replicate 3

TB-7 Lower

$\mathrm{R}-\mathrm{OS}$

$\mathrm{R}-\mathrm{BF}$

R-AM COMP

$R-A M-A$

$R-A M-B$

$R-A M-C$

$R-A M-D$

$R-A M-F$

$R-A M-G$

$\mathrm{R}-\mathrm{AM}-\mathrm{H}$

R-AM-I
Total Percent (dry weight) Sand Silt 62.5- 3.9- Clay

$\begin{array}{ll}2 & 0 \\ 2 & 0 \\ 2 & 0 \\ 1 & 1\end{array}$

7

7

7

3

41

43

44

41

55

21

$\begin{array}{rrr}34 & 45 & 21 \\ 5 & 39 & 56\end{array}$

97

99

98

99

98

79

97

97

98
1

0

1

1

12

1

1
56

1

1

1

1

9

2

2

Quality Control Data

Analytical Replicates

TB Lower COMP, Replicate 11

TB Lower COMP, Rep Ticate 21

TB Lower COMP, Replicate 31

$6 \quad 14$

$\begin{array}{ll}2 & 15 \\ 1 & 15\end{array}$

46

46

47

34

37

$N A^{(a)}$

$4 \%$

$1 \%$

$5 \%$

TB-3 Lower, Replicate 1

2

TB-3 Lower, Replicate 2

TB-3 Lower, Repl icate 3

0

13

12

51

53

36

14

53

34

2

NA

$8 \%$

$2 \%$

$4 \%$

TB-6 Lower, Replicate 1

TB-6 Lower, Replicate 2

$\begin{array}{ll}2 & 0 \\ 2 & 0 \\ 2 & 0\end{array}$

7
7
7

52

50

41

49

43

44

RSD

NA

$0 \%$

$3 \%$

$4 \%$

(a) NA Not applicable. 


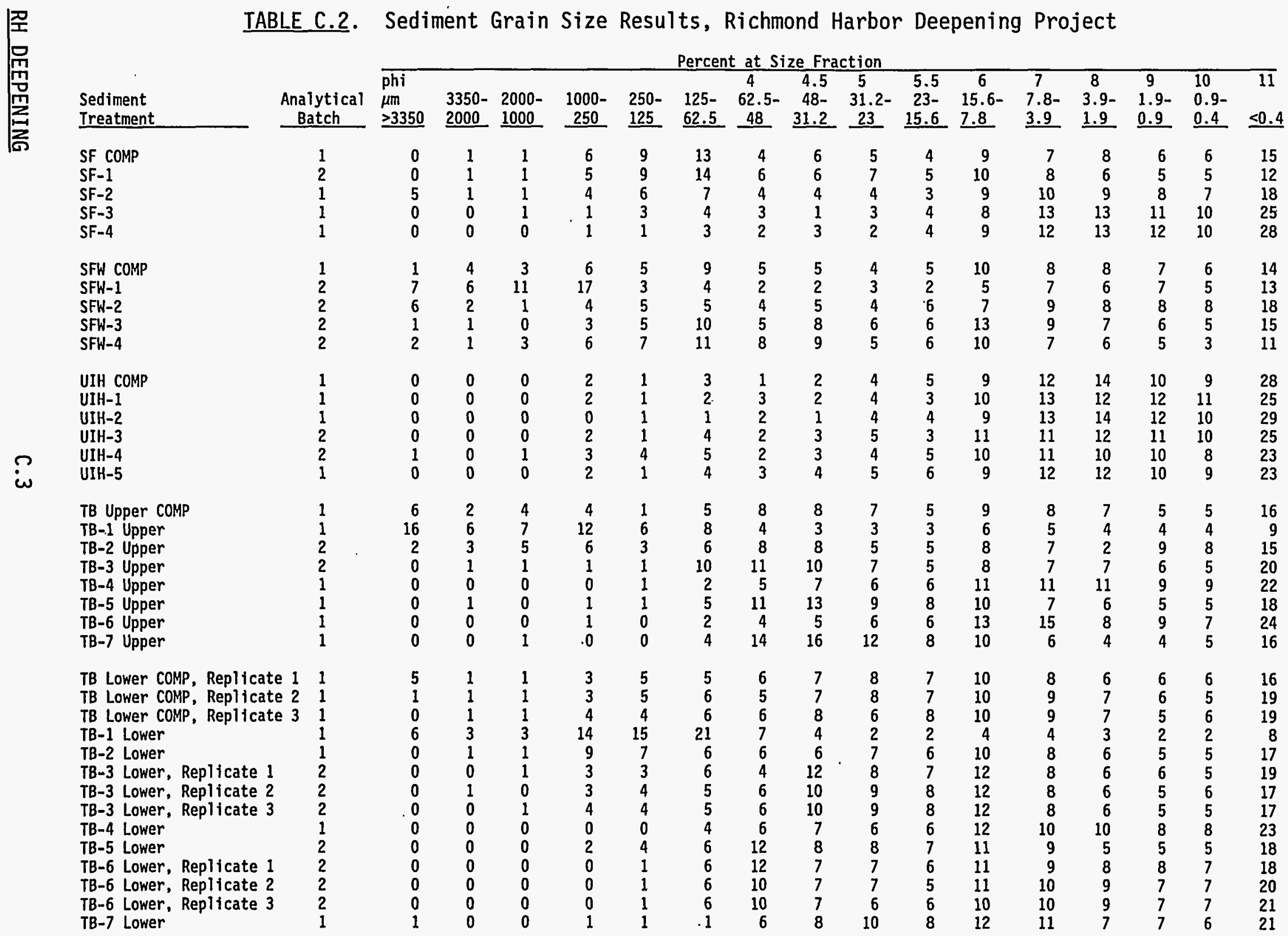


TABLE C.2. (contd)

Sediment Treatment

$R-0 S$

R-BF

R-AM COMP

R-AM-A

$R-A M-B$

R-AM-C

$R-A M-D$

R-AM-F

R-AM-G

$\mathrm{R}-\mathrm{AM}-\mathrm{H}$

R-AM-I

\begin{tabular}{|c|c|c|c|}
\hline $\begin{array}{l}\text { Analytical } \\
\text { Batch }\end{array}$ & $\begin{array}{l}\text { phi } \\
\mu \mathrm{m} \\
\geq 3350 \\
\end{array}$ & $\begin{array}{l}3350- \\
2000 \\
\end{array}$ & $\begin{array}{l}2000- \\
1000 \\
\end{array}$ \\
\hline 1 & 0 & 0 & 0 \\
\hline 1 & 0 & 0 & 0 \\
\hline 1 & 0 & 0 & 0 \\
\hline 2 & 0 & 0 & 0 \\
\hline 2 & 0 & 0 & 0 \\
\hline 2 & 0 & 0 & 0 \\
\hline 2 & 0 & 0 & 0 \\
\hline 2 & 0 & 0 & 0 \\
\hline 2 & 0 & 0 & 0 \\
\hline 2 & 0 & 0 & 0 \\
\hline 2 & 0 & 0 & 0 \\
\hline
\end{tabular}

Percent at Size Fraction

$1000-\quad 250-\quad 125-$

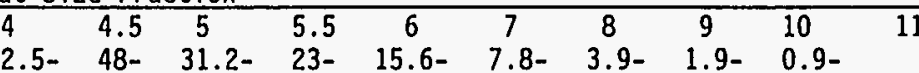

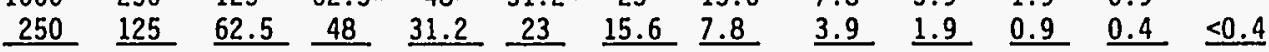

$\begin{array}{rrr}2 & 3 & 29 \\ 3 & 1 & 1 \\ 77 & 19 & 1 \\ 95 & 3 & 1 \\ 91 & 7 & 0 \\ 80 & 18 & 1 \\ 73 & 25 & 0 \\ 28 & 47 & 4 \\ 60 & 36 & 1 \\ 86 & 11 & 0 \\ 84 & 14 & 0\end{array}$

$\begin{array}{rrr}23 & 8 & 3 \\ 4 & 5 & 6 \\ 0 & 0 & 0 \\ 0 & 0 & 0 \\ 0 & 1 & 0 \\ 0 & 0 & 0 \\ 0 & 0 & 1 \\ 4 & 1 & 1 \\ 0 & 0 & 0 \\ 1 & 0 & 0 \\ 0 & 0 & 0\end{array}$

$\begin{array}{lll}3 & 3 & 5 \\ 6 & 5 & 9 \\ 0 & 0 & 1 \\ 0 & 0 & 0 \\ 0 & 0 & 0 \\ 0 & 0 & 0 \\ 1 & 0 & 0 \\ 1 & 1 & 2 \\ 0 & 1 & 0 \\ 0 & 0 & 0 \\ 0 & 0 & 0\end{array}$

$\begin{array}{rrrrr}3 & 4 & 3 & 3 & 11 \\ 10 & 11 & 10 & 10 & 25 \\ 0 & 0 & 1 & 0 & 1 \\ 0 & 0 & 0 & 0 & 1 \\ 0 & 0 & 0 & 0 & 1 \\ 0 & 0 & 0 & 0 & 1 \\ 0 & 0 & 0 & 0 & 1 \\ 3 & 2 & 2 & 2 & 3 \\ 0 & 0 & 0 & 1 & 1 \\ 0 & 0 & 0 & 0 & 2 \\ 0 & 0 & 1 & 0 & 1\end{array}$

is 


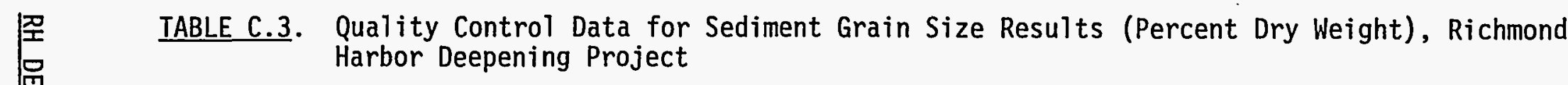
Harbor Deepening Project

Sediment

Treatment
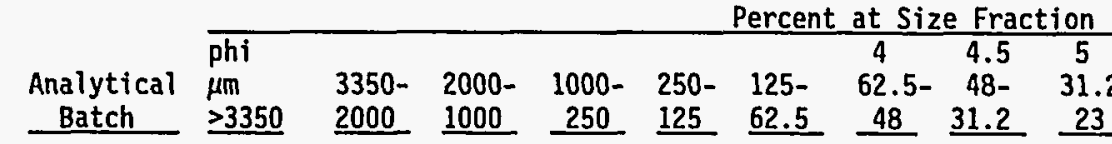

$\begin{array}{rr}51.2- & 5.5 \\ 31-23- & 13.6\end{array}$

$15.6-7.8$

$\begin{array}{cccc}8 & 9 & 10 & 11 \\ 3.9- & 1.9- & 0.9- & \\ 1.9 & 0.9 & 0.4 & \leq 0.4 \\ & & & \end{array}$

Analytical Replicates

TB Lower COMP, Replicate 11

TB Lower COMP, Replicate 21

TB Lower COMP, Replicate 31

RSD

TB-3 Lower, Replicate 1

TB-3 Lower, Replicate 2

TB-3 Lower, Replicate 3

$\begin{array}{lrrrr}5 & 1 & 1 & 3 & 5 \\ 1 & 1 & 1 & 3 & 5 \\ 0 & 1 & 1 & 4 & 4 \\ \text { NA (a) } & \text { NA } & \text { NA } & \text { NA } & 12 \% \\ 0 & 0 & 1 & 3 & 3 \\ 0 & 1 & 0 & 3 & 4 \\ 0 & 0 & 1 & 4 & 4 \\ \text { NA } & \text { NA } & \text { NA } & \text { NA } & \text { NA } \\ 0 & 0 & 0 & 0 & 1 \\ 0 & 0 & 0 & 0 & 1 \\ 0 & 0 & 0 & 0 & 1 \\ \text { NA } & \text { NA } & \text { NA } & \text { NA } & \text { NA }\end{array}$

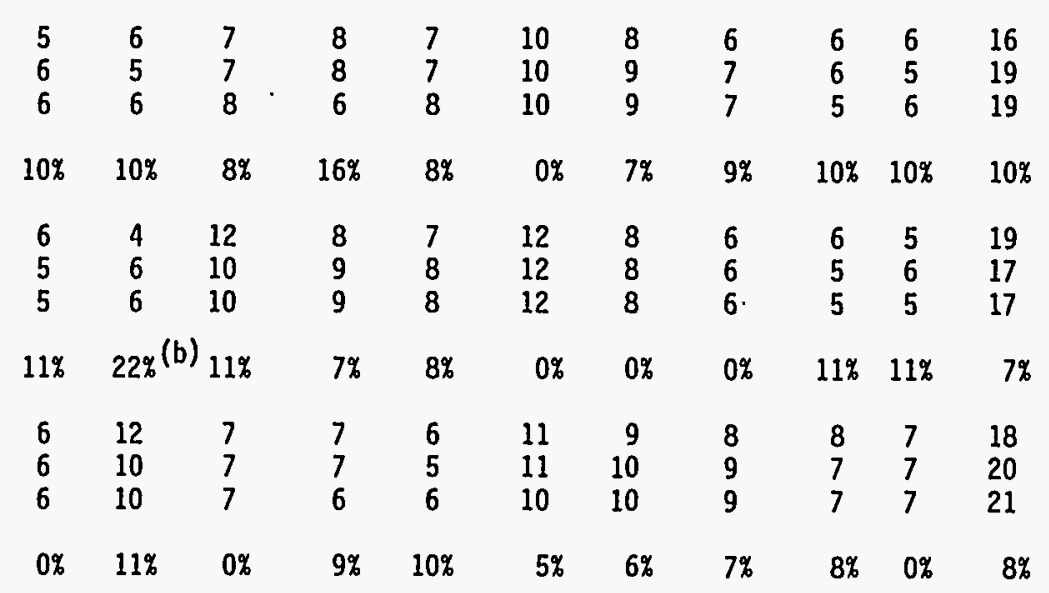

(a) NA Not applicable.

(b) Value exceeds relative precision goal of $\leq 20 \%$.

RSD

TB-6 Lower, Replicate 1

TB-6 Lower, Replicate 2$$
\text { NA NA NA NA }
$$

$0 \% \quad 11 \% \quad 0 \%$ 


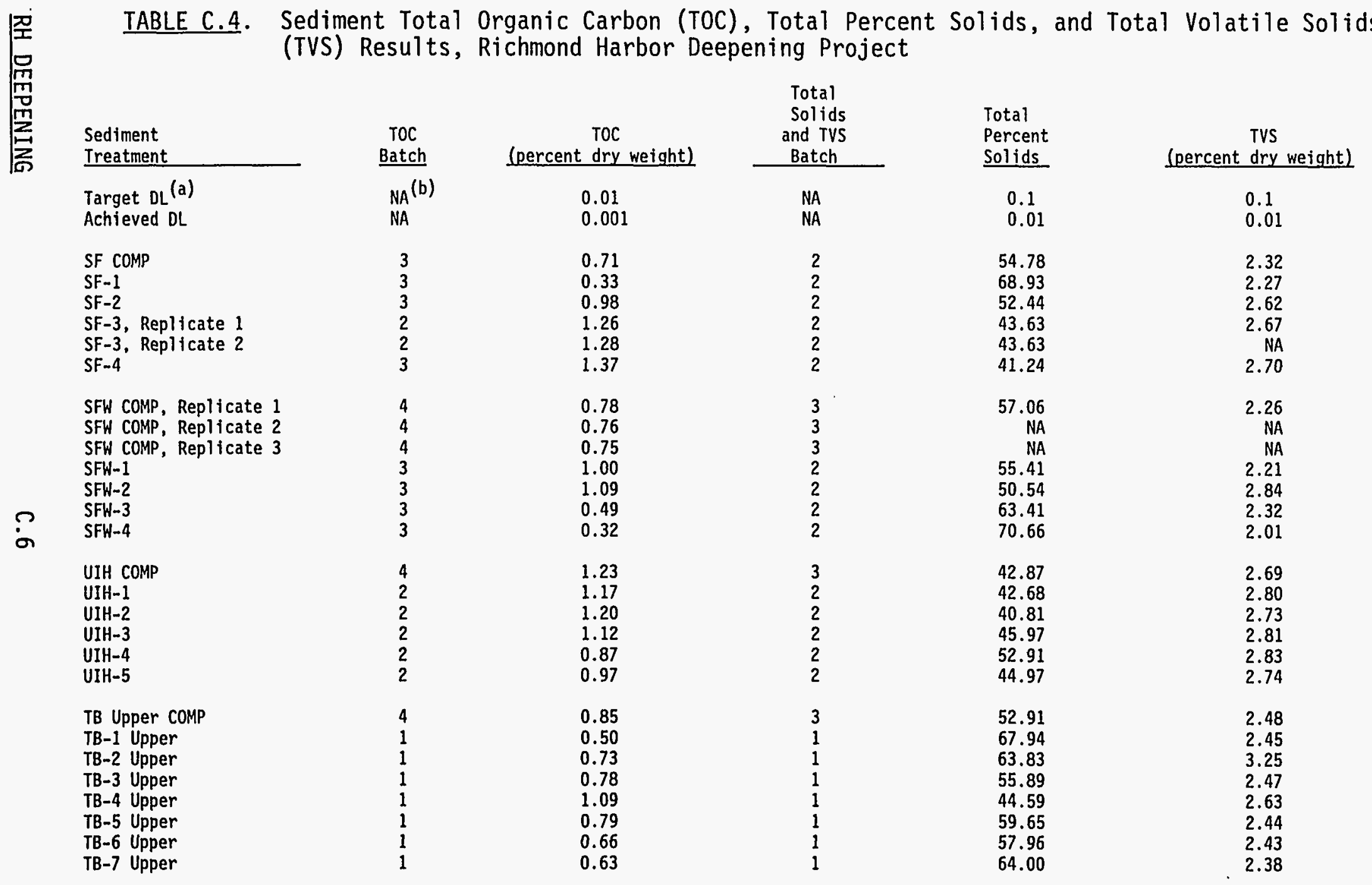


TABLE C.4. (contd)

Sediment Treatment

TB Lower COMp

TB-1 Lower

TB-2 Lower

TB-3 Lower

TB-4 Lower

TB-5 Lower

TB-6 Lower

TB-7 Lower

$R-O S$
$R-B F$

$R-B F$

R-AM COMP

R-AM-A

$R=A M-B$

R-AM-C, Replicate 1

R-AM-C, Replicate 2

R-AM-D, Replicate 1

$\because \quad \begin{aligned} & R-A M-D, \text { Repl icate } 2 \\ & \text { R-AM-D, Replicate } 3\end{aligned}$

$R-A M-F$

R-AM-G, Replicate 1

$R-A M-G$, Replicate 2

$R-A M-G$, Replicate 3

R-AM-H

$R-A M-I$

Batch

\begin{tabular}{c} 
TOC \\
(percent dry weight) \\
\hline 0.69 \\
0.05 \\
0.62 \\
0.70 \\
0.93 \\
0.70 \\
0.55 \\
0.72 \\
1.35 \\
1.24 \\
0.02 \\
0.03 \\
0.01 \\
0.01 \\
0.03 \\
0.03 \\
0.03 \\
0.03 \\
0.28 \\
0.04 \\
0.05 \\
0.04 \\
0.04 \\
0.04
\end{tabular}

\section{Total}

Solids Total

and TVS Percent

Solids

60.39

2.15

$\begin{array}{ll}81.56 & 1.73 \\ 66.81 & 2.08\end{array}$

62.25

52.95

$64.20 \quad 2.27$

$61.48 \quad 2.27$

$61.03 \quad 2.43$

54.33

35.54

78.26

90.72

89.91

79.09

$N A$
80.42

80.42

80.86

81.56
71.44

71.44
76.42

76.42
NA

NA

82.63

2.49

2.34

0.776

0.589

0.602

0.572

NA

0.623

0.622

0.594

1.73
0.707

0.707
NA

86.12

0.678

a) DL Detection Limit

(b) NA Not applicable. 


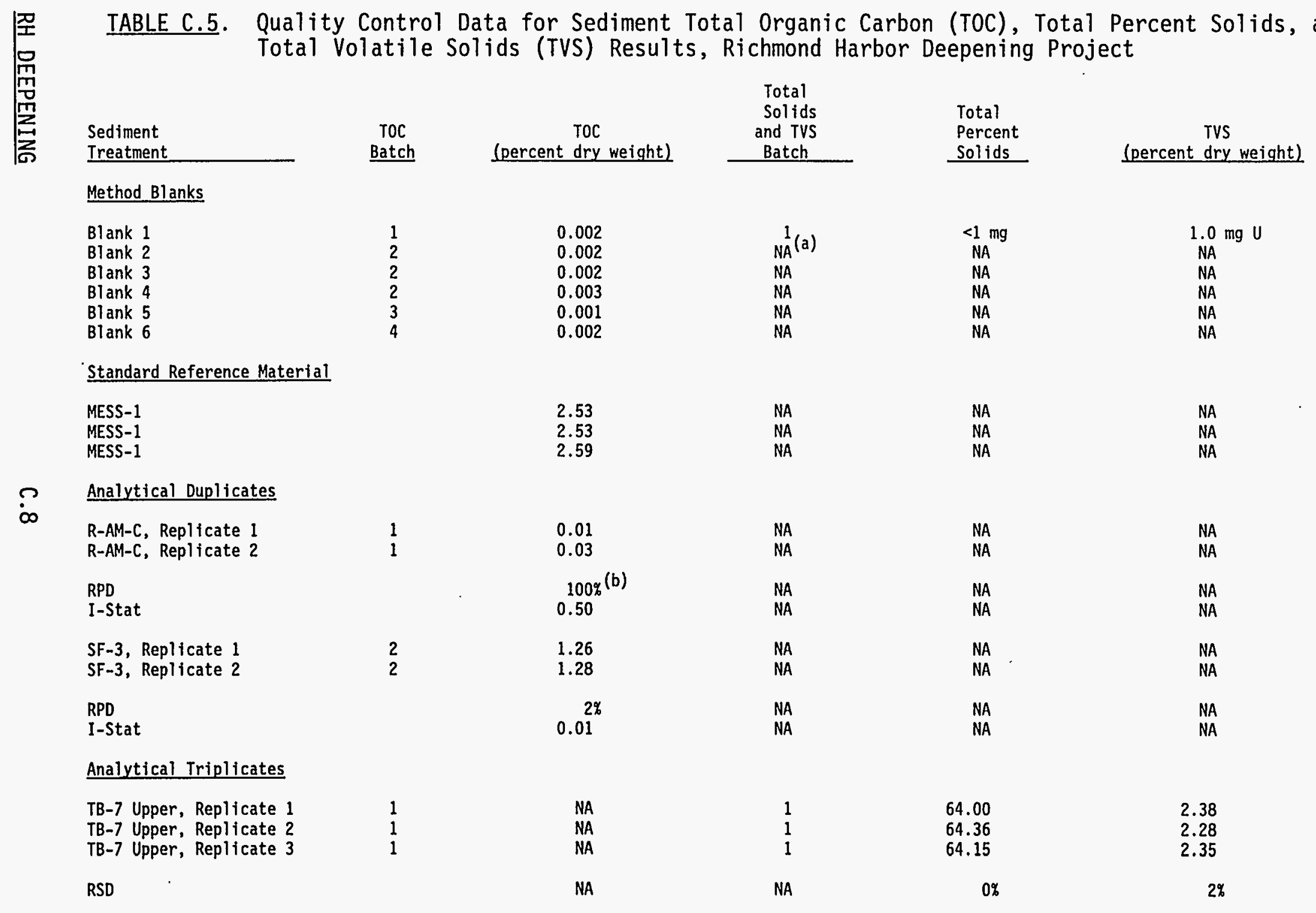




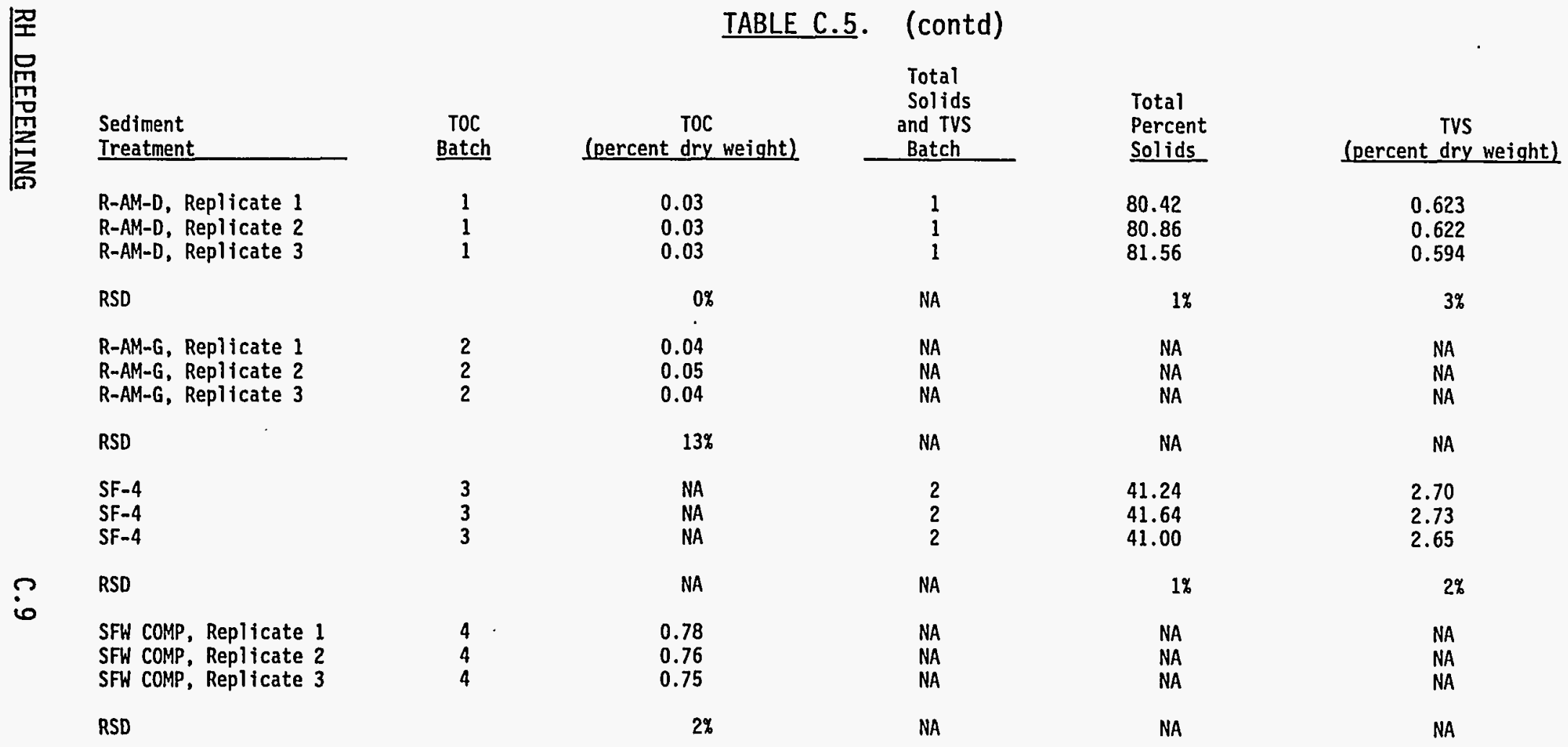

(a) NA Not applicable.

(b) Value exceeds relative precision goal of $\leq 20 \%$. 
TABLE C.6. Sediment $0 i 1$ \& Grease and Total Petroleum Hydrocarbons (TPH) Results, Richmond Harbor Deepening Project

\begin{tabular}{|c|c|c|c|}
\hline $\begin{array}{l}\text { Sediment } \\
\text { Ireatment }\end{array}$ & $\begin{array}{c}\text { Analytical } \\
\text { Batch } \\
\end{array}$ & $\begin{array}{c}0 i 1 \text { and Grease } \\
(\mathrm{mg} / \mathrm{kg} \text { dry weight) }\end{array}$ & $\begin{array}{c}\text { TPH } \\
\text { (mg/kg dry weight) } \\
\end{array}$ \\
\hline $\begin{array}{l}\text { Target } D L^{(a)} \\
\text { Achieved } D L\end{array}$ & & $\begin{array}{l}20 \\
18-29\end{array}$ & $\begin{array}{l}20 \\
17-38\end{array}$ \\
\hline $\begin{array}{l}\text { SF COMP } \\
\text { SF-1 } \\
\text { SF-2 } \\
\text { SF-3 } \\
\text { SF-4 }\end{array}$ & $\begin{array}{l}2 \\
2 \\
2 \\
2 \\
2\end{array}$ & $\begin{array}{c}29 U^{(b)} \\
36 \\
66 \\
136 \\
98\end{array}$ & $\begin{array}{l}29 \mathrm{U} \\
23 \mathrm{U} \\
34 \\
67 \\
57\end{array}$ \\
\hline $\begin{array}{l}\text { SFW COMP(c) } \\
\text { SFW COMP, Rep1 icate } 1 \\
\text { SFW COMP, Rep1 icate } 2 \\
\text { SFW COMP, Rep1 icate } 3 \\
\text { SFW-1 } \\
\text { SFW-2 } \\
\text { SFW-3 } \\
\text { SFW-4 }\end{array}$ & $\begin{array}{l}3 \\
3 \\
3 \\
3 \\
2 \\
2 \\
2 \\
2\end{array}$ & $\begin{array}{r}232 \\
106 \\
106 \\
95 \\
44 \\
79 \\
117 \\
27\end{array}$ & $\begin{array}{r}104 \\
80 \\
62 \\
62 \\
35 \\
69 \\
84 \\
22 \cup\end{array}$ \\
\hline $\begin{array}{l}\text { UIH COMP } \\
\text { UIH-1 } \\
\text { UIH-2 } \\
\text { UIH-3 } \\
\text { UIH-4 } \\
\text { UIH-5 }\end{array}$ & $\begin{array}{l}3 \\
2 \\
2 \\
2 \\
2 \\
2\end{array}$ & $\begin{array}{r}91 \\
204 \\
97 \\
80 \\
142 \\
139\end{array}$ & $\begin{array}{l}65 \\
75 \\
38 \mathrm{U} \\
34 \mathrm{U} \\
72 \\
70\end{array}$ \\
\hline $\begin{array}{l}\text { TB Upper COMP } \\
\text { TB-1 Upper } \\
\text { TB-2 Upper } \\
\text { TB-3 Upper } \\
\text { TB-4 Upper } \\
\text { TB-5 Upper } \\
\text { TB-6 Upper } \\
\text { TB-7 Upper } \\
\text { TB-7 Upper, Replicate } 1 \\
\text { TB-7 Upper, Replicate } 2 \\
\text { TB-7 Upper, Replicate 3 }\end{array}$ & $\begin{array}{l}3 \\
1 \\
1 \\
1 \\
1 \\
1 \\
1 \\
2 \\
2 \\
2 \\
2\end{array}$ & $\begin{array}{l}47 \\
36 \\
36 \\
28 \mathrm{U} \\
169 \\
26 \mathrm{U} \\
83 \\
20 \mathrm{U} \\
29 \\
33 \\
26\end{array}$ & $\begin{array}{l}30 U \\
23 U \\
25 U \\
28 U \\
57 \\
26 U \\
32 \\
20 U \\
25 U \\
25 U \\
24 U\end{array}$ \\
\hline $\begin{array}{l}\text { TB Lower COMP } \\
\text { TB-1 Lower } \\
\text { TB-2 Lower } \\
\text { TB-3 Lower } \\
\text { TB-4 Lower } \\
\text { TB-5 Lower } \\
\text { TB-6 Lower } \\
\text { TB-7 Lower }\end{array}$ & $\begin{array}{l}3 \\
1 \\
1 \\
1 \\
1 \\
1 \\
1 \\
2\end{array}$ & $\begin{array}{l}35 \\
19 U \\
29 \\
30 \\
58 \\
25 \mathrm{U} \\
26 \mathrm{U} \\
26 \mathrm{U}\end{array}$ & $\begin{array}{l}26 U \\
19 U \\
24 U \\
25 U \\
30 U \\
25 U \\
26 U \\
26 U\end{array}$ \\
\hline RH DEEPENING & & C. 10 & \\
\hline
\end{tabular}




\section{TABLE C.6. (contd)}

Sediment

Treatment

$R-0 S$

$\mathrm{R}-\mathrm{BF}$

R-AM COMP

R-AM-A

$R-A M-B$

$\mathrm{R}-\mathrm{AM}-\mathrm{C}$

$R-A M-D^{(c)}$

R-AM-D, Replicate 1

R-AM-D, Replicate 2

R-AM-D, Replicate 3

$R-A M-F$

$R-A M-G$

$\mathrm{R}-\mathrm{AM}-\mathrm{H}$

R-AM-I

Analytical

(mg/kg dry weight) (mg/kg dry weight)

$$
\begin{aligned}
& 2 \\
& 2 \\
& 2 \\
& 1 \\
& 1 \\
& 1 \\
& 1 \\
& 1 \\
& 1 \\
& 1 \\
& 1 \\
& 1 \\
& 2 \\
& 1
\end{aligned}
$$

(a) DL Detection limit.

(b) U Undetected at or above detection Timit.

(c) Sample re-analyzed approximately 1 month after initial analyses to provide appropriate matrix spike information.

39

143

26

23

$18 \mathrm{U}$

41

$18 \mathrm{U}$

42

43

62

38

37

$19 \mathrm{U}$

$18 \mathrm{U}$
$29 \mathrm{U}$

$45 \mathrm{U}$

$20 \mathrm{U}$

$17 \mathrm{U}$

$18 \mathrm{U}$

$20 \mathrm{U}$

$18 \mathrm{U}$

$19 \mathrm{U}$

$19 \mathrm{U}$

$20 \mathrm{U}$

$22 \mathrm{U}$

$20 \mathrm{U}$

$19 \mathrm{U}$

$18 \mathrm{U}$ 
TABLE C.7. Quality Control Data for Sediment 0il \& Grease and Total Petroleum Hydrocarbons (TPH) Results, Richmond Harbor Deepening Project

Sediment

Treatment

Analytical $0 i 1$ and Grease $\quad T P H$ Batch $(\mathrm{mg} / \mathrm{kg}$ dry weight) $\quad(\mathrm{mg} / \mathrm{kg}$ dry weight)

Method Blank

Blank

$$
20 U^{(a)} \quad 20 U
$$

Matrix Spikes

$R-A M-D^{(b)}$

R-AM-D, MS

Concentration Recovered

Amount Spiked

Percent Recovery

TB-7 Upper ${ }^{(b)}$

TB-7 Upper, MS

Concentration Recovered

Amount Spiked

Percent Recovery

SFW COMP(b)

SFW COMP, MS

Concentration Recovered

Amount Spiked

Percent Recovery

$18 \mathrm{U}$

6520

6520

6700

$97 \%$

2
2

3
3

Analytical Triplicates

R-AM-D, Repiicate 1

R-AM-D, Replicate 2

R-AM-D, Replicate 3

RSD

TB-7 Upper, Replicate 1

TB-7 Upper, Rep 7 icate 2

TB-7 Upper, Replicate 3

RSD

SFW COMP, Replicate 1

SFW COMP, Replicate 2

SFW COMP, Replicate 3

RSD

$\begin{array}{lll}1 & 42 & 19 \mathrm{U} \\ 1 & 43 & 19 \mathrm{U} \\ 1 & 62 & 20 \mathrm{U}\end{array}$

$23 \%$ NA

$\begin{array}{rrl}2 & 29 & 25 \mathrm{U} \\ 2 & 33 & 25 \mathrm{U} \\ 2 & 26 & 24 \mathrm{U} \\ & 12 \% & \text { NA } \\ 3 & 106 & 80 \\ 3 & 106 & 62 \\ 3 & 95 & 62 \\ & 6 \% & 15 \%\end{array}$

(a) U Undetected at or above detection limit.

(b) Sample re-analyzed approximately 1 month after initial analyses to provide appropriate matrix spike information. 
TABLE C.8. Sediment Total Polynuclear Aromatic Hydrocarbons (PAHs) Results, Richmond Harbor Deepening Project

\begin{tabular}{|c|c|c|c|c|}
\hline \multirow[b]{2}{*}{$\begin{array}{l}\text { Sediment } \\
\text { Ireatment }\end{array}$} & \multirow[b]{2}{*}{$\begin{array}{l}\text { Analytical } \\
\text { Batch }\end{array}$} & \multicolumn{3}{|c|}{$(\mu \mathrm{g} / \mathrm{kg}$ dry weight $)$} \\
\hline & & $\begin{array}{l}\text { Total } \\
\text { Low Molecular } \\
\text { Weight PAHs }\end{array}$ & $\begin{array}{l}\text { Total } \\
\text { High Molecular } \\
\text { Weight PAHs } \\
\end{array}$ & $\begin{array}{l}\text { Total } \\
\text { PAHs } \\
\end{array}$ \\
\hline $\begin{array}{l}\text { SF COMP } \\
\text { SF-1 } \\
\text { SF-2 } \\
\text { SF-3, Replicate } 1 \\
\text { SF-3, Rep 1 icate } 2 \\
\text { SF-4 }\end{array}$ & $\begin{array}{l}2 \\
2 \\
2 \\
3 \\
3 \\
2\end{array}$ & $\begin{array}{r}228 \\
79 \\
273 \\
414 \\
528 \\
489\end{array}$ & $\begin{array}{r}1345 \\
390 \\
1876 \\
3288 \\
3259 \\
3274\end{array}$ & $\begin{array}{r}1573 \\
469 \\
2149 \\
3702 \\
3787 \\
3763\end{array}$ \\
\hline $\begin{array}{l}\text { SFW COMP } \\
\text { SFW-1 } \\
\text { SFW-2 } \\
\text { SFW-3 } \\
\text { SFW-4 }\end{array}$ & $\begin{array}{l}2 \\
2 \\
2 \\
3 \\
2\end{array}$ & $\begin{array}{r}3897 \\
248 \\
386 \\
2188 \\
71\end{array}$ & $\begin{array}{r}1806 \\
1735 \\
3390 \\
1105 \\
396\end{array}$ & $\begin{array}{r}5703 \\
1983 \\
3776 \\
3293 \\
467\end{array}$ \\
\hline $\begin{array}{ll}\text { UIH COMP, Rep Ticate } 1 \\
\text { UIH COMP, Rep] icate } 2 \\
\text { UIH COMP, Rep Ticate } 3 \\
\text { UIH -1 } \\
\text { UIH-2 } \\
\text { UIH-3 } & \\
\text { UIH-4 } & \\
\text { UIH-5 } & \end{array}$ & $\begin{array}{l}3 \\
3 \\
3 \\
2 \\
2 \\
2 \\
2 \\
2\end{array}$ & $\begin{array}{l}260 \\
319 \\
697 \\
253 \\
278 \\
245 \\
227 \\
283\end{array}$ & $\begin{array}{l}1812 \\
2478 \\
2825 \\
1596 \\
1987 \\
1709 \\
1712 \\
1843\end{array}$ & $\begin{array}{l}2072 \\
2797 \\
3522 \\
1849 \\
2265 \\
1954 \\
1939 \\
2126\end{array}$ \\
\hline $\begin{array}{l}\text { TB Upper COMP } \\
\text { TB-1 Upper } \\
\text { TB-2 Upper, Rep1 icate } 1 \\
\text { TB-2 Upper, Rep1 icate } 2 \\
\text { TB-2 Upper, Rep1 icate } 3 \\
\text { TB-3 Upper } \\
\text { TB-4 Upper } \\
\text { TB-5 Upper } \\
\text { TB-6 Upper } \\
\text { TB-7 Upper }\end{array}$ & $\begin{array}{l}3 \\
1 \\
1 \\
1 \\
1 \\
1 \\
1 \\
1 \\
1 \\
1\end{array}$ & $\begin{array}{r}115 \\
48 \\
132 \\
217 \\
167 \\
161 \\
216 \\
91 \\
13 \\
26\end{array}$ & $\begin{array}{r}820 \\
368 \\
1063 \\
1371 \\
1206 \\
1322 \\
1622 \\
383 \\
18 \\
26\end{array}$ & $\begin{array}{r}935 \\
416 \\
1195 \\
1588 \\
1373 \\
1483 \\
1838 \\
474 \\
31 \\
52\end{array}$ \\
\hline $\begin{array}{l}\text { TB Lower COMP } \\
\text { TB-1 Lower } \\
\text { TB-2 Lower } \\
\text { TB-3 Lower } \\
\text { TB-4 Lower } \\
\text { TB-5 Lower } \\
\text { TB-6 Lower } \\
\text { TB-7 Lower }\end{array}$ & $\begin{array}{l}3 \\
1 \\
1 \\
1 \\
1 \\
1 \\
1 \\
2\end{array}$ & $\begin{array}{r}31 \\
0 \\
13 \\
16 \\
260 \\
19 \\
14 \\
28\end{array}$ & $\begin{array}{r}94 \\
2 \\
17 \\
26 \\
2023 \\
25 \\
20 \\
27\end{array}$ & $\begin{array}{r}125 \\
2 \\
30 \\
42 \\
2283 \\
44 \\
34 \\
55\end{array}$ \\
\hline OBM COMP & 3 & 8 & 4 & 12 \\
\hline
\end{tabular}

RH DEEPENING 
TABLE C.8. (contd)

\begin{tabular}{|c|c|c|c|c|}
\hline \multirow[b]{2}{*}{$\begin{array}{l}\text { Sediment } \\
\text { Treatment }\end{array}$} & \multirow[b]{2}{*}{$\begin{array}{l}\text { Analytical } \\
\text { Batch } \\
\end{array}$} & \multicolumn{3}{|c|}{$(\mu \mathrm{g} / \mathrm{kg}$ dry weight) } \\
\hline & & $\begin{array}{l}\text { Total } \\
\text { Low Molecular } \\
\text { Wejght PAHs } \\
\end{array}$ & $\begin{array}{c}\text { Total } \\
\text { High Molecular } \\
\text { Weight PAHs } \\
\end{array}$ & $\begin{array}{l}\text { Total } \\
\text { PAHs } \\
\end{array}$ \\
\hline $\begin{array}{l}\text { R-OS } \\
\text { R-BF } \\
\text { R-AM COMP, Replicate } 1 \\
\text { R-AM COMP, Replicate } 2 \\
\text { R-AM COMP, Replicate } 3 \\
\text { R-AM-A } \\
\text { R-AM-B } \\
\text { R-AM-C } \\
\text { R-AM-D } \\
\text { R-AM-F } \\
\text { R-AM-G } \\
\text { R-AM-H } \\
\text { R-AM-I }\end{array}$ & $\begin{array}{l}2 \\
2 \\
2 \\
2 \\
2 \\
1 \\
1 \\
1 \\
1 \\
1 \\
1 \\
2 \\
1\end{array}$ & $\begin{array}{r}48 \\
228 \\
1507 \\
773 \\
1251 \\
19 \\
16 \\
58 \\
354 \\
1062 \\
195 \\
220 \\
627\end{array}$ & $\begin{array}{r}68 \\
1527 \\
3229 \\
1772 \\
2277 \\
102 \\
45 \\
102 \\
744 \\
3325 \\
549 \\
477 \\
1533\end{array}$ & $\begin{array}{r}116 \\
1755 \\
4736 \\
2545 \\
3528 \\
121 \\
61 \\
160 \\
1098 \\
4387 \\
744 \\
697 \\
2160\end{array}$ \\
\hline
\end{tabular}


TABLE C.9. Sediment Low Molecular Weight Polynuclear Aromatic Hydrocarbons (LPAHs) Results, Richmond Harbor Deepening Project

\begin{tabular}{|c|c|c|c|c|c|c|c|}
\hline \multirow[b]{2}{*}{$\begin{array}{l}\text { Sediment } \\
\text { Treatment }\end{array}$} & \multirow[b]{2}{*}{$\begin{array}{c}\text { Analytical } \\
\text { Batch } \\
\end{array}$} & \multicolumn{6}{|c|}{ LPAHs ( $\mu \mathrm{g} / \mathrm{kg}$ dry weight) } \\
\hline & & $\begin{array}{c}\text { Naphtha- } \\
\text { lene } \\
\end{array}$ & $\begin{array}{l}\text { Acenaph- } \\
\text { thylene }\end{array}$ & $\begin{array}{l}\text { Acenaph- } \\
\text { thene }\end{array}$ & Fluorene & $\begin{array}{l}\text { Phenan- } \\
\text { threne }\end{array}$ & $\begin{array}{c}\begin{array}{c}\text { Anthra- } \\
\text { cene }\end{array} \\
\end{array}$ \\
\hline $\begin{array}{l}\text { Target DL (a) } \\
\text { Achieved DL }\end{array}$ & & $\begin{array}{r}20 \\
1.07-2.68\end{array}$ & $\begin{array}{r}20 \\
1.14-2.86\end{array}$ & $\begin{array}{r}20 \\
0.54-1.36\end{array}$ & $\begin{array}{r}20 \\
0.84-2.10\end{array}$ & $\begin{array}{r}20 \\
1.09-2.72\end{array}$ & $\begin{array}{r}20 \\
1.39-3.46\end{array}$ \\
\hline SF COMP & 2 & 37.5 & $12.4 \mathrm{~B}^{(\mathrm{b})}$ & 11.2 & 15.8 & 95.7 & 55.8 \\
\hline $\begin{array}{l}\text { SF-1 } \\
\text { SF-2 } \\
\text { SF-3, Replicate } 1 \\
\text { SF-3, Replicate } 2 \\
\text { SF-4 }\end{array}$ & $\begin{array}{l}2 \\
2 \\
3 \\
3 \\
2\end{array}$ & $\begin{array}{l}17.1 \quad B \\
47.3 \\
68.4 \\
76.1 \\
84.2\end{array}$ & $\begin{array}{l}5.23^{(c)} \text { B } \\
19.7 \\
23.0 \\
28.8 \\
31.3\end{array}$ & $\begin{array}{l}4.75^{(c)} \\
11.6 \\
15.6 \\
17.5 \\
20.7\end{array}$ & $\begin{array}{l}6.34 \\
20.5 \\
32.3 \\
35.9 \\
36.4\end{array}$ & $\begin{array}{l}29.0 \mathrm{~B} \\
99.7 \\
175 \\
198 \\
184\end{array}$ & $\begin{array}{l}16.4 \\
74.6 \\
99.7 \\
172 \\
132\end{array}$ \\
\hline $\begin{array}{l}\text { SFW COMP } \\
\text { SFH-1 } \\
\text { SFH-2 } \\
\text { SFH-3 } \\
\text { SFH-4 }\end{array}$ & $\begin{array}{l}2 \\
2 \\
2 \\
3 \\
2\end{array}$ & $\begin{array}{c}2830 \\
45.7 \\
74.5 \\
1300 \\
15.9 \mathrm{~B}\end{array}$ & $\begin{array}{l}13.8 \\
16.1 \\
21.7 \\
6.57(\mathrm{c})_{B} \\
4.95\end{array}$ & $\begin{array}{l}198 \\
10.1 \\
22.9 \\
151 \\
4.36\end{array}$ & $\begin{array}{l}181 \\
18.9^{(c)} \\
33.6 \\
290 \\
5.05 \\
\text { (c) }\end{array}$ & $\begin{array}{l}551 \\
87.9 \\
124 \\
323 \\
23.7 \mathrm{~B}\end{array}$ & $\begin{array}{l}123 \\
69.3 \\
109 \\
117 \\
17.2\end{array}$ \\
\hline $\begin{array}{l}\text { UIH COMP, Replicate } 1 \\
\text { UIH COMP, Replicate } 2 \\
\text { UIH COMP, Replicate } 3 \\
\text { UIH-1 } \\
\text { UIH-2 } \\
\text { UIH-3 } \\
\text { UIH-4 } \\
\text { UIH-5 }\end{array}$ & $\begin{array}{l}3 \\
3 \\
3 \\
2 \\
2 \\
2 \\
2 \\
2\end{array}$ & $\begin{array}{l}40.6 \\
43.1 \\
42.9 \\
43.7 \\
47.2 \\
43.3 \\
43.9 \\
49.6\end{array}$ & $\begin{array}{l}15.5 \\
17.2 \\
26.5 \\
13.9 \\
17.7 \\
17.3 \\
13.6 \\
18.4\end{array}$ & $\begin{array}{l}9.76 \\
13.0 \\
12.1(\mathrm{c}) \\
11.3^{(\mathrm{s})} \\
12.6 \\
9.51(\mathrm{c}) \\
8.90^{(\mathrm{c})} \\
11.8\end{array}$ & $\begin{array}{l}18.0 \\
22.3 \\
33.9 \\
15.4 \\
18.8 \\
17.3(\mathrm{c}) \\
14 .{ }^{(}(\mathrm{c}) \\
19.3\end{array}$ & $\begin{array}{l}112 \\
139 \\
314 \\
113 \\
114 \\
99.0 \\
86.8 \\
116\end{array}$ & $\begin{array}{r}64.1 \\
84.4 \\
268 \\
55.2 \\
67.9 \\
59.0 \\
59.4 \\
67.8\end{array}$ \\
\hline $\begin{array}{l}\text { TB Upper COMP } \\
\text { TB-1 Upper } \\
\text { TB-2 Upper, Replicate } 1 \\
\text { TB-2 Upper, Replicate } 2 \\
\text { TB-2 Upper, Replicate } 3 \\
\text { TB-3 Upper } \\
\text { TB-4 Upper } \\
\text { TB-5 Upper } \\
\text { TB-6 Upper } \\
\text { TB-7 Upper }\end{array}$ & $\begin{array}{l}3 \\
1 \\
1 \\
1 \\
1 \\
1 \\
1 \\
1 \\
1 \\
1\end{array}$ & $\begin{array}{c}18.2 \\
8.18 \\
20.6 \\
21.9 \\
21.5 \\
23.3 \\
34.4 \\
10.5 \\
1.99(c) \\
4.61\end{array}$ & $\begin{array}{l}7.82(\mathrm{c}) \\
3.18 \\
11.2 \\
13.9 \\
12.0 \\
13.4 \\
15.8(\mathrm{c}) \\
35.1 \\
1.85 \mathrm{U}^{(\mathrm{d})} \\
1.83 \mathrm{U}\end{array}$ & $\begin{array}{l}4.48 \\
2.63 \\
3.77 \\
5.94 \\
5.39(c) \\
3.01 \\
8.71 \\
1.94 \\
0.88 U \\
0.87 U\end{array}$ & $\begin{array}{l}6.57 \\
4.36(c) \\
7.77(c) \\
12.3 \\
9.66 \\
9.24 \\
15.9 \\
6.00 \\
4.67 \\
5.19\end{array}$ & $\begin{array}{c}60.8 \\
21.2 \\
64.7 \\
121 \\
86.9 \\
82.5 \\
104 \\
28.0 \\
6.47 \\
12.4\end{array}$ & $\begin{array}{l}17.4 \\
8.81 \\
23.9 \\
42.4 \\
31.6 \\
29.6 \\
37.0 \\
9.22 \\
2.25 \text { ( }) \\
4.22 \text { (c) }\end{array}$ \\
\hline $\begin{array}{l}\text { TB Lower COMP } \\
\text { TB-1 Lower } \\
\text { TB-2 Lower } \\
\text { TB-3 Lower } \\
\text { TB-4 Lower } \\
\text { TB-5 Lower } \\
\text { TB-6 Lower } \\
\text { TB-7 Lower }\end{array}$ & $\begin{array}{l}3 \\
1 \\
1 \\
1 \\
1 \\
1 \\
1 \\
2\end{array}$ & $\begin{array}{c}5.98 \mathrm{~B} \\
1.29 \mathrm{U} \\
2.40 \\
2.81 \\
40.5 \\
2.79 \text { (c) } \\
2.29 \mathrm{C} \\
7.25 \mathrm{~B}\end{array}$ & $\begin{array}{c}1.95(\mathrm{c}) \\
1.37 \mathrm{U} \\
1.6 \mathrm{U} \\
1.83 \mathrm{U} \\
18.4 \\
1.65 \mathrm{U} \\
1.76(\mathrm{U})_{B} \\
1.85\end{array}$ & $\begin{array}{l}1.94(c) \\
0.65 U \\
0.76 U \\
0.87 U \\
9.35 \\
0.78 U \\
0.84 U \\
3.33\end{array}$ & $\begin{array}{c}3.88^{(c)} \\
1.01 \mathrm{U} \\
3.70 \\
4.56(c) \\
14.7(\mathrm{c}) \\
4.02 \\
4.30 \\
4.74\end{array}$ & $\begin{array}{c}13.4 \\
1.31 \mathrm{U} \\
6.98 \\
8.67 \\
124 \\
8.52 \\
4.93 \\
11.2 \mathrm{~B}\end{array}$ & $\begin{array}{l}4.14(c) \\
1.66 \mathrm{U} \\
1.94 \mathrm{U} \\
2.22 \mathrm{U} \\
53.4(\mathrm{c}) \\
3.62 \mathrm{c} \\
2.13 \\
2.22 \mathrm{U}\end{array}$ \\
\hline OBM COMP & 3 . & $3.94 \mathrm{~B}$ & $1.47 \mathrm{U}$ & $1.62^{(c)}$ & $1.08 \mathrm{U}$ & 2.11 & $1.77 \mathrm{U}$ \\
\hline
\end{tabular}

RH DEEPENING 
TABLE C.9. (contd)

\begin{tabular}{l} 
Sediment \\
Ireatment \\
R-OS \\
R-BF \\
R-AM COMP, Replicate 1 \\
R-AM COMP, Replicate 2 \\
R-AM COMP, Replicate 3 \\
R-AM-A \\
R-AM-B \\
R-AM-C \\
R-AM-D \\
R-AM-F \\
R-AM-G \\
R-AM-H \\
R-AM-I \\
\hline
\end{tabular}

\begin{tabular}{|c|c|c|c|c|c|c|}
\hline \multirow[b]{2}{*}{$\begin{array}{l}\text { Analytical } \\
\text { Batch } \\
\end{array}$} & \multicolumn{6}{|c|}{ LPAHS ( $\mathrm{kg} / \mathrm{kg}$ ary Weight) } \\
\hline & $\begin{array}{c}\text { Naphtha- } \\
\text { lene }\end{array}$ & $\begin{array}{l}\text { Acenaph- } \\
\text { thylene }\end{array}$ & $\begin{array}{l}\text { Acenaph- } \\
\text { thene }\end{array}$ & Fluorene & $\begin{array}{l}\text { Phenan- } \\
\text { threne }\end{array}$ & $\begin{array}{c}\text { Anthra- } \\
\text { cene }\end{array}$ \\
\hline 2 & 12.3 & $2.37^{(\mathrm{C})_{B}}$ & $0.98 \mathrm{U}$ & 5.67 & $18.9 \mathrm{~B}$ & 8.90 \\
\hline 2 & 40.1 & 15.3 & 12.2 & 13.4 & 112 & 34.7 \\
\hline 2 & 46.0 & 63.6 & 32.4 & 92.2 & 925 & 348 \\
\hline 2 & 29.6 & 32.6 & 37.8 & 44.3 & 456 & 173 \\
\hline 2 & 38.1 & 56.6 & $20.5^{(c)}$ & 94.0 & 783 & 259 \\
\hline 1 & 5.62 & $2.11(c)$ & $0.54 \mathrm{U}$ & 0.84, & 7.30 & $3.93^{(C)}$ \\
\hline 1 & 2.40 & $1.17, \mathrm{U}$ & $0.56 \mathrm{U}$ & $2.54(c)$ & 7.49 & $3.57^{(c)}$ \\
\hline 1 & 9.12 & $3.18^{(\bar{c})}$ & 3.12 & 5.33 & 24.0 & 13.5 \\
\hline 1 & 10.5 & 20.0 & 5.28 & 13.6 & 213 & 91.7 \\
\hline 1 & 101 & 59.3 & 86.7 & 66.3 & 572 & 177 \\
\hline 1 & 9.95 & 11.8 & $4.27^{(c)}$ & 11.3 & 116 & 42.0 \\
\hline 2 & 36.4 & $11.4 \mathrm{~B}$ & 5.09 & $12.4^{(\mathrm{c})}$ & 113 & 41.9 \\
\hline 1 & 18.1 & 38.9 & $10.1^{(c)}$ & 39.9 & 377 & 143 \\
\hline
\end{tabular}

\footnotetext{
(a) DL Detection limit.

(b) B Analyte detected in sample is less than five times the value in associated method bilank.

(c) Ratio of confirmation ion between the primary and secondary column is outside of the theoretical ratio of $20 \%$ established for EPA-CLP programs.

(d) $U$ Undetected at or above detection limit.
} 


\begin{tabular}{|c|c|c|c|c|c|c|c|c|c|c|c|}
\hline \multirow{2}{*}{ 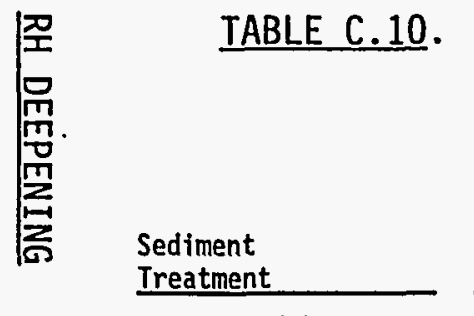 } & \multicolumn{11}{|c|}{$\begin{array}{l}\text { Sediment } \\
\text { Richmond }\end{array}$} \\
\hline & $\begin{array}{l}\text { Analytical } \\
\text { Batch } \\
\end{array}$ & $\begin{array}{l}\text { Fluor- } \\
\text { anthene }\end{array}$ & Pyrene & $\begin{array}{l}\text { Benzo(a)- } \\
\text { anthra- } \\
\text { cene } \\
\end{array}$ & Chrysene & $\begin{array}{c}\text { Benzo(b)- } \\
\text { fluor- } \\
\text { anthene }\end{array}$ & $\begin{array}{l}\text { Benzo }(k)- \\
\text { fluor- } \\
\text { anthene }\end{array}$ & $\begin{array}{l}\text { Benzo(a) } \\
\text { pyrene }\end{array}$ & $\begin{array}{c}\text { Indeno- } \\
(1,2,3- \\
\text {-cd) } \\
\text { pyrene }\end{array}$ & $\begin{array}{c}\text { Dibenzo- } \\
(\mathrm{a}, \mathrm{h}) \\
\text { anthra- } \\
\text { cene } \\
\end{array}$ & $\begin{array}{l}\text { Benzo- } \\
\text { (g,h,i) } \\
\text { perylene }\end{array}$ \\
\hline $\begin{array}{l}\text { Target } \mathrm{DL}(\mathrm{a}) \\
\text { Achieved } \mathrm{DL}\end{array}$ & & $\begin{array}{r}20 \\
1.48-3.69\end{array}$ & $\begin{array}{r}20 \\
1.19-2.97\end{array}$ & $\begin{array}{r}20 \\
0.59-1.48\end{array}$ & $\begin{array}{c}20 \\
1.09-2.72\end{array}$ & $\begin{array}{r}20 \\
0.50-1.25\end{array}$ & $\begin{array}{r}20 \\
1.09-2.73\end{array}$ & $\begin{array}{r}20 \\
1.19-2.97\end{array}$ & $\begin{array}{r}20 \\
2.32-5.80\end{array}$ & $\begin{array}{r}20 \\
3.34-8.36\end{array}$ & $\begin{array}{r}20 \\
3.63-9.08\end{array}$ \\
\hline $\begin{array}{l}\text { SF COMP } \\
\text { SF-1 } \\
\text { SF-2 } \\
\text { SF-3, Replicate 1 } \\
\text { SF-3, Replicate } 2 \\
\text { SF-4 }\end{array}$ & $\begin{array}{l}2 \\
2 \\
2 \\
3 \\
3 \\
2\end{array}$ & $\begin{array}{l}134 \\
38.2 \\
133 \\
312 \\
235 \\
235\end{array}$ & $\begin{array}{l}182 \\
42.4^{(b)} \\
216 \\
480 \\
438 \\
509\end{array}$ & $\begin{array}{l}94.6 \\
27.4 \\
111 \\
200 \\
194 \\
195\end{array}$ & $\begin{array}{l}139 \\
33.1 \\
174 \\
324 \\
332 \\
303\end{array}$ & $\begin{array}{l}238 \\
70.9 \\
398 \\
637 \\
685 \\
642\end{array}$ & $\begin{array}{l}84.2 \\
25.6 \\
131 \\
222 \\
236 \\
220\end{array}$ & $\begin{array}{l}156 \\
47.1 \\
261 \\
447 \\
466 \\
421\end{array}$ & $\begin{array}{l}146 \\
47.7 \\
213 \\
291 \\
297 \\
348\end{array}$ & $\begin{array}{l}34.3 \\
10.2 \\
47.8 \\
81.9 \\
80.2 \\
87.7\end{array}$ & $\begin{array}{l}137 \\
47.4 \\
191 \\
293 \\
296 \\
313\end{array}$ \\
\hline $\begin{array}{l}\text { SFW COMP } \\
\text { SFW-1 } \\
\text { SFW-2 } \\
\text { SFW-3 } \\
\text { SFW-4 }\end{array}$ & $\begin{array}{l}2 \\
2 \\
2 \\
3 \\
2\end{array}$ & $\begin{array}{l}297 \\
114 \\
396 \\
183 \\
28.9\end{array}$ & $\begin{array}{l}421 \\
263 \\
905 \\
296 \\
58.7\end{array}$ & $\begin{array}{l}117 \\
107 \\
268 \\
61.4 \\
21.7\end{array}$ & $\begin{array}{l}137 \\
169 \\
312 \\
72.5 \\
27.4\end{array}$ & $\begin{array}{c}248 \\
339 \\
457 \\
138 \\
72.5\end{array}$ & $\begin{array}{l}85.8 \\
119 \\
169 \\
42.9 \\
25.7\end{array}$ & $\begin{array}{l}166 \\
228 \\
328 \\
105 \\
49.7\end{array}$ & $\begin{array}{l}152 \\
182 \\
262 \\
90.5 \\
51.4\end{array}$ & $\begin{array}{l}29.3 \\
47.3 \\
57.2 \\
13.6 \\
9.65\end{array}$ & $\begin{array}{l}153 \\
167 \\
236 \\
102 \\
50.1\end{array}$ \\
\hline $\begin{array}{l}\text { UIH COMP, Replicate } 1 \\
\text { UIH COMP, Replicate } 2 \\
\text { UIH COMP, Replicate } 3 \\
\text { UIH-1 } \\
\text { UIH-2 } \\
\text { UIH-3 } \\
\text { UIH-4 } \\
\text { UIH-5 }\end{array}$ & $\begin{array}{l}3 \\
3 \\
3 \\
2 \\
2 \\
2 \\
2 \\
2\end{array}$ & $\begin{array}{l}166 \\
193 \\
335 \\
161 \\
160 \\
135 \\
113 \\
164\end{array}$ & $\begin{array}{l}309 \\
352 \\
541 \\
260 \\
373 \\
254(b) \\
311 \\
253\end{array}$ & $\begin{array}{l}106 \\
164 \\
228 \\
103 \\
121 \\
94.4 \\
97.9 \\
116\end{array}$ & $\begin{array}{l}153 \\
243 \\
260 \\
133 \\
165 \\
126 \\
161 \\
153\end{array}$ & $\begin{array}{l}314 \\
452 \\
420 \\
248 \\
330 \\
309 \\
313 \\
328\end{array}$ & $\begin{array}{l}104 \\
163 \\
150 \\
85.5 \\
115 \\
107 \\
110 \\
109\end{array}$ & $\begin{array}{l}232 \\
344 \\
343 \\
189 \\
241 \\
214 \\
218 \\
232\end{array}$ & $\begin{array}{l}190 \\
252 \\
245 \\
188 \\
217 \\
220 \\
180 \\
225\end{array}$ & $\begin{array}{l}36.2 \\
55.0 \\
51.6 \\
33.6 \\
43.6 \\
39.9 \\
39.3 \\
43.6\end{array}$ & $\begin{array}{l}202 \\
260 \\
251 \\
195 \\
221 \\
210 \\
169 \\
219\end{array}$ \\
\hline $\begin{array}{l}\text { TB Upper COMP } \\
\text { TB-1 Upper } \\
\text { TB-2 Upper, Replicate } 1 \\
\text { TB-2 Upper, Replicate } 2 \\
\text { TB-2 Upper, Replicate } 3 \\
\text { TB-3 Upper } \\
\text { TB-4 Upper } \\
\text { TB-5 Upper } \\
\text { TB-6 Upper }\end{array}$ & $\begin{array}{l}3 \\
1 \\
1 \\
1 \\
1 \\
1 \\
1 \\
1 \\
1\end{array}$ & $\begin{array}{l}105 \\
44.6 \\
122 \\
188 \\
147 \\
151 \\
196 \\
40.9 \\
4.42(\mathrm{~b})\end{array}$ & $\begin{array}{l}142 \\
58.6 \\
159 \\
224 \\
188 \\
197 \\
257 \\
50.9 \quad u^{(c)} \\
1.92 u^{(c)}\end{array}$ & $\begin{array}{l}51.1 \\
23.0 \\
74.2 \\
99.5 \\
88.0 \\
87.8 \\
98.1 \\
25.3 \\
3.71(b)\end{array}$ & $\begin{array}{l}56.0 \\
22.6 \\
76.8 \\
105 \\
88.9 \\
90.4 \\
110 \\
26.0 \\
2.73(\mathrm{~b})\end{array}$ & $\begin{array}{l}110 \\
51.5 \\
150 \\
187 \\
168 \\
184 \\
232 \\
59.6 \\
6.65(\mathrm{~b})\end{array}$ & $\begin{array}{l}35.0 \\
17.5 \\
53.4 \\
61.4 \\
55.6 \\
61.3 \\
78.0 \\
23.0 \\
1.77\end{array}$ & $\begin{array}{l}104 \\
43.9 \\
142 \\
174 \\
161 \\
183 \\
207 \\
51.5 \\
1.92\end{array}$ & $\begin{array}{c}97.3 \\
48.9 \\
129 \\
150 \\
141 \\
166 \\
200 \\
47.3 \\
3.76 U\end{array}$ & $\begin{array}{l}12.8 \\
6.13 \\
16.6 \\
20.6 \\
19.2 \\
20.0 \\
24.9 \\
7.03 \\
5.42 \mathrm{U}\end{array}$ & $\begin{array}{c}107 \\
51.7 \\
140 \\
161 \\
149 \\
181 \\
219 \\
51.7 \\
5.88 \quad U\end{array}$ \\
\hline TB-7 Upper & 1 & $4.73^{(b)}$ & $1.90 \mathrm{U}$ & $4.36^{(b)}$ & 3.42 & $7.95^{(b)}$ & $2.98^{(b)}$ & $2.13^{(b)}$ & $3.71 \mathrm{U}$ & $5.35 \mathrm{U}$ & $5.81 \mathrm{U}$ \\
\hline
\end{tabular}




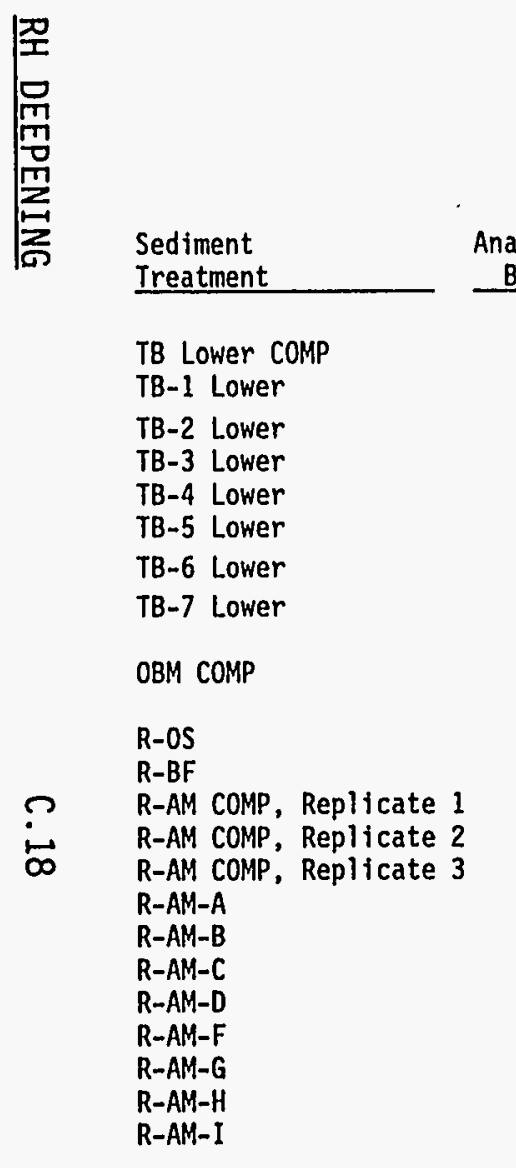

TABLE C.10. (contd)

HPAHs $(\mu \mathrm{g} / \mathrm{kg}$ dry weight)

\begin{tabular}{|c|c|c|c|c|c|c|c|c|c|c|}
\hline $\begin{array}{l}\text { alytical } \\
\text { Batch }\end{array}$ & $\begin{array}{c}\text { Fluor- } \\
\text { anthene }\end{array}$ & Pyrene & $\begin{array}{l}\text { Benzo (a) - } \\
\text { anthra- } \\
\text { cene } \\
\end{array}$ & Chrysene & $\begin{array}{l}\text { Benzo(b) - } \\
\text { fluor- } \\
\text { anthene }\end{array}$ & $\begin{array}{l}\text { Benzo }(k)- \\
\text { fluor- } \\
\text { anthene }\end{array}$ & $\begin{array}{l}\text { Benzo(a) } \\
\text { pyrene }\end{array}$ & $\begin{array}{c}\text { Indeno- } \\
(1,2,3- \\
-c d) \\
\text { pyrene } \\
\end{array}$ & $\begin{array}{c}\text { Dibenzo- } \\
(\mathrm{a}, \mathrm{h}) \\
\text { anthra- } \\
\text { cene } \\
\end{array}$ & $\begin{array}{l}\text { Benzo- } \\
(g, h, i) \\
\text { perylene }\end{array}$ \\
\hline $\begin{array}{l}3 \\
1\end{array}$ & $\begin{array}{l}15.0 \\
1.77 \mathrm{U}\end{array}$ & $\begin{array}{l}13.2 \\
1.42 U\end{array}$ & $\begin{array}{l}7.61 \\
2.47(B)\end{array}$ & $\begin{array}{l}7.19 \\
1.31 \cup\end{array}$ & $\begin{array}{l}13.3 \\
0.60 \mathrm{U}\end{array}$ & $\begin{array}{l}3.98 \\
1.31 \cup\end{array}$ & $\begin{array}{l}9.14 \\
1.42 u\end{array}$ & $\begin{array}{l}11.9 \\
2.79 \mathrm{U}\end{array}$ & $\begin{array}{l}5.35 U \\
4.01 U\end{array}$ & $\begin{array}{l}12.5 \\
4.36 \mathrm{U}\end{array}$ \\
\hline 1 & $\begin{array}{l}3.46^{(\mathrm{b})} \\
4.38^{(b)}\end{array}$ & $\begin{array}{l}1.66 \mathrm{U} \\
1.90 \mathrm{U}\end{array}$ & $\begin{array}{l}3.92 \text { (b) } \\
4.22 \text { (b) }\end{array}$ & $\begin{array}{l}2.53 \\
3.04\end{array}$ & $\begin{array}{l}5.22 \\
5.89\end{array}$ & $\begin{array}{l}1.53 \\
2.63(b)\end{array}$ & $\begin{array}{l}1.66^{(b)} \\
1.90 \mathrm{U}\end{array}$ & $\begin{array}{l}3.25 U \\
3.71 U\end{array}$ & $\begin{array}{l}4.68 U \\
5.35 U\end{array}$ & $\begin{array}{l}5.08 \mathrm{U} \\
5.81\end{array}$ \\
\hline 1 & 221 (b) & 338 & 112 (b) & 127 & 290 (b) & 93.9 (b) & 269 (b) & 259 & 29.8 & 283 \\
\hline 1 & $3.63^{(10)}$ & $1.71 \mathrm{U}$ & 3.80 (b) & $\begin{array}{l}2.90 \\
2.67\end{array}$ & $\begin{array}{l}5.62^{(0)} \\
6.59\end{array}$ & $\begin{array}{l}2.38^{\circ(1)} \\
1.68 \mathrm{U}\end{array}$ & $\begin{array}{l}1.71^{(0)} \\
1.83\end{array}$ & $\begin{array}{l}3.34 \mathrm{U} \\
3.57 \mathrm{U}\end{array}$ & $\begin{array}{l}4.82 \mathrm{U} \\
5.15 \mathrm{U}\end{array}$ & $\begin{array}{l}5.23 \\
5.59 \text { U }\end{array}$ \\
\hline $\begin{array}{l}1 \\
2\end{array}$ & $5.90^{4.90}(b)_{B}(d)$ & d) $1.90 \mathrm{U}$ & $4.42^{4.05}(b)$ & $\begin{array}{l}2.67 \\
1.94\end{array}$ & $\begin{array}{l}0.59 \\
4.66\end{array}$ & $\begin{array}{l}1.08 \mathrm{U} \\
1.75 \mathrm{U}\end{array}$ & $\begin{array}{l}1.830 \\
1.90 \mathrm{U}\end{array}$ & 3.94 (b) & $5.35 U$ & $\begin{array}{l}. .59(b) \\
6.11(b)\end{array}$ \\
\hline 3 & $2.50^{(b)} B$ & $1.52 U$ & $1.37^{(\mathrm{b})_{B}}$ & $1.39 \mathrm{U}$ & $0.64 \mathrm{U}$ & $1.40 \mathrm{U}$ & $\cdot 1.52 \mathrm{U}$ & $2.97 \mathrm{U}$ & $4.28 \mathrm{U}$ & $4.65 \mathrm{U}$ \\
\hline 2 & 11.3 & 7.39 & 6.88 & 4.55 & 9.30 & 3.41 & 2.58 & 10.1 & $6.02 \mathrm{U}$ & 12.2 \\
\hline ? & & 241 & & 103 & 200 & 66.7 & 175 & & & \\
\hline 2 & & & & & & & & & & \\
\hline 2 & 32 & 39 & 19 & 19 & 167 & 59.8 & 18 & 12 & 3 & \\
\hline 2 & & & & 25 & 200 & 71. & & & & 118 \\
\hline 1 & 18.7 & 19.7 & 12.4 & 10.2 & 11.6 & & 10.9 & 6.85 & & 6.34 \\
\hline$i$ & & & & & & & & & & 4.00 \\
\hline$i$ & 17.9 & 21.5 & 12. & 11.8 & 10.6 & 5.41 & 10. & 6.36 & $4.08 \mathrm{U}$ & 5.89 \\
\hline 1 & 164 & & & 67.4 & 69.7 & 27.2 & 70.3 & 45.6 & 9.1 & 43.1 \\
\hline 1 & 582 & 814 & 253 & 241 & 359 & 124 & 361 & 273 & 39. & 278 \\
\hline 1 & 91.0 & 117 & 55. & 56.2 & 61.2 & 23.1 & 62. & 37. & 7. & 36. \\
\hline 2 & 85.9 & 109 & 54.1 & 54.6 & 42.6 & 15.9 & 44.4 & 32.3 & 7.84 & 30.2 \\
\hline 1 & 308 & 371 & 161 & 163 & 137 & 52.3 & 143 & 91.0 & 19.4 & 87.3 \\
\hline
\end{tabular}

(a) DL Detection limit.

(b) Ratio of confirmation ion between the primary and secondary column is outside of the theoretical ratio of $20 \%$ established for EPA-CLP programs.

(c) U Undetected at or above detection limit.

(d) B Analyte detected in sample is less than five times the value in associated method blank. 
TABLE C.11. Quality. Control Data for Sediment Low Molecular Weight Polynuclear Aromatic Hydrocarbons (LPAHs) Results, Richmond Harbor Deepening Project

\begin{tabular}{|c|c|c|c|c|c|c|c|}
\hline \multirow{2}{*}{$\begin{array}{l}\text { Sediment } \\
\text { Ireatment } \\
\end{array}$} & \multirow[b]{2}{*}{$\begin{array}{l}\text { Analytical } \\
\text { Batch } \\
\end{array}$} & \multicolumn{4}{|c|}{ LPAHs $(\mu \mathrm{g} / \mathrm{kg}$ dry weight) } & \multirow{2}{*}{$\begin{array}{l}\text { Phenan- } \\
\text { threne }\end{array}$} & \multirow[b]{2}{*}{$\begin{array}{l}\text { Anthra- } \\
\text { cene }\end{array}$} \\
\hline & & $\begin{array}{l}\text { Naphtha- } \\
\text { lene } \\
\end{array}$ & $\begin{array}{l}\text { Acenaph- } \\
\text { thylene }\end{array}$ & $\begin{array}{l}\text { Acenaph- } \\
\text { thene } \\
\end{array}$ & Fluorene & & \\
\hline \multicolumn{8}{|l|}{ Method Blanks } \\
\hline $\begin{array}{l}\text { Blank-1 } \\
\text { Bl ank-2 } \\
\text { Blank-1 } \\
\text { Blank-1 }\end{array}$ & $\begin{array}{l}1 \\
1 \\
2 \\
3\end{array}$ & $\begin{array}{l}1.50 U^{(a)} \\
1.48 U^{(a)} \\
5.78 \\
2.70\end{array}$ & $\begin{array}{l}1.60 \mathrm{U} \\
1.58 \mathrm{U} \\
2.49 \mathrm{~b}) \\
1.92 \mathrm{U}\end{array}$ & $\begin{array}{l}0.76 \mathrm{U} \\
0.75 \mathrm{U} \\
0.93 \mathrm{U} \\
0.92 \mathrm{U}\end{array}$ & $\begin{array}{l}1.18 \mathrm{U} \\
1.16 \mathrm{U} \\
1.43 \mathrm{U} \\
1.41 \mathrm{U}\end{array}$ & $\begin{array}{l}1.52 \mathrm{U} \\
1.50(\mathrm{~b}) \\
6.32 \mathrm{~V} \\
1.83 \mathrm{U}\end{array}$ & $\begin{array}{l}0.19 \mathrm{U} \\
1.91 \mathrm{U} \\
2.36 \mathrm{U} \\
2.33 \mathrm{U}\end{array}$ \\
\hline \multicolumn{8}{|l|}{ Matrix Spikes } \\
\hline $\begin{array}{l}\text { R-AM-I } \\
\text { R-AM-I, MS } \\
\text { Concentration Recovered } \\
\text { Amount Spiked } \\
\text { Percent Recovery }\end{array}$ & 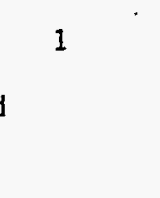 & $\begin{array}{l}18.1 \\
84.8 \\
66.7 \\
58.0 \\
115 \%\end{array}$ & $\begin{array}{l}38.9 \\
112 \\
73.1 \\
58.0 \\
126 \%(\mathrm{c})\end{array}$ & $\begin{array}{l}10.1^{(b)} \\
78.5 \\
68.4 \\
58.0 \\
118 \%\end{array}$ & $\begin{array}{l}39.9 \\
127 \\
87.1 \\
58.0 \\
150 \%(c)\end{array}$ & $\begin{array}{l}377 \\
592 \\
215 \\
58.0 \\
371 \%(c)\end{array}$ & $\begin{array}{l}143 \\
245 \\
102 \\
58.0 \\
176 \%(c)\end{array}$ \\
\hline $\begin{array}{l}\text { R-AM-H } \\
\text { R-AM-H, MS } \\
\text { Concentration Recovered } \\
\text { Amount Spiked } \\
\text { Percent Recovery }\end{array}$ & 1 & $\begin{array}{l}36.4 \\
54.6 \\
18.2 \\
28.5 \\
64 \%\end{array}$ & $\begin{array}{l}11.4 \\
44.2 \\
32.8 \\
28.5 \\
115 \%\end{array}$ & $\begin{array}{l}5.09 \\
33.0 \\
27.9 \\
28.5 \\
98 \%\end{array}$ & $\begin{array}{l}12.4^{(b)} \\
45.0 \\
32.6 \\
28.5 \\
114 \%\end{array}$ & $\begin{array}{l}113 \\
197 \\
84.0 \\
28.5 \\
295 \%(c)\end{array}$ & $\begin{array}{l}41.9 \\
132 \\
90.1 \\
28.5 \\
316 \%(c)\end{array}$ \\
\hline $\begin{array}{l}\text { TB Upper COMP } \\
\text { TB Upper COMP } \\
\text { Concentration Recovered } \\
\text { Amount Spiked } \\
\text { Percent Recovery }\end{array}$ & 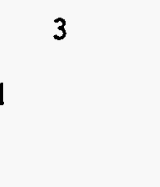 & $\begin{array}{l}18.2 \\
63.0 \\
44.8 \\
42.0 \\
107 \%\end{array}$ & $\begin{array}{l}7.82 \\
47.0 \\
39.2 \\
42.0 \\
93 \%\end{array}$ & $\begin{array}{l}4.48 \\
49.4 \\
44.9 \\
42.0 \\
107 \%\end{array}$ & $\begin{array}{l}6.57 \\
52.5 \\
45.9 \\
42.0 \\
109 \%\end{array}$ & $\begin{array}{l}60.8 \\
126 \\
65.2 \\
42.0 \\
155 \%(c)\end{array}$ & $\begin{array}{l}17.4 \\
73.2 \\
55.8 \\
42.0 \\
133 \%(c)\end{array}$ \\
\hline \multicolumn{8}{|c|}{ Standard Reference Material } \\
\hline $\begin{array}{l}\text { Certified } \\
\text { value NIST 1941a }\end{array}$ & & $\begin{array}{l}1010 \\
\pm 140\end{array}$ & $\begin{array}{l}N C^{(d)} \\
N C\end{array}$ & $\begin{array}{l}\text { NC } \\
\text { NC }\end{array}$ & $\begin{array}{l}97.3 \\
\pm 8.6\end{array}$ & $\begin{array}{l}489 \\
\pm 23\end{array}$ & $\begin{array}{l}184 \\
\pm 14\end{array}$ \\
\hline $\begin{array}{l}\text { SRM 1941a } \\
\text { SRM 1941a } \\
\text { SRM 1941a }\end{array}$ & $\begin{array}{l}1 \\
2 \\
3\end{array}$ & $\begin{array}{l}853 \\
865 \\
749\end{array}$ & $\begin{array}{l}\text { NA }(e) \\
N A \\
N A\end{array}$ & $\begin{array}{l}\text { NA } \\
\text { NA } \\
\text { NA }\end{array}$ & $\begin{array}{l}93.5 \\
90.6 \\
83.8\end{array}$ & $\begin{array}{l}478 \\
508 \\
455\end{array}$ & $\begin{array}{l}199 \\
208 \\
193\end{array}$ \\
\hline \multicolumn{8}{|l|}{ Analytical Duplicates } \\
\hline $\begin{array}{l}\text { SF-3, Replicate } 1 \\
\text { SF-3, Replicate } 2\end{array}$ & $\begin{array}{l}3 \\
3\end{array}$ & $\begin{array}{l}68.4 \\
76.1\end{array}$ & $\begin{array}{l}23.0 \\
28.8\end{array}$ & $\begin{array}{l}15.6 \\
17.5\end{array}$ & $\begin{array}{l}32.3 \\
35.9\end{array}$ & $\begin{array}{l}175 \\
198\end{array}$ & $\begin{array}{l}99.7 \\
172\end{array}$ \\
\hline $\begin{array}{l}\text { RPD } \\
\text { I-Stat }\end{array}$ & & 0.05 & $\begin{array}{l}22 \% \\
0.11\end{array}$ & 0.06 & 0.05 & 0.06 & $\begin{array}{l}53 \% \\
0.27\end{array}$ \\
\hline \multicolumn{8}{|l|}{ Analytical Triplicates } \\
\hline $\begin{array}{l}\text { TB-2 Upper, Replicate } 1 \\
\text { TB-2 Upper, Replicate } 2 \\
\text { TB-2 Upper, Replicate } 3\end{array}$ & $\begin{array}{l}1 \\
1 \\
1\end{array}$ & $\begin{array}{l}20.6 \\
21.9 \\
21.5\end{array}$ & $\begin{array}{l}11.2 \\
13.9 \\
12.0\end{array}$ & $\begin{array}{l}3.77 \\
5.94 \\
5.39\end{array}$ & $\begin{array}{l}7.77^{(b)} \\
12.3 \\
9.66\end{array}$ & $\begin{array}{c}64.7 \\
121 \\
86.9\end{array}$ & $\begin{array}{l}23.9 \\
42.4 \\
31.6\end{array}$ \\
\hline RSD & & $3 \%$ & $11 \%$ & $22 \%$ & $23 \%$ & $31 \%(f)$ & $28 \%$ \\
\hline $\begin{array}{l}\text { R-AM COMP, Replicate } 1 \\
\text { R-AM COMP, Replicate } 2 \\
\text { R-AM COMP, Replicate } 3\end{array}$ & $\begin{array}{l}2 \\
2 \\
2\end{array}$ & $\begin{array}{l}46.0 \\
29.6 \\
38.1\end{array}$ & $\begin{array}{l}63.6 \\
32.6 \\
56.6\end{array}$ & $\begin{array}{l}32.4 \\
37.8 \\
20.5\end{array}$ & $\begin{array}{l}92.2 \\
44.3 \\
94.0\end{array}$ & $\begin{array}{l}925 \\
456 \\
783\end{array}$ & $\begin{array}{l}348 \\
173 \\
259\end{array}$ \\
\hline RSD & & $22 \%$ & $32 \%(f)$ & $29 \%$ & $37 \%^{(f)}$ & $33 z^{(f)}$ & $34 \%^{(f)}$ \\
\hline RH DEEPENING & & & C. 19 & & & & \\
\hline
\end{tabular}




\section{TABLE C.11. (contd)}

\begin{tabular}{|c|c|c|c|c|c|c|c|}
\hline \multirow[b]{2}{*}{$\begin{array}{l}\text { Sediment } \\
\text { Treatment }\end{array}$} & \multirow[b]{2}{*}{$\begin{array}{l}\text { Analytical } \\
\text { Batch } \\
\end{array}$} & \multicolumn{4}{|c|}{ LPAHs $(\mu \mathrm{g} / \mathrm{kg}$ dry weight) } & \multirow[b]{2}{*}{$\begin{array}{l}\text { Phenan- } \\
\text { threne }\end{array}$} & \multirow[b]{2}{*}{$\begin{array}{l}\text { Anthra- } \\
\text { cene }\end{array}$} \\
\hline & & $\begin{array}{l}\text { Naphtha- } \\
\text { lene }\end{array}$ & $\begin{array}{l}\text { Acenaph- } \\
\text { thylene }\end{array}$ & $\begin{array}{l}\text { Acenaph- } \\
\text { thene }\end{array}$ & Fluorene & & \\
\hline $\begin{array}{l}\text { UIH COMP, Replicate } 1 \\
\text { UIH COMP, Replicate } 2 \\
\text { UIH COMP, Replicate } 3 .\end{array}$ & $\begin{array}{l}3 \\
3 \\
3\end{array}$ & $\begin{array}{l}40.6 \\
43.1 \\
42.9\end{array}$ & $\begin{array}{l}15.5 \\
17.2 \\
26.5\end{array}$ & $\begin{array}{l}9.76 \\
13.0 \\
12.1\end{array}$ & $\begin{array}{l}18.0 \\
22.3 \\
33.9\end{array}$ & $\begin{array}{l}112 \\
139 \\
314\end{array}$ & $\begin{array}{r}64.1 \\
84.4 \\
268\end{array}$ \\
\hline RSD & & $3 \%$ & $30 \%$ & $14 \%$ & $33 \%(f)$ & $58 \%(f)$ & $81 \%^{(f)}$ \\
\hline
\end{tabular}

(a) U Undetected at or above detection limit.

(b) Ratio of confirmation ion between the primary and secondary column is outside of the theoretical ratio of $20 \%$ established for EPA-CLP programs.

(c) Outside quality control criteria (40\%-120\%) for matrix spike recoveries.

(d) NC Not certified.

(e) NA Not applicable.

(f) Exceeds quality control criteria ( $\$ 30 \%$ ) for precision. 
刃्厂 TABLE C.12. Quality Control Data for Sediment High Molecular Weight Polynuclear Aromatic Hydrocarbons

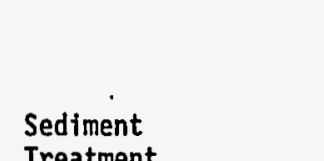

HPAHs ( $\mu \mathrm{g} / \mathrm{kg}$ dry weight)

Treatment

Analytical Fluor-

Benzo(a)-

Batch anthene

Pyrene

cene

Benzo(b) - Benzo(k)-

Method Blanks

Blank-1

Blank-2

Blank-1

$2.07 u^{(a)}$

$1.66 \mathrm{U}$
$1.64 \mathrm{U}$
$2.02 \mathrm{U}$

3.08 (b)

fluor-

fluor-

Indeno- Dibenzo-

$(a, h)$

Benzo-

Chrysene anthene anthene

anthra- $(g, h, i)$

Blank-1

2.85

$1.99 \mathrm{U}$

$\quad 1.50 \mathrm{~V}$

$1.01 \mathrm{U}$

$1.52 \mathrm{U}$
$1.50 \mathrm{U}$
$1.85 \mathrm{U}$
$1.83 \mathrm{U}$

$0.70 \mathrm{U}$

$0.69 \mathrm{U}$

$1.53 \mathrm{U}$

$1.51 \mathrm{U}$

$1.86 \mathrm{U}$

$1.66 \mathrm{U}$

pyrene

cene

perylene

Matrix Spikes

R-AM-I

R-AM-I, MS

Concentration Recovered

Amount Spiked

$\stackrel{?}{N}$

Percent Recovery

R-AM-H

R-AM-H, MS

Concentration Recovered

Amount Spiked

Percent Recovery

TB Upper COMP

TB Upper COMP

Concentration Recovered

Amount Spiked

Percent Recovery

$\begin{array}{llll}1 & 308 & 371 & 161 \\ & 456 & 541 & 283 \\ & 148 & 170 & 122 \\ & 58.0 & 58.0(c) & 58.0(c) \\ & 255 \% & 293 \%(c) & 210 \%\end{array}$

163
279
116
58.0
$200 \%(c)$

137

245
108

52.3
124
71.7
58.0

$3.20 \mathrm{U}$

$4.68 \mathrm{U}$

$5.08 \mathrm{U}$

$0.84 U$

$1.99 \mathrm{U}$

$3.90 \mathrm{U}$

$5.62 \mathrm{U}$

5.010

$6.17 \mathrm{U}$

$\underline{\text { Standard Reference Material }}$

Certified

Value NIST 1941a

$\begin{array}{ll} & 981 \\ & \pm 78 \\ & \\ 1 & 811 \\ 2 & 768(d) \\ 3 & 718\end{array}$

811
\pm 24

$109 \quad 54.1$

85.9

236
150

28.5 (c)

303

194

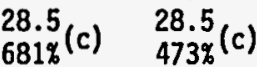

54.6

$186 \%(c)$

$124 \%(c)$

143

143
253
110

110

91.0

87.

19.4

83.6

64.2

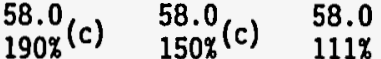

80.7

58.0

32.

84.8

7.84
52.9

$183 \quad 160$

$644 \%(c) \quad \begin{aligned} & 28.5 \\ & 563 \%\end{aligned}(c)$

68.9

\section{5}

150

45.0

$42: 0$

142

51.1

56.0

110

189

47.0

98.9

47.8

42.0

100

44.0

42.0

$112 \%$

$114 \%$

$105 \%$

157

47.0

42.0

$112 \%$

28.5 (c)

217
173

173
28.5

182
150

45.1

28.5 (c) 28.5

30.2

35 .

81.2

46.2

42.0

104

104
149

45.0

42.0

97.3
142

44.7

42.0

12.8

58.6

45.8

42.0

$109 \%$

175

145
28.5

SRM NIST 1941a

SRM NIST 1941a

SRM NIST 1941a

718

$\begin{array}{ll}647 & 407 \\ 625 & 421\end{array}$

427
\pm 25
407
421
371

$\begin{array}{ll}380 & 740 \\ \pm 24 & \pm 110 \\ 516^{(d)} & 1124^{(d)} \\ 519^{(d)} & 1010^{(d)} \\ 483 & 1010^{(d)}\end{array}$

361
\pm 18
370
343
327

628
\pm 52

563
519
508

501
\pm 72
520
532
489

73.9
\pm 9.7

$\begin{array}{ll}73.9 & 525 \\ \pm 9.7 & \pm 67\end{array}$

129 (d)

130 (d) 476

130 (d) 476
123 
TABLE C.12. (contd)

HPAHs $(\mu \mathrm{g} / \mathrm{kg}$ dry weight)

Sediment

Treatment

Analytical Fluor-
Batch
anthene Pyrene

Benzo(a)-

Benzo(b) - Benzo(k) -

fluor- fluor- Benzo(a) -cd)

Indeno-

Dibenzo-

anthra-

Chrysene

$(a, h)$ Benzo-

Analytical Duplicates

$\begin{array}{lcccccccccccc}\text { SF-3, Replicate 1 } & 3 & 312 & 480 & 200 & 324 & 637 & 222 & 447 & 291 & 81.9 & 293 \\ \text { SF-3, Replicate 2 } & 3 & 235 & 438 & 194 & 332 & 685 & 236 & 466 & 297 & 80.2 & 296 \\ \text { RPD } & & & 28 \% & 9 \% & 3 \% & 2 \% & 7 \% & 6 \% & 4 \% & 2 \% & 2 \% & 1 \% \\ \text { I-Stat } & & 0.14 & 0.05 & 0.02 & 0.01 & 0.04 & 0.03 & 0.02 & 0.01 & 0.01 & 0.01\end{array}$

\section{Analytical Triplicates}

TB-2 Upper, Replicate 11

TB-2 Upper, Replicate

TB-2 Upper, Replicate 3

N $R$ RSD

$\begin{array}{llll}122 & 159 & 74.2 & 7 \\ 188 & 224 & 99.5 & \\ 147 & 188 & 88.0 & 88 .\end{array}$

R-AM COMP, Replicate 1

R-AM COMP, Replicate 2

R-AM COMP, Replicate 3

$22 \%$

$17 \% \quad .15 \%$

$76.8 \quad 150$

$\begin{array}{rr}105 & 187 \\ 88.9 & 168\end{array}$

53.4

88.9

168

61.4
55.6

142

$16 \% \quad 11 \%$

$7 \%$

174

$\begin{array}{lll}129 & 16.6 & 140\end{array}$

$616 \quad 751 \quad 38$

386
194

382

290

105
59.8

$10 \%$

141

20.6

19.2

161

RSD

452

$545 \quad 261$

$\begin{array}{ll}190 & 167\end{array}$

59.8

308

$8 \% \quad 11 \% \quad 7 \%$

$32 \%(e)$

$32 \%(e)$

$5 \%(e)$

$35 \%$ (e) $29 \%$

71.3

185
215

182

44.3

44.3
23.5

30.4

165

UIH COMP Replicate 1

UIH COMP, Replicate 3

166
193
335

$309 \quad 106$

$153 \quad 314$

$30 \%$

$27 \%$

$23 \%$

$32 \%(e)$

118

$104 \quad 23$

232
344
343

$\begin{array}{ll}190 & 36.2 \\ 252 & 55.0\end{array}$

$21 \%$

$39 \%(e)$

$31 \%(\mathrm{e})$

$37 \%(e)$

260

150

343

245

51.6

202

RSD

$26 \% \quad 18 \%$

$22 \%$

$15 \%$

$21 \%$

$13 \%$

(a) U Undetected at or above detection limit.

(b) Ratio of confirmation ion between the primary and secondary column is outside of the

theoretical ratio of $20 \%$ established for EPA-CLP programs.

(c) Outside quality control criteria $(40 \%-120 \%)$ for matrix spike recoveries.

(d) Outside quality control criteria $( \pm 30 \%)$ for SRMs.

(e) Exceeds quality control criteria ( $\leq 30 \%)$ for precision. 
TABLE C.13. Sediment Phthalate Ester Results, Richmond Harbor Deepening Project

\begin{tabular}{|c|c|c|c|c|c|c|c|}
\hline \multirow[b]{2}{*}{$\begin{array}{l}\text { Sediment } \\
\text { Treatment }\end{array}$} & \multirow[b]{2}{*}{$\begin{array}{l}\text { Analytical } \\
\text { Batch } \\
\end{array}$} & \multicolumn{6}{|c|}{ Phthalates $(\mu \mathrm{g} / \mathrm{kg}$ dry weight) } \\
\hline & & $\begin{array}{l}\text { Dimethyl } \\
\text { Phthalate }\end{array}$ & $\begin{array}{c}\text { Diethyl } \\
\text { Phthalate }\end{array}$ & $\begin{array}{l}\text { Di-n-butyl } \\
\text { Phthalate }\end{array}$ & $\begin{array}{l}\text { Butyl } \\
\text { benzyl } \\
\text { Phthalate }\end{array}$ & $\begin{array}{c}\text { Bis } \\
\text { (2-ethylhexyl) } \\
\text { Phthalate } \\
\end{array}$ & $\begin{array}{l}\text { Di-n-octyl } \\
\text { Phthalate }\end{array}$ \\
\hline $\begin{array}{l}\text { Target } \mathrm{DL} \text { (a) } \\
\text { Achieved } \mathrm{DL}\end{array}$ & & $33.7-84.2^{20}(b)$ & $28.0-69^{20}(\mathrm{~g})$ & $22.7-56.7^{20}(b)$ & $26.0-65.0^{20}(b)$ & $65.3-163(b)$ & $47.3-118^{20}(b)$ \\
\hline $\begin{array}{l}\text { SF COMP } \\
\text { SF-1 } \\
\text { SF-2 } \\
\text { SF-3, Repl icate } 1 \\
\text { SF-3, Replicate } 2 \\
\text { SF-4 }\end{array}$ & $\begin{array}{l}2 \\
2 \\
2 \\
3 \\
3 \\
2\end{array}$ & $\begin{array}{l}58.0 U^{(c)} \\
47.2 \mathrm{U} \\
60.7 \mathrm{U} \\
75.5 \mathrm{U} \\
70.8 \mathrm{U} \\
72.1 \mathrm{U}\end{array}$ & $\begin{array}{l}48.1 \mathrm{U} \\
39.1 \mathrm{U} \\
50.3 \mathrm{U} \\
62.6 \mathrm{U} \\
58.7 \mathrm{U} \\
59.8 \mathrm{U}\end{array}$ & $\begin{array}{l}39.0 \mathrm{U} \\
31.7 \mathrm{U} \\
40.8 \mathrm{U} \\
50.8 \mathrm{U} \\
47.6 \mathrm{U} \\
48.5 \mathrm{U}\end{array}$ & $\begin{array}{l}44.7 \mathrm{U} \\
36.4 \mathrm{U} \\
46.8 \mathrm{U} \\
58.2 \mathrm{U} \\
54.6 \mathrm{U} \\
55.6 \mathrm{U}\end{array}$ & $\begin{array}{l}254 \\
131 \\
117 \mathrm{U} \\
328 \\
416 \\
473\end{array}$ & $\begin{array}{c}81.3 \mathrm{U} \\
66.2 \mathrm{U} \\
85.1 \mathrm{U} \\
106 \mathrm{U} \\
99.3 \mathrm{U} \\
101 \mathrm{U}\end{array}$ \\
\hline $\begin{array}{l}\text { SFW COMP } \\
\text { SFH-1 } \\
\text { SFW-2 } \\
\text { SFW-3 } \\
\text { SFW-4 }\end{array}$ & $\begin{array}{l}2 \\
2 \\
2 \\
3 \\
2\end{array}$ & $\begin{array}{l}59.3 \mathrm{U} \\
60.7 \mathrm{U} \\
59.3 \mathrm{U} \\
52.6 \mathrm{U} \\
45.8 \mathrm{U}\end{array}$ & $\begin{array}{l}49.2 \mathrm{U} \\
50.3 \mathrm{U} \\
49.2 \mathrm{U} \\
43.6 \mathrm{U} \\
38.0 \mathrm{U}\end{array}$ & $\begin{array}{l}39.9 \mathrm{U} \\
40.8 \mathrm{U} \\
39.9 \mathrm{U} \\
35.4 \mathrm{U} \\
30.8 \mathrm{U}\end{array}$ & $\begin{array}{l}45.7 \mathrm{U} \\
46.8 \mathrm{U} \\
45.7 \mathrm{U} \\
40.5 \mathrm{U} \\
35.3 \mathrm{U}\end{array}$ & $\begin{array}{l}367 \\
282 \\
439 \\
104 \\
88.8 \mathrm{U}\end{array}$ & $\begin{array}{l}83.2 \mathrm{U} \\
85.1 \mathrm{U} \\
83.2 \mathrm{U} \\
73.8 \mathrm{U} \\
64.3 \mathrm{U}\end{array}$ \\
\hline $\begin{array}{l}\text { UIH COMP, Replicate } 1 \\
\text { UIH COMP, Replicate } 2 \\
\text { UIH COMP, Replicate } 3 \\
\text { UIH-1 } \\
\text { UIH-2 } \\
\text { UIH-3 } \\
\text { UIH-4. } \\
\text { UIH-5 }\end{array}$ & $\begin{array}{l}3 \\
3 \\
3 \\
2 \\
2 \\
2 \\
2 \\
2\end{array}$ & $\begin{array}{l}61.3 \mathrm{U} \\
72.1 \mathrm{U} \\
72.8 \mathrm{U} \\
67.4 \mathrm{U} \\
80.9 \mathrm{U} \\
74.1 \mathrm{U} \\
53.9 \mathrm{U} \\
74.1 \mathrm{U}\end{array}$ & $\begin{array}{l}50.9 \mathrm{U} \\
59.8 \mathrm{U} \\
60.4 \mathrm{U} \\
55.9 \mathrm{U} \\
67.1 \mathrm{U} \\
61.5 \mathrm{U} \\
44.7 \mathrm{U} \\
61.5 \mathrm{U}\end{array}$ & $\begin{array}{l}41.3 \mathrm{U} \\
48.5 \mathrm{U} \\
49.0 \mathrm{U} \\
45.3 \mathrm{U} \\
54.4 \mathrm{U} \\
49.9 \mathrm{U} \\
36.3 \mathrm{U} \\
49.9 \mathrm{U}\end{array}$ & $\begin{array}{l}47.3 \mathrm{U} \\
55.6 \mathrm{U} \\
56.1 \mathrm{U} \\
52.0 \mathrm{U} \\
62.4 \mathrm{U} \\
57.2 \mathrm{U} \\
41.6 \mathrm{U} \\
58.0\end{array}$ & $\begin{array}{l}325 \\
354 \\
296 \\
205 \\
282 \\
404 \\
199 \\
416\end{array}$ & $\begin{array}{l}86.0 \mathrm{U} \\
101 \mathrm{U} \\
102 \mathrm{U} \\
94.6 \mathrm{U} \\
113 \mathrm{U} \\
104 \mathrm{U} \\
75.6 \mathrm{U} \\
104 \mathrm{U}\end{array}$ \\
\hline $\begin{array}{l}\text { TB Upper COMP } \\
\text { TB-1 Upper } \\
\text { TB-2 Upper, Replicate } 1 \\
\text { TB-2 Upper, Replicate } 2 \\
\text { TB-2 Upper, Replicate } 3 \\
\text { TB-3 Upper } \\
\text { TB-4 Upper } \\
\text { TB-5 Upper } \\
\text { TB-6 Upper } \\
\text { TB-7 Upper }\end{array}$ & $\begin{array}{l}3 \\
1 \\
1 \\
1 \\
1 \\
1 \\
1 \\
1 \\
1 \\
1\end{array}$ & $\begin{array}{l}59.3 \mathrm{U} \\
48.5 \mathrm{U} \\
53.9 \mathrm{U} \\
60.7 \mathrm{U} \\
60.7 \mathrm{U} \\
53.9 \mathrm{U} \\
74.1 \mathrm{U} \\
53.9 \mathrm{U} \\
54.6 \mathrm{U} \\
53.9 \mathrm{U}\end{array}$ & $\begin{array}{l}49.2 \mathrm{U} \\
40.3 \mathrm{U} \\
44.7 \mathrm{U} \\
50.3 \mathrm{U} \\
50.3 \mathrm{U} \\
44.7 \mathrm{U} \\
61.5 \mathrm{U} \\
44.7 \mathrm{U} \\
45.3 \mathrm{U} \\
44.7 \mathrm{U}\end{array}$ & $\begin{array}{l}39.9 \mathrm{U} \\
32.7 \mathrm{U} \\
36.3 \mathrm{U} \\
40.8 \mathrm{U} \\
40.8 \mathrm{U} \\
36.3 \mathrm{U} \\
49.9 \mathrm{U} \\
36.3 \mathrm{U} \\
36.7 \mathrm{U} \\
36.3 \mathrm{U}\end{array}$ & $\begin{array}{l}45.7 \mathrm{U} \\
37.4 \mathrm{U} \\
41.6 \mathrm{U} \\
46.8 \mathrm{U} \\
46.8 \mathrm{U} \\
41.6 \mathrm{U} \\
57.2 \mathrm{U} \\
41.6 \mathrm{U} \\
42.1 \mathrm{U} \\
41.6 \mathrm{U}\end{array}$ & $\begin{array}{l}115 U \\
126 \\
104 U \\
117 U \\
117 U \\
104 U \\
182 \\
104 U \\
106 U \\
104 U\end{array}$ & $\begin{array}{rl}83.2 & U \\
68.1 & U \\
75.6 & U \\
85.1 & U \\
85.1 & U \\
75.6 U & \\
104 U & \\
75.6 & U \\
76.6 & U \\
75.6 & U\end{array}$ \\
\hline
\end{tabular}


TABLE C. 13. (contd)

Sediment

Treatment

TB Lower COMP

TB-1 Lower

TB-2 Lower

TB-3 Lower

TB-4 Lower

TB-5 Lower

TB-6 Lower

TB-7 Lower

OBM COMP

$R-0 S$

R-BF

R-AM COMP, Replicate 1

R-AM COMP, Replicate 2

R-AM COMP, Replicate 3

R-AM-A

$R-A M-B$

$R-A M-D$

$R-A M-F$

$R-A M-G$

R-AM-H

R-AM-I
Phthalates ( $\mu \mathrm{g} / \mathrm{kg}$ dry weight)

Analytical
Batch

\begin{tabular}{llll} 
Dimethyl & Diethyl & Di-n-butyl & Butyl \\
Phthalate & Phthalate & Phthalate & Phthalate \\
\hline
\end{tabular}

$53.9 \mathrm{U}$

$40.4 \mathrm{U}$

$47.2 \mathrm{U}$

$53.9 \mathrm{U}$

$62.0 \mathrm{~V}$

$51.9 \mathrm{U}$

$53.9 \mathrm{U}$

$43.1 \mathrm{U}$

$60.7 \mathrm{U}$

$84.2 U$

$40.4 U$

$40.4 \mathrm{U}$

$40.4 \mathrm{U}$

$33.7 \mathrm{U}$

$34.4 \mathrm{U}$

$41.1 \mathrm{U}$

$33.7 U$

$42.5 \mathrm{U}$

$40.4 \mathrm{U}$

$40.4 \mathrm{U}$

$39.8 \mathrm{U}$

$\begin{array}{ll}44.7 & \mathrm{U} \\ 33.5 & \mathrm{U} \\ 39.1 & \mathrm{U} \\ 44.7 \mathrm{U} \\ 51.4 \mathrm{U} \\ 40.3 \mathrm{U} \\ 43.0 \mathrm{U} \\ 44.7 \mathrm{U} \\ 35.8 \mathrm{U} \\ \\ 50.3 \mathrm{U} \\ 69.9 \mathrm{U} \\ 33.5 \mathrm{U} \\ 33.5 \mathrm{U} \\ 33.5 \mathrm{U} \\ 28.0 \mathrm{U} \\ 28.5 \mathrm{U} \\ 34.1 \mathrm{U} \\ 28.0 \mathrm{U} \\ 35.2 \mathrm{U} \\ 33.5 \mathrm{U} \\ 33.5 \mathrm{U} \\ 33.0 \mathrm{U}\end{array}$

$36.3 \mathrm{U}$

$27.2 \mathrm{U}$

$31.7 \mathrm{U}$

$36.3 \mathrm{U}$

$41.7 \mathrm{U}$

$32.7 \mathrm{U}$

$34.9 \mathrm{U}$

$36.3 \mathrm{U}$

$29.0 \mathrm{U}$

$40.8 \mathrm{U}$

$56.7 \mathrm{U}$

$27.2 \mathrm{U}$

$27.2 \mathrm{U}$

$27.2 \mathrm{U}$

$23.1 \mathrm{U}$

$27.7 \mathrm{U}$

$22.7 \mathrm{U}$

$28.6 \mathrm{U}$

$27.2 \mathrm{U}$

$27.2 \mathrm{U}$

$26.8 \mathrm{U}$
Bis

(2-ethylhexy1) Di-n-octyl

Phthalate Phthalate

$104 \mathrm{U}$

$78.3 \mathrm{U}$

$91.4 \mathrm{U}$

104
130

$94.0 \mathrm{U}$

$101 \mathrm{U}$

104 U

$83.5 \mathrm{U}$

$117 \mathrm{U}$

$163 \mathrm{U}$

$78.3 \mathrm{U}$

136

$78.3 \mathrm{U}$

$65.3 \mathrm{U}$

$66.6 \mathrm{U}$

$79.6 \mathrm{U}$

$65.3 \mathrm{U}$

$82.2 \mathrm{U}$

$78.3 \mathrm{U}$

$78.3 \mathrm{U}$

102
$75.6 \mathrm{U}$

$56.7 \mathrm{U}$

$66.2 \mathrm{U}$

$75.6 \mathrm{U}$

$87.0 \mathrm{U}$

$68.1 \mathrm{U}$

$72.8 \mathrm{U}$

$75.6 \mathrm{U}$

$60.5 U$

$85.1 \mathrm{U}$

118 U

$56.7 \mathrm{U}$

$56.7 \mathrm{U}$

$56.7 \mathrm{U}$

$47.3 \mathrm{U}$

$48.2 \mathrm{U}$

57.7 U

$47.3 \mathrm{U}$

$59.6 \mathrm{U}$

$56.7 \cup$

$56.7 U$

$55.8 \mathrm{U}$

(a) DL Detection Iimit.

(b) These are Limits of Quantitation not MDLs.

(c) U Undetected at or above detection limit. 


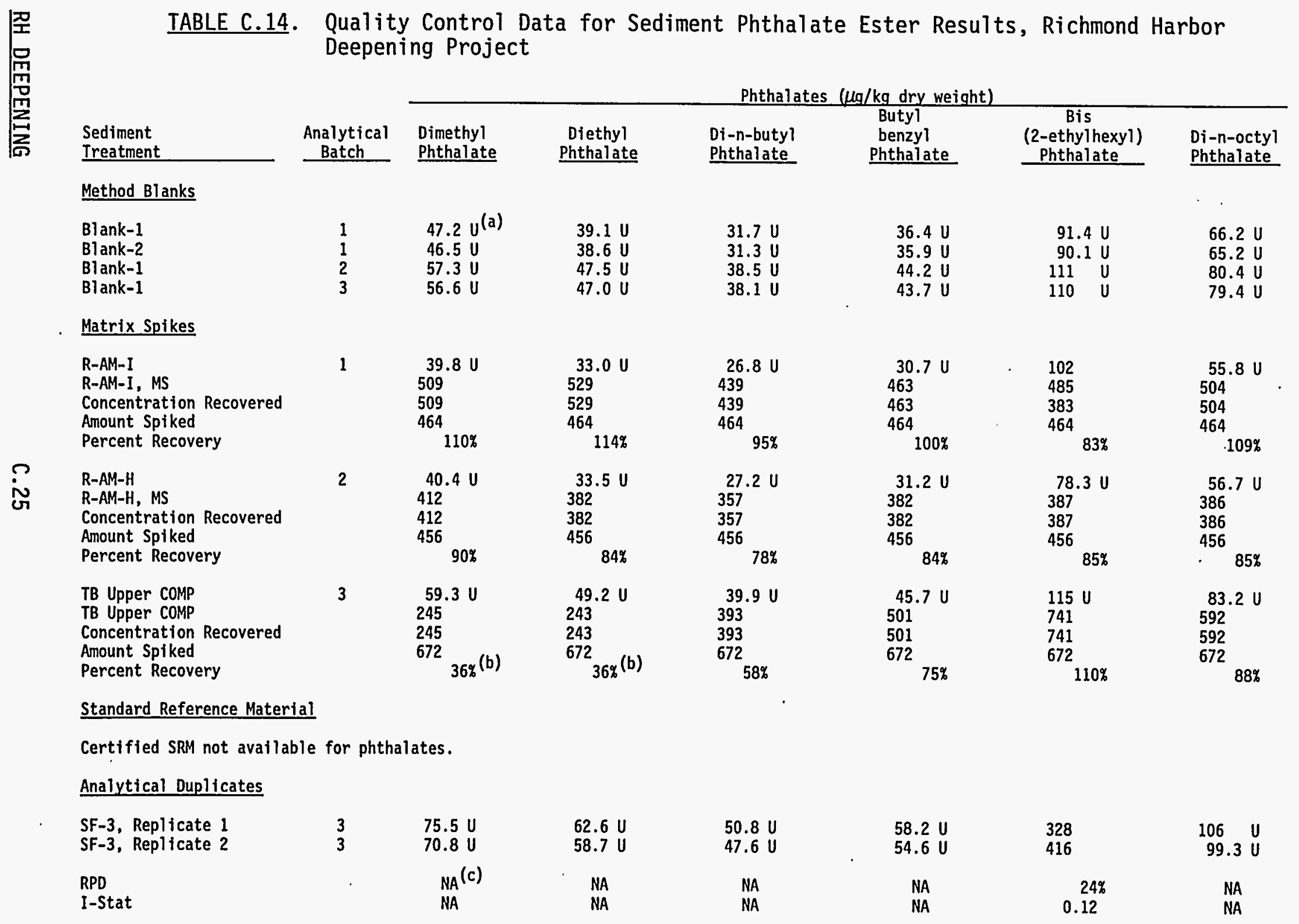


TABLE C.14. (contd)

Phthalates $(\mu \mathrm{g} / \mathrm{kg}$ dry weight

Sediment

Treatment

Analytical Triplicates

TB-2 Upper, Replicate 1

TB-2 Upper, Replicate 2

TB-2 Upper, Replicate 3

RSD

R-AM COMP, Replicate

R-AM COMP', Replicate

R-AM COMP, Replicate 3

RSD
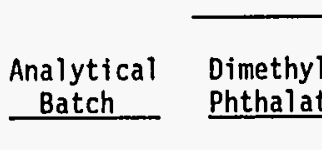

Diethyl Di-n-butyl

\section{Butyl}

benzyl

Bis

Bis

(2-ethylhexy1) Di-n-octyl

Phthalate

Phthalate

Phthalate

Phthalate

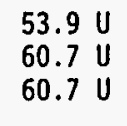

NA

\section{$40.4 \mathrm{U}$ \\ $40.4 \mathrm{U}$ \\ $40.4 \mathrm{U}$}

NA

$44.7 \mathrm{U}$
$50.3 \mathrm{U}$
$50.3 \mathrm{U}$

$36.3 \mathrm{U}$

$40.8 \mathrm{U}$

$40.8 \mathrm{U}$

NA

NA

$33.5 \mathrm{U}$

$33.5 \mathrm{U}$

$33.5 \mathrm{U}$

NA

$61.3 U$
$72.1 U$
$72.8 U$
NA

$50.9 \mathrm{U}$

$59.8 \mathrm{U}$

$60.4 \mathrm{U}$

NA

$41.6 \mathrm{U}$
$46.8 \mathrm{U}$
$46.8 \mathrm{U}$
NA
$31.2 \mathrm{U}$
$31.2 \mathrm{U}$
$31.2 \mathrm{U}$
NA

$47.3 \mathrm{~V}$

$55.6 \mathrm{U}$

$56.1 \mathrm{U}$

NA
$104 \mathrm{U}$

$117 \mathrm{U}$

$117 \mathrm{U}$

NA

$78.3 \mathrm{U}$

$78.3 \mathrm{U}$

NA

325

354

296

$9 \%$
$75.6 \mathrm{U}$

$85.1 \mathrm{U}$

$85.1 \mathrm{U}$

NA

$56.7 \mathrm{U}$

$56.7 \mathrm{U}$

$56.7 \mathrm{U}$

NA

$86.0 \mathrm{U}$

101 U

$102 \mathrm{U}$

NA

(a) $U$ Undetected at or above detection 1 imit.

(b) Outside quality control criteria $(40 \%-120 \%)$ for matrix spike recoveries.

(c) NA Not applicable. 
TABLE C.15. Surrogate Percent Recoveries for Sediment Polynuclear Aromatic Hydrocarbons (PAHs) Including Quality Control Data, Richmond Harbor Deepening Project

\begin{tabular}{|c|c|c|c|c|}
\hline \multirow[b]{2}{*}{$\begin{array}{l}\text { Analytical } \\
\text { Batch } \\
\end{array}$} & \multicolumn{4}{|c|}{ Surrogate Percent Recoveries } \\
\hline & $\begin{array}{l}\text { Naph- } \\
\text { thalene } \\
\text { d8 } \\
\end{array}$ & $\begin{array}{l}\text { Acenaph- } \\
\text { thene } \\
\text { d10 } \\
\end{array}$ & $\begin{array}{c}\begin{array}{c}\text { Chrysene } \\
\mathrm{d} 12\end{array} \\
\end{array}$ & $\begin{array}{c}\text { Dibenzo }(a, h, i) \\
\text { Anthracene } \\
\text { d14 } \\
\end{array}$ \\
\hline $\begin{array}{l}2 \\
2 \\
2 \\
3 \\
3 \\
2\end{array}$ & $\begin{array}{l}65 \\
70 \\
63 \\
75 \\
65 \\
62\end{array}$ & $\begin{array}{l}73 \\
75 \\
71 \\
78 \\
68 \\
72\end{array}$ & $\begin{array}{r}96 \\
106 \\
97 \\
89 \\
87 \\
95\end{array}$ & $\begin{array}{l}94 \\
95 \\
90 \\
80 \\
75 \\
95\end{array}$ \\
\hline $\begin{array}{l}2 \\
2 \\
2 \\
3 \\
2\end{array}$ & $\begin{array}{l}64 \\
65 \\
68 \\
67 \\
68\end{array}$ & $\begin{array}{l}72 \\
74 \\
75 \\
71 \\
78\end{array}$ & $\begin{array}{l}87 \\
96 \\
93 \\
85 \\
97\end{array}$ & $\begin{array}{l}84 \\
90 \\
93 \\
74 \\
87\end{array}$ \\
\hline $\begin{array}{l}3 \\
3 \\
3 \\
2 \\
2 \\
2 \\
2 \\
2\end{array}$ & $\begin{array}{l}68 \\
56 \\
72 \\
69 \\
66 \\
71 \\
58 \\
62\end{array}$ & $\begin{array}{l}75 \\
65 \\
75 \\
77 \\
73 \\
78 \\
66 \\
70\end{array}$ & $\begin{array}{r}95 \\
83 \\
91 \\
102 \\
93 \\
102 \\
92 \\
94\end{array}$ & $\begin{array}{l}86 \\
76 \\
83 \\
97 \\
86 \\
96 \\
79 \\
87\end{array}$ \\
\hline $\begin{array}{l}3 \\
1 \\
1 \\
1 \\
1 \\
1 \\
1 \\
1 \\
1 \\
1\end{array}$ & $\begin{array}{l}69 \\
81 \\
79 \\
74 \\
80 \\
82 \\
80 \\
68 \\
60 \\
77\end{array}$ & $\begin{array}{l}73 \\
78 \\
80 \\
75 \\
80 \\
81 \\
79 \\
69 \\
61 \\
75\end{array}$ & $\begin{array}{r}86 \\
94 \\
102 \\
97 \\
104 \\
403 \\
100 \\
88 \\
80 \\
96\end{array}$ & $\begin{array}{l}82 \\
80 \\
86 \\
80 \\
86 \\
87 \\
79 \\
70 \\
54 \\
67\end{array}$ \\
\hline $\begin{array}{l}3 \\
1 \\
1 \\
1 \\
1 \\
1 \\
1 \\
2\end{array}$ & $\begin{array}{l}66 \\
72 \\
76 \\
71 \\
64 \\
72 \\
75 \\
75\end{array}$ & $\begin{array}{l}70 \\
71 \\
74 \\
70 \\
65 \\
69 \\
72 \\
76\end{array}$ & $\begin{array}{l}82 \\
87 \\
88 \\
79 \\
90 \\
91 \\
88 \\
94\end{array}$ & $\begin{array}{l}77 \\
77 \\
71 \\
65 \\
68 \\
72 \\
71 \\
85\end{array}$ \\
\hline 3 & 69 & 72 & 84 & 79 \\
\hline $\begin{array}{l}2 \\
2 \\
2 \\
2 \\
2 \\
1 \\
1 \\
1 \\
1 \\
1 \\
1 \\
2 \\
1\end{array}$ & $\begin{array}{l}63 \\
69 \\
71 \\
65 \\
69 \\
78 \\
74 \\
68 \\
84 \\
54 \\
78 \\
54 \\
72\end{array}$ & $\begin{array}{l}67 \\
73 \\
72 \\
67 \\
71 \\
75 \\
71 \\
66 \\
82 \\
54 \\
76 \\
69 \\
69\end{array}$ & $\begin{array}{l}95 \\
96 \\
94 \\
85 \\
93 \\
89 \\
84 \\
80 \\
99 \\
67 \\
97 \\
85 \\
92\end{array}$ & $\begin{array}{l}90 \\
83 \\
84 \\
75 \\
84 \\
77 \\
64 \\
66 \\
87 \\
60 \\
71 \\
82 \\
83\end{array}$ \\
\hline
\end{tabular}

Sediment
Treatment
SF COMP
SF-1
SF-2
SF-3, Replicate 1
SF-3, Replicate 2
SF-4
SFH COMP
SFH-1
SFH-2
SFH-3
SFH-4
UIH COMP, Replicate 1
UIH COMP, Replicate 2
UIH COMP, Replicate 3
UIH-1
UIH-2
UIH-3 .
UIH-4
UIH-5

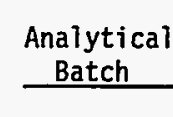

TB Upper COMP

TB-1 Upper

TB-2 Upper, Replicate 1

TB-2 Upper, Replicate 2

TB-2 Upper, Replicate 3

TB-3 Upper

TB-4 Upper

TB-5 Upper

TB-6 Upper

TB-7 Upper

TB Lower COMP

TB-1 Lower

TB-2 Lower

TB-3 Lower

TB-4 Lower

TB-5 Lower

TB-6 Lower

TB-7 Lower

OBM COMP

R-OS

$\mathrm{R}-\mathrm{BF}$

R-AM COMP, Replicate 1

R-AM COMP, Replicate 2

R-AM COMP, Replicate 3

$R-A M-A$

$R-A M-B$

$R-A M-C$

$R-A M-D$

$R-A M-F$

R-AM-G

R-AM-H

R-AM-I 
TABLE C.15. (contd)

Sediment

Treatment

Quality Control Data

\section{Method Blanks}

Blank-1

Blank-2

Blank-1

Bl ank-1

Matrix Spikes

R-AM-I

R-AM-I, MS

$\mathrm{R}-\mathrm{AM}-\mathrm{H}$

R-AM-H, MS

TB Upper COMP

TB Upper COMP, MS

2

Analytical Duplicates

SF-3, Replicate 1

SF-3, Replicate 2

3

75

65

78

68

89

87

80

75

Analytical Triplicates

TB-2 Upper, Replicate 1

TB-2 Upper, Replicate 2

TB-2 Upper, Replicate 3

R-AM COMP, Replicate 1

R-AM COMP, Replicate 2

R-AM COMP, Replicate 3

UIH COMP, Replicate 1

UIH COMP, Replicate 2

UIH COMP, Replicate 3 d14

d12

$\begin{array}{ll}78 & 63 \\ 78 & 62 \\ 80 & 69 \\ 90 & 75\end{array}$

92

83

86

$85-82$

$95 \quad 87$

$86 \quad 82$

$64-82$

63
62
9
5
83
86
82
82

Surrogate Percent Recoveries

Dibenzo $(a, h, i)$

Anthracene

92

5




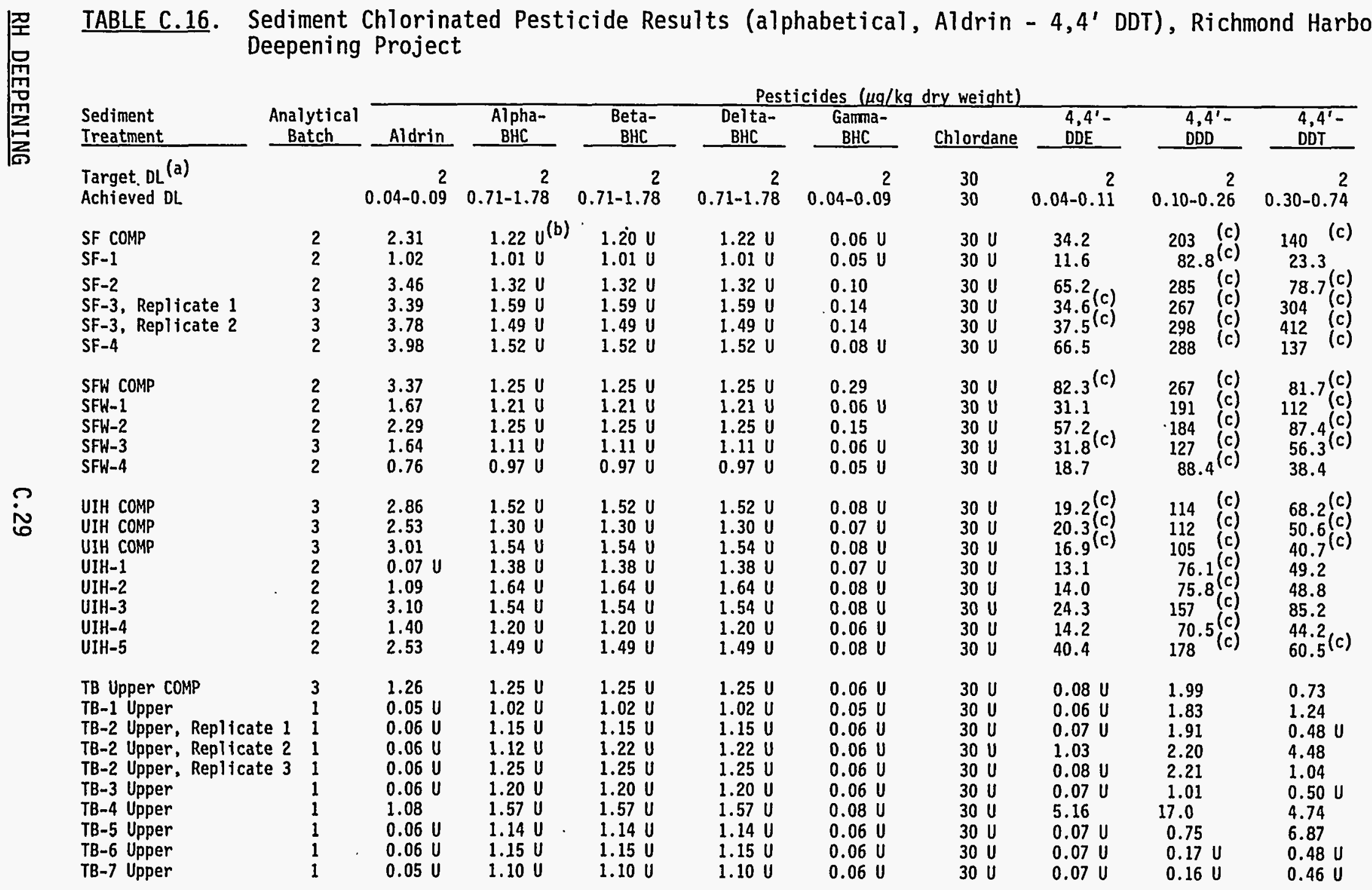


TABLE C.16. (contd)

Sediment

Ireatment

TB Lower COMP

TB-1 Lower

TB-2 Lower

TB-3 Lower

T8-4 Lower

TB-5 Lower

TB-6 Lower

TB-7 Lower

OBM COMP

$R-O S$
$R-B F$

R-AM COMP, Replicate 1

R-AM COMP, Replicate 2

R-AM COMP, Replicate 3

R-AM-A

$\Omega \quad R-A M-B$

$\omega$ R-AM-C

$R-A M-C$
$R-A M-D$

R-AM-F

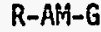

R-AM-H

R-AM-I

\begin{tabular}{|c|c|c|c|}
\hline $\begin{array}{l}\text { Analytical } \\
\text { Batch } \\
\end{array}$ & Aldrin & $\begin{array}{l}\text { Alpha- } \\
\text { BHC }\end{array}$ & $\begin{array}{l}\text { Beta- } \\
\text { BHC }\end{array}$ \\
\hline $\begin{array}{l}3 \\
1 \\
1 \\
1 \\
1 \\
1 \\
1 \\
2\end{array}$ & $\begin{array}{l}1.12 \\
0.04 U \\
0.05 U \\
0.05 U \\
0.07 U \\
0.05 U \\
0.05 U \\
0.05 U\end{array}$ & $\begin{array}{l}1.14 \mathrm{U} \\
0.95 \mathrm{U} \\
0.95 \mathrm{U} \\
1.10 \mathrm{U} \\
1.31 \mathrm{U} \\
1.02 \mathrm{U} \\
1.10 \mathrm{U} \\
1.08 \mathrm{U}\end{array}$ & $\begin{array}{l}1.14 U \\
0.85 U \\
0.95 U \\
1.10 U \\
1.31 U \\
1.02 U \\
1.10 U \\
1.08 U\end{array}$ \\
\hline 3 & $0.05 \mathrm{U}$ & $0.91 U$ & $0.91 U$ \\
\hline $\begin{array}{l}2 \\
2 \\
2 \\
2 \\
2 \\
1 \\
1 \\
1 \\
1 \\
1 \\
1 \\
2 \\
1\end{array}$ & $\begin{array}{l}0.06 U \\
5.07 \\
0.04 U \\
0.04 U \\
0.04 U \\
0.04 U \\
0.04 U \\
0.04 U \\
0.04 U \\
0.04 U \\
0.04 U \\
0.04 U \\
0.04 U\end{array}$ & $\begin{array}{l}1.22 U \\
1.78 U \\
0.90 U \\
0.88 U \\
0.87 U \\
0.71 U \\
0.73 U \\
0.87 U \\
0.71 U \\
0.90 U \\
0.87 U \\
0.83 U \\
0.84 U\end{array}$ & $\begin{array}{l}1.22 U \\
1.78 U \\
0.90 U \\
0.88 U \\
0.87 U \\
0.71 U \\
0.73 U \\
0.87 U \\
0.71 U \\
0.90 U \\
0.87 U \\
0.83 U \\
0.84 U\end{array}$ \\
\hline
\end{tabular}

Pesticides $(\mu \mathrm{g} / \mathrm{kg}$ dry weight

Delta- Gamma-
Gamma-

BHC $B H C$ Chiordane

-

$\begin{array}{lll}1.14 \mathrm{U} & 0.06 \mathrm{U} & 30\end{array}$

$\begin{array}{lll}0.85 U & 0.04 \mathrm{U} & 30 \mathrm{U}\end{array}$

$0.95 \mathrm{U}$

$0.05 \mathrm{U}$

$30 \mathrm{U}$

$1.10 \mathrm{U}$

$0.05 \mathrm{U}$

$0.07 \mathrm{U}$

$30 \mathrm{U}$

$0.05 \mathrm{U}$

$30 \mathrm{U}$

$1.10 \mathrm{U}$

$0.06 \mathrm{U}$

$30 \mathrm{U}$

$0.07 \mathrm{U}$

0.97

$1.08 \mathrm{U}$

$0.06 \mathrm{U}$

$30 \mathrm{U}$

$0.05 \mathrm{~V}$

0.97

$0.12 \mathrm{U}$

$0.06 \mathrm{~V}$

$0.08 \mathrm{U}$

0.16

$0.06 \mathrm{U} \quad 0.15$

$0.15 \mathrm{U}$
$0.16 \mathrm{U}$

$0.07 \mathrm{U} \quad 0.16 \mathrm{U}$

$0.13 \mathrm{U}$

$0.18 \mathrm{U}$

1.05

$1.22 \mathrm{U}$

$1.78 \mathrm{U}$

$0.90 \mathrm{~V}$

$0.88 \mathrm{U}$
$0.87 \mathrm{U}$

$0.71 \mathrm{U}$

$0.73 \mathrm{U}$

$0.87 \mathrm{U}$

$0.71 \mathrm{U}$

$0.90 \mathrm{U}$

$0.05 U$

$30 \mathrm{U}$

$0.06 \mathrm{U}$

4.06

$30 \mathrm{U}$

$0.05 \mathrm{U}$

$0.05 \mathrm{U}$

$0.05 \mathrm{U}$

$30 \mathrm{U}$

1.69

0.56

$0.06 \mathrm{U}$

0.56

0.66 U

$0.04 \mathrm{U} \quad 30 \mathrm{U}$

$0.05 \mathrm{~V}$

$0.13 \mathrm{U}$

$0.04 \mathrm{~V} \quad 30 \mathrm{U}$

0.04

$0.11 \mathrm{U}$

$0.05 \mathrm{~V}$

$0.13 \mathrm{U}$

30

$0.04 \mathrm{U}$

$0.87 \mathrm{U}$

$0.05 U$

$30 \mathrm{U}$

$0.10 \mathrm{U}$

1.25
0.64

$0.05 \mathrm{U} \quad 30 \mathrm{U}$

0.06

$0.05 \mathrm{~V}$

$0.12 \mathrm{U}$

$30 \mathrm{U}$

$0.05 \mathrm{U}$

$0.12 \mathrm{U}$

$0.47 \mathrm{U}$

$0.36 \mathrm{U}$

$0.40 \mathrm{U}$

$0.46 \mathrm{U}$

12.8

$0.43 U$

$0.45 \mathrm{U}$

$0.38 \mathrm{U}$

$0.51 \mathrm{U}$

12.1

$0.84 \mathrm{U} \quad 0.04 \mathrm{U}$

0.66

0.46

0.45

$0.30 \mathrm{U}$

$0.36 \mathrm{U}$

$0.30 \mathrm{U}$

0.30

3.21

$0.36 U$

$0.35 \mathrm{U}$

(a) DL Detection limit

(b) U Undetected at or above detection limit.

(c) Sample was diluted and analyzed due to analyte concentrations above the instrument linear range of calibration. 


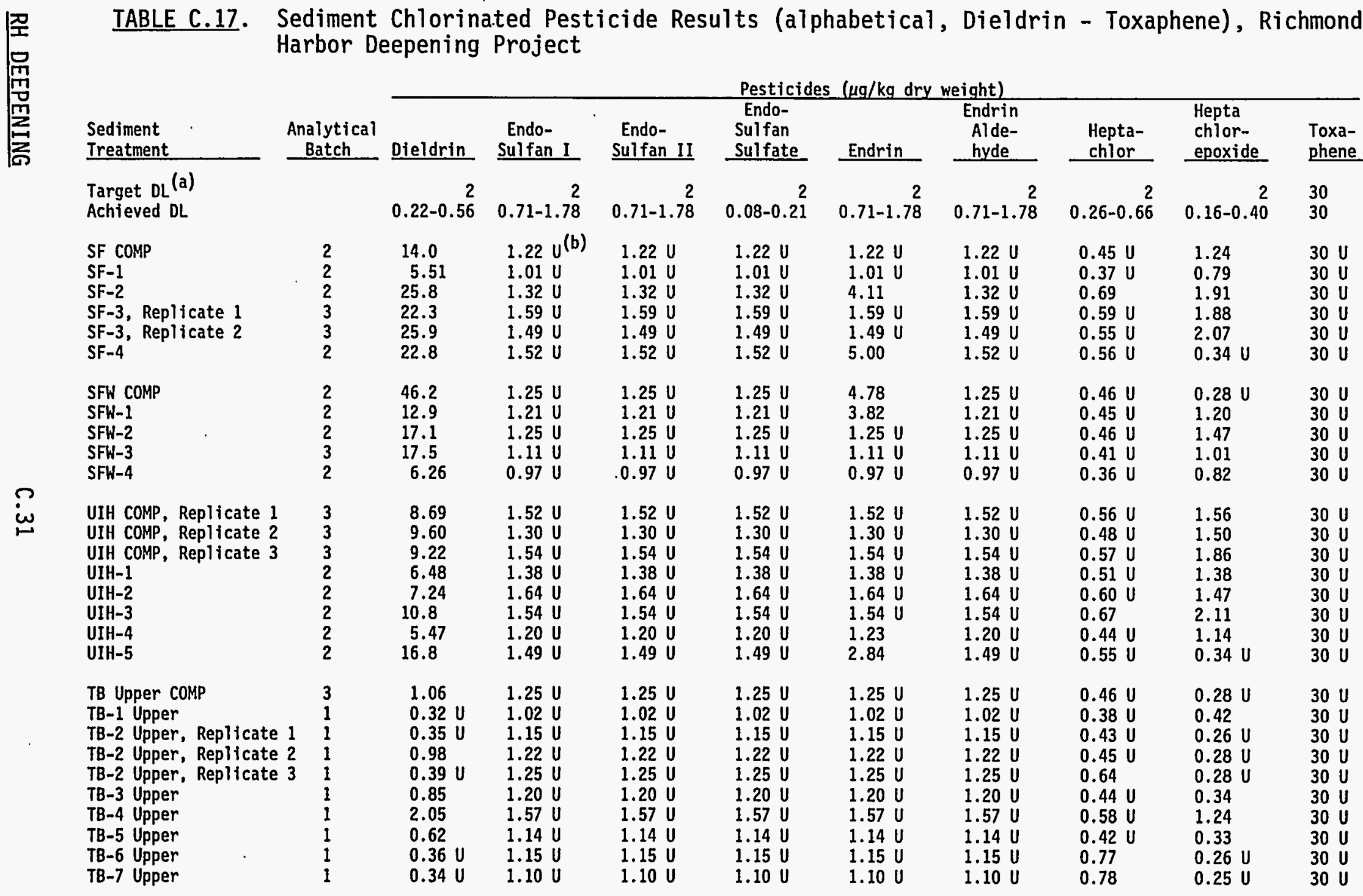




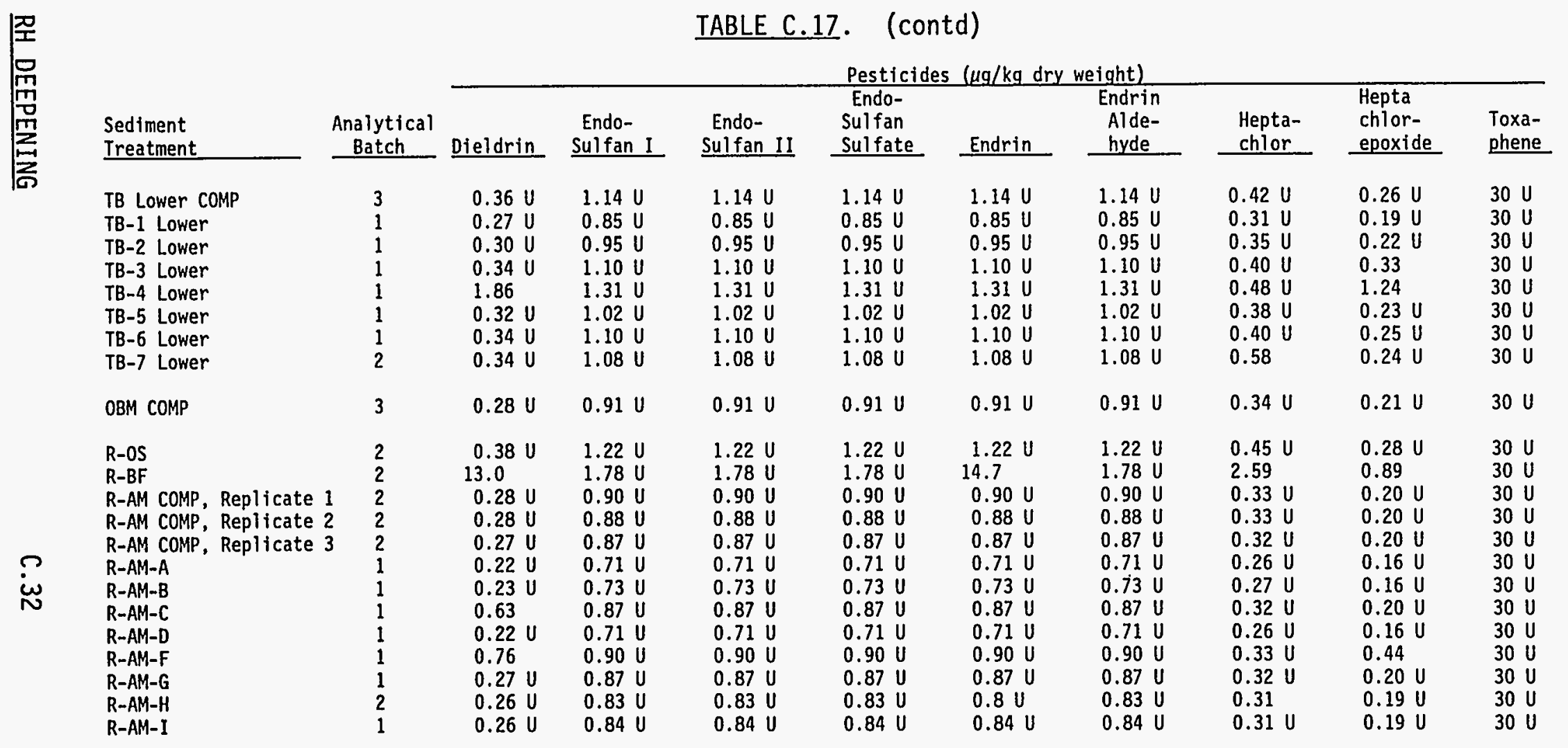

(a) DL Detection Iimit.

(b) U Undetected at or above detection limit. 


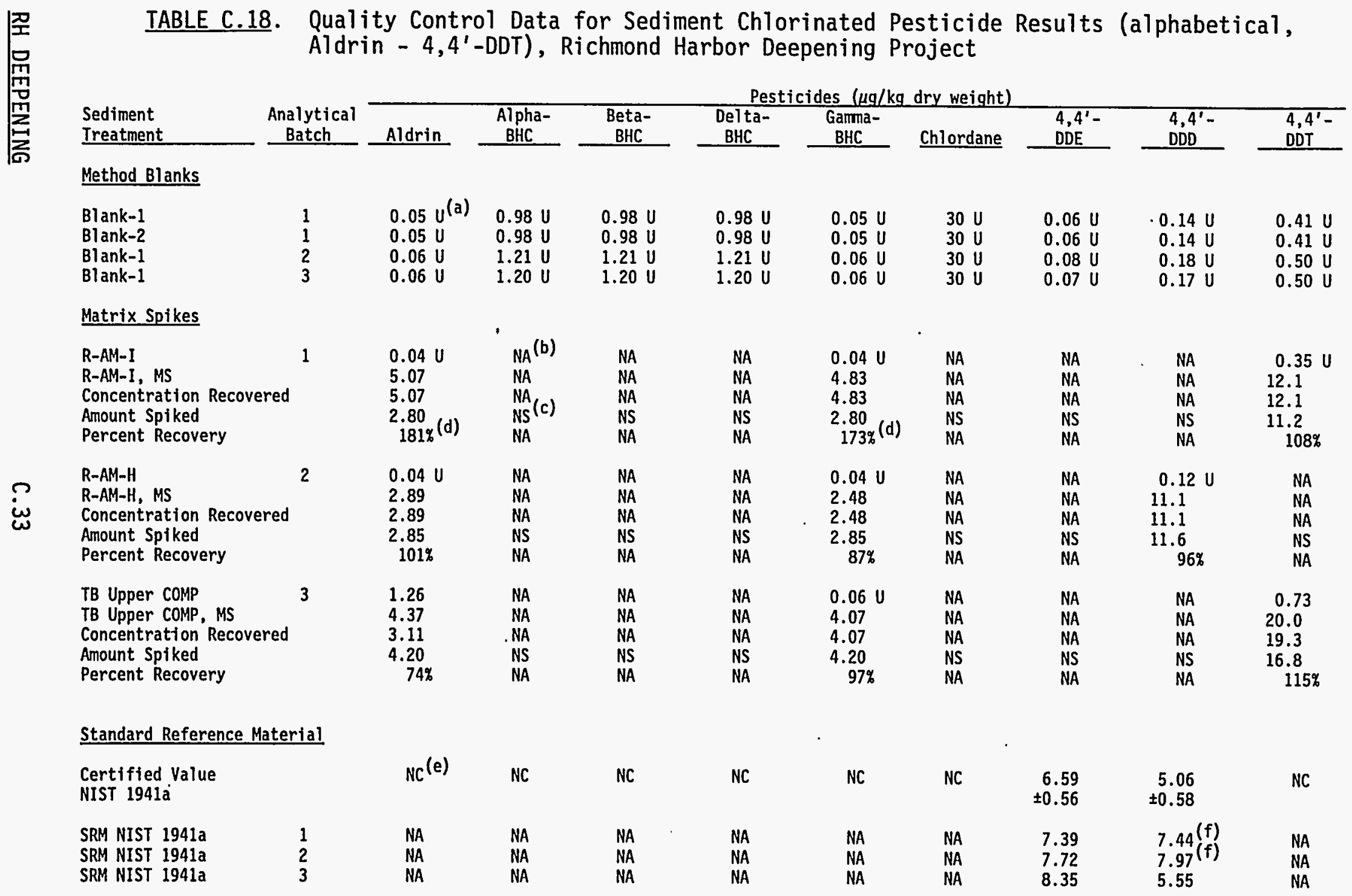


TABLE C.18. (contd)

Sediment

Ireatment

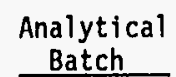

Aldrin $\begin{gathered}\text { Alpha- } \\ \mathrm{BHC}\end{gathered}$

Beta-

Beta-

Del ta-

esticides ( $\mu \mathrm{g} / \mathrm{kg}$ dry weight)

Analytical Duplicates

SF-3, Replicate 1

$\begin{array}{cc}3 & 3.39 \\ 3 & 3.78 \\ & \\ & 11 \% \\ & 0.05\end{array}$

$1.59 \mathrm{U}$
$1.49 \mathrm{U}$

$1.59 \cup \quad 1.59$

RPD

0.05

NA

$1.49 \mathrm{U}$

$1.49 \mathrm{U}$

NA

NA

Gamma-

Chlordane

$4,4^{\prime}-$
$\mathrm{DDE}$

$4,4^{\prime}-$
DDD

$4,4^{\prime}$
DDT

I-Stat

NA NA

$\begin{array}{ll}0.06 \mathrm{U} & 1.15 \mathrm{U} \\ 0.06 \mathrm{U} & 1.12 \mathrm{U} \\ 0.06 \mathrm{U} & 1.25 \mathrm{U} \\ & \\ \text { NA } & \text { NA }\end{array}$

$1.15 \mathrm{U}$
$1.22 \mathrm{U}$
$1.25 \mathrm{U}$

$1.15 U$
$1.22 U$
$1.25 U$

\section{$0.06 \mathrm{U}$}

$0.06 \mathrm{U}$

$0.06 \mathrm{U}$

$30 \mathrm{U}$

$30 \mathrm{U}$

$0.07 \mathrm{U}$

1.03

$34.6^{(g)}(g)$

$267^{(g)}$
$298^{(g)}$

$304(g)$

NA NA

NA

NA

- NA

1.91
2.20

$0.48 \mathrm{U}$

RSD

$\stackrel{n}{\omega}$

R-AM COMP, Replicate 1
R-AM COMP, Replicate 2
R-AM COMP, Replicate 3

$0.04 U$
$0.04 U$
$0.04 U$

$0.90 \mathrm{U}$

$0.90 \mathrm{U}$

$0.90 \mathrm{U}$

$0.05 \mathrm{U}$

\section{$30 \mathrm{~V}$}

$0.06 \mathrm{U}$

. $8 \%$

4.48

$0.88 \mathrm{U}$

$0.88 \mathrm{U}$

$0.88 \mathrm{U}$

$0.05 \mathrm{U}$

$30 \mathrm{U}$

$0.05 \mathrm{U}$

0.56

$0.13 \mathrm{U}$

$0.13 \mathrm{U}$

$30 \%$

\section{RSD}

NA

NA

NA

NA

NA

NA

NA

NA

UIH COMP, Replicate 1

$\begin{array}{ll}\text { UIH COMP, Replicate } 2 & 3 \\ \text { UIH COMP, Replifate } 3 & 3\end{array}$

$1.30 \mathrm{U}$

$1.30 \mathrm{U}$

$1.30 \mathrm{U}$

$0.07 \mathrm{U}$

$0.08 \mathrm{U}$

$30 \mathrm{U}$

$30 \mathrm{U}$

2.86
3.01

$1.52 \mathrm{U}$
$1.54 \mathrm{U}$

$1.52 \mathrm{U}$
$1.54 \mathrm{U}$

$1.54 \mathrm{U}$

$0.08 \mathrm{~V}$

$30 \mathrm{U}$

20.3 (g)

$19.2(\mathrm{~g})$
$16.9^{(\mathrm{g})}$

$112^{(\mathrm{g})}$

$114(\mathrm{~g})$

$105^{(g)}$

$9 \%$

$4 \%$

NA

0.66

0.46

$9 \%$

NA

- $23 \%$

$50.6^{(\mathrm{g})}$

$68.2(\mathrm{~g})$

$26 \%$

(a) U Undetected at or above detection limit.

(b) NA Not applicable.

(c) NS Not spiked.

(d) Outside quality control criteria (40\%-120\%) for matrix spike recoveries.

(e) NC Not certified.

(f) Outside quality control criteria $( \pm 30 \%)$ for SRMs.

(g) Sample was diluted and analyzed due to analyte concentrations above the instrument linear range of calibration. 


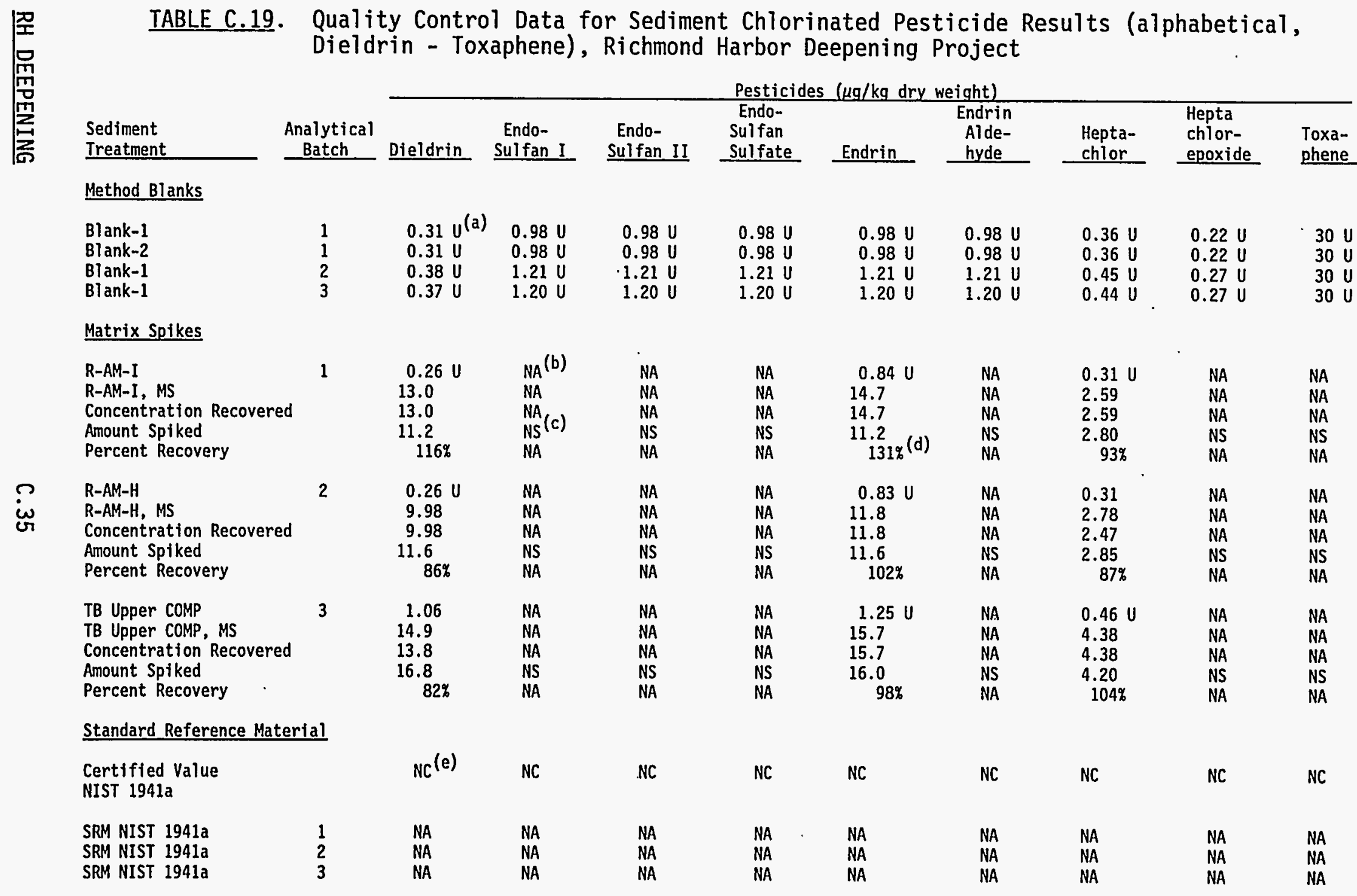


TABLE C.19. (contd)

Pesticides $(\mu \mathrm{g} / \mathrm{kg}$ dry weight)

Sediment

Analytical

Endo-

Endo-

Sulfan Sulfan

Sulfate

Endrin

Endrin

Alde-

Batch

Dieldrin Sulfan I

Analytical Duplicates

SF-3, Replicate 1

3
3

$\begin{array}{ll}22.3 & 1.59 \mathrm{U} \\ 25.9 & 1.49 \mathrm{U}\end{array}$

$1.59 \mathrm{U}$
$1.49 \mathrm{U}$

$1.59 \mathrm{U} \quad 1.59 \mathrm{U}$

$1.49 \mathrm{U} \quad 1.49 \mathrm{U}$

$1.59 \mathrm{U}$

$1.49 \mathrm{U}$

$0.59 \mathrm{U}$
0.55

1.88
2.07

$30 \mathrm{~V}$

RPD

$\begin{array}{ll}15 \% & \text { NA } \\ 0.07 & \text { NA }\end{array}$

NA

NA NA

NA

NA

$10 \%$

NA

\section{Analytical Triplicates}

TB-2 Upper, Replicate 1

$\begin{array}{lll}\text { TB-2 Upper, Replicate } 2 & 1 \\ \text { TB-2 Upper, Replicate } 3 & 1\end{array}$

$\begin{array}{ll}0.35 U & 1.15 U \\ 0.98 & 1.22 U \\ 0.39 U & 1.25 U\end{array}$

$1.15 \mathrm{U}$

$1.15 \mathrm{U}$
$1.22 \mathrm{U}$

$1.22 \mathrm{U}$
$1.25 \mathrm{U}$

$1.15 \mathrm{U} \quad 1.15 \mathrm{U}$

RSD

NA

NA

NA

$1.25 \mathrm{U} \quad 1.25 \mathrm{U}$

R-AM COMP, Replicate 1

R-AM COMP, Replicate 2
R-AM COMP, Replicate 3

RSD

$0.28 U$
$0.28 U$
$0.27 U$

\section{$0.90 \mathrm{U}$}

$0.88 \mathrm{U}$

$0.90 \mathrm{U}$

. NA

NA

$1.22 \mathrm{U}$

$1.25 \mathrm{U}$

$0.43 \mathrm{U}$

0.45

0.64

$0.26 \mathrm{U}$

$0.28 \mathrm{U}$

NA

NA

NA

$30 \mathrm{U}$ $30 \mathrm{U}$ $30 \mathrm{U}$

$\begin{array}{lll}0.90 \mathrm{U} & 0.33 \mathrm{U} & 0.20 \mathrm{U}\end{array}$

$0.88 \mathrm{U}$

$0.87 U$

$0.33 \mathrm{U}$

$0.87 \mathrm{U}$

$0.88 v \quad 0.88 U$

$0.87 \mathrm{U} \quad 0.87 \mathrm{U}$

NA

NA

NA

NA

NA

NA

NA

$0.20 \mathrm{U}$ $30 \mathrm{U}$
$30 \mathrm{U}$

UIH COMP, Replicate 1

UIH COMP, Replicate

$\begin{array}{ll}9.60 & 1.30 \mathrm{U} \\ 8.69 & 1.52 \mathrm{U} \\ 9.22 & 1.54 \mathrm{U}\end{array}$

$1.30 \mathrm{U}$

$1.52 \mathrm{U}$
$1.54 \mathrm{U}$

$1.30 \mathrm{U} \quad 1.30 \mathrm{U}$

UIH COMP, Replicate 3

$5 \%$

NA

NA

$\begin{array}{ll}1.52 \mathrm{U} & 1.52 \mathrm{U} \\ 1.54 \mathrm{U} & 1.54 \mathrm{U}\end{array}$

$1.30 \mathrm{U}$

$1.52 \mathrm{U}$

$0.48 U$

$0.56 \mathrm{U}$

NA

RSD

NA

NA

NA

$0.57 \mathrm{U}$

1.50

1.56

1.86

$30 \mathrm{U}$

$30 \mathrm{U}$

$30 \mathrm{U}$

(a) U Undetected at or above detection limit.

(b) NA Not applicable.

(c) NS Not spiked.

(d) Outside quality control criteria (40\%-120\%) for matrix spike recoveries.

(e) NC Not certified. 
TABLE C.20. Sediment Polychlorinated Biphenyls (PCBs) Results, Richmond Harbor Deepening Project

\begin{tabular}{|c|c|c|c|c|c|}
\hline \multirow[b]{2}{*}{$\begin{array}{l}\text { Sediment } \\
\text { Treatment }\end{array}$} & \multirow[b]{2}{*}{$\begin{array}{c}\text { Analytical } \\
\text { Batch }\end{array}$} & \multicolumn{4}{|c|}{ PCBs (ug/kg dry weight) } \\
\hline & & $\begin{array}{c}\text { Aroclor } \\
1242 \\
\end{array}$ & $\begin{array}{c}\text { Aroclor } \\
1248 \\
\end{array}$ & $\begin{array}{c}\text { Aroclor } \\
1254 \\
\end{array}$ & $\begin{array}{c}\text { Aroclor } \\
1260 \\
\end{array}$ \\
\hline Target DL(a) & & 20 & 20 & 20 & 20 \\
\hline Achieved DL & & 20 & 20 & 20 & 20 \\
\hline SF COMP & 2 & $20 \mathrm{U}(\mathrm{b})$ & $20 \mathrm{U}$ & 107 & $20 U$ \\
\hline SF-1 & 2 & $20 \mathrm{U}$ & $20 \mathrm{U}$ & 33.6 & $20 U$ \\
\hline SF-2 & 2 & $20 \mathrm{U}$ & $20 \mathrm{U}$ & 177 & $20 \mathrm{U}$ \\
\hline SF-3, Replicate 1 & 3 & $20 U$ & $20 U$ & 155 & $20 U$ \\
\hline SF-3, Replicate 2 & 3 & $20 U$ & $20 U$ & 210 & $20 U$ \\
\hline SF-4 & 2 & $20 \mathrm{U}$ & $20 \mathrm{U}$ & 198 & $20 \mathrm{U}$ \\
\hline SFW COMP & 2 & $20 U$ & $20 U$ & 145 & $20 \mathrm{U}$ \\
\hline SFW-1 & 2 & $20 U$ & $20 U$ & 108 & $20 U$ \\
\hline SFW-2 & 2 & $20 \mathrm{U}$ & $20 \mathrm{U}$ & $20 \mathrm{U}$ & $165^{\circ}$ \\
\hline SFW-3 & 3 & $20 U$ & $20 U$ & 39.4 & $20 \mathrm{U}$ \\
\hline SFW-4 & 2 & $20 U$ & $20 \mathrm{U}$ & $20 U$ & $20 \mathrm{U}$ \\
\hline UIH COMP, Replicate 1 & 3 & $20 U$ & $20 U$ & 93.8 & $20 U$ \\
\hline UIH COMP, Replicate 2 & 3 & $20 U$ & $20 \mathrm{U}$ & 82.7 & $20 \mathrm{U}$ \\
\hline UIH COMP, Replicate 3 & 3 & $20 \mathrm{U}$ & $20 \mathrm{U}$ & 101 & $20 \mathrm{U}$ \\
\hline UIH-1 & 2 & $20 \mathrm{U}$ & $20 \mathrm{U}$ & 72.0 & $20 U$ \\
\hline UIH-2 & 2 & $20 \mathrm{U}$ & $20 \mathrm{U}$ & 92.3 & $20 \mathrm{U}$ \\
\hline UIH-3 & 2 & $20 U$ & $20 \mathrm{U}$ & 157 & $20 U$ \\
\hline UIH-4 & 2 & $20 U$ & $20 \mathrm{U}$ & 67.5 & $20 U$ \\
\hline UIH-5 & 2 & $20 \mathrm{U}$ & $20 \mathrm{U}$ & 140 & $20 \mathrm{U}$ \\
\hline TB Upper COMP & 3 & $20 U$ & $20 U$ & $20 \mathrm{U}$ & $20 U$ \\
\hline TB-1 Upper & 1 & $20 U$ & $20 U$ & $8.51 \mathrm{~J}(\mathrm{c})$ & $20 U$ \\
\hline TB-2 Upper, Replicate 1 & $i$ & $20 U$ & $20 \mathrm{U}$ & $20 \mathrm{U}$ & $20 U$ \\
\hline TB-2 Upper, Replicate 2 & 1 & $20 \mathrm{U}$ & $20 \mathrm{U}$ & $20 \mathrm{U}$ & $20 U$ \\
\hline TB-2 Upper, Replicate 3 & 1 & $20 \mathrm{U}$ & $20 \mathrm{U}$ & $20 U$ & $20 \mathrm{U}$ \\
\hline TB-3 Upper & 1 & $20 \mathrm{U}$ & $20 \mathrm{U}$ & $4.68 \mathrm{~J}$ & $20 U$ \\
\hline TB-4 Upper & 1 & $20 \mathrm{U}$ & $20 \mathrm{U}$ & 46.8 & $20 \mathrm{U}$ \\
\hline TB-5 Upper & 1 & $20 \mathrm{U}$ & $20 U$ & $20 \mathrm{U}$ & $20 \mathrm{U}$ \\
\hline TB-6 Upper & 1 & $20 U$ & $20 \mathrm{U}$ & $20 U$ & $20 \mathrm{U}$ \\
\hline TB-7 Upper & 1 & $20 \mathrm{U}$ & $20 \mathrm{U}$ & $20 U$ & $20 \mathrm{U}$ \\
\hline TB Lower COMP & 3 & $20 U$ & $20 U$ & $20 \mathrm{U}$ & $20 U$ \\
\hline TB-1 Lower & 1 & $20 U$ & $20 U$ & $20 \mathrm{U}$ & $20 U$ \\
\hline TB-2 Lower & 1 & $20 U$ & $20 U$ & $20 U$ & $20 U$ \\
\hline TB-3 Lower & 1 & $20 U$ & $20 U$ & $20 \mathrm{U}$ & $20 U$ \\
\hline TB-4 Lower & 1 & $20 U$ & $20 \mathrm{U}$ & 59.3 & $20 \mathrm{U}$ \\
\hline TB-5 Lower & 1 & $20 U$ & $20 \mathrm{U}$ & $20 \mathrm{U}$ & $20 \mathrm{U}$ \\
\hline TB-6 Lower & 1 & $20 U$ & $20 \mathrm{U}$ & $20 \mathrm{U}$ & $20 U$ \\
\hline TB-7 Lower & 2 & $20 \mathrm{U}$ & $20 \mathrm{U}$ & $20 \mathrm{U}$ & $20 \mathrm{U}$ \\
\hline RH DEEPENING & & C. 37 & & & \\
\hline
\end{tabular}


TÁBLE C.20. (contd)

Sediment

Treatment

\begin{tabular}{ccccc} 
Analytical & \multicolumn{4}{c}{ PCBs (ug/kg dry weight) } \\
\cline { 2 - 5 } Batch & $\begin{array}{c}\text { Aroclor } \\
1242\end{array}$ & $\begin{array}{c}\text { Aroclor } \\
1248\end{array}$ & $\begin{array}{c}\text { Aroclor } \\
1254\end{array}$ & $\begin{array}{c}\text { Aroclor } \\
1260\end{array}$ \\
\hline 3 & $20 \mathrm{U}$ & $20 \mathrm{U}$ & $20 \mathrm{U}$ & $20 \mathrm{U}$ \\
& & & & \\
2 & $20 \mathrm{U}$ & $20 \mathrm{U}$ & $20 \mathrm{U}$ & $20 \mathrm{U}$ \\
2 & $20 \mathrm{U}$ & $20 \mathrm{U}$ & 23.3 & $20 \mathrm{U}$ \\
2 & $20 \mathrm{U}$ & $20 \mathrm{U}$ & $20 \mathrm{U}$ & $20 \mathrm{U}$ \\
2 & $20 \mathrm{U}$ & $20 \mathrm{U}$ & $20 \mathrm{U}$ & $20 \mathrm{U}$ \\
2 & $20 \mathrm{U}$ & $20 \mathrm{U}$ & $20 \mathrm{U}$ & $20 \mathrm{U}$ \\
1 & $20 \mathrm{U}$ & $20 \mathrm{U}$ & $20 \mathrm{U}$ & $20 \mathrm{U}$ \\
1 & $20 \mathrm{U}$ & $20 \mathrm{U}$ & $20 \mathrm{U}$ & $20 \mathrm{U}$ \\
1 & $20 \mathrm{U}$ & $20 \mathrm{U}$ & $20 \mathrm{U}$ & $20 \mathrm{U}$ \\
1 & $20 \mathrm{U}$ & $20 \mathrm{U}$ & $20 \mathrm{U}$ & $20 \mathrm{U}$ \\
1 & $20 \mathrm{U}$ & $20 \mathrm{U}$ & 33.6 & $20 \mathrm{U}$ \\
1 & $20 \mathrm{U}$ & $20 \mathrm{U}$ & $20 \mathrm{U}$ & $20 \mathrm{U}$ \\
2 & $20 \mathrm{U}$ & $20 \mathrm{U}$ & $20 \mathrm{U}$ & $20 \mathrm{U}$ \\
1 & $20 \mathrm{U}$ & $20 \mathrm{U}$ & $20 \mathrm{U}$ & $20 \mathrm{U}$
\end{tabular}

(a) DL Detection limit.

(b) U Undetected at or above detection limit.

(c) J Analyte detected below method detection limit (MDL), but above instrument detection limit (IDL). 
TABLE C.21. Quality Control Data for Sediment Polychlorinated Biphenyls (PCBs) Results, Richmond Harbor Deepening Project

Sediment

Treatment

Method Blanks

Blank-1

Blank-2

Blank-1

Blank-1

Matrix Spikes

R-AM-I

R-AM-I, MS

Concentration Recovered

Amount Spiked

Percent Recovery

$\mathrm{R}-\mathrm{AM}-\mathrm{H}$

R-AM-H, MS

Concentration Recovered

Amount Spiked

Percent Recovery

TB Upper COMP

TB Upper COMP, MS

Concentration Recovered

Amount Spiked

Percent Recovery

Standard Reference Material

Certified SRM not available for PCBs.

Analytical Duplicates

SF-3, Replicate 1

SF-3, Replicate 2

3

RPD

I-Stat

Anaiytical Triplicates

TB-2 Upper, Replicate 1

TB-2 Upper, Replicate 2

TB-2 Upper, Replicate 3

RSD

R-AM COMP, Replicate 1

R-AM COMP, Replicate 2

R-AM COMP, Replicate 3

RSD

Analytical
Batch

1

1

2

3

1

1

2

3

$20 U^{(a)}$
$20 U$
$20 U$
$20 U$

${ }_{N A}$ (b)

NA

${ }_{N S}^{N A}(c)$

NA

NA

NA

NA

NS

NA

NA

NA

NA

NS

NA
PCBs $(\mu \mathrm{g} / \mathrm{kg}$ dry weight $)$

Aroclor

Arocior

1254

Aroclor

1260

\begin{tabular}{llll} 
Aroclor & $\begin{array}{c}\text { Aroclor } \\
1248\end{array}$ & $\begin{array}{l}\text { Arocior } \\
1254\end{array}$ & $\begin{array}{c}\text { Aroclor } \\
1260\end{array}$ \\
\cline { 3 - 4 } & & &
\end{tabular}

$\mathrm{U}$

$20 \mathrm{U}$

$20 \mathrm{U}$

$20 \mathrm{U}$

$20 \mathrm{U}$

$20 \mathrm{U}$

$20 \mathrm{U}$

$20 \mathrm{U}$

$20 \mathrm{U}$

$20 \mathrm{U}$

$20 \mathrm{U}$

$20 \mathrm{U}$

$20 \mathrm{U}$

$20 \mathrm{U}$

59.6

59.6

56.0

$106 \%$

$20 \mathrm{U}$

55.8

55.8

57.0

$98 \%$

$20 \mathrm{U}$

92.1

92.1

84.0

$110 \%$

NA
NA
$N A$
NS
NA
NA
NA
NA
NS
NA
NA
NA
NA
NS
NA

NA

$20 \mathrm{U}$

$20 \mathrm{U}$

$20 \mathrm{U}$

155

210

$20 \mathrm{U}$

NA

NA

$30 \%$

$20 \mathrm{U}$

NA

NA

0.15

NA

NA

$20 \mathrm{U} \quad 20 \mathrm{U}$

$20 \mathrm{U}$

$20 \mathrm{U}$

$20 \mathrm{U}$

$20 \mathrm{U}$

$20 \mathrm{U}$

$20 \mathrm{U}$

$20 \mathrm{U}$

$20 \mathrm{U}$

NA

NA

NA

NA

$20 \mathrm{U}$

$20 \mathrm{U}$

$20 \mathrm{U}$

$20 \mathrm{U}$

$20 \mathrm{U}$

$20 \mathrm{U}$

$20 \mathrm{U}$

$20 \mathrm{U}$

$20 \mathrm{U}$

$20 \mathrm{U}$

NA

NA

NA 


\section{TABLE C.21. (contd)}

Sediment

Treatment

UIH COMP, Replicate 1

UIH COMP, Replicate 2

UIH COMP, Replicate 3

RSD

\begin{tabular}{l} 
Analytical \\
Batch \\
\hline
\end{tabular}

3

3

3

\begin{tabular}{ll}
\hline & \\
\hline Aroclor & Ar \\
1242 & \\
$20 U$ & \\
$20 U$ &
\end{tabular}

PCBs ( $\mu \mathrm{g} / \mathrm{kg}$ dry weight)

Aroclor Aroclor

1248

1254

Aroclor

$20 U$

$20 \mathrm{U}$

93.8

$20 \mathrm{U}$

101

$20 U$

NA

NA

$10 \%$

$20 \mathrm{U}$

NA

(a) U Undetected at or above detection limit.

(b) NA Not applicable.

(c) NS Not spiked. 
TABLE C.22. Surrogate Recoveries and Quality Control Data for Sediment Chlorinated Pesticides and Polychlorinated Biphenyls (PCBs) Results, Richmond Harbor Deepening Project

\begin{tabular}{|c|c|c|c|}
\hline Sediment & Analytical & $\frac{\text { Surroga }}{D \text { UR }}$ & coveries \\
\hline Treatment & Batch & PCB 10 & PCB 19 \\
\hline $\begin{array}{l}\text { SF COMP } \\
\text { SF-1 } \\
\text { SF-2 } \\
\text { SF-3, Replicate } 1 \\
\text { SF-3, Replicate } 2 \\
\text { SF-4 }\end{array}$ & $\begin{array}{l}2 \\
2 \\
2 \\
3 \\
3 \\
2\end{array}$ & $\begin{array}{l}66 \\
67 \\
64 \\
65 \\
59 \\
63\end{array}$ & $\begin{array}{l}75 \\
76 \\
80 \\
83 \\
75 \\
80\end{array}$ \\
\hline $\begin{array}{l}\text { SFW COMP } \\
\text { SFW-1 } \\
\text { SFW-2 } \\
\text { SFW-3 } \\
\text { SFW-4 }\end{array}$ & $\begin{array}{l}2 \\
2 \\
2 \\
3 \\
2\end{array}$ & $\begin{array}{l}60 \\
64 \\
61 \\
58 \\
65\end{array}$ & $\begin{array}{r}61 \\
75 \\
118 \\
71 \\
73\end{array}$ \\
\hline $\begin{array}{l}\text { UIH COMP } \\
\text { UIH COMP } \\
\text { UIH COMP } \\
\text { UIH-1 } \\
\text { UIH-2 } \\
\text { UIH-3 } \\
\text { UIH-4 } \\
\text { UIH-5 }\end{array}$ & $\begin{array}{l}3 \\
3 \\
3 \\
2 \\
2 \\
2 \\
2 \\
2\end{array}$ & $\begin{array}{l}55 \\
60 \\
62 \\
69 \\
63 \\
68 \\
56 \\
58\end{array}$ & $\begin{array}{l}70 \\
81 \\
78 \\
86 \\
78 \\
91 \\
82 \\
70\end{array}$ \\
\hline $\begin{array}{l}\text { TB Upper COMP } \\
\text { TB-1 Upper } \\
\text { TB-2 Upper, Replicate } 1 \\
\text { TB-2 Upper, Rep1 icate } 2 \\
\text { TB-2 Upper, Rep1 icate } 3 \\
\text { TB-3 Upper } \\
\text { TB-4 Upper } \\
\text { TB-5 Upper } \\
\text { TB-6 Upper } \\
\text { TB-7 Upper }\end{array}$ & $\begin{array}{l}3 \\
1 \\
1 \\
1 \\
1 \\
1 \\
1 \\
1 \\
1 \\
1\end{array}$ & $\begin{array}{l}65 \\
73 \\
62 \\
65 \\
73 \\
73 \\
66 \\
66 \\
63 \\
70\end{array}$ & $\begin{array}{l}71 \\
78 \\
88 \\
81 \\
85 \\
87 \\
84 \\
70 \\
60 \\
72\end{array}$ \\
\hline $\begin{array}{l}\text { TB Lower COMP } \\
\text { TB-1 Lower } \\
\text { TB-2 Lower } \\
\text { TB-3 Lower } \\
\text { TB-4 Lower } \\
\text { TB-5 Lower } \\
\text { TB-6 Lower } \\
\text { TB-7 Lower }\end{array}$ & $\begin{array}{l}3 \\
1 \\
1 \\
1 \\
1 \\
1 \\
1 \\
2\end{array}$ & $\begin{array}{l}67 \\
69 \\
66 \\
66 \\
57 \\
68 \\
69 \\
73\end{array}$ & $\begin{array}{l}69 \\
73 \\
72 \\
64 \\
75 \\
73 \\
73 \\
74\end{array}$ \\
\hline OBM COMP & 3 & 70 & 72 \\
\hline
\end{tabular}

RH DEEPENING 
TABLE C.22. (contd)

Sediment

Treatment

$R-0 S$

$\mathrm{R}-\mathrm{BF}$

R-AM COMP, Replicate 1

R-AM COMP, Replicate 2

R-AM COMP, Replicate 3

$R-A M-A$

$R-A M-B$

$\mathrm{R}-\mathrm{AM}-\mathrm{C}$

$R-A M-D$

$R-A M-F$

$R-A M-G$

$\mathrm{R}-\mathrm{AM}-\mathrm{H}$

R-AM-I

Quality Control Data

Method Blanks

Blank-1

Blank-2

Blank-1

Blank-1

Matrix Spikes

R-AM-I

R-AM-I, MS

1

R-AM-H

R-AM-H, MS

TB Upper COMP

TB Upper COMP, MS

Standard Reference Material

Certified SRM not available for PCBs.

Analytical Duplicates

SF-3, Replicate 1

SF-3, Replicate 2

3

2

3

1
1
2
3

67

71

74

76

70

72

75

78
70

94

76

70

73

74

70

65

77

59

74

67

75 
TABLE C.22. (contd)

Sediment

Treatment

Analytical

Batch

Surrogate Percent Recoveries

Analytical Triplicates

TB-2 Upper, Replicate 1

TB-2 Upper, Replicate 2

TB-2 Upper, Rep7icate 3

1

PCB 103

PCB 198

R-AM COMP, Rep 7 icate 1

R-AM COMP, Replicate 2

R-AM COMP, Replicate 3

UIH COMP, Replicate 1

UIH COMP, Replicate 2

UIH COMP, Replicate 3

62

88

65

81

73

85

2

65

76

61

70

65

73

60

81

55

70

62

78 
IABLE C.23. Sediment Metals Results, Richmond Harbor Deepening Project

\begin{tabular}{|c|c|c|c|c|c|c|c|c|c|c|c|}
\hline \multirow{2}{*}{$\begin{array}{l}\text { Sediment } \\
\text { Treatment }\end{array}$} & \multirow{2}{*}{$\begin{array}{l}\text { Analytical } \\
\text { Batch } \\
\end{array}$} & \multicolumn{10}{|c|}{ Metals (mg/kg dry weight) } \\
\hline & & $\mathrm{Ag}$ & As & cd & $\mathrm{Cr}$ & $\mathrm{Cu}$ & $\mathrm{Hq}$ & $\mathrm{Ni}$ & $\mathrm{Pb}$ & $\mathrm{Se}$ & $\mathrm{Zn}$ \\
\hline $\begin{array}{l}\text { Target } \mathrm{DL}(\mathrm{a}) \\
\text { Achieved } \mathrm{DL}\end{array}$ & & $\begin{array}{l}0.1 \\
0.01\end{array}$ & $\begin{array}{l}2.5 \\
2.5\end{array}$ & $\begin{array}{l}0.1 \\
0.016\end{array}$ & $\begin{array}{l}33 \\
33\end{array}$ & $\begin{array}{l}5.5 \\
5.5\end{array}$ & $\begin{array}{l}0.02 \\
0.02\end{array}$ & $\begin{array}{l}7.5 \\
7.5\end{array}$ & $\begin{array}{l}6.2 \\
6.2\end{array}$ & $\begin{array}{l}0.10 \\
0.128\end{array}$ & $\begin{array}{l}7.8 \\
7.8\end{array}$ \\
\hline $\begin{array}{l}\text { SF COMP } \\
\text { SF-1 } \\
\text { SF-2 } \\
\text { SF-3 } \\
\text { SF-4 }\end{array}$ & $\begin{array}{l}1 \\
1 \\
1 \\
1 \\
1\end{array}$ & $\begin{array}{l}0.391 \\
0.303 \\
0.566 \\
0.626 \\
0.694\end{array}$ & $\begin{array}{r}9.4 \\
7.0 \\
14.2 \\
13.4 \\
14.0\end{array}$ & $\begin{array}{l}0.511 \\
0.922 \\
0.654 \\
0.474 \\
0.564\end{array}$ & $\begin{array}{l}189 \\
178 \\
202 \\
214 \\
215\end{array}$ & $\begin{array}{r}55.0 \\
35.6 \\
71.7 \\
92.9 \\
107\end{array}$ & $\begin{array}{l}0.360 \\
0.115 \\
0.490 \\
0.528 \\
0.689\end{array}$ & $\begin{array}{l}80.3 \\
71.0 \\
93.5 \\
111 \\
109\end{array}$ & $\begin{array}{l}35.2 \\
18.9 \\
48.6 \\
56.5 \\
64.8\end{array}$ & $\begin{array}{l}0.235 \\
0.128 u^{(b)} \\
0.418 \\
0.336 \\
0.412\end{array}$ & $\begin{array}{l}130 \\
83.5 \\
176 \\
204 \\
208\end{array}$ \\
\hline $\begin{array}{l}\text { SFW COMP } \\
\text { SFW-1 } \\
\text { SFW-2 } \\
\text { SFW-3 } \\
\text { SFH-4 }\end{array}$ & $\begin{array}{l}1 \\
1 \\
1 \\
1 \\
1\end{array}$ & $\begin{array}{l}0.603 \\
0.438 \\
0.615 \\
0.537 \\
0.268\end{array}$ & $\begin{array}{c}12.4 \\
14.4 \\
4.48 \\
9.6 \\
13.1\end{array}$ & $\begin{array}{l}0.890 \\
0.482 \\
0.855 \\
0.782 \\
0.628\end{array}$ & $\begin{array}{l}192 \\
169 \\
158 \\
166 \\
183\end{array}$ & $\begin{array}{l}65.3 \\
68.5 \\
34.3 \\
55.6 \\
59.6\end{array}$ & $\begin{array}{l}0.943 \\
0.377 \\
0.857 \\
0.465 \\
0.158\end{array}$ & $\begin{array}{l}92.5 \\
82.6 \\
67.6 \\
86.6 \\
85.1\end{array}$ & $\begin{array}{l}45.8 \\
55.8 \\
20.1 \\
30.4 \\
44.3\end{array}$ & $\begin{array}{l}0.522 \\
0.235 \\
0.421 \\
0.796 \\
0.243\end{array}$ & $\begin{array}{l}157 \\
175 \\
86.7 \\
119 \\
153\end{array}$ \\
\hline $\begin{array}{l}\text { UIH COMP, Replicate } 1 \\
\text { UIH COMP, Replicate } 2 \\
\text { UIH COMP, Replicate } 3 \\
\text { UIH-1 } \\
\text { UIH-2 } \\
\text { UIH-3 } \\
\text { UIH-4 } \\
\text { UIH-5 }\end{array}$ & $\begin{array}{l}1 \\
1 \\
1 \\
1 \\
1 \\
1 \\
1 \\
1\end{array}$ & $\begin{array}{l}0.640 \\
0.648 \\
0.628 \\
0.599 \\
0.670 \\
0.713 \\
0.491 \\
0.663\end{array}$ & $\begin{array}{l}16.1 \\
12.7 \\
11.9 \\
14.2 \\
13.6 \\
14.8 \\
10.9 \\
15.4\end{array}$ & $\begin{array}{l}0.521 \\
0.503 \\
0.515 \\
0.484 \\
0.465 \\
0.596 \\
0.733 \\
0.570\end{array}$ & $\begin{array}{l}204 \\
205 \\
199 \\
192 \\
193 \\
189 \\
168 \\
202\end{array}$ & $\begin{array}{l}76.6 \\
85.3 \\
81.6 \\
75.6 \\
83.9 \\
85.7 \\
68.0 \\
82.1\end{array}$ & $\begin{array}{l}0.493 \\
0.537 \\
0.493 \\
0.607 \\
0.618 \\
0.644 \\
0.311 \\
0.516\end{array}$ & $\begin{array}{l}112 \\
114 \\
110 \\
115 \\
117 \\
111 \\
101 \\
114\end{array}$ & $\begin{array}{l}49.1 \\
56.0 \\
52.4 \\
53.6 \\
53.0 \\
59.5 \\
37.3 \\
58.2\end{array}$ & $\begin{array}{l}0.339 \\
0.328 \\
0.335 \\
0.507 \\
0.434 \\
0.331 \\
0.150 \\
0.413\end{array}$ & $\begin{array}{l}191 \\
191 \\
194 \\
180 \\
183 \\
190 \\
154 \\
192\end{array}$ \\
\hline $\begin{array}{l}\text { TB Upper COMP } \\
\text { TB-1 Upper } \\
\text { TB-2 Upper } \\
\text { TB-3 Upper } \\
\text { TB-4 Upper } \\
\text { TB-5 Upper } \\
\text { TB-6 Upper } \\
\text { TB-7 Upper }\end{array}$ & $\begin{array}{l}1 \\
1 \\
1 \\
1 \\
1 \\
1 \\
1 \\
1\end{array}$ & $\begin{array}{l}0.223 \\
0.163 \\
0.214 \\
0.275 \\
0.501 \\
0.145 \\
0.135 \\
0.102\end{array}$ & $\begin{array}{r}10.3 \\
11.0 \\
12.1 \\
12.0 \\
14.5 \\
9.6 \\
9.9 \\
9.2\end{array}$ & $\begin{array}{l}0.249 \\
0.159 \\
0.300 \\
0.306 \\
0.352 \\
0.299 \\
0.224 \\
0.288\end{array}$ & $\begin{array}{l}166 \\
210 \\
173 \\
169 \\
164 \\
171 \\
184 \\
212\end{array}$ & $\begin{array}{l}40.5 \\
33.6 \\
42.6 \\
46.3 \\
68.3 \\
34.0 \\
47.1 \\
26.0\end{array}$ & $\begin{array}{l}0.234 \\
0.201 \\
0.373 \\
0.532 \\
0.401 \\
0.175 \\
0.109 \\
0.066\end{array}$ & $\begin{array}{c}86.9 \\
71.7 \\
78.8 \\
91.5 \\
105 \\
84.4 \\
108 \\
74.1\end{array}$ & $\begin{array}{r}17.4 \\
14.7 \\
21.2 \\
27.2 \\
36.6 \\
13.8 \\
10.3 \\
9.4\end{array}$ & $\begin{array}{l}0.240 \\
0.128 \mathrm{U} \\
0.240 \\
0.337 \\
0.420 \\
0.426 \\
0.340 \\
0.243\end{array}$ & $\begin{array}{l}100 \\
73.4 \\
96.3 \\
117 \\
151 \\
90.6 \\
97.2 \\
85.0\end{array}$ \\
\hline 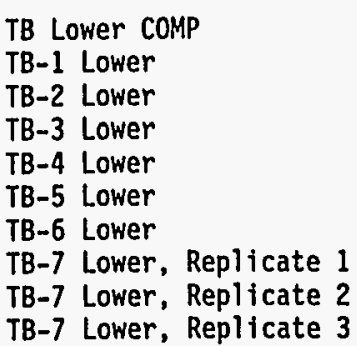 & $\begin{array}{l}1 \\
1 \\
1 \\
1 \\
1 \\
1 \\
1 \\
1 \\
1 \\
1\end{array}$ & $\begin{array}{l}0.158 \\
0.128 \\
0.106 \\
0.114 \\
0.501 \\
0.12 \\
0.143 \\
0.166 \\
0.130 \\
0.125\end{array}$ & $\begin{array}{r}11.6 \\
6.7 \\
11.4 \\
8.3 \\
13.8 \\
10.3 \\
10.7 \\
10.7 \\
11.5 \\
10.2\end{array}$ & $\begin{array}{l}0.252 \\
0.100 \\
0.250 \\
0.269 \\
0.549 \\
0.281 \\
0.217 \\
0.298 \\
0.273 \\
0.281\end{array}$ & $\begin{array}{l}180 \\
206 \\
201 \\
203 \\
181 \\
201 \\
205 \\
203 \\
196 \\
181\end{array}$ & $\begin{array}{l}39.4 \\
17.2 \\
33.5 \\
44.2 \\
65.0 \\
33.6 \\
47.6 \\
44.7 \\
43.3 \\
46.1\end{array}$ & $\begin{array}{l}0.140 \\
0.077 \\
0.073 \\
0.078 \\
0.642 \\
0.062 \\
0.088 \\
0.083 \\
0.078 \\
0.073\end{array}$ & $\begin{array}{l}90.3 \\
47.5 \\
91.5 \\
91.6 \\
98.2 \\
85.8 \\
101 \\
105 \\
102 \\
109\end{array}$ & $\begin{array}{r}9.4 \\
8.2 \\
13.7 \\
13.8 \\
40.2 \\
10.4 \\
12.7 \\
10.7 \\
8.7 \\
11.9\end{array}$ & $\begin{array}{l}0.128 U \\
0.128 U \\
0.346 \\
0.330 \\
0.413 \\
0.333 \\
0.240 \\
0.333 \\
0.239 \\
0.246\end{array}$ & $\begin{array}{c}91.8 \\
42.4 \\
81.0 \\
87.0 \\
155 \\
84.4 \\
87.1 \\
92.0 \\
95.5 \\
95.9\end{array}$ \\
\hline
\end{tabular}




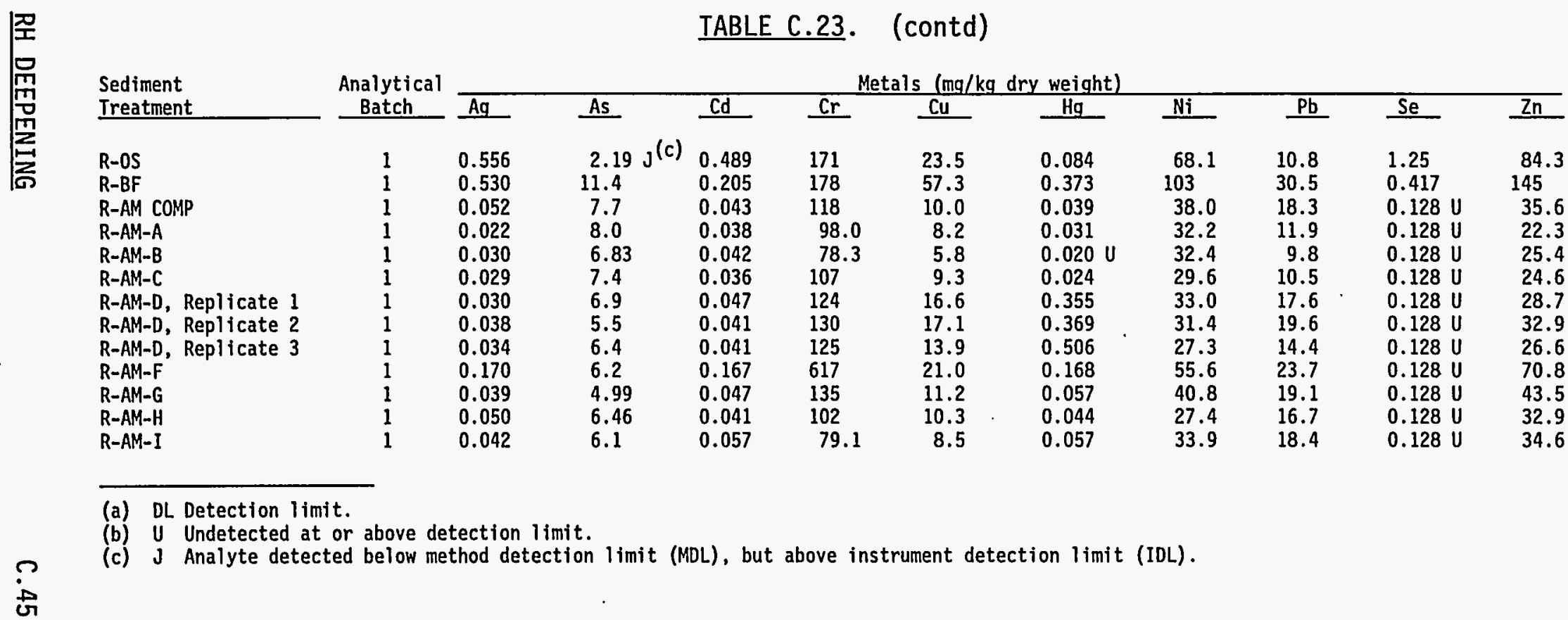


TABLE C.24. Quality Control Data for Sediment Metals Results, Richmond Harbor Deepening Project

Sediment Analytical

Treatment Batch

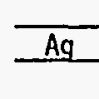

Method Blanks

Blank 1

Blank 2

Blank 3

0.021
0.025
0.021
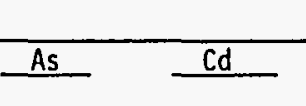

Metals (mg/kg dry weight)

\section{Matrix Spike}

UIH $\operatorname{comp}(c)$

UIH COMP, MS

Concentration Recovered

Amount Spiked

Percent Recovery

$\begin{array}{ll}{ }_{N A}(a) & 0.016 U^{(b)} \\ N A & 0.016 U \\ N A & 0.016 U\end{array}$

$\begin{array}{ll}\text { NA } & \text { NA } \\ \text { NA } & \text { NA } \\ \text { NA } & \text { NA }\end{array}$

$0.02 \mathrm{U}$
$0.02 \mathrm{U}$

$0.02 U$
$0.02 U$

$\mathrm{Hg}$

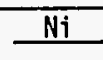

$\mathrm{Pb}$

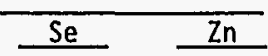

TB-7 Lower(c)

TB-7 Lower, MS

Amount Spiked

1.00

क

$\begin{array}{lll}\text { R-AM-D(c) } & 1 & 0.034 \\ \text { R-AM-D, HS } & 1 & 1.08 \\ \text { Concentration Recovered } & & 1.05 \\ \text { Amount Spiked } & & 1.00 \\ \text { Percent Recovery } & & 105 \%\end{array}$

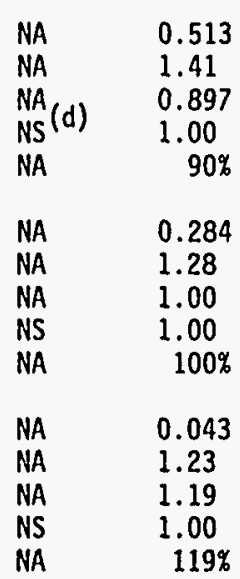

$\begin{array}{ll}\text { NA } & \text { NA } \\ \text { NA } & \text { NA } \\ \text { NA } & \text { NA } \\ \text { NS } & \text { NS } \\ \text { NA } & \text { NA } \\ \text { NA } & \text { NA } \\ \text { NA } & \text { NA } \\ \text { NA } & \text { NA } \\ \text { NS } & \text { NS } \\ \text { NA } & \text { NA } \\ & \\ \text { NA } & \text { NA } \\ \text { NA } & \text { NA } \\ \text { NA } & \text { NA } \\ \text { NS } & \text { NS } \\ \text { NA } & \text { NA }\end{array}$

0.508
1.35
0.842
0.979
$86 \%$

0.078
0.942
0.864
0.981
$88 \%$
0.410
1.29
0.880
1.03
$85 \%$

$\begin{array}{llll}\text { NA } & \text { NA } & 0.128 \mathrm{U} & \text { NA } \\ \text { NA } & \text { NA } & 0.128 \mathrm{U} & \text { NA } \\ \text { NA } & \text { NA } & 0.128 \mathrm{U} & \text { NA }\end{array}$

Standard Reference Material

\begin{tabular}{|c|c|c|c|c|c|c|c|c|c|c|c|}
\hline $\begin{array}{l}\text { Certified } \\
\text { Value } 1646 \\
\end{array}$ & & $\begin{array}{l}\mathrm{NC}^{(e)} \\
N C\end{array}$ & $\begin{array}{l}11.6 \\
\pm 1.3\end{array}$ & $\begin{array}{r}0.36 \\
\pm 0.07\end{array}$ & $\begin{array}{l}76 \\
\pm 3\end{array}$ & $\begin{array}{l}18 \\
\pm 3\end{array}$ & $\begin{array}{r}0.063 \\
\pm 0.012\end{array}$ & $\begin{array}{l}32 \\
\pm 3\end{array}$ & $\begin{array}{l}28.2 \\
\pm 1.8\end{array}$ & $\begin{array}{l}\text { NC } \\
\text { NC }\end{array}$ & $\begin{array}{l}138 \\
\pm 6\end{array}$ \\
\hline $\begin{array}{ll}\text { SRM } & 1646 \\
\text { SRM } 1646 \\
\text { SRM } 1646\end{array}$ & $\begin{array}{l}1 \\
1 \\
1\end{array}$ & $\begin{array}{l}\text { NA } \\
\text { NA } \\
\text { NA }\end{array}$ & $\begin{array}{l}10.7 \\
12.8 \\
12.7\end{array}$ & $\begin{array}{l}0.390 \\
0.373 \\
0.368\end{array}$ & $\begin{array}{l}56.0 \\
72.0 \\
55.0\end{array}$ & $\begin{array}{l}22.0 \\
21.4 \\
19.0\end{array}$ & $\begin{array}{l}0.085(f) \\
0.089^{(f)} \\
0.076\end{array}$ & $\begin{array}{l}27.2 \\
32.8 \\
30.8\end{array}$ & $\begin{array}{l}28.7 \\
28.1 \\
28.5\end{array}$ & $\begin{array}{l}\text { NA } \\
\text { NA } \\
\text { NA }\end{array}$ & $\begin{array}{l}126 \\
134 \\
134\end{array}$ \\
\hline $\begin{array}{l}\text { Certified } \\
\text { Value BEST-1 }\end{array}$ & & $\begin{array}{l}\text { NC } \\
\text { NC }\end{array}$ & $\begin{array}{l}\text { NC } \\
N C\end{array}$ & $\begin{array}{l}\text { NC } \\
\text { NC }\end{array}$ & $\begin{array}{l}\text { NC } \\
\text { NC }\end{array}$ & $\begin{array}{l}\text { NC } \\
\text { NC }\end{array}$ & $\begin{array}{r}0.092 \\
\pm 0.009\end{array}$ & $\begin{array}{l}\text { NC } \\
\text { NC }\end{array}$ & $\begin{array}{l}\text { NC } \\
N C\end{array}$ & $\begin{array}{l}\text { NC } \\
\text { NC }\end{array}$ & $\begin{array}{l}\text { NC } \\
\text { NC }\end{array}$ \\
\hline $\begin{array}{l}\text { BEST-1 } \\
\text { BEST-1 } \\
\text { BEST-1 }\end{array}$ & $\begin{array}{l}1 \\
1 \\
1\end{array}$ & $\begin{array}{l}\text { NA } \\
\text { NA } \\
\text { NA }\end{array}$ & $\begin{array}{l}\text { NA } \\
\text { NA } \\
\text { NA }\end{array}$ & $\begin{array}{l}\text { NA } \\
\text { NA } \\
\text { NÁ }\end{array}$ & $\begin{array}{l}\text { NA } \\
\text { NA } \\
\text { NA }\end{array}$ & $\begin{array}{l}\text { NA } \\
\text { NA } \\
\text { NA }\end{array}$ & $\begin{array}{l}0.096 \\
0.099 \\
0.081\end{array}$ & $\begin{array}{l}\text { NA } \\
\text { NA } \\
\text { NA }\end{array}$ & $\begin{array}{l}\text { NA } \\
\text { NA } \\
\text { NA }\end{array}$ & $\begin{array}{l}\text { NA } \\
\text { NA } \\
\text { NA }\end{array}$ & $\begin{array}{l}\text { NA } \\
\text { NA } \\
\text { NA }\end{array}$ \\
\hline
\end{tabular}




\begin{tabular}{|c|c|c|c|c|c|c|c|c|c|c|c|c|}
\hline \multirow{6}{*}{ 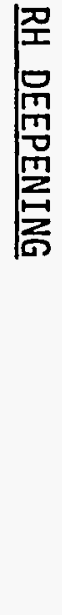 } & \multirow{2}{*}{$\begin{array}{l}\text { Sediment } \\
\text { Treatment }\end{array}$} & \multirow{2}{*}{$\begin{array}{l}\text { Analytical } \\
\text { Batch }\end{array}$} & \multicolumn{2}{|c|}{$\dot{ }$} & TABLE & 24 & ontd) & weight) & & & \multirow[b]{2}{*}{ Se } & \multirow[b]{2}{*}{$\mathrm{Zn}$} \\
\hline & & & $\mathrm{Ag}$ & As & $\mathrm{Cd}$ & $\mathrm{Cr}$ & $\mathrm{Cu}$ & $\mathrm{Hg}$ & $\mathrm{Ni}$ & $\mathrm{Pb}$ & & \\
\hline & Analytical Replicate & & & & & & & & & & & \\
\hline & $\begin{array}{l}\text { UIH COMP, Replicate } 1 \\
\text { UIH COMP, Replicate } 2 \\
\text { UIH COMP, Replicate } 3\end{array}$ & $\begin{array}{l}1 \\
1 \\
1\end{array}$ & $\begin{array}{l}0.640 \\
0.648 \\
0.628\end{array}$ & $\begin{array}{l}16.1 \\
12.7 \\
11.9\end{array}$ & $\begin{array}{l}0.521 \\
0.503 \\
0.515\end{array}$ & $\begin{array}{l}204 \\
205 \\
199\end{array}$ & $\begin{array}{l}76.6 \\
85.3 \\
81.6\end{array}$ & $\begin{array}{l}0.493 \\
0.537 \\
0.493\end{array}$ & $\begin{array}{l}112 \\
114 \\
110\end{array}$ & $\begin{array}{l}49.1 \\
56.0 \\
52.4\end{array}$ & $\begin{array}{l}0.339 \\
0.328 \\
0.335\end{array}$ & $\begin{array}{l}191 \\
191 \\
194\end{array}$ \\
\hline & RSD & & $2 \%$ & $16 \%$ & $2 \%$ & $2 \%$ & $5 \%$ & $5 \%$ & $2 \%$ & $7 \%$ & $2 \%$ & $1 \%$ \\
\hline & $\begin{array}{l}\text { TB-7 Lower, Replicate } 1 \\
\text { TB-7 Lower, Replicate } 2 \\
\text { TB-7 Lower, Replicate } 3\end{array}$ & $\begin{array}{l}1 \\
1 \\
1\end{array}$ & $\begin{array}{r}0.166 \\
.0 .130 \\
0.125\end{array}$ & $\begin{array}{l}10.7 \\
11.5 \\
10.2\end{array}$ & $\begin{array}{l}0.298 \\
0.273 \\
0.281\end{array}$ & $\begin{array}{l}203 \\
196 \\
181\end{array}$ & $\begin{array}{l}44.7 \\
43.3 \\
46.1\end{array}$ & $\begin{array}{l}0.083 \\
0.078 \\
0.073\end{array}$ & $\begin{array}{l}105 \\
102 \\
109\end{array}$ & $\begin{array}{r}10.7 \\
8.7 \\
11.9\end{array}$ & $\begin{array}{l}0.333 \\
0.239 \\
0.246\end{array}$ & $\begin{array}{l}92.0 \\
95.5 \\
95.9\end{array}$ \\
\hline & RSD & & $16 \%$ & $.6 \%$ & $4 \%$ & $6 \%$ & $3 \%$ & $6 \%$ & $3 \%$ & $15 \%$ & $19 \%$ & $2 \%$ \\
\hline$\Omega$ & $\begin{array}{l}\text { R-AM-D, Replicate } 1 \\
\text { R-AM-D, Replicate } 2 \\
\text { R-AM-D, Replicate } 3\end{array}$ & $\begin{array}{l}1 \\
1 \\
1\end{array}$ & $\begin{array}{l}0.030 \\
0.038 \\
0.034\end{array}$ & $\begin{array}{l}6.9 \\
5.5 \\
6.4\end{array}$ & $\begin{array}{l}0.047 \\
0.041 \\
0.041\end{array}$ & $\begin{array}{l}124 \\
130 \\
125\end{array}$ & $\begin{array}{l}16.6 \\
17.1 \\
13.9\end{array}$ & $\begin{array}{l}0.355 \\
0.369 \\
0.506\end{array}$ & $\begin{array}{l}33.0 \\
31.4 \\
27.3\end{array}$ & $\begin{array}{l}17.6 \\
19.6 \\
14.4\end{array}$ & $\begin{array}{l}0.128 \mathrm{U} \\
0.128 \mathrm{U} \\
0.128 \mathrm{U}\end{array}$ & $\begin{array}{l}28.7 \\
32.9 \\
26.6\end{array}$ \\
\hline & RSD & & $12 \%$ & $11 \%$. & $8 \%$ & $3 \%$ & $11 \%$ & $20 \%$ & $10 \%$ & $15 \%$ & NA & $11 \%$ \\
\hline & $\begin{array}{l}\text { (a) NA Not applicable. } \\
\text { (b) U Undetected at or } \\
\text { (c) Mean of replicated } \\
\text { (d) NS Not spiked. } \\
\text { (e) NC Not certified. } \\
\text { (f) Outside quality cor }\end{array}$ & $\begin{array}{l}\text { or above de } \\
\text { d sample. } \\
\text { ontrol crit }\end{array}$ & tection & $\begin{array}{l}\text { it. } \\
\text { for SRMs. }\end{array}$ & $\cdot$ & & & & & & & \\
\hline
\end{tabular}


TABLE C.25. Sediment Butyltin Results, Richmond Harbor Deepening Project

\begin{tabular}{|c|c|c|c|c|c|}
\hline \multirow[b]{2}{*}{$\begin{array}{l}\text { Sediment } \\
\text { Treatment }\end{array}$} & \multirow[b]{2}{*}{$\begin{array}{l}\text { Analytical } \\
\text { Batch } \\
\end{array}$} & \multirow{2}{*}{$\begin{array}{c}\text { Tripentyltin } \\
\text { Percent Internal } \\
\text { Standard } \\
\end{array}$} & \multicolumn{3}{|c|}{ Butyltin species $(\mu \mathrm{g} / \mathrm{kg}$ dry weight) } \\
\hline & & & $\begin{array}{c}\text { Tri- } \\
\text { butyitin }\end{array}$ & $\begin{array}{c}\text { Di- } \\
\text { butyltin }\end{array}$ & $\begin{array}{c}\text { Mono- } \\
\text { butyltin }\end{array}$ \\
\hline $\begin{array}{l}\text { Target DL (a) } \\
\text { Achieved DL. }\end{array}$ & & & $\begin{array}{l}1.00 \\
0.40\end{array}$ & $\begin{array}{l}1.00 \\
0.65\end{array}$ & $\begin{array}{l}1.00 \\
0.59\end{array}$ \\
\hline $\begin{array}{l}\text { SF COMP } \\
\text { SF-1 } \\
\text { SF-2 } \\
\text { SF-3 } \\
\text { SF-4 }\end{array}$ & $\begin{array}{l}3 \\
3 \\
2 \\
2 \\
3\end{array}$ & $\begin{array}{r}97 \\
98 \\
102 \\
106 \\
99\end{array}$ & $\begin{array}{l}8.52 \\
1.67 \\
6.78 \\
30.6 \\
27.0\end{array}$ & $\begin{array}{c}7.48 \\
1.59 \\
9.05 \\
18.2 \\
33.1\end{array}$ & $\begin{array}{l}2.50 \\
0.59 u^{(b)} \\
2.58 \\
3.59 \\
6.49\end{array}$ \\
\hline $\begin{array}{l}\text { SFW COMP } \\
\text { SFW-1 } \\
\text { SFW-2 } \\
\text { SFW-3 } \\
\text { SFW-4 }\end{array}$ & $\begin{array}{l}3 \\
3 \\
3 \\
3 \\
3\end{array}$ & $\begin{array}{r}96 \\
100 \\
99 \\
94 \\
92\end{array}$ & $\begin{array}{l}2.85 \\
5.76 \\
4.79 \\
0.40 \mathrm{U} \\
1.05\end{array}$ & $\begin{array}{l}5.73 \\
9.88 \\
8.46 \\
0.65 \mathrm{U} \\
2.01\end{array}$ & $\begin{array}{l}2.54 \\
1.71 \\
1.52 \\
0.59 \cup \\
0.59 \cup\end{array}$ \\
\hline $\begin{array}{l}\text { UIH COMP, Replicate } 1 \\
\text { UIH COMP, Replicate } 2 \\
\text { UIH COMP, Replicate } 3 \\
\text { UIH-1 } \\
\text { UIH-2 } \\
\text { UIH-3 } \\
\text { UIH-4 } \\
\text { UIH-5 }\end{array}$ & $\begin{array}{l}3 A \\
3 A \\
3 A \\
2 \\
2 \\
2 \\
2 \\
2\end{array}$ & $\begin{array}{r}107 \\
91 \\
100 \\
104 \\
99 \\
99 \\
100 \\
97\end{array}$ & $\begin{array}{l}9.32 \\
7.48 \\
8.98 \\
5.38 \\
6.67 \\
4.66 \\
7.12 \\
8.11\end{array}$ & $\begin{array}{l}9.30 \\
7.74 \\
8.11 \\
7.95 \\
9.67 \\
6.68 \\
6.02 \\
7.04\end{array}$ & $\begin{array}{l}0.59 \mathrm{U} \\
0.59 \mathrm{U} \\
1.61 \\
0.59 \mathrm{U} \\
3.05 \\
2.37 \\
0.59 \mathrm{U} \\
0.59 \mathrm{U}\end{array}$ \\
\hline $\begin{array}{l}\text { TB Upper COMP } \\
\text { TB-1 Upper } \\
\text { TB-2 Upper } \\
\text { TB-3 Upper } \\
\text { TB-4 Upper } \\
\text { TB-5 Upper } \\
\text { TB-6 Upper } \\
\text { TB-7 Upper }\end{array}$ & $\begin{array}{l}3 \\
1 \\
1 \\
1 \\
1 \\
1 \\
1 \\
1\end{array}$ & $\begin{array}{r}98 \\
102 \\
102 \\
100 \\
105 \\
99 \\
92 \\
99\end{array}$ & $\begin{array}{l}1.87 \\
0.40 \mathrm{U} \\
1.35 \\
0.40 \mathrm{U} \\
2.18 \\
0.40 \mathrm{U} \\
0.40 \mathrm{U} \\
0.40 \mathrm{U}\end{array}$ & $\begin{array}{l}0.65 \mathrm{U} \\
1.13 \\
0.65 \mathrm{U} \\
0.65 \mathrm{U} \\
2.38 \\
0.65 \mathrm{U} \\
0.65 \mathrm{U} \\
0.65 \mathrm{U}\end{array}$ & $\begin{array}{l}3.46 \\
1.03 \\
0.59 \mathrm{U} \\
0.59 \mathrm{U} \\
0.59 \mathrm{U} \\
3.65 \\
0.59 \mathrm{U} \\
0.59 \mathrm{U}\end{array}$ \\
\hline $\begin{array}{l}\text { TB Lower COMP } \\
\text { TB-1 Lower } \\
\text { TB-2 Lower } \\
\text { TB-3 Lower } \\
\text { TB-4 Lower } \\
\text { TB-5 Lower } \\
\text { TB-6 Lower } \\
\text { TB-7 Lower }\end{array}$ & $\begin{array}{l}3 \\
1 \\
1 \\
1 \\
1 \\
1 \\
1 \\
2\end{array}$ & $\begin{array}{r}92 \\
93 \\
91 \\
101 \\
103 \\
95 \\
93 \\
93\end{array}$ & $\begin{array}{l}0.40 \mathrm{U} \\
0.40 \mathrm{U} \\
0.40 \mathrm{U} \\
0.40 \mathrm{U} \\
0.40 \mathrm{U} \\
0.40 \mathrm{U} \\
0.40 \mathrm{U} \\
0.40 \mathrm{U}\end{array}$ & $\begin{array}{l}0.65 U \\
0.65 U \\
0.65 U \\
0.65 U \\
1.20 \\
0.65 U \\
0.65 U \\
0.65 U\end{array}$ & $\begin{array}{l}5.55 \\
0.59 \mathrm{U} \\
0.59 \mathrm{U} \\
0.59 \mathrm{U} \\
1.48 \\
0.59 \mathrm{U} \\
0.59 \mathrm{U} \\
0.59 \mathrm{U}\end{array}$ \\
\hline OBM СОMP & 3 & 80 & $0.40 \mathrm{U}$ & $0.65 U$ & $0.59 \mathrm{U}$ \\
\hline
\end{tabular}


TABLE C.25. (contd)

Sediment
Treatment
R-OS
R-BF
R-AM COMP
R-AM-A
R-AM-B, Replicate 1
R-AM-B, Replicate 2
R-AM-B, Replicate 3
R-AM-C
R-AM-D
R-AM-F
R-AM-G
R-AM-H, Replicate 1
R-AM-H, Replicate 2
R-AM-H, Replicate 3
R-AM-I

\begin{tabular}{c}
$\begin{array}{c}\text { Analytical } \\
\text { Batch }\end{array}$ \\
\hline 2 \\
2 \\
2 \\
1 \\
1 \\
1 \\
1 \\
1 \\
1 \\
1 \\
1 \\
2 \\
2 \\
2 \\
1
\end{tabular}
Tripentyltin Percent Internal Standard

99
102
104
90
96
80
97
85
96
100
93
91
94
105
99

Butyltin species ( $\mu \mathrm{g} / \mathrm{kg}$ dry weight)

\begin{tabular}{ccc}
\hline Tri- & Di- & $\begin{array}{c}\text { Mono- } \\
\text { butyltin }\end{array}$ \\
butyltin & butylin
\end{tabular}

$\begin{array}{lll}0.40 \mathrm{U} & 0.65 \mathrm{U} & 0.59 \mathrm{U} \\ 3.82 & 3.38 \mathrm{U}\end{array}$

3.82

3.38

$0.65 \mathrm{U}$

$0.65 \mathrm{U}$

$0.65 \mathrm{U}$

$0.65 \mathrm{U}$

$0.65 U$

$0.65 U$

$0.65 \mathrm{U}$

1.57

$0.65 \mathrm{U}$

$0.65 \mathrm{U}$

$0.65 \mathrm{U}$

$0.65 \mathrm{U}$

$0.65 U$

$0.59 \mathrm{U}$

$0.59 \mathrm{U}$

$0.59 \mathrm{U}$

$0.59 \mathrm{U}$

$0.59 \mathrm{U}$

$0.59 U$

$0.59 \mathrm{U}$

$0.59 \mathrm{U}$

$0.59 \mathrm{U}$

2.78

$0.59 \mathrm{U}$

$0.59 U$

$0.40 \mathrm{U}$

$0.59 \mathrm{U}$

$0.59 \mathrm{U}$

(a) DL Detection limit.

(b) $U$ Not detected above detection limit. 


\section{TABLE C.26. Quality Control Data for Sediment Butyltin Results, Richmond Harbor Deepening Project}

\begin{tabular}{|c|c|c|c|c|c|}
\hline \multirow[b]{2}{*}{$\begin{array}{l}\text { Sediment } \\
\text { Treatment } \\
\end{array}$} & \multirow[b]{2}{*}{$\begin{array}{l}\text { Analytical } \\
\text { Batch }\end{array}$} & \multirow{2}{*}{$\begin{array}{c}\text { Tripentyltin } \\
\text { Percent Internal } \\
\text { Standard } \\
\end{array}$} & \multicolumn{3}{|c|}{ Butyitin species ( $\mu \mathrm{g} / \mathrm{kg}$ dry weight) } \\
\hline & & & $\begin{array}{l}\text { Tri- } \\
\text { butyltin }\end{array}$ & $\begin{array}{c}\text { Di- } \\
\text { butyltin }\end{array}$ & $\begin{array}{c}\text { Mono- } \\
\text { butyltin }\end{array}$ \\
\hline \multicolumn{6}{|l|}{ Method Blanks } \\
\hline $\begin{array}{l}\text { Blank } \\
\text { Blank } \\
\text { Blank } \\
\text { Blank }\end{array}$ & $\begin{array}{l}1 \\
2 \\
3 \\
3 \mathrm{~A}\end{array}$ & $\begin{array}{r}92 \\
100 \\
91 \\
95\end{array}$ & $\begin{array}{l}0.40 U^{(a)} \\
0.40 U \\
0.40 U \\
0.40 U\end{array}$ & $\begin{array}{l}0.65 \mathrm{U} \\
0.65 \mathrm{U} \\
0.65 \mathrm{U} \\
0.65 \mathrm{U}\end{array}$ & $\begin{array}{l}0.59 U \\
0.59 U \\
0.59 U \\
0.59 U\end{array}$ \\
\hline \multicolumn{6}{|l|}{ Matrix Spikes } \\
\hline $\begin{array}{l}\text { R-AM-A } \\
\text { R-AM-A, MS } \\
\text { Concentration Recovered } \\
\text { Amount Spiked } \\
\text { Percent Recovery }\end{array}$ & 1 & $\begin{array}{l}90 \\
88 \\
N A \\
N A \\
N A\end{array}$ & $\begin{array}{l}0.40 \mathrm{U} \\
24.0 \\
24.0 \\
26.4 \\
91 \%\end{array}$ & $\begin{array}{l}0.65 \text { U } \\
24.9 \\
24.9 \\
26.4 \\
94 \%\end{array}$ & $\begin{array}{l}0.59 U \\
7.08 \\
7.08 \\
26.4 \\
27 \% \text { (c) }\end{array}$ \\
\hline $\begin{array}{l}\text { R-AM COMP } \\
\text { R-AM COMP, MS } \\
\text { Concentration Recovered } \\
\text { Amount Spiked } \\
\text { Percent Recovery }\end{array}$ & 2 & $\begin{array}{l}104 \\
103 \\
\text { NA } \\
\text { NA } \\
\text { NA }\end{array}$ & $\begin{array}{l}0.40 \mathrm{U} \\
31.9 \\
31.9 \\
30.9 \\
103 \%\end{array}$ & $\begin{array}{l}0.65 \cup \\
31.7 \\
31.7 \\
30.9 \\
103 \%\end{array}$ & $\begin{array}{l}0.59 \mathrm{U} \\
9.90 \\
9.90 \\
30.9 \\
32 \%(c)\end{array}$ \\
\hline $\begin{array}{l}\text { SF COMP } \\
\text { SF COMP, MS } \\
\text { Concentration Recovered } \\
\text { Amount Spiked } \\
\text { Percent Recovery }\end{array}$ & 3 & $\begin{array}{l}97 \\
90 \\
\text { NA } \\
\text { NA } \\
\text { NA }\end{array}$ & $\begin{array}{l}8.52 \\
64.6 \\
56.1 \\
43.9 \\
128 \%(c)\end{array}$ & $\begin{array}{l}7.48 \\
44.0 \\
36.5 \\
43.9 \\
83 \%\end{array}$ & $\begin{array}{l}2.50 \\
10.3 \\
7.80 \\
43.9 \\
18 \%(c)\end{array}$ \\
\hline \multicolumn{6}{|c|}{ Standard Reference Material } \\
\hline $\begin{array}{l}\text { Certified } \\
\text { Value PACS-1 }\end{array}$ & & $\begin{array}{l}\text { NA } \\
\text { NA }\end{array}$ & $\begin{array}{l}1270 \\
\pm 220\end{array}$ & $\begin{array}{l}1160 \\
\pm 180\end{array}$ & $\begin{array}{l}280 \\
170\end{array}$ \\
\hline $\begin{array}{l}\text { PACS-1 } \\
\text { PACS-1 } \\
\text { PACS-1 }\end{array}$ & $\begin{array}{l}1 \\
2 \\
3\end{array}$ & $\begin{array}{r}103 \\
103 \\
99\end{array}$ & $\begin{array}{l}1040 \\
1060 \\
1110\end{array}$ & $\begin{array}{l}1100 \\
659(d) \\
1210\end{array}$ & $\begin{array}{l}118{ }^{(d)} \\
88.4^{(d)} \\
138^{(d)}\end{array}$ \\
\hline \multicolumn{6}{|l|}{ Analytical Replicate } \\
\hline $\begin{array}{l}\text { R-AM-B, Replicate } 1 \\
\text { R-AM-B, Replicate } 2 \\
\text { R-AM-B, Replicate } 3\end{array}$ & $\begin{array}{l}1 \\
1 \\
1\end{array}$ & $\begin{array}{l}96 \\
80 \\
97\end{array}$ & $\begin{array}{l}0.40 U \\
0.40 U \\
0.40 U\end{array}$ & $\begin{array}{l}0.65 \mathrm{U} \\
0.65 \mathrm{U} \\
0.65 \mathrm{U}\end{array}$ & $\begin{array}{l}0.59 U \\
0.59 U \\
0.59 U\end{array}$ \\
\hline RSD . & & NA & NA & NA & NA \\
\hline $\begin{array}{l}\text { R-AM-H, Replicate } 1 \\
\text { R-AM-H, Replicate } 2 \\
\text { R-AM-H, Replicate } 3\end{array}$ & $\begin{array}{l}2 \\
2 \\
2\end{array}$ & $\begin{array}{r}91 \\
94 \\
105\end{array}$ & $\begin{array}{l}0.40 U \\
0.40 U \\
0.40 U\end{array}$ & $\begin{array}{l}0.65 U \\
0.65 U \\
0.65 U\end{array}$ & $\begin{array}{l}0.59 U \\
0.59 U \\
0.59 U\end{array}$ \\
\hline RSD & & NA & NA & NA & NA \\
\hline $\begin{array}{l}\text { UIH COMP, Replicate } 1 \\
\text { UIH COMP, Replicate } 2 \\
\text { UIH COMP, Replicate } 3\end{array}$ & $\begin{array}{l}3 A \\
3 A \\
3 A\end{array}$ & $\begin{array}{r}107 \\
91 \\
100\end{array}$ & $\begin{array}{l}9.32 \\
7.48 \\
8.98\end{array}$ & $\begin{array}{l}9.30 \\
7.74 \\
8.11\end{array}$ & $\begin{array}{l}0.59 U \\
0.59 U \\
1.61\end{array}$ \\
\hline RSD & & NA & $11 \%$ & $10 \%$ & NA \\
\hline
\end{tabular}

\footnotetext{
(a) U undetected at or above detection limit.

(b) NA Not applicable.

(c) Outside quality control criteria (40\%-120\%) for matrix spike recoveries.

(d) Outside quality control criteria $( \pm 30 \%)$ for SRMs.
} 


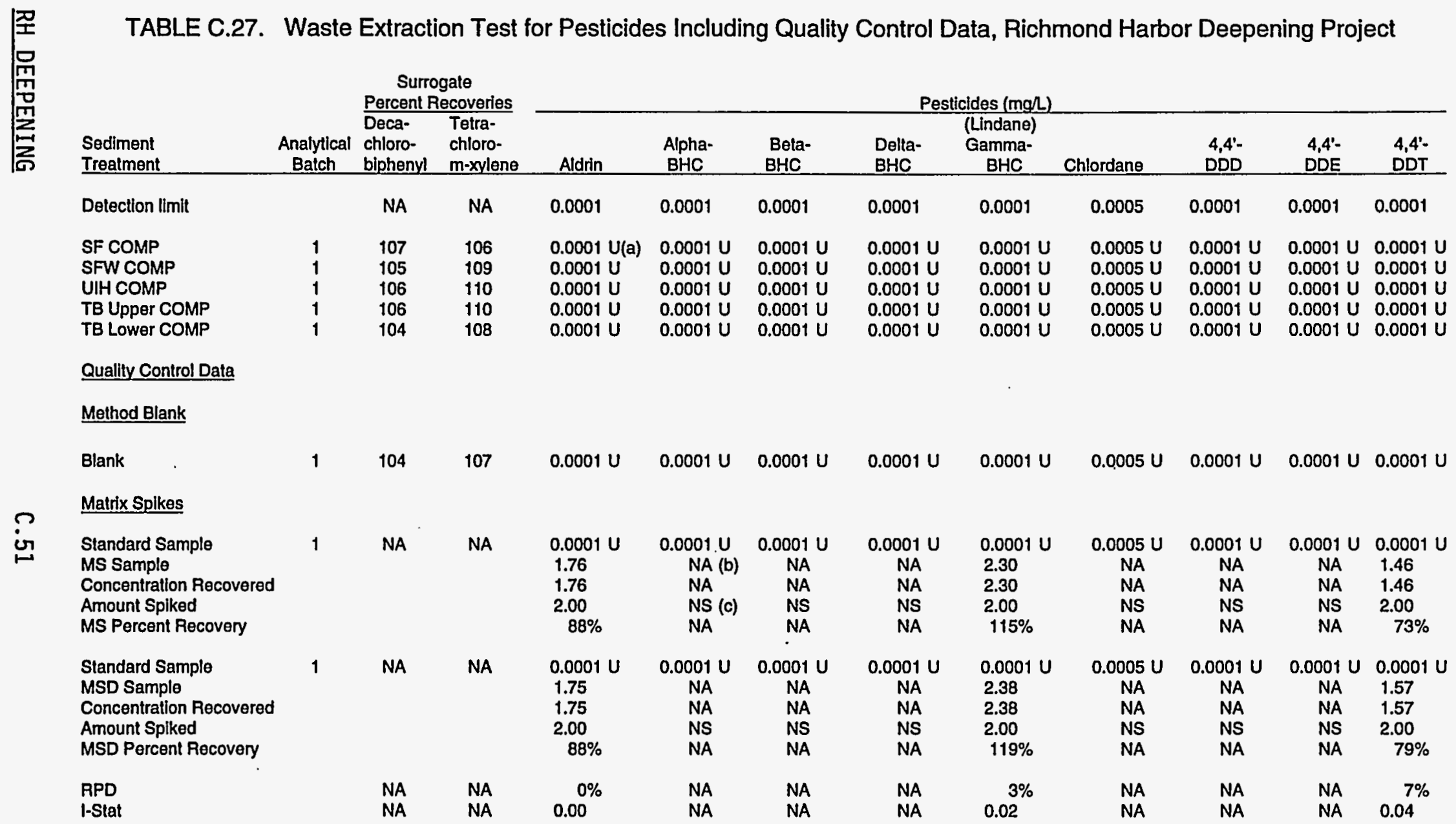


TABLE C.27. (contd)

Sediment

Treatmen

Detection limit

\section{SF COMP}

\section{SFW COMP}

UIH COMP

TB Upper COMP

TB Lower COMP

\section{Quality Control Data}

\section{Method Blank}

\section{Blank}

$0.0001 \mathrm{U}$

$0.0001 U$

$0.0001 U \quad 0.0001 U \quad 0.0001 U$

$\begin{array}{lll}0.0001 U & 0.0001 U & 0.0001 U\end{array}$

0.0005

$0.01 U$

Matrix Spikes

ĩ

Standard Sample
MS Sample
Concentration Recovered
Amount Spiked

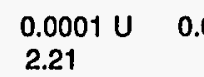

2.21

2.21

$0.0001 \mathrm{U}$

$0.0001 U \quad 0.0001 U \quad 0.0001 U$

$0.0001 \mathrm{U} \quad 0.0001 \mathrm{U}$

$$
111 \%
$$

NA

$\begin{array}{lll}\text { NA } & \text { NA } & 2.17 \\ \text { NA } & \text { NA } & 2.17 \\ \text { NS } & \text { NS } & 2.00 \\ \text { NA } & \text { NA } & 109 \%\end{array}$

NA

$0.0005 U$

$0.01 U$

NS

NA

NA $109 \%$

NA $\quad 1.75$

NS $\quad 2.00$

NA
NA
NS

NA
NS
NA

Standard Sample

MSD Sample

Concentration Recovered

$0.0001 U \quad 0.0001 U$

$\begin{array}{ll}0.0001 & \mathrm{U} \\ 2.27 & 0.0001\end{array}$

2.27

NA
NA
NS

2.00

$\begin{array}{lll}0.0001 U & 0.0001 U & 0.0001 U\end{array}$

NA

$88 \%$

NA

NA NA NA

NS NS

MSD Percent Recovery

$114 \%$

NA $\quad$ NA 2.25

$0.0001 \mathrm{U}$

NA

NA

RPD

0.01

NS

NA $\quad 2.25$

$\begin{array}{lll}N S & N S & 2.00 \\ N A & N A & 113 \%\end{array}$

$\begin{array}{ll}\text { NA } & 0.0001 \\ \text { NA } & 1.74\end{array}$

$0.0001 \mathrm{U}$

$0.0005 U \quad 0.01 U$

NA $\quad 1.74$

NA NA NA

NA

NA

NA $\quad 4 \%$

NA

0.02

NA

2.00

NS

NA

NS

NA

NA

NA

NA $\quad 1 \%$

NA

NA

NA

(a) U Undetected at or above detection limit.

(b) NA Not applicable.

(c) NS Not spiked. 
TABLE C.28. Waste Extraction Test for Polychlorinated Biphenyls (PCBs), Including Quality Control Data, Richmond Harbor Deepening Project

\begin{tabular}{|c|c|c|c|c|c|c|c|c|}
\hline \multirow[b]{2}{*}{$\begin{array}{l}\text { Sediment } \\
\text { Treatment }\end{array}$} & \multirow[b]{2}{*}{$\begin{array}{c}\text { Analytical } \\
\text { Batch }\end{array}$} & \multicolumn{7}{|c|}{ PCBs (mg/L) } \\
\hline & & $\begin{array}{c}\text { Aroclor } \\
1016\end{array}$ & $\begin{array}{c}\text { Aroclor } \\
1221\end{array}$ & $\begin{array}{c}\text { Aroclor } \\
1232 \\
\end{array}$ & $\begin{array}{l}\text { Aroclor } \\
1242 \\
\end{array}$ & $\begin{array}{c}\text { Aroclor } \\
1248 \\
\end{array}$ & $\begin{array}{c}\text { Aroclor } \\
1254 \\
\end{array}$ & $\begin{array}{c}\text { Aroclor } \\
1260 \\
\end{array}$ \\
\hline Detection limit & & 0.005 & 0.005 & 0.005 & 0.005 & 0.005 & 0.005 & 0.005 \\
\hline SF COMP & 1 & $0.005 U(a)$ & $0.005 U$ & $0.005 \mathrm{U}$ & $0.005 \mathrm{U}$ & $0.005 \mathrm{U}$ & $0.005 \mathrm{U}$ & $0.005 \mathrm{U}$ \\
\hline SFW COMP & 1 & $0.005 \mathrm{U}$ & $0.005 \mathrm{U}$ & $0.005 \mathrm{U}$ & $0.005 \mathrm{U}$ & $0.005 \mathrm{U}$ & $0.005 \mathrm{U}$ & $0.005 U$ \\
\hline UIH COMP & 1 & $0.005 \mathrm{U}$ & $0.005 U$ & $0.005 \mathrm{U}$ & $0.005 U$ & $0.005 \mathrm{U}$ & $0.005 U$ & $0.005 U$ \\
\hline TB Upper COMP & 1 & $0.005 \mathrm{U}$ & $0.005 \mathrm{U}$ & $0.005 \mathrm{U}$ & $0.005 U$ & $0.005 \mathrm{U}$ & $0.005 \mathrm{U}$ & $0.005 U$ \\
\hline TB Lower COMP & 1 & $0.005 \mathrm{U}$ & $0.005 \mathrm{U}$ & $0.005 \mathrm{U}$ & $0.005 U$ & $0.005 \mathrm{U}$ & $0.005 \mathrm{U}$ & $0.005 U$ \\
\hline
\end{tabular}

Quality Control Data

Method Blank

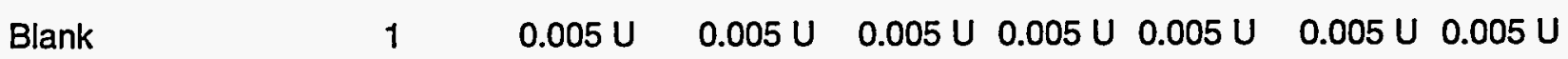

Matrix Spike

Matrix spike not available for PCBs.

(a) U Undetected at or above detection limit. 


\begin{tabular}{|c|c|c|c|c|c|c|c|c|c|c|}
\hline \multirow[b]{2}{*}{$\begin{array}{l}\text { Sediment } \\
\text { Treatment }\end{array}$} & \multirow[b]{2}{*}{$\begin{array}{c}\text { Analytical } \\
\text { Batch }\end{array}$} & \multicolumn{9}{|c|}{ Metals (mg/L) } \\
\hline & & Antimony & Arsenic & Barium & Beryllium & Cadmium & Chromium & Cobalt & Copper & $\begin{array}{l}\text { Hexavalent } \\
\text { Chromium }\end{array}$ \\
\hline Analytical method & & 6010 & 7060 & 6010 & 6010 & 6010 & 6010 & 6010 & 6010 & 7196 \\
\hline Detection Limit & & 0.2 & 0.05 & 0.1 & 0.05 & 0.05 & 0.1 & 0.1 & 0.1 & 0.01 \\
\hline $\begin{array}{l}\text { SF COMP } \\
\text { SFW COMP } \\
\text { UIH COMP } \\
\text { TB Upper COMP } \\
\text { TB Lower COMP }\end{array}$ & $\begin{array}{l}1 \\
1 \\
1 \\
1 \\
1\end{array}$ & $\begin{array}{l}0.2 U(a) \\
0.2 U \\
0.2 U \\
0.2 U \\
0.2 U\end{array}$ & $\begin{array}{l}0.05 \\
0.08 \\
0.06 \\
0.08 \\
0.08\end{array}$ & $\begin{array}{l}1.5 \\
2.5 \\
0.8 \\
1.1 \\
1.9\end{array}$ & $\begin{array}{l}0.05 U \\
0.05 U \\
0.05 U \\
0.05 U \\
0.05 U\end{array}$ & $\begin{array}{l}0.05 U \\
0.05 U \\
0.05 U \\
0.05 U \\
0.05 U\end{array}$ & $\begin{array}{l}0.2 \\
0.3 \\
0.4 \\
0.1 \\
0.1\end{array}$ & $\begin{array}{l}0.1 U \\
0.1 U \\
0.1 \\
0.1 U \\
0.1\end{array}$ & $\begin{array}{l}0.1 U \\
0.1 U \\
0.1 U \\
0.1 U \\
0.1 U\end{array}$ & $\begin{array}{l}0.01 U \\
0.01 U \\
0.01 U \\
0.01 U \\
0.01 U\end{array}$ \\
\hline Method Blank & \multicolumn{9}{|c|}{ Quality Control Data } & \\
\hline Blank & 1 & $0.2 \mathrm{U}$ & $0.05 \mathrm{U}$ & $0.1 \mathrm{U}$ & $0.05 \mathrm{U}$ & $0.05 \mathrm{U}$ & $0.1 \mathrm{U}$ & $0.1 U$ & $0.1 \mathrm{U}$ & $0.01 \mathrm{U}$ \\
\hline \multicolumn{11}{|l|}{ Matrix Spikes } \\
\hline $\begin{array}{l}\text { Standard Sample } \\
\text { MS Sample } \\
\text { Concentration Rec } \\
\text { Amount Spiked } \\
\text { MS Percent Recovery }\end{array}$ & 1 & $\begin{array}{l}0.2 U \\
9.19 \\
9.19 \\
10.0 \\
92 \%\end{array}$ & $\begin{array}{r}0.0770 \\
0.162 \\
0.085 \\
0.100 \\
85 \%\end{array}$ & $\begin{array}{r}0.110 \\
9.53 \\
9.42 \\
10.0 \\
94 \%\end{array}$ & $\begin{array}{l}0.05 \mathrm{U} \\
9.28 \\
9.28 \\
10.0 \\
93 \%\end{array}$ & $\begin{array}{l}0.05 \mathrm{U} \\
9.01 \\
9.01 \\
10.0 \\
90 \%\end{array}$ & $\begin{array}{l}0.1 \mathrm{U} \\
9.21 \\
9.21 \\
10.0 \\
92 \%\end{array}$ & $\begin{array}{l}0.1 \mathrm{U} \\
9.38 \\
9.38 \\
10.0 \\
94 \%\end{array}$ & $\begin{array}{l}0.1 \mathrm{U} \\
9.37 \\
9.37 \\
10.0 \\
94 \%\end{array}$ & $\begin{array}{l}0.01 U \\
0.178 \\
0.178 \\
0.200 \\
89 \%\end{array}$ \\
\hline $\begin{array}{l}\text { Standard Sample } \\
\text { MSD Sample } \\
\text { Concentration Rec } \\
\text { Amount Spiked } \\
\text { MSD Percent Recovery }\end{array}$ & 1 & $\begin{array}{l}0.2 \mathrm{U} \\
9.26 \\
9.26 \\
10.0 \\
93 \%\end{array}$ & $\begin{array}{r}0.0770 \\
0.169 \\
0.092 \\
0.100 \\
92 \%\end{array}$ & $\begin{array}{r}0.110 \\
9.55 \\
9.44 \\
10.0 \\
94 \%\end{array}$ & $\begin{array}{l}0.05 \mathrm{U} \\
9.34 \\
9.34 \\
10.0 \\
93 \%\end{array}$ & $\begin{array}{l}0.05 U \\
9.14 \\
9.14 \\
10.0 \\
91 \%\end{array}$ & $\begin{array}{l}0.1 \mathrm{U} \\
9.27 \\
9.27 \\
10.0 \\
93 \%\end{array}$ & $\begin{array}{l}0.1 U \\
9.47 \\
9.47 \\
10.0 \\
95 \%\end{array}$ & $\begin{array}{l}0.1 U \\
9.43 \\
9.43 \\
10.0 \\
94 \%\end{array}$ & $\begin{array}{c}0.01 \mathrm{U} \\
0.175 \\
0.175 \\
0.200 \\
87.5 \%\end{array}$ \\
\hline $\begin{array}{l}\text { RPD } \\
\text { I-Stat }\end{array}$ & & $\begin{array}{r}1 \% \\
0.01\end{array}$ & $\begin{array}{r}8 \% \\
0.04\end{array}$ & $\begin{array}{r}0 \% \\
0.00\end{array}$ & $\begin{array}{r}0 \% \\
0.00\end{array}$ & $\begin{array}{r}1 \% \\
0.01\end{array}$ & $\begin{array}{r}1 \% \\
0.01\end{array}$ & $\begin{array}{r}1 \% \\
0.01\end{array}$ & $\begin{array}{r}0 \% \\
0.00\end{array}$ & $\begin{array}{r}2 \% \\
0.01\end{array}$ \\
\hline
\end{tabular}


TABLE C.29. (contd)

\begin{tabular}{|c|c|c|c|c|c|c|c|c|c|c|}
\hline \multirow[b]{2}{*}{$\begin{array}{l}\text { Sediment } \\
\text { Treatment }\end{array}$} & \multirow[b]{2}{*}{$\begin{array}{c}\text { Analytical } \\
\text { Batch }\end{array}$} & \multicolumn{9}{|c|}{ Metals (mg/L) } \\
\hline & & Lead & Mercury & $\begin{array}{l}\text { Molyb- } \\
\text { denum }\end{array}$ & Nickel & Selenium & Silver & Thallium & Vanadium & Zinc \\
\hline Analytical method & & 6010 & 7470 & 6010 & 6010 & 7741 & 6010 & 6010 & 6010 & 6010 \\
\hline Detection Limit & & 0.1 & 0.01 & 0.1 & 0.1 & 0.05 & 0.1 & 0.2 & 0.1 & 0.1 \\
\hline SF COMP & 1 & 0.3 & $0.01 \mathrm{U}$ & $0.1 \mathrm{U}$ & 0.2 & $0.05 \mathrm{U}$ & $0.1 \mathrm{U}$ & $0.2 \mathrm{U}$ & 0.5 & 0.9 \\
\hline SFW COMP & 1 & 0.9 & $0.01 \mathrm{U}$ & $0.1 \mathrm{U}$ & 0.2 & $0.05 \mathrm{U}$ & $0.1 \mathrm{U}$ & $0.2 \mathrm{U}$ & 0.6 & 1.0 \\
\hline UIH COMP & 1 & 0.2 & $0.01 \mathrm{U}$ & $0.1 \mathrm{U}$ & 0.3 & $0.05 \mathrm{U}$ & $0.1 \mathrm{U}$ & $0.2 \mathrm{U}$ & 0.7 & 1.1 \\
\hline TB Upper COMP & 1 & 0.3 & $0.01 \mathrm{U}$ & $0.1 \mathrm{U}$ & 0.2 & $0.05 \mathrm{U}$ & $0.1 \mathrm{U}$ & $0.2 \mathrm{U}$ & 0.6 & 0.4 \\
\hline TB Lower COMP & 1 & $0.1 \mathrm{U}$ & $0.01 \mathrm{U}$ & $0.1 \mathrm{U}$ & 0.3 & $0.05 \mathrm{U}$ & $0.1 \mathrm{U}$ & $0.2 \mathrm{U}$ & 0.5 & $0.1 \mathrm{C}$ \\
\hline
\end{tabular}

Quality Control Data

Method Blank

$\begin{array}{ll}\text { if } & \text { Blank } \\ & \text { Matrix Spikes } \\ & \text { Standard Sample } \\ \text { MS Sample } \\ \text { Concentration Rec } \\ \text { Amount Spiked } \\ \text { MS Percent Recovery } \\ \text { Standard Sample } \\ \text { MSD Sample } \\ \text { Concentration Rec } \\ \text { Amount Spiked } \\ \text { MSD Percent Recovery } \\ \text { RPD } \\ \text { I-Stat }\end{array}$

\begin{tabular}{|c|c|c|c|c|c|c|c|c|}
\hline $0.1 \mathrm{U}$ & $0.01 \mathrm{U}$ & $0.1 \mathrm{U}$ & $0.1 \mathrm{U}$ & $0.05 \mathrm{U}$ & $0.1 \mathrm{U}$ & $0.2 \mathrm{U}$ & $0.1 \mathrm{U}$ & $0.1 \mathrm{U}$ \\
\hline $0.1 \mathrm{U}$ & $0.01 \mathrm{U}$ & $0.1 \mathrm{U}$ & 14.5 & $0.05 \mathrm{U}$ & $0.1 \mathrm{U}$ & $0.2 \mathrm{U}$ & $0.1 \mathrm{U}$ & $0.1 \mathrm{U}$ \\
\hline 9.05 & 0.104 & 9.45 & 24.3 & 0.0990 & 9.19 & 9.31 & 9.27 & 9.10 \\
\hline 9.05 & 0.104 & 9.45 & 9.8 & 0.0990 & 9.19 & 9.31 & 9.27 & 9.10 \\
\hline 10.0 & 0.100 & 10.0 & 10.0 & 0.100 & 10.0 & 10.0 & 10.0 & 10.0 \\
\hline $91 \%$ & $104 \%$ & $95 \%$ & $98 \%$ & $99 \%$ & $92 \%$ & $93 \%$ & $93 \%$ & $91 \%$ \\
\hline $0.1 \mathrm{U}$ & $0.01 \mathrm{U}$ & $0.1 \cup$ & 14.5 & $0.05 U$ & $0.1 \mathrm{U}$ & $0.2 \mathrm{U}$ & $0.1 \cup$ & $0.1 \mathrm{U}$ \\
\hline 9.20 & 0.106 & 9.57 & 24.2 & 0.106 & 9.28 & 9.67 & 9.34 & 9.19 \\
\hline 9.20 & 0.106 & 9.57 & 9.7 & 0.106 & 9.28 & 9.67 & 9.34 & 9.19 \\
\hline 10.0 & 0.100 & 10.0 & 10.0 & 0.100 & 10.0 & 10.0 & 10.0 & 10.0 \\
\hline $92 \%$ & $106 \%$ & $96 \%$ & $97 \%$ & $106 \%$ & $93 \%$ & $97 \%$ & $93 \%$ & $92 \%$ \\
\hline $\begin{array}{r}1 \% \\
0.01\end{array}$ & $\begin{array}{r}2 \% \\
0.01\end{array}$ & $\begin{array}{r}1 \% \\
0.01\end{array}$ & $\begin{array}{r}1 \% \\
0.01\end{array}$ & $\begin{array}{r}7 \% \\
0.03\end{array}$ & $\begin{array}{r}1 \% \\
0.01\end{array}$ & $\begin{array}{r}4 \% \\
0.02\end{array}$ & $\begin{array}{r}0 \% \\
0.00\end{array}$ & $\begin{array}{r}1 \% \\
0.05\end{array}$ \\
\hline
\end{tabular}

(a) U Undetected at or above detection limit. 


\section{APPENDIX D}

INTENSIVE STUDY OF THE TURNING BASIN SEDIMENT CHEMISTRY AND QUALITY ASSURANCE DATA 
QA/QC SUMMARY

PROGRAM:

PARAMETER: LABORATORY: MATRIX:
Richmond Harbor Deepening Project-Intensive Study of the Turning Basin

Grain Size

Soil Technology

Sediment

\section{SAMPLE CUSTODY}

Fourteen samples were received at Soil Technology on 10/25/94 in good condition. Samples were analyzed in one batch.

\section{QA/QC DATA QUALITY OBJECTIVES}

\begin{tabular}{|c|c|c|c|}
\hline Beference Method & $\begin{array}{r}\text { Range of } \\
\text { Recovery }\end{array}$ & Relative Precision & Detection Limit \\
\hline $\begin{array}{c}\text { PSEP } 1986 \\
\text { EPAVSACE } 1991\end{array}$ & Not applicable & $\begin{array}{l}\leq 20 \% \text { for fractions } \\
\text { greater than } 5 \%\end{array}$ & $1.0 \%$ \\
\hline
\end{tabular}

Sixteen grain size fractions were determined by a combination of sieve and pipette techniques. An additional measurement for salt content was performed and each grain size fraction was corrected for this salt measurement.

\section{HOLDING TIME}

The holding time of 6 months was met for all grain size analyses.

\section{REPLICATES}

A triplicate sample of one sample was analyzed with the samples. The precision criteria of $\leq 20 \%$ for the relative standard deviation (RSD) was met for the four main size fractions. One of the RSD values for the 16 size fractions was $30 \%$ which is outside the QC criteria.

\section{REFERENCES}

PSEP (Puget Sound Estuary Program). 1986. Recommended Protocols for Measuring Selected Environmental Variables in Puget Sound. Vols. 1 and 2. Prepared by Tetra Tech, Inc. for the Puget Sound Estuary Program, Bellevue, Washington.

U.S. Environmental Protection Agency/U.S. Army Corps of Engineers (EPA/USACE). 1991. Evaluation of Dredged Material Proposed for Ocean Disposal (Testing Manual).

EPA-68-C8-0105, U.S. Environmental Protection Agency, Office of Marine and Estuarine Protection, Washington, D.C. 


\section{QA/QC SUMMARY}

PROGRAM:

PARAMETER:

LABORATORY:

MATRIX:
Richmond Harbor Deepening Project-Intensive Study of the Turning Basin Total Organic Carbon (TOC)

Analytical Resources, Inc.

Sediment

\section{SAMPLE CUSTODY}

Eighteen samples were received at Analytical Resources, Inc. on 11/30/94 in good condition. Samples were analyzed in one batch.

\section{QA/QC DATA QUALITY OBJECTIVES}

\begin{tabular}{|c|c|c|c|}
\hline Reference Method & $\begin{array}{l}\text { Range of } \\
\text { Recovery }\end{array}$ & Relative Precision & Detection Limit \\
\hline Plumb 1981 & $\leq 20 \%$ & $\leq 10 \%$ & $0.1 \%$ \\
\hline
\end{tabular}

\section{METHOD}

Total organic carbon is the amount of non-volatile, partially volatile, volatile, and particulate organic carbon compounds in a sample. Each sample was dried and ball milled to a fine powder. Before combustion, inorganic carbon in the sample was removed by acidification. The TOC was then determination by measuring the carbon dioxide released during combustion of the sample.

\section{HOLDING TIME}

The holding time of 6 months was met for all TOC analyses.

\section{METHOD BLANKS}

The method blank analyzed with the samples was $0.002 \%$ TOC. No QC criteria are designated for TOC method blanks.

\section{REPLICATES}

One sample was analyzed in triplicate with the samples. The relative standard deviation was $13 \%$, which is above the relative precision criteria of $\leq 10 \%$.

\section{DETECTION LIMITS}

The achieved detection limit was lower than the target detection of $0.1 \%$ TOC.

\section{REFERENCE}

Plumb, R.H. Jr. 1981. Procedure for Handling and Chemical Analyses of Sediment and Water Samples. Technical Report EPAVCE-81-1, prepared for Great Lakes Laboratory, State University College at Buffalo, NY, for the U.S. Environmental Protection Agency/U.S. Army Corps of Engineers Technical Committee on Criteria for Dredged and Fill Material. Published by U.S. Army Corps of Engineers Waterways Experiment Station, Vicksburg, Mississippi. 


\section{QA/QC SUMMARY}

\section{PROGRAM: Richmond Harbor Deepening Project-Intensive Study of the}

PARAMETER: Total Volatile Solids (TVS)

LABORATORY: Analytical Resources, Inc.

MATRIX:

Sediment

\section{SAMPLE CUSTODY}

Fourteen samples were received at Analytical Resources, Inc. on 10/25/94 in good condition. Samples were analyzed in one batch.

\section{QA/QC DATA QUALITY OBJECTIVES}

\section{Reference Method}

EPA 160.4

\section{Range of \\ Recovery}

$N A$
Relative Precision

$\leq 20 \%$
Detection Limit

$0.1 \%$

\section{METHOD}

Total volatile solids are a measure of the fraction of total solids that are lost on ignition at higher temperature. First, the sample was oven dried to constant weight and then removed, weighed, and ignited at $550^{\circ} \mathrm{C}$. The sample was cooled in a desiccator and then reweighed. The amount of sample lost during ignition was defined as the volatile solids fraction.

\section{HOLDING TIME}

A holding time is not specified for TVS analyses.

\section{METHOD BLANKS}

One method blank was analyzed with the samples. No TVS were detected.

\section{REPLICATES}

One sample was analyzed in triplicate with the samples. The relative standard deviation was $7 \%$ which was within the QC criteria of $\leq 20 \%$.

\section{DETECTION LIMITS}

The achieved detection limit was lower the target detection limit of $0.1 \%$.

\section{REFERENCE}

U.S. Environmental Protection Agency (EPA. 1979. Methods for Chemical Analysis of Water and Wastes. EPA-600 4-79-020 Methods 160.4, 413.2, 418.1, Environmental Monitoring and Support Laboratory, Cincinnati, Ohio. 


\section{QA/QC SUMMARY}

PROGRAM:

PARAMETER:

LABORATORY:

MATRIX:
Richmond Harbor Deepening Project-Intensive Study of the

Turning Basin

Oil and Grease

Analytical Resources, Inc.

Sediment

\section{SAMPLE CUSTODY}

Fourteen samples were received at Analytical Resources, Inc. on 10/25/94 in good condition. Samples were analyzed in one batch.

\section{QA/QC DATA QUALITY OBJECTIVES}

$\begin{array}{cccc}\text { Reference Method } & \begin{array}{c}\text { Range of } \\ \text { Recovery }\end{array} \\ 418.1 & 50 \%-150 \%\end{array} \quad \frac{\text { Relative Precision }}{\leq 20 \%} \quad \frac{\text { Detection Limit }}{20 \mathrm{mg} / \mathrm{kg}}$

\section{METHOD}

Total oil and grease includes vegetable oils, animal fats, soaps, waxes, and any other carbonhydrogen material extractable by the solvent Freon. An aliquot of sample material was dried with anhydrous sodium sulfate and extracted with Freon. The extract was shaken, allowed to settle, removed, and scanned from 4000 to $600 \mathrm{~cm}^{-1}$ by infrared spectrophotometry (IR). The peak height measured at $2930 \mathrm{~cm}^{-1}$ was used to quantify the concentration of oil and grease in the sample.

\section{HOLDING TIME}

The samples were extracted and analyzed on 10/31/94, which is within the holding time of 28 days. There was blank contamination at concentrations above the detection limit. Therefore, the samples were re-extracted and re-analyzed until there was minimal or no blank contamination in the samples and the data presented is from the analysis on 12/27/94.

\section{METHOD BLANKS}

One procedural blank was processed with the samples. Concentrations of oil and grease were detected in the method blanks but at concentrations below the detection limit.

\section{MATRIX SPIKES}

One matrix spike (MS) was analyzed with the samples. The percent recovery was $99 \%$.

\section{REPLICATES}

One set of triplicates was analyzed with the samples. The relative standard deviation could not be calculated because the concentrations were all undetected at or below the detection limit.

\section{DETECTION LIMITS}

Achieved detection limits ranged from 10 to $18 \mathrm{mg} / \mathrm{kg}$, which are less than the target detection limit of $20 \mathrm{mg} / \mathrm{kg}$. 


\section{QA/QC SUMMARY}

PROGRAM:

PARAMETER:

LABORATORY:

MATRIX:
Richmond Harbor Deepening Project-Intensive Study of the Turning Basin Total Petroleum Hydrocarbons (TPH)

Analytical Resources, Inc.

Sediment

\section{SAMPLE CUSTODY}

Fourteen samples were received at Analytical Resources, Inc. on 10/25/94 in good condition. Samples were analyzed in one batch.

\section{QAJQC DATA QUALITY OBJECTIVES}

\section{Reference Method \\ Range of
Recovery}

418.1
$50 \%-150 \%$

\section{Relative Precision}

$\leq 20 \%$

\section{Detection Limit}

$20 \mathrm{mg} / \mathrm{kg}$

\section{METHOD}

Total petroleum hydrocarbons comprise the nonpolar mineral fraction of total oil and grease that is not removed by silica gel absorption. An aliquot of sample material was dried with anhydrous sodium sulfate and extracted with Freon. Silica gel was added to the extract to remove the more polar animal and vegetable based oils. The extract was shaken, allowed to settle, removed, and scanned from 4000 to $600 \mathrm{~cm}^{-1}$ by infrared spectrophotometry (IR). The peak height measured at $2930 \mathrm{~cm}^{-1}$ was used to quantify the concentration of hydrocarbons in the sample.

\section{HOLDING TIME}

The samples were extracted and analyzed on 10/31/94, which is within the holding time of 28 days. There was blank contamination at concentrations above the detection limit. Therefore, the samples were re-extracted and re-analyzed until there was minimal or no blank contamination in the samples and the data presented is from the analysis on 12/27/94.

\section{METHOD BLANKS}

One procedural blank was processed with the samples. Concentrations of TPH were detected in the method blanks but at concentrations below the detection limit.

\section{MATRIX SPIKES}

One matrix spike (MS) was analyzed with the samples. The percent recovery was $95 \%$.

\section{REPLICATES}

One set of triplicates was analyzed with the samples. The relative standard deviation could not be calculated because the concentrations were all undetected at or below the detection limit.

\section{DETECTION LIMITS}

Achieved detection limits ranged from 9.9 to $18 \mathrm{mg} / \mathrm{kg}$, which are less than the target detection limit of $20 \mathrm{mg} / \mathrm{kg}$. 


\section{QA/QC SUMMARY}

PROGRAM: Richmond Harbor Deepening Project - Intensive Study of the Turning Basin

P.ARAMETER: Polynuclear Aromatic Hydrocarbons (PAH)

LABORATORY: Battelle/Marine Sciences Laboratory, Sequim, Washington

MATRIX: Sediment

SAMPLE CUSTODY

Fourteen samples were received on 10/24/94 in good condition. Samples were assigned a Battelle Central File ID number and were logged into Battelle's log-in system.

QAVQ DATA QUALITY OBJECTIVES

$\begin{array}{ccccc}\begin{array}{c}\text { Reference } \\ \text { Method }\end{array} & \begin{array}{c}\text { Range of } \\ \text { Recovery }\end{array} & \begin{array}{c}\text { SRM } \\ \text { Accuracy }\end{array} & \begin{array}{c}\text { Relative } \\ \text { Precision }\end{array} & \begin{array}{c}\text { Detection } \\ \text { Limit (dry wt) }\end{array} \\ \text { GC/MS } & 40-120 \% & \leq 30 \% & \leq 30 \% & 20 \mu \mathrm{g} / \mathrm{kg}\end{array}$

\section{METHOD}

Sediment samples were extracted with methylene chloride using a roller under ambient conditions following a procedure based on methods used by the National Oceanic and Atmospheric Administration for their Status and Trends Program (Krahn et al, 1988). Samples were then cleaned using Silica/Alumina ( $5 \%$ deactivated) chromatography followed by HPLC cleanup (Krahn et al. 1988). Extracts were quantified using gas chromatography/mass spectrometry (GC/MS) in the selected ion mode (SIM) following a procedure based on EPA method 8270 (EPA 1986).

\section{HOLDING TIMES}

Samples were stored at approximately $-20^{\circ} \mathrm{C}$ until extraction. Samples were extracted on 11/3/94. Extracts were analyzed by GC/MS from 11/9-11/10/94.

\section{DETECTION LIMITS}

Target detection limits of $20 \mu \mathrm{g} / \mathrm{kg}$ dry wt. were met for all PAH compounds. Actual detection limits were determined from multiplying the standard deviation of 7 spiked sediment replicates by the student $t$-value.

\section{METHOD BLANKS}

One method blank was extracted with the samples. Five of the $16 \mathrm{PAH}$ compounds were detected in the method blank. Concentrations were less than 5 times the MDL for all compounds detected. Any sample value, however, that was less than 5 times the value in the method blank was flagged with a "B".

\section{SURROGATES}

Five isotopically labelled compounds were added prior to extraction to assess the efficiency of the method. These were d8-Naphthalene, d10-Acenaphthene, d12-Chrysene, d10-Perylene and d14-Dibenzo(a,h,i) Anthracene. Recoveries of all surrogates were within the quality control limits of $40-120 \%$. 


\section{QAVC SUMMARY (continued)}

\section{MATRIX SPIKES}

One sample was spiked with all PAH compounds. Matrix spike recoveries were within the control limits of $40-120 \%$ for all PAHs with the exception of pyrene and benzo(k)fluoranthene. Recoveries for these two compounds were $123 \%$ and $131 \%$ respectively.

\section{REPLICATES}

One sample was extracted in triplicate. Precision was measured by calculating the relative standard deviation (RSD) between the replicate results. All RSDs were within the control limit of $\leq 30 \%$.

\section{SRMs}

One SRM,1941, a marine sediment obtained by the National institute for Science and Technology was analyzed with the samples. Fourteen of the sixteen PAH compounds analyzed are certified. All PAHs were detected within $30 \%$ of the certified mean with the exception of anthracene, chrysene, benzo(b)fluoranthene, and dibenzo(a,h)anthracene.

\section{MISCELLANEOUS}

Some of the compounds are flagged to indicate that the ion ratio for that compound was outside of the QC range. This is due primarily to low levels of the compound of interest. Because the confirmation ion is present at only a fraction of the level of the parent ion, when the native level of the compound is low, the amount of error in the concentration measurement of the confirmation ion goes up. The compound is actually quantified from the parent ion only so most likely this will not effect the quality of the data. For sample values that are relatively high ( $>5$ times the MDL), it may be an indication of some sort of interference.

\section{REFERENCES}

Krahn, M.M., C.A. Wigren, R.W. Pearce, L.K. Moore, R.G. Bogar, W.D. MacLeod, Jr., S.L. Chan, and D.W. Brown. 1988. "New HPLC Cleanup and Revised Extraction Procedures for Organic Contaminants." NOAA Technical Memorandum NMFS f/NWC-153. NOAANMFS/NWFSC, Seattle, Washington.

U.S. Environmental Protection Agency (EPA). 1986. Test Methods for Evaluating Solid Waste: Physical/Chemical Methods. SW-846. EPA-955-001-00000, U.S. Government Printing Office, Washington D.C. 


\section{QA/QC SUMMARY}

PROGRAM: Richmond Harbor Deepening Project - Intensive Study of the

Turning Basin

PARAMETER: Chlorinated Pesticides and Polychlorinated Biphenyls (PCBs)

LABORATORY: Battelle/Marine Sciences Laboratory, Sequim, Washington

MATRIX:

Sediment

\section{SAMPLE CUSTODY}

Fourteen samples were received on 10/24/94 in good condition. Samples were assigned a Battelle Central File ID number and were logged into Battelle's log-in system.

QAVQC DATA QUALITY OBJECTIVES

\begin{tabular}{cccccc} 
Pesticides & $\begin{array}{c}\text { Reference } \\
\text { Method }\end{array}$ & $\begin{array}{c}\text { Range of } \\
\text { Recovery }\end{array}$ & $\begin{array}{c}\text { SRM } \\
\text { Accuracy }\end{array}$ & $\begin{array}{c}\text { Relative } \\
\text { Precision }\end{array}$ & $\begin{array}{c}\text { Detection } \\
\text { Limit (dry wt) }\end{array}$ \\
\hline GCDD & $40-120 \%$ & $\leq 30 \%$ & $\leq 30 \%$ & $2.0-30 \mu \mathrm{g} / \mathrm{kg}$
\end{tabular}

\section{METHOD}

Sediment samples were extracted with methylene chloride using a roller under ambient conditions following a procedure based on EPA method 3510 and 8080 (EPA1986) and NOAA status and trends methodology (Krahn et al. 1988). Samples were then cleaned using Silica/Alumina ( $5 \%$ deactivated) chromatography followed by HPLC cleanup (Krahn et al. 1988). Extracts were analyzed using Gas Chromatography/Electron Capture Detection (GC/ECD) following a procedure based on EPA method 8080 (1986). The column used was a J\&W DB-17 and the confirmatory column was a DB-1701, both capillary columns $(30 \mathrm{~m} \times 0.25 \mathrm{~mm} 1 . D$.).

\section{HOLDING TIMES}

Samples were stored at approximately $-20^{\circ} \mathrm{C}$ until extraction. Samples were extracted on 11/3/94. Extracts were analyzed by GC/ECD on 11/12-13/94.

\section{DETECTION LIMITS}

Target detection limits were met for all samples. Actual detection limits were determined from multiplying the standard deviation of 7 spiked sediment replicates by the student $t$-value.

\section{METHOD BLANKS}

One method blank was extracted with the extraction batch. No pesticides or PCBs were detected in the blank.

\section{SURROGATES}

Two compounds, PCB congeners 103 and 198, were added to all samples prior to extraction to assess the efficiency of the analysis. These compounds are also used to correct all sample results and are considered surrogate internal standards (SIS). Sample surrogate recoveries for these compounds were within the control limits of $40-120 \%$. 


\section{QA/QC SUMMARY/PCBs (continued)}

\section{MATRIX SPIKES}

One sample was spiked with a subset of 6 pesticides and Aroclor 1254. Matrix spike recoveries were within the control limits of $40-120 \%$ for all spiked compounds with the exception of 4,4'-DDT that had a recovery of $135 \%$.

\section{REPLICATES}

One sample was extracted in triplicate. Precision was measured by calculating the relative standard deviation (RSD) between the replicate results. No pesticides or PCBs were detected in any of the replicates; therefore, no RSD values were calculated.

\section{SRMs}

One SRM,1941, a marine sediment obtained by the National Institute for Science and Technology was analyzed with the samples. Only two pesticides are certified. The recovery of $4,4^{\prime}-$ DDD was within the control limit of $\leq 30 \%$ and the recovery of $4,4^{\prime}$-DDE was $34 \%$.

\section{MISCELLANEOUS}

All pesticide and PCB detections are confirmed on a secondary column. The RPD criteria is $67 \%$.

\section{REFERENCES}

Krahn, M.M., C.A. Wigren, R.W. Pearce, L.K. Moore, R.G. Bogar, W.D. MacLeod, Jr., S.L. Chan, and D.W. Brown. 1988, "New HPLC Cleanup and Revised Extraction Procedures for Organic Contaminants." NOAA Technical Memorandum NMFS f/NWC-153. NOAANMFS/NWFSC, Seattle, Washington.

U.S. Environmental Protection Agency (EPA). 1986. Test Methods for Evaluating Solid Waste: Physical/Chemical Methods. SW-846. EPA-955-001-00000, U.S. Government Printing Office, Washington D.C. 


\section{QA/QC SUMMARY}

PROGRAM: Richmond Harbor Deepening Project - Intensive Study of the Turning Basin

PARAMETER: Metals

LABORATORY: Battelle/Marine Sciences Laboratory, Sequim, Washington MATRIX: Sediment

\section{SAMPLE CUSTODY}

Fourteen samples were received on 10/24/94 in good condition. Samples were assigned a Battelle Central File ID number and were logged into Battelle's log-in system.

\section{QAVQ DATA QUALITY OBJECTIVES}

\begin{tabular}{|c|c|c|c|c|c|}
\hline & $\begin{array}{l}\text { Reference } \\
\text { Method } \\
\end{array}$ & $\begin{array}{r}\text { Range of } \\
\text { Recovery }\end{array}$ & $\begin{array}{c}\text { SRM } \\
\text { Accuracy }\end{array}$ & $\begin{array}{l}\text { Relative } \\
\text { Precision }\end{array}$ & $\begin{array}{c}\text { Detection } \\
\text { Limit (dry wt) }\end{array}$ \\
\hline $\begin{array}{l}\text { Arsenic } \\
\text { Cadmium } \\
\text { Chromium } \\
\text { Copper } \\
\text { Lead } \\
\text { Mercury } \\
\text { Nickel } \\
\text { Selenium } \\
\text { Silver } \\
\text { Zinc }\end{array}$ & $\begin{array}{c}\text { XRF } \\
\text { GFAA } \\
\text { XRF } \\
\text { XRF } \\
\text { XRF } \\
\text { CVAA } \\
\text { XRF } \\
\text { GFAA } \\
\text { GFAA } \\
\text { XRF }\end{array}$ & $\begin{array}{c}\text { NA } \\
75-125 \\
\text { NA } \\
\text { NA } \\
\text { NA } \\
75-125 \\
\text { NA } \\
75-125 \\
75-125 \\
\text { NA }\end{array}$ & $\begin{array}{l}\leq 30 \% \\
\leq 30 \% \\
\leq 30 \% \\
\leq 30 \% \\
\leq 30 \% \\
\leq 30 \% \\
\leq 30 \% \\
\leq 30 \% \\
\leq 30 \% \\
\leq 30 \%\end{array}$ & $\begin{array}{l}\leq 20 \% \\
\leq 20 \% \\
\leq 20 \% \\
\leq 20 \% \\
\leq 20 \% \\
\leq 20 \% \\
\leq 20 \% \\
\leq 20 \% \\
\leq 20 \% \\
\leq 20 \%\end{array}$ & $\begin{array}{l}2.5 \\
0.1 \\
33 \\
5.5 \\
6.2 \\
0.01 \\
7.5 \\
0.1 \\
0.02 \\
7.8\end{array}$ \\
\hline
\end{tabular}

\section{METHOD}

A total of ten (10) metals were analyzed for the Richmond Harbor Deepening project: silver (Ag), arsenic (As), cadmium (Cd), chromium (Cr), copper ( $\mathrm{Cu}$ ), mercury ( $\mathrm{Hg}$ ), nickel (Ni), lead ( $\mathrm{Pb}$ ), selenium (Se), and zinc ( $\mathrm{Zn}$ ). Six metals, $\mathrm{As}, \mathrm{Cr}, \mathrm{Cu}, \mathrm{Ni}, \mathrm{Pb}$, and $\mathrm{Zn}$, were analyzed by energy diffusive $x$-ray fluorescence (XRF) following a PNL SOP. Three metals, Ag, Cd, and Se, were analyzed using Zeeman Graphite Furnace Atomic Absorption (GFAA) spectrometry following the EPA Method 200.9 (EPA 1991). Mercury was analyzed using cold-vapor atomic absorption spectroscopy (CVAA) according to the method of Bloom and Crecelius (1983).

To prepare sediments for analysis, samples were freeze-dried and blended in a Spex mixer-mill. Approximately $5 \mathrm{~g}$ of mixed sample was ground in a ceramic ball mill. The XRF analysis was performed on a 0.5-g aliquot of dried, ground material pressed into a pellet with a diameter of $2 \mathrm{~cm}$. For GFAA and CVAA analyses, 0.2- to 0.5-g aliquots of dried homogenous sample were digested using a mixture of nitric/perchloric and hydrofluoric acids. 


\section{QAVQC SUMMARY (continued)}

\section{HOLDING TIMES}

Upon receipt, samples were frozen to $-80^{\circ} \mathrm{C}$ and subsequently freeze dried within approximately 14 days of sample receipt. Samples were all analyzed within 180 days of receipt. Analysis dates are summarized in the following table:

Task

Sample Digestion

XRF

GFAAAg

GFAAVC

GFAASe

CVAA-Hg
Date Performed

$11 / 16 / 94$

$11 / 29-30 / 94$

$12 / 6 / 94$

$12 / 6 / 94$

$12 / 6 / 94$

$12 / 12 / 94$

\section{DETECTION LIMITS}

Target detection limits were met for all metals except Se. The actual detection limit for Se was 0.17 which slightly exceeded the target limit of 0.10 . The method detection limits for XRF and CVAA were determined by multiplying the standard deviation of 7 replicate analyses of an SRM by 3 . The method detection limits for GFAA represent 3 times the standard deviation of 3 replicate analyses of the method blank.

\section{METHOD BLANKS}

One method blank was analyzed with the samples. The metals $\mathrm{Ag}$ and $\mathrm{Cd}$ were detected in the blank at approximately 3 times the MDL, which is less than the acceptable limit. All sample results for $\mathrm{Ag}$ and $\mathrm{Cd}$ are blank corrected. Method blanks are not analyzed by XRF; therefore, no blank results are reported for XRF metals.

\section{MATRIX SPIKES}

One sample was spiked with four metals ( $\mathrm{Ag}, \mathrm{Cd}, \mathrm{Hg}$, and $\mathrm{Se})$. All spike recoveries were within the control limits of $75-125 \%$.

\section{REPLICATES}

One sample was digested and analyzed in triplicate. Precision was measured by calculating the relative standard deviation (RSD) between the replicate results. All RSDs were within the control limits of $\leq 20 \%$ with the exception of $\mathrm{Hg}$.

\section{SRMs}

One sample of SRM 1646 (an estuarine sediment obtained from the National Research Council of Canada, NRCC), was analyzed with the samples for all metals. All results were within $30 \%$ of the certified value. A second SRM, BEST-1 (an estuarine sediment obtained from the National Research Council of Canada, NRCC), was also analyzed for $\mathrm{Hg}$ only. The result for BEST was within the QC limits. 


\section{QA/QC SUMMARY (continued)}

\section{REFERENCES}

Bloom, N. S., and E.A. Crecelius. 1983. "Determination of Mercury in Seawater at SubNanogram per Liter Levels." Marine Chemistry 21:337-390.

U.S. Environmental Protection Agency (EPA). 1991. Methods for the Detemination of Metals in Environmental Samples. EPA-600/4-91-010 Methods 200.8, 200.9, Environmental Services

Division, Monitoring Management Branch, Cincinnati, Ohio. 


\section{QA/QC SUMMARY}

PROGRAM: Richmond Harbor Deepening Project - Intensive Study of the PARAMETER: Turning Basin
LABORATORY:
MATRIX:
Battelle/Marine Sciences Laboratory, Sequim, Washington
Sediment

Butyltins

\section{SAMPLE CUSTODY}

Fourteen samples were received on 10/24/94 in good condition. Samples were assigned a Battelle Central File ID number and were logged into Battelle's log-in system.

\section{QAVQ DATA QUALITY OBJECTIVES}

$\begin{array}{ccccc}\begin{array}{c}\text { Reference } \\ \text { Method }\end{array} & \begin{array}{c}\text { Range of } \\ \text { Recovery }\end{array} & \begin{array}{c}\text { SRM } \\ \text { Accuracy }\end{array} & \begin{array}{c}\text { Relative } \\ \text { Precision }\end{array} & \begin{array}{c}\text { Detection } \\ \text { Limit (dry weight) }\end{array} \\ \text { Unger et al. } & 40-120 \% & \leq 30 \% & \leq 30 \% & 1 \mu \mathrm{g} / \mathrm{kg}\end{array}$

\section{METHOD}

Butyltin analyses were performed according to a procedure following the method of Unger et al. (1986). Sediment samples were extracted with methylene chloride using a roller under ambient conditions followed by derivitization using a Grignard reagent to change to a form compatible with gas chromatography. Sample extracts were then cleaned by passing through a florisil column. Extracts were analyzed using Gas Chromatography/Flame Photometric Detection (GC/FPD).

\section{HOLDING TIMES}

Samples were stored at approximately $-20^{\circ} \mathrm{C}$ until extraction. Samples were extracted on 10/31/94 and analyzed on 11/4/94. Hölding times were met.

\section{DETECTION LIMITS}

Target detection limits of $1 \mu \mathrm{g} / \mathrm{kg}$ dry wt. were met for di- and tributyltin compounds. Actual detection limits were determined from multiplying the standard deviation of 7 spiked sediment replicates by the student t-value.

\section{METHOD BLANKS}

One method blank was extracted with the samples and no butyltins were detected in the blanks.

\section{SURROGATES}

One compound, tripentyltin chloride, was added to all samples prior to extraction to assess the efficiency of the method. This compound is also used as an internal standard as all data is corrected for the recovery of the compound. Surrogate recoveries were within the QC limits of $40-120 \%$ for all samples. 


\section{QAVC SUMMARY (continued)}

\section{MATRIX SPIKES}

One sample was spiked with tri- and dibutyltin. Matrix spike recoveries for tri- and dibutyltin were within the control limits of $40-120 \%$.

\section{REPLICATES}

One sample was extracted and analyzed in triplicate. Precision was measured by calculating the relative standard deviation (RSD) between the replicate results. The RSD values were within the control limits of $\leq 30 \%$.

\section{SRMS}

The SRM, PACS-1, is an estuarine sediment obtained from the National Canadian Research Council (NRCC) and was analyzed along with the samples from each batch. The results for diand tributyltin were within $30 \%$ of the certified mean value.

NOTE: Monobutyltin results are provided for information only. Recoveries of monobutyltin are low due to the nature and the low efficiency of extraction of this compound. This is evidenced by the low matrix spike and SRM recoveries.

\section{REFERENCES}

Unger, M.A., W.G. Maclntyre, J. Reaves and R.J. Huggett. 1986. "GC Determination of Butyltins in Natural Waters by Flame Photometric Detection of Hexyl Derivatives with Mass Spectrometric Confirmation." Chemosphere. 15(4):461-470. 
TABLE D.1. Summary of Sediment Grain Size Including Quality Control Data, Richmond Harbor Deepening Project-Intensive Study of the Turning Basin

\begin{tabular}{|c|c|c|c|c|}
\hline \multirow[b]{2}{*}{$\begin{array}{l}\text { Sediment } \\
\text { Treatment }\end{array}$} & \multicolumn{4}{|c|}{ Total Percent (dry weight) } \\
\hline & $\begin{array}{c}\text { Gravel } \\
>2000 \mu \mathrm{m}\end{array}$ & $\begin{array}{c}\text { Sand } \\
62.5- \\
2000 \mu \mathrm{m} \\
\end{array}$ & $\begin{array}{c}\text { Silt } \\
3.9- \\
62.5 \mu \mathrm{m} \\
\end{array}$ & $\begin{array}{c}\text { Clay } \\
<3.9 \mu \mathrm{m} \\
\end{array}$ \\
\hline TB-1 Lower & 13 & 49 & 23 & 15 \\
\hline TB-2 Lower & 3 & 18 & 47 & 32 \\
\hline TB-3 Lower & 1 & 15 & 50 & 34 \\
\hline TB-4 Middle, Replicate 1 & 0 & 4 & 49 & 47 \\
\hline TB-4 Middle, Replicate 2 & 0 & 4 & 48 & 48 \\
\hline TB-4 Middle, Replicate 3 & 0 & 4 & 47 & 49 \\
\hline TB-4 Lower & 0 & 10 & 44 & 46 \\
\hline TB-5 Lower & 0 & 7 & 54 & 39 \\
\hline TB-6 Lower & 1 & 5 & 40 & 54 \\
\hline TB-7 Lower & 1 & 7 & 53 & 39 \\
\hline TB-8 Lower & 0 & 6 & 55 & 39 \\
\hline TB-9 Lower & 0 & 15 & 44 & 41 \\
\hline OBM COMP & 0 & 18 & 56 & 26 \\
\hline R-OS & 0 & 26 & 53 & 21 \\
\hline R-BF & 0 & 1 & 39 & 60 \\
\hline R-AM & 0 & 99 & 0 & 1 \\
\hline
\end{tabular}

Quality Control Data

Analytical Replicates

TB-4 Middle, Replicate 1

TB-4 Middle, Replicate 2

TB-4 Middle, Replicate 3

RSD

\begin{tabular}{|c|c|c|}
\hline 0 & 4 & 49 \\
\hline 0 & 4 & 48 \\
\hline 0 & 4 & 47 \\
\hline$J A^{(a)}$ & $0 \%$ & $2 \%$ \\
\hline
\end{tabular}

(a) NA Not applicable.

D.1 


\begin{tabular}{|c|c|c|c|c|c|c|c|c|c|c|c|c|c|c|c|c|}
\hline \multirow{4}{*}{$\begin{array}{l}\text { Sediment } \\
\text { Treatment }\end{array}$} & Basin & & & & & & & ercenta & Size Fra & iton & & & & & & \\
\hline & phi & & & & & & 4 & 4.5 & 5 & 5.5 & 6 & 7 & 8 & 9 & 10 & 11 \\
\hline & $\mu \mathrm{m}$ & 3350 - & 2000- & $1000-$ & $250-$ & $125-$ & 62.5- & 48- & 31.2- & 23. & 15.6- & $7.8-$ & $3.9-$ & 1.9- & 0.9 - & \\
\hline & & & & & & & & & & & & & & & & $<0.4$ \\
\hline TB-1 Lower & 9 & 4 & 3 & 8 & 14 & 24 & 6 & 4 & 3 & 2 & 5 & 3 & 3 & 3 & 1 & 8 \\
\hline TB-2 Lower & 3 & 0 & 1 & 3 & 6 & 8 & 8 & 9 & 6 & 7 & 10 & 7 & 6 & 5 & 5 & 16 \\
\hline TB-3 Lower & 1 & 0 & 0 & 3 & 5 & 7 & 7 & 9 & 9 & 7 & 11 & 7 & 6 & 6 & 5 & 17 \\
\hline TB-4 Middle, Replicate 1 & 0 & 0 & 0 & 0 & 1 & 3 & 8 & 9 & 6 & 6 & 9 & 11 & 8 & 10 & 7 & 22 \\
\hline TB-4 Middle, Replicate 2 & 0 & 0 & 0 & 0 & 1 & 3 & 11 & 6 & 5 & 6 & 10 & 10 & 9 & 9 & 7 & 23 \\
\hline TB-4 Middle, Replicate 3 & 0 & 0 & 0 & 0 & 1 & 3 & 6 & 8 & 7 & 6 & 10 & 10 & 9 & 10 & 6 & 24 \\
\hline TB-4 Lower & 0 & 0 & 0 & 0 & 1 & 9 & 13 & 3 & 4 & 5 & 9 & 10 & 9 & 8 & 7 & 22 \\
\hline TB-5 Lower & 0 & 0 & 0 & 2 & 2 & 3 & 9 & 11 & 6 & 8 & 11 & 9 & 7 & 7 & 4 & 21 \\
\hline TB-6 Lower & 0 & 1 & 0 & 1 & 1 & 3 & 5 & 2 & 4 & 4 & 12 & 13 & 10 & 11 & 7 & 26 \\
\hline TB-7 Lower & 1 & 0 & 0 & 1 & 3 & 3 & 7 & 8 & 9 & 7 & 13 & 9 & 7 & 7 & 5 & 20 \\
\hline TB-8 Lower & 0 & 0 & 0 & 1 & 1 & 4 & 8 & 9 & 9 & 8 & 12 & 9 & 7 & 7 & 5 & 20 \\
\hline TB-9 Lower & 0 & 0 & 0 & 2 & 2 & 11 & 9 & 6 & 4 & 5 & 10 & 10 & 8 & 8 & 5 & 20 \\
\hline OBM СОMP & 0 & 0 & 1 & 1 & 2 & 14 & 14 & 9 & 8 & 7 & 10 & 8 & 5 & 5 & 4 & 12 \\
\hline R-OS & 0 & 0 & 0 & 1 & 2 & 23 & 28 & 8 & 5 & 4 & 4 & 4 & 3 & 5 & 3 & 10 \\
\hline R-BF & 0 & 0 & 0 & 0 & 1 & 0 & 3 & 6 & 5 & 5 & 9 & 11 & 12 & 11 & 10 & 27 \\
\hline R-AM & 0 & 0 & 0 & 86 & 12 & 1 & 0 & 0 & 0 & 0 & 0 & 0 & 0 & 0 & 0 & 1 \\
\hline
\end{tabular}

\section{Quality Control Data}

\section{Analytical Repllicates}

TB-4 Middle, Replicate 1 TB-4 Middle, Replicate 2 TB-4 Middle, Replicate 3

RSD

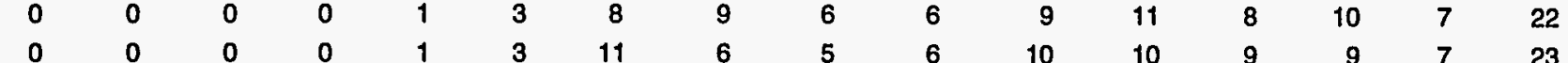

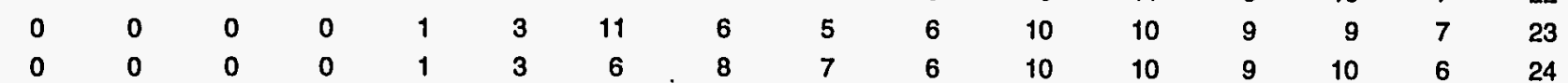

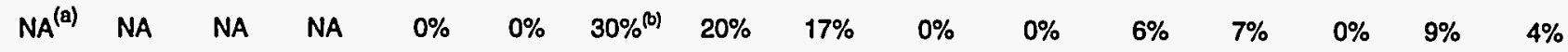

(a) NA Not applicable.

(b) Value exceeds relative precision goal of $\leq 20 \%$. 
TABLE D.3. Sediment Total Organic Carbon (TOC), Total Percent Solids, and Total Volatile Solids (TVS), Richmond Harbor Deepening Project-Intensive Study of the Turning Basin

\begin{tabular}{|c|c|c|c|}
\hline \multirow[b]{2}{*}{$\begin{array}{l}\text { Sediment } \\
\text { Treatment }\end{array}$} & \multicolumn{2}{|c|}{ (percent dry weight) } & \multirow[b]{2}{*}{$\begin{array}{l}\text { Total } \\
\text { Volatile } \\
\text { Solids } \\
\end{array}$} \\
\hline & TOC & $\begin{array}{c}\text { Total } \\
\text { Solids } \\
\end{array}$ & \\
\hline Method DL ${ }^{\text {(a) }}$ & 0.1 & 0.01 & 0.1 \\
\hline Achieved DL & 0.002 & 1.0 & 1.0 \\
\hline TB-1 Lower & 0.11 & 80.8 & 0.79 \\
\hline TB-2 Lower & 0.67 & 64.2 & 2.3 \\
\hline TB-3 Lower & 0.67 & 59.5 & 2.1 \\
\hline TB-4 Middle & 1.1 & 50.6 & 2.6 \\
\hline TB-4 Lower & 0.58 & 60.5 & 2.1 \\
\hline TB-5 Lower & 0.90 & 58.4 & 2.2 \\
\hline TB-6 Lower & 0.81 & 58.1 & 2.6 \\
\hline TB-7 Lower & 0.70 & 64.4 & 2.4 \\
\hline TB-8 Lower & 0.76 & 65.2 & 2.6 \\
\hline TB-9 Lower & 0.59 & 61.5 & 2.1 \\
\hline OBM & 0.16 & 74.1 & 1.9 \\
\hline OBM-0.4\% TOC ${ }^{(b)}$ & 0.24 & $N A^{(c)}$ & NA \\
\hline OBM-0.6\% TOC ${ }^{(b)}$ & 0.27 & NA & NA \\
\hline OBM-1.0\% TOC ${ }^{(b)}$ & 0.39 & NA & NA \\
\hline OBM-1.4\% TOC ${ }^{(b)}$ & 0.44 & NA & NA \\
\hline R-OS & 1.0 & 53 & 2.4 \\
\hline R-BF & 1.4 & 36.5 & 2.3 \\
\hline R-AM, Replicate 1 & 0.096 & 82.1 & 0.5 \\
\hline R-AM, Replicate 2 & 0.096 & 82.6 & 0.6 \\
\hline
\end{tabular}

(a) DL Detection limit.

(b) Prior to analysis, TOC was estimated in the OBM sediments; the actual values obtained from analysis are shown in the TOC column.

(c) NA Not applicable. 
IABLE D.4. Quality Control Data for Sediment Total Organic Carbon (TOC), Total Percent Solids, and Total Volatile Solids (TVS), Richmond Harbor Deepening Project-Intensive Study of the Turning Basin

\begin{tabular}{|c|c|c|c|}
\hline \multirow[b]{2}{*}{$\begin{array}{l}\text { Sediment } \\
\text { Treatment }\end{array}$} & \multicolumn{3}{|c|}{ (percent dry weight) } \\
\hline & TOC & $\begin{array}{l}\text { Total } \\
\text { Percent } \\
\text { Solids } \\
\end{array}$ & $\begin{array}{l}\text { Total } \\
\text { Volatile } \\
\text { Solids } \\
\end{array}$ \\
\hline \multicolumn{4}{|l|}{ Method Blank } \\
\hline Blank & 0.0018 & $1.0 \mathrm{mg} \mathrm{U}^{(\mathrm{a})}$ & $1.0 \mathrm{mg} \mathrm{U}$ \\
\hline \multicolumn{4}{|l|}{ Matrix Spike } \\
\hline $\begin{array}{l}\text { R-AM } \\
\text { R-AM, MS } \\
\text { Concentration Recovered } \\
\text { Amount Spiked } \\
\text { Percent Recovery }\end{array}$ & $\begin{array}{l}0.0962 \\
0.681 \\
0.585 \\
0.547 \\
107 \%\end{array}$ & $\begin{array}{l}\text { NA }{ }^{(0)} \\
N A \\
N A \\
N S^{(c)} \\
N A\end{array}$ & $\begin{array}{l}\text { NA } \\
\text { NA } \\
\text { NA } \\
\text { NS } \\
\text { NA }\end{array}$ \\
\hline $\begin{array}{l}\text { R-AM } \\
\text { R-AM, MSD } \\
\text { Concentration Recovered } \\
\text { Amount Spiked } \\
\text { Percent Recovery }\end{array}$ & $\begin{array}{l}0.0962 \\
0.782 \\
0.686 \\
0.711 \\
96 \%\end{array}$ & $\begin{array}{l}\text { NA } \\
\text { NA } \\
\text { NA } \\
\text { NS } \\
\text { NA }\end{array}$ & $\begin{array}{l}\text { NA } \\
\text { NA } \\
\text { NA } \\
\text { NS } \\
\text { NA }\end{array}$ \\
\hline RPD & $10 \%$ & NA & NA \\
\hline \multicolumn{4}{|l|}{ Standard Reference Material } \\
\hline MESS-1 & $2.80^{(d)}$ & NA & NA \\
\hline \multicolumn{4}{|l|}{ Certified value } \\
\hline $\begin{array}{l}\text { NBS } 2704 \\
\text { NBS } 2704\end{array}$ & $\begin{array}{l}2.87 \\
3.37\end{array}$ & $\begin{array}{l}\text { NA } \\
\text { NA }\end{array}$ & $\begin{array}{l}\text { NA } \\
\text { NA }\end{array}$ \\
\hline \multicolumn{4}{|l|}{ Analytical Replicates } \\
\hline $\begin{array}{l}\text { R-AM, Replicate } 1 \\
\text { R-AM, Replicate } 2 \\
\text { R-AM, Replicate } 3\end{array}$ & $\begin{array}{l}0.096 \\
0.096 \\
0.12\end{array}$ & $\begin{array}{r}82.1 \\
82.6 \\
\text { NA }\end{array}$ & $\begin{array}{l}0.5 \\
0.6 \\
\text { NA }\end{array}$ \\
\hline RSD/RPD & $13 \%$ & $.6 \%$ & $18 \%$ \\
\hline
\end{tabular}
(a) $U$ Undetected at or above detection limit.
(b) NA Not applicable.
(c) NS Not spiked.
(d) MESS- 1 is not certified for TOC, but frequent analysis at MSL indicates a value of $2.6 \%$. 
TABLE D.5. Sediment Oil \& Grease and Total Petroleum Hydrocarbons (TPH) Results, Richmond Harbor Deepening Project-Intensive Study of the Turning Basin

\begin{tabular}{lcc} 
& \multicolumn{2}{c}{ (mg/kg dry weight) } \\
\cline { 2 - 3 } $\begin{array}{l}\text { Oil and } \\
\text { Grease }\end{array}$ & TPH \\
\hline Treatment & 20 & 20 \\
Method DL (a) & $10-18$ & $9.9-18$ \\
Achieved DL & & \\
TB-1 Lower & 14 & $9.9 \mathrm{U}$ \\
TB-2 Lower & 50 & 27 \\
TB-3 Lower & 40 & $16 \mathrm{U}$ \\
TB-4 Middle & $18 \mathrm{U}(\mathrm{p})$ & $18 \mathrm{U}$ \\
TB-4 Lower & $16 \mathrm{U}$ & $16 \mathrm{U}$ \\
TB-5 Lower & 56 & 58 \\
TB-6 Lower & $17 \mathrm{U}$ & $17 \mathrm{U}$ \\
TB-7 Lower & $15 \mathrm{U}$ & $15 \mathrm{U}$ \\
TB-8 Lower & 43 & $16 \mathrm{U}$ \\
TB-9 Lower & 20 & $16 \mathrm{U}$ \\
& & \\
OBM & $11 \mathrm{U}$ & $11 \mathrm{U}$ \\
R-OS & 100 & 77 \\
R-BF & 130 & 100 \\
R-AM & $10 \mathrm{U}$ & $10 \mathrm{U}$ \\
\hline
\end{tabular}

(a) DL Detection limit.

(b) $U$ Undetected at or above detection limit. 
TABLE D.6. Quality Control Data for Sediment Oil \& Grease and Total Petroleum Hydrocarbons (TPH) Analysis, Richmond Harbor Deepening ProjectIntensive of the Turning Basin

Sediment

Treatment

Method Blank

Blank

Matrix Spike

R-AM

R-AM

Concentration Recovered

Amount Spiked

Percent Recovery

Analytical Replicates

R-AM, Replicate 1

R-AM, Replicate 2

R-AM, Replicate 3

RSD

(a) U Undetected at or above detection limit.

(b) NA Not applicable. (mg/kg dry weight)

Oil and

Grease

TPH

13

11

$\begin{array}{rc}10 U & 10 U^{(a)} \\ 11 U & 11 U \\ 12700 & 10600 \\ 12800 & 11100 \\ 99 \% & 95 \%\end{array}$

$11 \mathrm{U}$

$11 \mathrm{U}$

$11 \mathrm{U}$

$11 \mathrm{U}$

$10 U$

$10 \mathrm{U}$

$N A^{\text {(b) }}$

NA 
TABLE D.7. Total Polynuclear Aromatic Hydrocarbons (PAHs) Found in Sediment, Richmond Harbor Deepening Project-Intensive Study of the Tuming Basin

\begin{tabular}{lccc}
$\begin{array}{l}\text { Sediment } \\
\text { Treatment }\end{array}$ & $\begin{array}{c}\text { Total } \\
\text { Low Molecular } \\
\text { Weight PAHs }\end{array}$ & $\begin{array}{c}\text { Total } \\
\text { Low Molecular } \\
\text { Weight PAHs }\end{array}$ & $\begin{array}{c}\text { Total } \\
\text { PAHs }\end{array}$ \\
\hline TB-1 Lower & 17 & & \\
TB-2 Lower & 22 & 37 & 54 \\
TB-3 Lower & 38 & 36 & 58 \\
TB-4 Lower & 47 & 58 & 96 \\
TB-4 Middle & 339 & 66 & 113 \\
TB-5 Lower & 51 & 2355 & 2694 \\
TB-6 Lower & 52 & 62 & 113 \\
TB-7 Lower & 35 & 67 & 119 \\
TB-8 Lower & 38 & 69 & 104 \\
TB-9 Lower, Replicate 1 & 43 & 67 & 105 \\
TB-9 Lower, Replicate 2 & 40 & 65 & 108 \\
TB-9 Lower, Replicate 3 & 46 & 63 & 103 \\
OBM COMP & 29 & 58 & 104 \\
R-OS & 65 & 28 & 57 \\
R-BF & 355 & 124 & 189 \\
R-AM & 538 & 2116 & 2471 \\
& & 1055 & 1593
\end{tabular}


TABLE D.8. Low Molecular Weight Polynuclear Aromatic Hydrocarbons (LPAHs), Richmond Harbor Deepening Project-Intensive Study of the Turning Basin

\begin{tabular}{|c|c|c|c|c|c|c|}
\hline \multirow[b]{2}{*}{$\begin{array}{l}\text { Sediment } \\
\text { Treatment }\end{array}$} & \multicolumn{6}{|c|}{ LPAHs ( $\mu \mathrm{g} / \mathrm{kg}$ dry weight) } \\
\hline & $\begin{array}{l}\text { Naphtha- } \\
\text { lene }\end{array}$ & $\begin{array}{l}\text { Acenaph- } \\
\text { thylene }\end{array}$ & $\begin{array}{c}\text { Acenaph- } \\
\text { thene }\end{array}$ & Fluorene & $\begin{array}{l}\text { Phenan- } \\
\text { threne }\end{array}$ & $\begin{array}{c}\text { Anthra- } \\
\text { cene }\end{array}$ \\
\hline Target $\mathrm{DL}^{(\mathbf{a})}$ & 20 & 20 & 20 & 20 & 20 & 20 \\
\hline Achieved DL & $1.13-2.97$ & $1.02-2.70$ & $0.68-1.78$ & $1.47-3.89$ & $2.04-5.39$ & $2.18-5.75$ \\
\hline TB-1 Lower & $8.08 \mathrm{~B}^{(\mathrm{b})(\mathrm{c})}$ & $1.83 U^{(d)}$ & $1.64 \mathrm{U}$ & $3.27 \mathrm{U}$ & $8.93 \mathrm{~B}$ & $4.69 \mathrm{U}$ \\
\hline TB-2 Lower & $7.24 \mathrm{~B}$ & $1.47 \mathrm{U}$ & $1.32 \mathrm{U}$ & 3.37 & $11.1 \mathrm{~B}$ & $3.77 \mathrm{U}$ \\
\hline TB-3 Lower & $11.3 \mathrm{~B}$ & $2.34 \mathrm{U}$ & 5.32 & 4.97 & $16.2 \mathrm{~B}$ & $6.00 \mathrm{U}$ \\
\hline TB-4 Lower & $13.6 \mathrm{~B}$ & $2.31 \mathrm{U}$ & 5.31 & 5.72 & $15.9 \mathrm{~B}^{(\mathrm{c})}$ & 6.32 \\
\hline TB-4 Middle & 52.1 & 18.3 & 13.6 & 17.8 & 173 & 64.2 \\
\hline TB-5 Lower & $13.5 \mathrm{~B}$ & $2.40 \mathrm{U}$ & $5.61^{\text {(c) }}$ & 5.48 & $19.9 \mathrm{~B}$ & $6.31^{\text {(c) }}$ \\
\hline TB-6 Lower & $11.7 \mathrm{~B}$ & $4.39^{(c)}$ & 5.50 & 6.49 & $17.3 \mathrm{~B}$ & $6.85^{(c)}$ \\
\hline TB-7 Lower & $10.9 \mathrm{~B}$ & $2.40 \mathrm{U}$ & $2.15 \mathrm{U}$ & 5.58 & $18.1 \mathrm{~B}$ & $6.15 \mathrm{U}$ \\
\hline TB-8 Lower & $13.1 \mathrm{~B}^{(\mathrm{c})}$ & $2.43 \mathrm{U}$ & $2.18 \mathrm{U}$ & 5.78 & $19.4 \mathrm{~B}$ & $6.23 \mathrm{U}$ \\
\hline TB-9 Lower, Replicate 1 & $12.5 \mathrm{~B}$ & $2.46 \mathrm{U}$ & 5.98 & 6.03 & $18.4 \mathrm{~B}$ & $6.31 \mathrm{U}$ \\
\hline TB-9 Lower, Replicate 2 & $11.8 \mathrm{~B}^{(\mathrm{c})}$ & $2.43 \mathrm{U}$ & 6.25 & 5.97 & $16.2 \mathrm{~B}$ & $6.23 \mathrm{U}$ \\
\hline TB-9 Lower, Replicate 3 & $15.7 \mathrm{~B}$ & $2.31 U$ & 5.48 & 5.60 & $19.2 \mathrm{~B}$ & $5.92 U$ \\
\hline OBM COMP & $9.29 \mathrm{~B}$ & $3.27^{(c)}$ & 4.87 & $3.59 \mathrm{U}$ & $11.4 \mathrm{~B}$ & $5.15 \mathrm{U}$ \\
\hline R-OS & $16.5 \mathrm{~B}$ & $2.97 \mathrm{U}$ & 6.80 & 6.18 & $27.9 \mathrm{~B}$ & $7.91^{\text {(c) }}$ \\
\hline $\mathrm{R}-\mathrm{BF}$ & 55.0 & $19.8^{(c)}$ & 14.7 & 18.7 & 189 & 57.5 \\
\hline$R-A M^{(e)}$ & $28.8 \mathrm{~B}$ & 24.0 & 9.39 & 30.2 & 296 & 150 \\
\hline
\end{tabular}

(a) DL Detection limit.

(b) B Analyte detected in sample at less than five times value in associated method blank.

(c) Ratio of confirmation ion to primary ion is outside of the theoretical ratio of $20 \%$ established for EPA-CLP programs.

(d) $U$ Undetected at or above detection limit.

(e) Field station RAM-F was not included in the composite. 
TABLE D.9. High Molecular Weight Polynuclear Aromatic Hydrocarbons (HPAHs), Richmond Harbor Deepening ProjectIntensive Study of the Turning Basin

HPAHs ( $\mu \mathrm{g} / \mathrm{kg}$ dry weight)

\begin{tabular}{|c|c|c|c|c|c|c|c|c|c|c|}
\hline \multirow[b]{2}{*}{$\begin{array}{l}\text { Sediment } \\
\text { Treatment } \\
\end{array}$} & & & & & & & & & & \\
\hline & $\begin{array}{c}\text { Fluor- } \\
\text { anthene }\end{array}$ & Pyrene & $\begin{array}{l}\text { Benzo(a)- } \\
\text { anthra- } \\
\text { cene }\end{array}$ & Chrysene & $\begin{array}{c}\text { Benzo(b)- } \\
\text { fluor- } \\
\text { anthene }\end{array}$ & $\begin{array}{l}\text { Benzo(k)- } \\
\text { fluor- } \\
\text { anthene }\end{array}$ & $\begin{array}{l}\text { Benzo(a)- } \\
\text { pyrene }\end{array}$ & $\begin{array}{l}\text { Indeno- } \\
(1,2,3- \\
\text { cd) } \\
\text { pyrene }\end{array}$ & $\begin{array}{c}\text { Dibenzo- } \\
(\mathrm{a}, \mathrm{h}) \\
\text { anthra- } \\
\text { cene } \\
\end{array}$ & $\begin{array}{l}\text { Benzo- } \\
(g, h, i) \\
\text { perylene }\end{array}$ \\
\hline & s & & & & & & & & & \\
\hline Target $\mathrm{DL}^{(\mathrm{a})}$ & 20 & 20 & 20 & 20 & 20 & 20 & 20 & 20 & 20 & 20 \\
\hline Achieved DL & $0.80-2.10$ & $0.71-1.86$ & $0.44-1.15$ & $0.66-1.74$ & $0.77-2.02$ & $1.11-2.93$ & $0.99-2.62$ & $0.56-1.47$ & $0.59-1.55$ & $0.56-1.47$ \\
\hline TB-1 Lower & $7.84 \mathrm{~B}^{(\mathrm{b})(\mathrm{c})}$ & $10.3 \mathrm{~B}^{(\mathrm{c})}$ & $4.23^{(c)}$ & $0.71 u^{(d)}$ & $4.85^{(c)}$ & $2.29 \mathrm{U}$ & $2.73 \mathrm{~B}^{(\mathrm{c})}$ & $3.65^{\text {(c) }}$ & $1.04 \mathrm{U}$ & $3.70^{(c)}$ \\
\hline TB-2 Lower & $7.01 \mathrm{~B}^{(\mathrm{c})}$ & $9.26 \mathrm{~B}^{(\mathrm{c})}$ & $3.67^{(c)}$ & $2.31^{\text {(c) }}$ & $4.96^{(c)}$ & $1.84 \mathrm{U}$ & $2.45 \mathrm{~B}^{(c)}$ & $2.77^{(c)}$ & $0.83 U$ & $3.38^{\text {(c) }}$ \\
\hline TB-3 Lower & $11.0 \mathrm{~B}^{(\mathrm{c})}$ & $13.7 \mathrm{~B}^{(\mathrm{c})}$ & $5.88^{(c)}$ & $3.29^{(c)}$ & $7.21^{\text {(c) }}$ & $3.21^{(c)}$ & $3.78 \mathrm{~B}^{(c)}$ & $4.37^{(c)}$ & $1.33 \mathrm{U}$ & $5.29^{\text {(c) }}$ \\
\hline TB-4 Lower & $13.1 \mathrm{~B}$ & $15.5 \mathrm{~B}$ & $6.17^{(c)}$ & $3.98^{(c)}$ & 8.59 & $3.47^{(c)}$ & $3.42 \mathrm{~B}^{(c)}$ & $5.25^{(c)}$ & $1.31 \mathrm{U}$ & 6.69 \\
\hline TB-4 Middle & 293 & 441 & 129 & 150 & 305 & 107 & 288 & 295 & 32.8 & 314 \\
\hline TB-5 Lower & $12.7 \mathrm{~B}$ & $15.9 \mathrm{~B}$ & $6.21^{(c)}$ & $3.85^{\text {(c) }}$ & 9.39 & $3.00 \mathrm{U}$ & $3.87 \mathrm{~B}^{(c)}$ & $4.71^{(c)}$ & $1.36 \mathrm{U}$ & $5.77^{(c)}$ \\
\hline TB.6 Lower & $14.1 \mathrm{~B}$ & $16.2 \mathrm{~B}$ & $6.69^{(c)}$ & $4.48^{(c)}$ & 9.90 & $3.12 U$ & $3.56 \mathrm{~B}^{(c)}$ & $5.29^{(c)}$ & $1.41 \mathrm{U}$ & 6.40 \\
\hline TB-7 Lower & $12.5 \mathrm{~B}$ & $15.4 \mathrm{~B}$ & $6.42^{(c)}$ & $3.95^{\text {(c) }}$ & 9.32 & $3.70^{(c)}$ & $4.25 \mathrm{~B}^{\text {(c) }}$ & $6.07^{\text {(c) }}$ & $1.36 \mathrm{U}$ & 6.99 \\
\hline TB-8 Lower & $12.9 \mathrm{~B}^{(c)}$ & $16.7 \mathrm{~B}^{(\mathrm{c})}$ & $6.45^{\text {(c) }}$ & $4.36^{\text {(c) }}$ & 10.4 & $3.04 \mathrm{U}$ & $3.66 \mathrm{~B}^{(c)}$ & $5.33^{\text {(c) }}$ & $1.38 \mathrm{U}$ & 6.81 \\
\hline TB-9 Lower, Repllcate 1 & $14.4 \mathrm{~B}$ & $16.7 \mathrm{~B}$ & $6.36^{(c)}$ & $3.69^{(c)}$ & $8.87^{(c)}$ & $3.08 \mathrm{U}$ & $3.81 \mathrm{~B}^{(\mathrm{c})}$ & $5.11^{(c)}$ & $1.39 \mathrm{U}$ & $5.86^{(c)}$ \\
\hline TB-9 Lower, Replicate 2 & $12.6 \mathrm{~B}^{(\mathrm{c})}$ & $16.1 \mathrm{~B}$ & $6.23^{(c)}$ & $3.61^{(c)}$ & $8.83^{(c)}$ & $3.04 \mathrm{U}$ & $3.96 \mathrm{~B}^{(\mathrm{c})}$ & $4.92^{\text {(c) }}$ & $1.38 \mathrm{U}$ & $6.44^{(c)}$ \\
\hline TB.9 Lower, Replicate 3 & $14.2 \mathrm{~B}^{(c)}$ & $16.0 \mathrm{~B}$ & $5.88^{(c)}$ & $3.74^{(c)}$ & $7.77^{\text {(c) }}$ & $2.89 \mathrm{U}$ & $2.25 \mathrm{U}$ & $4.55^{\text {(c) }}$ & $1.31 \mathrm{U}$ & $5.54^{(c)}$ \\
\hline OBM COMP & $8.64 \mathrm{~B}^{(c)}$ & $11.2 \mathrm{~B}$ & $4.61^{(c)}$ & $0.78 U$ & $1.49 \mathrm{U}$ & $2.52 \mathrm{U}$ & $3.49 \mathrm{~B}^{(c)}$ & $0.90 \mathrm{U}$ & $1.14 \mathrm{U}$ & $0.82 U$ \\
\hline R-OS & $22.7 \mathrm{~B}$ & $27.1 \mathrm{~B}$ & 9.85 & 8.10 & 18.7 & $3.72 \mathrm{U}$ & $8.73 \mathrm{~B}$ & 10.9 & $4.50^{(c)}$ & 13.5 \\
\hline$R-B F$ & 287 & 337 & 114 & 147 & 280 & 110 & 250 & 279 & 29.8 & 282 \\
\hline$R \cdot A M^{(\theta)}$ & 199 & 238 & 113 & 133 & 96.5 & 42.7 & 105 & 60.8 & 14.0 & 53.0 \\
\hline
\end{tabular}

(a) DL Detection limit.

(b) B Analyte detected in sample at less than five times value in associated method blank.

(c) Ratio of confirmation ion to primary lon is outside of the theoretical ratio of $20 \%$ established for EPA-CLP programs.

(d) U Undetected at or above detection limit.

(e) Field station RAM-F was not included in the composite. 
TABLE D.10. Quality Control Data for Low Molecular Weight Polynuclear Aromatic Hydrocarbons (LPAHs), Richmond Harbor Deepening Project-Intensive Study of the Turning Basin

LPAHs ( $\mu \mathrm{g} / \mathrm{kg}$ dry weight)

\begin{tabular}{|c|c|c|c|c|c|c|}
\hline $\begin{array}{l}\text { Sediment } \\
\text { Treatment }\end{array}$ & $\begin{array}{l}\text { Naphtha- } \\
\text { lene }\end{array}$ & $\begin{array}{l}\text { Acenaph- } \\
\text { thylene }\end{array}$ & $\begin{array}{l}\text { Acenaph- } \\
\text { thene }\end{array}$ & Fluorene & $\begin{array}{l}\text { Phenan- } \\
\text { threne }\end{array}$ & $\begin{array}{l}\text { Anthra- } \\
\text { cene }\end{array}$ \\
\hline \multicolumn{7}{|l|}{ Method Blank } \\
\hline Blank & $8.11^{(a)}$ & $2.16 U^{(b)}$ & $1.94 \mathrm{U}$ & $3.86 U$ & 11.3 & $5.54 \mathrm{U}$ \\
\hline \multicolumn{7}{|l|}{ Matrix Spike } \\
\hline OBM СОМР & 9.29 & $3.27^{\text {(a) }}$ & 4.87 & $3.59 \mathrm{U}$ & 11.4 & $5.15 \mathrm{U}$ \\
\hline OBM COMP, MS & 29.5 & 22.1 & 24.8 & 20.1 & 28.7 & 19.3 \\
\hline Concentration Recovered & 20.2 & 18.8 & 19.9 & 20.1 & 17.3 & 19.3 \\
\hline Amount Spiked & 22.0 & 22.0 & 22.0 & 22.0 & 22.0 & 22.0 \\
\hline Percent Recovery & $92 \%$ & $86 \%$ & $91 \%$ & $91 \%$ & $79 \%$ & $88 \%$ \\
\hline \multicolumn{7}{|l|}{ Standard Reference Material } \\
\hline Certified & 1010 & $N C^{(c)}$ & NC & 97.3 & 489 & 184 \\
\hline value NIST 1941a & \pm 140 & NC & NC & \pm 8.6 & \pm 23 & \pm 14 \\
\hline $1941 a$ & 893 & $N A^{\text {(d) }}$ & NA & 92.3 & 608 & $242^{(e)}$ \\
\hline \multicolumn{7}{|l|}{ Analytical Replicate } \\
\hline TB-9 Lower, Replicate 1 & $12.5 \mathrm{~B}^{(\mathrm{f})}$ & $2.46 \mathrm{U}$ & 5.98 & 6.03 & $18.4 \mathrm{~B}$ & $6.31 \mathrm{U}$ \\
\hline TB-9 Lower, Replicate 2 & $11.8 \mathrm{~B}^{(\mathrm{a})}$ & $2.43 \mathrm{U}$ & 6.25 & 5.97 & $16.2 \mathrm{~B}$ & $6.23 \mathrm{U}$ \\
\hline TB-9 Lower, Replicate 3 & $15.7 \mathrm{~B}$ & $2.31 \mathrm{U}$ & 5.48 & 5.60 & $19.2 \mathrm{~B}$ & $5.92 \mathrm{U}$ \\
\hline RSD & $16 \%$ & NA & $7 \%$ & $4 \%$ & $9 \%$ & NA \\
\hline
\end{tabular}

(a) Ratio of confirmation ion to primary ion is outside of the theoretical ratio of $20 \%$ established for EPA-CLP programs.

(b) $U$ Undetected at or above detection limit.

(c) NC Not certified.

(d) NA Not applicable.

(e) Outside quality control criteria $( \pm 30 \%)$ for SRMs.

(f) B Analyte detected in sample at less than five times value in associated method blank. 


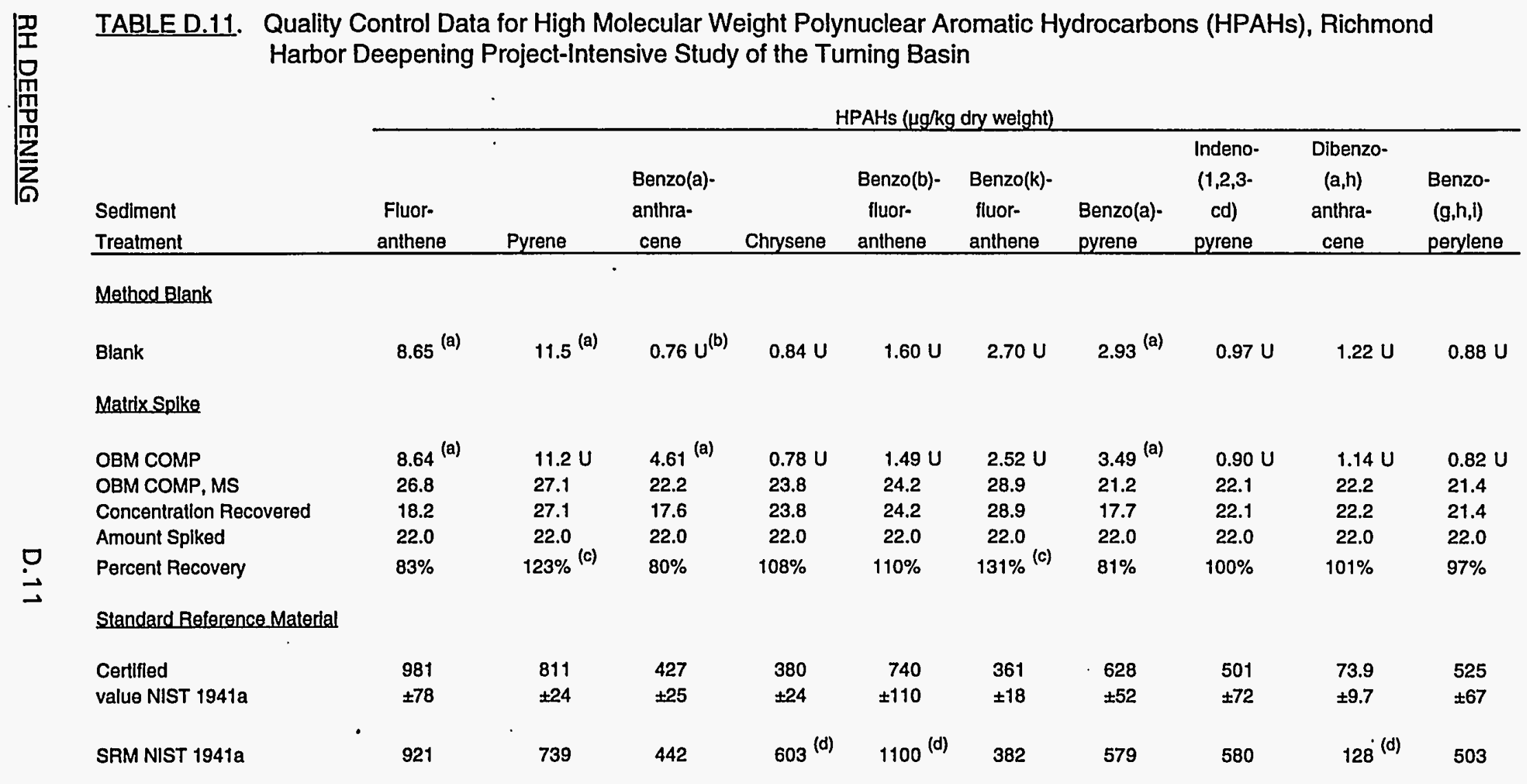




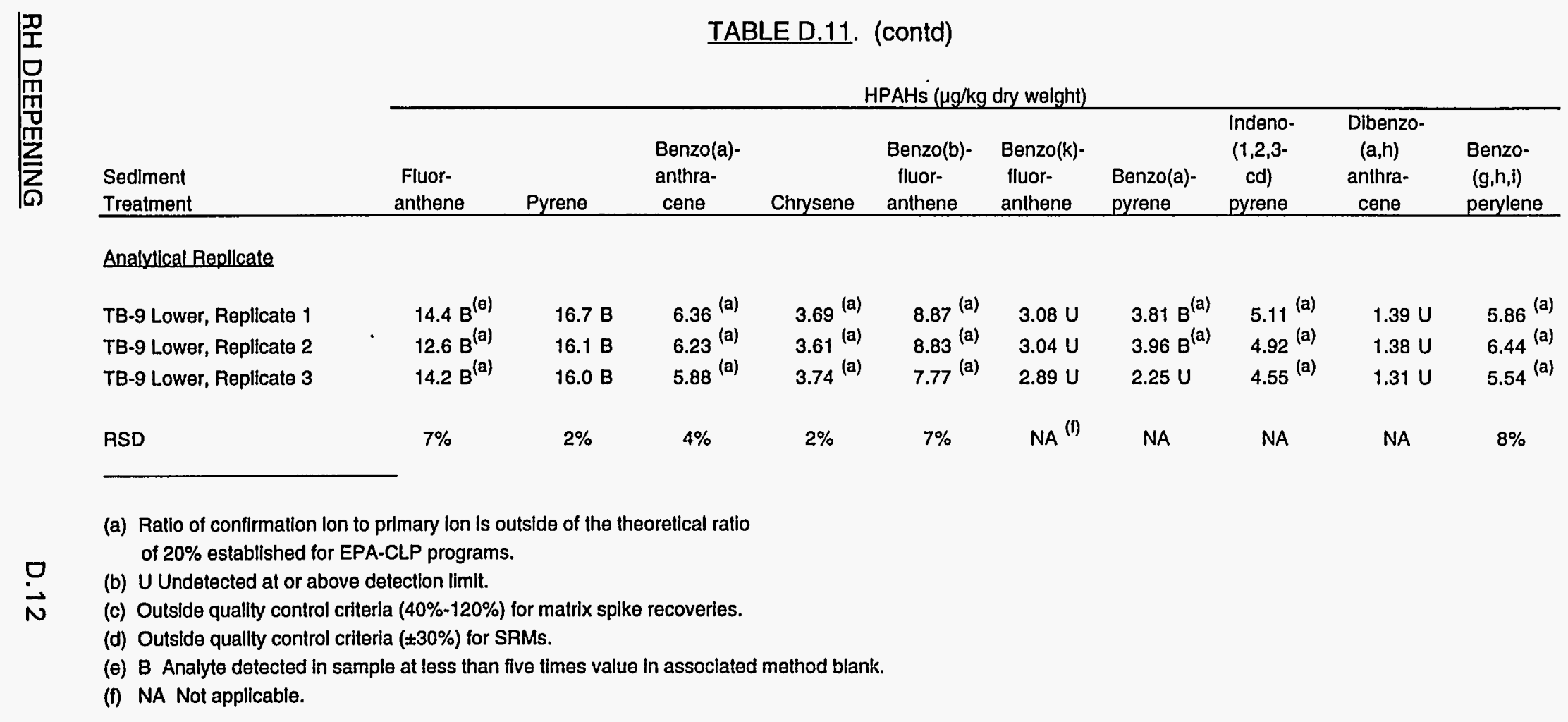


TABLE D.12. Surrogate Percent Recoveries for Polynuclear Aromatic Hydrocarbons (PAHs) Including Quality Control Data for Sediment, Richmond Harbor Deepening Project-Intensive Study of the Turning Basin

\begin{tabular}{|c|c|c|c|c|c|}
\hline \multirow[b]{2}{*}{$\begin{array}{l}\text { Sediment } \\
\text { Treatment }\end{array}$} & \multicolumn{5}{|c|}{ Surrogate Percent Recoveries } \\
\hline & $\begin{array}{l}\text { Naph- } \\
\text { thalene } \\
\text { d8 }\end{array}$ & $\begin{array}{c}\text { Acenaph- } \\
\text { thene } \\
\text { d10 }\end{array}$ & $\begin{array}{c}\text { Chrysene } \\
\text { d12 }\end{array}$ & $\begin{array}{c}\text { Perylene } \\
\mathrm{d} 12\end{array}$ & $\begin{array}{c}\text { Dibenzo(a,h,i) } \\
\text { Anthracene } \\
\text { d14 }\end{array}$ \\
\hline TB-1 Lower & 69 & 69 & 69 & 65 & 67 \\
\hline TB-2 Lower & 54 & 57 & 56 & 61 & 55 \\
\hline TB-3 Lower & 61 & 63 & 61 & 66 & 64 \\
\hline TB-4 Lower & 59 & 63 & 67 & 67 & 66 \\
\hline TB-4 Middle & 42 & 58 & 73 & 68 & 71 \\
\hline TB-5 Lower & 58 & 60 & 68 & 68 & 67 \\
\hline TB-6 Lower & 56 & 61 & 59 & 64 & 62 \\
\hline TB-7 Lower & 61 & 66 & 71 & 71 & 67 \\
\hline TB-8 Lower & 63 & 65 & 58 & 64 & 65 \\
\hline TB-9 Lower, Replicate 1 & 69 & 72 & 64 & 70 & 67 \\
\hline TB-9 Lower, Replicate 2 & 63 & 66 & 66 & 65 & 64 \\
\hline TB-9 Lower, Replicate 3 & 65 & 68 & 65 & 70 & 63 \\
\hline OBM COMP & 62 & 63 & 66 & 63 & 65 \\
\hline R-OS & 64 & 67 & 65 & 66 & 64 \\
\hline R-BF & 44 & 48 & 71 & 67 & 69 \\
\hline $\mathrm{R}-\mathrm{AM}^{(\mathrm{a})}$ & 48 & 57 & 76 & 70 & 75 \\
\hline \multicolumn{6}{|l|}{ Quality Control Data } \\
\hline \multicolumn{6}{|l|}{ Method Blank } \\
\hline Blank & 46 & 56 & 60 & 62 & 55 \\
\hline \multicolumn{6}{|l|}{ Matrix Spike } \\
\hline OBM COMP & 62 & 63 & 66 & 63 & 65 \\
\hline OBM COMP, MS & 58 & 61 & 64 & 61 & 64 \\
\hline \multicolumn{6}{|l|}{ Analytical Replicate } \\
\hline TB-9 Lower, Replicate 1 & 69 & 72 & 64 & 70 & 67 \\
\hline TB-9 Lower, Replicate 2 & 63 & 66 & 66 & 65 & 64 \\
\hline TB-9 Lower, Replicate 3 & 65 & 68 & 65 & 70 & 63 \\
\hline
\end{tabular}

(a) Field station RAM-F was not included in the composite. 


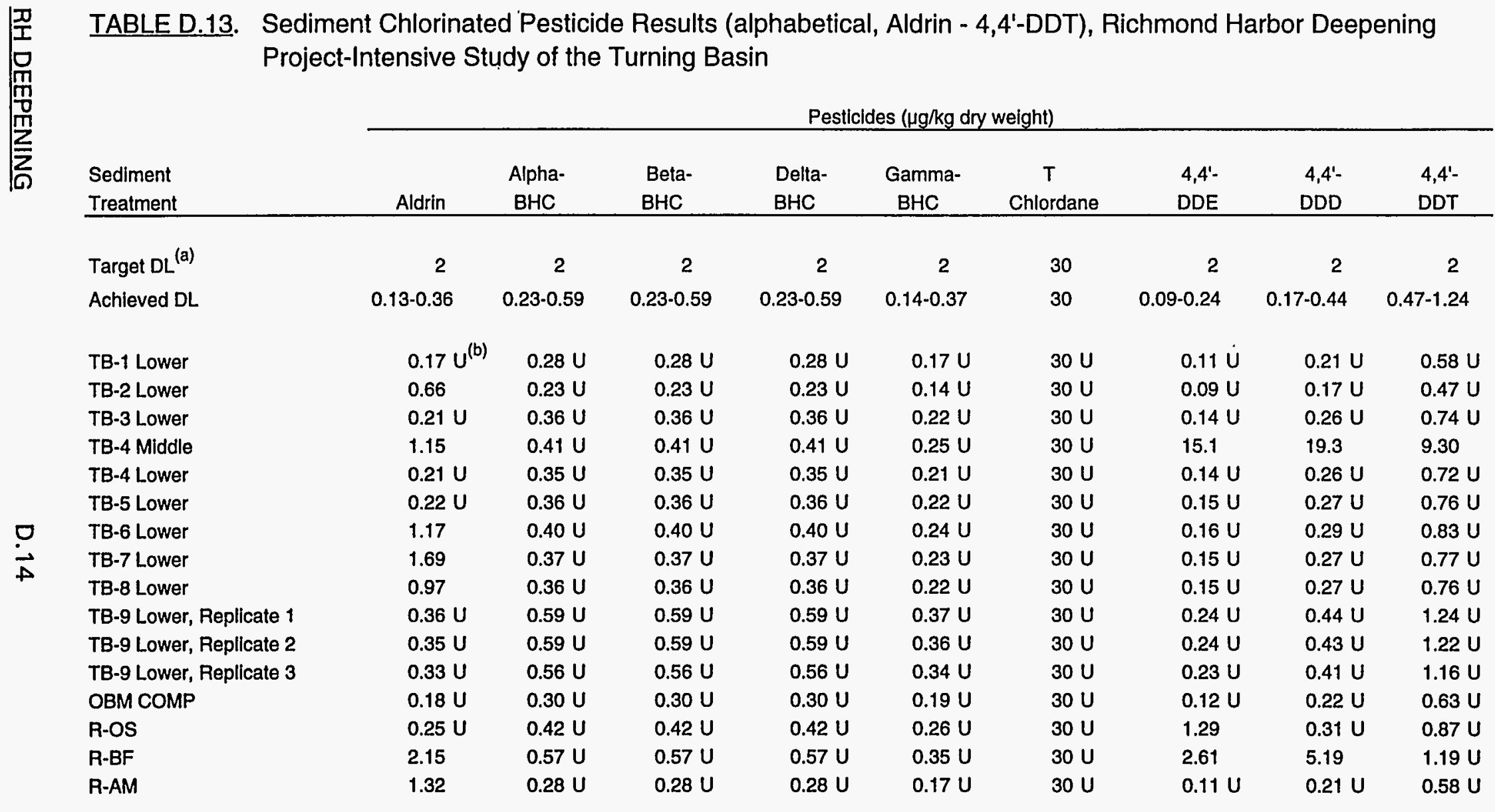

(a) DL Detection limit.

(b) U Undetected at or above detection limit. 


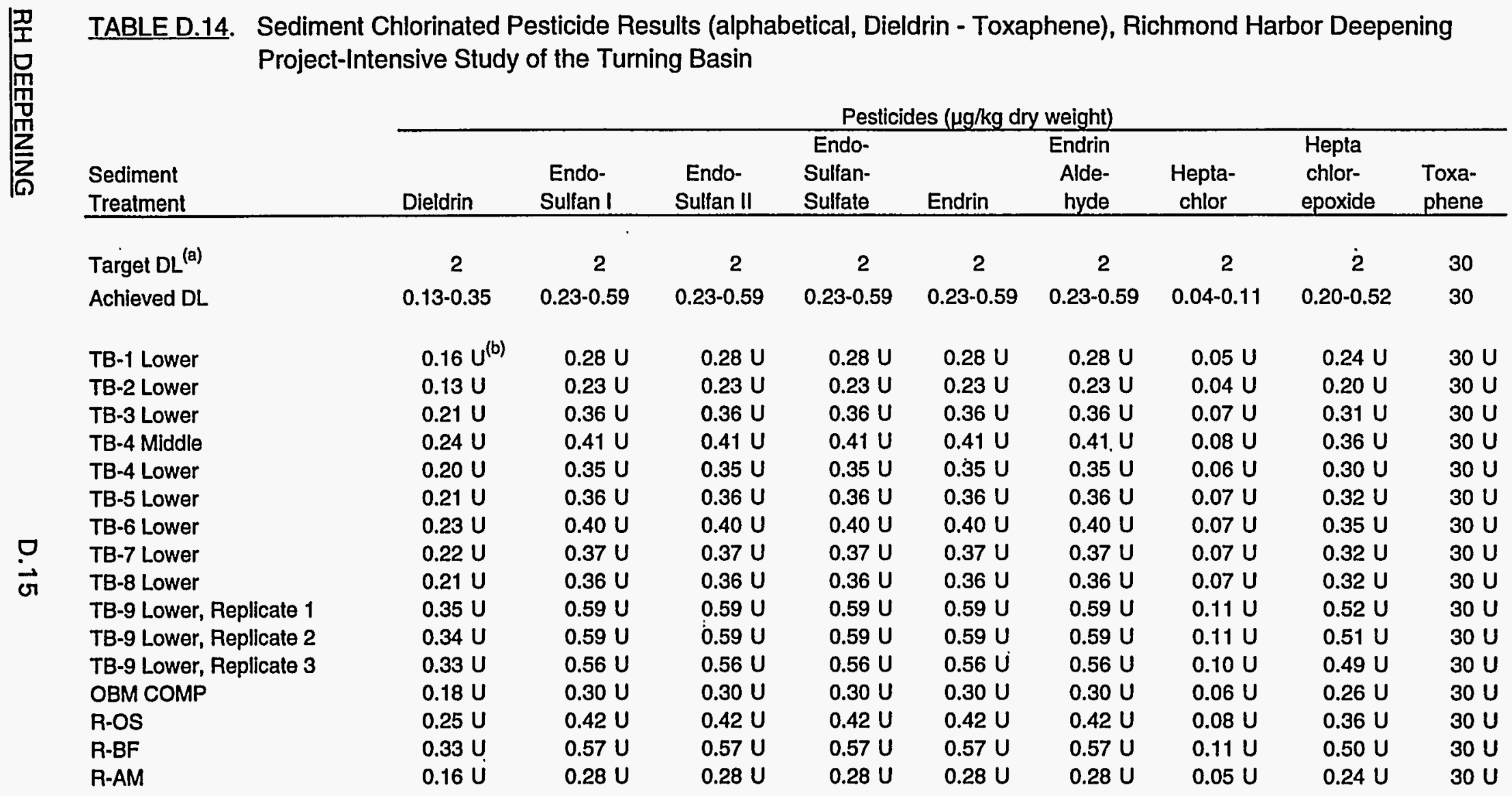

(a) DL Detection limit.

(b) U Undetected at or above detection limit. 


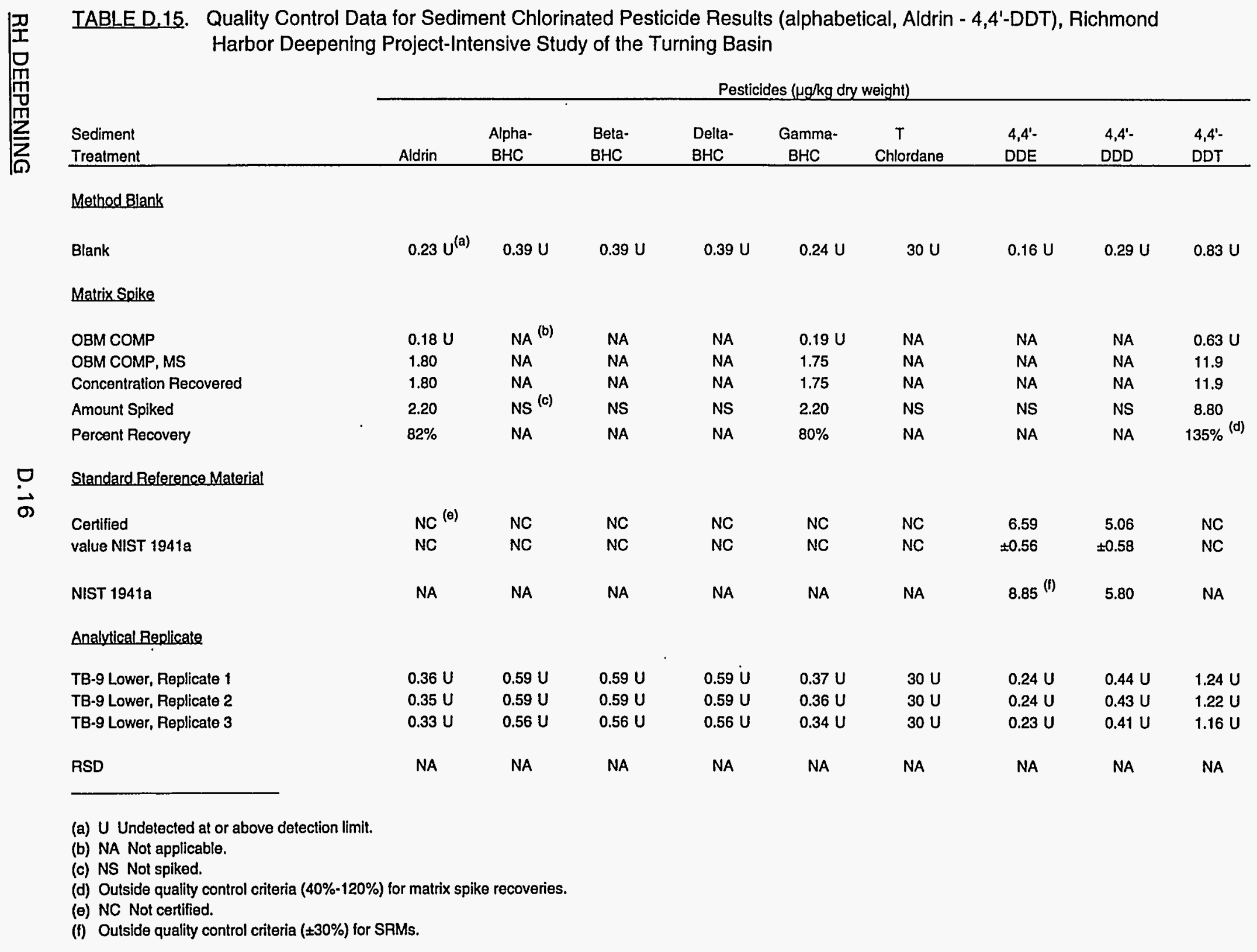




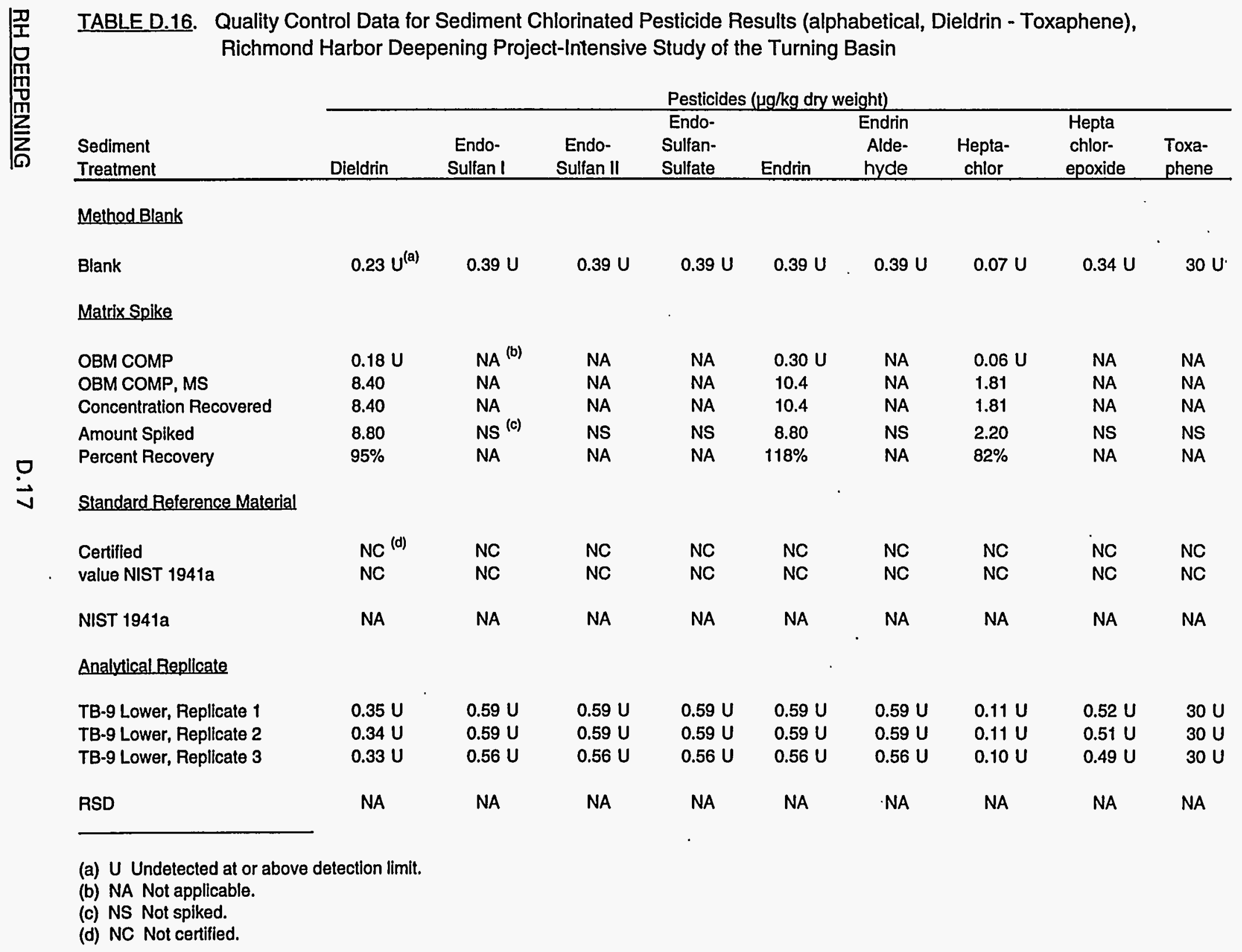


TABLE D.17. Sediment Polychlorinated Biphenyls (PCBs) Results, Richmond Harbor Deepening Project-Intensive Study of the Turning Basin

\begin{tabular}{|c|c|c|c|c|}
\hline \multirow[b]{2}{*}{$\begin{array}{l}\text { Sediment } \\
\text { Treatment }\end{array}$} & \multicolumn{4}{|c|}{ PCBs ( $\mu \mathrm{g} / \mathrm{kg}$ dry weight) } \\
\hline & $\begin{array}{c}\text { Aroclor } \\
1242 \\
\end{array}$ & $\begin{array}{l}\text { Aroclor } \\
1248 \\
\end{array}$ & $\begin{array}{c}\text { Aroclor } \\
1254 \\
\end{array}$ & $\begin{array}{c}\text { Aroclor } \\
1260 \\
\end{array}$ \\
\hline Target $\mathrm{DL}^{(\mathrm{a})}$ & 20 & 20 & 20 & 20 \\
\hline Achieved DL & 20 & 20 & 20 & 20 \\
\hline TB-1 Lower & $20 U^{(b)}$ & $20 \mathrm{U}$ & $20 \mathrm{U}$ & $20 \mathrm{U}$ \\
\hline TB-2 Lower & $20 U$ & $20 U$ & $20 \mathrm{U}$ & $20 \mathrm{U}$ \\
\hline TB-3 Lower & $20 \mathrm{U}$ & $20 \mathrm{U}$ & $20 U$ & $20 \mathrm{U}$ \\
\hline TB-4 Middle & $20 \mathrm{U}$ & $20 U$ & 101 & $20 \mathrm{U}$ \\
\hline TB-4 Lower & $20 U$ & $20 U$ & $20 U$ & $20 U$ \\
\hline TB-5 Lower & $20 U$ & $20 \mathrm{U}$ & $20 \mathrm{U}$ & $20 \mathrm{U}$ \\
\hline TB-6 Lower & $20 \mathrm{U}$ & $20 \mathrm{U}$ & $20 U$ & $20 \mathrm{U}$ \\
\hline TB-7 Lower & $20 U$ & $20 U$ & $20 \mathrm{U}$ & $20 \mathrm{U}$ \\
\hline TB-8 Lower & $20 \mathrm{U}$ & $20 U$ & $20 \mathrm{U}$ & $20 \mathrm{U}$ \\
\hline TB-9 Lower, Replicate 1 & $20 U$ & $20 \mathrm{U}$ & $20 \mathrm{U}$ & $20 \mathrm{U}$ \\
\hline TB-9 Lower, Replicate 2 & $20 \mathrm{U}$ & $20 U$ & $20 \mathrm{U}$ & $20 \mathrm{U}$ \\
\hline TB-9 Lower, Replicate 3 & $20 \mathrm{U}$ & $20 U$ & $20 \mathrm{U}$ & $20 \mathrm{U}$ \\
\hline OBM COMP & $20 U$ & $20 \mathrm{U}$ & $20 \mathrm{U}$ & $20 U$ \\
\hline R-OS & $20 U$ & $20 \mathrm{U}$ & $20 \mathrm{U}$ & $20 \mathrm{U}$ \\
\hline$R-B F$ & $20 U$ & $20 U$ & 46.8 & $20 U$ \\
\hline R-AM & $20 U$ & $20 U$ & $20 \mathrm{U}$ & $20 \mathrm{U}$ \\
\hline
\end{tabular}

(a) DL Detection limit.

(b) $U$ Undetected at or above detection limit. 
TABLE D.18. Quality Control Data for Sediment Polychlorinated Biphenyls (PCBs) Analysis, Richmond Harbor Deepening Project-Intensive Study of the Turning Basin

PCBs ( $\mu \mathrm{g} / \mathrm{kg}$ dry weight)

\begin{tabular}{|c|c|c|c|c|}
\hline $\begin{array}{l}\text { Sediment } \\
\text { Treatment }\end{array}$ & $\begin{array}{l}\text { Aroclor } \\
1242 \\
\end{array}$ & $\begin{array}{l}\text { Aroclor } \\
1248 \\
\end{array}$ & $\begin{array}{c}\text { Aroclor } \\
1254 \\
\end{array}$ & $\begin{array}{c}\text { Aroclor } \\
1260\end{array}$ \\
\hline \multicolumn{5}{|l|}{ Method Blank } \\
\hline Blank & $20 U^{(a)}$ & $20 \mathrm{U}$ & $20 U$ & 20 \\
\hline \multicolumn{5}{|l|}{ Matrix Spike } \\
\hline OBM COMP & $N A^{(b)}$ & NA & $20 \mathrm{U}$ & NA \\
\hline OBM COMP, MS & NA & NA & 44.5 & NA \\
\hline Concentration Recovered & NA & NA & 44.5 & NA \\
\hline Amount Spiked & $N S^{(c)}$ & NS & $44.0^{\circ}$ & NS \\
\hline Percent Recovery & NA & NA & $101 \%$ & NA \\
\hline
\end{tabular}

Standard Reference Material

SRMs not available for PCBs.

Analytical Replicate

TB-9 Lower, Replicate 1

TB-9 Lower, Replicate 2

TB-9 Lower, Replicate 3

$20 \mathrm{U}$

$20 \mathrm{U}$

$20 \mathrm{U}$

$20 \mathrm{U}$

$20 \mathrm{U}$

$20 \mathrm{U}$

$20 \mathrm{U}$

$20 \mathrm{U}$

$20 \mathrm{U}$

$20 \mathrm{U}$

RSD

NA

NA

NA

NA

(a) U Undetected at or above detection limit.

(b) NA Not applicable.

(c) NS Not spiked. 
TABLE D.19. Surrogate Percent Recoveries and Quality Control Data for Chlorinated Pesticides and Polychlorinated Biphenyls (PCBs) in Sediment, Richmond Harbor Deepening Project-Intensive Study of the Turning Basin

Sediment

Treatment

TB-1 Lower

TB-2 Lower

TB-3 Lower

TB-4 Middle

TB-4 Lower

TB-5 Lower

TB-6 Lower

TB-7 Lower

TB-8 Lower

TB-9 Lower, Replicate 1

TB-9 Lower, Replicate 2

TB-9 Lower, Replicate 3

OBM COMP

R-OS

R-BF

R-AM

Quality Control Data

Method Blank

Blank

Matrix Spike

OBM COMP

OBM COMP, MS

Standard Reference Material

Certified SRM not available for PCBs.

Analytical Replicates

TB-9 Lower, Replicate 1

TB-9 Lower, Replicate 2

TB-9 Lower, Replicate 3
Surrogate Percent Recoveries

\begin{tabular}{cc}
\hline PCB 103 & PCB 1 \\
\hline 69 & 68 \\
64 & 53 \\
73 & 60 \\
65 & 70 \\
79 & 62 \\
75 & 62 \\
73 & 59 \\
78 & 65 \\
74 & 62 \\
79 & 64 \\
75 & 61 \\
78 & 65 \\
70 & 63 \\
81 & 67 \\
77 & 61 \\
81 & 58
\end{tabular}

68

60

70

62

62

59

65

62

64

61

65

63

67

58

62

64

62

70

63

$70 \quad 62$ 


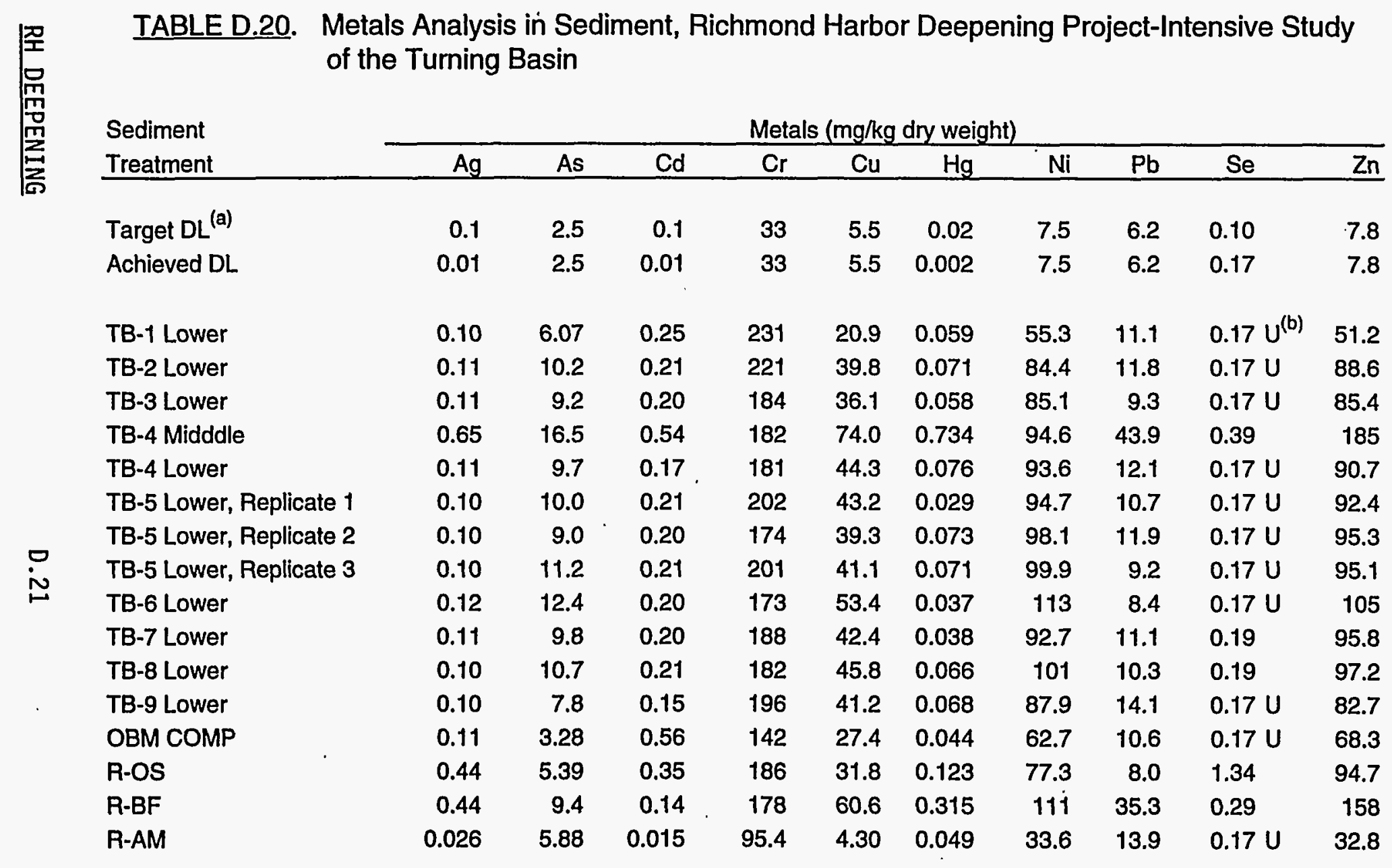

(a) DL Detection limit.

(b) U Undetected at or above detection limit. 


\begin{tabular}{|c|c|c|c|c|c|c|c|c|c|c|}
\hline \multirow{2}{*}{$\begin{array}{l}\text { Sediment } \\
\text { Treatment }\end{array}$} & \multicolumn{10}{|c|}{ Metals (mg/kg dry weight) } \\
\hline & $\mathrm{Ag}$ & As & $\mathrm{Cd}$ & $\mathrm{Cr}$ & $\mathrm{Cu}$ & $\mathrm{Hg}$ & $\mathrm{Ni}$ & $\mathrm{Pb}$ & $\mathrm{Se}$ & $\mathrm{Zn}$ \\
\hline \multicolumn{11}{|l|}{ Method Blank } \\
\hline Blank & 0.026 & $N A^{(a)}$ & 0.032 & NA & NA & $0.002 U^{(b)}$ & NA & NA & $0.17 \mathrm{U}$ & NA \\
\hline \multicolumn{11}{|l|}{ Matrix Spike } \\
\hline TB-5 Lower ${ }^{\text {(c) }}$ & 0.100 & NA & 0.207 & NA & NA & 0.058 & NA & NA & $0.17 \mathrm{U}$ & NA \\
\hline TB-5 Lower, MS & 2.39 & NA & 2.29 & NA & NA & 1.60 & NA & NA & 2.13 & NA \\
\hline Concentration Recovered & 2.29 & NA & 2.08 & NA & NA & 1.54 & NA & NA & 2.13 & NA \\
\hline Amount Spiked & 2.00 & $N S^{(d)}$ & 2.00 & NS & NS & 2.00 & NS & NS & 2.00 & NS \\
\hline Percent Recovery & $115 \%$ & NA & $104 \%$ & NA & NA & $77 \%$ & NA & NA & $107 \%$ & NA \\
\hline \multicolumn{11}{|l|}{ Standard Reference Material } \\
\hline Certified & $N C^{(\theta)}$ & 11.6 & 0.36 & 76 & 18 & 0.063 & 32 & 28.2 & NC & 138 \\
\hline Value 1646 & NC & \pm 1.3 & \pm 0.07 & \pm 3 & \pm 3 & \pm 0.012 & \pm 3 & \pm 1.8 & NC & \pm 6 \\
\hline 1646 & NA & 11.2 & 0.32 & 70.6 & 20.2 & 0.066 & 29.4 & 29.6 & NA & 138 \\
\hline Certified & NC & NC & NC & NC & NC & 0.092 & NC & NC & NC & NC \\
\hline Value BEST-1 & NC & NC & NC & NC & NC & \pm 0.009 & NC & NC & NC & NC \\
\hline BEST-1 & NA & NA & NA & NA & NA & 0.090 & NA & NA & NA & NA \\
\hline
\end{tabular}




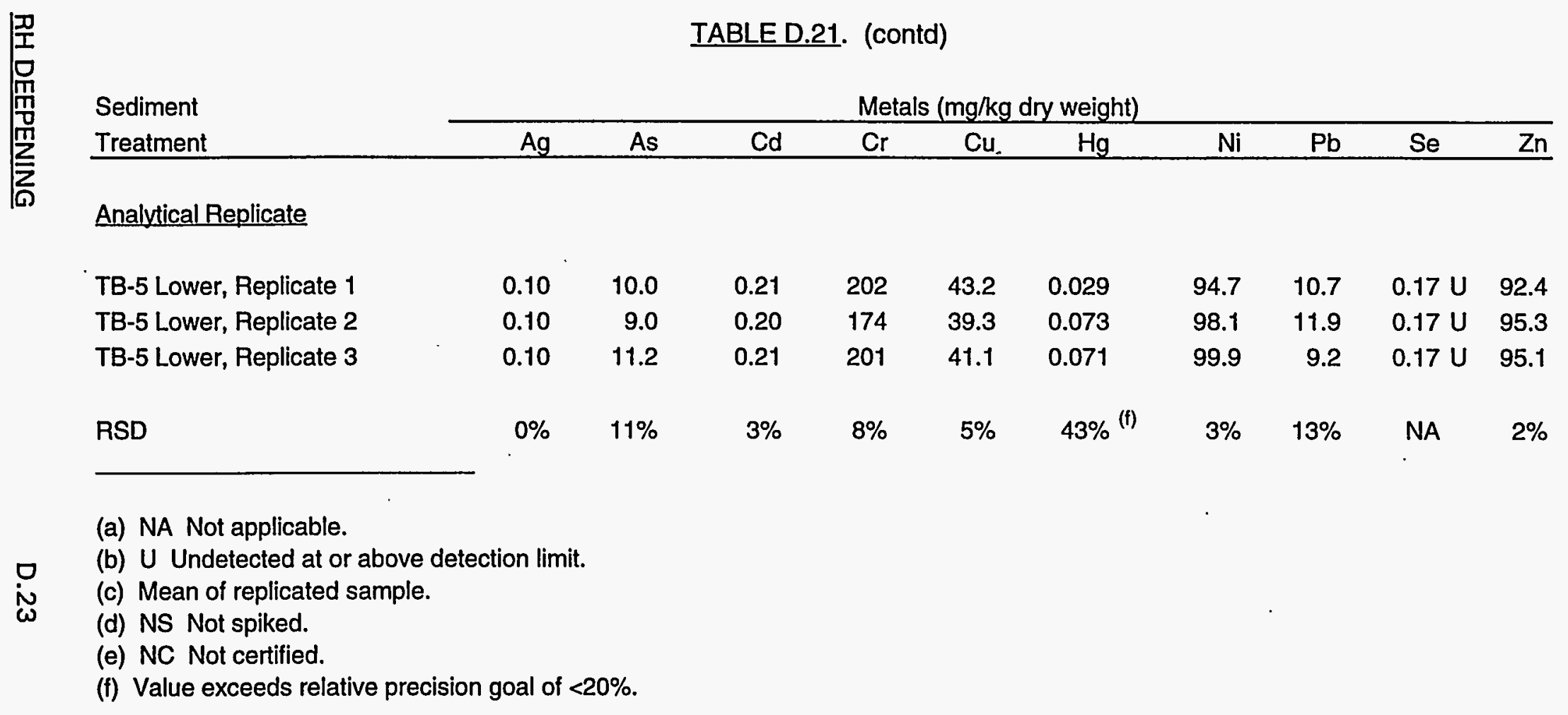


TABLE D.22. Sediment Butyltin Results, Richmond Harbor Deepening ProjectIntensive Study of the Turning Basin

\begin{tabular}{|c|c|c|c|c|c|}
\hline \multirow[b]{2}{*}{$\begin{array}{l}\text { Sediment } \\
\text { Treatment }\end{array}$} & \multirow[b]{2}{*}{ Batch } & \multirow{2}{*}{$\begin{array}{l}\text { Tripentyltin } \\
\% \text { Internal } \\
\text { Standard } \\
\end{array}$} & \multicolumn{3}{|c|}{ Butyltin Species ( $\mu \mathrm{g} / \mathrm{kg}$ dry weight) } \\
\hline & & & $\begin{array}{c}\text { Tri- } \\
\text { Butyltin }\end{array}$ & $\begin{array}{c}\text { Di- } \\
\text { Butyltin }\end{array}$ & $\begin{array}{l}\text { Mono- } \\
\text { Butyltin }\end{array}$ \\
\hline Target $\mathrm{DL}^{(\mathrm{a})}$ & & & 1.00 & 1.00 & 1.00 \\
\hline Achieved DL & & & 0.48 & 0.56 & 1.82 \\
\hline TB-1 Lower & 1 & 70 & 0.57 & $0.56 \mathrm{U}^{(\mathrm{b})}$ & $1.82 U$ \\
\hline TB-2 Lower & 1 & 90 & 0.53 & 1.05 & $1.82 \mathrm{U}$ \\
\hline TB-3 Lower & 1 & 92 & 0.49 & $0.56 \mathrm{U}$ & $1.82 \mathrm{U}$ \\
\hline TB-4 Midddle & 1 & 91 & 3.66 & 0.82 & $1.82 U$ \\
\hline TB-4 Lower & 1 & 79 & 0.61 & $0.56 \mathrm{U}$ & $1.82 \mathrm{U}$ \\
\hline TB-5 Lower & 1 & 101 & $0.48 U$ & 0.76 & $1.82 \mathrm{U}$ \\
\hline TB-6 Lower & 1 & 97 & 0.54 & $0.56 \mathrm{U}$ & $1.82 U$ \\
\hline TB-7 Lower & 1 & 94 & 0.52 & $0.56 \mathrm{U}$ & $1.82 \mathrm{U}$ \\
\hline TB-8 Lower & 1 & 95 & $0.48 \mathrm{U}$ & $0.56 \mathrm{U}$ & $1.82 \mathrm{U}$ \\
\hline TB-9 Lower & 1 & 99 & $0.48 \mathrm{U}$ & $0.56 \mathrm{U}$ & $1.82 \mathrm{U}$ \\
\hline OBM COMP & 1 & 94 & $0.48 \mathrm{U}$ & $0.56 \mathrm{U}$ & $1.82 \mathrm{U}$ \\
\hline R-OS, Replicate 1 & 1 & 98 & 0.67 & $0.56 \mathrm{U}$ & $1.82 \mathrm{U}$ \\
\hline R-OS, Replicate 2 & 1 & 103 & 0.54 & $0.56 \mathrm{U}$ & $1.82 \mathrm{U}$ \\
\hline R-OS, Replicate 3 & 1 & 98 & 0.66 & $0.56 U$ & $1.82 U$ \\
\hline R-BF & 1 & 104 & 2.27 & 2.11 & $1.82 \mathrm{U}$ \\
\hline R-AM & 1 & 93 & $0.48 \mathrm{U}$ & $0.56 \mathrm{U}$ & $1.82 U$ \\
\hline
\end{tabular}

(a) DL Detection limit.

(b) U Undetected at or above detection limit. 
IABLE D.23. Quality Control Data for Sediment Butyltin Results, Richmond Harbor Deepening Project-Intensive Study of the Turning Basin

\begin{tabular}{lccccc} 
& & Tripentyltin & \multicolumn{3}{c}{ Butyltin Species ( $\mu \mathrm{g} / \mathrm{kg}$ dry weight) } \\
\cline { 3 - 6 } \cline { 5 - 6 } Sediment & \% Internal & Tri- & Di- & Mono- \\
Treatment & Batch & Standard & Butyltin & Butyltin & Butyltin \\
\hline
\end{tabular}

Method Blank

Blank

1

101

0.55

$0.56 U^{(a)}$

$1.82 U$

Matrix Spike

TB-3 Lower

TB-3 Lower, MS

92

0.49

$0.56 \mathrm{U}$

$1.82 \mathrm{U}$

Concentration Recovered

85

$N A^{(c)}$

45.1

26.6

$0.89 J^{(b)}$

Amount Spiked

$N S^{(d)}$

44.6

26.6

$0.89 \mathrm{~J}$

NA

50.0

50.0

50.0

Percent Recovery

$89 \%$

$53 \%$

$2 \%{ }^{(\mathrm{e})}$

Standard Reference Material

Certified

Value PACS-1

$\begin{array}{lllr}N A & 1270 & 1160 & 280 \\ N A & \pm 220 & \pm 180 & \pm 170\end{array}$

PACS-1

1

96

897

1080

$142^{(1)}$

Analytical Replicate

R-OS, Replicate 1

R-OS, Replicate 2

R-OS, Replicate 3

$\begin{array}{lclll}1 & 98 & 0.67 & 0.56 U & 1.82 U \\ 1 & 103 & 0.54 & 0.56 U & 1.82 U \\ 1 & 98 & 0.66 & 0.56 U & 1.82 U\end{array}$

RSD

NA

$12 \%$

NA

NA
(a) U Undetected at or above detection limit.
(b) J Analyte detected below method detection limit (MDL), but above instrument detection limit (IDL:
(c) NA Not applicable.
(d) NS Not spiked.
(e) Outside quality control criteria of $40-120 \%$ for matrix spike recoveries.
(f) Outside quality control criteria $( \pm 30 \%)$ for SRMs. 
APPENDIX E

BIOASSAY RESULTS FOR 10-DAY SOLID-PHASE, STATIC TEST AND 96-HOUR REFERENCE TOXICANT TEST FOR RHEPOXYNIUS abronius 


\section{QA/QC SUMMARY}

PROGRAM: $\quad$ Richmond Harbor Deepening Project

TEST ORGANISM: Rhepoxynius abronius

TEST TYPE: $\quad$ Solid-phase, static with aeration

TEST DURATION: 10 days

WATER QUALITY ACCEPTABLE RANGES:

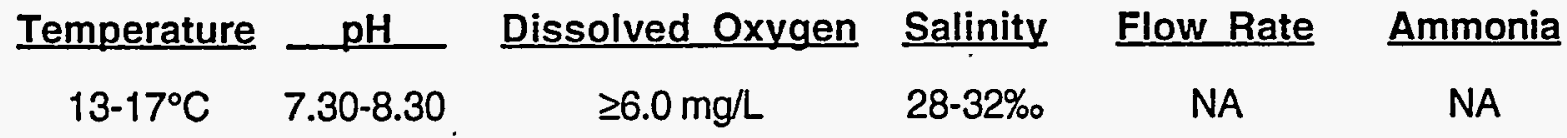

TEST MATRIX

SOURCE/AGE

HOLDING/ACCLIMATION

$\begin{array}{lccccc}\begin{array}{l}\text { acclimation } \\ \text { min/max }\end{array} & \text { Temperature } & \frac{\mathrm{pH}}{2} & & \text { Dissolved Oxygen } & \text { Salinity } \\ \begin{array}{l}\text { holding } \\ \text { min/max }\end{array} & 6.7-14.5^{\circ} \mathrm{C} & 7.65-7.70 & & 7.3-7.9 \mathrm{mg} / \mathrm{L} & 30.0-31.0 \% \\ & 13.9-15.1^{\circ} \mathrm{C} & 7.57-7.86 & & 7.7-8.9 \mathrm{mg} / \mathrm{L} & 30.5-32.0 \%\end{array}$

WATER QUALITY SUMMARY

TEST VALIDATION

REFERENCE TOXICANT TEST The test was validated by $93.3 \%$ survival in the seawater

COMMENTS
The test was validated by $93.3 \%$ survival in the sea
control. $A n L C_{50}$ value of $0.90 \mathrm{mg} / \mathrm{L}$ of cadmium was calculated.

Not applicable.

Sediments were collected from January 28, 1994 to February 3,1994 . Sediments were composited and tested within 6 weeks holding time after collection.

Battelle MSL personnel collected approximately 4000 wild captured (mixed age groups) organisms from West Beach, Whidbey Island, Washington.

Test organisms were held for 12 days at the following conditions prior to test initation. Temperature acclimation was abrupt under normal conditions but did not appear to affect the test organisms.

All water quality parameters remained within the acceptable ranges throughout the 10 days of testing except for $\mathrm{pH}$, that was above the acceptable range for C-SB for less than 24 hours, and salinity, that was above the acceptable range for OBM Comp for less than 96 hours. All water quality parameters for the cadmium reference toxicant test were within the acceptable ranges throughout the 96 hours of testing.

The test was validated by $98 \%$ survival in the control sediment (C-WB). 


\section{QAVC SUMMARY (contd)}

\section{REFERENCES}

ASTM (American Society for Testing and Materials). 1990. Standard Guide for Conducting 10-day Static Sediment Toxicity Tests with Marine and Estuarine Amphipods. ASTM

Designation: E 1367-90. American Society for Testing and Materials, Philadelphia, Pennsylvania.

EPAUUSACE (U.S. Environmental Protection Agency/ U.S. Army Corps of Engineers). 1991. Evaluation of Dredged Material Proposed for Ocean Disposal (Testing Manual).

EPA-68-C8-0105, U.S. Environmental Protection Agency, Office of Marine and Estuarine Protection, Washington, D.C. 
TABLE E.1. Test Results for 10-Day R. abronius Solid-Phase, Static Test, Richmond Harbor Deepening Project

\begin{tabular}{|c|c|c|c|c|c|c|}
\hline \multirow{2}{*}{$\begin{array}{l}\text { Sediment } \\
\text { Treatment }\end{array}$} & \multirow[b]{2}{*}{$\underline{\text { Replicate }}$} & \multicolumn{2}{|c|}{ R. abronius } & \multirow[b]{2}{*}{$\begin{array}{l}\text { Proportion } \\
\text { Surviving }\end{array}$} & \multirow{2}{*}{$\begin{array}{l}\text { Mean } \\
\text { Proportion } \\
\text { Surviving }\end{array}$} & \multirow[b]{2}{*}{$\begin{array}{l}\text { Standard } \\
\text { Deviation }\end{array}$} \\
\hline & & Live(a) & $\begin{array}{l}\text { Dead or } \\
\text { Missing }\end{array}$ & & & \\
\hline SF COMP & 1 & 18 & 2 & 0.90 & & \\
\hline SF COMP & 2 & 17 & 3 & 0.85 & & \\
\hline SF COMP & 3 & 17 & 3 & 0.85 & & \\
\hline SF COMP & 4 & 18 & 2 & 0.90 & & \\
\hline SF COMP & 5 & 19 & 1 & 0.95 & 0.89 & 0.04 \\
\hline SFW COMP & 1 & 15 & 5 & 0.75 & & \\
\hline SFW COMP & 2 & 16 & 4 & 0.80 & & \\
\hline SFW COMP & 3 & 12 & 8 & 0.60 & & \\
\hline SFW COMP & 4 & 18 & 2 & 0.90 & & \\
\hline SFW COMP & 5 & 16 & 4 & 0.80 & 0.77 & 0.11 \\
\hline UIH COMP & 1 & 16 & 4 & 0.80 & & \\
\hline UIH COMP & 2 & 15 & 5 & 0.75 & & \\
\hline UIH COMP & 3 & 14 & 6 & 0.70 & & \\
\hline UIH COMP & 4 & 17 & 3 & 0.85 & & \\
\hline UIH COMP & 5 & 15 & 5 & 0.75 & 0.77 & 0.06 \\
\hline TB UPPER COMP & 1 & 15 & 5 & 0.75 & & \\
\hline TB UPPER COMP & 2 & 14 & 6 & 0.70 & & \\
\hline TB UPPER COMP & 3 & 16 & 4 & 0.80 & & \\
\hline TB UPPER COMP & 4 & 9 & 11 & 0.45 & & \\
\hline TB UPPER COMP & 5 & 16 & 4 & 0.80 & 0.70 & 0.15 \\
\hline TB LOWER COMP & 1 & 13 & 7 & 0.65 & & \\
\hline TB LOWER COMP & 2 & 8 & 12 & 0.40 & & \\
\hline TB LOWER COMP & 3 & 12 & 8 & 0.60 & & \\
\hline TB LOWER COMP & 4 & 7 & 13 & 0.35 & & \\
\hline TB LOWER COMP & 5 & 10 & 10 & 0.50 & 0.50 & 0.13 \\
\hline OBM COMP & 1 & 14 & 6 & 0.70 & & \\
\hline OBM COMP & 2 & 13 & 7 & 0.65 & & \\
\hline OBM COMP & 3 & 17 & 3 & 0.85 & & \\
\hline OBM COMP & 4 & 13 & 7 & 0.65 & & \\
\hline OBM COMP & 5 & 15 & 5 & 0.75 & 0.72 & 0.08 \\
\hline R-OS & 1 & 17 & 3 & 0.85 & & \\
\hline R-OS & 2 & 19 & 1 & 0.95 & & \\
\hline R-OS & 3 & 19 & 1 & 0.95 & & \\
\hline R-OS & 4 & 16 & 4 & 0.80 & & \\
\hline R-OS & 5 & 18 & 2 & 0.90 & 0.89 & 0.07 \\
\hline
\end{tabular}


TABLE E.1. (contd)

\begin{tabular}{|c|c|c|c|c|c|c|}
\hline \multirow[b]{2}{*}{$\begin{array}{l}\text { Sediment } \\
\text { Treatment }\end{array}$} & \multirow[b]{2}{*}{ Replicate } & \multicolumn{2}{|c|}{ R. abronius } & \multirow[b]{2}{*}{$\begin{array}{l}\text { Proportion } \\
\text { Surviving }\end{array}$} & \multirow{2}{*}{$\begin{array}{l}\text { Mean } \\
\text { Proportion } \\
\text { Surviving }\end{array}$} & \multirow[b]{2}{*}{$\begin{array}{l}\text { Standard } \\
\text { Deviation }\end{array}$} \\
\hline & & Live(a) & $\begin{array}{l}\text { Dead or } \\
\text { Missing }\end{array}$ & & & \\
\hline R-BF & 1 & 17 & 3 & 0.85 & & \\
\hline$R-B F$ & 2 & 19 & 1 & 0.95 & & \\
\hline R-BF & 3 & 20 & 0 & 1.00 & & \\
\hline R-BF & 4 & 19 & 1 & 0.95 & & \\
\hline$R-B F$ & 5 & 19 & 1 & 0.95 & 0.94 & 0.05 \\
\hline R-AM COMP & 1 & 20 & 0 & 1.00 & & \\
\hline R-AM COMP & 2 & 20 & 0 & 1.00 & & \\
\hline R-AM COMP & 3 & 20 & 0 & 1.00 & & \\
\hline R-AM COMP & 4 & 20 & 0 & 1.00 & & \\
\hline R-AM COMP & 5 & 19 & 1 & 0.95 & 0.99 & 0.02 \\
\hline C-WB & 1 & 20 & 0 & 1.00 & & \\
\hline C-WB & 2 & 19 & 1 & 0.95 & & \\
\hline C-WB & 3 & 20 & 0 & 1.00 & & \\
\hline C-WB & 4 & 20 & 0 & 1.00 & & \\
\hline C-WB & 5 & 19 & 1 & 0.95 & 0.98 & 0.03 \\
\hline C-SB & 1 & 18 & 2 & 0.90 & & \\
\hline C-SB & 2 & 18 & 2 & 0.90 & & \\
\hline C-SB & 3 & 20 & 0 & 1.00 & & \\
\hline C-SB & 4 & 17 & 3 & 0.85 & & \\
\hline C-SB & 5 & 20 & 0 & 1.00 & 0.93 & 0.07 \\
\hline
\end{tabular}

(a) Survival based on initial exposure of 20 organisms per replicate. 
TABLE E.2. Daily Observations of R. abronius on Sediment Surface During 10-Day SolidPhase, Static Test, Richmond Harbor Deepening Project

Sediment

Treatment

\section{SF COMP}

SF COMP

SF COMP

SF COMP

SF COMP

SFW COMP

SFW COMP

SFW COMP

SFW COMP

SFW COMP

UIH COMP

UIH COMP

UIH COMP

UIH COMP

UIH COMP

TB Upper COMP

TB Upper COMP

TB Upper COMP

TB Upper COMP

TB Upper COMP

TB Lower COMP

TB Lower COMP

TB Lower COMP

TB Lower COMP

TB Lower COMP

OBM COMP

OBM COMP

OBM COMP

OBM COMP

OBM COMP

R-OS

R-OS

R-OS

R-OS

R-OS

R-BF

R-BF

R-BF

R-BF

R-BF
R. abronius on Sediment for Test Days 0 through 9

\begin{tabular}{lllllllllll} 
Replicate & 0 & 1 & 2 & 3 & 4 & 5 & 6 & 7 & 8 & 9 \\
\hline
\end{tabular}

1
2
3
4
5

2

3

4

2

3

4

5

1

2

3

4

5

1
2
3
4
5

1

1
2
3

$$
\begin{aligned}
& 1 \\
& 2 \\
& 3 \\
& 5
\end{aligned}
$$

1
2
3
4
5

0
0

$0 \quad 0$

0.0

$\begin{array}{ll}0 & 1 \\ 0 & 0 \\ 0 & 0 \\ 0 & 0 \\ 0 & 0\end{array}$

$\begin{array}{ll}0 & 0 \\ 0 & 0 \\ 0 & 1 \\ 1 & 0 \\ 0 & 0\end{array}$

$\begin{array}{llllll}0 & 0 & 0 & 0 & 0 & 0 \\ 0 & 0 & 0 & 0 & 0 & 0 \\ 1 & 0 & 0 & 0 & 0 & 0 \\ 0 & 0 & 0 & 0 & 0 & 0 \\ 0 & 0 & 0 & 0 & 0 & 0\end{array}$

$\begin{array}{lll}0 & 0 & 0 \\ 0 & 0 & 0 \\ 0 & 0 & 0 \\ 0 & 1 & 0 \\ 0 & 0 & 0\end{array}$

$\begin{array}{lll}1 & 0 \\ 1 & 0 \\ 0 & 2 \\ 0 & 0 \\ 1 & 1\end{array}$

$\begin{array}{ll}0 & 0 \\ 0 & 1 \\ 2 & 0 \\ 0 & 0 \\ 1 & 0\end{array}$

$\begin{array}{llll}0 & 0 & 0 & 0 \\ 0 & 0 & 0 & 0 \\ 0 & 0 & 0 & 0 \\ 0 & 0 & 0 & 0 \\ 0 & 0 & 1 & 0\end{array}$

$\begin{array}{lll}0 & 0 & 0 \\ 1 & 0 & 0 \\ 0 & 0 & 0 \\ 0 & 0 & 0 \\ 0 & 0 & 0\end{array}$

$\begin{array}{ll}0 & 0 \\ 1 & 0 \\ 0 & 0 \\ 0 & 0 \\ 0 & 0\end{array}$

$\begin{array}{llll}0 & 0 & 0 & 0 \\ 0 & 0 & 0 & 0 \\ 0 & 0 & 0 & 0 \\ 0 & 0 & 0 & 0 \\ 0 & 0 & 0 & 0\end{array}$

$\begin{array}{lll}0 & 0 & 0 \\ 0 & 0 & 0 \\ 0 & 0 & 0 \\ 0 & 0 & 0 \\ 0 & 0 & 0\end{array}$

$\begin{array}{lll}0 & 0 & 0 \\ 0 & 0 & 0 \\ 0 & 1 & 0 \\ 0 & 0 & 0 \\ 1 & 0 & 0\end{array}$

$\begin{array}{lllllll}0 & 0 & 0 & 0 & 0 & 0 & 0 \\ 0 & 1 & 0 & 0 & 0 & 0 & 0 \\ 1 & 1 & 0 & 0 & 0 & 0 & 0 \\ 0 & 0 & 0 & 0 & 0 & 1 & 0 \\ 0 & 0 & 0 & 0 & 0 & 0 & 1\end{array}$

$\begin{array}{llllllllll}0 & 0 & 0 & 0 & 0 & 0 & 0 & 0 & 0 & 0 \\ 0 & 0 & 0 & 0 & 1 & 0 & 0 & 0 & 0 & 0 \\ 0 & 0 & 0 & 0 & 0 & 0 & 0 & 0 & 0 & 0 \\ 0 & 0 & 0 & 0 & 0 & 0 & 0 & 0 & 0 & 0 \\ 0 & 0 & 0 & 0 & 0 & 0 & 0 & 0 & 0 & 0\end{array}$

1
2
3
4
5

$\begin{array}{lllllll}0 & 0 & 0 & 0 & 0 & 0 & 0 \\ 1 & 0 & 2 & 0 & 0 & 0 & 0 \\ 2 & 2 & 0 & 0 & 0 & 0 & 0 \\ 0 & 0 & 0 & 0 & 0 & 0 & 0 \\ 0 & 0 & 0 & 0 & 1 & 1 & 0\end{array}$

$\begin{array}{llllllllll}0 & 0 & 0 & 0 & 0 & 0 & 0 & 0 & 0 & 0 \\ 0 & 0 & 0 & 0 & 0 & 0 & 0 & 0 & 0 & 0 \\ 0 & 0 & 0 & 0 & 1 & 0 & 0 & 0 & 0 & 0 \\ 0 & 0 & 0 & 0 & 0 & 0 & 0 & 0 & 0 & 0 \\ 0 & 0 & 0 & 0 & 0 & 0 & 0 & 0 & 0 & 0\end{array}$

RH DEEPENING

$$
\text { E.3 }
$$


TABLE E.2. (contd)

Sediment

R. abronius on Sediment for Test Days 0 through 9

Treatment

Replicate

$\begin{array}{llllll}5 & 6 & 7 & 8 & 9\end{array}$

R-AM COMP

R-AM COMP

R-AM COMP

R-AM COMP

R-AM COMP

$\begin{array}{lllllllllll}1 & 0 & 0 & 0 & 0 & 0 & 0 & 0 & 0 & 0 & 0 \\ 2 & 0 & 0 & 0 & 0 & 0 & 0 & 0 & 0 & 0 & 0 \\ 3 & 0 & 0 & 0 & 0 & 0 & 0 & 0 & 0 & 0 & 0 \\ 4 & 0 & 0 & 0 & 0 & 0 & 0 & 0 & 1 & 1 & 0 \\ 5 & 0 & 0 & 0 & 0 & 0 & 0 & 0 & 0 & 0 & 0\end{array}$

C-WB

C-WB

C-WB

C-WB

C-WB

1
2
3
4
5

C-SB

C-SB

C-SB

C-SB

C-SB

$\begin{array}{llllllllll}0 & 0 & 0 & 0 & 0 & 0 & 0 & 0 & 0 & 0 \\ 0 & 0 & 0 & 0 & 0 & 0 & 0 & 0 & 0 & 0 \\ 0 & 0 & 0 & 0 & 0 & 0 & 0 & 0 & 0 & 0 \\ 0 & 0 & 0 & 1 & 0 & 0 & 0 & 0 & 0 & 0 \\ 0 & 0 & 0 & 0 & 0 & 0 & 0 & 0 & 1 & 1\end{array}$

1
2
3
4
5

$\begin{array}{llllllllll}0 & 0 & 0 & 0 & 0 & 0 & 0 & 0 & 0 & 0 \\ 0 & 0 & 1 & 0 & 0 & 0 & 0 & 0 & 0 & 0 \\ 0 & 0 & 0 & 0 & 0 & 0 & 0 & 0 & 0 & 0 \\ 1 & 0 & 0 & 0 & 0 & 0 & 0 & 0 & 0 & 0 \\ 0 & 0 & 0 & 0 & 0 & 0 & 0 & 0 & 0 & 0\end{array}$


TABLE E.3. Daily Observations of R. abronius Floating on Surface During 10-Day SolidSolid-Phase, Static Test, Richmond Harbor Deepening Project

Sediment

R. abronius Floating for Test Days 0 through 9
Treatment

SF COMP

SF COMP

SF COMP

SF COMP

SF COMP

SFW COMP

SFW COMP

SFW COMP

SFW COMP

SFW COMP

UIH COMP

UIH COMP

UIH COMP

UIH COMP

UIH COMP

TB Upper COMP

TB Upper COMP

TB Upper COMP

TB Upper COMP

TB Upper COMP

TB Lower COMP

TB Lower COMP

TB Lower COMP

TB Lower COMP

TB Lower COMP

OBM COMP

OBM COMP

OBM COMP

OBM COMP

OBM COMP

R-OS

R-OS

R-OS

R-OS

R-OS

R-BF

A-BF

A-BF

R-BF

R-BF
Replicate

1
2
3
4
5

1
2

3

4
5

1
2
3
4

1

3

4

1

2

3

4
5

5

1

2

4

5

1
2
3
4
5

1

2

4
5

-

\begin{tabular}{lllllllllll}
\multicolumn{10}{c}{ R. abronius Floating for Test Days 0 through 9} \\
0 & 1 & 2 & 3 & 4 & 5 & 6 & 7 & 8 & 9 \\
0 & 0 & 0 & 0 & 0 & 2 & 2 & 2 & 3 & 4 \\
0 & 0 & 0 & 0 & 0 & 0 & 0 & 1 & 0 & 2 \\
0 & 0 & 1 & 2 & 4 & 3 & 0 & 4 & 0 & 2 \\
0 & 0 & 0 & 2 & 2 & 1 & 4 & 0 & 6 & 4 \\
0 & 1 & 2 & 2 & 1 & 1 & 1 & 4 & 1 & 3 \\
& & & & & & & & & \\
1 & 0 & 4 & 5 & 2 & 2 & 5 & 4 & 5 & 4 \\
3 & 4 & 3 & 3 & 4 & 8 & 3 & 4 & 3 & 8 \\
0 & 2 & 3 & 2 & 3 & 5 & 3 & 4 & 3 & 2 \\
0 & 0 & 0 & 1 & 1 & 0 & 0 & 2 & 0 & 1 \\
0 & 0 & 0 & 0 & 2 & 0 & 2 & 3 & 2 & 3 \\
& & & & & & & & & \\
1 & 2 & 1 & 1 & 2 & 1 & 0 & 1 & 1 & 3 \\
0 & 1 & 1 & 2 & 2 & 2 & 2 & 0 & 3 & 2 \\
0 & 0 & 1 & 0 & 1 & 3 & 3 & 4 & 2 & 1 \\
0 & 0 & 0 & 0 & 2 & 1 & 1 & 2 & 0 & 3 \\
2 & 0 & 1 & 0 & 3 & 3 & 5 & 0 & 2 & 3
\end{tabular}

$\begin{array}{llllllllll}0 & 0 & 0 & 1 & 1 & 1 & 2 & 2 & 2 & 1 \\ 0 & 0 & 0 & 0 & 1 & 0 & 1 & 2 & 1 & 1 \\ 0 & 1 & 3 & 1 & 3 & 1 & 1 & 1 & 2 & 2 \\ 0 & 0 & 0 & 0 & 0 & 0 & 2 & 0 & 1 & 1 \\ 0 & 1 & 1 & 3 & 1 & 2 & 3 & 1 & 4 & 1\end{array}$

$\begin{array}{llllllllll}0 & 0 & 1 & 0 & 0 & 0 & 0 & 0 & 4 & 1 \\ 0 & 1 & 0 & 1 & 0 & 3 & 2 & 1 & 0 & 2 \\ 0 & 1 & 0 & 1 & 0 & 3 & 1 & 1 & 0 & 1 \\ 1 & 0 & 0 & 0 & 1 & 0 & 2 & 0 & 3 & 1 \\ 0 & 0 & 1 & 0 & 0 & 2 & 2 & 0 & 1 & 0\end{array}$

\begin{tabular}{|c|c|c|c|c|c|c|c|}
\hline 0 & 0 & 3 & 0 & 1 & 0 & 6 & 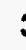 \\
\hline 0 & 0 & 1 & 3 & 1 & 3 & 1 & \\
\hline 0. & 2 & 2 & 3 & 2 & 4 & 2 & \\
\hline 1 & 2 & 2 & 2 & 3 & 1 & 3 & \\
\hline 0 & 0 & 0 & 0 & 0 & 1 & 2 & \\
\hline
\end{tabular}


TABLE E.3. (contd)

Sediment

R. abronius Floating for Test Days 0 through 9

Treatment

Replicate

$\begin{array}{llllll}5 & 6 & 7 & 8 & 9\end{array}$

R-AM COMP

R-AM COMP

R-AM COMP

R-AM COMP

R-AM COMP

C-WB

C-WB

C-WB

C-WB

$$
\begin{aligned}
& 1 \\
& 2 \\
& 3 \\
& 4 \\
& 5
\end{aligned}
$$

$\begin{array}{llllllllll}0 & 0 & 0 & 0 & 0 & 0 & 0 & 0 & 0 & 0 \\ 0 & 0 & 0 & 0 & 0 & 0 & 0 & 0 & 0 & 1 \\ 1 & 0 & 0 & 0 & 0 & 1 & 0 & -0 & 0 & 0 \\ 0 & 0 & 0 & 0 & 0 & 0 & 0 & 0 & 0 & 0 \\ 0 & 0 & 0 & 0 & 1 & 0 & 0 & 0 & 0 & 0\end{array}$

C-SB

C-SB

C-SB

C-SB

C-SB

$\begin{array}{lllllllllll}1 & 0 & 0 & 0 & 0 & 0 & 0 & 0 & 0 & 0 & 0 \\ 2 & 0 & 0 & -0 & 0 & 0 & 0 & 0 & 0 & 0 & 0 \\ 3 & 0 & 0 & 0 & 0 & 0 & 0 & 0 & 0 & 0 & 0 \\ 4 & 0 & 0 & 0 & 0 & 0 & 0 & 0 & 0 & 0 & 0 \\ 5 & 0 & 0 & 0 & 0 & 0 & 0 & 0 & 1 & 0 & 0\end{array}$

1
2
3
4
5

$\begin{array}{llllllllll}0 & 0 & 0 & 0 & 1 & 0 & 0 & 1 & 2 & 1 \\ 0 & 2 & 0 & 0 & 0 & 0 & 0 & 0 & 3 & 0 \\ 1 & 0 & 0 & 0 & 1 & 0 & 1 & 1 & 2 & 0 \\ 0 & 0 & 1 & 0 & 1 & 1 & 0 & 0 & 0 & 2 \\ 0 & 0 & 2 & 0 & 0 & 0 & 1 & 0 & 0 & 0\end{array}$


TABLE E.4. Water Quality Summary for 10-Day R. abronius Solid-Phase, Static Test, Richmond Harbor Deepening Project

\begin{tabular}{|c|c|c|c|c|c|c|c|c|}
\hline \multirow{2}{*}{$\begin{array}{l}\text { Sediment } \\
\text { Treatment }\end{array}$} & \multicolumn{2}{|c|}{$\begin{array}{c}\text { Temperature } \\
\left(\mathrm{C}^{\circ}\right)\end{array}$} & \multicolumn{2}{|c|}{$\mathrm{pH}$} & \multicolumn{2}{|c|}{$\begin{array}{l}\text { Dissolved } \\
\text { Oxygen } \\
\text { (mg/L) }\end{array}$} & \multicolumn{2}{|c|}{$\begin{array}{c}\text { Salinity } \\
\text { o/00 } \\
\end{array}$} \\
\hline & Min & Max & Min & $\operatorname{Max}$ & Min & $\operatorname{Max}$ & Min & $\operatorname{Max}$ \\
\hline $\begin{array}{l}\text { Acceptable } \\
\text { Range }\end{array}$ & 13.0 & 17.0 & 7.30 & 8.30 & 6.0 & NA (a). & 28.0 & 32.0 \\
\hline SF COMP & 14.6 & 15.9 & 7.74 & 7.97 & 7.3 & 8.5 & 31.0 & 32.0 \\
\hline SFW COMP & 14.6 & 15.9 & 7.61 & 8.06 & 7.4 & 8.3 & 31.0 & 32.0 \\
\hline UIH COMP & 14.6 & 15.9 & 7.72 & 8.11 & 7.3 & 8.5 & 31.0 & 32.0 \\
\hline TB Upper COMP & 14.6 & 15.8 & 7.71 & 8.17 & 7.4 & 8.4 & 30.0 & 32.0 \\
\hline TB Lower COMP & 14.6 & 15.9 & 7.65 & 8.18 & 7.3 & 8.4 & 30.0 & 32.0 \\
\hline OBM COMP & 14.6 & 16.1 & 7.89 & 8.10 & 7.2 & 8.6 & 31.0 & 32.5 (b) \\
\hline $\begin{array}{l}\text { R-OS } \\
\text { R-BF } \\
\text { R-AM COMP }\end{array}$ & $\begin{array}{l}14.6 \\
14.7 \\
14.6\end{array}$ & $\begin{array}{l}15.9 \\
15.9 \\
15.7\end{array}$ & $\begin{array}{l}7.49 \\
7.49 \\
7.49\end{array}$ & $\begin{array}{l}8.01 \\
7.92 \\
7.97\end{array}$ & $\begin{array}{l}7.4 \\
7.5 \\
7.3\end{array}$ & $\begin{array}{l}8.4 \\
8.5 \\
8.5\end{array}$ & $\begin{array}{l}31.0 \\
30.0 \\
31.0\end{array}$ & $\begin{array}{l}32.0 \\
32.0 \\
32.0\end{array}$ \\
\hline $\begin{array}{l}\text { C-WB } \\
\text { C-SB }\end{array}$ & $\begin{array}{l}14.6 \\
14.6\end{array}$ & $\begin{array}{l}16.0 \\
15.9\end{array}$ & $\begin{array}{l}7.67 \\
7.76\end{array}$ & $\begin{array}{l}7.99 \\
8.40 \text { (b) }\end{array}$ & $\begin{array}{l}7.3 \\
7.2\end{array}$ & $\begin{array}{l}8.3 \\
8.4\end{array}$ & $\begin{array}{l}31.5 \\
31.0\end{array}$ & $\begin{array}{l}32.0 \\
32.0\end{array}$ \\
\hline
\end{tabular}

(a) NA Not applicable.

(b) Data point out of range. 
TABLE E.5. Ammonia Measurements in Overlying Water for 10-Day R. abronius Solid-Phase, Static Test, Richmond Harbor Deepening Project

\begin{tabular}{lrrrrr}
$\begin{array}{l}\text { Sediment } \\
\text { Treatment }\end{array}$ & \multicolumn{5}{c}{$\begin{array}{c}\text { Ammonia } \\
\text { (mg/L) }\end{array}$} \\
\hline & Day 0 & Day 1 & Day 3 & Day 7 & Day 10 \\
\cline { 2 - 6 } SF COMP & 1.81 & 3.80 & 1.94 & 5.13 & 1.43 \\
SFW COMP & 4.55 & 8.79 & 8.95 & 9.99 & 1.84 \\
UIH COMP & 8.47 & 10.7 & 13.1 & 11.7 & 1.76 \\
TB Upper COMP & 3.33 & 9.35 & 9.70 & 9.45 & 1.80 \\
TB Lower COMP & 12.6 & 20.8 & 26.5 & 25.7 & 5.49 \\
OBM COMP & 1.11 & 1.96 & 2.14 & 3.34 & 1.32 \\
& & & & & \\
R-OS & 0.65 & 1.09 & 0.272 & 1.48 & 1.42 \\
R-BF & 0.78 & 1.43 & 1.74 & 0.700 & 1.23 \\
R-AM COMP & 0.42 & 0.493 & 0.261 & 0.896 & 1.19 \\
& & & & & \\
C-WB & 0.82 & 0.947 & 0.802 & 1.31 & 1.45 \\
C-SB & 0.76 & 1.94 & 0.844 & 1.14 & 1.30
\end{tabular}


TABLE E.6. Water Quality Measurements in Porewater for 10-Day R. abronius Solid-Phase, Static Test, Richmond Harbor Deepening Project

Sediment

Treatment

$\frac{\mathrm{pH}}{\operatorname{Min} \operatorname{Max}} \cdot \frac{\begin{array}{c}\text { Salinity } \\ (\mathrm{O} / 00)\end{array}}{\operatorname{Min}}$

SF COMP

$7.57 \quad 7.99$

32.0

32.0

$32.0 \quad 32.0$

Porewater

Ammonia

SFW COMP

$7.70 \quad 8.08$

$32.0 \quad 32.0$

9.64

3.08

UIH COMP

$\begin{array}{ll}7.79 & 7.94\end{array}$

13.70

3.00

TB Upper COMP

7.81

7.97

32.0

32.0

12.30

1.70

TB Lower COMP

7.88

8.11

31.5

31.5

24.9

13.8

OBM COMP

8.08

8.30

32.0

32.0

2.53

2.49

R-OS

R-BF

R-AM COMP

$\begin{array}{llll}7.87 & 8.00 & 32.0 & 32.0\end{array}$

$\begin{array}{ll}7.61 & 7.96\end{array}$

32.0

32.0

7.92

7.93

32.0

32.0

$3.61 \quad 1.05$

3.38

0.66

C-WB

C-SB

$\begin{array}{ll}7.71 & 7.71 \\ 7.82 & 7.85\end{array}$

32.0

32.0

32.0

32.0

3.25

1.03

(a) NI Not initiated; not enough water in sediment sample.

RH DEEPENING

$\begin{array}{ll}4.99 & \text { NI (a) } \\ 4.22 & 1.07\end{array}$


TABLE E.7. Test Results for 96-Hour R. abronius Cadmium Reference Toxicant Test, Richmond Harbor Deepening Project

\begin{tabular}{|c|c|c|c|c|c|c|}
\hline \multirow{2}{*}{$\begin{array}{l}\text { Cadmium } \\
\text { Concentration } \\
\text { (mg/L) }\end{array}$} & \multirow[b]{2}{*}{ Replicate } & \multicolumn{2}{|c|}{ R. abronius } & \multicolumn{3}{|c|}{ Mean } \\
\hline & & Live(a) & $\begin{array}{l}\text { Dead or } \\
\text { Missing }\end{array}$ & $\begin{array}{l}\text { Proportion } \\
\text { Surviving }\end{array}$ & $\begin{array}{l}\text { Proportion } \\
\text { Surviving }\end{array}$ & $\begin{array}{l}\text { Standard } \\
\text { Deviation }\end{array}$ \\
\hline 0.00 & 1 & 19 & 1 & 0.95 & & \\
\hline 0.00 & 2 & 17 & 3 & 0.85 & & \\
\hline 0.00 & 3 & 20 & 0 & 1.00 & 0.93 & 0.08 \\
\hline 0.38 & 1 & 15 & 5 & 0.75 & & \\
\hline 0.38 & 2 & 10 & 10 & 0.50 & & \\
\hline 0.38 & 3 & 5 & 15 & 0.25 & 0.50 & 0.25 \\
\hline 0.75 & 1 & 11 & 9 & 0.55 & & \\
\hline 0.75 & 2 & 12 & 8 & 0.60 & & \\
\hline 0.75 & 3 & 15 & 5 & 0.75 & 0.63 & 0.10 \\
\hline 1.50 & 1 & 5 & 15 & 0.25 & & \\
\hline 1.50 & 2 & 3 & 17 & 0.15 & & \\
\hline 1.50 & 3 & 3 & 17. & 0.15 & 0.18 & 0.06 \\
\hline 3.00 & 1 & 0 & 20 & 0.00 & & \\
\hline 3.00 & 2 & 0 & 20 & 0.00 & & \\
\hline 3.00 & 3 & 0 & 20 & 0.00 & 0.00 & 0.00 \\
\hline
\end{tabular}

(a) Survival based on initial exposure of 20 organisms per replicate. 
TABLE E.8. Daily Observations of R. abronius Floating on Surface During 96-Hour 96-Hour Cadmium Reference Toxicant Test, Richmond Harbor Deepening Project

\begin{tabular}{|c|c|c|c|c|c|}
\hline \multirow{2}{*}{$\begin{array}{l}\text { Cadmium } \\
\text { Concentration } \\
\text { (mg/L) }\end{array}$} & \multirow[b]{2}{*}{ Replicate } & \multicolumn{4}{|c|}{ R. abronius Floating on Surface } \\
\hline & & $2 h$ & $24 \mathrm{~h}$ & $48 \mathrm{~h}$ & $72 \mathrm{~h}$ \\
\hline 0.00 & 1 & 1 & 0 & 0 & 0 \\
\hline 0.00 & 2 & 0 & 0 & 0 & 0 \\
\hline 0.00 & 3 & 0 & 1 & 0 & 0 \\
\hline 0.38 & 1 & 0 & 0 & 3 & 2 \\
\hline 0.38 & 2 & 0 & 2 & 3 & 0 \\
\hline 0.38 & 3 & 0 & 1 & 1 & 0 \\
\hline 0.75 & 1 & 0 & 0 & 0 & 0 \\
\hline 0.75 & 2 & 0 & 2 & 0 & 0 \\
\hline 0.75 & 3 & 1 & 5 & 5 & 0 \\
\hline 1.50 & 1 & 0 & 1 & 6 & 0 \\
\hline 1.50 & 2 & 0 & 1 & 5 & 0 \\
\hline 1.50 & 3 & 0 & 3 & 3 & 0 \\
\hline 3.00 & 1 & 0 & 6 & 3 & 0 \\
\hline 3.00 & 2 & 1 & 4 & 4 & 2 \\
\hline 3.00 & 3 & 0 & 2 & 5 & 0 \\
\hline
\end{tabular}


TABLE E.9. Water Quality Summary for 96-Hour R. abronius Cadmium Reference Toxicant Test, Richmond Harbor Deepening Project

\begin{tabular}{|c|c|c|c|c|c|c|c|c|}
\hline \multirow{2}{*}{$\begin{array}{l}\text { Cadmium } \\
\text { Concentration } \\
\text { (mg/L) }\end{array}$} & \multicolumn{2}{|c|}{$\begin{array}{c}\text { Temperature } \\
\left({ }^{\circ} \mathrm{C}\right)\end{array}$} & \multicolumn{2}{|c|}{$\mathrm{pH}$} & \multicolumn{2}{|c|}{$\begin{array}{l}\text { Dissolved } \\
\text { Oxygen } \\
\text { (mg/L) } \\
\end{array}$} & \multicolumn{2}{|c|}{$\begin{array}{l}\text { Salinity } \\
\text { (o/oo) }\end{array}$} \\
\hline & Min & $\operatorname{Max}$ & Min & Max & Min & $\operatorname{Max}$ & Min & Max \\
\hline \multicolumn{9}{|l|}{ Acceptable } \\
\hline Range & 13.0 & 77.0 & 1.30 & 8.30 & 0.0 & $N A$ (a) & 20.0 & $0<.0$ \\
\hline 0.00 & 15.1 & 15.5 & 7.83 & 7.96 & 7.4 & 8.4 & 31.5 & 32.0 \\
\hline 0.38 & 15.1 & 15.5 & 7.83 & 7.92 & 7.3 & 8.6 & 31.5 & 32.0 \\
\hline 0.75 & 15.1 & 15.5 & 7.84 & 7.93 & 7.6 & 8.6 & 31.0 & 32.0 \\
\hline 1.50 & 15.1 & 15.4 & 7.79 & 7.91 & 7.7 & 8.7 & 31.5 & 32.0 \\
\hline 3.00 & 15.2 & 15.5 & 7.79 & 7.85 & 7.4 & 8.7 & 31.5 & 32.0 \\
\hline
\end{tabular}

(a) NA Not applicable. 


\section{APPENDIX $F$}

INTENSIVE STUDY OF THE TURNING BASIN

BIOASSAY RESULTS FOR 10-DAY SOLID-PHASE, STATIC TEST

AND 96-HOUR REFERENCE TOXICANT TEST FOR RHEPOXYNIUS abronius 


\section{QA/QC SUMMARY}

PROGRAM: Richmond Harbor Deepening Project-Intensive Study of the Tuming Basin TEST ORGANISM: Rhepoxynius abronius

TEST TYPE: $\quad$ Solid-phase; static with aeration

TEST DURATION: 10 days

WATER QUALITY ACCEPTABLE RANGES:

Temperature $\mathrm{pH}$ Dissolved Oxygen Salinity Flow Rate Ammonia $\begin{array}{llllll}13-17^{\circ} \mathrm{C} & 7.30-8.30 & 26.0 \mathrm{mg} / \mathrm{L} & 28-32 \% & \mathrm{NA} & \text { NA }\end{array}$

TEST MATRIX

SOURCE/AGE

HOLDING/ACCLIMATION

Temperature

$\min / \max$

$11.1-14.2^{\circ} \mathrm{C}$

WATER QUALITY SUMMARY

TEST VALIDATION

REFERENCE TOXICANT TEST
Sediments were collected from October 11-13, 1994. Sediments were composited and tested within 6 weeks holding time after collection.

Battelle MSL personnel collected approximately 5000 wild capture (mixed age groups) organisms from West Beach, Whidbey Island, Washington.

Test organisms were held for 4 days at the following conditions prior to test initiation.

\section{pH Dissolved Oxygen Salinity}

$7.55-7.80 \quad 6.1-7.5 \mathrm{mg} / \mathrm{L} \quad 30.5-31.5 \%$

All water quality parameters remained within the acceptable ranges throughout the 10 days of testing except for the $\mathrm{pH}$ and salinity in a few replicates. These exceedences did not appear to effect the test organisms. Ammonia was measured in the overlying and interstitial water in "dummy" jars on Day 0 and 10. Ammonia in the overlying water was measured in the test jars on Days $0,1,3,7$, and 10. All water quality parameters for the cadmium and ammonia reference toxicant tests were within the acceptable ranges throughout the 96 hours of testing.

The test was validated by $98 \%$ survival in the control sediment ( $C$-WB).

The cadmium chloride reference toxicant test was validated by $95 \%$ survival in the seawater control. An $L C_{50}$ value of $0.81 \mathrm{mg} / \mathrm{L}$ of cadmium was calculated.

The ammonia reference toxicant test was validated by $100 \%$ survival in the seawater control. An $L_{5}$ value of $80.57 \mathrm{mg} / \mathrm{L}$ of ammonia was calculated.

Not applicable.
COMMENTS

BH-DEEPENING 


\section{QAVQC SUMMARY (contd)}

\section{REFERENCES}

ASTM (American Society for Testing and Materials). 1990. Standard Guide for Conducting 10-day Static Sediment Toxicity Tests with Marine and Estuarine Amphipods. ASTM Designation: E 1367-90. American Society for Testing and Materials, Philadelphia, Pennsylvania.

EPAIUSACE (U.S. Environmental Protection Agency/U.S. Army Corps of Engineers). 1991. Evaluation of Dredged Material Proposed for Ocean Disposal (Testing Manual).

EPA-68-C8-0105, U.S. Environmental Protection Agency, Office of Marine and Estuarine Protection, Washington, D.C. 
TABLE F.1. Test Results for 10-Day R. abronius Solid-Phase Static Test, Richmond Harbor Deepening Project-Intensive Study of the Turning Basin

\begin{tabular}{|c|c|c|c|c|c|c|}
\hline $\begin{array}{l}\text { Sediment } \\
\text { Treatment } \\
\end{array}$ & Replicate & Live $^{(a)}$ & $\begin{array}{l}\text { Dead or } \\
\text { Missing }\end{array}$ & $\begin{array}{c}\text { Proportion } \\
\text { Surviving }\end{array}$ & $\begin{array}{c}\text { Mean } \\
\text { Proportion } \\
\text { Surviving } \\
\end{array}$ & $\begin{array}{l}\text { Standard } \\
\text { Deviation }\end{array}$ \\
\hline TB-1 Lower & 1 & 17 & 3 & 0.85 & & \\
\hline TB-1 Lower & 2 & 17 & 3 & 0.85 & & \\
\hline TB-1 Lower & 3 & 16 & 4 & 0.80 & & \\
\hline TB-1 Lower & 4 & 17 & 3 & 0.85 & & \\
\hline TB-1 Lower & 5 & 20 & 0 & 1.00 & 0.87 & 0.08 \\
\hline TB-2 Lower & 1 & 14 & 6 & 0.70 & & \\
\hline TB-2 Lower & 2 & 10 & 10 & 0.50 & & \\
\hline TB-2 Lower & 3 & 8 & 12 & 0.40 & & \\
\hline TB-2 Lower & 4 & 11 & 9 & 0.55 & & \\
\hline TB-2 Lower & 5 & 9 & 11 & 0.45 & 0.52 & 0.12 \\
\hline TB-3 Lower & 1 & 4 & 16 & 0.20 & & \\
\hline TB-3 Lower & 2 & 7 & 13 & 0.35 & & \\
\hline TB-3 Lower & 3 & 2 & 18 & 0.10 & & \\
\hline TB-3 Lower & 4 & 6 & 14 & 0.30 & & \\
\hline TB-3 Lower & 5 & 6 & 14 & 0.30 & 0.25 & 0.10 \\
\hline TB-4 Middle & 1 & 17 & 3 & 0.85 & & \\
\hline TB-4 Middle & 2 & 13 & 7 & 0.65 & & \\
\hline TB-4 Middle & 3 & 17 & 3 & 0.85 & & \\
\hline TB-4 Middle & 4 & 16 & 4 & 0.80 & & \\
\hline TB-4 Middle & 5 & 19 & 1 & 0.95 & 0.82 & 0.12 \\
\hline TB-4 Lower & 1 & 16 & 4 & 0.80 & & \\
\hline TB-4 Lower & 2 & 19 & 1 & 0.95 & & \\
\hline TB-4 Lower & 3 & 16 & 4 & 0.80 & & \\
\hline TB-4 Lower & 4 & 12 & 8 & 0.60 & & \\
\hline TB-4 Lower & 5 & 13 & 7 & 0.65 & 0.76 & 0.14 \\
\hline TB-5 Lower & 1 & 14 & 6 & 0.70 & & \\
\hline TB-5 Lower & 2 & 15 & 5 & 0.75 & & \\
\hline TB-5 Lower & 3 & 11 & 9 & 0.55 & & \\
\hline TḄ-5 Lower & 4 & 12 & 8 & 0.60 & & \\
\hline TB-5 Lower & 5 & 10 & 10 & 0.50 & 0.62 & 0.10 \\
\hline
\end{tabular}


TABLE F.1. (contd)

\begin{tabular}{|c|c|c|c|c|c|c|}
\hline $\begin{array}{l}\text { Sediment } \\
\text { Treatment }\end{array}$ & Replicate & Live & $\begin{array}{l}\text { Dead or } \\
\text { Missing }\end{array}$ & $\begin{array}{c}\text { Proportion } \\
\text { Surviving } \\
\end{array}$ & $\begin{array}{c}\text { Mean } \\
\text { Proportion } \\
\text { Surviving } \\
\end{array}$ & $\begin{array}{l}\text { Standard } \\
\text { Deviation }\end{array}$ \\
\hline TB-6 Lower & 1 & 12 & 8 & 0.60 & & \\
\hline TB-6 Lower & 2 & 16 & 4 & 0.80 & & \\
\hline TB-6 Lower & 3 & 15 & 5 & 0.75 & & \\
\hline TB-6 Lower & 4 & 17 & 3 & 0.85 & & \\
\hline TB-6 Lower & 5 & 16 & 4 & 0.80 & 0.76 & 0.10 \\
\hline TB-7 Lower & 1 & 10 & 10 & 0.50 & & \\
\hline TB-7 Lower & 2 & 11 & 9 & 0.55 & & \\
\hline TB-7 Lower & 3 & 9 & 11 & 0.45 & & \\
\hline TB-7 Lower & 4 & 14 & 6 & 0.70 & & \\
\hline TB-7 Lower & 5 & 11 & 9 & 0.55 & 0.55 . & 0.09 \\
\hline TB-8 Lower & 1 & 15 & 5 & 0.75 & & \\
\hline TB-8 Lower & 2 & 12 & 8 & 0.60 & & \\
\hline TB-8 Lower & 3 & 10 & 10 & 0.50 & & \\
\hline TB-8 Lower & 4 & 13 & 7 & 0.65 & & \\
\hline TB-8 Lower & 5 & 14 & 6 & 0.70 & 0.64 & 0.10 \\
\hline TB-9 Lower & 1 & 8 & 12 & 0.40 & & \\
\hline TB-9 Lower & 2 & 3 & 17 & 0.15 & & \\
\hline TB-9 Lower & 3 & 4 & 16 & 0.20 & & \\
\hline TB-9 Lower & 4 & 4 & 16 & 0.20 & & \\
\hline TB-9 Lower & 5 & 9 & 11 & 0.45 & 0.28 & 0.14 \\
\hline OBM COMP & 1 & 13 & 7 & 0.65 & & \\
\hline OBM COMP & 2 & 15 & 5 & 0.75 & & \\
\hline OBM COMP & 3 & 16 & 4 & 0.80 & & \\
\hline OBM COMP & 4 & 13 & 7 & 0.65 & & \\
\hline OBM COMP & 5 & 11 & 9 & 0.55 & 0.68 & 0.10 \\
\hline R-OS & 1 & 19 & 1 & 0.95 & & \\
\hline R-OS & 2 & 17 & 3 & 0.85 & & \\
\hline R-OS & 3 & 19 & 1 & 0.95 & & \\
\hline R-OS & 4 & 20 & 0 & 1.00 & & \\
\hline R-OS & 5 & 19 & 1 & 0.95 & 0.94 & 0.05 \\
\hline
\end{tabular}


TABLEF.1. (contd)

\begin{tabular}{|c|c|c|c|c|c|c|}
\hline $\begin{array}{l}\text { Sediment } \\
\text { Treatment }\end{array}$ & Replicate & Live & $\begin{array}{l}\text { Dead or } \\
\text { Missing }\end{array}$ & $\begin{array}{l}\text { Proportion } \\
\text { Surviving }\end{array}$ & $\begin{array}{c}\text { Mean } \\
\text { Proportion } \\
\text { Surviving }\end{array}$ & $\begin{array}{l}\text { Standard } \\
\text { Deviation }\end{array}$ \\
\hline R-BF & 1 & 19 & 1 & 0.95 & & \\
\hline R-BF & 2 & 17 & 3 & 0.85 & & \\
\hline $\mathrm{R}-\mathrm{BF}$ & 3 & 15 & 5 & 0.75 & & \\
\hline $\mathrm{R}-\mathrm{BF}$ & 4 & 19 & 1 & 0.95 & & \\
\hline R-BF & 5 & 14 & 6 & 0.70 & 0.84 & 0.11 \\
\hline R-AM & 1 & 17 & 3 & 0.85 & & \\
\hline R-AM & 2 & 20 & 0 & 1.00 & & \\
\hline R-AM & 3 & 20 & 0 & 1.00 & & \\
\hline R-AM & 4 & 20 & 0 & 1.00 & & \\
\hline R-AM & 5 & 20 & 0 & 1.00 & 0.97 & 0.07 \\
\hline$C-W B$ & 1 & 19 & 1 & 0.95 & & \\
\hline C-WB & 2 & 19 & 1 & 0.95 & & \\
\hline$C-W B$ & 3 & 20 & 0 & 1.00 & & \\
\hline$C-W B$ & 4 & 20 & 0 & 1.00 & & \\
\hline$C-W B$ & 5 & 20 & 0 & 1.00 & 0.98 & 0.03 \\
\hline C-SB & 1 & 18 & 2 & 0.90 & & \\
\hline C-SB & 2 & 17 & 3 & 0.85 & & \\
\hline C-SB & 3 & 17 & 3 & 0.85 & & \\
\hline C-SB & 4 & 20 & 0 & 1.00 & & \\
\hline C-SB & 5 & 17 & 3 & 0.85 & 0.89 & 0.07 \\
\hline
\end{tabular}

(a) Survival based on initial exposure of 20 organisms per replicate. 
TABLE F.2. Daily Observations of $R$. abronius on Sediment During 10-Day Solid-Phase, Static Test, Richmond Harbor Deepening Project-Intensive Study of the Turning Basin

Sediment

R. abronius on Sediment for Day 0 through 9

Treatment

Replicate

TB-1 Lower

TB-1 Lower

TB-1 Lower

TB-1 Lower

TB-1 Lower

TB-2 Lower

TB-2 Lower

TB-2 Lower

TB-2 Lower

TB-2 Lower

TB-3 Lower

TB-3 Lower

TB-3 Lower

TB-3 Lower

TB-3 Lower

TB-4 Middle

TB-4 Middle

TB-4 Middle

TB-4 Middle

TB-4 Middle

TB-4 Lower

TB-4 Lower

TB-4 Lower

TB-4 Lower

TB-4 Lower

TB-5 Lower

TB-5 Lower

TB-5 Lower

TB-5 Lower

TB-5 Lower

TB-6 Lower

TB-6 Lower

TB-6 Lower

TB-6 Lower

TB-6 Lower

$\begin{array}{lllllllllll}1 & 0 & 0 & 0 & 0 & 0 & 0 & 0 & 0 & 1 & 0 \\ 2 & 0 & 0 & 0 & 0 & 0 & 0 & 0 & 0 & 0 & 0 \\ 3 & 0 & 0 & 0 & 0 & 0 & 0 & 0 & 0 & 1 & 0 \\ 4 & 0 & 0 & 0 & 0 & 0 & 0 & 0 & 0 & 0 & 0 \\ 5 & 0 & 1 & 0 & 0 & 1 & 0 & 0 & 0 & 0 & 0\end{array}$

$\begin{array}{lllllllllll}1 & 0 & 0 & 0 & 2 & 0 & 0 & 0 & 2 & 2 & 3 \\ 2 & 0 & 0 & 0 & 0 & 0 & 0 & 0 & 1 & 3 & 3 \\ 3 & 0 & 0 & 0 & 0 & 0 & 0 & 0 & 0 & 0 & 1 \\ 4 & 1 & 0 & 0 & 0 & 0 & 0 & 0 & 0 & 1 & 0 \\ 5 & 0 & 0 & 0 & 1 & 1 & 0 & 1 & 1 & 1 & 1\end{array}$

$\begin{array}{lllllllllll}1 & 0 & 1 & 0 & 0 & 0 & 0 & 0 & 0 & 1 & 2 \\ 2 & 1 & 0 & 0 & 0 & 2 & 0 & 2 & 1 & 2 & 0 \\ 3 & 2 & 0 & 0 & 0 & 0 & 0 & 0 & 0 & 1 & 0 \\ 4 & 0 & 0 & 0 & 0 & 0 & 0 & 0 & 0 & 0 & 0 \\ 5 & 0 & 0 & 0 & 0 & 0 & 0 & 1 & 0 & 1 & 0\end{array}$

1

2

3

4

5

1

2

3

4

5

1

2

3

4

$\begin{array}{llllllllll}2 & 1 & 0 & 1 & 0 & 0 & 0 & 1 & 1 & 1 \\ 0 & 1 & 0 & 0 & 0 & 0 & 0 & 0 & 1 & 1 \\ 1 & 1 & 0 & 0 & 0 & 0 & 0 & 0 & 0 & 1 \\ 1 & 0 & 0 & 0 & 0 & 0 & 0 & 0 & 0 & 0 \\ 0 & 0 & 0 & 0 & 0 & 0 & 0 & 0 & 0 & 0\end{array}$

(2)

$\begin{array}{lll}0 & 0 & 0\end{array}$

$\begin{array}{llll}0 & 0 & 0 & 0 \\ 0 & 0 & 0 & 0 \\ 0 & 0 & 0 & 0 \\ 0 & 0 & 0 & 0 \\ 0 & 0 & 0 & 0\end{array}$

1
2
3
4
5

$\begin{array}{llllllllll}0 & 0 & 0 & 0 & 0 & 0 & 0 & 0 & 0 & 0 \\ 0 & 0 & 0 & 0 & 0 & 0 & 0 & 0 & 0 & 0 \\ 1 & 1 & 0 & 0 & 1 & 0 & 0 & 0 & 0 & 0 \\ 0 & 0 & 0 & 0 & 0 & 0 & 0 & 0 & 0 & 0 \\ 1 & 0 & 0 & 0 & 0 & 0 & 0 & 0 & 0 & 0\end{array}$

$\begin{array}{llllllllll}0 & 0 & 0 & 0 & 1 & 0 & 1 & 1 & 1 & 0 \\ 0 & 0 & 0 & 0 & 0 & 0 & 0 & 0 & 0 & 1 \\ 0 & 0 & 0 & 0 & 0 & 0 & 0 & 0 & 0 & 0 \\ 0 & 0 & 0 & 0 & 0 & 0 & 0 & 1 & 1 & 1 \\ 0 & 0 & 0 & 0 & 0 & 0 & 0 & 0 & 0 & 0\end{array}$

$\begin{array}{lllllllllll}1 & 1 & 0 & 0 & 1 & 0 & 0 & 0 & 0 & 0 & 0 \\ 2 & 0 & 1 & 0 & 0 & 0 & 0 & 0 & 0 & 0 & 0 \\ 3 & 0 & 0 & 0 & 0 & 0 & 0 & 0 & 0 & 0 & 0 \\ 4 & 0 & 1 & 0 & 0 & 0 & 0 & 0 & 0 & 0 & 0 \\ 5 & 1 & 0 & 0 & 0 & 0 & 0 & 0 & 0 & 1 & 0\end{array}$


TABLEF.2. (contd)

Sediment

R. abronius on Sediment for Day 0 through 9

Treatment

Replicate

TB-7 Lower

TB-7 Lower

TB-7 Lower

TB-7 Lower

TB-7 Lower

TB-8 Lower

TB-8 Lower

TB-8 Lower

TB-8 Lower

TB-8 Lower

TB-9 Lower

TB-9 Lower

TB-9 Lower

TB-9 Lower

TB-9 Lower

$\begin{array}{lllllllllll}1 & 0 & 0 & 0 & 1 & 0 & 0 & 0 & 0 & 1 & 0 \\ 2 & 0 & 0 & 0 & 0 & 0 & 0 & 1 & 1 & 1 & 1 \\ 3 & 0 & 1 & 0 & 1 & 1 & 0 & 0 & 0 & 0 & 0 \\ 4 & 0 & 1 & 0 & 0 & 0 & 0 & 0 & 0 & 0 & 0 \\ 5 & 0 & 0 & 0 & 0 & 0 & 0 & 0 & 0 & 0 & 0\end{array}$

OBM COMP

OBM COMP

OBM COMP

OBM COMP

OBM COMP

R-OS

R-OS

R-OS

R-OS

R-OS

1

2

3

4

1
2
3
4
5

1

0

00

$\begin{array}{ll}1 & 0 \\ 0 & 0\end{array}$

$\begin{array}{llllllll}0 & 0 & 0 & 0 & 0 & 0 & 0 & 0 \\ 0 & 0 & 0 & 0 & 0 & 0 & 0 & 0 \\ 0 & 1 & 1 & 1 & 1 & 0 & 0 & 0 \\ 0 & 0 & 0 & 0 & 0 & 0 & 0 & 0 \\ 0 & 0 & 0 & 0 & 0 & 1 & 0 & 0\end{array}$

R-BF

R-BF

R-BF

R-BF

R-BF

$\begin{array}{llllllllll}0 & 0 & 0 & 0 & 0 & 0 & 0 & 1 & 3 & 4 \\ 0 & 0 & 0 & 1 & 1 & 0 & 0 & 1 & 6 & 4 \\ 0 & 1 & 0 & 2 & 0 & 0 & 0 & 0 & 3 & 4 \\ 0 & 0 & 0 & 0 & 0 & 0 & 0 & 0 & 0 & 0 \\ 0 & 0 & 0 & 0 & 0 & 0 & 1 & 2 & 2 & 2\end{array}$

1

2
3

4

4
5

$\begin{array}{ll}0 & 0 \\ 1 & 0 \\ 0 & 0 \\ 1 & 0 \\ 1 & 0\end{array}$

$\begin{array}{llllllll}0 . & 1 & 0 & 0 & 1 & 0 & 1 & 0 \\ 0 & 0 & 0 & 0 & 0 & 0 & 0 & 0 \\ 0 & 0 & 0 & 0 & 0 & 0 & 1 & 1 \\ 0 & 1 & 2 & 2 & 3 & 1 & \mathrm{~T}^{(b)} & 0 \\ 0 & 0 & 0 & 0 & 0 & 0 & 2 & 0\end{array}$

R-AM

R-AM

R-AM

R-AM

PI-AM

1
2
3
4
5

$\begin{array}{ll}0 & 0\end{array}$

$\begin{array}{llllllllll}0 & 0 & 0 & 0 & 0 & 0 & 1 & 0 & 0 & 0\end{array}$

$\begin{array}{llllllllll}0 & 0 & 0 & 0 & 0 & 0 & 0 & 0 & 0 & 0\end{array}$

$\begin{array}{ll}0 & 0 \\ 0 & 0\end{array}$

$\begin{array}{llllllll}0 & 0 & 0 & 1 & 1 & 0 & 1 & 1\end{array}$

1
2
3
4
5

$\begin{array}{ll}0 & 1 \\ 1 & 0 \\ 0 & 0 \\ 0 & 0 \\ 0 & 0\end{array}$

$\begin{array}{llllllll}0 & 0 & 0 & 0 & 1 & 0 & 2 & 0 \\ 0 & 0 & 1 & 0 & 1 & 0 & 0 & 0 \\ 0 & 0 & 0 & 0 & 0 & 0 & 0 & 0 \\ 0 & 0 & 0 & 0 & 0 & 0 & 0 & 0 \\ 0 & 0 & 0 & 0 & 0 & 0 & 0 & 0\end{array}$

1
2
3
4
5

$\begin{array}{ll}0 & 0 \\ 0 & 0 \\ 0 & 1 \\ 0 & 0 \\ 1 & 0\end{array}$

0
0
0
0
0

$\begin{array}{lllllll}0 & 1 & 0 & 0 & 1 & 1 & 1 \\ 0 & 0 & 0 & 0 & 0 & 0 & 0 \\ 0 & 0 & 0 & 0 & 0 & 0 & 2 \\ 0 & 0 & 0 & 0 & 0 & 0 & 0 \\ 0 & 0 & 0 & 0 & 0 & 0 & 0\end{array}$

BH DEEPENING 
TABLE F.2. (contd)

Sediment

Treatment

\begin{tabular}{ll} 
C-WB & 1 \\
C-WB & 2 \\
C-WB & 3 \\
C-WB & 4 \\
C-WB & 5 \\
& \\
C-SB & 1 \\
C-SB & 2 \\
C-SB & 3 \\
C-SB & 4 \\
C-SB & 5 \\
\hline
\end{tabular}

R. abronius on Sediment for Day 0 through 9

\begin{tabular}{lllllllllllll} 
& \multicolumn{1}{c}{ Replicate } & 0 & 1 & 2 & 3 & 4 & 5 & 6 & 7 & 8 & 9 \\
\hline
\end{tabular}

$\begin{array}{llllllllll}0 & 0 & 0 & 0 & 0 & 0 & 0 & 0 & 1 & 1 \\ 0 & 0 & 0 & 0 & 0 & 0 & 0 & 1 & 1 & 1 \\ 0 & 0 & 0 & 0 & 0 & 0 & 0 & 0 & 0 & 0 \\ 0 & 0 & 0 & 0 & 1 & 0 & 0 & 0 & 0 & 0 \\ 0 & 0 & 0 & 0 & 0 & 0 & 0 & 0 & 0 & 0\end{array}$

$\begin{array}{llllllllll}0 & 0 & 0 & 1 & 1 & 1 & 1 & 1 & 1 & 0 \\ 0 & 1 & 0 & 2 & 0 & 0 & 0 & 0 & 0 & 0 \\ 0 & 0 & 0 & -0 & 1 & 0 & 1 & 0 & 2 & 0 \\ 0 & 0 & 0 & 0 & 0 & 0 & 0 & 0 & 2 & 0 \\ 0 & 1 & 0 & 1 & 2 & 0 & 1 & 0 & 1 & 0\end{array}$

(a) On Test Day 0 observations were performed 2 hours after test initiation.

(b) T Too turbid for observations. 
TABLEF.3. Daily Observations of $R$. abronius Floating on Surface During 10-Day SolidPhase, Static Test, Richmond Harbor Deepening Project-Intensive Study of the Turning Basin

Sediment R. abronius Floating on Surface for Day 0 through 9

Treatment

Replicate

TB-1 Lower

TB-1 Lower

TB-1 Lower

TB-1 Lower

TB-1 Lower

TB-2 Lower

TB-2 Lower

TB-2 Lower

TB-2 Lower

TB-2 Lower

TB-3 Lower

TB-3 Lower

TB-3 Lower

TB-3 Lower

TB-3 Lower

TB-4 Middle

TB-4 Middle

TB-4 Middle

TB-4 Middle

TB-4 Middle

TB-4 Lower

TB-4 Lower

TB-4 Lower

TB-4 Lower

TB-4 Lower

TB-5 Lower

TB-5 Lower

TB-5 Lower

TB-5 Lower

TB-5 Lower

TB-6 Lower

TB-6 Lower

TB-6 Lower

TB-6 Lower

TB-6 Lower

$\begin{array}{lllllllllll}1 & 0 & 0 & 0 & 1 & 0 & 0 & 4 & 0 & 2 & 0 \\ 2 & 0 & 0 & 1 & 0 & 0 & 2 & 0 & 3 & 2 & 1 \\ 3 & 0 & 2 & 0 & 1 & 1 & 1 & 0 & 0 & 1 & 2 \\ 4 & 0 & 0 & 2 & 1 & 1 & 2 & 2 & 3 & 2 & 1 \\ 5 & 0 & 0 & 0 & 1 & 0 & 2 & 2 & 1 & 2 & 2\end{array}$

$\begin{array}{lllllllllll}1 & 0 & 0 & 0 & 0 & 1 & 0 & 2 & 0 & 0 & 1 \\ 2 & 0 & 0 & 1 & 0 & 0 & 1 & 2 & 0 & 0 & 0 \\ 3 & 0 & 0 & 0 & 0 & 1 & 0 & 0 & 0 & 1 & 0 \\ 4 & 0 & 0 & 0 & 0 & 0 & 1 & 0 & 0 & 0 & 0 \\ 5 & 1 & 0 & 0 & 0 & 1 & 0 & 0 & 0 & 2 & 2\end{array}$

$\begin{array}{lllllllllll}1 & 0 & 0 & 0 & 0 & 1 & 1 & 1 & 0 & 0 & 0 \\ 2 & 0 & 0 & 0 & 0 & 0 & 1 & 0 & 0 & 0 & 0 \\ 3 & 0 & 0 & 0 & 0 & 0 & 0 & 0 & 0 & 0 & 0 \\ 4 & 0 & 0 & 0 & 2 & 0 & 0 & 0 & 0 & 2 & 0 \\ 5 & 0 & 0 & 0 & 0 & 1 & 0 & 2 & 0 & 0 & 0\end{array}$

$\begin{array}{lllllllllll}1 & 0 & 0 & 0 & 1 & 1 & 1 & 2 & 1 & 1 & 1 \\ 2 & 0 & 0 & 0 & 0 & 0 & 1 & 1 & 1 & 0 & 1 \\ 3 & 0 & 0 & 0 & 3 & 0 & 2 & 0 & 2 & 2 & 2 \\ 4 & 0 & 0 & 0 & 1 & 1 & 0 & 0 & 0 & 0 & 0 \\ 5 & 0 & 1 & 0 & 0 & 1 & 1 & 1 & 1 & 1 & 0\end{array}$

$\begin{array}{lllllllllll}1 & 0 & 0 & 0 & 0 & 0 & 0 & 0 & 1 & 0 & 0 \\ 2 & 0 & 0 & 0 & 1 & 0 & 1 & 1 & 0 & 1 & 0 \\ 3 & 0 & 1 & 0 & 1 & 0 & 0 & 2 & 3 & 1 & 0 \\ 4 & 0 & 0 & 0 & 0 & 0 & 0 & 0 & 0 & 0 & 0 \\ 5 & 1 & 0 & 0 & 0 & 0 & 0 & 0 & 1 & 1 & 1\end{array}$

$\begin{array}{lllllllllll}1 & 0 & 0 & 0 & 0 & 0 & 0 & 0 & 0 & 0 & 0 \\ 2 & 0 & 0 & 0 & 0 & 1 & 1 & 0 & 1 & 0 & 2 \\ 3 & 0 & 0 & 0 & 0 & 2 & 0 & 0 & 0 & 0 & 0 \\ 4 & 0 & 0 & 1 & 1 & 4 & 1 & 1 & 0 & 1 & 0 \\ 5 & 0 & 0 & 0 & 0 & 0 & 0 & 0 & 1 & 0 & 0\end{array}$

$\begin{array}{lllllllllll}1 & 0 & 1 & 0 & 0 & 1 & 0 & 0 & 1 & 0 & 2 \\ 2 & 0 & 0 & 0 & 1 & 0 & 0 & 0 & 1 & 0 & 0 \\ 3 & 0 & 0 & 1 & 0 & 2 & 0 & 0 & 1 & 0 & 0 \\ 4 & 0 & 0 & 1 & 0 & 0 & 2 & 1 & 0 & 2 & 1 \\ 5 & 0 & 0 & 0 & 0 & 1 & 2 & 0 & 0 & 0 & 0\end{array}$

BHDEEPENING 
TABLEF.3. (contd)

Sediment

R. abronius Floating on Surface for Day 0 through 9

Treatment

Replicate

TB-7 Lower

TB-7 Lower

TB-7 Lower

TB-7 Lower

TB-7 Lower

TB-8 Lower

TB-8 Lower

TB-8 Lower

TB-8 Lower

TB-8 Lower

TB-9 Lower

TB-9 Lower

TB-9 Lower

TB-9 Lower

TB-9 Lower

$\begin{array}{lllllllllll}1 & 0 & 0 & 0 & 0 & 0 & 1 & 1 & 1 & 0 & 0 \\ 2 & 0 & 0 & 1 & 1 & 1 & 3 & 1 & 0 & 1 & 0 \\ 3 & 0 & 0 & 0 & 2 & 0 & 0 & 0 & 1 & 0 & 0 \\ 4 & 0 & 0 & 0 & 0 & 0 & 1 & 0 & 0 & 0 & 0 \\ 5 & 0 & 0 & 0 & 0 & 0 & 0 & 1 & 2 & 0 & 1\end{array}$

OBM COMP

OBM COMP

OBM COMP

OBM COMP

OBM COMP

R-OS

R-OS

R-OS

R-OS

R-OS

R-BF

R-BF

R-BF

R-BF

R-BF

$\begin{array}{lllllllllll}1 & 0 & 0 & 0 & 0 & 0 & 1 & 2 & 1 & 1 & 1 \\ 2 & 0 & 0 & 0 & 1 & 0 & 0 & 0 & 0 & 0 & 0 \\ 3 & 0 & 0 & 0 & 0 & 0 & 1 & 0 & 0 & 1 & 1 \\ 4 & 0 & 0 & 0 & 0 & 0 & 0 & 0 & 0 & 1 & 0 \\ 5 & 0 & 0 & 0 & 0 & 0 & 0 & 0 & 0 & 0 & 1\end{array}$

$\begin{array}{lllllllllll}1 & 0 & 0 & 0 & 0 & 0 & 0 & 0 & 0 & 0 & 3 \\ 2 & 0 & 0 & 0 & 0 & 0 & 3 & 1 & 0 & 0 & 0\end{array}$

$3 \cdot \begin{array}{llllllllll}3 & 0 & 0 & 0 & 0 & 2 & 0 & 1 & 0 & 1\end{array}$

$\begin{array}{lllllllllll}4 & 0 & 0 & 0 & 0 & 0 & 1 & 0 & 0 & 0 & 0\end{array}$

$\begin{array}{lllllllllll}5 & 0 & 0 & 0 & 0 & 0 & 0 & 0 & 0 & 0 & 2\end{array}$

R-AM

R-AM

$\begin{array}{lllllllllll}1 & 0 & 0 & 0 & 0 & 0 & 0 & 1 & 0 & 0 & 0 \\ 2 & 0 & 0 & 0 & 1 & 0 & 0 & 0 & 0 & 0 & 0 \\ 3 & 0 & 1 & 0 & 0 & 0 & 0 & 0 & 0 & 0 & 0 \\ 4 & 0 & 0 & 0 & 0 & 0 & 0 & 0 & 0 & 0 & 0 \\ 5 & 0 & 0 & 0 & 0 & 0 & 0 & 0 & 0 & 0 & 0\end{array}$

R-AM

R-AM

R-AM

$\begin{array}{lllllllllll}1 & 0 & T^{(b)} & 0 & 1 & 1 & 1 & 0 & 0 & 0 & 0 \\ 2 & 0 & 0 & 0 & 0 & 0 & 0 & 0 & 0 & 1 & 0 \\ 3 & 0 & \mathrm{~T} & 0 & 0 & 0 & 0 & 0 & 0 & 0 & 0 \\ 4 & 0 & \mathrm{~T} & 0 & 0 & 0 & 0 & 0 & 0 & 0 & 0 \\ 5 & 0 & 0 & 0 & 0 & 0 & 0 & 0 & 0 & 0 & 0\end{array}$

$\begin{array}{lllllllllll}1 & 0 & 0 & 0 & 0 & 0 & 1 & 2 & 1 & 1 & 2 \\ 2 & 0 & 0 & 0 & 0 & 0 & 0 & 0 & 0 & 0 & 0 \\ 3 & 0 & 0 & 0 & 0 & 0 & 0 & 0 & 0 & 0 & 0 \\ 4 & 0 & 0 & 0 & 0 & 0 & 1 & 0 & 0 & 0 & 0 \\ 5 & 0 & 0 & 0 & 0 & 1 & 1 & 0 & 0 & 0 & 0\end{array}$

$\begin{array}{lllllllllll}1 & 0 & 0 & 0 & 0 & 0 & 0 & 0 & 0 & 0 & 0 \\ 2 & 0 & 0 & 0 & 0 & 0 & 0 & 0 & 0 & 0 & 0 \\ 3 & 0 & 0 & 0 & 0 & 0 & 0 & 0 & 0 & 0 & 0 \\ 4 & 0 & 0 & 0 & 0 & 0 & 0 & 0 & 0 & 0 & 0 \\ 5 & 0 & 0 & 0 & 0 & 0 & 0 & 0 & 0 & 0 & 0\end{array}$


TABLEF.3. (contd)

Sediment

R. abronius Floating on Surface for Day 0 through 9

Treatment

Replicate

$C-W B$
$C-W B$
$C-W B$
C-WB
C-WB

100

20

300

$\begin{array}{lllll}3 & 0 & 0 & 0 & 0 \\ 4 & 0 & 0 & 0 & 0 \\ 5 & 0 & 0 & 0 & 0\end{array}$

C-SB

C-SB

C-SB

C-SB

C-SB

$\begin{array}{ll}1 & 0 \\ 2 & 1 \\ 3 & 0 \\ 4 & 1 \\ 5 & 0\end{array}$

$\begin{array}{llllllllll}0 & 2 & 0 & 2 & 0 & 4 & 2 & 1 & 3 & 3 \\ 1 & 0 & 1 & 2 & 1 & 2 & 2 & 1 & 2 & 2 \\ 0 & 0 & 2 & 3 & 3 & 1 & 3 & 1 & 3 & 1 \\ 1 & 1 & 2 & 2 & 5 & 1 & 0 & 0 & 0 & 2 \\ 0 & 3 & 0 & 4 & 1 & 4 & 4 & 3 & 4 & 2\end{array}$

(a) On Test Day 0 observations were performed 2 hours after test initiation.

(b) $T$ Too turbid for observations. 
IABLE F.4. Water Quality Summary for 10-day R. abronius Solid-Phase, Static Test Richmond Harbor Deepening Project-Intensive Study of the Turning Basin

\begin{tabular}{|c|c|c|c|c|c|c|c|c|}
\hline \multirow{2}{*}{$\begin{array}{l}\text { Sediment } \\
\text { Treatment } \\
\end{array}$} & \multicolumn{2}{|c|}{$\begin{array}{c}\text { Temperature } \\
\left({ }^{\circ} \mathrm{C}\right)\end{array}$} & \multicolumn{2}{|c|}{$\mathrm{pH}$} & \multicolumn{2}{|c|}{$\begin{array}{c}\text { Dissolved } \\
\text { Oxygen } \\
\text { (mg/L) }\end{array}$} & \multicolumn{2}{|c|}{$\begin{array}{l}\text { Salinity } \\
(\mathrm{O} / \mathrm{oo})\end{array}$} \\
\hline & Min & Max & Min & Max & Min & Max & Min & $\operatorname{Max}$ \\
\hline \multicolumn{9}{|l|}{ Acceptable } \\
\hline Range & 13.0 & 17.0 & 7.30 & 8.30 & 6.0 & $N A^{(a)}$ & 28.0 & 32.0 \\
\hline TB-1 Lower & 15.0 & 15.9 & 7.95 & 8.14 & 7.5 & 7.9 & 30.5 & 32.0 \\
\hline TB-2 Lower & 15.0 & 15.9 & 8.15 & $8.39^{\text {(b) }}$ & 7.3 & 7.9 & 30.0 & 31.5 \\
\hline TB-3 Lower & 15.0 & 16.0 & 8.14 & $8.42^{\text {(b) }}$ & 7.3 & 7.9 & 30.0 & 31.5 \\
\hline TB-4 Middle & 15.0 & 15.9 & 8.08 & $8.40^{\text {(b) }}$ & 7.2 & 7.9 & 30.5 & 31.5 \\
\hline TB-4 Lower & 15.0 & 15.5 & 8.11 & 8.29 & 7.4 & 7.9 & 30.5 & 31.5 \\
\hline TB-5 Lower & 15.1 & 16.0 & 8.11 & $8.37^{\text {(b) }}$ & 7.3 & 7.9 & 30.0 & 31.5 \\
\hline TB-6 Lower & 15.1 & 16.0 & 7.99 & 8.19 & 7.4 & 8.0 & 30.0 & 31.0 \\
\hline TB-7 Lower & 15.0 & 15.8 & 8.02 & 8.26 & 7.1 & 7.9 & 30.0 & 30.5 \\
\hline TB-8 Lower & 15.1 & 15.9 & 8.07 & 8.28 & 7.3 & 8.0 & 30.0 & 31.0 \\
\hline TB-9 Lower & 14.9 & 15.8 & 8.10 & $8.41^{(b)}$ & 7.4 & 7.9 & 30.5 & 32.0 \\
\hline OBM СОMP & 15.0 & 15.8 & 7.98 & 8.18 & 7.6 & 8.0 & 31.0 & $33.0^{(b)}$ \\
\hline R-OS & 15.0 & 15.9 & 7.94 & 8.11 & 7.5 & 7.9 & 31.0 & $33.0^{\text {(b) }}$ \\
\hline R-BF & 15.1 & 15.8 & 7.86 & 8.09 & 7.4 & 7.8 & 31.0 & $32.5^{(b)}$ \\
\hline R-AM & 15.0 & 15.9 & 7.87 & 8.10 & 7.4 & 7.9 & 30.5 & $33.0^{(b)}$ \\
\hline C-WB & 15.0 & 15.9 & 7.80 & 8.09 & 7.3 & 7.9 & 31.0 & $32.5^{(b)}$ \\
\hline C-SB & 15.0 & 15.9 & 7.81 & 8.19 & 7.3 & 7.9 & 31.0 & $33.0^{(b)}$ \\
\hline
\end{tabular}

(a) NA Not applicable.

(b) Data point out of range. 
TABLE F.5. Ammonia Measurements in Overlying Water for 10-Day R. abronius Solid-Phase, Static Test, Richmond Harbor Deepening ProjectIntensive Study of the Turning Basin

\begin{tabular}{lccccc}
$\begin{array}{l}\text { Sediment } \\
\text { Treatment }\end{array}$ & $\begin{array}{c}\text { Ammonia } \\
(\mathrm{mg} / \mathrm{L})\end{array}$ & $\begin{array}{c}\text { Temperature } \\
\left({ }^{\circ} \mathrm{C}\right)\end{array}$ & $\mathrm{pH}$ & $\begin{array}{c}\text { Oissolved } \\
\text { Oxygen } \\
(\mathrm{mg} / \mathrm{L})\end{array}$ & $\begin{array}{r}\text { Salinity } \\
(\mathrm{O} / \mathrm{oO})\end{array}$ \\
\hline & & & & & \\
& & & & & \\
Day 0 & & & \\
TB-1 Lower & 3.10 & 16.3 & 8.03 & 7.5 & 31.0 \\
TB-2 Lower & 13.4 & 16.0 & 8.39 & 7.7 & 30.5 \\
TB-3 Lower & 11.7 & 16.1 & 8.45 & 7.8 & 30.5 \\
TB-4 Middle & 12.5 & 16.3 & 8.13 & 6.8 & 31.0 \\
TB-4 Lower & 10.6 & 16.3 & 8.18 & 7.5 & 31.0 \\
TB-5 Lower & 11.6 & 16.0 & 8.28 & 7.5 & 30.0 \\
TB-6 Lower & 7.82 & 15.9 & 8.17 & 7.6 & 30.0 \\
TB-7 Lower & 8.38 & 15.8 & 8.25 & 7.6 & 30.0 \\
TB-8 Lower & 7.46 & 15.9 & 8.21 & 7.5 & 30.5 \\
TB-9 Lower & 25.3 & 15.9 & 8.40 & 7.8 & 30.0 \\
OBM COMP & 0.734 & 15.9 & 8.21 & 7.7 & 31.0 \\
R-OS & 0.447 & 15.9 & 8.12 & 7.7 & 32.0 \\
R-BF & 2.71 & 16.1 & 8.11 & 7.6 & 31.5 \\
R-AM & 0.140 & 15.9 & 8.05 & 7.7 & 31.0 \\
C-WB & 0.347 & 16.0 & 7.95 & 7.4 & 32.0 \\
C-SB & 1.67 & 16.0 & 8.08 & 7.5 & 31.5
\end{tabular}

TB-1 Lower

TB-2 Lower

TB-3 Lower

TB-4 Middle

TB-4 Lower

TB-5 Lower

TB-6 Lower

TB-7 Lower

TB-8 Lower

TB-9 Lower

OBM COMP

R-OS

R-BF

R-AM

C-WB

C-SB

Day 1

\begin{tabular}{rrrrr}
\hline 3.06 & 14.8 & 8.05 & 7.7 & 30.5 \\
16.1 & 14.9 & 8.35 & 7.6 & 30.5 \\
12.3 & 14.8 & 8.31 & 7.7 & 31.0 \\
13.0 & 14.7 & 8.22 & 7.5 & 30.5 \\
14.2 & 14.6 & 8.22 & 7.6 & 31.0 \\
10.2 & 14.6 & 8.32 & 7.6 & 30.5 \\
10.9 & 15.0 & 8.15 & 7.5 & 30.0 \\
11.3 & 15.0 & 8.21 & 7.5 & 30.5 \\
5.57 & 14.6 & 8.19 & 7.4 & 30.5 \\
18.5 & 14.8 & 8.30 & 7.6 & 30.5 \\
0.639 & 15.1 & 8.10 & 7.7 & 31.0 \\
0.396 & 14.5 & 8.07 & 7.6 & 31.0 \\
2.83 & 14.8 & 8.08 & 7.6 & 31.0 \\
0.180 & 14.8 & 8.02 & 7.7 & 30.5 \\
0.330 & 14.8 & 7.92 & 7.4 & 31.0 \\
1.61 & 14.8 & 8.02 & 7.6 & 31.0
\end{tabular}


TABLE F.5. (contd)

\begin{tabular}{|c|c|c|c|c|c|}
\hline $\begin{array}{l}\text { Sediment } \\
\text { Treatment }\end{array}$ & $\begin{array}{l}\text { Ammonia } \\
(\mathrm{mg} / \mathrm{L})\end{array}$ & $\begin{array}{c}\text { Temperature } \\
\left({ }^{\circ} \mathrm{C}\right) \\
\end{array}$ & $\mathrm{pH}$ & $\begin{array}{l}\text { Dissolved } \\
\text { Oxygen } \\
\text { (mg/L) }\end{array}$ & $\begin{array}{r}\text { Salinity } \\
(0 / 00)\end{array}$ \\
\hline & \multicolumn{5}{|c|}{ Day 3} \\
\hline TB-1 Lower & 2.55 & 15.3 & 8.06 & 7.9 & 31.5 \\
\hline TB-2 Lower & 14.3 & 15.2 & 8.39 & 7.9 & 30.0 \\
\hline TB-3 Lower & 14.4 & 15.3 & 8.38 & 7.8 & 30.5 \\
\hline TB-4 Middle & 14.2 & 15.2 & 8.26 & 7.9 & 31.0 \\
\hline TB-4 Lower & 14.0 & 15.2 & 8.33 & 7.9 & 31.0 \\
\hline TB-5 Lower & 12.7 & 15.3 & 8.34 & 7.8 & 30.5 \\
\hline TB-6 Lower & 11.4 & 15.1 & 8.20 & 8.0 & 30.0 \\
\hline TB-7 Lower & 12.1 & 15.3 & 8.06 & 7.7 & 30.0 \\
\hline TB-8 Lower & 8.12 & 15.3 & 8.20 & 7.8 & 30.0 \\
\hline TB-9 Lower & 27.7 & 15.6 & 8.42 & 7.9 & 30.5 \\
\hline OBM COMP & 0.723 & 15.1 & 8.11 & 7.8 & 31.5 \\
\hline R-OS & 0.579 & 15.5 & 8.07 & 7.8 & 31.5 \\
\hline R-BF & 2.60 & 15.5 & 8.10 & 7.8 & 31.5 \\
\hline R-AM & 0.177 & 15.4 & 8.02 & 7.7 & 31.5 \\
\hline C-WB & 0.778 & 15.5 & 8.03 & 7.8 & 31.5 \\
\hline \multirow[t]{2}{*}{ C-SB } & 1.23 & 15.4 & 7.98 & 7.9 & 31.5 \\
\hline & \multicolumn{5}{|c|}{ Day 7} \\
\hline TB-1 Lower & 4.94 & 15.7 & 8.13 & 7.8 & 31.0 \\
\hline TB-2 Lower & 19.0 & 15.7 & 8.35 & 7.8 & 31.5 \\
\hline TB-3 Lower & 19.3 & 15.7 & 8.42 & 7.9 & 30.5 \\
\hline TB-4 Middie & 21.0 & 15.8 & 8.39 & 7.9 & 31.5 \\
\hline TB-4 Lower & 19.7 & 15.7 & 8.23 & 7.8 & 31.0 \\
\hline TB-5 Lower & 16.4 & 15.7 & 8.33 & 7.7 & 30.5 \\
\hline TB-6 Lower & 12.5 & 15.7 & 8.15 & 7.9 & 30.5 \\
\hline TB-7 Lower & 13.7 & 15.7 & 8.26 & 7.8 & 30.0 \\
\hline TB-8 Lower & 11.5 & 15.7 & 8.22 & 7.9 & 30.5 \\
\hline TB-9 Lower & 28.3 & 15.8 & 8.40 & 7.7 & 30.5 \\
\hline OBM COMP & 1.13 & 15.7 & 8.12 & 8.0 & 32.0 \\
\hline R-OS & 1.12 & 15.7 & 8.08 & 7.9 & 32.0 \\
\hline $\mathrm{R}-\mathrm{BF}$ & 1.90 & 15.8 & 8.03 & 7.8 & 31.5 \\
\hline R-AM & 0.350 & 15.7 & 8.07 & 7.8 & 31.5 \\
\hline C-WB & 1.39 & 15.8 & 8.08 & 7.9 & 32.0 \\
\hline C-SB & 1.08 & 15.7 & 8.03 & 7.8 & 32.0 \\
\hline
\end{tabular}


TABLEF.5. (contd)

\begin{tabular}{|c|c|c|c|c|c|}
\hline $\begin{array}{l}\text { Sediment } \\
\text { Treatment }\end{array}$ & $\begin{array}{l}\text { Ammonia } \\
(\mathrm{mg} / \mathrm{L})\end{array}$ & $\begin{array}{c}\text { Temperature } \\
\left({ }^{\circ} \mathrm{C}\right) \\
\end{array}$ & $\mathrm{pH}$ & $\begin{array}{l}\text { Dissolved } \\
\text { Oxygen } \\
\text { (mg/L) } \\
\end{array}$ & $\begin{array}{r}\text { Salinity } \\
(0 / 00)\end{array}$ \\
\hline & \multicolumn{5}{|c|}{ Day 10} \\
\hline TB-1 Lower & 2.42 & 14.8 & 8.15 & 7.6 & 32.0 \\
\hline TB-2 Lower & 15.8 & 14.7 & 8.34 & 7.4 & 31.0 \\
\hline TB-3 Lower & 14.7 & 14.7 & 8.44 & 7.6 & 31.0 \\
\hline TB-4 Middle & 15.9 & 14.8 & 8.36 & 7.6 & 31.5 \\
\hline TB-4 Lower & 16.3 & 14.9 & 8.14 & 7.2 & 30.5 \\
\hline TB-5 Lower & 13.6 & 14.7 & 8.36 & 7.5 & 30.5 \\
\hline TB-6 Lower & 11.7 & 14.7 & 8.21 & 7.6 & 30.5 \\
\hline TB-7 Lower & 12.0 & 14.7 & 8.12 & 7.5 & 30.5 \\
\hline TB-8 Lower & 9.63 & 14.7 & 8.27 & 7.6 & 30.5 \\
\hline TB-9 Lower & 32.1 & 14.6 & 8.33 & 7.5 & 30.5 \\
\hline OBM COMP & 0.380 & 14.9 & 8.09 & 7.7 & 32.0 \\
\hline R-OS & 0.566 & 14.9 & 8.12 & 7.6 & 32.5 \\
\hline R-BF & 0.630 & 14.9 & 8.14 & 7.6 & 32.0 \\
\hline R-AM & 0.295 & 14.9 & 8.05 & 7.6 & 32.0 \\
\hline C-WB & 0.564 & 14.9 & 8.08 & 7.6 & 32.0 \\
\hline C-SB & 0.597 & 14.9 & 8.34 & 7.5 & 32.0 \\
\hline
\end{tabular}


TABLE F.6. Water Quality Measurements in Porewater for 10-Day R. abronius SolidPhase, Static Test, Richmond Harbor Deepening Project-Intensive Study of the Turning Basin

\begin{tabular}{|c|c|c|c|c|c|}
\hline $\begin{array}{l}\text { Sediment } \\
\text { Treatment }\end{array}$ & $\begin{array}{l}\text { Ammonia } \\
(\mathrm{mg} / \mathrm{L})\end{array}$ & $\begin{array}{c}\text { Temperature } \\
\left({ }^{\circ} \mathrm{C}\right)\end{array}$ & $\mathrm{pH}$ & $\begin{array}{l}\text { Dissolved } \\
\text { Oxygen } \\
\text { (mg/L) }\end{array}$ & $\begin{array}{l}\text { Salinity } \\
(\mathrm{o} / 00)\end{array}$ \\
\hline & \multicolumn{5}{|c|}{ Day 0} \\
\hline TB-1 Lower & 8.18 & 15.8 & 7.85 & 6.7 & 30.0 \\
\hline TB-2 Lower & 31.4 & 15.4 & 8.08 & 4.4 & 30.0 \\
\hline TB-3 Lower & 24.7 & 15.5 & 8.11 & 4.9 & 30.0 \\
\hline TB-4 Middle & 33.4 & 15.0 & 7.90 & 3.7 & 30.0 \\
\hline TB-4 Lower & 32.9 & 15.8 & 7.93 & 4.7 & 29.5 \\
\hline TB-5 Lower & 22.4 & 15.4 & 8.05 & 4.8 & 30.0 \\
\hline TB-6 Lower & 20.0 & 14.6 & 7.70 & 4.8 & 28.5 \\
\hline TB-7 Lower & 17.9 & 14.1 & 8.07 & 4.4 & 29.0 \\
\hline TB-8 Lower & 16.2 & 15.2 & 8.00 & 4.6 & 29.5 \\
\hline TB-9 Lower & 38.5 & 14.8 & 7.93 & 4.4 & 30.0 \\
\hline OBM COMP & 1.14 & 14.7 & 8.31 & 5.8 & 32.0 \\
\hline R-OS & 1.18 & 14.7 & 7.95 & 5.3 & 32.0 \\
\hline R-BF & 6.98 & 15.4 & 7.45 & 4.0 & 31.5 \\
\hline R-AM & 0.476 & 14.4 & 7.84 & 7.5 & 32.0 \\
\hline$C-W B$ & 2.20 & 15.6 & 7.79 & 5.6 & 31.0 \\
\hline \multirow[t]{2}{*}{ C-SB } & 2.46 & 15.4 & 7.71 & 3.6 & 32.0 \\
\hline & \multicolumn{5}{|c|}{ Day 10} \\
\hline TB-1 Lower & 5.61 & 15.6 & 7.75 & 6.8 & 32.0 \\
\hline TB-2 Lower & 23.7 & 15.5 & 7.98 & 4.9 & 31.0 \\
\hline TB-3 Lower & 21.9 & 15.4 & 7.98 & 4.8 & 31.0 \\
\hline TB-4 Middle & 24.9 & 15.6 & 7.68 & 4.3 & 32.0 \\
\hline TB-4 Lower & 23.6 & 15.6 & 7.86 & 5.3 & 32.0 \\
\hline TB-5 Lower & 19.2 & 15.5 & 7.92 & 4.9 & 30.5 \\
\hline TB-6 Lower & 15.6 & 15.5 & 7.67 & 5.5 & 29.5 \\
\hline TB-7 Lower & 14.9 & 15.5 & 7.82 & 5.4 & 30.0 \\
\hline TB-8 Lower & 14.9 & 15.5 & 7.82 & 5.0 & 30.5 \\
\hline TB-9 Lower & 39.4 & 15.3 & 7.86 & 4.6 & 30.5 \\
\hline OBM COMP & 0.637 & 15.5 & 8.25 & 6.7 & 31.5 \\
\hline R-OS & 1.01 & 15.5 & 7.76 & 5.4 & 32.5 \\
\hline R-BF & 2.11 & 15.5 & 7.46 & 4.4 & 32.0 \\
\hline R-AM & 0.156 & 15.6 & 7.47 & $N A^{(a)}$ & 32.0 \\
\hline C-WB & 2.71 & 15.5 & 7.60 & NA & 32.0 \\
\hline C-SB & 1.08 & 15.4 & 7.30 & 4.2 & 32.0 \\
\hline
\end{tabular}

(a) NA Not applicable. 
TABLE F.7. Test Results for 96-Hour R. abronius Cadmium Reference Toxicant Test, Richmond Harbor Deepening Project-Intensive Study of the Turning Basin

Cadmium

\begin{tabular}{cccc}
$\begin{array}{c}\text { Concentration } \\
(\mathrm{mg} / \mathrm{L})\end{array}$ & Live $^{(\mathrm{a})}$ & $\begin{array}{c}\text { Dead or } \\
\text { Missing }\end{array}$ & $\begin{array}{c}\text { Proportion } \\
\text { Surviving }\end{array}$ \\
\hline & & & \\
0.00 & 19 & 1 & 0.95 \\
0.25 & 15 & 5 & 0.75 \\
0.50 & 12 & 8 & 0.60 \\
1.00 & 10 & 10 & 0.50 \\
1.50 & 5 & 15 & 0.25 \\
2.00 & 2 & 18 & 0.10 \\
4.00 & 0 & 20 & 0.00
\end{tabular}

(a) Survival based on initial exposure of 20 organisms per replicate. 
TABLE F.8. Daily Observations of $R$. abronius Floating on Surface During 96-Hour Cadmium Reference Toxicant Test, Richmond Harbor Deepening

Project-Intensive Study of the Turning Basin

Cadmium

Concentration

$(\mathrm{mg} / \mathrm{L})$

0.00

0.25

0.50

1.00

1.50

2.00

4.00
R. abronius Floating on Surface

\begin{tabular}{llll}
\hline $2 h$ & $24 h$ & $48 h$ & $72 h$ \\
\hline
\end{tabular}

$\begin{array}{ll}0 & 0 \\ 0 & 2 \\ 1 & 4 \\ 0 & 3 \\ 2 & 3 \\ 0 & 4 \\ 0 & 3\end{array}$

2
1
0
0
0
0
0


TABLE F.9. Water Quality Summary for 96-Hour R. abronius Cadmium Reference Toxicant Test, Richmond Harbor Deepening Project-Intensive Study of the Turning Basin

\begin{tabular}{|c|c|c|c|c|c|c|c|c|}
\hline \multirow{2}{*}{$\begin{array}{c}\text { Cadmium } \\
\text { Concentration } \\
\mathrm{mg} / \mathrm{L} \\
\end{array}$} & \multicolumn{2}{|c|}{$\begin{array}{c}\text { Temperature } \\
\left({ }^{\circ} \mathrm{C}\right)\end{array}$} & & & \multicolumn{2}{|c|}{$\begin{array}{c}\text { Oxygen } \\
(\mathrm{mg} / \mathrm{L})\end{array}$} & \multicolumn{2}{|c|}{$\begin{array}{c}\text { Salinity } \\
(\mathrm{o} / \mathrm{oo})\end{array}$} \\
\hline & Min & Max & Min & Max & Min & Max & Min & Max \\
\hline \multicolumn{9}{|l|}{ Acceptable } \\
\hline Range & 13.0 & 17.0 & 7.30 & 8.30 & 6.0 & $N A^{(a)}$ & 28.0 & 32.0 \\
\hline 0.00 & 15.1 & 15.5 & 7.78 & 8.09 & 7.7 & 7.8 & 31.5 & 32.0 \\
\hline 0.25 & 15.2 & 15.5 & 7.73 & 8.09 & 7.7 & 8.0 & 31.5 & 32.0 \\
\hline 0.50 & 15.2 & 15.4 & 7.78 & 8.08 & 7.8 & 8.1 & 31.5 & 32.0 \\
\hline 1.00 & 15.1 & 15.5 & 7.77 & 8.05 & 7.8 & 8.0 & 31.5 & 32.0 \\
\hline 1.50 & 15.2 & 15.5 & 7.71 & 8.04 & 7.9 & 8.1 & 31.5 & 32.0 \\
\hline 2.00 & 15.1 & 15.5 & 7.62 & 8.01 & 7.8 & 8.0 & 31.5 & 32.0 \\
\hline 4.00 & 15.1 & 15.5 & 7.60 & 7.96 & 7.9 & 8.0 & 31.5 & 32.0 \\
\hline
\end{tabular}

(a) NA Not applicable. 
TABLEF.10. Test Results for 96-Hour R. abronius Ammonia Reference Toxicant Test, Richmond Harbor Deepening Project-Intensive Study of the Turning Basin

Ammonia

Concentration

\begin{tabular}{lll} 
Live & Dead or & $\begin{array}{c}\text { Proportion } \\
\text { Surviving }\end{array}$ \\
\hline
\end{tabular}

0

20

0

1.00

10

20

0

1.00

20

20

0

1.00

40

19

1

0.95

80

13

7

0.65

120

5

15

0.25

160

0

20

0.00

(a) Survival based on initial exposure of 20 organisms per replicate. 
TABLEF.11. Daily Observations of $R$. abronius Floating on Surface During. 96-Hour Ammonia Reference Toxicant Test, Richmond Harbor Deepening Project-Intensive Study of the Turning Basin

Ammonia

Concentration

R. abronius Floating on Surface

(mg/L)

$2 \mathrm{~h} \quad 24 \mathrm{~h}$

$48 \mathrm{~h}$

$72 \mathrm{~h}$

$\begin{array}{ccccc}0 & 0 & 2 & 3 & 2 \\ 10 & 1 & 0 & 2 & 5 \\ 20 & 0 & 0 & 1 & 0 \\ 40 & 2 & 0 & 1 & 1 \\ 80 & 1 & 2 & 1 & 0 \\ 120 & 2 & 2 & 0 & 0 \\ 160 & 3 & 1 & 0 & 0\end{array}$


TABLE F.12. Water Quality Summary for 96-Hour R. abronius Ammonia Reference Toxicant Test, Richmond Harbor Deepening Project-Intensive Study of the Turning Basin

\begin{tabular}{|c|c|c|c|c|c|c|c|c|c|c|}
\hline \multirow{2}{*}{$\begin{array}{c}\text { Ammonia } \\
\text { Concentration } \\
\mathrm{mg} / \mathrm{L} \\
\end{array}$} & \multicolumn{2}{|c|}{$\begin{array}{c}\text { Temperature } \\
\left({ }^{\circ} \mathrm{C}\right)\end{array}$} & \multicolumn{4}{|c|}{$\begin{array}{c}\text { Dissolved } \\
\text { Oxygen } \\
(\mathrm{mg} / \mathrm{L})\end{array}$} & \multicolumn{2}{|c|}{$\begin{array}{l}\text { Salinity } \\
(0 / 00)\end{array}$} & \multicolumn{2}{|c|}{$\begin{array}{c}\text { Ammonia } \\
(\mathrm{mg} / \mathrm{L})\end{array}$} \\
\hline & Min & Max & Min & $\operatorname{Max}$ & Min & Max & Min & $\operatorname{Max}$ & Min & Max \\
\hline \multicolumn{11}{|l|}{ Acceptable } \\
\hline Range & 13.0 & 17.0 & 7.30 & 8.30 & 6.0 & $N A^{(a)}$ & 28.0 & 32.0 & $N E^{(b)}$ & NE \\
\hline 0 & 15.0 & 15.6 & 7.71 & 8.05 & 7.7 & 7.8 & 31.5 & 32.0 & 0.212 & 0.419 \\
\hline 10 & 15.0 & 15.6 & 7.65 & 8.04 & 7.8 & 8.0 & 31.5 & 32.0 & 9.15 & 10.5 \\
\hline 20 & 14.9 & 15.6 & 7.65 & 8.05 & 7.7 & 8.0 & 31.0 & 32.0 & 17.3 & 21.7 \\
\hline 40 & 14.9 & 15.5 & 7.60 & 8.08 & 7.8 & 8.1 & 31.0 & 32.0 & 34.7 & 40.0 \\
\hline 80 & 14.9 & 15.5 & 7.59 & 8.06 & 7.8 & 8.0 & 31.5 & 32.0 & 66.2 & 78.6 \\
\hline 120 & 15.0 & 15.5 & 7.60 & 8.03 & 7.8 & 8.1 & 31.5 & 32.0 & 99.5 & 126 \\
\hline 160 & 15.0 & 15.5 & 7.45 & 8.01 & 7.8 & 8.1 & 31.5 & 32.0 & 132 & 179 \\
\hline
\end{tabular}

(a) NA Not applicable.

(b) NE Not established. 
APPENDIX G

INTENSIVE STUDY OF THE TURNING BASIN BIOASSAY RESULTS FOR 10-DAY SOLID-PHASE,

AMMONIA REDUCTION TO $<20 \mathrm{MG} / \mathrm{L}$ TEST FOR RHEPOXYNIUS abronius 


\section{QA/QC SUMMARY}

PROGRAM: $\quad$ Richmond Harbor Deepening Project-Intensive Study of the Tuming Basin TEST ORGANISM: Rhepoxynius abronius

TEST TYPE: $\quad$ Solid-phase; flow-through to reduce ammonia to $<20 \mathrm{mg} / \mathrm{L}$ then static with aeration

TEST DURATION: 10 days

WATER QUALITY ACCEPTABLE RANGES:

Temperature $\mathrm{pH}$ Dissolved Oxygen Salinity Flow Rate Ammonia
$13-17^{\circ} \mathrm{C}$
$7.30-8.30$
$\geq 6.0 \mathrm{mg} / \mathrm{L}$
$28-32 \%$
NA
NA

TEST MATRIX

SOURCE/AGE

HOLDING/ACCLIMATION

Temperature

$\min /$ max

$11.1-14.2^{\circ} \mathrm{C}$

WATER QUALITY SUMMARY

TEST VALIDATION
Sediments were collected from October 11-13, 1994. Sediments were composited and tested within 6 weeks holding time after collection.

Battelle MSL personnel collected approximately 5000 wild capture (mixed age groups) organisms from West Beach, Whidbey Island, Washington.

Test organisms were held for 4 days at the following conditions prior to test initiation.
$\mathrm{pH}$
Dissolved Oxygen
Salinity
$7.55-7.80$
$6.1-7.5 \mathrm{mg} / \mathrm{L}$
$30.5-31.5 \%$

All water quality parameters remained within the acceptable ranges throughout the 10 days of testing except for salinity in a few replicates. These exceedences did not appear to effect the test organisms. Two pre-initiation "dummy" jars were measured for interstitial and overlying ammonia 4 days and 2 days prior to initiation of the organisms. When the ammonia was $<20 \mathrm{mg} / \mathrm{L}$ in the interstitial water, the test was initiated. Ammonia was then measured in the overlying and interstitial water in "dummy" jars on Day 0 and 10 . Ammonia in the overlying water was measured in the test jars on Days $0,1,3,6$, and 10 . All water quality parameters for the cadmium and ammonia reference toxicant tests were within the acceptable ranges throughout the 96 hours of testing.

The test was validated by $98 \%$ survival in the control sediment (C-WB). 


\section{QA/QC SUMMARY (contd)}

REFERENCE TOXICANT TEST The cadmium chloride reference toxicant test was validated by $95 \%$ survival in the seawater control. An LC 50 value of $0.81 \mathrm{mg} / \mathrm{L}$ of cadmium was calculated.

The ammonia reference toxicant test was validated by $100 \%$ survival in the seawater control. An $L C_{50}$ value of $80.57 \mathrm{mg} / \mathrm{L}$ of ammonia was calculated.

COMMENTS

Not applicable.

\section{REFERENCES}

ASTM (American Society for Testing and Materials). 1990. Standard Guide for Conducting 10-day Static Sediment Toxicity Tests with Marine and Estuarine Amphipods. ASTM

Designation: E 1367-90. American Society for Testing and Materials, Philadelphia, Pennsylvania.

EPAUUSACE (U.S. Environmental Protection Agency/U.S. Army Corps of Engineers). 1991. Evaluation of Dredged Material Proposed for Ocean Disposal (Testing Manual).

EPA-68-C8-0105, U.S. Environmental Protection Agency, Office of Marine and Estuarine Protection, Washington, D.C. 
TABLE G.1. Test Results for 10-Day R. abronius Solid-Phase Ammonia Reduction to $<20 \mathrm{mg} / \mathrm{L}$ Test, Richmond Harbor Deepening Project-Intensive Study of the Turning Basin

\begin{tabular}{|c|c|c|c|c|c|c|}
\hline $\begin{array}{l}\text { Sediment } \\
\text { Treatment }\end{array}$ & Replicate & $\operatorname{Live}^{(a)}$ & $\begin{array}{l}\text { Dead or } \\
\text { Missing }\end{array}$ & $\begin{array}{c}\text { Proportion } \\
\text { Surviving } \\
\end{array}$ & $\begin{array}{c}\text { Mean } \\
\text { Proportion } \\
\text { Surviving }\end{array}$ & $\begin{array}{l}\text { Standard } \\
\text { Deviation }\end{array}$ \\
\hline TB-2 Lower & 1 & 14 & 6 & 0.70 & & \\
\hline TB-2 Lower & 2 & 17 & 3 & 0.85 & & \\
\hline TB-2 Lower & 3 & 19 & 1 & 0.95 & & \\
\hline TB-2 Lower & 4 & 14 & 6 & 0.70 & & \\
\hline TB-2 Lower & 5 & 15 & 5 & 0.75 & 0.79 & 0.11 \\
\hline TB-3 Lower & 1 & 18 & 2 & 0.90 & & \\
\hline TB-3 Lower & 2 & 15 & 5 & 0.75 & & \\
\hline TB-3 Lower & 3 & 11 & 9 & 0.55 & & \\
\hline TB-3 Lower & 4 & 8 & 12 & 0.40 & & \\
\hline TB-3 Lower & 5 & 18 & 2 & 0.90 & 0.70 & 0.22 \\
\hline TB-4 Middle & 1 & 18 & 2 & 0.90 & & \\
\hline TB-4 Middle & 2 & 20 & 0 & 1.00 & & \\
\hline TB-4 Middle & 3 & 16 & 4 & 0.80 & & \\
\hline TB-4 Middle & 4 & 17 & 3 & 0.85 & & \\
\hline TB-4 Middle & 5 & 18 & 2 & 0.90 & 0.89 & 0.07 \\
\hline TB-4 Lower & 1 & 16 & 4 & 0.80 & & \\
\hline TB-4 Lower & 2 & 18 & 2 & 0.90 & & \\
\hline TB-4 Lower & 3 & 14 & 6 & 0.70 & & \\
\hline TB-4 Lower & 4 & 15 & 5 & 0.75 & & \\
\hline TB-4 Lower & 5 & 18 & 2 & 0.90 & 0.81 & 0.09 \\
\hline TB-5 Lower & 1 & 14 & 6 & 0.70 & & \\
\hline TB-5 Lower & 2 & 16 & 4 & 0.80 & & \\
\hline TB-5 Lower & 3 & 17 & 3 & 0.85 & & \\
\hline TB-5 Lower & 4 & 16 & 4 & 0.80 & & \\
\hline TB-5 Lower & 5 & 19 & 1 & 0.95 & 0.82 & 0.09 \\
\hline TB-9 Lower & 1 & 14 & 6 & 0.70 & & \\
\hline TB-9 Lower & 2 & 17 & 3 & 0.85 & & \\
\hline TB-9 Lower & 3 & 15 & 5 & 0.75 & & \\
\hline TB-9 Lower & 4 & 10 & 10 & 0.50 & & \\
\hline TB-9 Lower & 5 & 18 & 2 & 0.90 & 0.74 & 0.16 \\
\hline
\end{tabular}

(a) Survival based on initial exposure of 20 organisms per replicate. 
TABLE G.2. Daily Observations of $R$. abronius on Sediment Surface During 10-Day SolidPhase, Ammonia Reduction to $<20 \mathrm{mg} / \mathrm{L}$ Test, Richmond Harbor Deepening Project-Intensive Study of the Turning Basin

Sediment

R. abronius on Sediment for Days 0 through 9

Treatment

Replicate

TB-2 Lower

TB-2 Lower

TB-2 Lower

TB-2 Lower

TB-2 Lower

TB-3 Lower

TB-3 Lower

TB-3 Lower

TB-3 Lower

TB-3 Lower

TB-4 Lower

TB-4 Lower

TB-4 Lower

TB-4 Lower

TB-4 Lower

TB-4 Middle

TB-4 Middle

TB-4 Middle

TB-4 Middle

TB-4 Middle

TB-5 Lower

TB-5 Lower

TB-5 Lower

TB-5 Lower

TB-5 Lower

TB-9 Lower

TB-9 Lower

TB-9 Lower

TB-9 Lower

TB-9 Lower

4

$\begin{array}{lllllllllll}1 & 0 & 0 & 0 & 0 & 0 & 1 & 1 & 1 & 1 & 1 \\ 2 & 0 & 0 & 0 & 0 & 0 & 0 & 2 & 1 & 0 & 0 \\ 3 & 0 & 0 & 0 & 0 & 0 & 0 & 0 & 0 & 0 & 0 \\ 4 & T^{(b)} & 0 & 0 & 0 & 0 & 0 & 0 & 0 & 0 & 0 \\ 5 & 0 & 0 & 0 & 0 & 0 & 0 & 0 & 0 & 0 & 0\end{array}$

$\begin{array}{lllllllllll}1 & 0 & 0 & 0 & 0 & 0 & 0 & 1 & 0 & 0 & 0 \\ 2 & 0 & 0 & 0 & 0 & 0 & 0 & 0 & 0 & 0 & 0 \\ 3 & 0 & 0 & 0 & 0 & 0 & 0 & 0 & 0 & 0 & 0 \\ 4 & 0 & 0 & 0 & 0 & 0 & 0 & 0 & 0 & 0 & 0 \\ 5 & 0 & 0 & 0 & 0 & 0 & 0 & 0 & 0 & 0 & 0\end{array}$

$\begin{array}{lllllllllll}1 & 0 & 0 & 0 & 0 & 0 & 1 & 0 & 0 & 0 & 0 \\ 2 & 0 & 0 & 0 & 0 & 0 & 0 & 0 & 0 & 0 & 0 \\ 3 & 0 & 0 & 0 & 0 & 0 & 0 & 0 & 0 & 0 & 0 \\ 4 & 0 & 0 & 0 & 0 & 0 & 0 & 0 & 0 & 0 & 0 \\ 5 & 0 & 0 & 0 & 0 & 0 & 0 & 0 & 0 & 0 & 0\end{array}$

$\begin{array}{lllllllllll}1 & 0 & 0 & 0 & 0 & 0 & 0 & 0 & 0 & 0 & 0 \\ 2 & 0 & 0 & 0 & 0 & 0 & 0 & 0 & 0 & 0 & 0 \\ 3 & 0 & 0 & 0 & 0 & 0 & 0 & 0 & 0 & 0 & 0 \\ 4 & 0 & 0 & 0 & 0 & 0 & 0 & 0 & 0 & 0 & 0 \\ 5 & 0 & 0 & 0 & 0 & 0 & 0 & 0 & 0 & 0 & 0\end{array}$

$\begin{array}{lllllllllll}1 & 0 & 0 & 0 & 0 & 0 & 0 & 0 & 1 & 0 & 0 \\ 2 & 0 & 0 & 0 & 0 & 0 & 0 & 0 & 0 & 0 & 0 \\ 3 & 0 & 0 & 0 & 0 & 0 & 0 & 0 & 0 & 0 & 0 \\ 4 & 0 & 0 & 0 & 0 & 0 & 0 & 0 & 0 & 0 & 0 \\ 5 & 0 & 0 & 0 & 0 & 0 & 0 & 0 & 0 & 0 & 0\end{array}$

(a) On Test Day 0 observations were performed 2 hours after test initiation.

(b) Too turbid. 
TABLE G.3. Daily. Observations of $R$. abronius Floating on Surface During 10-Day SolidPhase, Ammonia Reduction to $<20 \mathrm{mg} / \mathrm{L}$ Test, Richmond Harbor Deepening Project-Intensive Study of the Turning Basin

\begin{tabular}{|c|c|c|c|c|c|c|c|c|c|c|c|}
\hline \multirow{2}{*}{$\begin{array}{l}\text { Sediment } \\
\text { Treatment }\end{array}$} & \multirow[b]{2}{*}{ Replicate } & \multicolumn{10}{|c|}{ R. abronius Floating for Days 0 through 9} \\
\hline & & $0^{(a)}$ & 1 & 2 & 3 & 4 & 5 & 6 & 7 & 8 & 9 \\
\hline TB-2 Lower & 1 & 0 & 0 & 0 & 0 & 1 & 0 & 0 & 0 & 0 & 1 \\
\hline TB-2 Lower & 2 & 0 & 0 & 0 & 1 & 1 & 1 & 0 & 2 & 3 & 0 \\
\hline TB-2 Lower & 3 & 0 & 0 & 0 & 0 & 0 & 1 & 2 & 1 & 0 & 0 \\
\hline TB-2 Lower & 4 & 0 & 0 & 0 & 0 & 2 & 0 & 1 & 1 & 3 & 1 \\
\hline TB-2 Lower & 5 & 0 & 0 & 0 & 0 & 0 & 0 & 0 & 2 & 0 & 1 \\
\hline TB-3 Lower & 1 & 1 & 0 & 0 & 0 & 1 & 0 & 2 & 2 & 0 & 1 \\
\hline TB-3 Lower & 2 & 0 & 0 & 0 & 1 & 0 & 1 & 3 & 0 & 0 & 1 \\
\hline TB-3 Lower & 3 & 0 & 0 & 0 & 0 & 0 & 1 & 0 & 0 & 0 & 1 \\
\hline TB-3 Lower & 4 & 1 & 0 & 0 & 0 & 0 & 1 & 1 & 0 & 0 & 0 \\
\hline TB-3 Lower & 5 & 0 & 0 & 0 & 0 & 2 & 0 & 1 & 0 & 1 & 0 \\
\hline TB-4 Lower & 1 & 0 & 0 & 0 & 0 & 1 & 1 & 2 & 3 & 1 & 1 \\
\hline TB-4 Lower & 2 & 0 & 0 & 0 & 0 & 0 & 0 & 1 & 1 & 1 & 0 \\
\hline TB-4 Lower & 3 & 0 & 0 & 0 & 1 & 1 & 2 & 0 & 1 & 1 & 1 \\
\hline TB-4 Lower & 4 & 0 & 0 & 1 & 0 & 0 & 1 & 0 & 0 & 0 & 3 \\
\hline TB-4 Lower & 5 & 0 & 0 & 0 & 0 & 0 & 0 & 0 & 0 & 1 & 0 \\
\hline TB-4 Middle & 1 & 0 & 0 & 0 & 0 & 2 & 3 & 0 & 4 & 1 & 5 \\
\hline TB-4 Middle & 2 & 0 & 0 & 0 & 0 & 0 & 2 & 3 & 1 & 1 & 3 \\
\hline TB-4 Middle & 3 & 0 & 0 & 0 & 1 & 0 & 2 & 1 & 4 & 3 & 3 \\
\hline TB-4 Middle & 4 & 0 & 0 & 0 & 1 & 1 & 1 & 1 & 2 & 1 & 4 \\
\hline TB-4 Middle & 5 & 0 & 1 & 2 & 0 & 1 & 2 & 3 & 4 & 2 & 1 \\
\hline TB-5 Lower & 1 & 0 & 1 & 1 & 1 & 1 & 0 & 1 & 1 & 0 & 1 \\
\hline TB-5 Lower & 2 & 0 & 0 & 0 & 0 & 0 & 2 & 0 & 0 & 2 & 2 \\
\hline TB-5 Lower & 3 & 0 & 0 & 0 & 1 & 0 & 1 & 1 & 0 & 2 & 0 \\
\hline TB-5 Lower & 4 & 0 & 0 & 0 & 1 & 2 & 1 & 2 & 2 & 1 & 3 \\
\hline TB-5 Lower & 5 & 0 & 0 & 0 & 0 & 0 & 1 & 1 & 0 & 1 & 2 \\
\hline TB-9 Lower & 1 & 0 & 2 & 0 & 0 & 0 & 0 & 0 & 1 & 1 & 0 \\
\hline TB-9 Lower & 2 & 0 & 0 & 0 & 1 & 3 & 0 & 0 & 2 & 1 & 0 \\
\hline TB-9 Lower & 3 & 0 & 0 & 0 & 0 & 1 & 1 & 0 & 1 & 2 & 1 \\
\hline TB-9 Lower & 4 & 0 & 0 & 0 & 0 & 0 & 0 & 1 & 0 & 1 & 1 \\
\hline TB-9 Lower & 5 & 0 & 0 & 0 & 0 & 0 & 0 & 0 & 1 & 0 & 0 \\
\hline
\end{tabular}

(a) On Test Day 0 observations were performed 2 hours after test initiation. 
TABLE G.4. Water Quality Summary for 10-day R. abronius Solid-Phase Ammonia Reduction to $<20 \mathrm{mg} / \mathrm{L}$ Test, Richmond Harbor Deepening ProjectIntensive Study of the Turning Basin

\begin{tabular}{|c|c|c|c|c|c|c|c|c|}
\hline \multirow{2}{*}{$\begin{array}{l}\text { Sediment } \\
\text { Treatment }\end{array}$} & \multicolumn{2}{|c|}{$\begin{array}{c}\text { Temperature } \\
\left({ }^{\circ} \mathrm{C}\right)\end{array}$} & \multicolumn{2}{|c|}{$\mathrm{pH}$} & \multicolumn{2}{|c|}{$\begin{array}{c}\text { Dissolved } \\
\text { Oxygen } \\
\text { (mg/L) }\end{array}$} & \multicolumn{2}{|c|}{$\begin{array}{l}\text { Salinity } \\
(0 / 00)\end{array}$} \\
\hline & Min & Max & Min & $\operatorname{Max}$ & Min & Max & Min & $\operatorname{Max}$ \\
\hline \multicolumn{9}{|l|}{ Acceptable } \\
\hline Range & 13.0 & 17.0 & 7.30 & 8.30 & 6.0 & $N A^{(a)}$ & 28.0 & 32.0 \\
\hline TB-2 Lower & 14.8 & 16.0 & 7.86 & 8.10 & 7.1 & 8.0 & 31.5 & $32.5^{(b)}$ \\
\hline TB-3 Lower & 14.8 & 16.0 & 7.81 & 8.06 & 7.5 & 8.0 & 31.0 & $32.5^{(\mathrm{b})}$ \\
\hline TB-4 Middle & 14.8 & 16.1 & 7.83 & 8.16 & 7.6 & 8.0 & 31.0 & $32.5^{(\mathrm{b})}$ \\
\hline TB-4 Lower & 14.8 & 16.0 & 7.89 & 8.09 & 7.6 & 8.0 & 31.0 & $32.5^{(\mathrm{b})}$ \\
\hline TB-5 Lower & 14.8 & 16.1 & 7.78 & 8.13 & 7.5 & 8.1 & 31.0 & $33.0^{(b)}$ \\
\hline TB-9 Lower & 14.7 & 16.1 & 7.77 & 8.11 & 7.5 & 8.0 & 31.0 & $33.0^{(b)}$ \\
\hline
\end{tabular}

(a) NA Not applicable.

(b) Data point out of range. 
TABLE G.5. Ammonia Measurements in Overlying Water and Porewater Prior to Initiation of the 10-Day $R$. abronius Solid-Phase, Ammonia Reduction to $<20 \mathrm{mg} / \mathrm{L}$ Test, Richmond Harbor Deepening ProjectIntensive Study of the Turning Basin

\begin{tabular}{|c|c|c|c|c|c|}
\hline $\begin{array}{l}\text { Sediment } \\
\text { Treatment } \\
\end{array}$ & $\begin{array}{c}\text { Ammonia } \\
(\mathrm{mg} / \mathrm{L})\end{array}$ & $\begin{array}{c}\text { Temperature } \\
\left({ }^{\circ} \mathrm{C}\right) \\
\end{array}$ & $\mathrm{pH}$ & $\begin{array}{l}\text { Dissolved } \\
\text { Oxygen } \\
\text { (mg/L) }\end{array}$ & $\begin{array}{l}\text { Salinity } \\
(\mathrm{o} / 00)\end{array}$ \\
\hline Overlying & \multicolumn{5}{|c|}{4 Days Prior to Initiation } \\
\hline TB-2 Lower & 1.30 & 14.9 & 8.06 & 7.3 & 31.5 \\
\hline TB-3 Lower & 3.09 & 14.7 & 7.98 & 7.0 & 31.5 \\
\hline TB-4 Middle & 1.75 & 14.7 & 7.97 & 7.6 & 31.5 \\
\hline TB-4 Lower & 1.57 & 14.8 & 8.07 & 7.6 & 31.5 \\
\hline TB-5 Lower & 3.19 & 14.8 & 8.01 & 7.2 & 31.5 \\
\hline TB-9 Lower & 4.21 & 14.9 & 8.02 & 7.4 & 31.5 \\
\hline Porewater & \multicolumn{5}{|c|}{4 Days Prior to Initiation } \\
\hline TB-2 Lower & 20.7 & 15.1 & 7.91 & 4.4 & 30.0 \\
\hline TB-3 Lower & 16.1 & 15.1 & 7.87 & 4.9 & 30.0 \\
\hline TB-4 Middle & 19.1 & 15.4 & 7.61 & 5.0 & 30.5 \\
\hline TB-4 Lower & 20.4 & 15.2 & 7.83 & 5.0 & 30.0 \\
\hline TB-5 Lower & 17.9 & 15.5 & 7.87 & 6.0 & 30.0 \\
\hline TB-9 Lower & 31.8 & 15.1 & 7.91 & 4.8 & 30.0 \\
\hline Overlying & \multicolumn{5}{|c|}{2 Days Prior to Initiation } \\
\hline TB-2 Lower & 1.32 & 15.0 & 7.94 & 7.6 & 31.5 \\
\hline TB-3 Lower & 2.02 & 14.9 & 7.94 & 7.5 & 31.5 \\
\hline TB-4 Middle & 1.58 & 14.9 & 7.88 & 7.3 & 31.5 \\
\hline TB-4 Lower & 1.35 & 15.0 & 7.97 & 7.5 & 31.5 \\
\hline TB-5 Lower & 1.73 & 15.1 & 8.00 & 7.6 & 31.5 \\
\hline TB-9 Lower & 3.39 & 15.1 & 7.95 & 7.7 & 31.5 \\
\hline Porewater & \multicolumn{5}{|c|}{2 Days Prior to Initiation } \\
\hline TB-2 Lower & 20.2 & 15.2 & 7.87 & 4.0 & 31.5 \\
\hline TB-3 Lower & 20.4 & 15.3 & 7.94 & 4.5 & 31.5 \\
\hline TB-4 Middle & 16.3 & 15.2 & 7.63 & 4.4 & 31.5 \\
\hline TB-4 Lower & 17.9 & 15.2 & 7.76 & 4.5 & 31.0 \\
\hline TB-5 Lower & 15.5 & 15.2 & 7.84 & 4.1 & 30.0 \\
\hline TB-9 Lower & 28.8 & 15.2 & 7.86 & 4.1 & 30.5 \\
\hline DEEPENING & & G.5 & & & \\
\hline
\end{tabular}


TABLE G.6. Ammonia Measurements in Overlying Water for 10-Day R. abronius Solid-Phase, Ammonia Reduction to $<20 \mathrm{mg} / \mathrm{L}$ Test, Richmond Harbor Deepening Project-Intensive Study of the Turning Basin

\begin{tabular}{lccccc}
$\begin{array}{l}\text { Sediment } \\
\text { Treatment }\end{array}$ & $\begin{array}{c}\text { Ammonia } \\
(\mathrm{mg} / \mathrm{L})\end{array}$ & $\begin{array}{c}\text { Temperature } \\
\left({ }^{\circ} \mathrm{C}\right)\end{array}$ & $\mathrm{pH}$ & $\begin{array}{c}\text { Dissolved } \\
\text { Oxygen } \\
(\mathrm{mg} / \mathrm{L})\end{array}$ & $\begin{array}{c}\text { Salinity } \\
(\mathrm{o} / \mathrm{oo})\end{array}$ \\
\hline & \multicolumn{5}{c}{ Day 0 } \\
\cline { 2 - 6 } & & & & \\
TB-2 Lower & 1.23 & 14.7 & 7.88 & 8.0 & 31.5 \\
TB-3 Lower & 0.733 & 14.9 & 7.86 & 7.9 & 31.5 \\
TB-4 Middle & 1.07 & 14.9 & 7.89 & 7.9 & 31.0 \\
TB-4 Lower & ND (a) & 14.9 & 7.90 & 7.9 & 31.5 \\
TB-5 Lower & 0.915 & 14.7 & 7.86 & 7.8 & 31.5 \\
TB-9 Lower & 3.79 & 14.8 & 7.85 & 7.9 & 31.5
\end{tabular}

TB-2 Lower

TB-3 Lower

TB-4 Middle

TB-4 Lower

TB-5 Lower

TB-9 Lower

TB-2 Lower

TB-3 Lower

TB-4 Middle

TB-4 Lower

TB-5 Lower

TB-9 Lower

TB-2 Lower

TB-3 Lower

TB-4 Middle

TB-4 Lower

TB-5 Lower

TB-9 Lower
3.79

14.8

Day 1

\begin{tabular}{rrrrr}
\hline & & & & \\
1.15 & 13.8 & 8.02 & 7.8 & 31.5 \\
1.23 & 13.9 & 7.90 & 7.7 & 31.5 \\
1.14 & 13.9 & 7.96 & 7.8 & 31.0 \\
0.991 & 13.9 & 8.02 & 7.8 & 31.5 \\
1.20 & 13.9 & 7.99 & 7.7 & 31.5 \\
1.72 & 14.0 & 7.93 & 7.8 & 31.5
\end{tabular}

Day 3

\begin{tabular}{lllll}
\hline & & & & \\
2.18 & 15.7 & 8.01 & 7.7 & 31.5 \\
2.51 & 15.7 & 8.06 & 7.5 & 32.0 \\
2.89 & 15.6 & 7.94 & 7.6 & 32.0 \\
1.92 & 15.7 & 8.03 & 7.6 & 31.5 \\
2.81 & 15.7 & 8.04 & 7.7 & 31.5 \\
4.24 & 15.6 & 7.99 & 7.6 & 31.5
\end{tabular}

Day 6

\begin{tabular}{lllll}
\hline & & & & \\
4.75 & 13.9 & 8.01 & 7.6 & 32.0 \\
3.56 & 13.8 & 7.94 & 7.5 & 32.0 \\
4.63 & 13.9 & 8.09 & 7.6 & 32.0 \\
4.16 & 13.9 & 8.03 & 7.6 & 32.5 \\
4.94 & 13.8 & 7.98 & 7.6 & 32.5 \\
8.64 & 13.8 & 8.08 & 7.7 & 32.5
\end{tabular}




\section{TABLE G.6. (contd)}

\begin{tabular}{lccccc} 
& & & Dissolved & \\
Sediment & Ammonia & Temperature & & Oxygen & Salinity \\
Treatment & $(\mathrm{mg} / \mathrm{L})$ & $\left({ }^{\circ} \mathrm{C}\right)$ & $\mathrm{pH}$ & $(\mathrm{mg} / \mathrm{L})$ & $(\mathrm{o} / \mathrm{oo})$ \\
\hline
\end{tabular}

Day 10

TB-2 Lower

TB-3 Lower

TB-4 Middle

TB-4 Lower

TB-5 Lower

TB-9 Lower

\begin{tabular}{|c|c|}
\hline 8.87 & \\
\hline 4.97 & \\
\hline 9.01 & \\
\hline 8.30 & \\
\hline 6.08 & \\
\hline 7.28 & \\
\hline
\end{tabular}

8.02

7.5

$7.5 \quad 32.0$

8.06

$7.6 \quad 32.0$

8.11

7.79

6.0

32.0

8.09

$7.9 \quad 32.0$

8.02

7.4

32.0

(a) ND No data. 
TABLE G.7. Water Quality Measurements of Porewater for 10-Day Solid-Phase, Ammonia Reduction to $<20 \mathrm{mg} / \mathrm{L}$ Test, Richmond Harbor Deepening Project-Intensive Study of the Turning Basin

\begin{tabular}{|c|c|c|c|c|c|}
\hline $\begin{array}{l}\text { Sediment } \\
\text { Treatment }\end{array}$ & $\begin{array}{c}\text { Ammonia } \\
(\mathrm{mg} / \mathrm{L})\end{array}$ & $\begin{array}{c}\text { Temperature } \\
\left({ }^{\circ} \mathrm{C}\right)\end{array}$ & $\mathrm{pH}$ & $\begin{array}{l}\text { Dissolved } \\
\text { Oxygen } \\
\text { (mg/L) }\end{array}$ & $\begin{array}{l}\text { Salinity } \\
\text { (o/oo) }\end{array}$ \\
\hline & \multicolumn{5}{|c|}{ Day 0} \\
\hline TB-2 Lower & 14.2 & 15.0 & 7.97 & 5.6 & 31.5 \\
\hline TB-3 Lower & 9.87 & 14.9 & 7.94 & 5.4 & 31.5 \\
\hline TB-4 Middle & 15.1 & 14.9 & 7.73 & 4.5 & 31.5 \\
\hline TB-4 Lower & $N D^{(a)}$ & ND & ND & ND & ND \\
\hline TB-5 Lower & 11.7 & 14.9 & 7.96 & 5.3 & 31.5 \\
\hline \multirow[t]{2}{*}{ TB-9 Lower } & 18.0 & 14.9 & 7.94 & 6.0 & 31.5 \\
\hline & \multicolumn{5}{|c|}{ Day 10} \\
\hline TB-2 Lower & 10.3 & 16.4 & 7.83 & 5.3 & 32.0 \\
\hline TB-3 Lower & 12.6 & 16.4 & 7.79 & 5.2 & 32.0 \\
\hline TB-4 Middle & 9.49 & 16.3 & 7.61 & 5.0 & 32.0 \\
\hline TB-4 Lower & 13.9 & 16.3 & 7.64 & 5.1 & 32.0 \\
\hline TB-5 Lower & 12.5 & 16.3 & 7.84 & 5.6 & 32.0 \\
\hline TB-9 Lower & 15.6 & 16.3 & 7.77 & 5.4 & 32.0 \\
\hline
\end{tabular}

(a) ND No data. 
APPENDIX H

INTENSIVE STUDY OF THE TURNING BASIN

BIOASSAY RESULTS FOR 10-DAY SOLID-PHASE, AMMONIA REDUCTION TO <15 MG/L TEST AND 96-HOUR REFERENCE TOXICANT TEST FOR RHEPOXYNIUS abroniUS 


\section{QA/QC SUMMARY}

PROGRAM: $\quad$ Richmond Harbor Deepening Project-Intensive Study of the Turning Basin TEST ORGANISM: Rhepoxynius abronius

TEST TYPE: $\quad$ Solid-phase; flow-through to reduce ammonia to $<15 \mathrm{mg} / \mathrm{L}$ then static with aeration

TEST DURATION: 10 days

WATER QUALITY ACCEPTABLE RANGES:

Temperature $\mathrm{pH}$ Dissolved Oxygen Salinity Flow Rate Ammonia $\begin{array}{llllll}13-17^{\circ} \mathrm{C} & 7.30-8.30 & \geq 6.0 \mathrm{mg} / \mathrm{L} & 28-32 \% & \mathrm{NA} & \mathrm{NA}\end{array}$

TEST MATRIX

SOURCE/AGE

HOLDING/ACCLIMATION

Temperature

$\min / \max$

$7.3-15.4^{\circ} \mathrm{C}$

WATER QUALITY SUMMARY

TEST VALIDATION
Sediments were collected from October 11-13, 1994. Sediments were composited and tested within 6 weeks holding time after collection.

Battelle MSL personnel collected approximately 1000 wild captured (mixed age groups) organisms from West Beach, Whidbey Island, Washington.

Test organisms were held for 14 days at the following conditions prior to test initiation.
$\mathrm{PH}$
Dissolved Oxygen
Salinity

7.66-7.83

7.3-8.4 mg/L

30.5-32.0\%

All water quality parameters remained within the acceptable ranges throughout the 10 days of testing. Pre-initiation "dummy" jars were measured for interstitial and overlying ammonia 13 days, 10 days, 6 days, and 3 days prior to initiation of the organisms. When the ammonia was $<15 \mathrm{mg} / \mathrm{L}$ in the interstitial water, the test was initiated. Ammonia was then measured in the overlying and interstitial water in "dummy" jars on Day 0 and 10. Ammonia in the overlying water was measured in the test jars on Days $1,3,7$, and 10.

The test was validated by $100 \%$ survival in the control sediment (C-WB). 


\section{QA/QC SUMMARY (contd)}

REFERENCE TOXICANT TEST The cadmium chloride reference toxicant test was validated by $95 \%$ survival in the seawater control. An $L C_{50}$ value of $0.27 \mathrm{mg} / \mathrm{L}$ of cadmium was calculated.

The ammonia reference toxicant test was validated by $95 \%$ survival in the seawater control. An LC 50 value of $30.92 \mathrm{mg} / \mathrm{L}$ of ammonia was calculated.

COMMENTS

Not applicable.

REFERENCES

ASTM (American Society for Testing and Materials). 1990. Standard Guide for Conducting 10-day Static Sediment Toxicity Tests with Marine and Estuarine Amphipods. ASTM

Designation: E 1367-90. American Society for Testing and Materials, Philadelphia, Pennsylvania.

EPAUSACE (U.S. Environmental Protection Agency/U.S. Army Corps of Engineers). 1991. Evaluation of Dredged Material Proposed for Ocean Disposal (Testing Manual).

EPA-68-C8-0105, U.S. Environmental Protection Agency, Office of Marine and Estuarine

Protection, Washington, D.C. 
TABLE H.1. Test Results for 10-Day R. abronius Solid-Phase, Ammonia Reduction to $<15 \mathrm{mg} / \mathrm{L}$ Test, Richmond Harbor Deepening Project-Intensive Study of the Turning Basin

\begin{tabular}{|c|c|c|c|c|c|}
\hline Treatment & Replicate & Live $^{(a)}$ & $\begin{array}{l}\text { Dead or } \\
\text { Missing }\end{array}$ & $\begin{array}{l}\text { Proportion } \\
\text { Surviving }\end{array}$ & $\begin{array}{c}\text { Mean } \\
\text { Proportion } \\
\text { Surviving }\end{array}$ \\
\hline TB-3 Lower & 1 & 17 & 3 & 0.85 & \\
\hline TB-3 Lower & 2 & 19 & 1 & 0.95 & \\
\hline TB-3 Lower & 3 & 16 & 4 & 0.80 & \\
\hline TB-3 Lower & 4 & 14 & 6 & 0.70 & \\
\hline TB-3 Lower & 5 & 17 & 3 & 0.85 & 0.83 \\
\hline TB-7 Lower & 1 & 17 & 3 & 0.85 & \\
\hline TB-7 Lower & 2 & 12 & 8 & 0.60 & \\
\hline TB-7 Lower & 3 & 9 & 11 & 0.45 & \\
\hline TB-7 Lower & 4 & 18 & 2 & 0.90 & \\
\hline TB-7 Lower & 5 & 19 & 1 & 0.95 & 0.75 \\
\hline TB-8 Lower & 1 & 15 & 5 & 0.75 & \\
\hline TB-8 Lower & 2 & 17 & 3 & 0.85 & \\
\hline TB-8 Lower & 3 & 16 & 4 & 0.80 & \\
\hline TB-8 Lower & 4 & 16 & 4 & 0.80 & \\
\hline TB-8 Lower & 5 & 17 & 3 & 0.85 & 0.81 \\
\hline TB-9 Lower & 1 & 17 & 3 & 0.85 & \\
\hline TB-9 Lower & 2 & 12 & 8 & 0.60 & \\
\hline TB-9 Lower & 3 & 16 & 4 & 0.80 & \\
\hline TB-9 Lower & 4 & 18 & 2 & 0.90 & \\
\hline TB-9 Lower & 5 & 17 & 3 & 0.85 & 0.80 \\
\hline$C-W B$ & 1 & 20 & 0 & 1.00 & \\
\hline C-WB & 2 & 20 & 0 & 1.00 & \\
\hline C-WB & 3 & 20 & 0 & 1.00 & \\
\hline$C-W B$ & 4 & 20 & 0 & 1.00 & \\
\hline$C-W B$ & 5 & 20 & 0 & 1.00 & 1.00 \\
\hline
\end{tabular}

(a) Survival based on initial exposure of 20 organisms per replicate. 
TABLE H.2. Daily Observations of $R$. abronius on Sediment Surface During 10-Day SolidPhase, Ammonia Reduction to $<15 \mathrm{mg} / \mathrm{L}$ Test, Richmond Harbor Deepening Project-Intensive Study of the Turning Basin

Sediment R. abronius on Sediment for Test Days 0 through 9

Treatment Replicate

$\begin{array}{llllllllllll}\text { TB-3 Lower } & 1 & 0 & 0 & 0 & 0 & 0 & 0 & 0 & 0 & 0 & 0 \\ \text { TB-3 Lower } & 2 & 0 & 0 & 0 & 0 & 0 & 0 & 0 & 0 & 0 & 1 \\ \text { TB-3 Lower } & 3 & 0 & 0 & 0 & 0 & 0 & 0 & 0 & 0 & 0 & 0 \\ \text { TB-3 Lower } & 4 & 0 & 0 & 0 & 0 & 0 & 0 & 0 & 0 & 0 & 0 \\ \text { TB-3 Lower } & 5 & 0 & 0 & 0 & 0 & 0 & 0 & 0 & 0 & 0 & 0 \\ \text { TB-7 Lower } & 1 & 0 & 0 & 0 & 0 & 1 & 0 & 0 & 0 & 0 & 0 \\ \text { TB-7 Lower } & 2 & 0 & 0 & 0 & 1 & 0 & 0 & 0 & 0 & 1 & 0 \\ \text { TB-7 Lower } & 3 & 0 & 0 & 0 & 0 & 0 & 0 & 0 & 0 & 0 & 0 \\ \text { TB-7 Lower } & 4 & 0 & 0 & 0 & 0 & 0 & 0 & 0 & 0 & 0 & 1 \\ \text { TB-7 Lower } & 5 & 0 & 0 & 0 & 0 & 0 & 0 & 0 & 0 & 0 & 0 \\ & & & & & & & & & & & \\ \text { TB-8 Lower } & 1 & 0 & 0 & 0 & 1 & 0 & 0 & 0 & 0 & 0 & 0 \\ \text { TB-8 Lower } & 2 & 0 & 0 & 0 & 0 & 0 & 0 & 0 & 0 & 0 & 0 \\ \text { TB-8 Lower } & 3 & 0 & 0 & 0 & 0 & 0 & 1 & 0 & 0 & 0 & 2 \\ \text { TB-8 Lower } & 4 & 0 & 0 & 0 & 0 & 0 & 0 & 0 & 0 & 0 & 0 \\ \text { TB-8 Lower } & 5 & 0 & 0 & 0 & 0 & 0 & 0 & 0 & 0 & 0 & 0 \\ & & & & & & & & & & & \\ \text { TB-9 Lower } & 1 & 1 & 0 & 0 & 0 & 0 & 0 & 0 & 0 & 0 & 0 \\ \text { TB-9 Lower } & 2 & 0 & 0 & 0 & 0 & 2 & 0 & 0 & 0 & 0 & 0 \\ \text { TB-9 Lower } & 3 & 0 & 0 & 0 & 0 & 0 & 0 & 0 & 0 & 0 & 0 \\ \text { TB-9 Lower } & 4 & 0 & 0 & 0 & 0 & 0 & 0 & 0 & 0 & 0 & 0 \\ \text { TB-9 Lower } & 5 & 0 & 0 & 0 & 0 & 0 & 0 & 0 & 0 & 0 & 0 \\ & & & & & & & & & & & \\ \text { C-WB } & 1 & 0 & 0 & 0 & 0 & 0 & 0 & 0 & 0 & 0 & 0 \\ \text { C-WB } & 2 & 0 & 0 & 0 & 0 & 0 & 0 & 0 & 0 & 0 & 0 \\ \text { C-WB } & 3 & 0 & 0 & 0 & 0 & 0 & 0 & 0 & 0 & 0 & 0 \\ \text { C-WB } & 4 & 0 & 0 & 0 & 0 & 0 & 0 & 0 & 0 & 0 & 0 \\ \text { C-WB } & 5 & 0 & 0 & 0 & 0 & 0 & 0 & 0 & 0 & 0 & 0\end{array}$

(a) On Test Day 0 observations were performed 2 hours after test initiation. 
TABLE H.3. Daily Observations of $R$. abronius Floating on Surface During 10-Day SolidPhase, Ammonia Reduction to $<15 \mathrm{mg} / \mathrm{L}$ Test, Richmond Harbor Deepening Project-Intensive Study of the Turning Basin

Sediment

Treatment

R. abronius Floating on Surface for Test Days 0 through 9

TB-3 Lower

TB-3 Lower

TB-3 Lower

TB-3 Lower

TB-3 Lower

TB-7 Lower

TB-7 Lower

TB-7 Lower

TB-7 Lower

TB-7 Lower

TB-8 Lower

TB-8 Lower

TB-8 Lower

TB-8 Lower

TB-8 Lower

TB-9 Lower

TB-9 Lower

TB-9 Lower

TB-9 Lower

TB-9 Lower

$\begin{array}{ll}\text { C-WB } & 1 \\ \text { C-WB } & 2 \\ \text { C-WB } & 3 \\ \text { C-WB } & 4 \\ \text { C-WB } & 5\end{array}$

$\begin{array}{lllllllllll}1 & 0 & 0 & 0 & 0 & 0 & 0 & 0 & 0 & 0 & 0 \\ 2 & 0 & 0 & 0 & 0 & 1 & 0 & 1 & 0 & 0 & 0 \\ 3 & 0 & 1 & 0 & 0 & 0 & 1 & 0 & 0 & 2 & 1 \\ 4 & 0 & 1 & 0 & 1 & 0 & 1 & 3 & 1 & 0 & 2 \\ 5 & 0 & 0 & 1 & 0 & 1 & 1 & 0 & 0 & 1 & 1\end{array}$

$\begin{array}{lllllllllll}1 & 1 & 0 & 1 & 0 & 2 & 1 & 0 & 0 & 0 & 0 \\ 2 & 0 & 1 & 1 & 0 & 0 & 0 & 2 & 3 & 1 & 2 \\ 3 & 0 & 0 & 1 & 2 & 0 & 0 & 0 & 1 & 1 & 0 \\ 4 & 0 & 0 & 1 & 0 & 0 & 2 & 3 & 1 & 1 & 3 \\ 5 & 0 & 2 & 0 & 0 & 0 & 0 & 0 & 2 & 3 & 3\end{array}$

$\begin{array}{lllllllllll}1 & 0 & 0 & 0 & 2 & 0 & 0 & 0 & 1 & 0 & 1 \\ 2 & 0 & 1 & 0 & 1 & 0 & 1 & 1 & 1 & 0 & 0 \\ 3 & 0 & 0 & 0 & 3 & 0 & 2 & 2 & 0 & 2 & 2 \\ 4 & 0 & 0 & 1 & 0 & 1 & 0 & 0 & 0 & 2 & 4 \\ 5 & 0 & 3 & 1 & 0 & 1 & 2 & 4 & 1 & 3 & 1\end{array}$

(a) On Test Day 0 observations were performed 2 hours after test initiation. 
TABLE H.4. Water Quality Summary for 10-Day R. abronius Solid-Phase, Ammonia Reduction to $<15 \mathrm{mg} / \mathrm{L}$ Test, Richmond Harbor Deepening ProjectIntensive Study of the Turning Basin

\begin{tabular}{|c|c|c|c|c|c|c|c|c|}
\hline \multirow{2}{*}{$\begin{array}{l}\text { Sediment } \\
\text { Treatment }\end{array}$} & \multicolumn{2}{|c|}{$\begin{array}{c}\text { Temperature } \\
\left({ }^{\circ} \mathrm{C}\right)\end{array}$} & \multicolumn{2}{|c|}{$\mathrm{pH}$} & \multicolumn{2}{|c|}{$\begin{array}{l}\text { Dissolved } \\
\text { Oxygen } \\
\text { (mg/L) }\end{array}$} & \multicolumn{2}{|c|}{$\begin{array}{l}\text { Salinity } \\
(0 / 00)\end{array}$} \\
\hline & Min & Max & Min & $\operatorname{Max}$ & Min & Max & Min & Max \\
\hline \multicolumn{9}{|l|}{ Acceptable } \\
\hline Range & 13.0 & 17.0 & 7.30 & 8.30 & 6.0 & $N A^{(a)}$ & 28.0 & 32.0 \\
\hline TB-3 Lower & 15.1 & 15.7 & 7.77 & 8.03 & 7.5 & 7.9 & 30.5 & 32.0 \\
\hline TB-7 Lower & 15.1 & 15.8 & 7.76 & 7.96 & 6.9 & 7.9 & 30.5 & 31.5 \\
\hline TB-8 Lower & 15.1 & 15.8 & 7.71 & 7.99 & 7.1 & 8.0 & 30.5 & 32.0 \\
\hline TB-9 Lower & 15.1 & 15.7 & 7.82 & 8.12 & 7.4 & 8.0 & 30.5 & 32.0 \\
\hline$C-W B$ & 15.1 & 15.8 & 7.85 & 8.13 & 7.5 & 8.0 & 30.5 & 32.0 \\
\hline
\end{tabular}

(a) NA Not applicable. 
TABLE H.5. Ammonia Measurements in Overyling and Porewater Prior to Initiation of the 10-Day R. abronius Solid-Phase, Ammonia Reduction to $<15 \mathrm{mg} / \mathrm{L}$ Test, Richmond Harbor Deepening Project-Intensive Study of the Turning Basin

\begin{tabular}{|c|c|c|c|c|c|}
\hline $\begin{array}{l}\text { Sediment } \\
\text { Treatment }\end{array}$ & $\begin{array}{l}\text { Ammonia } \\
(\mathrm{mg} / \mathrm{L})\end{array}$ & $\begin{array}{c}\text { Temperature } \\
\left({ }^{\circ} \mathrm{C}\right)\end{array}$ & $\mathrm{pH}$ & $\begin{array}{l}\text { Dissolved } \\
\text { Oxygen } \\
(\mathrm{mg} / \mathrm{L})\end{array}$ & $\begin{array}{l}\text { Salinity } \\
(0 / 00)\end{array}$ \\
\hline Overlying & \multicolumn{5}{|c|}{13 Days Prior to Initiation } \\
\hline TB-3 Lower & 1.66 & 13.3 & 8.00 & 5.7 & 31.5 \\
\hline TB-7 Lower & 0.640 & 13.3 & 7.92 & 5.8 & 31.5 \\
\hline TB-8 Lower & 0.837 & 13.4 & 7.95 & 5.8 & 31.5 \\
\hline TB-9 Lower & 0.955 & 13.3 & 7.90 & 5.9 & 31.5 \\
\hline C-WB & ND ${ }^{(a)}$ & ND & ND & ND & ND \\
\hline
\end{tabular}

Porewater

TB-3 Lower

TB-7 Lower

TB-8 Lower

TB-9 Lower

C-WB

Overlying

TB-3 Lower

TB-7 Lower

TB-8 Lower

TB-9 Lower

C-WB

Porewater

TB-3 Lower

TB-7 Lower

TB-8 Lower

TB-9 Lower

C-WB
13 Days Prior to Initiation

\begin{tabular}{rrrrr}
\hline 20.3 & 13.2 & 7.94 & 4.4 & 30.0 \\
19.0 & 13.3 & 7.94 & 3.9 & 28.0 \\
18.6 & 13.3 & 7.93 & 3.9 & 28.0 \\
37.3 & 13.3 & 8.18 & 4.0 & 30.0 \\
ND & ND & ND & ND & ND
\end{tabular}

10 Days Prior to Initiation

\begin{tabular}{rrrrr}
\hline & & & \\
1.81 & 14.9 & 8.05 & 7.3 & 31.0 \\
1.56 & 14.9 & 8.05 & 7.4 & 31.5 \\
1.98 & 14.9 & 7.99 & 7.5 & 31.0 \\
2.03 & 14.9 & 8.08 & 7.2 & 31.5 \\
0.164 & 14.9 & 7.98 & 7.6 & 31.0
\end{tabular}

10 Days Prior to Initiation

\begin{tabular}{lllll}
\hline 14.8 & 14.9 & 7.92 & 5.1 & 30.0 \\
13.3 & 14.8 & 7.87 & 4.5 & 28.5 \\
12.9 & 14.8 & 7.84 & 4.6 & 28.5 \\
29.9 & 14.8 & 8.01 & 4.6 & 30.0 \\
2.07 & 14.9 & 7.52 & 5.9 & 31.5
\end{tabular}


TABLE H.5. (contd)

\begin{tabular}{|c|c|c|c|c|c|}
\hline $\begin{array}{l}\text { Sediment } \\
\text { Treatment }\end{array}$ & $\begin{array}{l}\text { Ammonia } \\
(\mathrm{mg} / \mathrm{L})\end{array}$ & $\begin{array}{c}\text { Temperature } \\
\left({ }^{\circ} \mathrm{C}\right)\end{array}$ & $\mathrm{pH}$ & $\begin{array}{l}\text { Dissolved } \\
\text { Oxygen } \\
\text { (mg/L) }\end{array}$ & $\begin{array}{l}\text { Salinity } \\
(0 / 00)\end{array}$ \\
\hline Overlying & \multicolumn{5}{|c|}{6 Days Prior to Initiation } \\
\hline TB-3 Lower & 1.82 & 14.4 & 7.98 & 7.4 & 32.0 \\
\hline TB-7 Lower & 1.99 & 14.4 & 7.93 & 7.3 & 32.0 \\
\hline TB-8 Lower & 1.60 & 14.4 & 7.94 & 7.1 & 32.0 \\
\hline TB-9 Lower & 3.58 & 14.4 & 7.97 & 7.4 & 32.0 \\
\hline C-WB & 0.116 & 14.4 & 7.83 & 7.6 & 32.0 \\
\hline Porewater & \multicolumn{5}{|c|}{6 Days Prior to Initiation } \\
\hline TB-3 Lower & 9.99 & 14.5 & 7.91 & 5.1 & 30.5 \\
\hline TB-7 Lower & 11.2 & 14.4 & 7.73 & 4.1 & 29.5 \\
\hline TB-8 Lower & 10.4 & 14.4 & 7.68 & 4.0 & 29.5 \\
\hline TB-9 Lower & 22.5 & 14.4 & 7.92 & 3.7 & 30.0 \\
\hline C-WB & 2.32 & 14.5 & 7.58 & 5.6 & 31.0 \\
\hline
\end{tabular}

Overlying

TB-3 Lower

TB-7 Lower

TB-8 Lower

TB-9 Lower

C-WB

Porewater

TB-3 Lower

TB-7 Lower

TB-8 Lower

TB-9 Lower

C-WB
3 Days Prior to Initiation

\begin{tabular}{rrrrr}
\hline 0.246 & 14.9 & 7.84 & 7.7 & 31.0 \\
1.45 & 14.9 & 7.83 & 7.2 & 31.0 \\
0.179 & 14.8 & 7.83 & 7.6 & 31.0 \\
0.537 & 14.9 & 7.83 & 7.6 & 31.0 \\
0.054 & 14.9 & 7.85 & 7.6 & 31.0
\end{tabular}

3 Days Prior to Initiation

$\begin{array}{lllll}11.0 & 14.8 & 7.85 & 6.0 & 31.0 \\ 12.9 & 14.9 & 7.85 & 4.8 & 30.5 \\ 10.9 & 14.8 & 7.79 & 6.0 & 30.5 \\ 17.5 & 14.9 & 7.93 & 5.2 & 31.0 \\ 4.78 & 14.8 & \text { ND } & \text { ND } & 31.0\end{array}$

(a) ND No data. 
TABLE H.6. Ammonia Measurements in Overlying Water for 10-Day R. abronius Solid-Phase, Ammonia Reduction to $<15 \mathrm{mg} / \mathrm{L}$ Test, Richmond Harbor Deepening Project-Intensive Study of the Turning Basin

\begin{tabular}{l} 
Sediment \\
Treatment \\
\hline \\
TB-3 Lower \\
TB-7 Lower \\
TB-8 Lower \\
TB-9 Lower \\
C-WB
\end{tabular}

TB-3 Lower

TB-7 Lower

TB-8 Lower

TB-9 Lower

C-WB

TB-3 Lower

TB-7 Lower

TB-8 Lower

TB-9 Lower

C-WB

TB-3 Lower

TB-7 Lower

TB-8 Lower

TB-9 Lower

C-WB

TB-3 Lower

TB-7 Lower

TB-8 Lower

TB-9 Lower

C-WB

\begin{tabular}{cc}
$\begin{array}{c}\text { Ammonia } \\
(\mathrm{mg} / \mathrm{L})\end{array}$ & $\begin{array}{c}\text { Temperature } \\
\left({ }^{\circ} \mathrm{C}\right)\end{array}$ \\
\hline
\end{tabular}

\begin{tabular}{lllll}
\hline 0.135 & 13.3 & 7.84 & 7.7 & 30.5 \\
0.189 & 13.2 & 7.88 & 7.5 & 30.5 \\
0.121 & 13.4 & 7.85 & 7.5 & 30.5 \\
0.356 & 13.3 & 7.88 & 7.7 & 30.5 \\
0.038 & 13.3 & 7.86 & 7.7 & 30.5
\end{tabular}

\begin{tabular}{rrrrr}
\hline \multicolumn{5}{c}{ Day 1 } \\
\hline 0.944 & 13.2 & 7.99 & 7.7 & 31.0 \\
3.28 & 13.1 & 7.95 & 7.5 & 31.0 \\
0.706 & 13.2 & 7.97 & 7.7 & 30.5 \\
1.76 & 13.1 & 7.97 & 7.5 & 30.5 \\
0.133 & 13.2 & 8.01 & 7.6 & 30.5
\end{tabular}

\begin{tabular}{rrrrr}
\hline \multicolumn{5}{c}{ Day 3 } \\
\hline 2.45 & 14.0 & 7.89 & 7.6 & 31.0 \\
3.27 & 13.9 & 7.92 & 7.6 & 30.5 \\
2.18 & 13.9 & 7.89 & 7.6 & 31.0 \\
4.41 & 14.0 & 7.99 & 7.7 & 31.0 \\
0.211 & 14.0 & 8.08 & 7.8 & 31.0
\end{tabular}

\begin{tabular}{rrrrr}
\hline$\cdot$ & \multicolumn{5}{c}{ Day 7 } \\
\hline 2.55 & 15.2 & 7.92 & 7.7 & 31.5 \\
4.17 & 15.2 & 7.95 & 7.8 & 31.5 \\
2.81 & 15.2 & 7.96 & 7.9 & 31.5 \\
7.43 & 15.1 & 8.02 & 7.8 & 31.5 \\
0.124 & 15.1 & 8.02 & 7.9 & 31.5
\end{tabular}

\begin{tabular}{rrrrl}
\hline$\cdot$ & \multicolumn{5}{c}{ Day 10 } \\
\hline 1.66 & 13.9 & 8.11 & 7.4 & 32.0 \\
2.13 & 13.8 & 8.04 & 7.5 & 32.0 \\
1.01 & 13.8 & 7.93 & 7.6 & 31.5 \\
6.56 & 14.0 & 8.17 & 7.6 & $34.0^{\text {(a) }}$ \\
0.051 & 13.7 & 8.17 & 7.6 & 32.0
\end{tabular}

(a) Data point out of range. 
TABLE H.7. Water Quality Measurements of Porewater for 10-Day Solid-Phase Ammonia Reduction to $<15 \mathrm{mg} / \mathrm{L}$ Test, Richmond Harbor Deepening Project-Intensive Study of the Turning Basin

\begin{tabular}{lccccc}
$\begin{array}{l}\text { Sediment } \\
\text { Treatment }\end{array}$ & $\begin{array}{c}\text { Ammonia } \\
(\mathrm{mg} / \mathrm{L})\end{array}$ & $\begin{array}{c}\text { Temperature } \\
\left({ }^{\circ} \mathrm{C}\right)\end{array}$ & $\mathrm{pH}$ & $\begin{array}{c}\text { Dissolved } \\
\text { Oxygen } \\
(\mathrm{mg} / \mathrm{L})\end{array}$ & $\begin{array}{c}\text { Salinity } \\
(\mathrm{o} / \mathrm{oO})\end{array}$ \\
\hline & \multicolumn{5}{c}{ Day 0 } \\
TB-3 Lower & 4.71 & 12.9 & 7.90 & 6.3 & 32.5 \\
TB-7 Lower & 7.79 & 12.8 & 7.79 & 6.2 & 31.0 \\
TB-8 Lower & 8.18 & 12.9 & 7.80 & 5.9 & 31.5 \\
TB-9 Lower & 14.7 & 12.8 & 7.89 & 6.0 & 32.0 \\
C-WB & 1.34 & 13.0 & 7.81 & 6.0 & 32.0
\end{tabular}

Day 10

TB-3 Lower

TB-7 Lower

TB-8 Lower

TB-9 Lower

C-WB

7.14

13.9

8.14

7.4

32.0

7.75

13.8

7.99

7.6

32.0

4.42

14.0

8.06

7.5

31.5

12.8

14.0

8.09

7.7

$33.0^{(a)}$

ND ${ }^{(b)} \quad$ ND

ND

ND

ND

(a) Data point out of range.

(b) ND No data. 
TABLE H.8. Test Results for 96-Hour $R$. abronius Cadmium Reference Toxicant Test, Richmond Harbor Deepening Project-Intensive Study of the Turning Basin

\begin{tabular}{cccc}
$\begin{array}{c}\text { Cadmium } \\
\begin{array}{c}\text { Concentration } \\
(\mathrm{mg} / \mathrm{L})\end{array}\end{array}$ & Live $^{(\mathrm{a})}$ & $\begin{array}{c}\text { Dead or } \\
\text { Missing }\end{array}$ & $\begin{array}{c}\text { Proportion } \\
\text { Surviving }\end{array}$ \\
\hline 0.00 & 19 & 1 & 0.95 \\
0.25 & 10 & 10 & 0.50 \\
0.50 & 6 & 14 & 0.30 \\
1.00 & 2 & 18 & 0.10 \\
1.50 & 1 & 19 & 0.05 \\
2.00 & 0 & 20 & 0.00 \\
4.00 & 0 & 20 & 0.00
\end{tabular}

(a) Survival based on initial exposure of 20 organisms per replicate. 
TABLE H.9. Daily Observations of $R$. abronius Floating on Surface During 96-Hour Cadmium Reference Toxicant Test, Richmond Harbor Deepening

Project-Intensive Study of the Turning Basin

\section{Cadmium}

Concentration

$(\mathrm{mg} / \mathrm{L})$

0.00

0.25

0.50

1.00

1.50

2.00

4.00
R. abronius Floating on Surface

\begin{tabular}{cccc}
\hline $2 \mathrm{~h}$ & $24 \mathrm{~h}$ & $48 \mathrm{~h}$ & $72 \mathrm{~h}$ \\
3 & 0 & 2 & 1 \\
1 & 2 & 0 & 3 \\
1 & 4 & 4 & 4 \\
0 & 1 & 0 & 3 \\
0 & 1 & 1 & 1 \\
2 & 3 & 2 & 0 \\
1 & 4 & 1 & 0
\end{tabular}


TABLE H.10. Water Quality Summary for 96-Hour R. abronius Cadmium Reference Toxicant Test, Richmond Harbor Deepening Project-Intensive Study of the Turning Basin

\begin{tabular}{|c|c|c|c|c|c|c|c|c|}
\hline \multirow{2}{*}{$\begin{array}{c}\text { Cadmium. } \\
\text { Concentration } \\
(\mathrm{mg} / \mathrm{L})\end{array}$} & \multicolumn{2}{|c|}{$\begin{array}{c}\text { Temperature } \\
\left({ }^{\circ} \mathrm{C}\right)\end{array}$} & \multicolumn{2}{|c|}{$\mathrm{pH}$} & \multicolumn{2}{|c|}{$\begin{array}{c}\text { Dissolved } \\
\text { Oxygen } \\
\text { (mg/L) }\end{array}$} & \multicolumn{2}{|c|}{$\begin{array}{c}\text { Salinity } \\
(0 / 00)\end{array}$} \\
\hline & Min & Max & Min & $\operatorname{Max}$ & Min & $\operatorname{Max}$ & Min & Max \\
\hline \multicolumn{9}{|l|}{ Acceptable } \\
\hline Range & 13.0 & 17.0 & 7.30 & 8.30 & 6.0 & $N A^{(a)}$ & 28.0 & 32.0 \\
\hline 0.00 & 15.2 & 15.5 & 8.09 & 8.14 & 7.6 & 8.1 & 30.5 & 31.5 \\
\hline 0.25 & 15.3 & 15.6 & 8.04 & 8.14 & 7.8 & 8.0 & 30.5 & 31.5 \\
\hline 0.50 & 15.3 & 15.6 & 8.06 & 8.13 & 7.8 & 8.1 & 30.5 & 31.5 \\
\hline 1.00 & 15.3 & 15.6 & 8.05 & 8.12 & 7.8 & 8.1 & 30.5 & 31.5 \\
\hline 1.50 & 15.3 & 15.6 & 8.00 & 8.09 & 7.8 & 8.1 & 30.5 & 31.5 \\
\hline 2.00 & 15.3 & 15.6 & 7.89 & 8.08 & 7.9 & 8.1 & 30.5 & 31.5 \\
\hline 4.00 & 15.2 & 15.6 & 7.89 & 7.97 & 7.7 & 8.1 & 30.5 & 31.0 \\
\hline
\end{tabular}

(a) NA Not applicable. 
TABLE H.11. Test Results for 96-Hour R. abronius Ammonia Reference Toxicant Test, Richmond Harbor Deepening Project-Intensive Study of the Turning Basin

\begin{tabular}{cccc}
$\begin{array}{c}\text { Ammonia } \\
\begin{array}{c}\text { Concentration } \\
\text { (mg/L) }\end{array}\end{array}$ & Live $^{(\mathrm{a})}$ & $\begin{array}{c}\text { Dead or } \\
\text { Missing }\end{array}$ & $\begin{array}{c}\text { Proportion } \\
\text { Surviving }\end{array}$ \\
\hline 0 & 19 & 1 & 0.95 \\
10 & 20 & 0 & 1.00 \\
20 & 19 & 1 & 0.95 \\
40 & 7 & 13 & 0.35 \\
80 & 3 & 17 & 0.15 \\
120 & 0 & 20 & 0.00 \\
160 & 0 & 20 & 0.00 \\
\hline
\end{tabular}

(a) Survival based on initial exposure of 20 organisms per replicate. 
TABLE H.12. Daily Observations of $R$. abronius Floating on Surface During 96-Hour Ammonia Reference Toxicant Test, Richmond Harbor Deepening Project-Intensive Study of the Turning Basin Ammonia Concentration R. abronius Floating on Surface $(\mathrm{mg} / \mathrm{L})$ $24 \mathrm{~h}$ $48 \mathrm{~h}$ $72 \mathrm{~h}$

0
10
20
40
80
120
160

0

0

0

3

10

20

2

1

0

1

0

1

0

0

3

$0 \quad 0$

$\begin{array}{ll}0 & 2\end{array}$

$0 \quad 0$

160

0

0

$0 \quad 0$


TABLE H.13. Water Quality Summary for 96-Hour R. abronius Ammonia Reference Toxicant Test, Richmond Harbor Deepening Project-Intensive Study of the Turning Basin

\begin{tabular}{|c|c|c|c|c|c|c|c|c|c|c|}
\hline \multirow{2}{*}{$\begin{array}{c}\text { Ammonia } \\
\text { Concentration } \\
\text { (mg/L) }\end{array}$} & \multicolumn{2}{|c|}{$\begin{array}{c}\text { Temperature } \\
\left({ }^{\circ} \mathrm{C}\right) \\
\end{array}$} & \multicolumn{2}{|c|}{$\mathrm{pH}$} & \multicolumn{2}{|c|}{$\begin{array}{l}\text { Dissolved } \\
\text { Oxygen } \\
\text { (mg/L) }\end{array}$} & \multicolumn{2}{|c|}{$\begin{array}{c}\text { Salinity } \\
(0 / 00)\end{array}$} & \multicolumn{2}{|c|}{$\begin{array}{c}\text { Ammonia } \\
(\mathrm{mg} / \mathrm{L})\end{array}$} \\
\hline & Min & $\operatorname{Max}$ & Min & Max & Min & Max & Min & Max & Min & $\operatorname{Max}$ \\
\hline \multicolumn{11}{|l|}{ Acceptable } \\
\hline Range & 13.0 & 17.0 & 7.30 & 8.30 & 6.0 & $N A^{(a)}$ & 28.0 & 32.0 & $N E^{(0)}$ & NE \\
\hline 0 & 15.2 & 15.5 & 7.89 & 8.14 & 7.6 & 8.1 & 30.5 & 31.5 & 0.069 & 0.217 \\
\hline 10 & 15.3 & 15.6 & 7.85 & 8.13 & 7.6 & 8.1 & 30.5 & 31.5 & 7.58 & 8.46 \\
\hline 20 & 15.3 & 15.6 & 7.84 & 8.14 & 7.6 & 8.1 & 30.5 & 31.5 & 15.2 & 16.1 \\
\hline 40 & 15.3 & 15.6 & 7.81 & 8.13 & 7.8 & 8.1 & 30.5 & 31.5 & 29.7 & 30.8 \\
\hline 80 & 15.3 & 15.6 & 7.84 & 8.11 & 7.7 & 8.1 & 30.5 & 31.5 & 60.0 & 66.0 \\
\hline 120 & 15.3 & 15.6 & 7.69 & 8.11 & 7.8 & 8.0 & 30.5 & 31.5 & 97.4 & 102 \\
\hline 160 & 15.3 & 15.7 & 7.66 & 8.08 & 7.7 & 8.0 & 30.5 & 31.0 & 145 & 151 \\
\hline
\end{tabular}

(a) NA Not applicable

(b) NE Not established. 


\section{APPENDIX I}

BIOASSAY RESULTS FOR 10-DAY SOLID-PHASE, FLOW-THROUGH TEST WITH MACOMA nasuta AND NEPHTYS caecoides. 


\section{QA/QC SUMMARY}

PROGRAM: $\quad$ Richmond Harbor Deepening Project

TEST ORGANISM: Macoma nasuta

TEST TYPE: $\quad$ Solid-phase, flow-through

TEST DURATION: 10 days

WATER QUALITY ACCEPTABLE RANGES:

Temperature $\mathrm{pH}$ Dissolved Oxygen Salinity Flow Rate Ammonia

$13-17^{\circ} \mathrm{C} \quad 7.30-8.30 \quad \geq 6.0 \mathrm{mg} / \mathrm{L} \quad 28-32 \%$ 。 $115-135 \mathrm{~m} / \mathrm{min} \quad \mathrm{NA}$

TEST MATRIX

SOURCE/AGE

HOLDING/ACCLIMATION

17 days acclimation

\section{Temperature}

$\min / \max$

$6.7-14.1^{\circ} \mathrm{C}$

8 days holding

$\min / \max$

$9.6-14.7^{\circ} \mathrm{C}$

WATER QUALITY SUMMARY

TEST VALIDATION

REFERENCE TOXICANT TEST Not applicable.

COMMENTS

Flow rates generally remained within the acceptable range of $115-135 \mathrm{~m} / \mathrm{min}$. Slight fluctuations ( $<5 \mathrm{ml}$ ) did occur during the 10 days of testing but were corrected within 24 hours.
Sediments were collected from January 28,1994 to February 3, 1994. Sediments were composited and tested within 6 weeks holding time after collection:

Johnson and Gunstone, Discovery Bay, Washington. Wild captured organisms (mixed age group-1 to 2.5 in. in size) were collected in Discovery Bay.

Approximately 3500 organisms were received dry in mesh bags between January 24 and 26 . The organisms were held for 25 days at the following conditions prior to test initiation.

pH Dissolved Oxygen Salinity
$7.57-7.96$
$7.4-9.7 \mathrm{mg} / \mathrm{L}$
$30.5-32.0 \%$

7.59-7.74

8.0-9.1 mg/L

$31.0-32.0 \%$

All water quality parameters remained within the acceptable ranges throughout the 10 days of testing.

The test was validated by $100 \%$ survival in the control sediment (C-SB).

\section{REFERENCES}

EPAUUSACE (U.S. Environmental Protection Agency/ U.S. Army Corps of Engineers). 1991. Evaluation of Dredged Material Proposed for Ocean Disposal (Testing Manual).

EPA-68-C8-0105, U.S. Environmental Protection Agency, Office of Marine and Estuarine Protection, Washington, D.C. 


\section{QA/QC SUMMARY}

PROGRAM: Richmond Harbor Deepening Project

TEST ORGANISM: Nephtys caecoides

TEST TYPE: Solid-phase, flow-through

TEST DURATION: 10 days

WATER QUALITY ACCEPTABLE RANGES:

Temperature $\mathrm{pH}$ Dissolved Oxygen Salinity Flow Rate Ammonia

$\begin{array}{llllll}13-17^{\circ} \mathrm{C} & 7.30-8.30 & \geq 6.0 \mathrm{mg} / \mathrm{L} & 28-32 \% & 115-135 \mathrm{~m} / \mathrm{min} & \mathrm{NA}\end{array}$

TEST MATRIX

SOURCE/AGE

HOLDING/ACCLIMATION

Temperature

8 days acclimation/holding

$\min / \max$

$9.5-14.7^{\circ} \mathrm{C}$

WATER QUALITY SUMMARY

TEST VALIDATION

REFERENCE TOXICANT TEST Not applicable.

COMMENTS

\section{REFERENCES}

EPAUSACE (U.S. Environmental Protection Agency/ U.S. Army Corps of Engineers). 1991. Evaluation of Dredged Material Proposed for Ocean Disposal (Testing Manual).

EPA-68-C8-0105, U.S. Environmental Protection Agency, Office of Marine and Estuarine Protection, Washington, D.C.
Sediments were collected from January 28, 1994 to February 3,1994 . Sediments were composited and tested within 6 weeks holding time after collection.

Brezina and Associates, Dillon Beach, California. Wild captured organisms (mixed age group-less than 3 in. length) were collected in Dillon Beach.

Approximately 2000 organisms were received on February 10, 1994 and held for 8 days at the following conditions prior to test initiation.

$\mathrm{pH} \quad$ Dissolved Oxygen Salinity
7.16-7.75
8.0-12.2 mg/L
$31.5-33.0 \%$

All water quality parameters remained within the acceptable ranges throughout the 10 days of testing.

The test was validated by $94 \%$ survival in the control sediment (C-NE).

Flow rates generally remained within the acceptable range of $115-135 \mathrm{~m}$ Umin. Slight fluctuations ( $<5 \mathrm{ml}$ ) did occur during the 10 days of testing but were corrected within 24 hours. 
TABLE I.1. Test Results for 10-Day M. nasuta Solid-Phase, Flow-Through Test, Richmond Harbor Deepening Project

\begin{tabular}{|c|c|c|c|c|c|c|}
\hline \multirow[b]{2}{*}{$\begin{array}{l}\text { Sediment } \\
\text { Treatment }\end{array}$} & \multirow[b]{2}{*}{ Replicate } & \multicolumn{2}{|c|}{ M. nasuta } & \multirow[b]{2}{*}{$\begin{array}{l}\text { Proportion } \\
\text { Surviving }\end{array}$} & \multirow{2}{*}{$\begin{array}{l}\text { Mean } \\
\text { Proportion } \\
\text { Surviving }\end{array}$} & \multirow[b]{2}{*}{$\begin{array}{l}\text { Standard } \\
\text { Deviation }\end{array}$} \\
\hline & & Live(a) & $\begin{array}{l}\text { Dead or } \\
\text { Missing }\end{array}$ & & & \\
\hline SF COMP & 1 & 20 & 0 & 1.00 & & \\
\hline SF COMP & 2 & 20 & 0 & 1.00 & & \\
\hline SF COMP & 3 & 20 & 0 & 1.00 & & \\
\hline SF COMP & 4 & 20 & 0 & 1.00 & & \\
\hline SF COMP & 5 & 20 & 0 & 1.00 & 1.00 & 0.00 \\
\hline SFW COMP & 1 & 23 & 2 & 0.92 & & \\
\hline SFW COMP & 2 & 25 & 0 & 1.00 & & \\
\hline SFW COMP & 3 & 25 & 0 & 1.00 & & \\
\hline SFW COMP & 4 & 25 & 0 & 1.00 & & \\
\hline SFW COMP & 5 & 25 & 0 & 1.00 & 0.98 & 0.04 \\
\hline UIH COMP & 1 & 25 & 0 & 1.00 & & \\
\hline UIH COMP & 2 & 25 & 0 & 1.00 & & \\
\hline UIH COMP & 3 & 25 & 0 & 1.00 & & \\
\hline UIH COMP & 4 & 25 & 0 & 1.00 & & \\
\hline UIH COMP & 5 & 25 & 0 & 1.00 & 1.00 & 0.00 \\
\hline TB Upper COMP & 1 & 20 & 0 & 1.00 & & \\
\hline TB Upper COMP & 2 & 20 & 0 & 1.00 & & \\
\hline TB Upper COMP & 3 & 20 & 0 & 1.00 & & \\
\hline TB Upper COMP & 4 & 20 & 0 & 1.00 & & \\
\hline TB Upper COMP & 5 & 19 & 1 & 0.95 & 0.99 & 0.02 \\
\hline TB Lower COMP & 1 & 25 & 0 & 1.00 & & \\
\hline TB Lower COMP & 2 & 24 & 1 & 0.96 & & \\
\hline TB Lower COMP & 3 & 25 & 0 & 1.00 & & \\
\hline TB Lower COMP & 4 & 25 & 0 & 1.00 & & \\
\hline TB Lower COMP & 5 & 24 & 1 & 0.96 & 0.98 & 0.02 \\
\hline OBM COMP & 1 & 25 & 0 & 1.00 & & \\
\hline OBM COMP & 2 & 25 & 0 & 1.00 & & \\
\hline OBM COMP & 3 & 24 & 1 & 0.96 & & \\
\hline OBM COMP & 4 & 25 & 0 & 1.00 & & \\
\hline OBM COMP & 5 & 24 & 1 & 0.96 & 0.98 & 0.02 \\
\hline R-OS & 1 & 25 & 0 & 1.00 & & \\
\hline R-OS & 2 & 25 & 0 & 1.00 & & \\
\hline R-OS & 3 & 25 & 0 & 1.00 & & \\
\hline R-OS & 4 & 25 & 0 & 1.00 & & \\
\hline R-OS & 5 & 25 & 0 & 1.00 & 1.00 & 0.00 \\
\hline R-BF & 1. & 25 & 0 & 1.00 & & \\
\hline R-BF & 2 & 25 & 0 & 1.00 & & \\
\hline R-BF & 3 & 25 & 0 & 1.00 & & \\
\hline R-BF & 4 & 25 & 0 & 1.00 & $\cdot$ & \\
\hline R-BF & 5 & 25 & 0 & 1.00 & 1.00 & 0.00 \\
\hline RH DEEPENING & & & I. 1 & & & \\
\hline
\end{tabular}


TABLE I.1. (contd)

\begin{tabular}{|c|c|c|c|c|c|c|}
\hline \multirow[b]{2}{*}{$\begin{array}{l}\text { Sediment } \\
\text { Treatment }\end{array}$} & \multirow[b]{2}{*}{ Replicate } & \multicolumn{2}{|c|}{ M. nasuta } & \multicolumn{3}{|c|}{ Mean } \\
\hline & & Live & $\begin{array}{l}\text { Dead or } \\
\text { Missing }\end{array}$ & $\begin{array}{l}\text { Proportion } \\
\text { Surviving }\end{array}$ & $\begin{array}{l}\text { Proportion } \\
\text { Surviving } \\
\end{array}$ & $\begin{array}{l}\text { Standard } \\
\text { Deviation }\end{array}$ \\
\hline R-AM COMP & 1 & 25 & 0 & 1.00 & & \\
\hline R-AM COMP & 2 & 25 & 0 & 1.00 & & \\
\hline R-AM COMP & 3 & 25 & 0 & 1.00 & & \\
\hline R-AM COMP & 4 & $N I(b)$ & NI & $N A(c)$ & & \\
\hline R-AM COMP & 5 & 25 & 0 & 1.00 & 1.00 & 0.00 \\
\hline C-SB & 1 & 20 & 0 & 1.00 & & \\
\hline C-SB & 2 & 20 & 0 & 1.00 & & \\
\hline C-SB & 3 & 20 & 0 & 1.00 & & \\
\hline C-SB & 4 & 20 & 0 & 1.00 & & \\
\hline C-SB & 5 & 20 & 0 & 1.00 & 1.00 & 0.00 \\
\hline C-NE & 1 & 20 & 0 & 1.00 & & \\
\hline C-NE & 2 & 20 & 0 & 1.00 & & \\
\hline C-NE & 3 & 20 & 0 & 1.00 & $\cdot$ & \\
\hline $\mathrm{C}-\mathrm{NE}$ & 4 & 20 & 0 & 1.00 & & \\
\hline C-NE & 5 & 20 & 0 & 1.00 & 1.00 & 0.00 \\
\hline
\end{tabular}

\footnotetext{
(a) Survival based on initial exposure of either 20 or 25 organisms per replicate.

(b) NI Not initiated; insufficient organisms to test all five replicates.

(c) NA Not applicable.
} 
TABLE 1.2. Daily Observations of M. nasuta on Sediment Surface During 10-Day Solid-Phase, Flow-Through Test, Richmond Harbor Deepening Project

Sediment

Treatment

M. nasuta on Sediment Test Days 0 through 9

\begin{tabular}{|c|c|c|c|c|c|c|c|c|c|c|}
\hline SF COMP & 1 & 1 & 1 & 1 & 1 & 1 & 1 & 1 & 1 & 1 \\
\hline SF COMP & 2 & 1 & 1 & 1 & 1 & 1 & 0 & 1 & 1 & 1 \\
\hline SF COMP & 3 & 4 & 3 & 2 & 1 & 1 & 1 & 1 & 1 & 1 \\
\hline SF COMP & 4 & 1 & 1 & 1 & 0 & 0 & 0 & 0 & 0 & 0 \\
\hline SF COMP & 5 & 2 & 2 & 2 & 1 & 0 & 0 & 0 & 0 & 0 \\
\hline SFW COMP & 1 & 10 & 7 & 6 & 2 & 1 & 1 & 0 & 0 & 0 \\
\hline SFW COMP & 2 & 8 & 5 & 1 & 1 & 1 & 0 & 0 & 0 & 0 \\
\hline SFW COMP & 3 & 9 & 5 & 3 & 0 & 0 & 0 & 0 & $0^{\circ}$ & 0 \\
\hline SFW COMP & 4 & 8 & 6 & 3 & 2 & 1 & 2 & 1 & 2 & 1 \\
\hline SFW COMP & 5 & 3 & 7 & 4 & 3 & 1 & 1 & 1 & 0 & 0 \\
\hline UIH COMP & 1 & 2 & 1 & 2 & 1 & 0 & 0 & 0 & 0 & 0 \\
\hline UIH COMP & 2 & 3 & 2 & 1 & 1 & 1 & 0 & 1 & 1 & 1 \\
\hline UIH COMP & 3 & 3 & 1 & 0 & 1 & 0 & 0 & 0 & 0 & 0 \\
\hline UIH COMP & 4 & 2 & 1 & 2 & 1 & 1 & 1 & 0 & 0 & 0 \\
\hline UIH COMP & 5 & 4 & 4 & 3 & 2 & 2 & 1 & 1 & 0 & 0 \\
\hline TB Upper COMP & 1 & $T(a)$ & 1 & 0 & 0 & 0 & 0 & 0 & 0 & 0 \\
\hline TB Upper COMP. & 2 & 4 & 3 & 3 & 3 & 2 & 2 & 2 & 2 & 2 \\
\hline TB Upper COMP & 3 & 5 & 4 & 4 & 3 & 1 & 1 & 2 & 1 & 1 \\
\hline TB Upper COMP & 4 & 9 & 3 & 1 & 0 & 0 & 0 & 0 & 1 & 0 \\
\hline TB Upper COMP & 5 & 4 & 3 & 3 & 2 & 2 & 2 & 2 & 1 & 0 \\
\hline TB Lower COMP & 1 & 3 & 2 & 2 & 2 & 1 & 1 & 1 & 0 & 1 \\
\hline TB Lower COMP & 2 & 8 & 6 & 4 & 3 & 2 & 2 & 1 & 1 & 0 \\
\hline TB Lower COMP & 3 & 10 & 5 & 6 & 5 & 4 & 4 & 3 & 2 & 2 \\
\hline TB Lower COMP & 4 & 4 & 4 & 4 & 4 & 4 & 4 & 3 & 3 & 2 \\
\hline TB Lower COMP & 5 & 6 & 5 & 4 & 3 & 3 & 2 & 2 & 1 & 0 \\
\hline OBM COMP & 1 & 21 & 23 & 22 & 21 & 13 & 13 & 12 & 12 & 10 \\
\hline OBM COMP & 2 & 17 & 15 & 12 & 11 & 11 & 10 & 10 & 9 & 8 \\
\hline OBM COMP & 3 & 25 & 23 & 25 & 22 & 19 & 18 & 17 & 17 & 16 \\
\hline OBM COMP & 4 & 19 & 20 & 19 & 18 & 18 & 17 & 14 & 15 & 13 \\
\hline OBM COMP & 5 & 22 & 19 & 18 & $16^{\circ}$ & 16 & 13 & 13 & 13 & 13 \\
\hline R-OS & 1 & 0 & 0 & 0 & 0 & 0 & 0 & 0 & 0 & 0 \\
\hline R-OS & 2 & 0 & 0 & 0 & 0 & 0 & 0 & 0 & 0 & 0 \\
\hline R-OS & 3 & 0 & 0 & 0 & 0 & 1 & 0 & 0 & 0 & 0 \\
\hline R-OS & 4 & 0 & 0 & 0 & 0 & 0 & 0 & 0 & 0 & 0 \\
\hline R-OS & 5 & 1 & 0 & 0 & 0 & 0 & 0 & 0 & 0 & 0 \\
\hline
\end{tabular}

RH DEEPENING 
TABLE I.2. (contd)

Sediment

M. nasuta on Sediment Test Days 0 through 9

Treatment

Replicate

R-BF

$R-B F$

$\mathrm{R}-\mathrm{BF}$

$R-B F$

$\mathrm{R}-\mathrm{BF}$

R-AM COMP

R-AM COMP

R-AM COMP

R-AM COMP

R-AM COMP

1
2
3
4
5

$\mathrm{C}-\mathrm{NE}$

C-NE

C-NE

C-NE

C-NE

C-SB

C-SB

C-SB

$\mathrm{C}-\mathrm{SB}$

C-SB

\section{2
3
4
5}

$\begin{array}{rrrrrrrrrr}2 & 2 & 1 & 1 & 1 & 1 & 1 & 2 & 1 & 1 \\ 1 & 0 & 0 & 0 & 0 & 0 & 0 & 1 & 0 & 0 \\ 1 & 2 & 2 & 2 & 2 & 2 & 2 & 2 & 2 & 1 \\ \text { NI (b) } & \text { NI } & \text { NI } & \text { NI } & \text { NI } & \text { NI } & \text { NI } & \text { NI } & \text { NI } & \text { NI } \\ 2 & 3 & 2 & 0 & 1 & 0 & 1 & 1 & 1 & 1\end{array}$

$\begin{array}{lllllllllll}1 & 0 & 0 & 0 & 1 & 0 & 1 & 1 & 0 & 0 & 1 \\ 2 & 1 & 2 & 2 & 3 & 3 & 1 & 2 & 3 & 3 & 3 \\ 3 & 3 & 2 & 0 & 1 & 2 & 2 & 1 & 4 & 2 & 3 \\ 4 & 0 & 0 & 0 & 0 & 0 & 0 & 1 & 1 & 1 & 1 \\ 5 & 3 & 1 & 3 & 2 & 2 & 1 & 1 & 5 & 6 & 5\end{array}$

(a) T Too turbid for observations.

(b) NI Not initiated; insufficient organisms to test all five replicates. 
TABLE 1.3. Daily Observations of M. nasuta Siphons Exposed During 10-Day Solid-Phase, FlowThrough Test, Richmond Harbor Deepening Project

Sediment M. nasuta Siphons Exposed Test Days 0 through 9

Treatment Replicate

SF COMP

SF COMP

SF COMP

SF COMP

SF COMP

SFW COMP

SFW COMP

SFW COMP

SFW COMP

SFW COMP

UIH COMP

UIH COMP

UIH COMP

UIH COMP

UIH COMP

TB Upper COMP

TB Upper COMP

TB Upper COMP

TB Upper COMP

TB Upper COMP

TB Lower COMP

TB Lower COMP

TB Lower COMP

TB Lower COMP

TB Lower COMP

OBM COMP

OBM COMP

OBM COMP

OBM COMP

OBM COMP

R-OS

R-OS

R-OS

R-OS

R-OS

1
2
3
4
5

1

2

3

4

5

1
2
3
4
5

1
2
3
4
5

1

2

3

4

5

1
2
3
4
5

1
2
3
4
5 $\begin{array}{lll}14 & 10 & 11\end{array}$

12

17

8

2

$\begin{array}{llllllllll}0 & 2 & 4 & 1 & 1 & 0 & 0 & 0 & 0 & 0 \\ 5 & 5 & 2 & 4 & 1 & 0 & 1 & 0 & 3 & 0 \\ 4 & 4 & 2 & 1 & 2 & 1 & 0 & 0 & 0 & 0 \\ 9 & 7 & 7 & 2 & 3 & 1 & 2 & 2 & 1 & 2 \\ 4 & 4 & 2 & 0 & 2 & 1 & 0 & 0 & 0 & 0\end{array}$

$\begin{array}{rrrrrr}T(a) & 3 & 3 & 1 & 1 & 2 \\ 8 & 3 & 3 & 6 & 7 & 3 \\ 6 & 3 & 5 & 0 & 2 & 1 \\ 4 & 2 & 4 & 2 & 3 & 1 \\ 10 & 13 & 13 & 6 & 8 & 6\end{array}$

12

10

15

5
9

$\begin{array}{rr}8 & 7 \\ 12 & 7 \\ 11 & 8 \\ 7 & 4 \\ 2 & 2\end{array}$

$\begin{array}{llll}17 & 13 & 30 & 25\end{array}$

$\begin{array}{lll}29 & 17 & 20\end{array}$

$\begin{array}{lll}36 & 26 & 26\end{array}$

$\begin{array}{lll}21 & 27 & 25\end{array}$

$\begin{array}{lll}18 & 11 & 18\end{array}$

$\begin{array}{llll}1 & 0 & 1 & 0\end{array}$

$\begin{array}{llll}2 & 3 & 1 & 0\end{array}$

$\begin{array}{llll}3 & 3 & 4 & 0\end{array}$

$\begin{array}{llll}6 & 3 & 2 & 0\end{array}$ 4

\begin{tabular}{llll}
6 & 7 & 8 & 9 \\
\hline
\end{tabular}

$\begin{array}{llll}4 & 4 & 4 & 4 \\ 2 & 2 & 2 & 0 \\ 2 & 1 & 2 & 1 \\ 0 & 0 & 0 & 0 \\ 0 & 0 & 0 & 1\end{array}$

$\begin{array}{llllllllll}0 & 0 & 2 & 0 & 0 & 0 & 1 & 0 & 0 & 0 \\ 4 & 6 & 2 & 0 & 2 & 1 & 2 & 1 & 1 & 2 \\ 2 & 3 & 1 & 2 & 0 & 1 & 1 & 2 & 2 & 2 \\ 0 & 0 & 0 & 1 & 1 & 0 & 0 & 0 & 0 & 0 \\ 3 & 2 & 2 & 2 & 3 & 4 & 1 & 2 & 1 & 1\end{array}$


TABLE I.3. (contd)

Sediment

Treatment

R-BF

R-BF

R-BF

R-BF

R-BF

R-AM COMP

R-AM COMP

R-AM COMP

R-AM COMP

R-AM COMP

C-NE

C-NE.

C-NE

C-NE

C-NE

C-SB

C-SB

C-SB

C-SB
C-SB

M. nasuta Siphons Exposed Test Days 0 through 9

\section{Replicate}

1
2
3
4
5

0
1
6
0
2

12

$\begin{array}{lll}3 & 4 & 5\end{array}$

\begin{tabular}{llll}
6 & 7 & 8 & 9 \\
\hline
\end{tabular}

$\begin{array}{lllllllll}1 & 0 & 1 & 0 & 0 & 0 & 0 & 0 & 0 \\ 4 & 1 & 1 & 1 & 0 & 1 & 0 & 0 & 0 \\ 2 & 0 & 2 & 1 & 2 & 3 & 1 & 1 & 1 \\ 0 & 0 & 0 & 1 & 0 & 0 & 0 & 0 & 0 \\ 0 & 0 & 0 & 0 & 0 & 0 & 0 & 0 & 0\end{array}$

1
2
3
4
5

011

$0 \quad 5$

33

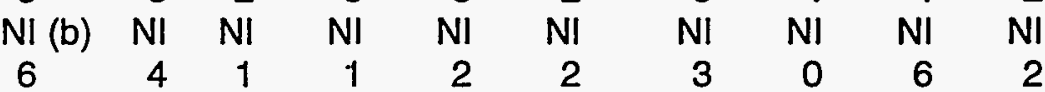

$\begin{array}{rrrrrrrrrrr}1 & 1 & 0 & 8 & 0 & 0 & 0 & 2 & 1 & 0 & 0 \\ 2 & 6 & 4 & 5 & 6 & 5 & 1 & 5 & 5 & 6 & 7 \\ 3 & 11 & 6 & 6 & 5 & 5 & 5 & 7 & 6 & 5 & 4 \\ 4 & 5 & 2 & 2 & 4 & 0 & 0 & 0 & 0 & 0 & 1 \\ 5 & 3 & 2 & 4 & 1 & 2 & 2 & 3 & 7 & 8 & 5\end{array}$

(a) T Too turbid for observations.

(b) NI Not initiated; insufficient organisms to test all five replicates. 
TABLE 1.4. Daily Observations of M. nasuta Dead and Removed During 10-Day Solid, FlowThrough Test, Richmond Harbor Deepening Project

Sediment

M. nasuta Dead and Removed Test Days 0 through 9

Treatment Replicate

0

SF COMP
SF COMP
SF COMP
SF COMP
SF COMP
SFW COMP
SFW COMP
SFW COMP
SFW COMP
SFW COMP

UIH COMP

UIH COMP

UIH COMP

UIH COMP

UIH COMP

1
2
3
4

$\begin{array}{llllllllll}0 & 0 & 0 & 0 & 0 & 0 & 0 & 0 & 0 & 0 \\ 0 & 0 & 0 & 0 & 0 & 0 & 0 & 0 & 0 & 0 \\ 0 & 0 & 0 & 0 & 0 & 0 & 0 & 0 & 0 & 0 \\ 0 & 0 & 0 & 0 & 0 & 0 & 0 & 0 & 0 & 0 \\ 0 & 0 & 0 & 0 & 0 & 0 & 0 & 0 & 0 & 0\end{array}$

$\begin{array}{lllllllllll}1 & 0 & 0 & 1 & 0 & 0 & 0 & 0 & 0 & 0 & 0 \\ 2 & 0 & 0 & 0 & 0 & 0 & 0 & 0 & 0 & 0 & 0 \\ 3 & 0 & 0 & 0 & 0 & 0 & 0 & 0 & 0 & 0 & 0 \\ 4 & 0 & 0 & 0 & 0 & 0 & 0 & 0 & 0 & 0 & 0 \\ 5 & 0 & 0 & 0 & 0 & 0 & 0 & 0 & 0 & 0 & 0\end{array}$

TB Upper COMP

TB Upper COMP

TB Upper COMP

TB Upper COMP

TB Upper COMP

1
2
3
4
5

TB Lower COMP

TB Lower COMP

TB Lower COMP

TB Lower COMP

TB Lower COMP

1
2
3
4
5

$\begin{array}{llllllllll}0 & 0 & 0 & 0 & 0 & 0 & 0 & 0 & 0 & 0 \\ 0 & 0 & 0 & 0 & 0 & 0 & 0 & 0 & 0 & 0 \\ 0 & 0 & 0 & 0 & 0 & 0 & 0 & 0 & 0 & 0 \\ 0 & 0 & 0 & 0 & 0 & 0 & 0 & 0 & 0 & 0 \\ 0 & 0 & 0 & 0 & 0 & 0 & 0 & 0 & 0 & 0\end{array}$

OBM COMP

OBM COMP

OBM COMP

OBM COMP

OBM COMP

$\begin{array}{llllllllll}0 & 0 & 0 & 0 & 0 & 0 & 0 & 0 & 0 & 0 \\ 0 & 0 & 0 & 0 & 0 & 0 & 0 & 0 & 0 & 0 \\ 0 & 0 & 0 & 0 & 0 & 0 & 0 & 0 & 0 & 0 \\ 0 & 0 & 0 & 0 & 0 & 0 & 0 & 0 & 0 & 0 \\ 0 & 0 & 1 & 0 & 0 & 0 & 0 & 0 & 0 & 0\end{array}$

$\begin{array}{ll}1 & 0 \\ 2 & 0 \\ 3 & 0 \\ 4 & 0 \\ 5 & 0\end{array}$

R-OS

R-OS

R-OS

R-OS

R-OS

$\begin{array}{lllllllllll}1 & 0 & 0 & 0 & 0 & 0 & 0 & 0 & 0 & 0 & 0 \\ 2 & 0 & 0 & 0 & 0 & 0 & 0 & 0 & 0 & 0 & 0 \\ 3 & 0 & 0 & 0 & 0 & 0 & 1 & 0 & 0 & 0 & 0 \\ 4 & 0 & 0 & 0 & 0 & 0 & 0 & 0 & 0 & 0 & 0 \\ 5 & 0 & 0 & 0 & 0 & 0 & 1 & 0 & 0 & 0 & 0\end{array}$

$\begin{array}{lllllllllll}1 & 0 & 0 & 0 & 0 & 0 & 0 & 0 & 0 & 0 & 0 \\ 2 & 0 & 0 & 0 & 0 & 0 & 0 & 0 & 0 & 0 & 0 \\ 3 & 0 & 0 & 0 & 0 & 0 & 0 & 0 & 0 & 0 & 0 \\ 4 & 0 & 0 & 0 & 0 & 0 & 0 & 0 & 0 & 0 & 0 \\ 5 & 0 & 0 & 0 & 0 & 0 & 0 & 0 & 0 & 0 & 0\end{array}$

RH DEEPENING 
TABLE I.4. (contd)

Sediment M. nasuta Dead and Removed Test Days 0 through 9

Treatment Replicate

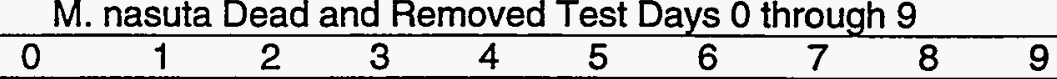

\begin{tabular}{|c|c|c|c|c|c|c|c|c|c|c|c|}
\hline R-BF & 1 & 0 & 0 & 0 & 0 & 0 & 0 & 0 & 0 & 0 & 0 \\
\hline R-BF & 2 & 0 & 0 & 0 & 0 & 0 & 0 & 0 & 0 & 0 & 0 \\
\hline R-BF & 3 & 0 & 0 & 0 & 0 & 0 & 0 & 0 & 0 & 0 & 0 \\
\hline$R-B F$ & 4 & 0 & 0 & 0 & 0 & 0 & 0 & 0 & 0 & 0 & 0 \\
\hline R-BF & 5 & 0 & 0 & 0 & 0 & 0 & 0 & 0 & 0 & 0 & 0 \\
\hline R-AM COMP & 1 & 0 & 0 & 0 & 0 & 0 & 0 & 0 & 0 & 0 & 0 \\
\hline R-AM COMP & 2 & 0 & 0 & 0 & 0 & 0 & 0 & 0 & 0 & 0 & 0 \\
\hline R-AM COMP & 3 & 0 & 0 & 0 & 0 & 0 & 0 & 0 & 0 & 0 & \\
\hline R-AM COMP & 4 & $\mathrm{NI}$ (a) & NI & $\mathrm{NI}$ & $\mathrm{NI}$ & $\mathrm{NI}$ & $\mathrm{NI}$ & $\mathrm{NI}$ & $\mathrm{NI}$ & $\mathrm{NI}$ & $\mathrm{NI}$ \\
\hline R-AM COMP & 5 & 0 & 0 & 0 & 0 & 0 & 0 & 0 & 0 & 0 & 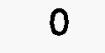 \\
\hline C-NE & 1 & 0 & 0 & 0 & 0 & 0 & 0 & 0 & 0 & 0 & \\
\hline C-NE & 2 & 0 & 0 & 0 & 0 & 0 & 0 & 0 & 0 & 0 & 0 \\
\hline C-NE & 3 & 0 & 0 & 0 & 0 & 0 & 0 & 0 & 0 & 0 & \\
\hline C-NE & 4 & 0 & 0 & 0 & 0 & 0 & 0 & 0 & 0 & 0 & 0 \\
\hline C-NE & 5 & 0 & 0 & 0 & 0 & 0 & 0 & 0 & 0 & 0 & 0 \\
\hline C-SB & 1 & 0 & 0 & 0 & 0 & 0 & 0 & 0 & 0 & 0 & \\
\hline C-SB & 2 & 0 & 0 & 0 & 0 & 0 & 0 & 0 & 0 & 0 & \\
\hline C-SB & 3 & 0 & 0 & 0 & 0 & 0 & 0 & 0 & 0 & 0 & \\
\hline C-SB & 4 & 0 & 0 & 0 & 0 & 0 & 0 & 0 & 0 & 0 & \\
\hline C-SB & 5 & 0 & 0 & 0 & 0 & 0 & 0 & 0 & 0 & 0 & \\
\hline
\end{tabular}

(a) NI Not initiated; insufficient organisms to test all five replicates. 
TABLE 1.5. Water Quality Summary for 10-Day M. nasuta/N. caecoides Solid-Phase, Flow-Through Test, Richmond Harbor Deepening Project

\begin{tabular}{|c|c|c|c|c|c|c|c|c|}
\hline \multirow{2}{*}{$\begin{array}{l}\text { Sediment } \\
\text { Treatment }\end{array}$} & \multicolumn{2}{|c|}{$\begin{array}{c}\text { Temperature } \\
\left({ }^{\circ} \mathrm{C}\right)\end{array}$} & \multicolumn{2}{|c|}{$\mathrm{pH}$} & \multicolumn{2}{|c|}{$\begin{array}{c}\text { Dissolved } \\
\text { Oxygen } \\
\text { (mg/L) }\end{array}$} & \multicolumn{2}{|c|}{$\begin{array}{c}\text { Salinity } \\
(\mathrm{o} / 00)\end{array}$} \\
\hline & Min & $\operatorname{Max}$ & Min & $\operatorname{Max}$ & Min & Max & Min & Max \\
\hline $\begin{array}{l}\text { Acceptable } \\
\text { Range }\end{array}$ & 13.0 & 17.0 & 7.30 & 8.30 & 5.0 & NA (a) & 28.0 & 32.0 \\
\hline SF COMP & 14.3 & 15.6 & 7.37 & 7.97 & 7.2 & 8.5 & 30.5 & 31.5 \\
\hline SFW COMP & 14.3 & 15.5 & 7.39 & 7.90 & 7.3 & 8.5 & 30.5 & 31.5 \\
\hline UIH COMP & 14.2 & 15.5 & 7.39 & 8.07 & 7.5 & 8.5 & 31.0 & 32.0 \\
\hline TB Upper COMP & 14.2 & 15.6 & 7.45 & 8.02 & 7.3 & 8.5 & 30.5 & 32.0 \\
\hline TB Lower COMP & 14.2 & 15.5 & 7.37 & 7.86 & 7.5 & 8.4 & 30.5 & 31.5 \\
\hline OBM COMP & 14.3 & 15.6 & 7.32 & 7.87 & 7.4 & 8.6 & 30.5 & 32.0 \\
\hline $\begin{array}{l}\text { R-OS } \\
\text { R-BF } \\
\text { R-AM COMP }\end{array}$ & $\begin{array}{l}14.2 \\
14.2 \\
14.3\end{array}$ & $\begin{array}{l}15.5 \\
15.5 \\
15.6\end{array}$ & $\begin{array}{l}7.40 \\
7.32 \\
7.43\end{array}$ & $\begin{array}{l}7.90 \\
7.89 \\
8.00\end{array}$ & $\begin{array}{l}7.4 \\
7.3 \\
7.5\end{array}$ & $\begin{array}{l}8.5 \\
8.5 \\
8.5\end{array}$ & $\begin{array}{l}30.5 \\
30.5 \\
31.0\end{array}$ & $\begin{array}{l}32.0 \\
32.0 \\
32.0\end{array}$ \\
\hline $\begin{array}{l}\text { C-NE } \\
\text { C-SB }\end{array}$ & $\begin{array}{l}14.3 \\
14.2\end{array}$ & $\begin{array}{l}15.6 \\
15.6\end{array}$ & $\begin{array}{l}7.34 \\
7.42\end{array}$ & $\begin{array}{l}8.20 \\
7.89\end{array}$ & $\begin{array}{l}7.1 \\
7.2\end{array}$ & $\begin{array}{l}8.5 \\
8.4\end{array}$ & $\begin{array}{l}30.5 \\
30.5\end{array}$ & $\begin{array}{l}32.0 \\
32.0\end{array}$ \\
\hline
\end{tabular}

(a) NA Not applicable. 
TABLE I.6. Ammonia Measurements in Overlying Water for 10-Day M. nasuta/N. caecoides Solid-Phase, Flow-Through Test, Richmond Harbor Deepening Project

\begin{tabular}{lllll}
\multirow{2}{*}{$\begin{array}{l}\text { Sediment } \\
\text { Treatment }\end{array}$} & \multicolumn{4}{c}{$\begin{array}{c}\text { Ammonia } \\
\text { (mg/L) }\end{array}$} \\
\cline { 2 - 5 } SF COMP & Day 1 & Day 3 & Day 7 & Day 10 \\
SFW COMP & 0.151 & 0.211 & 0.368 & 0.137 \\
UIH COMP & 0.220 & 0.159 & 0.357 & 0.123 \\
TB Upper COMP & 0.136 & 0.261 & 0.420 & 0.150 \\
TB Lower COMP & 0.161 & 0.188 & 0.351 & 0.131 \\
OBM COMP & 0.314 & 0.224 & 0.393 & 0.319 \\
R-OS & 0.134 & 0.159 & 0.372 & 0.177 \\
R-BF & 0.149 & 0.348 & 0.352 & 0.232 \\
R-AM COMP & 0.177 & 0.143 & 0.352 & 0.178 \\
C-NE & 0.118 & 0.300 & 0.364 & 0.125 \\
C-SB & 0.137 & 0.150 & 0.361 & 0.133 \\
& 0.127 & 0.358 & 0.373 & 0.144
\end{tabular}


TABLE 1.7. Test Results for 10-Day N. caecoides Solid-Phase, Flow-Through Test, Richmond Harbor Deepening Project

\begin{tabular}{|c|c|c|c|c|c|c|}
\hline \multirow[b]{2}{*}{$\begin{array}{l}\text { Sediment } \\
\text { Treatment }\end{array}$} & \multirow[b]{2}{*}{ Replicate } & \multicolumn{2}{|c|}{ N. caecoides } & \multirow[b]{2}{*}{$\begin{array}{l}\text { Proportion } \\
\text { Surviving }\end{array}$} & \multirow{2}{*}{$\begin{array}{l}\text { Mean } \\
\text { Proportion } \\
\text { Surviving }\end{array}$} & \multirow[b]{2}{*}{$\begin{array}{l}\text { Standard } \\
\text { Deviation }\end{array}$} \\
\hline & & Live & $\begin{array}{l}\text { Dead or } \\
\text { Missing }\end{array}$ & & & \\
\hline SF COMP & 1 & 14 & 6 & 0.70 & & \\
\hline SF COMP & 2 & 16 & 4 & 0.80 & & \\
\hline SF COMP & 3 & 17 & 3 & 0.85 & & \\
\hline SF COMP & 4 & 15 & 5 & 0.75 & & \\
\hline SF COMP & 5 & 17 & 3 & 0.85 & 0.79 & 0.07 \\
\hline SFW COMP & 1 & 17 & 3 & 0.85 & & \\
\hline SFW COMP & 2 & 15 & 5 & 0.75 & & \\
\hline SFW COMP & 3 & 17 & 3 & 0.85 & & \\
\hline SFW COMP & 4 & 17 & 3 & 0.85 & & \\
\hline SFW COMP & 5 & 15 & 5 & 0.75 & 0.81 & 0.05 \\
\hline UIH COMP & 1 & 17 & 3 & 0.85 & & \\
\hline UIH COMP & 2 & 14 & 6 & 0.70 & & \\
\hline UIH COMP & 3 & 18 & 2 & 0.90 & & \\
\hline UIH COMP & 4 & 19 & 1 & 0.95 & & \\
\hline UIH COMP & 5 & 20 & 0 & 1.00 & 0.88 & 0.12 \\
\hline TB Upper COMP & 1 & 18 & 2 & 0.90 & & \\
\hline TB Upper COMP & 2 & 17 & 3 & 0.85 & & \\
\hline TB Upper COMP & 3 & 15 & 5 & 0.75 & & \\
\hline TB Upper COMP & 4 & 18 & 2 & 0.90 & & $\cdot$ \\
\hline TB Upper COMP & 5 & 18 & 2 & 0.90 & 0.86 & 0.07 \\
\hline TB Lower COMP & 1 & 19 & 1 & 0.95 & & \\
\hline TB Lower COMP & 2 & 20 & 0 & 1.00 & & \\
\hline TB Lower COMP & 3 & 18 & 2 & 0.90 & & \\
\hline TB Lower COMP & 4 & 20 & 0 & 1.00 & & \\
\hline TB Lower COMP & 5 & 19 & 1 & 0.95 & 0.96 & 0.04 \\
\hline OBM COMP & 1 & 6 & 14 & 0.30 & & \\
\hline OBM COMP & 2 & 11 & 9 & 0.55 & & \\
\hline OBM COMP & 3 & 4 & 16 & 0.20 & & \\
\hline OBM COMP & 4 & 11 & 9 & 0.55 & & \\
\hline OBM COMP & 5 & 6 & 14 & 0.30 & 0.38 & 0.16 \\
\hline R-OS & 1 & 19 & 1 & 0.95 & & \\
\hline R-OS & 2 & 20 & 0 & 1.00 & & \\
\hline R-OS & 3 & 19 & 1 & 0.95 & & \\
\hline R-OS & 4 & 18 & 2 & 0.90 & & \\
\hline R-OS & 5 & 20 & 0 & 1.00 & 0.96 & 0.04 \\
\hline RH DEEPENING & & & I.11 & & & \\
\hline
\end{tabular}


TABLE I.7. (contd)

\begin{tabular}{|c|c|c|c|c|c|c|}
\hline \multirow[b]{2}{*}{$\begin{array}{l}\text { Sediment } \\
\text { Treatment }\end{array}$} & \multirow[b]{2}{*}{ Replicate } & \multicolumn{2}{|c|}{ N. caecoides } & \multirow[b]{2}{*}{$\begin{array}{l}\text { Proportion } \\
\text { Surviving }\end{array}$} & \multirow{2}{*}{$\begin{array}{l}\text { Mean } \\
\text { Proportion } \\
\text { Surviving }\end{array}$} & \multirow[b]{2}{*}{$\begin{array}{l}\text { Standard } \\
\text { Deviation }\end{array}$} \\
\hline & & Live & $\begin{array}{l}\text { Dead or } \\
\text { Missing }\end{array}$ & & & \\
\hline R-BF & 1 & 17 & 3 & 0.85 & & \\
\hline $\mathrm{R}-\mathrm{BF}$ & 2 & 19 & 1 & 0.95 & & \\
\hline R-BF & 3 & 17 & 3 & 0.85 & & \\
\hline R-BF & 4 & 18 & 2 & 0.90 & & \\
\hline R-BF & 5 & 20 & 0 & 1.00 & 0.91 & 0.07 \\
\hline R-AM COMP & 1 & 19 & 1 & 0.95 & & \\
\hline R-AM COMP & 2 & 20 & 0 & 1.00 & & \\
\hline R-AM COMP & 3 & 19 & 1 & 0.95 & & \\
\hline R-AM COMP & 4 & $\mathrm{NI}$ (b) & $\mathrm{NI}$ & $N A(c)$ & & \\
\hline R-AM COMP & 5 & 19 & 1 & 0.95 & 0.96 & 0.03 \\
\hline C-NE & 1 & 18 & 2 & 0.90 & & \\
\hline C-NE & 2 & 20 & 0 & 1.00 & & \\
\hline C-NE & 3 & 18 & 2 & 0.90 & & \\
\hline C-NE & 4 & 18 & 2 & 0.90 & & \\
\hline $\mathrm{C}-\mathrm{NE}$ & 5 & 20 & 0 & 1.00 & 0.94 & 0.05 \\
\hline C-SB & 1 & 20 & 0 & 1.00 & & \\
\hline C-SB & 2 & 19 & 1 & 0.95 & & \\
\hline C-SB & 3 & 19 & 1 & 0.95 & & \\
\hline C-SB & 4 & 19 & 1 & 0.95 & & \\
\hline C-SB & 5 & 19 & 1 & 0.95 & 0.96 & 0.02 \\
\hline
\end{tabular}

(a) Survival based on initial exposure of 20 organisms per replicate.

(b) NI Not initiated; insufficient organisms for all five replicates.

(c) NA Not applicable. 
TABLE I.8. Daily Observations of N. caecoides on Sediment Surface During 10-Day Solid-Phase, FlowThrough Test, Richmond Harbor Deepening

Sediment

N. caecoides on Sediment Test Days 0 through 9

Treatment Replicate

$\begin{array}{lllllll}1 & 2 & 3 & 4 & 5 & 6 & 7\end{array}$

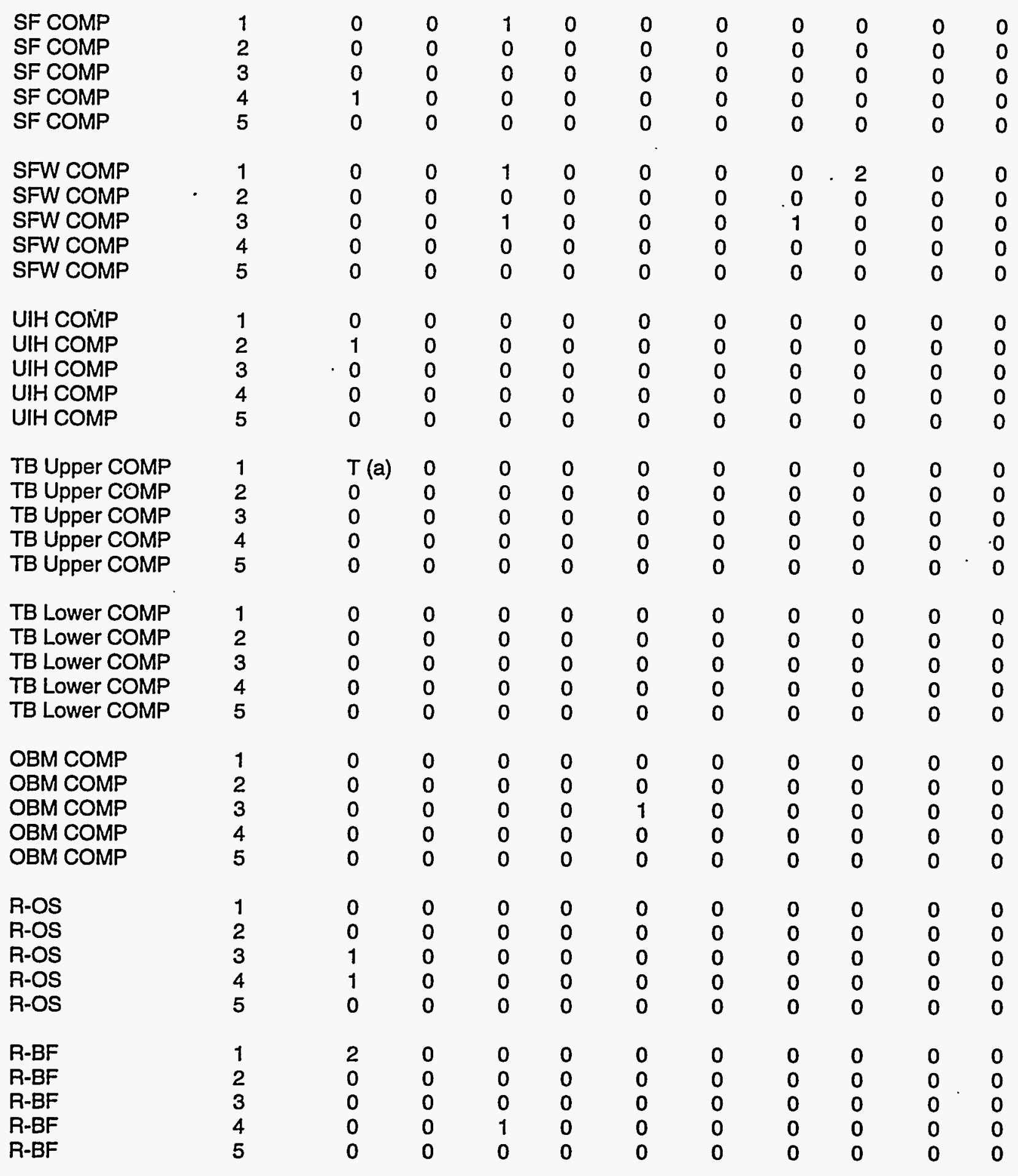

RH DEEPENING 
TABLE 1.8. (contd)

Sediment

Treatment

N. caecoides on Sediment Test Days 0 through 9

\begin{tabular}{ll} 
R-AM COMP & 1 \\
R-AM COMP & 2 \\
R-AM COMP & 3 \\
R-AM COMP & 4 \\
R-AM COMP & 5 \\
C-NE & \\
C-NE & 1 \\
C-NE & 2 \\
C-NE & 3 \\
C-NE & 4 \\
& 5 \\
C-SB & \\
C-SB & 1 \\
C-SB & 2 \\
C-SB & 3 \\
C-SB & 4 \\
\hline
\end{tabular}

(a) T Too turbid for observations.

(b) NI Not initiated; insufficient organisms to test all five replicates. 
TABLE I.9. Daily Observations of N. caecoides Dead and Removed During 10-Day Solid-Phase, Flow-Through Test, Richmond Harbor Deepening Project

Sediment

N. caecoides Dead and Removed Test Days 0 through 9

Treatment

Replicate

$\begin{array}{ll}\text { SF COMP } & 1 \\ \text { SF COMP } & 2 \\ \text { SF COMP } & 3 \\ \text { SF COMP } & 4 \\ \text { SF COMP } & 5\end{array}$

SFW COMP

SFW COMP

SFW COMP

SFW COMP

SFW COMP

$$
\begin{aligned}
& 1 \\
& 2 \\
& 3 \\
& 4 \\
& 5
\end{aligned}
$$

1

$\begin{array}{ll}\text { UIH COMP } & 1 \\ \text { UIH COMP } & 2 \\ \text { UIH COMP } & 3 \\ \text { UIH COMP } & 4 \\ \text { UIH COMP } & 5\end{array}$

TB Upper COMP 1

TB Upper COMP 2

TB Upper COMP 3

TB Upper COMP 4

TB Upper COMP 5

TB Lower COMP 1

TB Lower COMP 2

TB Lower COMP 3

TB Lower COMP 4

TB Lower COMP 5

$\begin{array}{ll}\text { OBM COMP } & 1 \\ \text { OBM COMP } & 2 \\ \text { OBM COMP } & 3 \\ \text { OBM COMP } & 4 \\ \text { OBM COMP } & 5\end{array}$

$\begin{array}{ll}\text { R-OS } & 1 \\ \text { R-OS } & 2 \\ \text { R-OS } & 3 \\ \text { R-OS } & 4 \\ \text { R-OS } & 5\end{array}$

$\begin{array}{lllllllllll}1 & 0 & 0 & 0 & 0 & 0 & 0 & 0 & 0 & 0 & 0 \\ 2 & 0 & 0 & 0 & 0 & 0 & 0 & 0 & 0 & 0 & 0 \\ 3 & 0 & 0 & 0 & 0 & 0 & 0 & 0 & 0 & 0 & 0 \\ 4 & 0 & 0 & 0 & 0 & 0 & 0 & 0 & 0 & 0 & 0 \\ 5 & 0 & 0 & 0 & 0 & 0 & 0 & 0 & 0 & 0 & 0\end{array}$

$\begin{array}{lllllllllll}1 & 0 & 0 & 0 & 0 & 0 & 0 & 0 & 0 & 0 & 0 \\ 2 & 0 & 0 & 0 & 0 & 0 & 0 & 0 & 0 & 0 & 0 \\ 3 & 1(a) & 0 & 0 & 0 & 0 & 0 & 0 & 0 & 0 & 0 \\ 4 & 1(a) & 0 & 0 & 0 & 0 & 0 & 0 & 0 & 0 & 0 \\ 5 & 0 & 0 & 0 & 0 & 0 & 0 & 0 & 0 & 0 & 0\end{array}$

RH DEEPENING 
TABLE 1.9. (contd)

Sediment

N. caecoides Dead and Removed Test Days 0 through 9

Treatment

Replicate 45 $\begin{array}{llll}6 & 7 & 8 & 9\end{array}$

$R-B F$

R-BF

R-BF

R-BF

$\mathrm{R}$-BF

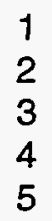

$\begin{array}{llllllllll}2 \text { (a) } & 0 & 0 & 0 & 0 & 0 & 0 & 0 & 0 & 0\end{array}$ $\begin{array}{llllllllll}0 & 0 & 0 & 0 & 0 & 0 & 0 & 0 & 0 & 0\end{array}$

$\begin{array}{llllllllll}0 & 0 & 0 & 0 & 0 & 0 & 0 & 0 & 0 & 0\end{array}$

R-BF

$\begin{array}{llllllllll}0 & 0 & 0 & 0 & 0 & 0 & 0 & 0 & 0 & 0\end{array}$

R-AM COMP

R-AM COMP

R-AM COMP

R-AM COMP

R-AM COMP

$\begin{array}{rcrrrrrrrrr}1 & 0 & 0 & 0 & 0 & 0 & 0 & 0 & 0 & 0 & 0 \\ 2 & 0 & 0 & 0 & 0 & 0 & 0 & 0 & 0 & 0 & 0 \\ 3 & 0 & 0 & 0 & 0 & 0 & 0 & 0 & 0 & 0 & 0 \\ 4 & \text { NI (b) } & \text { NI } & \text { NI } & \text { NI } & \text { NI } & \text { NI } & \text { NI } & \text { NI } & \text { NI } & \text { NI } \\ 5 & 0 & 0 & 0 & 0 & 0 & 0 & 0 & 0 & 1 & 0\end{array}$

C-NE

C-NE

C-NE

C-NE

C-NE

$\begin{array}{lllllllllll}1 & 0 & 0 & 1 & 0 & 0 & 0 & 0 & 0 & 0 & 0 \\ 2 & 0 & 0 & 0 & 0 & 0 & 0 & 0 & 0 & 0 & 0 \\ 3 & 0 & 0 & 0 & 0 & 0 & 0 & 0 & 0 & 0 & 0 \\ 4 & 0 & 0 & 0 & 0 & 0 & 0 & 0 & 0 & 0 & 0 \\ 5 & 0 & 0 & 0 & 0 & 0 & 0 & 0 & 0 & 0 & 0\end{array}$

C-SB

C-SB

C-SB

C-SB

C-SB

$\begin{array}{lllllllllll}1 & 1(a) & 0 & 0 & 0 & 0 & 0 & 0 & 0 & 0 & 0 \\ 2 & 1(a) & 0 & 0 & 0 & 0 & 0 & 0 & 0 & 0 & 0 \\ 3 & 0 & 0 & 0 & 0 & 0 & 0 & 0 & 0 & 0 & 0 \\ 4 & 0 & 0 & 0 & 0 & 0 & 0 & 0 & 0 & 0 & 0 \\ 5 & 0 & 0 & 0 & 0 & 0 & 0 & 0 & 0 & 0 & 0\end{array}$

(a) For Day 0 observations only, replaced dead organisms with live N. caecoides.

(b) NI Not initiated; insufficient organisms to test all five replicates. 
APPENDIX J

BIOASSAY RESULTS FOR 28-DAY SOLID-PHASE, FLOW-THROUGH TEST WITH MACOMA nasuta 


\section{QA/QC SUMMARY}

PROGRAM: $\quad$ Richmond Harbor Deepening Project

TEST ORGANISM: Macoma nasuta

TEST TYPE: $\quad$ Solid-phase, flow-through; Bioaccumulation

TEST DURATION: 28 days

WATER QUALITY ACCEPTABLE RANGES:

Temperature $\mathrm{pH}$ Dissolved Oxygen Salinity Flow Rate Ammonia

$\begin{array}{llllll}13-17^{\circ} \mathrm{C} & 7.30-8.30 & \geq 6.0 \mathrm{mg} / \mathrm{L} & 28-32 \% & 115-135 \mathrm{~m} / \mathrm{min} \quad \mathrm{NA}\end{array}$

TEST MATRIX

SOURCE/AGE

HOLDING/ACCLIMATION

17 days acclimation

Temperature

$\min / \max$

$6.7-14.1^{\circ} \mathrm{C}$

8 days holding

$\min / \max$

$9.6-14.7^{\circ} \mathrm{C}$

WATER QUALITY SUMMARY

TEST VALIDATION

REFERENCE TOXICANT TEST COMMENTS
Sediments were collected from January 28,1994 to February 3,1994 . Sediments were composited and tested within 6 weeks holding time after collection.

Johnson and Gunstone, Discovery Bay, Washington. Wild captured organisms (mixed age group-1 to 2.5 in. in size) were collected in Discovery Bay.

Approximately 3500 organisms were received dry in mesh bags between January 24 and 26 . The organisms were held for 25 days at the following conditions prior to test initiation.

$\mathrm{pH}$

Dissolved Oxygen

Salinity

7.57-7.96

$7.4-9.7 \mathrm{mg} / \mathrm{L}$

$30.5-32.0 \%$

$7.59-7.74$

$8.0-9.1 \mathrm{mg} / \mathrm{L}$

31.0-32.0\%

All water quality parameters remained within the acceptable ranges throughout the 28 days of testing with the exception of a $2^{\circ} \mathrm{C}$ drop in temperature $\left(10.9^{\circ} \mathrm{C}\right)$ which occurred between test days 22 and 23 in all test chambers. This temporary drop in temperature did not appear to have any detrimental effect on any of the test organisms.

The test was validated by $91 \%$ survival in the control sediment (C-SB).

Not applicable.

Flow rates generally remained within the acceptable range of $115-135 \mathrm{ml} \mathrm{min}$. Slight fluctuations ( $<5 \mathrm{ml}$ ) did occur during the 28 days of testing but were corrected within 24 hours. 


\section{QA/QC SUMMARY (contd)}

\section{REFERENCES}

EPAUUSACE (U.S. Environmental Protection Agency/ U.S. Army Corps of Engineers). 1991. Evaluation of Dredged Material Proposed for Ocean Disposal (Testing Manual).

EPA-68-C8-0105, U.S. Environmental Protection Agency, Office of Marine and Estuarine Protection, Washington, D.C. 
TABLE J.1. Test Results for 28-Day M. nasuta Solid-Phase, Flow-Through Test, Richmond Harbor Deepening Project

\begin{tabular}{|c|c|c|c|c|c|c|}
\hline \multirow[b]{2}{*}{$\begin{array}{l}\text { Sediment } \\
\text { Treatment }\end{array}$} & \multirow[b]{2}{*}{ Replicate } & \multicolumn{2}{|c|}{ M. nasuta } & \multicolumn{3}{|c|}{ Mean } \\
\hline & & Live(a) & $\begin{array}{l}\text { Dead or } \\
\text { Missing }\end{array}$ & $\begin{array}{l}\text { Proportion } \\
\text { Surviving } \\
\end{array}$ & $\begin{array}{l}\text { Proportion } \\
\text { Surviving }\end{array}$ & $\begin{array}{l}\text { Standard } \\
\text { Deviation }\end{array}$ \\
\hline SF COMP & 1 & 25 & 0 & 1.00 & & \\
\hline SF COMP & 2 & 22 & 3 & 0.88 & & \\
\hline SF COMP & 3 & 23 & 2 & 0.92 & & \\
\hline SF COMP & 4 & 24 & 1 & 0.96 & & \\
\hline SF COMP & 5 & 25 & 0 & 1.00 & 0.95 & 0.05 \\
\hline SFW COMP & 1 & 23 & 2 & 0.92 & & \\
\hline SFW COMP & 2 & 21 & 4 & 0.84 & & \\
\hline SFW COMP & 3 & 25 & 0 & 1.00 & & \\
\hline SFW COMP & 4 & 25 & 0 & 1.00 & & \\
\hline SFW COMP & 5 & 24 & 1 & 0.96 & 0.94 & 0.07 \\
\hline UIH COMP & 1 & 25 & 0 & 1.00 & & \\
\hline UIH COMP & 2 & 23 & 2 & 0.92 & & \\
\hline UIH COMP & 3 & 24 & $\overline{1}$ & 0.96 & & \\
\hline UIH COMP & 4 & 24 & 1 & 0.96 & & \\
\hline UIH COMP & 5 & 24 & 1 & 0.96 & 0.96 & 0.03 \\
\hline TB Upper COMP & 1 & 25 & 0 & 1.00 & & \\
\hline TB Upper COMP & 2 & 24 & 1 & 0.96 & & \\
\hline TB Upper COMP & 3 & 24 & 1 & 0.96 & & \\
\hline TB Upper COMP & 4 & 23 & 2 & 0.92 & & \\
\hline TB Upper COMP & 5 & 22 & 3 & 0.88 & 0.94 & 0.05 \\
\hline TB Lower COMP & 1 & 23 & 2 & 0.92 & & \\
\hline TB Lower COMP & 2 & 24 & $\overline{1}$ & 0.96 & & \\
\hline TB Lower COMP & 3 & 22 & 3 & 0.88 & & \\
\hline TB Lower COMP & 4 & 20 & 5 & 0.80 & & \\
\hline TB Lower COMP & 5 & 24 & 1 & 0.96 & 0.90 & 0.07 \\
\hline OBM COMP & 1 & 25 & 0 & 1.00 & & \\
\hline OBM СОMP & 2 & 22 & 3 & 0.88 & & \\
\hline OBM COMP & 3 & 25 & 0 & 1.00 & & \\
\hline OBM COMP & 4 & 22 & 3 & 0.88 & & \\
\hline OBM COMP & 5 & 24 & 1 & 0.96 & 0.94 & 0.06 \\
\hline R-OS & 1 & 25 & 0 & 1.00 & & \\
\hline R-OS & 2 & 23 & 2 & 0.92 & & \\
\hline R-OS & 3 & 22 & 3 & 0.88 & & \\
\hline R-OS & 4 & 25 & 0 & 1.00 & & \\
\hline R-OS & 5 & 25 & 0 & 1.00 & 0.96 & 0.06 \\
\hline$R-B F$ & 1 & 25 & 0 & 1.00 & & \\
\hline R-BF & 2 & 25 & 0 & 1.00 & & \\
\hline R-BF & 3 & 23 & 2 & 0.92 & & \\
\hline R-BF & 4 & 22 & 3 & 0.88 & & \\
\hline R-BF & 5 & 23 & 2 & 0.92 & 0.94 & 0.05 \\
\hline RH DEEPENING & & & $\mathrm{J} .1$ & & & \\
\hline
\end{tabular}


TABLE J.1. (contd)

\begin{tabular}{lc}
$\begin{array}{l}\text { Sediment } \\
\text { Treatment }\end{array}$ & Replicate \\
\hline R-AM COMP & 1 \\
R-AM COMP & 2 \\
R-AM COMP & 3 \\
R-AM COMP & 4 \\
R-AM COMP & 5 \\
C-SB & \\
C-SB & 1 \\
C-SB & 2 \\
C-SB & 3 \\
C-SB & 4 \\
& 5 \\
\hline
\end{tabular}

\begin{tabular}{|c|c|c|c|c|}
\hline \multicolumn{2}{|c|}{ M. nasuta } & \multicolumn{3}{|c|}{ Mean } \\
\hline Live(a) & $\begin{array}{l}\text { Dead or } \\
\text { Missing }\end{array}$ & $\begin{array}{l}\text { Proportion } \\
\text { Surviving }\end{array}$ & $\begin{array}{l}\text { Proportion } \\
\text { Surviving }\end{array}$ & $\begin{array}{l}\text { Standard } \\
\text { Deviation }\end{array}$ \\
\hline
\end{tabular}

(a) Survival based on initial exposure of 25 organisms per replicate. 


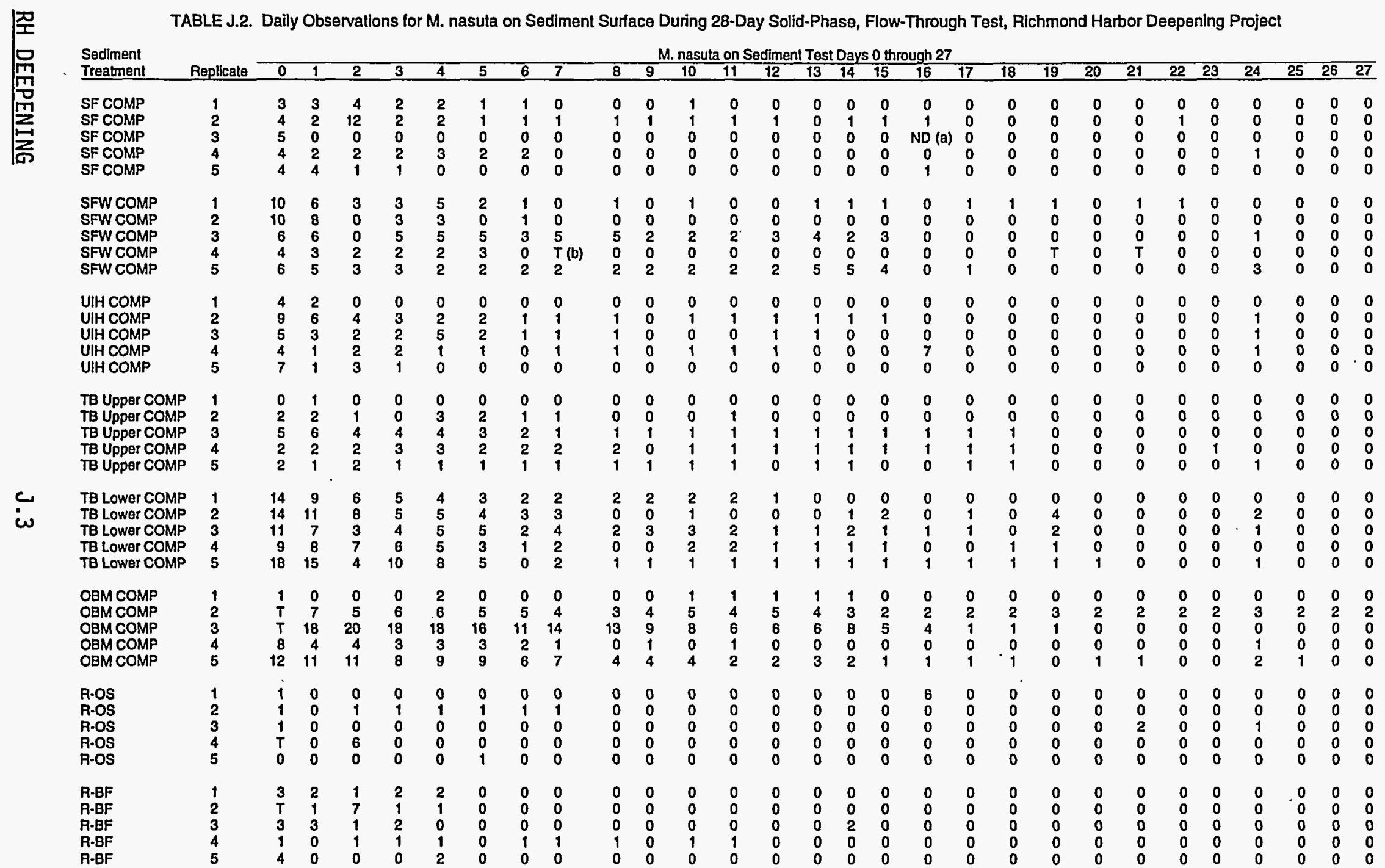




\begin{tabular}{|c|c|c|c|c|c|c|c|c|c|c|c|c|c|c|c|c|c|c|c|c|c|c|c|c|c|c|c|c|c|}
\hline 胥 & & & & & & & & & & & & nasu & a on & edime & t Test & Days & sothr & ugh 2 & & & & & & & & & & & \\
\hline Treatment & Replicate & 0 & 1 & 2 & 3 & 4 & 5 & 6 & 7 & 8 & 9 & 10 & 11 & 12 & 13 & 14 & 15 & 16 & 17 & 18 & 19 & 20 & 21 & 22 & 23 & 24 & 25 & 26 & 27 \\
\hline $\begin{array}{l}\text { R-AM COMP } \\
\text { R-AM COMP } \\
\text { R-AM COMP } \\
\text { R-AM COMP } \\
\text { R-AM COMP }\end{array}$ & $\begin{array}{l}1 \\
2 \\
3 \\
4 \\
5\end{array}$ & $\begin{array}{l}2 \\
1 \\
1 \\
1 \\
4\end{array}$ & $\begin{array}{l}1 \\
0 \\
2 \\
1 \\
1\end{array}$ & $\begin{array}{l}1 \\
1 \\
2 \\
1 \\
1\end{array}$ & $\begin{array}{l}1 \\
1 \\
0 \\
2 \\
1\end{array}$ & $\begin{array}{l}4 \\
3 \\
3 \\
2 \\
1\end{array}$ & $\begin{array}{l}3 \\
4 \\
4 \\
2 \\
3\end{array}$ & $\begin{array}{l}0 \\
4 \\
3 \\
3 \\
2\end{array}$ & $\begin{array}{l}0 \\
5 \\
6 \\
6 \\
2\end{array}$ & $\begin{array}{l}2 \\
6 \\
5 \\
5 \\
3\end{array}$ & $\begin{array}{l}0 \\
3 \\
7 \\
7 \\
4\end{array}$ & $\begin{array}{l}4 \\
4 \\
3 \\
8 \\
6\end{array}$ & $\begin{array}{l}6 \\
3 \\
4 \\
5 \\
5\end{array}$ & $\begin{array}{l}6 \\
3 \\
5 \\
4 \\
5\end{array}$ & $\begin{array}{l}6 \\
1 \\
4 \\
3 \\
4\end{array}$ & $\begin{array}{l}6 \\
4 \\
5 \\
4 \\
6\end{array}$ & $\begin{array}{l}7 \\
6 \\
5 \\
6 \\
6\end{array}$ & $\begin{array}{l}7 \\
4 \\
3 \\
0 \\
0\end{array}$ & $\begin{array}{l}7 \\
2 \\
3 \\
6 \\
4\end{array}$ & $\begin{array}{l}5 \\
6 \\
3 \\
6 \\
5\end{array}$ & $\begin{array}{l}4 \\
7 \\
0 \\
6 \\
6\end{array}$ & $\begin{array}{l}5 \\
6 \\
1 \\
5 \\
7\end{array}$ & $\begin{array}{l}5 \\
6 \\
2 \\
4 \\
4\end{array}$ & $\begin{array}{l}4 \\
6 \\
4 \\
3 \\
4\end{array}$ & $\begin{array}{l}1 \\
6 \\
3 \\
5 \\
3\end{array}$ & $\begin{array}{l}4 \\
6 \\
3 \\
6 \\
1\end{array}$ & $\begin{array}{l}2 \\
3 \\
3 \\
4 \\
4\end{array}$ & $\begin{array}{l}4 \\
6 \\
3 \\
5 \\
4\end{array}$ & $\begin{array}{l}4 \\
3 \\
3 \\
5 \\
1\end{array}$ \\
\hline $\begin{array}{l}\text { C-SB } \\
\text { C-SB } \\
\text { C-SB } \\
\text { C-SB } \\
\text { C.SB }\end{array}$ & $\begin{array}{l}1 \\
2 \\
3 \\
4 \\
5\end{array}$ & $\begin{array}{l}0 \\
0 \\
1 \\
0 \\
0\end{array}$ & $\begin{array}{l}0 \\
0 \\
1 \\
0 \\
0\end{array}$ & $\begin{array}{l}0 \\
0 \\
1 \\
2 \\
5\end{array}$ & $\begin{array}{l}0 \\
0 \\
0 \\
0 \\
0\end{array}$ & $\begin{array}{l}0 \\
0 \\
0 \\
0 \\
0\end{array}$ & $\begin{array}{l}0 \\
0 \\
0 \\
0 \\
0\end{array}$ & $\begin{array}{l}0 \\
0 \\
0 \\
0 \\
0\end{array}$ & $\begin{array}{l}0 \\
0 \\
0 \\
0 \\
0\end{array}$ & $\begin{array}{l}0 \\
0 \\
0 \\
0 \\
0\end{array}$ & $\begin{array}{l}0 \\
0 \\
0 \\
0 \\
0\end{array}$ & $\begin{array}{l}0 \\
0 \\
0 \\
0 \\
0\end{array}$ & $\begin{array}{l}0 \\
0 \\
0 \\
0 \\
0\end{array}$ & $\begin{array}{l}0 \\
0 \\
0 \\
0 \\
0\end{array}$ & $\begin{array}{l}0 \\
0 \\
0 \\
0 \\
0\end{array}$ & $\begin{array}{l}0 \\
0 \\
0 \\
0 \\
0\end{array}$ & $\begin{array}{l}0 \\
0 \\
0 \\
0 \\
0\end{array}$ & $\begin{array}{l}1 \\
0 \\
0 \\
0 \\
0\end{array}$ & $\begin{array}{l}0 \\
0 \\
0 \\
0 \\
0\end{array}$ & $\begin{array}{l}0 \\
0 \\
0 \\
0 \\
0\end{array}$ & $\begin{array}{l}0 \\
0 \\
0 \\
0 \\
0\end{array}$ & $\begin{array}{l}0 \\
0 \\
0 \\
0 \\
0\end{array}$ & $\begin{array}{l}0 \\
0 \\
0 \\
0 \\
0\end{array}$ & $\begin{array}{l}0 \\
0 \\
0 \\
0 \\
0\end{array}$ & $\begin{array}{l}0 \\
0 \\
0 \\
0 \\
0\end{array}$ & $\begin{array}{l}0 \\
0 \\
0 \\
0 \\
0\end{array}$ & $\begin{array}{l}0 \\
0 \\
0 \\
0 \\
0\end{array}$ & $\begin{array}{l}0 \\
0 \\
0 \\
0 \\
0\end{array}$ & $\begin{array}{l}0 \\
0 \\
0 \\
0 \\
0\end{array}$ \\
\hline
\end{tabular}

(a) ND No Data.

(b) T Too Turbld for obsenvations

is 


\begin{tabular}{|c|c|c|c|c|c|c|c|c|c|c|c|c|c|c|c|c|c|c|c|c|c|c|c|c|c|c|c|c|c|}
\hline $\begin{array}{l}\text { Sediment } \\
\text { Treatment }\end{array}$ & Replicate & 0 & 1 & 2 & 3 & 4 & 5 & 6 & 7 & 8 & $\frac{N}{9}$ & 10 & te Sipho & $\frac{h o n s}{12} x_{x}$ & $\frac{\text { Expos }}{13}$ & $\frac{1}{14}$ & $\frac{1 \text { Days }}{15}$ & $s 0$ throu & 3 & 18 & 19 & & 31 & & & 21 & & & \\
\hline $\begin{array}{l}\text { SF COMP } \\
\text { SF COMP } \\
\text { SF COMP } \\
\text { SF COMP } \\
\text { SF COMP }\end{array}$ & $\begin{array}{l}1 \\
2 \\
3 \\
4 \\
5\end{array}$ & $\begin{array}{r}16 \\
8 \\
12 \\
15 \\
10\end{array}$ & $\begin{array}{r}13 \\
3 \\
4 \\
11 \\
8\end{array}$ & $\begin{array}{r}11 \\
13 \\
7 \\
4 \\
9\end{array}$ & $\begin{array}{r}7 \\
11 \\
7 \\
9 \\
4\end{array}$ & $\begin{array}{l}5 \\
5 \\
1 \\
3 \\
1\end{array}$ & $\begin{array}{l}4 \\
3 \\
5 \\
6 \\
1\end{array}$ & $\begin{array}{l}1 \\
2 \\
2 \\
2 \\
3\end{array}$ & $\begin{array}{l}3 \\
3 \\
3 \\
2 \\
2 \\
2\end{array}$ & $\begin{array}{l}1 \\
3 \\
2 \\
1 \\
0\end{array}$ & $\begin{array}{l}4 \\
3 \\
2 \\
4 \\
4\end{array}$ & $\begin{array}{r}13 \\
3 \\
1 \\
6 \\
1\end{array}$ & $\begin{array}{l}1 \\
1 \\
1 \\
3 \\
2 \\
2\end{array}$ & $\begin{array}{l}1 \\
2 \\
1 \\
0 \\
2\end{array}$ & $\begin{array}{l}2 \\
2 \\
2 \\
2 \\
2\end{array}$ & $\begin{array}{l}2 \\
1 \\
3 \\
2 \\
0\end{array}$ & $\begin{array}{l}3 \\
2 \\
2 \\
2 \\
2\end{array}$ & $\begin{array}{c}3 \\
3 \\
N D \\
4 \\
1\end{array}$ & $\begin{array}{l}3 \\
2 \\
4 \\
8 \\
0\end{array}$ & $\begin{array}{l}1 \\
2 \\
2 \\
3 \\
0\end{array}$ & $\begin{array}{l}0 \\
0 \\
0 \\
2 \\
1\end{array}$ & $\begin{array}{l}3 \\
1 \\
0 \\
3 \\
2\end{array}$ & $\begin{array}{l}1 \\
3 \\
1 \\
1 \\
2\end{array}$ & $\begin{array}{l}1 \\
2 \\
1 \\
0 \\
2\end{array}$ & $\begin{array}{l}1 \\
1 \\
0 \\
0 \\
2\end{array}$ & $\begin{array}{l}4 \\
3 \\
0 \\
2 \\
2\end{array}$ & $\begin{array}{l}1 \\
3 \\
1 \\
2 \\
2\end{array}$ & $\begin{array}{l}1 \\
3 \\
1 \\
2 \\
2\end{array}$ & $\begin{array}{l}2 \\
1 \\
1 \\
2 \\
2\end{array}$ \\
\hline $\begin{array}{l}\text { SFW COMP } \\
\text { SFW COMP } \\
\text { SFW COMP } \\
\text { SFW COMP } \\
\text { SFW COMP }\end{array}$ & $\begin{array}{l}1 \\
2 \\
3 \\
4 \\
5\end{array}$ & $\begin{array}{r}19 \\
10 \\
12 \\
4 \\
9\end{array}$ & $\begin{array}{r}7 \\
12 \\
3 \\
5 \\
8\end{array}$ & $\begin{array}{l}8 \\
1 \\
0 \\
4 \\
6\end{array}$ & $\begin{array}{r}8 \\
14 \\
6 \\
3 \\
3\end{array}$ & $\begin{array}{l}2 \\
5 \\
4 \\
4 \\
3\end{array}$ & $\begin{array}{l}2 \\
6 \\
5 \\
4 \\
6\end{array}$ & $\begin{array}{l}2 \\
5 \\
6 \\
2 \\
4\end{array}$ & $\begin{array}{l}2 \\
5 \\
8 \\
T(b) \\
4\end{array}$ & $\begin{array}{l}4 \\
6 \\
6 \\
0 \\
0 \\
5\end{array}$ & $\begin{array}{l}1 \\
4 \\
3 \\
0 \\
6\end{array}$ & $\begin{array}{l}1 \\
8 \\
3 \\
0 \\
6\end{array}$ & $\begin{array}{l}1 \\
6 \\
6 \\
5 \\
4\end{array}$ & $\begin{array}{r}3 \\
11 \\
9 \\
9 \\
5\end{array}$ & $\begin{array}{l}1 \\
5 \\
2 \\
3 \\
5\end{array}$ & $\begin{array}{l}2 \\
6 \\
2 \\
1 \\
5\end{array}$ & $\begin{array}{l}1 \\
3 \\
6 \\
1 \\
3\end{array}$ & $\begin{array}{l}2 \\
2 \\
4 \\
0 \\
2\end{array}$ & $\begin{array}{l}2 \\
2 \\
4 \\
0 \\
1\end{array}$ & $\begin{array}{l}2 \\
3 \\
3 \\
0 \\
2\end{array}$ & $\begin{array}{l}1 \\
5 \\
2 \\
T \\
2\end{array}$ & $\begin{array}{l}3 \\
3 \\
4 \\
0 \\
2\end{array}$ & $\begin{array}{l}1 \\
2 \\
0 \\
T \\
2\end{array}$ & $\begin{array}{l}2 \\
1 \\
1 \\
0 \\
1\end{array}$ & $\begin{array}{l}1 \\
1 \\
2 \\
1 \\
1\end{array}$ & $\begin{array}{l}3 \\
0 \\
0 \\
2 \\
0\end{array}$ & $\begin{array}{l}0 \\
0 \\
1 \\
0 \\
4\end{array}$ & $\begin{array}{l}\mathbf{0} \\
0 \\
0 \\
1 \\
\mathbf{3}\end{array}$ & $\begin{array}{l}0 \\
0 \\
2 \\
0 \\
4\end{array}$ \\
\hline $\begin{array}{l}\text { UIH COMP } \\
\text { UHH COMP } \\
\text { UIH COMP } \\
\text { UHH COMP } \\
\text { UIH COMP }\end{array}$ & $\begin{array}{l}1 \\
2 \\
3 \\
4 \\
5\end{array}$ & $\begin{array}{r}4 \\
8 \\
13 \\
17 \\
16\end{array}$ & $\begin{array}{r}3 \\
7 \\
10 \\
9 \\
11\end{array}$ & $\begin{array}{r}1 \\
10 \\
8 \\
6 \\
15\end{array}$ & $\begin{array}{l}4 \\
6 \\
5 \\
8 \\
8\end{array}$ & $\begin{array}{l}3 \\
4 \\
7 \\
3 \\
9\end{array}$ & $\begin{array}{l}2 \\
3 \\
6 \\
4 \\
2\end{array}$ & $\begin{array}{l}0 \\
2 \\
5 \\
2 \\
2\end{array}$ & $\begin{array}{l}0 \\
1 \\
5 \\
6 \\
3\end{array}$ & $\begin{array}{l}0 \\
2 \\
5 \\
2 \\
1\end{array}$ & $\begin{array}{l}0 \\
2 \\
5 \\
2 \\
2\end{array}$ & $\begin{array}{l}0 \\
2 \\
3 \\
3 \\
2\end{array}$ & $\begin{array}{l}1 \\
1 \\
5 \\
3 \\
3\end{array}$ & $\begin{array}{l}0 \\
1 \\
3 \\
2 \\
2\end{array}$ & $\begin{array}{l}1 \\
1 \\
4 \\
0 \\
2\end{array}$ & $\begin{array}{l}1 \\
1 \\
3 \\
0 \\
6\end{array}$ & $\begin{array}{l}0 \\
2 \\
3 \\
2 \\
2\end{array}$ & $\begin{array}{r}0 \\
2 \\
3 \\
11 \\
0\end{array}$ & $\begin{array}{l}0 \\
8 \\
3 \\
0 \\
0\end{array}$ & $\begin{array}{l}0 \\
9 \\
0 \\
1\end{array}$ & $\begin{array}{l}1 \\
7 \\
3 \\
1 \\
2\end{array}$ & $\begin{array}{l}0 \\
5 \\
3 \\
0 \\
0\end{array}$ & $\begin{array}{l}0 \\
4 \\
3 \\
1 \\
1\end{array}$ & $\begin{array}{l}1 \\
2 \\
3 \\
0 \\
1\end{array}$ & $\begin{array}{l}0 \\
2 \\
2 \\
3 \\
0\end{array}$ & $\begin{array}{l}0 \\
2 \\
0 . \\
2 \\
0\end{array}$ & $\begin{array}{l}0 \\
1 \\
2 \\
1 \\
1\end{array}$ & $\begin{array}{l}0 \\
1 \\
0 \\
1 \\
1\end{array}$ & $\begin{array}{l}0 \\
0 \\
0 \\
2 \\
2\end{array}$ \\
\hline $\begin{array}{l}\text { TB Upper COMP } \\
\text { TB Upper COMP } \\
\text { TB Upper COMP } \\
\text { TB Upper COMP } \\
\text { TB Upper COMP }\end{array}$ & $\begin{array}{l}1 \\
2 \\
3 \\
4 \\
5\end{array}$ & $\begin{array}{r}7 \\
12 \\
10 \\
16 \\
9\end{array}$ & $\begin{array}{r}5 \\
5 \\
11 \\
7 \\
10\end{array}$ & $\begin{array}{r}8 \\
9 \\
11 \\
5 \\
7\end{array}$ & $\begin{array}{r}4 \\
8 \\
10 \\
5 \\
4\end{array}$ & $\begin{array}{l}1 \\
8 \\
7 \\
6 \\
5\end{array}$ & $\begin{array}{l}2 \\
7 \\
5 \\
7 \\
6\end{array}$ & $\begin{array}{l}1 \\
6 \\
4 \\
5 \\
5\end{array}$ & $\begin{array}{l}2 \\
6 \\
1 \\
4 \\
4\end{array}$ & $\begin{array}{l}2 \\
6 \\
4 \\
6 \\
3\end{array}$ & $\begin{array}{l}0 \\
4 \\
3 \\
5 \\
5\end{array}$ & $\begin{array}{l}0 \\
6 \\
3 \\
3 \\
3\end{array}$ & $\begin{array}{l}1 \\
3 \\
1 \\
3 \\
3 \\
3\end{array}$ & $\begin{array}{r}0 \\
3 \\
10 \\
2 \\
4\end{array}$ & $\begin{array}{l}1 \\
2 \\
3 \\
2 \\
3\end{array}$ & $\begin{array}{l}1 \\
1 \\
3 \\
2 \\
4\end{array}$ & $\begin{array}{l}2 \\
3 \\
4 \\
3 \\
6\end{array}$ & $\begin{array}{l}0 \\
1 \\
3 \\
0 \\
2\end{array}$ & $\begin{array}{l}0 \\
2 \\
1 \\
1 \\
5\end{array}$ & $\begin{array}{l}0 \\
1 \\
1 \\
0 \\
4\end{array}$ & $\begin{array}{l}0 \\
2 \\
3 \\
1 \\
4\end{array}$ & $\begin{array}{l}0 \\
0 \\
2 \\
3 \\
4\end{array}$ & $\begin{array}{l}0 \\
0 \\
3 \\
0 \\
4\end{array}$ & $\begin{array}{l}0 \\
3 \\
3 \\
1 \\
3\end{array}$ & $\begin{array}{l}0 \\
0 \\
0 \\
2 \\
4\end{array}$ & $\begin{array}{l}2 \\
3 \\
2 \\
3 \\
3\end{array}$ & $\begin{array}{l}0 \\
2 \\
1 \\
3 \\
0\end{array}$ & $\begin{array}{l}0 \\
1 \\
1 \\
1 \\
1\end{array}$ & $\begin{array}{l}1 \\
0 \\
3 \\
2 \\
2\end{array}$ \\
\hline $\begin{array}{l}\text { TB Lower COMP } \\
\text { TB Lower COMP } \\
\text { TB Lower COMP } \\
\text { TB L Lower COMP } \\
\text { TB Lower COMP }\end{array}$ & $\begin{array}{l}1 \\
2 \\
3 \\
4 \\
5\end{array}$ & $\begin{array}{r}23 \\
29 \\
12 \\
8 \\
21\end{array}$ & $\begin{array}{r}7 \\
20 \\
3 \\
8 \\
23\end{array}$ & $\begin{array}{r}9 \\
22 \\
6 \\
10 \\
16\end{array}$ & $\begin{array}{r}6 \\
16 \\
5 \\
6 \\
22\end{array}$ & $\begin{array}{r}3 \\
11 \\
6 \\
6 \\
17\end{array}$ & $\begin{array}{r}5 \\
13 \\
6 \\
7 \\
5\end{array}$ & $\begin{array}{l}3 \\
8 \\
3 \\
3 \\
6\end{array}$ & $\begin{array}{r}3 \\
10 \\
0 \\
2 \\
5\end{array}$ & $\begin{array}{l}2 \\
6 \\
5 \\
3 \\
7\end{array}$ & $\begin{array}{l}1 \\
9 \\
5 \\
4 \\
4\end{array}$ & $\begin{array}{l}2 \\
9 \\
6 \\
3 \\
3\end{array}$ & $\begin{array}{l}1 \\
5 \\
4 \\
6 \\
5\end{array}$ & $\begin{array}{l}1 \\
4 \\
2 \\
2 \\
4\end{array}$ & $\begin{array}{l}2 \\
5 \\
2 \\
2 \\
6\end{array}$ & $\begin{array}{l}1 \\
5 \\
7 \\
2 \\
6\end{array}$ & $\begin{array}{l}1 \\
5 \\
3 \\
3 \\
6\end{array}$ & $\begin{array}{l}2 \\
7 \\
5 \\
2 \\
5\end{array}$ & $\begin{array}{l}1 \\
8 \\
2 \\
3 \\
7\end{array}$ & $\begin{array}{l}2 \\
8 \\
1 \\
3 \\
2\end{array}$ & $\begin{array}{l}0 \\
0 \\
5 \\
1 \\
3\end{array}$ & $\begin{array}{l}1 \\
4 \\
3 \\
1 \\
3\end{array}$ & $\begin{array}{l}1 \\
3 \\
4 \\
0 \\
2\end{array}$ & $\begin{array}{l}1 \\
2 \\
0 \\
0 \\
2\end{array}$ & $\begin{array}{l}0 \\
3 \\
0 \\
0 \\
2\end{array}$ & $\begin{array}{l}0 \\
4 \\
0 \\
0 \\
3\end{array}$ & $\begin{array}{l}1 \\
4 \\
1 \\
0 \\
0\end{array}$ & $\begin{array}{l}0 \\
2 \\
0 \\
0 \\
3\end{array}$ & $\begin{array}{l}0 \\
4 \\
0 \\
2 \\
1\end{array}$ \\
\hline $\begin{array}{l}\text { OBM COMP } \\
\text { OBM COMP } \\
\text { OBM COMP } \\
\text { OBM COMP } \\
\text { OBM COMP }\end{array}$ & $\begin{array}{l}1 \\
2 \\
3 \\
4 \\
5\end{array}$ & $\begin{array}{r}4 \\
T \\
T \\
15 \\
22\end{array}$ & $\begin{array}{r}7 \\
16 \\
14 \\
7 \\
76\end{array}$ & $\begin{array}{r}1 \\
17 \\
26 \\
10 \\
32\end{array}$ & $\begin{array}{r}5 \\
13 \\
12 \\
8 \\
80\end{array}$ & $\begin{array}{r}9 \\
15 \\
18 \\
9 \\
26\end{array}$ & $\begin{array}{r}11 \\
9 \\
20 \\
8 \\
24\end{array}$ & $\begin{array}{r}7 \\
13 \\
21 \\
4 \\
17\end{array}$ & $\begin{array}{r}18 \\
11 \\
27 \\
9 \\
21\end{array}$ & $\begin{array}{r}7 \\
12 \\
29 \\
9 \\
98\end{array}$ & $\begin{array}{r}3 \\
10 \\
16 \\
2 \\
13\end{array}$ & $\begin{array}{r}7 \\
9 \\
15 \\
3 \\
14\end{array}$ & $\begin{array}{r}6 \\
7 \\
17 \\
2 \\
10\end{array}$ & $\begin{array}{r}10 \\
8 \\
17 \\
2 \\
9\end{array}$ & $\begin{array}{r}5 \\
9 \\
12 \\
3 \\
13\end{array}$ & $\begin{array}{r}2 \\
11 \\
14 \\
2 \\
9\end{array}$ & $\begin{array}{r}3 \\
6 \\
17 \\
2 \\
7\end{array}$ & $\begin{array}{r}3 \\
2 \\
15 \\
0 \\
0 \\
4\end{array}$ & $\begin{array}{l}5 \\
4 \\
4 \\
1 \\
7\end{array}$ & $\begin{array}{r}3 \\
2 \\
12 \\
12 \\
1 \\
7\end{array}$ & $\begin{array}{r}2 \\
4 \\
11 \\
4 \\
6\end{array}$ & $\begin{array}{l}3 \\
3 \\
9 \\
2 \\
6\end{array}$ & $\begin{array}{l}5 \\
3 \\
7 \\
3 \\
2\end{array}$ & $\begin{array}{l}2 \\
3 \\
6 \\
3 \\
3\end{array}$ & $\begin{array}{l}0 \\
4 \\
4 \\
2 \\
4\end{array}$ & $\begin{array}{l}3 \\
4 \\
2 \\
2 \\
5\end{array}$ & $\begin{array}{l}4 \\
3 \\
5 \\
4 \\
3\end{array}$ & $\begin{array}{l}3 \\
3 \\
3 \\
0 \\
4\end{array}$ & $\begin{array}{l}1 \\
2 \\
4 \\
1 \\
4\end{array}$ \\
\hline $\begin{array}{l}\text { R-OS } \\
\text { R-OS } \\
\text { R-OS } \\
\text { R-OS } \\
\text { R.OS }\end{array}$ & $\begin{array}{l}1 \\
2 \\
3 \\
4 \\
5\end{array}$ & $\begin{array}{r}4 \\
12 \\
11 \\
T \\
7\end{array}$ & $\begin{array}{l}4 \\
7 \\
2 \\
1 \\
3\end{array}$ & $\begin{array}{r}0 \\
6 \\
8 \\
12 \\
5\end{array}$ & $\begin{array}{l}1 \\
4 \\
4 \\
0 \\
1\end{array}$ & $\begin{array}{r}2 \\
5 \\
17 \\
0 \\
3\end{array}$ & $\begin{array}{l}0 \\
3 \\
1 \\
2 \\
3\end{array}$ & $\begin{array}{l}1 \\
2 \\
2 \\
0 \\
2\end{array}$ & $\begin{array}{l}0 \\
6 \\
2 \\
0 \\
3\end{array}$ & $\begin{array}{l}0 \\
3 \\
1 \\
0 \\
3\end{array}$ & $\begin{array}{l}1 \\
4 \\
4 \\
1 \\
3\end{array}$ & $\begin{array}{l}2 \\
3 \\
2 \\
2 \\
2\end{array}$ & $\begin{array}{l}1 \\
3 \\
2 \\
0 \\
3\end{array}$ & $\begin{array}{l}2 \\
6 \\
3 \\
3 \\
3\end{array}$ & $\begin{array}{l}3 \\
5 \\
2 \\
0 \\
1\end{array}$ & $\begin{array}{l}0 \\
7 \\
4 \\
1 \\
0\end{array}$ & $\begin{array}{l}1 \\
7 \\
3 \\
0 \\
3\end{array}$ & $\begin{array}{r}11 \\
0 \\
2 \\
0 \\
2\end{array}$ & $\begin{array}{l}2 \\
4 \\
3 \\
0 \\
2\end{array}$ & $\begin{array}{l}3 \\
4 \\
0 \\
1 \\
2\end{array}$ & $\begin{array}{l}0 \\
5 \\
4 \\
0 \\
4\end{array}$ & $\begin{array}{l}3 \\
4 \\
2 \\
1 \\
1\end{array}$ & $\begin{array}{l}0 \\
0 \\
2 \\
0 \\
3\end{array}$ & $\begin{array}{l}0 \\
2 \\
2 \\
0 \\
0\end{array}$ & $\begin{array}{l}0 \\
2 \\
1 \\
0 \\
0\end{array}$ & $\begin{array}{l}2 \\
4 \\
0 \\
2 \\
0\end{array}$ & $\begin{array}{l}2 \\
1 \\
1 \\
0 \\
0\end{array}$ & $\begin{array}{l}3 \\
5 \\
1 \\
0 \\
2\end{array}$ & $\begin{array}{l}0 \\
3 \\
0 \\
0 \\
2\end{array}$ \\
\hline $\begin{array}{l}\mathrm{A} \cdot \mathrm{BF} \\
\mathrm{A} \cdot \mathrm{BF} \\
\mathrm{A} \cdot \mathrm{BF} \\
\mathrm{A} \cdot \mathrm{BF} \\
\mathrm{A} \cdot \mathrm{BF}\end{array}$ & $\begin{array}{l}1 \\
2 \\
3 \\
4 \\
5\end{array}$ & $\begin{array}{r}5 \\
1 \\
3 \\
7 \\
12\end{array}$ & $\begin{array}{l}4 \\
3 \\
5 \\
5 \\
7\end{array}$ & $\begin{array}{l}4 \\
7 \\
5 \\
6 \\
6\end{array}$ & $\begin{array}{l}0 \\
7 \\
5 \\
4 \\
2\end{array}$ & $\begin{array}{l}3 \\
1 \\
3 \\
4 \\
3\end{array}$ & $\begin{array}{l}3 \\
0 \\
2 \\
3 \\
2\end{array}$ & $\begin{array}{l}1 \\
1 \\
6 \\
2 \\
2\end{array}$ & $\begin{array}{l}2 \\
3 \\
3 \\
5 \\
1\end{array}$ & $\begin{array}{l}3 \\
0 \\
0 \\
5 \\
2\end{array}$ & $\begin{array}{l}2 \\
0 \\
0 \\
4 \\
2\end{array}$ & $\begin{array}{l}1 \\
0 \\
0 \\
4 \\
4\end{array}$ & $\begin{array}{l}1 \\
1 \\
1 \\
5 \\
2\end{array}$ & $\begin{array}{l}1 \\
0 \\
0 \\
2 \\
2\end{array}$ & $\begin{array}{l}2 \\
0 \\
1 \\
2 \\
2\end{array}$ & $\begin{array}{l}2 \\
2 \\
1 \\
2 \\
2\end{array}$ & $\begin{array}{l}2 \\
1 \\
2 \\
3 \\
2\end{array}$ & $\begin{array}{l}0 \\
1 \\
0 \\
2 \\
2\end{array}$ & $\begin{array}{l}2 \\
1 \\
1 \\
4 \\
0\end{array}$ & $\begin{array}{l}1 \\
1 \\
1 \\
4\end{array}$ & $\begin{array}{l}0 \\
1 \\
0 \\
4 \\
0\end{array}$ & $\begin{array}{l}2 \\
2 \\
2 \\
3 \\
0\end{array}$ & $\begin{array}{l}0 \\
0 \\
4 \\
2 \\
3\end{array}$ & $\begin{array}{l}0 \\
1 \\
0 \\
3 \\
2\end{array}$ & $\begin{array}{l}0 \\
2 \\
0 \\
4 \\
1\end{array}$ & $\begin{array}{l}2 \\
3 \\
0 \\
3 \\
2\end{array}$ & $\begin{array}{l}0 \\
2 \\
1 \\
0 \\
2\end{array}$ & $\begin{array}{l}0 \\
1 \\
2 \\
0 \\
2\end{array}$ & $\begin{array}{l}0 \\
2 \\
1 \\
0 \\
1\end{array}$ \\
\hline $\begin{array}{l}\text { R-AM COMP } \\
\text { R-AM COMP } \\
\text { P-AM COMP } \\
\text { R-AM COMP } \\
\text { R-AM COMP }\end{array}$ & $\begin{array}{l}1 \\
2 \\
3 \\
4 \\
5\end{array}$ & $\begin{array}{l}9 \\
2 \\
3 \\
2 \\
9\end{array}$ & $\begin{array}{l}0 \\
1 \\
3 \\
1 \\
5\end{array}$ & $\begin{array}{l}1 \\
7 \\
5 \\
2 \\
7\end{array}$ & $\begin{array}{l}2 \\
1 \\
6 \\
5 \\
3\end{array}$ & $\begin{array}{l}6 \\
2 \\
4 \\
2 \\
3\end{array}$ & $\begin{array}{l}5 \\
4 \\
3 \\
4 \\
3\end{array}$ & $\begin{array}{l}3 \\
6 \\
8 \\
6 \\
5\end{array}$ & $\begin{array}{r}4 \\
7 \\
6 \\
10 \\
4\end{array}$ & $\begin{array}{l}6 \\
4 \\
7 \\
8 \\
5\end{array}$ & $\begin{array}{r}2 \\
4 \\
8 \\
10 \\
7\end{array}$ & $\begin{array}{r}6 \\
7 \\
10 \\
12 \\
10\end{array}$ & $\begin{array}{r}6 \\
10 \\
11 \\
6 \\
11\end{array}$ & $\begin{array}{r}10 \\
4 \\
4 \\
8 \\
7\end{array}$ & $\begin{array}{r}13 \\
13 \\
6 \\
10 \\
7\end{array}$ & $\begin{array}{r}13 \\
8 \\
10 \\
8 \\
8 \\
10\end{array}$ & $\begin{array}{r}10 \\
9 \\
13 \\
8 \\
14\end{array}$ & $\begin{array}{r}14 \\
6 \\
4 \\
1 \\
4\end{array}$ & $\begin{array}{r}22 \\
9 \\
4 \\
10 \\
16\end{array}$ & $\begin{array}{r}20 \\
15 \\
2 \\
10 \\
15\end{array}$ & $\begin{array}{r}9 \\
8 \\
2 \\
10 \\
12\end{array}$ & $\begin{array}{r}16 \\
7 \\
9 \\
5 \\
16\end{array}$ & $\begin{array}{r}14 \\
8 \\
5 \\
3 \\
3\end{array}$ & $\begin{array}{r}10 \\
9 \\
7 \\
6 \\
10\end{array}$ & $\begin{array}{l}3 \\
8 \\
3 \\
9 \\
6\end{array}$ & $\begin{array}{l}7 \\
7 \\
3 \\
7 \\
2\end{array}$ & $\begin{array}{c}10 \\
10 \\
5 \\
10 \\
11\end{array}$ & $\begin{array}{r}9 \\
13 \\
4 \\
9 \\
12\end{array}$ & $\begin{array}{r}8 \\
6 \\
6 \\
13 \\
6\end{array}$ \\
\hline
\end{tabular}


TABLE J.3. (conto)

Sediment

M. nasuta Siphons Exposed Test Days 0 through 27

Sediment

(1)

Masuta Siphons Exposed Test Days o through 27

\begin{tabular}{|c|c|c|c|c|c|c|c|c|c|c|c|c|c|c|c|c|c|c|c|c|c|c|c|c|c|c|c|c|c|c|}
\hline $\begin{array}{l}\text { C-SB } \\
\text { C-SB } \\
\text { C-SB } \\
\text { C-SB } \\
\text { C-SB }\end{array}$ & $\begin{array}{l}1 \\
2 \\
3 \\
4 \\
5\end{array}$ & $\begin{array}{l}7 \\
3 \\
6 \\
6 \\
1\end{array}$ & $\begin{array}{l}1 \\
3 \\
2 \\
1 \\
0\end{array}$ & $\begin{array}{r}1 \\
4 \\
1 \\
14 \\
10\end{array}$ & $\begin{array}{l}1 \\
2 \\
1 \\
1 \\
0\end{array}$ & $\begin{array}{l}1 \\
1 \\
0 \\
1 \\
0\end{array}$ & $\begin{array}{l}0 \\
0 \\
0 \\
0 \\
0\end{array}$ & $\begin{array}{l}0 \\
1 \\
1 \\
0 \\
1\end{array}$ & $\begin{array}{l}0 \\
2 \\
1 \\
2 \\
0\end{array}$ & $\begin{array}{l}0 \\
0 \\
1 \\
1 \\
2\end{array}$ & $\begin{array}{l}1 \\
0 \\
0 \\
0 \\
1\end{array}$ & $\begin{array}{l}0 \\
0 \\
0 \\
1 \\
2\end{array}$ & $\begin{array}{l}0 \\
3 \\
0 \\
0 \\
2\end{array}$ & $\begin{array}{l}0 \\
1 \\
0 \\
2 \\
1\end{array}$ & $\begin{array}{l}1 \\
1 \\
0 \\
2 \\
2\end{array}$ & $\begin{array}{l}1 \\
2 \\
0 \\
2 \\
1\end{array}$ & $\begin{array}{l}1 \\
0 \\
0 \\
1 \\
3\end{array}$ & $\begin{array}{l}2 \\
2 \\
0 \\
3 \\
2\end{array}$ & $\begin{array}{l}0 \\
1 \\
0 \\
0 \\
0\end{array}$ & $\begin{array}{l}0 \\
1 \\
0 \\
1 \\
1\end{array}$ & $\begin{array}{r}0 \\
12 \\
1 \\
1 \\
0\end{array}$ & 1 & $\begin{array}{l}1 \\
2 \\
1 \\
0 \\
1\end{array}$ & $\begin{array}{l}0 \\
2 \\
0 \\
0 \\
2\end{array}$ & $\begin{array}{l}1 \\
4 \\
0 \\
0 \\
5\end{array}$ & 2 & & $\begin{array}{l}3 \\
2 \\
0 \\
2 \\
2\end{array}$ & $\begin{array}{l}2 \\
5 \\
0 \\
0 \\
1\end{array}$ & $\begin{array}{l}1 \\
2 \\
1 \\
0 \\
1\end{array}$ \\
\hline
\end{tabular}

(a) ND No data.

(b) T Too turbld for observations. 


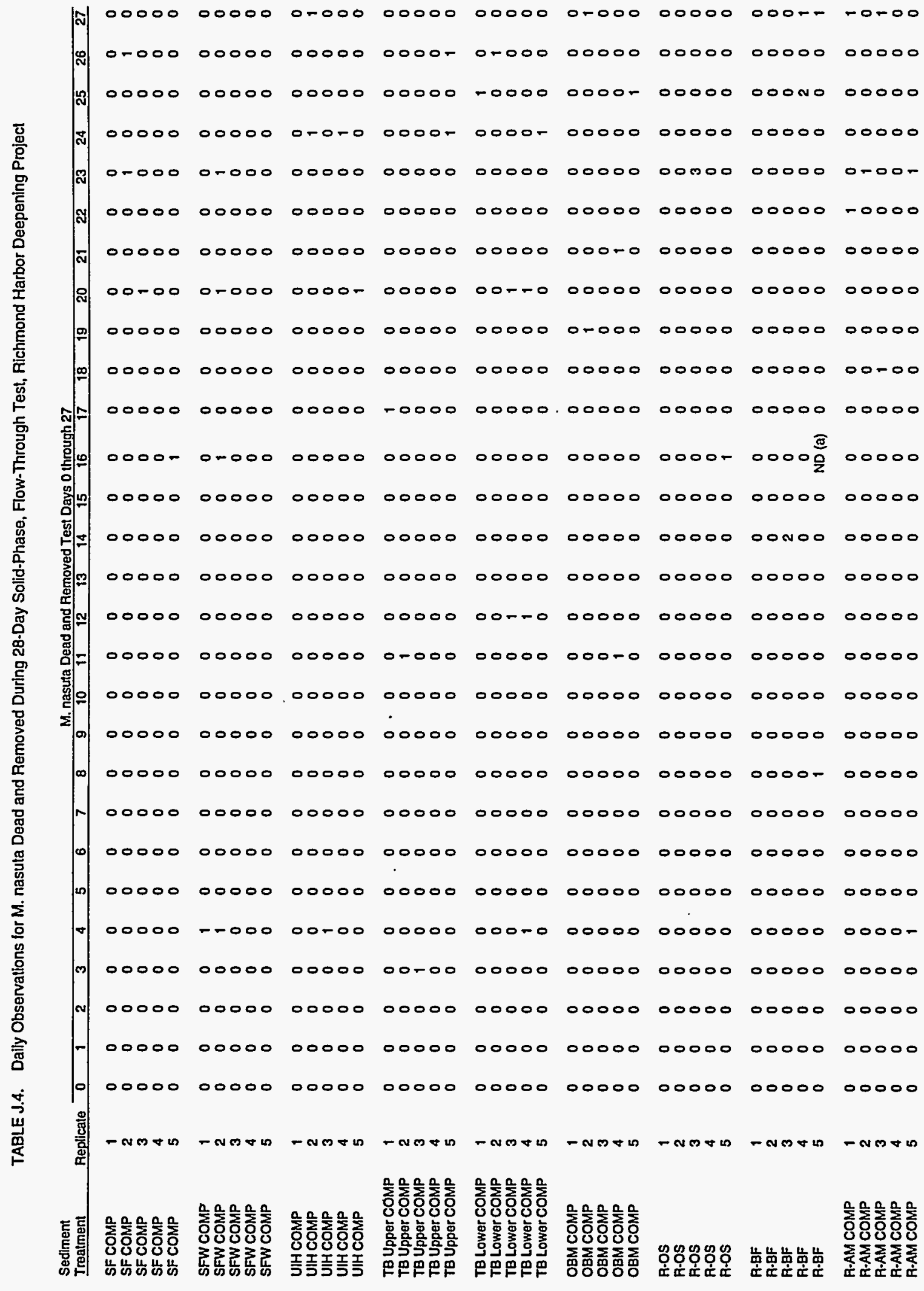

RH DEEPENING

3.7 


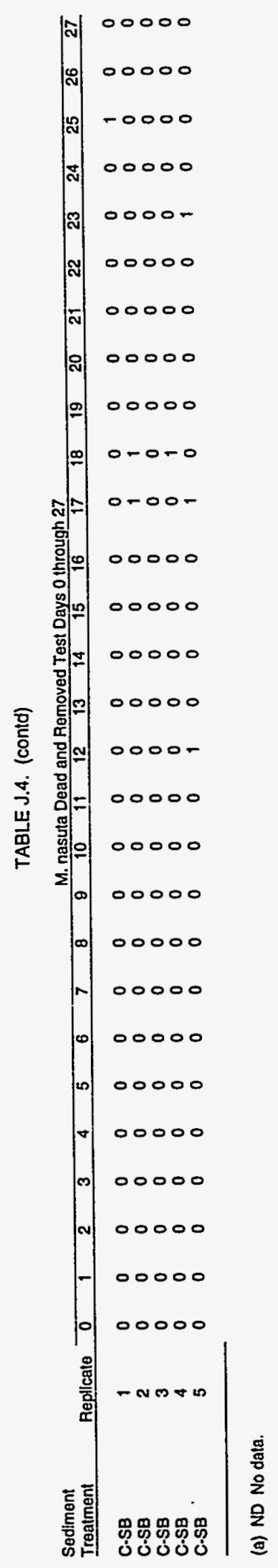


TABLE J.5. Water Quality Summary for 28-Day M. nasuta Solid-Phase, FlowThrough Test, Richmond Harbor Deepening Project

\begin{tabular}{|c|c|c|c|c|c|c|c|c|}
\hline \multirow{2}{*}{$\begin{array}{l}\text { Sediment } \\
\text { Treatment }\end{array}$} & \multicolumn{2}{|c|}{$\begin{array}{c}\text { Temperature } \\
\text { ("C) }\end{array}$} & \multicolumn{2}{|c|}{$\mathrm{pH}$} & \multicolumn{2}{|c|}{$\begin{array}{c}\text { Dissolved } \\
\text { Oxygen } \\
\text { (mg/L) }\end{array}$} & \multicolumn{2}{|c|}{$\begin{array}{l}\text { Salinity } \\
(0 / 00)\end{array}$} \\
\hline & Min & Max & Min & $\operatorname{Max}$ & Min & Max & Min & Max \\
\hline $\begin{array}{l}\text { Acceptable } \\
\text { Range }\end{array}$ & 13.0 & 17.0 & 7.30 & 8.30 & 6.0 & NA (a) & 28.0 & 32.0 \\
\hline SF COMP & 11.2 (b) & 16.4 & 7.55 & 7.93 & 7.5 & 8.9 & 30.0 & 32.0 \\
\hline SFW COMP & 11.1 (b) & 16.5 & 7.55 & 7.93 & 7.4 & 8.8 & 30.0 & 32.0 \\
\hline UIH COMP & 10.9 (b) & 16.5 & 7.57 & 7.93 & 7.4 & 8.8 & 30.0 & 32.0 \\
\hline TB Upper COMP & 11.0 (b) & 16.5 & 7.54 & 7.93 & 7.2 & 8.9 & 30.0 & 32.0 \\
\hline TB Lower COMP & 10.9 (b) & 16.4 & 7.56 & 7.93 & 7.3 & 8.8 & 30.0 & 32.0 \\
\hline OBM COMP & 11.0 (b) & 16.4 & 7.56 & 7.93 & 7.4 & 8.9 & 30.0 & 32.0 \\
\hline $\begin{array}{l}\text { R-OS } \\
\text { R-BF } \\
\text { R-AM COMP }\end{array}$ & $\begin{array}{l}10.9 \text { (b) } \\
11.0 \text { (b) } \\
11.0 \text { (b) }\end{array}$ & $\begin{array}{l}16.5 \\
16.5 \\
16.5\end{array}$ & $\begin{array}{l}7.56 \\
7.53 \\
7.52\end{array}$ & $\begin{array}{l}7.94 \\
7.93 \\
7.93\end{array}$ & $\begin{array}{l}7.4 \\
7.3 \\
7.4\end{array}$ & $\begin{array}{l}8.9 \\
8.8 \\
8.8\end{array}$ & $\begin{array}{l}30.0 \\
30.0 \\
30.0\end{array}$ & $\begin{array}{l}32.0 \\
32.0 \\
32.0\end{array}$ \\
\hline C-SB & $10.9(b)$ & 16.5 & 7.51 & 7.90 & 7.3 & 8.8 & 30.0 & 32.0 \\
\hline
\end{tabular}

(a) NA Not applicable.

(b) Data point out of range. 
APPENDIX $K$

- BIOASSAY RESULTS FOR 28-DAY SOLID-PHASE, FLOW-THROUGH TEST WITH NEREIS virens 


\section{QA/QC SUMMARY}

PROGRAM: $\quad$ Richmond Harbor Deepening Project

TEST ORGANISM: Nereis virens

TEST TYPE: $\quad$ Solid-phase, flow-through; Bioaccumulation

TEST DURATION: 28 days

WATER QUALITY ACCEPTABLE RANGES:

$\underset{13-17^{\circ} \mathrm{C}}{\frac{\mathrm{pH}}{7.30-8.30}} \frac{\text { Dissolved Oxygen }}{\geq 6.0 \mathrm{mg} / \mathrm{L}} \underset{28-32 \%}{\frac{\text { Salinity }}{115-135 \mathrm{~m} / \mathrm{min}}} \frac{\text { Flow Rate }}{\mathrm{NA}}$

TEST MATRIX

SOURCE/AGE

HOLDING/ACCLIMATION

Temperature

$\min / \max$

$9.4-13.7^{\circ} \mathrm{C}$

WATER QUALITY SUMMARY

TEST VALIDATION

REFERENCE TOXICANT TEST Not applicable.

COMMENTS
Sediments were collected from January 28, 1994 to February 3,1994 . Sediments were composited and tested within 6 weeks holding time after collection.

Aquatic Research Organisms, Hampton, New Hampshire. Wild captured organisms (mixed age groups) were collected off the Maine coast.

Approximately 2500 organisms were received in moist algal mats on February 11, 1994. The organisms were delayed in transit for 3 days but appeared healthy upon arrival at the Battelle MSL. The organisms were then acclimated for 5 days prior to testing.

$\mathrm{pH}$ Dissolved Oxygen Salinity
$7.57-8.07$
$8.1-9.0 \mathrm{mg} / \mathrm{L}$
31.5-32.0\%

All water quality parameters remained within the acceptable ranges throughout the 28 days of testing with the exception of a $2^{\circ} \mathrm{C}$ drop in temperature $\left(11^{\circ} \mathrm{C}\right)$ which occurred between test days 22 and 23 in all test chambers. This temporary drop in temperature did not appear to have any detrimental effect on any of the test organisms.

The test was validated by $95 \%$ survival in the control sediment (C-NV).

Flow rates generally remained within the acceptable range of $115-135 \mathrm{~m} / \mathrm{min}$. Slight fluctuations $(<5 \mathrm{ml})$ did occur during the 28 days of testing but were corrected within 24 hours. 


\section{QA/QC SUMMARY (contd)}

\section{REFERENCES}

EPA/USACE (U.S. Environmental Protection Agency/ U.S. Army Corps of Engineers). 1991. Evaluation of Dredged Material Proposed for Ocean Disposal (Testing Manual).

EPA-68-C8-0105, U.S. Environmental Protection Agency, Office of Marine and Estuarine Protection, Washington, D.C. 
TABLE K.1. Test Results for 28-Day N. virens Solid-Phase, Flow-Through Test, Richmond Harbor Deepening Project

\begin{tabular}{|c|c|c|c|c|c|c|}
\hline \multirow[b]{2}{*}{$\begin{array}{l}\text { Sediment } \\
\text { Treatment } \\
\end{array}$} & \multirow[b]{2}{*}{ Replicate } & \multicolumn{2}{|c|}{ N. virens } & \multirow[b]{2}{*}{$\begin{array}{l}\text { Proportion } \\
\text { Surviving }\end{array}$} & \multirow{2}{*}{$\begin{array}{l}\text { Mean } \\
\text { Proportion } \\
\text { Surviving } \\
\end{array}$} & \multirow[b]{2}{*}{$\begin{array}{l}\text { Standard } \\
\text { Deviation }\end{array}$} \\
\hline & & Live(a) & $\begin{array}{l}\text { Dead or } \\
\text { Missing }\end{array}$ & & & \\
\hline SF COMP & 1 & 20 & 5 & 0.80 & & \\
\hline SF COMP & 2 & 24 & 1 & 0.96 & & \\
\hline SF COMP & 3 & 24 & 1 & 0.96 & & \\
\hline SF COMP & 4 & 24 & 1 & 0.96 & & \\
\hline SF COMP & 5 & 24 & 1 & 0.96 & 0.93 & 0.07 \\
\hline SFW COMP & 1 & 23 & 2 & 0.92 & & \\
\hline SFW COMP & 2 & 25 & 0 & 1.00 & & \\
\hline SFW COMP & 3 & 24 & 1 & 0.96 & & \\
\hline SFW COMP & 4 & 23 & 2 & 0.92 & & \\
\hline SFW COMP & 5 & 23 & 2 & 0.92 & 0.94 & 0.04 \\
\hline UIH COMP & 1 & 23 & 2 & 0.92 & & \\
\hline UIH COMP & 2 & 25 & 0 & 1.00 & & \\
\hline UIH COMP & 3 & 24 & 1 & 0.96 & & \\
\hline UIH COMP & 4 & 25 & 0 & 1.00 & & \\
\hline UIH COMP & 5 & 23 & 2 & 0.92 & 0.96 & 0.04 \\
\hline TB Upper COMP & 1 & 25 & 0 & 1.00 & & \\
\hline TB Upper COMP & 2 & 25 & 0 & 1.00 & & \\
\hline TB Upper COMP & 3 & 24 & 1 & 0.96 & & \\
\hline TB Upper COMP & 4 & 21 & 4 & 0.84 & & \\
\hline TB Upper COMP & 5 & 25 & 0 & 1.00 & 0.96 & 0.07 \\
\hline TB Lower COMP & 1 & 23 & 2 & 0.92 & & \\
\hline TB Lower COMP & 2 & 25 & 0 & 1.00 & & \\
\hline TB Lower COMP & 3 & 25 & 0 & 1.00 & & \\
\hline TB Lower COMP & 4 & 25 & 0 & 1.00 & & \\
\hline TB Lower COMP & 5 & 25 & 0 & 1.00 & 0.98 & 0.04 \\
\hline R-OS & 1 & 25 & 0 & 1.00 & & \\
\hline R-OS & 2 & 25 & 0 & 1.00 & & \\
\hline R-OS & 3 & 25 & 0 & 1.00 & & \\
\hline R-OS & 4 & 24 & 1 & 0.96 & & \\
\hline R-OS & 5 & 23 & 2 & 0.92 & 0.98 & 0.04 \\
\hline R-BF & 1 & 24 & 1 & 0.96 & & \\
\hline R-BF & 2 & 24 & 1 & 0.96 & & \\
\hline R-BF & 3 & 24 & 1 & 0.96 & & \\
\hline R-BF & 4 & 24 & 1 & 0.96 & & \\
\hline R-BF & 5 & 24 & 1 & 0.96 & 0.96 & 0.00 \\
\hline R-AM COMP & 1 & 25 & 0 & 1.00 & & \\
\hline R-AM COMP & 2 & 25 & 0 & 1.00 & & \\
\hline R-AM COMP & 3 & 24 & 1 & 0.96 & & \\
\hline R-AM COMP & 4 & 25 & 0 & 1.00 & & \\
\hline R-AM COMP & 5 & 25 & 0 & 1.00 & 0.99 & 0.02 \\
\hline RH DEEPENING & & & K.1 & & & \\
\hline
\end{tabular}


TABLE K.1. (contd)

\begin{tabular}{|c|c|c|c|c|c|c|}
\hline \multirow[b]{2}{*}{$\begin{array}{l}\text { Sediment } \\
\text { Treatment }\end{array}$} & \multirow[b]{2}{*}{ Replicate } & \multicolumn{2}{|c|}{ N. virens } & \multirow[b]{2}{*}{$\begin{array}{l}\text { Proportion } \\
\text { Surviving }\end{array}$} & \multirow{2}{*}{$\begin{array}{l}\text { Mean } \\
\text { Proportion } \\
\text { Surviving }\end{array}$} & \multirow[b]{2}{*}{$\begin{array}{l}\text { Standard } \\
\text { Deviation }\end{array}$} \\
\hline & & Live(a) & $\begin{array}{l}\text { Dead or } \\
\text { Missing }\end{array}$ & & & \\
\hline C-NV & 1 & 23 & 2 & 0.92 & & \\
\hline C-NV & 2 & 25 & 0 & 1.00 & & \\
\hline C-NV & 3 & 24 & 1 & 0.96 & & \\
\hline C-NV & 4 & 23 & 2 & 0.92 & & \\
\hline C-NV & 5 & $\mathrm{NI}$ (a) & NI & $\mathrm{NI}$ & 0.95 & 0.04 \\
\hline
\end{tabular}

(a) Survival based on initial exposure of 25 organisms per replicate.

(b) NI Not initiated; insufficient sediment to test all five replicates. 


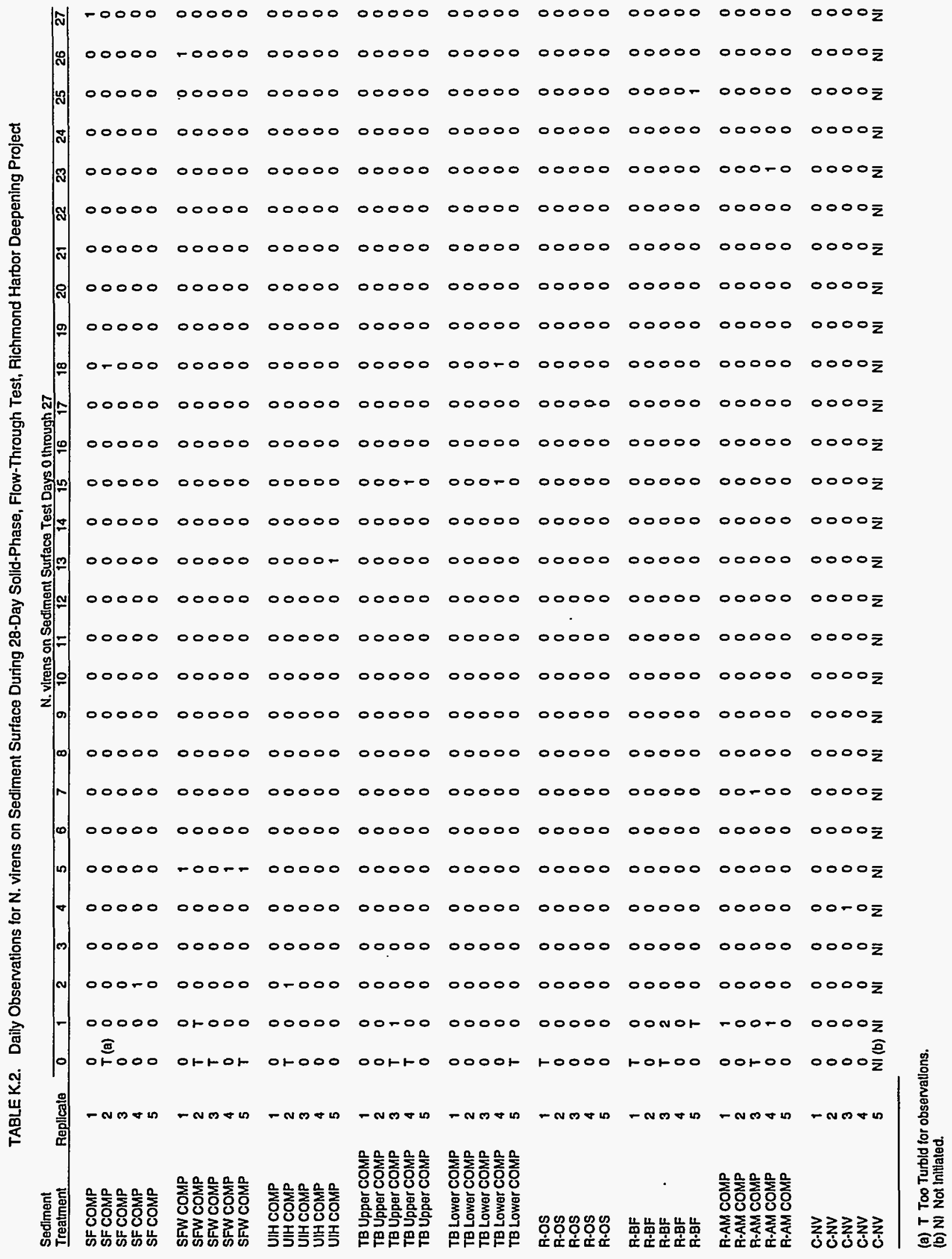

RH DEEPENING

K.3 


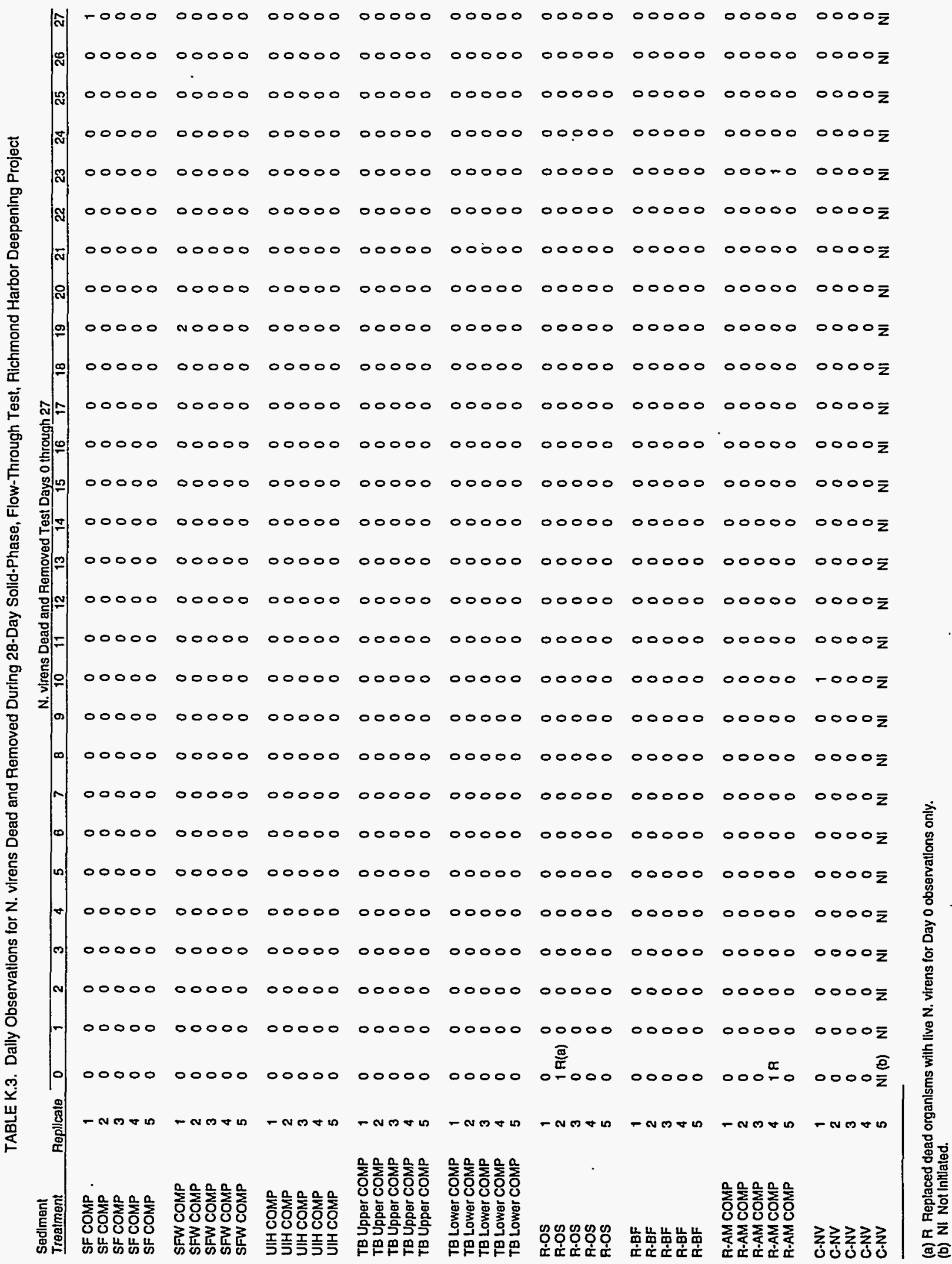

RH DEEPENING

K. 4 
TABLE K.4. Water Quality Summary for 28-Day N. virens Solid-Phase, Flow-Through Test, Richmond Harbor Deepening Project

\begin{tabular}{|c|c|c|c|c|c|c|c|c|}
\hline \multirow{2}{*}{$\begin{array}{l}\text { Sediment } \\
\text { Treatment }\end{array}$} & \multicolumn{2}{|c|}{$\begin{array}{c}\text { Temperature } \\
\left({ }^{\circ} \mathrm{C}\right)\end{array}$} & \multicolumn{2}{|c|}{$\mathrm{pH}$} & \multicolumn{2}{|c|}{$\begin{array}{c}\text { Dissolved } \\
\text { Oxygen } \\
\text { (mg/L) }\end{array}$} & \multicolumn{2}{|c|}{$\begin{array}{l}\text { Salinity } \\
\text { o/oo }\end{array}$} \\
\hline & Min & $\operatorname{Max}$ & Min & $\operatorname{Max}$ & Min & Max & Min & $\operatorname{Max}$ \\
\hline $\begin{array}{l}\text { Acceptable } \\
\text { Range }\end{array}$ & 13.0 & 17.0 & 7.30 & 8.30 & 6.0 & NA (a) & 28.0 & 32.0 \\
\hline SF COMP & $11.4(b)$ & 16.5 & 7.56 & 7.95 & 7.3 & 8.7 & 30.0 & 32.0 \\
\hline SFW COMP & $11.0(b)$ & 16.5 & 7.58 & 7.94 & 7.2 & 8.9 & 30.0 & 32.0 \\
\hline UIH COMP & 11.2 (b) & 16.5 & 7.51 & 7.95 & 7.2 & 8.8 & 30.0 & 32.0 \\
\hline TB Upper COMP & $11.0(b)$ & 16.5 & 7.51 & 7.95 & 7.3 & 8.8 & 30.0 & 32.0 \\
\hline TB Lower COMP & 11.2 (b) & 16.5 & 7.53 & 7.93 & 7.2 & 8.8 & 30.0 & 32.0 \\
\hline $\begin{array}{l}\text { R-OS } \\
\text { R-BF } \\
\text { R-AM COMP }\end{array}$ & $\begin{array}{l}11.0(\mathrm{~b}) \\
11.0(\mathrm{~b}) \\
11.0(\mathrm{~b})\end{array}$ & $\begin{array}{l}16.5 \\
16.5 \\
16.5\end{array}$ & $\begin{array}{l}7.55 \\
7.56 \\
7.54\end{array}$ & $\begin{array}{l}7.94 \\
7.94 \\
7.94\end{array}$ & $\begin{array}{l}7.3 \\
7.4 \\
7.3\end{array}$ & $\begin{array}{l}8.7 \\
8.7 \\
8.6\end{array}$ & $\begin{array}{l}30.0 \\
30.0 \\
30.0\end{array}$ & $\begin{array}{l}32.0 \\
32.0 \\
32.0\end{array}$ \\
\hline C-NV & $11.0(b)$ & 16.5 & 7.57 & 7.97 & 7.4 & 8.6 & 30.0 & 32.0 \\
\hline
\end{tabular}

(a) Not applicable.

(b) Data point out of range. 


\section{APPENDIX L}

BIOASSAY RESULTS FOR 96-HOUR SUSPENDED-PARTICULATE-PHASE TEST AND 96-HOUR REFERENCE TOXICANT TESTS FOR CITHARICHTHYS stigmaeus 


\section{QA/QC SUMMARY}

PROGRAM: Richmond Harbor Deepening Project

TEST ORGANISM: Citharichthys stigmaeus

TEST TYPE: $\quad$ Suspended-particulate-phase; static with aeration

TEST DURATION: 96 hours

WATER QUALITY ACCEPTABLE RANGES:

\begin{tabular}{|c|c|c|c|c|c|}
\hline Temperature & $\mathrm{pH}$ & Dissolved Oxygen & Salinity & Flow Rate & Ammonia \\
\hline $13-17^{\circ} \mathrm{C}$ & $7.30-8.30$ & $\geq 6.0 \mathrm{mg} / \mathrm{L}$ & $28-32 \%$ & NA & NA \\
\hline
\end{tabular}

TEST MATRIX

SOURCE/AGE

HOLDING/ACCLIMATION

Temperature

$\min / \max$

$10.6-16.3^{\circ} \mathrm{C}$

WATER QUALITY SUMMARY

TEST VALIDATION

REFERENCE TOXICANT TEST

COMMENTS

REFERENCES
Sediments were collected from January 28, 1994 to February 3,1994 . Sediments were composited and tested within 6 weeks holding time after collection. Each SPP was tested within 24 hours after preparation.

Brezina and Associates, Dillon Beach, California. Wild captured organisms (juveniles sorted 1 in. to 2 in. size) were collected in Tomales Bay, California.

Approximately 1300 organisms were received on each of 2 days (February 25 and March 2, 1994) and held for a minimum of 48 hours prior to testing.

pH Dissolved Oxygen Salinity

6.79-7.76

$7.3->20 \mathrm{mg} / \mathrm{L}$

29.5-33.0\%

All water quality parameters remained within the acceptable ranges throughout the 96 hours of testing for the SPP and ammonia and cadmium reference toxicant tests.

The test was validated by $>90 \%$ survival in the seawater controls estabilished for each of the tests.

Validation of $>90 \%$ survival in the seawater controls. An $L C_{50}$ value of $0.88 \mathrm{mg} / \mathrm{L}$ of copper and an $L C_{50}$ value of $23.92 \mathrm{mg} / \mathrm{L}$ of ammonia were calculated.

Fish were fed 8 oz of finely ground salmon feed once or twice daily throughout the holding/acclimation period.

EPAVUSACE (U.S. Environmental Protection Agency/ U.S. Army Corps of Engineers). 1991. Evaluation of Dredged Material Proposed for Ocean Disposal (Testing Manual).

EPA-68-C8-0105, U.S. Environmental Protection Agency, Office of Marine and Estuarine Protection, Washington, D.C. 
TABLE L.1. Test Results for 96-Hour C. stigmaeus Suspended-Particulate-Phase Test, Richmond Harbor Deepening Project

\begin{tabular}{|c|c|c|c|c|c|c|c|}
\hline \multirow[b]{2}{*}{$\begin{array}{l}\text { Sediment } \\
\text { Treatment }\end{array}$} & \multirow[b]{2}{*}{$\begin{array}{l}\text { Concentration } \\
\text { (Percent SPP) }\end{array}$} & \multirow[b]{2}{*}{ Replicate } & \multicolumn{2}{|c|}{ C. stigmaeus } & \multirow[b]{2}{*}{$\begin{array}{l}\text { Proportion } \\
\text { Surviving }\end{array}$} & \multirow{2}{*}{$\begin{array}{c}\text { Mean } \\
\text { Proportion } \\
\text { Surviving }\end{array}$} & \multirow{2}{*}{$\begin{array}{l}\text { Standard } \\
\text { Deviation }\end{array}$} \\
\hline & & & Live(a) & $\begin{array}{l}\text { Dead or } \\
\text { Missing }\end{array}$ & & & \\
\hline SF COMP & 0 & 1 & 10 & 0 & 1.00 & & \\
\hline SF COMP & 0 & 2 & 10 & 0 & 1.00 & & \\
\hline SF COMP & 0 & 3 & 10 & 0 & 1.00 & & \\
\hline SF COMP & 0 & 4 & 10 & 0 & 1.00 & & \\
\hline SF COMP & 0 & 5 & 10 & 0 & 1.00 & 1.00 & 0.00 \\
\hline SF COMP & 10 & 1 & 10 & 0 & 1.00 & & \\
\hline SF COMP & 10 & 2 & 10 & 0 & 1.00 & & \\
\hline SF COMP & 10 & 3 & 10 & 0 & 1.00 & & \\
\hline SF COMP & 10 & 4 & 10 & 0 & 1.00 & & \\
\hline SF COMP & 10 & 5 & 10 & 0 & 1.00 & 1.00 & 0.00 \\
\hline SF COMP & 50 & 1 & 10 & 0 & 1.00 & & \\
\hline SF COMP & 50 & 2 & 10 & 0 & 1.00 & & \\
\hline SF COMP & 50 & 3 & 10 & 0 & 1.00 & & \\
\hline SF COMP & 50 & 4 & 10 & 0 & 1.00 & & \\
\hline SF COMP & 50 & 5 & 10 & 0 & 1.00 & 1.00 & 0.00 \\
\hline SF COMP & 100 & 1 & 10 & 0 & 1.00 & & \\
\hline SF COMP & 100 & 2 & 10 & 0 & 1.00 & & \\
\hline SF COMP & 100 & 3 & 10 & 0 & 1.00 & & \\
\hline SF COMP & 100 & 4 & 10 & 0 & 1.00 & & . \\
\hline SF COMP & 100 & 5 & 10 & 0 & 1.00 & 1.00 & 0.00 \\
\hline SFW COMP & 0 & 1 & 10 & 0 & 1.00 & & \\
\hline SFW COMP & 0 & 2 & 10 & 0 & 1.00 & & \\
\hline SFW COMP & 0 & 3 & 9 & 1 & 0.90 & & \\
\hline SFW COMP & 0 & 4 & 10 & 0 & 1.00 & & \\
\hline SFW COMP & 0 & 5 & 10 & 0 & 1.00 & 0.98 & 0.04 \\
\hline SFW COMP & 10 & 1 & 10 & 0 & 1.00 & & \\
\hline SFW COMP & 10 & 2 & 10 & 0 & 1.00 & & \\
\hline SFW COMP & 10 & 3 & 10 & 0 & 1.00 & & \\
\hline SFW COMP & 10 & 4 & NI (b) & $\mathrm{NI}$ & NI & & \\
\hline SFW COMP & 10 & 5 & $\mathrm{NI}$ & $\mathrm{NI}$ & NI & 1.00 & 0.00 \\
\hline SFW COMP & 50 & 1 & 10 & 0 & 1.00 & & \\
\hline SFW COMP & 50 & 2 & 10 & 0 & 1.00 & & \\
\hline SFW COMP & 50 & 3 & 10 & 0 & 1.00 & & \\
\hline SFW COMP & 50 & 4 & NI & $\mathrm{NI}$ & NI & & \\
\hline SFW COMP & 50 & 5 & $\mathrm{NI}$ & NI & $\mathrm{NI}$ & 1.00 & 0.00 \\
\hline SFW COMP & 100 & 1 & 10 & 0 & 1.00 & & \\
\hline SFW COMP & 100 & 2 & 10 & 0 & 1.00 & & \\
\hline SFW COMP & 100 & 3 & 10 & 0 & 1.00 & & \\
\hline SFW COMP & 100 & 4 & NI & NI & NI & & \\
\hline SFW COMP & 100 & 5 & $\mathrm{NI}$ & NI & NI & 1.00 & 0.00 \\
\hline RH DEEPENING & & & L. 1 & & & & \\
\hline
\end{tabular}


TABLE L.1. (contd)

\begin{tabular}{|c|c|c|c|c|c|c|c|}
\hline \multirow[b]{2}{*}{$\begin{array}{l}\text { Sediment } \\
\text { Treatment }\end{array}$} & \multirow[b]{2}{*}{$\begin{array}{l}\text { Concentration } \\
\text { (Percent SPP) }\end{array}$} & \multirow[b]{2}{*}{ Replicate } & \multicolumn{2}{|c|}{ C. stigmaeus } & \multirow[b]{2}{*}{$\begin{array}{l}\text { Proportion } \\
\text { Surviving }\end{array}$} & \multirow{2}{*}{$\begin{array}{c}\text { Mean } \\
\text { Proportion } \\
\text { Surviving } \\
\end{array}$} & \multirow{2}{*}{$\begin{array}{l}\text { Standard } \\
\text { Deviation }\end{array}$} \\
\hline & & & Live(a) & $\begin{array}{l}\text { Dead or } \\
\text { Missing }\end{array}$ & & & \\
\hline UIH COMP & 0 & 1 & 10 & 0 & 1.00 & & \\
\hline UIH COMP & 0 & 2 & 10 & 0 & 1.00 & & \\
\hline UIH COMP & 0 & 3 & 9 & 1 & 0.90 & & \\
\hline UIH COMP & 0 & 4 & 10 & 0 & 1.00 & & \\
\hline UIH COMP & 0 & 5 & 10 & 0 & 1.00 & 0.98 & 0.04 \\
\hline UIH COMP & 10 & 1 & 10 & 0 & 1.00 & & \\
\hline UIH COMP & 10 & 2 & 10 & 0 & 1.00 & & \\
\hline UIH COMP & 10 & 3 & 10 & 0 & 1.00 & & \\
\hline UIH COMP & 10 & 4 & 10 & 0 & 1.00 & & \\
\hline UIH COMP & 10 & 5 & 10 & 0 & 1.00 & 1.00 & 0.00 \\
\hline UIH COMP & 50 & 1 & 10 & 0 & 1.00 & & \\
\hline UIH COMP & 50 & 2 & 10 & 0 & 1.00 & & \\
\hline UIH COMP & 50 & 3 & 10 & 0 & 1.00 & & \\
\hline UIH COMP & 50 & 4 & 10 & 0 & 1.00 & & \\
\hline UIH COMP & 50 & 5 & 10 & 0 & 1.00 & 1.00 & 0.00 \\
\hline UIH COMP & 100 & 1 & 9 & 1 & 0.90 & & \\
\hline UIH COMP & 100 & 2 & 10 & 0 & 1.00 & & \\
\hline UIH COMP & 100 & 3 & 10 & 0 & 1.00 & & \\
\hline UIH COMP & 100 & 4 & 10 & 0 & 1.00 & & \\
\hline UIH COMP & 100 & 5 & 10 & 0 & 1.00 & 0.98 & 0.04 \\
\hline TB Upper COMP & 0 & 1 & 10 & 0 & 1.00 & & \\
\hline TB Upper COMP & 0 & 2 & 10 & 0 & 1.00 & & \\
\hline TB Upper COMP & 0 & 3 & 10 & 0 & 1.00 & & \\
\hline TB Upper COMP & 0 & 4 & 10 & 0 & $1: 00$ & & \\
\hline TB Upper COMP & 0 & 5 & 10 & 0 & 1.00 & 1.00 & 0.00 \\
\hline TB Upper COMP & 10 & 1 & 10 & 0 & 1.00 & & \\
\hline TB Upper COMP & 10 & 2 & 9 & 1 & 0.90 & & \\
\hline TB Upper COMP & 10 & 3 & 10 & 0 & 1.00 & & \\
\hline TB Upper COMP & 10 & 4 & 10 & 0 & 1.00 & & \\
\hline TB Upper COMP & 10 & 5 & 10 & 0 & 1.00 & 0.98 & 0.04 \\
\hline TB Upper COMP & 50 & 1 & 10 & 0 & 1.00 & & \\
\hline TB Upper COMP & 50 & 2 & 10 & 0 & 1.00 & & \\
\hline TB Upper COMP & 50 & 3 & 10 & 0 & 1.00 & & \\
\hline TB Upper COMP & 50 & 4 & 10 & 0 & 1.00 & & \\
\hline TB Upper COMP & 50 & 5 & 10 & 0 & 1.00 & 1.00 & 0.00 \\
\hline TB Upper COMP & 100 & 1 & 10 & 0 & 1.00 & & \\
\hline TB Upper COMP & 100 & 2 & 10 & 0 & 1.00 & & \\
\hline TB Upper COMP & 100 & 3 & 10 & 0 & 1.00 & & \\
\hline TB Upper COMP & 100 & 4 & 10 & 0 & 1.00 & & \\
\hline TB Upper COMP & 100 & 5 & 10 & 0 & 1.00 & 1.00 & 0.00 \\
\hline RH DEEPENING & & & $\mathrm{L} .2$ & & & & \\
\hline
\end{tabular}


TABLE L.1. (contd)

\begin{tabular}{|c|c|c|c|c|c|c|c|}
\hline \multirow[b]{2}{*}{$\begin{array}{l}\text { Sediment } \\
\text { Treatment }\end{array}$} & \multirow[b]{2}{*}{$\begin{array}{l}\text { Concentration } \\
\text { (Percent SPP) }\end{array}$} & \multirow[b]{2}{*}{ Replicate } & \multicolumn{2}{|c|}{ C. stigmaeus } & \multirow[b]{2}{*}{$\begin{array}{l}\text { Proportion } \\
\text { Surviving }\end{array}$} & \multirow{2}{*}{$\begin{array}{c}\text { Mean } \\
\text { Proportion } \\
\text { Surviving } \\
\end{array}$} & \multirow[b]{2}{*}{$\begin{array}{l}\text { Standard } \\
\text { Deviation }\end{array}$} \\
\hline & & & Live(a) & $\begin{array}{l}\text { Dead or } \\
\text { Missing }\end{array}$ & & & \\
\hline $\begin{array}{l}\text { TB Lower COMP } \\
\text { TB Lower COMP } \\
\text { TB Lower COMP } \\
\text { TB Lower COMP } \\
\text { TB Lower COMP }\end{array}$ & $\begin{array}{l}0 \\
0 \\
0 \\
0 \\
0\end{array}$ & $\begin{array}{l}1 \\
2 \\
3 \\
4 \\
5\end{array}$ & $\begin{array}{r}9 \\
10 \\
10 \\
10 \\
10\end{array}$ & $\begin{array}{l}1 \\
0 \\
0 \\
0 \\
0\end{array}$ & $\begin{array}{l}0.90 \\
1.00 \\
1.00 \\
1.00 \\
1.00\end{array}$ & 0.98 & 0.04 \\
\hline $\begin{array}{l}\text { TB Lower COMP } \\
\text { TB Lower COMP } \\
\text { TB Lower COMP } \\
\text { TB Lower COMP } \\
\text { TB Lower COMP }\end{array}$ & $\begin{array}{l}10 \\
10 \\
10 \\
10 \\
10\end{array}$ & $\begin{array}{l}1 \\
2 \\
3 \\
4 \\
5\end{array}$ & $\begin{array}{l}10 \\
10 \\
10 \\
10 \\
10\end{array}$ & $\begin{array}{l}0 \\
0 \\
0 \\
0 \\
0\end{array}$ & $\begin{array}{l}1.00 \\
1.00 \\
1.00 \\
1.00 \\
1.00\end{array}$ & 1.00 & 0.00 \\
\hline $\begin{array}{l}\text { TB Lower COMP } \\
\text { TB Lower COMP } \\
\text { TB Lower COMP } \\
\text { TB Lower COMP } \\
\text { TB Lower COMP }\end{array}$ & $\begin{array}{l}50 \\
50 \\
50 \\
50 \\
50\end{array}$ & $\begin{array}{l}1 \\
2 \\
3 \\
4 \\
5\end{array}$ & $\begin{array}{l}10 \\
10 \\
10 \\
10 \\
10\end{array}$ & $\begin{array}{l}0 \\
0 \\
0 \\
0 \\
0\end{array}$ & $\begin{array}{l}1.00 \\
1.00 \\
1.00 \\
1.00 \\
1.00\end{array}$ & 1.00 & 0.00 \\
\hline $\begin{array}{l}\text { TB Lower COMP } \\
\text { TB Lower COMP } \\
\text { TB Lower COMP } \\
\text { TB Lower COMP } \\
\text { TB Lower COMP }\end{array}$ & $\begin{array}{l}100 \\
100 \\
100 \\
100 \\
100\end{array}$ & $\begin{array}{l}1 \\
2 \\
3 \\
4 \\
5\end{array}$ & $\begin{array}{l}10 \\
10 \\
10 \\
10 \\
10\end{array}$ & $\begin{array}{l}0 \\
0 \\
0 \\
0 \\
0\end{array}$ & $\begin{array}{l}1.00 \\
1.00 \\
1.00 \\
1.00 \\
1.00\end{array}$ & 1.00 & 0.00 \\
\hline $\begin{array}{l}\text { OBM COMP } \\
\text { OBM COMP } \\
\text { OBM COMP } \\
\text { OBM COMP } \\
\text { OBM COMP }\end{array}$ & $\begin{array}{l}0 \\
0 \\
0 \\
0 \\
0\end{array}$ & $\begin{array}{l}1 \\
2 \\
3 \\
4 \\
5\end{array}$ & $\begin{array}{l}10 \\
10 \\
10 \\
10 \\
10\end{array}$ & $\begin{array}{l}0 \\
0 \\
0 \\
0 \\
0\end{array}$ & $\begin{array}{l}1.00 \\
1.00 \\
1.00 \\
1.00 \\
1.00\end{array}$ & 1.00 & 0.00 \\
\hline $\begin{array}{l}\text { OBM COMP } \\
\text { OBM COMP } \\
\text { OBM COMP } \\
\text { OBM COMP } \\
\text { OBM COMP }\end{array}$ & $\begin{array}{l}10 \\
10 \\
10 \\
10 \\
10\end{array}$ & $\begin{array}{l}1 \\
2 \\
3 \\
4 \\
5\end{array}$ & $\begin{array}{l}10 \\
10 \\
10 \\
10 \\
10\end{array}$ & $\begin{array}{l}0 \\
0 \\
0 \\
0 \\
0\end{array}$ & $\begin{array}{l}1.00 \\
1.00 \\
1.00 \\
1.00 \\
1.00\end{array}$ & 1.00 & 0.00 \\
\hline $\begin{array}{l}\text { OBM COMP } \\
\text { OBM COMP } \\
\text { OBM COMP } \\
\text { OBM COMP } \\
\text { OBM COMP }\end{array}$ & $\begin{array}{l}50 \\
50 \\
50 \\
50 \\
50\end{array}$ & $\begin{array}{l}1 \\
2 \\
3 \\
4 \\
5\end{array}$ & $\begin{array}{r}10 \\
10 \\
10 \\
9 \\
10\end{array}$ & $\begin{array}{l}0 \\
0 \\
0 \\
1 \\
0\end{array}$ & $\begin{array}{l}1.00 \\
1.00 \\
1.00 \\
0.90 \\
1.00\end{array}$ & 0.98 & 0.04 \\
\hline $\begin{array}{l}\text { OBM COMP } \\
\text { OBM COMP } \\
\text { OBM COMP } \\
\text { OBM COMP } \\
\text { OBM COMP }\end{array}$ & $\begin{array}{l}100 \\
100 \\
100 \\
100 \\
100\end{array}$ & $\begin{array}{l}1 \\
2 \\
3 \\
4 \\
5\end{array}$ & $\begin{array}{l}10 \\
10 \\
10 \\
10 \\
10\end{array}$ & $\begin{array}{l}0 \\
0 \\
0 \\
0 \\
0\end{array}$ & $\begin{array}{l}1.00 \\
1.00 \\
1.00 \\
1.00 \\
1.00\end{array}$ & 1.00 & 0.00 \\
\hline
\end{tabular}

(a) Survival based on initial exposure of 10 organisms per replicate.

(b) NI Not initiated; insufficient organisms to test all 5 replicates.

RH DEEPENING

L.3 
TABLE L.2. Summary of Mean Proportion Surviving 96-Hour C. stigmaeus SuspendedParticulate-Phase Test, Richmond Harbor Deepening Project

Sediment

Treatment

SF COMP

SF COMP

SF COMP

SF COMP

SFW COMP

SFW COMP

SFW COMP

SFW COMP

UIH COMP

UIH COMP

UIH COMP

UIH COMP

TB Upper COMP

TB Upper COMP

TB Upper COMP

TB Upper COMP

TB Lower COMP

TB Lower COMP

TB Lower COMP

TB Lower COMP

OBM COMP

OBM COMP

OBM COMP

OBM COMP
Concentration

(Percent SPP)

0

10

50

100

0

10

50

100

0

10

50

100

0

10

50

100

0

10

50

100

0

10

50

100
Mean

Proportion

Surviving

1.00

1.00

1.00

1.00

0.98

1.00

1.00

1.00

0.98

1.00

1.00

0.98

1.00

0.98

1.00

1.00

0.98

1.00

1.00

1.00

1.00

1.00

0.98

1.00 
TABLE L.3. Daily Observations of C. stigmaeus During 96-Hour SuspendedParticulate-Phase Test, Richmond Harbor Deepening Project

\begin{tabular}{|c|c|c|c|c|c|c|c|c|c|c|}
\hline \multirow{2}{*}{$\begin{array}{l}\text { Sediment } \\
\text { Treatment }\end{array}$} & \multirow{2}{*}{$\begin{array}{l}\text { Concentration } \\
\text { (Percent SPP) }\end{array}$} & \multirow[b]{2}{*}{ Replicate } & \multicolumn{4}{|c|}{ C. stigmaeus Live } & \multicolumn{4}{|c|}{ C. stigmaeus Dead } \\
\hline & & & $2 \mathrm{~h}$ & $24 \mathrm{~h}$ & $48 \mathrm{~h}$ & $72 \mathrm{~h}$ & $2 h$ & $24 \mathrm{~h}$ & $48 \mathrm{~h}$ & $72 \mathrm{~h}$ \\
\hline SF COMP & 0 & 1 & 10 & 10 & 10 & 10 & 0 & 0 & 0 & 0 \\
\hline SF COMP & 0 & 2 & 10 & 10 & 10 & 10 & 0 & 0 & 0 & 0 \\
\hline SF COMP & 0 & 3 & 10 & 10 & 10 & 10 & 0 & 0 & 0 & 0 \\
\hline SF COMP & 0 & 4 & 10 & 10 & 10 & 10 & 0 & 0 & 0 & 0 \\
\hline SF COMP & 0 & 5 & 10 & 10 & 10 & 10 & 0 & 0 & 0 & 0 \\
\hline SF COMP & 10 & 1 & 10 & 10 & 10 & 10 & 0 & 0 & 0 & 0 \\
\hline SF COMP & 10 & 2 & 10 & 10 & 10 & 10 & 0 & 0 & 0 & 0 \\
\hline SF COMP & 10 & 3 & 10 & 10 & 10 & 10 & 0 & 0 & 0 & 0 \\
\hline SF COMP & 10 & 4 & 10 & 10 & 10 & 10 & 0 & 0 & 0 & 0 \\
\hline SF COMP & 10 & 5 & 10 & 10 & 10 & 10 & 0 & 0 & 0 & 0 \\
\hline SF COMP & 50 & 1 & 10 & 10 & 10 & 10 & 0 & 0 & 0 & 0 \\
\hline SF COMP & 50 & 2 & 10 & 10 & 10 & 10 & 0 & 0 & 0 & 0 \\
\hline SF COMP & 50 & 3 & 10 & 10 & 10 & 10 & 0 & 0 & 0 & 0 \\
\hline SF COMP & 50 & 4 & 10 & 10 & 10 & 10 & 0 & 0 & 0 & 0 \\
\hline SF COMP & 50 & 5 & 10 & 10 & 10 & 10 & 0 & 0 & 0 & 0 \\
\hline SF COMP & 100 & 1 & 10 & 10 & 10 & 10 & 0 & 0 & 0 & 0 \\
\hline SF COMP & 100 & 2 & 10 & 10 & 10 & 10 & 0 & 0 & 0 & 0 \\
\hline SF COMP & 100 & 3 & 10 & 10 & 10 & 10 & 0 & 0 & 0 & 0 \\
\hline SF COMP & 100 & 4 & 10 & 10 & 10 & 10 & 0 & 0 & 0 & 0 \\
\hline SF COMP & 100 & 5 & 10 & 10 & 10 & 10 & 0 & 0 & 0 & 0 \\
\hline SFW COMP & 0 & 1 & 10 & 10 & 10 & 10 & 0 & 0 & 0 & 0 \\
\hline SFW COMP & 0 & 2 & 10 & 10 & 10 & 10 & 0 & 0 & 0 & 0 \\
\hline SFW COMP & 0 & 3 & $10^{\circ}$ & 10 & 9 & 9 & 0 & 0 & 1 & 0 \\
\hline SFW COMP & 0 & 4 & 10 & 10 & 10 & 10 & 0 & 0 & 0 & 0 \\
\hline SFW COMP & 0 & 5 & 10 & 10 & 10 & 10 & 0 & 0 & 0 & 0 \\
\hline SFW COMP & 10 & 1 & 10 & 10 & 10 & 10 & 0 & 0 & 0 & 0 \\
\hline SFW COMP & 10 & 2 & 10 & 10 & 10 & 10 & 0 & 0 & 0 & 0 \\
\hline SFW COMP & 10 & 3 & 10 & 10 & 10 & 10 & 0 & 0 & 0 & 0 \\
\hline SFW COMP & 10 & 4 & $\mathrm{NI}$ (a) & $\mathrm{NI}$ & NI & $\mathrm{NI}$ & $\mathrm{NI}$ & $\mathrm{NI}$ & NI & $\mathrm{NI}$ \\
\hline SFW COMP & 10 & 5 & $\mathrm{NI}$ & $\mathrm{NI}$ & $\mathrm{NI}$ & $\mathrm{NI}$ & $\mathrm{NI}$ & $\mathrm{NI}$ & NI & NI \\
\hline SFW COMP & 50 & 1 & 10 & 10 & 10 & 10 & 0 & 0 & 0 & 0 \\
\hline SFW COMP & 50 & 2 & 10 & 10 & 10 & 10 & 0 & 0 & 0 & 0 \\
\hline SFW COMP & 50 & 3 & 10 & 10 & 10 & 10 & 0 & 0 & 0 & 0 \\
\hline SFW COMP & 50 & 4 & $\mathrm{NI}$ & $\mathrm{NI}$ & $\mathrm{NI}$ & $\mathrm{NI}$ & $\mathrm{NI}$ & NI & $\mathrm{NI}$ & NI \\
\hline SFW COMP & 50 & 5 & $\mathrm{NI}$ & $\mathrm{NI}$ & $\mathrm{NI}$ & $\mathrm{NI}$ & NI & NI & $\mathrm{NI}$ & NI \\
\hline SFW COMP & 100 & 1 & 10 & 10 & 10 & 10 & 0 & 0 & 0 & 0 \\
\hline SFW COMP & 100 & 2 & 10 & 10 & 10 & 10 & 0 & 0 & 0 & 0 \\
\hline SFW COMP & 100 & 3 & 10 & 10 & 10 & 10 & 0 & 0 & 0 & 0 \\
\hline SFW COMP & 100 & 4 & $\mathrm{NI}$ & $\mathrm{NI}$ & $\mathrm{NI}$ & $\mathrm{NI}$ & $\mathrm{NI}$ & NI & NI & NI \\
\hline SFW COMP & 100 & 5 & NI & NI & NI & NI & $\mathrm{NI}$ & $\mathrm{NI}$ & NI & $\mathrm{NI}$ \\
\hline
\end{tabular}


TABLE L.3. (contd)

\begin{tabular}{|c|c|c|c|c|c|c|c|c|c|c|}
\hline \multirow{2}{*}{$\begin{array}{l}\text { Sediment } \\
\text { Treatment }\end{array}$} & \multirow{2}{*}{$\begin{array}{l}\text { Concentration } \\
\text { (Percent SPP) }\end{array}$} & \multirow[b]{2}{*}{ Replicate } & \multicolumn{4}{|c|}{ C. stigmaeus Live } & \multicolumn{4}{|c|}{ C. stigmaeus Dead } \\
\hline & & & $2 \mathrm{~h}$ & $24 \mathrm{~h}$ & $48 \mathrm{~h}$ & $72 \mathrm{~h}$ & $2 \mathrm{~h}$ & $24 \mathrm{~h}$ & $48 \mathrm{~h}$ & $72 \mathrm{~h}$ \\
\hline UIH COMP & 0 & 1 & 10 & 10 & 10 & 10 & 0 & 0 & 0 & 0 \\
\hline UIH COMP & 0 & 2 & 10 & 10 & 10 & 10 & 0 & 0 & 0 & 0 \\
\hline UIH COMP & 0 & 3 & 10 & 10 & 10 & 9 & 0 & 0 & 0 & 1 \\
\hline UIH COMP & 0 & 4 & 10 & 10 & 10 & 10 & 0 & 0 & 0 & 0 \\
\hline UIH COMP & 0 & 5 & 10 & 10 & 10 & 10 & 0 & 0 & 0 & 0 \\
\hline UIH COMP & 10 & 1 & 10 & 10 & 10 & 10 & 0 & 0 & 0 & 0 \\
\hline UIH COMP & 10 & 2 & 10 & 10 & 10 & 10 & 0 & 0 & 0 & 0 \\
\hline UIH COMP & 10 & 3 & 10 & 10 & 10 & 10 & 0 & 0 & 0 & 0 \\
\hline UIH COMP & 10 & 4 & 10 & 10 & 10 & 10 & 0 & 0 & 0 & 0 \\
\hline UIH COMP & 10 & 5 & 10 & 10 & 10 & 10 & 0 & 0 & 0 & 0 \\
\hline UIH COMP & 50 & 1 & 10 & 10 & 10 & 10 & 0 & 0 & 0 & 0 \\
\hline UIH COMP & 50 & 2 & 10 & 10 & 10 & 10 & 0 & 0 & 0 & 0 \\
\hline UIH COMP & 50 & 3 & 10 & 10 & 10 & 10 & 0 & 0 & 0 & 0 \\
\hline UIH COMP & 50 & 4 & 10 & 10 & 10 & 10 & 0 & 0 & 0 & 0 \\
\hline UIH COMP & 50 & 5 & 10 & 10 & 10 & 10 & 0 & 0 & 0 & 0 \\
\hline UIH COMP & 100 & 1 & 10 & 9 & 9 & 9 & 0 & 1 & 0 & 0 \\
\hline UIH COMP & 100 & 2 & 10 & 10 & 10 & 10 & 0 & 0 & 0 & 0 \\
\hline UIH COMP & 100 & 3 & 10 & 10 & 10 & 10 & 0 & 0 & 0 & 0 \\
\hline UIH COMP & 100 & 4 & 10 & 10 & 10 & 10 & 0 & 0 & 0 & 0 \\
\hline UIH COMP & 100 & 5 & 10 & 10 & 10 & 10 & 0 & 0 & 0 & 0 \\
\hline TB Upper COMP & 0 & 1 & 10 & 10 & 10 & 10 & 0 & 0 & 0 & 0 \\
\hline TB Upper COMP & 0 & 2 & 10 & 10 & 10 & 10 & 0 & 0 & 0 & 0 \\
\hline TB Upper COMP & 0 & 3 & 10 & 10 & 10 & 10 & 0 & 0 & 0 & 0 \\
\hline TB Upper COMP & 0 & 4 & 10 & 10 & 10 & 10 & 0 & 0 & 0 & 0 \\
\hline TB Upper COMP & 0 & 5 & 10 & 10 & 10 & 10 & 0 & 0 & 0 & 0 \\
\hline TB Upper COMP & 10 & 1 & 10 & 10 & 10 & 10 & 0 & 0 & 0 & 0 \\
\hline TB Upper COMP & 10 & 2 & 10 & 10 & 10 & 9 & 0 & 0 & 0 & 1 \\
\hline TB Upper COMP & 10 & 3 & 10 & 10 & 10 & 10 & 0 & 0 & 0 & 0 \\
\hline TB Upper COMP & 10 & 4 & 10 & 10 & 10 & 10 & 0 & 0 & 0 & 0 \\
\hline TB Upper COMP & 10 & 5 & 10 & 10 & 10 & 10 & 0 & 0 & 0 & 0 \\
\hline TB Upper COMP & 50 & 1 & 10 & 10 & 10 & 10 & 0 & 0 & 0 & 0 \\
\hline TB Upper COMP & 50 & 2 & 10 & 10 & 10 & 10 & 0 & 0 & 0 & 0 \\
\hline TB Upper COMP & 50 & 3 & 10 & 10 & 10 & 10 & 0 & 0 & 0 & 0 \\
\hline TB Upper COMP & 50 & 4 & 10 & 10 & 10 & 10 & 0 & 0 & 0 & 0 \\
\hline TB Upper COMP & 50 & 5 & 10 & 10 & 10 & 10 & 0 & 0 & 0 & 0 \\
\hline TB Upper COMP & 100 & 1 & 10 & 10 & 10 & 10 & 0 & 0 & 0 & 0 \\
\hline TB Upper COMP & 100 & 2 & 10 & 10 & 10 & 10 & 0 & 0 & 0 & 0 \\
\hline TB Upper COMP & 100 & 3 & 10 & 10 & 10 & 10 & 0 & 0 & 0 & 0 \\
\hline TB Upper.COMP & 100 & 4 & 10 & 10 & 10 & 10 & 0 & 0 & 0 & 0 \\
\hline TB Upper COMP & 100 & 5 & 10 & 10 & 10 & 10 & 0 & 0 & 0 & 0 \\
\hline
\end{tabular}

RH DEEPENING 
TABLE L.3. (contd)

\begin{tabular}{|c|c|c|c|c|c|c|c|c|c|c|}
\hline \multirow{2}{*}{$\begin{array}{l}\text { Sediment } \\
\text { Treatment }\end{array}$} & \multirow{2}{*}{$\begin{array}{l}\text { Concentration } \\
\text { (Percent SPP) }\end{array}$} & \multirow[b]{2}{*}{ Replicate } & \multicolumn{4}{|c|}{ C. stigmaeus Live } & \multicolumn{4}{|c|}{ C. stigmaeus Dead } \\
\hline & & & $2 \mathrm{~h}$ & $24 \mathrm{~h}$ & $48 \mathrm{~h}$ & $72 \mathrm{~h}$ & $2 \mathrm{~h}$ & $24 \mathrm{~h}$ & $48 \mathrm{~h}$ & $72 h$ \\
\hline TB Lower COMP & 0 & 1 & 10 & 10 & 10 & 9 & 0 & 0 & 0 & 1 \\
\hline TB Lower COMP & 0 & 2 & 10 & 10 & 10 & 10 & 0 & 0 & 0 & 0 \\
\hline TB Lower COMP & 0 & 3 & 10 & 10 & 10 & 10 & 0 & 0 & 0 & 0 \\
\hline TB Lower COMP & 0 & 4 & 10 & 10 & 10 & 10 & 0 & 0 & 0 & 0 \\
\hline TB Lower COMP & 0 & 5 & 10 & 10 & 10 & 10 & 0 & 0 & 0 & 0 \\
\hline TB Lower COMP & 10 & 1 & 10 & 10 & 10 & 10 & 0 & 0 & 0 & 0 \\
\hline TB Lower COMP & 10 & 2 & 10 & 10 & 10 & 10 & 0 & 0 & 0 & 0 \\
\hline TB Lower COMP & 10 & 3 & 10 & 10 & 10 & 10 & 0 & 0 & 0 & 0 \\
\hline TB Lower COMP & 10 & 4 & 10 & 10 & 10 & 10 & 0 & 0 & 0 & 0 \\
\hline TB Lower COMP & 10 & 5 & 10 & 10 & 10 & 10 & 0 & 0 & 0 & 0 \\
\hline TB Lower COMP & 50 & 1 & 10 & 10 & 10 & 10 & 0 & 0 & 0 & 0 \\
\hline TB Lower COMP & 50 & 2 & 10 & 10 & 10 & 10 & 0 & 0 & 0 & 0 \\
\hline TB Lower COMP & 50 & 3 & 10 & 10 & 10 & 10 & 0 & 0 & 0 & 0 \\
\hline TB Lower COMP & 50 & 4 & 10 & 10 & 10 & 10 & 0 & 0 & 0 & 0 \\
\hline TB Lower COMP & 50 & 5 & 10 & 10 & 10 & 10 & 0 & 0 & 0 & 0 \\
\hline TB Lower COMP & 100 & 1 & 10 & 10 & 10 & 10 & 0 & 0 & 0 & 0 \\
\hline TB Lower COMP & 100 & 2 & 10 & 10 & 10 & 10 & 0 & 0 & 0 & 0 \\
\hline TB Lower COMP & 100 & 3 & 10 & 10 & 10 & 10 & 0 & 0 & 0 & 0 \\
\hline TB Lower COMP & 100 & 4 & 10 & 10 & 10 & 10 & 0 & 0 & 0 & 0 \\
\hline TB Lower COMP & 100 & 5 & 10 & 10 & 10 & 10 & 0 & 0 & 0 & 0 \\
\hline OBM COMP & 0 & 1 & 10 & 10 & 10 & 10 & 0 & 0 & 0 & 0 \\
\hline OBM COMP & 0 & 2 & 10 & 10 & 10 & 10 & 0 & 0 & 0 & 0 \\
\hline OBM COMP & 0 & 3 & 10 & 10 & 10 & 10 & 0 & 0 & 0 & 0 \\
\hline OBM COMP & 0 & 4 & 10 & 10 & 10 & 10 & 0 & 0 & 0 & 0 \\
\hline OBM COMP & 0 & 5 & 10 & 10 & 10 & 10 & 0 & 0 & 0 & 0 \\
\hline OBM COMP & 10 & 1 & 10 & 10 & 10 & 10 & 0 & 0 & 0 & 0 \\
\hline OBM COMP & 10 & 2 & 10 & 10 & 10 & 10 & 0 & 0 & 0 & 0 \\
\hline OBM COMP & 10 & 3 & 10 & 10 & 10 & 10 & 0 & 0 & 0 & 0 \\
\hline OBM COMP & 10 & 4 & 10 & 10 & 10 & 10 & 0 & 0 & 0 & 0 \\
\hline OBM COMP & 10 & 5 & 10 & 10 & 10 & 10 & 0 & 0 & 0 & 0 \\
\hline OBM COMP & 50 & 1 & 10 & 10 & 10 & 10 & 0 & 0 & 0 & 0 \\
\hline OBM COMP & 50 & 2 & 10 & 10 & 10 & 10 & 0 & 0 & 0 & 0 \\
\hline OBM COMP & 50 & 3 & 10 & 10 & 10 & 10 & 0 & 0 & 0 & 0 \\
\hline OBM COMP & 50 & 4 & 10 & 10 & 10 & 9 & 0 & 0 & 0 & 1 \\
\hline OBM COMP & 50 & 5 & 10 & 10 & 10 & 10 & 0 & 0 & 0 & 0 \\
\hline OBM COMP & 100 & 1 & 10 & 10 & 10 & 10 & 0 & 0 & 0 & 0 \\
\hline OBM COMP & 100 & 2 & 10 & 10 & 10 & 10 & 0 & 0 & 0 & 0 \\
\hline OBM COMP & 100 & 3 & 10 & 10 & 10 & 10 & 0 & 0 & 0 & 0 \\
\hline OBM COMP & 100 & 4 & 10 & 10 & 10 & 10 & 0 & 0 & 0 & 0 \\
\hline OBM COMP & 100 & 5 & 10 & 10 & 10 & 10 & 0 & 0 & 0 & 0 \\
\hline
\end{tabular}

(a) NI Not initiated

RH DEEPENING 
TABLE L.4. Water Quality Summary for 96-Hour C. stigmaeus Suspended-Particulate-Phase Test, Richmond Harbor Deepening Project

\begin{tabular}{|c|c|c|c|c|c|c|c|c|c|c|}
\hline \multirow{2}{*}{$\begin{array}{l}\text { Sediment } \\
\text { Treatment }\end{array}$} & \multirow{2}{*}{$\begin{array}{l}\text { Concentration } \\
\text { (Percent SPP) }\end{array}$} & \multicolumn{2}{|c|}{$\begin{array}{c}\text { Temperature } \\
\text { ('C) }\end{array}$} & \multicolumn{2}{|c|}{$\mathrm{pH}$} & \multicolumn{2}{|c|}{$\begin{array}{l}\text { Dissolved } \\
\text { Oxygen } \\
\text { (mg/L) }\end{array}$} & \multicolumn{2}{|c|}{$\begin{array}{l}\text { Salinity } \\
(0 / 00)\end{array}$} & \multirow[t]{2}{*}{$\begin{array}{l}\text { Ammonia } \\
\text { (mg/L) } \\
\text { Average(a) }\end{array}$} \\
\hline & & Min & Max & Min & Max & Min & Max & & Max & \\
\hline $\begin{array}{l}\text { Acceptable } \\
\text { Range }\end{array}$ & & 13.0 & 17.0 & 7.30 & 8.30 & 6.0 & NA (b) & 28.0 & 32.0 & NE (c) \\
\hline $\begin{array}{l}\text { SF COMP } \\
\text { SF COMP } \\
\text { SF COMP } \\
\text { SF COMP }\end{array}$ & $\begin{array}{r}0 \\
10 \\
50 \\
100\end{array}$ & $\begin{array}{l}13.8 \\
14.2 \\
14.1 \\
14.1\end{array}$ & $\begin{array}{l}15.5 \\
15.6 \\
15.4 \\
15.4\end{array}$ & $\begin{array}{l}7.63 \\
7.69 \\
7.67 \\
7.76\end{array}$ & $\begin{array}{l}7.95 \\
7.96 \\
8.02 \\
8.14\end{array}$ & $\begin{array}{l}7.7 \\
7.7 \\
7.1 \\
7.6\end{array}$ & $\begin{array}{l}8.4 \\
8.4 \\
8.4 \\
8.8\end{array}$ & $\begin{array}{l}30.5 \\
30.5 \\
30.0 \\
30.0\end{array}$ & $\begin{array}{l}32.0 \\
31.5 \\
31.0 \\
30.5\end{array}$ & $\begin{array}{l}N M(d) \\
N M \\
N M \\
4.02\end{array}$ \\
\hline $\begin{array}{l}\text { SFW COMP } \\
\text { SFW COMP } \\
\text { SFW COMP } \\
\text { SFW COMP }\end{array}$ & $\begin{array}{r}0 \\
10 \\
50 \\
100\end{array}$ & $\begin{array}{l}14.0 \\
14.2 \\
13.9 \\
14.1\end{array}$ & $\begin{array}{l}14.9 \\
14.9 \\
14.9 \\
14.9\end{array}$ & $\begin{array}{l}7.71 \\
7.73 \\
7.78 \\
7.89\end{array}$ & $\begin{array}{l}8.00 \\
7.98 \\
8.02 \\
8.15\end{array}$ & $\begin{array}{l}7.8 \\
7.6 \\
7.8 \\
7.5\end{array}$ & $\begin{array}{l}8.9 \\
8.8 \\
8.7 \\
8.8\end{array}$ & $\begin{array}{l}30.0 \\
30.0 \\
30.0 \\
30.0\end{array}$ & $\begin{array}{l}32.0 \\
31.5 \\
31.5 \\
30.5\end{array}$ & $\begin{array}{l}\text { NM } \\
\text { NM } \\
\text { NM } \\
2.38\end{array}$ \\
\hline $\begin{array}{l}\text { UIH COMP } \\
\text { UIH COMP } \\
\text { UIH COMP } \\
\text { UIH COMP }\end{array}$ & $\begin{array}{r}0 \\
10 \\
50 \\
100\end{array}$ & $\begin{array}{l}14.6 \\
14.8 \\
14.9 \\
15.1\end{array}$ & $\begin{array}{l}15.6 \\
15.5 \\
15.7 \\
15.6\end{array}$ & $\begin{array}{l}7.42 \\
7.50 \\
7.74 \\
7.75\end{array}$ & $\begin{array}{l}7.88 \\
7.95 \\
8.11 \\
8.24\end{array}$ & $\begin{array}{l}7.4 \\
7.4 \\
7.4 \\
6.6\end{array}$ & $\begin{array}{l}8.3 \\
8.2 \\
8.2 \\
8.2\end{array}$ & $\begin{array}{l}30.5 \\
30.5 \\
30.0 \\
29.0\end{array}$ & $\begin{array}{l}32.0 \\
32.0 \\
32.0 \\
30.5\end{array}$ & $\begin{array}{l}\text { NM } \\
\text { NM } \\
\text { NM } \\
3.02\end{array}$ \\
\hline $\begin{array}{l}\text { TB Upper COMP } \\
\text { TB Upper COMP } \\
\text { TB Upper COMP } \\
\text { TB Upper COMP }\end{array}$ & $\begin{array}{r}0 \\
10 \\
50 \\
100\end{array}$ & $\begin{array}{l}13.9 \\
14.3 \\
14.4 \\
14.3\end{array}$ & $\begin{array}{l}14.8 \\
14.9 \\
14.9 \\
14.9\end{array}$ & $\begin{array}{l}7.66 \\
7.67 \\
7.76 \\
7.94\end{array}$ & $\begin{array}{l}8.01 \\
8.02 \\
8.11 \\
8.21\end{array}$ & $\begin{array}{l}7.8 \\
7.9 \\
7.7 \\
6.6\end{array}$ & $\begin{array}{l}8.8 \\
8.7 \\
8.8 \\
8.8\end{array}$ & $\begin{array}{l}30.5 \\
30.5 \\
30.0 \\
29.5\end{array}$ & $\begin{array}{l}31.5 \\
31.5 \\
31.0 \\
30.0\end{array}$ & $\begin{array}{l}\text { NM } \\
\text { NM } \\
\text { NM } \\
3.31\end{array}$ \\
\hline $\begin{array}{l}\text { TB Lower COMP } \\
\text { TB Lower COMP } \\
\text { TB Lower COMP } \\
\text { TB Lower COMP }\end{array}$ & $\begin{array}{r}0 \\
10 \\
50 \\
100\end{array}$ & $\begin{array}{l}13.5 \\
14.0 \\
14.2 \\
14.2\end{array}$ & $\begin{array}{l}15.1 \\
14.9 \\
15.0 \\
15.0\end{array}$ & $\begin{array}{l}7.52 \\
7.62 \\
7.73 \\
7.77\end{array}$ & $\begin{array}{l}7.94 \\
7.99 \\
8.10 \\
8.15\end{array}$ & $\begin{array}{l}7.2 \\
7.4 \\
7.4 \\
7.0\end{array}$ & $\begin{array}{l}8.2 \\
8.2 \\
8.4 \\
8.3\end{array}$ & $\begin{array}{l}30.0 \\
30.0 \\
30.0 \\
28.5\end{array}$ & $\begin{array}{l}32.0 \\
31.5 \\
30.0 \\
31.0\end{array}$ & $\begin{array}{l}\text { NM } \\
\text { NM } \\
\text { NM } \\
4.75\end{array}$ \\
\hline $\begin{array}{l}\text { OBM COMP } \\
\text { OBM COMP } \\
\text { OBM COMP } \\
\text { OBM COMP }\end{array}$ & $\begin{array}{r}0 \\
10 \\
50 \\
100\end{array}$ & $\begin{array}{l}13.9 \\
13.9 \\
14.3 \\
14.5\end{array}$ & $\begin{array}{l}14.9 \\
14.8 \\
14.8 \\
15.1\end{array}$ & $\begin{array}{l}7.68 \\
7.73 \\
7.78 \\
7.81\end{array}$ & $\begin{array}{l}7.96 \\
7.98 \\
7.99 \\
8.07\end{array}$ & $\begin{array}{l}7.8 \\
7.9 \\
7.7 \\
7.7\end{array}$ & $\begin{array}{l}8.6 \\
8.6 \\
8.6 \\
8.7\end{array}$ & $\begin{array}{l}31.0 \\
30.0 \\
30.0 \\
29.5\end{array}$ & $\begin{array}{l}31.5 \\
31.5 \\
31.0 \\
30.0\end{array}$ & $\begin{array}{c}\text { NM } \\
\text { NM } \\
\text { NM } \\
1.00\end{array}$ \\
\hline
\end{tabular}

(a) Average of Day 4 measurements.

(b) NA Not applicable.

(c) NE Not established.

(d) NM Not measured. 
TABLE L.5. Test Results for 96-Hour C. stigmaeús Copper Reference Toxicant Test, Richmond Harbor Deepening Project

\begin{tabular}{|c|c|c|c|c|c|c|}
\hline \multirow{2}{*}{$\begin{array}{c}\text { Copper } \\
\text { Concentration } \\
(\mathrm{mg} / \mathrm{L})\end{array}$} & \multirow[b]{2}{*}{ Replicate } & \multicolumn{2}{|c|}{ C. stigmaeus } & \multirow[b]{2}{*}{$\begin{array}{c}\text { Proportion } \\
\text { Surviving }\end{array}$} & \multirow{2}{*}{$\begin{array}{l}\text { Mean } \\
\text { Proportion } \\
\text { Survival } \\
\end{array}$} & \multirow[b]{2}{*}{$\begin{array}{l}\text { Standard } \\
\text { Deviation }\end{array}$} \\
\hline & & Live(a) & $\begin{array}{l}\text { Dead or } \\
\text { Missing }\end{array}$ & & & \\
\hline 0.00 & 1 & 10 & 0 & 1.00 & & \\
\hline 0.00 & 2 & 10 & 0 & 1.00 & & \\
\hline 0.00 & 3 & 10 & 0 & 1.00 & 1.00 & 0.00 \\
\hline 0.50 & 1 & 10 & 0 & 1.00 & & \\
\hline 0.50 & 2 & 10 & 0 & 1.00 & & \\
\hline 0.50 & 3 & 9 & 1 & 0.90 & 0.97 & 0.06 \\
\hline 1.00 & 1 & 0 & 10 & 0.00 & & \\
\hline 1.00 & 2 & 1 & 9 & 0.10 & & \\
\hline 1.00 & 3 & 10 & 0 & 1.00 & 0.37 & 0.55 \\
\hline 1.50 & 1 & 0 & 10 & 0.00 & & \\
\hline 1.50 & 2 & 0 & 10 & 0.00 & & \\
\hline 1.50 & 3 & 4 & 6 & 0.40 & 0.13 & 0.23 \\
\hline 2.00 & 1 & 0 & 10 & 0.00 & & \\
\hline 2.00 & 2 & 1 & 9 & 0.10 & & \\
\hline 2.00 & 3 & 0 & 10 & 0.00 & 0.03 & 0.06 \\
\hline
\end{tabular}

(a) Survival based on initial exposure of 10 organisms per replicate. 
TABLE L.6. Daily Observations for C. stigmaeus During Copper Reference Toxicant Test, Richmond Harbor Deepening Project

Copper

Concentration (mg/L)

$$
\text { Replicate }
$$

C. stigmaeus Live

C. stigmaeus Dead

\begin{tabular}{|c|c|c|c|c|c|c|c|c|}
\hline 0.00 & 1 & 10 & 10 & 10 & 10 & 0 & 0 & 0 \\
\hline 0.00 & 2 & 10 & 10 & 10 & 10 & 0 & 0 & 0 \\
\hline 0.00 & 3 & 10 & 10 & 10 & 10 & 0 & 0 & 0 \\
\hline 0.50 & 1 & 10 & 10 & 10 & 10 & 0 & 0 & 0 \\
\hline 0.50 & 2 & 10 & 10 & 10 & 10 & 0 & 0 & 0 \\
\hline 0.50 & 3 & 10 & 10 & 10 & 9 & 0 & 0 & 0 \\
\hline 1.00 & 1 & 10 & 9 & 6 & 1 & 0 & 1 & 3 \\
\hline 1.00 & 2 & 10 & 9 & 3 & 1 & 0 & 1 & 6 \\
\hline 1.00 & 3 & 10 & 10 & 10 & 10 & 0 & 0 & 0 \\
\hline 1.50 & 1 & 10 & 6 & 0 & 0 & 0 & 4 & 6 \\
\hline 1.50 & 2 & 10 & 7 & 1 & 0 & 0 & 3 & 6 \\
\hline 1.50 & 3 & 10 & 10 & 10 & 8 & 0 & 0 & 0 \\
\hline 2.00 & 1 & 10 & 2 & 0 & 0 & 0 & 8 & 2 \\
\hline 2.00 & 2 & 10 & 10 & 7 & 3 & 0 & 0 & 3 \\
\hline 2.00 & 3 & 10 & 1 & 0 & 0 & 0 & 9 & 1 \\
\hline
\end{tabular}


TABLE L.7. Water Quality Summary for $96-$ Hour C. stigmaeus Copper Reference Toxicant Test, Richmond Harbor Deepening Project

\begin{tabular}{|c|c|c|c|c|c|c|c|c|}
\hline \multirow{2}{*}{$\begin{array}{l}\text { Copper } \\
\text { Concentration } \\
\text { (mg/L) }\end{array}$} & \multicolumn{2}{|c|}{$\begin{array}{l}\text { Temperature } \\
\text { ('C) }\end{array}$} & \multicolumn{2}{|c|}{$\mathrm{pH}$} & \multicolumn{2}{|c|}{$\begin{array}{c}\text { Dissolved } \\
\text { Oxygen } \\
\text { (mg/L) }\end{array}$} & \multicolumn{2}{|c|}{$\begin{array}{l}\text { Salinity } \\
(\mathrm{o} / \mathrm{oo})\end{array}$} \\
\hline & Min & Max & Min & Max & Min & Max & Min & $\operatorname{Max}$ \\
\hline \multicolumn{9}{|l|}{ Acceptable } \\
\hline Range & 13.0 & 17.0 & 7.30 & 8.30 & 6.0 & NA (a) & 28.0 & 32.0 \\
\hline 0.00 & 14.2 & 15.4 & 7.72 & 7.90 & 7.7 & 8.4 & 30.5 & 32.0 \\
\hline 0.50 & 14.0 & 15.0 & 7.78 & 7.93 & 8.1 & 8.5 & 30.5 & 31.5 \\
\hline 1.00 & 14.0 & 15.4 & 7.68 & 7.95 & 8.0 & 8.4 & 30.5 & 32.0 \\
\hline 1.50 & 14.1 & 15.3 & 7.67 & 7.96 & 8.2 & 8.5 & 30.5 & 31.5 \\
\hline 2.00 & 14.1 & 15.4 & 7.63 & 7.91 & 8.0 & 8.4 & 30.5 & 32.0 \\
\hline
\end{tabular}

(a) NA Not applicable. 
TABLE L.8. Test Results for 96-Hour C. stigmaeus Ammonia Reference Toxicant Test, Richmond Harbor Deepening Project

\begin{tabular}{|c|c|c|c|c|c|c|}
\hline \multirow{2}{*}{$\begin{array}{l}\text { Ammonia } \\
\text { Concentration } \\
\text { (mg/L) }\end{array}$} & \multirow[b]{2}{*}{ Replicate } & \multicolumn{2}{|c|}{ C. stigmaeus } & \multirow[b]{2}{*}{$\begin{array}{c}\text { Proportion } \\
\text { Surviving }\end{array}$} & \multirow{2}{*}{$\begin{array}{l}\text { Mean } \\
\text { Proportion } \\
\text { Survival } \\
\end{array}$} & \multirow[b]{2}{*}{$\begin{array}{l}\text { Standard } \\
\text { Deviation }\end{array}$} \\
\hline & & Live(a) & $\begin{array}{l}\text { Dead or } \\
\text { Missing }\end{array}$ & & & \\
\hline 0.350 & 1 & 10 & 0 & 1.00 & & \\
\hline 0.350 & 2 & 10 & 0 & 1.00 & & \\
\hline 0.350 & 3 & 10 & 0 & 1.00 & 1.00 & 0.00 \\
\hline 12.9 & 1 & 10 & 0 & 1.00 & & \\
\hline 12.9 & 2 & 10 & 0 & 1.00 & & \\
\hline 12.9 & 3 & 10 & 0 & 1.00 & 1.00 & 0.00 \\
\hline 17.1 & 1 & 10 & 0 & 1.00 & & \\
\hline 17.1 & 2 & 10 & 0 & 1.00 & & \\
\hline 17.1 & 3 & 10 & 0 & 1.00 & 1.00 & 0.00 \\
\hline 21.7 & 1 & 9 & 1 & 0.90 & & \\
\hline 21.7 & 2 & 7 & 3 & 0.70 & & \\
\hline 21.7 & 3 & 8 & 2 & 0.80 & 0.80 & 0.10 \\
\hline 25.8 & 1 & 2 & 8 & 0.20 & & \\
\hline 25.8 & 2 & 1 & 9 & 0.10 & & \\
\hline 25.8 & 3 & 5 & 5 & 0.50 & 0.27 & 0.21 \\
\hline
\end{tabular}

(a) Survival based on initial exposure of 10 organisms per replicate.

RH DEEPENING $\quad$ L.12 
TABLE L.9. Daily Observations for C. stigmaeus During Ammonia Reference Toxicant Test, Richmond Harbor Deepening Project

Ammonia

\begin{tabular}{|c|c|c|c|c|c|c|c|c|c|}
\hline \multirow{2}{*}{$\begin{array}{l}\text { Concentration } \\
\text { (mg/L) }\end{array}$} & \multirow[b]{2}{*}{ Replicate } & \multicolumn{4}{|c|}{ C. stigmaeus Live } & \multicolumn{4}{|c|}{ C. stigmaeus Dead } \\
\hline & & $2 \mathrm{~h}$ & $24 \mathrm{~h}$ & $48 \mathrm{~h}$ & $72 \mathrm{~h}$ & $2 \mathrm{~h}$ & $24 \mathrm{~h}$ & $48 \mathrm{~h}$ & $72 \mathrm{~h}$ \\
\hline 0.350 & 1 & 10 & 10 & 10 & 10 & 0 & 0 & 0 & \\
\hline 0.350 & 2 & 10 & 10 & 10 & 10 & 0 & 0 & 0 & \\
\hline 0.350 & 3 & 10 & 10 & 10 & 10 & 0 & 0 & 0 & 0 \\
\hline 12.9 & 1 & 10 & 10 & 10 & 10 & 0 & 0 & 0 & 0 \\
\hline 12.9 & 2 & 10 & 10 & 10 & 10 & 0 & 0 & 0 & 0 \\
\hline 12.9 & 3 & 10 & 10 & 10 & 10 & 0 & 0 & 0 & 0 \\
\hline 17.1 & 1 & 10 & 10 & 10 & 10 & 0 & 0 & 0 & 0 \\
\hline 17.1 & 2 & 10 & 10 & 10 & 10 & 0 & 0 & 0 & 0 \\
\hline 17.1 & 3 & 10 & 10 & 10 & 10 & 0 & 0 & 0 & 0 \\
\hline 21.7 & 1 & 10 & 9 & 9 & 9 & 0 & 1 & 0 & 0 \\
\hline 21.7 & 2 & 10 & 7 & 7 & 7 & 0 & 3 & 0 & 0 \\
\hline 21.7 & 3 & 10 & 8 & 8 & 8 & 0 & 2 & 0 & 0 \\
\hline 25.8 & 1 & 10 & 2 & 2 & 2 & 0 & 8 & 0 & 0 \\
\hline 25.8 & 2 & 10 & 1 & 1 & 1 & 0 & 9 & 0 & 0 \\
\hline 25.8 & 3 & 10 & 5 & 5 & 5 & 0 & 5 & 0 & 0 \\
\hline
\end{tabular}


TABLE L.10. Water Quality Summary for 96-Hour C. stigmaeus Ammonia Reference Toxicant Test, Richmond Harbor Deepening Project.

\begin{tabular}{|c|c|c|c|c|c|c|c|c|c|c|}
\hline \multirow{2}{*}{$\begin{array}{l}\text { Ammonia } \\
\text { Concentration } \\
\text { (mg/L) }\end{array}$} & \multicolumn{2}{|c|}{$\begin{array}{c}\text { Temperature } \\
\left({ }^{\circ} \mathrm{C}\right)\end{array}$} & \multicolumn{2}{|c|}{$\mathrm{pH}$} & \multicolumn{2}{|c|}{$\begin{array}{c}\text { Dissolved } \\
\text { Oxygen } \\
\text { (mg/L) } \\
\end{array}$} & \multicolumn{2}{|c|}{$\begin{array}{c}\text { Salinity } \\
(0 / 00)\end{array}$} & \multicolumn{2}{|c|}{$\begin{array}{c}\text { Ammonia } \\
(\mathrm{mg} / \mathrm{L})\end{array}$} \\
\hline & Min & Max & Min & Max & Min & Max & Min & Max & Min & Max \\
\hline \multicolumn{11}{|l|}{ Acceptable } \\
\hline Range & 13.0 & 17.0 & 7.30 & 8.30 & 6.0 & NA (a) & 28.0 & 32.0 & NE (b) & NE \\
\hline 0.350 & 14.1 & 14.7 & 7.68 & 7.93 & 7.8 & 8.3 & 31.0 & 32.0 & 0.234 & 0.548 \\
\hline 12.9 & 14.0 & 14.4 & 7.70 & 7.88 & 8.0 & 8.4 & 31.0 & 32.0 & 11.2 & 17.5 \\
\hline 17.1 & 14.1 & 14.3 & 7.78 & 7.89 & 8.0 & 8.4 & 31.0 & 32.0 & 14.6 & 20.8 \\
\hline 21.7 & 14.1 & 14.3 & 7.77 & 7.92 & 7.9 & 8.4 & 31.0 & 31.5 & 18.4 & 24.5 \\
\hline 25.8 & 14.1 & 14.6 & 7.82 & 7.95 & 7.8 & 8.4 & 31.5 & 32.0 & 21.3 & 28.5 \\
\hline
\end{tabular}

(a) NA Not applicable.

(b) NE Not established. 
APPENDIX M

BIOASSAY RESULTS FOR 96-HOUR SUSPENDED-PARTICULATE-PHASE TEST AND 96-HOUR REFERENCE TOXICANT TESTS FOR HOLMESIMYSIS costata 


\section{QA/QC SUMMARY}

PROGRAM: · Richmond Harbor Deepening Project

TEST ORGANISM: Holmesimysis costata

TEST TYPE: $\quad$ Suspended-particulate-phase; static with aeration

TEST DURATION: 96 hours

WATER QUALITY ACCEPTABLE RANGES:

Temperature $\mathrm{pH}$ Dissolved Oxygen Salinity Flow Rate Ammonia

$\begin{array}{llllll}13-17^{\circ} \mathrm{C} & 7.30-8.30 & \geq 6.0 \mathrm{mg} / \mathrm{L} & 28-32 \% & \mathrm{NA} & \mathrm{NA}\end{array}$

TEST MATRIX

SOURCE/AGE

HOLDING/ACCLIMATION

Temperature

$\min / \max$

$11.7-16.2^{\circ} \mathrm{C}$

WATER QUALITY SUMMARY

TEST VALIDATION

REFERENCE TOXICANT TEST

COMMENTS

\section{REFERENCES}

EPAUUSACE (U.S. Environmental Protection Agency/ U.S. Army Corps of Engineers). 1991. Evaluation of Dredged Material Proposed for Ocean Disposal (Testing Manual).

EPA-68-C8-0105, U.S. Environmental Protection Agency, Office of Marine and Estuarine Protection, Washington, D.C.
Sediments were collected from January 28, 1994 to February 3, 1994. Sediments were composited and tested within 6 weeks holding time after collection. Each SPP was tested within 24 hours after preparation.

Brezina and Associates, Dillon Beach, California. Wild captured organisms (sorted to uniform juvenile size) were collected in Tomales Bay, California.

Approximately 1500 and 1300 organisms were received on each of 2 days (February 25 and March 2, 1994), respectively, and held for a minimum of 48 hours prior to testing.

\section{$\mathrm{pH}$ Dissolved Oxygen Salinity}

7.18-7.85

$6.5->20.0 \mathrm{mg} / \mathrm{L}$

$30.0-33.0 \%$

All water quality parameters remained within the acceptable ranges throughout the 96 hours of testing for the SPP and ammonia and cadmium reference toxicant tests.

The test was validated by $>90 \%$ survival in the seawater controls estabilished for each of the tests.

Validation of $>90 \%$ survival in the seawater controls. An $L C_{50}$ value of $70.71 \mu \mathrm{g} / \mathrm{L}$ of copper and an $L C_{50}$ value of $39.75 \mathrm{mg} / \mathrm{L}$ of ammonia were calculated.

Mysids were fed 24-h-old brine shrimp nauplii once or twice daily during holding/acclimation and testing periods. 
TABLE M.1. Test Results for 96-Hour H. costata Suspended-Particulate-Phase Test, Richmond Harbor Deepening Project

\begin{tabular}{|c|c|c|c|c|c|c|c|}
\hline \multirow[b]{2}{*}{$\begin{array}{l}\text { Sediment } \\
\text { Treatment }\end{array}$} & \multirow[b]{2}{*}{$\begin{array}{l}\text { Concentration } \\
\text { (Percent SPP) }\end{array}$} & \multirow[b]{2}{*}{ Replicate } & \multicolumn{2}{|c|}{ H. costata } & \multirow[b]{2}{*}{$\begin{array}{l}\text { Proportion } \\
\text { Surviving }\end{array}$} & \multirow{2}{*}{$\begin{array}{l}\text { Mean } \\
\text { Proportion } \\
\text { Surviving } \\
\end{array}$} & \multirow[b]{2}{*}{$\begin{array}{l}\text { Standard } \\
\text { Deviation }\end{array}$} \\
\hline & & & Live(a) & $\begin{array}{l}\text { Dead or } \\
\text { Missing }\end{array}$ & & & \\
\hline SF COMP & 0 & 1 & 9 & 1 & 0.90 & & \\
\hline SF COMP & 0 & 2 & 10 & 0 & 1.00 & & \\
\hline SF COMP & 0 & 3 & 9 & 1 & 0.90 & & \\
\hline SF COMP & 0 & 4 & 10 & 0 & 1.00 & & \\
\hline SF COMP & 0 & 5 & 9 & 1 & 0.90 & 0.94 & 0.05 \\
\hline SF COMP & 10 & 1 & 10 & 0 & 1.00 & & \\
\hline SF COMP & 10 & 2 & 10 & 0 & 1.00 & & \\
\hline SF COMP & 10 & 3 & 9 & 1 & 0.90 & & \\
\hline SF COMP & 10 & 4 & 10 & 0 & 1.00 & & \\
\hline SF COMP & 10 & 5 & 10 & 0 & 1.00 & 0.98 & 0.04 \\
\hline SF COMP & 50 & 1 & 9 & 1 & 0.90 & & \\
\hline SF COMP & 50 & 2 & 9 & 1 & 0.90 & & \\
\hline SF COMP & 50 & 3 & 10 & 0 & 1.00 & & \\
\hline SF COMP & 50 & 4 & 10 & 0 & 1.00 & & \\
\hline SF COMP & 50 & 5 & 10 & 0 & 1.00 & 0.96 & 0.05 \\
\hline SF COMP & 100 & 1 & 10 & 0 & 1.00 & & \\
\hline SF COMP & 100 & 2 & 9 & 1 & 0.90 & & \\
\hline SF COMP & 100 & 3 & 7 & 3 & 0.70 & & \\
\hline SF COMP & 100 & 4 & 9 & 1 & 0.90 & & \\
\hline SF COMP & 100 & 5 & 8 & 2 & 0.80 & 0.86 & 0.11 \\
\hline SFW COMP & 0 & 1 & 10 & 0 & 1.00 & & \\
\hline SFW COMP & 0 & 2 & 9 & 1 & 0.90 & & \\
\hline SFW COMP & 0 & 3 & 10 & 0 & 1.00 & & \\
\hline SFW COMP & 0 & 4 & 10 & 0 & 1.00 & & \\
\hline SFW COMP & 0 & 5 & 10 & 0 & 1.00 & 0.98 & 0.04 \\
\hline SFW COMP & 10 & 1. & 9 & 1 & 0.90 & & \\
\hline SFW COMP & 10 & 2 & 10 & 0 & 1.00 & & \\
\hline SFW COMP & 10 & 3 & 10 & 0 & 1.00 & & \\
\hline SFW COMP & 10 & 4 & 10 & 0 & 1.00 & & \\
\hline SFW COMP & 10 & 5 & 9 & 1 & 0.90 & 0.96 & 0.05 \\
\hline SFW COMP & 50 & 1 & 9 & 1 & 0.90 & & \\
\hline SFW COMP & 50 & 2 & 10 & 0 & 1.00 & & \\
\hline SFW COMP & 50 & 3 & 10 & 0 & 1.00 & & \\
\hline SFW COMP & 50 & 4 & 9 & 1 & 0.90 & & \\
\hline SFW COMP & 50 & 5 & 10 & 0 & 1.00 & 0.96 & 0.05 \\
\hline SFW COMP & 100 & 1 & 9 & 1 & 0.90 & & \\
\hline SFW COMP & 100 & 2 & 9 & 1 & 0.90 & & \\
\hline SFW COMP & 100 & 3 & 9 & 1 & 0.90 & & \\
\hline SFW COMP & 100 & 4 & 10 & 0 & 1.00 & & \\
\hline SFW COMP & 100 & 5 & 7 & 3 & 0.70 & 0.88 & 0.11 \\
\hline RH DEEPENING & & & & & & & \\
\hline
\end{tabular}


TABLE M.1 (contd)

\begin{tabular}{|c|c|c|c|c|c|c|c|}
\hline \multirow[b]{2}{*}{$\begin{array}{l}\text { Sediment } \\
\text { Treatment }\end{array}$} & \multirow[b]{2}{*}{$\begin{array}{l}\text { Concentration } \\
\text { (Percent SPP) }\end{array}$} & \multirow[b]{2}{*}{ Replicate } & \multicolumn{2}{|c|}{ H. costata } & \multirow[b]{2}{*}{$\begin{array}{l}\text { Proportion } \\
\text { Surviving }\end{array}$} & \multirow{2}{*}{$\begin{array}{l}\text { Mean } \\
\text { Proportion } \\
\text { Surviving }\end{array}$} & \multirow[b]{2}{*}{$\begin{array}{l}\text { Standard } \\
\text { Deviation }\end{array}$} \\
\hline & & & Live(a) & $\begin{array}{l}\text { Dead or } \\
\text { Missing }\end{array}$ & & & \\
\hline UIH COMP & 0 & 1 & 10 & 0 & 1.00 & & \\
\hline UIH COMP & 0 & 2 & 10 & 0 & 1.00 & & \\
\hline UIH COMP & 0 & 3 & 10 & 0 & 1.00 & & \\
\hline UIH COMP & 0 & 4 & 10 & 0 & 1.00 & & \\
\hline UIH COMP & 0 & 5 & 10 & 0 & 1.00 & 1.00 & 0.00 \\
\hline UIH COMP & 10 & 1 & 10 & 0 & 1.00 & & \\
\hline UIH COMP & 10 & 2 & 9 & 1 & 0.90 & & \\
\hline UIH COMP & 10 & 3 & 10 & 0 & 1.00 & & \\
\hline UIH COMP & 10 & 4 & 10 & 0 & 1.00 & & \\
\hline UIH COMP & 10 & 5 & 9 & 1 & 0.90 & 0.96 & 0.05 \\
\hline UIH COMP & 50 & 1 & 9 & 1 & 0.90 & & \\
\hline UIH COMP & 50 & 2 & 10 & 0 & 1.00 & & \\
\hline UIH COMP & 50 & 3 & 10 & 0 & 1.00 & & \\
\hline UIH COMP & 50 & 4 & 9 & 1 & 0.90 & & \\
\hline UIH COMP & 50 & 5 & 9 & 1 & 0.90 & 0.94 & 0.05 \\
\hline UIH COMP & 100 & 1 & 8 & 2 & 0.80 & & \\
\hline UIH COMP & 100 & 2 & 10 & 0 & 1.00 & & \\
\hline UIH COMP & 100 & 3 & 10 & 0 & 1.00 & & \\
\hline UIH COMP & 100 & 4 & 9 & 1 & 0.90 & & \\
\hline UIH COMP & 100 & 5 & 8 & 2 & 0.80 & 0.90 & 0.10 \\
\hline TB Upper COMP & 0 & 1 & 9 & 1 & 0.90 & & \\
\hline TB Upper COMP & 0 & 2 & 10 & 0 & 1.00 & & \\
\hline TB Upper COMP & 0 & 3 & 10 & 0 & 1.00 & & \\
\hline TB Upper COMP & 0 & 4 & 9 & 1 & 0.90 & & \\
\hline TB Upper COMP & 0 & 5 & 10 & 0 & 1.00 & 0.96 & 0.05 \\
\hline TB Upper COMP & 10 & 1 & 10 & 0 & 1.00 & & \\
\hline TB Upper COMP & 10 & 2 & 10 & 0 & 1.00 & & \\
\hline TB Upper COMP & 10 & 3 & 9 & 1 & 0.90 & & \\
\hline TB Upper COMP & 10 & 4 & 10 & 0 & 1.00 & & \\
\hline TB Upper COMP & 10 & 5 & 10 & 0 & 1.00 & 0.98 & 0.04 \\
\hline TB Upper COMP & 50 & 1 & 10 & 0 & 1.00 & & \\
\hline TB Upper COMP & 50 & 2 & 9 & 1 & 0.90 & & \\
\hline TB Upper COMP & 50 & 3 & 9 & 1 & 0.90 & & \\
\hline TB Upper COMP & 50 & 4 & 10 & 0 & 1.00 & & \\
\hline TB Upper COMP & 50 & 5 & 10 & 0 & 1.00 & 0.96 & 0.05 \\
\hline TB Upper COMP & 100 & 1 & 10 & 0 & 1.00 & & \\
\hline TB Upper COMP & 100 & 2 & 10 & 0 & 1.00 & & \\
\hline TB Upper COMP & 100 & 3 & 9 & 1 & 0.90 & & \\
\hline TB Upper COMP & 100 & 4 & 9 & 1 & 0.90 & & \\
\hline TB Upper COMP & 100 & 5 & 10 & 0 & 1.00 & 0.96 & 0.05 \\
\hline
\end{tabular}

RH DEEPENING

M.2 
TABLE M.1 (contd)

\begin{tabular}{|c|c|c|c|c|c|c|c|}
\hline \multirow[b]{2}{*}{$\begin{array}{l}\text { Sediment } \\
\text { Treatment }\end{array}$} & \multirow[b]{2}{*}{$\begin{array}{l}\text { Concentration } \\
\text { (Percent SPP) }\end{array}$} & \multirow[b]{2}{*}{ Replicate } & \multicolumn{2}{|c|}{ H. costata } & \multirow[b]{2}{*}{$\begin{array}{l}\text { Proportion } \\
\text { Surviving }\end{array}$} & \multirow{2}{*}{$\begin{array}{l}\text { Mean } \\
\text { Proportion } \\
\text { Surviving }\end{array}$} & \multirow[b]{2}{*}{$\begin{array}{l}\text { Standard } \\
\text { Deviation }\end{array}$} \\
\hline & & & Live(a) & $\begin{array}{l}\text { Dead or } \\
\text { Missing }\end{array}$ & & & \\
\hline TB Lower COMP & 0 & 1 & 10 & 0 & 1.00 & & \\
\hline TB Lower COMP & 0 & 2 & 10 & 0 & 1.00 & & \\
\hline TB Lower COMP & 0 & 3 & 10 & 0 & 1.00 & & \\
\hline TB Lower COMP & 0 & 4 & 10 & 0 & 1.00 & & \\
\hline TB Lower COMP & 0 & 5 & 9 & 1 & 0.90 & 0.98 & 0.04 \\
\hline TB Lower COMP & 10 & 1 & 9 & 1 & 0.90 & & \\
\hline TB Lower COMP & 10 & 2 & 10 & 0 & 1.00 & & \\
\hline TB Lower COMP & 10 & 3 & 10 & 0 & 1.00 & & \\
\hline TB Lower COMP & 10 & 4 & 8 & 2 & 0.80 & & \\
\hline TB Lower COMP & 10 & 5 & 10 & 0 & 1.00 & 0.94 & 0.09 \\
\hline TB Lower COMP & $50^{\circ}$ & 1 & 10 & 0 & 1.00 & & \\
\hline TB Lower COMP & 50 & 2 & 10 & 0 & 1.00 & & \\
\hline TB Lower COMP & 50 & 3 & 10 & 0 & 1.00 & & \\
\hline TB Lower COMP & 50 & 4 & 10 & 0 & 1.00 & & \\
\hline TB Lower COMP & 50 & 5 & 10 & 0 & 1.00 & 1.00 & 0.00 \\
\hline TB Lower COMP & 100 & 1 & 9 & 1 & 0.90 & & \\
\hline TB Lower COMP & 100 & 2 & 9 & 1 & 0.90 & & \\
\hline TB Lower COMP & 100 & 3 & 10 & 0 & 1.00 & & \\
\hline TB Lower COMP & 100 & 4 & 10 & 0 & 1.00 & & \\
\hline TB Lower COMP & 100 & 5 & 9 & 1 & 0.90 & 0.94 & 0.05 \\
\hline OBM COMP & 0 & 1 & 10 & 0 & 1.00 & & \\
\hline OBM COMP & 0 & 2 & 9 & 1 & 0.90 & & \\
\hline OBM COMP & 0 & 3 & 10 & 0 & 1.00 & & \\
\hline OBM COMP & 0 & 4 & $10^{\circ}$ & 0 & 1.00 & & \\
\hline OBM COMP & 0 & 5 & 10 & 0 & 1.00 & 0.98 & 0.04 \\
\hline OBM COMP & 10 & 1 & 9 & 1 & 0.90 & & \\
\hline OBM COMP & 10 & 2 & 10 & 0 & 1.00 & & \\
\hline OBM COMP & 10 & 3 & 9 & 1 & 0.90 & & \\
\hline OBM COMP & 10 & 4 & 10 & 0 & 1.00 & & \\
\hline OBM COMP & 10 & 5 & 9 & 1 & 0.90 & 0.94 & 0.05 \\
\hline OBM COMP & 50 & 1 & 10 & 0 & 1.00 & & \\
\hline OBM COMP & 50 & 2 & 9 & 1 & 0.90 & & \\
\hline OBM COMP & 50 & 3 & 10 & 0 & 1.00 & & \\
\hline OBM COMP & 50 & 4 & 10 & 0 & 1.00 & & \\
\hline OBM COMP & 50 & 5 & 10 & 0 & 1.00 & 0.98 & 0.04 \\
\hline OBM COMP & 100 & 1 & 10 & 0 & 1.00 & & \\
\hline OBM COMP & 100 & 2 & 10 & 0 & 1.00 & & \\
\hline OBM COMP & 100 & 3 & 9 & 1 & 0.90 & & \\
\hline OBM COMP & 100 & 4 & 10 & 0 & 1.00 & & \\
\hline OBM COMP & 100 & 5 & 9 & 1 & 0.90 & 0.96 & 0.05 \\
\hline
\end{tabular}

(a) Survival based on initial exposure of 10 organisms per replicate.

RH DEEPENING

M.3 
TABLE M.2. Summary of Mean Proportion Surviving 96-Hour H. costata SuspendedParticulate-Phase Test, Richmond Harbor Deepening Project

Sediment

Treatment

SF COMP

SF COMP

SF COMP

SF COMP

SFW COMP

SFW COMP

SFW COMP

SFW COMP

UIH COMP

UIH COMP

UIH COMP

UIH COMP

TB Upper COMP

TB Upper COMP

TB Upper COMP

TB Upper COMP

TB Lower COMP

TB Lower COMP

TB Lower COMP

TB Lower COMP

OBM COMP

OBM COMP

OBM COMP

OBM COMP

\begin{tabular}{lc} 
& Mean \\
Concentration & Proportion \\
(Percent SPP) & Surviving(a) \\
\hline
\end{tabular}

0.94

0.98

0.96

0.86

0.98

0.96

0.96

0.88

1.00

0.96

0.94

0.90

0.96

0.98

0.96

0.96

0.98

0.94

1.00

0.94

0.98

0.94

0.98

0.96

(a) Survival based on initial exposure of 10 organisms per replicate. 
TABLE M.3. Daily Observations of H. costata During 96-Hour Suspended-Particulate-Phase Test, Richmond Harbor Deepening Project

\begin{tabular}{|c|c|c|c|c|c|c|c|c|c|c|}
\hline \multirow{2}{*}{$\begin{array}{l}\text { Sediment } \\
\text { Treatment }\end{array}$} & \multirow{2}{*}{$\begin{array}{l}\text { Concentration } \\
\text { (Percent SPP) }\end{array}$} & \multirow[b]{2}{*}{ Replicate } & \multicolumn{4}{|c|}{ H. costata Live } & \multicolumn{4}{|c|}{ H. costata Dead } \\
\hline & & & $2 \mathrm{~h}$ & $24 \mathrm{~h}$ & $48 \mathrm{~h}$ & $72 \mathrm{~h}$ & $2 h$ & $24 \mathrm{~h}$ & $48 \mathrm{~h}$ & $72 h$ \\
\hline SF COMP & 0 & 1 & 10 & 10 & 10 & 10 & 0 & 0 & 0 & 0 \\
\hline SF COMP & 0 & 2 & 10 & 10 & 10 & 10 & 0 & 0 & 0 & 0 \\
\hline SF COMP & 0 & 3 & 10 & 10 & 10 & 10 & 0 & 0 & 0 & 0 \\
\hline SF COMP & 0 & 4 & 10 & 10 & 10 & 10 & 0 & 0 & 0 & 0 \\
\hline SF COMP & 0 & 5 & 10 & 10 & 10 & 9 & 0 & 0 & 0 & 1 \\
\hline SF COMP & 10 & 1 & 10 & 10 & 10 & 10 & 0 & 0 & 0 & 0 \\
\hline SF COMP & 10 & 2 & 10 & 10 & 10 & 10 & 0 & 0 & 0 & 0 \\
\hline SF COMP & 10 & 3 & 10 & 10 & 9 & 9 & 0 & 0 & 1 & 0 \\
\hline SF COMP & 10 & 4 & 10 & 10 & 10 & 10 & 0 & 0 & 0 & 0 \\
\hline SF COMP & 10 & 5 & 10 & 10 & 10 & 10 & 0 & 0 & 0 & 0 \\
\hline SF COMP & 50 & 1 & 10 & 9 & 9 & 9 & 0 & 1 & 0 & 0 \\
\hline SF COMP & 50 & 2 & 10 & 10 & 10 & 10 & 0 & 0 & 0 & 0 \\
\hline SF COMP & 50 & 3 & 10 & 10 & 10 & 10 & 0 & 0 & 0 & 0 \\
\hline SF COMP & 50 & 4 & 10 & 10 & 10 & 10 & 0 & 0 & 0 & 0 \\
\hline SF COMP & 50 & 5 & 10 & 10 & 10 & 10 & 0 & 0 & 0 & 0 \\
\hline SF COMP & 100 & 1 & 10 & 10 & 10 & 10 & 0 & 0 & 0 & 0 \\
\hline SF COMP & 100 & 2 & 10 & 9 & 9 & 9 & 0 & 1 & 0 & 0 \\
\hline SF COMP & 100 & 3 & 10 & 10 & 9 & 7 & 0 & 0 & 1 & 2 \\
\hline SF COMP & 100 & 4 & 10 & 10 & 10 & 10 & 0 & 0 & 0 & 0 \\
\hline SF COMP. & 100 & 5 & 10 & 10 & 10 & 9 & 0 & 0 & 0 & 1 \\
\hline SFW COMP & 0 & 1 & 10 & 10 & 10 & 10 & 0 & 0 & 0 & 0 \\
\hline SFW COMP & 0 & 2 & 10 & 10 & 10 & 10 & 0 & 0 & 0 & 0 \\
\hline SFW COMP & 0 & 3 & 10 & 10 & 10 & 10 & 0 & 0 & 0 & 0 \\
\hline SFW COMP & 0 & 4 & 10 & 10 & 10 & 10 & 0 & 0 & 0 & 0 \\
\hline SFW COMP & 0 & 5 & 10 & 10 & 10 & 10 & 0 & 0 & 0 & 0 \\
\hline SFW COMP & 10 & 1 & 10 & 10 & 10 & 10 & 0 & 0 & 0 & 0 \\
\hline SFW COMP & 10 & 2 & 10 & 10 & 10 & 10 & 0 & 0 & 0 & 0 \\
\hline SFW COMP & 10 & 3 & 10 & 10 & 10 & 10 & 0 & 0 & 0 & 0 \\
\hline SFW COMP & 10 & 4 & 10 & 10 & 10 & 10 & 0 & 0 & 0 & 0 \\
\hline SFW COMP & 10 & $\dot{5}$ & 10 & 10 & 10 & 9 & 0 & 0 & 0 & 1 \\
\hline SFW COMP & 50 & 1 & 10 & 10 & 9 & 9 & 0 & 0 & 1 & 0 \\
\hline SFW COMP & 50 & 2 & 10 & 10 & 10 & 10 & 0 & 0 & 0 & 0 \\
\hline SFW COMP & 50 & 3 & 10 & 10 & 10 & 10 & 0 & 0 & 0 & 0 \\
\hline SFW COMP & 50 & 4 & 10 & 10 & 10 & 9 & 0 & 0 & 0 & 1 \\
\hline SFW COMP & 50 & 5 & 10 & 10 & 10 & 10 & 0 & 0 & 0 & 0 \\
\hline SFW COMP & 100 & 1 & 10 & 10 & 10 & 9 & 0 & 0 & 0 & 1 \\
\hline SFW COMP & 100 & 2 & 10 & 9 & 9 & 9 & 0 & 1 & 0 & 0 \\
\hline SFW COMP & 100 & 3 & 10 & 10 & 10 & 9 & 0 & 0 & 0 & 1 \\
\hline SFW COMP & 100 & 4 & 10 & 10 & 10 & 10 & 0 & 0 & 0 & 0 \\
\hline SFW COMP & 100 & 5 & 10 & 10 & 10 & 8 & 0 & 0 & 0 & 2 \\
\hline
\end{tabular}

RH DEEPENING 
TABLE M.3. (contd)

\begin{tabular}{|c|c|c|c|c|c|c|c|c|c|c|}
\hline \multirow{2}{*}{$\begin{array}{l}\text { Sediment } \\
\text { Treatment }\end{array}$} & \multirow{2}{*}{$\begin{array}{l}\text { Concentration } \\
\text { (Percent SPP) }\end{array}$} & \multirow[b]{2}{*}{ Replicate } & \multicolumn{4}{|c|}{ H. costata Live } & \multicolumn{4}{|c|}{ H. costata Dead } \\
\hline & & & $2 h$ & $24 \mathrm{~h}$ & $48 \mathrm{~h}$ & $72 \mathrm{~h}$ & $2 \mathrm{~h}$ & $24 \mathrm{~h}$ & $48 \mathrm{~h}$ & $72 \mathrm{~h}$ \\
\hline UIH COMP & 0 & 1 & 10 & 10 & 10 & 10 & 0 & 0 & 0 & 0 \\
\hline UIH COMP & 0 & 2 & 10 & 10 & 10 & 10 & 0 & 0 & 0 & 0 \\
\hline UIH COMP & 0 & 3 & 10 & 10 & 10 & 10 & 0 & 0 & 0 & 0 \\
\hline UIH COMP & 0 & 4 & 10 & 10 & 10 & 10 & 0 & 0 & 0 & 0 \\
\hline UIH COMP & 0 & 5 & 10 & 10 & 10 & 10 & 0 & 0 & 0 & 0 \\
\hline UIH COMP & 10 & 1 & 10 & 10 & 10 & 10 & 0 & 0 & 0 & 0 \\
\hline UIH COMP & 10 & 2 & 10 & 9 & 9 & 9 & 0 & 1 & 0 & 0 \\
\hline UIH COMP & 10 & 3 & 10 & 10 & 10 & 10 & 0 & 0 & 0 & 0 \\
\hline UIH COMP & 10 & 4 & 10 & 10 & 10 & 10 & 0 & 0 & 0 & 0 \\
\hline UIH COMP & 10 & 5 & 10 & 10 & 9 & 9 & 0 & 0 & 1 & 0 \\
\hline UIH COMP & 50 & 1 & 10 & 10 & 10 & 9 & 0 & 0 & 0 & 1 \\
\hline UIH COMP & 50 & 2 & 10 & 10 & 10 & 10 & 0 & 0 & 0 & 0 \\
\hline UIH COMP & 50 & 3 & 10 & 10 & 10 & 10 & 0 & 0 & 0 & 0 \\
\hline UIH COMP & 50 & 4 & 10 & 9 & 9 & 9 & 0 & 1 & 0 & 0 \\
\hline UIH COMP & 50 & 5 & 10 & 10 & 9 & 9 & 0 & 0 & 1 & 0 \\
\hline UIH COMP & 100 & 1 & 10 & 10 & 9 & 9 & 0 & 0 & 1 & 0 \\
\hline UIH COMP & 100 & 2 & 10 & 10 & 10 & 10 & 0 & 0 & 0 & 0 \\
\hline UIH COMP & 100 & 3 & 10 & 10 & 10 & 10 & 0 & 0 & 0 & 0 \\
\hline UIH COMP & 100 & 4 & 10 & 10 & 9 & 9 & 0 & 0 & 1 & 0 \\
\hline UIH COMP & 100 & 5 & 10 & 9 & 9 & 8 & 0 & 1 & 0 & 1 \\
\hline TB Upper COMP & 0 & 1 & 10 & 10 & 10 & 10 & 0 & 0 & 0 & 0 \\
\hline TB Upper COMP & 0 & 2 & 10 & 10 & 10 & 10 & 0 & 0 & 0 & 0 \\
\hline TB Upper COMP & 0 & 3 & 10 & 10 & 10 & 10 & 0 & 0 & 0 & 0 \\
\hline TB Upper COMP & 0 & 4 & 10 & 10 & 10 & 10 & 0 & 0 & 0 & 0 \\
\hline TB Upper COMP & 0 & 5 & 10 & 10 & 10 & 10 & 0 & 0 & 0 & 0 \\
\hline TB Upper COMP & 10 & 1 & 10 & 10 & 10 & 10 & 0 & 0 & 0 & 0 \\
\hline TB Upper COMP & 10 & 2 & 10 & 10 & 10 & 10 & 0 & 0 & 0 & 0 \\
\hline TB Upper COMP & 10 & 3 & 10 & 10 & 10 & 10 & 0 & 0 & 0 & 0 \\
\hline TB Upper COMP & 10 & 4 & 10 & 10 & 10 & 10 & 0 & 0 & 0 & 0 \\
\hline TB Upper COMP & 10 & 5 & 10 & 10 & 10 & 10 & 0 & 0 & 0 & 0 \\
\hline TB Upper COMP & 50 & 1 & 10 & 10 & 10 & 10 & 0 & 0 & 0 & 0 \\
\hline TB Upper COMP & 50 & 2 & 10 & 9 & 9 & 9 & 0 & 1 & 0 & 0 \\
\hline TB Upper COMP & 50 & 3 & 10 & 10 & 10 & 10 & 0 & 0 & 0 & 0 \\
\hline TB Upper COMP & 50 & 4 & 10 & 10 & 10 & 10 & 0 & 0 & 0 & 0 \\
\hline TB Upper COMP & 50 & 5 & 10 & 10 & 10 & 10 & 0 & 0 & 0 & 0 \\
\hline TB Upper COMP & 100 & 1 & 10 & 10 & 10 & 10 & 0 & 0 & 0 & 0 \\
\hline TB Upper COMP & 100 & 2 & 10 & 10 & 10 & 10 & 0 & 0 & 0 & 0 \\
\hline TB Upper COMP & 100 & 3 & 10 & 10 & 10 & 9 & 0 & 0 & 0 & 1 \\
\hline TB Upper COMP & 100 & 4 & 10 & 10 & 10 & 9 & 0 & 0 & 0 & 1 \\
\hline TB Upper COMP & 100 & 5 & 10 & 10 & 10 & 10 & 0 & 0 & 0 & 0 \\
\hline
\end{tabular}

RH DEEPENING

M. 6 
TABLE M.3. (contd)

\begin{tabular}{|c|c|c|c|c|c|c|c|c|c|c|}
\hline \multirow{2}{*}{$\begin{array}{l}\text { Sediment } \\
\text { Treatment }\end{array}$} & \multirow{2}{*}{$\begin{array}{l}\text { Concentration } \\
\text { (Percent SPP) }\end{array}$} & \multirow[b]{2}{*}{ Replicate } & \multicolumn{4}{|c|}{ H. costata Live } & \multicolumn{4}{|c|}{ H. costata Dead } \\
\hline & & & $2 \mathrm{~h}$ & $24 \mathrm{~h}$ & $48 \mathrm{~h}$ & $72 \mathrm{~h}$ & $2 h$ & $24 \mathrm{~h}$ & $48 \mathrm{~h}$ & $72 \mathrm{~h}$ \\
\hline TB Lower COMP & 0 & 1 & 10 & 10 & 10 & 10 & 0 & 0 & 0 & 0 \\
\hline TB Lower COMP & 0 & 2 & 10 & 10 & 10 & 10 & 0 & 0 & 0 & 0 \\
\hline TB Lower COMP & 0 & 3 & 10 & 10 & 10 & 10 & 0 & 0 & 0 & 0 \\
\hline TB Lower COMP & 0 & 4 & 10 & 10 & 10 & 10 & 0 & 0 & 0 & 0 \\
\hline TB Lower COMP & 0 & 5 & 10 & 10 & 10 & 10 & 0 & 0 & 0 & 0 \\
\hline TB Lower COMP & 10 & 1 & 10 & 10 & 10 & 10 & 0 & 0 & 0 & 0 \\
\hline TB Lower COMP & 10 & 2 & 10 & 10 & 10 & 10 & 0 & 0 & 0 & 0 \\
\hline TB Lower COMP & 10 & 3 & 10 & 10 & 10 & 10 & 0 & 0 & 0 & 0 \\
\hline TB Lower COMP & 10 & 4 & 10 & 10 & 10 & 9 & 0 & 0 & 0 & 1 \\
\hline TB Lower COMP & 10 & 5 & 10 & 10 & 10 & 10 & 0 & 0 & 0 & 0 \\
\hline TB Lower COMP & 50 & 1 & 10 & 10 & 10 & 10 & 0 & 0 & 0 & 0 \\
\hline TB Lower COMP & 50 & 2 & 10 & 10 & 10 & 10 & 0 & 0 & 0 & 0 \\
\hline TB Lower COMP & 50 & 3 & 10 & 10 & 10 & 10 & 0 & 0 & 0 & 0 \\
\hline TB Lower COMP & 50 & 4 & 10 & 10 & 10 & 10 & 0 & 0 & 0 & 0 \\
\hline TB Lower COMP & 50 & 5 & 10 & 10 & 10 & 10 & 0 & 0 & 0 & 0 \\
\hline TB Lower COMP & 100 & 1 & 10 & 9 & 9 & 9 & 0 & 1 & 0 & 0 \\
\hline TB Lower COMP & 100 & 2 & 10 & 9 & 9 & 9 & 0 & 1 & 0 & 0 \\
\hline TB Lower COMP & 100 & 3 & 10 & 10 & 10 & 10 & 0 & 0 & 0 & 0 \\
\hline TB Lower COMP & 100 & 4 & 10 & 10 & 10 & 10 & 0 & 0 & 0 & 0 \\
\hline TB Lower COMP & 100 & 5 & 10 & 10 & 10 & 10 & 0 & 0 & 0 & 0 \\
\hline OBM COMP & 0 & 1 & 10 & 10 & 10 & 10 & 0 & 0 & 0 & 0 \\
\hline OBM COMP & 0 & 2 & 10 & 10 & 9 & 9 & 0 & 0 & 1 & 0 \\
\hline OBM COMP & 0 & 3 & 10 & 10 & 10 & 10 & 0 & 0 & 0 & 0 \\
\hline OBM COMP & 0 & 4 & 10 & 10 & 10 & 10 & 0 & 0 & 0 & 0 \\
\hline OBM COMP & 0 & 5 & 10 & 10 & 10 & 10 & 0 & 0 & 0 & 0 \\
\hline OBM COMP & 10 & 1 & 10 & 10 & 10 & 9 & 0 & 0 & 0 & 1 \\
\hline OBM COMP & 10 & 2 & 10 & 10 & 10 & 10 & 0 & 0 & 0 & 0 \\
\hline OBM COMP & 10 & 3 & 10 & 10 & 10 & 9 & 0 & 0 & 0 & 1 \\
\hline OBM COMP & 10 & 4 & 10 & 10 & 10 & 10 & 0 & 0 & 0 & 0 \\
\hline OBM COMP & 10 & 5 & 10 & 10 & 10 & 10 & 0 & 0 & 0 & 0 \\
\hline OBM COMP & 50 & 1 & 10 & 10 & 10 & 10 & 0 & 0 & 0 & 0 \\
\hline OBM COMP & 50 & 2 & 10 & 10 & 10 & 9 & 0 & 0 & 0 & 1 \\
\hline OBM СOMP & 50 & 3 & 10 & 10 & 10 & 10 & 0 & 0 & 0 & 0 \\
\hline OBM COMP & 50 & 4 & 10 & 10 & 10 & 10 & 0 & 0 & 0 & 0 \\
\hline OBM COMP & 50 & 5 & 10 & 10 & 10 & 10 & 0 & 0 & 0 & 0 \\
\hline OВM СОМР & 100 & 1 & 10 & 10 & 10 & 10 & 0 & 0 & 0 & 0 \\
\hline OBM COMP & 100 & 2 & 10 & 10 & 10 & 10 & 0 & 0 & 0 & 0 \\
\hline OBM COMP & 100 & 3 & 10 & 10 & 10 & 9 & 0 & 0 & 0 & 1 \\
\hline OBM СОMP & 100 & 4 & 10 & 10 & 10 & 10 & 0 & 0 & 0 & 0 \\
\hline OBM COMP & 100 & 5 & 10 & 10 & 10 & 9 & 0 & 0 & 0 & 1 \\
\hline
\end{tabular}

RH DEEPENING 


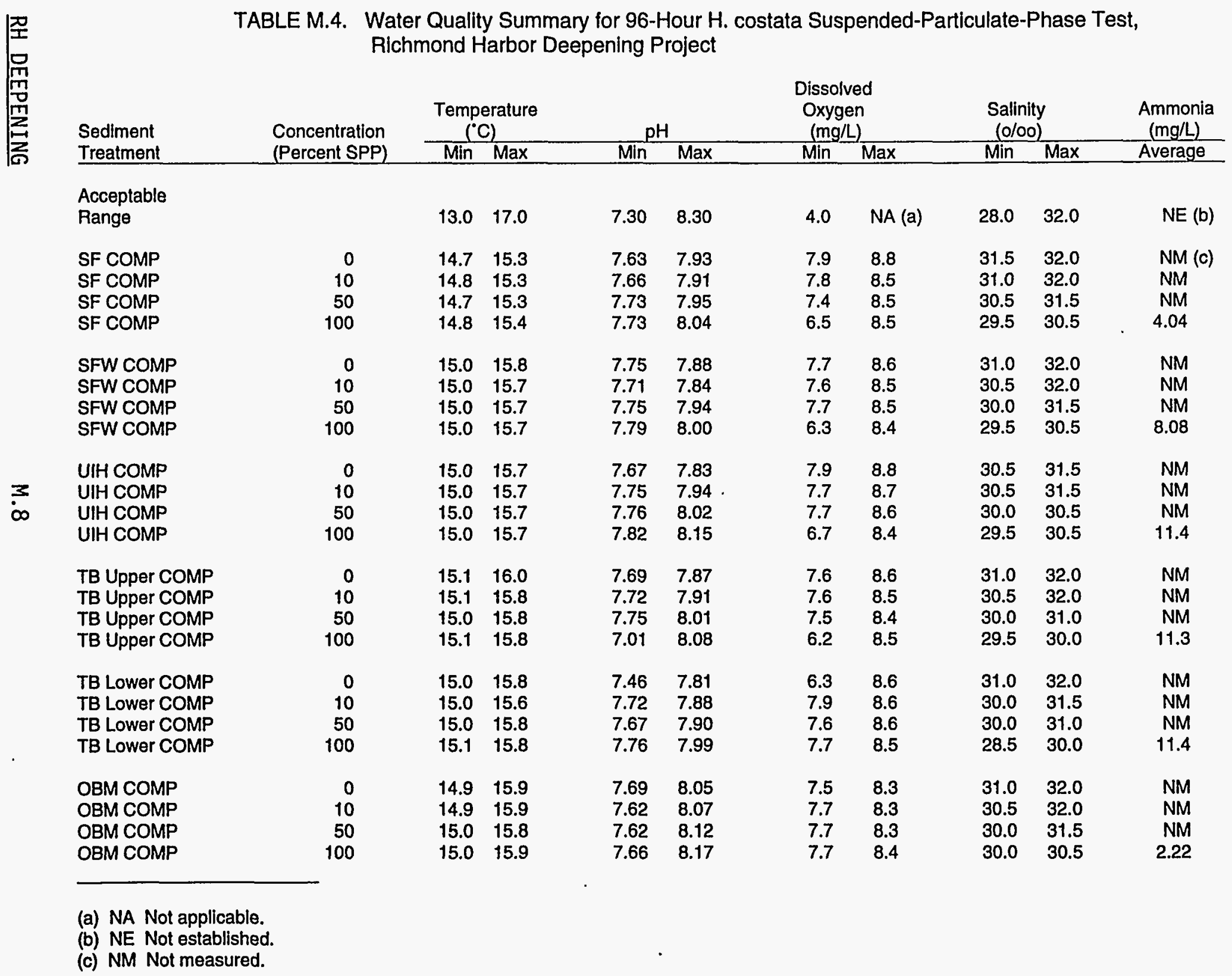


TABLE M.5. Test Results for 96-Hour H. costata Copper Reference Toxicant Test, Richmond Harbor Deepening Project

\begin{tabular}{|c|c|c|c|c|c|c|}
\hline \multirow{2}{*}{$\begin{array}{l}\text { Copper } \\
\text { Concentration } \\
\text { (ug/L) }\end{array}$} & \multirow[b]{2}{*}{ Replicate } & \multicolumn{2}{|c|}{ H. costata } & \multirow{2}{*}{\multicolumn{2}{|c|}{$\begin{array}{l}\text { Mean } \\
\text { Proportion } \\
\text { Surviving } \\
\end{array}$}} & \multirow[b]{2}{*}{$\begin{array}{l}\text { Standard } \\
\text { Deviation }\end{array}$} \\
\hline & & Live(a) & $\begin{array}{l}\text { Dead or } \\
\text { Missing }\end{array}$ & & & \\
\hline 0.0 & 1 & 10 & 0 & 1.00 & & \\
\hline 0.0 & 2 & 9 & 1 & 0.90 & & \\
\hline 0.0 & 3 & 9 & 1 & 0.90 & 0.93 & 0.06 \\
\hline 50.0 & 1 & 9 & 1 & 0.90 & & \\
\hline 50.0 & 2 & 8 & 2 & 0.80 & & \\
\hline 50.0 & 3 & 9 & 1 & 0.90 & 0.87 & 0.06 \\
\hline 100.0 & 1 & 1 & 9 & 0.10 & & \\
\hline 100.0 & 2 & 1 & 9 & 0.10 & & \\
\hline 100.0 & 3 & 0 & 10 & 0.00 & 0.07 & 0.06 \\
\hline 150.0 & 1 & 0 & 10 & 0.00 & & \\
\hline 150.0 & 2 & 0 & 10 & 0.00 & & \\
\hline 150.0 & 3 & 0 & 10 & 0.00 & 0.00 & 0.00 \\
\hline 200.0 & 1 & 0 & 10 & 0.00 & & \\
\hline 200.0 & 2 & 0 & 10 & 0.00 & & \\
\hline 200.0 & 3 & 0 & 10 & 0.00 & 0.00 & 0.00 \\
\hline
\end{tabular}

(a) Survival based on initial exposure of 10 organisms per replicate. 
TABLE M.6. Daily Observations of $H$. costata During Copper Reference Toxicant Test, Richmond Harbor Deepening Project

\begin{tabular}{|c|c|c|c|c|c|c|c|c|c|}
\hline \multirow{2}{*}{$\begin{array}{l}\text { Copper } \\
\text { Concentration } \\
\text { (ug/L) }\end{array}$} & \multirow[b]{2}{*}{ Replicate } & \multicolumn{4}{|c|}{ H. costata Live } & \multicolumn{4}{|c|}{ H. costata Dead } \\
\hline & & $2 h$ & $24 \mathrm{~h}$ & $48 \mathrm{~h}$ & $72 \mathrm{~h}$ & $2 h$ & $24 \mathrm{~h}$ & $48 \mathrm{~h}$ & $72 \mathrm{~h}$ \\
\hline 0.0 & 1 & 10 & 10 & 10 & 10 & 0 & 0 & 0 & 0 \\
\hline 0.0 & 2 & 10 & 10 & 10 & 10 & 0 & 0 & 0 & 0 \\
\hline 0.0 & 3 & 10 & 10 & 10 & 9 & 0 & 0 & 0 & 1 \\
\hline 50.0 & 1 & 10 & 10 & 10 & 9 & 0 & 0 & 0 & 1 \\
\hline 50.0 & 2 & 10 & 10 & 9 & 8 & 0 & 0 & 1 & 1 \\
\hline 50.0 & 3 & 10 & 9 & 9 & 9 & 0 & 1 & 0 & 0 \\
\hline 100.0 & 1 & 10 & 6 & 6 & 2 & 0 & 4 & 0 & 4 \\
\hline 100.0 & 2 & 10 & 5 & 5 & 1 & 0 & 5 & 0 & 4 \\
\hline 100.0 & 3 & 10 & 6 & 5 & 2 & 0 & 4 & 1 & 3 \\
\hline 150.0 & 1 & 10 & 0 & 0 & 0 & 0 & 10 & TRM (a) & TRM \\
\hline 150.0 & 2 & 10 & 0 & 0 & 0 & 0 & 10 & TRM & TRM \\
\hline 150.0 & 3 & 10 & 0 & 0 & 0 & 0 & 10 & TRM & TRM \\
\hline 200.0 & 1 & 10 & 0 & 0 & 0 & 0 & 10 & TRM & TRM \\
\hline 200.0 & 2 & 10 & 0 & 0 & 0 & 0 & 10 & TRM & TRM \\
\hline 200.0 & 3 & 10 & 0 & 0 & 0 & 0 & 10 & TRM & TRM \\
\hline
\end{tabular}

(a) TRM Terminated. 
TABLE-M.7. Water Quality Summary for 96-Hour H. costata Copper Reference Toxicant Test, Richmond Harbor Deepening Project

\begin{tabular}{|c|c|c|c|c|c|c|c|c|}
\hline \multirow{2}{*}{$\begin{array}{l}\text { Copper } \\
\text { Concentration } \\
\text { (ug/L) }\end{array}$} & \multicolumn{2}{|c|}{$\begin{array}{c}\text { Temperature } \\
\text { ("C) }\end{array}$} & \multicolumn{4}{|c|}{$\begin{array}{l}\text { Dissolved } \\
\text { Oxygen } \\
(\mathrm{mg} / \mathrm{L})\end{array}$} & \multicolumn{2}{|c|}{$\begin{array}{l}\text { Salinity } \\
\text { (o/oo) }\end{array}$} \\
\hline & Min & Max & Min & Max & Min & Max & Min & Max \\
\hline \multicolumn{9}{|l|}{ Acceptable } \\
\hline Range & 13.0 & 17.0 & 7.30 & 8.30 & 4.0 & $N A(a)$ & 28.0 & 32.0 \\
\hline 0.0 & 14.7 & 15.7 & 7.62 & 7.91 & 7.8 & 8.7 & 30.5 & 32.0 \\
\hline 50.0 & 14.8 & 15.8 & 7.69 & 7.88 & 7.7 & 8.4 & 30.5 & 32.0 \\
\hline 100.0 & 14.7 & 15.9 & 7.72 & 8.01 & 7.8 & 8.5 & 30.5 & 32.0 \\
\hline 150.0 & 15.1 (b) & 15.5 & 7.75 & 7.77 & 7.8 & 8.5 & 30.0 & 31.5 \\
\hline 200.0 & 15.1 & 15.9 & 7.75 & 7.79 & 8.0 & 8.1 & 30.5 & 31.5 \\
\hline
\end{tabular}

(a) NA Not applicable.

(b) There was $100 \%$ mortality of $H$. costata after 24 hours. 
TABLE M.8. Test Results for 96-Hour H. costata Ammonia Reference Toxicant Test, Richmond Harbor Deepening Project

\begin{tabular}{|c|c|c|c|c|c|c|}
\hline \multirow{2}{*}{$\begin{array}{l}\text { Ammonia } \\
\text { Concentration } \\
\text { (mg/L) }\end{array}$} & \multirow[b]{2}{*}{ Replicate } & \multicolumn{2}{|c|}{ H. costata } & \multirow[b]{2}{*}{$\begin{array}{l}\text { Proportion } \\
\text { Surviving }\end{array}$} & \multirow{2}{*}{$\begin{array}{l}\text { Mean } \\
\text { Proportion } \\
\text { Surviving }\end{array}$} & \multirow[b]{2}{*}{$\begin{array}{l}\text { Standa } \\
\text { Deviati }\end{array}$} \\
\hline & & Live(a) & $\begin{array}{l}\text { Dead or } \\
\text { Missing }\end{array}$ & & & \\
\hline \multicolumn{7}{|l|}{ Test 1} \\
\hline 0.68 & 1 & 9 & 1 & 0.90 & & \\
\hline 0.68 & 2 & 10 & 0 & 1.00 & & \\
\hline 0.68 & 3 & 10 & 0 & 1.00 & 0.97 & 0.06 \\
\hline 0.71 & 1 & 8 & 2 & 0.80 & & \\
\hline 0.71 & 2 & 10 & 0 & 1.00 & & \\
\hline 0.71 & 3 & 9 & 1 & 0.90 & 0.90 & 0.10 \\
\hline 0.79 & 1 & 9 & 1 & 0.90 & & \\
\hline 0.79 & 2 & 9 & 1 & 0.90 & & \\
\hline 0.79 & 3 & 10 & 0 & 1.00 & 0.93 & 0.06 \\
\hline 0.87 & 1 & 9 & 1 & 0.90 & & \\
\hline 0.87 & 2 & 9 & 1 & 0.90 & & \\
\hline 0.87 & 3 & 9 & 1 & 0.90 & 0.90 & 0.00 \\
\hline 1.32 & 1 & 9 & 1 & 0.90 & & \\
\hline 1.32 & 2 & 10 & 0 & 1.00 & & \\
\hline 1.32 & 3 & 8 & 2 & 0.80 & 0.90 & 0.10 \\
\hline
\end{tabular}

Test 2

1.64

1.64

1.64

3.03

3.03

3.03

6.66

6.66

6.66

14.8

14.8

14.8

29.96

29.96

29.96$$
\begin{aligned}
& 1 \\
& 2 \\
& 3
\end{aligned}
$$

1

2
3

1
2
3

1
2
3

3

1
2
3

3

$\begin{array}{rl}9 & 1 \\ 10 & 0 \\ 9 & 1\end{array}$

10

8

9

9

9

8

$\begin{array}{ll}8 & 2 \\ 8 & 2 \\ 8 & 2\end{array}$

$\begin{array}{ll}9 & 1 \\ 9 & 1 \\ 7 & 3\end{array}$

M. 12
0.90

1.00

0.90

$0.93 \quad 0.06$

1.00

0.80

0.90

0.90

0.10

0.90

0.90

0.80

0.87

0.06

0.80

0.80

0.80

0.80

0.00

0.90

0.90

0.70

0.83

0.12

RH DEEPENING 
TABLE M.8. (contd)

\begin{tabular}{|c|c|c|c|c|c|c|}
\hline \multirow{2}{*}{$\begin{array}{l}\text { Ammonia } \\
\text { Concentration } \\
\text { (mg/L) }\end{array}$} & \multirow[b]{2}{*}{ Replicate } & \multicolumn{2}{|c|}{ H. costata } & \multirow[b]{2}{*}{$\begin{array}{l}\text { Proportion } \\
\text { Surviving }\end{array}$} & \multirow{2}{*}{$\begin{array}{l}\text { Mean } \\
\text { Proportion } \\
\text { Surviving }\end{array}$} & \multirow[b]{2}{*}{$\begin{array}{l}\text { Standard } \\
\text { Deviation }\end{array}$} \\
\hline & & Live(a) & $\begin{array}{l}\text { Dead or } \\
\text { Missing }\end{array}$ & & & \\
\hline \multicolumn{7}{|l|}{ Test 3} \\
\hline 2.37 & 1 & 10 & 0 & 1.00 & & \\
\hline 2.37 & 2 & 10 & 0 & 1.00 & & \\
\hline 2.37 & 3 & 9 & 1 & 0.90 & 0.97 & 0.06 \\
\hline 57.99 & 1 & 3 & 7 & 0.30 & & \\
\hline 57.99 & 2 & 5 & 5 & 0.50 & & \\
\hline 57.99 & 3 & 6 & 4 & 0.60 & 0.47 & 0.15 \\
\hline 79.11 & 1 & 0 & 10 & 0.00 & & \\
\hline 79.11 & 2 & 0 & 10 & 0.00 & & \\
\hline 79.11 & 3 & 0 & 10 & 0.00 & 0.00 & 0.00 \\
\hline 96.8 & 1 & 0 & 10 & 0.00 & & \\
\hline 96.8 & 2 & 0 & 10 & 0.00 & & \\
\hline 96.8 & 3 & 0 & 10 & 0.00 & 0.00 & 0.00 \\
\hline
\end{tabular}

(a) Survival based on initial exposure of 10 organisms per replicate. 
TABLE M.9. Daily Observations of $H$. costata During Ammonia Reference Toxicant Test, Richmond Harbor Deepening Project

Ammonia

\begin{tabular}{|c|c|c|c|c|c|c|c|c|c|}
\hline Concentration & & & -1. $\cos$ & Live & & & $\cos$ & Dea & \\
\hline$(\mathrm{mg} / \mathrm{L})$ & Replicate & $2 \mathrm{~h}$ & $24 h$ & $48 \mathrm{~h}$ & $72 \mathrm{~h}$ & $2 \mathrm{~h}$ & $24 \mathrm{~h}$ & & \\
\hline
\end{tabular}

\section{Test 1}

$\begin{array}{lrrrrrrrrr}0.68 & 1 & 10 & 10 & 9 & 9 & 0 & 0 & 1 & 0 \\ 0.68 & 2 & 10 & 10 & 10 & 10 & 0 & 0 & 0 & 0 \\ 0.68 & 3 & 10 & 10 & 10 & 10 & 0 & 0 & 0 & 0 \\ 0.71 & 1 & 10 & 10 & 10 & 9 & 0 & 0 & 0 & 1 \\ 0.71 & 2 & 10 & 10 & 10 & 10 & 0 & 0 & 0 & 0 \\ 0.71 & 3 & 10 & 10 & 9 & 9 & 0 & 0 & 1 & 0 \\ 0.79 & 1 & 10 & 10 & 10 & 10 & 0 & 0 & 0 & 0 \\ 0.79 & 2 & 10 & 10 & 10 & 9 & 0 & 0 & 0 & 1 \\ 0.79 & 3 & 10 & 10 & 10 & 10 & 0 & 0 & 0 & 0 \\ 0.87 & 1 & 10 & 10 & 10 & 9 & 0 & 0 & 0 & 1 \\ 0.87 & 2 & 10 & 10 & 10 & 10 & 0 & 0 & 0 & 0 \\ 0.87 & 3 & 10 & 10 & 10 & 10 & 0 & 0 & 0 & 0 \\ 1.32 & 1 & 10 & 10 & 10 & 10 & 0 & 0 & 0 & 0 \\ 1.32 & 2 & 10 & 10 & 10 & 10 & 0 & 0 & 0 & 0 \\ 1.32 & 3 & 10 & 10 & 10 & 9 & 0 & 0 & 0 & 1\end{array}$

$\underline{\text { Test } 2}$

$\begin{array}{lrrrrrrrrr}1.64 & 1 & 10 & 10 & 10 & 10 & 0 & 0 & 0 & 0 \\ 1.64 & 2 & 10 & 10 & 10 & 10 & 0 & 0 & 0 & 0 \\ 1.64 & 3 & 10 & 10 & 10 & 10 & 0 & 0 & 0 & 0 \\ 3.03 & 1 & 10 & 10 & 10 & 10 & 0 & 0 & 0 & 0 \\ 3.03 & 2 & 10 & 10 & 9 & 8 & 0 & 0 & 1 & 1 \\ 3.03 & 3 & 10 & 10 & 10 & 10 & 0 & 0 & 0 & 0 \\ 6.66 & 1 & 10 & 9 & 9 & 9 & 0 & 1 & 0 & 0 \\ 6.66 & 2 & 10 & 10 & 10 & 10 & 0 & 0 & 0 & 0 \\ 6.66 & 3 & 10 & 10 & 10 & 9 & 0 & 0 & 0 & 1 \\ 14.8 & 1 & 10 & 10 & 8 & 8 & 0 & 0 & 2 & 0 \\ 14.8 & 2 & 10 & 10 & 10 & 10 & 0 & 0 & 0 & 0 \\ 14.8 & 3 & 10 & 10 & 10 & 10 & 0 & 0 & 0 & 0 \\ 29.96 & 1 & 10 & 9 & 9 & 9 & 0 & 1 & 0 & 0 \\ 29.96 & 2 & 10 & 9 & 9 & 9 & 0 & 1 & 0 & 0 \\ 29.96 & 3 & 10 & 10 & 10 & 10 & 0 & 0 & 0 & 0\end{array}$


TABLE M.9. (contd)

Ammonia

Concentration (mg/L)

Test 3

2.37

2.37

2.37

57.99

57.99

57.99

79.11

79.11

79.11

96.8

96.8

96.8
H. costata Live Replicate $2 \mathrm{~h} \quad 24 \mathrm{~h} \quad 48 \mathrm{~h}$
H. costata Dead

$24 \mathrm{~h}$
$72 \mathrm{~h}$

$2 h \quad 24 h \quad 48 h \quad 72 h$


TABLE M.10. Water Quality Summary for $96-$ Hour H. costata Ammonia Reference Toxicant Test, Richmond Harbor Deepening Project

\begin{tabular}{|c|c|c|c|c|c|c|c|c|c|c|}
\hline \multirow{2}{*}{$\begin{array}{l}\text { Ammonia } \\
\text { Concentration } \\
\text { (mg/L) }\end{array}$} & \multicolumn{2}{|c|}{$\begin{array}{c}\text { Temperature } \\
\left({ }^{\circ} \mathrm{C}\right)\end{array}$} & \multicolumn{4}{|c|}{$\begin{array}{c}\text { Dissolved } \\
\text { Oxygen } \\
\text { (mg/L) }\end{array}$} & \multicolumn{2}{|c|}{$\begin{array}{l}\text { Salinity } \\
\text { (o/oo) }\end{array}$} & \multicolumn{2}{|c|}{$\begin{array}{c}\text { Ammonia } \\
\text { (mg/L) }\end{array}$} \\
\hline & Min & Max & Min & Max & Min & Max & Min & Max & Min & Max \\
\hline $\begin{array}{l}\text { Acceptable } \\
\text { Range }\end{array}$ & 13.0 & 17.0 & 7.30 & 8.30 & 4.0 & NA (a) & 28.0 & 32.0 & NE (b) & NE \\
\hline Test 1 & & & & & & & & & & \\
\hline 0.68 & 14.6 & 15.1 & 7.73 & 7.94 & 7.7 & 8.4 & 31.5 & 32.0 & 0.212 & 1.04 \\
\hline 0.71 & 14.7 & 15.3 & 7.78 & 7.93 & 7.7 & 8.5 & 31.5 & 32.0 & 0.246 & 1.20 \\
\hline 0.79 & 14.7 & 15.3 & 7.80 & 7.96 & 8.0 & 8.5 & 31.0 & 32.0 & 0.289 & 1.27 \\
\hline 0.87 & 14.6 & 15.3 & 7.78 & 7.99 & 7.8 & 8.5 & 31.0 & 32.5 (c) & 0.406 & 1.31 \\
\hline 1.32 & 14.7 & 15.4 & 7.76 & 8.01 & 7.9 & 8.4 & 31.0 & 32.0 & 0.785 & 1.87 \\
\hline
\end{tabular}

Test 2

$\begin{array}{crrrrrrrrrr}1.64 & 14.7 & 14.9 & 7.60 & 7.98 & 7.0 & 8.3 & 30.5 & 31.5 & 0.286 & 4.18 \\ 3.03 & 14.7 & 14.8 & 7.59 & 7.98 & 7.4 & 8.4 & 30.5 & 31.5 & 1.73 & 5.25 \\ 6.66 & 14.7 & 14.9 & 7.69 & 7.97 & 7.7 & 8.4 & 30.5 & 31.5 & 4.79 & 7.81 \\ 14.8 & 14.7 & 14.8 & 7.68 & 7.95 & 7.6 & 8.5 & 31.0 & 31.5 & 11.9 & 17.6 \\ 29.96 & 14.7 & 14.9 & 7.69 & 7.90 & 7.8 & 8.4 & 30.5 & 31.5 & 18.7 & 37.7\end{array}$

Test 3

$\begin{array}{rrrrrrrrrrr}2.37 & 14.8 & 15.6 & 7.46 & 7.84 & 7.4 & 8.3 & 30.5 & 31.0 & 0.556 & 3.93 \\ 57.99 & 14.7 & 15.5 & 7.65 & 7.78 & 7.7 & 8.2 & 30.5 & 31.0 & 51.2 & 68.9 \\ 79.11 & 14.6 & 15.6 & 7.54 & 7.84 & 7.1 & 8.2 & 30.5 & 31.0 & 63.7 & 96.4 \\ 96.8 & 14.6 & 15.4 & 7.48 & 7.88 & 7.6 & 8.3 & 30.5 & 31.0 & 75.4 & 120\end{array}$
(a) NA Not applicable.
(b) NE Not established.
(c) Data point out of range. 


\section{APPENDIX N}

BIOASSAY RESULTS FOR 48-HOUR SUSPENDED-PARTICULATE-PHASE TEST AND 48-HOUR REFERENCE TOXICANT TESTS FOR MYTILUS qalloprovincial is 


\section{QA/QC SUMMARY}

PROGRAM: Richmond Harbor Deepening Program

TEST ORGANISM: Mytilus galloprovincialis

TEST TYPE: $\quad$ Suspended-particulate-phase; static with aeration

TEST DURATION: 48 hours

WATER QUALITY ACCEPTABLE RANGES:

$\frac{\text { Temperature }}{14-18^{\circ} \mathrm{C}} \frac{\mathrm{pH}}{7.30-8.30} \underset{24.0 \mathrm{mg} / \mathrm{L}}{28-32 \%} \frac{\text { Dissolved Oxygen }}{\mathrm{NA}} \frac{\text { Salinity }}{\text { FA }}$

TEST MATRIX

SOURCE/AGE

HOLDINGIACCLIMATION

Temperature

$\min / \max$

$4.9-8.9^{\circ} \mathrm{C}$

WATER QUALITY SUMMARY

TEST VALIDATION

REFERENCE TOXICANT TEST

COMMENTS

RH-DEEPENING
Sediments were collected from January 28, 1994 to February 3,1994 . Sediments were composited and tested within 6 weeks holding time after collection. Each SPP was tested within 24 hours after preparation.

Marinus, Inc., Long Beach, California. Adult mussels.

Approximately 125 adult mussels were received on January 16, 1994 (dry on ice). They were placed in outside holding tanks under ambient conditions and removed for spawning conditions as needed. Holding conditions for Februany 11 through 25, 1994, are as follows:

\section{$\mathrm{pH}$ Dissolved Oxygen Salinity}

7.40-7.80 $\quad 8.1-10.4 \mathrm{mg} / \mathrm{L} \quad 30.0-32.0 \%$

All water quality parameters remained within the acceptable ranges throughout the 48 hours of testing for the SPP and ammonia and cadmium reference toxicant tests.

The test was validated by $>90 \%$ survival in the seawater controls estabilished for each of the tests.

Validation by a mean percent survival and mean percent normal larvae of $>90 \%$ in the seawater controls. The $\mathrm{LC}_{50}$ values for copper ranged from $12.1 \mu \mathrm{g} / \mathrm{L}$ to $24.5 \mu \mathrm{g} / \mathrm{L}$. The $E_{50}$ values for copper ranged from $7.3 \mu \mathrm{g} / \mathrm{L}$ to $8.0 \mu \mathrm{g} / \mathrm{L}$. The $L C_{50}$ values for ammonia ranged from $43.2 \mathrm{mg} / \mathrm{L}$ to $63.0 \mathrm{mg} / \mathrm{L}$. The $\mathrm{EC}_{50}$ values for ammonia ranged from $2.23 \mathrm{mg} / \mathrm{L}$ to $2.76 \mathrm{mg} / \mathrm{L}$.

One replicate of the seawater control for Berth 7 Comp was inadvertently knocked over during water quality measurements on Day 2 and not included in the test results. 
QA/QC SUMMARY (contd)

\section{REFERENCES}

ASTM (American Society for Testing and Materials). 1989. Standard Guide for Conducting Static Acute Toxicity Tests Starting with Embryos of Four Species of Saltwater Bivalve Molluscs. ASTM Designation: E 724-89. American Society for Testing and Materials, Philadelphia, Pennsylvania.

EPAVUSACE (U.S. Environmental Protection Agency/ U.S. Army Corps of Engineers). 1991. Evaluation of Dredged Material Proposed for Ocean Disposal (Testing Manual).

EPA-68-C8-0105, U.S. Environmental Protection Agency, Office of Marine and Estuarine Protection, Washington, D.C. 


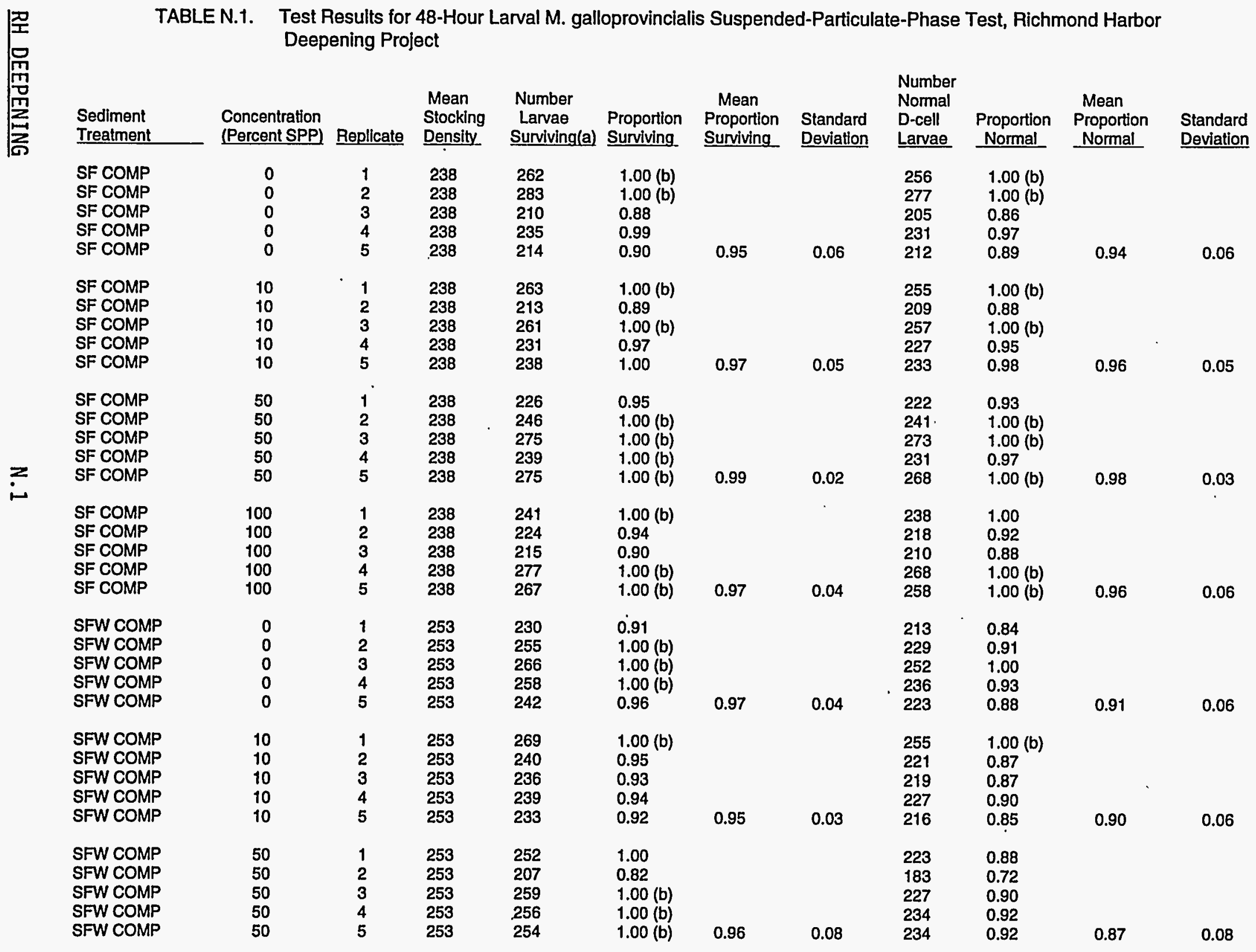




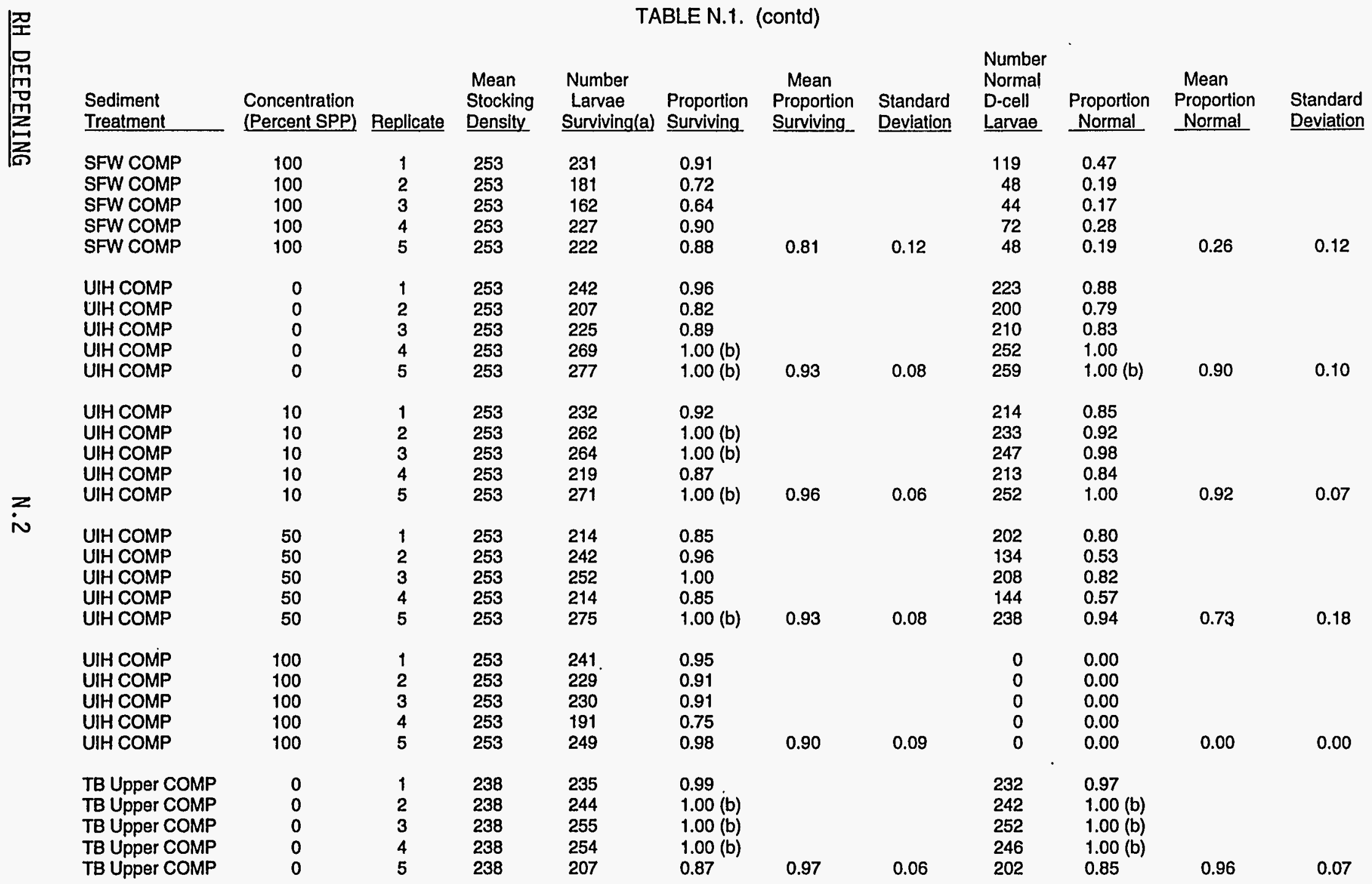




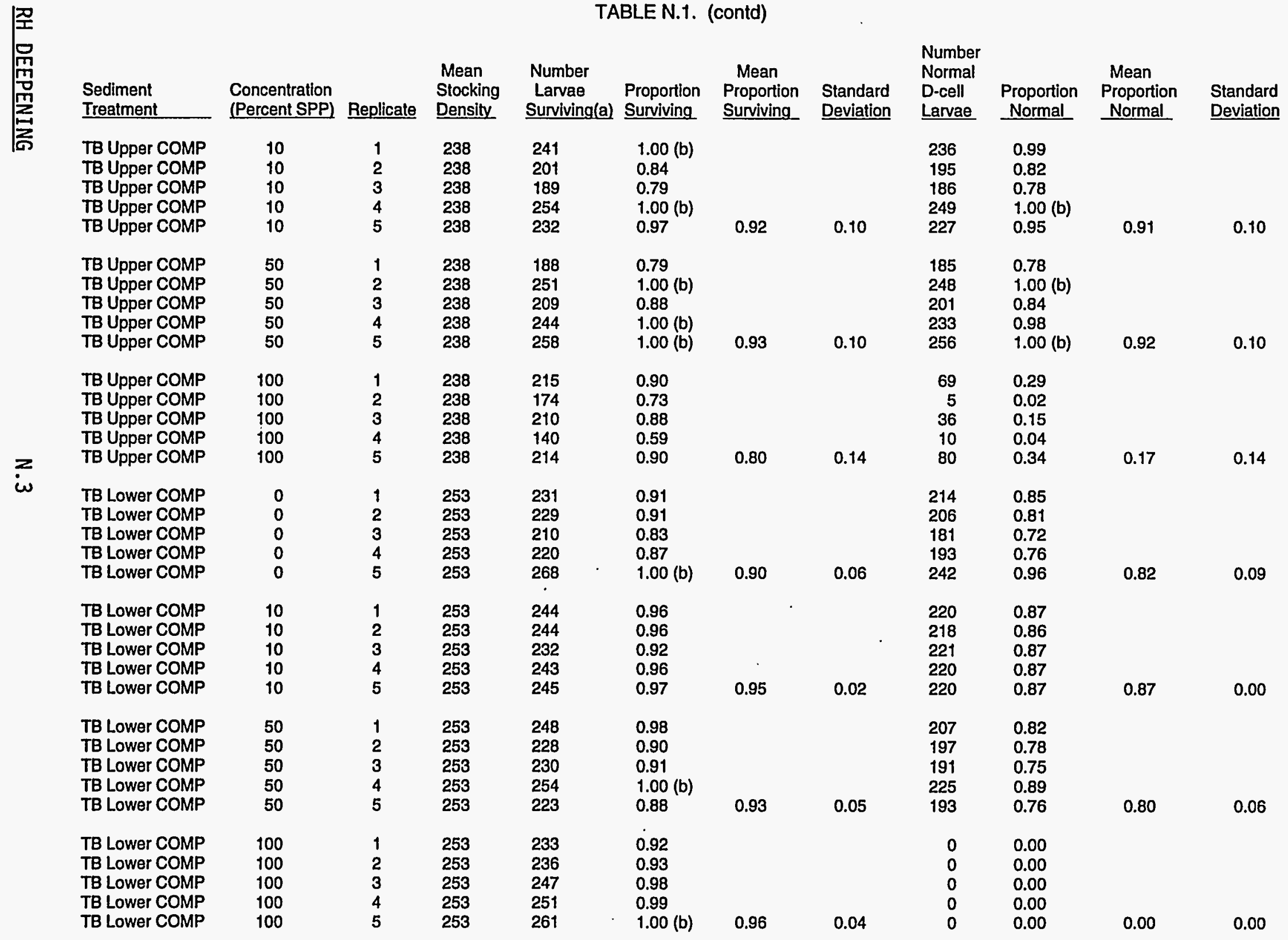




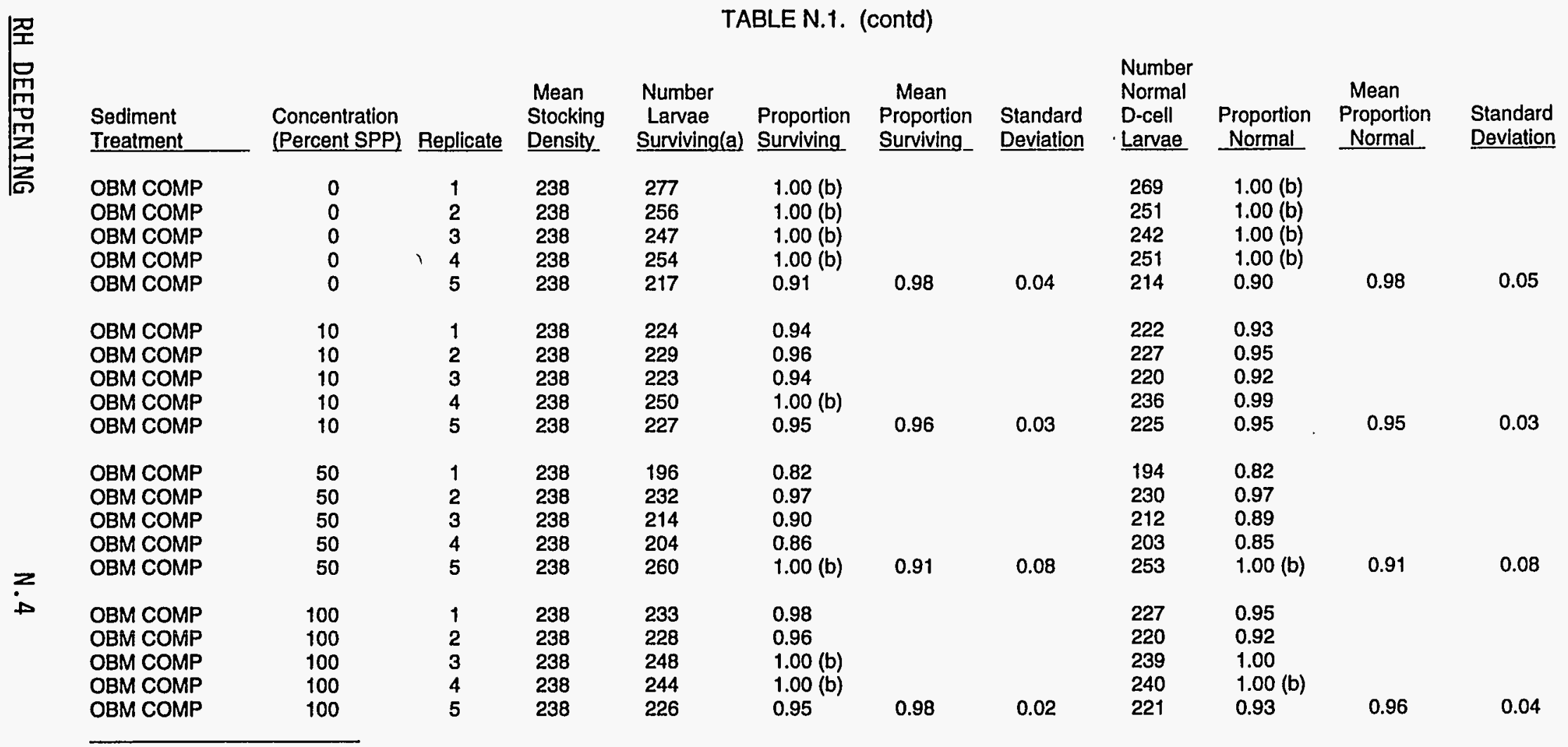

(a) Sum total of normal D-cell, abnormal D-cell, and developmentally delayed larvae.

(b) When number normal or number surviving exceeded the stocking density, a proportion normal and/or proportion survival of 1.00 was used for mean calculation and statistical analysis. 


\begin{tabular}{|c|c|c|c|c|c|c|c|c|c|c|c|}
\hline \multirow[t]{2}{*}{ 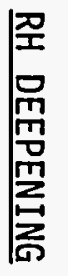 } & \multirow{2}{*}{$\begin{array}{l}\text { Sediment } \\
\text { Treatment }\end{array}$} & \multirow{2}{*}{$\begin{array}{l}\text { Concentration } \\
\text { (Percent SPP) }\end{array}$} & \multicolumn{2}{|c|}{$\begin{array}{c}\text { Temperature } \\
\text { ('C) }\end{array}$} & \multicolumn{2}{|c|}{$\mathrm{pH}$} & \multicolumn{2}{|c|}{$\begin{array}{c}\text { Dissolved } \\
\text { Oxygen } \\
\text { (mg/L) } \\
\end{array}$} & \multicolumn{2}{|c|}{$\begin{array}{l}\text { Salinity } \\
(0 / 00)\end{array}$} & \multirow{2}{*}{$\begin{array}{l}\begin{array}{c}\text { Ammonia } \\
\text { (mg/l) }\end{array} \\
\text { Average(a) }\end{array}$} \\
\hline & & & Min & $\operatorname{Max}$ & Min & Max & Min & Max & Min & Max & \\
\hline \multirow{8}{*}{ in } & $\begin{array}{l}\text { Acceptable } \\
\text { Range }\end{array}$ & & 14.0 & 18.0 & 7.30 & 8.30 & 4.0 & NA (b) & 28.0 & 32.0 & NE (c) \\
\hline & $\begin{array}{l}\text { SF COMP } \\
\text { SF COMP } \\
\text { SF COMP } \\
\text { SF COMP }\end{array}$ & $\begin{array}{r}0 \\
10 \\
50 \\
100\end{array}$ & $\begin{array}{l}15.4 \\
15.4 \\
15.4 \\
15.4\end{array}$ & $\begin{array}{l}15.6 \\
15.5 \\
15.6 \\
15.7\end{array}$ & $\begin{array}{l}7.75 \\
7.76 \\
7.79 \\
7.84\end{array}$ & $\begin{array}{l}8.05 \\
8.05 \\
8.06 \\
8.09\end{array}$ & $\begin{array}{l}7.2 \\
7.3 \\
7.0 \\
5.4\end{array}$ & $\begin{array}{l}8.2 \\
8.1 \\
8.0 \\
7.9\end{array}$ & $\begin{array}{l}32.0 \\
31.5 \\
30.5 \\
30.0\end{array}$ & $\begin{array}{l}32.0 \\
32.0 \\
32.0 \\
30.5\end{array}$ & $\begin{array}{l}1.23 \\
\text { NM (d) } \\
\cdot \mathrm{NM} \\
2.10\end{array}$ \\
\hline & $\begin{array}{l}\text { SFW COMP } \\
\text { SFW COMP } \\
\text { SFW COMP } \\
\text { SFW COMP }\end{array}$ & $\begin{array}{r}0 \\
10 \\
50 \\
100\end{array}$ & $\begin{array}{l}15.4 \\
15.4 \\
15.4 \\
15.4\end{array}$ & $\begin{array}{l}15.8 \\
15.9 \\
15.8 \\
15.9\end{array}$ & $\begin{array}{l}7.80 \\
7.84 \\
7.91 \\
7.94\end{array}$ & $\begin{array}{l}8.01 \\
7.99 \\
8.04 \\
8.04\end{array}$ & $\begin{array}{l}6.9 \\
6.8 \\
6.5 \\
4.9\end{array}$ & $\begin{array}{l}8.1 \\
8.1 \\
8.1 \\
8.1\end{array}$ & $\begin{array}{l}31.0 \\
31.0 \\
31.0 \\
30.5\end{array}$ & $\begin{array}{l}32.0 \\
32.0 \\
32.0 \\
32.0\end{array}$ & $\begin{array}{r}0.41 \\
\text { NM } \\
\text { NM } \\
5.08\end{array}$ \\
\hline & $\begin{array}{l}\text { UHH COMP } \\
\text { UIH COMP } \\
\text { UIH COMP } \\
\text { UIH COMP }\end{array}$ & $\begin{array}{r}0 \\
10 \\
50 \\
100\end{array}$ & $\begin{array}{l}15.4 \\
15.4 \\
15.4 \\
15.4\end{array}$ & $\begin{array}{l}15.8 \\
15.7 \\
15.7 \\
15.8\end{array}$ & $\begin{array}{l}7.45 \\
7.49 \\
7.38 \\
7.63\end{array}$ & $\begin{array}{l}8.01 \\
8.07 \\
8.13 \\
8.19\end{array}$ & $\begin{array}{l}6.8 \\
6.8 \\
6.7 \\
4.7\end{array}$ & $\begin{array}{l}8.0 \\
8.0 \\
8.0 \\
8.1\end{array}$ & $\begin{array}{l}31.5 \\
31.5 \\
31.0 \\
31.0\end{array}$ & $\begin{array}{l}32.0 \\
32.0 \\
32.0 \\
31.5\end{array}$ & $\begin{array}{r}0.409 \\
\text { NM } \\
\text { NM } \\
7.85\end{array}$ \\
\hline & $\begin{array}{l}\text { TB Upper COMP } \\
\text { TB Upper COMP } \\
\text { TB Upper COMP } \\
\text { TB Upper COMP }\end{array}$ & $\begin{array}{r}0 \\
10 \\
50 \\
100\end{array}$ & $\begin{array}{l}15.3 \\
15.3 \\
15.4 \\
15.3\end{array}$ & $\begin{array}{l}15.6 \\
15.5 \\
15.5 \\
15.5\end{array}$ & $\begin{array}{l}7.70 \\
7.76 \\
7.84 \\
7.90\end{array}$ & $\begin{array}{l}8.02 \\
8.07 \\
8.09 \\
8.17\end{array}$ & $\begin{array}{l}7.2 \\
7.2 \\
7.3 \\
6.4\end{array}$ & $\begin{array}{l}8.8 \\
8.5 \\
8.2 \\
8.1\end{array}$ & $\begin{array}{l}30.5 \\
30.5 \\
30.0 \\
30.0\end{array}$ & $\begin{array}{l}32.0 \\
32.0 \\
31.0 \\
30.0\end{array}$ & $\begin{array}{l}1.23 \\
\text { NM } \\
\text { NM } \\
3.47\end{array}$ \\
\hline & $\begin{array}{l}\text { TB Lower COMP } \\
\text { TB Lower COMP } \\
\text { TB Lower COMP } \\
\text { TB Lower COMP }\end{array}$ & $\begin{array}{r}0 \\
10 \\
50 \\
100\end{array}$ & $\begin{array}{l}15.4 \\
15.4 \\
15.4 \\
15.4\end{array}$ & $\begin{array}{l}15.8 \\
15.8 \\
15.8 \\
15.8\end{array}$ & $\begin{array}{l}7.76 \\
7.76 \\
7.90 \\
7.98\end{array}$ & $\begin{array}{l}8.06 \\
8.03 \\
8.02 \\
8.10\end{array}$ & $\begin{array}{l}6.9 \\
6.8 \\
6.9 \\
6.9\end{array}$ & $\begin{array}{l}8.3 \\
8.2 \\
8.2 \\
8.1\end{array}$ & $\begin{array}{l}32.0 \\
31.0 \\
30.5 \\
30.0\end{array}$ & $\begin{array}{l}32.0 \\
32.0 \\
32.0 \\
31.0\end{array}$ & $\begin{array}{l}0.41 \\
N M \\
N M \\
6.42\end{array}$ \\
\hline & $\begin{array}{l}\text { OBM COMP } \\
\text { OBM COMP } \\
\text { OBM COMP } \\
\text { OBM COMP }\end{array}$ & $\begin{array}{r}0 \\
10 \\
50 \\
100\end{array}$ & $\begin{array}{l}15.4 \\
15.3 \\
15.4 \\
15.4\end{array}$ & $\begin{array}{l}15.6 \\
15.7 \\
15.6 \\
15.6\end{array}$ & $\begin{array}{l}7.74 \\
7.77 \\
7.88 \\
7.88\end{array}$ & $\begin{array}{l}7.99 \\
8.03 \\
8.01 \\
8.09\end{array}$ & $\begin{array}{l}7.2 \\
7.2 \\
7.3 \\
7.2\end{array}$ & $\begin{array}{l}8.2 \\
8.3 \\
8.2 \\
8.4\end{array}$ & $\begin{array}{l}31.5 \\
31.0 \\
30.5 \\
30.0\end{array}$ & $\begin{array}{l}32.0 \\
32.0 \\
31.0 \\
30.0\end{array}$ & $\begin{array}{c}1.23 \\
\text { NM } \\
\text { NM } \\
1.95\end{array}$ \\
\hline & $\begin{array}{l}\text { (a) Average of ar } \\
\text { (b) NA Not appli } \\
\text { (c) NE Not estal } \\
\text { (d) NM Not mea }\end{array}$ & $\begin{array}{l}\text { onia measurer } \\
\text { e. } \\
\text { ed. } \\
\text { d. }\end{array}$ & & & & & & & & & \\
\hline
\end{tabular}




\begin{tabular}{|c|c|c|c|c|c|c|c|c|c|c|}
\hline $\begin{array}{c}\text { Copper } \\
\text { Concentration } \\
\text { ug/L }\end{array}$ & Replicate & $\begin{array}{l}\text { Mean } \\
\text { Stocking } \\
\text { Density }\end{array}$ & $\begin{array}{l}\text { Number } \\
\text { Lanvae } \\
\text { Surviving }\end{array}$ & $\begin{array}{l}\text { Proportion } \\
\text { Surviving }\end{array}$ & $\begin{array}{c}\text { Mean } \\
\text { Proportion } \\
\text { Surviving }\end{array}$ & $\begin{array}{l}\text { Standard } \\
\text { Deviation }\end{array}$ & $\begin{array}{l}\text { Number } \\
\text { Normal } \\
\text { D-cell } \\
\text { Larvae } \\
\end{array}$ & $\begin{array}{c}\text { Proportion } \\
\text { Normal }\end{array}$ & $\begin{array}{c}\text { Mean } \\
\text { Proportion } \\
\text { Normal }\end{array}$ & $\begin{array}{l}\text { Standard } \\
\text { Deviation }\end{array}$ \\
\hline \multicolumn{11}{|l|}{ Test 1} \\
\hline $\begin{array}{l}\text { Site water } \\
\text { Site water } \\
\text { Site water }\end{array}$ & $\begin{array}{l}1 \\
2 \\
3\end{array}$ & $\begin{array}{l}253 \\
253 \\
253\end{array}$ & $\begin{array}{l}228 \\
258 \\
233\end{array}$ & $\begin{array}{l}0.90 \\
1.00(a) \\
0.92\end{array}$ & 0.94 & 0.05 & $\begin{array}{l}222 \\
256 \\
223\end{array}$ & $\begin{array}{l}0.88 \\
1.00 \text { (a) } \\
0.88\end{array}$ & 0.92 & 0.07 \\
\hline $\begin{array}{l}\text { brine } \\
\text { brine } \\
\text { brine }\end{array}$ & $\begin{array}{l}1 \\
2 \\
3\end{array}$ & $\begin{array}{l}253 \\
253 \\
253\end{array}$ & $\begin{array}{l}281 \\
252 \\
235\end{array}$ & $\begin{array}{l}1.00(a) \\
1.00 \\
0.93\end{array}$ & 0.97 & 0.04 & $\begin{array}{l}252 \\
235 \\
211\end{array}$ & $\begin{array}{l}1.00 \\
0.93 \\
0.83\end{array}$ & 0.92 & 0.08 \\
\hline $\begin{array}{l}0.00 \\
0.00 \\
0.00\end{array}$ & $\begin{array}{l}1 \\
2 \\
3\end{array}$ & $\begin{array}{l}253 \\
253 \\
253\end{array}$ & $\begin{array}{l}\text { ND (b) } \\
312 \\
277\end{array}$ & $\begin{array}{l}\text { NA (c) } \\
1.00(a) \\
1.00(a)\end{array}$ & 1.00 & 0.00 & $\begin{array}{l}\text { ND } \\
279 \\
252\end{array}$ & $\begin{array}{l}\text { NA } \\
1.00 \text { (a) } \\
1.00\end{array}$ & 0.67 & 0.00 \\
\hline $\begin{array}{l}1.00 \\
1.00 \\
1.00\end{array}$ & $\begin{array}{l}1 \\
2 \\
3\end{array}$ & $\begin{array}{l}253 \\
253 \\
253\end{array}$ & $\begin{array}{l}245 \\
196 \\
206\end{array}$ & $\begin{array}{l}0.97 \\
0.77 \\
0.81\end{array}$ & 0.85 & 0.10 & $\begin{array}{l}224 \\
182 \\
181\end{array}$ & $\begin{array}{l}0.89 \\
0.72 \\
0.72\end{array}$ & 0.77 & 0.10 \\
\hline $\begin{array}{l}4.00 \\
4.00\end{array}$ & $\begin{array}{l}1 \\
2\end{array}$ & $\begin{array}{l}253 \\
253\end{array}$ & $\begin{array}{l}257 \\
244\end{array}$ & $\begin{array}{l}1.00(a) \\
0.96\end{array}$ & & & $\begin{array}{l}221 \\
205\end{array}$ & $\begin{array}{l}0.87 \\
0.81\end{array}$ & & \\
\hline 4.00 & 3 & 253 & 237 & 0.94 & 0.97 & 0.03 & 195 & 0.77 & 0.82 & 0.05 \\
\hline 16.0 & 1 & 253 & 162 & 0.64 & & & 0 & 0.00 & & \\
\hline 16.0 & 2 & 253 & 202 & 0.80 & & & 0 & 0.00 & & \\
\hline 16.0 & 3 & 253 & 81 & 0.32 & 0.59 & 0.24 & 0 & 0.00 & 0.00 & 0.00 \\
\hline $\begin{array}{l}64.0 \\
64.0 \\
64.0\end{array}$ & $\begin{array}{l}1 \\
2 \\
3\end{array}$ & $\begin{array}{l}253 \\
253 \\
253\end{array}$ & $\begin{array}{l}44 \\
15 \\
39\end{array}$ & $\begin{array}{l}0.17 \\
0.06 \\
0.15\end{array}$ & 0.13 & 0.06 & $\begin{array}{l}0 \\
0 \\
0\end{array}$ & $\begin{array}{l}0.00 \\
0.00 \\
0.00\end{array}$ & 0.00 & 0.00 \\
\hline
\end{tabular}




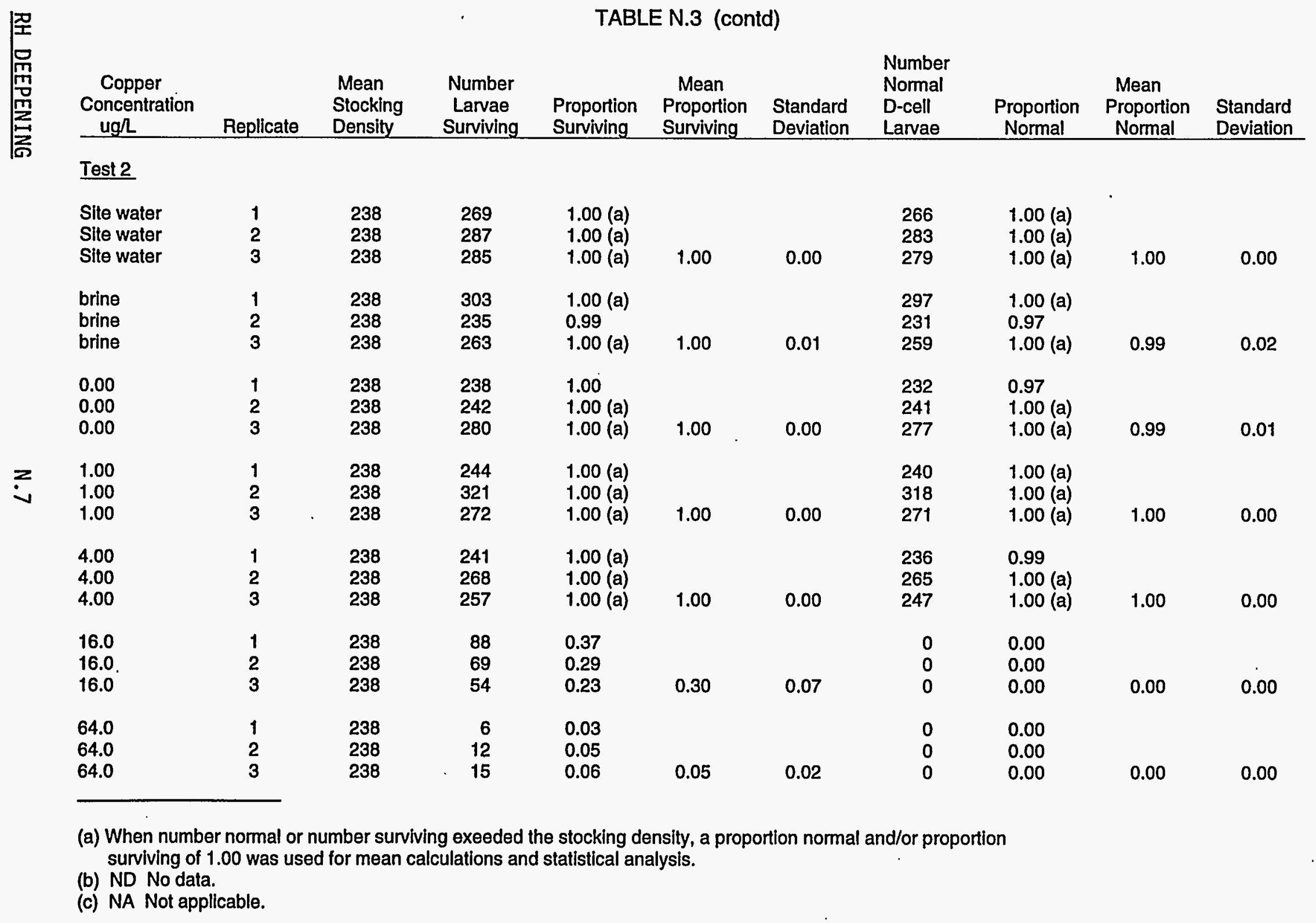


TABLE N.4. Water Quality Summary for 48-Hour Larval M. galloprovincialis Copper Reference Toxicant Test, Richmond Harbor Deepening Project

\begin{tabular}{|c|c|c|c|c|c|c|c|c|}
\hline \multirow{2}{*}{$\begin{array}{l}\text { Copper } \\
\text { Concentration } \\
\text { (ug/L) }\end{array}$} & \multicolumn{2}{|c|}{$\begin{array}{c}\text { Temperature } \\
\text { ("C) }\end{array}$} & \multicolumn{4}{|c|}{$\begin{array}{c}\text { Dissolved } \\
\text { Oxygen } \\
\text { (mg/L) }\end{array}$} & \multicolumn{2}{|c|}{$\begin{array}{c}\text { Salinity } \\
(0 / 00)\end{array}$} \\
\hline & Min & Max & Min & Max & Min & Max & Min & $\operatorname{Max}$ \\
\hline \multicolumn{8}{|l|}{ Acceptable } & 32.0 \\
\hline \multicolumn{9}{|l|}{ Test 1} \\
\hline Site water & 15.5 & 15.9 & 7.88 & 7.95 & 8.0 & 8.7 & 29.5 & 30.0 \\
\hline brine & 15.4 & 15.8 & 7.83 & 7.97 & 6.9 & 7.9 & 30.0 & 32.0 \\
\hline 0.0 & 15.5 & 15.8 & 7.70 & 7.86 & 6.8 & 7.9 & 31.0 & 32.0 \\
\hline 1.00 & 15.4 & 15.7 & 7.77 & 7.89 & 6.9 & 7.9 & 31.0 & 32.0 \\
\hline 4.00 & 15.4 & 15.7 & 7.79 & 7.91 & 6.9 & 7.7 & 31.0 & 31.5 \\
\hline 16.0 & 15.4 & 15.7 & 7.82 & 7.92 & 6.9 & 8.0 & 31.0 & 31.5 \\
\hline 64.0 & 15.4 & 15.8 & 7.81 & 7.94 & 6.9 & 7.9 & 30.5 & 31.0 \\
\hline
\end{tabular}

Test 2

$\begin{array}{lllllllll}\text { Site water } & 15.4 & 15.5 & 7.75 & 7.83 & 7.2 & 7.9 & 30.0 & 30.0 \\ \text { brine } & 15.4 & 15.7 & 7.75 & 7.79 & 6.9 & 7.5 & 30.0 & 31.5 \\ & & & & & & & & \\ 0.0 & 15.4 & 15.5 & 7.72 & 7.89 & 6.9 & 7.5 & 31.5 & 32.0 \\ 1.00 & 15.4 & 15.5 & 7.72 & 7.94 & 7.0 & 7.6 & 31.5 & 32.0 \\ 4.00 & 15.4 & 15.5 & 7.71 & 7.95 & 7.1 & 7.6 & 31.5 & 32.0 \\ 16.0 & 15.4 & 15.5 & 7.71 & 7.96 & 7.0 & 7.5 & 31.5 & 32.0 \\ 64.0 & 15.4 & 15.5 & 7.70 & 7.97 & 7.0 & 7.5 & 31.5 & 32.0\end{array}$

(a) NA Not applicable. 
TABLE N.5. Test Results for 48-Hour Larval M. galloprovincialis Ammonia Reference Toxicant Test, Richmond Harbor Deepening Project

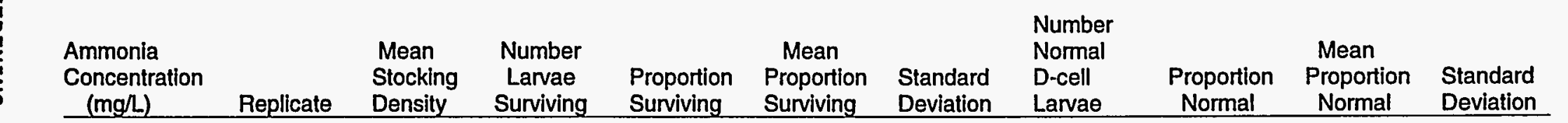

\section{Test 1}

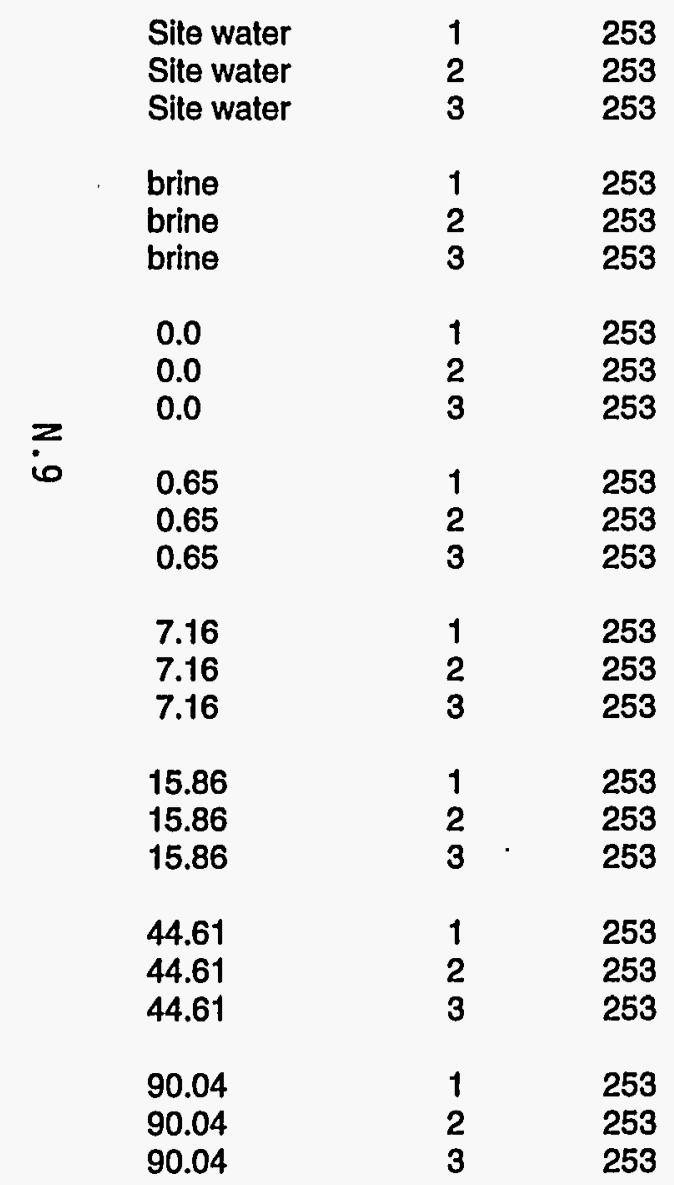

\begin{tabular}{|c|c|c|c|}
\hline $\begin{array}{l}228 \\
258 \\
233\end{array}$ & $\begin{array}{l}0.90 \\
1.00 \text { (a) } \\
0.92\end{array}$ & 0.94 & 0.05 \\
\hline $\begin{array}{l}281 \\
252 \\
235\end{array}$ & $\begin{array}{l}1.00(a) \\
1.00 \\
0.93\end{array}$ & 0.97 & 0.04 \\
\hline $\begin{array}{l}\text { ND (b) } \\
312 \\
277\end{array}$ & $\begin{array}{r}\text { NA (c) } \\
1.00 \text { (a) } \\
1.00 \text { (a) }\end{array}$ & 1.00 & 0.00 \\
\hline $\begin{array}{l}316 \\
264 \\
238\end{array}$ & $\begin{array}{l}1.00(a) \\
1.00(a) \\
0.94\end{array}$ & 0.98 & 0.03 \\
\hline $\begin{array}{l}295 \\
277 \\
252\end{array}$ & $\begin{array}{l}1.00(a) \\
1.00(a) \\
1.00\end{array}$ & 1.00 & 0.00 \\
\hline $\begin{array}{l}262 \\
230 \\
237\end{array}$ & $\begin{array}{l}1.00 \text { (a) } \\
0.91 \\
0.94\end{array}$ & 0.95 & 0.05 \\
\hline $\begin{array}{l}245 \\
223 \\
210\end{array}$ & $\begin{array}{l}0.97 \\
0.88 \\
0.83\end{array}$ & 0.89 & 0.07 \\
\hline $\begin{array}{l}32 \\
14 \\
24\end{array}$ & $\begin{array}{l}0.13 \\
0.06 \\
0.09\end{array}$ & 0.09 & 0.04 \\
\hline
\end{tabular}

\begin{tabular}{|c|c|c|c|}
\hline $\begin{array}{l}222 \\
256 \\
223\end{array}$ & $\begin{array}{l}0.88 \\
1.00 \text { (a) } \\
0.88\end{array}$ & 0.92 & 0.07 \\
\hline 252 & 1.00 & & \\
\hline 235 & 0.93 & & \\
\hline 211 & 0.83 & 0.92 & 0.08 \\
\hline ND & NA & & \\
\hline 279 & 1.00 (a) & & \\
\hline 252 & 1.00 & 0.67 & 0.00 \\
\hline 292 & 1.00 (a) & & \\
\hline 251 & 0.99 & & \\
\hline 223 & 0.88 & 0.96 & 0.07 \\
\hline 17 & 0.07 & & \\
\hline 6 & 0.02 & & \\
\hline 27 & 0.11 & 0.07 & 0.04 \\
\hline 0 & 0.00 & & \\
\hline 0 & 0.00 & & \\
\hline 0 & 0.00 & 0.00 & 0.00 \\
\hline 0 & 0.00 & & \\
\hline 0 & 0.00 & & \\
\hline 0 & 0.00 & 0.00 & 0.00 \\
\hline 0 & 0.00 & & \\
\hline 0 & 0.00 & & \\
\hline 0 & 0.00 & 0.00 & 0.00 \\
\hline
\end{tabular}


TABLE N.5. (contd)

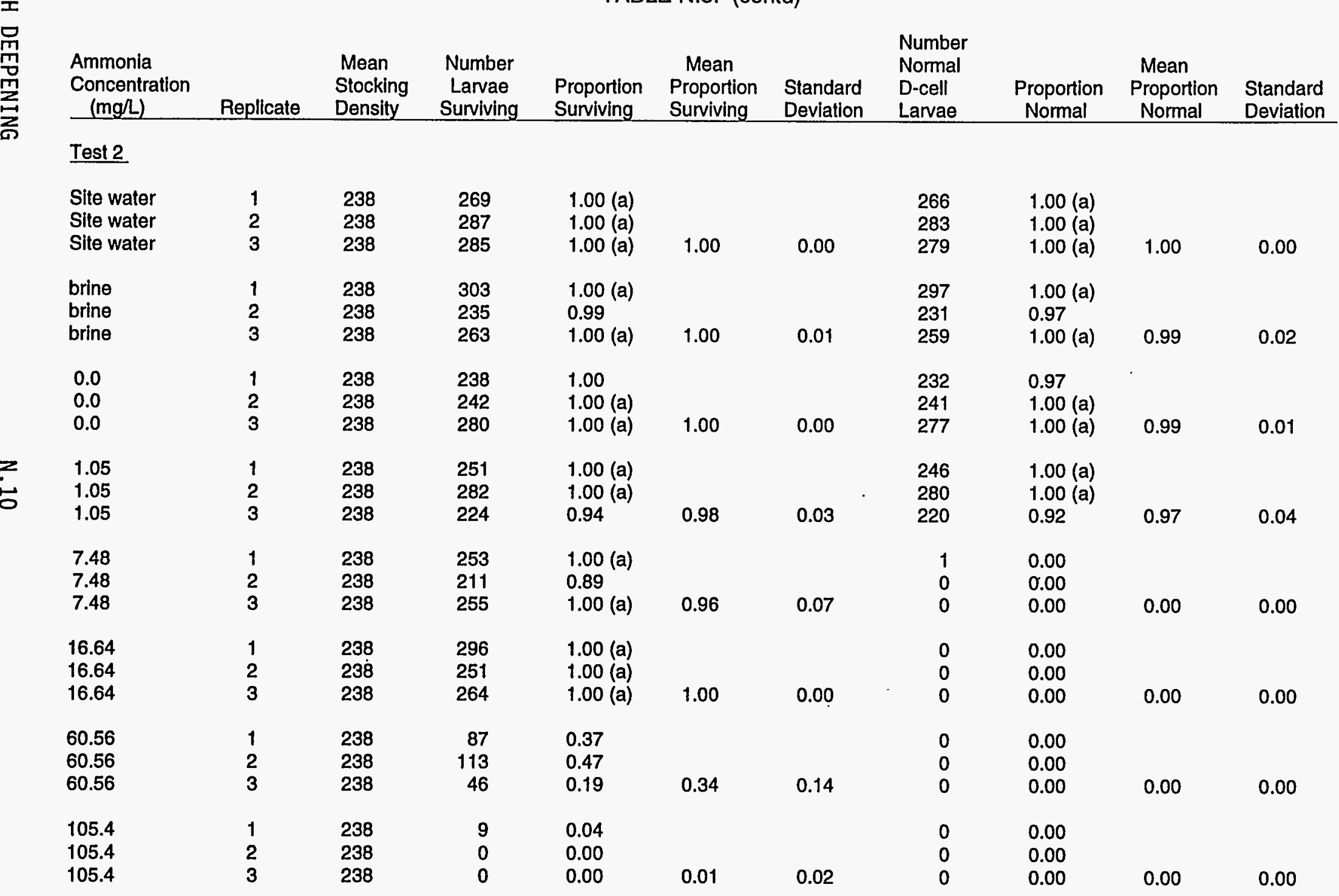

(a) When number normal or number surviving exeeded the stocking density, a proportion normal and/or proportion surviving of 1.00 was used for mean calculations and statistical analysis. 
TABLE N.6. Water Quality Summary for 48-Hour Larval M. galloprovincialis Ammonia Reference Toxicant Test, Richmond Harbor Deepening Project

\begin{tabular}{|c|c|c|c|c|c|c|c|c|c|c|}
\hline \multirow{2}{*}{$\begin{array}{l}\text { Ammonia } \\
\text { Concentration } \\
\text { (mg/L) }\end{array}$} & \multicolumn{2}{|c|}{$\begin{array}{c}\text { Temperature } \\
\text { ("C) }\end{array}$} & \multicolumn{4}{|c|}{$\begin{array}{c}\text { Dissolved } \\
\text { Oxygen } \\
\text { (mg/L) }\end{array}$} & \multicolumn{2}{|c|}{$\begin{array}{l}\text { Salinity } \\
(0 / 00)\end{array}$} & \multicolumn{2}{|c|}{$\begin{array}{c}\text { Ammonia } \\
(\mathrm{mg} / \mathrm{L})\end{array}$} \\
\hline & Min & Max & Min & Max & Min & Max & Min & Max & Min & Max \\
\hline \multicolumn{11}{|l|}{ Acceptable } \\
\hline Range & 14.0 & 18.0 & 7.30 & 8.30 & 4.0 & NA (a) & 28.0 & 32.0 & NE (b) & NE \\
\hline \multicolumn{11}{|l|}{ Test 1} \\
\hline Site water & 15.5 & 15.9 & 7.88 & 7.95 & 8.0 & 8.7 & 29.5 & 30.0 & NM (c) & NM \\
\hline brine & 15.4 & 15.8 & 7.83 & 7.97 & 6.9 & 7.9 & 30.0 & 32.0 & NM & NM \\
\hline 0.0 & 15.5 & 15.8 & 7.70 & 7.86 & 6.8 & 7.9 & 31.0 & 32.0 & NM & NM \\
\hline 0.65 & 15.4 & 15.7 & 7.79 & 7.89 & 6.8 & 8.2 & 31.0 & 32.0 & 0.203 & 1.17 \\
\hline 7.16 & 15.5 & 15.7 & 7.72 & 7.83 & 6.9 & 7.9 & 31.0 & 32.0 & 4.00 & 9.75 \\
\hline 15.86 & 15.4 & 15.7 & 7.72 & 7.81 & 6.9 & 8.0 & 31.0 & 32.0 & 8.30 & 20.4 \\
\hline 44.61 & 15.5 & 15.7 & 7.61 & 7.79 & 6.9 & 8.0 & 31.0 & 32.0 & 18.8 & 66.8 \\
\hline 90.04 & 15.4 & 15.7 & 7.56 & 7.77 & 6.9 & 8.0 & 31.0 & 32.0 & 69.1 & 108 \\
\hline
\end{tabular}

Test 2

$\begin{array}{lrlllllllll}\text { Site water } & 15.4 & 15.5 & 7.75 & 7.83 & 7.2 & 7.9 & 30.0 & 30.0 & \text { NM } & \text { NM } \\ \text { brine } & 15.4 & 15.8 & 7.83 & 7.97 & 6.9 & 7.9 & 30.0 & 32.0 & \text { NM } & \text { NM } \\ & & & & & & & & & & \\ 0.0 & 15.5 & 15.8 & 7.70 & 7.86 & 6.8 & 7.9 & 31.0 & 32.0 & \text { NM } & \text { NM } \\ 1.05 & 15.4 & 15.5 & 7.68 & 7.84 & 7.2 & 8.0 & 31.5 & 32.0 & 0.80 & 1.90 \\ 7.48 & 15.4 & 15.4 & 7.64 & 7.85 & 7.2 & 8.0 & 31.0 & 32.0 & 6.6 & 9.66 \\ 16.64 & 15.3 & 15.5 & 7.65 & 7.86 & 7.2 & 7.9 & 30.0 & 31.0 & 14 & 20.9 \\ 60.56 & 15.4 & 15.5 & 7.57 & 7.85 & 7.2 & 8.0 & 28.5 & 30.0 & 46 & 80.7 \\ 105.4 & 15.4 & 15.5 & 7.48 & 7.78 & 7.2 & 8.0 & 28.0 & 28.0 & 89 & 123\end{array}$

(a) NA Not applicable.

(b) NE Not established.

(c) NM Not measured. 
APPENDIX 0

IISSUE CHEMISTRY AND QUALITY ASSURANCE DATA FOR MACOMA nasuta 


\section{QA/QC SUMMARY}
PROGRAM:
PARAMETER:
Richmond Harbor Deepening Project
LABORATORY:
MATRIX: Polynuclear Aromatic Hydrocarbons (PAH) and Phthalates Battelle/Marine Sciences Laboratory, Sequim, Washington Tissue

QA/QC DATA QUALITY OBJECTIVES

$\begin{array}{cccc}\begin{array}{c}\text { Reference } \\ \text { Method }\end{array} & \begin{array}{c}\text { Range of } \\ \text { Recovery }\end{array} & \begin{array}{c}\text { Relative } \\ \text { Precision }\end{array} & \begin{array}{c}\text { Detection } \\ \text { Limit (dry wt) }\end{array} \\ \text { GC/MS } & 40-120 \% & \leq 30 \% & 20 \mu \mathrm{g} / \mathrm{kg}\end{array}$

METHOD

HOLDING TIMES
Tissue samples were extracted with methylene chloride using a roller under ambient conditions following SOP MSL-042, "Extraction and Clean-up of Sediment and Tissue for Semivolatile Organics," which is based on methods used by the National Oceanic and Atmospheric Administration for their Status and Trends Program (Krahn et al. 1988). Samples were then cleaned using silica/alumina chromatography followed by HPLC cleanup. The following modifications in the extraction and clean-up methods were required to adequately recover the phthalate compounds: twice the usual amount of methylene chloride was used in the extraction, and $4 \%$ rather than $2 \%$ deactivated silica was used. Extracts were quantified using gas chromatography/mass spectrometry (GC/MS) in the selected ion mode (SIM) following SOP MSL-M-043, "Identification and Quantification of Polynuclear Aromatic Hydrocarbons by GC/MS," which is based on EPA method 8270 (EPA 1986).

Ninety-nine (99) samples were received on 3/21/94 in good condition. Samples were logged into Battelle's log-in system and stored at approximately $-20^{\circ} \mathrm{C}$ until extraction. The following summarizes the extraction dates and GC/MS/SIM analysis dates:

\begin{tabular}{|c|c|c|}
\hline Batch & Extraction & Analysis \\
\hline $\begin{array}{l}\text { Batch } 1 \\
\text { Batch } 2 \\
\text { Batch } 3 \\
\text { Batch } 4 \\
\text { Batch } 5 \\
\text { Batch } 6\end{array}$ & $\begin{array}{l}3 / 30 / 94 \\
4 / 14 / 94 \\
4 / 26 / 94 \\
5 / 6 / 94 \\
5 / 20 / 94 \\
5 / 20 / 94\end{array}$ & $\begin{array}{l}4 / 22-26 / 94 \\
4 / 28-30 / 94 \\
5 / 10-12 / 94 \\
5 / 24-26 / 94 \\
5 / 26-28 / 94 \\
5 / 26-28 / 94\end{array}$ \\
\hline
\end{tabular}

Target detection limits of $20 \mu \mathrm{g} / \mathrm{kg}$ wet wt were met for all PAH compounds. Achieved detection limits for PAHs were determined by multiplying the standard deviation of 7 spiked replicates by the student $\mathrm{t}$ value. Achieved detection limits for phthalates ranged from $19.2 \mu \mathrm{g} / \mathrm{kg}$ to $80 \mu \mathrm{g} / \mathrm{kg}$. The target detection limits were $20 \mu \mathrm{g} / \mathrm{kg}$. Detection limits for phthalates were derived from the lowest calibration standard. 


\section{QA/QC SUMMARY (continued)}

METHOD BLANKS

SURROGATES

MATRIX SPIKES

REPLICATES

MISC.
One method blank was extracted with each batch of samples. No compounds were detected in the method blanks at concentrations greater than 5 times the method detection limit. Any sample values that were less than 5 times the value in the associated method blank were flagged with a " $B$ ".

Five isotopically labelled compounds were added prior to extraction to assess the efficiency of the method. These were d8-naphthalene, d8acenaphthene, d12-chrysene, d10-pyrene and d14-

dibenzo( $a, h)$ anthracene. Recoveries of all surrogates were within the quality control limits of $40 \%-120 \%$ with the exception of d14-

dibenzo(a,h)anthracene in the method blank for Batch 1 , with a recovery of $33 \%$.

One sample from each batch was spiked with all PAH and phthalate compounds. Matrix spike recoveries for PAHs were within the QC criteria of $40 \%-120 \%$ with the following exceptions:

benzo $(\mathrm{g}, \mathrm{h}, \mathrm{i})$ perylene in Batch $3(125 \%)$, and benzo(b)fluoranthene $(123 \%)$ and benzo(k)fluoranthene $(121 \%)$ in Batch 5 . Phthalate recoveries were within QC criteria with the following exceptions: di-noctyl phthalate in all batches except Batch 3 (greater than 120\%), bis(2-ethylhexyl)phthalate in Batch 1 (122\%), and dimethyl- and diethylphthalate in Batch 2 (less than $40 \%$ ).

One sample from each batch was extracted and analyzed in triplicate. Precision was measured by calculating the relative standard deviation (RSD) between the replicate results. The RSDs were within the QC criteria of $\leq 30 \%$ for analytes greater than 10 times the MDL.

Samples TB Lower COMP Rep. 5 for both $M$. nasuta and $N$. virens were re-extracted and re-analyzed because the initial results showed unusually high concentrations of bis(2-ethylhexyl)phthalate. The results of the re-analyses are reported.

Some of the sample results are flagged to indicate that the confirmation ion ratio for that compound was outside of the QC range. This is due to a combination of two factors: low levels of the compound of interest, and interferences resulting from the modified cleanup method. Because the confirmation ion is present at only a fraction of the level of the parent ion, when the native level of the compound is low, the amount of error in the concentration measurement of the confirmation ion goes up. The compound is actually quantified from the parent ion only, so most likely this will not effect the quality of the data.

\section{REFERENCES}

Krahn, M. M., C. A. Wigren, R. W. Pearch, L. K. Moore, R. G. Bogar, W. D. MacLeod, Jr., S. L. Chan, and D. W. Brown. 1988. "A Rapid High-Performance Liquid Chromatographic Method for Isolating Organic Contaminants from Tissue and Sediment Extracts." NOAA Technical Memorandum NMFS F/NWC-153, Silver Spring, Maryland.

U.S. Environmental Protection Agency (EPA). 1986. Test Methods for Evaluating Solid Waste: Physical/Chemical Methods. SW-846. U.S. Document No. 955-001-00000, USEPA, Washington D.C. 


\title{
QA/QC SUMMARY
}

\author{
PROGRAM: Richmond Harbor Deepening Project \\ PARAMETER: Chlorinated Pesticides and PCBS \\ LABORATORY: Battelle/Marine Sciences Laboratory, Sequim, Washington \\ MATRIX: \\ Tissue
}

QA/QC DATA QUALITY OBJECTIVES

$\begin{array}{cccc}\begin{array}{c}\text { Reference } \\ \text { Method }\end{array} & \begin{array}{c}\text { Range of } \\ \text { Recovery }\end{array} & \begin{array}{c}\text { Relative } \\ \text { Precision }\end{array} & \begin{array}{c}\text { Detection } \\ \text { Limit (wet wt) }\end{array} \\ \text { GC/ECD } & 40-120 \% & \leq 30 \% & 2.0-30 \mu \mathrm{g} / \mathrm{kg}\end{array}$

METHOD

HOLDING TIMES

DETECTION LIMITS

METHOD BLANKS
Tissue samples were extracted with methylene chloride using a roller under ambient conditions following SOP MSL-M-079, "Extraction and Clean-up of Sediment and Tissue for Semivolatile Organics following the Surrogate Intemal Standard Method" based on EPA method 3510 and 8080 (EPA 1986) and NOAA status and trends methods (Krahn et al. 1988). Samples were then cleaned using silica/alumina chromatography followed by HPLC cleanup (Krahn et al. 1988). The following modifications in the clean-up method were required to adequately recover the phthalate compounds: twice the usual amount of methylene chloride was used in the extraction, and $4 \%$ rather than $2 \%$ deactivated silica was used. Extracts were analyzed using Gas Chromatography/ Electron Capture Detection (GC/ECD) following SOP MSL-M-044, "Analysis of PCBs and Chlorinated Pesticides by GC/ECD" based on EPA method 8080 (1986). The column used was a J\&W DB-17 and the confirmatory column was a DB-1701, both capillary columns ( $30 \mathrm{~m} \times 0.25 \mathrm{~mm}$ l.D.).

One hundred four (104) samples were received on 3/21/94 in good condition. Samples were logged into Battelle's log-in system and stored at approximately $-20^{\circ} \mathrm{C}$ until extraction. The following summarizes the extraction dates and GC/ECD analysis dates:

$\begin{array}{lll}\text { Batch } & \text { Extraction } & \text { Analysis } \\ \text { Batch 1 } & 3 / 30 / 94 & 4 / 22-26 / 94 \\ \text { Batch 2 } & 4 / 14 / 94 & 4 / 28-30 / 94 \\ \text { Batch 3 } & 4 / 26 / 94 & 5 / 10-12 / 94 \\ \text { Batch 4 } & 5 / 6 / 94 & 5 / 21-24 / 94 \\ \text { Batch 5 } & 5 / 20 / 94 & 6 / 2-6 / 94 \\ \text { Batch 6 } & 5 / 20 / 94 & 6 / 2-6 / 94\end{array}$

Target detection limits were met for all samples. Detection limits reported are based on an MDL study involving low level spikes of 7 replicate extractions. MDLs are defined as the standard deviation of the mean recovery multiplied by the student $t$ value.

One method blank was extracted with the batch of samples. No pesticides or PCBs were detected in the blanks at concentrations exceeding the QC limit of 5 times the detection limit. 


\section{QA/QC SUMMARY (continued)}

\section{SURROGATES}

MATRIX SPIKES

REPLICATES
Two compounds, PCB congeners 103 and 198, were added to all samples prior to extraction to assess the efficiency of the analysis. These compounds are also used to correct all sample results and are considered surrogate internal standards (SIS). Recoveries of these compounds were within the QC guidelines of $40-120 \%$ for all samples analyzed.

One sample from each batch was spiked with a subset of 6 pesticides and Aroclor 1254. Matrix spike recoveries were within the QC limits of $40 \%-120 \%$ with the exception of DDT in Batch $1(130 \%)$.

One sample from each batch was extracted in triplicate. Precision was measured by calculating the relative standard deviation (RSD) between the replicate results. RSDs were less than the QC limit of $30 \%$.

SRMS

NA

\section{REFERENCES}

Krahn, M. M., C. A. Wigren, R. W. Pearch, L. K. Moore, R. G. Bogar, W. D. MacLeod, Jr., S. L. Chan, and D. W. Brown. 1988. "A Rapid High-Performance Liquid Chromatographic Method for Isolating Organic Contaminants from Tissue and Sediment Extracts." NOAA Technical Memorandum NMFS F/NWC-153, Silver Spring, Maryland.

U.S. Environmental Protection Agency (EPA). 1986. Test Methods for Evaluating Solid Waste: Physical/Chemical Methods. SW-846. U.S. Document No. 955-001-00000, USEPA, Washington D.C. 


\title{
QA/QC SUMMARY
}

\author{
PROGRAM: $\quad$ Richmond Harbor Deepening Project \\ PARAMETER: Metals \\ LABORATORY: Battelle/Marine Sciences Laboratory, Sequim, Washington \\ MATRIX: Tissue
}

\section{SAMPLE CUSTODY}

Ninety nine samples (49 N. virens and $50 \mathrm{M}$. nasuta tissue samples) were received on 3/21/94 in good condition. Samples and were logged into Battelle's log-in system.

\section{QA/QC DATA QUALITY OBJECTIVES}

\begin{tabular}{|c|c|c|c|c|c|}
\hline & $\begin{array}{c}\text { Reference } \\
\text { Method } \\
\end{array}$ & $\begin{array}{l}\text { Range of } \\
\text { Recovery }\end{array}$ & $\begin{array}{c}\text { SRM } \\
\text { Accuracy }\end{array}$ & $\begin{array}{l}\text { Relative } \\
\text { Precision } \\
\end{array}$ & $\begin{array}{c}\text { Detection } \\
\text { Limit } \\
\text { (mg/kg wet wt) }\end{array}$ \\
\hline $\begin{array}{l}\text { Arsenic } \\
\text { Cadmium } \\
\text { Chromium } \\
\text { Copper } \\
\text { Lead } \\
\text { Mercury } \\
\text { Nickel } \\
\text { Selenium } \\
\text { Silver } \\
\text { Zinc }\end{array}$ & $\begin{array}{l}\text { ICP/MS } \\
\text { ICP/MS } \\
\text { ICP/MS } \\
\text { ICP/MS } \\
\text { ICP/MS } \\
\text { CCVAA } \\
\text { ICP/MS } \\
\text { GFAA } \\
\text { ICP/MS } \\
\text { ICP/MS }\end{array}$ & $\begin{array}{l}75 \%-125 \% \\
75 \%-125 \% \\
75 \%-125 \% \\
75 \%-125 \% \\
75 \%-125 \% \\
75 \%-125 \% \\
75 \%-125 \% \\
75 \%-125 \% \\
75 \%-125 \% \\
75 \%-125 \%\end{array}$ & $\begin{array}{l}\leq 30 \% \\
\leq 30 \% \\
\leq 30 \% \\
\leq 30 \% \\
\leq 30 \% \\
\leq 30 \% \\
\leq 30 \% \\
\leq 30 \% \\
\leq 30 \% \\
\leq 30 \%\end{array}$ & $\begin{array}{l}\leq 20 \% \\
\leq 20 \% \\
\leq 20 \% \\
\leq 20 \% \\
\leq 20 \% \\
\leq 20 \% \\
\leq 20 \% \\
\leq 20 \% \\
\leq 20 \% \\
\leq 20 \%\end{array}$ & $\begin{array}{l}2.0 \\
0.1 \\
1.0 \\
4.3 \\
1.0 \\
0.02 \\
1.0 \\
1.0 \\
0.1 \\
35\end{array}$ \\
\hline
\end{tabular}

METHOD

A total of 10 metals were analyzed for the Richmond Harbor Deepening Project: silver (Ag), arsenic (As), cadmium (Cd), chromium ( $\mathrm{Cr}$ ), copper (Cu), mercury ( $\mathrm{Hg}$ ), nickel $(\mathrm{Ni})$, lead $(\mathrm{Pb})$, selenium ( $\mathrm{Se}$ ) and zinc $(\mathrm{Zn})$. Eight metals (As, $\mathrm{Cd}, \mathrm{Cr}, \mathrm{Cu}$, $\mathrm{Pb}, \mathrm{Ni}, \mathrm{Ag}$, and $\mathrm{Zn}$ ) were analyzed by inductively coupled plasma/mass spectrometry (ICP/MS) following EPA Method 200.8 (EPA 1991). One metal (Se) was analyzed using Zeeman Graphite Fumace Atomic Absorption (GFAA) spectrometry following SOP MSL-M-033, Trace Elements in Sediment in Tissue by Graphite Furnace Atomic Absorption, which is based on EPA Method 200.9 (EPA 1991). Mercury was analyzed using cold-vapor atomic absorption spectroscopy (CVAA) according to the method of Bloom and Crecelius (1983).

To prepare tissues for analysis, samples were freeze-dried and blended in a Spex mixer-mill. Approximately $5 \mathrm{~g}$ of mixed sample was ground in a ceramic ball mill. For ICP/MS and CVAA analyses, $0.2-$ to $0.5-\mathrm{g}$ aliquots of dried homogenous sample were digested using a mixture of nitric, perchloric and hydrofluoric acids.

\section{HOLDING TIMES}

Upon receipt, samples were frozen to $-80^{\circ} \mathrm{C}$ and subsequently freeze-dried within approximately 14 days of sample receipt. All samples were analyzed within 180 days of sample receipt with the exception of $\mathrm{Hg}$, which was analyzed within 30 days of receipt. Analysis dates are summarized in the following table: 
QAVC SUMMARY (continued)

\begin{tabular}{lcc} 
Task & Batch 1 (Worms) & Batch 2 (Clams) \\
\cline { 2 - 3 } Sample Digestion & $4 / 6 / 94$ & $4 / 11 / 94$ \\
GFAASSe & $5 / 18-20 / 94$ & $5 / 20-23 / 94$ \\
CVAA-Hg & $4 / 12-13 / 94$ & $4 / 13-14 / 94$ \\
ICP/MS & $4 / 20 / 94$ & $4 / 21 / 94$ \\
ICP/MS, 715RHI-16 rerun & $\mathrm{NA}$ & $6 / 2 / 94$
\end{tabular}

Two samples (N. virens SFW COMP Rep 4 and $N$. virens background rep. 4) were reanalyzed for ICP. metals because the initial results for some metals were unusually high. The reanalysis of the background sample confirmed the initial results, and the initial results were reported. The results of the reanalysis of SFW COMP rep. 4 were lower than the initial values for selected metals, and consistent with the other tissues; therefore, the results of the reanalysis are reported.

\section{DETECTION LIMITS}

Target detection limits were met for all metals except As and $\mathrm{Zn}$. Achieved detection limits for As and $\mathrm{Zn}$ were higher than the target detection limits; however, these metals were detected in all of the samples. ICP/MS detection limits were determined by multiplying the standard deviation of 8 blank spike samples by the student " $t$ " value (3.0). CVAA MDLs were determined by multiplying the standard deviation of 7 replicate analyses of an SRM by 3 . GFAA detection limits represent 3 times the standard deviation of the 3 replicate analyses of the method blank.

\section{METHOD BLANKS}

Six method blanks were analyzed with the samples. No metals were detected in the blanks at concentrations exceeding the QC criteria of three times the MDL. All sample results are blank corrected.

\section{MATRIX SPIKES}

Six tissue samples ( $3 \mathrm{M}$. nasuta and $3 \mathrm{~N}$. virens) were spiked with 10 metals. All spike recoveries were within the control limits of $75 \%-125 \%$ limits with the following exceptions: As in one N. virens sample (128\%), $\mathrm{Zn}$ in two $N$. virens samples (190\% and $158 \%)$, and $\mathrm{Ag}$ in one M. nasuta sample (74\%).

\section{REPLICATES}

Six tissue samples ( 3 M. nasuta and $3 . N$. virens) were digested and analyzed in triplicate. Precision was measured by calculating the relative standard deviation (RSD) between the replicate results. The RSDs were all within the QC limits of $\leq 20 \%$ with the exception of $\mathrm{Cr}$ in one set of $N$. virens replicates $(41 \%)$, and $\mathrm{Zn}$ in all three $N$. virens replicates ( $41 \%$ to $61 \%$ ).

\section{SRMs}

Six samples of the SRM 1566a (obtained from the National Research Council of Canada, NRCC), were analyzed with the samples for all metals. All results were within $30 \%$ of the certified values with the exception of $Z n$ in one sample, which had a high recovery, and $\mathrm{Ag}$ in one sample, with a low recovery. 


\section{QAVC SUMMARY (continued)}

\section{REFERENCES}

Bloom, N. S., and E.A. Crecelius. 1983. "Determination of Mercury in Seawater at SubNanogram per Liter Levels." Mar. Chem. 14:49-59.

EPA. 1991. Methods for the Determination of Metals in Environmental Samples. EPA-600/4-91010. Environmental Services Division, Monitoring Management Branch. 


\section{QAVQC SUMMAFY}

PROGRAM: Richmond Harbor Deepening Project

PARAMETER: Butyltins

LABORATORY: Battelle/Marine Sciences Laboratory, Sequim, Washington

MATRIX: Tissue

QA/QC DATA QUALITY OBJECTIVES

$\begin{array}{ccccc}\begin{array}{c}\text { Reference } \\ \text { Method }\end{array} & \begin{array}{c}\text { Range of } \\ \text { Recovery }\end{array} & \begin{array}{c}\text { SRM } \\ \text { Accuracy }\end{array} & \begin{array}{c}\text { Relative } \\ \text { Precision }\end{array} & \begin{array}{c}\text { Detection } \\ \text { Limit (dry weight) }\end{array} \\ \text { Unger et al. } & 40-120 \% & \leq 30 \% & \leq 30 \% & 1 \mu \mathrm{g} / \mathrm{kg}\end{array}$

METHOD

HOLDING TIMES

DETECTION LIMITS

METHOD BLANKS

SURROGATES
Butyltin analyses were performed according to MSL-SOP-M-004 following the method of Unger et al. (1986). Tissue samples were extracted with methylene chloride using a roller under ambient conditions followed by derivitization using a Grignard reagent to change to a form compatible with gas chromatography. Sample extracts were then cleaned by passing through a florisil column. Extracts were analyzed using Gas Chromatography/Flame Photometric Detection (GC/FPD).

One hundred four (104) samples of worm and clam tissue were received on 3/21/94 in good condition. Samples were logged into Battelle's log-in system and stored at approximately $-20^{\circ} \mathrm{C}$ until extraction. Samples were extracted and analyzed in six batches, as follows:

$\begin{array}{ccc} & \begin{array}{c}\text { Date } \\ \text { Extracted }\end{array} & \begin{array}{c}\text { Date } \\ \text { Analyzed }\end{array} \\ \text { Batch 1 } & 4 / 11 / 94 & 4 / 14-15 / 94 \\ \text { Batch 2 } & 4 / 18 / 94 & 4 / 22-23 / 94 \\ \text { Batch 3 } & 4 / 25 / 94 & 4 / 29-30 / 94 \\ \text { Batch 4 } & 5 / 2 / 94 & 5 / 12-13 / 94 \\ \text { Batch 5 } & 5 / 9 / 94 & 5 / 12-13 / 94 \\ \text { Batch 6 } & 5 / 25 / 94 & 5 / 26-27 / 94\end{array}$

The target detection limit of $1 \mu \mathrm{g} / \mathrm{kg}$ wet wt was met for tri- and monobutyltin, but was exceeded for dibutyltin. The achieved detection limit for dibutyltin was $1.39 \mu \mathrm{g} / \mathrm{kg}$. The method detection limits are defined as roughly 3 times the standard deviation of results from 7 replicate low level matrix spikes.

One method blank was extracted with each extraction batch. No butyltins were detected in the blanks.

One compound, Tripentyltin chloride, is added prior to extraction to assess the efficiency of the method. This compound also is used as an internal standard as all data is corrected for the recovery of the compound. Sample recoveries ranged from $52 \%$ to $112 \%$. All sample surrogate recoveries were within the QC limits of $40 \%-120 \%$. 


\section{QA/QC SUMMARY (continued)}

MATRIX SPIKES

REPLICATES

SRM
One sample from each extraction batch was spiked with mono-, di- and tributyltin. Matrix spike recoveries ranged from $93 \%$ to $114 \%$ for the triand dibutyltins, within the QC limits of $40-120 \%$. The recovery for monobutyltin ranged from $26 \%$ to $51 \%$. The lower recovery for monobutyltin is expected due to the inefficiency of the extraction of this compound as a result of its increased ionic nature.

One sample in each batch was digested in triplicate. Precision was measured by calculating the relative standard deviation (RSD) for the triplicate results. Tributyltin was detected in replicates for four of the batches; RSDs ranged from $3 \%$ to $6 \%$.

Not applicable.

\section{REFERENCES}

Unger, M.A., W.G. Macintyre, J. Reaves and R.J. Huggett. 1986. "GC Determination of Butyltins in Natural Waters by Flame Photometric Detection of Hexyl Derivatives with Mass Spectrometric Confirmation." Chemosphere. 15:461-470. 
TABLE 0.1. Total Detected Polynuclear Aromatic Hydrocarbons (PAHs), Dry Weight, in Tissue of M. nasuta, Richmond Harbor Deepening Project

\begin{tabular}{|c|c|c|c|c|c|c|}
\hline \multirow[b]{2}{*}{$\begin{array}{l}\text { Sediment } \\
\text { Treatment } \\
\end{array}$} & \multirow[b]{2}{*}{ Replicate } & \multirow[b]{2}{*}{$\begin{array}{c}\text { Analytical } \\
\text { Batch }\end{array}$} & \multirow[b]{2}{*}{$\begin{array}{l}\text { Percent } \\
\text { Dry } \\
\text { Weight }\end{array}$} & \multicolumn{3}{|c|}{ M. nasuta PAHs (ug/kg dry weight) } \\
\hline & & & & $\begin{array}{c}\text { Total } \\
\text { Low Molecular } \\
\text { Weight PAHs }\end{array}$ & $\begin{array}{l}\text { Total } \\
\text { High Molecular } \\
\text { Weight PAHs }\end{array}$ & $\begin{array}{l}\text { Total } \\
\text { PAHs }\end{array}$ \\
\hline SF COMP & 1 & 5 & 12.76 & 65 & 1157 & 1222 \\
\hline SF COMP & 2 & 5 & 12.94 & 48 & 1163 & 1211 \\
\hline SF COMP & 3 & 5 & 12.26 & 40 & 976 & 1016 \\
\hline SF COMP & 4 & 5 & 12.60 & 30 & 905 & 935 \\
\hline SF COMP & 5 & 5 & 14.42 & 45 & 821 & 866 \\
\hline SFW COMP & 1 & 4 & 14.61 & 807 & 2431 & 3238 \\
\hline SFW COMP & 2 & 4 & 17.91 & 1019 & 2559 & 3578 \\
\hline SFW COMP & 3 & 6 & 14.49 & 635 & 1931 & 2566 \\
\hline SFW COMP & 4 & 4 & 14.31 & 1083 & 3061 & 4144 \\
\hline SFW COMP & 5 & 6 & 14.58 & 605 & 2174 & 2779 \\
\hline UIH COMP & 1 & 5 & 13.71 & 52 & 921 & 973 \\
\hline UIH COMP & 2 & 6 & 14.06 & 9 & 789 & 798 \\
\hline UIH COMP, Replicate 1 & 3 & 6 & 13.52 & 27 & 682 & 709 \\
\hline UIH COMP, Replicate 2 & 3 & 6 & 13.52 & 22 & 672 & 694 \\
\hline UIH COMP, Replicate 3 & 3 & 6 & 13.52 & 40 & 728 & 768 \\
\hline UIH COMP & 4 & 5 & 15.23 & 49 & 828 & 877 \\
\hline UIH COMP & 5 & 5 & 13.02 & 64 & 921 & 985 \\
\hline TB Upper COMP & 1 & 4 & 15.21 & 22 & 279 & 301 \\
\hline TB Upper COMP, Replicate 1 & 2 & 4 & 14.75 & 24 & 296 & 321 \\
\hline TB Upper COMP, Replicate 2 & 2 & 4 & 14.75 & 49 & 286 & 335 \\
\hline TB Upper COMP, Replicate 3 & 2 & 4 & 14.75 & 21 & 312 & 333 \\
\hline TB Upper COMP & 3 & 3 & 13.66 & 36 & 334 & 370 \\
\hline TB Upper COMP & 4 & 3 & 15.16 & 43 & 345 & 388 \\
\hline TB Upper COMP & 5 & 4 & 15.00 & 37 & 340 & 377 \\
\hline TB Lower COMP & 1 & 4 & 13.17 & 33 & 131 & 164 \\
\hline TB Lower COMP & 2 & 3 & 13.30 & 37 & 169 & 206 \\
\hline TB Lower COMP & 3 & 5 & 12.74 & 15 & 94 & 109 \\
\hline TB Lower COMP & 4 & 5 & 12.37 & 15 & 135 & 150 \\
\hline TB Lower COMP & 5 & 6 & 13.89 & 18 & 85 & 103 \\
\hline R-OS & 1 & 5 & 12.71 & 12 & 85 & 97 \\
\hline R-OS, Replicate 1 & 2 & 5 & 12.62 & 16 & 119 & 135 \\
\hline R-OS, Replicate 2 & 2 & 5 & 12.62 & 20 & 91 & 111 \\
\hline R-OS, Replicate 3 & 2 & 5 & 12.62 & 16 & 114 & 130 \\
\hline R-OS & 3 & 5 & 13.84 & 25 & 73 & 98 \\
\hline R-OS & 4 & 5 & 12.69 & 24 & 94 & 118 \\
\hline R-OS & 5 & 5 & 13.41 & 13 & 71 & 84 \\
\hline $\mathrm{R}-\mathrm{BF}$ & 1 & 4 & 15.28 & 29 & 423 & 452 \\
\hline R-BF & 2 & 3 & 14.64 & 47 & 449 & 496 \\
\hline R-BF & 3 & 4 & 14.78 & 73 & 323 & 396 \\
\hline $\mathrm{R}-\mathrm{BF}$ & 4 & 4 & 15.91 & 23 & 310 & 333 \\
\hline R-BF & 5 & 4 & 14.92 & 13 & 300 & 313 \\
\hline RH DEEPENING & & & & & & \\
\hline
\end{tabular}


TABLE 0.1. (contd)

\begin{tabular}{|c|c|c|c|c|c|c|}
\hline \multirow[b]{2}{*}{$\begin{array}{l}\text { Sediment } \\
\text { Treatment }\end{array}$} & \multirow[b]{2}{*}{ Replicate } & \multirow[b]{2}{*}{$\begin{array}{c}\text { Analytical } \\
\text { Batch }\end{array}$} & \multirow[b]{2}{*}{$\begin{array}{l}\text { Percent } \\
\text { Dry } \\
\text { Weight }\end{array}$} & \multicolumn{3}{|c|}{ M. nasuta PAHs (ug/kg dry weight) } \\
\hline & & & & $\begin{array}{l}\text { Total } \\
\text { Low Molecular } \\
\text { Weight PAHs }\end{array}$ & $\begin{array}{l}\text { Total } \\
\text { High Molecular } \\
\text { Weight PAHs }\end{array}$ & $\begin{array}{l}\text { Total } \\
\text { PAHs }\end{array}$ \\
\hline R-AM COMP & 1 & 3 & 15.79 & 293 & 3321 & 3614 \\
\hline R-AM COMP & 2 & 4 & 13.81 & 212 & 2072 & 2284 \\
\hline R-AM COMP & 3 & 4 & 15.44 & 323 & 3188 & 3511 \\
\hline R-AM COMP & 4 & 3 & 14.52 & 276 & 2414 & 2690 \\
\hline R-AM COMP & 5 & 4 & 14.71 & 375 & 2739 & 3114 \\
\hline C-SB & .1 & 5 & 14.43 & 23 & 122 & 146 \\
\hline C-SB & 2 & 5 & 13.25 & 26 & 292 & 317 \\
\hline C-SB & 3 & 5 & 14.03 & 26 & 137 & 163 \\
\hline C-SB & 4 & 5 & 13.57 & 22 & 138 & 160 \\
\hline C-SB & 5 & 5 & 13.60 & 22 & 130 & 152 \\
\hline M. nasuta Background & 1 & 3 & 13.46 & 53 & 271 & 324 \\
\hline M. nasuta Background & 2 & 3 & 12.00 & 63 & 300 & 363 \\
\hline M. nasuta Background, Replicate 1 & 3 & 3 & 13.05 & 75 & 299 & 374 \\
\hline M. nasuta Background, Replicate 2 & 3 & 3 & 13.05 & 87 & 379 & 466 \\
\hline M. nasuta Background, Replicate 3 & 3 & 3 & 13.05 & 52 & 375 & 427 \\
\hline M. nasuta Background & 4 & 3 & 14.21 & 57 & 283 & 340 \\
\hline M. nasuta Background & 5 & 3 & 17.65 & 44 & 144 & 187 \\
\hline
\end{tabular}




\begin{tabular}{|c|c|c|c|c|c|c|c|c|c|}
\hline \multirow{2}{*}{ 胥 } & \multirow[b]{2}{*}{ Replicate } & \multirow[b]{2}{*}{$\begin{array}{c}\text { Analytical } \\
\text { Batch }\end{array}$} & \multirow[b]{2}{*}{$\begin{array}{l}\text { Percent } \\
\text { Dry } \\
\text { Weight }\end{array}$} & \multirow[b]{2}{*}{$\begin{array}{l}\text { Naphtha- } \\
\text { lene }\end{array}$} & \multicolumn{3}{|c|}{ M. nasuta LPAHs (ug/kg dry weight) } & \multirow[b]{2}{*}{$\begin{array}{l}\text { Phenan- } \\
\text { threne }\end{array}$} & \multirow[b]{2}{*}{$\begin{array}{l}\text { Anthra- } \\
\text { cene } \\
\end{array}$} \\
\hline & & & & & $\begin{array}{l}\text { Acenaph- } \\
\text { thylene }\end{array}$ & $\begin{array}{l}\text { Acenaph- } \\
\text { thene }\end{array}$ & Fluorene & & \\
\hline $\begin{array}{l}\text { SF COMP } \\
\text { SF COMP } \\
\text { SF COMP } \\
\text { SF COMP } \\
\text { SF COMP }\end{array}$ & $\begin{array}{l}1 \\
2 \\
3 \\
4 \\
5\end{array}$ & $\begin{array}{l}5 \\
5 \\
5 \\
5 \\
5\end{array}$ & $\begin{array}{l}12.76 \\
12.94 \\
12.26 \\
12.60 \\
14.42\end{array}$ & $\begin{array}{ll}11.8 & \\
8.35 & \text { (b) } \\
7.75 & \text { (b) } \\
19.4 & \\
12.3 & \end{array}$ & $\begin{array}{l}6.43 U(a) \\
6.26 U \\
6.69 U \\
12.8 U \\
5.69 U\end{array}$ & $\begin{array}{l}6.50 \quad(b) \\
5.95 U^{(b)} \\
6.36 U \\
12.1 U \\
5.41 U\end{array}$ & $\begin{array}{l}10.8 U \\
10.4 U \\
11.3 U \\
21.4 U \\
9.57 U\end{array}$ & $\begin{array}{ll}17.6 & \\
10.9 & \\
9.30 & \text { (b) } \\
10.6 & \text { (b) } \\
10.6 & \end{array}$ & $\begin{array}{l}28.9 \\
28.3 \\
23.0 \\
34.7 \mathrm{U} \\
22.3\end{array}$ \\
\hline $\begin{array}{l}\text { SFW COMP } \\
\text { SFW COMP } \\
\text { SFW COMP } \\
\text { SFW COMP } \\
\text { SFW COMP }\end{array}$ & $\begin{array}{l}1 \\
2 \\
3 \\
4 \\
5\end{array}$ & $\begin{array}{l}4 \\
4 \\
6 \\
4 \\
6\end{array}$ & $\begin{array}{l}14.61 \\
17.91 \\
14.49 \\
14.31 \\
14.58\end{array}$ & $\begin{array}{l}27.9 \mathrm{~B}(\mathrm{C}) \\
43.9 \mathrm{~B} \\
32.5 \\
34.3 \mathrm{~B} \\
28.7\end{array}$ & $\begin{array}{l}10.7 U \\
9.10 \mathrm{U} \\
6.69 \text { (b) } \\
11.4 U^{\prime} \\
6.04 \text { (b) }\end{array}$ & $\begin{array}{l}58.7 \\
72.0 \\
38.6 \\
65.6 \\
35.9\end{array}$ & $\begin{array}{l}80.8 \\
90.5 \\
54.2 \\
97.1 \\
50.8\end{array}$ & $\begin{array}{l}537 \\
692 \\
418 \\
762 \\
403\end{array}$ & $\begin{array}{r}103 \\
121 \\
84.9 \\
124 \\
80.2\end{array}$ \\
\hline $\begin{array}{l}\text { UIH COMP } \\
\text { UIH COMP } \\
\text { UIH COMP, Replicate } 1 \\
\text { UIH COMP, Replicate } 2 \\
\text { UIH COMP, Replicate } 3 \\
\text { UIH COMP } \\
\text { UIH COMP }\end{array}$ & $\begin{array}{l}1 \\
2 \\
3 \\
3 \\
3 \\
4 \\
5\end{array}$ & $\begin{array}{l}5 \\
6 \\
6 \\
6 \\
6 \\
5 \\
5\end{array}$ & $\begin{array}{l}13.71 \\
14.06 \\
13.52 \\
13.52 \\
13.52 \\
15.23 \\
13.02\end{array}$ & $\begin{array}{l}10.1 \\
8.82 \\
17.7 \\
10.3 \\
27.1 \\
6.89 \\
9.83 \quad \text { (b) }\end{array}$ & $\begin{array}{l}5.98 U \\
10.5 U \\
12.1 U \\
11.9 U \\
12.1 U \\
5.32 U \\
6.22 U\end{array}$ & $\begin{array}{l}5.69 U \\
10.0 \mathrm{U} \\
11.5 \mathrm{U} \\
11.3 \mathrm{U} \\
11.5 \mathrm{U} \\
5.06 \mathrm{U} \\
5.91 \mathrm{U}\end{array}$ & $\begin{array}{l}10.1 \mathrm{U} \\
17.6 \mathrm{U} \\
20.3 \mathrm{U} \\
20.0 \mathrm{U} \\
20.3 \mathrm{U} \\
9.52 \text { (b) } \\
12.1 \text { (b) }\end{array}$ & $\begin{array}{l}15.0 \\
8.32 \mathrm{U} \\
9.62 \\
11.5 \\
13.3 \quad \text { (b) } \\
12.3 \\
15.6\end{array}$ & $\begin{array}{l}26.5 \\
28.5 U \\
33.0 U \\
32.3 U \\
33.0 U \\
19.8 \\
26.3\end{array}$ \\
\hline $\begin{array}{l}\text { TB Upper COMP } \\
\text { TB Upper COMP, Replicate } 1 \\
\text { TB Upper COMP, Replicate } 2 \\
\text { TB Upper COMP, Replicate } 3 \\
\text { TB Upper COMP } \\
\text { TB Upper COMP } \\
\text { TB Upper COMP }\end{array}$ & $\begin{array}{l}1 \\
2 \\
2 \\
2 \\
3 \\
4 \\
5\end{array}$ & $\begin{array}{l}4 \\
4 \\
4 \\
4 \\
3 \\
3 \\
4\end{array}$ & $\begin{array}{l}15.21 \\
14.75 \\
14.75 \\
14.75 \\
13.66 \\
15.16 \\
15.00\end{array}$ & $\begin{array}{l}12.3 \mathrm{~B}(\mathrm{~b}) \\
24.3 \mathrm{~B}(\mathrm{~b}) \\
32.5 \mathrm{~B} \\
21.4 \mathrm{~B} \\
5.27 \mathrm{~B} \\
3.36 \mathrm{U} \\
37.1 \mathrm{~B}\end{array}$ & $\begin{array}{l}10.2 \mathrm{U} \\
20.5 \mathrm{U} \\
20.1 \mathrm{U} \\
19.6 \mathrm{U} \\
5.93 \mathrm{U} \\
5.41 \mathrm{u}^{(\mathrm{b})} \\
21.9 \mathrm{U}^{\mathrm{m}}\end{array}$ & $\begin{array}{l}9.66 U \\
19.5 U \\
19.1 U \\
18.6 U \\
5.64 U \\
6.86 \\
20.9 U\end{array}$ & $\begin{array}{l}17.0 \mathrm{U} \\
34.4 \mathrm{U} \\
33.6 \mathrm{U} \\
32.9 \mathrm{U} \\
9.88 \mathrm{U} \\
9.10 \mathrm{U} \\
36.7 \mathrm{U}\end{array}$ & 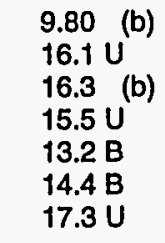 & $\begin{array}{l}27.5 \mathrm{U} \\
55.6 \mathrm{U} \\
54.4 \mathrm{U} \\
53.2 \mathrm{U} \\
18.0 \\
16.7 \quad \text { (b) } \\
59.4 U^{(3)}\end{array}$ \\
\hline $\begin{array}{l}\text { TB Lower COMP } \\
\text { TB Lower COMP } \\
\text { TB Lower COMP } \\
\text { TB Lower COMP } \\
\text { TB Lower COMP }\end{array}$ & $\begin{array}{l}1 \\
2 \\
3 \\
4 \\
5\end{array}$ & $\begin{array}{l}4 \\
3 \\
5 \\
5 \\
6\end{array}$ & $\begin{array}{l}13.17 \\
13.30 \\
12.74 \\
12.37 \\
13.89\end{array}$ & $\begin{array}{l}23.1 \mathrm{~B}(\mathrm{~b}) \\
9.17 \mathrm{~B} \\
9.11 \quad(\mathrm{~b}) \\
6.55 \\
11.5 \mathrm{~B}(\mathrm{~b})\end{array}$ & $\begin{array}{l}12.5 U \\
6.17 U \\
6.44 U \\
6.63 U \\
5.90 U\end{array}$ & $\begin{array}{l}11.8 U \\
5.86 U \\
6.12 U \\
6.31 U \\
5.62 U\end{array}$ & $\begin{array}{l}20.9 U \\
10.4 U \\
10.8 U \\
11.2 U \\
9.94 U\end{array}$ & $\begin{array}{l}10.3 \text { (b) } \\
10.8 \mathrm{~B} \\
5.57 \text { (b) } \\
8.25 \\
6.62\end{array}$ & $\begin{array}{l}33.9 \mathrm{U} \\
17.4 \quad(\mathrm{~b}) \\
17.5 \mathrm{U}^{-} \\
18.0 \mathrm{U} \\
16.1 \mathrm{U}\end{array}$ \\
\hline $\begin{array}{l}\text { R-OS } \\
\text { R-OS, Replicate } 1 \\
\text { R-OS, Replicate } 2 \\
\text { R-OS, Replicate } 3 \\
\text { R-OS } \\
\text { R-OS } \\
\text { R-OS }\end{array}$ & $\begin{array}{l}1 \\
2 \\
2 \\
2 \\
3 \\
4 \\
5\end{array}$ & $\begin{array}{l}\mathbf{5} \\
\mathbf{5} \\
\mathbf{5} \\
\mathbf{5} \\
\mathbf{5} \\
\mathbf{5} \\
\mathbf{5}\end{array}$ & $\begin{array}{l}12.71 \\
12.62 \\
12.62 \\
12.62 \\
13.84 \\
12.69 \\
13.41\end{array}$ & $\begin{array}{l}6.53 \\
16.3 \\
20.3 \quad \text { (b) } \\
15.8 \\
8.38 \\
10.2 \\
5.97\end{array}$ & $\begin{array}{l}6.37 U \\
12.8 U \\
12.6 U \\
12.8 U \\
5.85 U \\
6.46 U \\
6.11 U\end{array}$ & $\begin{array}{l}6.06 \mathrm{U} \\
12.1 \mathrm{U} \\
12.0 \mathrm{U} \\
12.1 \mathrm{U} \\
5.56 \mathrm{U} \\
6.93 \\
5.82 \mathrm{U}\end{array}$ & $\begin{array}{l}10.6 \mathrm{U} \\
21.4 \mathrm{U} \\
21.2 \mathrm{U} \\
21.4 \mathrm{U} \\
10.7 \mathrm{u}^{(\mathrm{b})} \\
10.9 \mathrm{U}^{\prime} \\
10.3 \mathrm{U}\end{array}$ & $\begin{array}{l}5.82 \mathrm{U}^{(\mathrm{b})} \\
10.1 \mathrm{U}^{-} \\
10.0 \mathrm{U}^{-} \\
10.1 \mathrm{U} \\
6.14 \\
6.93 \\
7.08\end{array}$ & $\begin{array}{l}17.2 \mathrm{U} \\
34.6 \mathrm{U} \\
34.2 \mathrm{U} \\
34.6 \mathrm{U} \\
15.8 \mathrm{U} \\
17.6 \mathrm{U} \\
16.6 \mathrm{U}\end{array}$ \\
\hline
\end{tabular}




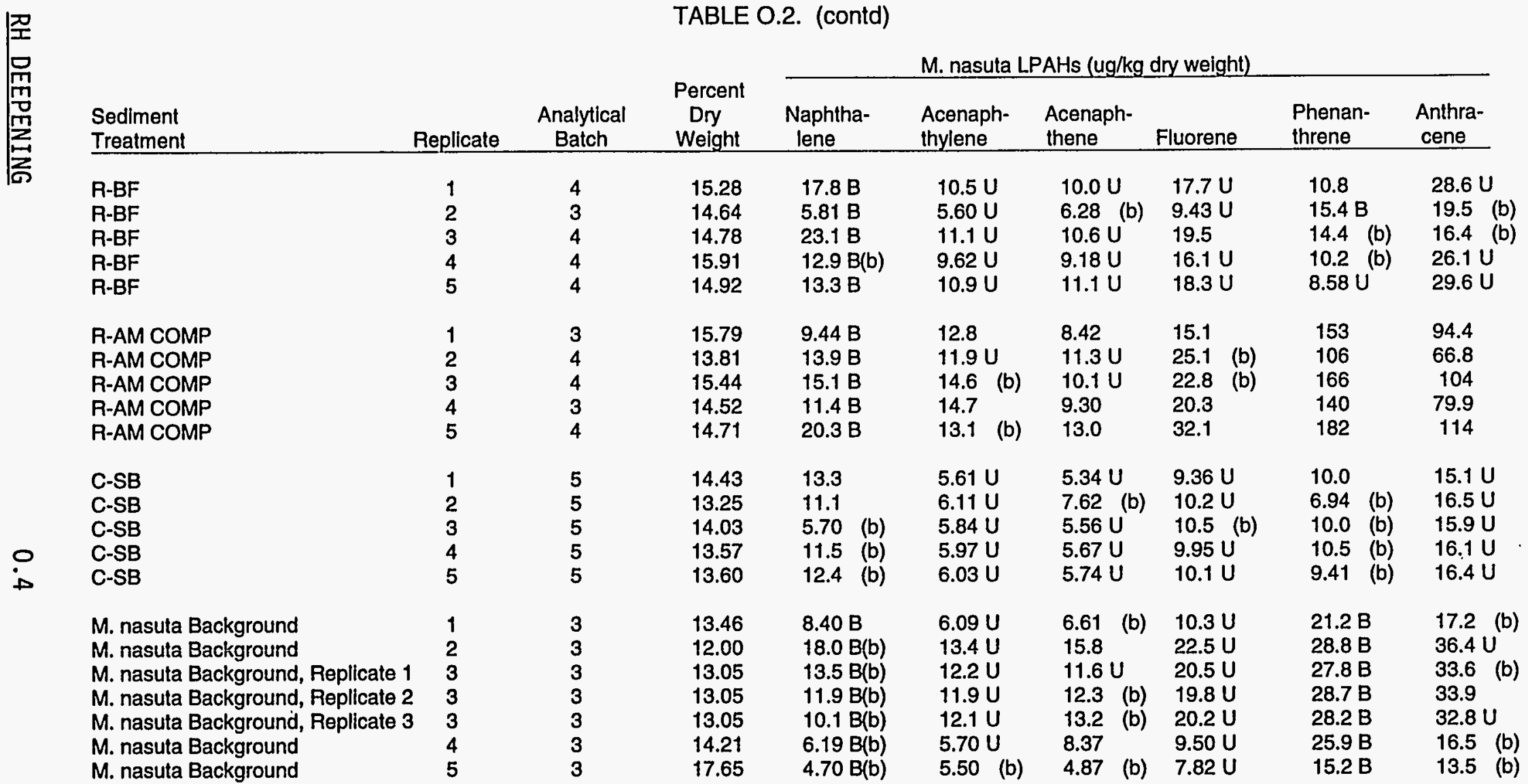

(a) U Undetected at or above detection limit.

(b) Ratio of confirmation ion to primary lon is outside of the theoretical ratio of $20 \%$ established for EPA-CLP programs.

(c) B Analyte detected in sample at less than five times value in associated method blank. 


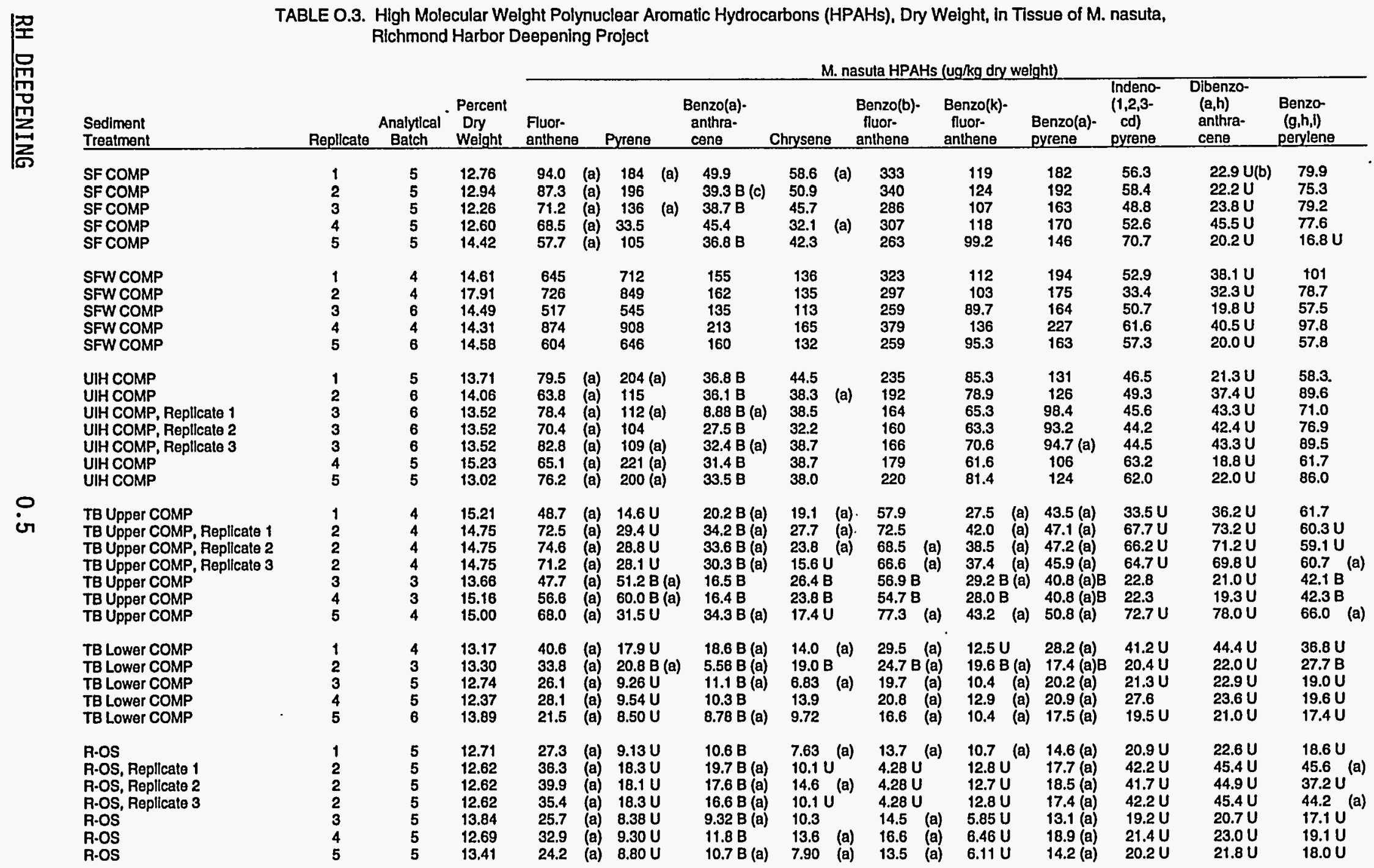




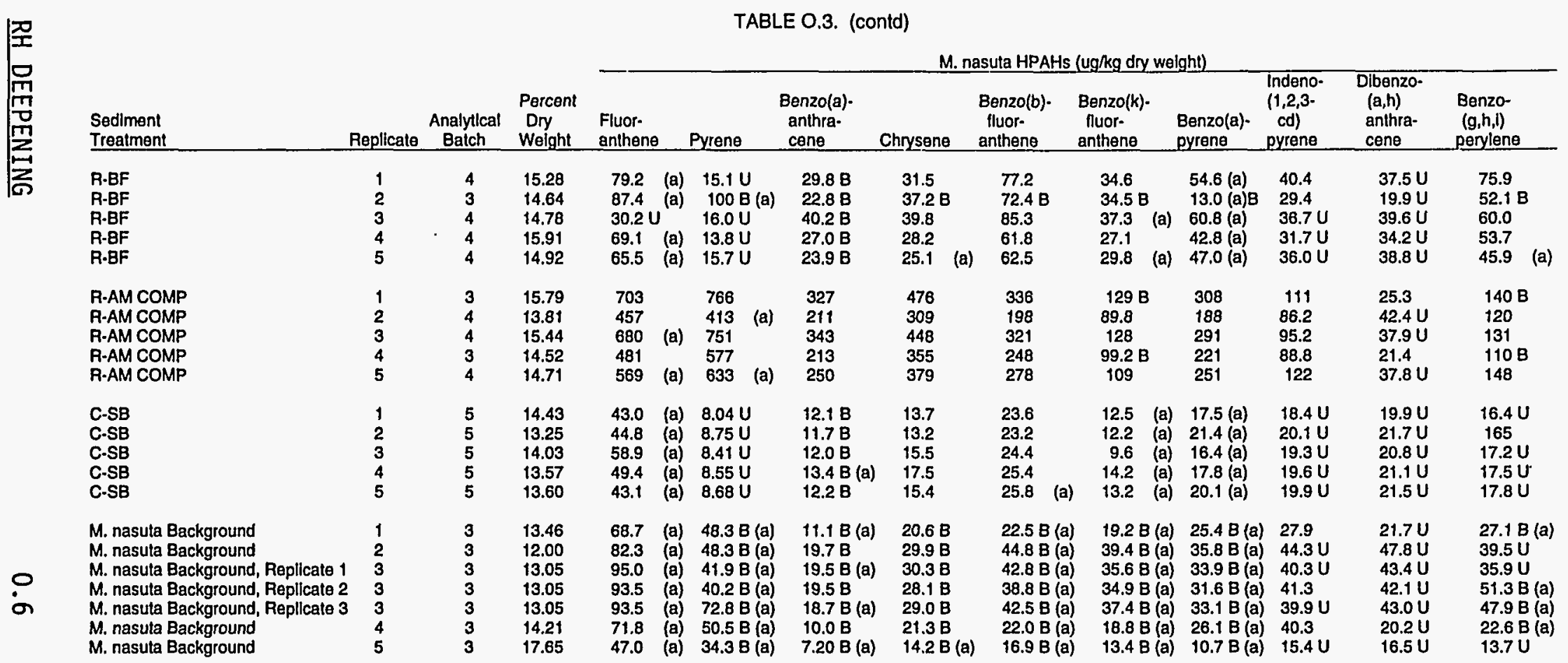

(a) Ratlo of confirmation ion to primary lon is outside of the theoretical ratlo of $20 \%$ establlshed for EPA.CLP programs.

(b) U Undetected at or above detection limit.
(c) B Analyte detected in sample at less than five times value in assoclated method blank. 
TABLE 0.4. Total Detected Polynuclear Aromatic Hydrocarbons (PAHs), Wet Weight, . in Tissue of M. nasuta, Richmond Harbor Deepening Project

\begin{tabular}{|c|c|c|c|c|c|}
\hline \multirow[b]{2}{*}{$\begin{array}{l}\text { Sediment } \\
\text { Treatment }\end{array}$} & \multirow[b]{2}{*}{ Replicate } & \multirow[b]{2}{*}{$\begin{array}{c}\text { Analytical } \\
\text { Batch }\end{array}$} & \multicolumn{3}{|c|}{ M. nasuta PAHs (ug/kg wet weight) } \\
\hline & & & $\begin{array}{l}\text { Total } \\
\text { Low Molecular } \\
\text { Weight PAHs }\end{array}$ & $\begin{array}{l}\text { Total } \\
\text { High Molecular } \\
\text { Weight PAHs }\end{array}$ & $\begin{array}{l}\text { Total } \\
\text { PAHs }\end{array}$ \\
\hline SF COMP & 1 & 5 & 8 & $\uparrow 48$ & 156 \\
\hline SF COMP & 2 & 5 & 6 & 150 & 156 \\
\hline SF COMP & 3 & 5 & 5 & 120 & 125 \\
\hline SF COMP & 4 & 5 & 4 & 114 & 118 \\
\hline SF COMP & 5 & 5 & 7 & 118 & 125 \\
\hline SFW COMP & 1 & 4 & 118 & 355 & 473 \\
\hline SFW COMP & 2 & 4 & 183 & 458 & 641 \\
\hline SFW COMP & 3 & 6 & 92 & 280 & 372 \\
\hline SFW COMP & 4 & 4 & 155 & 438 & 593 \\
\hline SFW COMP & 5 & 6 & 88 & 317 & 405 \\
\hline UIH COMP & 1 & 5 & 7 & 126 & 133 \\
\hline UIH COMP & 2 & 6 & 1 & 111 & 112 \\
\hline UIH COMP, Replicate 1 & 3 & 6 & 4 & 92 & 96 \\
\hline UIH COMP, Replicate 2 & 3 & 6 & 3 & 91 & 94 \\
\hline UIH COMP, Replicate 3 & 3 & 6 & 5 & 98 & 103 \\
\hline UIH COMP & 4 & 5 & 7 & 126 & 133 \\
\hline UIH COMP & 5 & 5 & 8 & 120 & 128 \\
\hline TB Upper COMP & 1 & 4 & 3 & 42 & 45 \\
\hline TB Upper COMP, Replicate 1 & 2 & 4 & 4 & 44 & 48 \\
\hline TB Upper COMP, Replicate 2 & 2 & 4 & 7 & 42 & 49 \\
\hline TB Upper COMP, Replicate 3 & 2 & 4 & 3 & 46 & 49 \\
\hline TB Upper COMP & 3 & 3 & 5 & 46 & 51 \\
\hline TB Upper COMP & 4 & 3 & 7 & 52 & 59 \\
\hline TB Upper COMP & 5 & 4 & 6 & 51 & 57 \\
\hline TB Lower COMP & 1 & 4 & 4 & 17 & 21 \\
\hline TB Lower COMP & 2 & 3 & 5 & 22 & 27 \\
\hline TB Lower COMP & 3 & 5 & 2 & 12 & 14 \\
\hline TB Lower COMP & 4 & 5 & 2 & 17 & 19 \\
\hline TB Lower COMP & 5 & 6 & 3 & 12 & 15 \\
\hline R-OS & 1 & 5 & 2 & 11 & 13 \\
\hline R-OS, Replicate 1 & 2 & 5 & 2 & 15 & 17 \\
\hline R-OS, Replicate 2 & 2 & 5 & 3 & 11 & 14 \\
\hline R-OS, Replicate 3 & 2 & 5 & 2 & 14 & 16 \\
\hline R-OS & 3 & 5 & 3 & 10 & 13 \\
\hline R-OS & 4 & 5 & 3 & 12 & 15 \\
\hline R-OS & 5 & 5 & 2 & 10 & 12 \\
\hline
\end{tabular}

RH DEEPENING

0.7 
TABLE 0.4. (contd)

\begin{tabular}{|c|c|c|c|c|c|}
\hline \multirow[b]{2}{*}{$\begin{array}{l}\text { Sediment } \\
\text { Treatment }\end{array}$} & \multirow[b]{2}{*}{ Replicate } & \multirow[b]{2}{*}{$\begin{array}{c}\text { Analytical } \\
\text { Batch }\end{array}$} & \multicolumn{3}{|c|}{ M. nasuta PAHs (ug/kg wet weight) } \\
\hline & & & $\begin{array}{l}\text { Total } \\
\text { Low Molecular } \\
\text { Weight PAHs }\end{array}$ & $\begin{array}{l}\text { Total } \\
\text { High Molecular } \\
\text { Weight PAHs }\end{array}$ & $\begin{array}{l}\text { Total } \\
\text { PAHs }\end{array}$ \\
\hline R-BF & 1 & 4 & 4 & 65 & 69 \\
\hline R-BF & 2 & 3 & 7 & 66 & 73 \\
\hline R-BF & 3 & 4 & 11 & 48 & 59 \\
\hline R-BF & 4 & 4 & 4 & 49 & 53 \\
\hline R-BF & 5 & 4 & 2 & 45 & 47 \\
\hline R-AM COMP & 1 & 3 & 46 & 524 & 570 \\
\hline R-AM COMP & 2 & 4 & 29 & 286 & 315 \\
\hline R-AM COMP & 3 & 4 & 50 & 492 & 542 \\
\hline R-AM COMP & 4 & 3 & 40 & 351 & 391 \\
\hline R-AM COMP & 5 & 4 & 55 & 403 & 458 \\
\hline C-SB & 1 & 5 & 3 & 18 & 21 \\
\hline C-SB & 2 & 5 & 3 & 39 & 42 \\
\hline C-SB & 3 & 5 & 4 & 19 & 23 \\
\hline C-SB & 4 & 5 & 3 & 19 & 22 \\
\hline C-SB & 5 & 5 & 3 & 18 & 21 \\
\hline M. nasuta Background & 1 & 3 & 7 & 36 & 43 \\
\hline M. nasuta Background & 2 & 3 & 8 & 36 & 44 \\
\hline M. nasuta Background, Replicate 1 & 3 & 3 & 10 & 39 & 49 \\
\hline M. nasuta Background, Replicate 2 & 3 & 3 & 11 & 49 & 60 \\
\hline M. nasuta Background, Replicate 3 & 3 & 3 & 7 & 49 & 56 \\
\hline M. nasuta Background & 4 & 3 & 8 & 40 & 48 \\
\hline M. nasuta Background & 5 & 3 & 8 & 25 & 33 \\
\hline
\end{tabular}


TABLE 0.5. Low Molecular Weight Polynuclear Aromatic Hydrocarbons (LPAHs), Wet Weight, in Tissue of M. nasuta, Richmond Harbor Deepening Project

\begin{tabular}{|c|c|c|c|c|c|c|c|c|}
\hline \multirow[b]{2}{*}{$\begin{array}{l}\text { Sediment } \\
\text { Treatment }\end{array}$} & \multirow[b]{2}{*}{ Replicate } & \multirow[b]{2}{*}{$\begin{array}{c}\text { Analytical } \\
\text { Batch }\end{array}$} & \multicolumn{6}{|c|}{ M. nasuta LPAHs (ug/kg wet weight) } \\
\hline & & & $\begin{array}{l}\text { Naphtha- } \\
\text { lene }\end{array}$ & $\begin{array}{l}\text { Acenaph- } \\
\text { thylene }\end{array}$ & $\begin{array}{l}\text { Acenaph- } \\
\text { thene }\end{array}$ & Fluorene & $\begin{array}{l}\text { Phenan- } \\
\text { threne }\end{array}$ & $\begin{array}{c}\text { Anthra- } \\
\text { cene }\end{array}$ \\
\hline Target $D L(a)$ & & & 20 & 20 & 20 & 20 & 20 & 20 \\
\hline Achleved DL & & & $0.49-2.03$ & $0.79-3.29$ & $0.75-3.13$ & $1.32-5.51$ & $0.62-2.59$ & $2.14-8.91$ \\
\hline SF COMP & 1 & 5 & 1.51 & $0.82 U(b)$ & $0.83(c)$ & $1.38 \mathrm{U}$ & 2.24 & 3.69 \\
\hline SF COMP & 2 & 5 & 1.08 (c) & $0.81 \mathrm{U}$ & $0 . \pi \mathrm{U}$ & $1.35 \mathrm{U}$ & 1.41 & 3.66 \\
\hline SF COMP & 3 & 5 & 0.95 (c) & $0.82 \mathrm{U}$ & $0.78 \mathrm{U}$ & $1.38 \mathrm{U}$ & 1.14 (c) & 2.82 \\
\hline SF COMP & 4 & 5 & 2.44 & $1.61 \mathrm{U}$ & $1.53 \mathrm{U}$ & $2.70 \mathrm{U}$ & 1.33 (c) & $4.37 \mathrm{U}$ \\
\hline SF COMP & 5 & 5 & 1.77 & $0.82 \mathrm{U}$ & $0.78 \mathrm{U}$ & $1.38 \mathrm{U}$ & 1.53 & 3.21 \\
\hline SFW COMP & 1 & 4 & $4.07 \mathrm{~B}$ & $1.56 \mathrm{U}$ & 8.58 & 11.8 & 78.4 & 15.0 \\
\hline SFW COMP. & 2 & 4 & $7.87 \mathrm{~B}$ & $1.63 \mathrm{U}$ & 12.9 & 16.2 & 124 & 21.6 \\
\hline SFW COMP & 3 & 6 & 4.71 & 0.97 (c) & 5.60 & 7.85 & 60.6 & 12.3 \\
\hline SFW COMP & 4 & 4 & $4.91 \mathrm{~B}$ & $1.63 \mathrm{U}$ & 9.39 & 13.9 & 109 & 17.7 \\
\hline SFW COMP & 5 & 6 & 4.19 & $0.88(c)$ & 5.23 & 7.40 & 58.7 & 11.7 \\
\hline UIH COMP & 1 & 5 & 1.39 & $0.82 \mathrm{U}$ & $0.78 \mathrm{U}$ & $1.38 \mathrm{U}$ & 2.05 & 3.63 \\
\hline UIH COMP & 2 & 6 & 1.24 & $1.48 \mathrm{U}$ & $1.41 \mathrm{U}$ & $2.48 \mathrm{U}$ & $1.17 \mathrm{U}$ & $4.01 \mathrm{U}$ \\
\hline UIH COMP, Replicate 1 & 3 & 6 & 2.39 & $1.64 \mathrm{U}$ & $1.56 \mathrm{U}$ & $2.75 \mathrm{U}$ & 1.30 & $4.46 \mathrm{U}$ \\
\hline UIH COMP, Replicate 2 & 3 & 6 & 1.39 & $1.61 \mathrm{U}$ & $1.53 \mathrm{U}$ & $2.70 \mathrm{U}$ & 1.55 & $4.37 \mathrm{U}$ \\
\hline UIH COMP, Replicate 3 & 3 & 6 & 3.67 & $1.64 \mathrm{U}$ & $1.56 \mathrm{U}$ & $2.75 \mathrm{U}$ & 1.80 (c) & $4.46 \mathrm{U}$ \\
\hline UIH COMP & 4 & 5 & 1.05 & $0.81 \mathrm{U}$ & $0.77 \mathrm{U}$ & 1.45 (c) & 1.87 & 3.02 \\
\hline UIH COMP & 5 & 5 & 1.28 (c) & $0.81 \mathrm{U}$ & $0.77 \mathrm{U}$ & 1.58 (c) & 2.03 & 3.42 \\
\hline TB Upper COMP & 1 & 4 & $1.87 \mathrm{~B}(\mathrm{c})$ & $1.55 \mathrm{U}$ & $1.47 \mathrm{U}$ & $2.59 \mathrm{U}$ & 1.49 (c) & $4.19 \mathrm{U}$ \\
\hline TB Upper COMP, Replicate 1 & 2 & 4 & $3.58 \mathrm{~B}(\mathrm{c})$ & $3.02 \mathrm{U}$ & $2.88 \mathrm{U}$ & $5.07 \mathrm{U}$ & $2.38 \mathrm{U}$ & $8.20 \mathrm{U}$ \\
\hline TB Upper COMP, Replicate 2 & 2 & 4 & $4.80 \mathrm{~B}$ & $2.96 \mathrm{U}$ & $2.82 U$ & $4.96 U$ & 2.40 (c) & $8.02 \mathrm{U}$ \\
\hline TB Upper COMP, Replicate 3 & 2 & 4 & $3.15 \mathrm{~B}$ & $2.89 \mathrm{U}$ & $2.75 U$ & $4.85 \mathrm{U}$ & $2.28 \mathrm{U}$ & $7.84 \mathrm{U}$ \\
\hline TB Upper COMP & 3 & 3 & $0.72 \mathrm{~B}$ & $0.81 \mathrm{U}$ & $0.77 U$ & $1.35 \mathrm{U}$ & $1.80 \mathrm{~B}$ & 2.46 \\
\hline TB Upper COMP & 4 & 3 & $0.51 \mathrm{U}$ & 0.82 (c) & 1.04 & $1.38 \mathrm{U}$ & $2.18 \mathrm{~B}$ & 2.53 (c) \\
\hline TB Upper COMP & 5 & 4 & $5.56 \mathrm{~B}$ & $3.29 \mathrm{U}$ & $3.13 \mathrm{U}$ & $5.51 \mathrm{U}$ & $2.59 \mathrm{U}$ & $8.91 \mathrm{U}$ \\
\hline TB Lower COMP & 1 & 4 & $3.04 \mathrm{~B}(\mathrm{c})$ & $1.64 \mathrm{U}$ & $1.56 \mathrm{U}$ & $2.75 \mathrm{U}$ & 1.35 (c) & $4.46 \mathrm{U}$ \\
\hline TB Lower COMP & 2 & 3 & $1.22 \mathrm{~B}$ & $0.82 U$ & $0.78 \mathrm{U}$ & $1.38 \mathrm{U}$ & $1.43 \mathrm{~B}$ & 2.31 (c) \\
\hline TB Lower COMP & 3 & 5 & 1.16 (c) & $0.82 U$ & $0.78 \mathrm{U}$ & $1.38 \mathrm{U}$ & 0.71 (c) & $2.23 \mathrm{U}$ \\
\hline TB Lower COMP & 4 & 5 & 0.81 & $0.82 \mathrm{U}$ & $0.78 \mathrm{U}$ & $1.38 \mathrm{U}$ & 1.02 & $2.23 \mathrm{U}$ \\
\hline ṪB Lower COMP & 5 & 6 & $1.60 \mathrm{~B}(\mathrm{c})$ & $0.82 \mathrm{U}$ & $0.78 \mathrm{U}$ & $1.38 \mathrm{U}$ & 0.92 & $2.23 \mathrm{U}$ \\
\hline R-OS & $\cdot 1$ & 5 & 0.83 & $0.81 \mathrm{U}$ & $0.77 \mathrm{U}$ & $1.35 \mathrm{U}$ & 0.74 (c) & $2.18 \mathrm{U}$ \\
\hline R-OS, Replicate 1 & 2 & 5 & 2.06 & $1.61 \mathrm{U}$ & $1.53 \mathrm{U}$ & $2.70 \mathrm{U}$ & $1.27 \mathrm{U}$ & $4.37 \mathrm{U}$ \\
\hline R-OS, Replicate 2 & 2 & 5 & 2.56 (c) & $1.59 \mathrm{U}$ & $1.52 \mathrm{U}$ & $2.67 \mathrm{U}$ & $1.26 \mathrm{U}$ & $4.32 \mathrm{U}$ \\
\hline R-OS, Replicate 3 & 2 & 5 & 2.00 & $1.61 \mathrm{U}$ & $1.53 \mathrm{U}$ & $2.70 \mathrm{U}$ & $1.27 \mathrm{U}$ & $4.37 \mathrm{U}$ \\
\hline R-OS & 3 & 5 & 1.16 & $0.81 \mathrm{U}$ & $0.77 \mathrm{U}$ & 1.48 (c) & 0.85 & $2.18 \mathrm{U}$ \\
\hline R-OS & 4 & 5 & 1.29 & $0.82 U$ & 0.88 & $1.38 \mathrm{U}$ & 0.88 & $2.23 U$ \\
\hline R-OS & 5 & 5 & 0.80 & $0.82 U$ & $0.78 U$ & $1.38 \mathrm{U}$ & 0.95 & $2.23 \mathrm{U}$ \\
\hline R-BF & 1 & 4 & $2.72 \mathrm{~B}$ & $1.61 U$ & $1.53 \mathrm{U}$ & $2.70 \mathrm{U}$ & 1.65 & $4.37 \mathrm{U}$ \\
\hline$R \cdot B F$ & 2 & 3 & $0.85 \mathrm{~B}$ & $0.82 U$ & 0.92 (c) & $1.38 \mathrm{U}$ & $2.26 \mathrm{~B}$ & 2.86 (c) \\
\hline$R \cdot B F$ & 3 & 4 & $3.42 \mathrm{~B}$ & $1.64 \mathrm{U}$ & $1.56 U$ & 2.88 & 2.13 (c) & 2.42 (c) \\
\hline$R-B F$ & 4 & 4 & $2.05 B(c)$ & $1.53 \mathrm{U}$ & $1.46 \mathrm{U}$ & $2.56 \mathrm{U}$ & 1.63 (c) & $4.15 U$ \\
\hline R-BF & 5 & 4 & $1.98 \mathrm{~B}$ & $1.63 \mathrm{U}$ & $1.65 \mathrm{U}$ & $2.73 \mathrm{U}$ & $1.28 \mathrm{U}$ & $4.41 \mathrm{U}$ \\
\hline
\end{tabular}


TABLE 0.5. (contd)

\begin{tabular}{|c|c|c|c|c|c|c|c|c|}
\hline \multirow[b]{2}{*}{$\begin{array}{l}\text { Sediment } \\
\text { Treatment }\end{array}$} & \multirow[b]{2}{*}{ Replicate } & \multirow[b]{2}{*}{$\begin{array}{c}\text { Analytical } \\
\text { Batch }\end{array}$} & \multicolumn{6}{|c|}{ M. nasuta LPAHs (ug/kg wet weight) } \\
\hline & & & $\begin{array}{l}\text { Naphtha- } \\
\text { lene }\end{array}$ & $\begin{array}{l}\text { Acenaph- } \\
\text { thylene }\end{array}$ & $\begin{array}{l}\text { Acenaph- } \\
\text { thene }\end{array}$ & Fluorene & $\begin{array}{l}\text { Phenan- } \\
\text { threne }\end{array}$ & $\begin{array}{l}\text { Anthra- } \\
\text { cene }\end{array}$ \\
\hline R-AM COMP & 1 & 3 & $1.49 \mathrm{~B}$ & 2.02 & 1.33 & 2.39 & 24.1 & 14.9 \\
\hline R-AM COMP & 2 & 4 & $1.92 \mathrm{~B}$ & $1.64 \mathrm{U}$ & $1.56 \mathrm{U}$ & 3.46 (c) & 14.6 & 9.23 \\
\hline R-AM COMP & 3 & 4 & $2.33 \mathrm{~B}$ & 2.26 (c) & $1.56 \mathrm{U}$ & 3.52 (c) & 25.6 & 16.1 \\
\hline R-AM COMP & 4 & 3 & $1.66 \mathrm{~B}$ & 2.14 & 1.35 & 2.95 & 20.3 & 11.6 \\
\hline R-AM COMP & 5 & 4 & $2.98 \mathrm{~B}$ & 1.92 (c) & 1.91 & 4.72 & 26.7 & 16.7 \\
\hline C-SB & 1 & 5 & 1.92 & $0.81 U$ & $0.77 \mathrm{U}$ & $1.35 \mathrm{U}$ & 1.45 & $2.18 \mathrm{U}$ \\
\hline C-SB & 2 & 5 & 1.47 & $0.81 \mathrm{U}$ & 1.01 (c) & $1.35 \mathrm{U}$ & 0.92 (c) & $2.18 \mathrm{U}$ \\
\hline C-SB & 3 & 5 & 0.80 (c) & $0.82 \mathrm{U}$ & $0.78 \mathrm{U}$ & 1.48 (c) & 1.40 (c) & $2.23 \mathrm{U}$ \\
\hline C-SB & 4 & 5 & $1.56(c)$ & $0.81 \mathrm{U}$ & $0.77 \mathrm{U}$ & $1.35 U^{\circ}$ & 1.42 (c) & $2.18 \mathrm{U}$ \\
\hline C-SB & 5 & 5 & 1.69 (c) & $0.82 U$ & $0.78 \mathrm{U}$ & $1.38 \mathrm{U}$ & 1.28 (c) & $2.23 \mathrm{U}$ \\
\hline M. nasuta Background & 1 & 3 & $1.13 \mathrm{~B}$ & $0.82 \mathrm{U}$ & 0.89 (c) & $1.38 \mathrm{U}$ & $2.86 \mathrm{~B}$ & 2.32 (c) \\
\hline M. nasuta Background & 2 & 3 & $2.16 \mathrm{~B}(\mathrm{c})$ & $1.61 \mathrm{U}$ & 1.89 & $2.70 \mathrm{U}$ & $3.45 \mathrm{~B}$ & $4.37 \mathrm{U}$ \\
\hline M. nasuta Background, Replicate 1 & 3 & 3 & $1.76 \mathrm{~B}(\mathrm{c})$ & $1.59 \mathrm{U}$ & $1.52 \mathrm{U}$ & $2.67 \mathrm{U}$ & $3.63 \mathrm{~B}$ & 4.39 (c) \\
\hline M. nasuta Background, Replicate 2 & 3 & 3 & $1.55 \mathrm{~B}(\mathrm{c})$ & $1.55 \mathrm{U}$ & 1.61 (c) & $2.59 \mathrm{U}$ & $3.75 \mathrm{~B}$ & 4.42 \\
\hline M. nasuta Background, Replicate 3 & 3 & 3 & $1.32 \mathrm{~B}(\mathrm{c})$ & $1.58 \mathrm{U}$ & 1.72 (c) & $2.64 \mathrm{U}$ & $3.68 \mathrm{~B}$ & $4.28 \mathrm{U}$ \\
\hline M. nasuta Background & 4 & 3 & $0.88 \mathrm{~B}(\mathrm{c})$ & $0.81 \mathrm{U}$ & 1.19 & $1.35 \mathrm{U}$ & $3.68 \mathrm{~B}$ & 2.34 (c) \\
\hline M. nasuta Background & 5 & 3 & $0.83 \mathrm{~B}(\mathrm{c})$ & $0.97(c)$ & 0.86 (c) & $1.38 \mathrm{U}$ & $2.68 \mathrm{~B}$ & 2.38 (c) \\
\hline
\end{tabular}

(a) DL Detection limit.

(b) U Undetected at or above detection limit.

(c) Ratio of confirmation ion to primany ion is outside of the theoretical ratio of $20 \%$ established for EPA-CLP programs. 


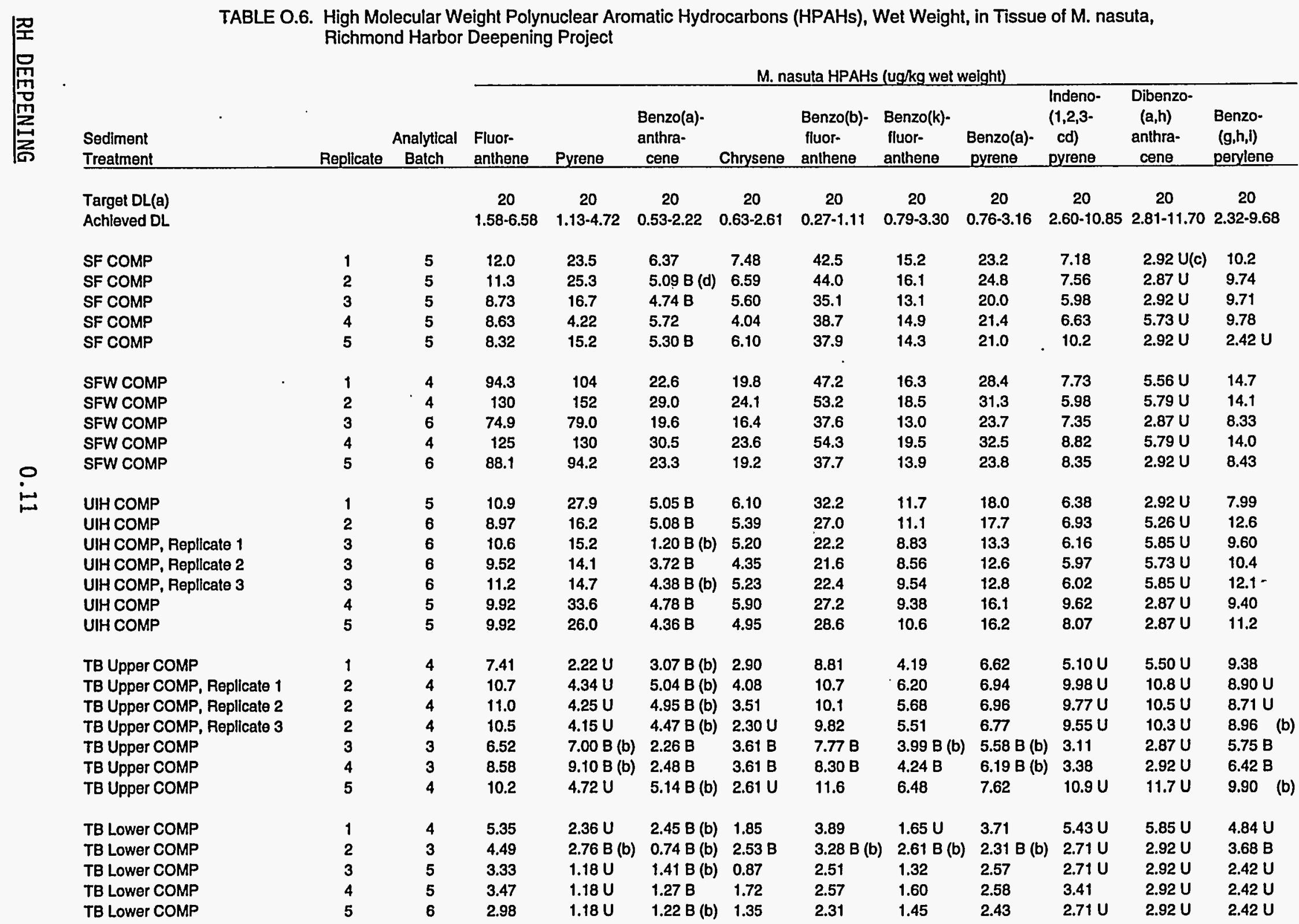




\begin{tabular}{|c|c|c|c|c|c|c|c|c|c|c|c|c|c|c|}
\hline R-OS & 1 & 5 & 3.47 & (b) & $1.16 \mathrm{U}$ & $1.35 \mathrm{~B}$ & 0.97 & 1.74 (b) & 1.36 & 1.85 & (b) & $2.66 \mathrm{U}$ & $2.87 \mathrm{U}$ & $2.37 \mathrm{U}$ \\
\hline R-OS, Repllcate 1 & 2 & 5 & 4.58 & (b) & $2.31 \mathrm{U}$ & $2.49 \mathrm{~B} \mathrm{(b)}$ & $1.28 \mathrm{U}$ & $0.54 \mathrm{U}$ & $1.62 \mathrm{U}$ & 2.23 & (b) & $5.32 \mathrm{U}$ & $5.73 \mathrm{U}$ & 5.75 (b) \\
\hline R-OS, Repllcate 2 & 2 & 5 & 5.04 & (b) & $2.29 \mathrm{U}$ & $2.22 \mathrm{~B}(\mathrm{~b})$ & $1.84 \quad$ (b) & $0.54 \mathrm{U}$ & $1.60 \mathrm{U}$ & 2.34 & (b) & $5.26 \mathrm{U}$ & $5.67 \mathrm{U}$ & $4.69 \mathrm{U}$ \\
\hline R-OS, Replicate 3 & 2 & 5 & 4.47 & (b) & $2.31 \mathrm{U}$ & $2.09 \mathrm{~B}(\mathrm{~b})$ & $1.28 \mathrm{U}$ & $0.54 \mathrm{U}$ & $1.62 \mathrm{U}$ & 2.20 & (b) & $5.32 \mathrm{U}$ & $5.73 \mathrm{U}$ & 5.58 (b) \\
\hline R-OS & 3 & 5 & 3.55 & (b) & $1.16 \mathrm{U}$ & $1.29 \mathrm{~B}(\mathrm{~b})$ & 1.42 & 2.00 (b) & $0.81 \mathrm{U}$ & 1.81 & (b) & $2.66 \mathrm{U}$ & $2.87 \mathrm{U}$ & $2.37 \mathrm{U}$ \\
\hline R.OS & 4 & 5 & 4.17 & (b) & $1.18 \mathrm{U}$ & $1.50 \mathrm{~B}$ & 1.72 & 2.11 (b) & $0.82 \mathrm{U}$ & 2.40 & (b) & $2.71 \mathrm{U}$ & $2.92 \mathrm{U}$ & $2.42 \mathrm{U}$ \\
\hline R.OS & 5 & 5 & 3.25 & (b) & $1.18 \mathrm{U}$ & $1.43 \mathrm{~B}(\mathrm{~b})$ & 1.06 & 1.81 (b) & $0.82 U$ & 1.91 & (b) & $2.71 \mathrm{U}$ & $2.92 \mathrm{U}$ & $2.42 \mathrm{U}$ \\
\hline R-BF & 1 & 4 & 12.1 & (b) & $2.31 \mathrm{U}$ & $4.56 \mathrm{~B}$ & 4.82 & 11.8 & 5.28 & 8.35 & (b) & 6.17 & $5.73 \mathrm{U}$ & 11.6 \\
\hline R-BF & 2 & 3 & 12.8 & (b) & $14.7 \mathrm{~B}(\mathrm{~b})$ & $3.34 \mathrm{~B}$ & $5.45 \mathrm{~B}$ & $10.6 \mathrm{~B}$ & $5.05 \mathrm{~B}$ & $1.90 \mathrm{~B}$ & 3 (b) & 4.30 & $2.92 \mathrm{U}$ & $7.63 \mathrm{~B}$ \\
\hline R-BF & 4 & 4 & 11.0 & (b) & $2.19 \mathrm{U}$ & $4.30 \mathrm{~B}$ & 4.49 & 9.83 & 4.31 & 6.81 & (b) & $5.05 \mathrm{U}$ & $5.44 \mathrm{U}$ & 8.55 \\
\hline R-BF & 5 & 4 & 9.78 & (b) & $2.34 \mathrm{U}$ & $3.56 \mathrm{~B}$ & 3.75 (b) & 9.32 & 4.45 & 7.01 & (b) & $5.37 U$ & $5.79 U$ & 6.85 (b) \\
\hline R-AM COMP & 1 & 3 & 111 & & 121 & 51.6 & 75.2 & 53.0 & $20.3 \mathrm{~B}$ & 48.7 & & 17.5 & 4.00 & $22.1 \mathrm{~B}$ \\
\hline R-AM COMP & 2 & 4 & 63.1 & & 57.1 & 29.2 & 42.7 & 27.3 & 12.4 & 26.0 & & 11.9 & $5.85 \mathrm{U}$ & 16.6 \\
\hline R-AM COMP & 3 & 4 & 105 & (b) & 116 & 52.9 & 69.2 & 49.5 & 19.8 & 44.9 & & 14.7 & $5.85 \mathrm{U}$ & 20.2 \\
\hline R-AM COMP & 4 & 3 & 69.8 & & 83.8 & 30.9 & 51.5 & 36.0 & $14.4 \mathrm{~B}$ & 32.1 & & 12.9 & 3.11 & $16.0 \mathrm{~B}$ \\
\hline R-AM COMP & 5 & 4 & 83.7 & (b) & 93.1 (b) & 36.8 & 55.8 & 40.9 & 16.0 & 36.9 & & 18.0 & $5.56 \mathrm{U}$ & 21.7 \\
\hline C-SB & 3 & 5 & 8.26 & (b) & $1.18 \mathrm{U}$ & $1.68 \mathrm{~B}$ & 2.18 & 3.43 & 1.34 & 2.30 & (b) & $2.71 \mathrm{U}$ & $2.92 \mathrm{U}$ & $2.42 \mathrm{U}$ \\
\hline C-SB & 4 & 5 & 6.71 & (b) & $1.16 \mathrm{U}$ & $1.82 \mathrm{~B}(\mathrm{~b})$ & 2.38 & 3.45 & 1.93 & 2.41 & (b) & $2.66 \mathrm{U}$ & $2.87 U$ & $2.37 \mathrm{U}$ \\
\hline C-SB & 5 & 5 & 5.86 & (b) & $1.18 \mathrm{U}$ & $1.66 \mathrm{~B}$ & 2.09 & $3.51 \quad$ (b) & 1.79 & 2.74 & (b) & $2.71 \mathrm{U}$ & $2.92 \mathrm{U}$ & $2.42 \mathrm{U}$ \\
\hline M. nasuta Background & 1 & 3 & 9.25 & (b) & $6.50 \mathrm{~B}(\mathrm{~b})$ & $1.49 \mathrm{~B}(\mathrm{~b})$ & $2.77 \mathrm{~B}$ & $3.03 \mathrm{~B}(\mathrm{~b})$ & $2.58 \mathrm{~B}(\mathrm{~b})$ & $3.42 \mathrm{~B}$ & 3 (b) & 3.75 & $2.92 U$ & $3.65 \mathrm{~B}(\mathrm{~b})$ \\
\hline M. nasula Background & 2 & 3 & 9.88 & (b) & $5.80 \mathrm{~B}(\mathrm{~b})$ & $2.36 \mathrm{~B}$ & $3.59 \mathrm{~B}$ & $5.38 \mathrm{~B}(\mathrm{~b})$ & $4.73 \mathrm{~B}(\mathrm{~b})$ & $4.30 \mathrm{~B}$ & 3 (b) & $5.32 \mathrm{U}$ & $5.73 \mathrm{U}$ & $4.74 \mathrm{U}$ \\
\hline M. nasuta Background, Repllcate 1 & 3 & 3 & 12.4 & (b) & $5.47 \mathrm{~B}(\mathrm{~b})$ & $2.55 \mathrm{~B}(\mathrm{~b})$ & $3.95 \mathrm{~B}$ & $5.59 \mathrm{~B}$ & $4.64 \mathrm{~B}(\mathrm{~b})$ & $4.42 \mathrm{~B}$ & 3 (b) & $5.26 \mathrm{U}$ & $5.67 \mathrm{U}$ & $4.69 \mathrm{U}$ \\
\hline M. nasuta Background, Replicate 2 & 3 & 3 & 12.2 & (b) & $5.24 \mathrm{~B}(\mathrm{~b})$ & $2.55 \mathrm{~B}$ & $3.67 \mathrm{~B}$ & $5.06 \mathrm{~B}(\mathrm{~b})$ & $4.56 \mathrm{~B}(\mathrm{~b})$ & $4.13 \mathrm{~B}$ & 3 (b) & 5.39 & $5.50 \mathrm{U}$ & $6.70 \mathrm{~B}(\mathrm{~b})$ \\
\hline M. nasula Background, Replicate 3 & 3 & 3 & 12.2 & (b) & $9.50 \mathrm{~B}(\mathrm{~b})$ & $2.44 \mathrm{~B}(\mathrm{~b})$ & $3.78 \mathrm{~B}$ & $5.55 \mathrm{~B}(\mathrm{~b})$ & $4.88 \mathrm{~B}(\mathrm{~b})$ & $4.32 \mathrm{~B}$ & 3 (b) & $5.21 \mathrm{U}$ & $5.61 \mathrm{U}$ & $6.25 \mathrm{~B}(\mathrm{~b})$ \\
\hline M. nasula Background & 4 & 3 & 10.2 & (b) & $7.18 \mathrm{~B}(\mathrm{~b})$ & $1.42 \mathrm{~B}$ & $3.02 \mathrm{~B}$ & $3.12 \mathrm{~B}(\mathrm{~b})$ & $2.678(\mathrm{~b})$ & $3.71 \mathrm{~B}$ & 3 (b) & 5.72 & $2.87 \mathrm{U}$ & $3.21 \mathrm{~B}(\mathrm{~b})$ \\
\hline M. nasuta Background & 5 & 3 & 8.29 & (b) & $6.05 \mathrm{~B}(\mathrm{~b})$ & $1.27 \mathrm{~B}(\mathrm{~b})$ & $2.50 \mathrm{~B}(\mathrm{~b})$ & $2.98 \mathrm{~B}(\mathrm{~b})$ & $2.36 \mathrm{~B}(\mathrm{~b})$ & $1.88 \mathrm{~B}$ & 3 (b) & $2.71 \mathrm{U}$ & $2.92 \mathrm{U}$ & $2.42 \mathrm{U}$ \\
\hline
\end{tabular}


TABLE 0.7. Quality Control Data for Low Molecular Weight Polynuclear Aromatic Hydrocarbons (LPAHs), Wet Weight, in Tissue of M. nasuta, Richmond Harbor Deepening Project

\begin{tabular}{|c|c|c|c|c|c|c|c|c|}
\hline \multirow[b]{2}{*}{$\begin{array}{l}\text { Sediment } \\
\text { Treatment }\end{array}$} & \multirow[b]{2}{*}{ Replicate } & \multirow[b]{2}{*}{$\begin{array}{c}\text { Analytical } \\
\text { Batch }\end{array}$} & \multicolumn{6}{|c|}{ M. nasula LPAHs (ug/kg wet weight) } \\
\hline & & & $\begin{array}{l}\text { Naphtha- } \\
\text { lene }\end{array}$ & $\begin{array}{l}\text { Acenaph- } \\
\text { thylene }\end{array}$ & $\begin{array}{l}\text { Acenaph- } \\
\text { thene. }\end{array}$ & Fluorene & $\begin{array}{l}\text { Phenan- } \\
\text { threne }\end{array}$ & $\begin{array}{c}\text { Anthra- } \\
\text { cene }\end{array}$ \\
\hline \multicolumn{9}{|l|}{ Method Blanks } \\
\hline $\begin{array}{l}\text { Blank-1 } \\
\text { Blank-1 } \\
\text { Blank-2 } \\
\text { Blank-1 } \\
\text { Blank-2 }\end{array}$ & & $\begin{array}{l}3 \\
4 \\
6 \\
5 \\
6\end{array}$ & $\begin{array}{l}1.25 \text { (a) } \\
1.79 \text { (a) } \\
0.88 \text { (a) } \\
0.60 \mathrm{U}^{-} \\
0.60 \mathrm{U}\end{array}$ & $\begin{array}{l}1.73 U(b) \\
1.79 U \\
0.82 U \\
0.97 U \\
0.97 U\end{array}$ & $\begin{array}{l}1.64 \mathrm{U} \\
1.71 \mathrm{U} \\
0.78 \mathrm{U} \\
0.92 \mathrm{U} \\
0.92 \mathrm{U}\end{array}$ & $\begin{array}{l}2.89 U \\
3.00 U \\
1.38 U \\
1.62 U \\
1.62 U\end{array}$ & $\begin{array}{l}1.62 \text { (a) } \\
1.41 U^{-1} \\
0.65 U \\
0.76 U \\
0.76 U\end{array}$ & $\begin{array}{l}4.68 \mathrm{U} \\
4.86 \mathrm{U} \\
2.23 \mathrm{U} \\
2.63 \mathrm{U} \\
2.63 \mathrm{U}\end{array}$ \\
\hline \multicolumn{9}{|l|}{ Matrix Spikes } \\
\hline $\begin{array}{l}\text { M. nasuta Background } \\
\text { M. nasuta Background, MS } \\
\text { Concentration Recovered } \\
\text { Amount Spiked } \\
\text { Percent Recovery }\end{array}$ & $\begin{array}{l}2 \\
2\end{array}$ & $\begin{array}{l}3 \\
3\end{array}$ & $\begin{array}{l}2.16 \mathrm{~B}(\mathrm{a})(\mathrm{c}) \\
44.7 \\
42.5 \\
47.6 \\
89 \%\end{array}$ & $\begin{array}{l}1.61 U \\
42.8 \\
42.8 \\
47.6 \\
90 \%\end{array}$ & $\begin{array}{l}1.89 \\
45.5 \\
43.6 \\
47.6 \\
92 \%\end{array}$ & $\begin{array}{l}2.70 \mathrm{U} \\
42.9 \\
42.9 \\
47.6 \\
90 \%\end{array}$ & $\begin{array}{l}3.45 B \\
46.5 \\
43.1 \\
47.6 \\
90 \%\end{array}$ & $\begin{array}{l}4.37 \mathrm{U} \\
46.4 \\
46.4 \\
47.6 \\
97 \%\end{array}$ \\
\hline $\begin{array}{l}\text { TB Upper COMP } \\
\text { TB Upper COMP, MS } \\
\text { Concentration Recovered } \\
\text { Amount Spiked } \\
\text { Percent Recovery }\end{array}$ & $\begin{array}{l}5 \\
5\end{array}$ & $\begin{array}{l}4 \\
4\end{array}$ & $\begin{array}{l}5.56 \mathrm{~B} \\
90.4 \\
84.8 \\
91.4 \\
93 \%\end{array}$ & $\begin{array}{l}3.29 U \\
85.2 \\
85.2 \\
91.4 \\
93 \%\end{array}$ & $\begin{array}{l}3.13 \mathrm{U} \\
89.7 \\
89.7 \\
91.4 \\
98 \%\end{array}$ & $\begin{array}{l}5.51 \mathrm{U} \\
86.1 \\
86.1 \\
91.4 \\
94 \%\end{array}$ & $\begin{array}{l}2.59 \mathrm{U} \\
83.5 \\
83.5 \\
91.4 \\
91 \%\end{array}$ & $\begin{array}{l}8.91 \mathrm{U} \\
89.0 \\
89.0 \\
91.4 \\
97 \%\end{array}$ \\
\hline $\begin{array}{l}\text { SF COMP } \\
\text { SF COMP, MS } \\
\text { Concentration Recovered } \\
\text { Amount Spiked } \\
\text { Percent Recovery }\end{array}$ & $\begin{array}{l}4 \\
4\end{array}$ & $\begin{array}{l}5 \\
5\end{array}$ & $\begin{array}{l}2.44 \\
50.5 \\
48.1 \\
50.0 \\
96 \%\end{array}$ & $\begin{array}{l}1.61 U \\
48.3 \\
48.3 \\
50.0 \\
97 \%\end{array}$ & $\begin{array}{c}1.53 \mathrm{U} \\
50.7 \\
50.7 \\
50.0 \\
101 \%\end{array}$ & $\begin{array}{l}2.70 \mathrm{U} \\
48.8 \\
48.8 \\
50.0 \\
98 \%\end{array}$ & $\begin{array}{l}1.33 \text { (a) } \\
49.1 \\
47.8 \\
50.0 \\
96 \%\end{array}$ & $\begin{array}{r}4.37 \cup \\
56.6 \\
56.6 \\
50.0 \\
113 \%\end{array}$ \\
\hline $\begin{array}{l}\text { UIH COMP } \\
\text { UIH COMP, MS } \\
\text { Concentration Recovered } \\
\text { Amount Spiked } \\
\text { Percent Recovery }\end{array}$ & $\begin{array}{l}2 \\
2\end{array}$ & $\begin{array}{l}6 \\
6\end{array}$ & $\begin{array}{l}1.24 \\
51.8 \\
50.6 \\
51.8 \\
98 \%\end{array}$ & $\begin{array}{l}1.48 \mathrm{U} \\
48.3 \\
48.3 \\
51.8 \\
93 \%\end{array}$ & $\begin{array}{l}1.41 \mathrm{U} \\
50.1 \\
50.1 \\
51.8 \\
97 \%\end{array}$ & $\begin{array}{l}2.48 \mathrm{U} \\
50.6 \\
50.6 \\
51.8 \\
98 \%\end{array}$ & $\begin{array}{l}1.17 \mathrm{U} \\
50.9 \\
50.9 \\
51.8 \\
98 \%\end{array}$ & $\begin{array}{l}4.01 U \\
59.5 \\
59.5 \\
51.8 \\
115 \%\end{array}$ \\
\hline
\end{tabular}

\section{Standard Reference Material}

Certified SRM not available for PAHs.

Anafytical Replicates

M. nasuta Background, Replicate 13 M. nasuta Background, Replicate 2 M. nasuta Background, Replicate 3

RSD

TB Upper COMP, Replicate 1 TB Upper COMP, Replicate 2 TB Upper COMP, Replicate 3

RSD

3
3
3

$\begin{array}{ll}3 & 1.76 \mathrm{~B}(\mathrm{a}) \\ 3 & 1.55 \mathrm{~B}(\mathrm{a}) \\ 3 & 1.32 \mathrm{~B}(\mathrm{a})\end{array}$

$1.59 \mathrm{U}$

$1.52 \mathrm{U}$

1.61 (a)

$2.67 \mathrm{U}$
$2.59 \mathrm{U}$

$3.63 \mathrm{~B}$

4.39 (a)

$1.32 \mathrm{~B}(\mathrm{a})$

$1.58 \mathrm{U}$

1.72 (a)

$2.64 \mathrm{U}$

$3.68 \mathrm{~B}$

4.28

$14 \%$

NA (d)

NA

NA $2 \%$

NA

$3.58 \mathrm{~B}(\mathrm{a})$
$4.80 \mathrm{~B}$

$3.02 \mathrm{U}$

$2.88 \mathrm{U}$

$2.96 \mathrm{U} \quad 2.82 \mathrm{U}$

$3.15 \mathrm{~B}$

$2.75 \mathrm{U}$

$5.07 \mathrm{U}$

$4.96 \mathrm{U}$

$2.38 U$
2.40 (a)

$8.20 \mathrm{U}$

$2.89 \mathrm{U}$

$4.85 \mathrm{U}$

$2.28 \mathrm{U}$

$8.02 \mathrm{U}$

$22 \%$

NA

NA

NA

NA

NA 
TABLE 0.7. (contd)

\begin{tabular}{|c|c|c|c|c|c|c|c|c|}
\hline \multirow[b]{2}{*}{$\begin{array}{l}\text { Sediment } \\
\text { Treatment }\end{array}$} & \multirow[b]{2}{*}{ Replicate } & \multirow[b]{2}{*}{$\begin{array}{c}\text { Analytical } \\
\text { Batch }\end{array}$} & \multicolumn{6}{|c|}{ M. nasuta LPAHs (ug/kg wet weight) } \\
\hline & & & $\begin{array}{l}\text { Naphtha- } \\
\text { lene }\end{array}$ & $\begin{array}{l}\text { Acenaph- } \\
\text { thylene }\end{array}$ & $\begin{array}{l}\text { Acenaph- } \\
\text { thene }\end{array}$ & Fluorene & $\begin{array}{l}\text { Phenan- } \\
\text { threne }\end{array}$ & $\begin{array}{l}\text { Anthra- } \\
\text { cene }\end{array}$ \\
\hline \multicolumn{9}{|c|}{ Anafytical Replicates (contd) } \\
\hline $\begin{array}{l}\text { R.OS, Replicate } 1 \\
\text { R-OS, Replicate } 2 \\
\text { R-OS, Replicate } 3\end{array}$ & $\begin{array}{l}2 \\
2 \\
2\end{array}$ & $\begin{array}{l}5 \\
5 \\
5\end{array}$ & $\begin{array}{l}2.06 \\
2.56(a) \\
2.00\end{array}$ & $\begin{array}{l}1.61 \mathrm{U} \\
1.59 \mathrm{U} \\
1.61 \mathrm{U}\end{array}$ & $\begin{array}{l}1.53 \mathrm{U} \\
1.52 \mathrm{U} \\
1.53 \mathrm{U}\end{array}$ & $\begin{array}{l}2.70 \mathrm{U} \\
2.67 \mathrm{U} \\
2.70 \mathrm{U}\end{array}$ & $\begin{array}{l}1.27 U \\
1.26 U \\
1.27 U\end{array}$ & $\begin{array}{l}4.37 U \\
4.32 U \\
4.37 U\end{array}$ \\
\hline RSD & & & $14 \%$ & NA & NA & NA & NA & NA \\
\hline $\begin{array}{l}\text { UIH COMP, Replicate } 1 \\
\text { UIH COMP, Replicate } 2 \\
\text { UIH COMP, Replicate } 3\end{array}$ & $\begin{array}{l}3 \\
3 \\
3\end{array}$ & $\begin{array}{l}6 \\
6 \\
6\end{array}$ & $\begin{array}{l}2.39 \\
1.39 \\
3.67\end{array}$ & $\begin{array}{l}1.64 \mathrm{U} \\
1.61 \mathrm{U} \\
1.64 \mathrm{U}\end{array}$ & $\begin{array}{l}1.56 \mathrm{U} \\
1.53 \mathrm{U} \\
1.56 \mathrm{U}\end{array}$ & $\begin{array}{l}2.75 U \\
2.70 U \\
2.75 U\end{array}$ & $\begin{array}{l}1.30 \\
1.55 \\
1.80 \quad(a)\end{array}$ & $\begin{array}{l}4.46 U \\
4.37 U \\
4.46 U\end{array}$ \\
\hline RSD & & & $46 \%$ & NA & NA & NA & $16 \%$ & NA \\
\hline
\end{tabular}

(a) Ratio of confirmation ion to primary ion is outside of the theoretical ratio of $20 \%$ established for EPA-CLP programs.

(b) U Undetected at or above detection limit.

(c) B Analyte detected in sample at less than five times value in associated method blank.

(d) NA Not applicable. 


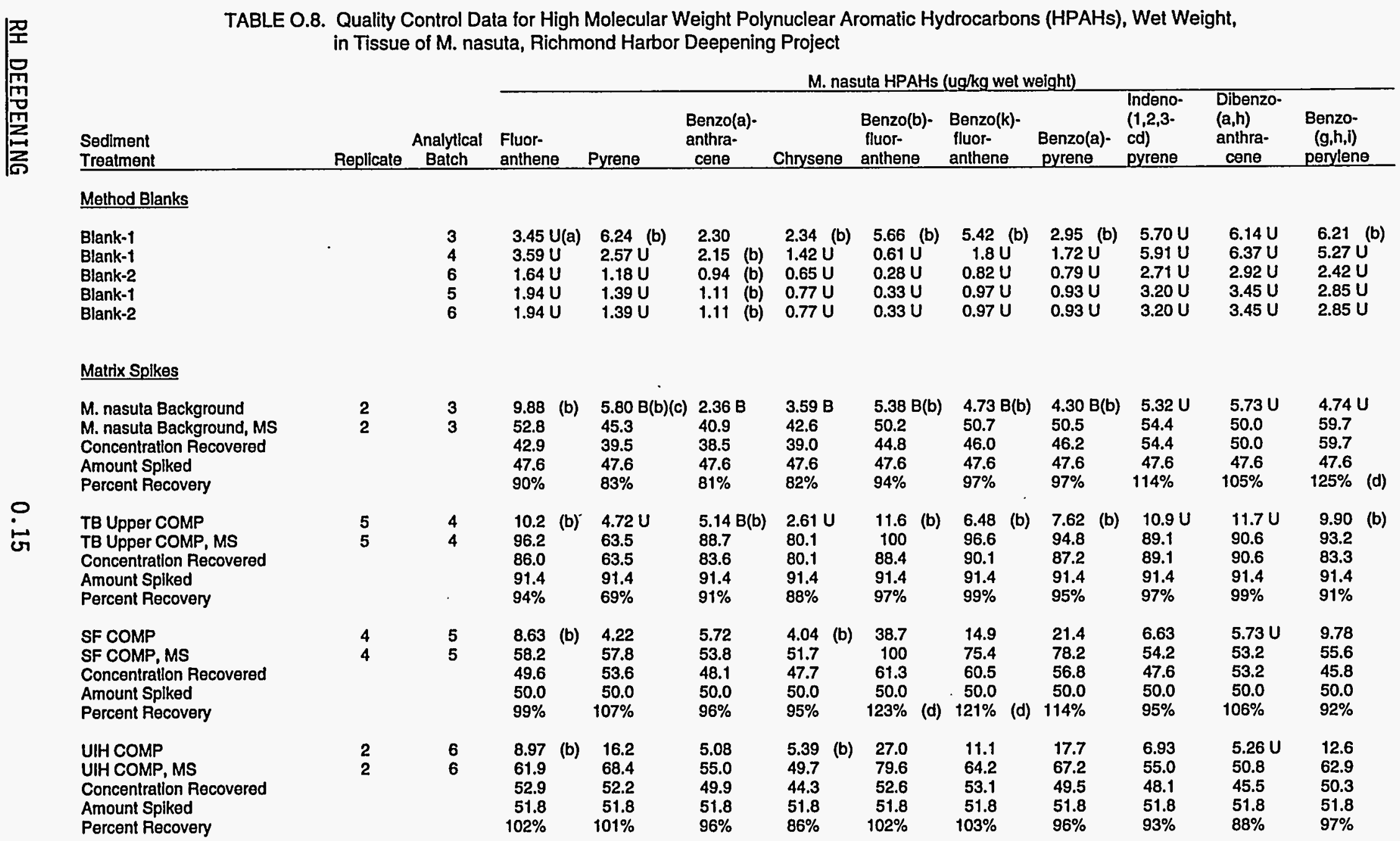


TABLE 0.8. (contd)

M. nasuta HPAHs (ug/kg wet weight)

Sediment

Treatment

Standard Reference Material

Certfled SRM not avallable for PAHs.

Analytical Replicales

M. nasuta Background, Repllcate 1

M. nasuta Background, Replicate 3

RSD

TB Upper COMP, Replicate 1

TB Upper COMP, Repllcate 2

TB Upper COMP, Replicate 3

ASD

R-OS, Replicate 1

R-OS, Replicate 3

RSD

UIH COMP, Replicate 1

UIH COMP, Replicate 2

UIH COMP, Replicate 3

RSD

2
2
2

3
3
3

$\begin{array}{rrrr}12.4 & \text { (b) } & 5.47 \mathrm{~B}(\mathrm{~b}) \\ 12.2 & \text { (b) } & 5.24 \mathrm{~B}(\mathrm{~b}) \\ 12.2 & \text { (b) } & 9.50 \mathrm{~B}(\mathrm{~b}) \\ 1 \% & & 36 \% & \text { (e) } \\ 1 \% & & & \\ 10.7 & \text { (b) } & 4.34 \mathrm{U} \\ 11.0 & \text { (b) } & 4.25 \mathrm{U} \\ 10.5 & \text { (b) } & 4.15 \mathrm{U} \\ & & & \\ 2 \% & & \mathrm{NA}\end{array}$

$2.55 \mathrm{~B}$ (b) $3.95 \mathrm{~B}$

$\begin{array}{llllll}5.59 \mathrm{~B} & 4.64 \mathrm{~B}(\mathrm{~b}) & 4.42 \mathrm{~B}(\mathrm{~b}) & 5.26 \mathrm{U} & 5.67 \mathrm{U} & 4.69 \mathrm{U}\end{array}$

$\begin{array}{llllllll}2.55 \mathrm{~B} & 3.67 \mathrm{~B} & 5.06 \mathrm{~B}(\mathrm{~b}) & 4.56 \mathrm{~B}(\mathrm{~b}) & 4.13 \mathrm{~B}(\mathrm{~b}) & 5.39 & 5.50 \mathrm{U} & 6.70 \mathrm{~B}(\mathrm{~b})\end{array}$

$\begin{array}{llllllll}2.44 \mathrm{~B}(\mathrm{~b}) & 3.78 \mathrm{~B} & 5.55 \mathrm{~B}(\mathrm{~b}) & 4.88 \mathrm{~B}(\mathrm{~b}) & 4.32 \mathrm{~B}(\mathrm{~b}) & 5.21 \mathrm{U} & 5.61 \mathrm{U} & 6.25 \mathrm{~B}(\mathrm{~b})\end{array}$

$3 \%$

$4 \%$

$5 \%$

$4 \%$

$3 \%$

NA (f) NA

NA

5.048 (b) 4.08 (b) 10.7

$\begin{array}{ll}4.95 \mathrm{~B}(\mathrm{~b}) & 3.51 \mathrm{u}^{(\mathrm{b})} \\ 4.47 \mathrm{~B}(\mathrm{~b}) & 2.30 \mathrm{u}\end{array}$

$10.7 \quad 6.20 \quad$ (b)

$\begin{array}{lllllll}10.1 & \text { (b) } 5.68 & \text { (b) } 6.96 & \text { (b) } 9.77 U & 10.5 \cup & 8.71 U\end{array}$

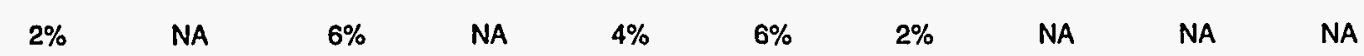

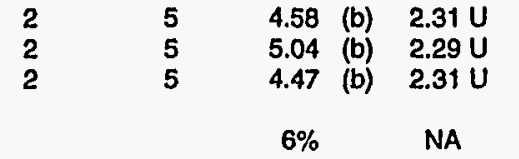

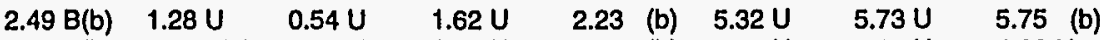

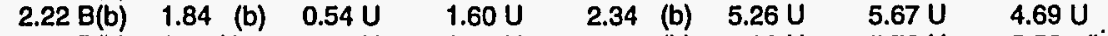

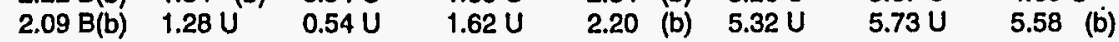

$6 \%$

$9 \%$

NA

NA

NA

$3 \%$

NA

NA

NA

3
3
3

$\begin{array}{llll}10.6 & \text { (b) } & 15.2 & \text { (b) } \\ 9.52 & \text { (b) } & 14.1 & \\ 11.2 & \text { (b) } & 14.7 & \text { (b) } \\ & & & \\ 8 \% & & 4 \% & \end{array}$

$1.20 \mathrm{~B}(\mathrm{~b}) \quad 5.20$

$\begin{array}{ll}3.72 \mathrm{~B} & 4.35 \\ 4.38 \mathrm{~B}(\mathrm{~b}) & 5.23\end{array}$

22.2
21.6

21.6
22.4

8.83

8.56

9.54

13.3

$12.6 \quad 6.16$

12.8 (b) 6.0

$5.85 \mathrm{U} \quad 9.60$

$54 \%$ (e) $10 \%$

$2 \% \quad 6 \%$

$3 \%$

$2 \%$

$5.85 \mathrm{U}$

10.4

12.1

(a) U Undetected at or above detection limit.

(b) Ratlo of confirmation lon to primary lon is outside of the theoretical ratio of $20 \%$ established for EPA-CLP programs.

(c) B Analyte delected in sample at less than five times value in associated method blank

(d) Outside quality control criteria $(40-120 \%)$ for matrix spike recoveries.

(e) Value exceeds relative precision goal of $<30 \%$ ).

(f) NA Not applicable. 


\begin{tabular}{|c|c|c|c|c|c|c|c|c|c|c|}
\hline \multirow[b]{2}{*}{$\begin{array}{l}\text { Sediment } \\
\text { Treatment }\end{array}$} & \multirow[b]{2}{*}{ Replicate } & \multirow[b]{2}{*}{$\begin{array}{c}\text { Analytical } \\
\text { Batch }\end{array}$} & \multirow[b]{2}{*}{$\begin{array}{c}\text { Percent } \\
\text { Dry } \\
\text { Weight }\end{array}$} & \multicolumn{7}{|c|}{ M. nasuta phthalate esters (ug/kg dry weight) } \\
\hline & & & & $\begin{array}{l}\text { Dimethyl } \\
\text { Phthalate }\end{array}$ & $\begin{array}{l}\text { Diethyl } \\
\text { Phthalate }\end{array}$ & $\begin{array}{l}\text { Di-n-butyl } \\
\text { Phthalate }\end{array}$ & $\begin{array}{l}\text { Butyl } \\
\text { benzyl } \\
\text { Phthalate }\end{array}$ & & $\begin{array}{l}\text { Bis } \\
\text { (2-ethylhexyl) } \\
\text { Phthalate }\end{array}$ & $\begin{array}{l}\text { Di-n-octyl } \\
\text { Phthalate }\end{array}$ \\
\hline $\begin{array}{l}\text { SF COMP } \\
\text { SF COMP } \\
\text { SF COMP } \\
\text { SF COMP } \\
\text { SF COMP }\end{array}$ & $\begin{array}{l}1 \\
2 \\
3 \\
4 \\
5\end{array}$ & $\begin{array}{l}5 \\
5 \\
5 \\
5 \\
5\end{array}$ & $\begin{array}{l}12.76 \\
12.94 \\
12.26 \\
12.60 \\
14.42\end{array}$ & $\begin{array}{l}157 U(a) \\
151 U \\
163 U \\
311 U \\
139 U\end{array}$ & $\begin{array}{l}196 \mathrm{~B}(\mathrm{~b}) \\
282 \mathrm{~B} \\
232 \mathrm{~B} \\
467 \mathrm{~B} \\
262 \mathrm{~B}\end{array}$ & $\begin{array}{l}157 \mathrm{U} \\
186 \mathrm{~B} \\
166 \mathrm{~B} \\
615 \mathrm{~B} \\
139 \mathrm{U}\end{array}$ & $\begin{array}{l}831 \\
673 \\
527 \\
532 \\
310\end{array}$ & $\begin{array}{l}\text { (c) } \\
\text { (c) } \\
\text { (c) } \\
\text { (c) }\end{array}$ & $\begin{array}{r}815 \\
966 \\
664 \\
1230 \\
621\end{array}$ & $\begin{array}{l}157 U \\
151 U \\
163 U \\
311 U \\
139 U\end{array}$ \\
\hline $\begin{array}{l}\text { SFW COMP } \\
\text { SFW COMP } \\
\text { SFW COMP } \\
\text { SFW COMP } \\
\text { SFW COMP }\end{array}$ & $\begin{array}{l}1 \\
2 \\
3 \\
4 \\
5\end{array}$ & $\begin{array}{l}4 \\
4 \\
6 \\
4 \\
6\end{array}$ & $\begin{array}{l}14.61 \\
17.91 \\
14.49 \\
14.31 \\
14.58\end{array}$ & $\begin{array}{l}260 U \\
221 U \\
135 U \\
277 U \\
137 U\end{array}$ & $\begin{array}{l}363 \mathrm{~B} \\
248 \mathrm{~B} \\
214 \mathrm{~B} \\
277 \mathrm{U} \\
183 \mathrm{~B}\end{array}$ & $\begin{array}{l}529 \\
221 \mathrm{U} \\
266 \\
541 \\
234\end{array}$ & $\begin{array}{l}605 \\
547 \\
423 \\
525 \\
367\end{array}$ & $\begin{array}{l}\text { (c) } \\
(c) \\
(c) \\
(c) \\
(c)\end{array}$ & $\begin{array}{l}1080 \\
804 \quad(c) \\
669 \mathrm{~B}(\mathrm{~b}) \\
915 \\
584 \mathrm{~B}\end{array}$ & $\begin{array}{l}260 U \\
221 U \\
135 U \\
277 U \\
137 U\end{array}$ \\
\hline $\begin{array}{l}\text { UIH COMP } \\
\text { UIH COMP } \\
\text { UIH COMP, Replicate } 1 \\
\text { UIH COMP, Replicate } 2 \\
\text { UIH COMP, Replicate } 3 \\
\text { UIH COMP } \\
\text { UIH COMP }\end{array}$ & $\begin{array}{l}1 \\
2 \\
3 \\
3 \\
3 \\
4 \\
5\end{array}$ & $\begin{array}{l}5 \\
6 \\
6 \\
6 \\
6 \\
5 \\
5\end{array}$ & $\begin{array}{l}13.71 \\
14.06 \\
13.52 \\
13.52 \\
13.52 \\
15.23 \\
13.02\end{array}$ & $\begin{array}{l}146 U \\
256 U \\
296 U \\
290 U \\
296 U \\
129 U \\
151 U\end{array}$ & $\begin{array}{l}146 \mathrm{U} \\
341 \mathrm{~B} \\
296 \mathrm{U} \\
425 \mathrm{~B} \\
473 \mathrm{~B} \\
134 \mathrm{~B}(\mathrm{~b}) \\
157 \mathrm{~B}\end{array}$ & $\begin{array}{l}146 \mathrm{U} \\
464 \\
296 \mathrm{U} \\
1240 \\
570 \\
320 \mathrm{~B} \\
151 \mathrm{U}\end{array}$ & $\begin{array}{l}766 \\
635 \\
581 \\
649 \\
791 \\
650 \\
799\end{array}$ & $\begin{array}{l}\text { (c) } \\
\text { (c) } \\
\text { (c) }\end{array}$ & $\begin{array}{r}832 \\
903 \mathrm{~B}(\mathrm{~b}) \\
1050 \mathrm{~B}(\mathrm{~b}) \\
984 \mathrm{~B}(\mathrm{~b}) \\
1040 \mathrm{~B}(\mathrm{~b}) \\
775 \quad \text { (c) } \\
998 \quad(\mathrm{c})\end{array}$ & $\begin{array}{l}146 U \\
256 U \\
296 U \\
290 U \\
296 U \\
129 U \\
151 U\end{array}$ \\
\hline $\begin{array}{l}\text { TB Upper COMP } \\
\text { TB Upper COMP, Replicate } 1 \\
\text { TB Upper COMP, Replicate } 2 \\
\text { TB Upper COMP, Replicate } 3 \\
\text { TB Upper COMP } \\
\text { TB Upper COMP } \\
\text { TB Upper COMP }\end{array}$ & $\begin{array}{l}1 \\
2 \\
2 \\
2 \\
3 \\
3 \\
4 \\
5\end{array}$ & $\begin{array}{l}4 \\
4 \\
4 \\
4 \\
3 \\
3 \\
4\end{array}$ & $\begin{array}{l}15.21 \\
14.75 \\
14.75 \\
14.75 \\
13.66 \\
15.16 \\
15.00\end{array}$ & $\begin{array}{l}247 U \\
499 U \\
488 U \\
477 U \\
143 U \\
132 U \\
533 U\end{array}$ & $\begin{array}{r}953 \mathrm{~B} \\
1831 \mathrm{~B} \\
1400 \mathrm{~B} \\
1660 \mathrm{~B} \\
143 \mathrm{U} \\
132 \mathrm{U} \\
1580 \mathrm{~B}\end{array}$ & $\begin{array}{l}300 \\
567 \\
566 \\
634 \\
143 \cup \\
158 \\
650\end{array}$ & $\begin{array}{l}548 \\
499 \text { U } \\
506 \\
483 \\
988 \\
732 \\
707\end{array}$ & $\begin{array}{l}\text { (c) } \\
\text { (c) } \\
\text { (c) }\end{array}$ & $\begin{array}{r}927 \\
1170 \\
1110 \\
1130 \\
981 \\
831 \\
1230\end{array}$ & $\begin{array}{l}247 U \\
499 U \\
488 U \\
477 U \\
143 U \\
132 U \\
533 U\end{array}$ \\
\hline $\begin{array}{l}\text { TB Lower COMP } \\
\text { TB Lower COMP } \\
\text { TB Lower COMP } \\
\text { TB Lower COMP } \\
\text { TB Lower COMP }\end{array}$ & $\begin{array}{l}1 \\
2 \\
3 \\
4 \\
5\end{array}$ & $\begin{array}{l}4 \\
3 \\
5 \\
5 \\
6\end{array}$ & $\begin{array}{l}13.17 \\
13.30 \\
12.74 \\
12.37 \\
13.89\end{array}$ & $\begin{array}{l}304 U \\
150 U \\
157 U \\
162 U \\
144 U\end{array}$ & $\begin{array}{l}311 \mathrm{~B} \\
150 \mathrm{U} \\
199 \mathrm{~B} \\
229 \mathrm{~B} \\
274 \mathrm{~B}(\mathrm{~b})\end{array}$ & $\begin{array}{l}503 \\
150 \mathrm{U} \\
157 \mathrm{U} \\
193 \mathrm{~B} \\
279 \mathrm{~B}\end{array}$ & $\begin{array}{l}534 \\
533 \\
934 \\
632 \\
145\end{array}$ & $\begin{array}{l}\text { (c) } \\
\text { (c) } \\
\text { (c) }\end{array}$ & $\begin{aligned} 858 & \text { (c) } \\
812 & \\
673 & \text { (c) } \\
1080 & \\
361 & \end{aligned}$ & $\begin{array}{l}304 U \\
150 U \\
157 U \\
162 U \\
144 U\end{array}$ \\
\hline
\end{tabular}


TABLE 0.9. (contd)

Treatment

Percent

Analytical Dry

\begin{tabular}{ccccc} 
M. nasuta phthalate esters (ug/kg dry weight) \\
\hline Dimethyl Diethyl Di-n-butyl & $\begin{array}{c}\text { Butyl } \\
\text { benzyl }\end{array}$ & (2-ethylhexyl) & Di-n-octyl
\end{tabular}

R-OS

R-OS, Replicate 1

R-OS, Replicate 2

R-OS, Replicate 3

R-OS

R-OS

R-OS

R-BF

R-BF

$\mathrm{R}-\mathrm{BF}$

$R-B F$

R-BF

R-AM COMP

$\begin{array}{ll}0 & \text { R-AM COMP } \\ i \infty & \text { R-AM COMP } \\ \infty & \text { R-AM COMP }\end{array}$

R-AM COMP

C-SB

C-SB

C-SB

C-SB

C-SB

M. nasula Background

M. nasuta Background

M. nasuta Background, Replicate 1

M. nasuta Background, Replicate 2

M. nasula Background, Replicate 3

M. nasula Background

M. nasuta Background

Replicate $\begin{gathered}\text { Analytical } \\ \text { Batch }\end{gathered}$

Phthalate Phthalate Phthalate Phthalate Phthalate

Phthalate

1
2
2
2
3
4
5
1
2
3
4
5

12.71

$154 U$

$300 \mathrm{~B}(\mathrm{~b})$
$616 \mathrm{~B}$

$736 \mathrm{~B}$

12.62

311

616

$311 \mathrm{U}$

$464 \mathrm{~B}$

$307 \mathrm{~B}$

549 (c) 723

(c)

$154 \mathrm{U}$

12.62

13.84

$142 U$

$198 \mathrm{~B}$

$370 \mathrm{~B}$

666 (c) 1070

677 (c) $967 \quad$ (c)

(c) $307 \mathrm{U}$

$1269 \quad 158 \mathrm{U} \quad 198 \mathrm{~B}$

13.41

$149 U$

$183 \mathrm{~B}$

$142 \mathrm{U} \quad 525$ (c) 622

$325 \mathrm{~B}(\mathrm{~b}) \quad 883 \quad$ (c) $835 \quad$ (c)

$311 \mathrm{U}$

$\begin{array}{lllll}B(b) & 883 & \text { (c) } 835 & \text { (c) } 158 \mathrm{U}\end{array}$

15.28

$257 \mathrm{U}$

$397 \mathrm{~B}$

$137 U$

$137 \mathrm{U}$

451

143

479 (c)

658

$149 U$

14.78

$271 \mathrm{U}$

$421 \mathrm{~B}$

516

489 (c) 988

$840 \quad 908$

$\begin{array}{llll}578 & \text { (c) } 954 \quad \text { (c) }\end{array}$

$257 \mathrm{U}$

15.91
14.92

$265 \mathrm{U}$

295 B 311

$\begin{array}{llll}660 & \text { (c) } & 918 & \text { (c) } \\ 422 & \text { (c) } & 744 & \text { (c) }\end{array}$

$137 \mathrm{U}$

$\begin{array}{lll}1 & 3 & 15.79\end{array}$

13.81

$124 \mathrm{U}$

$290 \mathrm{U}$

$124 U$

$124 U$

$\begin{array}{lll}652 & & 912 \\ 356 & \text { (c) } & 700\end{array}$

$1060 \mathrm{~B} \quad 481$

15.44

259

$751 \mathrm{~B}$

$259 \mathrm{U}$

699 (c) 920

14.52

$258 \mathrm{U}$

372 B

132 U 625

$124 \mathrm{U}$

14.71

$136 \mathrm{U}$

13.25

$148 \mathrm{U}$

$141 \mathrm{~B}$

333

809 (c) 1560

$290 \mathrm{U}$

14.03

$143 \mathrm{U}$

$198 \mathrm{~B}$

$136 \mathrm{U}$

667 (c) $901 \quad$ (c)

2590

13.57

$144 \mathrm{U}$

$220 \mathrm{~B}$

$148 \mathrm{U}$

13.60

$147 \mathrm{U}$

U 144 U

$\begin{array}{llll}796 & \text { (c) } 936 & \text { (c) } 144 \mathrm{U}\end{array}$

$144 \mathrm{U} \quad 144$

$147 \mathrm{U}$

846

882 (c)

$144 U$

13.46

$149 \mathrm{U}$

181

$149 \mathrm{U}$

$149 \mathrm{U}$

491

$149 \mathrm{U}$

12.00
13.05

$327 \mathrm{U}$
$297 \mathrm{U}$

$327 \mathrm{U}$

$327 \mathrm{U}$

$327 \mathrm{U}$

698

$327 \mathrm{U}$

13.05

$288 \mathrm{U}$

$288 \mathrm{U}$

338

$297 \mathrm{U}$

717

$297 U$

13.05

294 U

$294 U$

$294 U$

$288 \mathrm{U}$

542

$138 \mathrm{U}$.

$138 \mathrm{U} \quad 138 \mathrm{U}$

$113 \mathrm{U}$

280

$294 U$

$138 U$

(a) U Undetected at or above detection limit.

(b) B Analyte detected in sample at less than five times value in associated method blank.

(c) Ratio of confirmation ion to primary ion is outside of the theoretical ratio of $20 \%$ established for EPA-CLP programs. 


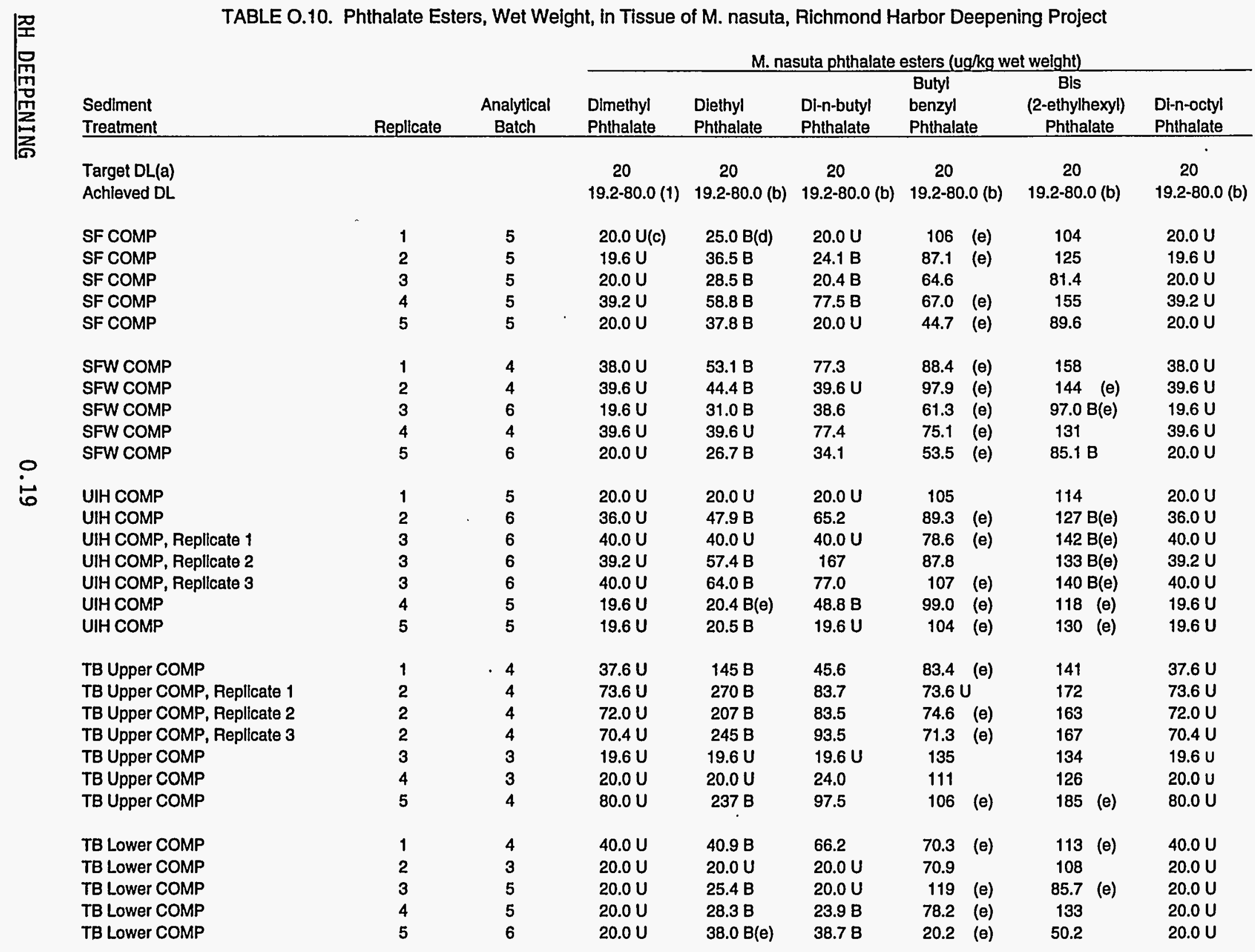


TABLE O.10. (contd)

\begin{tabular}{|c|c|c|c|c|c|c|c|c|}
\hline \multirow[b]{2}{*}{$\begin{array}{l}\text { Sediment } \\
\text { Treatment }\end{array}$} & \multirow[b]{2}{*}{ Replicato } & \multirow[b]{2}{*}{$\begin{array}{c}\text { Analytical } \\
\text { Batch }\end{array}$} & \multicolumn{6}{|c|}{ M. nasuta phthalate esters (ug $/ \mathrm{kg}$ wet weight) } \\
\hline & & & $\begin{array}{l}\text { Dimethyl } \\
\text { Phthalate }\end{array}$ & $\begin{array}{l}\text { Diethyl } \\
\text { Phthalate }\end{array}$ & $\begin{array}{l}\text { Di-n-butyl } \\
\text { Phthalate }\end{array}$ & $\begin{array}{l}\text { Butyl } \\
\text { benzyl } \\
\text { Phthalate }\end{array}$ & $\begin{array}{c}\text { Bis } \\
\text { (2-ethylhexyl) } \\
\text { Phthalate }\end{array}$ & $\begin{array}{l}\text { Di-n-octyl } \\
\text { Phithalate }\end{array}$ \\
\hline A-OS & 1 & 5 & $19.6 \mathrm{U}$ & $38.1 \mathrm{~B}(\mathrm{~d})$ & $55.4 \mathrm{~B}$ & 69.8 & $91.9(\mathrm{e})$ & $19.6 \mathrm{U}$ \\
\hline R-OS, Replicate 1 & 2 & 5 & $39.2 \mathrm{U}$ & $77.8 \mathrm{~B}$ & $94.2 \mathrm{~B}$ & $84.0(\theta)$ & 135 & $39.2 U$ \\
\hline R-OS, Replicate 2 & 2 & 5 & 38.8 & $58.5 \mathrm{~B}$ & $38.8 \mathrm{~B}$ & $85.4(e)$ & $122(\theta)$ & $38.8 \mathrm{U}$ \\
\hline R-OS, Replicate 3 & 2 & 5 & $39.2 \mathrm{U}$ & $69.0 \mathrm{~B}$ & $46.7 \mathrm{~B}$ & $78.2(e)$ & 138 & $39.2 \mathrm{U}$ \\
\hline R-OS & 3 & 5 & $19.6 \mathrm{U}$ & $27.4 \mathrm{~B}$ & $19.6 U$ & $72.6 \quad(e)$ & $86.1(e)$ & $19.6 \mathrm{U}$ \\
\hline R-OS & 4 & 5 & $20.0 \mathrm{U}$ & $35.6 \mathrm{~B}$ & $41.3 \mathrm{~B}(\theta)$ & $112(e)$ & $106(e)$ & $20.0 \mathrm{U}$ \\
\hline R-OS & 5 & 5 & $20.0 \mathrm{U}$ & $24.6 \mathrm{~B}$ & $36.4 \mathrm{~B}$ & $64.2(\theta)$ & 88.3 & $20.0 \mathrm{U}$ \\
\hline R-BF & 1 & 4 & $39.2 \mathrm{U}$ & $60.6 \mathrm{~B}$ & 68.9 & 74.7 & 151 & $39.2 \mathrm{U}$ \\
\hline R-BF & 2 & 3 & $20.0 \mathrm{U}$ & $20.0 \mathrm{U}$ & 21.0 & 123 & 133 & $20.0 \mathrm{U}$ \\
\hline R-BF & 3 & 4 & $40.0 \mathrm{U}$ & $62.2 \mathrm{~B}$ & 76.2 & $85.4 \quad(\theta)$ & $141(e)$ & $40.0 \mathrm{U}$ \\
\hline$R-B F$ & 4 & 4 & $37.2 \mathrm{U}$ & $109 \mathrm{~B}$ & 78.2 & $105(e)$ & $146(e)$ & $37.2 \mathrm{U}$ \\
\hline R-BF & 5 & 4 & $39.6 U$ & $44.0 \mathrm{~B}$ & 46.4 & $62.9\langle e\rangle$ & $111(e)$ & $39.6 \mathrm{U}$ \\
\hline R-AM COMP & 1 & 3 & $19.6 U$ & $19.6 U$ & $19.6 U$ & 103 & 144 & $19.6 U$ \\
\hline R-AM COMP & 2 & 4 & $40.0 \mathrm{U}$ & $147 \mathrm{~B}$ & 66.4 & 49.2 (e) & 96.7 & $40.0 \mathrm{U}$ \\
\hline R-AM COMP & 3 & 4 & $40.0 \mathrm{U}$ & $116 \mathrm{~B}$ & $40.0 \mathrm{U}$ & $108(\theta)$ & $142(e)$ & $40.0 \mathrm{U}$ \\
\hline R-AM COMP & 4 & 3 & $19.2 U$ & 22.5 & $19.2 U$ & $19.2 U$ & 90.7 & $19.2 \mathrm{U}$ \\
\hline R-AM COMP & 5 & 4 & $38.0 \mathrm{U}$ & $54.7 \mathrm{~B}$ & 49.0 & $119(\theta)$ & 229 & $38.0 \mathrm{U}$ \\
\hline C-SB & 1 & 5 & $19.6 U$ & $20.4 \mathrm{~B}$ & $19.6 U$ & $96.3(e)$ & $130(\theta)$ & $19.6 U$ \\
\hline C-SB & 2 & 5 & $19.6 U$ & $26.3 \mathrm{~B}$ & $19.6 U$ & $112(\theta)$ & $94.0(e)$ & $19.6 \mathrm{U}$ \\
\hline C-SB & 3 & 5 & $20.0 \mathrm{U}$ & $30.8 \mathrm{~B}$ & $20.0 \mathrm{U}$ & $117(e)$ & 112 & $20.0 \mathrm{U}$ \\
\hline C-SB & 4 & 5 & $19.6 \mathrm{U}$ & $19.6 U$ & $19.6 \mathrm{U}$ & $108(\theta)$ & $127(\theta)$ & $19.6 U$ \\
\hline C-SB & 5 & 5 & $20.0 \mathrm{U}$ & $32.3 \mathrm{~B}$ & $20.0 \mathrm{U}$ & $115(\theta)$ & $120(e)$ & $20.0 \mathrm{U}$ \\
\hline M. nasula Background & 1 & 3 & $20.0 \mathrm{U}$ & 24.3 & $20.0 \mathrm{U}$ & $20.0 \mathrm{U}$ & 66.1 & $20.0 \mathrm{U}$ \\
\hline M. nasuta Background & 2 & 3 & $39.2 \mathrm{U}$ & $39.2 \mathrm{U}$ & $39.2 \mathrm{U}$ & $39.2 U$ & 83.8 & $39.2 U$ \\
\hline M. nasuta Background, Replicate 1 & 3 & 3 & $38.8 U$ & $38.8 \mathrm{U}$ & $38.8 \mathrm{U}$ & $38.8 U$ & 93.6 & $38.8 \mathrm{U}$ \\
\hline M. nasuta Background, Replicate 2 & 3 & 3 & $37.6 \mathrm{U}$ & $37.6 \mathrm{U}$ & 44.1 & $37.6 \mathrm{U}$ & 70.7 & $37.6 U$ \\
\hline M. nasuta Background, Replicale 3 & 3 & 3 & $38.4 \mathrm{U}$ & $38.4 \mathrm{U}$ & $38.4 U$ & $38.4 U$ & 70.4 & $38.4 \mathrm{U}$ \\
\hline M. nasuta Background & 4 & 3 & $19.6 \mathrm{U}$ & $19.6 U$ & $19.6 U$ & $19.6 \mathrm{U}$ & 62.9 & $19.6 \mathrm{U}$ \\
\hline M. nasuta Background & 5 & 3 & $20.0 U$ & $20.0 \mathrm{U}$ & $20.0 \mathrm{U}$ & $20.0 \mathrm{U}$ & 49.4 & $20.0 \mathrm{U}$ \\
\hline
\end{tabular}

(a) DL Detection limit.

(b) Detection limit derived from lowest calibration standard as sample.

(c) U Undelected at or above detection limit.

(d) B Analyte detected in sample at less than five times value in associated method blank.

(e) Ratio of confirmation ion to primary ion is outside of the theoretical ratio of

$20 \%$ established for EPA-CLP programs. 
TABLE 0.11. Quality Control Data for Phthalate Esters, Wet Weight, in Tissue of M. nasuta, Richmond Harbor Deepening Project

Method Blanks

Blank-1

Blank-1

Blank-2

Blank-1

Blank-2

\section{Matrix Spikes}

M. nasuta Background

M. nasula Background, MS

Concentration Recovered

Amount Spiked

Percent Recovery

TB Upper COMP

TB Upper COMP, MS

Concentration Recovered

Amount Spiked

Percent Recovery

SF COMP

SF COMP, MS

Concentration Recovered

Amount Splked

Percent Recovery

UIH COMP

UIH COMP, MS

Concentration Recovered

Amount Spiked

Percent Recovery

$\begin{array}{llllrrr}3 & 42.0 \mathrm{U}(\mathrm{a}) & 42.0 \mathrm{U} & 42.0 \mathrm{U} & 42.0 \mathrm{U} & 42.0 \mathrm{U} & 42.0 \mathrm{U} \\ 4 & 43.6 \mathrm{U} & 132 & 43.6 \mathrm{U} & 43.6 \mathrm{U} & 43.6 \mathrm{U} & 43.6 \mathrm{U} \\ 6 & 20 \mathrm{U} & 36.9 & 29.1 & 20 \mathrm{U} & 20 \mathrm{U} & 20 \mathrm{U} \\ 5 & 23.6 \mathrm{U} & 48.9 & 25.2 & 23.6 \mathrm{U} & 23.6 \mathrm{U} & 23.6 \mathrm{U} \\ 6 & 23.6 \mathrm{U} & 34.9 & 23.6 \mathrm{U} & 23.6 \mathrm{U} & 33.0 & 23.6 \mathrm{U}\end{array}$

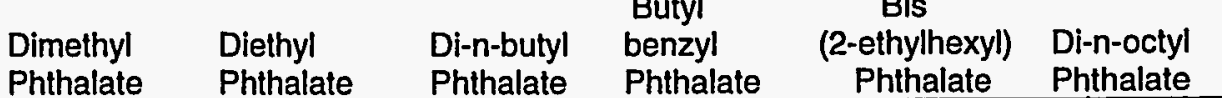

\begin{tabular}{|c|c|c|c|c|c|c|c|}
\hline $\begin{array}{l}2 \\
2\end{array}$ & $\begin{array}{l}3 \\
3\end{array}$ & $\begin{array}{c}39.2 \mathrm{U} \\
314 \\
314 \\
762 \\
41 \%\end{array}$ & $\begin{array}{c}39.2 U \\
370 \\
370 \\
762 \\
49 \%\end{array}$ & $\begin{array}{c}39.2 \mathrm{U} \\
413 \\
413 \\
762 \\
54 \%\end{array}$ & $\begin{array}{c}39.2 \mathrm{U} \\
463 \\
463 \\
762 \\
61 \%\end{array}$ & $\begin{array}{r}83.8 \\
509 \\
425 \\
762 \\
56 \%\end{array}$ & $\begin{array}{l}39.2 \mathrm{U} \\
602 \\
602 \\
762 \\
79 \%\end{array}$ \\
\hline $\begin{array}{l}5 \\
5\end{array}$ & $\begin{array}{l}4 \\
4\end{array}$ & $\begin{array}{l}80.0 \mathrm{U} \\
1160 \\
1160 \\
1460 \\
79 \%\end{array}$ & $\begin{array}{l}237 \mathrm{~B}(\mathrm{~b}) \\
1380 \\
1140 \\
1460 \\
78 \%\end{array}$ & $\begin{array}{r}97.5 \\
1450 \\
1350 \\
1460 \\
93 \%\end{array}$ & $\begin{array}{r}106 \text { (c) } \\
1580 \\
1470 \\
1460 \\
101 \%\end{array}$ & $\begin{aligned} 185 & \text { (c) } \\
1560 & \\
1380 & \\
1460 & \\
94 \% & \end{aligned}$ & $\begin{array}{l}80.0 \mathrm{U} \\
1910 \\
1910 \\
1460 \\
131 \% \quad \text { (d) }\end{array}$ \\
\hline $\begin{array}{l}4 \\
4\end{array}$ & $\begin{array}{l}5 \\
5\end{array}$ & $\begin{array}{c}39.2 U \\
461 \\
461 \\
799 \\
58 \%\end{array}$ & $\begin{array}{c}58.8 \mathrm{~B} \\
513 \\
454 \\
799 \\
57 \%\end{array}$ & $\begin{array}{l}77.5 \mathrm{~B} \\
826 \\
749 \\
799 \\
94 \%\end{array}$ & $\begin{array}{r}67.0 \quad \text { (c) } \\
909 \\
842 \\
799 \\
105 \%\end{array}$ & \begin{tabular}{r|}
155 \\
893 \\
738 \\
799 \\
$92 \%$
\end{tabular} & $\begin{array}{c}39.2 \mathrm{U} \\
1120 \\
1120 \\
799 \\
140 \% \quad \text { (d) }\end{array}$ \\
\hline $\begin{array}{l}2 \\
2\end{array}$ & $\begin{array}{l}6 \\
6\end{array}$ & $\begin{array}{l}36.0 \mathrm{U} \\
740 \\
740 \\
798 \\
93 \%\end{array}$ & $\begin{array}{r}47.9 \\
836 \\
788 \\
798 \\
99 \%\end{array}$ & $\begin{array}{r}65.2 \\
898 \\
833 \\
798 \\
104 \%\end{array}$ & $\begin{aligned} 89.3 & (c) \\
977 & \\
888 & \\
798 & \\
111 \% & \end{aligned}$ & $\begin{array}{r}127 \quad \text { (c) } \\
931 \\
804 \\
798 \\
101 \%\end{array}$ & $\begin{array}{c}36.0 \mathrm{U} \\
1130 \\
1130 \\
798 \\
142 \% \quad \text { (d) }\end{array}$ \\
\hline
\end{tabular}


TABLE 0.11. (contd)

咞

M. nasuta phthalate esters (ug/kg wet weight)

Sediment

Replicate

Analytical

Dimethyl

Diethyl Phthalate

Di-n-butyl

Butyl

Standard Reference Material

Certified SRM not available for phthalates.

\section{Analytical Replicates}

M. nasuta Background, Replicate 1

M. nasuta Background, Replicate 2

M. nasuta Background, Replicate 3

$3 \quad 38.8 \mathrm{U}$

$38.8 \mathrm{U}$

$38.8 \mathrm{U}$

$38.8 \mathrm{U}$

93.6

2-ethylhexyl)

benzy! Phthalate

Di-n-octyl

RSD

TB Upper COMP, Replicate 1

TB Upper COMP, Replicate 2

- TB Upper COMP, Replicate 3

3

$37.6 \mathrm{U}$

$38.4 \mathrm{U}$

44.1

$37.6 \mathrm{U}$

70.7

$\begin{array}{lll}38.4 \mathrm{U} & 38.4 \mathrm{U} & 70.4\end{array}$

$37.6 \mathrm{U}$

NA

NA

NA

$17 \%$

NA

$73.6 \mathrm{U} \quad 270 \mathrm{~B}$

$270 \mathrm{~B}$

$72.0 \mathrm{U}$

$207 \mathrm{~B}$

83.7
83.5

\section{$73.6 \mathrm{U}$}

172

$73.6 \mathrm{U}$

93.5

74.6 (c) 163

71.3 (c) 167

$72.0 \mathrm{U}$

NA

$13 \%$

R-OS, Replicate 1

R-OS, Replicate 2

R-OS, Replicate 3

2
2
2

5
5
5

$39.2 \mathrm{U}$

$13 \%$

$7 \%$

NA $3 \%$

$70.4 \mathrm{U}$

RSD

UIH COMP, Replicate 1

UIH COMP, Replicate 2

UIH COMP, Replicate 3

$\begin{array}{llll}3 & 6 & 40.0 \mathrm{U} & 40.0 \mathrm{U} \\ 3 & 6 & 39.2 \mathrm{U} & 57.4 \mathrm{~B} \\ 3 & 6 & 40.0 \mathrm{U} & 64.0 \mathrm{~B}\end{array}$

$38.8 \quad 58.5 \mathrm{~B}$

$94.2 \mathrm{~B}$

84.0 (c) 135

NA

RSD

NA NA

NA

$38.8 \mathrm{~B}$

85.4 (c) 122

78.2 (c) 138

$39.2 \mathrm{U}$

$39.2 \mathrm{U}$

$46.7 \mathrm{~B}$

$5 \%$

$6 \%$

$50 \%$ (f) $5 \% \quad 6 \%$

NA

$\begin{array}{cccc}40.0 \mathrm{U} & 78.6 & \text { (c) } & 142 \mathrm{~B}(\mathrm{c}) \\ 167 & 87.8 & & 133 \mathrm{~B}(\mathrm{c}) \\ 77.0 & 107 & \text { (c) } & 140 \mathrm{~B}(\mathrm{c})\end{array}$

$40.0 \mathrm{U}$

77.0

107 (c)

$140 \mathrm{~B}(\mathrm{c})$

NA $\quad 16 \% \quad 3 \%$

NA

(a) U Undetected at or above detection limit.

(b) B Analyte detected in sample at less than five times value in associated method blank.

(c) Ratio of confirmation ion to primary ion is outside of the theoretical ratio of $20 \%$ established for EPA-CLP programs.

(d) Outside quality control criteria $(40-120 \%)$ for matrix spike recoveries.

(e) NA Not applicable.

(f) Value exceeds relative precision goal of $<30 \%$. 
TABLE 0.12. Surrogate Percent Recoveries for Polynuclear Aromatic Hydrocarbons (PAHs), Including Quality Control Data, in Tissue of M. nasuta, Richmond Harbor Deepening Project

\begin{tabular}{|c|c|c|c|c|c|c|}
\hline \multirow[b]{2}{*}{$\begin{array}{l}\text { Sediment } \\
\text { Treatment }\end{array}$} & \multirow[b]{2}{*}{ Replicate } & \multirow[b]{2}{*}{$\begin{array}{c}\text { Analytical } \\
\text { Batch }\end{array}$} & \multicolumn{4}{|c|}{ Surrogate Percent Recoveries } \\
\hline & & & $\begin{array}{l}\text { Naph- } \\
\text { thalene } \\
\text { d8 }\end{array}$ & $\begin{array}{c}\text { Acenaph- } \\
\text { thene } \\
\text { d10 }\end{array}$ & $\begin{array}{c}\text { Chrysene } \\
\text { d12 }\end{array}$ & $\begin{array}{c}\text { Dibenzo } \\
(a, h, i) \\
\text { Anthracene } \\
\text { d14 } \\
\end{array}$ \\
\hline $\begin{array}{l}\text { SF COMP } \\
\text { SF COMP } \\
\text { SF COMP } \\
\text { SF COMP } \\
\text { SF COMP }\end{array}$ & $\begin{array}{l}1 \\
2 \\
3 \\
4 \\
5\end{array}$ & $\begin{array}{l}5 \\
5 \\
5 \\
5 \\
5\end{array}$ & $\begin{array}{l}73 \\
72 \\
75 \\
71 \\
65\end{array}$ & $\begin{array}{l}79 \\
78 \\
81 \\
77 \\
73\end{array}$ & $\begin{array}{l}79 \\
85 \\
82 \\
91 \\
79\end{array}$ & $\begin{array}{l}88 \\
86 \\
90 \\
75 \\
76\end{array}$ \\
\hline $\begin{array}{l}\text { SFW COMP } \\
\text { SFW COMP } \\
\text { SFW COMP } \\
\text { SFW COMP } \\
\text { SFW COMP }\end{array}$ & $\begin{array}{l}1 \\
2 \\
3 \\
4 \\
5\end{array}$ & $\begin{array}{l}4 \\
4 \\
6 \\
4 \\
6\end{array}$ & $\begin{array}{l}72 \\
64 \\
71 \\
64 \\
70\end{array}$ & $\begin{array}{l}78 \\
69 \\
77 \\
69 \\
75\end{array}$ & $\begin{array}{l}81 \\
73 \\
75 \\
75 \\
76\end{array}$ & $\begin{array}{l}89 \\
82 \\
82 \\
82 \\
89\end{array}$ \\
\hline $\begin{array}{l}\text { UIH COMP } \\
\text { UIH COMP } \\
\text { UIH COMP, Replicate } 1 \\
\text { UIH COMP, Replicate } 2 \\
\text { UIH COMP, Replicate } 3 \\
\text { UIH COMP } \\
\text { UIH COMP }\end{array}$ & $\begin{array}{l}1 \\
2 \\
3 \\
3 \\
3 \\
4 \\
5\end{array}$ & $\begin{array}{l}5 \\
6 \\
6 \\
6 \\
6 \\
5 \\
5\end{array}$ & $\begin{array}{l}80 \\
70 \\
68 \\
75 \\
64 \\
66 \\
65\end{array}$ & $\begin{array}{l}90 \\
73 \\
73 \\
78 \\
68 \\
72 \\
78\end{array}$ & $\begin{array}{l}84 \\
71 \\
75 \\
76 \\
70 \\
71 \\
67\end{array}$ & $\begin{array}{l}96 \\
85 \\
88 \\
92 \\
77 \\
84 \\
79\end{array}$ \\
\hline $\begin{array}{l}\text { TB Upper COMP } \\
\text { TB Upper COMP, Replicate } 1 \\
\text { TB Upper COMP, Replicate } 2 \\
\text { TB Upper COMP, Replicate } 3 \\
\text { TB Upper COMP } \\
\text { TB Upper COMP } \\
\text { TB Upper COMP }\end{array}$ & $\begin{array}{l}1 \\
2 \\
2 \\
2 \\
3 \\
4 \\
5\end{array}$ & $\begin{array}{l}4 \\
4 \\
4 \\
4 \\
3 \\
3 \\
4\end{array}$ & $\begin{array}{l}78 \\
66 \\
63 \\
71 \\
71 \\
80 \\
73\end{array}$ & $\begin{array}{l}82 \\
71 \\
66 \\
77 \\
75 \\
84 \\
76\end{array}$ & $\begin{array}{l}90 \\
83 \\
68 \\
81 \\
81 \\
88 \\
75\end{array}$ & $\begin{array}{l}85 \\
75 \\
77 \\
85 \\
81 \\
88 \\
85\end{array}$ \\
\hline $\begin{array}{l}\text { TB Lower COMP } \\
\text { TB Lower COMP } \\
\text { TB Lower COMP } \\
\text { TB Lower COMP } \\
\text { TB Lower COMP }\end{array}$ & $\begin{array}{l}1 \\
2 \\
3 \\
4 \\
5\end{array}$ & $\begin{array}{l}4 \\
3 \\
5 \\
5 \\
6\end{array}$ & $\begin{array}{l}66 \\
69 \\
72 \\
76 \\
70\end{array}$ & $\begin{array}{l}71 \\
75 \\
78 \\
83 \\
74\end{array}$ & $\begin{array}{l}77 \\
82 \\
80 \\
91 \\
76\end{array}$ & $\begin{array}{l}77 \\
82 \\
80 \\
89 \\
74\end{array}$ \\
\hline $\begin{array}{l}\text { R-OS } \\
\text { R-OS, Replicate } 1 \\
\text { R-OS, Replicate } 2 \\
\text { R-OS, Replicate } 3 \\
\text { R-OS } \\
\text { R-OS } \\
\text { R-OS }\end{array}$ & $\begin{array}{l}1 \\
2 \\
2 \\
2 \\
3 \\
4 \\
5\end{array}$ & $\begin{array}{l}5 \\
5 \\
5 \\
5 \\
5 \\
5 \\
5\end{array}$ & $\begin{array}{l}77 \\
69 \\
73 \\
71 \\
72 \\
78 \\
73\end{array}$ & $\begin{array}{l}82 \\
74 \\
77 \\
78 \\
77 \\
81 \\
77\end{array}$ & $\begin{array}{l}86 \\
78 \\
80 \\
83 \\
81 \\
79 \\
79\end{array}$ & $\begin{array}{l}91 \\
82 \\
87 \\
83 \\
86 \\
85 \\
87\end{array}$ \\
\hline $\begin{array}{l}\text { R-BF } \\
\text { R-BF } \\
\text { R-BF } \\
\text { R-BF } \\
\text { R-BF }\end{array}$ & $\begin{array}{l}1 \\
2 \\
3 \\
4 \\
5\end{array}$ & $\begin{array}{l}4 \\
3 \\
4 \\
4 \\
4\end{array}$ & $\begin{array}{l}65 \\
74 \\
62 \\
71 \\
78\end{array}$ & $\begin{array}{l}72 \\
79 \\
65 \\
75 \\
79\end{array}$ & $\begin{array}{l}74 \\
82 \\
66 \\
84 \\
83\end{array}$ & $\begin{array}{l}84 \\
81 \\
74 \\
77 \\
90\end{array}$ \\
\hline RH DEEPENING & & & & & & \\
\hline
\end{tabular}


TABLE 0.12. (contd)

\begin{tabular}{|c|c|c|c|c|c|c|}
\hline \multirow[b]{2}{*}{$\begin{array}{l}\text { Sediment } \\
\text { Treatment }\end{array}$} & \multirow[b]{2}{*}{ Replicate } & \multirow[b]{2}{*}{$\begin{array}{c}\text { Analytical } \\
\text { Batch }\end{array}$} & \multicolumn{4}{|c|}{ Surrogate Percent Recoveries } \\
\hline & & & $\begin{array}{c}\text { Naph- } \\
\text { thalene } \\
\text { d8 }\end{array}$ & $\begin{array}{c}\text { Acenaph- } \\
\text { thene } \\
\text { d10 } \\
\end{array}$ & $\begin{array}{c}\text { Chrysene } \\
\text { d12 }\end{array}$ & $\begin{array}{c}\text { Dibenzo } \\
(\mathrm{a}, \mathrm{h}, \mathrm{i}) \\
\text { Anthracene } \\
\text { d14 }\end{array}$ \\
\hline R-AM COMP & 1 & 3 & 73 & 78 & 82 & 87 \\
\hline R-AM COMP & 2 & 4 & 75 & 78 & 79 & 85 \\
\hline R-AM COMP & 3 & 4 & 70 & 73 & 79 & 84 \\
\hline R-AM COMP & 4 & 3 & 72 & 74 & 78 & 79 \\
\hline R-AM COMP & 5 & 4 & 76 & 81 & 88 & 87 \\
\hline C-SB & 1 & 5 & 70 & 82 & 78 & 80 \\
\hline C-SB & 2 & 5 & 74 & 80 & 84 & 89 \\
\hline C-SB & 3 & 5 & 72 & 79 & 74 & 80 \\
\hline C-SB & 4 & 5 & 59 & 67 & 69 & 66 \\
\hline C-SB & 5 & 5 & 64 & 70 & 70 & 71 \\
\hline M. nasuta Background & 1 & 3 & 69 & 73 & 77 & 68 \\
\hline M. nasuta Background & 2 & 3 & 65 & 71 & 72 & 69 \\
\hline M. nasuta Background, Replicate 1 & 3 & 3 & 70 & 77 & 81 & 77 \\
\hline M. nasuta Background, Replicate 2 & 3 & 3 & 62 & 67 & 72 & 69 \\
\hline M. nasuta Background, Replicate 3 & 3 & 3 & 70 & 72 & 73 & 68 \\
\hline M. nasuta Background & 4 & 3 & 76 & 81 & 84 & 75 \\
\hline M. nasuta Background & 5 & 3 & 77 & 79 & 82 & 81 \\
\hline
\end{tabular}

\section{Quality Control Data}

\section{Method Blanks}

Blank-1

Blank-1

Blank-2

Blank-1

Blank-2

$\begin{array}{lllll}3 & 82 & 77 & 77 & 47 \\ 4 & 76 & 73 & 71 & 69 \\ 6 & 74 & 74 & 78 & 62 \\ 5 & 58 & 57 & 73 & 78 \\ 6 & 66 & 67 & 65 & 73\end{array}$

\section{Matrix Spikes}

M. nasuta Background

M. nasuta Background, MS

2

\section{TB Upper COMP}

TB Upper COMP, MS

$\begin{array}{ll}5 & 4 \\ 5 & 4\end{array}$

SF COMP

SF COMP, MS

$\begin{array}{ll}4 & 5 \\ 4 & 5\end{array}$

UIH COMP

UIH COMP, MS

$\begin{array}{ll}2 & 6 \\ 2 & 6\end{array}$

65

67

73

76

71

76

70

68
71

72

76

78

77

80

73

73
47

69

78

73 
TABLE 0.12. (contd)

\begin{tabular}{lcccccc} 
& & \multicolumn{3}{c}{ Surrogate Percent Recoveries } \\
\cline { 3 - 7 } & & & & & & Dibenzo \\
& & & Naph- & Acenaph- & & (a,h,i) \\
Sediment & & Analytical & thalene & thene & Chrysene & Anthracene \\
Treatment & Replicate & Batch & d8 & d10 & d12 & d14 \\
\hline
\end{tabular}

\section{Analytical Replicates}

M. nasuta Background, Replicate 1

M. nasuta Background, Replicate 2

M. nasuta Background, Replicate 3

3

$3 \quad 3$

$3 \quad 3$

33

TB Upper COMP, Replicate 1

TB Upper COMP, Replicate 2

TB Upper COMP, Replicate 3

2

2

R-OS, Replicate 1

R-OS, Replicate 2

R-OS, Replicate 3

UIH COMP, Replicate 1

UIH COMP, Replicate 2

UIH COMP, Replicate 3

(a) NA Not applicable. 


\begin{tabular}{|c|c|c|c|c|c|c|c|c|c|c|c|c|}
\hline \multirow[b]{2}{*}{$\begin{array}{l}\text { Sediment } \\
\text { Treatment }\end{array}$} & \multirow[b]{2}{*}{ Replicate } & \multirow[b]{2}{*}{$\begin{array}{c}\text { Analytical } \\
\text { Batch }\end{array}$} & \multirow{2}{*}{$\begin{array}{c}\text { Percent } \\
\text { Dry } \\
\text { Weight }\end{array}$} & \multicolumn{9}{|c|}{ M. nasuta Pesticides (ug/kg dry weight) } \\
\hline & & & & Aldrin & $\begin{array}{l}\text { Alpha } \\
\text { BHC }\end{array}$ & $\begin{array}{l}\text { Beta } \\
\text { BHC } \\
\end{array}$ & $\begin{array}{l}\text { Delta } \\
\text { BHC }\end{array}$ & $\begin{array}{l}\text { Gamma } \\
\text { BHC }\end{array}$ & Chlordane & $\begin{array}{l}4,4^{\prime}- \\
\text { DDD }\end{array}$ & $\begin{array}{l}4,4^{\prime}- \\
\text { DDE }\end{array}$ & $\begin{array}{l}4,4^{\prime}- \\
\text { DDT }\end{array}$ \\
\hline $\begin{array}{l}\text { SF COMP } \\
\text { SF COMP } \\
\text { SF COMP } \\
\text { SF COMP } \\
\text { SF COMP }\end{array}$ & $\begin{array}{l}1 \\
2 \\
3 \\
4 \\
5\end{array}$ & $\begin{array}{l}5 \\
5 \\
5 \\
5 \\
5\end{array}$ & $\begin{array}{l}12.76 \\
12.94 \\
12.26 \\
12.60 \\
14.42\end{array}$ & $\begin{array}{c}0.7 U(a) \\
0.7 U \\
0.7 U \\
1.43 U \\
0.6 U\end{array}$ & $\begin{array}{l}2.0 U \\
1.9 U \\
2.0 U \\
3.9 U \\
1.7 U\end{array}$ & $\begin{array}{l}2.0 U \\
1.9 U \\
2.0 U \\
3.9 U \\
1.7 U\end{array}$ & $\begin{array}{l}2.0 \mathrm{U} \\
1.9 \mathrm{U} \\
2.0 \mathrm{U} \\
3.9 \mathrm{U} \\
1.7 \mathrm{U}\end{array}$ & $\begin{array}{l}0.9 \mathrm{U} \\
0.9 \mathrm{U} \\
1.0 \mathrm{U} \\
1.9 \mathrm{U} \\
0.8 \mathrm{U}\end{array}$ & $\begin{array}{l}240 U \\
230 U \\
250 U \\
240 U \\
210 U\end{array}$ & $\begin{array}{l}548 \\
549 \\
476 \\
475 \\
399\end{array}$ & $\begin{array}{r}123 \\
130 \\
111 \\
104 \\
93.6\end{array}$ & $\begin{array}{l}1.4 \mathrm{U} \\
1.3 \mathrm{U} \\
1.4 \mathrm{U} \\
2.8 \mathrm{U} \\
1.2 \mathrm{U}\end{array}$ \\
\hline $\begin{array}{l}\text { SFW COMP } \\
\text { SFW COMP } \\
\text { SFW COMP } \\
\text { SFW COMP } \\
\text { SFW COMP }\end{array}$ & $\begin{array}{l}1 \\
2 \\
3 \\
4 \\
5\end{array}$ & $\begin{array}{l}4 \\
4 \\
6 \\
4 \\
6\end{array}$ & $\begin{array}{l}14.61 \\
17.91 \\
14.49 \\
14.31 \\
14.58\end{array}$ & $\begin{array}{r}1.16 \mathrm{U} \\
1.01 \mathrm{U} \\
0.6 \mathrm{U} \\
1.26 \mathrm{U} \\
0.6 \mathrm{U}\end{array}$ & $\begin{array}{l}3.3 U \\
2.8 U \\
1.7 U \\
3.5 U \\
1.7 U\end{array}$ & $\begin{array}{l}3.3 U \\
2.8 U \\
1.7 U \\
3.5 U \\
1.7 U\end{array}$ & $\begin{array}{l}3.3 U \\
2.8 U \\
1.9 \\
3.5 U \\
1.7 U\end{array}$ & $\begin{array}{l}1.6 \mathrm{U} \\
1.3 \mathrm{U} \\
3.2 \\
1.7 \mathrm{U} \\
0.8 \mathrm{U}\end{array}$ & $\begin{array}{l}210 U \\
170 U \\
210 U \\
210 U \\
210 U\end{array}$ & $\begin{array}{l}608 \\
538 \\
470 \\
635 \\
464\end{array}$ & $\begin{array}{l}371 \\
309 \\
293 \\
387 \\
286\end{array}$ & $\begin{array}{l}2.3 U \\
2.0 U \\
1.2 U \\
2.4 U \\
1.2 U\end{array}$ \\
\hline $\begin{array}{l}\text { UIH COMP } \\
\text { UIH COMP } \\
\text { UIH COMP, Replicate } 1 \\
\text { UIH COMP, Replicate } 2 \\
\text { UIH COMP, Replicate } 3 \\
\text { UIH COMP } \\
\text { UIH COMP }\end{array}$ & $\begin{array}{l}1 \\
2 \\
3 \\
3 \\
3 \\
4 \\
5\end{array}$ & $\begin{array}{l}5 \\
6 \\
6 \\
6 \\
6 \\
5 \\
5\end{array}$ & $\begin{array}{l}13.71 \\
14.06 \\
13.52 \\
13.52 \\
13.52 \\
15.23 \\
13.02\end{array}$ & $\begin{array}{r}0.7 U \\
1.21 U \\
1.33 U \\
1.33 U \\
1.26 U \\
0.6 U \\
0.7 U\end{array}$ & $\begin{array}{l}1.8 U \\
3.3 \mathrm{U} \\
3.7 \mathrm{U} \\
3.6 \mathrm{U} \\
3.6 \mathrm{U} \\
1.6 \mathrm{U} \\
1.9 \mathrm{U}\end{array}$ & $\begin{array}{l}1.8 \mathrm{U} \\
3.3 \mathrm{U} \\
7.1 \\
3.6 \mathrm{U} \\
3.6 \mathrm{U} \\
1.6 \mathrm{U} \\
1.9 \mathrm{U}\end{array}$ & $\begin{array}{l}1.8 U \\
3.3 U \\
3.7 U \\
3.6 U \\
3.6 U \\
1.6 U \\
1.9 U\end{array}$ & $\begin{array}{l}0.8 \mathrm{U} \\
1.6 \mathrm{U} \\
1.8 \mathrm{U} \\
1.8 \mathrm{U} \\
1.7 \mathrm{U} \\
0.8 \mathrm{U} \\
0.9 \mathrm{U}\end{array}$ & $\begin{array}{l}220 U \\
210 U \\
220 U \\
220 U \\
220 U \\
200 U \\
230 U\end{array}$ & $\begin{array}{l}225 \\
156 \\
135 \\
131 \\
112 \\
186 \\
215\end{array}$ & $\begin{array}{r}0.5 U \\
0.92 U \\
1.04 U \\
1.04 U \\
0.96 U \\
0.5 U \\
0.5 U\end{array}$ & $\begin{array}{l}1.2 U \\
2.3 U \\
2.7 U \\
2.6 U \\
2.5 U \\
1.1 U \\
1.3 U\end{array}$ \\
\hline $\begin{array}{l}\text { TB Upper COMP } \\
\text { TB Upper COMP, Replicate } 1 \\
\text { TB Upper COMP, Replicate } 2 \\
\text { TB Upper COMP, Replicate } 3 \\
\text { TB Upper COMP } \\
\text { TB Upper COMP } \\
\text { TB Upper COMP }\end{array}$ & $\begin{array}{l}1 \\
2 \\
2 \\
2 \\
3 \\
4 \\
5\end{array}$ & $\begin{array}{l}4 \\
4 \\
4 \\
4 \\
3 \\
3 \\
4\end{array}$ & $\begin{array}{l}15.21 \\
14.75 \\
14.75 \\
14.75 \\
13.66 \\
15.16 \\
15.00\end{array}$ & $\begin{array}{l}1.12 \mathrm{U} \\
2.31 \mathrm{U} \\
2.24 \mathrm{U} \\
2.17 \mathrm{U} \\
0.66 \mathrm{U} \\
0.59 \mathrm{U} \\
2.40 \mathrm{U}\end{array}$ & $\begin{array}{l}3.1 \mathrm{U} \\
6.2 \mathrm{U} \\
6.1 \mathrm{U} \\
6.0 \mathrm{U} \\
1.8 \mathrm{U} \\
1.6 \mathrm{U} \\
6.5 \mathrm{U}\end{array}$ & $\begin{array}{l}3.1 U \\
6.2 U \\
6.1 U \\
6.0 U \\
1.8 U \\
1.6 U \\
6.5 U\end{array}$ & $\begin{array}{l}3.1 \mathrm{U} \\
6.2 \mathrm{U} \\
6.1 \mathrm{U} \\
6.0 \mathrm{U} \\
1.8 \mathrm{U} \\
1.6 \mathrm{U} \\
6.5 \mathrm{U}\end{array}$ & $\begin{array}{l}1.5 U \\
3.0 U \\
2.9 U \\
2.8 U \\
0.9 U \\
0.8 U \\
3.1 U\end{array}$ & $\begin{array}{l}200 U \\
200 U \\
200 U \\
200 U \\
220 U \\
200 U \\
200 U\end{array}$ & $\begin{array}{l}2.9 U \\
5.8 U \\
5.8 U \\
5.6 U \\
1.7 U \\
1.5 U \\
6.1 U\end{array}$ & $\begin{array}{l}0.85 \mathrm{U} \\
1.76 \mathrm{U} \\
1.69 \mathrm{U} \\
1.69 \mathrm{U} \\
5.34 \\
3.69 \\
1.80 \mathrm{U}\end{array}$ & $\begin{array}{l}2.2 \mathrm{U} \\
4.4 \mathrm{U} \\
4.3 \mathrm{U} \\
4.3 \mathrm{U} \\
1.2 \mathrm{U} \\
5.3 \\
4.7 \mathrm{U}\end{array}$ \\
\hline $\begin{array}{l}\text { TB Lower COMP } \\
\text { TB Lower COMP } \\
\text { TB Lower COMP } \\
\text { TB Lower COMP } \\
\text { TB Lower COMP }\end{array}$ & $\begin{array}{l}1 \\
2 \\
3 \\
4 \\
5\end{array}$ & $\begin{array}{l}4 \\
3 \\
5 \\
5 \\
4\end{array}$ & $\begin{array}{l}13.17 \\
13.30 \\
12.74 \\
12.37 \\
13.89\end{array}$ & $\begin{array}{r}1.37 U \\
0.7 U \\
0.7 U \\
0.73 U \\
1.30 U\end{array}$ & $\begin{array}{l}3.8 \mathrm{U} \\
1.9 \mathrm{U} \\
2.0 \mathrm{U} \\
2.0 \mathrm{U} \\
3.6 \mathrm{U}\end{array}$ & $\begin{array}{l}3.8 \mathrm{U} \\
1.9 \mathrm{U} \\
2.0 \mathrm{U} \\
2.0 \mathrm{U} \\
3.6 \mathrm{U}\end{array}$ & $\begin{array}{l}3.8 \mathrm{U} \\
1.9 \mathrm{U} \\
2.0 \mathrm{U} \\
2.0 \mathrm{U} \\
3.6 \mathrm{U}\end{array}$ & $\begin{array}{l}1.8 \mathrm{U} \\
0.9 \mathrm{U} \\
0.9 \mathrm{U} \\
1.0 \mathrm{U} \\
1.7 \mathrm{U}\end{array}$ & $\begin{array}{l}230 U \\
230 U \\
240 U \\
240 U \\
220 U\end{array}$ & $\begin{array}{l}3.6 \mathrm{U} \\
1.7 \mathrm{U} \\
1.8 \mathrm{U} \\
1.9 \mathrm{U} \\
3.4 \mathrm{U}\end{array}$ & $\begin{array}{r}1.06 U \\
0.5 U \\
0.5 U \\
0.1 U \\
1.01 U\end{array}$ & $\begin{array}{l}2.7 U \\
1.3 U \\
1.4 U \\
1.4 U \\
2.6 U\end{array}$ \\
\hline $\begin{array}{l}\text { OBM COMP } \\
\text { OBM COMP } \\
\text { OBM COMP } \\
\text { OBM COMP } \\
\text { OBM COMP }\end{array}$ & $\begin{array}{l}1 \\
2 \\
3 \\
4 \\
5\end{array}$ & $\begin{array}{l}4 \\
4 \\
4 \\
4 \\
4\end{array}$ & $\begin{array}{l}14.01 \\
13.17 \\
12.21 \\
14.29 \\
14.51\end{array}$ & $\begin{array}{l}1.28 U \\
1.37 U \\
1.39 U \\
1.26 U \\
1.24 U\end{array}$ & $\begin{array}{l}3.6 \mathrm{U} \\
3.8 \mathrm{U} \\
3.9 \mathrm{U} \\
3.5 \mathrm{U} \\
3.4 \mathrm{U}\end{array}$ & $\begin{array}{l}3.6 \mathrm{U} \\
3.8 \mathrm{U} \\
3.9 \mathrm{U} \\
3.5 \mathrm{U} \\
3.4 \mathrm{U}\end{array}$ & $\begin{array}{l}3.6 \mathrm{U} \\
3.8 \mathrm{U} \\
3.9 \mathrm{U} \\
3.5 \mathrm{U} \\
3.4 \mathrm{U}\end{array}$ & $\begin{array}{l}1.7 \mathrm{U} \\
1.8 \mathrm{U} \\
1.9 \mathrm{U} \\
1.7 \mathrm{U} \\
1.7 \mathrm{U}\end{array}$ & $\begin{array}{l}210 U \\
230 U \\
250 U \\
210 U \\
210 U\end{array}$ & $\begin{array}{l}3.3 U \\
3.5 U \\
3.7 U \\
3.3 U \\
3.2 U\end{array}$ & $\begin{array}{l}1.00 \mathrm{U} \\
1.06 \mathrm{U} \\
1.06 \mathrm{U} \\
0.98 \mathrm{U} \\
0.96 \mathrm{U}\end{array}$ & $\begin{array}{l}2.5 U \\
2.7 U \\
2.8 U \\
2.5 U \\
2.5 U\end{array}$ \\
\hline
\end{tabular}




\begin{tabular}{|c|c|c|c|c|c|c|c|c|c|c|c|c|c|}
\hline \multirow{3}{*}{ 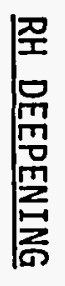 } & \multicolumn{13}{|c|}{ TABLE 0.13. (contd) } \\
\hline & \multirow[b]{2}{*}{$\begin{array}{l}\text { Sediment } \\
\text { Treatment }\end{array}$} & \multirow[b]{2}{*}{ Replicate } & \multirow[b]{2}{*}{$\begin{array}{c}\text { Analytical } \\
\text { Batch }\end{array}$} & \multirow{2}{*}{$\begin{array}{l}\text { Percent } \\
\text { Dry } \\
\text { Weight }\end{array}$} & \multicolumn{9}{|c|}{ M. nasuta Pesticides (ug/kg dry weight) } \\
\hline & & & & & Aldrin & $\begin{array}{l}\text { Alpha } \\
\text { BHC }\end{array}$ & $\begin{array}{l}\text { Beta } \\
\text { BHC } \\
\end{array}$ & $\begin{array}{l}\text { Delta } \\
\text { BHC } \\
\end{array}$ & $\begin{array}{l}\text { Gamma } \\
\mathrm{BHC}\end{array}$ & Chlordane & $\begin{array}{l}4,4^{\prime}- \\
\text { DDD } \\
\end{array}$ & $\begin{array}{l}4,4^{\prime}- \\
\text { DDE }\end{array}$ & $\begin{array}{l}4,4^{\prime}- \\
\text { DDT }\end{array}$ \\
\hline 依 & $\begin{array}{l}\text { R-OS } \\
\text { R-OS, Replicate } 1 \\
\text { R-OS, Replicate } 2 \\
\text { R-OS, Replicate } 3 \\
\text { R-OS } \\
\text { R-OS } \\
\text { R-OS }\end{array}$ & $\begin{array}{l}1 \\
2 \\
2 \\
2 \\
3 \\
4 \\
5\end{array}$ & $\begin{array}{l}5 \\
5 \\
5 \\
5 \\
5 \\
5 \\
5\end{array}$ & $\begin{array}{l}12.71 \\
12.62 \\
12.62 \\
12.62 \\
13.84 \\
12.69 \\
13.41\end{array}$ & $\begin{array}{l}0.71 U \\
1.43 U \\
1.43 U \\
1.43 U \\
0.65 U \\
0.71 U \\
0.67 U\end{array}$ & $\begin{array}{l}2.0 U \\
3.9 U \\
3.9 U \\
3.9 U \\
1.8 U \\
2.0 U \\
1.9 U\end{array}$ & $\begin{array}{l}2.0 U \\
3.9 U \\
3.9 U \\
3.9 U \\
1.8 U \\
2.0 U \\
1.9 U\end{array}$ & $\begin{array}{l}2.0 U \\
3.9 U \\
3.9 U \\
3.9 U \\
1.8 U \\
2.0 U \\
1.9 U\end{array}$ & $\begin{array}{l}1.0 \\
1.9 U \\
1.8 U \\
1.9 U \\
0.9 U \\
0.9 U \\
0.9 U\end{array}$ & $\begin{array}{l}240 U \\
240 U \\
240 U \\
240 U \\
220 U \\
240 U \\
220 U\end{array}$ & $\begin{array}{l}1.8 \mathrm{U} \\
3.6 \mathrm{U} \\
3.6 \mathrm{U} \\
3.6 \mathrm{U} \\
1.7 \mathrm{U} \\
1.8 \mathrm{U} \\
1.7 \mathrm{U}\end{array}$ & $\begin{array}{l}0.6 \mathrm{U} \\
1.11 \mathrm{U} \\
1.11 \mathrm{U} \\
1.11 \mathrm{U} \\
0.5 \mathrm{U} \\
0.6 \mathrm{U} \\
0.5 \mathrm{U}\end{array}$ & $\begin{array}{l}1.3 U \\
2.8 U \\
2.8 U \\
2.8 U \\
1.2 U \\
1.4 U \\
1.3 U\end{array}$ \\
\hline & $\begin{array}{l}\text { R-BF } \\
\text { R-BF } \\
\text { R-BF } \\
\text { R-BF } \\
\text { R-BF . }\end{array}$ & $\begin{array}{l}1 \\
2 \\
3 \\
4 \\
5\end{array}$ & $\begin{array}{l}4 \\
3 \\
4 \\
4 \\
4\end{array}$ & $\begin{array}{l}15.28 \\
14.64 \\
14.78 \\
15.91 \\
14.92\end{array}$ & $\begin{array}{l}1.11 \mathrm{U} \\
0.61 \mathrm{U} \\
1.22 \mathrm{U} \\
1.07 \mathrm{U} \\
1.21 \mathrm{U}\end{array}$ & $\begin{array}{l}3.1 \mathrm{U} \\
1.7 \mathrm{U} \\
3.4 \mathrm{U} \\
3.0 \mathrm{U} \\
3.4 \mathrm{U}\end{array}$ & $\begin{array}{l}3.1 \mathrm{U} \\
1.7 \mathrm{U} \\
3.4 \mathrm{U} \\
3.0 \mathrm{U} \\
3.4 \mathrm{U}\end{array}$ & $\begin{array}{l}3.1 \mathrm{U} \\
1.7 \mathrm{U} \\
3.4 \mathrm{U} \\
3.0 \mathrm{U} \\
3.4 \mathrm{U}\end{array}$ & $\begin{array}{l}1.5 \mathrm{U} \\
0.8 \mathrm{U} \\
1.6 \mathrm{U} \\
1.4 \mathrm{U} \\
1.6 \mathrm{U}\end{array}$ & $\begin{array}{l}200 U \\
210 U \\
200 U \\
190 U \\
200 U\end{array}$ & $\begin{array}{l}2.9 \mathrm{U} \\
1.6 \mathrm{U} \\
3.2 \mathrm{U} \\
2.8 \mathrm{U} \\
3.1 \mathrm{U}\end{array}$ & $\begin{array}{l}0.85 \mathrm{U} \\
7.79 \\
0.95 \mathrm{U} \\
0.82 \mathrm{U} \\
0.94 \mathrm{U}\end{array}$ & $\begin{array}{c}2.2 \mathrm{U} \\
12.4 \\
2.4 \mathrm{U} \\
2.1 \mathrm{U} \\
2.3 \mathrm{U}\end{array}$ \\
\hline $\begin{array}{l}0 \\
\text { is }\end{array}$ & $\begin{array}{l}\text { R-AM COMP } \\
\text { R-AM COMP } \\
\text { R-AM COMP } \\
\text { R-AM COMP } \\
\text { R-AM COMP }\end{array}$ & $\begin{array}{l}1 \\
2 \\
3 \\
4 \\
5\end{array}$ & $\begin{array}{l}3 \\
4 \\
4 \\
3 \\
4\end{array}$ & $\begin{array}{l}15.79 \\
13.81 \\
15.44 \\
14.52 \\
14.71\end{array}$ & $\begin{array}{l}0.6 \mathrm{U} \\
1.30 \mathrm{U} \\
1.17 \mathrm{U} \\
0.62 \mathrm{U} \\
1.16 \mathrm{U}\end{array}$ & $\begin{array}{l}1.6 U \\
3.6 U \\
3.2 U \\
1.7 U \\
3.3 U\end{array}$ & $\begin{array}{l}1.6 U \\
3.6 U \\
3.2 U \\
1.7 U \\
3.3 U\end{array}$ & $\begin{array}{l}1.6 \mathrm{U} \\
3.6 \mathrm{U} \\
3.2 \mathrm{U} \\
1.7 \mathrm{U} \\
3.3 \mathrm{U}\end{array}$ & $\begin{array}{l}0.8 U \\
1.7 U \\
1.6 U \\
0.8 U \\
1.6 U\end{array}$ & $\begin{array}{l}190 U \\
220 U \\
190 U \\
210 U \\
200 U\end{array}$ & $\begin{array}{l}1.5 \mathrm{U} \\
3.3 \mathrm{U} \\
3.0 \mathrm{U} \\
1.6 \mathrm{U} \\
3.1 \mathrm{U}\end{array}$ & $\begin{array}{l}0.4 U \\
1.01 U \\
0.91 U \\
7.09 \\
0.88 U\end{array}$ & $\begin{array}{c}18.4 \\
2.5 U \\
2.3 U \\
1.2 U \\
2.3 U\end{array}$ \\
\hline & $\begin{array}{l}\text { C-SB } \\
\text { C-SB } \\
\text { C-SB } \\
\text { C-SB } \\
\text { C-SB }\end{array}$ & $\begin{array}{l}1 \\
2 \\
3 \\
4 \\
5\end{array}$ & $\begin{array}{l}5 \\
5 \\
5 \\
5 \\
5\end{array}$ & $\begin{array}{l}14.43 \\
13.25 \\
14.03 \\
13.57 \\
13.60\end{array}$ & $\begin{array}{l}0.62 U \\
0.68 U \\
0.64 U \\
0.07 U \\
0.66 U\end{array}$ & $\begin{array}{l}1.7 U \\
1.9 U \\
1.8 U \\
1.8 U \\
1.8 U\end{array}$ & $\begin{array}{l}1.7 U \\
1.9 U \\
1.8 U \\
1.8 U \\
1.8 U\end{array}$ & $\begin{array}{l}1.7 U \\
1.9 U \\
1.8 U \\
1.8 U \\
1.8 U\end{array}$ & $\begin{array}{l}1.0 \\
0.9 U \\
0.9 U \\
0.9 U \\
1.0\end{array}$ & $\begin{array}{l}210 U \\
230 U \\
210 U \\
220 U \\
220 U\end{array}$ & $\begin{array}{l}1.6 U \\
1.7 U \\
1.6 U \\
1.7 U \\
1.7 U\end{array}$ & $\begin{array}{l}0.5 U \\
0.5 U \\
0.5 U \\
0.5 U \\
0.5 U\end{array}$ & $\begin{array}{l}1.2 U \\
1.3 U \\
1.2 U \\
1.3 U \\
1.3 U\end{array}$ \\
\hline & $\begin{array}{l}\text { M. nasuta Background } \\
\text { M. nasuta Background } \\
\text { M. nasuta Background, Replicate } 1 \\
\text { M. nasuta Background, Replicate } 2 \\
\text { M. nasuta Background, Replicate } 3 \\
\text { M. nasuta Background } \\
\text { M. nasuta Background }\end{array}$ & $\begin{array}{l}1 \\
2 \\
3 \\
3 \\
3 \\
4 \\
5\end{array}$ & $\begin{array}{l}3 \\
3 \\
3 \\
3 \\
3 \\
3 \\
3\end{array}$ & $\begin{array}{l}13.46 \\
12.00 \\
13.05 \\
13.05 \\
13.05 \\
14.21 \\
17.65\end{array}$ & $\begin{array}{l}14.3 \\
1.50 \mathrm{U} \\
18.0 \\
21.4 \\
22.6 \\
0.63 \mathrm{U} \\
7.82\end{array}$ & $\begin{array}{l}1.9 \mathrm{U} \\
4.1 \mathrm{U} \\
3.8 \mathrm{U} \\
3.6 \mathrm{U} \\
3.7 \mathrm{U} \\
1.8 \mathrm{U} \\
1.4 \mathrm{U}\end{array}$ & $\begin{array}{l}1.9 U \\
4.1 U \\
3.8 U \\
3.6 U \\
3.7 U \\
1.8 U \\
1.4 U\end{array}$ & $\begin{array}{l}1.9 \mathrm{U} \\
4.1 \mathrm{U} \\
3.8 \mathrm{U} \\
3.6 \mathrm{U} \\
3.7 \mathrm{U} \\
1.8 \mathrm{U} \\
1.4 \mathrm{U}\end{array}$ & $\begin{array}{l}0.9 U \\
2.0 U \\
1.8 U \\
1.8 U \\
1.8 U \\
0.8 U \\
0.7 U\end{array}$ & $\begin{array}{l}220 U \\
250 U \\
230 U \\
230 U \\
230 U \\
210 U \\
170 U\end{array}$ & $\begin{array}{l}1.7 \mathrm{U} \\
3.8 \mathrm{U} \\
3.5 \mathrm{U} \\
3.4 \mathrm{U} \\
3.4 \mathrm{U} \\
1.6 \mathrm{U} \\
1.3 \mathrm{U}\end{array}$ & $\begin{array}{l}4.01 \\
3.17 \\
1.07 \mathrm{U} \\
4.06 \\
1.00 \mathrm{U} \\
2.18 \\
3.12\end{array}$ & $\begin{array}{l}15.3 \\
33.8 \\
22.1 \\
26.5 \\
19.5 \\
8.23 \\
7.25\end{array}$ \\
\hline
\end{tabular}

(a) U Undetected at or above detection limit. 


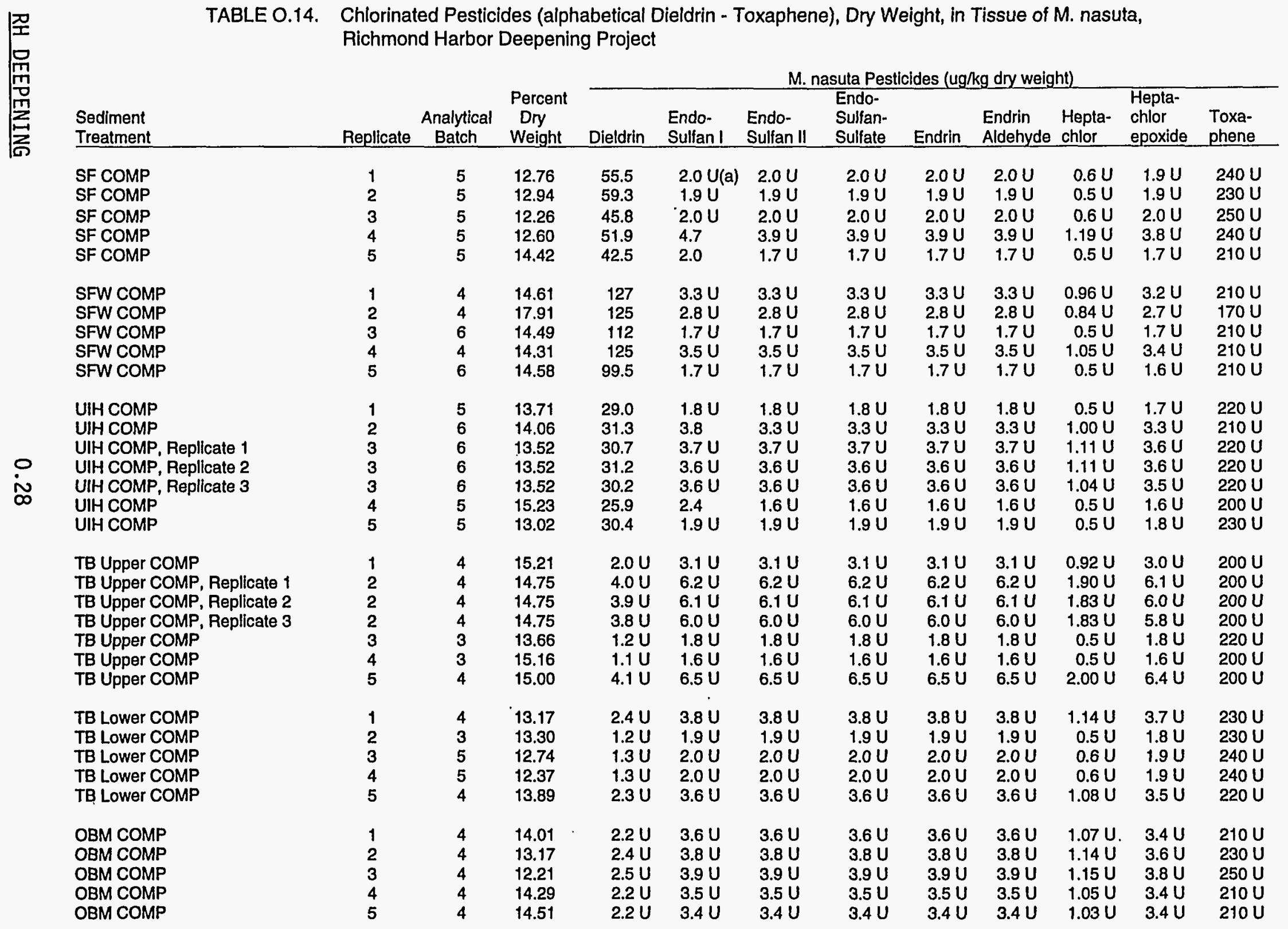




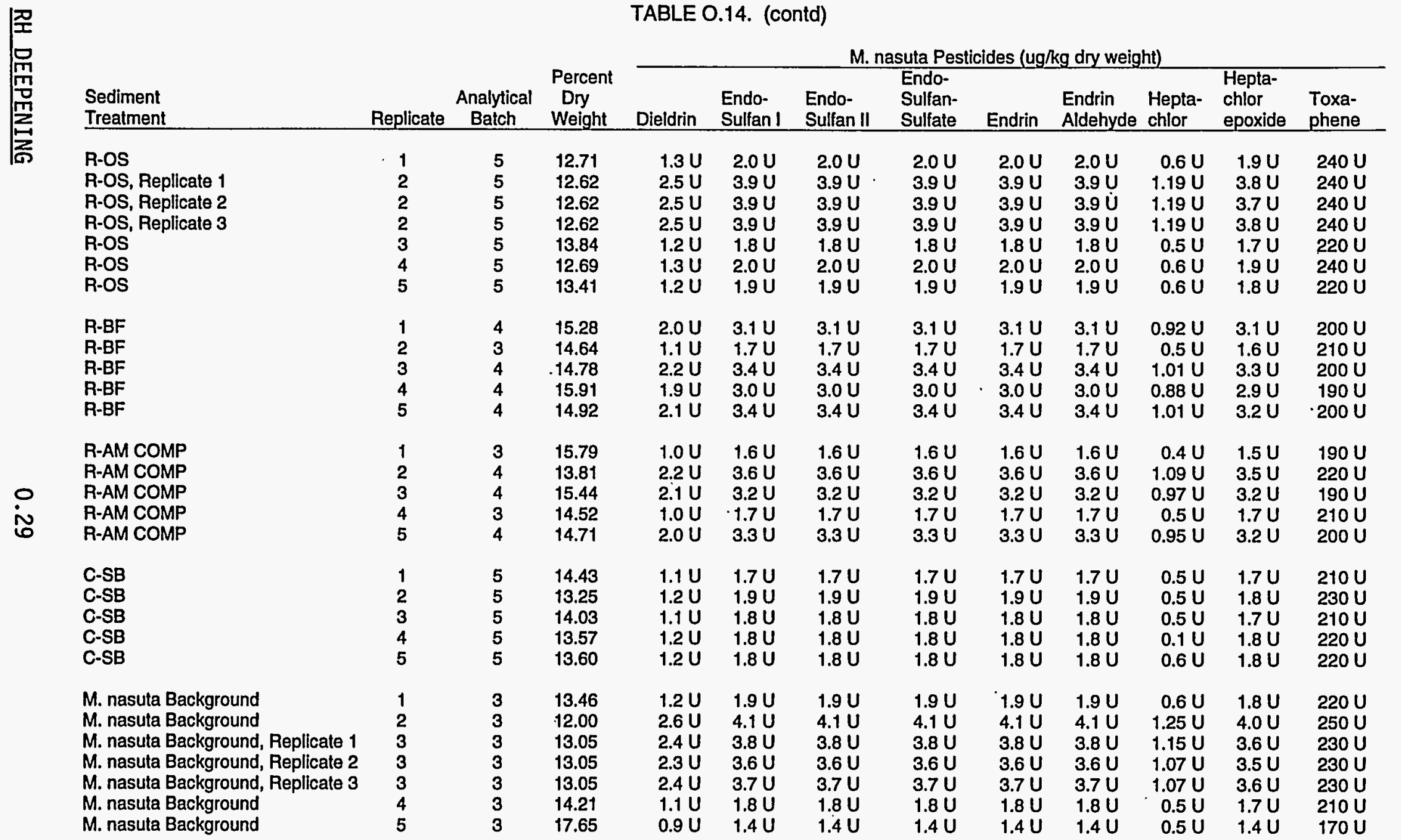

(a) U Undetected at or above detection limit. 


\begin{tabular}{|c|c|c|c|c|c|c|c|c|c|c|c|}
\hline \multirow[b]{2}{*}{$\begin{array}{l}\text { Sediment } \\
\text { Treatment }\end{array}$} & \multirow[b]{2}{*}{ Replicate } & \multirow[b]{2}{*}{$\begin{array}{c}\text { Analytical } \\
\text { Batch }\end{array}$} & \multicolumn{8}{|c|}{ M. nasula Pesticides (ug/kg wel weight) } & \multirow[b]{2}{*}{$\begin{array}{l}4,4^{\prime}- \\
\text { DDT }\end{array}$} \\
\hline & & & Aldrin & $\begin{array}{l}\text { Alpha } \\
\text { BHC }\end{array}$ & $\begin{array}{l}\text { Bela } \\
\text { BHC }\end{array}$ & $\begin{array}{l}\text { Delta } \\
\text { BHC }\end{array}$ & $\begin{array}{l}\text { Gamma } \\
\text { BHC }\end{array}$ & Chlordane & $\begin{array}{l}4,4^{\prime}- \\
\text { DDD }\end{array}$ & $\begin{array}{l}4,4^{\prime}- \\
\text { DDE }\end{array}$ & \\
\hline $\begin{array}{l}\text { Targel DL(a) } \\
\text { Achieved DL }\end{array}$ & & & $\begin{array}{c}2 \\
0.09 \cdot 0.36\end{array}$ & $\stackrel{2}{2} 0.24-1.00$ & $\begin{array}{c}2 \\
0.24-1.00\end{array}$ & $\begin{array}{c}2 \\
0.24-1.00\end{array}$ & $\begin{array}{c}2 \\
0.12-0.48\end{array}$ & $\begin{array}{r}30 \\
30-30\end{array}$ & $\begin{array}{c}2 \\
0.23-0.94\end{array}$ & $\begin{array}{c}2 \\
0.07-0.28\end{array}$ & $\begin{array}{c}2 \\
0.17-0.71\end{array}$ \\
\hline $\begin{array}{l}\text { SF COMP } \\
\text { SF COMP } \\
\text { SF COMP } \\
\text { SF COMP } \\
\text { SF COMP }\end{array}$ & $\begin{array}{l}1 \\
2 \\
3 \\
4 \\
5\end{array}$ & $\begin{array}{l}5 \\
5 \\
5 \\
5 \\
5\end{array}$ & $\begin{array}{l}0.09 U(b) \\
0.09 U \\
0.09 U \\
0.18 U \\
0.09 U\end{array}$ & $\begin{array}{l}0.25 U \\
0.25 U \\
0.25 U \\
0.49 U \\
0.25 U\end{array}$ & $\begin{array}{l}0.25 U \\
0.25 U \\
0.25 U \\
0.49 U \\
0.25 U\end{array}$ & $\begin{array}{l}0.25 U \\
0.25 U \\
0.25 U \\
0.49 U \\
0.25 U\end{array}$ & $\begin{array}{l}0.12 U \\
0.12 U \\
0.12 U \\
0.24 U \\
0.12 U\end{array}$ & $\begin{array}{l}30 \mathrm{U} \\
30 \mathrm{U} \\
30 \mathrm{U} \\
30 \mathrm{U} \\
30 \mathrm{U}\end{array}$ & $\begin{array}{l}69.9 \\
71.1 \\
58.3 \\
59.9 \\
57.5\end{array}$ & $\begin{array}{l}15.7 \\
16.8 \\
13.6 \\
13.1 \\
13.5\end{array}$ & $\begin{array}{l}0.18 U \\
0.17 U \\
0.17 U \\
0.35 U \\
0.17 U\end{array}$ \\
\hline $\begin{array}{l}\text { SFW COMP } \\
\text { SFW COMP } \\
\text { SFW COMP } \\
\text { SFW COMP } \\
\text { SFW COMP }\end{array}$ & $\begin{array}{l}1 \\
2 \\
3 \\
4 \\
5\end{array}$ & $\begin{array}{l}4 \\
4 \\
6 \\
4 \\
6\end{array}$ & $\begin{array}{l}0.17 U \\
0.18 U \\
0.09 U \\
0.18 U \\
0.09 U\end{array}$ & $\begin{array}{l}0.48 U \\
0.50 U \\
0.25 U \\
0.50 U \\
0.25 U\end{array}$ & $\begin{array}{l}0.48 \mathrm{U} \\
0.50 \mathrm{U} \\
0.25 \mathrm{U} \\
0.50 \mathrm{U} \\
0.25 \mathrm{U}\end{array}$ & $\begin{array}{l}0.48 \mathrm{U} \\
0.50 \mathrm{U} \\
0.28 \\
0.50 \mathrm{U} \\
0.25 \mathrm{U}\end{array}$ & $\begin{array}{l}0.23 \mathrm{U} \\
0.24 \mathrm{U} \\
0.46 \\
0.24 \mathrm{U} \\
0.12 \mathrm{U}\end{array}$ & $\begin{array}{l}30 U \\
30 U \\
30 U \\
30 U \\
30 U\end{array}$ & $\begin{array}{l}88.8 \\
96.3 \\
68.1 \\
90.8 \\
67.7\end{array}$ & $\begin{array}{l}54.2 \\
55.4 \\
42.4 \\
55.4 \\
41.7\end{array}$ & $\begin{array}{l}0.34 U \\
0.35 U \\
0.17 U \\
0.35 U \\
0.18 U\end{array}$ \\
\hline $\begin{array}{l}\text { UIH COMP } \\
\text { UIH COMP } \\
\text { UIH COMP, Replicate } 1 \\
\text { UIH COMP, Replicate } 2 \\
\text { UIH COMP, Replicale } 3 \\
\text { UIH COMP } \\
\text { UIH COMP }\end{array}$ & $\begin{array}{l}1 \\
2 \\
3 \\
3 \\
3 \\
4 \\
5\end{array}$ & $\begin{array}{l}5 \\
6 \\
6 \\
6 \\
6 \\
5 \\
5\end{array}$ & $\begin{array}{l}0.09 U \\
0.17 U \\
0.18 U \\
0.18 U \\
0.17 U \\
0.09 U \\
0.09 U\end{array}$ & $\begin{array}{l}0.24 U \\
0.47 U \\
0.50 U \\
0.49 U \\
0.48 U \\
0.25 U \\
0.25 U\end{array}$ & $\begin{array}{l}0.24 U \\
0.47 U \\
0.96 \\
0.49 U \\
0.48 U \\
0.25 U \\
0.25 U\end{array}$ & $\begin{array}{l}0.24 U \\
0.47 U \\
0.50 U \\
0.49 U \\
0.48 U \\
0.25 U \\
0.25 U\end{array}$ & $\begin{array}{l}0.11 U \\
0.22 U \\
0.24 U \\
0.24 U \\
0.23 U \\
0.12 U \\
0.12 U\end{array}$ & $\begin{array}{l}30 U \\
30 U \\
30 U \\
30 U \\
30 U \\
30 U \\
30 U\end{array}$ & $\begin{array}{l}30.9 \\
21.9 \\
18.3 \\
17.7 \\
15.2 \\
28.3 \\
28.0\end{array}$ & $\begin{array}{l}0.07 U \\
0.13 U \\
0.14 U \\
0.14 U \\
0.13 U \\
0.07 U \\
0.07 U\end{array}$ & $\begin{array}{l}0.17 U \\
0.33 U \\
0.36 U \\
0.35 U \\
0.34 U \\
0.17 U \\
0.17 U\end{array}$ \\
\hline $\begin{array}{l}\text { TB Upper COMP } \\
\text { TB Upper COMP, Replicate } 1 \\
\text { TB Upper COMP, Replicate } 2 \\
\text { TB Upper COMP, Replicate } 3 \\
\text { TB Upper COMP } \\
\text { TB Upper COMP } \\
\text { TB Upper COMP }\end{array}$ & $\begin{array}{l}1 \\
2 \\
2 \\
2 \\
3 \\
4 \\
5\end{array}$ & $\begin{array}{l}4 \\
4 \\
4 \\
4 \\
3 \\
3 \\
4\end{array}$ & $\begin{array}{l}0.17 U \\
0.34 U \\
0.33 U \\
0.32 U \\
0.09 U \\
0.09 U \\
0.36 U\end{array}$ & $\begin{array}{l}0.47 U \\
0.92 U \\
0.90 U \\
0.88 U \\
0.25 U \\
0.25 U \\
0.98 U\end{array}$ & $\begin{array}{l}0.47 U \\
0.92 U \\
0.90 U \\
0.88 U \\
0.25 U \\
0.25 U \\
0.98 U\end{array}$ & $\begin{array}{l}0.47 U \\
0.92 U \\
0.90 U \\
0.88 U \\
0.25 U \\
0.25 U \\
0.98 U\end{array}$ & $\begin{array}{l}0.23 U \\
0.44 U \\
0.43 U \\
0.42 U \\
0.12 U \\
0.12 U \\
0.47 U\end{array}$ & $\begin{array}{l}30 U \\
30 U \\
30 U \\
30 U \\
30 U \\
30 U \\
30 U\end{array}$ & $\begin{array}{l}0.44 U \\
0.86 U \\
0.85 U \\
0.83 U \\
0.23 U \\
0.23 U \\
0.92 U\end{array}$ & $\begin{array}{l}0.13 U \\
0.26 U \\
0.25 U \\
0.25 U \\
0.73 \\
0.56 \\
0.27 U\end{array}$ & $\begin{array}{l}0.33 U \\
0.65 U \\
0.64 U \\
0.63 U \\
0.17 U \\
0.81 \\
0.70 U\end{array}$ \\
\hline $\begin{array}{l}\text { TB Lower COMP } \\
\text { TB Lower COMP } \\
\text { TB Lower COMP } \\
\text { TB Lower COMP } \\
\text { TB Lower COMP }\end{array}$ & $\begin{array}{l}1 \\
2 \\
3 \\
4 \\
5\end{array}$ & $\begin{array}{l}4 \\
3 \\
5 \\
5 \\
4\end{array}$ & $\begin{array}{l}0.18 U \\
0.09 U \\
0.09 U \\
0.09 U \\
0.18 U\end{array}$ & $\begin{array}{l}0.50 U \\
0.25 U \\
0.25 U \\
0.25 U \\
0.50 U\end{array}$ & $\begin{array}{l}0.50 U \\
0.25 U \\
0.25 U \\
0.25 U \\
0.50 U\end{array}$ & $\begin{array}{l}0.50 U \\
0.25 U \\
0.25 U \\
0.25 U \\
0.50 U\end{array}$ & $\begin{array}{l}0.24 U \\
0.12 U \\
0.12 U \\
0.12 U \\
0.24 U\end{array}$ & $\begin{array}{l}30 U \\
30 U \\
30 U \\
30 U \\
30 U\end{array}$ & $\begin{array}{l}0.47 U \\
0.23 U \\
0.23 U \\
0.23 U \\
0.47 U\end{array}$ & $\begin{array}{l}0.14 U \\
0.07 U \\
0.07 U \\
0.01 U \\
0.14 U\end{array}$ & $\begin{array}{l}0.36 U \\
0.17 U \\
0.18 U \\
0.17 U \\
0.36 U\end{array}$ \\
\hline $\begin{array}{l}\text { OBM COMP } \\
\text { OBM COMP } \\
\text { OBM COMP } \\
\text { OBM COMP } \\
\text { OBM COMP }\end{array}$ & $\begin{array}{l}1 \\
2 \\
3 \\
4 \\
5\end{array}$ & $\begin{array}{l}4 \\
4 \\
4 \\
4 \\
4\end{array}$ & $\begin{array}{l}0.18 U \\
0.18 U \\
0.17 U \\
0.18 U \\
0.18 U\end{array}$ & $\begin{array}{l}0.50 U \\
0.50 U \\
0.48 U \\
0.50 U \\
0.50 U\end{array}$ & $\begin{array}{l}0.50 U \\
0.50 U \\
0.48 U \\
0.50 U \\
0.50 U\end{array}$ & $\begin{array}{l}0.50 U \\
0.50 U \\
0.48 U \\
0.50 U \\
0.50 U\end{array}$ & $\begin{array}{l}0.24 U \\
0.24 U \\
0.23 U \\
0.24 U \\
0.24 U\end{array}$ & $\begin{array}{l}30 U \\
30 U \\
30 U \\
30 U \\
30 U\end{array}$ & $\begin{array}{l}0.46 U \\
0.46 U \\
0.45 U \\
0.47 U \\
0.47 U\end{array}$ & $\begin{array}{l}0.14 U \\
0.14 U \\
0.13 U \\
0.14 U \\
0.14 U\end{array}$ & $\begin{array}{l}0.35 U \\
0.35 U \\
0.34 U \\
0.36 U \\
0.36 U\end{array}$ \\
\hline
\end{tabular}




\begin{tabular}{|c|c|c|c|c|c|c|c|c|c|c|c|}
\hline 㘴 & & & & ГABLE O & M. nasuta & esticides & $\mathrm{g} / \mathrm{kg}$ wet we & ight) & & & \\
\hline $\begin{array}{l}\text { Sediment } \\
\text { Treatment }\end{array}$ & Replicate & $\begin{array}{c}\text { Analytical } \\
\text { Batch }\end{array}$ & Aldrin & $\begin{array}{l}\text { Alpha } \\
\text { BHC }\end{array}$ & $\begin{array}{l}\text { Bota } \\
\text { BHC }\end{array}$ & $\begin{array}{l}\text { Della } \\
\text { BHC } \\
\end{array}$ & $\begin{array}{l}\text { Gamma } \\
\text { BHC }\end{array}$ & Chlordane & $\begin{array}{l}4,4^{\prime}- \\
\text { DDD }\end{array}$ & $\begin{array}{l}4,4^{\prime}- \\
\text { DDE }\end{array}$ & $\begin{array}{l}4,4^{\circ}- \\
\text { DDT }\end{array}$ \\
\hline $\begin{array}{l}\text { R-OS } \\
\text { R-OS, Repllcate } 1 \\
\text { R-OS, Replicate } 2 \\
\text { R-OS, Replicate } 3 \\
\text { R-OS } \\
\text { R-OS } \\
\text { R-OS }\end{array}$ & $\begin{array}{l}1 \\
2 \\
2 \\
2 \\
3 \\
4 \\
5\end{array}$ & $\begin{array}{l}5 \\
5 \\
5 \\
5 \\
5 \\
5 \\
5\end{array}$ & $\begin{array}{l}0.09 U \\
0.18 U \\
0.18 U \\
0.18 U \\
0.09 U \\
0.09 U \\
0.09 U\end{array}$ & $\begin{array}{l}0.25 U \\
0.49 U \\
0.49 U \\
0.49 U \\
0.25 U \\
0.25 U \\
0.25 U\end{array}$ & $\begin{array}{l}0.25 U \\
0.49 U \\
0.49 U \\
0.49 U \\
0.25 U \\
0.25 U \\
0.25 U\end{array}$ & $\begin{array}{l}0.25 U \\
0.49 U \\
0.49 U \\
0.49 U \\
0.25 U \\
0.25 U \\
0.25 U\end{array}$ & $\begin{array}{l}0.13 \\
0.24 U \\
0.23 U \\
0.24 U \\
0.12 U \\
0.12 U \\
0.12 U\end{array}$ & $\begin{array}{l}30 \mathrm{U} \\
30 \mathrm{U} \\
30 \mathrm{U} \\
30 \mathrm{U} \\
30 \mathrm{U} \\
30 \mathrm{U} \\
30 \mathrm{U}\end{array}$ & $\begin{array}{l}0.23 U \\
0.46 U \\
0.46 U \\
0.46 U \\
0.23 U \\
0.23 U \\
0.23 U\end{array}$ & $\begin{array}{l}0.07 U \\
0.14 U \\
0.14 U \\
0.14 U \\
0.07 U \\
0.07 U \\
0.07 U\end{array}$ & $\begin{array}{l}0.17 U \\
0.35 U \\
0.35 U \\
0.35 U \\
0.17 U \\
0.18 U \\
0.18 U\end{array}$ \\
\hline $\begin{array}{l}R \cdot B F \\
R \cdot B F \\
R \cdot B F \\
R \cdot B F \\
R \cdot B F\end{array}$ & $\begin{array}{l}1 \\
2 \\
3 \\
4 \\
5\end{array}$ & $\begin{array}{l}4 \\
3 \\
4 \\
4 \\
4\end{array}$ & $\begin{array}{l}0.17 U \\
0.09 U \\
0.18 U \\
.0 .17 U \\
0.18 U\end{array}$ & $\begin{array}{l}0.48 U \\
0.25 U \\
0.50 U \\
0.47 U \\
0.50 U\end{array}$ & $\begin{array}{l}0.48 U \\
0.25 U \\
0.50 U \\
0.47 U \\
0.50 U\end{array}$ & $\begin{array}{l}0.48 U \\
0.25 U \\
0.50 U \\
0.47 U \\
0.50 U\end{array}$ & $\begin{array}{l}0.23 U \\
0.12 U \\
0.24 U \\
0.22 U \\
0.24 U\end{array}$ & $\begin{array}{l}30 \mathrm{U} \\
30 \mathrm{U} \\
30 \mathrm{U} \\
30 \mathrm{U} \\
30 \mathrm{U}\end{array}$ & $\begin{array}{l}0.45 U \\
0.23 U \\
0.47 U \\
0.44 U \\
0.46 U\end{array}$ & $\begin{array}{l}0.13 U \\
1.14 \\
0.14 U \\
0.13 U \\
0.14 U\end{array}$ & $\begin{array}{l}0.34 \mathrm{U} \\
1.81 \\
0.36 \mathrm{U} \\
0.33 \mathrm{U} \\
0.35 \mathrm{U}\end{array}$ \\
\hline $\begin{array}{l}\text { R-AM COMP } \\
\text { R-AM COMP } \\
\text { R-AM COMP } \\
\text { R-AM COMP } \\
\text { R-AM COMP }\end{array}$ & $\begin{array}{l}1 \\
2 \\
3 \\
4 \\
5\end{array}$ & $\begin{array}{l}3 \\
4 \\
4 \\
3 \\
4\end{array}$ & $\begin{array}{l}0.09 U \\
0.18 U \\
0.18 U \\
0.09 U \\
0.17 U\end{array}$ & $\begin{array}{l}0.25 U \\
0.50 U \\
0.50 U \\
0.24 U \\
0.48 U\end{array}$ & $\begin{array}{l}0.25 U \\
0.50 U \\
0.50 U \\
0.24 U \\
0.48 U\end{array}$ & $\begin{array}{l}0.25 U \\
0.50 U \\
0.50 U \\
0.24 U \\
0.48 U\end{array}$ & $\begin{array}{l}0.12 U \\
0.24 U \\
0.24 U \\
0.12 U \\
0.23 U\end{array}$ & $\begin{array}{l}30 \mathrm{U} \\
30 \mathrm{U} \\
30 \mathrm{U} \\
30 \mathrm{U} \\
30 \mathrm{U}\end{array}$ & $\begin{array}{l}0.23 U \\
0.46 U \\
0.47 U \\
0.23 U \\
0.45 U\end{array}$ & $\begin{array}{l}0.07 U \\
0.14 U \\
0.14 U \\
1.03 \\
0.13 U\end{array}$ & $\begin{array}{l}2.91 \\
0.35 U \\
0.36 U \\
0.17 U \\
0.34 U\end{array}$ \\
\hline $\begin{array}{l}\text { C-SB } \\
\text { C-SB } \\
\text { C-SB } \\
\text { C-SB } \\
\text { C-SB }\end{array}$ & $\begin{array}{l}1 \\
2 \\
3 \\
4 \\
5\end{array}$ & $\begin{array}{l}5 \\
5 \\
5 \\
5 \\
5\end{array}$ & $\begin{array}{l}0.09 U \\
0.09 U \\
0.09 U \\
0.01 U \\
0.09 U\end{array}$ & $\begin{array}{l}0.25 U \\
0.25 U \\
0.25 U \\
0.25 U \\
0.25 U\end{array}$ & $\begin{array}{l}0.25 U \\
0.25 U \\
0.25 U \\
0.25 U \\
0.25 U\end{array}$ & $\begin{array}{l}0.25 U \\
0.25 U \\
0.25 U \\
0.25 U \\
0.25 U\end{array}$ & $\begin{array}{l}0.15 \\
0.12 U \\
0.12 U \\
0.12 U \\
0.14\end{array}$ & $\begin{array}{l}30 U \\
30 U \\
30 U \\
30 U \\
30 U\end{array}$ & $\begin{array}{l}0.23 U \\
0.23 U \\
0.23 U \\
0.23 U \\
0.23 U\end{array}$ & $\begin{array}{l}0.07 U \\
0.07 U \\
0.07 U \\
0.07 U \\
0.07 U\end{array}$ & $\begin{array}{l}0.17 \cup \\
0.17 \cup \\
0.17 U \\
0.17 \cup \\
0.18 U\end{array}$ \\
\hline $\begin{array}{l}\text { M. nasuta Background } \\
\text { M. nasuta Background } \\
\text { M. nasuta Background, Repllcate } 1 \\
\text { M. nasuta Background, Replicate } 2 \\
\text { M. nasuta Background, Replicate } 3 \\
\text { M. nasuta Background } \\
\text { M. nasuta Background }\end{array}$ & $\begin{array}{l}1 \\
2 \\
3 \\
3 \\
3 \\
4 \\
5\end{array}$ & $\begin{array}{l}3 \\
3 \\
3 \\
3 \\
3 \\
3 \\
3\end{array}$ & $\begin{array}{l}1.93 \\
0.18 \mathrm{U} \\
2.35 \\
2.79 \\
2.95 \\
0.09 \mathrm{U} \\
1.38\end{array}$ & $\begin{array}{l}0.25 U \\
0.49 U \\
0.49 U \\
0.47 U \\
0.48 U \\
0.25 U \\
0.25 U\end{array}$ & $\begin{array}{l}0.25 U \\
0.49 U \\
0.49 U \\
0.47 U \\
0.48 U \\
0.25 U \\
0.25 U\end{array}$ & $\begin{array}{l}0.25 U \\
0.49 U \\
0.49 U \\
0.47 U \\
0.48 U \\
0.25 U \\
0.25 U\end{array}$ & $\begin{array}{l}0.12 U \\
0.24 U \\
0.23 U \\
0.23 U \\
0.23 U \\
0.12 U \\
0.12 U\end{array}$ & $\begin{array}{l}30 \mathrm{U} \\
30 \mathrm{U} \\
30 \mathrm{U} \\
30 \mathrm{U} \\
30 \mathrm{U} \\
30 \mathrm{U} \\
30 \mathrm{U}\end{array}$ & $\begin{array}{l}0.23 U \\
0.46 U \\
0.46 U \\
0.44 U \\
0.45 U \\
0.23 U \\
0.23 U\end{array}$ & $\begin{array}{l}0.54 \\
0.38 \\
0.14 \mathrm{U} \\
0.53 \\
0.13 \mathrm{U} \\
0.31 \\
0.55\end{array}$ & $\begin{array}{l}2.06 \\
4.06 \\
2.88 \\
3.46 \\
2.55 \\
1.17 \\
1.28\end{array}$ \\
\hline
\end{tabular}

(a) DL Detection limit.

(b) U Undetected at or above detection IImit. 
TABLE 0.16. Chlorinated Pesticides (alphabetical, Dieldrin - Toxaphene), Wet Weight, in Tissue of M. nasuta, Richmond Harbor Deepening Project

\begin{tabular}{|c|c|c|c|c|c|c|c|c|c|c|c|}
\hline \multirow[b]{2}{*}{$\begin{array}{l}\text { Sediment } \\
\text { Treatment }\end{array}$} & \multirow[b]{2}{*}{ Replicale } & \multirow[b]{2}{*}{$\begin{array}{c}\text { Analytical } \\
\text { Batch }\end{array}$} & \multicolumn{9}{|c|}{ M. nasuta Pesticides (ug/kg wet weight) } \\
\hline & & & Dieldrin & $\begin{array}{l}\text { Endo- } \\
\text { Sullan I }\end{array}$ & $\begin{array}{l}\text { Endo- } \\
\text { Sulfan II }\end{array}$ & $\begin{array}{l}\text { Endo- } \\
\text { Sulfan- } \\
\text { Sulfate }\end{array}$ & Endrin & $\begin{array}{l}\text { Endrin } \\
\text { Aldehyde }\end{array}$ & $\begin{array}{l}\text { Hepta- } \\
\text { chlor }\end{array}$ & $\begin{array}{l}\text { Hepta- } \\
\text { chlor } \\
\text { epoxide }\end{array}$ & $\begin{array}{l}\text { Toxa- } \\
\text { phene }\end{array}$ \\
\hline $\begin{array}{l}\text { Target DL(a) } \\
\text { Achieved DL }\end{array}$ & & & $\begin{array}{c}2 \\
0.15-0.64\end{array}$ & $\begin{array}{c}2 \\
0.24-1.00\end{array}$ & $\begin{array}{c}2 \\
0.24-1.00\end{array}$ & $\begin{array}{c}2 \\
0.24-1.00\end{array}$ & $\begin{array}{c}2 \\
0.24-1.00\end{array}$ & $\begin{array}{c}2 \\
0.24-1.00\end{array}$ & $\stackrel{2}{2} 0.07-0.30$ & $\stackrel{2}{2} 0.24-0.98$ & $\begin{array}{c}30 \\
30-30\end{array}$ \\
\hline $\begin{array}{l}\text { SF COMP } \\
\text { SF COMP } \\
\text { SF COMP } \\
\text { SF COMP } \\
\text { SF COMP }\end{array}$ & $\begin{array}{l}1 \\
2 \\
3 \\
4 \\
5\end{array}$ & $\begin{array}{l}5 \\
5 \\
5 \\
5 \\
5\end{array}$ & $\begin{array}{l}7.08 \\
7.67 \\
5.62 \\
6.54 \\
6.13\end{array}$ & $\begin{array}{l}0.25 U(b) \\
0.25 U \\
0.25 U \\
0.59 \\
0.29\end{array}$ & $\begin{array}{l}0.25 U \\
0.25 U \\
0.25 U \\
0.49 U \\
0.25 U\end{array}$ & $\begin{array}{l}0.25 U \\
0.25 U \\
0.25 U \\
0.49 U \\
0.25 U\end{array}$ & $\begin{array}{l}0.25 U \\
0.25 U \\
0.25 U \\
0.49 U \\
0.25 U\end{array}$ & $\begin{array}{l}0.25 U \\
0.25 U \\
0.25 U \\
0.49 U \\
0.25 U\end{array}$ & $\begin{array}{l}0.08 U \\
0.07 U \\
0.07 U \\
0.15 U \\
0.07 U\end{array}$ & $\begin{array}{l}0.24 U \\
0.24 U \\
0.24 U \\
0.48 U \\
0.24 U\end{array}$ & $\begin{array}{l}30 \mathrm{U} \\
30 \mathrm{U} \\
30 \mathrm{U} \\
30 \mathrm{U} \\
30 \mathrm{U}\end{array}$ \\
\hline $\begin{array}{l}\text { SFW COMP } \\
\text { SFW COMP } \\
\text { SFW COMP } \\
\text { SFW COMP } \\
\text { SFW COMP }\end{array}$ & $\begin{array}{l}1 \\
2 \\
3 \\
4 \\
5\end{array}$ & $\begin{array}{l}4 \\
4 \\
6 \\
4 \\
6\end{array}$ & $\begin{array}{l}18.5 \\
22.4 \\
16.3 \\
17.9 \\
14.5\end{array}$ & $\begin{array}{l}0.48 U \\
0.50 U \\
0.25 U \\
0.50 U \\
0.25 U\end{array}$ & $\begin{array}{l}0.48 U \\
0.50 U \\
0.25 U \\
0.50 U \\
0.25 U\end{array}$ & $\begin{array}{l}0.48 U \\
0.50 U \\
0.25 U \\
0.50 U \\
0.25 U\end{array}$ & $\begin{array}{l}0.48 U \\
0.50 U \\
0.25 U \\
0.50 U \\
0.25 U\end{array}$ & $\begin{array}{l}0.48 U \\
0.50 U \\
0.25 U \\
0.50 U \\
0.25 U\end{array}$ & $\begin{array}{l}0.14 U \\
0.15 U \\
0.07 U \\
0.15 U \\
0.08 U\end{array}$ & $\begin{array}{l}0.47 \mathrm{U} \\
0.48 \mathrm{U} \\
0.24 \mathrm{U} \\
0.48 \mathrm{U} \\
0.24 \mathrm{U}\end{array}$ & $\begin{array}{l}30 U \\
30 U \\
30 U \\
30 U \\
30 U\end{array}$ \\
\hline $\begin{array}{l}\text { UIH COMP } \\
\text { UIH COMP } \\
\text { UIH COMP, Replicate } 1 \\
\text { UIH COMP, Replicate } 2 \\
\text { UIH COMP, Replicate } 3 \\
\text { UIH COMP } \\
\text { UIH COMP }\end{array}$ & $\begin{array}{l}1 \\
2 \\
3 \\
3 \\
3 \\
4 \\
4\end{array}$ & $\begin{array}{l}5 \\
6 \\
6 \\
6 \\
6 \\
5 \\
5\end{array}$ & $\begin{array}{l}3.98 \\
4.40 \\
4.15 \\
4.22 \\
4.08 \\
3.95 \\
3.96\end{array}$ & $\begin{array}{l}0.24 U \\
0.53 \\
0.50 U \\
0.49 U \\
0.48 U \\
0.37 \\
0.25 U\end{array}$ & $\begin{array}{l}0.24 U \\
0.47 U \\
0.50 U \\
0.49 U \\
0.48 U \\
0.25 U \\
0.25 U\end{array}$ & $\begin{array}{l}0.24 U \\
0.47 U \\
0.50 U \\
0.49 U \\
0.48 U \\
0.25 U \\
0.25 U\end{array}$ & $\begin{array}{l}0.24 U \\
0.47 U \\
0.50 U \\
0.49 U \\
0.48 U \\
0.25 U \\
0.25 U\end{array}$ & $\begin{array}{l}0.24 U \\
0.47 U \\
0.50 U \\
0.49 U \\
0.48 U \\
0.25 U \\
0.25 U\end{array}$ & $\begin{array}{l}0.07 U \\
0.14 U \\
0.15 U \\
0.15 U \\
0.14 U \\
0.07 U \\
0.07 U\end{array}$ & $\begin{array}{l}0.23 U \\
0.46 U \\
0.49 U \\
0.48 U \\
0.47 U \\
0.24 U \\
0.24 U\end{array}$ & $\begin{array}{l}30 \mathrm{U} \\
30 \mathrm{U} \\
30 \mathrm{U} \\
30 \mathrm{U} \\
30 \mathrm{U} \\
30 \mathrm{U} \\
30 \mathrm{U}\end{array}$ \\
\hline $\begin{array}{l}\text { TB Upper COMP } \\
\text { TB Upper COMP, Replicate } 1 \\
\text { TB Upper COMP, Replicate } 2 \\
\text { TB Upper COMP, Replicate } 3 \\
\text { TB Upper COMP } \\
\text { TB Upper COMP } \\
\text { TB Upper COMP }\end{array}$ & $\begin{array}{l}1 \\
2 \\
2 \\
2 \\
3 \\
4 \\
5\end{array}$ & $\begin{array}{l}4 \\
4 \\
4 \\
4 \\
3 \\
3 \\
4\end{array}$ & $\begin{array}{l}0.30 U \\
0.59 U \\
0.57 U \\
0.56 U \\
0.16 U \\
0.16 U \\
0.62 U\end{array}$ & $\begin{array}{l}0.47 U \\
0.92 U \\
0.90 U \\
0.88 U \\
0.25 U \\
0.25 U \\
0.98 U\end{array}$ & $\begin{array}{l}0.47 U \\
0.92 U \\
0.90 U \\
0.88 U \\
0.25 U \\
0.25 U \\
0.98 U\end{array}$ & $\begin{array}{l}0.47 U \\
0.92 U \\
0.90 U \\
0.88 U \\
0.25 U \\
0.25 U \\
0.98 U\end{array}$ & $\begin{array}{l}0.47 U \\
0.92 U \\
0.90 U \\
0.88 U \\
0.25 U \\
0.25 U \\
0.98 U\end{array}$ & $\begin{array}{l}0.47 U \\
0.92 U \\
0.90 U \\
0.88 U \\
0.25 U \\
0.25 U \\
0.98 U\end{array}$ & $\begin{array}{l}0.14 U \\
0.28 U \\
0.27 U \\
0.27 U \\
0.07 U \\
0.08 U \\
0.30 U\end{array}$ & $\begin{array}{l}0.46 U \\
0.90 U \\
0.88 U \\
0.86 U \\
0.24 U \\
0.24 U \\
0.96 U\end{array}$ & $\begin{array}{l}30 \mathrm{U} \\
30 \mathrm{U} \\
30 \mathrm{U} \\
30 \mathrm{U} \\
30 \mathrm{U} \\
30 \mathrm{U} \\
30 \mathrm{U}\end{array}$ \\
\hline $\begin{array}{l}\text { TB Lower COMP } \\
\text { TB Lower COMP } \\
\text { TB Lower COMP } \\
\text { TB Lower COMP } \\
\text { TB Lower COMP }\end{array}$ & $\begin{array}{l}1 \\
2 \\
3 \\
4 \\
5\end{array}$ & $\begin{array}{l}4 \\
3 \\
5 \\
5 \\
4\end{array}$ & $\begin{array}{l}0.32 U \\
0.16 U \\
0.16 U \\
0.16 U \\
0.32 U\end{array}$ & $\begin{array}{l}0.50 U \\
0.25 U \\
0.25 U \\
0.25 U \\
0.50 U\end{array}$ & $\begin{array}{l}0.50 \mathrm{U} \\
0.25 \mathrm{U} \\
0.25 \mathrm{U} \\
0.25 \mathrm{U} \\
0.50 \mathrm{U}\end{array}$ & $\begin{array}{l}0.50 U \\
0.25 U \\
0.25 U \\
0.25 U \\
0.50 U\end{array}$ & $\begin{array}{l}0.50 U \\
0.25 U \\
0.25 U \\
0.25 U \\
0.50 U\end{array}$ & $\begin{array}{l}0.50 U \\
0.25 U \\
0.25 U \\
0.25 U \\
0.50 U\end{array}$ & $\begin{array}{l}0.15 U \\
0.07 U \\
0.08 U \\
0.07 U \\
0.15 U\end{array}$ & $\begin{array}{l}0.49 U \\
0.24 U \\
0.24 U \\
0.24 U \\
0.49 U\end{array}$ & $\begin{array}{l}30 U \\
30 U \\
30 U \\
30 U \\
30 U\end{array}$ \\
\hline $\begin{array}{l}\text { OBM COMP } \\
\text { OBM COMP } \\
\text { OBM COMP } \\
\text { OBM COMP } \\
\text { OBM COMP }\end{array}$ & $\begin{array}{l}1 \\
2 \\
3 \\
4 \\
5\end{array}$ & $\begin{array}{l}4 \\
4 \\
4 \\
4 \\
4\end{array}$ & $\begin{array}{l}0.31 U \\
0.31 U \\
0.31 U \\
0.32 U \\
0.32 U\end{array}$ & $\begin{array}{l}0.50 U \\
0.50 U \\
0.48 U \\
0.50 U \\
0.50 U\end{array}$ & $\begin{array}{l}0.50 U \\
0.50 U \\
0.48 U \\
0.50 U \\
0.50 U\end{array}$ & $\begin{array}{l}0.50 U \\
0.50 U \\
0.48 U \\
0.50 U \\
0.50 U\end{array}$ & $\begin{array}{l}0.50 \mathrm{U} \\
0.50 \mathrm{U} \\
0.48 \mathrm{U} \\
0.50 \mathrm{U} \\
0.50 \mathrm{U}\end{array}$ & $\begin{array}{l}0.50 U \\
0.50 U \\
0.48 U \\
0.50 U \\
0.50 U\end{array}$ & $\begin{array}{l}0.15 U \\
0.15 U \\
0.14 U \\
0.15 U \\
0.15 U\end{array}$ & $\begin{array}{l}0.48 U \\
0.48 U \\
0.47 U \\
0.49 U \\
0.49 U\end{array}$ & $\begin{array}{l}30 U \\
30 U \\
30 U \\
30 U \\
30 U\end{array}$ \\
\hline
\end{tabular}


TABLE 0.16. (contd)

\begin{tabular}{|c|c|c|c|c|c|c|c|c|c|c|c|}
\hline \multirow[b]{2}{*}{$\begin{array}{l}\text { Sedlment } \\
\text { Treatment }\end{array}$} & \multirow[b]{2}{*}{ Repllcate } & \multirow[b]{2}{*}{$\begin{array}{c}\text { Analytical } \\
\text { Batch }\end{array}$} & \multicolumn{9}{|c|}{ M. nasuta Pesticides (ug/kg wet weight) } \\
\hline & & & Dleldrin & $\begin{array}{l}\text { Endo- } \\
\text { Sulfan 1 }\end{array}$ & $\begin{array}{l}\text { Endo: } \\
\text { Sulfan II }\end{array}$ & $\begin{array}{l}\text { Endo- } \\
\text { Sulfan- } \\
\text { Sulfate } \\
\end{array}$ & Endrin & $\begin{array}{l}\text { Endrin } \\
\text { Aldehyde }\end{array}$ & $\begin{array}{l}\text { Hepta- } \\
\text { chlor }\end{array}$ & $\begin{array}{l}\text { Hepta- } \\
\text { chlor } \\
\text { epoxide } \\
\end{array}$ & $\begin{array}{l}\text { Toxa- } \\
\text { phene }\end{array}$ \\
\hline R-OS & 1 & 5 & $0.16 \mathrm{U}$ & $0.25 \mathrm{U}$ & $0.25 \mathrm{U}$ & $0.25 \mathrm{U}$ & $0.25 \mathrm{U}$ & $0.25 \mathrm{U}$ & $0.07 \mathrm{U}$ & $0.24 \mathrm{U}$ & $30 \mathrm{U}$ \\
\hline R-OS, Repllcate 1 & 2 & 5 & $0.31 \mathrm{U}$ & $0.49 \mathrm{U}$ & $0.49 \mathrm{U}$ & $0.49 U$ & $0,49 \mathrm{U}$ & $0.49 \mathrm{U}$ & $0.15 U$ & $0.48 \mathrm{U}$ & $30 \mathrm{U}$ \\
\hline R-OS, Repllcate 2 & 2 & 5 & $0.31 \mathrm{U}$ & $0.49 \mathrm{U}$ & $0.49 \mathrm{U}$ & $0.49 \mathrm{U}$ & $0.49 \mathrm{U}$ & $0.49 \mathrm{U}$ & $0.15 \mathrm{U}$ & $0.47 \mathrm{U}$ & $30 \mathrm{U}$ \\
\hline R-OS, Repllcate 3 & 2 & 5 & $0.31 \mathrm{U}$ & $0.49 \mathrm{U}$ & $0.49 \mathrm{U}$ & $0.49 \mathrm{U}$ & $0.49 \mathrm{U}$ & $0.49 \mathrm{U}$ & $0.15 \mathrm{U}$ & $0.48 \mathrm{U}$ & $30 \mathrm{U}$ \\
\hline R-OS & 3 & 5 & $0.16 \mathrm{U}$ & $0.25 \mathrm{U}$ & $0.25 \mathrm{U}$ & $0.25 \mathrm{U}$ & $0.25 \mathrm{U}$ & $0.25 \mathrm{U}$ & $0.07 \mathrm{U}$ & $0.24 \mathrm{U}$ & $30 \mathrm{U}$ \\
\hline R-OS & 4 & 5 & $0.16 \mathrm{U}$ & $0.25 \mathrm{U}$ & $0.25 \mathrm{U}$ & $0.25 \mathrm{U}$ & $0.25 \mathrm{U}$ & $0.25 \mathrm{U}$ & $0.08 \mathrm{U}$ & $0.24 \mathrm{U}$ & $30 \mathrm{U}$ \\
\hline R-OS & 5 & 5 & $0.16 U$ & $0.25 \mathrm{U}$ & $0.25 \mathrm{U}$ & $0.25 U$ & $0.25 U$ & $0.25 \mathrm{U}$ & $0.08 U$ & $0.24 \mathrm{U}$ & $30 \mathrm{U}$ \\
\hline R-BF & 1 & 4 & $0.31 \mathrm{U}$ & $0.48 \mathrm{U}$ & $0.48 U$ & $0.48 \mathrm{U}$ & $0.48 \mathrm{U}$ & $0.48 \mathrm{U}$ & $0.14 \mathrm{U}$ & $0.47 \mathrm{U}$ & $30 \mathrm{U}$ \\
\hline $\mathrm{R}-\mathrm{BF}$ & 2 & 3 & $0.16 U$ & $0.25 \mathrm{U}$ & $0.25 \mathrm{U}$ & $0.25 \mathrm{U}$ & $0.25 \mathrm{U}$ & $0.25 U$ & $0.08 \mathrm{U}$ & $0.24 \mathrm{U}$ & $30 \mathrm{U}$ \\
\hline $\mathrm{R}-\mathrm{BF}$ & 3 & 4 & $0.32 \mathrm{U}$ & $0.50 \mathrm{U}$ & $0.50 \mathrm{U}$ & $0.50 \mathrm{U}$ & $0.50 \mathrm{U}$ & $0.50 \mathrm{U}$ & $0.15 U$ & $0.49 \mathrm{U}$ & $30 \mathrm{U}$ \\
\hline R-BF & 4 & 4 & $0.30 \mathrm{U}$ & $0.47 \mathrm{U}$ & $0.47 \mathrm{U}$ & $0.47 \mathrm{U}$ & $0.47 \mathrm{U}$ & $0.47 \mathrm{U}$ & $0.14 \mathrm{U}$ & $0.46 \mathrm{U}$ & $30 \mathrm{U}$ \\
\hline R-BF & 5 & 4 & $0.31 \mathrm{U}$ & $0.50 \mathrm{U}$ & $0.50 \mathrm{U}$ & $0.50 \mathrm{U}$ & $0.50 \mathrm{U}$ & $0.50 \mathrm{U}$ & $0.15 \mathrm{U}$ & $0.48 \mathrm{U}$ & $30 \mathrm{U}$ \\
\hline R-AM COMP & 1 & 3 & $0.16 \mathrm{U}$ & $0.25 \mathrm{U}$ & $0.25 \mathrm{U}$ & $0.25 \mathrm{U}$ & $0.25 \mathrm{U}$ & $0.25 \mathrm{U}$ & $0.07 \mathrm{U}$ & $0.24 \mathrm{U}$ & $30 \mathrm{U}$ \\
\hline R-AM COMP & 2 & 4 & $0.31 \mathrm{U}$ & $0.50 \mathrm{U}$ & $0.50 \mathrm{U}$ & $0.50 \mathrm{U}$ & $0.50 \mathrm{U}$ & $0.50 \mathrm{U}$ & $0.15 \mathrm{U}$ & $0.48 \mathrm{U}$ & $30 \mathrm{U}$ \\
\hline R-AM COMP & 3 & 4 & $0.32 \mathrm{U}$ & $0.50 \mathrm{U}$ & $0.50 \mathrm{U}$ & $0.50 \mathrm{U}$ & $0.50 \mathrm{U}$ & $0.50 \mathrm{U}$ & $0.15 \mathrm{U}$ & $0.49 \mathrm{U}$ & $30 \mathrm{U}$ \\
\hline R-AM COMP & 4 & 3 & $0.15 \mathrm{U}$ & $0.24 \mathrm{U}$ & $0.24 \mathrm{U}$ & $0.24 \mathrm{U}$ & $0.24 \mathrm{U}$ & $0.24 \mathrm{U}$ & $0.07 \mathrm{U}$ & $0.24 \mathrm{U}$ & $30 \mathrm{U}$ \\
\hline R-AM COMP & 5 & 4 & $0.30 \mathrm{U}$ & $0.48 \mathrm{U}$ & $0.48 \mathrm{U}$ & $0.48 \mathrm{U}$ & $0.48 \mathrm{U}$ & $0.48 U$ & $0.14 \mathrm{U}$ & $0.47 \mathrm{U}$ & $30 \mathrm{U}$ \\
\hline C-SB & 1 & 5 & $0.16 \mathrm{U}$ & $0.25 \mathrm{U}$ & $0.25 \mathrm{U}$ & $0.25 \mathrm{U}$ & $0.25 \mathrm{U}$ & $0.25 \mathrm{U}$ & $0.07 \mathrm{U}$ & $0.24 \mathrm{U}$ & $30 \mathrm{U}$ \\
\hline C-SB & 2 & 5 & $0.16 \mathrm{U}$ & $0.25 \mathrm{U}$ & $0.25 \mathrm{U}$ & $0.25 \mathrm{U}$ & $0.25 \mathrm{U}$ & $0.25 \mathrm{U}$ & $0.07 U$ & $0.24 \mathrm{U}$ & $30 \mathrm{U}$ \\
\hline C-SB & 3 & 5 & $0.16 U$ & $0.25 U$ & $0.25 \mathrm{U}$ & $0.25 \mathrm{U}$ & $0.25 \mathrm{U}$ & $0.25 \mathrm{U}$ & $0.07 \mathrm{U}$ & $0.24 \mathrm{U}$ & $30 \mathrm{U}$ \\
\hline C-SB & 4 & 5 & $0.16 \mathrm{U}$ & $0.25 \mathrm{U}$ & $0.25 \mathrm{U}$ & $0.25 \mathrm{U}$ & $0.25 \mathrm{U}$ & $0.25 \mathrm{U}$ & $0.01 \mathrm{U}$ & $0.24 \mathrm{U}$ & $30 \mathrm{U}$ \\
\hline C-SB & 5 & 5 & $0.16 \mathrm{U}$ & $0.25 \mathrm{U}$ & $0.25 \mathrm{U}$ & $0.25 \mathrm{U}$ & $0.25 \mathrm{U}$ & $0.25 \mathrm{U}$ & $0.08 \mathrm{U}$ & $0.24 U$ & $30 \mathrm{U}$ \\
\hline & 1 & 3 & $0.16 \mathrm{U}$ & $0.25 U$ & $0.25 \mathrm{U}$ & $0.25 \mathrm{U}$ & $0.25 \mathrm{U}$ & $0.25 \mathrm{U}$ & $0.08 \mathrm{U}$ & $0.24 \mathrm{U}$ & $30 u$ \\
\hline M. nasula Background & 2 & 3 & $0.31 \mathrm{U}$ & $0.49 U$ & $0.49 \mathrm{U}$ & $0.49 \mathrm{U}$ & $0.49 \mathrm{U}$ & $0.49 U$ & $0.15 \mathrm{U}$ & $0.48 \mathrm{U}$ & $30 \mathrm{U}$ \\
\hline M. nasula Background, Repllcate 1 & 3 & 3 & $0.31 \mathrm{U}$ & $0.49 U$ & $0.49 \mathrm{U}$ & $0.49 \mathrm{U}$ & $0.49 \mathrm{U}$ & $0.49 u$ & $0.15 U$ & $0.47 \mathrm{U}$ & $30 \mathrm{U}$ \\
\hline M. nasula Background, Repllcate 2 & 3 & 3 & $0.30 \mathrm{U}$ & $0.47 \mathrm{U}$ & $0.47 \mathrm{U}$ & $0.47 \mathrm{U}$ & $0.47 \mathrm{U}$ & $0.47 \mathrm{U}$ & $0.14 U$ & $0.46 \mathrm{U}$ & $30 \mathrm{U}$ \\
\hline M. nasula Background, Repllcate 3 & 3 & 3 & $0.31 \mathrm{U}$ & $0.48 \mathrm{U}$ & $0.48 \mathrm{U}$ & $0.48 \mathrm{U}$ & $0.48 U$ & $0.48 \mathrm{U}$ & $0.14 \mathrm{U}$ & $0.47 \mathrm{U}$ & $30 \mathrm{U}$ \\
\hline M. nasula Background & 4 & 3 & $0.16 \mathrm{U}$ & $0.25 \mathrm{U}$ & $0.25 \mathrm{U}$ & $0.25 \mathrm{U}$ & $0.25 \mathrm{U}$ & $0.25 U$ & $0.07 \mathrm{U}$ & $0.24 \mathrm{U}$ & $30 \mathrm{U}$ \\
\hline M. nasula Background & 5 & 3 & $0.16 \mathrm{U}$ & $0.25 \mathrm{U}$ & $0.25 \mathrm{U}$ & $0.25 \mathrm{U}$ & $0.25 \mathrm{U}$ & $0.25 \mathrm{U}$ & $0.08 \mathrm{U}$ & $0.24 \mathrm{U}$ & $30 \mathrm{U}$ \\
\hline
\end{tabular}

(a) DL Detectlon IImit.

(b) U Undetected at or above detectlon limit. 
王 TABLE 0.17. Quality Control Data for Chlorinated Pesticides (alphabetical, Aldrin - 4,4'-DDT), Wet Weight, in Tissue of M. nasuta,

Richmond Harbor Deepening Project

Sediment

Treatment

Analytical

M. nasuta Pesticides (ug/kg wet weight

Method Blank

Blank-1

Blank-1

Blank

Blank

Replicate

Batch

Aldrin

BHC

BHC

BHC

Chlordane

$4,4^{\prime}-$

4,4-

$4,4^{-}$

.

Matrix Spikes

M. nasuta Background

M. nasuta Background, MS

Concentration Recovered

Amount Spiked

Percent Recovery

$\begin{array}{ll}\infty & \text { TB Upper COMP } \\ \omega & \text { TB Upper COMP, MS } \\ \text { Concentration Recovered } \\ \text { Amount Spiked }\end{array}$

Percent Aecovery

$\begin{array}{lllll}3 & 0.19 U(a) & 0.53 U & 0.53 U & 0.53 U \\ 4 & 0.20 U & 0.55 U & 0.55 U & 0.55 U \\ 5 & 0.11 U & 0.30 U & 0.30 U & 0.30 U\end{array}$

$\begin{array}{lllll}0.25 U & 30 U & 0.49 U & 0.15 U & 0.37 U \\ 0.26 U & 30 U & 0.51 U & 0.15 U & 0.39 U \\ 0.14 U & 30 U & 0.28 U & 0.08 U & 0.21 U \\ 0.14 U & 30 U & 0.28 U & 0.08 U & 0.21 U\end{array}$

SF COMP
SF COMP, MS
Concentration Recovered
Amount Spiked

Percent Pecovery

$\begin{array}{llll}0.11 \mathrm{U} & 0.30 \mathrm{U} & 0.30 \mathrm{U} & 0.30 \mathrm{U}\end{array}$

$0.14 \mathrm{U}$

$30 \mathrm{U}$

$0.28 \mathrm{U}$

$0.08 \cup \quad 0.21 U$

\section{UIH COMP}

UIH COMP, MS

Concentration Recovered

Amount Spiked

Percent Recovery

$\begin{array}{ccc}2 & 3 & 0.18 \mathrm{U} \\ 2 & 3 & 3.75 \\ & & 3.75 \\ & & 4.75 \\ & & 79\end{array}$

NA (b)
NA
NA
NS (c)
NA

NA NA

0.24

4.08

$\begin{array}{lll}\text { NA } & \text { NA } & 4.08 \\ \text { NS } & \text { NS } & 4.75\end{array}$

$\begin{array}{lll}\text { NA } & \text { NA } & 4.08 \\ \text { NS } & \text { NS } & 4.75\end{array}$

NA

NA NA $\quad 4.06$

NA

NS

NA

NA

NS

$\begin{array}{ll}\text { NA } & 4.06 \\ \text { NA } & 19.3\end{array}$

NA $\quad 15.2$

79

NA

NA $\quad 0.47 \mathrm{U}$

$\begin{array}{lll}5 & 4 & 0.36 \\ 5 & 4 & 6.35\end{array}$

NA

6.35

NA

NA NA $\quad 9.90$

NA

NA
NA

9.90

9.15

NS

$\begin{array}{lll}N A & N A & 9.90 \\ N S & N S & 9.15\end{array}$

NA NA $108 \%$

NA

NS

NA NA $\quad 0.70 U$

NA NA 34.1

$\begin{array}{lll}\text { NA } & \text { NA } & 34.1 \\ \text { NS } & \text { NS } & 36.6\end{array}$

NS $\quad$ NS $\quad 36.6$

Standard Reference Material

Certified SRM not avallable for pesticides. 


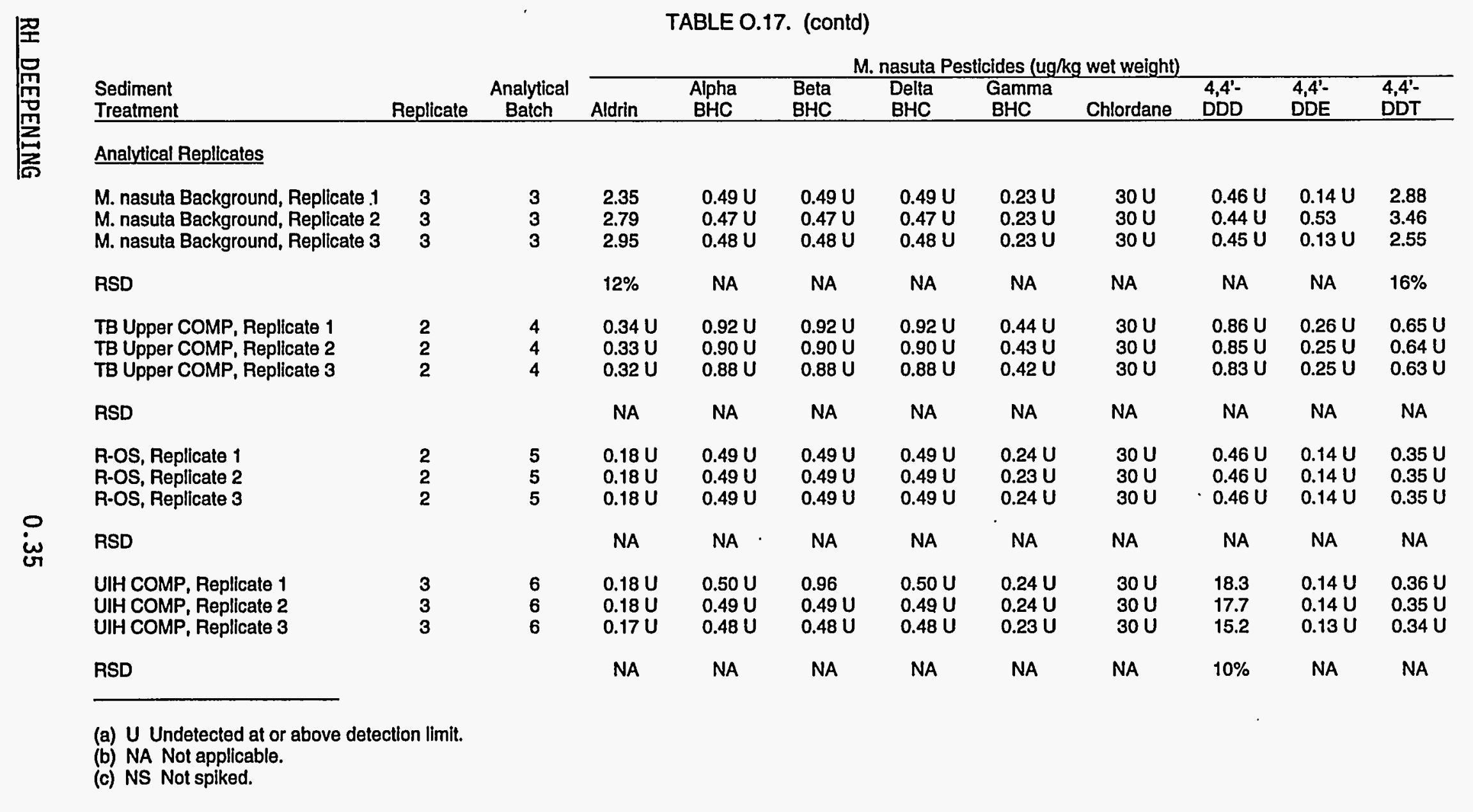


TABLE 0.18. Quality Control Data for Chlorinated Pesticides (alphabetical, Dieldrin - Toxaphene), Wet Weight, in Tissue of M. nasuta, Richmond Harbor Deepening Project

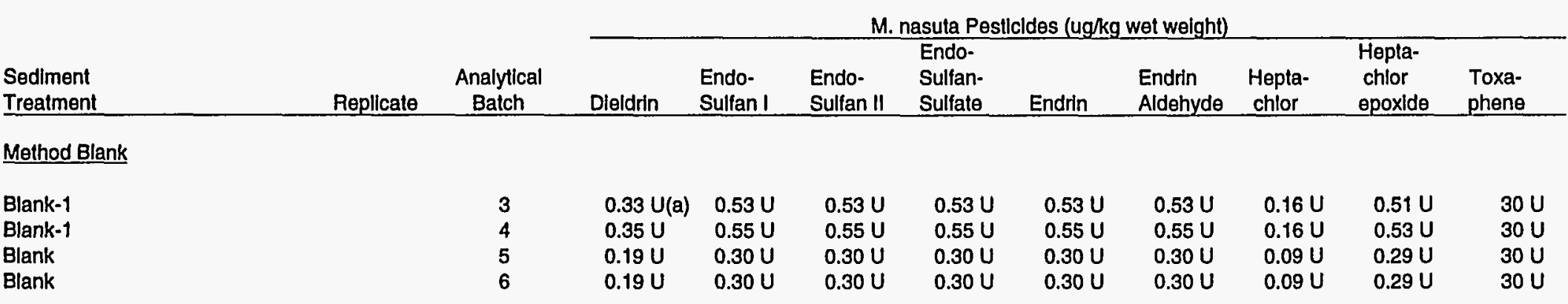

\section{Matrix Splkes}

M. nasuta Background

M. nasuta Background, MS

Concentration Recovered

Amount Splked

Percent Recovery

TB Upper COMP

TB Upper COMP, MS

Concentration Recovered

Amount Splked

Percent Recovery

\section{SF COMP}

SF COMP, MS

Concentration Recovered

Amount Splked

Percent Recovery

\section{UIH COMP}

UIH COMP, MS

Concentration Recovered

Amount Splked

Percent Recovery

$\begin{array}{lll}2 & 3 & 0.31 \mathrm{U} \\ 2 & 3 & 16.3 \\ & & 16.3 \\ & & 19.0 \\ & & 86 \% \\ & & \\ 5 & 4 & 0.62 \mathrm{U} \\ 5 & 4 & 30.6 \\ & & 30.6 \\ & & 36.6 \\ & & 84 \% \\ 4 & & \\ 4 & 5 & 6.54 \\ & 5 & 24.2 \\ & & 17.7 \\ & & 20.0 \\ & & 88 \% \\ 2 & 6 & 4.40 \\ 2 & 6 & 20.4 \\ & & 16.0 \\ & & 20.0 \\ & & 80 \%\end{array}$

$\begin{array}{ll}\text { NA (b) } & \text { NA } \\ \text { NA } & \text { NA } \\ \text { NA } & \text { NA } \\ \text { NS (c) } & \text { NS } \\ \text { NA } & \text { NA } \\ & \\ \text { NA } & \text { NA } \\ \text { NA } & \text { NA } \\ \text { NA } & \text { NA } \\ \text { NS } & \text { NS } \\ \text { NA } & \text { NA } \\ & \\ \text { NA } & \text { NA } \\ \text { NA } & \text { NA } \\ \text { NA } & \text { NA } \\ \text { NS } & \text { NS } \\ \text { NA } & \text { NA } \\ & \\ \text { NA } & \text { NA } \\ \text { NA } & \text { NA } \\ \text { NA } & \text { NA } \\ \text { NS } & \text { NS } \\ \text { NA } & \text { NA }\end{array}$

$\begin{array}{lll}\text { NA } & 0.49 U & \text { NA } \\ \text { NA } & 15.9 & \text { NA } \\ \text { NA } & 15.9 & \text { NA } \\ \text { NS } & 19.0 & \text { NS } \\ \text { NA } & 84 \% & \text { NA } \\ & & \\ \text { NA } & 0.98 \mathrm{U} & \text { NA } \\ \text { NA } & 24.4 & \text { NA } \\ \text { NA } & 24.4 & \text { NA } \\ \text { NS } & 36.6 & \text { NS } \\ \text { NA } & 67 \% & \text { NA } \\ & & \\ \text { NA } & 0.49 U & \text { NA } \\ \text { NA } & 12.7 & \text { NA } \\ \text { NA } & 12.7 & \text { NA } \\ \text { NS } & 20.0 & \text { NS } \\ \text { NA } & 64 \% & \text { NA } \\ & & \\ \text { NA } & 0.47 \mathrm{U} & \text { NA } \\ \text { NA } & 12.2 & \text { NA } \\ \text { NA } & 12.2 & \text { NA } \\ \text { NS } & 20.0 & \text { NS } \\ \text { NA } & 61 \% & \text { NA }\end{array}$

$0.15 \mathrm{U}$
3.79
3.79
4.75
$80 \%$

$0.30 \mathrm{U}$
4.53
4.53
9.15
$50 \%$

$0.15 \mathrm{U}$
3.07
3.07
5.00
$61 \%$

$0.14 \mathrm{U}$
2.96
2.96
5.00
$59 \%$

NA NA

Standard Reference Material

Certifled SAM not available for pesticldes. 


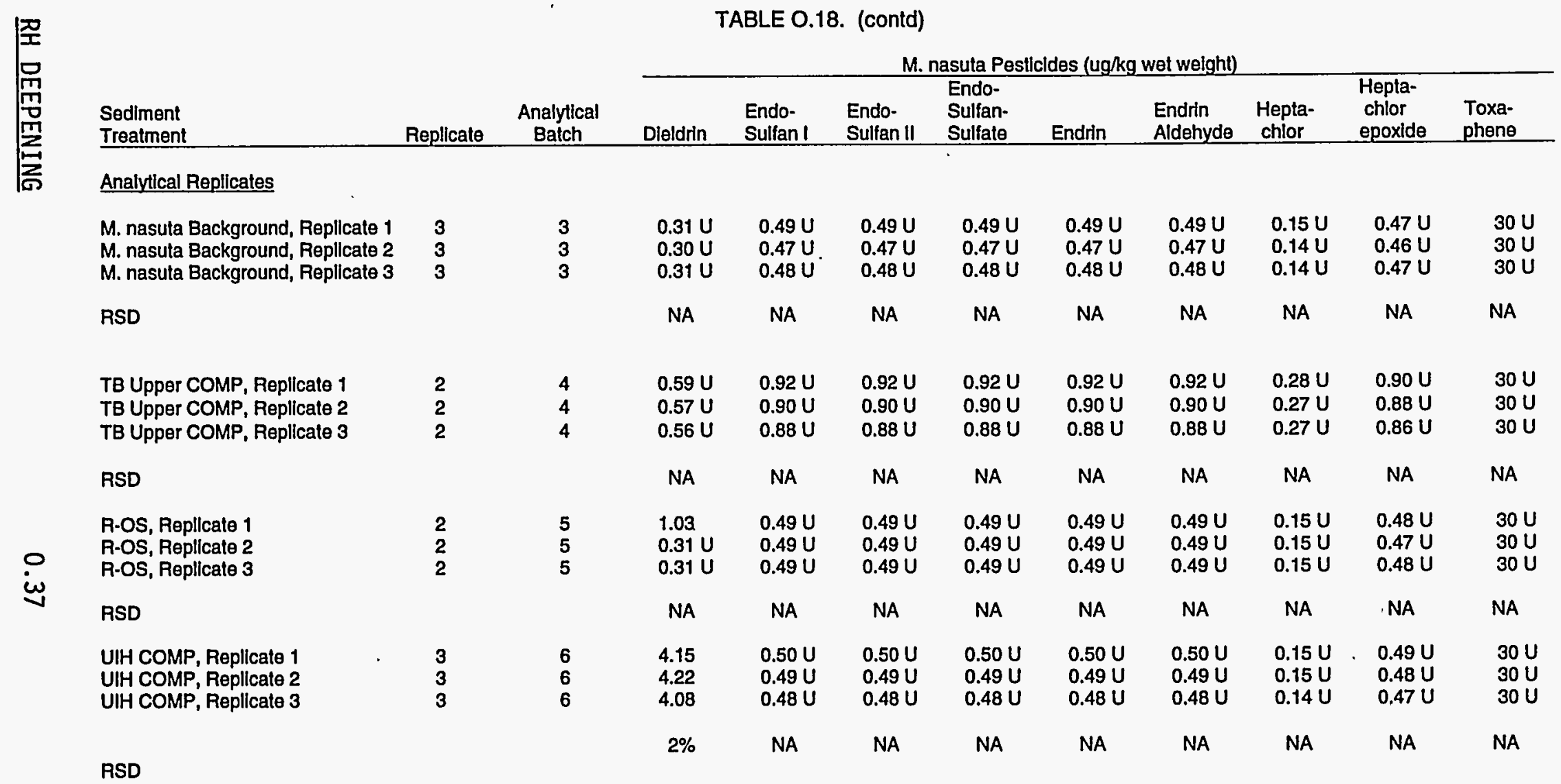

(a) U Undefected at or above detection limit.
(b) NA Not applicable.

(c) NS Not splked. 
TABLE 0.19. Polychlorinated Biphenyls (PCBs), Dry Weight, in Tissue of M. nasuta, Richmond Harbor Deepening Project

\begin{tabular}{|c|c|c|c|c|c|c|c|}
\hline \multirow[b]{2}{*}{$\begin{array}{l}\text { Sediment } \\
\text { Treatment }\end{array}$} & \multirow[b]{2}{*}{ Replicate } & \multirow[b]{2}{*}{$\begin{array}{c}\text { Analytical } \\
\text { Batch }\end{array}$} & \multirow[b]{2}{*}{$\begin{array}{l}\text { Percent } \\
\text { Dry } \\
\text { Weight }\end{array}$} & \multicolumn{4}{|c|}{ M. nasuta PCBs (ug/kg dry weight) } \\
\hline & & & & $\begin{array}{c}\text { Aroclor } \\
1242\end{array}$ & $\begin{array}{c}\text { Aroclor } \\
1248\end{array}$ & $\begin{array}{c}\text { Aroclor } \\
1254\end{array}$ & $\begin{array}{c}\text { Aroclor } \\
1260\end{array}$ \\
\hline SF COMP & 1 & 5 & 12.76 & $160 \cup(a)$ & $160 \mathrm{U}$ & $160 \mathrm{U}$ & $160 U$ \\
\hline SF COMP & 2 & 5 & 12.94 & $160 U^{\circ}$ & $160 U$ & $160 \mathrm{U}$ & $160 \mathrm{U}$ \\
\hline SF COMP & 3 & 5 & 12.26 & $160 \mathrm{U}$ & $160 \mathrm{U}$ & $160 \mathrm{U}$ & $160 \mathrm{U}$ \\
\hline SF COMP & 4 & 5 & 12.60 & $160 \mathrm{U}$ & $160 \mathrm{U}$ & $160 \mathrm{U}$ & $160 \mathrm{U}$ \\
\hline SF COMP & 5 & 5 & 14.42 & $140 U$ & $140 U$ & $140 \mathrm{U}$ & $140 \mathrm{U}$ \\
\hline SFW COMP & 1 & 4 & 14.61 & $140 \mathrm{U}$ & $140 \mathrm{U}$ & 180 & $140 \mathrm{U}$ \\
\hline SFW COMP & 2 & 4 & 17.91 & $110 \mathrm{U}$ & $110 \mathrm{U}$ & 150 & $110 \mathrm{U}$ \\
\hline SFW COMP & 3 & 6 & 14.49 & $140 U$ & $140 U$ & 240 & $140 \mathrm{U}$ \\
\hline SFW COMP & 4 & 4 & 14.31 & $140 \mathrm{U}$ & $140 \mathrm{U}$ & 230 & $140 \mathrm{U}$ \\
\hline SFW COMP & 5 & 6 & 14.58 & $140 \mathrm{U}$ & $140 \mathrm{U}$ & 270 & $140 \mathrm{U}$ \\
\hline UIH COMP & 1 & 5 & 13.71 & $150 \mathrm{U}$ & $150 \mathrm{U}$ & 140 & $150 \mathrm{U}$ \\
\hline UIH COMP & 2 & 6 & 14.06 & $140 \mathrm{U}$ & $140 U$ & $140 \mathrm{U}$ & $140 \mathrm{U}$ \\
\hline UIH COMP, Replicate 1 & 3 & 6 & 13.52 & $150 \mathrm{U}$ & $150 \mathrm{U}$ & $150 U$ & $150 U$ \\
\hline UIH COMP, Replicate 2 & 3 & 6 & 13.52 & $150 \mathrm{U}$ & $150 \mathrm{U}$ & $150 U$ & $150 \mathrm{U}$ \\
\hline UIH COMP, Replicate 3 & 3 & 6 & 13.52 & $150 \mathrm{U}$ & $150 \mathrm{U}$ & $150 \mathrm{U}$ & $150 \mathrm{U}$ \\
\hline UIH COMP & 4 & 5 & 15.23 & $130 \mathrm{U}$ & $130 \mathrm{U}$ & 120 & $130 \mathrm{U}$ \\
\hline UIH COMP & 5 & 5 & 13.02 & $150 U$ & $150 U$ & 140 & $150 \mathrm{U}$ \\
\hline TB Upper COMP & 1 & 4 & 15.21 & $130 \mathrm{U}$ & $130 \mathrm{U}$ & $130 \mathrm{U}$ & $130 \mathrm{U}$ \\
\hline TB Upper COMP, Replicate 1 & 2 & 4 & 14.75 & $140 \mathrm{U}$ & $140 \mathrm{U}$ & $140 \mathrm{U}$ & $140 \mathrm{U}$ \\
\hline TB Upper COMP, Replicate 2 & 2 & 4 & 14.75 & $140 \mathrm{U}$ & $140 U$ & $140 U$ & $140 \mathrm{U}$ \\
\hline TB Upper COMP, Replicate 3 & 2 & 4 & 14.75 & $140 \mathrm{U}$ & $140 U$ & $140 U$ & $140 \mathrm{U}$ \\
\hline TB Upper COMP & 3 & 3 & 13.66 & $146 U$ & $150 \mathrm{U}$ & $150 U$ & $150 \mathrm{U}$ \\
\hline TB Upper COMP & 4 & 3 & 15.16 & $130 \mathrm{U}$ & $130 \mathrm{U}$ & $130 \mathrm{U}$ & $130 \mathrm{U}$ \\
\hline TB Upper COMP & 5 & 4 & 15.00 & $130 \mathrm{U}$ & $130 \mathrm{U}$ & $130 \mathrm{U}$ & $130 \mathrm{U}$ \\
\hline TB Lower COMP & 1 & 4 & 13.17 & $150 \mathrm{U}$ & $150 \mathrm{U}$ & $150 \mathrm{U}$ & $150 \mathrm{U}$ \\
\hline TB Lower COMP & 2 & 3 & 13.30 & $150 \mathrm{U}$ & $150 \mathrm{U}$ & $150 \mathrm{U}$ & $150 \mathrm{U}$ \\
\hline TB Lower COMP & 3 & 5 & 12.74 & $160 \mathrm{U}$ & $160 \mathrm{U}$ & $160 \mathrm{U}$ & $157 \mathrm{U}$ \\
\hline TB Lower COMP & 4 & 5 & 12.37 & $160 U$ & $160 \mathrm{U}$ & $160 \mathrm{U}$ & $160 \mathrm{U}$ \\
\hline TB Lower COMP & 5 & 4 & 13.89 & $140 U$ & $140 U$ & $140 U$ & $140 \mathrm{U}$ \\
\hline OBM COMP & 1 & 4 & 14.01 & $140 \mathrm{U}$ & $140 U$ & $140 U$ & $140 U$ \\
\hline OBM COMP & 2 & 4 & 13.17 & $150 \mathrm{U}$ & $150 \mathrm{U}$ & $150 \mathrm{U}$ & $150 \mathrm{U}$ \\
\hline OBM COMP & 3 & 4 & 12.21 & $160 \mathrm{U}$ & $160 \mathrm{U}$ & $160 \mathrm{U}$ & $160 \mathrm{U}$ \\
\hline OBM COMP & 4 & 4 & 14.29 & $140 U$ & $140 U$ & $140 \mathrm{U}$ & $140 \mathrm{U}$ \\
\hline OBM COMP & 5 & 4 & 14.51 & $140 U$ & $140 \mathrm{U}$ & $140 \mathrm{U}$ & $140 \mathrm{U}$ \\
\hline R-OS & 1 & 5 & 12.71 & $160 \mathrm{U}$ & $160 \mathrm{U}$ & $160 \mathrm{U}$ & $160 \mathrm{U}$ \\
\hline R-OS, Replicate 1 & 2 & 5 & 12.62 & $160 U$ & $160 U$ & $160 \mathrm{U}$ & $160 \mathrm{U}$ \\
\hline R-OS, Replicate 2 & 2 & 5 & 12.62 & $160 \mathrm{U}$ & $160 \mathrm{U}$ & $160 \mathrm{U}$ & $160 \mathrm{U}$ \\
\hline R-OS, Replicate 3 & 2 & 5 & 12.62 & $160 \mathrm{U}$ & $160 \mathrm{U}$ & $160 \mathrm{U}$ & $160 \mathrm{U}$ \\
\hline R-OS & 3 & 5 & 13.84 & $150 \mathrm{U}$ & $150 u$ & $150 \mathrm{U}$ & $150 U$ \\
\hline R-OS & 4 & 5 & 12.69 & $160 \mathrm{U}$ & $160 \mathrm{U}$ & $160 \mathrm{U}$ & $160 \mathrm{U}$ \\
\hline R-OS & 5 & 5 & 13.41 & $150 \mathrm{U}$ & $150 \mathrm{U}$ & $150 \mathrm{U}$ & $150 \mathrm{U}$ \\
\hline
\end{tabular}

RH DEEPENING 
TABLE 0.19. (contd)

\begin{tabular}{|c|c|c|c|c|c|c|c|}
\hline \multirow[b]{2}{*}{$\begin{array}{l}\text { Sediment } \\
\text { Treatment }\end{array}$} & \multirow[b]{2}{*}{ Replicate } & \multirow[b]{2}{*}{$\begin{array}{c}\text { Analytical } \\
\text { Batch }\end{array}$} & \multirow[b]{2}{*}{$\begin{array}{l}\text { Percent } \\
\text { Dry } \\
\text { Weight }\end{array}$} & \multicolumn{4}{|c|}{ M. nasuta PCBs (ug/kg dry weight) } \\
\hline & & & & $\begin{array}{c}\text { Aroclor } \\
1242\end{array}$ & $\begin{array}{c}\text { Aroclor } \\
1248 \\
\end{array}$ & $\begin{array}{c}\text { Aroclor } \\
1254 \\
\end{array}$ & $\begin{array}{c}\text { Aroclor } \\
1260\end{array}$ \\
\hline R-BF & 1 & 4 & 15.28 & $130 \mathrm{U}$ & $130 \mathrm{U}$ & $130 \mathrm{U}$ & $130 \mathrm{U}$ \\
\hline R-BF & 2 & 3 & 14.64 & $140 \mathrm{U}$ & $140 U$ & $140 \mathrm{U}$ & $140 \mathrm{U}$ \\
\hline R-BF & 3 & 4 & 14.78 & $140 U$ & $140 \mathrm{U}$ & $140 U$ & $140 \mathrm{U}$ \\
\hline R-BF & 4 & 4 & 15.91 & $130 \mathrm{U}$ & $130 \mathrm{U}$ & $130 \mathrm{U}$ & $130 \mathrm{U}$ \\
\hline R-BF & 5 & 4 & 14.92 & $130 \mathrm{U}$ & $130 \mathrm{U}$ & $130 \mathrm{U}$ & $130 \mathrm{U}$ \\
\hline R-AM COMP & 1 & 3 & 15.79 & $130 \mathrm{U}$ & $130 \mathrm{U}$ & $130 U$ & $130 \mathrm{U}$ \\
\hline R-AM COMP & 2 & 4 & 13.81 & $150 \mathrm{U}$ & $150 U$ & $150 U$ & $150 \mathrm{U}$ \\
\hline R-AM COMP & 3 & 4 & 15.44 & $130 \mathrm{U}$ & $130 \mathrm{U}$ & $130 \mathrm{U}$ & $130 \mathrm{U}$ \\
\hline R-AM COMP & 4 & 3 & 14.52 & $140 U$ & $140 \mathrm{U}$ & $140 U$ & $140 \mathrm{U}$ \\
\hline R-AM COMP & 5 & 4 & 14.71 & $140 \mathrm{U}$ & $140 \mathrm{U}$ & $140 U$ & $140 \mathrm{U}$ \\
\hline C-SB & 1 & 5 & 14.43 & $140 U$ & $140 \mathrm{U}$ & $140 U$ & $140 \mathrm{U}$ \\
\hline C-SB & 2 & 5 & 13.25 & $150 U$ & $150 \mathrm{U}$ & $150 \mathrm{U}$ & $150 \mathrm{U}$ \\
\hline C-SB & 3 & 5 & 14.03 & $140 \mathrm{U}$ & $140 \mathrm{U}$ & $140 U$ & $140 \mathrm{U}$ \\
\hline C-SB & 4 & 5 & 13.57 & $150 U$ & $150 \mathrm{U}$ & $150 \mathrm{U}$ & $150 \mathrm{U}$ \\
\hline C-SB & 5 & 5 & 13.60 & $150 \mathrm{U}$ & $150 \mathrm{U}$ & $150 \mathrm{U}$ & $150 \mathrm{U}$ \\
\hline M. nasuta Background & 1 & 3 & 13.46 & $150 \mathrm{U}$ & $150 \mathrm{U}$ & $150 \mathrm{U}$ & $150 \mathrm{U}$ \\
\hline M. nasuta Background & 2 & 3 & 12.00 & $170 \mathrm{U}$ & $170 \mathrm{U}$ & $170 U$ & $170 \mathrm{U}$ \\
\hline M. nasuta Background, Replicate 1 & 3 & 3 & 13.05 & $150 \mathrm{U}$ & $150 \mathrm{U}$ & $150 \mathrm{U}$ & $150 \mathrm{U}$ \\
\hline M. nasuta Background, Replicate 2 & 3 & 3 & 13.05 & $150 \mathrm{U}$ & $150 \mathrm{U}$ & $150 U$ & $150 \mathrm{U}$ \\
\hline M. nasuta Background, Replicate 3 & 3 & 3 & 13.05 & $150 \mathrm{U}$ & $150 U$ & $150 \mathrm{U}$ & $150 \mathrm{U}$ \\
\hline M. nasuta Background & 4 & 3 & 14.21 & $140 \mathrm{U}$ & $140 U$ & $140 U$ & $140 \mathrm{U}$ \\
\hline M. nasuta Background & 5 & 3 & 17.65 & $110 \mathrm{U}$ & $110 \mathrm{U}$ & $110 \mathrm{U}$ & $110 \mathrm{U}$ \\
\hline
\end{tabular}

(a) Undetected at or above detection limit. 
TABLE 0.20. Polychlorinated Biphenyls (PCBs), Wet Weight, in Tissue of M. nasuta, Richmond Harbor Deepening Project

\begin{tabular}{|c|c|c|c|c|c|c|}
\hline \multirow[b]{2}{*}{$\begin{array}{l}\text { Sediment } \\
\text { Treatment }\end{array}$} & \multirow[b]{2}{*}{ Replicate } & \multirow[b]{2}{*}{$\begin{array}{c}\text { Analytical } \\
\text { Batch }\end{array}$} & \multicolumn{4}{|c|}{ M. nasuta PCBs (ug/kg wet weight) } \\
\hline & & & $\begin{array}{l}\text { Aroclor } \\
1242 \\
\end{array}$ & $\begin{array}{c}\text { Aroclor } \\
1248\end{array}$ & $\begin{array}{l}\text { Aroclor } \\
1254\end{array}$ & $\begin{array}{c}\text { Aroclor } \\
1260\end{array}$ \\
\hline Target $D L(a)$ & & & 20 & 20 & 20 & 20 \\
\hline Achieved DL & & & 20 & 20 & 20 & 20 \\
\hline SF COMP & 1 & 5 & $20 U(b)$ & $20 U$ & $20 U$ & $20 U$ \\
\hline SF COMP & 2 & 5 & $20 \mathrm{U}$ & $20 U$ & $20 U$ & $20 U$ \\
\hline SF COMP & 3 & 5 & $20 \mathrm{U}$ & $20 U$ & $20 U$ & $20 U$ \\
\hline SF COMP & 4 & 5 & $20 U$ & $20 \mathrm{U}$ & $20 U$ & $20 U$ \\
\hline SF COMP & 5 & 5 & $20 \mathrm{U}$ & $20 \mathrm{U}$ & $20 U$ & $20 \mathrm{U}$ \\
\hline SFW COMP & 1 & 4 & $20 \mathrm{U}$ & $20 U$ & 26.5 & $20 \mathrm{U}$ \\
\hline SFW COMP & 2 & 4 & $20 \mathrm{U}$ & $20 U$ & 26.0 & $20 U$ \\
\hline SFW COMP & 3 & 6 & $20 U$ & $20 U$ & 34.0 & $20 U$ \\
\hline SFW COMP & 4 & 4 & $20 \mathrm{U}$ & $20 \mathrm{U}$ & 32.2 & $20 \mathrm{U}$ \\
\hline SFW COMP & 5 & 6 & $20 \mathrm{U}$ & $20 \mathrm{U}$ & 40.0 & $20 U$ \\
\hline UIH COMP & 1 & 5 & $20 \mathrm{U}$ & $20 \mathrm{U}$ & 18.7 & $20 U$ \\
\hline UIH COMP & 2 & 6 & $20 U$ & $20 \mathrm{U}$ & $20 \mathrm{U}$ & $20 U$ \\
\hline UIH COMP, Replicate 1 & 3 & 6 & $20 \mathrm{U}$ & $20 U$ & $20 U$ & $20 U$ \\
\hline UIH COMP, Replicate 2 & 3 & 6 & $20 \mathrm{U}$ & $20 \mathrm{U}$ & $20 U$ & $20 \mathrm{U}$ \\
\hline UIH COMP, Replicate 3 & 3 & 6 & $20 U$ & $20 \mathrm{U}$ & $20 U$ & $20 U$ \\
\hline UIH COMP & 4 & 5 & $20 \mathrm{U}$ & $20 U$ & 18.8 & $20 U$ \\
\hline UIH COMP & 5 & 5 & $20 U$ & $20 \mathrm{U}$ & 18.3 & $20 U$ \\
\hline TB Upper COMP & 1 & 4 & $20 \mathrm{U}$ & $20 U$ & $20 U$ & $20 U$ \\
\hline TB Upper COMP, Replicate 1 & 2 & 4 & $20 \mathrm{U}$ & $20 \mathrm{U}$ & $20 \mathrm{U}$ & $20 \mathrm{U}$ \\
\hline TB Upper COMP, Replicate 2 & 2 & 4 & $20 U^{\circ}$ & $20 \mathrm{U}$ & $20 \mathrm{U}$ & $20 \mathrm{U}$ \\
\hline TB Upper COMP, Replicate 3 & 2 & 4 & $20 U$ & $20 \mathrm{U}$ & $20 \mathrm{U}$ & $20 \mathrm{U}$ \\
\hline TB Upper COMP & 3 & 3 & $20 \mathrm{U}$ & $20 \mathrm{U}$ & $20 \mathrm{U}$ & $20 U$ \\
\hline TB Upper COMP & 4 & 3 & $20 \mathrm{U}$ & $20 U$ & $20 U$ & $20 U$ \\
\hline TB Upper COMP & 5 & 4 & $20 U$ & $20 \mathrm{U}$ & $20 U$ & $20 U$ \\
\hline TB Lower COMP & 1 & 4 & $20 \mathrm{U}$ & $20 U$ & $20 U$ & $20 \mathrm{U}$ \\
\hline TB Lower COMP & 2 & 3 & $20 U$ & $20 \mathrm{U}$ & $20 U$ & $20 U$ \\
\hline TB Lower COMP & 3 & 5 & $20 \mathrm{U}$ & $20 U$ & $20 U$ & $20 U$ \\
\hline TB Lower COMP & 4 & 5 & $20 U$ & $20 U$ & $20 \mathrm{U}$ & $20 \mathrm{U}$ \\
\hline TB Lower COMP & 5 & 4 & $20 \mathrm{U}$ & $20 U$ & $20 \mathrm{U}$ & $20 \mathrm{U}$ \\
\hline OBM COMP & 1 & 4 & $20 \mathrm{U}$ & $20 \mathrm{U}$ & $20 U$ & $20 U$ \\
\hline OBM COMP & 2 & 4 & $20 U$ & $20 U$ & $20 \mathrm{U}$ & $20 U$ \\
\hline OBM COMP & 3 & 4 & $20 \mathrm{U}$ & $20 \mathrm{U}$ & $20 \mathrm{U}$ & $20 \mathrm{U}$ \\
\hline OBM COMP & 4 & 4 & $20 U$ & $20 \mathrm{U}$ & $20 \mathrm{U}$ & $20 \mathrm{U}$ \\
\hline OBM COMP & 5 & 4 & $20 U$ & $20 U$ & $20 \mathrm{U}$ & $20 U$ \\
\hline
\end{tabular}

RH DEEPENING 
TABLE 0.20. (contd)

Sediment

Treatment

R-OS

R-OS, Replicate 1

R-OS, Replicate 2

R-OS, Replicate 3

R-OS

R-OS

R-OS

R-BF

R-BF

$R-B F$

$R-B F$

R-BF

R-AM COMP

R-AM COMP

R-AM COMP

R-AM COMP

R-AM COMP

C-SB

C-SB

C-SB

C-SB

C-SB

M. nasuta Background

$M$. nasuta Background

M. nasuta Background, Replicate 1

M. nasuta Background, Replicate 2

M. nasuta Background, Replicate 3

$M$. nasuta Background
M. nasuta Background

Replicate $\begin{gathered}\text { Analytical } \\ \text { Batch }\end{gathered}$

1

2

2

2

3

4

5

1

2

3

4

5

1

2

3

4

5

1

2

3

4

5

1
2
3
3
3
.4
5

(a) DL Detection limit.

(b) Undetected at or above detection limit.
M. nasuta PCBs (ug/kg wet weight)

\begin{tabular}{cccc} 
Aroclor & Aroclor & Aroclor & Aroclor \\
1242 & 1248 & 1254 & 1260 \\
\hline
\end{tabular}

$20 \mathrm{U} 20 \mathrm{U} \quad 20 \mathrm{U} 20 \mathrm{U}$

$20 \mathrm{U} 20 \mathrm{U} \quad 20 \mathrm{U} \quad 20 \mathrm{U}$

$20 \mathrm{U} 20 \mathrm{U} 20 \mathrm{U} 20 \mathrm{U}$

$20 \mathrm{U} 20 \mathrm{U} \quad 20 \mathrm{U} \quad 20 \mathrm{U}$

$20 \mathrm{U} \quad 20 \mathrm{U} \quad 20 \mathrm{U} \quad 20 \mathrm{U}$

$20 \mathrm{U} 20 \mathrm{U} \quad 20 \mathrm{U} \quad 20 \mathrm{U}$

$20 \mathrm{U} 20 \mathrm{U} \quad 20 \mathrm{U} \quad 20 \mathrm{U}$

$20 \mathrm{U} 20 \mathrm{U} \quad 20 \mathrm{U} \quad 20 \mathrm{U}$

$20 \mathrm{U} 20 \mathrm{U} \quad 20 \mathrm{U} 20 \mathrm{U}$

$20 \mathrm{U} 20 \mathrm{U} 20 \mathrm{U} 20 \mathrm{U}$

$20 \mathrm{U} 20 \mathrm{U} 20 \mathrm{U} 20 \mathrm{U}$

$20 \mathrm{U} 20 \mathrm{U} \quad 20 \mathrm{U} \quad 20 \mathrm{U}$

$20 \mathrm{U} 20 \mathrm{U} \quad 20 \mathrm{U} \quad 20 \mathrm{U}$

$20 \mathrm{U} 20 \mathrm{U} \quad 20 \mathrm{U} 20 \mathrm{U}$

$20 \mathrm{U} 20 \mathrm{U} 20 \mathrm{U} 20 \mathrm{U}$

$20 \mathrm{U} 20 \mathrm{U} \quad 20 \mathrm{U} \quad 20 \mathrm{U}$

$20 \mathrm{U} 20 \mathrm{U} 20 \mathrm{U} 20 \mathrm{U}$

$20 \mathrm{U} 20 \mathrm{U} \quad 20 \mathrm{U} \quad 20 \mathrm{U}$

$20 \mathrm{U} 20 \mathrm{U} \quad 20 \mathrm{U} \quad 20 \mathrm{U}$

$20 \mathrm{U} \quad 20 \mathrm{U} \quad 20 \mathrm{U} \quad 20 \mathrm{U}$

$20 \mathrm{U} 20 \mathrm{U} \quad 20 \mathrm{U} 20 \mathrm{U}$

$20 \mathrm{U} 20 \mathrm{U} 20 \mathrm{U} 20 \mathrm{U}$

$20 \mathrm{U} 20 \mathrm{U} \quad 20 \mathrm{U} \quad 20 \mathrm{U}$

$20 \mathrm{U} 20 \mathrm{U} 20 \mathrm{U} 20 \mathrm{U}$

$20 \mathrm{U} 20 \mathrm{U} \quad 20 \mathrm{U} 20 \mathrm{U}$

$20 \mathrm{U} 20 \mathrm{U} 20 \mathrm{U} 20 \mathrm{U}$

$20 \mathrm{U} 20 \mathrm{U} 20 \mathrm{U} 20 \mathrm{U}$

$20 \mathrm{U} 20 \mathrm{U} 20 \mathrm{U} 20 \mathrm{U}$

$20 \mathrm{U} 20 \mathrm{U} 20 \mathrm{U} \cdot 20 \mathrm{U}$

RH DEEPENING 
TABLE 0.21. Quality Control Data for Polychlorinated Biphenyls (PCBs), Wet Weight, in Tissue of M. nasuta, Richmond Harbor Deepening Project

Sediment

Treatment

Method Blanks

Blank-1

Blank-1

Blank

Blank

Matrix Spikes

M. nasuta Background

M. nasuta Background, MS

Concentration Recovered

Amount Spiked

Percent Recovery

TB Upper COMP

TB Upper COMP, MS

Concentration Recovered

Amount Spiked

Percent Recovery

SF COMP

SF COMP, MS

Concentration Recovered

Amount Spiked

Percent Recovery

UIH COMP

UIH COMP, MS

Concentration Recovered

Amount Spiked

Percent Recovery

Standard Reference Material

Certified SRM not available for PCBs.

\section{Analytical Replicates}

M. nasuta Background, Replicate 13

M. nasuta Background, Replicate 23

M. nasuta Background, Replicate 3

RSD

5

4
4

2
2
M. nasuta PCBs (ug/kg wet weight)

Aroclor Aroclor Aroclor Aroclor

Replicate Analytical

1248

1254

1260

$\begin{array}{ll}2 & 3 \\ 2 & 3\end{array}$

NA (b)

NA

NA

NS (c)

$\begin{array}{ll}20 U(a) & 20 U \\ 20 U & 20 U \\ 20 U & 20 U \\ 20 U & 20 U\end{array}$

$20 \mathrm{U}$

$20 \mathrm{U}$

$20 \mathrm{U} \quad 20 \mathrm{U}$

$20 U \quad 20 U$

$20 \mathrm{U} 20 \mathrm{U}$

NA

NA

NA

NA

NS

NA

5

5

NA

NA

NA

NS

NA
NS

NS

NS

NS

NS
NA

NA

NA

NS

NA

NA

NA

NA

NS

NA

NA

NA

NA

NS

NA

NS

NS

NS

NS

NS
$20 \mathrm{U}$

101

101

95

106

$20 \mathrm{U}$

131

131

183

$72 \%$

$20 \mathrm{U}$

101

101

100

$101 \%$

20.1

110

90

100

$90 \%$
NA

NA

NA

NS

NA

NA

NA

NA

NS

NA

NA

NA

NA

NS

NA

NS

NS

NS

NS

NS

$\begin{array}{llll}20 U & 20 U & 20 U & 20 U \\ 20 U & 20 U & 20 U & 20 U \\ 20 U & 20 U & 20 U & 20 U\end{array}$

NA NA NA NA

RH DEEPENING 
TABLE 0.21. (contd)

\begin{tabular}{|c|c|c|c|c|c|c|}
\hline \multirow[b]{2}{*}{$\begin{array}{l}\text { Sediment } \\
\text { Treatment }\end{array}$} & \multirow[b]{2}{*}{ Replicate } & \multirow[b]{2}{*}{$\begin{array}{l}\text { Analytical } \\
\text { Batch }\end{array}$} & \multicolumn{4}{|c|}{ M. nasuta PCBs (ug/kg wet weight) } \\
\hline & & & $\begin{array}{c}\text { Aroclor } \\
1242\end{array}$ & $\begin{array}{c}\text { Aroclor } \\
1248\end{array}$ & $\begin{array}{l}\text { Aroclor } \\
1254\end{array}$ & $\begin{array}{l}\text { Aroclor } \\
1260\end{array}$ \\
\hline $\begin{array}{l}\text { TB Upper COMP, Replicate } 1 \\
\text { TB Upper COMP, Replicate } 2 \\
\text { TB Upper COMP, Replicate } 3\end{array}$ & $\begin{array}{l}2 \\
2 \\
2\end{array}$ & $\begin{array}{l}4 \\
4 \\
4\end{array}$ & $\begin{array}{l}20 U \\
20 U \\
20 U\end{array}$ & $\begin{array}{l}20 U \\
20 U \\
20 U\end{array}$ & $\begin{array}{l}20 U \\
20 U \\
20 U\end{array}$ & $\begin{array}{l}20 U \\
20 U \\
20 U\end{array}$ \\
\hline RSD & & & NA & NA & NA & NA \\
\hline $\begin{array}{l}\text { R-OS, Replicate } 1 \\
\text { R-OS, Replicate } 2 \\
\text { R-OS, Replicate } 3\end{array}$ & $\begin{array}{l}2 \\
2 \\
2\end{array}$ & $\begin{array}{l}5 \\
5 \\
5\end{array}$ & $\begin{array}{l}20 U \\
20 U \\
20 U\end{array}$ & $\begin{array}{l}20 U \\
20 U \\
20 U\end{array}$ & $\begin{array}{l}20 U \\
20 U \\
20 U\end{array}$ & $\begin{array}{l}20 U \\
20 U \\
20 U\end{array}$ \\
\hline RSD & & & NA & NA & NA & NA \\
\hline $\begin{array}{l}\text { UIH COMP, Replicate } 1 \\
\text { UIH COMP, Replicate } 2 \\
\text { UIH COMP, Replicate } 3\end{array}$ & $\begin{array}{l}3 \\
3 \\
3\end{array}$ & $\begin{array}{l}6 \\
6 \\
6\end{array}$ & $\begin{array}{l}20 U \\
20 U \\
20 U \\
N A\end{array}$ & $\begin{array}{l}20 U \\
20 U \\
20 U \\
N A\end{array}$ & $\begin{array}{l}20 U \\
20 U \\
20 U \\
\text { NA }\end{array}$ & $\begin{array}{l}20 U \\
20 U \\
20 U \\
N A\end{array}$ \\
\hline
\end{tabular}

RSD

(a) U Undetected at or above detection limit.

(b) NA Not applicable.

(c) NS Not spiked. 
TABLE 0.22. Surrogate Percent Recoveries and Quality Control Data for Pesticides and Polychlorinated Biphenyls (PCBs), Wet Weight, in Tissue of M. nasuta, Richmond Harbor Deepening Project

\begin{tabular}{|c|c|c|c|c|}
\hline \multirow{2}{*}{$\begin{array}{l}\text { Sediment } \\
\text { Treatment }\end{array}$} & \multirow[b]{2}{*}{ Replicate } & \multirow{2}{*}{$\begin{array}{c}\text { Analytical } \\
\text { Batch }\end{array}$} & \multicolumn{2}{|c|}{ Surrogate Percent Recoverie } \\
\hline & & & PCB 103 & PCB 19 \\
\hline SF COMP & 1 & 5 & 75 & 66 \\
\hline SF COMP & 2 & 5 & 80 & 68 \\
\hline SF COMP & 3 & 5 & 80 & 66 \\
\hline SF COMP & 4 & 5 & 78 & 64 \\
\hline SF COMP & 5 & 5 & 72 & 68 \\
\hline SFW COMP & 1 & 4 & 81 & 64 \\
\hline SFW COMP. & 2 & 4 & 65 & 57 \\
\hline SFW COMP & 3 & 6 & 79 & 73 \\
\hline SFW COMP & 4 & 4 & 71 & 56 \\
\hline SFW COMP & 5 & 6 & 72 & 73 \\
\hline UIH COMP & 1 & 5 & 89 & 89 \\
\hline UIH COMP & 2 & 6 & 76 & 66 \\
\hline UIH COMP, Replicate 1 & 3 & 6 & 77 & 65 \\
\hline UIH COMP, Replicate 2 & 3 & 6 & 83 & 68 \\
\hline UIH COMP, Replicate 3 & 3 & 6 & 74 & 60 \\
\hline UIH COMP & 4 & 5 & 77 & 71 \\
\hline UIH COMP & 5 & 5 & 78 & 78 \\
\hline TB Upper COMP & 1 & 4 & 82 & 71 \\
\hline TB Upper COMP, Replicate 1 & 2 & 4 & 71 & 61 \\
\hline TB Upper COMP, Replicate 2 & 2 & 4 & 66 & 57 \\
\hline TB Upper COMP, Replicate 3 & 2 & 4 & 73 & 64 \\
\hline TB Upper COMP & 3 & 3 & 65 & 69 \\
\hline TB Upper COMP & 4 & 3 & 70 & 71 \\
\hline TB Upper COMP & 5 & 4 & 71 & 60 \\
\hline TB Lower COMP & 1 & 4 & 70 & 59 \\
\hline TB Lower COMP & 2 & 3 & 67 & 69 \\
\hline TB Lower COMP & 3 & 5 & 81 & 72 \\
\hline TB Lower COMP & 4 & 5 & 79 & 81 \\
\hline TB Lower COMP & 5 & 4 & 69 & 64 \\
\hline OBM COMP & 1 & 4 & 66 & 51 \\
\hline OBM COMP & 2 & 4 & 66 & 54 \\
\hline OBM COMP & 3 & 4 & 61 & 53 \\
\hline OBM COMP & 4 & 4 & 65 & 55 \\
\hline OBM COMP & 5 & 4 & 72 & 61 \\
\hline R-OS & 1 & 5 & 83 & 69 \\
\hline R-OS, Replicate 1 & 2 & 5 & 73 & 62 \\
\hline R-OS, Replicate 2 & 2 & 5 & 74 & 66 \\
\hline R-OS, Replicate 3 & 2 & 5 & 71 & 66 \\
\hline R-OS & 3 & 5 & 78 & 67 \\
\hline R-OS & 4 & 5 & 79 & 73 \\
\hline R-OS & 5 & 5 & 77 & 69 \\
\hline
\end{tabular}


TABLE 0.22. (contd)

Sediment

Treatment

R-BF

R-BF

$R-B F$

R-BF

R-BF

R-AM COMP

R-AM COMP

R-AM COMP

R-AM COMP

R-AM COMP

C-SB

C-SB

C-SB

C-SB

C-SB

M. nasuta Background

$M$. nasuta Background

M. nasuta Background, Replicate 1

M. nasuta Background, Replicate 2

$M$. nasuta Background, Replicate 3

$M$. nasuta Background

M. nasuta Background
Analytical

Replicate

1

2

3

4

5

1

2

3

4
5

5

1

2

3

4
5

13

$2 \quad \because 3$

3

3

3

4

5

Batch

$\begin{array}{lll}4 & 64 & 63 \\ 3 & 69 & 70 \\ 4 & 59 & 53 \\ 4 & 75 & 62 \\ 4 & 74 & 70\end{array}$

72

75

72

69

76

78

82

79

74

77

67

67

70

63

62

67

71
75

72

66

65

68

87

77

73

62

65

95

80

93

80

93

116

75

\section{Quality Control Data}

Method Blank

\section{Blank-1}

Blank-1

Blank

Blank

\section{Matrix Spike}

M. nasuta Background

M. nasuta Background, MS

23

67

73

77

3
4

68

70

74

69

65

TB Upper COMP

TB Upper COMP, MS

$\begin{array}{llll}5 & 4 & 71 & 60\end{array}$

SF COMP

SF COMP, MS

45

73

64

UIH COMP

UIH COMP, MS

78

64

4

81

68

2

6

76

66

73

68

RH DEEPENING 
TABLE 0.22. (contd)

Sediment

Treatment

Analytical Replicates

M. nasuta Background, Replicate 1

M. nasuta Background, Replicate 2

M. nasuta Background, Replicate 3

TB Upper COMP, Replicate 1

TB Upper COMP, Replicate 2

TB Upper COMP, Replicate 3

R-OS, Replicate 1

R-OS, Replicate 2

R-OS, Replicate 3

UIH COMP, Replicate 1

UIH COMP, Replicate 2

UIH COMP, Replicate 3
Analytical

Replicate
Surrogate Percent Recoveries

PCB 103

PCB 198

3

3

3

2

2

2

2

2

2

3

3

3
3

3

3

4

4

4

5

5

5

6

6

6
70

63

62

71

66

73

73

74

71

77

83

74
93

80

93

61

57

64

62

66

66

65

68

60 


\begin{tabular}{|c|c|c|c|c|c|c|c|c|c|c|c|c|c|}
\hline \multirow{2}{*}{$\begin{array}{l}\text { Sediment } \\
\text { Treatment }\end{array}$} & \multirow{2}{*}{\multicolumn{2}{|c|}{$\begin{array}{c}\text { Analytical } \\
\text { Balch }\end{array}$}} & \multirow{2}{*}{$\begin{array}{l}\text { Percent } \\
\text { Dry } \\
\text { Weight }\end{array}$} & \multicolumn{10}{|c|}{ M. nasula Metals (mg/kg wet weight) } \\
\hline & & & & $\mathrm{Ag}$ & As & Cd & $\mathrm{Cr}$ & $\mathrm{Cu}$ & $\mathrm{Hg}$ & $\mathrm{Ni}$ & $\mathrm{Pb}$ & Se & $\mathrm{Zn}$ \\
\hline SF COMP & 1 & 2 & 12.76 & 0.026 & 2.68 & 0.033 & 0.227 & 1.34 & 0.007 & 0.465 & 0.256 & 0.209 & 13.9 \\
\hline SF COMP & 1 & 2 & 12.26 & 0.035 & 4.07 & 0.035 & 0.283 & 2.07 & 0.006 & 0.645 & 0.273 & 0.253 & 17.2 \\
\hline SF COMP & 2 & 2 & 12.94 & 0.023 & 2.87 & 0.019 & 0.259 & 1.69 & 0.011 & 0.450 & 0.274 & 0.192 & 12.0 \\
\hline SF COMP & 4 & 2 & 12.60 & 0.035 & 3.72 & 0.021 & 0.235 & 1.66 & 0.005 & 0.450 & 0.287 & 0.200 & 10.9 \\
\hline SF COMP & 5 & 2 & 14.42 & 0.020 & 2.54 & 0.022 & 0.290 & 1.48 & 0.010 & 0.481 & 0.272 & 0.244 & 15.4 \\
\hline SFW COMP & 1 & 2 & 14.61 & 0.016 & 3.29 & 0.024 & 0.282 & 1.44 & 0.013 & 0.447 & 0.301 & 0.247 & 16.7 \\
\hline SFW COMP, Replicate 1 & 2 & 2 & 17.91 & 0.022 & 5.54 & 0.037 & 0.256 & 1.67 & 0.018 & 0.616 & 0.358 & 0.369 & 21.0 \\
\hline SFW COMP, Replicale 2 & 2 & 2 & 17.91 & 0.022 & 5.66 & 0.034 & 0.281 & 1.70 & 0.016 & 0.609 & 0.361 & 0.344 & 21.3 \\
\hline SFW COMP, Replicate 3 & 2 & 2 & 17.91 & 0.020 & 5.63 & 0.035 & 0.284 & 1.70 & 0.018 & 0.614 & 0.377 & 0.353 & 21.0 \\
\hline SFW COMP & 3 & 2 & 14.49 & 0.045 & 3.48 & 0.033 & 0.361 & 1.69 & 0.009 & 0.610 & 0.407 & 0.229 & 16.1 \\
\hline SFW COMP & 4 & 2 & 14.31 & 0.031 & 4.34 & 0.035 & 0.365 & 1.86 & 0.011 & 0.631 & 0.360 & 0.275 & 17.5 \\
\hline SFW COMP & 5 & 2 & 14.58 & 0.030 & 4.00 & 0.022 & 0.293 & 1.85 & 0.008 & 0.479 & 0.298 & 0.257 & 12.6 \\
\hline UIH COMP & 1 & 2 & 13.71 & 0.038 & 3.04 & 0.025 & 0.241 & 2.20 & 0.007 & 0.510 & 0.263 & 0.228 & 12.8 \\
\hline UIH COMP & 2 & 2 & 14.06 & 0.022 & 2.22 & 0.023 & 0.256 & 1.49 & 0.010 & 0.475 & 0.298 & 0.226 & 10.2 \\
\hline UIH COMP & 3 & 2 & 13.52 & 0.018 & 3.10 & 0.021 & 0.324 & 1.66 & 0.010 & 0.522 & 0.289 & 0.226 & 14.7 \\
\hline UIH COMP, Replicate 1 & 4 & 2 & 15.23 & 0.027 & 3.61 & 0.036 & 0.335 & 1.78 & 0.009 & 0.546 & 0.336 & 0.268 & 14.9 \\
\hline UIH COMP, Replicate 2 & 4 & 2 & 15.23 & 0.026 & 3.38 & 0.032 & 0.289 & 1.70 & 0.009 & 0.549 & 0.301 & 0.239 & 13.9 \\
\hline UIH COMP, Replicate 3 & 4 & 2 & 15.23 & 0.025 & 3.25 & 0.031 & 0.262 & 1.66 & 0.011 & 0.518 & $0: 280$ & 0.250 & 13.6 \\
\hline UIH COMP & 5 & 2 & 13.02 & 0.022 & 2.68 & 0.027 & 0.306 & 1.51 & 0.007 & 0.497 & 0.307 & 0.219 & 13.3 \\
\hline TB Upper COMP & 1 & 2 & 15.21 & 0.019 & 3.96 & 0.026 & 0.459 & 3.14 & 0.014 & 0.673 & 0.211 & 0.192 & 15.4 \\
\hline TB Upper COMP & 2 & 2 & 14.75 & 0.041 & 3.47 & 0.034 & 0.308 & 2.47 & 0.012 & 0.606 & 0.264 & 0.288 & 19.6 \\
\hline TB Upper COMP & 3 & 2 & 13.66 & 0.019 & 2.79 & 0.024 & 0.278 & 1.48 & 0.009 & 0.541 & 0.200 & 0.216 & 11.0 \\
\hline TB Upper COMP & 4 & 2 & 15.16 & 0.025 & 3.17 & 0.032 & 0.251 & 1.53 & 0.012 & 0.571 & 0.204 & 0.215 & 11.3 \\
\hline TB Upper COMP & 5 & 2 & 15.00 & 0.041 & 3.51 & 0.032 & 0.339 & 2.53 & 0.015 & 0.628 & 0.276 & 0.303 & 20.1 \\
\hline TB Lower COMP & 1 & 2 & 13.17 & 0.026 & 2.89 & 0.024 & 0.195 & 1.50 & 0.008 & 0.515 & 0.156 & 0.191 & 13.1 \\
\hline TB Lower COMP & 2 & 2 & 13.30 & 0.018 & 3.11 & 0.027 & 0.315 & 1.25 & 0.007 & 0.642 & 0.146 & 0.198 & 10.9 \\
\hline TB Lower COMP & 3 & 2 & 12.74 & 0.029 & 4.01 & 0.028 & 0.249 & 1.59 & 0.008 & 0.558 & 0.156 & 0.210 & 17.7 \\
\hline TB Lower COMP & 4 & 2 & 12.37 & 0.034 & 2.38 & 0.036 & 0.272 & 1.58 & 0.008 & 0.733 & 0.178 & 0.215 & 10.9 \\
\hline TB Lower COMP & 5 & 2 & 13.89 & 0.020 & 2.89 & 0.020 & 0.307 & 1.57 & 0.011 & 0.758 & 0.169 & 0.208 & 10.3 \\
\hline R-OS & 1 & 2 & 12.71 & 0.022 & 2.31 & 0.023 & 0.204 & 1.23 & 0.007 & 0.512 & 0.138 & 0.214 & 14.4 \\
\hline R.OS & 2 & 2 & 12.62 & 0.031 & 2.99 & 0.024 & 0.289 & 1.37 & 0.009 & 0.648 & 0.170 & 0.247 & 11.5 \\
\hline R-OS & 3 & 2 & 13.84 & 0.024 & 2.87 & 0.023 & 0.300 & 1.50 & 0.010 & 0.621 & 0.127 & 0.241 & 13.1 \\
\hline R.OS & 4 & 2 & 12.69 & 0.058 & 4.05 & 0.026 & 0.440 & 2.51 & 0.013 & 0.847 & 0.167 & 0.273 & 12.9 \\
\hline R-OS & 5 & 2 & 13.41 & 0.026 & 2.90 & 0.023 & 0.269 & 1.46 & 0.006 & 0.524 & 0.116 & 0.221 & 11.3 \\
\hline
\end{tabular}




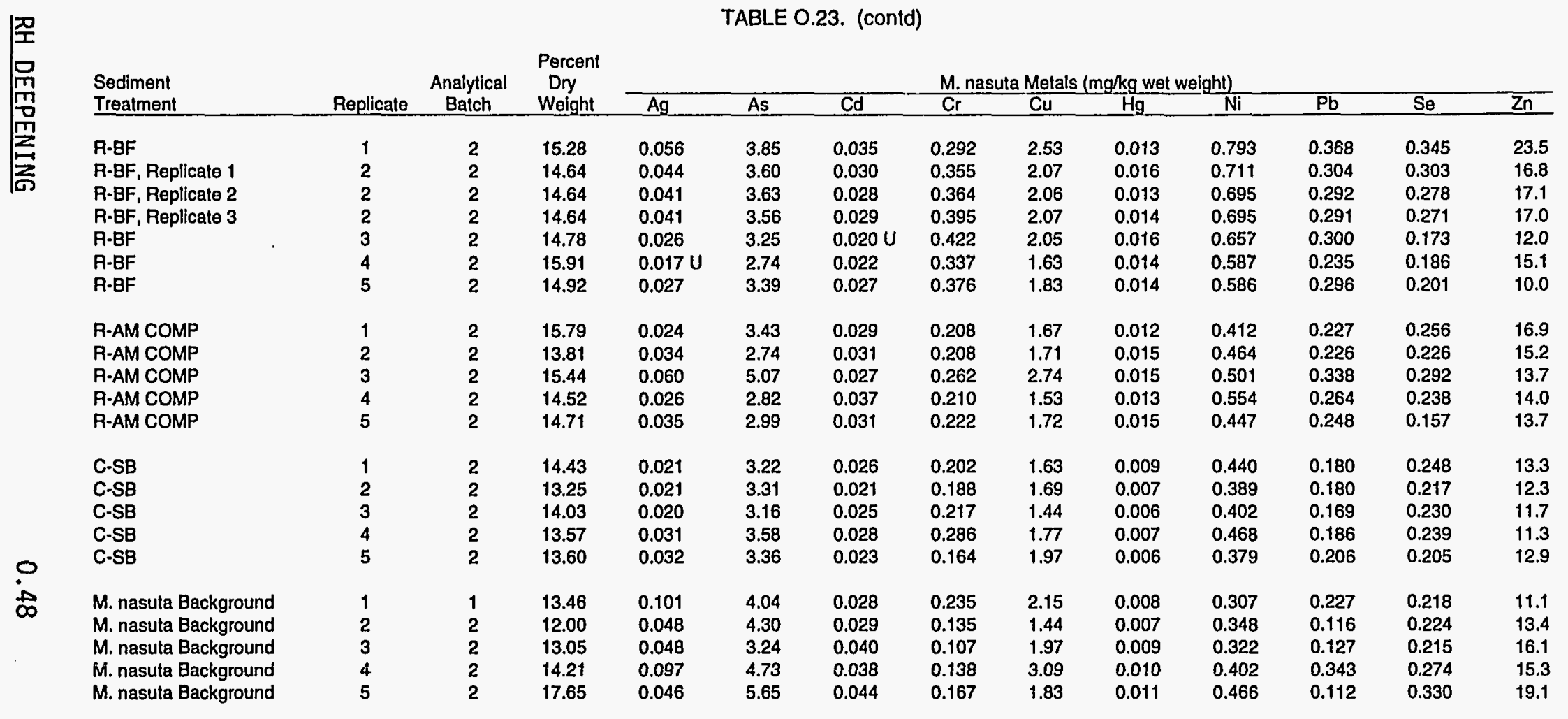

(a) U Undetected at or above detection limit. 


\begin{tabular}{|c|c|c|c|c|c|c|c|c|c|c|c|c|}
\hline \multirow{2}{*}{$\begin{array}{l}\text { Sediment } \\
\text { Treatment }\end{array}$} & \multirow[b]{2}{*}{ Replicate } & \multirow{2}{*}{$\begin{array}{c}\text { Analytical } \\
\text { Batch }\end{array}$} & \multicolumn{10}{|c|}{ M. nasuta Metals ( $\mathrm{mg} / \mathrm{kg}$ dry weight) } \\
\hline & & & $\mathrm{Ag}$ & As & Cd & $\mathrm{Cr}$ & $\mathrm{Cu}$ & $\mathrm{Hg}$ & $\mathrm{Ni}$ & $\mathrm{Pb}$ & Se & $\mathrm{Zn}$ \\
\hline Target DL(a) & & & 0.1 & 2.0 & 0.1 & 1.0 & 4.3 & 0.02 & 1.0 & 1.0 & 1.0 & 35 \\
\hline Achieved DL & & & 0.109 & 2.93 & 0.132 & 0.758 & 3.34 & 0.004 & 0.933 & 0.417 & 0.11 & 39.7 \\
\hline SF COMP & 1 & 2 & 0.203 & 21.0 & 0.260 & 1.78 & 10.5 & 0.057 & 3.65 & 2.01 & 1.64 & 109 \\
\hline SF COMP & 1 & 2 & 0.285 & 33.2 & 0.286 & 2.31 & 16.9 & 0.052 & 5.26 & 2.23 & 2.06 & 140 \\
\hline SF COMP & 2 & 2 & 0.177 & 22.2 & 0.143 & 2.00 & 13.1 & 0.083 & 3.48 & 2.12 & 1.48 & 93.1 \\
\hline ȘF COMP & 4 & 2 & 0.276 & 29.5 & 0.167 & 1.87 & 13.2 & 0.038 & 3.57 & 2.28 & 1.59 & 86.4 \\
\hline SF COMP & 5 & 2 & 0.137 & 17.6 & 0.153 & 2.01 & 10.3 & 0.068 & 3.34 & 1.89 & 1.69 & 107 \\
\hline SFW COMP & 1 & 2 & $0.109 \mathrm{U}(\mathrm{b})$ & 22.5 & 0.167 & 1.93 & 9.87 & 0.087 & 3.06 & 2.06 & 1.69 & 114 \\
\hline SFW COMP, Replicate 1 & 2 & 2 & 0.121 & 30.9 & 0.208 & 1.43 & 9.30 & 0.099 & 3.44 & 2.00 & 2.06 & 117 \\
\hline SFW COMP, Replicate 2 & 2 & 2 & 0.122 & 31.6 & 0.190 & 1.57 & 9.51 & 0.092 & 3.40 & 2.02 & 1.92 & 119 \\
\hline SFW COMP, Replicate 3 & 2 & 2 & 0.112 & 31.4 & 0.196 & 1.59 & 9.52 & 0.098 & 3.43 & 2.11 & 1.97 & 117 \\
\hline SFW COMP & 3 & 2 & 0.308 & 24.0 & 0.231 & 2.49 & 11.7 & 0.064 & 4.21 & 2.81 & 1.58 & 111 \\
\hline SFW COMP & 4 & 2 & 0.217 & 30.3 & 0.247 & 2.55 & 13.0 & 0.078 & 4.41 & 2.52 & 1.92 & 122 \\
\hline SFW COMP & 5 & 2 & 0.206 & 27.4 & 0.151 & 2.01 & 12.7 & 0.057 & 3.29 & 2.05 & 1.76 & 86.2 \\
\hline UIH COMP & 1 & 2 & 0.278 & 22.2 & 0.179 & 1.76 & 16.1 & 0.050 & 3.72 & 1.92 & 1.66 & 93.3 \\
\hline UIH COMP & 2 & 2 & 0.157 & 15.8 & 0.162 & 1.82 & 10.6 & 0.072 & 3.38 & 2.12 & 1.61 & 72.4 \\
\hline UIH COMP & 3 & 2 & 0.136 & 22.9 & 0.153 & 2.40 & 12.3 & 0.076 & 3.86 & 2.14 & 1.67 & 109 \\
\hline UIH COMP, Replicate 1 & 4 & 2 & 0.177 & 23.7 & 0.234 & 2.20 & 11.7 & 0.058 & 3.59 & 2.21 & 1.76 & 97.6 \\
\hline UIH COMP, Replicate 2 & 4 & 2 & 0.171 & 22.2 & 0.213 & 1.90 & 11.2 & 0.058 & 3.61 & 1.98 & 1.57 & 91.0 \\
\hline UIH COMP, Replicate 3 & 4 & 2 & 0.161 & 21.3 & 0.204 & 1.72 & 10.9 & 0.070 & 3.40 & 1.84 & 1.64 & 89.5 \\
\hline UIH COMP & 5 & 2 & 0.172 & 20.6 & 0.206 & 2.35 & 11.6 & 0.055 & 3.82 & 2.36 & 1.68 & 102 \\
\hline TB Upper COMP & 1 & 2 & 0.126 & 26.0 & 0.169 & 3.02 & 20.7 & 0.089 & 4.43 & 1.39 & 1.26 & 101 \\
\hline TB Upper COMP & 2 & 2 & 0.276 & 23.5 & 0.229 & 2.09 & 16.8 & 0.083 & 4.11 & 1.79 & 1.95 & 133 \\
\hline TB Upper COMP & 3 & 2 & 0.141 & 20.4 & 0.174 & 2.04 & 10.9 & 0.066 & 3.96 & 1.47 & 1.58 & 80.8 \\
\hline TB Upper COMP & 4 & 2 & 0.163 & 20.9 & 0.214 & 1.66 & 10.1 & 0.082 & 3.77 & 1.35 & 1.42 & 74.8 \\
\hline TB Upper COMP & 5 & 2 & 0.276 & 23.4 & 0.216 & 2.26 & 16.9 & 0.102 & 4.19 & 1.84 & 2.02 & 134 \\
\hline
\end{tabular}




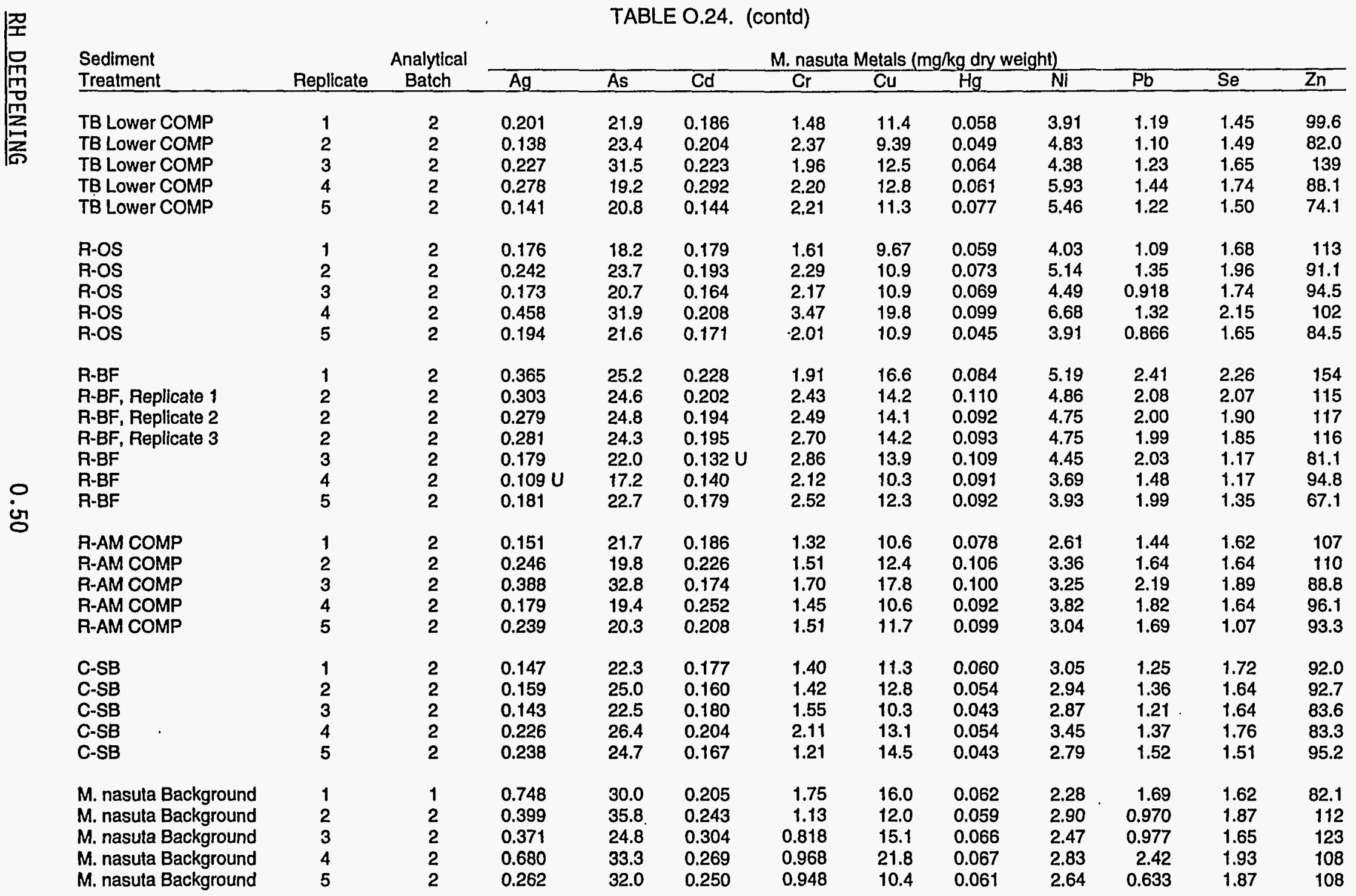

(a) DL Detection limit.

(b) U Undetected at or above detection limit. 


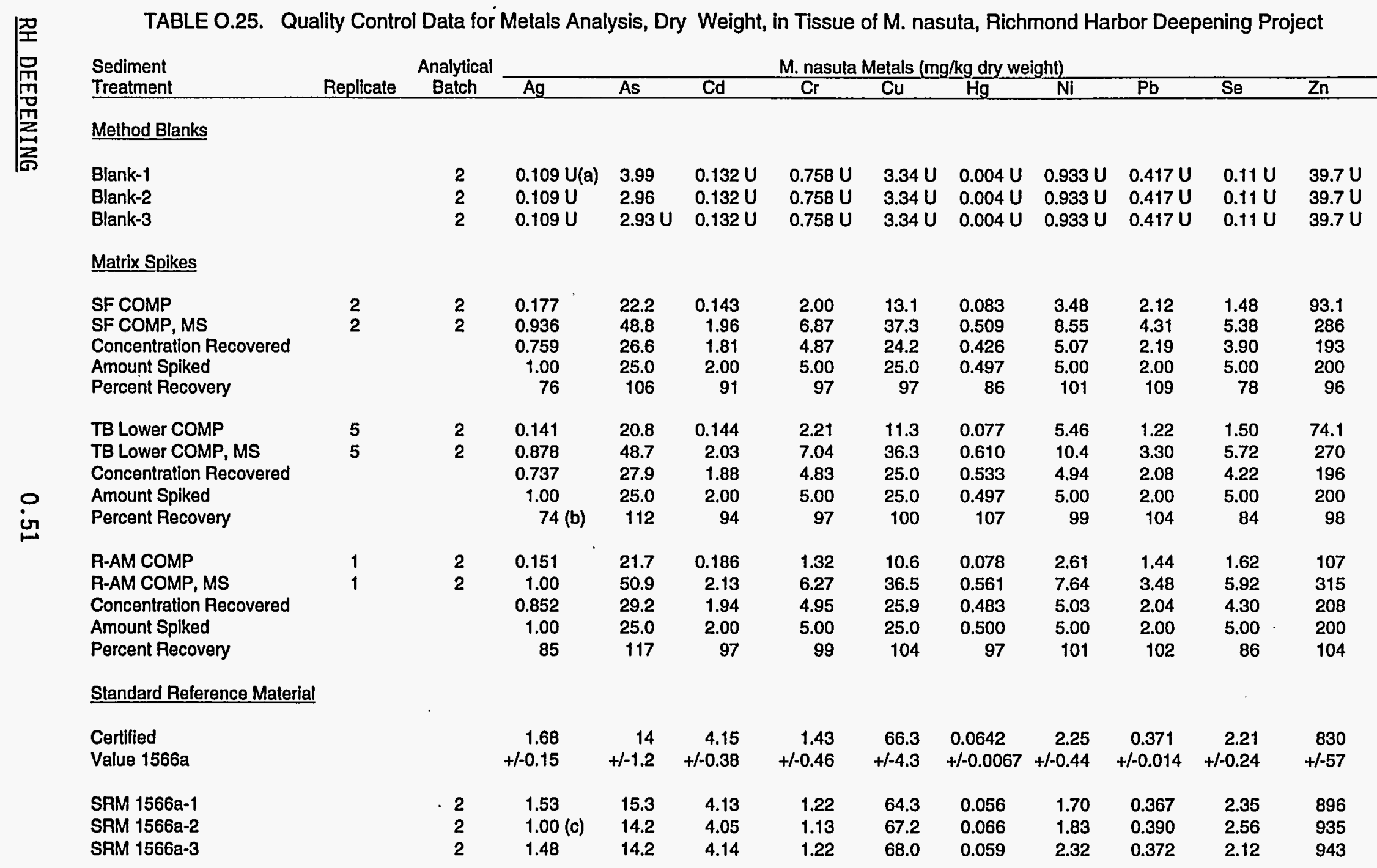




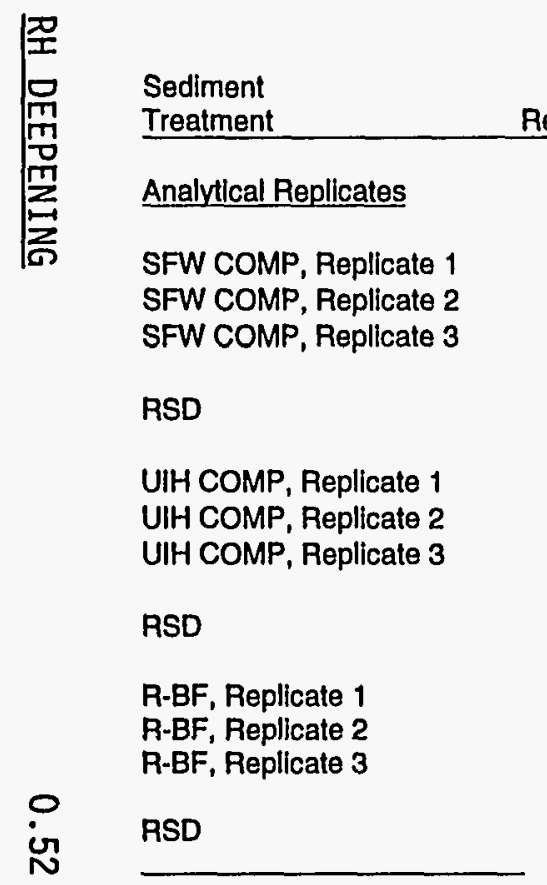

TABLE 0.25. (contd)

Analytical Analytical
Batch

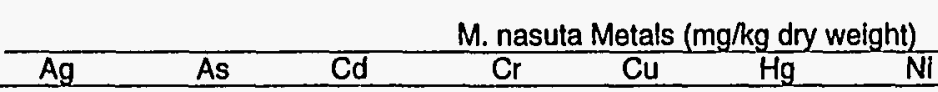
$\mathrm{NI} \quad \mathrm{Pb}-\mathrm{Se}-\mathrm{Zn}$ Replcale Batch Ag As

$\begin{array}{lll}2 & 2 & 0.1 \\ 2 & 2 & 0.1 \\ 2 & 2 & 0.11\end{array}$

\begin{tabular}{|c|c|c|c|c|c|c|c|c|}
\hline 30.9 & 0.208 & 1.43 & 9.30 & 0.099 & 3.44 & 2.00 & 2.06 & 117 \\
\hline 31.6 & 0.190 & 1.57 & 9.51 & 0.092 & 3.40 & 2.02 & 1.92 & 119 \\
\hline 31.4 & 0.196 & 1.59 & 9.52 & 0.098 & 3.43 & 2.11 & 1.97 & 117 \\
\hline $1 \%$ & $5 \%$ & $6 \%$ & $1 \%$ & $4 \%$ & $1 \%$ & $3 \%$ & $4 \%$ & $1 \%$ \\
\hline 23.7 & 0.234 & 2.20 & 11.7 & 0.058 & 3.59 & 2.21 & 1.76 & 97.6 \\
\hline 22.2 & 0.213 & 1.90 & 11.2 & 0.058 & 3.61 & 1.98 & 1.57 & 91.0 \\
\hline 21.3 & 0.204 & 1.72 & 10.9 & 0.070 & 3.40 & 1.84 & 1.64 & 89.5 \\
\hline $5 \%$ & $7 \%$ & $13 \%$ & $4 \%$ & $11 \%$. & $3 \%$ & $9 \%$ & $6 \%$ & $5 \%$ \\
\hline 24.6 & 0.202 & 2.43 & 14.2 & 0.110 & 4.86 & 2.08 & 2.07 & 115 \\
\hline 24.8 & 0.194 & 2.49 & 14.1 & 0.092 & 4.75 & 2.00 & 1.90 & 117 \\
\hline 24.3 & 0.195 & 2.70 & 14.2 & 0.093 & 4.75 & 1.99 & 1.85 & 116 \\
\hline
\end{tabular}

(a) $U$ Undetected at or above detection limit.

(b) Outside quality control range $(75-125 \%)$ for matrix spike recoveries.

(c) Outside quality control criteria $(+/-30 \%)$ for SRMs. 


\begin{tabular}{|c|c|c|c|c|c|c|c|c|c|c|}
\hline \multirow[b]{2}{*}{$\begin{array}{l}\text { Sediment } \\
\text { Treatment }\end{array}$} & \multirow[b]{2}{*}{ Replicate } & \multirow[b]{2}{*}{$\begin{array}{c}\text { Analytical } \\
\text { Batch }\end{array}$} & \multirow{2}{*}{$\begin{array}{l}\text { Tripentyltin } \\
\% \text { Internal } \\
\text { Standard }\end{array}$} & \multicolumn{3}{|c|}{ (ug/kg wet weight) } & \multirow{2}{*}{$\begin{array}{c}\text { Percent } \\
\text { Dry } \\
\text { Weight }\end{array}$} & \multicolumn{3}{|c|}{ (ug/kg dry weight) } \\
\hline & & & & $\begin{array}{c}\text { Tri- } \\
\text { Butyltin }\end{array}$ & $\begin{array}{c}\text { Di- } \\
\text { Butyltin }\end{array}$ & $\begin{array}{l}\text { Mono- } \\
\text { Butyiltin }\end{array}$ & & $\begin{array}{l}\text { Tri- } \\
\text { Butylitin } \\
\end{array}$ & $\begin{array}{c}\text { Di- } \\
\text { Butyltin }\end{array}$ & $\begin{array}{l}\text { Mono- } \\
\text { Butyltin }\end{array}$ \\
\hline $\begin{array}{l}\text { Target DL(a) } \\
\text { Achieved DL }\end{array}$ & & $\begin{array}{l}\text { NA } \\
\text { NA }\end{array}$ & $\begin{array}{l}\text { NA (b) } \\
\text { NA }\end{array}$ & $\begin{array}{l}1.00 \\
0.48\end{array}$ & $\begin{array}{l}1.00 \\
1.39\end{array}$ & $\begin{array}{l}1.00 \\
0.39\end{array}$ & $\begin{array}{l}\text { NA } \\
\text { NA }\end{array}$ & $\begin{array}{l}\text { NA } \\
\text { NA }\end{array}$ & $\begin{array}{l}\text { NA } \\
\text { NA }\end{array}$ & $\begin{array}{l}\text { NA } \\
\text { NA }\end{array}$ \\
\hline $\begin{array}{l}\text { SF COMP } \\
\text { SF COMP } \\
\text { SF COMP } \\
\text { SF COMP } \\
\text { SF COMP, Replicate } 1 \\
\text { SF COMP, Replicate } 2 \\
\text { SF COMP, Replicate } 3\end{array}$ & $\begin{array}{l}1 \\
2 \\
3 \\
4 \\
5 \\
5 \\
5\end{array}$ & $\begin{array}{l}6 \\
6 \\
6 \\
5 \\
6 \\
6 \\
6\end{array}$ & $\begin{array}{l}95 \\
89 \\
95 \\
94 \\
99 \\
92 \\
95\end{array}$ & $\begin{array}{l}3.22 \\
3.18 \\
2.42 \\
3.52 \\
2.97 \\
2.82 \\
2.97\end{array}$ & $\begin{array}{l}1.86 \\
1.52 \\
1.39 \mathrm{U} \\
1.51 \\
1.39 \mathrm{U} \\
1.39 \mathrm{U} \\
1.39 \mathrm{U}\end{array}$ & $\begin{array}{l}0.39 U(c) \\
0.39 U \\
0.39 U \\
0.39 U \\
0.39 U \\
0.39 U \\
0.39 U\end{array}$ & $\begin{array}{l}12.76 \\
12.94 \\
12.26 \\
12.60 \\
14.42 \\
14.42 \\
14.42\end{array}$ & $\begin{array}{l}25.2 \\
24.6 \\
19.7 \\
27.9 \\
20.6 \\
19.6 \\
20.6\end{array}$ & $\begin{array}{l}14.6 \\
11.7 \\
11.3 \mathrm{U} \\
12.0 \\
9.64 \mathrm{U} \\
9.64 \mathrm{U} \\
9.64 \mathrm{U}\end{array}$ & $\begin{array}{l}3.06 \mathrm{U} \\
3.01 \mathrm{U} \\
3.18 \mathrm{U} \\
3.10 \mathrm{U} \\
2.70 \mathrm{U} \\
2.70 \mathrm{U} \\
2.70 \mathrm{U}\end{array}$ \\
\hline $\begin{array}{l}\text { SFW COMP } \\
\text { SFW COMP } \\
\text { SFW COMP } \\
\text { SFW COMP } \\
\text { SFW COMP }\end{array}$ & $\begin{array}{l}1 \\
2 \\
3 \\
4 \\
5\end{array}$ & $\begin{array}{l}5 \\
5 \\
6 \\
5 \\
6\end{array}$ & $\begin{array}{l}99 \\
96 \\
84 \\
95 \\
86\end{array}$ & $\begin{array}{l}1.87 \\
1.93 \\
1.41 \\
2.00 \\
1.47\end{array}$ & $\begin{array}{l}1.39 \mathrm{U} \\
1.39 \mathrm{U} \\
1.39 \mathrm{U} \\
1.45 \mathrm{U} \\
1.39 \mathrm{U}\end{array}$ & $\begin{array}{l}0.39 U \\
0.39 U \\
0.39 U \\
0.39 U \\
0.39 U\end{array}$ & $\begin{array}{l}14.61 \\
17.91 \\
14.49 \\
14.31 \\
14.58\end{array}$ & $\begin{array}{l}12.8 \\
10.8 \\
9.73 \\
14.0 \\
10.1\end{array}$ & $\begin{array}{l}9.51 \mathrm{U} \\
7.76 \mathrm{U} \\
9.59 \mathrm{U} \\
10.1 \\
9.53 \mathrm{U}\end{array}$ & $\begin{array}{l}2.67 U \\
2.18 U \\
2.69 U \\
2.73 U \\
2.67 U\end{array}$ \\
\hline $\begin{array}{l}\text { UIH COMP } \\
\text { UIH COMP } \\
\text { UIH COMP } \\
\text { UIH COMP } \\
\text { UIH COMP }\end{array}$ & $\begin{array}{l}1 \\
2 \\
3 \\
4 \\
5\end{array}$ & $\begin{array}{l}6 \\
6 \\
6 \\
6 \\
6\end{array}$ & $\begin{array}{l}89 \\
87 \\
95 \\
80 \\
82\end{array}$ & $\begin{array}{l}2.43 \\
2.60 \\
2.09 \\
2.23 \\
2.59\end{array}$ & $\begin{array}{l}1.39 \mathrm{U} \\
1.56 \\
1.39 \mathrm{U} \\
1.48 \mathrm{U} \\
1.39 \mathrm{U}\end{array}$ & $\begin{array}{l}0.39 U \\
0.39 U \\
0.39 U \\
0.39 U \\
0.39 U\end{array}$ & $\begin{array}{l}13.71 \\
14.06 \\
13.52 \\
15.23 \\
13.02\end{array}$ & $\begin{array}{l}17.7 \\
18.5 \\
15.5 \\
14.6 \\
19.9\end{array}$ & $\begin{array}{l}10.1 U \\
11.1 \\
10.3 U \\
9.72 \\
10.7 U\end{array}$ & $\begin{array}{l}2.84 \mathrm{U} \\
2.77 \mathrm{U} \\
2.88 \mathrm{U} \\
2.56 \mathrm{U} \\
3.00 \mathrm{U}\end{array}$ \\
\hline $\begin{array}{l}\text { TB Upper COMP, Replicate } 1 \\
\text { TB Upper COMP, Replicate } 2 \\
\text { TB Upper COMP, Replicate } 3 \\
\text { TB Upper COMP } \\
\text { TB Upper COMP } \\
\text { TB Upper COMP } \\
\text { TB Upper COMP }\end{array}$ & $\begin{array}{l}1 \\
1 \\
1 \\
2 \\
3 \\
4 \\
5\end{array}$ & $\begin{array}{l}4 \\
4 \\
4 \\
4 \\
4 \\
4 \\
4\end{array}$ & $\begin{array}{l}92 \\
96 \\
95 \\
95 \\
94 \\
90 \\
91\end{array}$ & $\begin{array}{l}1.21 \\
1.26 \\
1.11 \\
1.23 \\
1.38 \\
1.51 \\
1.11\end{array}$ & $\begin{array}{l}1.39 U \\
1.39 U \\
1.39 U \\
1.39 U \\
1.39 U \\
1.39 U \\
1.39 U\end{array}$ & $\begin{array}{l}0.39 U \\
0.39 U \\
0.39 U \\
0.39 U \\
0.39 U \\
0.39 U \\
0.39 U\end{array}$ & $\begin{array}{l}15.21 \\
15.21 \\
15.21 \\
14.75 \\
13.66 \\
15.16 \\
15.00\end{array}$ & $\begin{array}{l}7.96 \\
8.28 \\
7.30 \\
8.34 \\
10.1 \\
9.96 \\
7.40\end{array}$ & $\begin{array}{l}9.14 U \\
9.14 U \\
9.14 U \\
9.42 U \\
10.2 U \\
9.17 U \\
9.27 U\end{array}$ & $\begin{array}{l}2.56 \mathrm{U} \\
2.56 \mathrm{U} \\
2.56 \mathrm{U} \\
2.64 \mathrm{U} \\
2.86 \mathrm{U} \\
2.57 \mathrm{U} \\
2.60 \mathrm{Y}\end{array}$ \\
\hline $\begin{array}{l}\text { TB Lower COMP } \\
\text { TB Lower COMP } \\
\text { TB Lower COMP } \\
\text { TB Lower COMP } \\
\text { TB Lower COMP }\end{array}$ & $\begin{array}{l}1 \\
2 \\
3 \\
4 \\
5\end{array}$ & $\begin{array}{l}5 \\
4 \\
6 \\
6 \\
5\end{array}$ & $\begin{array}{r}102 \\
95 \\
94 \\
65 \\
100\end{array}$ & $\begin{array}{l}1.68 \\
0.77 \\
0.92 \\
1.02 \\
1.56\end{array}$ & $\begin{array}{l}1.39 \mathrm{U} \\
1.39 \mathrm{U} \\
1.39 \mathrm{U} \\
2.22 \\
1.39 \mathrm{U}\end{array}$ & $\begin{array}{l}0.39 U \\
0.39 U \\
0.39 U \\
0.39 U \\
0.39 U\end{array}$ & $\begin{array}{l}13.17 \\
13.30 \\
12.74 \\
12.37 \\
13.89\end{array}$ & $\begin{array}{l}12.8 \\
5.79 \\
7.22 \\
8.25 \\
11.2\end{array}$ & $\begin{array}{l}10.6 \mathrm{U} \\
10.5 \mathrm{U} \\
10.9 \mathrm{U} \\
17.9 \\
10.0 \mathrm{U}\end{array}$ & $\begin{array}{l}2.96 \mathrm{U} \\
2.93 \mathrm{U} \\
3.06 \mathrm{U} \\
3.15 \mathrm{U} \\
2.81 \mathrm{U}\end{array}$ \\
\hline
\end{tabular}




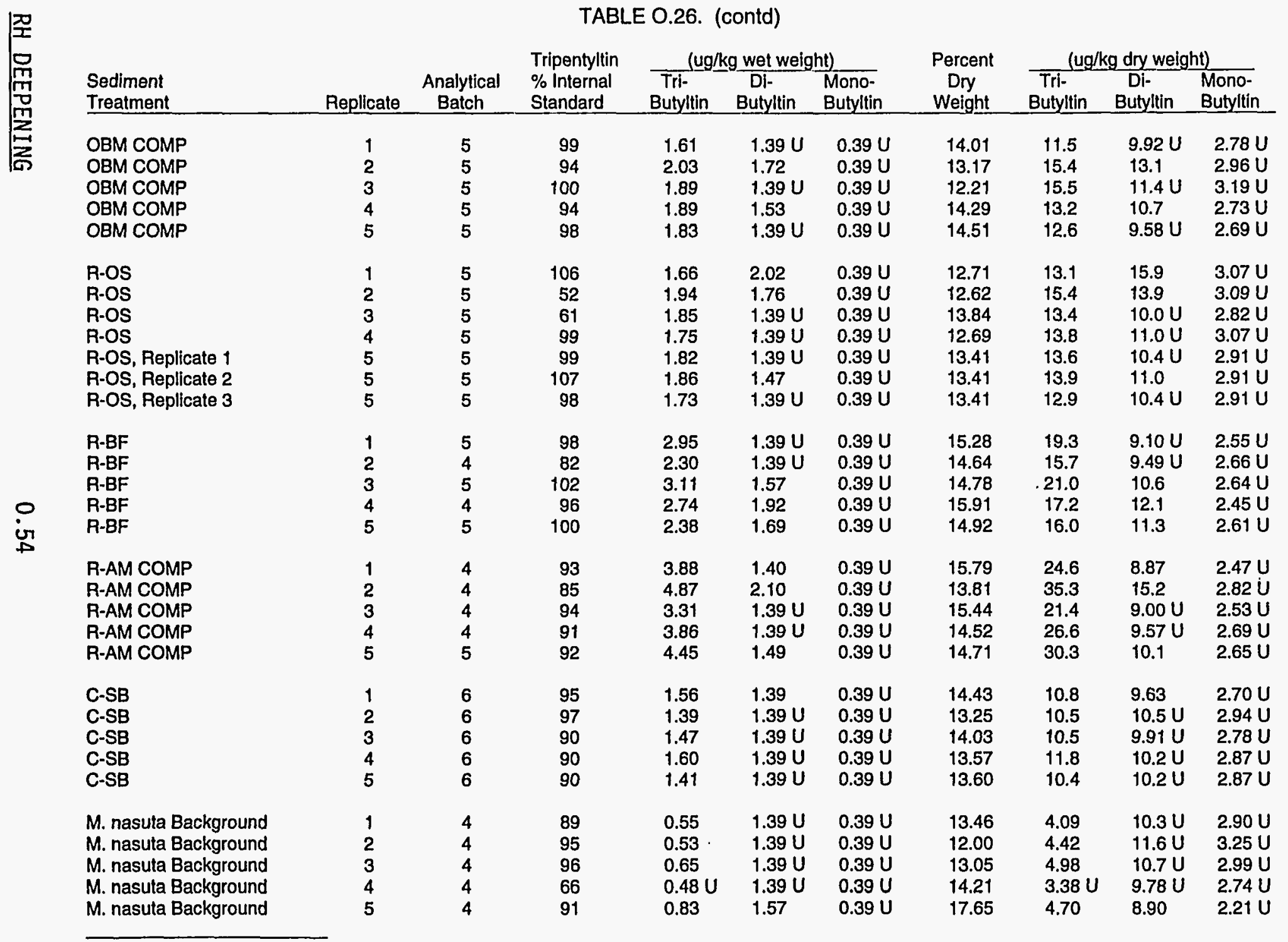

(a) DL Detection limit.

(c) U Undetected at or above detection limit. 
TABLE 0.27. Quality Control Data for Butyltin Results, Wet Weight, in Tissue of M. nasuta, Richmond Harbor Deepening Project

\begin{tabular}{|c|c|c|c|c|c|c|}
\hline \multirow{2}{*}{$\begin{array}{l}\text { Sediment } \\
\text { Treatment }\end{array}$} & \multirow[b]{2}{*}{ Replicate } & \multirow[b]{2}{*}{$\begin{array}{c}\text { Analytical } \\
\text { Batch }\end{array}$} & \multirow{2}{*}{$\begin{array}{l}\text { Tripentyltin } \\
\% \text { Internal } \\
\text { Standard } \\
\end{array}$} & \multicolumn{3}{|c|}{ (ug/kg wet weight) } \\
\hline & & & & $\begin{array}{l}\text { Tri- } \\
\text { Butylitin }\end{array}$ & $\begin{array}{c}\text { Di- } \\
\text { Butyltin }\end{array}$ & $\begin{array}{l}\text { Mono- } \\
\text { Butylitin }\end{array}$ \\
\hline \multicolumn{7}{|l|}{ Method Blanks } \\
\hline $\begin{array}{l}\text { Blank-1 } \\
\text { Blank-1 } \\
\text { Blank-1 }\end{array}$ & & $\begin{array}{l}4 \\
5 \\
6\end{array}$ & $\begin{array}{r}100 \\
103 \\
97\end{array}$ & $\begin{array}{l}0.48 U(a) \\
0.48 U \\
0.48 U\end{array}$ & $\begin{array}{l}1.39 \mathrm{U} \\
1.39 \mathrm{U} \\
1.39 \mathrm{U}\end{array}$ & $\begin{array}{l}0.39 U \\
0.39 U \\
0.39 U\end{array}$ \\
\hline \multicolumn{7}{|l|}{ Matrix Spikes } \\
\hline $\begin{array}{l}\text { TB Lower COMP } \\
\text { TB Lower COMP, MS } \\
\text { Concentration Recovered } \\
\text { Amount Spiked } \\
\text { Percent Recovery }\end{array}$ & 2 & $\begin{array}{l}4 \\
4\end{array}$ & $\begin{array}{l}95 \\
98 \\
\text { NA (b) } \\
\text { NA } \\
\text { NA }\end{array}$ & $\begin{array}{r}0.77 \\
54.2 \\
54.2 \\
50.0 \\
108 \%\end{array}$ & $\begin{array}{l}1.39 \mathrm{U} \\
46.6 \\
46.6 \\
50.0 \\
93 \%\end{array}$ & $\begin{array}{l}0.39 \mathrm{U} \\
12.8 \\
12.8 \\
50.0 \\
26 \% \text { (c) }\end{array}$ \\
\hline $\begin{array}{l}\text { OBM COMP } \\
\text { OBM COMP, MS } \\
\text { Concentration Recovered } \\
\text { Amount Spiked } \\
\text { Percent Recovery }\end{array}$ & $\begin{array}{l}3 \\
3\end{array}$ & $\begin{array}{l}5 \\
5\end{array}$ & $\begin{array}{r}100 \\
99 \\
\text { NA } \\
\text { NA } \\
\text { NA }\end{array}$ & $\begin{array}{l}1.89 \\
49.0 \\
47.1 \\
49.6 \\
95 \%\end{array}$ & $\begin{array}{l}1.39 \mathrm{U} \\
48.7 \\
48.7 \\
49.6 \\
98 \%\end{array}$ & $\begin{array}{l}0.39 U \\
15.9 \\
15.9 \\
49.6 \\
32 \%(c)\end{array}$ \\
\hline $\begin{array}{l}\text { C-SB } \\
\text { C-SB, MS } \\
\text { Concentration Recovered } \\
\text { Amount Spiked } \\
\text { Percent Recovery }\end{array}$ & $\begin{array}{l}4 \\
4\end{array}$ & $\begin{array}{l}6 \\
6\end{array}$ & $\begin{array}{l}90 \\
93 \\
\text { NA } \\
\text { NA } \\
\text { NA }\end{array}$ & $\begin{array}{r}1.60 \\
52.5 \\
50.9 \\
48.7 \\
105 \%\end{array}$ & $\begin{array}{l}1.39 \mathrm{U} \\
49.8 \\
49.8 \\
48.7 \\
102 \%\end{array}$ & $\begin{array}{l}0.39 U \\
25.0 \\
25.0 \\
48.7 \\
51 \%\end{array}$ \\
\hline \multicolumn{7}{|l|}{ Analytical Replicates } \\
\hline $\begin{array}{l}\text { TB Upper COMP, Replicate } 1 \\
\text { TB Upper COMP, Replicate } 2 \\
\text { TB Upper COMP, Replicate } 3\end{array}$ & $\begin{array}{l}1 \\
1 \\
1\end{array}$ & $\begin{array}{l}4 \\
4 \\
4\end{array}$ & $\begin{array}{l}92 \\
96 \\
95\end{array}$ & $\begin{array}{l}1.21 \\
1.26 \\
1.11\end{array}$ & $\begin{array}{l}1.39 \mathrm{U} \\
1.39 \mathrm{U} \\
1.39 \mathrm{U}\end{array}$ & $\begin{array}{l}0.39 U \\
0.39 U \\
0.39 U\end{array}$ \\
\hline RSD & & & NA & $6 \%$ & NA & NA \\
\hline $\begin{array}{l}\text { R-OS, Replicate } 1 \\
\text { R-OS, Replicate } 2 \\
\text { R-OS, Replicate } 3\end{array}$ & $\begin{array}{l}5 \\
5 \\
5\end{array}$ & $\begin{array}{l}\mathbf{5} \\
\mathbf{5} \\
\mathbf{5}\end{array}$ & $\begin{array}{r}99 \\
107 \\
98\end{array}$ & $\begin{array}{l}1.82 \\
1.86 \\
1.73\end{array}$ & $\begin{array}{l}1.39 U \\
1.47 \\
1.39 U\end{array}$ & $\begin{array}{l}0.39 U \\
0.39 U \\
0.39 U\end{array}$ \\
\hline RSD & & & NA & $4 \%$ & NA & NA \\
\hline $\begin{array}{l}\text { SF COMP, Replicate } 1 \\
\text { SF COMP, Replicate } 2 \\
\text { SF COMP, Replicate } 3\end{array}$ & $\begin{array}{l}5 \\
5 \\
5\end{array}$ & $\begin{array}{l}6 \\
6 \\
6\end{array}$ & $\begin{array}{l}99 \\
92 \\
95\end{array}$ & $\begin{array}{l}2.97 \\
2.82 \\
2.97\end{array}$ & $\begin{array}{l}1.39 U \\
1.39 U \\
1.39 U\end{array}$ & $\begin{array}{l}0.39 U \\
0.39 U \\
0.39 U\end{array}$ \\
\hline RSD & & & NA & $3 \%$ & NA & NA \\
\hline
\end{tabular}

(a) $U$ Undetected at or above detection limit.

(b) NA Not applicable.

(c) Outside quality control range (40-120\%) for matrix spike recoveries.
RH DEEPENING
0.55 . 

. 


\section{APPENDIX $P$}

IISSUE CHEMISTRY AND QUALITY ASSURANCE DATA FOR NEREIS virens 


\section{QA/QC SUMMARY}
PROGRAM:
Richmond Harbor Deepening Project
PARAMETER: Polynuclear Aromatic Hydrocarbons (PAH) and Phthalates
LABORATORY: Battelle/Marine Sciences Laboratory, Sequim, Washington MATRIX: Tissue

QAVC DATA QUALITY OBJECTIVES

$\begin{array}{cccc}\begin{array}{c}\text { Reference } \\ \text { Method }\end{array} & \begin{array}{c}\text { Range of } \\ \text { Recovery }\end{array} & \begin{array}{c}\text { Relative } \\ \text { Precision }\end{array} & \begin{array}{c}\text { Detection } \\ \text { Limit (dry wt) }\end{array} \\ \text { GC/MS } & 40-120 \% & \leq 30 \% & 20 \mu \mathrm{g} / \mathrm{kg}\end{array}$

METHOD

Tissue samples were extracted with methylene chloride using a roller under ambient conditions following SOP MSL-042, "Extraction and Clean-up of Sediment and Tissue for Semivolatile Organics," which is based on methods used by the National Oceanic and Atmospheric Administration for their Status and Trends Program (Krahn et al. 1988). Samples were then cleaned using silica/alumina chromatography followed by HPLC cleanup. The following modifications in the extraction and clean-up methods were required to adequately recover the phthalate compounds: twice the usual amount of methylene chloride was used in the extraction, and $4 \%$ rather than $2 \%$ deactivated silica was used. Extracts were quantified using gas chromatography/mass spectrometry (GC/MS) in the selected ion mode (SIM) following SOP MSL-M-043, "Identification and Quantification of Polynuclear Aromatic Hydrocarbons by GC/MS," which is based on EPA method 8270 (EPA 1986).

HOLDING TIMES

Ninety-nine (99) samples were received on 3/21/94 in good condition. Samples were logged into Battelle's log-in system and stored at approximately $-20^{\circ} \mathrm{C}$ until extraction. The following summarizes the extraction dates and GC/MS/SIM analysis dates:

$\begin{array}{lll}\text { Batch } & \text { Extraction } & \text { Analysis } \\ \text { Batch 1 } & 3 / 30 / 94 & \\ \text { Batch 2 } & 4 / 14 / 94 & 4 / 22-26 / 94 \\ \text { Batch 3 } & 4 / 26 / 94 & 5 / 28-30 / 94 \\ \text { Batch 4 } & 5 / 6 / 94 & 5 / 24-12 / 94 \\ \text { Batch 5 } & 5 / 20 / 94 & 5 / 26-28 / 94 \\ \text { Batch 6 } & 5 / 20 / 94 & 5 / 26-28 / 94\end{array}$

DETECTION LIMITS Target detection limits of $20 \mu \mathrm{g} / \mathrm{kg}$ wet wt were met for all PAH compounds. Achieved detection limits for PAHs were determined by multiplying the standard deviation of 7 spiked replicates by the student t value. Achieved detection limits for phthalates ranged from $19.2 \mu \mathrm{g} / \mathrm{kg}$ to $80 \mu \mathrm{g} / \mathrm{kg}$. The target detection limits were $20 \mu \mathrm{g} / \mathrm{kg}$. Detection limits for phthalates were derived from the lowest calibration standard. 


\section{QAVQ SUMMARY (contd)}

METHOD BLANKS

SURROGATES

MATRIX SPIKES

REPLICATES

MISC.
One method blank was extracted with each batch of samples. No compounds were detected in the method blanks at concentrations greater than 5 times the method detection limit. Any sample values that were less than 5 times the value in the associated method blank were flagged with a "B."

Five isotopically labelled compounds were added prior to extraction to assess the efficiency of the method. These were d8-naphthalene, d8-acenaphthene, d12-chrysene, d10-pyrene and d14-dibenzo(a,h)anthracene. Recoveries of all surrogates were within the quality control limits of $40 \%-120 \%$ with the exception of d14-dibenzo(a,h)anthracene in the method blank for Batch 1 , with a recovery of $33 \%$.

One sample from each batch was spiked with all PAH and phthalate compounds. Matrix spike recoveries for PAHs were within the QC criteria of $40 \%-120 \%$ with the following exceptions:

benzo $(\mathrm{g}, \mathrm{h}, \mathrm{i})$ perylene in Batch $3(125 \%)$, and benzo(b)fluoranthene $(123 \%)$ and benzo(k)fluoranthene $(121 \%)$ in Batch 5 . Phthalate recoveries were within QC criteria with the following exceptions: di-n-octyl phthalate in all batches except Batch 3 (greater than 120\%), bis(2-ethylhexyl)phthalate in Batch $1(122 \%)$, and dimethyl- and diethylphthalate in Batch 2 (less than $40 \%$ ).

One sample from each batch was extracted and analyzed in triplicate. Precision was measured by calculating the relative standard deviation (RSD) between the replicate results. The RSDs were within the QC criteria of $\leq 30 \%$ for analytes greater than 10 times the MDL.

Samples TB Lower COMP Rep. 5 for both $M$. nasuta and $N$. virens were re-extracted and re-analyzed because the initial results showed unusually high concentrations of bis(2-ethylhexyl)phthalate. The results of the re-analyses are reported.

Some of the sample results are flagged to indicate that the confirmation ion ratio for that compound was outside of the $\mathrm{QC}$ range. This is due to a combination of two factors: low levels of the compound of interest, and interferences resulting from the modified cleanup method. Because the confirmation ion is present at only a fraction of the level of the parent ion, when the native level of the compound is low, the amount of error in the concentration measurement of the confirmation ion goes up. The compound is actually quantified from the parent ion only, so most likely this will not effect the quality of the data.

\section{REFERENCES}

Krahn, M. M., C. A. Wigren, R. W. Pearch, L. K. Moore, R. G. Bogar, W. D. MacLeod, Jr., S. L. Chan, and D. W. Brown. 1988. "A Rapid High-Performance Liquid Chromatographic Method for Isolating Organic Contaminants from Tissue and Sediment Extracts." NOAA Technical Memorandum NMFS FINWC-153, Silver Spring, Maryland.

U.S. Environmental Protection Agency (EPA). 1986. Test Methods for Evaluating Solid Waste: Physical/Chemical Methods, SW-846. U.S. Document No. 955-001-00000, USEPA, Washington D.C. 


\section{QA/QC SUMMARY}
PROGRAM:
PARAMETER:
Richmond Harbor Deepening Project
LABORATORY:
MATRIX:
Chlorinated Pesticides and PCBs
Battelle/Marine Sciences Laboratory, Sequim, Washington
Tissue

QA/QC DATA QUALITY OBJECTIVES

$\begin{array}{cccc}\begin{array}{c}\text { Reference } \\ \text { Method }\end{array} & \begin{array}{c}\text { Range of } \\ \text { Recovery }\end{array} & \begin{array}{c}\text { Relative } \\ \text { Precision }\end{array} & \begin{array}{c}\text { Detection } \\ \text { Limit (wet wt) }\end{array} \\ \text { GC/ECD } & 40-120 \% & \leq 30 \% & 2.0-30 \mu \mathrm{g} / \mathrm{kg}\end{array}$

METHOD

HOLDING TIMES

DETECTION LIMITS

METHOD BLANKS
Tissue samples were extracted with methylene chloride using a roller under ambient conditions following SOP MSL-M-079, "Extraction and Clean-up of Sediment and Tissue for Semivolatile Organics following the Surrogate Internal Standard Method" based on EPA Method 3510 and 8080 (EPA 1986) and NOAA status and trends methods (Krahn et al. 1988). Samples were then cleaned using silica/alumina chromatography followed by HPLC cleanup (Krahn et al. 1988). The following modifications in the clean-up method were required to adequately recover the phthalate compounds: twice the usual amount of methylene chloride was used in the extraction, and $4 \%$ rather than $2 \%$ deactivated silica was used. Extracts were analyzed using Gas Chromatography/ Electron Capture Detection (GC/ECD) following SOP MSL-M-044, "Analysis of PCBs and Chlorinated Pesticides by GC/ECD" based on EPA method 8080 (1986). The column used was a J\&W DB-17 and the confirmatory column was a DB-1701, both capillary columns (30 $\mathrm{m} \times 0.25 \mathrm{~mm}$ l.D.).

One hundred four (104) samples were received on $3 / 21 / 94$ in good condition. Samples were logged into Battelle's log-in system and stored at approximately $-20^{\circ} \mathrm{C}$ until extraction. The following summarizes the extraction dates and GC/ECD analysis dates:

\begin{tabular}{|c|c|c|}
\hline Batch & Extraction & Analysis \\
\hline $\begin{array}{l}\text { Batch } 1 \\
\text { Batch } 2 \\
\text { Batch } 3 \\
\text { Batch } 4 \\
\text { Batch } 5 \\
\text { Batch } 6\end{array}$ & $\begin{array}{l}3 / 30 / 94 \\
4 / 14 / 94 \\
4 / 26 / 94 \\
5 / 6 / 94 \\
5 / 20 / 94 \\
5 / 20 / 94\end{array}$ & $\begin{array}{l}4 / 22-26 / 94 \\
4 / 28-30 / 94 \\
5 / 10-12 / 94 \\
5 / 21-24 / 94 \\
6 / 2-6 / 94 \\
6 / 2-6 / 94\end{array}$ \\
\hline
\end{tabular}

Target detection limits were met for all samples. Detection limits reported are based on an MDL study involving low level spikes of 7 replicate extractions. MDLs are defined as the standard deviation of the mean recovery multiplied by the student $t$ value.

One method blank was extracted with the batch of samples. No pesticides or PCBs were detected in the blanks at concentrations exceeding the QC limit of 5 times the detection limit. 


\section{QA/QC SUMMARY (contd)}

SURROGATES

MATRIX SPIKES

REPLICATES
Two compounds, PCB congeners 103 and 198, were added to all samples prior to extraction to assess the efficiency of the analysis. These compounds are also used to correct all sample results and are considered surrogate internal standards (SIS). Recoveries of these compounds were within the QC guidelines of $40-120 \%$ for all samples analyzed.

One sample from each batch was spiked with a subset of 6 pesticides and Aroclor 1254. Matrix spike recoveries were within the QC limits of $40 \%-120 \%$ with the exception of DDT in Batch $1(130 \%)$.

One sample from each batch was extracted in triplicate. Precision was measured by calculating the relative standard deviation (RSD) between the replicate results. RSDs were less than the QC limit of $30 \%$.

SRMS

NA

\section{REFERENCES}

Krahn, M. M., C. A. Wigren, R. W. Pearch, L. K. Moore, R. G. Bogar, W. D. MacLeod, Jr., S. L. Chan, and D. W. Brown. 1988. "A Rapid High-Performance Liquid Chromatographic Method for Isolating Organic Contaminants from Tissue and Sediment Extracts." NOAA Technical Memorandum NMFS FINWC-153, Silver Spring, Maryland.

U.S. Environmental Protection Agency (EPA). 1986. Test Methods for Evaluating Solid Waste: Physical/Chemical Methods. SW-846. U.S. Document No. 955-001-00000, USEPA, Washington D.C. 


\title{
QA/QC SUMMARY
}

\author{
PROGRAM: $\quad$ Richmond Harbor Deepening Project \\ PARAMETER: Metals \\ LABORATORY: Battelle/Marine Sciences Laboratory, Sequim, Washington \\ MATRIX: Tissue
}

\section{SAMPLE CUSTODY}

Ninety nine samples (49 N. virens and $50 \mathrm{M}$. nasuta tissue samples) were received on 3/21/94 in good condition. Samples and were logged into Battelle's log-in system.

\section{QAVQC.DATA QUALITY OBJECTIVES}

\begin{tabular}{|c|c|c|c|c|c|}
\hline & $\begin{array}{l}\text { Reference } \\
\text { Method } \\
\end{array}$ & $\begin{array}{l}\text { Range of } \\
\text { Recovery }\end{array}$ & $\begin{array}{c}\text { SRM } \\
\text { Accuracy }\end{array}$ & $\begin{array}{l}\text { Relative } \\
\text { Precision }\end{array}$ & $\begin{array}{c}\text { Detection } \\
\text { Limit } \\
\text { (mg/kg wet wt) }\end{array}$ \\
\hline $\begin{array}{l}\text { Arsenic } \\
\text { Cadmium } \\
\text { Chromium } \\
\text { Copper } \\
\text { Lead } \\
\text { Mercury } \\
\text { Nickel } \\
\text { Selenium } \\
\text { Silver } \\
\text { Zinc }\end{array}$ & $\begin{array}{l}\text { ICP/MS } \\
\text { ICP/MS } \\
\text { ICP/MS } \\
\text { ICP/MS } \\
\text { ICP/MS } \\
\text { CVAA } \\
\text { ICP/MS } \\
\text { GFAA } \\
\text { ICP/MS } \\
\text { ICP/MS }\end{array}$ & $\begin{array}{l}75 \%-125 \% \\
75 \%-125 \% \\
75 \%-125 \% \\
75 \%-125 \% \\
75 \%-125 \% \\
75 \%-125 \% \\
75 \%-125 \% \\
75 \%-125 \% \\
75 \%-125 \% \\
75 \%-125 \%\end{array}$ & $\begin{array}{l}\leq 30 \% \\
\leq 30 \% \\
\leq 30 \% \\
\leq 30 \% \\
\leq 30 \% \\
\leq 30 \% \\
\leq 30 \% \\
\leq 30 \% \\
\leq 30 \% \\
\leq 30 \%\end{array}$ & $\begin{array}{l}\leq 20 \% \\
\leq 20 \% \\
\leq 20 \% \\
\leq 20 \% \\
\leq 20 \% \\
\leq 20 \% \\
\leq 20 \% \\
\leq 20 \% \\
\leq 20 \% \\
\leq 20 \%\end{array}$ & $\begin{array}{l}2.0 \\
0.1 \\
1.0 \\
4.3 \\
1.0 \\
0.02 \\
1.0 \\
1.0 \\
0.1 \\
35\end{array}$ \\
\hline
\end{tabular}

METHOD

A total of 10 metals was analyzed for the Richmond Harbor Deepening Project: silver (Ag), arsenic (As), cadmium (Cd), chromium (Cr), copper (Cu), mercury ( $\mathrm{Hg}$ ), nickel ( $(\mathrm{Ni})$, lead $(\mathrm{Pb})$, selenium $(\mathrm{Se})$ and zinc $(\mathrm{Zn})$. Eight metals (As, $\mathrm{Cd}, \mathrm{Cr}, \mathrm{Cu}$, $\mathrm{Pb}, \mathrm{Ni}, \mathrm{Ag}$, and $\mathrm{Zn}$ ) were analyzed by inductively coupled plasma/mass spectrometry (ICP/MS) following EPA Method 200.8 (EPA 1991). One metal (Se) was analyzed using Zeeman Graphite Furnace Atomic Absorption (GFAA) spectrometry following SOP MSL-M-033, Trace Elements in Sediment in Tissue by Graphite Furnace Atomic Absorption, which is based on EPA Method 200.9 (EPA 1991). Mercury was analyzed using cold-vapor atomic absorption spectroscopy (CVAA) according to the method of Bloom and Crecelius (1983).

To prepare tissues for analysis, samples were freeze-dried and blended in a Spex mixer-mill. Approximately $5 \mathrm{~g}$ of mixed sample was ground in a ceramic ball mill. For ICP/MS and CVAA analyses, $0.2-$ to $0.5-\mathrm{g}$ aliquots of dried homogenous sample were digested using a mixture of nitric, perchloric and hydrofluoric acids.

\section{HOLDING TIMES}

Upon receipt, samples were frozen to $-80^{\circ} \mathrm{C}$ and subsequently freeze-dried within approximately 14 days of sample receipt. All samples were analyzed within 180 days of sample receipt with the exception of $\mathrm{Hg}$, which was analyzed within 30 days of receipt. Analysis dates are summarized in the following table: 


\section{QAVC SUMMARY (contd)}

Task

Sample Digestion

GFAA/Se

CVAA- $\mathrm{Hg}$

ICP/MS

ICP/MS, 715RHI-16 rerun
Batch 1 (Worms)

$$
\begin{gathered}
4 / 6 / 94 \\
5 / 18-20 / 94 \\
4 / 12-13 / 94 \\
4 / 20 / 94 \\
\text { NA }
\end{gathered}
$$

Batch 2 (Clams)

$$
\begin{gathered}
4 / 11 / 94 \\
5 / 20-23 / 94 \\
4 / 13-14 / 94 \\
4 / 21 / 94 \\
6 / 2 / 94
\end{gathered}
$$

Two samples ( $N$. virens SFW COMP Rep 4 and $N$. virens background rep. 4) were reanalyzed for ICP metals because the initial results for some metals were unusually high. The reanalysis of the background sample confirmed the initial results, and the initial results were reported. The results of the reanalysis of SFW COMP rep. 4 were lower than the initial values for selected metals, and consistent with the other tissues; therefore, the results of the reanalysis are reported.

\section{DETECTION LIMITS}

Target detection limits were met for all metals except $\mathrm{As}$ and $\mathrm{Zn}$. Achieved detection limits for As and $\mathrm{Zn}$ were higher than the target detection limits; however, these metals were detected in all of the samples. ICP/MS detection limits were determined by multiplying the standard deviation of 8 blank spike samples by the student " $\mathrm{t}$ " value (3.0). CVAA MDLs were determined by multiplying the standard deviation of 7 replicate analyses of an SRM by 3 . GFAA detection limits represent 3 times the standard deviation of the 3 replicate analyses of the method blank.

\section{METHOD BLANKS}

Six method blanks were analyzed with the samples. No metals were detected in the blanks at concentrations exceeding the QC criteria of three times the MDL. All sample results are blank corrected.

\section{MATRIX SPIKES}

Six tissue samples ( $3 M$. nasuta and $3 N$. virens) were spiked with ten metals. All spike recoveries were within the control limits of $75 \%-125 \%$ limits with the following exceptions: As in one $N$. virens sample (128\%), $\mathrm{Zn}$ in two $N$. virens samples (190\% and $158 \%)$, and $\mathrm{Ag}$ in one $\mathrm{M}$. nasuta sample (74\%).

\section{REPLICATES}

Six tissue samples ( $3 M$. nasuta and $3 N$. virens) were digested and analyzed in triplicate. Precision was measured by calculating the relative standard deviation (RSD) between the replicate results. The RSDs were all within the QC limits of $\leq 20 \%$ with the exception of $\mathrm{Cr}$ in one set of $N$. virens replicates $(41 \%)$, and $\mathrm{Zn}$ in all three $N$. virens replicates ( $41 \%$ to $61 \%$ ).

\section{SRMs}

Six samples of the SRM 1566a (obtained from the National Research Council of Canada, NRCC), were analyzed with the samples for all metals. All results were within $30 \%$ of the certified values with the exception of $Z n$ in one sample, which had a high recovery, and $\mathrm{Ag}$ in one sample, with a low recovery. 


\section{QA/QC SUMMARY (contd)}

\section{REFERENCES}

Bloom, N. S., and E.A. Crecelius. 1983. "Determination of Mercury in Seawater at SubNanogram per Liter Levels." Mar. Chem. 14:49-59.

EPA. 1991. Methods for the Determination of Metals in Environmental Samples.

EPA-600/4-91-010. Environmental Services Division, Monitoring Management Branch, Cincinnati, Ohio. 


\title{
QA/QC SUMMARY
}

\author{
PROGRAM: \\ Richmond Harbor Deepening Project \\ PARAMETER: \\ Butyltins
LABORATORY: Battelle/Marine Sciences Laboratory, Sequim, Washington MATRIX: \\ Tissue
}

\section{QAVC DATA QUALITY OBJECTIVES}

$\begin{array}{ccccc}\begin{array}{c}\text { Reference } \\ \text { Method }\end{array} & \begin{array}{c}\text { Range of } \\ \text { Recovery }\end{array} & \begin{array}{c}\text { SRM } \\ \text { Accuracy }\end{array} & \begin{array}{c}\text { Relative } \\ \text { Precision }\end{array} & \begin{array}{c}\text { Detection } \\ \text { Limit (dry weight) }\end{array} \\ \text { Unger et al. } & 40-120 \% & \leq 30 \% & \leq 30 \% & 1 \mu \mathrm{g} / \mathrm{kg}\end{array}$

METHOD

HOLDING TIMES

DETECTION LIMITS

METHOD BLANKS

SURROGATES
Butyltin analyses were performed according to MSL-SOP-M-004 following the method of Unger et al. (1986). Tissue samples were extracted with methylene chloride using a roller under ambient conditions followed by derivitization using a Grignard reagent to change to a form compatible with gas chromatography. Sample extracts were then cleaned by passing through a florisil column. Extracts were analyzed using Gas Chromatography/Flame Photometric Detection (GC/FPD).

One hundred four (104) samples of worm and clam tissue were received on 3/21/94 in good condition. Samples were logged into Battelle's log-in system and stored at approximately $-20^{\circ} \mathrm{C}$ until extraction. Samples were extracted and analyzed in six batches, as follows:

\section{Date Date

Extracted Analyzed

$\begin{array}{lcc}\text { Batch 1 } & 4 / 11 / 94 & 4 / 14-15 / 94 \\ \text { Batch 2 } & 4 / 18 / 94 & 4 / 22-23 / 94 \\ \text { Batch 3 } & 4 / 25 / 94 & 4 / 29-30 / 94 \\ \text { Batch 4 } & 5 / 2 / 94 & 5 / 12-13 / 94 \\ \text { Batch 5 } & 5 / 9 / 94 & 5 / 12-13 / 94 \\ \text { Batch 6 } & 5 / 25 / 94 & 5 / 26-27 / 94\end{array}$

The target detection limit of $1 \mu \mathrm{g} / \mathrm{kg}$ wet wt was met for tri- and monobutyltin, but was exceeded for dibutyltin. The achieved detection limit for dibutyltin was $1.39 \mu \mathrm{g} / \mathrm{kg}$. The method detection limits are defined as roughly 3 times the standard deviation of results from 7 replicate low level matrix spikes.

One method blank was extracted with each extraction batch. No butyltins were detected in the blanks.

One compound, Tripentyltin chloride, is added prior to extraction to assess the efficiency of the method. This compound also is used as an internal standard as all data is corrected for the recovery of the compound. Sample recoveries ranged from $52 \%$ to $112 \%$. All sample surrogate recoveries were within the QC limits of $40 \%-120 \%$. 


\section{QA/QC SUMMARY (contd)}

MATRIX SPIKES

REPLICATES

SRM

\section{REFERENCES}

Unger, M.A., W.G. Macintyre, J. Reaves and R.J. Huggett. 1986. "GC Determination of Butyltins in Natural Waters by Flame Photometric Detection of Hexyl Derivatives with Mass Spectrometric Confirmation." Chemosphere. 15:461-470.
One sample from each extraction batch was spiked with mono-, di- and tributyltin. Matrix spike recoveries ranged from $93 \%$ to $114 \%$ for the triand dibutyltins, within the QC limits of $40-120 \%$. The recovery for monobutyltin ranged from $26 \%$ to $51 \%$. The lower recovery for monobutyltin is expected due to the inefficiency of the extraction of this compound as a result of its increased ionic nature.

One sample in each batch was digested in triplicate. Precision was measured by calculating the relative standard deviation (RSD) for the triplicate results. Tributyltin was detected in replicates for four of the batches; RSDs ranged from $3 \%$ to $6 \%$.

Not applicable. 
TABLE P.1. Total Detected Polynuclear Aromatic Hydrocarbons, Dry Weight, in Tissue of N. virens, Richmond Harbor Deepening Project

\begin{tabular}{|c|c|c|c|c|c|c|}
\hline \multirow[b]{2}{*}{$\begin{array}{l}\text { Sediment } \\
\text { Treatment }\end{array}$} & \multirow[b]{2}{*}{ Replicate } & \multirow[b]{2}{*}{$\begin{array}{c}\text { Analytical } \\
\text { Batch }\end{array}$} & \multirow[b]{2}{*}{$\begin{array}{l}\text { Percent } \\
\text { Dry } \\
\text { Weight }\end{array}$} & \multicolumn{3}{|c|}{ N. virens PAHs (ug/kg dry weight) } \\
\hline & & & & $\begin{array}{l}\text { Total } \\
\text { Low Molecular } \\
\text { Weight PAHs }\end{array}$ & $\begin{array}{l}\text { Total } \\
\text { High Molecular } \\
\text { Weight PAHs }\end{array}$ & $\begin{array}{l}\text { Total } \\
\text { PAHs } \\
\end{array}$ \\
\hline SF COMP & 1 & 1 & 13.45 & 41 & 196 & 237 \\
\hline SF COMP, Replicate 1 & 2 & 3 & 13.61 & 47 & 413 & 460 \\
\hline SF COMP, Replicate 2 & 2 & 3 & 13.61 & 19 & 434 & 453 \\
\hline SF COMP, Replicate 3 & 2 & 3 & 13.61 & 77 & 441 & 518 \\
\hline SF COMP & 3 & 1 & 13.25 & 89 & 365 & 454 \\
\hline SF COMP & 4 & 1 & 13.42 & 86 & 201 & 287 \\
\hline SF COMP & 5 & 2 & 12.94 & 86 & 295 & 381 \\
\hline SFW COMP, Replicate 1 & 1 & 1 & 12.99 & 138 & 567 & 705 \\
\hline SFW COMP, Replicate 2 & 1 & 1 & 13.36 & 142 & 436 & 578 \\
\hline SFW COMP, Replicate 3 & 1 & 1 & 13.85 & 117 & 340 & 457 \\
\hline SFW COMP & 2 & 2 & 12.32 & 92 & 408 & 500 \\
\hline SFW COMP & 3 & 2 & 13.78 & 163 & 477 & 640 \\
\hline SFW COMP & 4 & 1 & 13.08 & 154 & 339 & 493 \\
\hline SFW COMP & 5 & 1 & 13.95 & 179 & 413 & 592 \\
\hline UIH COMP & 1 & 2 & 13.70 & 32 & 195 & 227 \\
\hline UIH COMP & 2 & 1 & 13.21 & 26 & 223 & 249 \\
\hline UIH COMP & 3 & 3 & 13.03 & 35 & 368 & 403 \\
\hline UIH COMP & 4 & 1 & 13.28 & 62 & 276 & 338 \\
\hline UIH COMP & 5 & 1 & 12.99 & 84 & 304 & 388 \\
\hline TB Upper COMP & 1 & 1 & 14.09 & 34 & 141. & 175 \\
\hline TB Upper COMP & 2 & 1 & 13.33 & 35 & 201 & 236 \\
\hline TB Upper COMP & 3 & 2 & 13.17 & 52 & 211 & 263 \\
\hline TB Upper COMP & 4 & 1 & 13.45 & 60 & 115 & 175 \\
\hline TB Upper COMP & 5 & 2 & 14.65 & 56 & 199 & 255 \\
\hline TB Lower COMP & 1 & 2 & 13.26 & 52 & 214 & 266 \\
\hline TB Lower COMP & 2 & 1 & 12.88 & 43 & 128 & 171 \\
\hline TB Lower COMP & 3 & 2 & 13.79 & 46 & 194 & 240 \\
\hline TB Lower COMP & 4 & 2 & 12.49 & 48 & 167 & 215 \\
\hline TB Lower COMP & 5 & 2 & 13.61 & 14 & 79 & 93 \\
\hline R-OS & 1 & 2 & 14.02 & 48 & 153 & 201 \\
\hline R-OS & 2 & 1 & 13.37 & 31 & 124 & 155 \\
\hline R-OS & 3 & 1 & 13.54 & 33 & 124 & 157 \\
\hline R-OS & 4 & 2 & 13.97 & 35 & 150 & 185 \\
\hline R-OS & 5 & 1 & 13.34 & 80 & 190 & 270 \\
\hline
\end{tabular}


TABLE P.1. (contd)

\begin{tabular}{|c|c|c|c|c|c|c|}
\hline \multirow[b]{2}{*}{$\begin{array}{l}\text { Sediment } \\
\text { Treatment }\end{array}$} & \multirow[b]{2}{*}{ Replicate } & \multirow[b]{2}{*}{$\begin{array}{c}\text { Analytical } \\
\text { Batch }\end{array}$} & \multirow[b]{2}{*}{$\begin{array}{l}\text { Percent } \\
\text { Dry } \\
\text { Weight }\end{array}$} & \multicolumn{3}{|c|}{ N. virens PAHs (ug/kg dry weight) } \\
\hline & & & & $\begin{array}{l}\text { Total } \\
\text { Low Molecular } \\
\text { Weight PAHs }\end{array}$ & $\begin{array}{l}\text { Total } \\
\text { High Molecular } \\
\text { Weight PAHs }\end{array}$ & $\begin{array}{l}\text { Total } \\
\text { PAHs }\end{array}$ \\
\hline R-BF & 1 & 1 & 14.51 & 75 & 127 & 202 \\
\hline R-BF & 2 & 2 & 13.20 & 49 & 129 & 178 \\
\hline R-BF & 3 & 2 & 13.95 & 50 & 205 & 255 \\
\hline R-BF & 4 & 2 & 12.57 & 50 & 216 & 266 \\
\hline R-BF & 5 & 2 & 13.94 & 45 & 133 & 178 \\
\hline R-AM COMP & 1 & 1 & 13.57 & 107 & 297 & 404 \\
\hline R-AM COMP & 2 & 2 & 13.43 & 46 & 223 & 269 \\
\hline R-AM COMP & 3 & 2 & 13.95 & 49 & 169 & 218 \\
\hline R-AM COMP & 4 & 1 & 13.45 & 27 & 213 & 240 \\
\hline R-AM COMP & 5 & 3 & 13.75 & 46 & 279 & 325 \\
\hline C-NV & 1 & 1 & 12.66 & 103 & 290 & 393 \\
\hline G-NV, Replicate 1 & 2 & 2 & 14.27 & 86 & 383 & 469 \\
\hline C-NV, Replicate 2 & 2 & 2 & 14.27 & 91 & 216 & 307 \\
\hline C-NV, Replicate 3 & 2 & 2 & 14.27 & 64 & 248 & 312 \\
\hline C-NV & 3 & 2 & 13.15 & 35 & 238 & 273 \\
\hline C-NV & 4 & 3 & 13.21 & 60 & 238 & 298 \\
\hline N. virens Background & 1 & 3 & 14.64 & 45 & 406 & 451 \\
\hline N. virens Background & 2 & 3 & 13.30 & 51 & 277 & 328 \\
\hline N. virens Background & 3 & 3 & 13.79 & 26 & 202 & 228 \\
\hline N. virens Background & 4 & 3 & 14.11 & 37 & 178 & 215 \\
\hline N. virens Background & 5 & 3 & 13.99 & 27 & 220 & 247 \\
\hline
\end{tabular}


TABLE P.2. Low Molecular Weight Polynuclear Aromatic Hydrocarbons, Dry Weight, in Tissue of N. virens, Richmond Harbor Deepening Project

N. virens LPAHs (ug/kg dry weight)

Sediment

Percent

Treatment

Analytical Dry Naphtha- Acenaph- Acenaph-

SF COMP

SF COMP, Replicate 1

SF COMP, Replicate 2

SF COMP, Replicate 3

SF COMP

SF COMP

SF COMP

Batch

Weight

SFW COMP, Replicate

SFW COMP, Replicate 2

SFW COMP, Replicate 3

SFW COMP

SFW COMP

SFW COMP

SFW COMP

UIH COMP
UIH COMP
UIH COMP
UIH COMP
UIH COMP

TB Upper COMP

TB Upper COMP

TB Upper COMP

TB Upper COMP

TB Upper COMP

TB Lower COMP

TB Lower COMP

TB Lower COMP

TB Lower COMP

TB Lower COMP

R-OS

R.OS

R-OS

R-OS

R-OS

R-BF

R-BF

R-BF

R-BF

R-BF

R-AM COMP

R-AM COMP

R-AM COMP

R-AM COMP

R-AM COMP

Replicate

lene

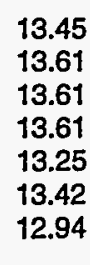

12.99

13.36

13.85

12.32

13.78

13.08

13.95

13.70

13.21

13.03

13.28

12.99

14.09

13.33

13.17

13.45

14.65

13.26

12.88

13.79

12.49

13.61

14.02

13.37

13.54

13.97

13.34

14.51

13.20

13.95

12.57

13.94

13.57

13.43

13.95

13.45

13.75 lene thylene thene

\begin{tabular}{|c|c|c|c|c|c|}
\hline $\begin{array}{l}16.2 \\
23.8 \mathrm{~B}(\mathrm{C}) \\
18.8 \mathrm{~B} \\
22.9 \mathrm{~B} \\
22.5 \\
20.4 \\
21.7 \mathrm{~B}\end{array}$ & $\begin{array}{l}11.8 \mathrm{U}(\mathrm{a}) \\
24.2 \mathrm{U} \\
24.2 \mathrm{U} \\
24.2 \mathrm{U} \\
12.3 \mathrm{U} \\
12.0 \mathrm{U} \\
12.6 \mathrm{U}\end{array}$ & $\begin{array}{l}12.0 \text { (b) } \\
23.0 \mathrm{U} \\
23.0 \mathrm{U} \\
28.9 \\
14.0 \text { (b) } \\
19.4 \text { (b) } \\
13.8\end{array}$ & $\begin{array}{l}19.9 U \\
40.5 U \\
40.5 U \\
40.5 U \\
20.6 U \\
20.1 U \\
21.1 U\end{array}$ & $\begin{array}{l}12.5 \\
22.9 \text { (b) } \\
19.0 \mathrm{U} \\
25.3(\mathrm{~b}) \\
16.5 \text { (b) } \\
9.91 \text { (b) } \\
15.5 \text { (b) }\end{array}$ & $\begin{array}{l}32.1 U \\
65.5 U \\
65.5 U \\
65.5 U \\
36.3 \text { (b) } \\
35.8 \\
34.9\end{array}$ \\
\hline $\begin{array}{l}35.6(b) \\
36.5 \\
2.9 \\
.12 \mathrm{U} \\
34.7 \mathrm{~B} \\
24.7 \\
4.2\end{array}$ & $\begin{array}{l}23.2 U \\
23.4 U \\
22.5 U \\
13.2 U \\
11.9 U \\
12.5(\mathrm{~b}) \\
12.7(\mathrm{~b})\end{array}$ & $\begin{array}{l}71.2 \\
67.1 \\
55.2 \\
63.6 \\
62.4 \\
59.4 \\
77.4\end{array}$ & $\begin{array}{l}39.0 \mathrm{U} \\
39.1 \mathrm{U} \\
37.5 \mathrm{U} \\
22.2 \mathrm{U} \\
20.0 \mathrm{U} \\
20.6 \mathrm{U} \\
19.1 \mathrm{U}\end{array}$ & $\begin{array}{l}30.9 \\
38.0(\mathrm{~b}) \\
29.0(\mathrm{~b}) \\
28.7 \\
29.4 \\
22.2 \\
28.2\end{array}$ & $\begin{array}{l}63.1 \mathrm{U} \\
63.4 \mathrm{U} \\
60.8 \mathrm{U} \\
35.8 \mathrm{U} \\
36.1 \\
35.3 \text { (b) } \\
36.3 \text { (b) }\end{array}$ \\
\hline $\begin{array}{l}17.0 \mathrm{~B} \\
14.5 \\
19.9 \mathrm{~B} \\
13.6 \\
36.2\end{array}$ & $\begin{array}{l}11.8 U \\
12.4 U \\
12.6 U \\
12.3 U \\
24.4 U\end{array}$ & $\begin{array}{l}11.2 U \\
11.8 U \\
12.0 U \\
11.7 U \\
23.5(b)\end{array}$ & & $\begin{array}{l}14.5 \text { (b) } \\
11.6(\mathrm{~b}) \\
14.8 \text { (b) } \\
13.7 \text { (b) } \\
23.9 \text { (b) }\end{array}$ & $\begin{array}{l}31.9 \mathrm{U} \\
33.8 \mathrm{U} \\
34.2 \mathrm{U} \\
35.1 \text { (b) } \\
66.2 \mathrm{U}\end{array}$ \\
\hline $\begin{array}{l}19.2 \\
21.5 \\
22.2 \mathrm{~B} \\
17.2 \\
20.0 \mathrm{~B}\end{array}$ & $\begin{array}{l}11.6 \mathrm{U} \\
12.1 \mathrm{U} \\
12.2 \mathrm{U} \\
11.7 \mathrm{U} \\
12.2(\mathrm{~b})\end{array}$ & $\begin{array}{l}1.0 \mathrm{U} \\
1.5 \mathrm{U} \\
5.9(\mathrm{~b}) \\
1.2 \mathrm{U} \\
0.8(\mathrm{~b})\end{array}$ & $\begin{array}{l}19.4 U \\
20.3 U \\
20.5 U \\
19.6 U \\
18.4 U\end{array}$ & $\begin{array}{l}14.3(\mathrm{~b}) \\
13.8(\mathrm{~b}) \\
14.0(\mathrm{~b}) \\
10.8(\mathrm{~b}) \\
13.3(\mathrm{~b})\end{array}$ & $\begin{array}{l}31.3 \mathrm{U} \\
32.8 \mathrm{U} \\
33.2 \mathrm{U} \\
31.9 \mathrm{~b}) \\
29.8 \mathrm{U}\end{array}$ \\
\hline $\begin{array}{l}22.9 \mathrm{~B} \\
16.5 \\
21.8 \mathrm{~B} \\
18.3 \mathrm{~B} \\
13.7 \mathrm{~B}\end{array}$ & $\begin{array}{l}12.1 \mathrm{U} \\
12.7 \mathrm{U} \\
11.8 \mathrm{U} \\
13.1 \mathrm{U} \\
12.0 \mathrm{U}\end{array}$ & $\begin{array}{l}13.4(\mathrm{~b}) \\
12.3(\mathrm{~b}) \\
12.3(\mathrm{~b}) \\
15.3(\mathrm{~b}) \\
11.5 \mathrm{U}\end{array}$ & $\begin{array}{l}20.4 U \\
21.2 U \\
19.8 U \\
21.9 U \\
20.2 U\end{array}$ & $\begin{array}{l}15.6(\mathrm{~b}) \\
14.1(\mathrm{~b}) \\
12.0(\mathrm{~b}) \\
13.9 \\
9.55 \mathrm{U}\end{array}$ & $\begin{array}{l}33.0 \mathrm{U} \\
34.2 \mathrm{U} \\
32.0 \mathrm{U} \\
35.3 \mathrm{U} \\
32.8 \mathrm{U}\end{array}$ \\
\hline $\begin{array}{l}22.3 \mathrm{~B} \\
18.9 \\
19.7 \\
21.5 \mathrm{~B} \\
16.9\end{array}$ & $\begin{array}{l}11.6 \mathrm{U} \\
12.3 \mathrm{U} \\
12.0 \mathrm{U} \\
11.7 \mathrm{U} \\
12.1 \mathrm{U}\end{array}$ & $\begin{array}{l}12.4(b) \\
11.7 \mathrm{U} \\
11.4 \mathrm{U} \\
11.1 \mathrm{U} \\
12.1\end{array}$ & $\begin{array}{l}19.5 \\
20.6 \\
20.2 \\
19.5 \\
20.2\end{array}$ & $\begin{array}{l}13.1(\mathrm{~b}) \\
12.0(\mathrm{~b}) \\
13.2(\mathrm{~b}) \\
13.6(\mathrm{~b}) \\
16.4(\mathrm{~b})\end{array}$ & $\begin{array}{l}31.5 \mathrm{U} \\
33.4 \mathrm{U} \\
40.8 \mathrm{U} \\
31.6 \mathrm{U} \\
34.6 \text { (b) }\end{array}$ \\
\hline $\begin{array}{l}14.9 \\
21.0 \mathrm{~B} \\
21.5 \mathrm{~B} \\
22.9 \mathrm{~B} \\
18.7 \mathrm{~B}\end{array}$ & $\begin{array}{l}11.0 \mathrm{U} \\
12.4 \mathrm{U} \\
11.7 \mathrm{U} \\
13.0 \mathrm{U} \\
11.7 \mathrm{U}\end{array}$ & $\begin{array}{l}10.5 \mathrm{U} \\
14.3(\mathrm{~b}) \\
16.2 \\
13.3(\mathrm{~b}) \\
14.6 \text { (b) }\end{array}$ & $\begin{array}{l}18.4 U \\
20.8 U \\
19.6 U \\
21.7 U \\
19.6 U\end{array}$ & $\begin{array}{l}25.6(b) \\
13.6 \\
12.7(b) \\
14.2(b) \\
11.9(b)\end{array}$ & $\begin{array}{l}34.8 \text { (b) } \\
33.8 U \\
31.6 U \\
35.1 U \\
31.6 U\end{array}$ \\
\hline $\begin{array}{l}15.8(\mathrm{~b}) \\
18.9 \mathrm{~B} \\
23.3 \mathrm{~B} \\
14.0 \mathrm{~b}) \\
14.9 \mathrm{~B}\end{array}$ & $\begin{array}{l}11.6(\mathrm{~b}) \\
12.0 \mathrm{U} \\
11.5 \mathrm{U} \\
12.0 \mathrm{U} \\
11.9 \mathrm{U}\end{array}$ & $\begin{array}{l}13.5 \text { (b) } \\
12.3 \\
12.5(b) \\
11.4 U \\
14.2(b)\end{array}$ & $\begin{array}{l}19.5(b) \\
20.1 U \\
19.4 U \\
20.1 U \\
20.0 U\end{array}$ & $\begin{array}{l}14.6 \text { (b) } \\
15.2 \text { (b) } \\
13.5 \\
13.3 \text { (b) } \\
17.0 \text { (b) }\end{array}$ & $\begin{array}{l}31.5 \text { (b) } \\
32.5 \mathrm{U} \\
31.3 \mathrm{U} \\
32.5 \mathrm{U} \\
32.4 \mathrm{U}\end{array}$ \\
\hline
\end{tabular}

RH DEEPENING 
TABLE P.2. (contd)

\begin{tabular}{|c|c|c|c|c|c|c|c|c|c|}
\hline \multirow[b]{2}{*}{$\begin{array}{l}\text { Sediment } \\
\text { Treatment }\end{array}$} & \multirow[b]{2}{*}{ Replicate } & \multirow[b]{2}{*}{$\begin{array}{c}\text { Analytical } \\
\text { Batch }\end{array}$} & \multirow[b]{2}{*}{$\begin{array}{c}\text { Percent } \\
\text { Dry } \\
\text { Weight }\end{array}$} & \multicolumn{6}{|c|}{ N. virens LPAHs (ug/kg dry weight) } \\
\hline & & & & $\begin{array}{l}\text { Naphtha- } \\
\text { lene }\end{array}$ & $\begin{array}{l}\text { Acenaph- } \\
\text { thylene }\end{array}$ & $\begin{array}{l}\text { Acenaph- } \\
\text { thene }\end{array}$ & Fluorene & $\begin{array}{l}\text { Phenan- } \\
\text { threne }\end{array}$ & $\begin{array}{l}\text { Anthra- } \\
\text { cene }\end{array}$ \\
\hline $\begin{array}{l}\text { C-NV } \\
\text { C-NV, Replicate } 1 \\
\text { C-NV, Replicate } 2 \\
\text { C-NV, Replicate } 3 \\
\text { C-NV } \\
\text { C-NV }\end{array}$ & $\begin{array}{l}1 \\
2 \\
2 \\
2 \\
3 \\
4\end{array}$ & $\begin{array}{l}1 \\
2 \\
2 \\
2 \\
2 \\
3\end{array}$ & $\begin{array}{l}12.66 \\
14.27 \\
14.27 \\
14.27 \\
13.15 \\
13.21\end{array}$ & $\begin{array}{l}19.4 \text { (b) } \\
29.5 \mathrm{~B} \\
40.5 \mathrm{~B} \\
39.9 \mathrm{~B} \\
34.7 \mathrm{~B} \\
15.4 \mathrm{~B}\end{array}$ & $\begin{array}{l}13.4(\mathrm{~b}) \\
23.1 \cup \\
25.4(\mathrm{~b}) \\
22.6 U \\
24.5 \mathrm{U} \\
14.7(\mathrm{~b})\end{array}$ & $\begin{array}{l}16.0 \\
35.3 \\
21.8 U \\
21.5 U \\
23.3 U \\
14.9\end{array}$ & $\begin{array}{l}21.3 \mathrm{U} \\
38.6 \mathrm{U} \\
38.4 \mathrm{U} \\
37.8 \mathrm{U} \\
41.1 \mathrm{U} \\
20.8 \mathrm{U}\end{array}$ & $\begin{array}{l}18.6(\mathrm{~b}) \\
21.3 \\
25.4(\mathrm{~b}) \\
23.8(\mathrm{~b}) \\
19.3 \mathrm{U} \\
15.1(\mathrm{~b})\end{array}$ & $\begin{array}{l}35.2(b) \\
62.4 U \\
62.2 U \\
61.2 U \\
66.5 U \\
33.8 U\end{array}$ \\
\hline $\begin{array}{l}\text { N. virens Background } \\
\text { N. virens Background } \\
\text { N. virens Background } \\
\text { N. virens Background } \\
\text { N. virens Background }\end{array}$ & $\begin{array}{l}1 \\
2 \\
3 \\
4 \\
5\end{array}$ & $\begin{array}{l}3 \\
3 \\
3 \\
3 \\
3\end{array}$ & $\begin{array}{l}14.64 \\
13.30 \\
13.79 \\
14.11 \\
13.99\end{array}$ & $\begin{array}{l}24.1 \mathrm{~B} \\
11.6 \mathrm{~B} \\
13.8 \mathrm{~B} \\
13.5 \mathrm{~B} \\
14.9 \mathrm{~B}\end{array}$ & $\begin{array}{l}22.5 \mathrm{U} \\
13.3 \mathrm{(b)} \\
11.9 \mathrm{U} \\
11.8(\mathrm{~b}) \\
11.4 \mathrm{U}\end{array}$ & $\begin{array}{l}21.4 \mathrm{U} \\
13.1 \mathrm{~b}) \\
11.3 \mathrm{U} \\
11.1 \mathrm{U} \\
10.9 \mathrm{U}\end{array}$ & $\begin{array}{l}37.6 U \\
20.3 U \\
19.9 U \\
19.5 U \\
19.1 U\end{array}$ & $\begin{array}{l}20.8(\mathrm{~b}) \\
12.9(\mathrm{~b}) \\
11.8(\mathrm{~b}) \\
12.0 \mathrm{~B} \\
11.7 \mathrm{~B}\end{array}$ & $\begin{array}{l}60.9 \mathrm{U} \\
32.9 \mathrm{U} \\
32.3 \mathrm{U} \\
31.6 \mathrm{U} \\
30.9 \mathrm{U}\end{array}$ \\
\hline
\end{tabular}

(a) U Undetected at or above detection limit.

(b) Ratio of confirmation ion to primary ion is outside of the theoretical ratio of $20 \%$ established for EPA-CLP programs.

(c) B Analyte detected in sample at less than five times value in associated method blank. 


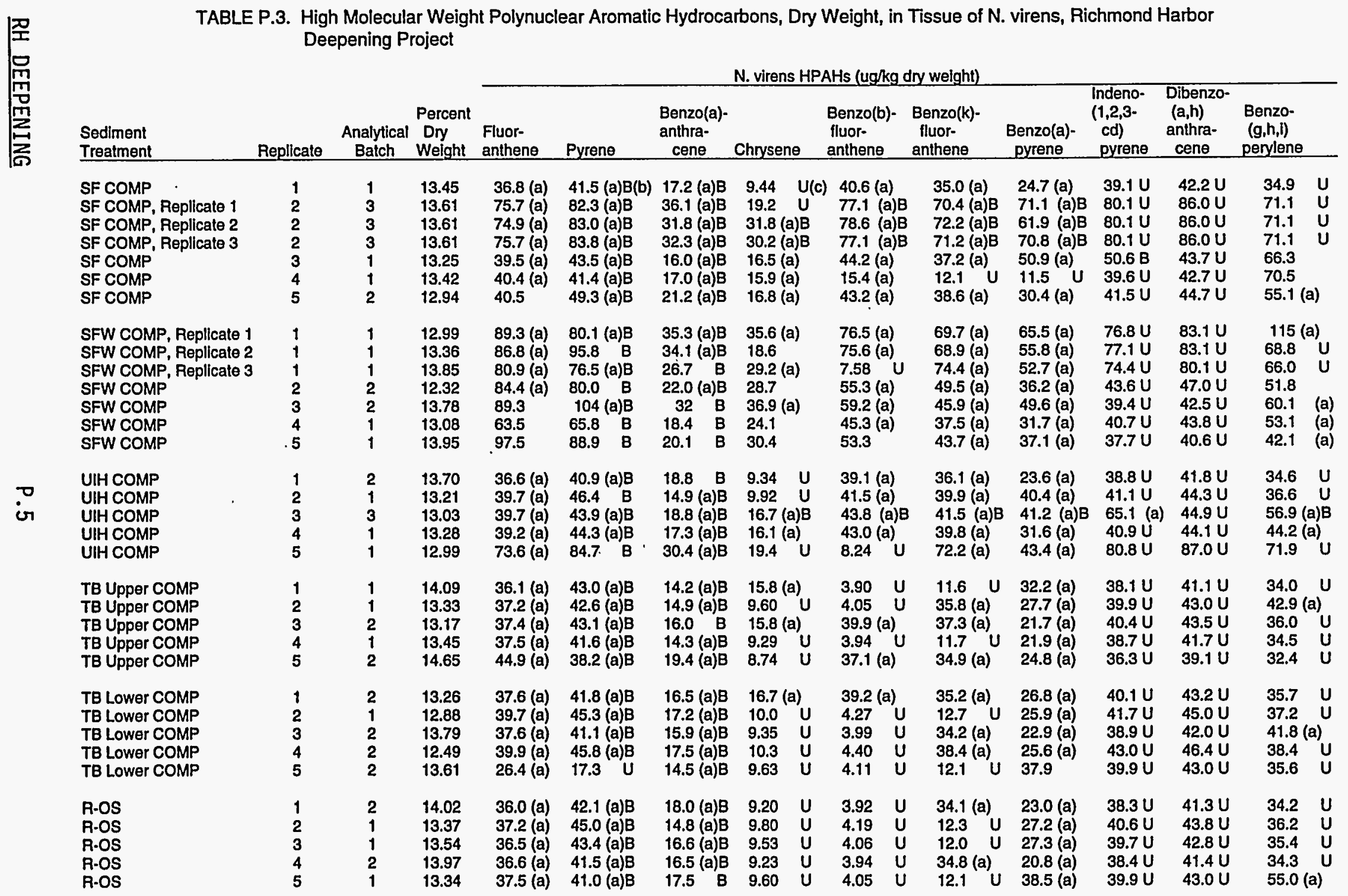




\begin{tabular}{|c|c|c|c|c|c|c|c|c|c|c|c|c|c|c|}
\hline 檉 & \multicolumn{13}{|c|}{ N. virens HPAHs (ug/kg dry weight) } & \\
\hline $\begin{array}{l}\text { Sediment } \\
\text { Treatment }\end{array}$ & Replicate & $\begin{array}{c}\text { Analytical } \\
\text { Batch }\end{array}$ & $\begin{array}{l}\text { Percent } \\
\text { Dry } \\
\text { Weight }\end{array}$ & $\begin{array}{l}\text { Fluor- } \\
\text { anthene }\end{array}$ & Pyrene & $\begin{array}{l}\text { Benzo(a)- } \\
\text { anthra- } \\
\text { cene }\end{array}$ & Chrysene & $\begin{array}{l}\text { Benzo(b)- } \\
\text { fluor- } \\
\text { anthene }\end{array}$ & $\begin{array}{l}\text { Benzo(k)- } \\
\text { fluor- } \\
\text { anthene }\end{array}$ & $\begin{array}{c}\text { Benzo(a)- } \\
\text { pyrene }\end{array}$ & $\begin{array}{l}\text { Indeno- } \\
(1,2,3- \\
\text { cd) } \\
\text { pyrene }\end{array}$ & $\begin{array}{c}\text { Dibenzo- } \\
(\mathrm{a}, \mathrm{h}) \\
\text { anthra- } \\
\text { cene }\end{array}$ & $\begin{array}{c}\text { Benzo- } \\
\text { (g,h,l) } \\
\text { perylene }\end{array}$ & \\
\hline $\begin{array}{l}R \cdot B F \\
R \cdot B F \\
R \cdot B F \\
R \cdot B F \\
R \cdot B F\end{array}$ & $\begin{array}{l}1 \\
2 \\
3 \\
4 \\
5\end{array}$ & $\begin{array}{l}1 \\
2 \\
2 \\
2 \\
2\end{array}$ & $\begin{array}{l}14.51 \\
13.20 \\
13.95 \\
12.57 \\
13.94\end{array}$ & $\begin{array}{l}37.0(a) \\
39.8(a) \\
37.3(a) \\
41.7(a) \\
35.8(a)\end{array}$ & $\begin{array}{l}38.3(\mathrm{a}) \mathrm{B} \\
49.4(\mathrm{a}) \mathrm{B} \\
41.4(\mathrm{a}) \mathrm{B} \\
52.3(\mathrm{a}) \mathrm{B} \\
40.8(\mathrm{a}) \mathrm{B}\end{array}$ & $\begin{array}{l}16.3(a) B \\
17.7 \mathrm{~B} \\
15.4(\mathrm{a}) \mathrm{B} \\
17.6(\mathrm{a}) \mathrm{B} \\
16.9(\mathrm{a}) \mathrm{B}\end{array}$ & $\begin{array}{l}14.7(a) \\
9.92 U \\
15.3(a) \\
10.3 U \\
15.4 \text { (a) }\end{array}$ & $\begin{array}{l}3.72 \cup U \\
4.24 U \\
37.6(a) \\
41.7 \text { (a) } \\
3.95 \cup U\end{array}$ & $\begin{array}{l}11.0 \mathrm{U} \\
12.5 \mathrm{U} \\
34.1 \text { (a) } \\
39.1 \text { (a) } \\
11.7 \mathrm{U}\end{array}$ & $\begin{array}{l}20.8(a) \\
22.4(a) \\
24.3(a) \\
23.5(a) \\
24.1(a)\end{array}$ & $\begin{array}{l}36.3 \\
41.1 \\
38.5 \\
42.7 \\
38.5\end{array}$ & $\begin{array}{ll}U & 39.1 \mathrm{U} \\
U & 44.3 \mathrm{U} \\
U & 41.5 \mathrm{U} \\
U & 46.1 \mathrm{U} \\
U & 41.5 \mathrm{U}\end{array}$ & $\begin{array}{l}32.3 \\
36.7 \\
34.3 \\
38.1 \\
34.4\end{array}$ & $\begin{array}{l}U \\
U \\
U \\
U \\
U\end{array}$ \\
\hline $\begin{array}{l}\text { R-AM COMP } \\
\text { R-AM COMP } \\
\text { R-AM COMP } \\
\text { R-AM COMP } \\
\text { R-AM COMP }\end{array}$ & $\begin{array}{l}1 \\
2 \\
3 \\
4 \\
5\end{array}$ & $\begin{array}{l}1 \\
2 \\
2 \\
1 \\
3\end{array}$ & $\begin{array}{l}13.57 \\
13.43 \\
13.95 \\
13.45 \\
13.75\end{array}$ & $\begin{array}{l}40.8(a) \\
41.6(a) \\
37.1(a) \\
39.9(a) \\
45.0(a)\end{array}$ & $\begin{array}{l}40.7 \text { (a) } \\
41.5 \text { (a)B } \\
41.1 \text { (a)B } \\
42.4 \text { (a)B } \\
40.7 \text { (a)B }\end{array}$ & $\begin{array}{l}16.6 \\
19.1(a) B \\
15.6(a) B \\
15.3(a) B \\
18.8(a) B\end{array}$ & $\begin{array}{l}15.3(a) \\
17.1(a) \\
15.6(a) \\
16.9(a) \\
19.6(a) 8\end{array}$ & $\begin{array}{l}38.2 \text { (a) } \\
40.1 \text { (a) } \\
3.87 \mathrm{U} \\
38.5 \text { (a) } \\
40.2 \text { (a)B }\end{array}$ & $\begin{array}{l}35.2(a) \\
38.3(a) \\
35.0(a) \\
35.1(a) \\
37.2(a) B\end{array}$ & & $\begin{array}{l}38.4 \\
39.6 \\
38.1 \\
39.6 \\
40.7(a\end{array}$ & $\begin{array}{ll}U & 41.3(a) \\
U & 42.7 U^{(a)} \\
U & 41.1 U \\
U & 42.6 U \\
\text { a) } 42.5 U\end{array}$ & $\begin{array}{l}41.6(a) \\
35.3 \\
34.0 \\
35.2 \\
35.2\end{array}$ & $\begin{array}{l}\text { a) } \\
U \\
U \\
U\end{array}$ \\
\hline $\begin{array}{l}\text { C-NV } \\
\text { C-NV, Replicate } 1 \\
\text { C-NV, Replicate } 2 \\
\text { C-NV, Replicate } 3 \\
\text { C-NV } \\
\text { C-NV }\end{array}$ & $\begin{array}{l}1 \\
2 \\
2 \\
2 \\
3 \\
4\end{array}$ & $\begin{array}{l}1 \\
2 \\
2 \\
2 \\
2 \\
3\end{array}$ & $\begin{array}{l}12.66 \\
14.27 \\
14.27 \\
14.27 \\
13.15 \\
13.21\end{array}$ & $\begin{array}{l}47.5(\mathrm{a}) \\
71.5(\mathrm{a}) \\
67.8(\mathrm{a}) \\
70.1 \text { (a) } \\
76.0 \text { (a) } \\
43.4 \text { (a) }\end{array}$ & $\begin{array}{l}44.9 \text { (a)B } \\
80.6 \text { (a)B } \\
79.2 \text { (a)B } \\
79.9 \text { (a)B } B \\
85.9 \text { (a)B } \\
43.1 \text { (a)B } B\end{array}$ & $\begin{array}{l}20.3(\mathrm{a}) \mathrm{B} \\
31.0 \text { (a)B } \\
28.0 \text { (a)B } \\
29.8 \text { (a)B } \\
33.5 \text { (a)B } \\
20.7 \text { (a)B }\end{array}$ & $\begin{array}{l}18.6(a) \\
18.3 \mathrm{U} \\
18.2 \mathrm{U} \\
29.2(\mathrm{a}) \\
19.5 \mathrm{U} \\
15.5 \text { (a)B }\end{array}$ & $\begin{array}{l}43.6(a) \\
7.78 \quad U \\
7.78 \quad U \\
7.64 \quad U \\
8.29 \quad U \\
40.2(a) B\end{array}$ & $\begin{array}{l}37.6(a) \\
66.9(a) \\
23.0 \cup \\
22.6 \quad U \\
24.6 \quad U \\
35.9 \text { (a)B }\end{array}$ & $\begin{array}{l}31.2 \text { (a) } \\
46.7 \text { (a) } \\
41.2 \text { (a) } \\
38.6 \text { (a) } \\
42.7 \text { (a) } \\
39.0 \text { (a)B }\end{array}$ & $\begin{array}{l}42.0 \\
76.4 \\
75.7 \\
74.3 \\
80.6 \\
41.1\end{array}$ & $\begin{array}{ll}U & 45.3 U \\
U & 82.0 U \\
U & 81.3 U \\
U & 80.6 U \\
U & 87.5 U \\
U & 44.3 U\end{array}$ & $\begin{array}{l}45.8(a) \\
86.2 \\
67.5 \\
66.4 \\
72.1 \\
36.6\end{array}$ & $\begin{array}{l}U \\
U \\
U \\
U\end{array}$ \\
\hline $\begin{array}{l}\text { N. virens Background } \\
\text { N. virens Background } \\
\text { N. virens Background } \\
\text { N. virens Background } \\
\text { N. virens Background }\end{array}$ & $\begin{array}{l}1 \\
2 \\
3 \\
4 \\
5\end{array}$ & $\begin{array}{l}3 \\
3 \\
3 \\
3 \\
3\end{array}$ & $\begin{array}{l}14.64 \\
13.30 \\
13.79 \\
14.11 \\
13.99\end{array}$ & $\begin{array}{l}68.0(a) \\
43.3(a) \\
35.1(a) \\
38.2(a) \\
39.5 \text { (a) }\end{array}$ & $\begin{array}{l}87.4(a) B \\
43.7(a) B \\
41.5(a) B \\
40.8(a) B \\
40.2 \text { (a)B }\end{array}$ & $\begin{array}{l}30.2(a) B \\
15.9(a) B \\
19.8 \text { B } \\
18.4(a) B \\
16.3(a) B\end{array}$ & $\begin{array}{l}28.6 \text { (a)B } \\
19.6 U \\
9.50 U \\
15.5(a) B \\
17.9 \text { (a)B }\end{array}$ & $\begin{array}{l}72.4 \text { (a)B } \\
39.5 \text { (a)B } \\
38.3 \text { (a)B } \\
3.97 \underset{U}{U} \\
37.6 \text { (a) } \mathrm{B}\end{array}$ & $\begin{array}{l}69.0 \text { (a) } B \\
38.5 \text { (a) } B \\
36.0 \text { (a) } B \\
34.7 \text { (a) } B \\
34.2 \text { (a) } B\end{array}$ & $\begin{array}{l}50.5 \text { (a)B } \\
25.0 \text { (a)B } \\
31.2 \text { (a)B } \\
30.4 \text { (a)B } \\
34.6 \text { (a)B }\end{array}$ & $\begin{array}{l}74.5 \\
40.0 \\
39.4 \\
38.5 \\
37.6\end{array}$ & $\begin{array}{ll}U & 79.9 U \\
U & 43.1 U \\
U & 42.4 U \\
U & 41.5 U \\
U & 40.5 U\end{array}$ & $\begin{array}{l}66.1 \\
51.7(a) \\
35.1 \\
34.3 \\
33.5\end{array}$ & $\begin{array}{l}U \\
\text { U) } \\
U \\
U \\
U\end{array}$ \\
\hline
\end{tabular}

(a) Ratlo of confirmation lon to primary lon is outside of the theoretical ratio

of $20 \%$ established for EPA-CLP programs.

(b) B Analyte detected in sample at less than five times value in associated method blank.

(c) U Undelected at or above detection limit. 
TABLE P.4. Total Detected Polynuclear Aromatic Hydrocarbons (PAHs), Wet Weight, in Tissue of $\mathrm{N}$. virens, Richmond Harbor Deepening Project

Sediment

Treatment

SF COMP

SF COMP, Replicate 1

SF COMP, Replicate 2

SF COMP, Replicate 3

SF COMP

SF COMP

SF COMP

SFW COMP, Replicate 1

SFW COMP, Replicate 2

SFW COMP, Replicate 3

SFW COMP

SFW COMP

SFW COMP

SFW COMP

UIH COMP

UIH COMP

UIH COMP

UIH COMP

UIH COMP

TB Upper COMP

TB Upper COMP

TB Upper COMP

TB Upper COMP

TB Upper COMP

TB Lower COMP

TB Lower COMP

TB Lower COMP

TB Lower COMP

TB Lower COMP

R-OS

R-OS

R-OS

R-OS

R-OS
Replicate

N. virens PAHs (ug/kg wet weight)

Total Total

Analytical Low Molecular High Molecular Total Batch Weight PAHs Weight PAHs
PAHS

$\begin{array}{ll}2 & 3 \\ 2 & 3 \\ 2 & 3 \\ 3 & 1 \\ 4 & 1 \\ 5 & 2\end{array}$

\section{5}

6

3

10

12

11

11

18

19

16

11

22

20

25

\section{4}

3

5

8

11

5

1

1
2

3

\section{4}

5

1

2

3

4

5

1

2

3

4

5
26

56

59

60

48

27

38

74

58

47

50

66

44

58

27

29

48

37

40

20

27

28

16

29

28

16

27

21

11

21

17

17

21

25
31

62

62

70

60

38

49

92

77

63

61

88

64

83

31

32

53

45

51

25

32

35

24

37

35

22

33

27

13

28

21

21

26

36

RH DEEPENING 
TABLE P.4. (contd)

\begin{tabular}{|c|c|c|c|c|c|}
\hline \multirow[b]{2}{*}{$\begin{array}{l}\text { Sediment } \\
\text { Treatment }\end{array}$} & \multirow[b]{2}{*}{ Replicate } & \multirow[b]{2}{*}{$\begin{array}{c}\text { Analytical } \\
\text { Batch }\end{array}$} & \multicolumn{3}{|c|}{ N. virens PAHs (ug $/ \mathrm{kg}$ wet weight) } \\
\hline & & & $\begin{array}{l}\text { Total } \\
\text { Low Molecular } \\
\text { Weight PAHs }\end{array}$ & $\begin{array}{l}\text { Total } \\
\text { High Molecular } \\
\text { Weight PAHs }\end{array}$ & $\begin{array}{l}\text { Total } \\
\text { PAHs }\end{array}$ \\
\hline$R-B F$ & 1 & 1 & 11 & 18 & 29 \\
\hline R-BF & 2 & 2 & 6 & 17 & 23 \\
\hline R-BF & 3 & 2 & 7 & 29 & 36 \\
\hline R-BF & 4 & 2 & 6 & 27 & 33 \\
\hline $\mathrm{R}-\mathrm{BF}$ & 5 & 2 & 6 & 19 & 25 \\
\hline R-AM COMP & 1 & 1 & 6 & 35 & 41 \\
\hline R-AM COMP. & 2 & 2 & 6 & 30 & 36 \\
\hline R-AM COMP & 3 & 2 & 7 & 24 & 31 \\
\hline R-AM COMP & 4 & 1 & 4 & 29 & 33 \\
\hline R-AM COMP & 5 & 3 & 6 & 38 & 44 \\
\hline C-NV & 1 & 1 & 13 & 37 & 50 \\
\hline C-NV, Replicate 1 & 2 & 2 & 12 & 55 & 67 \\
\hline C-NV, Replicate 2 & 2 & 2 & 13 & 31 & 44 \\
\hline C-NV, Replicate 3 & 2 & 2 & 9 & 35 & 44 \\
\hline C-NV & 3 & 2 & 5 & 31 & 36 \\
\hline C-NV & 4 & 3 & 8 & 31 & 39 \\
\hline N. virens Background & 1 & 3 & 7 & 59 & 66 \\
\hline N. virens Background & 2 & 3 & 7 & 37 & 44 \\
\hline N. virens Background & 3 & 3 & 4 & 28 & 32 \\
\hline N. virens Background & 4 & 3 & 5 & 25 & 30 \\
\hline N. virens Background & 5 & 3 & 4 & 31 & 35 \\
\hline
\end{tabular}


TABLE P.5. Low Molecular Weight Polynuclear Aromatic Hydrocarbons, Wet Weight, in Tissue of N. virens, Richmond Harbor Deepening Project

N. virens LPAHs (ug/kg wet weight)

\begin{tabular}{|c|c|c|c|c|c|c|c|c|}
\hline & & & & & & & & \\
\hline $\begin{array}{l}\text { Sediment } \\
\text { Treatment } \\
\end{array}$ & Replicate & $\begin{array}{c}\text { Analytical } \\
\text { Batch }\end{array}$ & $\begin{array}{l}\text { Naphtha- } \\
\text { lene }\end{array}$ & $\begin{array}{l}\text { Acenaph- } \\
\text { thylene }\end{array}$ & $\begin{array}{l}\text { Acenaph- } \\
\text { thene }\end{array}$ & Fluorene & $\begin{array}{l}\text { Phenan- } \\
\text { threne }\end{array}$ & $\begin{array}{l}\text { Anthra- } \\
\text { cene }\end{array}$ \\
\hline $\begin{array}{l}\text { Target DL(a) } \\
\text { Achieved DL }\end{array}$ & & & $\begin{array}{c}20 \\
0.49-2.03\end{array}$ & $\begin{array}{c}20 \\
0.79-3.29\end{array}$ & $\begin{array}{c}20 \\
0.75-3.13\end{array}$ & $\begin{array}{c}20 \\
1.32-5.51\end{array}$ & $\begin{array}{c}20 \\
0.62-2.59\end{array}$ & $\begin{array}{c}20 \\
2.14-8.91\end{array}$ \\
\hline SF COMP & 1 & 1 & 2.18 & $1.59 \mathrm{U}(\mathrm{a})$ & 1.61 (b) & $2.67 \mathrm{U}$ & 1.68 & $4.32 \mathrm{U}$ \\
\hline SF COMP, Replicate 1 & 2 & 3 & $3.24 B(c)$ & $3.29 \mathrm{U}$ & $3.13 \mathrm{U}$ & $5.51 \mathrm{U}$ & 3.12 (b)B & $8.91 \mathrm{U}$ \\
\hline SF COMP, Replicate 2 & 2 & 3 & $2.56 \mathrm{~B}$ & $3.29 \mathrm{U}$ & $3.13 \mathrm{U}$ & $5.51 \mathrm{U}$ & $2.59 \mathrm{U}$ & $8.91 \mathrm{U}$ \\
\hline SF COMP, Replicate 3 & 2 & 3 & $3.11 \mathrm{~B}$ & $3.29 \mathrm{U}$ & 3.93 & $5.51 \mathrm{U}$ & 3.44 (b)B. & $8.91 \mathrm{U}$ \\
\hline SF COMP & 3 & 1 & 2.98 & $1.63 \mathrm{U}$ & 1.85 (b) & $2.73 \mathrm{U}$ & $2.18(b)$ & 4.81 (b) \\
\hline SF COMP & 4 & 1 & 2.74 & $1.61 \mathrm{U}$ & 2.60 (b) & $2.70 \mathrm{U}$ & $1.33(b)$ & 4.81 \\
\hline SF COMP & 5 & 2 & $2.81 \mathrm{~B}$ & $1.63 \mathrm{U}$ & 1.78 & $2.73 \mathrm{U}$ & 2.00 (b) & 4.52 \\
\hline SFW COMP, Replicate 1 & 1 & 1 & 4.63 (b) & $3.02 \mathrm{U}$ & 9.25 & $5.07 \mathrm{U}$ & 4.01 & $8.20 \mathrm{U}$ \\
\hline SFW COMP, Replicate 2 & 1 & 1 & 4.87 & $3.12 \mathrm{U}$ & 8.97 & $5.23 \mathrm{U}$ & $5.08(b)$ & $8.47 \mathrm{U}$ \\
\hline SFW COMP, Replicate 3 & 1 & 1 & 4.55 & $3.11 \mathrm{U}$ & 7.64 & $5.20 \mathrm{U}$ & 4.02 (b) & $8.42 U$ \\
\hline SFW COMP & 2 & 2 & $1.00 \mathrm{U}$ & $1.63 \mathrm{U}$ & 7.84 & $2.73 \mathrm{U}$ & 3.54 & $4.41 \mathrm{U}$ \\
\hline SFW COMP & 3 & 2 & $4.78 \mathrm{~B}$ & $1.64 \mathrm{U}$ & 8.60 & $2.75 \mathrm{U}$ & 4.05 & 4.98 \\
\hline SFW COMP & 4 & 1 & 3.23 & $1.63(\mathrm{~b})$ & 7.77 & $2.70 \mathrm{U}$ & 2.90 & 4.62 (b) \\
\hline SFW COMP & 5 & 1 & 3.38 & $1.77(b)$ & 10.8 & $2.67 \mathrm{U}$ & 3.93 & 5.06 (b) \\
\hline UIH COMP & 1 & 2 & $2.33 \mathrm{~B}$ & $1.61 \mathrm{U}$ & $1.53 U$ & $2.70 \mathrm{U}$ & 1.99 (b) & $4.37 \mathrm{U}$ \\
\hline UIH COMP & 2 & 1 & 1.92 & $1.64 \mathrm{U}$ & $1.56 \mathrm{U}$ & $2.75 \mathrm{U}$ & $1.53(b)$ & $4.46 \mathrm{U}$ \\
\hline UIH COMP & 3 & 3 & $2.59 \mathrm{~B}$ & $1.64 \mathrm{U}$ & $1.56 \mathrm{U}$ & $2.75 \mathrm{U}$ & 1.93 (b)B & $4.46 \mathrm{U}$ \\
\hline UIH COMP & 4 & 1 & 1.81 & $1.64 U$ & $1.56 \mathrm{U}$ & $2.75 \mathrm{U}$ & $1.82(b)$ & 4.66 (b) \\
\hline UIH COMP & 5 & 1 & 4.70 & $3.17 \mathrm{U}$ & 3.05 (b) & $5.31 \mathrm{U}$ & 3.11 (b) & $8.60 \mathrm{U}$ \\
\hline TB Upper COMP & 1 & 1 & 2.70 & $1.63 \mathrm{U}$ & $1.55 U$ & $2.73 \mathrm{U}$ & 2.01 (b) & $4.41 \mathrm{U}$ \\
\hline TB Upper COMP & 2 & 1 & 2.86 & $1.61 \mathrm{U}$ & $1.53 U$ & $2.70 U$ & 1.84 (b) & $4.37 \mathrm{U}$ \\
\hline TB Upper COMP & 3 & 2 & $2.92 \mathrm{~B}$ & $1.61 \mathrm{U}$ & $2.09(b)$ & $2.70 \mathrm{U}$ & 1.84 (b) & $4.37 \mathrm{U}$ \\
\hline TB Upper COMP & 4 & 1 & 2.31 & $1.58 \mathrm{U}$ & $1.50 \mathrm{U}$ & $2.64 \mathrm{U}$ & 1.45 (b) & 4.29 (b) \\
\hline TB Upper COMP & 5 & 2 & $2.93 \mathrm{~B}$ & $1.78(b)$ & 1.58 (b) & $2.70 \mathrm{U}$ & 1.95 (b) & $4.37 \mathrm{U}$ \\
\hline TB Lower COMP & 1 & 2 & $3.04 \mathrm{~B}$ & $1.61 \mathrm{U}$ & $1.78(b)$ & $2.70 \mathrm{U}$ & 2.07 (b) & $4.37 \cup$ \\
\hline TB Lower COMP & 2 & 1 & 2.12 & $1.63 U$ & $1.58(b)$ & $2.73 U$ & 1.81 (b) & $4.41 \mathrm{U}$ \\
\hline TB Lower COMP & 3 & 2 & $3.00 \mathrm{~B}$ & $1.63 \mathrm{U}$ & 1.69 (b) & $2.73 \mathrm{U}$ & 1.66 (b) & $4.41 \mathrm{U}$ \\
\hline TB Lower COMP & 4 & 2 & $2.28 \mathrm{~B}$ & $1.63 \mathrm{U}$ & 1.91 (b) & $2.73 \mathrm{U}$ & 1.74 & $4.41 \mathrm{U}$ \\
\hline TB Lower COMP & 5 & 2 & $1.86 \mathrm{~B}$ & $1.64 \mathrm{U}$ & $1.56 \mathrm{U}$ & $2.75 \mathrm{U}$ & $1.30 \mathrm{U}$ & $4.46 \mathrm{U}$ \\
\hline R-OS & 1 & 2 & $3.12 \mathrm{~B}$ & $1.63 \mathrm{U}$ & 1.74 (b) & $2.73 \mathrm{U}$ & $1.83(b)$ & $4.41 \mathrm{U}$ \\
\hline R-OS & 2 & 1 & 2.53 & $1.64 \mathrm{U}$ & $1.56 \mathrm{U}$ & $2.75 \mathrm{U}$ & 1.60 (b) & $4.46 \mathrm{U}$ \\
\hline R-OS & 3 & 1 & 2.67 & $1.63 \mathrm{U}$ & $1.55 \mathrm{U}$ & $2.73 \mathrm{U}$ & 1.79 (b) & $5.52 \mathrm{U}$ \\
\hline R-OS & 4 & 2 & $3.00 \mathrm{~B}$ & $1.63 \mathrm{U}$ & $1.55 \mathrm{U}$ & $2.73 U$ & $1.90(b)$ & $4.41 \mathrm{U}$ \\
\hline R-OS & 5 & 1 & 2.26 & $1.61 \mathrm{U}$ & 1.62 & $2.70 \mathrm{U}$ & 2.19 (b) & $4.61(b)$ \\
\hline
\end{tabular}


TABLE P.5. (contd)

\begin{tabular}{|c|c|c|c|c|c|c|c|c|}
\hline \multirow[b]{2}{*}{$\begin{array}{l}\text { Sediment } \\
\text { Treatment }\end{array}$} & \multirow[b]{2}{*}{ Replicate } & \multirow[b]{2}{*}{$\begin{array}{c}\text { Analytical } \\
\text { Batch }\end{array}$} & \multicolumn{6}{|c|}{ N. virens LPAHs (ug/kg wet weight) } \\
\hline & & & $\begin{array}{l}\text { Naphtha- } \\
\text { lene }\end{array}$ & $\begin{array}{l}\text { Acenaph- } \\
\text { thylene }\end{array}$ & $\begin{array}{l}\text { Acenaph- } \\
\text { thene }\end{array}$ & Fluorene & $\begin{array}{l}\text { Phenan- } \\
\text { threne }\end{array}$ & $\begin{array}{l}\text { Anthra- } \\
\text { cene }\end{array}$ \\
\hline R-BF & 1 & 1 & 2.16 & $1.59 \mathrm{U}$ & $1.52 \mathrm{U}$ & $2.67 \mathrm{U}$ & 3.71 (b) & 5.05 (b) \\
\hline R-BF & 2 & 2 & $2.77 \mathrm{~B}$ & $1.64 \mathrm{U}$ & 1.89 (b) & $2.75 \mathrm{U}$ & 1.79 & $4.46 \mathrm{U}$ \\
\hline R-BF & 3 & 2 & $3: 00 \mathrm{~B}$ & $1.63 \mathrm{U}$ & 2.26 & $2.73 \mathrm{U}$ & 1.77 (b) & $4.41 \mathrm{U}$ \\
\hline R-BF & 4 & 2 & $2.88 \mathrm{~B}$ & $1.63 \mathrm{U}$ & $1.67(\mathrm{~b})$ & $2.73 \mathrm{U}$ & $1.79(\mathrm{~b})$ & $4.41 \mathrm{U}$ \\
\hline $\mathrm{R}-\mathrm{BF}$ & 5 & 2 & $2.60 \mathrm{~B}$ & $1.63 \mathrm{U}$ & $2.03(b)$ & $2.73 \mathrm{U}$ & $1.66(b)$ & $4.41 \mathrm{U}$ \\
\hline R-AM COMP & 1 & 1 & 2.15 (b) & $1.58 \mathrm{U}$ & $1.83(\mathrm{~b})$ & $2.64 \mathrm{U}$ & $1.98(b)$ & $4.28 \mathrm{U}$ \\
\hline R-AM COMP & 2 & 2 & $2.54 \mathrm{~B}$ & $1.61 \mathrm{U}$ & 1.65 & $2.70 \mathrm{U}$ & $2.04(\mathrm{~b})$ & $4.37 \mathrm{U}$ \\
\hline R-AM COMP & 3 & 2 & $3.25 \mathrm{~B}$ & $1.61 \mathrm{U}$ & 1.74 (b) & $2.70 \mathrm{U}$ & 1.88 & $4.37 \mathrm{U}$ \\
\hline R-AM COMP & 4 & 1 & $1.88(b)$ & $1.61 \mathrm{U}$ & $1.53 \mathrm{U}$ & $2.70 \mathrm{U}$ & $1.79(b)$ & $4.37 \mathrm{U}$ \\
\hline R-AM COMP & 5 & 3 & $2.05 \mathrm{~B}$ & $1.64 \mathrm{U}$ & $1.95(b)$ & $2.75 \mathrm{U}$ & 2.34 (b)B & $4.46 \mathrm{U}$ \\
\hline C-NV & 1 & 1 & 2.46 (b) & $1.70(\mathrm{~b})$ & 2.02 & $2.70 \mathrm{U}$ & $2.36(b)$ & $4.46(b)$ \\
\hline C-NV, Replicate 1 & 2 & 2 & $4.21 \mathrm{~B}$ & $3.29 \mathrm{U}$ & 5.04 & $5.51 \mathrm{U}$ & 3.04 & $8.91 \mathrm{U}$ \\
\hline C-NV, Replicate 2 & 2 & 2 & $5.78 \mathrm{~B}$ & $3.63(b)$ & $3.11 \mathrm{U}$ & $5.48 \mathrm{U}$ & $3.63(b)$ & $8.87 \mathrm{U}$ \\
\hline C-NV, Replicate 3 & 2 & 2 & $5.69 \mathrm{~B}$ & $3.22 \mathrm{U}$ & $3.07 \mathrm{U}$ & $5.40 \mathrm{U}$ & 3.40 (b) & $8.74 U$ \\
\hline C-NV & 3 & 2 & $4.56 \mathrm{~B}$ & $3.22 \mathrm{U}$ & $3.07 \mathrm{U}$ & $5.40 \mathrm{U}$ & $2.54 \mathrm{U}$ & $8.74 \mathrm{U}$ \\
\hline C-NV & 4 & 3 & $2.04 \mathrm{~B}$ & 1.94 (b) & 1.97 & $2.75 \mathrm{U}$ & 1.99 (b)B & $4.46 \mathrm{U}$ \\
\hline N. virens Background & 1 & 3 & $3.53 \mathrm{~B}$ & $3.29 \mathrm{U}$ & $3.13 \mathrm{U}$ & $5.51 \mathrm{U}$ & 3.04 (b)B & $8.91 U$ \\
\hline N. virens Background & 2 & 3 & $1.54 \mathrm{~B}$ & 1.77 (b) & 1.74 (b) & $2.70 \mathrm{U}$ & 1.71 (b) B & $4.37 U$ \\
\hline N. virens Background & 3 & 3 & $1.90 \mathrm{~B}$ & $1.64 U$ & $1.56 \mathrm{U}$ & $2.75 \mathrm{U}$ & 1.63 (b)B & $4.46 U$ \\
\hline N. virens Background & 4 & 3 & $1.90 \mathrm{~B}$ & $1.66(b)$ & $1.56 \mathrm{U}$ & $2.75 \mathrm{U}$ & $1.69 \mathrm{~B}$ & $4.46 U$ \\
\hline N. virens Background & 5 & 3 & $2.09 \mathrm{~B}$ & $1.59 \mathrm{U}$ & $1.52 \mathrm{U}$ & $2.67 \mathrm{U}$ & $1.64 \mathrm{~B}$ & $4.32 U$ \\
\hline
\end{tabular}

(a) $U$ Undetected at or above detection limit.

(b) Ratio of confirmation ion to primary ion is outside of the theoretical ratio of $20 \%$ established for EPA-CLP programs.

(c) B Analyte detected in sample is less than five times value in associated method blank.

RH DEEPENING 


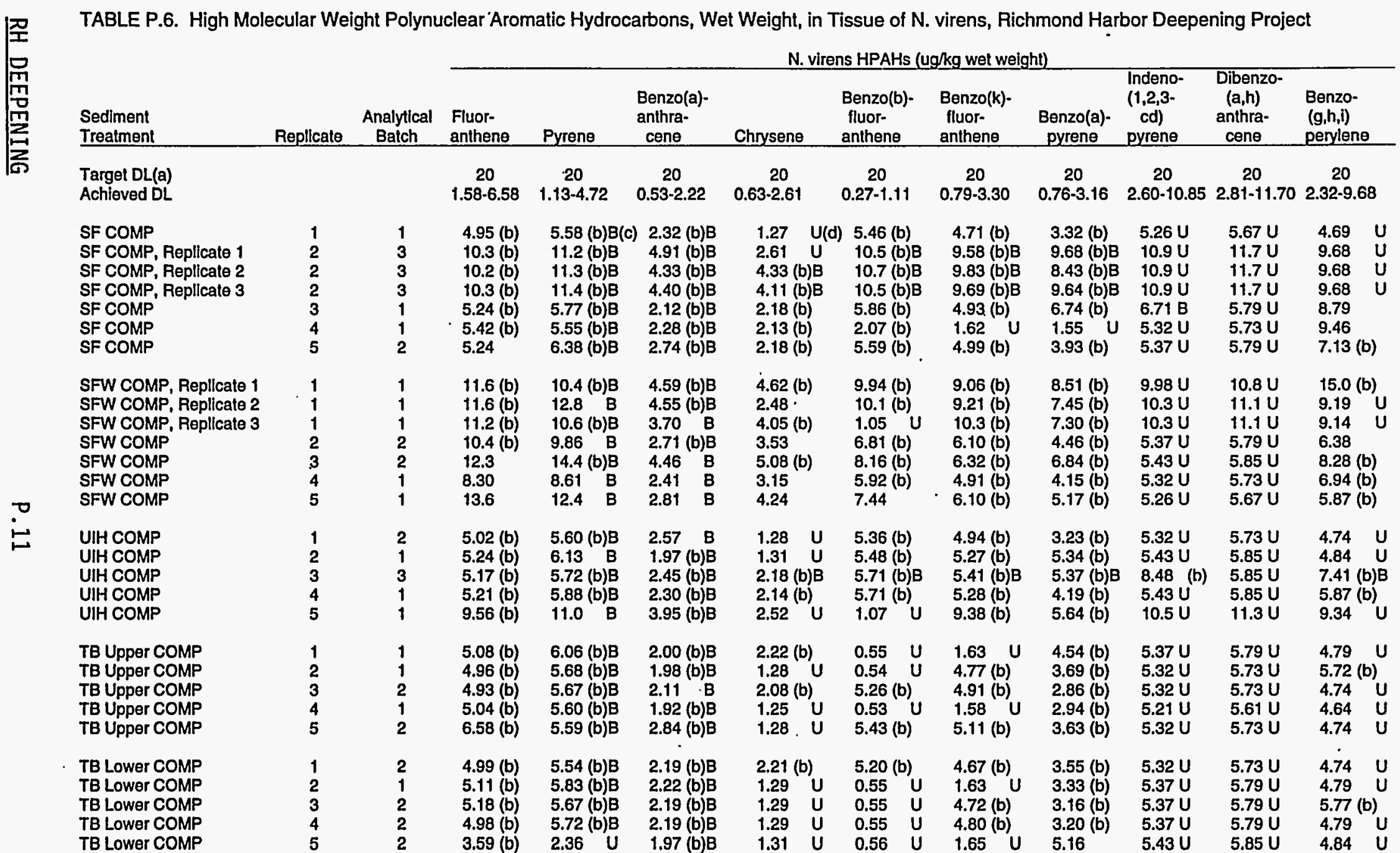


TABLE P.6. (contd)

\begin{tabular}{|c|c|c|c|c|c|c|c|c|c|c|c|c|c|}
\hline \multirow[b]{2}{*}{$\begin{array}{l}\text { Sediment } \\
\text { Treatment }\end{array}$} & \multirow[b]{2}{*}{ Replicate } & \multirow[b]{2}{*}{$\begin{array}{c}\text { Analytical } \\
\text { Balch }\end{array}$} & \multicolumn{11}{|c|}{ N. virens HPAHs (ug/kg wet weight) } \\
\hline & & & $\begin{array}{l}\text { Fluor- } \\
\text { anthene }\end{array}$ & Pyrene & $\begin{array}{l}\text { Benzo(a)- } \\
\text { anthra- } \\
\text { cene }\end{array}$ & Chrysene & $\begin{array}{l}\text { Benzo(b)- } \\
\text { fluor- } \\
\text { anthene }\end{array}$ & $\begin{array}{l}\text { Benzo(k)- } \\
\text { fluor- } \\
\text { anthene }\end{array}$ & $\begin{array}{l}\text { Benzo(a)- } \\
\text { pyrene }\end{array}$ & $\begin{array}{l}\text { Indeno- } \\
(1,2,3- \\
\text { cd) } \\
\text { pyrene } \\
\end{array}$ & $\begin{array}{c}\text { Dibenzo- } \\
(\mathrm{a}, \mathrm{h}) \\
\text { anthra. } \\
\text { cene }\end{array}$ & $\begin{array}{l}\text { Benzo- } \\
\text { (g,h,i) } \\
\text { perylene }\end{array}$ & \\
\hline $\begin{array}{l}\text { R-OS } \\
\text { R-OS } \\
\text { R-OS } \\
\text { R-OS } \\
\text { R-OS }\end{array}$ & $\begin{array}{l}1 \\
2 \\
3 \\
4 \\
5\end{array}$ & $\begin{array}{l}2 \\
1 \\
1 \\
2 \\
1\end{array}$ & $\begin{array}{l}5.05(\mathrm{~b}) \\
4.98(\mathrm{~b}) \\
4.94(\mathrm{~b}) \\
5.12(\mathrm{~b}) \\
5.00(\mathrm{~b})\end{array}$ & $\begin{array}{l}5.90 \text { (b)B } \\
6.02 \text { (b)B } \\
5.88 \text { (b) } B \\
5.80 \text { (b) B } \\
5.47 \text { (b)B }\end{array}$ & $\begin{array}{l}2.52 \text { (b)B } \\
1.98 \text { (b)B } \\
2.25 \text { (b)B } \\
2.31 \text { (b)B } \\
2.33 \quad B\end{array}$ & $\begin{array}{ll}1.29 & U \\
1.31 & U \\
1.29 & U \\
1.29 & U \\
1.28 & U\end{array}$ & $\begin{array}{ll}0.55 & 4 \\
0.56 & L \\
0.55 & L \\
0.55 & L \\
0.54 & L\end{array}$ & $\begin{array}{l}4.78(b) \\
1.65 U \\
1.63 U \\
4.86(b) \\
1.62 U\end{array}$ & $\begin{array}{l}3.22(\mathrm{~b}) \\
3.64(\mathrm{~b}) \\
3.69(\mathrm{~b}) \\
2.90(\mathrm{~b}) \\
5.13(\mathrm{~b})\end{array}$ & $\begin{array}{l}5.37 U \\
5.43 U \\
5.37 U \\
5.37 U \\
5.32 U\end{array}$ & $\begin{array}{l}5.79 U \\
5.85 U \\
5.79 U \\
5.79 U \\
5.73 U\end{array}$ & $\begin{array}{l}4.79 \\
4.84 \\
4.79 \\
4.79 \\
7.34 \text { (b) }\end{array}$ & $\begin{array}{l}U \\
U \\
U \\
U \\
\text { b) }\end{array}$ \\
\hline $\begin{array}{l}R \cdot B F \\
R-B F \\
R-B F \\
R-B F \\
R-B F\end{array}$ & $\begin{array}{l}1 \\
2 \\
3 \\
4 \\
5\end{array}$ & $\begin{array}{l}1 \\
2 \\
2 \\
2 \\
2\end{array}$ & $\begin{array}{l}5.37(\mathrm{~b}) \\
5.25(\mathrm{~b}) \\
5.21(\mathrm{~b}) \\
5.24(\mathrm{~b}) \\
4.99(\mathrm{~b})\end{array}$ & $\begin{array}{l}5.56 \text { (b)B } \\
6.52 \text { (b)B } \\
5.78 \text { (b)B } \\
6.57 \text { (b)B } \\
5.69 \text { (b)B }\end{array}$ & $\begin{array}{l}2.36 \text { (b)B } \\
2.34 \quad \mathrm{~B} \\
2.15 \text { (b)B } \\
2.21 \text { (b)B } \\
2.36 \text { (b)B }\end{array}$ & $\begin{array}{l}2.14 \text { (b) } \\
1.31 U \\
2.14 \text { (b) } \\
1.29 U \\
2.14 \text { (b) }\end{array}$ & $\begin{array}{l}0.54 \quad \\
0.56 \quad \text { L } \\
5.24 \text { (b) } \\
5.24 \text { (b) } \\
0.55\end{array}$ & $\begin{array}{l}1.60 U \\
1.65 U \\
4.76(\mathrm{~b}) \\
4.92(\mathrm{~b}) \\
1.63 U\end{array}$ & $\begin{array}{l}3.02(\mathrm{~b}) \\
2.96(\mathrm{~b}) \\
3.39(\mathrm{~b}) \\
2.95(\mathrm{~b}) \\
3.36(\mathrm{~b})\end{array}$ & $\begin{array}{l}5.26 U \\
5.43 U \\
5.37 U \\
5.37 U \\
5.37 U\end{array}$ & $\begin{array}{l}5.67 U \\
5.85 U \\
5.79 U \\
5.79 U \\
5.79 U\end{array}$ & $\begin{array}{l}4.69 \\
4.84 \\
4.79 \\
4.79 \\
4.79\end{array}$ & $\begin{array}{l}U \\
U \\
U \\
U \\
U\end{array}$ \\
\hline $\begin{array}{l}\text { R-AM COMP } \\
\text { R-AM COMP } \\
\text { R-AM COMP } \\
\text { R-AM COMP } \\
\text { R-AM COMP }\end{array}$ & $\begin{array}{l}1 \\
2 \\
3 \\
4 \\
5\end{array}$ & $\begin{array}{l}1 \\
2 \\
2 \\
1 \\
3\end{array}$ & $\begin{array}{l}5.54(\mathrm{~b}) \\
5.59(\mathrm{~b}) \\
5.18(\mathrm{~b}) \\
5.37(\mathrm{~b}) \\
6.19(\mathrm{~b})\end{array}$ & $\begin{array}{l}5.52 \text { (b) } \\
5.57 \text { (b)B } \\
5.74 \text { (b)B } \\
5.70 \text { (b)B } \\
5.59 \text { (b)B }\end{array}$ & $\begin{array}{l}2.25 \text { (b) } \\
2.56 \text { (b)B } \\
2.17 \text { (b)B } \\
2.06 \text { (b)B } \\
2.58 \text { (b)B }\end{array}$ & $\begin{array}{l}2.08 \text { (b) } \\
2.29 \text { (b) } \\
2.18 \text { (b) } \\
2.27 \text { (b) } \\
2.69 \text { (b)B }\end{array}$ & $\begin{array}{l}5.18(b) \\
5.38 \text { (b) } \\
0.54 \quad \text { L } \\
5.18 \text { (b) } \\
5.53(b)\end{array}$ & $\begin{array}{l}4.77(\mathrm{~b}) \\
5.14(\mathrm{~b}) \\
4.88(\mathrm{~b}) \\
4.72(\mathrm{~b}) \\
5.12(\mathrm{~b}) \mathrm{B}\end{array}$ & $\begin{array}{l}3.76(\mathrm{~b}) \\
3.43(\mathrm{~b}) \\
3.36(\mathrm{~b}) \\
3.33(\mathrm{~b}) \\
5.02(\mathrm{~b}) \mathrm{B}\end{array}$ & $\begin{array}{l}5.21 U \\
5.32 U \\
5.32 U \\
5.32 U \\
5.60 \text { (b) }\end{array}$ & $\begin{array}{l}5.61 U \\
5.73 U \\
5.73 U \\
5.73 U \\
5.85 U\end{array}$ & $\begin{array}{l}5.64 \text { (b) } \\
4.74 \\
4.74 \\
4.74 \\
4.84\end{array}$ & $\begin{array}{l}U \\
U \\
U \\
U\end{array}$ \\
\hline $\begin{array}{l}\text { C-NV } \\
\text { C-NV, Replicate } 1 \\
\text { C-NV, Repllcate } 2 \\
\text { C-NV, Replicate } 3 \\
\text { C-NV } \\
\text { C-NV }\end{array}$ & $\begin{array}{l}1 \\
2 \\
2 \\
2 \\
3 \\
4\end{array}$ & $\begin{array}{l}1 \\
2 \\
2 \\
2 \\
2 \\
3\end{array}$ & $\begin{array}{l}6.01(\mathrm{~b}) \\
10.2(\mathrm{~b}) \\
9.67(\mathrm{~b}) \\
10.0(\mathrm{~b}) \\
10.0(\mathrm{~b}) \\
5.73(\mathrm{~b})\end{array}$ & $\begin{array}{l}5.68 \text { (b)B } \\
11.5(\mathrm{~b}) \mathrm{B} \\
11.3(\mathrm{~b}) \mathrm{B} \\
11.4(\mathrm{~b}) \mathrm{B} \\
11.3(\mathrm{~b}) \mathrm{B} \\
5.70 \text { (b)B }\end{array}$ & $\begin{array}{l}2.57 \text { (b)B } \\
4.42 \text { (b)B } \\
3.99 \text { (b)B } \\
4.25 \text { (b)B } \\
4.41 \text { (b)B } \\
2.74 \text { (b)B }\end{array}$ & $\begin{array}{l}2.35 \text { (b) } \\
2.61 U \\
2.60 U \\
4.17 \text { (b) } \\
2.56 U \\
2.05 \text { (b)B }\end{array}$ & $\begin{array}{l}5.52 \text { (b) } \\
1.11 \\
1.11 \quad \\
1.09 \quad \\
1.09 \quad \mathrm{~L} \\
5.31(\mathrm{~b}) \mathrm{E}\end{array}$ & $\begin{array}{l}4.76(\mathrm{~b}) \\
9.55(\mathrm{~b}) \\
3.28 U \\
3.23 U \\
3.23 \quad U \\
4.74(\mathrm{~b}) \mathrm{B}\end{array}$ & $\begin{array}{l}3.95(\mathrm{~b}) \\
6.67(\mathrm{~b}) \\
5.88(\mathrm{~b}) \\
5.51(\mathrm{~b}) \\
5.62(\mathrm{~b}) \\
5.15(\mathrm{~b}) \mathrm{B}\end{array}$ & $\begin{array}{l}5.32 U \\
10.9 U \\
10.8 U \\
10.6 U \\
10.6 U \\
5.43 U\end{array}$ & $\begin{array}{l}5.73 U \\
11.7 U \\
11.6 U \\
11.5 U \\
11.5 U \\
5.85 U\end{array}$ & $\begin{array}{l}5.80(b) \\
12.3 \\
9.63 \\
9.48 \\
9.48 \\
4.84\end{array}$ & $\begin{array}{l}U \\
U \\
U \\
U\end{array}$ \\
\hline $\begin{array}{l}\text { N. virens Background } \\
\text { N. virens Background } \\
\text { N. virens Background } \\
\text { N. virens Background } \\
\text { N. virens Background }\end{array}$ & $\begin{array}{l}1 \\
2 \\
3 \\
4 \\
5\end{array}$ & $\begin{array}{l}3 \\
3 \\
3 \\
3 \\
3\end{array}$ & $\begin{array}{l}9.95(\mathrm{~b}) \\
5.76(\mathrm{~b}) \\
4.84(\mathrm{~b}) \\
5.39 \mathrm{bb} \\
5.53(\mathrm{~b})\end{array}$ & $\begin{array}{l}12.8 \text { (b)B } \\
5.81(\mathrm{~b}) \mathrm{B} \\
5.72(\mathrm{~b}) \mathrm{B} \\
5.75(\mathrm{~b}) \mathrm{B} \\
5.62(\mathrm{~b}) \mathrm{B}\end{array}$ & $\begin{array}{l}4.42(\mathrm{~b}) \mathrm{B} \\
2.11 \text { (b)B } \\
2.73 \mathrm{~B} \\
2.59 \text { (b)B } \\
2.28 \text { (b)B }\end{array}$ & $\begin{array}{l}4.18 \text { (b)B } \\
2.6 t \quad B \\
1.31 \mathrm{U} \\
2.18 \text { (b)B } \\
2.50 \text { (b) B }\end{array}$ & $\begin{array}{l}10.6 \text { (b) } \\
5.25 \text { (b)E } \\
5.28 \text { (b) } \\
0.56 \text { L } \\
5.26 \text { (b)E }\end{array}$ & $\begin{array}{l}10.1 \text { (b) } \mathrm{B} \\
5.12 \text { (b) } \mathrm{B} \\
4.96 \text { (b) } \mathrm{B} \\
4.90 \text { (b) } \mathrm{B} \\
4.79 \text { (b) } \mathrm{B}\end{array}$ & $\begin{array}{l}7.40 \text { (b) B } \\
3.33 \text { (b)B } \\
4.30 \text { (b)B } \\
4.29 \text { (b)B } \\
4.84 \text { (b)B }\end{array}$ & $\begin{array}{ll} & 10.9 U \\
& 5.32 U \\
5.43 U \\
3.43 U \\
3 \\
5.26 U\end{array}$ & $\begin{array}{l}11.7 U \\
5.73 U \\
5.85 U \\
5.85 U \\
5.67 U\end{array}$ & $\begin{array}{l}9.68 \\
6.88(b) \\
4.84 \\
4.84 \\
4.69\end{array}$ & $\begin{array}{r}U \\
\text { b) } \\
U \\
U \\
U\end{array}$ \\
\hline
\end{tabular}

(a) DL Detection limit.

(b) Ratio of confirmation lon to primary lon is outside of the theoretlcal ratio of $20 \%$ established for EPA.CLP programs.

(c) B Analyte detected in sample is less than five times value in associated method blank.

(d) U Undetected at or above detection limit. 
TABLE P.7. Quality Control Data for Low Molecular Weight Polynuclear Aromatic Hydrocarbons, Wet Weight, in Tissue of N. virens, Richmond Harbor Deepening Project

\begin{tabular}{|c|c|c|c|c|c|c|c|c|}
\hline \multirow[b]{2}{*}{$\begin{array}{l}\text { Sediment } \\
\text { Treatment }\end{array}$} & \multirow[b]{2}{*}{ Replicate } & \multirow[b]{2}{*}{$\begin{array}{c}\text { Analytical } \\
\text { Batch }\end{array}$} & \multicolumn{6}{|c|}{ N. virens (ug/kg wet weight) } \\
\hline & & & $\begin{array}{l}\text { Naphtha- } \\
\text { lene }\end{array}$ & $\begin{array}{l}\text { Acenaph- } \\
\text { thylene }\end{array}$ & $\begin{array}{l}\text { Acenaph- } \\
\text { thene }\end{array}$ & Fluorene & $\begin{array}{l}\text { Phenan- } \\
\text { threne }\end{array}$ & $\begin{array}{l}\text { Anthra- } \\
\text { cene }\end{array}$ \\
\hline \multicolumn{9}{|l|}{ Method Blanks } \\
\hline $\begin{array}{l}\text { Blank-1 } \\
\text { Blank-1 } \\
\text { Blank-1 }\end{array}$ & & $\begin{array}{l}1 \\
2 \\
3\end{array}$ & $\begin{array}{l}0.99 \mathrm{U}(\mathrm{a}) \\
1.19 \text { (b) } \\
1.25 \text { (b) }\end{array}$ & $\begin{array}{l}1.61 \mathrm{U} \\
1.63 \mathrm{U} \\
1.73 \mathrm{U}\end{array}$ & $\begin{array}{l}1.53 \mathrm{U} \\
1.55 \mathrm{U} \\
1.64 \mathrm{U}\end{array}$ & $\begin{array}{l}2.70 \mathrm{U} \\
2.73 \mathrm{U} \\
2.89 \mathrm{U}\end{array}$ & $\begin{array}{l}1.27 \mathrm{U} \\
1.28 \mathrm{U} \\
1.62 \text { (b) }\end{array}$ & $\begin{array}{l}4.37 \mathrm{U} \\
4.41 \mathrm{U} \\
4.68 \mathrm{U}\end{array}$ \\
\hline \multicolumn{9}{|l|}{ Matrix Spikes } \\
\hline $\begin{array}{l}\text { UIH COMP } \\
\text { UIH COMP, MS } \\
\text { Concentration Recovered } \\
\text { Amount Spiked } \\
\text { Percent Recovery }\end{array}$ & $\begin{array}{l}5 \\
5 .\end{array}$ & $\begin{array}{l}1 \\
1\end{array}$ & $\begin{array}{l}4.70 \\
91.4 \\
86.7 \\
89.6 \\
97 \%\end{array}$ & $\begin{array}{l}3.17 \mathrm{U} \\
84.2 \\
84.2 \\
89.6 \\
94 \%\end{array}$ & $\begin{array}{l}3.05 \text { (b) } \\
89.8 \\
86.8 \\
89.6 \\
97 \%\end{array}$ & $\begin{array}{l}5.31 \mathrm{U} \\
83.5 \\
83.5 \\
89.6 \\
93 \%\end{array}$ & $\begin{array}{l}3.11(b) \\
84.5 \\
81.4 \\
89.6 \\
91 \%\end{array}$ & $\begin{array}{l}8.60 \mathrm{U} \\
84.8 \\
84.8 \\
89.6 \\
95 \%\end{array}$ \\
\hline $\begin{array}{l}\text { C-NV } \\
\text { C-NV, MS } \\
\text { Concentration Recovered } \\
\text { Amount Spiked } \\
\text { Percent Recovery }\end{array}$ & $\begin{array}{l}3 \\
3\end{array}$ & $\begin{array}{l}2 \\
2\end{array}$ & $\begin{array}{l}4.56 \mathrm{~B}(\mathrm{c}) \\
100 \\
95: 4 \\
96.9 \\
98 \%\end{array}$ & $\begin{array}{l}3.22 \mathrm{U} \\
92.9 \\
92.9 \\
96.9 \\
96 \%\end{array}$ & $\begin{array}{r}3.07 \text { U } \\
99.9 \\
99.9 \\
96.9 \\
103 \%\end{array}$ & $\begin{array}{l}5.40 \mathrm{U} \\
90.3 \\
90.3 \\
96.9 \\
93 \%\end{array}$ & $\begin{array}{l}2.54 \\
95.0 \\
95.0 \\
96.9 \\
98 \%\end{array}$ & $\begin{array}{l}8.74 \mathrm{U} \\
95.3 \\
95.3 \\
96.9 \\
98 \%\end{array}$ \\
\hline $\begin{array}{l}\text { N. virens Background } \\
\text { N. virens Background, MS } \\
\text { Concentration Recovered } \\
\text { Amount Spiked } \\
\text { Percent Recovery }\end{array}$ & $\begin{array}{l}1 \\
1\end{array}$ & $\begin{array}{l}3 \\
3\end{array}$ & $\begin{array}{l}3.53 \mathrm{~B} \\
96.2 \\
92.7 \\
96.9 \\
96 \%\end{array}$ & $\begin{array}{l}3.29 \mathrm{U} \\
89.7 \\
89.7 \\
96.9 \\
93 \%\end{array}$ & $\begin{array}{c}3.13 U \\
96.7 \\
96.7 \\
96.9 \\
100 \%\end{array}$ & $\begin{array}{l}5.51 \mathrm{U} \\
88.0 \\
88.0 \\
96.9 \\
91 \%\end{array}$ & $\begin{array}{l}3.04 \text { (b)B } \\
92.3 \\
89.3 \\
96.9 \\
92 \%\end{array}$ & $\begin{array}{l}8.91 \mathrm{U} \\
95.5 \\
95.5 \\
96.9 \\
99 \%\end{array}$ \\
\hline
\end{tabular}

Standard Reference Material .

Certified SRM not available for PAHs.

Analytical Replicates

\begin{tabular}{|c|c|c|c|c|c|c|c|c|}
\hline $\begin{array}{l}\text { SFW COMP, Replicate } 1 \\
\text { SFW COMP, Replicate } 2 \\
\text { SFW COMP, Replicate } 3\end{array}$ & $\begin{array}{l}1 \\
1 \\
1\end{array}$ & $\begin{array}{l}1 \\
1 \\
1\end{array}$ & $\begin{array}{ll}4.63 & \text { (b) } \\
4.87 & \\
4.55 & \end{array}$ & $\begin{array}{l}3.02 \mathrm{U} \\
3.12 \mathrm{U} \\
3.11 \mathrm{U}\end{array}$ & $\begin{array}{l}9.25 \\
8.97 \\
7.64\end{array}$ & $\begin{array}{l}5.07 \mathrm{U} \\
5.23 \mathrm{U} \\
5.20 \mathrm{U}\end{array}$ & $\begin{array}{l}4.01 \\
5.08(b) \\
4.02(b)\end{array}$ & $\begin{array}{l}8.20 \mathrm{U} \\
8.47 \mathrm{U} \\
8.42 \mathrm{U}\end{array}$ \\
\hline RSD & & & $4 \%$ & NA (d) & $10 \%$ & NA & $14 \%$ & NA \\
\hline $\begin{array}{l}\text { C-NV, Replicate } 1 \\
\text { C-NV, Replicate } 2 \\
\text { C-NV, Replicate } 3\end{array}$ & $\begin{array}{l}2 \\
2 \\
2\end{array}$ & $\begin{array}{l}2 \\
2 \\
2\end{array}$ & $\begin{array}{l}4.21 \mathrm{~B} \\
5.78 \mathrm{~B} \\
5.69 \mathrm{~B}\end{array}$ & $\begin{array}{l}3.29 \mathrm{U} \\
3.63 \text { (b) } \\
3.22 \mathrm{U}^{-}\end{array}$ & $\begin{array}{l}5.04 \\
3.11 \mathrm{U} \\
3.07 \mathrm{U}\end{array}$ & $\begin{array}{l}5.51 \mathrm{U} \\
5.48 \mathrm{U} \\
5.40 \mathrm{U}\end{array}$ & $\begin{array}{l}3.04 \\
3.63(b) \\
3.40(b)\end{array}$ & $\begin{array}{l}8.91 U \\
8.87 U \\
8.74 U\end{array}$ \\
\hline RSD & & & $17 \%$ & NA & NA & NA & $9 \%$ & NA \\
\hline $\begin{array}{l}\text { SF COMP, Replicate } 1 \\
\text { SF COMP, Replicate } 2 \\
\text { SF COMP, Replicate } 3\end{array}$ & $\begin{array}{l}2 \\
2 \\
2\end{array}$ & $\begin{array}{l}3 \\
3 \\
3\end{array}$ & $\begin{array}{l}3.24 \mathrm{~B} \\
2.56 \mathrm{~B} \\
3.11 \mathrm{~B}\end{array}$ & $\begin{array}{l}3.29 U \\
3.29 U \\
3.29 U\end{array}$ & $\begin{array}{l}3.13 \mathrm{U} \\
3.13 \mathrm{U} \\
3.93\end{array}$ & $\begin{array}{l}5.51 \mathrm{U} \\
5.51 \mathrm{U} \\
5.51 \mathrm{U}\end{array}$ & $\begin{array}{l}3.12(b) B \\
2.59 \mathrm{U} \\
3.44 \text { (b)B }\end{array}$ & $\begin{array}{l}8.91 \mathrm{U} \\
8.91 \mathrm{U} \\
8.91 \mathrm{U}\end{array}$ \\
\hline RSD & & & $12 \%$ & NA & NA & NA & NA & NA \\
\hline
\end{tabular}

(a) U Undetected at or above detection limit.

(b) Ratio of confirmation ion to primary ion is outside of the theoretical ratio of $20 \%$ established for EPA-CLP programs.

(c) B Analyte detected in sample is less than five times value in associated method blank.

(d) NA Not applicable.

RH DEEPENING 
TABLE P.8. Quality Control Data for High Molecular Weight Polynuclear Aromatic Hydrocarbons, Wet Weight, in Tissue of N. virens, Richmond Harbor Deepening Project

\begin{tabular}{|c|c|c|c|c|c|c|c|c|c|c|c|}
\hline \multirow[b]{2}{*}{$\begin{array}{l}\text { Sediment } \\
\text { Treatment }\end{array}$} & \multirow[b]{2}{*}{ Replicate } & \multicolumn{10}{|c|}{ N. virens (ug/kg wet weight) } \\
\hline & & $\begin{array}{l}\text { Fluor- } \\
\text { anthene }\end{array}$ & Pyrene & $\begin{array}{l}\text { Benzo(a)- } \\
\text { anthra- } \\
\text { cene }\end{array}$ & Chrysene & $\begin{array}{l}\text { Benzo(b)- } \\
\text { fluor- } \\
\text { anthene }\end{array}$ & $\begin{array}{l}\text { Benzo(k)- } \\
\text { fluor- } \\
\text { anthene }\end{array}$ & $\begin{array}{l}\text { Benzo(a)- } \\
\text { pyreno }\end{array}$ & $\begin{array}{l}\text { Indeno- } \\
(1,2,3- \\
\text { cd) } \\
\text { pyrene }\end{array}$ & $\begin{array}{l}\text { Dlbenzo- } \\
\text { (a,h) } \\
\text { anthra- } \\
\text { cene }\end{array}$ & $\begin{array}{l}\text { Benzo- } \\
\text { (g,h,i) } \\
\text { perylene }\end{array}$ \\
\hline & & & & & & & & & & & \\
\hline $\begin{array}{l}\text { 3lank-1 } \\
\text { Slank-1 } \\
\text { lank-1 }\end{array}$ & $\begin{array}{l}1 \\
2 \\
3\end{array}$ & $\begin{array}{l}3.22 U(a) \\
3.26 U \\
3.45 U\end{array}$ & $\begin{array}{l}5.66(\mathrm{~b}) \\
5.66(\mathrm{~b}) \\
6.24(\mathrm{~b})\end{array}$ & $\begin{array}{l}1.96(b) \\
1.96(b) \\
2.30\end{array}$ & $\begin{array}{l}1.28 U \\
1.29 U \\
2.34(b)\end{array}$ & $\begin{array}{l}0.54 U \\
0.55 \\
5.66 \text { (b) }\end{array}$ & $\begin{array}{l}1.62 \\
1.63 \\
5.42(b)\end{array}$ & $\begin{array}{l}1.55 \\
1.57 \\
2.95 \text { (b) }\end{array}$ & $\begin{array}{l}\mathbf{5 . 3 2}(\mathrm{b}) \\
\mathbf{5 . 3 7} \\
5.70\end{array}$ & $\begin{array}{l}5.73 U \\
U \\
5.79 U \\
U \\
6.14 U\end{array}$ & $\begin{array}{l}4.74 \\
4.79 \\
6.21 \text { (b) }\end{array}$ \\
\hline
\end{tabular}

Matrix Spikes

UIH COMP

UIH COMP, MS

Concentration Recovered

Amount Spiked

Percent Recovery

C C-NV

C-NV, MS
Concentration Recovered
Amount Spiked

Amount Spiked

Percent Recovery

N. virens Background

N. virens Background, MS

Concentration Recovered

Amount Spiked

Percent Recovery

\section{Standard Reference Material}

Certified SRM not available for PAHs. 


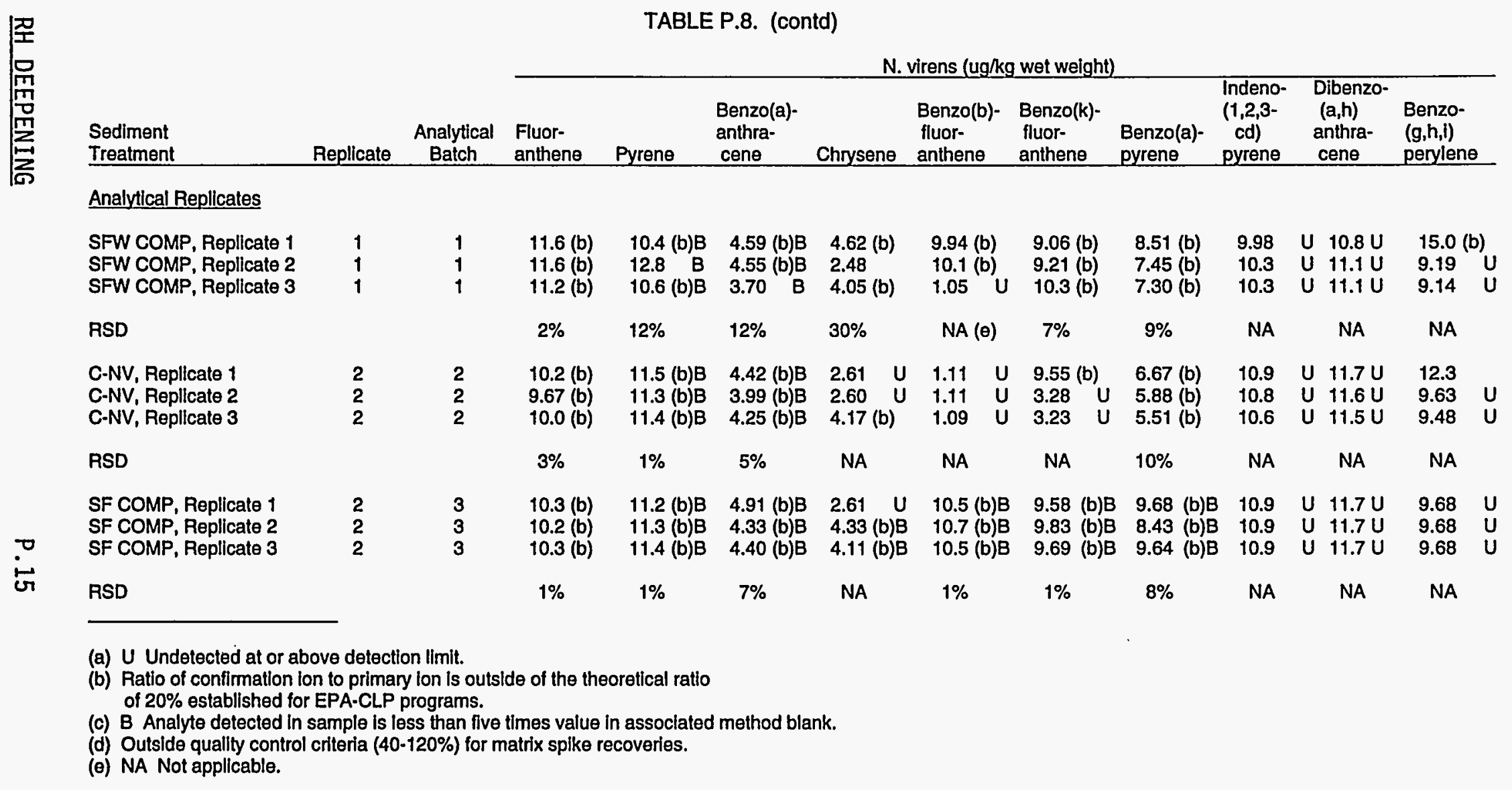


TABLE P.9. Phthalate Esters, Dry Weight, in Tissue of N. virens, Richmond Harbor Deepening Project

\begin{tabular}{|c|c|c|c|c|c|c|c|c|c|}
\hline \multirow[b]{2}{*}{$\begin{array}{l}\text { Sediment } \\
\text { Treatment }\end{array}$} & \multirow[b]{2}{*}{ Replicate } & \multirow[b]{2}{*}{$\begin{array}{c}\text { Analytical } \\
\text { Batch }\end{array}$} & \multirow[b]{2}{*}{$\begin{array}{l}\text { Percent } \\
\text { Dry } \\
\text { Weight }\end{array}$} & \multicolumn{6}{|c|}{ N. virens phthalate esters ( $\mathrm{ug} / \mathrm{kg} \mathrm{dry}$ weight) } \\
\hline & & & & $\begin{array}{l}\text { Dimethyl } \\
\text { Phthalate }\end{array}$ & $\begin{array}{l}\text { Diethyl } \\
\text { Phthalate }\end{array}$ & $\begin{array}{l}\text { Di-n-butyl } \\
\text { Phthalate }\end{array}$ & $\begin{array}{l}\text { Butyl } \\
\text { benzyl } \\
\text { Phthalate }\end{array}$ & $\begin{array}{c}\text { Bis } \\
\text { (2-ethylhexyl) } \\
\text { Phthalate }\end{array}$ & $\begin{array}{l}\text { Di-n-octyl } \\
\text { Phthalate }\end{array}$ \\
\hline $\begin{array}{l}\text { SF COMP } \\
\text { SF COMP, Replicate } 1 \\
\text { SF COMP, Replicate } 2 \\
\text { SF COMP, Replicate } 3 \\
\text { SF COMP } \\
\text { SF COMP } \\
\text { SF COMP }\end{array}$ & $\begin{array}{l}1 \\
2 \\
2 \\
2 \\
3 \\
4 \\
5\end{array}$ & $\begin{array}{l}1 \\
3 \\
3 \\
3 \\
1 \\
1 \\
2\end{array}$ & $\begin{array}{l}13.45 \\
13.61 \\
13.61 \\
13.61 \\
13.25 \\
13.42 \\
12.94\end{array}$ & $\begin{array}{l}288 U(a) \\
588 U \\
588 U \\
588 U \\
299 U \\
292 U \\
306 U\end{array}$ & $\begin{array}{l}288 U \\
588 U \\
588 U \\
588 U \\
299 U \\
292 U \\
321\end{array}$ & $\begin{array}{l}288 U \\
588 U \\
588 U \\
588 U \\
299 U \\
292 U \\
306 U\end{array}$ & $\begin{array}{l}288 U \\
604 \\
588 U \\
588 U \\
299 U \\
1006 \\
529\end{array}$ & $\begin{array}{c}351 \\
1010 \\
697 \\
1270 \\
299 \mathrm{U} \\
564 \\
1140\end{array}$ & $\begin{array}{l}288 U \\
588 U \\
588 U \\
588 U \\
299 U \\
292 U \\
306 U\end{array}$ \\
\hline $\begin{array}{l}\text { SFW COMP, Replicate } 1 \\
\text { SFW COMP, Replicate } 2 \\
\text { SFW COMP, Replicate } 3 \\
\text { SFW COMP } \\
\text { SFW COMP } \\
\text { SFW COMP } \\
\text { SFW COMP }\end{array}$ & $\begin{array}{l}1 \\
1 \\
1 \\
2 \\
3 \\
4 \\
5\end{array}$ & $\begin{array}{l}1 \\
1 \\
1 \\
2 \\
2 \\
1 \\
1\end{array}$ & $\begin{array}{l}12.99 \\
13.36 \\
13.85 \\
12.32 \\
13.78 \\
13.08 \\
13.95\end{array}$ & $\begin{array}{l}567 U \\
569 U \\
546 U \\
321 U \\
290 U \\
300 U \\
278 U\end{array}$ & $\begin{array}{l}567 U \\
569 U \\
546 U \\
321 U \\
290 U \\
300 U \\
278 U\end{array}$ & $\begin{array}{l}567 U \\
569 U \\
546 U \\
321 U \\
290 U \\
300 U \\
278 U\end{array}$ & $\begin{array}{l}567 U \\
569 U \\
546 U \\
537 \\
366 \\
300 U \\
278 U\end{array}$ & $\begin{array}{c}567 \mathrm{U} \\
569 \mathrm{U} \\
546 \mathrm{U} \\
1240 \\
784 \\
757 \\
478\end{array}$ & $\begin{array}{l}567 U \\
569 U \\
546 U \\
321 U \\
290 U \\
300 U \\
278 U\end{array}$ \\
\hline $\begin{array}{l}\text { UIH COMP } \\
\text { UIH COMP } \\
\text { UIH COMP } \\
\text { UIH COMP } \\
\text { UIH COMP }\end{array}$ & $\begin{array}{l}1 \\
2 \\
3 \\
4 \\
5\end{array}$ & $\begin{array}{l}2 \\
1 \\
3 \\
1 \\
1\end{array}$ & $\begin{array}{l}13.70 \\
13.21 \\
13.03 \\
13.28 \\
12.99\end{array}$ & $\begin{array}{l}286 U \\
303 U \\
307 U \\
301 U \\
594 U\end{array}$ & $\begin{array}{l}286 U \\
303 U \\
307 U \\
301 U \\
594 U\end{array}$ & $\begin{array}{l}286 U \\
303 U \\
307 U \\
301 U \\
594 U\end{array}$ & $\begin{array}{l}286 U \\
303 U \\
646 \\
301 U \\
594 U\end{array}$ & $\begin{array}{r}1160 \\
481 \\
829 \\
499 \\
665\end{array}$ & $\begin{array}{l}286 U \\
303 U \\
307 U \\
301 U \\
594 U\end{array}$ \\
\hline $\begin{array}{l}\text { TB Upper COMP } \\
\text { TB Upper COMP } \\
\text { TB Upper COMP } \\
\text { TB Upper COMP } \\
\text { TB Upper COMP }\end{array}$ & $\begin{array}{l}1 \\
2 \\
3 \\
4 \\
5\end{array}$ & $\begin{array}{l}1 \\
1 \\
2 \\
1 \\
2\end{array}$ & $\begin{array}{l}14.09 \\
13.33 \\
13.17 \\
13.45 \\
14.65\end{array}$ & $\begin{array}{l}281 U \\
294 U \\
298 U \\
286 U \\
268 U\end{array}$ & $\begin{array}{l}281 U \\
294 U \\
298 U \\
286 U \\
268 U\end{array}$ & $\begin{array}{l}281 U \\
294 U \\
298 U \\
286 U \\
268 U\end{array}$ & $\begin{array}{l}281 U \\
294 U \\
323 \\
286 U \\
268 U\end{array}$ & $\begin{array}{r}1120 \\
335 \\
964 \\
391 \\
846\end{array}$ & $\begin{array}{l}281 U \\
294 U \\
298 U \\
1180 \\
268 \mathrm{U}\end{array}$ \\
\hline $\begin{array}{l}\text { TB Lower COMP } \\
\text { TB Lower COMP } \\
\text { TB Lower COMP } \\
\text { TB Lower COMP } \\
\text { TB Lower COMP }\end{array}$ & $\begin{array}{l}1 \\
2 \\
3 \\
4 \\
5\end{array}$ & $\begin{array}{l}2 \\
1 \\
2 \\
2 \\
2\end{array}$ & $\begin{array}{l}13.26 \\
12.88 \\
13.79 \\
12.49 \\
13.61\end{array}$ & $\begin{array}{l}296 U \\
307 U \\
287 U \\
317 U \\
294 U\end{array}$ & $\begin{array}{l}296 U \\
307 U \\
287 U \\
317 U \\
294 U\end{array}$ & $\begin{array}{l}296 U \\
307 U \\
287 U \\
317 U \\
294 U\end{array}$ & $\begin{array}{l}296 U \\
307 U \\
287 U \\
378 \\
294 U\end{array}$ & $\begin{array}{r}958 \\
521 \\
631 \\
1170 \\
629\end{array}$ & $\begin{array}{l}296 U \\
307 U \\
287 U \\
317 U \\
294 U\end{array}$ \\
\hline $\begin{array}{l}\text { R-OS } \\
\text { R-OS } \\
\text { R-OS } \\
\text { R-OS } \\
\text { R-OS }\end{array}$ & $\begin{array}{l}1 \\
2 \\
3 \\
4 \\
5\end{array}$ & $\begin{array}{l}2 \\
1 \\
1 \\
2 \\
1\end{array}$ & $\begin{array}{l}14.02 \\
13.37 \\
13.54 \\
13.97 \\
13.34\end{array}$ & $\begin{array}{l}282 U \\
299 U \\
292 U \\
283 U \\
294 U\end{array}$ & $\begin{array}{l}282 U \\
299 U \\
292 U \\
283 U \\
294 U\end{array}$ & $\begin{array}{l}282 U \\
299 U \\
292 U \\
283 U \\
294 U\end{array}$ & $\begin{array}{l}282 U \\
299 U \\
292 U \\
407 \\
294 U\end{array}$ & $\begin{array}{l}785 \\
441 \\
303 \\
945 \\
294 \mathrm{U}\end{array}$ & $\begin{array}{l}282 U \\
299 U \\
292 U \\
283 U \\
294 U\end{array}$ \\
\hline $\begin{array}{l}R-B F \\
R-B F \\
R-B F \\
R-B F \\
R-B F\end{array}$ & $\begin{array}{l}1 \\
2 \\
3 \\
4 \\
5\end{array}$ & $\begin{array}{l}1 \\
2 \\
2 \\
2 \\
2\end{array}$ & $\begin{array}{l}14.51 \\
13.20 \\
13.95 \\
12.57 \\
13.94\end{array}$ & $\begin{array}{l}267 U \\
303 U \\
284 U \\
315 U \\
284 U\end{array}$ & $\begin{array}{l}267 U \\
303 U \\
284 U \\
315 U \\
284 U\end{array}$ & $\begin{array}{l}267 U \\
303 U \\
284 U \\
315 U \\
284 U\end{array}$ & $\begin{array}{l}267 U \\
303 U \\
366 \\
315 U \\
284 U\end{array}$ & $\begin{array}{l}307 \\
717 \\
652 \\
649 \\
421\end{array}$ & $\begin{array}{l}267 U \\
303 U \\
284 U \\
315 U \\
284 U\end{array}$ \\
\hline $\begin{array}{l}\text { R-AM COMP } \\
\text { R-AM COMP } \\
\text { R-AM COMP } \\
\text { R-AM COMP } \\
\text { R-AM COMP }\end{array}$ & $\begin{array}{l}1 \\
2 \\
3 \\
4 \\
5\end{array}$ & $\begin{array}{l}1 \\
2 \\
2 \\
1 \\
3\end{array}$ & $\begin{array}{l}13.57 \\
13.43 \\
13.95 \\
13.45 \\
13.75\end{array}$ & $\begin{array}{l}283 U \\
292 U \\
281 U \\
291 U \\
291 U\end{array}$ & $\begin{array}{l}283 U \\
292 U \\
281 U \\
291 U \\
291 U\end{array}$ & $\begin{array}{l}283 U \\
292 U \\
281 U \\
291 U \\
291 U\end{array}$ & $\begin{array}{l}283 U \\
396 \\
281 U \\
291 U \\
401\end{array}$ & $\begin{array}{r}588 \\
1360 \\
669 \\
345 \\
640\end{array}$ & $\begin{array}{l}283 U \\
292 U \\
281 U \\
291 U \\
291 U\end{array}$ \\
\hline
\end{tabular}

RH DEEPENING 
TABLE P.9. (contd)

\begin{tabular}{|c|c|c|c|c|c|c|c|c|c|}
\hline \multirow[b]{2}{*}{$\begin{array}{l}\text { Sediment } \\
\text { Treatment }\end{array}$} & \multirow[b]{2}{*}{ Replicate } & \multirow[b]{2}{*}{$\begin{array}{c}\text { Analytical } \\
\text { Batch }\end{array}$} & \multirow[b]{2}{*}{$\begin{array}{c}\text { Percent } \\
\text { Dry } \\
\text { Weight }\end{array}$} & \multicolumn{6}{|c|}{ N. virens phthalate esters (ug/kg dry weight) } \\
\hline & & & & $\begin{array}{l}\text { Dimethyl } \\
\text { Phthalate }\end{array}$ & $\begin{array}{l}\text { Diethyl } \\
\text { Phthalate }\end{array}$ & $\begin{array}{l}\text { Di-n-butyl } \\
\text { Phthalate }\end{array}$ & $\begin{array}{l}\text { Butyl } \\
\text { benzyl } \\
\text { Phthalate }\end{array}$ & $\begin{array}{c}\text { Bis } \\
\text { (2-ethylhexyl) } \\
\text { Phthalate }\end{array}$ & $\begin{array}{l}\text { Di-n-octy } \\
\text { Phthalate }\end{array}$ \\
\hline $\begin{array}{l}\text { C-NV } \\
\text { C-NV, Replicate } 1 \\
\text { C-NV, Replicate } 2 \\
\text { C-NV, Replicate } 3 \\
\text { C-NV } \\
\text { C-NV }\end{array}$ & $\begin{array}{l}1 \\
2 \\
2 \\
2 \\
3 \\
4\end{array}$ & $\begin{array}{l}1 \\
2 \\
2 \\
2 \\
2 \\
3\end{array}$ & $\begin{array}{l}12.66 \\
14.27 \\
14.27 \\
14.27 \\
13.15 \\
13.21\end{array}$ & $\begin{array}{l}310 U \\
561 \mathrm{U} \\
558 \mathrm{U} \\
549 \mathrm{U} \\
596 \mathrm{U} \\
303 \mathrm{U}\end{array}$ & $\begin{array}{l}310 U \\
561 U \\
558 U \\
549 U \\
596 U \\
303 U\end{array}$ & $\begin{array}{l}310 U \\
561 U \\
558 U \\
549 U \\
596 U \\
303 U\end{array}$ & $\begin{array}{l}310 U \\
799 \\
558 \mathrm{U} \\
549 \mathrm{U} \\
596 \mathrm{U} \\
303 \mathrm{U}\end{array}$ & $\begin{array}{r}932 \\
1230 \\
1140 \\
1030 \\
1050 \\
969\end{array}$ & $\begin{array}{l}310 U \\
561 U \\
558 U \\
549 U \\
596 U \\
303 U\end{array}$ \\
\hline $\begin{array}{l}\text { N. virens Background } \\
\text { N. virens Background } \\
\text { N. virens Background } \\
\text { N. virens Background } \\
\text { N. virens Background }\end{array}$ & $\begin{array}{l}1 \\
2 \\
3 \\
4 \\
5\end{array}$ & $\begin{array}{l}3 \\
3 \\
3 \\
3 \\
3\end{array}$ & $\begin{array}{l}14.64 \\
13.30 \\
13.79 \\
14.11 \\
13.99\end{array}$ & $\begin{array}{l}546 U \\
295 U \\
290 U \\
283 U \\
277 U\end{array}$ & $\begin{array}{l}546 U \\
295 U \\
290 U \\
312 \\
277 U\end{array}$ & $\begin{array}{l}546 U \\
295 U \\
290 U \\
283 U \\
277 U\end{array}$ & $\begin{array}{l}546 U \\
374 \\
351 \\
283 \cup \\
277 U\end{array}$ & $\begin{array}{r}1150 \\
409 \\
661 \\
692 \\
552\end{array}$ & $\begin{array}{l}546 U \\
295 U \\
290 U \\
283 U \\
277 U\end{array}$ \\
\hline
\end{tabular}

(a) U Undetected at or above detection limit. 
TABLE P.10. Phthalate Esters, Wet Weight, in Tissue of N. virens, Richmond Harbor Deepening Project

\begin{tabular}{|c|c|c|c|c|c|c|c|c|}
\hline \multirow[b]{2}{*}{$\begin{array}{l}\text { Sediment } \\
\text { Treatment }\end{array}$} & \multirow[b]{2}{*}{ Replicate } & \multirow[b]{2}{*}{$\begin{array}{c}\text { Analytical } \\
\text { Batch }\end{array}$} & \multicolumn{6}{|c|}{ N. virens phthalate esters (ug/kg wel weight) } \\
\hline & & & $\begin{array}{l}\text { Dimethyl } \\
\text { Phthalate }\end{array}$ & $\begin{array}{l}\text { Diethyl } \\
\text { Phthalate }\end{array}$ & $\begin{array}{l}\text { Di-n-butyl } \\
\text { Phthalate } \\
\end{array}$ & $\begin{array}{c}\text { Butyl } \\
\text { benzyl } \\
\text { Phthalate }\end{array}$ & $\begin{array}{c}\text { Bis } \\
\text { (2-ethylhexyl) } \\
\text { Phthalate }\end{array}$ & $\begin{array}{l}\text { Di-n-octyl } \\
\text { Phthalate }\end{array}$ \\
\hline $\begin{array}{l}\text { Target DL(a) } \\
\text { Achieved DL }\end{array}$ & & & $\begin{array}{c}20 \\
19.2-80.0(b)\end{array}$ & $\begin{array}{c}20 \\
19.2-80.0(b)\end{array}$ & $\begin{array}{c}20 \\
19.2-80.0 \text { (b) }\end{array}$ & $\begin{array}{c}20 \\
19.2-80.0(b)\end{array}$ & $\begin{array}{c}20 \\
19.2-80.0(b)\end{array}$ & $\begin{array}{c}20 \\
19.2-80.0(b)\end{array}$ \\
\hline $\begin{array}{l}\text { SF COMP } \\
\text { SF COMP, Replicate } 1 \\
\text { SF COMP, Replicate } 2 \\
\text { SF COMP, Replicate } 3 \\
\text { SF COMP } \\
\text { SF COMP } \\
\text { SF COMP }\end{array}$ & $\begin{array}{l}1 \\
2 \\
2 \\
2 \\
3 \\
4 \\
5\end{array}$ & $\begin{array}{l}1 \\
3 \\
3 \\
3 \\
1 \\
1 \\
2\end{array}$ & $\begin{array}{l}38.8 \mathrm{U}(\mathrm{c}) \\
80.0 \mathrm{U} \\
80.0 \mathrm{U} \\
80.0 \mathrm{U} \\
39.6 \mathrm{U} \\
39.2 \mathrm{U} \\
39.6 \mathrm{U}\end{array}$ & $\begin{array}{l}38.8 \mathrm{U} \\
80.0 \mathrm{U} \\
80.0 \mathrm{U} \\
80.0 \mathrm{U} \\
39.6 \mathrm{U} \\
39.2 \mathrm{U} \\
41.5\end{array}$ & $\begin{array}{l}38.8 U \\
80.0 \mathrm{U} \\
80.0 \mathrm{U} \\
80.0 \mathrm{U} \\
39.6 \mathrm{U} \\
39.2 \mathrm{U} \\
39.6 \mathrm{U}\end{array}$ & $\begin{array}{l}38.8 \mathrm{U} \\
82.2 \\
80.0 \mathrm{U} \\
80.0 \mathrm{U} \\
39.6 \mathrm{U} \\
135 \\
68.5\end{array}$ & $\begin{array}{c}47.2 \\
137 \\
94.9 \\
173 \\
39.6 \mathrm{U} \\
75.7 \\
148\end{array}$ & $\begin{array}{l}38.8 \mathrm{U} \\
80.0 \mathrm{U} \\
80.0 \mathrm{U} \\
80.0 \mathrm{U} \\
39.6 \mathrm{U} \\
39.2 \mathrm{U} \\
39.6 \mathrm{U}\end{array}$ \\
\hline $\begin{array}{l}\text { SFW COMP, Replicate } 1 \\
\text { SFW COMP, Replicate } 2 \\
\text { SFW COMP, Replicate } 3 \\
\text { SFW COMP } \\
\text { SFW COMP } \\
\text { SFW COMP } \\
\text { SFW COMP }\end{array}$ & $\begin{array}{l}1 \\
1 \\
1 \\
2 \\
3 \\
4 \\
5\end{array}$ & $\begin{array}{l}1 \\
1 \\
1 \\
2 \\
2 \\
1 \\
1\end{array}$ & $\begin{array}{l}73.6 \mathrm{U} \\
76.0 \mathrm{U} \\
75.6 \mathrm{U} \\
39.6 \mathrm{U} \\
40.0 \mathrm{U} \\
39.2 \mathrm{U} \\
38.8 \mathrm{U}\end{array}$ & $\begin{array}{l}73.6 \mathrm{U} \\
76.0 \mathrm{U} \\
75.6 \mathrm{U} \\
39.6 \mathrm{U} \\
40.0 \mathrm{U} \\
39.2 \mathrm{U} \\
38.8 \mathrm{U}\end{array}$ & $\begin{array}{l}73.6 \mathrm{U} \\
76.0 \mathrm{U} \\
75.6 \mathrm{U} \\
39.6 \mathrm{U} \\
40.0 \mathrm{U} \\
39.2 \mathrm{U} \\
38.8 \mathrm{U}\end{array}$ & $\begin{array}{l}73.6 \mathrm{U} \\
76.0 \mathrm{U} \\
75.6 \mathrm{U} \\
66.1 \\
50.4 \\
39.2 \mathrm{U} \\
38.8 \mathrm{U}\end{array}$ & $\begin{array}{c}73.6 \mathrm{U} \\
76.0 \mathrm{U} \\
75.6 \mathrm{U} \\
153 \\
108 \\
99.0 \\
66.7\end{array}$ & $\begin{array}{l}73.6 U \\
76.0 U \\
75.6 U \\
39.6 U \\
40.0 U \\
39.2 U \\
38.8 U\end{array}$ \\
\hline $\begin{array}{l}\text { UIH COMP } \\
\text { UIH COMP } \\
\text { UIH COMP } \\
\text { UIH COMP } \\
\text { UIH COMP }\end{array}$ & $\begin{array}{l}1 \\
2 \\
3 \\
4 \\
5\end{array}$ & $\begin{array}{l}2 \\
1 \\
3 \\
1 \\
1\end{array}$ & $\begin{array}{l}39.2 \mathrm{U} \\
40.0 \mathrm{U} \\
40.0 \mathrm{U} \\
40.0 \mathrm{U} \\
77.2 \mathrm{U}\end{array}$ & $\begin{array}{l}39.2 U \\
40.0 U \\
40.0 U \\
40.0 U \\
77.2 U\end{array}$ & $\begin{array}{l}39.2 \mathrm{U} \\
40.0 \mathrm{U} \\
40.0 \mathrm{U} \\
40.0 \mathrm{U} \\
77.2 \mathrm{U}\end{array}$ & $\begin{array}{l}39.2 \mathrm{U} \\
40.0 \mathrm{U} \\
84.2 \\
40.0 \mathrm{U} \\
77.2 \mathrm{U}\end{array}$ & $\begin{array}{r}159 \\
63.5 \\
108 \\
66.3 \\
86.4\end{array}$ & $\begin{array}{l}39.2 U \\
40.0 U \\
40.0 U \\
40.0 U \\
77.2 U\end{array}$ \\
\hline $\begin{array}{l}\text { TB Upper COMP } \\
\text { TB Upper COMP } \\
\text { TB Upper COMP } \\
\text { TB Upper COMP } \\
\text { TB Upper COMP }\end{array}$ & $\begin{array}{l}1 \\
2 \\
3 \\
4 \\
5\end{array}$ & $\begin{array}{l}1 \\
1 \\
2 \\
1 \\
2\end{array}$ & $\begin{array}{l}39.6 U \\
39.2 \mathrm{U} \\
39.2 \mathrm{U} \\
38.4 \mathrm{U} \\
39.2 \mathrm{U}\end{array}$ & $\begin{array}{l}39.6 U \\
39.2 U \\
39.2 U \\
38.4 U \\
39.2 U\end{array}$ & $\begin{array}{l}39.6 \mathrm{U} \\
39.2 \mathrm{U} \\
39.2 \mathrm{U} \\
38.4 \mathrm{U} \\
39.2 \mathrm{U}\end{array}$ & $\begin{array}{l}39.6 U \\
39.2 U \\
42.6 \\
38.4 U \\
39.2 U\end{array}$ & $\begin{array}{r}158 \\
44.6 \\
127 \\
52.6 \\
124\end{array}$ & $\begin{array}{l}39.6 \mathrm{U} \\
39.2 \mathrm{U} \\
39.2 \mathrm{U} \\
159 \\
39.2 \mathrm{U}\end{array}$ \\
\hline $\begin{array}{l}\text { TB Lower COMP } \\
\text { TB Lower COMP } \\
\text { TB Lower COMP } \\
\text { TB Lower COMP } \\
\text { TB Lower COMP }\end{array}$ & $\begin{array}{l}1 \\
2 \\
3 \\
4 \\
5\end{array}$ & $\begin{array}{l}2 \\
1 \\
2 \\
2 \\
2\end{array}$ & $\begin{array}{l}39.2 \mathrm{U} \\
39.6 \mathrm{U} \\
39.6 \mathrm{U} \\
39.6 \mathrm{U} \\
40.0 \mathrm{U}\end{array}$ & $\begin{array}{l}39.2 \mathrm{U} \\
39.6 \mathrm{U} \\
39.6 \mathrm{U} \\
39.6 \mathrm{U} \\
40.0 \mathrm{U}\end{array}$ & $\begin{array}{l}39.2 \mathrm{U} \\
39.6 \mathrm{U} \\
39.6 \mathrm{U} \\
39.6 \mathrm{U} \\
40.0 \mathrm{U}\end{array}$ & $\begin{array}{l}39.2 \mathrm{U} \\
39.6 \mathrm{U} \\
39.6 \mathrm{U} \\
47.2 \\
40.0 \mathrm{U}\end{array}$ & $\begin{array}{r}127 \\
67.1 \\
87.0 \\
146 \\
85.6\end{array}$ & $\begin{array}{l}39.2 U \\
39.6 U \\
39.6 U \\
39.6 U \\
40.0 U\end{array}$ \\
\hline $\begin{array}{l}\text { R-OS } \\
\text { R-OS } \\
\text { R-OS } \\
\text { R-OS } \\
\text { R-OS }\end{array}$ & $\begin{array}{l}1 \\
2 \\
3 \\
4 \\
5\end{array}$ & $\begin{array}{l}2 \\
1 \\
1 \\
2 \\
1\end{array}$ & $\begin{array}{l}39.6 \mathrm{U} \\
40.0 \mathrm{U} \\
39.6 \mathrm{U} \\
39.6 \mathrm{U} \\
39.2 \mathrm{U}\end{array}$ & $\begin{array}{l}39.6 U \\
40.0 \mathrm{U} \\
39.6 \mathrm{U} \\
39.6 \mathrm{U} \\
39.2 \mathrm{U}\end{array}$ & $\begin{array}{l}39.6 \mathrm{U} \\
40.0 \mathrm{U} \\
39.6 \mathrm{U} \\
39.6 \mathrm{U} \\
39.2 \mathrm{U}\end{array}$ & $\begin{array}{l}39.6 \mathrm{U} \\
40.0 \mathrm{U} \\
39.6 \mathrm{U} \\
56.8 \\
39.2 \mathrm{U}\end{array}$ & $\begin{array}{c}110 \\
58.9 \\
41.0 \\
132 \\
39.2 U\end{array}$ & $\begin{array}{l}39.6 U \\
40.0 U \\
39.6 U \\
39.6 U \\
39.2 U\end{array}$ \\
\hline $\begin{array}{l}\text { R-BF } \\
\text { R-BF } \\
\text { R-BF } \\
\text { R-BF } \\
\text { R-BF }\end{array}$ & $\begin{array}{l}1 \\
2 \\
3 \\
4 \\
5\end{array}$ & $\begin{array}{l}1 \\
2 \\
2 \\
2 \\
2\end{array}$ & $\begin{array}{l}38.8 \mathrm{U} \\
40.0 \mathrm{U} \\
39.6 \mathrm{U} \\
39.6 \mathrm{U} \\
39.6 \mathrm{U}\end{array}$ & $\begin{array}{l}38.8 \mathrm{U} \\
40.0 \mathrm{U} \\
39.6 \mathrm{U} \\
39.6 \mathrm{U} \\
39.6 \mathrm{U}\end{array}$ & $\begin{array}{l}38.8 \mathrm{U} \\
40.0 \mathrm{U} \\
39.6 \mathrm{U} \\
39.6 \mathrm{U} \\
39.6 \mathrm{U}\end{array}$ & $\begin{array}{l}38.8 \mathrm{U} \\
40.0 \mathrm{U} \\
51.1 \\
39.6 \mathrm{U} \\
39.6 \mathrm{U}\end{array}$ & $\begin{array}{l}44.5 \\
94.6 \\
91.0 \\
81.6 \\
58.7\end{array}$ & $\begin{array}{l}38.8 U \\
40.0 U \\
39.6 U \\
39.6 U \\
39.6 U\end{array}$ \\
\hline $\begin{array}{l}\text { R-AM COMP } \\
\text { R-AM COMP } \\
\text { R-AM COMP } \\
\text { R-AM COMP } \\
\text { R-AM COMP }\end{array}$ & $\begin{array}{l}1 \\
2 \\
3 \\
4 \\
5\end{array}$ & $\begin{array}{l}1 \\
2 \\
2 \\
1 \\
3\end{array}$ & $\begin{array}{l}38.4 \mathrm{U} \\
39.2 \mathrm{U} \\
39.2 \mathrm{U} \\
39.2 \mathrm{U} \\
40.0 \mathrm{U}\end{array}$ & $\begin{array}{l}38.4 \mathrm{U} \\
39.2 \mathrm{U} \\
39.2 \mathrm{U} \\
39.2 \mathrm{U} \\
40.0 \mathrm{U}\end{array}$ & $\begin{array}{l}38.4 \mathrm{U} \\
39.2 \mathrm{U} \\
39.2 \mathrm{U} \\
39.2 \mathrm{U} \\
40.0 \mathrm{U}\end{array}$ & $\begin{array}{l}38.4 U \\
53.2 \\
39.2 U \\
39.2 U \\
55.2\end{array}$ & \begin{tabular}{r|}
79.8 \\
183 \\
93.3 \\
46.4 \\
88.0
\end{tabular} & $\begin{array}{l}38.4 U \\
39.2 U \\
39.2 U \\
39.2 U \\
40.0 U\end{array}$ \\
\hline
\end{tabular}


TABLE P.10. (contd)

N. virens phthalate esters (ug/ $\mathrm{kg}$ wet weight)

\begin{tabular}{|c|c|c|c|c|c|c|c|c|}
\hline $\begin{array}{l}\text { Sediment } \\
\text { Treatment }\end{array}$ & Replicate & $\begin{array}{c}\text { Analytical } \\
\text { Batch }\end{array}$ & $\begin{array}{l}\text { Dimethyl } \\
\text { Phthalate } \\
\end{array}$ & $\begin{array}{l}\text { Diethyl } \\
\text { Phthalate }\end{array}$ & $\begin{array}{l}\text { Di-n-butyl } \\
\text { Phthalate }\end{array}$ & $\begin{array}{c}\text { Butyl } \\
\text { benzyl } \\
\text { Phthalate }\end{array}$ & $\begin{array}{c}\text { Bis } \\
\text { (2-ethylhexyl) } \\
\text { Phthalate }\end{array}$ & $\begin{array}{l}\text { Di-n-octyl } \\
\text { Phthalate }\end{array}$ \\
\hline $\begin{array}{l}\text { C-NV } \\
\text { C-NV, Replicate } 1 \\
\text { C-NV, Replicate } 2 \\
\text { C-NV, Replicate } 3 \\
\text { C-NV } \\
\text { C-NV }\end{array}$ & $\begin{array}{l}1 \\
2 \\
2 \\
2 \\
3 \\
4\end{array}$ & $\begin{array}{l}1 \\
2 \\
2 \\
2 \\
2 \\
3\end{array}$ & $\begin{array}{l}39.2 \mathrm{U} \\
80.0 \mathrm{U} \\
79.6 \mathrm{U} \\
78.4 \mathrm{U} \\
78.4 \mathrm{U} \\
40.0 \mathrm{U}\end{array}$ & $\begin{array}{l}39.2 \mathrm{U} \\
80.0 \mathrm{U} \\
79.6 \mathrm{U} \\
78.4 \mathrm{U} \\
78.4 \mathrm{U} \\
40.0 \mathrm{U}\end{array}$ & $\begin{array}{l}39.2 \mathrm{U} \\
80.0 \mathrm{U} \\
79.6 \mathrm{U} \\
78.4 \mathrm{U} \\
78.4 \mathrm{U} \\
40.0 \mathrm{U}\end{array}$ & $\begin{array}{l}39.2 \mathrm{U} \\
114 \\
79.6 \mathrm{U} \\
78.4 \mathrm{U} \\
78.4 \mathrm{U} \\
40.0 \mathrm{U}\end{array}$ & $\begin{array}{l}118 \\
176 \\
162 \\
147 \\
138 \\
128\end{array}$ & $\begin{array}{l}39.2 \mathrm{U} \\
80.0 \mathrm{U} \\
79.6 \mathrm{U} \\
78.4 \mathrm{U} \\
78.4 \mathrm{U} \\
40.0 \mathrm{U}\end{array}$ \\
\hline $\begin{array}{l}\text { N. virens Background } \\
\text { N. virens Background } \\
\text { N. virens Background } \\
\text { N. virens Background } \\
\text { N. virens Background }\end{array}$ & $\begin{array}{l}1 \\
2 \\
3 \\
4 \\
5\end{array}$ & $\begin{array}{l}3 \\
3 \\
3 \\
3 \\
3\end{array}$ & $\begin{array}{l}80.0 U \\
39.2 U \\
40.0 U \\
40.0 U \\
38.8 U\end{array}$ & $\begin{array}{l}80.0 \mathrm{U} \\
39.2 \mathrm{U} \\
40.0 \mathrm{U} \\
44.0 \\
38.8 \mathrm{U}\end{array}$ & $\begin{array}{l}80.0 \mathrm{U} \\
39.2 \mathrm{U} \\
40.0 \mathrm{U} \\
40.0 \mathrm{U} \\
38.8 \mathrm{U}\end{array}$ & $\begin{array}{l}80.0 \mathrm{U} \\
49.8 \\
48.4 \\
40.0 \mathrm{U} \\
38.8 \mathrm{U}\end{array}$ & $\begin{array}{r}169 \\
54.4 \\
91.2 \\
97.7 \\
77.2\end{array}$ & $\begin{array}{l}80.0 \mathrm{U} \\
39.2 \mathrm{U} \\
40.0 \mathrm{U} \\
40.0 \mathrm{U} \\
38.8 \mathrm{U}\end{array}$ \\
\hline
\end{tabular}

(a) DL Delection limit.

(b) Delection limit derived from lowest calibration standard as sample.

(c) U Undetected at or above detection limit. 
TABLE P.11. Quality Control Data for Phthalate Esters, Wet Weight, in Tissue of N. virens, Richmond Harbor Deepening Project

\begin{tabular}{|c|c|c|c|c|c|c|c|c|}
\hline \multirow[b]{2}{*}{$\begin{array}{l}\text { Sediment } \\
\text { Treatment }\end{array}$} & \multirow[b]{2}{*}{ Replicate } & \multirow[b]{2}{*}{$\begin{array}{c}\text { Analytica! } \\
\text { Batch }\end{array}$} & \multicolumn{6}{|c|}{ N. virens phthalates (ug/kg wet weight) } \\
\hline & & & $\begin{array}{l}\text { Dimethyl } \\
\text { Phthalate }\end{array}$ & $\begin{array}{l}\text { Diethyl } \\
\text { Phthalate }\end{array}$ & $\begin{array}{l}\text { Di-n-butyl } \\
\text { Phthalate } \\
\end{array}$ & $\begin{array}{l}\text { Butyl } \\
\text { benzyl } \\
\text { Phthalate }\end{array}$ & $\begin{array}{c}\text { Bis } \\
\text { (2-ethyihexyl) } \\
\text { Phithalate }\end{array}$ & $\begin{array}{l}\text { Di-n-octyl } \\
\text { Phthalate }\end{array}$ \\
\hline \multicolumn{9}{|l|}{ Method Blanks } \\
\hline $\begin{array}{l}\text { Blank-1 } \\
\text { Blank-1 } \\
\text { Blank-1 }\end{array}$ & . & $\begin{array}{l}1 \\
2 \\
3\end{array}$ & $\begin{array}{l}39.2 \mathrm{U}(\mathrm{a}) \\
39.6 \mathrm{U} \\
42.0 \mathrm{U}\end{array}$ & $\begin{array}{l}39.2 \mathrm{U} \\
39.6 \mathrm{U} \\
42.0 \mathrm{U}\end{array}$ & $\begin{array}{l}39.2 \mathrm{U} \\
39.6 \mathrm{U} \\
42.0 \mathrm{U}\end{array}$ & $\begin{array}{l}39.2 \mathrm{U} \\
39.6 \mathrm{U} \\
42.0 \mathrm{U}\end{array}$ & $\begin{array}{l}39.2 \mathrm{U} \\
39.6 \mathrm{U} \\
42.0 \mathrm{U}\end{array}$ & $\begin{array}{l}39.2 \mathrm{U} \\
39.6 \mathrm{U} \\
42.0 \mathrm{U}\end{array}$ \\
\hline \multicolumn{9}{|l|}{ Matrix Spikes } \\
\hline $\begin{array}{l}\text { UiH COMP } \\
\text { UiH COMP, MS } \\
\text { Concentration Recovered } \\
\text { Amount Spiked } \\
\text { Percent Recovery }\end{array}$ & $\begin{array}{l}5 \\
5\end{array}$ & $\begin{array}{l}1 \\
1\end{array}$ & $\begin{array}{l}77.2 \mathrm{U} \\
973 \\
973 \\
1430 \\
68 \%\end{array}$ & $\begin{array}{l}77.2 \mathrm{U} \\
1100 \\
1100 \\
1430 \\
77 \%\end{array}$ & $\begin{array}{c}77.2 \mathrm{U} \\
1480 \\
1480 \\
1430 \\
103 \%\end{array}$ & $\begin{array}{l}77.2 \mathrm{U} \\
1640 \\
1640 \\
1430 \\
115 \%\end{array}$ & $\begin{array}{l}86.4 \\
1840 \\
1750 \\
1430 \\
122 \% \text { (b) }\end{array}$ & $\begin{array}{c}77.2 \mathrm{U} \\
2380 \\
2380 \\
1430 \\
166 \% \text { (b) }\end{array}$ \\
\hline $\begin{array}{l}\text { C-NV } \\
\text { C-NV, MS } \\
\text { Concentration Recovered } \\
\text { Amount Spiked } \\
\text { Percent Recovery }\end{array}$ & $\begin{array}{l}3 \\
3\end{array}$ & $\begin{array}{l}2 \\
2\end{array}$ & $\begin{array}{l}78.4 U \\
437 \\
437 \\
1550 \\
28 \%(b)\end{array}$ & $\begin{array}{l}78.4 \mathrm{U} \\
520 \\
520 \\
1550 \\
34 \% \text { (b) }\end{array}$ & $\begin{array}{l}78.4 \mathrm{U} \\
1230 \\
1230 \\
1550 \\
79 \%\end{array}$ & $\begin{array}{l}78.4 U \\
1490 \\
1490 \\
1550 \\
96 \%\end{array}$ & $\begin{array}{r}138 \\
1770 \\
1630 \\
1550 \\
105 \%\end{array}$ & $\begin{array}{l}78.4 \mathrm{U} \\
2050 \\
2050 \\
1550 \\
132 \% \text { (b) }\end{array}$ \\
\hline $\begin{array}{l}\text { N. virens Background } \\
\text { N. virens Background, MS } \\
\text { Concentration Recovered } \\
\text { Amount Spiked } \\
\text { Percent Recovery }\end{array}$ & $\begin{array}{l}1 \\
1\end{array}$ & $\begin{array}{l}3 \\
3\end{array}$ & $\begin{array}{l}80.0 \mathrm{U} \\
1140 \\
1140 \\
1550 \\
74 \%\end{array}$ & $\begin{array}{l}80.0 \mathrm{U} \\
1210 \\
1210 \\
1550 \\
78 \%\end{array}$ & $\begin{array}{l}80.0 \mathrm{U} \\
1440 \\
1440 \\
1550 \\
93 \%\end{array}$ & $\begin{array}{c}80.0 \mathrm{U} \\
1630 \\
1630 \\
1550 \\
105 \%\end{array}$ & $\begin{array}{r}169 \\
1820 \\
1650 \\
1550 \\
106 \%\end{array}$ & $\begin{array}{c}80.0 \mathrm{U} \\
2170 \\
2170 \\
1550 \\
140 \% \text { (b) }\end{array}$ \\
\hline \multicolumn{9}{|l|}{ Standard Reference Material } \\
\hline $\begin{array}{l}\text { Certified SRM not available } \\
\text { Analytical Replicates }\end{array}$ & for phthala & ates. & & & & & & \\
\hline $\begin{array}{l}\text { SFW COMP, Replicate } 1 \\
\text { SFW COMP, Replicate } 2 \\
\text { SFW COMP, Replicate } 3\end{array}$ & $\begin{array}{l}1 \\
1 \\
1\end{array}$ & $\begin{array}{l}1 \\
1 \\
1\end{array}$ & $\begin{array}{l}73.6 \mathrm{U} \\
76.0 \mathrm{U} \\
75.6 \mathrm{U}\end{array}$ & $\begin{array}{l}73.6 \mathrm{U} \\
76.0 \mathrm{U} \\
75.6 \mathrm{U}\end{array}$ & $\begin{array}{l}73.6 \mathrm{U} \\
76.0 \mathrm{U} \\
75.6 \mathrm{U}\end{array}$ & $\begin{array}{l}73.6 \mathrm{U} \\
76.0 \mathrm{U} \\
75.6 \mathrm{U}\end{array}$ & $\begin{array}{l}73.6 \mathrm{U} \\
76.0 \mathrm{U} \\
75.6 \mathrm{U}\end{array}$ & $\begin{array}{l}73.6 \mathrm{U} \\
76.0 \mathrm{U} \\
75.6 \mathrm{U}\end{array}$ \\
\hline RSD & & & NA (c) & NA & NA & NA & NA & NA \\
\hline $\begin{array}{l}\text { C-NV, Replicate } 1 \\
\text { C-NV, Replicate } 2 \\
\text { C-NV, Replicate } 3\end{array}$ & $\begin{array}{l}2 \\
2 \\
2\end{array}$ & $\begin{array}{l}2 \\
2 \\
2\end{array}$ & $\begin{array}{l}80.0 \mathrm{U} \\
79.6 \mathrm{U} \\
78.4 \mathrm{U}\end{array}$ & $\begin{array}{l}80.0 \mathrm{U} \\
79.6 \mathrm{U} \\
78.4 \mathrm{U}\end{array}$ & $\begin{array}{l}80.0 \mathrm{U} \\
79.6 \mathrm{U} \\
78.4 \mathrm{U}\end{array}$ & $\begin{array}{l}114 \\
79.6 U \\
78.4 U\end{array}$ & $\begin{array}{l}176 \\
162 \\
147\end{array}$ & $\begin{array}{l}80.0 \mathrm{U} \\
79.6 \mathrm{U} \\
78.4 \mathrm{U}\end{array}$ \\
\hline RSD & & & NA & NA & NA & NA & $9 \%$ & NA \\
\hline $\begin{array}{l}\text { SF COMP, Replicate } 1 \\
\text { SF COMP, Replicate } 2 \\
\text { SF COMP, Replicate } 3\end{array}$ & $\begin{array}{l}2 \\
2 \\
2\end{array}$ & $\begin{array}{l}3 \\
3 \\
3\end{array}$ & $\begin{array}{l}80.0 \mathrm{U} \\
80.0 \mathrm{U} \\
80.0 \mathrm{U}\end{array}$ & $\begin{array}{l}80.0 \mathrm{U} \\
80.0 \mathrm{U} \\
80.0 \mathrm{U}\end{array}$ & $\begin{array}{l}80.0 \mathrm{U} \\
80.0 \mathrm{U} \\
80.0 \mathrm{U}\end{array}$ & $\begin{array}{l}82.2 \\
80.0 \mathrm{U} \\
80.0 \mathrm{U}\end{array}$ & $\begin{array}{r}137 \\
94.9 \\
173\end{array}$ & $\begin{array}{l}80.0 \mathrm{U} \\
80.0 \mathrm{U} \\
80.0 \mathrm{U}\end{array}$ \\
\hline RSD & & & NA & NA & NA & NA & $29 \%$ & NA \\
\hline
\end{tabular}

(a) U Undetected at or above detection limit.

(b) Outside quality control criteria (40-120\%) for matrix spike recoveries.

(c) NA Not applicable. 
TABLE P.12. Surrogate Percent Recoveries for Polynuclear Aromatic Hydrocarbons, Including Quality Control Data, in Tissue of N. virens, Richmond Harbor Deepening Project

\begin{tabular}{|c|c|c|c|c|c|c|}
\hline \multirow[b]{2}{*}{$\begin{array}{l}\text { Sediment } \\
\text { Treatment }\end{array}$} & \multirow[b]{2}{*}{ Replicate } & \multirow[b]{2}{*}{$\begin{array}{c}\text { Analytical } \\
\text { Batch }\end{array}$} & \multicolumn{4}{|c|}{ Surrogate Percent Recoveries } \\
\hline & & & $\begin{array}{l}\text { Naptha- } \\
\text { lene } \\
\text { d8 } \\
\end{array}$ & $\begin{array}{l}\text { Acenaph- } \\
\text { thene } \\
\text { d10 }\end{array}$ & $\begin{array}{c}\text { Chrysene } \\
\text { d12 }\end{array}$ & $\begin{array}{l}\text { Dibenzo } \\
(a, h, i) \\
\text { Anthracene } \\
\text { d14 } \\
\end{array}$ \\
\hline SF COMP & 1 & 1 & 70 & 74 & 77 & 70 \\
\hline SF COMP, Replicate 1 & 2 & 3 & 77 & 86 & 94 & 85 \\
\hline SF COMP, Replicate 2 & 2 & 3 & 86 & 90 & 77 & 88 \\
\hline SF COMP, Replicate 3 & 2 & 3 & 75 & 82 & 90 & 81 \\
\hline SF COMP & $\overline{3}$ & 1 & 73 & $\overline{75}$ & 74 & 60 \\
\hline SF COMP & 4 & 1 & 75 & 78 & 82 & 77 \\
\hline SF COMP & 5 & 2 & 70 & 73 & 68 & 63 \\
\hline SFW COMP, Replicate 1 & 1 & 1 & 73 & 76 & 76 & 63 \\
\hline SFW COMP, Replicate 2 & 1 & 1 & 74 & 76 & 82 & 64 \\
\hline SFW COMP, Replicate 3 & 1 & 1 & 74 & 75 & 62 & 62 \\
\hline SFW COMP & 2 & 2 & 72 & 77 & 80 & 78 \\
\hline SFW COMP & 3 & 2 & 74 & 77 & 77 & 67 \\
\hline SFW COMP & 4 & 1 & 72 & 76 & 74 & 68 \\
\hline SFW COMP & 5 & 1 & 58 & 63 & 65 & 61 \\
\hline UIH COMP & 1 & 2 & 76 & 81 & 84 & 83 \\
\hline UIH COMP & 2 & 1 & 62 & 64 & 68 & 58 \\
\hline UIH COMP & 3 & 3 & 83 & 88 & 92 & 78 \\
\hline UIH COMP & 4 & 1 & 64 & 68 & 72 & 67 \\
\hline UIH COMP & 5 & 1 & 68 & 71 & 70 & 65 \\
\hline TB Upper COMP & 1 & 1 & 63 & 66 & 69 & 63 \\
\hline TB Upper COMP & 2 & 1 & 70 & 74 & 83 & 77 \\
\hline TB Upper COMP & 3 & 2 & 71 & 76 & 80 & 77 \\
\hline TB Upper COMP & 4 & 1 & 63 & 66 & 70 & 56 \\
\hline TB Upper COMP & 5 & 2 & 70 & 73 & 76 & 73 \\
\hline TB Lower COMP & 1 & 2 & 71 & 75 & 81 & 78 \\
\hline TB Lower COMP & 2 & $\overline{1}$ & 68 & 71 & 74 & 68 \\
\hline TB Lower COMP & $\overline{3}$ & 2 & 86 & 89 & 88 & 85 \\
\hline TB Lower COMP & 4 & 2 & 73 & 77 & 80 & 76 \\
\hline TB Lower COMP & 5 & 2 & 76 & 77 & 77 & 85 \\
\hline R-OS & 1 & 2 & 70 & 69 & 69 & 67 \\
\hline R-OS & 2 & 1 & 64 & 68 & 73 & 65 \\
\hline R-OS & 3 & 1 & 68 & 69 & 73 & 64 \\
\hline R-OS & 4 & 2 & 76 & 80 & 82 & 77 \\
\hline R-OS & 5 & 1 & 67 & 70 & 74 & 62 \\
\hline
\end{tabular}


TABLE P.12. (contd)

\begin{tabular}{|c|c|c|c|c|c|c|}
\hline \multirow[b]{2}{*}{$\begin{array}{l}\text { Sediment } \\
\text { Treatment }\end{array}$} & \multirow[b]{2}{*}{ Replicate } & \multirow[b]{2}{*}{$\begin{array}{c}\text { Analytical } \\
\text { Batch }\end{array}$} & \multicolumn{4}{|c|}{ Surrogate Percent Recoveries } \\
\hline & & & $\begin{array}{l}\text { Naptha- } \\
\text { lene } \\
\text { d8 }\end{array}$ & $\begin{array}{l}\text { Acenaph- } \\
\text { thene } \\
\text { d10 }\end{array}$ & $\begin{array}{c}\text { Chrysene } \\
\text { d12 }\end{array}$ & $\begin{array}{l}\text { Dibenzo } \\
\text { (a,h,i) } \\
\text { Anthracene } \\
\quad \text { d14 } \\
\end{array}$ \\
\hline R-BF & 1 & 1 & 71 & 75 & 78 & 69 \\
\hline R-BF & 2 & 2 & 72 & 74 & 79 & 75 \\
\hline R-BF & 3 & 2 & 84 & 87 & 89 & 82 \\
\hline R-BF & 4 & 2 & 73 & 74 & 76 & 71 \\
\hline R-BF & 5 & 2 & 79 & 81 & 82 & 79 \\
\hline R-AM COMP & 1 & 1 & 67 & 71 & 74 & 72 \\
\hline R-AM COMP & 2 & 2 & 73 & 76 & 78 & 71 \\
\hline R-AM COMP & 3 & 2 & 76 & 78 & 75 & 70 \\
\hline R-AM COMP & 4 & 1 & 65 & 69 & 70 & 64 \\
\hline R-AM COMP & 5 & 3 & 70 & 88 & 93 & 82 \\
\hline C-NV & 1 & 1 & 66 & 69 & 72 & 64 \\
\hline C-NV, Replicate 1 & 2 & 2 & 93 & 93 & 68 & 70 \\
\hline C-NV Replicate 2 & 2 & 2 & 74 & 80 & 81 & 68 \\
\hline C-NV, Replicate 3 & 2 & 2 & 80 & 81 & 82 & 72 \\
\hline C-NV & 3 & 2 & 87 & 88 & 86 & 78 \\
\hline $\mathrm{C}-\mathrm{NV}$ & 4 & 3 & 75 & 80 & 83 & 78 \\
\hline N. virens Background & 1 & 3 & 70 & 74 & 76 & 72 \\
\hline N. virens Background & 2 & 3 & 62 & 67 & 70 & $6 \overline{5}$ \\
\hline N. virens Background & 3 & 3 & 79 & 82 & 87 & 80 \\
\hline N. virens Background & 4 & 3 & 79 & 84 & 87 & 83 \\
\hline N. virens Background & 5 & 3 & 75 & 80 & 82 & 76 \\
\hline
\end{tabular}

\section{Quality Control Data}

Method Blanks

Blank-1

Blank-1

Blank-1

Matrix Spikes

UIH COMP

UIH COMP, MS

C-NV

C-NV, MS

$N$. virens Background

$N$. virens Background, MS

$\begin{array}{ll}1 & 72 \\ 2 & 92 \\ 3 & 82\end{array}$

72
92
82

70

89

77
84

89

77
46

\section{RH DEEPENING}

P.22 
TABLE P.12. (contd)

Surrogate Percent Recoveries

Sediment

Treatment

Replicate

thene

d10

$(a, h, i)$

Batch

lene

Chrysene

Anthracene

Analytical Replicates

SFW COMP, Replicate 1

SFW COMP, Replicate 2

$1 \quad 1 \quad 73$

73
74

74
74

76

76

75

d12

d14

C-NV, Replicate 1

C-NV, Replicate 2

C-NV, Replicate 3

2

2
2
2

93

93

80

81

76

82

62

63

174

64

SF COMP, Replicate 1

SF COMP, Replicate 2

SF COMP, Replicate 3

$\begin{array}{lll}2 & 3 & 77 \\ 2 & 3 & 86 \\ 2 & 3 & 75\end{array}$

86

90

82

68

81

82

80

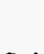

72

86

75

77

85

88

81

RH DEEPENING 


\begin{tabular}{|c|c|c|c|c|c|c|c|c|c|c|c|c|}
\hline \multirow[b]{2}{*}{$\begin{array}{l}\text { Sediment } \\
\text { Treatment }\end{array}$} & \multirow[b]{2}{*}{ Replicate } & \multirow[b]{2}{*}{$\begin{array}{c}\text { Analytical } \\
\text { Batch }\end{array}$} & \multirow{2}{*}{$\begin{array}{l}\text { Percent } \\
\text { Dry } \\
\text { Weight }\end{array}$} & \multicolumn{9}{|c|}{ N. virens Pesticides (ug/kg dry weight) } \\
\hline & & & & Aldrin & $\begin{array}{l}\text { Alpha- } \\
\text { BHC }\end{array}$ & $\begin{array}{l}\text { Beta } \\
\text { BHC } \\
\end{array}$ & $\begin{array}{l}\text { Delta } \\
\text { BHC }\end{array}$ & $\begin{array}{c}\text { Gamma- } \\
\text { BHC }\end{array}$ & Chlordane & $\begin{array}{l}4,4^{4}- \\
\text { DDD }\end{array}$ & $\begin{array}{l}4,4^{\prime}- \\
\text { DDE }\end{array}$ & $\begin{array}{l}4,4^{\prime}- \\
\text { DDT }\end{array}$ \\
\hline SF COMP & 1 & 1 & 13.45 & $1.3 \mathrm{U}(\mathrm{a})$ & $3.6 \mathrm{U}$ & $3.6 \mathrm{U}$ & $3.6 \mathrm{U}$ & $1.7 \mathrm{U}$ & $220 \mathrm{U}$ & 102 & 7.73 & 52.9 \\
\hline SF COMP, Replicate 1 & 2 & 3 & 13.61 & 8.60 & $7.2 \mathrm{U}$ & $7.2 \mathrm{U}$ & $7.2 \mathrm{U}$ & $3.5 \mathrm{U}$ & $220 \mathrm{U}$ & 90.4 & 12.4 & 63.9 \\
\hline SF COMP, Replicate 2 & 2 & 3 & 13.61 & $2.7 \mathrm{U}$ & $7.3 \mathrm{U}$ & $7.3 \mathrm{U}$ & $7.3 \mathrm{U}$ & $3.5 \mathrm{U}$ & $220 \mathrm{U}$ & 88.2 & 9.33 & 58.6 \\
\hline SF COMP, Replicate 3 & 2 & 3 & 13.61 & 9.55 & $7.2 \mathrm{U}$ & $7.2 \mathrm{U}$ & $7.2 \mathrm{U}$ & $3.5 \mathrm{U}$ & $220 \mathrm{U}$ & 91.8 & 14.7 & 50.6 \\
\hline SF COMP & 3 & 1 & 13.25 & $1.4 \mathrm{U}$ & $3.8 \mathrm{U}$ & $3.8 \mathrm{U}$ & $3.8 \mathrm{U}$ & $1.8 \mathrm{U}$ & $230 \mathrm{U}$ & 111 & 9.06 & $23.7 \mathrm{U}$ \\
\hline SF COMP & 4 & 1 & 13.42 & $1.3 \mathrm{U}$ & $3.7 \mathrm{U}$ & $3.7 \mathrm{U}$ & $3.7 \mathrm{U}$ & $1.8 \mathrm{U}$ & $220 \mathrm{U}$ & 210 & 9.61 & 32.0 \\
\hline SF COMP & 5 & 2 & 12.94 & $1.4 \mathrm{U}$ & $3.9 \mathrm{U}$ & $3.9 \mathrm{U}$ & $3.9 \mathrm{U}$ & $1.9 \mathrm{U}$ & $230 \mathrm{U}$ & 177 & 10.0 & 21.6 \\
\hline SFW COMP, Replicate 1 & 1 & 1 & 12.99 & 19.9 & $7.1 \mathrm{U}$ & $7.1 \mathrm{U}$ & $7.1 \mathrm{U}$ & $3.4 \mathrm{U}$ & $230 \mathrm{U}$ & 247 & $2.0 \mathrm{U}$ & 44.0 \\
\hline SFW COMP, Replicate 2 & 1 & 1 & 13.36 & 19.9 & $6.9 \mathrm{U}$ & $6.9 \mathrm{U}$ & $6.9 \mathrm{U}$ & $3.3 \mathrm{U}$ & $230 \mathrm{U}$ & 203 & $1.9 \mathrm{U}$ & 36.8 \\
\hline SFW COMP, Replicate 3 & 1 & 1 & 13.85 & 19.0 & $6.9 \mathrm{U}$ & $6.9 \mathrm{U}$ & $6.9 \mathrm{U}$ & $3.3 \mathrm{U}$ & $220 \mathrm{U}$ & 168 & $1.9 \mathrm{U}$ & 27.9 \\
\hline SFW COMP & 2 & 2 & 12.32 & $1.5 \mathrm{U}$ & $4.1 \mathrm{U}$ & $4.1 \mathrm{U}$ & $4.1 \mathrm{U}$ & $1.9 \mathrm{U}$ & $240 \mathrm{U}$ & 372 & $1.1 \mathrm{U}$ & 27.3 \\
\hline SFW COMP & 3 & 2 & 13.78 & $1.3 \mathrm{U}$ & $3.6 \mathrm{U}$ & $3.6 \mathrm{U}$ & $3.6 \mathrm{U}$ & $1.7 \mathrm{U}$ & $220 \mathrm{U}$ & 342 & $1.0 \mathrm{U}$ & 29.2 \\
\hline SFW COMP & 4 & 1 & 13.08 & 11.0 & $3.7 \mathrm{U}$ & $3.7 \mathrm{U}$ & $3.7 \mathrm{U}$ & $1.8 \mathrm{U}$ & $230 \mathrm{U}$ & 310 & $1.1 \mathrm{U}$ & 33.4 \\
\hline SFW COMP & 5 & 1 & 13.95 & 11.2 & $3.5 \mathrm{U}$ & $3.5 \mathrm{U}$ & $3.5 \mathrm{U}$ & $1.6 \mathrm{U}$ & $220 \mathrm{U}$ & 642 & $1.0 \mathrm{U}$ & 45.6 \\
\hline UIH COMP & 1 & 2 & 13.70 & $1.3 \mathrm{U}$ & $3.6 \mathrm{U}$ & $3.6 \mathrm{U}$ & $3.6 \mathrm{U}$ & $1.8 \mathrm{U}$ & $220 \mathrm{U}$ & 17.6 & $1.0 \mathrm{U}$ & 39.6 \\
\hline UIH COMP & 2 & 1 & 13.21 & $1.4 \mathrm{U}$ & $3.8 \mathrm{U}$ & $3.8 \mathrm{U}$ & $3.8 \mathrm{U}$ & $1.8 \mathrm{U}$ & $230 \mathrm{U}$ & 37.6 & $1.1 \mathrm{U}$ & 24.1 \\
\hline UIH COMP & 3 & 3 & 13.03 & $1.4 \mathrm{U}$ & $3.8 \mathrm{U}$ & $3.8 \mathrm{U}$ & $3.8 \mathrm{U}$ & $1.8 \mathrm{U}$ & $230 \mathrm{U}$ & 79.8 & 9.13 & 47.4 \\
\hline UIH COMP & 4 & 1 & 13.28 & $1.4 \mathrm{U}$ & $3.7 \mathrm{U}$ & $3.7 \mathrm{U}$ & $3.7 U$ & $1.8 \mathrm{U}$ & $230 \mathrm{U}$ & 78.2 & 8.28 & $2.6 \mathrm{U}$ \\
\hline UIH COMP & 5 & 1 & 12.99 & $2.7 \mathrm{U}$ & $7.5 \mathrm{U}$ & $7.5 \mathrm{U}$ & $7.5 \mathrm{U}$ & $3.6 \mathrm{U}$ & $230 \mathrm{U}$ & 70.4 & $2.1 \mathrm{U}$ & $5.3 \mathrm{U}$ \\
\hline TB Upper COMP & 1 & 1 & 14.09 & $1.3 \mathrm{U}$ & $3.5 \mathrm{U}$ & $3.5 \mathrm{U}$ & $3.5 \mathrm{U}$ & $1.7 \mathrm{U}$ & $210 U$ & $3.3 \mathrm{U}$ & $1.0 \mathrm{U}$ & $2.5 \mathrm{U}$ \\
\hline TB Upper COMP & 2 & 1 & 13.33 & $1.4 \mathrm{U}$ & $3.7 \mathrm{U}$ & $3.7 \mathrm{U}$ & $3.7 \mathrm{U}$ & $1.8 \mathrm{U}$ & $230 \mathrm{U}$ & $3.5 \mathrm{U}$ & $1.1 \mathrm{U}$ & $2.6 \mathrm{U}$ \\
\hline TB Upper COMP & 3 & 2 & 13.17 & $1.4 \mathrm{U}$ & $3.7 \mathrm{U}$ & $3.7 \mathrm{U}$ & $3.7 \mathrm{U}$ & $1.8 \mathrm{U}$ & $230 \mathrm{U}$ & $3.5 \mathrm{U}$ & $1.1 \mathrm{U}$ & $2.7 \mathrm{U}$ \\
\hline TB Upper COMP & 4 & 1 & 13.45 & $1.3 \mathrm{U}$ & $3.6 \mathrm{U}$ & $3.6 \mathrm{U}$ & $3.6 \mathrm{U}$ & $1.7 \mathrm{U}$ & $220 \mathrm{U}$ & $3.3 \mathrm{U}$ & $1.0 \mathrm{U}$ & 15.0 \\
\hline TB Upper COMP & 5 & 2 & 14.65 & $1.2 \mathrm{U}$ & $3.3 \mathrm{U}$ & $3.3 \mathrm{U}$ & $3.3 \mathrm{U}$ & $1.6 \mathrm{U}$ & $210 \mathrm{U}$ & $3.1 \mathrm{U}$ & $1.0 \mathrm{U}$ & 18.1 \\
\hline TB Lower COMP & 1 & 2 & 13.26 & $1.4 \mathrm{U}$ & $3.7 \mathrm{U}$ & $3.7 \mathrm{U}$ & $3.7 \mathrm{U}$ & $1.8 \mathrm{U}$ & $230 \mathrm{U}$ & $3.5 \mathrm{U}$ & $1.1 \mathrm{U}$ & 18.3 \\
\hline TB Lower COMP & 2 & 1 & 12.88 & $1.4 \mathrm{U}$ & $3.9 \mathrm{U}$ & $3.9 \mathrm{U}$ & $3.9 \mathrm{U}$ & $1.9 \mathrm{U}$ & $230 \mathrm{U}$ & $3.6 \mathrm{U}$ & $1.1 \mathrm{U}$ & 16.3 \\
\hline TB Lower COMP & 3 & 2 & 13.79 & $1.3 \mathrm{U}$ & $3.6 \mathrm{U}$ & $3.6 \mathrm{U}$ & $3.6 \mathrm{U}$ & $1.7 \mathrm{U}$ & $220 U$ & $3.3 \mathrm{U}$ & $1.0 \mathrm{U}$ & 13.6 \\
\hline TB Lower COMP & 4 & 2 & 12.49 & $1.4 \mathrm{U}$ & $4.0 \mathrm{U}$ & $4.0 \mathrm{U}$ & $4.0 \mathrm{U}$ & $1.9 \mathrm{U}$ & $240 U$ & $3.7 \mathrm{U}$ & $1.1 \mathrm{U}$ & 15.6 \\
\hline TB Lower COMP & 5 & 4 & 13.61 & $1.3 \mathrm{U}$ & $3.7 \mathrm{U}$ & $3.7 \mathrm{U}$ & $3.7 \mathrm{U}$ & $1.8 \mathrm{U}$ & $220 \mathrm{U}$ & $3.5 \mathrm{U}$ & $1.0 \mathrm{U}$ & $2.6 \mathrm{U}$ \\
\hline R-OS & 1 & 2 & 14.02 & $1.3 \mathrm{U}$ & $3.6 \mathrm{U}$ & $3.6 \mathrm{U}$ & $3.6 \mathrm{U}$ & $1.7 \mathrm{U}$ & $210 U$ & $3.3 \mathrm{U}$ & $1.0 \mathrm{U}$ & 18.4 \\
\hline R-OS & 2 & 1 & 13.37 & $1.3 \mathrm{U}$ & $3.7 \mathrm{U}$ & $3.7 \mathrm{U}$ & $3.7 \mathrm{U}$ & $1.8 \mathrm{U}$ & $220 \mathrm{U}$ & $3.5 \mathrm{U}$ & $1.0 \mathrm{U}$ & $2.7 U$ \\
\hline R-OS & 3 & 1 & 13.54 & $1.3 \mathrm{U}$ & $3.7 \mathrm{U}$ & $3.7 \mathrm{U}$ & $3.7 \mathrm{U}$ & $1.8 \mathrm{U}$ & $220 \mathrm{U}$ & $3.4 \mathrm{U}$ & $1.0 \mathrm{U}$ & $2.6 \mathrm{U}$ \\
\hline R-OS & 4 & 2 & 13.97 & $1.3 \mathrm{U}$ & $3.6 \mathrm{U}$ & $3.6 \mathrm{U}$ & $3.6 \mathrm{U}$ & $1.7 \mathrm{U}$ & $220 \mathrm{U}$ & $3.3 \mathrm{U}$ & $1.0 \mathrm{U}$ & $2.5 \mathrm{U}$ \\
\hline R-OS & 5 & 1 & 13.34 & $1.3 \mathrm{U}$ & $3.7 \mathrm{U}$ & $3.7 \mathrm{U}$ & $3.7 \mathrm{U}$ & $1.8 \mathrm{U}$ & $230 \mathrm{U}$ & $3.4 \mathrm{U}$ & $1.0 \mathrm{U}$ & $2.6 \mathrm{U}$ \\
\hline
\end{tabular}




\begin{tabular}{|c|c|c|c|c|c|c|c|c|c|c|c|c|c|}
\hline \multirow{4}{*}{ 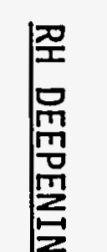 } & \multicolumn{13}{|c|}{ TABLE P.13. (contd) } \\
\hline & \multirow[b]{2}{*}{$\begin{array}{l}\text { Sediment } \\
\text { Treatment }\end{array}$} & \multirow[b]{2}{*}{ Replicate } & \multirow[b]{2}{*}{$\begin{array}{c}\text { Análytical } \\
\text { Batch }\end{array}$} & \multirow{2}{*}{$\begin{array}{l}\text { Percent } \\
\text { Dry } \\
\text { Weight }\end{array}$} & \multicolumn{9}{|c|}{ N. virens Pesticides (ug/kg dry weight) } \\
\hline & & & & & Aldrin & $\begin{array}{l}\text { Alpha- } \\
\text { BHC }\end{array}$ & $\begin{array}{l}\text { Beta } \\
\text { BHC }\end{array}$ & $\begin{array}{l}\text { Delta } \\
\text { BHC }\end{array}$ & $\begin{array}{l}\text { Gamma- } \\
\text { BHC }\end{array}$ & Chlordane & $\begin{array}{l}4,4^{\prime}- \\
\text { DDD }\end{array}$ & $\begin{array}{l}4,4^{\prime}- \\
\text { DDE }\end{array}$ & $\begin{array}{l}4,4^{4}- \\
\text { DDT }\end{array}$ \\
\hline & R-BF & 1 & 1 & 14.51 & $1.2 \mathrm{U}$ & $3.4 \mathrm{U}$ & $3.4 \mathrm{U}$ & $3.4 \mathrm{U}$ & $1.6 \mathrm{U}$ & $210 \mathrm{U}$ & $3.2 \mathrm{U}$ & $1.0 \mathrm{U}$ & $2.4 \mathrm{U}$ \\
\hline & R-BF & 2 & 2 & 13.20 & $1.4 \mathrm{U}$ & $3.8 \mathrm{U}$ & $3.8 \mathrm{U}$ & $3.8 \mathrm{U}$ & $1.8 \mathrm{U}$ & $230 \mathrm{U}$ & $3.6 \mathrm{U}$ & $1.1 \mathrm{U}$ & 24.1 \\
\hline & R-BF & 3 & 2 & 13.95 & $1.3 \mathrm{U}$ & $3.6 \mathrm{U}$ & $3.6 \mathrm{U}$ & $3.6 \mathrm{U}$ & $1.7 \mathrm{U}$ & $220 \mathrm{U}$ & $3.3 \mathrm{U}$ & $1.0 \mathrm{U}$ & 18.7 \\
\hline & R-BF & 4 & 2 & 12.57 & $1.4 \mathrm{U}$ & $4.0 \mathrm{U}$ & $4.0 \mathrm{U}$ & $4.0 \mathrm{U}$ & $1.9 \mathrm{U}$ & $240 U$ & $3.7 \mathrm{U}$ & $1.1 \mathrm{U}$ & $2.8 \mathrm{U}$ \\
\hline & R-BF & 5 & 2 & 13.94 & $1.3 U$ & $3.6 \mathrm{U}$ & $3.6 \mathrm{U}$ & $3.6 \mathrm{U}$ & $1.7 \mathrm{U}$ & $220 \mathrm{U}$ & $3.3 \mathrm{U}$ & $1.0 \mathrm{U}$ & 15.7 \\
\hline & R-AM COMP & 1 & 1 & 13.57 & $1.3 \mathrm{U}$ & $3.5 \mathrm{U}$ & $3.5 \mathrm{U}$ & $3.5 \mathrm{U}$ & $1.7 \mathrm{U}$ & $220 \mathrm{U}$ & $3.3 \mathrm{U}$ & $1.0 \mathrm{U}$ & 17.9 \\
\hline & R-AM COMP & 2 & 2 & 13.43 & $1.3 \mathrm{U}$ & $3.6 \mathrm{U}$ & $3.6 \mathrm{U}$ & $3.6 \mathrm{U}$ & $1.8 \mathrm{U}$ & $220 \mathrm{U}$ & $3.4 \mathrm{U}$ & $1.0 \mathrm{U}$ & 20.6 \\
\hline & R-AM COMP & 3 & 2 & 13.95 & $1.3 \mathrm{U}$ & $2.9 \mathrm{U}$ & $3.5 \mathrm{U}$ & $3.5 \mathrm{U}$ & $1.7 \mathrm{U}$ & $220 \mathrm{U}$ & $3.3 \mathrm{U}$ & $1.0 \mathrm{U}$ & 17.5 \\
\hline & R-AM COMP & 4 & 1 & 13.45 & $1.3 U$ & $3.6 \mathrm{U}$ & $3.6 \mathrm{U}$ & $3.6 \mathrm{U}$ & $1.8 \mathrm{U}$ & $220 \mathrm{U}$ & $3.4 \mathrm{U}$ & $1.0 \mathrm{U}$ & $2.6 \mathrm{U}$ \\
\hline & R-AM COMP & 5 & 3 & 13.75 & 17.3 & $3.6 \mathrm{U}$ & $3.6 \mathrm{U}$ & $3.6 \mathrm{U}$ & $1.7 \mathrm{U}$ & $220 U$ & $3.4 \mathrm{U}$. & $1.0 \mathrm{U}$ & 33.7 \\
\hline & C-NV : & 1 & 1 & 12.66 & $1.4 U$ & $3.9 \mathrm{U}$ & $3.9 \mathrm{U}$ & $3.9 \mathrm{U}$ & $1.9 U$ & $240 \mathrm{U}$ & $3.6 \mathrm{U}$ & $1.1 \mathrm{U}$ & $2.8 U$ \\
\hline & C-NV, Replicate 1 & 2 & 2 & 14.27 & $2.5 \mathrm{U}$ & $7.01 \mathrm{U}$ & $7.01 \mathrm{U}$ & $7.01 \mathrm{U}$ & $3.4 \mathrm{U}$ & $210 \mathrm{U}$ & $6.6 \mathrm{U}$ & $2.0 \mathrm{U}$ & 43.6 \\
\hline & C-NV, Replicate 2 & 2 & 2 & 14.27 & $2.5 \mathrm{U}$ & $7.01 \mathrm{U}$ & $7.01 \mathrm{U}$ & $7.01 \mathrm{U}$ & $3.4 \mathrm{U}$ & $210 U$ & $6.6 \mathrm{U}$ & $2.0 \mathrm{U}$ & 30.6 \\
\hline ס & C-NV, Replicate 3 & 2 & 2 & 14.27 & $2.5 \mathrm{U}$ & $7.01 \mathrm{U}$ & $7.01 \mathrm{U}$ & $7.01 \mathrm{U}$ & $3.4 \mathrm{U}$ & $210 \mathrm{U}$ & $6.6 \mathrm{U}$ & $2.0 \mathrm{U}$ & 26.2 \\
\hline & C-NV & 3 & 2 & 13.15 & $2.7 \mathrm{U}$ & $7.5 \mathrm{U}$ & $7.5 \mathrm{U}$ & $7.5 \mathrm{U}$ & $3.6 \mathrm{U}$ & $230 \mathrm{U}$ & $7.0 \mathrm{U}$ & $2.1 \mathrm{U}$ & 21.6 \\
\hline & $C-N V(b)$ & 4 & 3 & 13.21 & 16.5 & $3.7 \mathrm{U}$ & $3.7 \mathrm{U}$ & $3.7 \mathrm{U}$ & $1.8 \mathrm{U}$ & $230 \mathrm{U}$ & $3.5 \mathrm{U}$ & $1.1 \mathrm{U}$ & 37.5 \\
\hline & N. virens Background & 1 & 3 & 14.64 & $2.5 \mathrm{U}$ & $6.8 \mathrm{U}$ & $6.8 \mathrm{U}$ & $6.8 \mathrm{U}$ & $3.3 \mathrm{U}$ & $210 \mathrm{U}$ & $6.4 \mathrm{U}$ & $1.9 U$ & $4.8 \mathrm{U}$ \\
\hline & N. virens Background & 2 & 3 & 13.30 & 12.0 & $3.7 \mathrm{U}$ & $3.7 \mathrm{U}$ & $3.7 \mathrm{U}$ & $1.8 \mathrm{U}$ & & $3.5 \mathrm{U}$ & 8.87 & $2.6 U$ \\
\hline & N. virens Background & 3 & 3 & 13.79 & 13.5 & $3.6 \mathrm{U}$ & $3.6 \mathrm{U}$ & $3.6 \mathrm{U}$ & $1.7 \mathrm{U}$ & $.220 \mathrm{U}$ & $3.3 \mathrm{U}$ & 7.90 & $2.5 \mathrm{U}$ \\
\hline & N. virens Background & 4 & 3 & 14.11. & 9.78 & $3.5 \mathrm{U}$ & $3.5 \mathrm{U}$ & $3.5 \mathrm{U}$ & $1.6 \mathrm{U}$ & $210 U$ & $3.3 \mathrm{U}$ & $1.0 \mathrm{U}$ & $2.5 \mathrm{U}$ \\
\hline & N. virens Background & 5 & 3 & 13.99 & 11.3 & $3.5 \mathrm{U}$ & $3.5 \mathrm{U}$ & $3.5 \mathrm{U}$ & $1.6 \mathrm{U}$ & $210 U$ & $3.3 \mathrm{U}$ & $1.0 \mathrm{U}$ & $2.5 \mathrm{U}$ \\
\hline
\end{tabular}

(a) U Undetected at or above detection limit.

(b) Insufficient organisms to test all five replicates. 


\begin{tabular}{|c|c|c|c|c|c|c|c|c|c|c|c|c|}
\hline \multirow[b]{2}{*}{$\begin{array}{l}\text { Sediment } \\
\text { Treatment }\end{array}$} & \multirow[b]{2}{*}{ Replicate } & \multirow[b]{2}{*}{$\begin{array}{c}\text { Analytical } \\
\text { Batch }\end{array}$} & \multirow[b]{2}{*}{$\begin{array}{l}\text { Percent } \\
\text { Dry } \\
\text { Weight }\end{array}$} & \multicolumn{9}{|c|}{ N. virens Pesticides (ug/kg dry weight) } \\
\hline & & & & Dieldrin & $\begin{array}{l}\text { Endo- } \\
\text { Sulfan I }\end{array}$ & $\begin{array}{l}\text { Endo- } \\
\text { Sulfan II }\end{array}$ & $\begin{array}{l}\text { Endo- } \\
\text { Sulfan- } \\
\text { Sulfate } \\
\end{array}$ & Endrin & $\begin{array}{c}\text { Endrin } \\
\text { Aldehyde }\end{array}$ & $\begin{array}{l}\text { Hepta- } \\
\text { chlor }\end{array}$ & $\begin{array}{l}\text { Hepta- } \\
\text { chlor- } \\
\text { epoxide }\end{array}$ & $\begin{array}{l}\text { Toxa- } \\
\text { phene }\end{array}$ \\
\hline $\begin{array}{l}\text { SF COMP } \\
\text { SF COMP, Replicate } 1 \\
\text { SF COMP, Replicate } 2 \\
\text { SF COMP, Replicate } 3 \\
\text { SF COMP } \\
\text { SF COMP } \\
\text { SF COMP }\end{array}$ & $\begin{array}{l}1 \\
2 \\
2 \\
2 \\
3 \\
4 \\
5\end{array}$ & $\begin{array}{l}1 \\
3 \\
3 \\
3 \\
1 \\
1 \\
2\end{array}$ & $\begin{array}{l}13.45 \\
13.61 \\
13.61 \\
13.61 \\
13.25 \\
13.42 \\
12.94\end{array}$ & $\begin{array}{l}43.4 \\
47.5 \\
45.6 \\
49.1 \\
45.9 \\
60.6 \\
40.7\end{array}$ & $\begin{array}{l}3.6 U(a) \\
7.2 U \\
7.3 U \\
7.2 U \\
3.8 U \\
3.7 U \\
3.9 U\end{array}$ & $\begin{array}{r}36.4 \mathrm{U} \\
7.2 \mathrm{U} \\
7.3 \mathrm{U} \\
7.2 \mathrm{U} \\
3.8 \mathrm{U} \\
3.7 \mathrm{U} \\
3.9 \mathrm{U}\end{array}$ & $\begin{array}{l}3.6 U \\
7.2 U \\
7.3 U \\
7.2 U \\
3.8 U \\
3.7 U \\
3.9 U\end{array}$ & $\begin{array}{l}3.6 U \\
7.2 U \\
7.3 U \\
7.2 U \\
3.8 U \\
3.7 U \\
3.9 U\end{array}$ & $\begin{array}{l}3.6 U \\
7.2 U \\
7.3 U \\
7.2 U \\
3.8 U \\
3.7 U \\
3.9 U\end{array}$ & $\begin{array}{l}1.1 \mathrm{U} \\
2.1 \mathrm{U} \\
2.2 \mathrm{U} \\
2.1 \mathrm{U} \\
1.1 \mathrm{U} \\
1.1 \mathrm{U} \\
1.2 \mathrm{U}\end{array}$ & $\begin{array}{l}3.5 \mathrm{U} \\
7.0 \mathrm{U} \\
7.1 \mathrm{U} \\
7.0 \mathrm{U} \\
3.6 \mathrm{U} \\
3.6 \mathrm{U} \\
3.7 \mathrm{U}\end{array}$ & $\begin{array}{l}220 U \\
220 U \\
220 U \\
220 U \\
230 U \\
220 U \\
230 U\end{array}$ \\
\hline $\begin{array}{l}\text { SFW COMP, Replicate } 1 \\
\text { SFW COMP, Replicate } 2 \\
\text { SFW COMP, Replicate } 3 \\
\text { SFW COMP } \\
\text { SFW COMP } \\
\text { SFW COMP } \\
\text { SFW COMP }\end{array}$ & $\begin{array}{l}1 \\
1 \\
1 \\
2 \\
3 \\
4 \\
5\end{array}$ & $\begin{array}{l}1 \\
1 \\
1 \\
2 \\
2 \\
1 \\
1\end{array}$ & $\begin{array}{l}12.99 \\
13.36 \\
13.85 \\
12.32 \\
13.78 \\
13.08 \\
13.95\end{array}$ & $\begin{array}{l}158 \\
129 \\
109 \\
165 \\
132 \\
127 \\
198\end{array}$ & $\begin{array}{l}7.1 U \\
6.9 U \\
6.9 U \\
4.1 U \\
3.6 U \\
3.7 U \\
3.5 U\end{array}$ & $\begin{array}{l}7.1 \mathrm{U} \\
6.9 \mathrm{U} \\
6.9 \mathrm{U} \\
4.1 \mathrm{U} \\
3.6 \mathrm{U} \\
3.7 \mathrm{U} \\
3.5 \mathrm{U}\end{array}$ & $\begin{array}{l}7.1 \mathrm{U} \\
6.9 \mathrm{U} \\
6.9 \mathrm{U} \\
4.1 \mathrm{U} \\
3.6 \mathrm{U} \\
3.7 \mathrm{U} \\
3.5 \mathrm{U}\end{array}$ & $\begin{array}{l}7.1 \mathrm{U} \\
6.9 \mathrm{U} \\
6.9 \mathrm{U} \\
4.1 \mathrm{U} \\
3.6 \mathrm{U} \\
3.7 \mathrm{U} \\
3.5 \mathrm{U}\end{array}$ & $\begin{array}{l}7.1 U \\
6.9 U \\
6.9 U \\
4.1 U \\
3.6 U \\
3.7 U \\
3.5 U\end{array}$ & $\begin{array}{l}2.2 U \\
2.1 U \\
2.0 U \\
1.2 U \\
1.1 U \\
1.1 U \\
1.1 U\end{array}$ & $\begin{array}{l}6.9 U \\
6.7 U \\
6.7 U \\
3.9 U \\
3.6 U \\
3.7 U \\
3.4 U\end{array}$ & $\begin{array}{l}230 \mathrm{U} \\
230 \mathrm{U} \\
220 \mathrm{U} \\
240 \mathrm{U} \\
220 \mathrm{U} \\
230 \mathrm{U} \\
220 \mathrm{U}\end{array}$ \\
\hline $\begin{array}{l}\text { UIH COMP } \\
\text { UIH COMP } \\
\text { UIH COMP } \\
\text { UIH COMP } \\
\text { UIH COMP }\end{array}$ & $\begin{array}{l}1 \\
2 \\
3 \\
4 \\
5\end{array}$ & $\begin{array}{l}2 \\
1 \\
3 \\
1 \\
1\end{array}$ & $\begin{array}{l}13.70 \\
13.21 \\
13.03 \\
13.28 \\
12.99\end{array}$ & $\begin{array}{l}22.5 \\
31.9 \\
31.5 \\
28.2 \\
30.6\end{array}$ & $\begin{array}{l}3.6 U \\
3.8 U \\
3.8 U \\
3.7 U \\
7.5 U\end{array}$ & $\begin{array}{l}3.6 \mathrm{U} \\
3.8 \mathrm{U} \\
3.8 \mathrm{U} \\
3.7 \mathrm{U} \\
7.5 \mathrm{U}\end{array}$ & $\begin{array}{l}3.6 \mathrm{U} \\
3.8 \mathrm{U} \\
3.8 \mathrm{U} \\
3.7 \mathrm{U} \\
7.5 \mathrm{U}\end{array}$ & $\begin{array}{l}3.6 \mathrm{U} \\
3.8 \mathrm{U} \\
3.8 \mathrm{U} \\
3.7 \mathrm{U} \\
7.5 \mathrm{U}\end{array}$ & $\begin{array}{l}3.6 U \\
3.8 U \\
3.8 U \\
3.7 U \\
7.5 U\end{array}$ & $\begin{array}{l}1.1 \mathrm{U} \\
1.1 \mathrm{U} \\
1.2 \mathrm{U} \\
1.1 \mathrm{U} \\
2.2 \mathrm{U}\end{array}$ & $\begin{array}{l}3.5 \mathrm{U} \\
3.7 \mathrm{U} \\
3.8 \mathrm{U} \\
3.6 \mathrm{U} \\
7.2 \mathrm{U}\end{array}$ & $\begin{array}{l}220 \mathrm{U} \\
230 \mathrm{U} \\
230 \mathrm{U} \\
230 \mathrm{U} \\
230 \mathrm{U}\end{array}$ \\
\hline $\begin{array}{l}\text { TB Upper COMP } \\
\text { TB Upper COMP } \\
\text { TB Upper COMP } \\
\text { TB Upper COMP } \\
\text { TB Upper COMP }\end{array}$ & $\begin{array}{l}1 \\
2 \\
3 \\
4 \\
5\end{array}$ & $\begin{array}{l}1 \\
1 \\
2 \\
1 \\
2\end{array}$ & $\begin{array}{l}14.09 \\
13.33 \\
13.17 \\
13.45 \\
14.65\end{array}$ & $\begin{array}{l}2.2 \mathrm{U} \\
6.5 \\
2.4 \mathrm{U} \\
2.3 \mathrm{U} \\
2.1 \mathrm{U}\end{array}$ & $\begin{array}{l}3.5 \mathrm{U} \\
3.7 \mathrm{U} \\
3.7 \mathrm{U} \\
3.6 \mathrm{U} \\
3.3 \mathrm{U}\end{array}$ & $\begin{array}{l}3.5 \mathrm{U} \\
3.7 \mathrm{U} \\
3.7 \mathrm{U} \\
3.6 \mathrm{U} \\
3.3 \mathrm{U}\end{array}$ & $\begin{array}{l}3.5 U \\
3.7 U \\
3.7 U \\
3.6 U \\
3.3 U\end{array}$ & $\begin{array}{l}3.5 \mathrm{U} \\
3.7 \mathrm{U} \\
3.7 \mathrm{U} \\
3.6 \mathrm{U} \\
3.3 \mathrm{U}\end{array}$ & $\begin{array}{l}3.5 U \\
3.7 U \\
3.7 U \\
3.6 U \\
3.3 U\end{array}$ & $\begin{array}{l}1.1 \mathrm{U} \\
1.1 \mathrm{U} \\
1.1 \mathrm{U} \\
1.0 \mathrm{U} \\
1.0 \mathrm{U}\end{array}$ & $\begin{array}{l}3.4 \mathrm{U} \\
3.6 \mathrm{U} \\
3.6 \mathrm{U} \\
3.5 \mathrm{U} \\
3.3 \mathrm{U}\end{array}$ & $\begin{array}{l}210 U \\
230 U \\
230 U \\
220 U \\
210 U\end{array}$ \\
\hline $\begin{array}{l}\text { TB Lower COMP } \\
\text { TB Lower COMP } \\
\text { TB Lower COMP } \\
\text { TB Lower COMP } \\
\text { TB Lower COMP }\end{array}$ & $\begin{array}{l}1 \\
2 \\
3 \\
4 \\
5\end{array}$ & $\begin{array}{l}2 \\
1 \\
2 \\
2 \\
4\end{array}$ & $\begin{array}{l}13.26 \\
12.88 \\
13.79 \\
12.49 \\
13.61\end{array}$ & $\begin{array}{l}2.3 U \\
2.4 U \\
2.2 U \\
2.5 U \\
2.4 U\end{array}$ & $\begin{array}{l}3.7 U \\
3.9 U \\
3.6 U \\
4.0 U \\
3.7 U\end{array}$ & $\begin{array}{l}3.7 \mathrm{U} \\
3.9 \mathrm{U} \\
3.6 \mathrm{U} \\
4.0 \mathrm{U} \\
3.7 \mathrm{U}\end{array}$ & $\begin{array}{l}3.7 \mathrm{U} \\
3.9 \mathrm{U} \\
3.6 \mathrm{U} \\
4.0 \mathrm{U} \\
3.7 \mathrm{U}\end{array}$ & $\begin{array}{l}3.7 \mathrm{U} \\
3.9 \mathrm{U} \\
3.6 \mathrm{U} \\
4.0 \mathrm{U} \\
3.7 \mathrm{U}\end{array}$ & $\begin{array}{l}3.7 \mathrm{U} \\
3.9 \mathrm{U} \\
3.6 \mathrm{U} \\
4.0 \mathrm{U} \\
3.7 \mathrm{U}\end{array}$ & $\begin{array}{l}1.1 \mathrm{U} \\
1.2 \mathrm{U} \\
1.1 \mathrm{U} \\
1.2 \mathrm{U} \\
1.1 \mathrm{U}\end{array}$ & $\begin{array}{l}3.6 \mathrm{U} \\
3.7 \mathrm{U} \\
3.5 \mathrm{U} \\
3.8 \mathrm{U} \\
3.6 \mathrm{U}\end{array}$ & $\begin{array}{l}230 U \\
230 U \\
220 U \\
240 U \\
220 U\end{array}$ \\
\hline
\end{tabular}




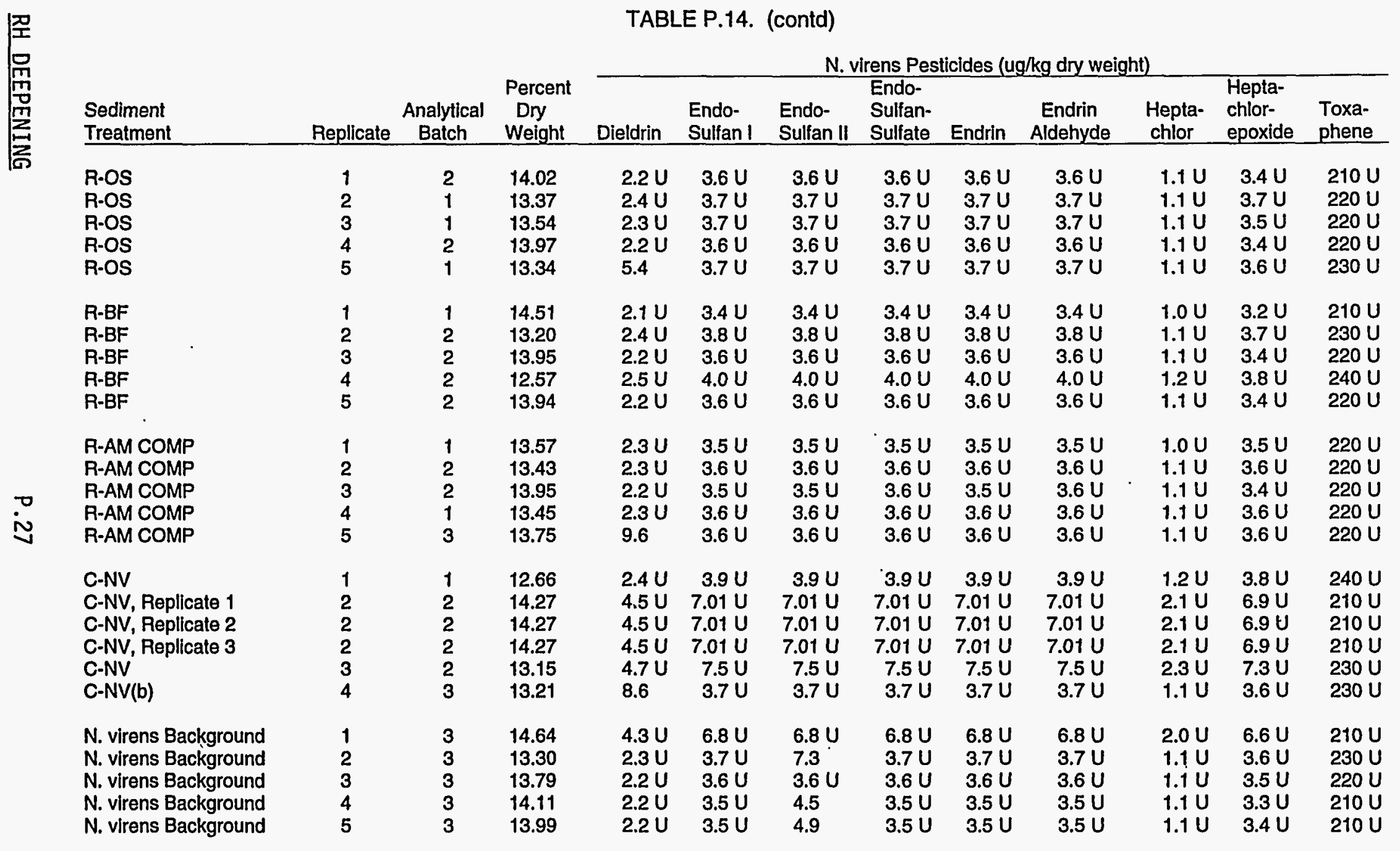

(a) U Undetected at or above detection limit.

(b) Insufficient organisms to test all five replicates. 


\begin{tabular}{|c|c|c|c|c|c|c|c|c|c|c|c|}
\hline \multirow[b]{2}{*}{$\begin{array}{l}\text { Sediment } \\
\text { Treatment }\end{array}$} & \multirow[b]{2}{*}{ Replicate } & \multirow[b]{2}{*}{$\begin{array}{c}\text { Analytical } \\
\text { Batch }\end{array}$} & \multicolumn{9}{|c|}{ N. virens Pesticides (ug $/ \mathrm{kg}$ wet weight) } \\
\hline & & & Aldrin & $\begin{array}{l}\text { Alpha- } \\
\text { BHC }\end{array}$ & $\begin{array}{l}\text { Beta- } \\
\text { BHC } \\
\end{array}$ & $\begin{array}{l}\text { Delta- } \\
\text { BHC }\end{array}$ & $\begin{array}{l}\text { Gamma- } \\
\text { BHC }\end{array}$ & Chlordane & $\begin{array}{l}4,44^{\prime}- \\
\text { DDD }\end{array}$ & $\begin{array}{l}4,4^{\prime}- \\
\text { DDE }\end{array}$ & $\begin{array}{l}4,4^{\prime}- \\
\text { DDT }\end{array}$ \\
\hline $\begin{array}{l}\text { Target DL(a) } \\
\text { Achieved DL }\end{array}$ & & & $\begin{array}{c}2 \\
0.09-0.36\end{array}$ & $\begin{array}{c}2 \\
0.24-1.00\end{array}$ & $\begin{array}{c}2 \\
0.24-1.00\end{array}$ & $\begin{array}{c}2 \\
0.24-1.00\end{array}$ & $\begin{array}{c}2 \\
0.12-0.48\end{array}$ & $\begin{array}{r}30 \\
30-30\end{array}$ & $\begin{array}{c}2 \\
0.23-0.94\end{array}$ & $\begin{array}{c}2 \\
0.07-0.28\end{array}$ & $\begin{array}{c}2 \\
0.17-0.71\end{array}$ \\
\hline $\begin{array}{l}\text { SF COMP } \\
\text { SF COMP, Replicate } 1 \\
\text { SF COMP, Replicate } 2 \\
\text { SF COMP, Replicate } 3 \\
\text { SF COMP } \\
\text { SF COMP } \\
\text { SF COMP }\end{array}$ & $\begin{array}{l}1 \\
2 \\
2 \\
2 \\
3 \\
4 \\
5\end{array}$ & $\begin{array}{l}1 \\
3 \\
3 \\
3 \\
1 \\
1 \\
2\end{array}$ & $\begin{array}{l}0.18 U(b) \\
1.17 \\
0.36 U \\
1.30 \\
0.18 U \\
0.18 U \\
0.18 U\end{array}$ & $\begin{array}{l}0.49 \mathrm{U} \\
0.98 \mathrm{U} \\
0.99 \mathrm{U} \\
0.98 \mathrm{U} \\
0.50 \mathrm{U} \\
0.49 \mathrm{U} \\
0.50 \mathrm{U}\end{array}$ & $\begin{array}{l}0.49 U \\
0.98 U \\
0.99 U \\
0.98 U \\
0.50 U \\
0.49 U \\
0.50 U\end{array}$ & $\begin{array}{l}0.49 U \\
0.98 U \\
0.99 U \\
0.98 U \\
0.50 U \\
0.49 U \\
0.50 U\end{array}$ & $\begin{array}{l}0.23 U \\
0.47 U \\
0.48 U \\
0.47 U \\
0.24 U \\
0.24 U \\
0.24 U\end{array}$ & $\begin{array}{l}30 U \\
30 U \\
30 U \\
30 U \\
30 U \\
30 U \\
30 U\end{array}$ & $\begin{array}{l}13.7 \\
12.3 \\
12.0 \\
12.5 \\
14.8 \\
28.2 \\
22.9\end{array}$ & $\begin{array}{l}1.04 \\
1.69 \\
1.27 \\
2.00 \\
1.20 \\
1.29 \\
1.30\end{array}$ & $\begin{array}{l}7.11 \\
8.69 \\
7.98 \\
6.89 \\
3.14 U \\
4.30 \\
2.80\end{array}$ \\
\hline $\begin{array}{l}\text { SFW COMP, Replicate } 1 \\
\text { SFW COMP, Replicate } 2 \\
\text { SFW COMP, Replicate } 3 \\
\text { SFW COMP } \\
\text { SFW COMP } \\
\text { SFW COMP } \\
\text { SFW COMP }\end{array}$ & $\begin{array}{l}1 \\
1 \\
1 \\
2 \\
3 \\
4 \\
5\end{array}$ & $\begin{array}{l}1 \\
1 \\
1 \\
2 \\
2 \\
1 \\
1\end{array}$ & $\begin{array}{l}2.59 \\
2.66 \\
2.63 \\
0.18 U \\
0.18 U \\
1.44 \\
1.56\end{array}$ & $\begin{array}{l}0.92 U \\
0.92 U \\
0.95 U \\
0.50 U \\
0.50 U \\
0.49 U \\
0.49 U\end{array}$ & $\begin{array}{l}0.92 U \\
0.92 U \\
0.95 U \\
0.50 U \\
0.50 U \\
0.49 U \\
0.49 U\end{array}$ & $\begin{array}{l}0.92 U \\
0.92 U \\
0.95 U \\
0.50 U \\
0.50 U \\
0.49 U \\
0.49 U\end{array}$ & $\begin{array}{l}0.44 U \\
0.44 U \\
0.46 U \\
0.24 U \\
0.24 U \\
0.24 U \\
0.23 U\end{array}$ & $\begin{array}{l}30 U \\
30 U \\
30 U \\
30 U \\
30 U \\
30 U \\
30 U\end{array}$ & $\begin{array}{l}32.1 \\
27.1 \\
23.2 \\
45.8 \\
47.1 \\
40.5 \\
89.6\end{array}$ & $\begin{array}{l}0.26 U \\
0.26 U \\
0.26 U \\
0.14 U \\
0.14 U \\
0.14 U \\
0.14 U\end{array}$ & $\begin{array}{l}5.72 \\
4.92 \\
3.87 \\
3.36 \\
4.03 \\
4.37 \\
6.36\end{array}$ \\
\hline $\begin{array}{l}\text { UIH COMP } \\
\text { UIH COMP } \\
\text { UIH COMP } \\
\text { UIH COMP } \\
\text { UIH COMP }\end{array}$ & $\begin{array}{l}1 \\
2 \\
3 \\
4 \\
5\end{array}$ & $\begin{array}{l}2 \\
1 \\
3 \\
1 \\
1\end{array}$ & $\begin{array}{l}0.18 U \\
0.18 U \\
0.18 U \\
0.18 U \\
0.35 U\end{array}$ & $\begin{array}{l}0.49 U \\
0.50 U \\
0.50 U \\
0.49 U \\
0.97 U\end{array}$ & $\begin{array}{l}0.49 U \\
0.50 U \\
0.50 U \\
0.49 U \\
0.97 U\end{array}$ & $\begin{array}{l}0.49 U \\
0.50 U \\
0.50 U \\
0.49 U \\
0.97 U\end{array}$ & $\begin{array}{l}0.24 U \\
0.24 U \\
0.24 U \\
0.24 U \\
0.47 U\end{array}$ & $\begin{array}{l}30 \mathrm{U} \\
30 \mathrm{U} \\
30 \mathrm{U} \\
30 \mathrm{U} \\
30 \mathrm{U}\end{array}$ & $\begin{array}{l}2.41 \\
4.97 \\
10.4 \\
10.4 \\
9.15\end{array}$ & $\begin{array}{l}0.14 U \\
0.14 U \\
1.19 \\
1.10 \\
0.27 U\end{array}$ & $\begin{array}{l}5.43 \\
3.19 \\
6.18 \\
0.35 U \\
0.69 U\end{array}$ \\
\hline $\begin{array}{l}\text { TB Upper COMP } \\
\text { TB Upper COMP } \\
\text { TB Upper COMP } \\
\text { TB Upper COMP } \\
\text { TB Upper COMP }\end{array}$ & $\begin{array}{l}1 \\
2 \\
3 \\
4 \\
5\end{array}$ & $\begin{array}{l}1 \\
1 \\
2 \\
1 \\
2\end{array}$ & $\begin{array}{l}0.18 U \\
0.18 U \\
0.18 U \\
0.17 U \\
0.18 U\end{array}$ & $\begin{array}{l}0.50 U \\
0.49 U \\
0.49 U \\
0.48 U \\
0.49 U\end{array}$ & $\begin{array}{l}0.50 U \\
0.49 U \\
0.49 U \\
0.48 U \\
0.49 U\end{array}$ & $\begin{array}{l}0.50 U \\
0.49 U \\
0.49 U \\
0.48 U \\
0.49 U\end{array}$ & $\begin{array}{l}0.24 U \\
0.24 U \\
0.24 U \\
0.23 U \\
0.24 U\end{array}$ & $\begin{array}{l}30 U \\
30 U \\
30 U \\
30 U \\
30 U\end{array}$ & $\begin{array}{l}0.46 U \\
0.46 U \\
0.46 U \\
0.45 U \\
0.46 U\end{array}$ & $\begin{array}{l}0.14 U \\
0.14 U \\
0.14 U \\
0.13 U \\
0.14 U\end{array}$ & $\begin{array}{l}0.35 U \\
0.35 U \\
0.35 U \\
2.02 \\
2.65\end{array}$ \\
\hline $\begin{array}{l}\text { TB Lower COMP } \\
\text { TB Lower COMP } \\
\text { TB Lower COMP } \\
\text { TB Lower COMP } \\
\text { TB Lower COMP }\end{array}$ & $\begin{array}{l}1 \\
2 \\
3 \\
4 \\
5\end{array}$ & $\begin{array}{l}2 \\
1 \\
2 \\
2 \\
4\end{array}$ & $\begin{array}{l}0.18 U \\
0.18 U \\
0.18 U \\
0.18 U \\
0.18 U\end{array}$ & $\begin{array}{l}0.49 U \\
0.50 U \\
0.50 U \\
0.50 U \\
0.50 U\end{array}$ & $\begin{array}{l}0.49 U \\
0.50 U \\
0.50 U \\
0.50 U \\
0.50 U\end{array}$ & $\begin{array}{l}0.49 U \\
0.50 U \\
0.50 U \\
0.50 U \\
0.50 U\end{array}$ & $\begin{array}{l}0.24 U \\
0.24 U \\
0.24 U \\
0.24 U \\
0.24 U\end{array}$ & $\begin{array}{l}30 U \\
30 U \\
30 U \\
30 U \\
30 U\end{array}$ & $\begin{array}{l}0.46 U \\
0.46 U \\
0.46 U \\
0.46 U \\
0.47 U\end{array}$ & $\begin{array}{l}0.14 U \\
0.14 U \\
0.14 U \\
0.14 U \\
0.14 U\end{array}$ & $\begin{array}{l}2.42 \\
2.10 \\
1.87 \\
1.95 \\
0.36 \mathrm{U}\end{array}$ \\
\hline
\end{tabular}




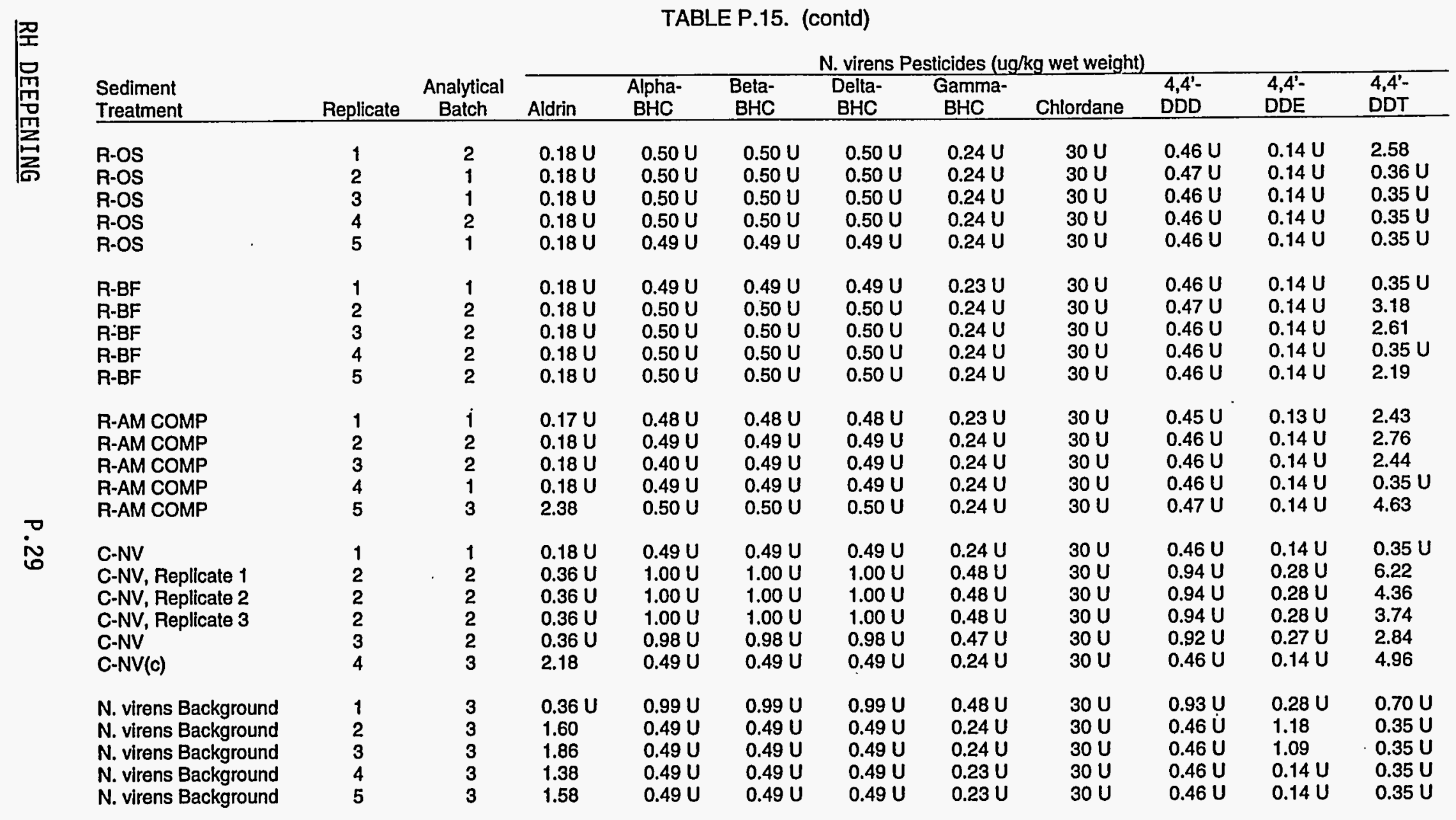

(a) DL Detection limit.

(b) U Undetected at or above detection limit.

(c) Insufficient organisms to test all five replicates. 


\begin{tabular}{|c|c|c|c|c|c|c|c|c|c|c|c|}
\hline \multirow[b]{2}{*}{$\begin{array}{l}\text { Sediment } \\
\text { Treatment }\end{array}$} & \multirow[b]{2}{*}{ Replicate } & \multirow[b]{2}{*}{$\begin{array}{c}\text { Analytical } \\
\text { Batch }\end{array}$} & \multicolumn{9}{|c|}{ N. virens Pesticldes (ug/kg wet weight) } \\
\hline & & & Dieldrin & $\begin{array}{l}\text { Endo- } \\
\text { Sulfan I }\end{array}$ & $\begin{array}{l}\text { Endo- } \\
\text { Sulfan II }\end{array}$ & $\begin{array}{l}\text { Endo- } \\
\text { Sulfan- } \\
\text { Sulfate } \\
\end{array}$ & Endrin & $\begin{array}{l}\text { Endrin } \\
\text { Aldehyde }\end{array}$ & $\begin{array}{c}\text { Hepta- } \\
\text { chlor }\end{array}$ & $\begin{array}{l}\text { Hepta- } \\
\text { chlor- } \\
\text { epoxide }\end{array}$ & $\begin{array}{l}\text { Toxa- } \\
\text { phene }\end{array}$ \\
\hline $\begin{array}{l}\text { Target } \mathrm{DL}(\mathrm{a}) \\
\text { Achileved } \mathrm{DL}\end{array}$ & & & $\begin{array}{c}2 \\
0.15-0.64\end{array}$ & $\begin{array}{c}2 \\
0.24-1.00\end{array}$ & $\begin{array}{c}2 \\
0.24-1.00\end{array}$ & $\begin{array}{c}2 \\
0.24-1.00\end{array}$ & $\begin{array}{c}2 \\
0.24-1.00\end{array}$ & $\begin{array}{c}2 \\
0.24-1.00\end{array}$ & $\begin{array}{c}2 \\
0.07-0.30\end{array}$ & $\begin{array}{c}2 \\
0.24-0.98\end{array}$ & $\begin{array}{c}30 \\
30-30\end{array}$ \\
\hline SF COMP & 1 & 1 & 5.84 & $0.49 U(b)$ & $4.90 \mathrm{U}$ & $0.49 \mathrm{U}$ & $0.49 U$ & $0.49 \mathrm{U}$ & $0.15 \mathrm{U}$ & $0.47 \mathrm{U}$ & $30 \mathrm{U}$ \\
\hline SF COMP, Replicate 1 & 2 & 3 & 6.47 & $0.98 \mathrm{U}$ & $0.98 \mathrm{U}$ & $0.98 \mathrm{U}$ & $0.98 \mathrm{U}$ & $0.98 \mathrm{U}$ & $0.29 \mathrm{U}$ & $0.95 \mathrm{U}$ & $30 \mathrm{U}$ \\
\hline SF COMP, Replicate 2 & 2 & 3 & 6.20 & $0.99 \mathrm{U}$ & $0.99 \mathrm{U}$ & $0.99 \mathrm{U}$ & $0.99 \mathrm{U}$ & $0.99 \mathrm{U}$ & $0.30 \mathrm{U}$ & $0.97 \mathrm{U}$ & $30 \mathrm{U}$ \\
\hline SF COMP, Replicate 3 & 2 & 3 & 6.68 & $0.98 \mathrm{U}$ & $0.98 \mathrm{U}$ & $0.98 \mathrm{U}$ & $0.98 \mathrm{U}$ & $0.98 \mathrm{U}$ & $0.29 \mathrm{U}$ & $0.95 \mathrm{U}$ & $30 \mathrm{U}$ \\
\hline SF COMP & 3 & 1 & 6.08 & $0.50 \mathrm{U}$ & $0.50 \mathrm{U}$ & $0.50 \mathrm{U}$ & $0.50 \mathrm{U}$ & $0.50 \mathrm{U}$ & $0.15 \mathrm{U}$ & $0.48 U$ & $30 \mathrm{U}$ \\
\hline SF COMP & 4 & 1 & 8.13 & $0.49 \mathrm{U}$ & $0.49 \mathrm{U}$ & $0.49 \mathrm{U}$ & $0.49 \mathrm{U}$ & $0.49 \mathrm{U}$ & $0.15 U$ & $0.48 \mathrm{U}$ & $30 \mathrm{U}$ \\
\hline SF COMP & 5 & 2 & 5.27 & $0.50 \mathrm{U}$ & $0.50 \mathrm{U}$ & $0.50 \mathrm{U}$ & $0.50 \mathrm{U}$ & $0.50 \mathrm{U}$ & $0.15 U$ & $0.48 \mathrm{U}$ & $30 \mathrm{U}$ \\
\hline SFW COMP, Replicate 1 & 1 & 1 & 20.5 & $0.92 \mathrm{U}$ & $0.92 \mathrm{U}$ & $0.92 U$ & $0.92 U$ & $0.92 U$ & $0.28 \mathrm{U}$ & $0.90 \mathrm{U}$ & $30 \mathrm{U}$ \\
\hline SFW COMP, Replicate 2 & 1 & 1 & 17.2 & $0.92 U$ & $0.92 \mathrm{U}$ & $0.92 U$ & $0.92 U$ & $0.92 \mathrm{U}$ & $0.28 \mathrm{U}$ & $0.90 \mathrm{U}$ & $30 \mathrm{U}$ \\
\hline SFW COMP, Replicate 3 & 1 & 1 & 15.1 & $0.95 \mathrm{U}$ & $0.95 \mathrm{U}$ & $0.95 \mathrm{U}$ & $0.95 U$ & $0.95 \mathrm{U}$ & $0.28 U$ & $0.93 U$ & $30 \mathrm{U}$ \\
\hline SFW COMP & 2 & 2 & 20.3 & $0.50 \mathrm{U}$ & $0.50 \mathrm{U}$ & $0.50 \mathrm{U}$ & $0.50 \mathrm{U}$ & $0.50 \mathrm{U}$ & $0.15 U$ & $0.48 \mathrm{U}$ & $30 \mathrm{U}$ \\
\hline SFW COMP & 3 & 2 & 18.2 & $0.50 \mathrm{U}$ & $0.50 \mathrm{U}$ & $0.50 \mathrm{U}$ & $0.50 \mathrm{U}$ & $0.50 \mathrm{U}$ & $0.15 U$ & $0.49 \mathrm{U}$ & $30 \mathrm{U}$ \\
\hline SFW COMP & 4 & 1 & 16.7 & $0.49 \mathrm{U}$ & $0.49 \mathrm{U}$ & $0.49 U$ & $0.49 \mathrm{U}$ & $0.49 U$ & $0.15 \mathrm{U}$ & $0.48 \mathrm{U}$ & $30 \mathrm{U}$ \\
\hline SFW COMP & 5 & 1 & 27.7 & $0.49 \mathrm{U}$ & $0.49 \mathrm{U}$ & $0.49 \mathrm{U}$ & $0.49 \mathrm{U}$ & $0.49 \mathrm{U}$ & $0.15 \mathrm{U}$ & $0.47 \mathrm{U}$ & $30 \mathrm{U}$ \\
\hline UIH COMP & 1 & 2 & 3.08 & $0.49 \mathrm{U}$ & $0.49 \mathrm{U}$ & $0.49 \mathrm{U}$ & $0.49 \mathrm{U}$ & $0.49 \mathrm{U}$ & $0.15 \mathrm{U}$ & $0.48 \mathrm{U}$ & $30 U$ \\
\hline UIH COMP & 2 & 1 & 4.21 & $0.50 \mathrm{U}$ & $0.50 \mathrm{U}$ & $0.50 \mathrm{U}$ & $0.50 \mathrm{U}$ & $0.50 \mathrm{U}$ & $0.15 \mathrm{U}$ & $0.49 \mathrm{U}$ & $30 \mathrm{U}$ \\
\hline UIH COMP & 3 & 3 & 4.10 & $0.50 \mathrm{U}$ & $0.50 \mathrm{U}$ & $0.50 \mathrm{U}$ & $0.50 \mathrm{U}$ & $0.50 \mathrm{U}$ & $0.15 U$ & $0.49 U$ & $30 \mathrm{U}$ \\
\hline UIH COMP & 4 & 1 & 3.75 & $0.49 \mathrm{U}$ & $0.49 \mathrm{U}$ & $0.49 \mathrm{U}$ & $0.49 \mathrm{U}$ & $0.49 \mathrm{U}$ & $0.15 U$ & $0.48 \mathrm{U}$ & $30 \mathrm{U}$ \\
\hline UIH COMP & 5 & 1 & 3.97 & $0.97 \mathrm{U}$ & $0.97 \mathrm{U}$ & $0.97 \mathrm{U}$ & $0.97 \mathrm{U}$ & $0.97 \mathrm{U}$ & $0.29 U$ & $0.94 \mathrm{U}$ & $30 \mathrm{U}$ \\
\hline TB Upper COMP & 1 & 1 & $0.31 U$ & $0.50 \mathrm{U}$ & $0.50 \mathrm{U}$ & $0.50 \mathrm{U}$ & $0.50 \mathrm{U}$ & $0.50 \mathrm{U}$ & $0.15 \mathrm{U}$ & $0.48 \mathrm{U}$ & $30 \mathrm{U}$ \\
\hline TB Upper COMP & 2 & 1 & 0.87 & $0.49 \mathrm{U}$ & $0.49 U$ & $0.49 U$ & $0.49 \mathrm{U}$ & $0.49 \mathrm{U}$ & $0.15 \mathrm{U}$ & $0.48 \mathrm{U}$ & $30 \mathrm{U}$ \\
\hline TB Upper COMP & 3 & 2 & $0.31 \mathrm{U}$ & $0.49 U$ & $0.49 \mathrm{U}$ & $0.49 U$ & $0.49 \mathrm{U}$ & $0.49 U$ & $0.15 \mathrm{U}$ & $0.48 \mathrm{U}$ & $30 \mathrm{U}$ \\
\hline TB Upper COMP & 4 & 1 & $0.31 \mathrm{U}$ & $0.48 \mathrm{U}$ & $0.48 \mathrm{U}$ & $0.48 \mathrm{U}$ & $0.48 \mathrm{U}$ & $0.48 U$ & $0.14 \mathrm{U}$ & $0.47 \mathrm{U}$ & $30 \mathrm{U}$ \\
\hline TB Upper COMP & 5 & 2 & $0.31 \mathrm{U}$ & $0.49 \mathrm{U}$ & $0.49 \mathrm{U}$ & $0.49 \mathrm{U}$ & $0.49 \mathrm{U}$ & $0.49 \mathrm{U}$ & $0.15 \mathrm{U}$ & $0.48 \mathrm{U}$ & $30 \mathrm{U}$ \\
\hline TB Lower COMP & 1 & 2 & $0.31 U$ & $0.49 U$ & $0.49 \mathrm{U}$ & $0.49 \mathrm{U}$ & $0.49 \mathrm{U}$ & $0.49 \mathrm{U}$ & $0.15 U$ & $0.48 \mathrm{U}$ & $30 \mathrm{U}$ \\
\hline TB Lower COMP & 2 & 1 & $0.31 \mathrm{U}$ & $0.50 \mathrm{U}$ & $0.50 \mathrm{U}$ & $0.50 \mathrm{U}$ & $0.50 \mathrm{U}$ & $0.50 \mathrm{U}$ & $0.15 \mathrm{U}$ & $0.48 \mathrm{U}$ & $30 \mathrm{U}$ \\
\hline TB Lower COMP & 3 & 2 & $0.31 U$ & $0.50 \mathrm{U}$ & $0.50 \mathrm{U}$ & $0.50 \mathrm{U}$ & $0.50 \mathrm{U}$ & $0.50 \mathrm{U}$ & $0.15 \mathrm{U}$ & $0.48 \mathrm{U}$ & $30 \mathrm{U}$ \\
\hline TB Lower COMP & 4 & 2 & $0.31 \mathrm{U}$ & $0.50 \mathrm{U}$ & $0.50 \mathrm{U}$ & $0.50 \mathrm{U}$ & $0.50 \mathrm{U}$ & $0.50 \mathrm{U}$ & $0.15 \mathrm{U}$ & $0.48 \mathrm{U}$ & $30 \mathrm{U}$ \\
\hline TB Lower COMP & 5 & 4 & $0.32 U$ & $0.50 \mathrm{U}$ & $0.50 \mathrm{U}$ & $0.50 \mathrm{U}$ & $0.50 \mathrm{U}$ & $0.50 \mathrm{U}$ & $0.15 \mathrm{U}$ & $0.49 \mathrm{U}$ & $30 \mathrm{U}$ \\
\hline
\end{tabular}




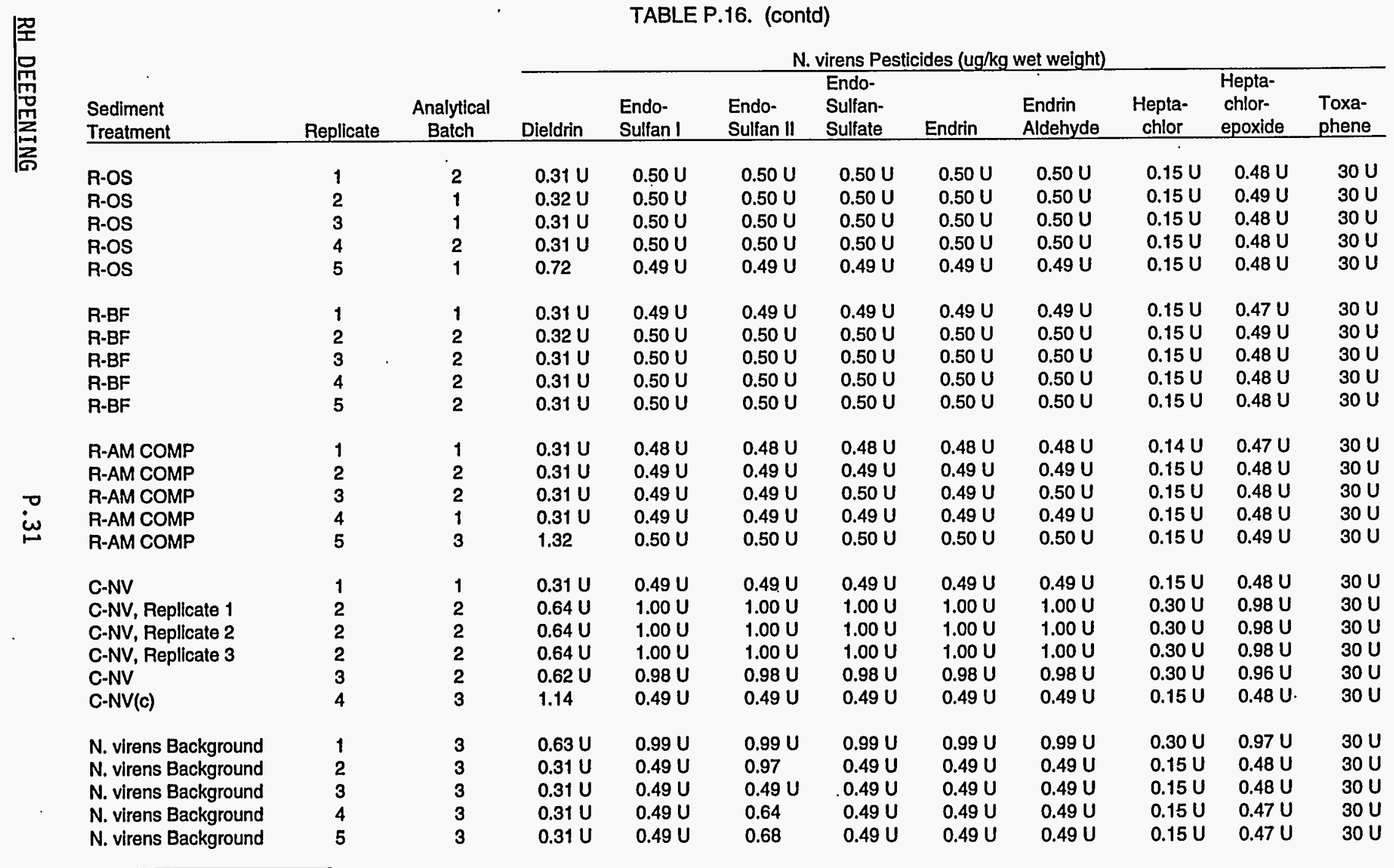

(a) DL Detection limit.

(b) U Undetected at or above detection limit.

(c) Insufficient organisms to test all five replicates. 
TABLE P.17. Quality Control Data for Chlorinated Pesticides (alphabetical, Aldrin - 4,4'-DDT), Wet Weight, Wet Weight, in Tissue of N. virens, Richmond Harbor Deepening Project

\begin{tabular}{|c|c|c|c|c|c|c|c|c|c|c|c|}
\hline \multirow[b]{2}{*}{$\begin{array}{l}\text { Sediment } \\
\text { Treatment }\end{array}$} & \multirow[b]{2}{*}{ Replicate } & \multirow[b]{2}{*}{$\begin{array}{c}\text { Analytical } \\
\text { Batch }\end{array}$} & \multicolumn{9}{|c|}{ N. virens Pesticides (ug/kg wet weight) } \\
\hline & & & Aldrin. & $\begin{array}{l}\text { Alpha- } \\
\text { BHC }\end{array}$ & $\begin{array}{l}\text { Beta- } \\
\text { BHC }\end{array}$ & $\begin{array}{l}\text { Delta- } \\
\text { BHC }\end{array}$ & $\begin{array}{l}\text { Gamma- } \\
\text { BHC }\end{array}$ & Chlordane & $\begin{array}{l}4,4 '- \\
\text { DDD }\end{array}$ & $\begin{array}{l}\text { 4,4'- } \\
\text { DDE }\end{array}$ & $\begin{array}{l}4,4^{\prime}- \\
\text { DDT }\end{array}$ \\
\hline \multicolumn{12}{|l|}{ Method Blanks } \\
\hline $\begin{array}{l}\text { Blank-1 } \\
\text { Blank-1 } \\
\text { Blank-1 }\end{array}$ & & $\begin{array}{l}1 \\
2 \\
3\end{array}$ & $\begin{array}{l}0.18 U(a) \\
0.18 U \\
0.19 U\end{array}$ & $\begin{array}{l}0.49 \mathrm{U} \\
0.50 \mathrm{U} \\
0.53 \mathrm{U}\end{array}$ & $\begin{array}{l}0.49 \mathrm{U} \\
0.50 \mathrm{U} \\
0.53 \mathrm{U}\end{array}$ & $\begin{array}{l}0.49 U \\
0.50 U \\
0.53 U\end{array}$ & $\begin{array}{l}0.24 U \\
0.24 U \\
0.25 U\end{array}$ & $\begin{array}{l}30 \mathrm{U} \\
30 \mathrm{U} \\
30 \mathrm{U}\end{array}$ & $\begin{array}{l}0.46 U \\
0.46 U \\
0.49 U\end{array}$ & $\begin{array}{l}0.14 U \\
0.14 U \\
0.15 U\end{array}$ & $\begin{array}{l}0.35 U \\
0.35 U \\
0.37 U\end{array}$ \\
\hline \multicolumn{12}{|l|}{ Matrix Spikes } \\
\hline $\begin{array}{l}\text { UIH COMP } \\
\text { UIH COMP, MS } \\
\text { Concentration Recovered } \\
\text { Amount Spiked } \\
\text { Percent Recovery }\end{array}$ & $\begin{array}{l}5 \\
5\end{array}$ & $\begin{array}{l}1 \\
1\end{array}$ & $\begin{array}{l}0.35 \mathrm{U} \\
7.99 \\
7.99 \\
8.95 \\
89\end{array}$ & $\begin{array}{l}\text { NA (b) } \\
\text { NA } \\
\text { NA } \\
\text { NS (c) } \\
\text { NA }\end{array}$ & $\begin{array}{l}\text { NA } \\
\text { NA } \\
\text { NA } \\
\text { NS } \\
\text { NA }\end{array}$ & $\begin{array}{l}\text { NA } \\
\text { NA } \\
\text { NA } \\
\text { NS } \\
\text { NA }\end{array}$ & $\begin{array}{l}0.47 \mathrm{U} \\
5.42 \\
5.42 \\
8.95 \\
61\end{array}$ & $\begin{array}{l}\text { NA } \\
\text { NA } \\
\text { NA } \\
\text { NS } \\
\text { NA }\end{array}$ & $\begin{array}{l}\text { NA } \\
\text { NA } \\
\text { NA } \\
\text { NS } \\
\text { NA }\end{array}$ & $\begin{array}{l}\text { NA } \\
\text { NA } \\
\text { NA } \\
\text { NS } \\
\text { NA }\end{array}$ & $\begin{array}{l}0.69 \mathrm{U} \\
46.4 \\
46.4 \\
35.8 \\
130(d)\end{array}$ \\
\hline $\begin{array}{l}\text { C-NV } \\
\text { C-NV, MS } \\
\text { Concentration Recovered } \\
\text { Amount Spiked } \\
\text { Percent Recovery }\end{array}$ & $\begin{array}{l}3 \\
3\end{array}$ & $\begin{array}{l}2 \\
2\end{array}$ & $\begin{array}{l}0.36 \mathrm{U} \\
8.56 \\
8.56 \\
9.70 \\
88\end{array}$ & $\begin{array}{l}\text { NA } \\
\text { NA } \\
\text { NA } \\
\text { NS } \\
\text { NA }\end{array}$ & $\begin{array}{l}\text { NA } \\
\text { NA } \\
\text { NA } \\
\text { NS } \\
\text { NA }\end{array}$ & $\begin{array}{l}\text { NA } \\
\text { NA } \\
\text { NA } \\
\text { NS } \\
\text { NA }\end{array}$ & $\begin{array}{l}0.47 \mathrm{U} \\
10.1 \\
10.1 \\
9.70 \\
104\end{array}$ & $\begin{array}{l}\text { NA } \\
\text { NA } \\
\text { NA } \\
\text { NS } \\
\text { NA }\end{array}$ & $\begin{array}{l}\text { NA } \\
\text { NA } \\
\text { NA } \\
\text { NS } \\
\text { NA }\end{array}$ & $\begin{array}{l}\text { NA } \\
\text { NA } \\
\text { NA } \\
\text { NS } \\
\text { NA }\end{array}$ & $\begin{array}{r}2.84 \\
40.9 \\
38.1 \\
38.8 \\
98\end{array}$ \\
\hline $\begin{array}{l}\text { N. virens Background } \\
\text { N. virens Background, MS } \\
\text { Concentration Recovered } \\
\text { Amount Spiked } \\
\text { Percent Recovery }\end{array}$ & $\begin{array}{l}1 \\
1\end{array}$ & $\begin{array}{l}3 \\
3\end{array}$ & $\begin{array}{l}0.36 \\
7.84 \\
7.84 \\
9.70 \\
81 \%\end{array}$ & $\begin{array}{l}\text { NA } \\
\text { NA } \\
\text { NA } \\
\text { NS } \\
\text { NA }\end{array}$ & $\begin{array}{l}\text { NA } \\
\text { NA } \\
\text { NA } \\
\text { NS } \\
\text { NA }\end{array}$ & $\begin{array}{l}\text { NA } \\
\text { NA } \\
\text { NA } \\
\text { NS } \\
\text { NA }\end{array}$ & $\begin{array}{l}\text { NA } \\
\text { NA } \\
\text { NA } \\
\text { NS } \\
\text { NA }\end{array}$ & $\begin{array}{l}\text { NA } \\
\text { NA } \\
\text { NA } \\
\text { NS } \\
\text { NA }\end{array}$ & $\begin{array}{l}\text { NA } \\
\text { NA } \\
\text { NA } \\
\text { NS } \\
\text { NA }\end{array}$ & $\begin{array}{l}\text { NA } \\
\text { NA } \\
\text { NA } \\
\text { NS } \\
\text { NA }\end{array}$ & $\begin{array}{l}0.70 \\
36.0 \\
35.3 \\
38.8 \\
91 \%\end{array}$ \\
\hline
\end{tabular}

Standard Reference Material

Certified SRM not available for pesticides.

Analytical Replicates

\begin{tabular}{|c|c|c|c|c|c|c|c|c|c|c|c|}
\hline $\begin{array}{l}\text { SFW COMP, Replicate } 1 \\
\text { SFW COMP, Replicate } 2 \\
\text { SFW COMP, Replicate } 3\end{array}$ & $\begin{array}{l}1 \\
1 \\
1\end{array}$ & $\begin{array}{l}1 \\
1 \\
1\end{array}$ & $\begin{array}{l}2.59 \\
2.66 \\
2.63\end{array}$ & $\begin{array}{l}0.92 \mathrm{U} \\
0.92 \mathrm{U} \\
0.95 \mathrm{U}\end{array}$ & $\begin{array}{l}0.92 \mathrm{U} \\
0.92 \mathrm{U} \\
0.95 \mathrm{U}\end{array}$ & $\begin{array}{l}0.92 \mathrm{U} \\
0.92 \mathrm{U} \\
0.95 \mathrm{U}\end{array}$ & $\begin{array}{l}0.44 \mathrm{U} \\
0.44 \mathrm{U} \\
0.46 \mathrm{U}\end{array}$ & $\begin{array}{l}30 \mathrm{U} \\
30 \mathrm{U} \\
30 \mathrm{U}\end{array}$ & $\begin{array}{l}32.1 \\
27.1 \\
23.2\end{array}$ & $\begin{array}{l}0.26 \mathrm{U} \\
0.26 \mathrm{U} \\
0.26 \mathrm{U}\end{array}$ & $\begin{array}{l}5.72 \\
4.92 \\
3.87\end{array}$ \\
\hline RSD & & & $1 \%$ & NA & NA & NA & NA & NA & $16 \%$ & NA & $19 \%$ \\
\hline $\begin{array}{l}\text { C-NV, Replicate } 1 \\
\text { C-NV, Replicate } 2 \\
\text { C-NV, Replicate } 3\end{array}$ & $\begin{array}{l}2 \\
2 \\
2\end{array}$ & $\begin{array}{r}2 \\
2 \\
2\end{array}$ & $\begin{array}{l}0.36 U \\
0.36 U \\
0.36 U\end{array}$ & $\begin{array}{l}1.00 \mathrm{U} \\
1.00 \mathrm{U} \\
1.00 \mathrm{U}\end{array}$ & $\begin{array}{l}1.00 \mathrm{U} \\
1.00 \mathrm{U} \\
1.00 \mathrm{U}\end{array}$ & $\begin{array}{l}1.00 \mathrm{U} \\
1.00 \mathrm{U} \\
1.00 \mathrm{U}\end{array}$ & $\begin{array}{l}0.48 U \\
0.48 U \\
0.48 U\end{array}$ & $\begin{array}{l}30 \mathrm{U} \\
30 \mathrm{U} \\
30 \mathrm{U}\end{array}$ & $\begin{array}{l}0.94 U \\
0.94 U \\
0.94 U\end{array}$ & $\begin{array}{l}0.28 \mathrm{U} \\
0.28 \mathrm{U} \\
0.28 \mathrm{U}\end{array}$ & $\begin{array}{l}6.22 \\
4.36 \\
3.74\end{array}$ \\
\hline RSD & & & NA & NA & NA & NA & NA & NA & NA & NA & $27 \%$ \\
\hline $\begin{array}{l}\text { SF COMP, Replicate } 1 \\
\text { SF COMP, Replicate } 2 \\
\text { SF COMP, Replicate } 3\end{array}$ & $\begin{array}{l}2 \\
2 \\
2\end{array}$ & $\begin{array}{l}3 \\
3 \\
3\end{array}$ & $\begin{array}{l}1.17 \\
0.36 \mathrm{U} \\
1.30\end{array}$ & $\begin{array}{l}0.98 \mathrm{U} \\
0.99 \mathrm{U} \\
0.98 \mathrm{U}\end{array}$ & $\begin{array}{l}0.98 \mathrm{U} \\
0.99 \mathrm{U} \\
0.98 \mathrm{U}\end{array}$ & $\begin{array}{l}0.98 \mathrm{U} \\
0.99 \mathrm{U} \\
0.98 \mathrm{U}\end{array}$ & $\begin{array}{l}0.47 \mathrm{U} \\
0.48 \mathrm{U} \\
0.47 \mathrm{U}\end{array}$ & $\begin{array}{l}30 \mathrm{U} \\
30 \mathrm{U} \\
30 \mathrm{U}\end{array}$ & $\begin{array}{l}12.3 \\
12.0 \\
12.5\end{array}$ & $\begin{array}{l}1.69 \\
1.27 \\
2.00\end{array}$ & $\begin{array}{l}8.69 \\
7.98 \\
6.89\end{array}$ \\
\hline RSD & & & NA & NA & NA & NA & NA & NA & $2 \%$ & $22 \%$ & \\
\hline
\end{tabular}

(a) U Undetected at or above detection limit.

(b) NA Not applicable.

(c) NS Not spiked.

(d) Outside quality control criteria (40-120\%) for matrix spike recoveries. 


\begin{tabular}{|c|c|c|c|c|c|c|c|c|c|c|c|}
\hline Richmo & ond Harbc & Deepenin & Project & & & virens Pes & ides (ug/k & wet weight) & & & \\
\hline $\begin{array}{l}\text { Sediment } \\
\text { Treatment } \\
\end{array}$ & Replicate & $\begin{array}{c}\text { Analytical } \\
\text { Batch }\end{array}$ & Dieldrin & $\begin{array}{l}\text { Endo- } \\
\text { Sulfan I }\end{array}$ & $\begin{array}{l}\text { Endo- } \\
\text { Sullan II }\end{array}$ & $\begin{array}{l}\text { Endo- } \\
\text { Sulfan- } \\
\text { Sulfato } \\
\end{array}$ & Endrin & $\begin{array}{l}\text { Endrin } \\
\text { Aldehyde }\end{array}$ & $\begin{array}{c}\text { Hepta- } \\
\text { chlor }\end{array}$ & $\begin{array}{l}\text { Hepla- } \\
\text { chlor- } \\
\text { epoxide }\end{array}$ & $\begin{array}{l}\text { Toxa- } \\
\text { phene }\end{array}$ \\
\hline \multicolumn{12}{|l|}{ Method Blanks } \\
\hline $\begin{array}{l}\text { Blank-1 } \\
\text { Blank-1 } \\
\text { Blank-1 }\end{array}$ & & $\begin{array}{l}1 \\
2 \\
3\end{array}$ & $\begin{array}{l}0.31 U(a) \\
0.31 U \\
0.33 U\end{array}$ & $\begin{array}{l}0.49 U \\
0.50 U \\
0.53 U\end{array}$ & $\begin{array}{l}0.49 U \\
0.50 U \\
0.53 U\end{array}$ & $\begin{array}{l}0.49 U \\
0.50 U \\
0.53 U\end{array}$ & $\begin{array}{l}0.49 \mathrm{U} \\
0.50 \mathrm{U} \\
0.53 \mathrm{U}\end{array}$ & $\begin{array}{l}0.49 U \\
0.50 U \\
0.53 U\end{array}$ & $\begin{array}{l}0.15 U \\
0.15 U \\
0.16 U\end{array}$ & $\begin{array}{l}0.48 \mathrm{U} \\
0.48 \mathrm{U} \\
0.51 \mathrm{U}\end{array}$ & $\begin{array}{l}30 \mathrm{U} \\
30 \mathrm{U} \\
30 \mathrm{U}\end{array}$ \\
\hline \multicolumn{12}{|l|}{ Matrix Spike } \\
\hline $\begin{array}{l}\text { UIH COMP } \\
\text { UIH COMP, MS } \\
\text { Concentration Recovered } \\
\text { Amount Spiked } \\
\text { Percent Recovery }\end{array}$ & $\begin{array}{l}5 \\
5\end{array}$ & $\begin{array}{l}1 \\
1\end{array}$ & $\begin{array}{l}3.97 \\
34.1 \\
30.1 \\
35.8 \\
84 \%\end{array}$ & $\begin{array}{l}\text { NA (b) } \\
\text { NA } \\
\text { NA } \\
\text { NS (c) } \\
\text { NA }\end{array}$ & $\begin{array}{l}\text { NA } \\
\text { NA } \\
\text { NA } \\
\text { NS } \\
\text { NA }\end{array}$ & $\begin{array}{l}\text { NA } \\
\text { NA } \\
\text { NA } \\
\text { NS } \\
\text { NA }\end{array}$ & $\begin{array}{l}0.97 \mathrm{U} \\
30.6 \\
30.6 \\
35.8 \\
85 \%\end{array}$ & $\begin{array}{l}\text { NA } \\
\text { NA } \\
\text { NA } \\
\text { NS } \\
\text { NA }\end{array}$ & $\begin{array}{c}0.29 \mathrm{U} \\
10.2 \\
10.2 \\
8.95 \\
114 \%\end{array}$ & $\begin{array}{l}\text { NA } \\
\text { NA } \\
\text { NA } \\
\text { NS } \\
\text { NA }\end{array}$ & $\begin{array}{l}\text { NA } \\
\text { NA } \\
\text { NA } \\
\text { NS } \\
\text { NA }\end{array}$ \\
\hline $\begin{array}{l}\text { C-NV } \\
\text { C-NV, MS } \\
\text { Concentration Recovered } \\
\text { Amount Spiked } \\
\text { Percent Recovery }\end{array}$ & $\begin{array}{l}3 \\
3\end{array}$ & $\begin{array}{l}2 \\
2\end{array}$ & $\begin{array}{l}0.62 \mathrm{U} \\
35.2 \\
35.2 \\
38.8 \\
91 \%\end{array}$ & $\begin{array}{l}\text { NA } \\
\text { NA } \\
\text { NA } \\
\text { NS } \\
\text { NA }\end{array}$ & $\begin{array}{l}\text { NA } \\
\text { NA } \\
\text { NA } \\
\text { NS } \\
\text { NA }\end{array}$ & $\begin{array}{l}\text { NA } \\
\text { NA } \\
\text { NA } \\
\text { NS } \\
\text { NA }\end{array}$ & $\begin{array}{l}0.98 \mathrm{U} \\
35.4 \\
35.4 \\
38.8 \\
91 \%\end{array}$ & $\begin{array}{l}\text { NA } \\
\text { NA } \\
\text { NA } \\
\text { NS } \\
\text { NA }\end{array}$ & $\begin{array}{l}0.30 \mathrm{U} \\
7.90 \\
7.90 \\
9.70 \\
81 \%\end{array}$ & $\begin{array}{l}\text { NA } \\
\text { NA } \\
\text { NA } \\
\text { NS } \\
\text { NA }\end{array}$ & $\begin{array}{l}\text { NA } \\
\text { NA } \\
\text { NA } \\
\text { NS } \\
\text { NA }\end{array}$ \\
\hline $\begin{array}{l}\text { N. virens Background } \\
\text { N. virens Background, MS } \\
\text { Concentration Recovered } \\
\text { Amount Splked } \\
\text { Percent Recovery }\end{array}$ & $\begin{array}{l}1 \\
1\end{array}$ & $\begin{array}{l}3 \\
3\end{array}$ & $\begin{array}{l}0.63 \\
34.7 \\
34.7 \\
38.8 \\
89 \%\end{array}$ & $\begin{array}{l}\text { NA } \\
\text { NA } \\
\text { NA } \\
\text { NS } \\
\text { NA }\end{array}$ & $\begin{array}{l}\text { NA } \\
\text { NA } \\
\text { NA } \\
\text { NS } \\
\text { NA }\end{array}$ & $\begin{array}{l}\text { NA } \\
\text { NA } \\
\text { NA } \\
\text { NS } \\
\text { NA }\end{array}$ & $\begin{array}{l}0.99 \\
34.5 \\
34.5 \\
38.8 \\
89 \%\end{array}$ & $\begin{array}{l}\text { NA } \\
\text { NA } \\
\text { NA } \\
\text { NS } \\
\text { NA }\end{array}$ & $\begin{array}{l}0.30 \\
7.32 \\
7.32 \\
9.70 \\
75 \%\end{array}$ & $\begin{array}{l}\text { NA } \\
\text { NA } \\
\text { NA } \\
\text { NS } \\
\text { NA }\end{array}$ & $\begin{array}{l}\text { NA } \\
\text { NA } \\
\text { NA } \\
\text { NS } \\
\text { NA }\end{array}$ \\
\hline
\end{tabular}

Standard Reference Material

Certifled SRM not avallable for pesticides.

Analytical Replicates

\begin{tabular}{|c|c|c|c|c|c|c|c|c|c|c|c|}
\hline $\begin{array}{l}\text { SFW COMP, Replicale } 1 \\
\text { SFW COMP, Replicate } 2 \\
\text { SFW COMP, Replicate } 3\end{array}$ & $\begin{array}{l}1 \\
1 \\
1\end{array}$ & $\begin{array}{l}1 \\
1 \\
1\end{array}$ & $\begin{array}{l}20.5 \\
17.2 \\
15.1\end{array}$ & $\begin{array}{l}0.92 U \\
0.92 U \\
0.95 U\end{array}$ & $\begin{array}{l}0.92 U \\
0.92 U \\
0.95 U\end{array}$ & $\begin{array}{l}0.92 U \\
0.92 U \\
0.95 U\end{array}$ & $\begin{array}{l}0.92 U \\
0.92 U \\
0.95 U\end{array}$ & $\begin{array}{l}0.92 U \\
0.92 U \\
0.95 U\end{array}$ & $\begin{array}{l}0.28 U \\
0.28 U \\
0.28 U\end{array}$ & $\begin{array}{l}0.90 \mathrm{U} \\
0.90 \mathrm{U} \\
0.93 \mathrm{U}\end{array}$ & $\begin{array}{l}30 \mathrm{U} \\
30 \mathrm{U} \\
30 \mathrm{U}\end{array}$ \\
\hline RSD & & & $15 \%$ & NA & NA & NA & NA & NA & NA & NA & NA \\
\hline $\begin{array}{l}\text { C-NV, Replicate } 1 \\
\text { C-NV, Replicate } 2 \\
\text { C-NV, Replicate } 3\end{array}$ & $\begin{array}{l}2 \\
2 \\
2\end{array}$ & $\begin{array}{l}2 \\
2 \\
2\end{array}$ & $\begin{array}{l}0.64 U \\
0.64 U \\
0.64 U\end{array}$ & $\begin{array}{l}1.00 \mathrm{U} \\
1.00 \mathrm{U} \\
1.00 \mathrm{U}\end{array}$ & $\begin{array}{l}1.00 \mathrm{U} \\
1.00 \mathrm{U} \\
1.00 \mathrm{U}\end{array}$ & $\begin{array}{l}1.00 U \\
1.00 U \\
1.00 U\end{array}$ & $\begin{array}{l}1.00 \mathrm{U} \\
1.00 \mathrm{U} \\
1.00 \mathrm{U}\end{array}$ & $\begin{array}{l}1.00 \mathrm{U} \\
1.00 \mathrm{U} \\
1.00 \mathrm{U}\end{array}$ & $\begin{array}{l}0.30 U \\
0.30 U \\
0.30 U\end{array}$ & $\begin{array}{l}0.98 U \\
0.98 U \\
0.98 U\end{array}$ & $\begin{array}{l}30 \mathrm{U} \\
30 \mathrm{U} \\
30 \mathrm{U}\end{array}$ \\
\hline RSD & & & NA & NA & NA & NA & NA & NA & NA & NA & NA \\
\hline
\end{tabular}


TABLE P.18. (contd)

囬

Sediment $\quad$ Replicate
Treatment

Analy

SF COMP Replicate 2

SF COMP, Replicate 3

2
2
2

RSD
(a) U Undetected at or above detection limit.
(b) NA Not applicable.

(c) NS Not spiked.

N. virens Pesticides (ug/kg wet weight)

$\begin{array}{llll}\text { Endo- } & \text { Hepta- } & \\ \text { Sullan- } & \text { Endrin } & \text { Hepla- } & \text { chlor- }\end{array}$ Toxa-

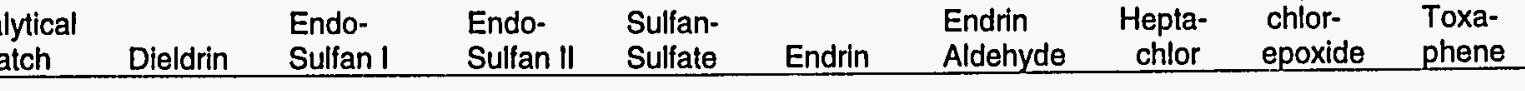

$\begin{array}{llllllllll}3 & 6.47 & 0.98 U & 0.98 U & 0.98 U & 0.98 U & 0.98 U & 0.29 U & 0.95 U & 30 U \\ 3 & 6.20 & 0.99 U & 0.99 U & 0.99 U & 0.99 U & 0.99 U & 0.30 U & 0.97 U & 30 U \\ 3 & 6.68 & 0.98 U & 0.98 U & 0.98 U & 0.98 U & 0.98 U & 0.29 U & 0.95 U & 30 U\end{array}$


TABLE P.19. Polychlorinated Biphenyls (PCBs), Dry Weight, in Tissue of N. virens, Richmond Harbor Deepening Project

\begin{tabular}{|c|c|c|c|c|c|c|c|}
\hline \multirow[b]{2}{*}{$\begin{array}{l}\text { Sediment } \\
\text { Treatment }\end{array}$} & \multirow[b]{2}{*}{ Replicate } & \multirow[b]{2}{*}{$\begin{array}{c}\text { Analytical } \\
\text { Batch }\end{array}$} & \multirow{2}{*}{$\begin{array}{l}\text { Percent } \\
\text { Dry } \\
\text { Weight }\end{array}$} & \multicolumn{4}{|c|}{ N. virens PCBs (ug/kg dry weight) } \\
\hline & & & & $\begin{array}{l}\text { Aroclor } \\
1242\end{array}$ & $\begin{array}{c}\text { Aroclor } \\
1248\end{array}$ & $\begin{array}{l}\text { Aroclor } \\
1254\end{array}$ & $\begin{array}{l}\text { Aroclor } \\
1260\end{array}$ \\
\hline $\begin{array}{l}\text { SF COMP } \\
\text { SF COMP, Replicate } 1 \\
\text { SF COMP, Replicate } 2 \\
\text { SF COMP, Replicate } 3 \\
\text { SF COMP } \\
\text { SF COMP } \\
\text { SF COMP }\end{array}$ & $\begin{array}{l}1 \\
2 \\
2 \\
2 \\
3 \\
4 \\
5\end{array}$ & $\begin{array}{l}1 \\
3 \\
3 \\
3 \\
1 \\
1 \\
2\end{array}$ & $\begin{array}{l}13.45 \\
13.61 \\
13.61 \\
13.61 \\
13.25 \\
13.42 \\
12.94\end{array}$ & $\begin{array}{l}150 U \\
150 U \\
150 U \\
150 U \\
150 U \\
150 U \\
160 U\end{array}$ & $\begin{array}{l}150 U \\
150 U \\
150 U \\
150 U \\
150 U \\
150 U \\
160 U\end{array}$ & $\begin{array}{l}150 U \\
150 U \\
150 U \\
150 U \\
150 U \\
150 U \\
160 U\end{array}$ & $\begin{array}{l}150 U \\
150 U \\
150 U \\
150 U \\
150 U \\
150 U \\
160 U\end{array}$ \\
\hline $\begin{array}{l}\text { SFW COMP, Replicate } 1 \\
\text { SFW COMP, Replicate } 2 \\
\text { SFW COMP, Replicate } 3 \\
\text { SFW COMP } \\
\text { SFW COMP } \\
\text { SFW COMP } \\
\text { SFW COMP }\end{array}$ & $\begin{array}{l}1 \\
1 \\
1 \\
2 \\
3 \\
4 \\
5\end{array}$ & $\begin{array}{l}1 \\
1 \\
1 \\
2 \\
2 \\
1 \\
1\end{array}$ & $\begin{array}{l}12.99 \\
13.36 \\
13.85 \\
12.32 \\
13.78 \\
13.08 \\
13.95\end{array}$ & $\begin{array}{l}150 U \\
150 U \\
140 U \\
160 U \\
150 U \\
150 U \\
140 U\end{array}$ & $\begin{array}{l}150 U \\
150 U \\
140 U \\
160 U \\
150 U \\
150 U \\
140 U\end{array}$ & $\begin{array}{l}150 U \\
150 U \\
140 U \\
160 U \\
150 U \\
150 U \\
140 U\end{array}$ & $\begin{array}{l}150 U \\
150 U \\
140 U \\
160 U \\
150 U \\
150 U \\
140 U\end{array}$ \\
\hline $\begin{array}{l}\text { UIH COMP } \\
\text { UIH COMP } \\
\text { UIH COMP } \\
\text { UIH COMP } \\
\text { UIH COMP }\end{array}$ & $\begin{array}{l}1 \\
2 \\
3 \\
4 \\
5\end{array}$ & $\begin{array}{l}2 \\
1 \\
3 \\
1 \\
1\end{array}$ & $\begin{array}{l}13.70 \\
13.21 \\
13.03 \\
13.28 \\
12.99\end{array}$ & $\begin{array}{l}150 U \\
150 U \\
150 U \\
150 U \\
150 U\end{array}$ & $\begin{array}{l}150 U \\
150 U \\
150 U \\
150 U \\
150 U\end{array}$ & $\begin{array}{l}150 U \\
150 U \\
150 U \\
150 U \\
150 U\end{array}$ & $\begin{array}{l}150 U \\
150 U \\
150 U \\
150 U \\
150 U\end{array}$ \\
\hline $\begin{array}{l}\text { TB Upper COMP } \\
\text { TB Upper COMP } \\
\text { TB Upper COMP } \\
\text { TB Upper COMP } \\
\text { TB Upper COMP }\end{array}$ & $\begin{array}{l}1 \\
2 \\
3 \\
4 \\
5\end{array}$ & $\begin{array}{l}1 \\
1 \\
2 \\
1 \\
2\end{array}$ & $\begin{array}{l}14.09 \\
13.33 \\
13.17 \\
13.45 \\
14.65\end{array}$ & $\begin{array}{l}140 U \\
150 U \\
150 U \\
150 U \\
140 U\end{array}$ & $\begin{array}{l}140 U \\
150 U \\
150 U \\
150 U \\
140 U\end{array}$ & $\begin{array}{l}140 U \\
150 U \\
150 U \\
150 U \\
140 U\end{array}$ & $\begin{array}{l}140 U \\
150 U \\
150 U \\
150 U \\
140 U\end{array}$ \\
\hline $\begin{array}{l}\text { TB Lower COMP } \\
\text { TB Lower COMP } \\
\text { TB Lower COMP } \\
\text { TB Lower COMP } \\
\text { TB Lower COMP }\end{array}$ & $\begin{array}{l}1 \\
2 \\
3 \\
4 \\
5\end{array}$ & $\begin{array}{l}2 \\
1 \\
2 \\
2 \\
4\end{array}$ & $\begin{array}{l}13.26 \\
12.88 \\
13.79 \\
12.49 \\
13.61\end{array}$ & $\begin{array}{l}150 U \\
160 U \\
150 U \\
160 U \\
150 U\end{array}$ & $\begin{array}{l}150 U \\
160 U \\
150 U \\
160 U \\
150 U\end{array}$ & $\begin{array}{l}150 U \\
160 U \\
150 U \\
160 U \\
150 U\end{array}$ & $\begin{array}{l}150 U \\
160 U \\
150 U \\
160 U \\
150 U\end{array}$ \\
\hline $\begin{array}{l}\text { R-OS } \\
\text { R-OS } \\
\text { R-OS } \\
\text { R-OS } \\
\text { R-OS }\end{array}$ & $\begin{array}{l}1 \\
2 \\
3 \\
4 \\
.5\end{array}$ & $\begin{array}{l}2 \\
1 \\
1 \\
2 \\
1\end{array}$ & $\begin{array}{l}14.02 \\
13.37 \\
13.54 \\
13.97 \\
13.34\end{array}$ & $\begin{array}{l}140 U \\
150 U \\
150 U \\
140 U \\
150 U\end{array}$ & $\begin{array}{l}140 U \\
150 U \\
150 U \\
140 U \\
150 U\end{array}$ & $\begin{array}{l}140 U \\
150 U \\
150 U \\
140 U \\
150 U\end{array}$ & $\begin{array}{l}140 U \\
150 U \\
150 U \\
140 U \\
150 U\end{array}$ \\
\hline $\begin{array}{l}R-B F \\
R-B F \\
R-B F \\
R-B F \\
R-B F\end{array}$ & $\begin{array}{l}1 \\
2 \\
3 \\
4 \\
5\end{array}$ & $\begin{array}{l}1 \\
2 \\
2 \\
2 \\
2\end{array}$ & $\begin{array}{l}14.51 \\
13.20 \\
13.95 \\
12.57 \\
13.94\end{array}$ & $\begin{array}{l}140 U \\
150 U \\
140 U \\
160 U \\
140 U\end{array}$ & $\begin{array}{l}140 U \\
150 U \\
140 U \\
160 U \\
140 U\end{array}$ & $\begin{array}{l}140 U \\
150 U \\
140 U \\
160 U \\
140 U\end{array}$ & $\begin{array}{l}140 \mathrm{U} \\
150 \mathrm{U} \\
140 \mathrm{U} \\
160 \mathrm{U} \\
140 \mathrm{U}\end{array}$ \\
\hline
\end{tabular}

RH DEEPENING 
TABLE P.19. (contd)

\begin{tabular}{|c|c|c|c|c|c|c|c|}
\hline \multirow[b]{2}{*}{$\begin{array}{l}\text { Sediment } \\
\text { Treatment }\end{array}$} & \multirow[b]{2}{*}{ Replicate } & \multirow[b]{2}{*}{$\begin{array}{c}\text { Analytical } \\
\text { Batch }\end{array}$} & \multirow{2}{*}{$\begin{array}{l}\text { Percent } \\
\text { Dry } \\
\text { Weight }\end{array}$} & \multicolumn{4}{|c|}{ N. virens PCBs (ug/kg dry weight) } \\
\hline & & & & $\begin{array}{l}\text { Aroclor } \\
1242 \\
\end{array}$ & $\begin{array}{c}\text { Aroclor } \\
1248 \\
\end{array}$ & $\begin{array}{l}\text { Aroclor } \\
1254\end{array}$ & $\begin{array}{l}\text { Aroclor } \\
1260\end{array}$ \\
\hline R-AM COMP & 1 & 1 & 13.57 & $150 \mathrm{U}$ & $150 \mathrm{U}$ & $150 \mathrm{U}$ & $150 \mathrm{U}$ \\
\hline R-AM COMP & 2 & 2 & 13.43 & $150 \mathrm{U}$ & $150 \mathrm{U}$ & $150 \mathrm{U}$ & $150 \mathrm{U}$ \\
\hline R-AM COMP & 3 & 2 & 13.95 & $140 \mathrm{U}$ & $140 U$ & $140 \mathrm{U}$ & $140 \mathrm{U}$ \\
\hline R-AM COMP & 4 & 1 & 13.45 & $150 U$ & $150 U$ & $150 \mathrm{U}$ & $150 \mathrm{U}$ \\
\hline R-AM COMP & 5 & 3 & 13.75 & $150 U$ & $150 U$ & $150 U$ & $150 \mathrm{U}$ \\
\hline C-NV & 1 & 1 & 12.66 & $160 U$ & $160 U$ & $160 U$ & $160 U$ \\
\hline C-NV, Replicate 1 & 2 & 2 & 14.27 & $140 U$ & $140 \mathrm{U}$ & $140 U$ & $140 U$ \\
\hline C-NV, Replicate 2 & 2 & 2 & 14.27 & $140 U$ & $140 \mathrm{U}$ & $140 U$ & $140 U$ \\
\hline C-NV, Replicate 3 & 2 & 2 & 14.27 & $140 \mathrm{U}$ & $140 U$ & $140 U$ & $140 U$ \\
\hline C-NV & 3 & 2 & 13.15 & $150 \mathrm{U}$ & $150 \mathrm{U}$ & $150 U$ & $150 U$ \\
\hline$C-N V(b)$ & 4 & 3 & 13.21 & $150 U$ & $150 U$ & $150 U$ & $150 U$ \\
\hline N. virens Background & 1 & 3 & 14.64 & $140 \mathrm{U}$ & $140 U$ & $140 U$ & $140 U$ \\
\hline N. virens Background & 2 & 3 & 13.30 & $150 U$ & $150 U$ & $150 U$ & $150 \mathrm{U}$ \\
\hline N. virens Background & 3 & 3 & 13.79 & $150 \mathrm{U}$ & $150 \mathrm{U}$ & $150 \mathrm{U}$ & $150 \mathrm{U}$ \\
\hline N. virens Background & 4 & 3 & 14.11 & $140 \mathrm{U}$ & $140 \mathrm{U}$ & $140 U$ & $140 U$ \\
\hline N. virens Background & 5 & 3 & 13.99 & $140 U$ & $140 \mathrm{U}$ & $140 U$ & $140 \mathrm{U}$ \\
\hline
\end{tabular}

(a) $U$ Undetected at or above detection limit.

(b) Insufficient organisms to test all five replicates. 
TABLE P.20. Polychlorinated Biphenyls, Wet Weight, in Tissue of N. virens, Richmond Harbor Deepening Project

\begin{tabular}{|c|c|c|c|c|c|c|}
\hline \multirow[b]{2}{*}{$\begin{array}{l}\text { Sediment } \\
\text { Treatment }\end{array}$} & \multirow[b]{2}{*}{ Replicate } & \multirow[b]{2}{*}{$\begin{array}{c}\text { Analytical } \\
\text { Batch }\end{array}$} & \multicolumn{4}{|c|}{ N. virens PCBs (ug/kg wet weight) } \\
\hline & & & $\begin{array}{l}\text { Aroclor } \\
1242 \\
\end{array}$ & $\begin{array}{c}\text { Aroclor } \\
1248\end{array}$ & $\begin{array}{c}\text { Aroclor } \\
1254\end{array}$ & $\begin{array}{c}\text { Aroclor } \\
1260\end{array}$ \\
\hline Target DL(a) & & $\cdot$ & 20 & 20 & 20 & 20 \\
\hline Achieved DL & & & 20 & 20 & 20 & 20 \\
\hline SF COMP & 1 & 1 & $20 U(b)$ & $20 U$ & $20 \mathrm{U}$ & $20 \mathrm{U}$ \\
\hline SF COMP, Replicate 1 & 2 & 3 & $20 \mathrm{U}$ & $20 \mathrm{U}$ & $20 \mathrm{U}$ & $20 \mathrm{U}$ \\
\hline SF COMP, Replicate 2 & 2 & 3 & $20 \mathrm{U}$ & $20 \mathrm{U}$ & $20 \mathrm{U}$ & $20 \mathrm{U}$ \\
\hline SF COMP, Replicate 3 & 2 & 3 & $20 U$ & $20 U$ & $20 \mathrm{U}$ & $20 \mathrm{U}$ \\
\hline SF COMP & 3 & 1 & $20 \mathrm{U}$ & $20 \mathrm{U}$ & $20 U$ & $20 U$ \\
\hline SF COMP & 4 & 1 & $20 U$ & $20 U$ & $20 \mathrm{U}$ & $20 U$ \\
\hline SF COMP & 5 & 2 & $20 \mathrm{U}$ & $20 \mathrm{U}$ & $20 \mathrm{U}$ & $20 \mathrm{U}$ \\
\hline SFW COMP, Replicate 1 & 1 & 1 & $20 U$ & $20 \mathrm{U}$ & $20 \mathrm{U}$ & $20 \mathrm{U}$ \\
\hline SFW COMP, Replicate 2 & 1 & 1 & $20 U$ & $20 \mathrm{U}$ & $20 \mathrm{U}$ & $20 \mathrm{U}$ \\
\hline SFW COMP, Replicate 3 & 1 & 1 & $20 U$ & $20 \mathrm{U}$ & $20 U$ & $20 \mathrm{U}$ \\
\hline SFW COMP & 2 & 2 & $20 \mathrm{U}$ & $20 \mathrm{U}$ & $20 \mathrm{U}$ & $20 U$ \\
\hline SFW COMP & 3 & 2 & $20 \mathrm{U}$ & $20 \mathrm{U}$ & $20 \mathrm{U}$ & $20 \mathrm{U}$ \\
\hline SFW COMP & 4 & 1 & $20 \mathrm{U}$ & $20 U$ & $20 U$ & $20 \mathrm{U}$ \\
\hline SFW COMP & 5 & 1 & $20 \mathrm{U}$ & $20 U$ & $20 U$ & $20 \mathrm{U}$ \\
\hline UIH COMP & 1 & 2 & $20 U$ & $20 U$ & $20 U$ & $20 \mathrm{U}$ \\
\hline UIH COMP & 2 & 1 & $20 U$ & $20 U$ & $20 U$ & $20 \mathrm{U}$ \\
\hline UIH COMP & 3 & 3 & $20 U$ & $20 \mathrm{U}$ & $20 \mathrm{U}$ & $20 \mathrm{U}$ \\
\hline UIH COMP & 4 & 1 & $20 \mathrm{U}$ & $20 \mathrm{U}$ & $20 \mathrm{U}$ & $20 \mathrm{U}$ \\
\hline UIH COMP & 5 & 1 & $20 \mathrm{U}$ & $20 \mathrm{U}$ & $20 \mathrm{U}$ & $20 \mathrm{U}$ \\
\hline TB Upper COMP & 1 & 1 & $20 \mathrm{U}$ & $20 \mathrm{U}$ & $20 \mathrm{U}$ & $20 \mathrm{U}$ \\
\hline TB Upper COMP & 2 & 1 & $20 \mathrm{U}$ & $20 U$ & $20 U$ & $20 \mathrm{U}$ \\
\hline TB Upper COMP & 3 & 2 & $20 \mathrm{U}$ & $20 \mathrm{U}$ & $20 \mathrm{U}$ & $20 U$ \\
\hline TB Upper COMP & 4 & 1 & $20 \mathrm{U}$ & $20 \mathrm{U}$ & $20 \mathrm{U}$ & $20 \mathrm{U}$ \\
\hline TB Upper COMP & 5 & 2 & $20 U$ & $20 \mathrm{U}$ & $20 \mathrm{U}$ & $20 U$ \\
\hline TB Lower COMP & 1 & 2 & $20 \mathrm{U}$ & $20 \mathrm{U}$ & $20 \mathrm{U}$ & $20 \mathrm{U}$ \\
\hline TB Lower COMP & 2 & 1 & $20 \mathrm{U}$ & $20 \mathrm{U}$ & $20 \mathrm{U}$ & $20 \mathrm{U}$ \\
\hline TB Lower COMP & 3 & 2 & $20 \mathrm{U}$ & $20 \mathrm{U}$ & $20 \mathrm{U}$ & $20 U$ \\
\hline TB Lower COMP & 4 & 2 & $20 \mathrm{U}$ & $20 \mathrm{U}$ & $20 \mathrm{U}$ & $20 \mathrm{U}$ \\
\hline TB Lower COMP & 5 & 4 & $20 \mathrm{U}$ & $20 \mathrm{U}$ & $20 \mathrm{U}$ & $20 \mathrm{U}$ \\
\hline
\end{tabular}


TABLE P.20. (contd)

\begin{tabular}{|c|c|c|c|c|c|c|}
\hline \multirow[b]{2}{*}{$\begin{array}{l}\text { Sediment } \\
\text { Treatment }\end{array}$} & \multirow[b]{2}{*}{ Replicate } & \multirow[b]{2}{*}{$\begin{array}{c}\text { Analytical } \\
\text { Batch }\end{array}$} & \multicolumn{4}{|c|}{ N. virens $\mathrm{PCBs}$ (ug/kg wet weight) } \\
\hline & & & $\begin{array}{c}\text { Aroclor } \\
1242 \\
\end{array}$ & $\begin{array}{c}\text { Aroclor } \\
1248 \\
\end{array}$ & $\begin{array}{c}\text { Arocior } \\
1254 \\
\end{array}$ & $\begin{array}{c}\text { Aroclor } \\
1260 \\
\end{array}$ \\
\hline R-OS & 1 & 2 & $20 \mathrm{U}$ & $20 U$ & $20 \mathrm{U}$ & $20 \mathrm{U}$ \\
\hline R-OS & 2 & 1 & $20 U$ & $20 U$ & $20 U$ & $20 U$ \\
\hline R-OS & 3 & 1 & $20 \mathrm{U}$ & $20 U$ & $20 \mathrm{U}$ & $20 \mathrm{U}$ \\
\hline R-OS & 4 & 2 & $20 U$ & $20 U$ & $20 U$ & $20 U$ \\
\hline R-OS & 5 & 1 & $20 U$ & $20 \mathrm{U}$ & $20 \mathrm{U}$ & $20 U$ \\
\hline $\mathrm{R}-\mathrm{BF}$ & 1 & 1 & $20 U$ & $20 \mathrm{U}$ & $20 \mathrm{U}$ & $20 \mathrm{U}$ \\
\hline R-BF & 2 & 2 & $20 \mathrm{U}$ & $20 \mathrm{U}$ & $20 \mathrm{U}$ & $20 \mathrm{U}$ \\
\hline R-BF & 3 & 2 & $20 \mathrm{U}$ & $20 U$ & $20 \mathrm{U}$ & $20 \mathrm{U}$ \\
\hline $\mathrm{R}-\mathrm{BF}$ & 4 & 2 & $20 U$ & $20 U$ & $20 \mathrm{U}$ & $20 \mathrm{U}$ \\
\hline$R-B F$ & 5 & 2 & $20 U$ & $20 U$ & $20 \mathrm{U}$ & $20 U$ \\
\hline R-AM COMP & 1 & 1 & $20 \mathrm{U}$ & $20 U$ & $20 \mathrm{U}$ & $20 \mathrm{U}$ \\
\hline R-AM COMP & 2 & 2 & $20 \mathrm{U}$ & $20 \mathrm{U}$ & $20 U$ & $20 U$ \\
\hline R-AM COMP & 3 & 2 & $20 \mathrm{U}$ & $20 \mathrm{U}$ & $20 \mathrm{U}$ & $20 \mathrm{U}$ \\
\hline R-AM COMP & 4 & 1 & $20 \mathrm{U}$ & $20 \mathrm{U}$ & $20 \mathrm{U}$ & $20 U$ \\
\hline R-AM COMP & 5 & 3 & $20 \mathrm{U}$ & $20 \mathrm{U}$ & $20 \mathrm{U}$ & $20 \mathrm{U}$ \\
\hline C-NV & 1 & 1 & $20 U$ & $20 \mathrm{U}$ & $20 U$ & $20 U$ \\
\hline C-NV, Replicate 1 & 2 & 2 & $20 U$ & $20 U$ & $20 \mathrm{U}$ & $20 \mathrm{U}$ \\
\hline C-NV, Replicate 2 & 2 & 2 & $20 \mathrm{U}$ & $20 U$ & $20 \mathrm{U}$ & $20 \mathrm{U}$ \\
\hline C-NV, Replicate 3 & 2 & 2 & $20 \mathrm{U}$ & $20 U$ & $20 \mathrm{U}$ & $20 \mathrm{U}$ \\
\hline C-NV & 3 & 2 & $20 \mathrm{U}$ & $20 U$ & $20 \mathrm{U}$ & $20 \mathrm{U}$ \\
\hline$C-N V(c)$ & 4 & 3 & $20 \mathrm{U}$ & $20 \mathrm{U}$ & $20 \mathrm{U}$ & $20 \mathrm{U}$ \\
\hline N. virens Background & 1 & 3 & $20 U$ & $20 \mathrm{U}$ & $20 U$ & $20 \mathrm{U}$ \\
\hline N. virens Background & 2 & 3 & $20 \mathrm{U}$ & $20 \mathrm{U}$ & $20 \mathrm{U}$ & $20 \mathrm{U}$ \\
\hline N. virens Background & 3 & 3 & $20 \mathrm{U}$ & $20 U$ & $20 \mathrm{U}$ & $20 \mathrm{U}$ \\
\hline N. virens Background & 4 & 3 & $20 \mathrm{U}$ & $20 \mathrm{U}$ & $20 \mathrm{U}$ & $20 \mathrm{U}$ \\
\hline N. virens Background & 5 & 3 & $20 \mathrm{U}$ & $20 U$ & $20 \mathrm{U}$ & $20 \mathrm{U}$ \\
\hline
\end{tabular}

(a) DL Detection limit.

(b) U Undetected at or above detection limit.

(c) Insufficient organisms to test all five replicates. 
TABLE P.21. Quality Control Data for Polychlorinated Biphenyls, Wet Weight, in Tissue of N. virens, Richmond Harbor Deepening Project

\begin{tabular}{|c|c|c|c|c|c|c|}
\hline \multirow[b]{2}{*}{$\begin{array}{l}\text { Sediment } \\
\text { Treatment }\end{array}$} & \multirow[b]{2}{*}{ Replicate } & \multirow[b]{2}{*}{$\begin{array}{c}\text { Analytical } \\
\text { Batch }\end{array}$} & \multicolumn{4}{|c|}{ N. virens PCBs (ug/kg wet weight) } \\
\hline & & & $\begin{array}{c}\text { Aroclor } \\
1242\end{array}$ & $\begin{array}{c}\text { Aroclor } \\
1248 \\
\end{array}$ & $\begin{array}{c}\text { Aroclor } \\
1254\end{array}$ & $\begin{array}{c}\text { Aroclor } \\
1260\end{array}$ \\
\hline \multicolumn{7}{|l|}{ Method Blanks } \\
\hline $\begin{array}{l}\text { Blank-1 } \\
\text { Blank-1 } \\
\text { Blank-1 }\end{array}$ & & $\begin{array}{l}1 \\
2 \\
3\end{array}$ & $\begin{array}{l}20 U(a) \\
20 U \\
20 U\end{array}$ & $\begin{array}{l}20 U \\
20 U \\
20 U\end{array}$ & $\begin{array}{l}20 U \\
20 U \\
20 U\end{array}$ & $\begin{array}{l}20 U \\
20 U \\
20 U\end{array}$ \\
\hline \multicolumn{7}{|l|}{ Matrix Spikes } \\
\hline $\begin{array}{l}\text { UIH COMP } \\
\text { UIH COMP, MS } \\
\text { Concentration Recovered } \\
\text { Amount Spiked } \\
\text { Percent Recovery }\end{array}$ & $\begin{array}{l}5 \\
5\end{array}$ & $\begin{array}{l}1 \\
1\end{array}$ & $\begin{array}{l}\text { NA (b) } \\
\text { NA } \\
\text { NA } \\
\text { NS (c) } \\
\text { NA }\end{array}$ & $\begin{array}{l}\text { NA } \\
\text { NA } \\
\text { NA } \\
\text { NS } \\
\text { NA }\end{array}$ & $\begin{array}{l}20 U \\
182 \\
182 \\
179 \\
102\end{array}$ & $\begin{array}{l}\text { NA } \\
\text { NA } \\
\text { NA } \\
\text { NS } \\
\text { NA }\end{array}$ \\
\hline $\begin{array}{l}\text { C-NV } \\
\text { C-NV, MS } \\
\text { Concentration Recovered } \\
\text { Amount Spiked } \\
\text { Percent Recovery }\end{array}$ & $\begin{array}{l}3 \\
3\end{array}$ & $\begin{array}{l}2 \\
2\end{array}$ & $\begin{array}{l}\text { NA } \\
\text { NA } \\
\text { NA } \\
\text { NS } \\
\text { NA }\end{array}$ & $\begin{array}{l}\text { NA } \\
\text { NA } \\
\text { NA } \\
\text { NS } \\
\text { NA }\end{array}$ & $\begin{array}{l}20 U \\
186 \\
186 \\
194 \\
96\end{array}$ & $\begin{array}{l}\text { NA } \\
\text { NA } \\
\text { NA } \\
\text { NS } \\
\text { NA }\end{array}$ \\
\hline $\begin{array}{l}\text { N. virens Background } \\
\text { N. virens Background, MS } \\
\text { Concentration Recovered } \\
\text { Amount Spiked } \\
\text { Percent Recovery }\end{array}$ & $\begin{array}{l}1 \\
1\end{array}$ & $\begin{array}{l}3 \\
3\end{array}$ & $\begin{array}{l}\text { NA } \\
\text { NA } \\
\text { NA } \\
\text { NS } \\
\text { NA }\end{array}$ & $\begin{array}{l}\text { NA } \\
\text { NA } \\
\text { NA } \\
\text { NS } \\
\text { NA }\end{array}$ & $\begin{array}{r}20 U \\
200 \\
200 \\
194 \\
103 \%\end{array}$ & $\begin{array}{l}\text { NA } \\
\text { NA } \\
\text { NA } \\
\text { NS } \\
\text { NA }\end{array}$ \\
\hline
\end{tabular}

\section{Standard Reference Material}

Certified SRM not available for PCBs.

Analytical Replicates

SFW COMP, Replicate 1
SFW COMP, Replicate 2
SFW COMP, Replicate 3

RSD

C-NV, Replicate 1

C-NV, Replicate 2

C-NV, Replicate 3

RSD

SF COMP, Replicate 1

SF COMP, Replicate 2

SF COMP, Replicate 3

RSD

(a) U Undetected at or above detection limit.

(b) NA Not applicable.

(c) NS Not spiked.

$\begin{array}{ll}1 & 1 \\ 1 & 1\end{array}$

$20 \mathrm{U}$

$20 \mathrm{U}$

$20 \mathrm{U}$

$20 \mathrm{U}$

$20 \mathrm{U}$

$20 \mathrm{U}$

$20 \mathrm{U}$

$20 \mathrm{U}$

$20 \mathrm{U}$

$20 \mathrm{U}$

$20 \mathrm{U}$

$20 \mathrm{U}$

NA NA NA NA

$\begin{array}{ll}2 & 2 \\ 2 & 2 \\ 2 & 2\end{array}$

$20 \mathrm{U}$

$20 \mathrm{U}$

$20 \mathrm{U}$

$20 \mathrm{U}$

$20 \mathrm{U}$

$20 \mathrm{U}$

$20 \mathrm{U}$

$20 \mathrm{U}$

NA NA NA NA

$20 \mathrm{U}$

$20 \mathrm{U}$

$20 \mathrm{U}$

$20 \mathrm{U}$

$20 \mathrm{U}$

$20 \mathrm{U}$

$20 \mathrm{U}$

$20 \mathrm{U}$

$20 \mathrm{U}$

$20 \mathrm{U}$

$20 \mathrm{U}$

$20 \mathrm{U}$

NA

NA

NA

NA 
TABLE P.22. Surrogate Percent Recoveries for Chlorinated Pesticides and Polychlorinated Biphenyls (PCBs), Including Quality Control Data, in Tissue of N. virens, Richmond Harbor Deepening Project

\begin{tabular}{|c|c|c|c|c|c|}
\hline \multirow{2}{*}{$\begin{array}{l}\text { Sediment } \\
\text { Treatment }\end{array}$} & \multirow[b]{2}{*}{ Replicate } & \multirow{2}{*}{$\begin{array}{c}\text { Analytical } \\
\text { Batch }\end{array}$} & \multirow[t]{2}{*}{$\begin{array}{c}\text { Percent } \\
\text { Dry } \\
\text { Weight }\end{array}$} & \multicolumn{2}{|c|}{ Surrogate Percent Recoveries } \\
\hline & & & & PCB 103 & PCB 198 \\
\hline SF COMP & 1 & 1 & 13.45 & 66 & 68 \\
\hline SF COMP, Replicate 1 & 2 & 3 & 13.61 & 88 & 107 \\
\hline SF COMP, Replicate 2 & 2 & 3 & 13.61 & 89 & 99 \\
\hline SF COMP, Replicate 3 & 2 & 3 & 13.61 & 86 & 100 \\
\hline SF COMP & 3 & 1 & 13.25 & 66 & 71 \\
\hline SF COMP & 4 & 1 & 13.42 & 70 & $\pi$ \\
\hline SF COMP & 5 & 2 & 12.94 & 72 & 62 \\
\hline SFW COMP, Replicate 1 & 1 & 1 & 12.99 & 69 & 67 \\
\hline SFW COMP, Replicate 2 & 1 & 1 & 13.36 & 73 & 69 \\
\hline SFW COMP, Replicate 3 & 1 & 1 & 13.85 & 68 & 69 \\
\hline SFW COMP & 2 & 2 & 12.32 & 82 & 69 \\
\hline SFW COMP & 3 & 2 & 13.78 & 81 & 77 \\
\hline SFW COMP & 4 & 1 & 13.08 & 66 & 64 \\
\hline SFW COMP & 5 & 1 & 13.95 & 57 & 54 \\
\hline UIH COMP & 1 & 2 & 13.70 & 82 & 73 \\
\hline UIH COMP & 2 & 1 & 13.21 & 60 & 62 \\
\hline UIH COMP & 3 & 3 & 13.03 & 86 & 106 \\
\hline UIH COMP & 4 & 1 & 13.28 & 61 & 63 \\
\hline UIH COMP & 5 & 1 & 12.99 & 69 & 58 \\
\hline TB Upper COMP & 1 & 1 & 14.09 & 63 & 60 \\
\hline TB Upper COMP & 2 & 1 & 13.33 & 74 & 73 \\
\hline TB Upper COMP & 3 & 2 & 13.17 & 81 & 69 \\
\hline TB Upper COMP & 4 & 1 & 13.45 & 66 & 60 \\
\hline TB Upper COMP & 5 & 2 & 14.65 & 76 & 68 \\
\hline TB Lower COMP & 1 & 2 & 13.26 & 81 & 74 \\
\hline TB Lower COMP & 2 & 1 & 12.88 & 67 & 63 \\
\hline TB Lower COMP & 3 & 2 & 13.79 & 89 & 76 \\
\hline TB Lower COMP & 4 & 2 & 12.49 & 79 & 84 \\
\hline TB Lower COMP & 5 & 4 & 13.61 & 78 & 115 \\
\hline R-OS & 1 & 2 & 14.02 & 73 & 61 \\
\hline R-OS & 2 & 1 & 13.37 & 65 & 64 \\
\hline R-OS & 3 & 1 & 13.54 & 62 & 64 \\
\hline R-OS & 4 & 2 & 13.97 & 81 & 72 \\
\hline R-OS & 5 & 1 & 13.34 & 69 & 67 \\
\hline$R \cdot B F$ & 1 & 1 & 14.51 & 69 & 65 \\
\hline R-BF & 2 & 2 & 13.20 & 81 & 68 \\
\hline R-BF & 3 & 2 & 13.95 & 89 & 76 \\
\hline R-BF & 4 & 2 & 12.57 & 77 & 65 \\
\hline$R-B F$ & 5 & 2 & 13.94 & 82 & 74 \\
\hline R-AM COMP & 1 & 1 & 13.57 & 66 & 65 \\
\hline R-AM COMP & 2 & 2 & 13.43 & 79 & 64 \\
\hline R-AM COMP & 3 & 2 & 13.95 & 75 & 63 \\
\hline R-AM COMP & 4 & 1 & 13.45 & 70 & 59 \\
\hline R-AM COMP & 5 & 3 & 13.75 & 90 & 105 \\
\hline
\end{tabular}

RH DEEPENING 
TABLE P.22. (contd)

\begin{tabular}{lccccc}
$\begin{array}{l}\text { Sediment } \\
\text { Treatment }\end{array}$ & Replicate & $\begin{array}{c}\text { Analytical } \\
\text { Batch }\end{array}$ & $\begin{array}{c}\text { Percent } \\
\text { Dry } \\
\text { Weight }\end{array}$ & \multicolumn{2}{c}{ Surrogate Percent Recoveries } \\
\hline C-NV & 1 & 1. & 12.66 & 65 & PCB 198 \\
C-NV, Replicate 1 & 2 & 2 & 14.27 & 90 & 63 \\
C-NV, Replicate 2 & 2 & 2 & 14.27 & 81 & 77 \\
C-NV, Replicate 3 & 2 & 2 & 14.27 & 84 & 71 \\
C-NV & 3 & 2 & 13.15 & 87 & 68 \\
C-NV(a) & 4 & 3 & 13.21 & 78 & 101 \\
N. virens Background & 1 & 3 & 14.64 & 76 & 84 \\
N. virens Background & 2 & 3 & 13.30 & 66 & 73 \\
N. virens Background & 3. & 3 & 13.79 & 82 & 103 \\
N. virens Background & 4 & 3 & 14.11 & 85 & 95 \\
N. virens Background & 5 & 3 & 13.99 & 78 & 100
\end{tabular}

\section{Quality Control Data}

\section{Method Blanks}

Blank-1

Blank-1

Blank-1

\section{Matrix Spikes}

UIH COMP
UIH COMP, MS
C-NV
C-NV, MS

5
5
3

N. virens Background

N. virens Background, MS

1$$
1
$$$$
12.99
$$$$
\text { NA }
$$$$
69
$$

87

82

Standard Reference Material

Certified SAM not available for pesticides and PCBs.

Analytical Replicates

\section{SFW COMP, Replicate 1 SFW COMP, Replicate 2 SFW COMP, Replicate 3}

C-NV, Replicate 1

C-NV, Replicate 2

C-NV, Replicate 3

SF COMP, Replicate 1

SF COMP, Replicate 2

SF COMP, Replicate 3

1
1
1
2
2
2
2
2
2

(a) Insufficient organisms to test all five replicates.

(b) NA Not applicable.

$\begin{array}{rrr}12.99 & 69 & 67 \\ 13.36 & 73 & 69 \\ 13.85 & 68 & 69 \\ 14.27 & 90 & 77 \\ 14.27 & 81 & 71 \\ 14.27 & 84 & 68 \\ 13.61 & 88 & \\ 13.61 & 89 & 107 \\ 13.61 & 86 & 99 \\ & & 100\end{array}$




\begin{tabular}{|c|c|c|c|c|c|c|c|c|c|c|c|c|c|}
\hline \multirow{2}{*}{$\begin{array}{l}\text { Sediment } \\
\text { Treatment }\end{array}$} & \multirow[b]{2}{*}{ Replicate } & \multirow{2}{*}{$\begin{array}{c}\text { Analytical } \\
\text { Batch }\end{array}$} & \multirow{2}{*}{$\begin{array}{c}\text { Percent } \\
\text { Dry } \\
\text { Weight }\end{array}$} & \multicolumn{10}{|c|}{ N. virens Metals (mg/kg wet weight) } \\
\hline & & & & $\mathrm{Ag}$ & As & $\mathrm{Cd}$ & $\mathrm{Cr}$ & $\mathrm{Cu}$ & $\mathrm{Hg}$ & $\mathrm{NI}$ & $\mathrm{Pb}$ & Se & $\mathrm{Zn}$ \\
\hline SF COMP & 1 & 1 & 14.09 & 0.0617 & 2.07 & 0.0452 & $0.107 \cup(a)$ & 1.67 & 0.0266 & 0.160 & 0.098 & 0.290 & 51.3 \\
\hline SF COMP & 2 & 1 & 13.61 & $0.0148 U$ & 1.73 & 0.0440 & $0.103 U$ & 1.41 & 0.0238 & 0.196 & 0.163 & 0.237 & 41.6 \\
\hline SF COMP & 3 & 1 & 13.28 & 0.0548 & 2.02 & 0.0438 & 0.198 & 1.23 & 0.0266 & 0.173 & 0.129 & 0.244 & 37.2 \\
\hline SF COMP & 4 & 1 & 13.54 & 0.0605 & 1.94 & 0.0492 & 0.141 & 1.38 & 0.0355 & 0.202 & 0.113 & 0.244 & 28.0 \\
\hline SFCOMP & 5 & 1 & 12.94 & $0.0141 U$ & 1.86 & 0.0413 & 0.349 & 1.71 & 0.0307 & 0.405 & 0.185 & 0.254 & 25.2 \\
\hline SFW COMP & 1 & 1 & 12.99 & 0.0501 & 1.75 & 0.0423 & 0.124 & 1.53 & 0.0300 & 0.232 & 0.108 & 0.233 & 19.9 \\
\hline SFW COMP & 2 & 1 & 12.32 & $0.0134 U$ & 1.72 & 0.0444 & 0.126 & 1.25 & 0.0249 & 0.207 & 0.138 & 0.208 & 15.6 \\
\hline SFW COMP & 3 & 1 & 13.78 & 0.0373 & 2.09 & 0.0506 & $0.104 U$ & 1.46 & 0.0280 & 0.211 & 0.137 & 0.291 & 23.6 \\
\hline SFW COMP & 4 & 1 & 13.08 & 0.0349 & 2.37 & 0.0420 & 0.167 & 1.30 & 0.0311 & 0.175 & 0.150 & 0.230 & 40.4 \\
\hline SFW COMP & 5 & 1 & 13.95 & 0.0716 & 1.84 & 0.0502 & 0.136 & 1.46 & 0.0293 & 0.248 & 0.136 & 0.259 & 31.1 \\
\hline UIH COMP & 1 & 1 & 13.70 & 0.0200 & 2.23 & 0.0480 & $0.104 \mathrm{U}$ & 1.68 & 0.0284 & 0.203 & 0.117 & 0.284 & 21.2 \\
\hline UIH COMP & 2 & 1 & 13.85 & 0.0564 & 1.87 & 0.0507 & 0.140 & 1.36 & 0.0317 & 0.220 & 0.113 & 0.262 & 34.6 \\
\hline UIH COMP & 3 & 1 & 13.03 & 0.0208 & 2.01 & 0.0503 & 0.107 & 1.44 & 0.0306 & 0.201 & 0.145 & 0.240 & 38.8 \\
\hline UIH COMP & 4 & 1 & 13.21 & 0.0505 & 1.88 & 0.0511 & 0.134 & 1.37 & 0.0322 & 0.215 & 0.105 & 0.235 & 18.5 \\
\hline UIH COMP & 5 & 1 & 12.99 & 0.0491 & 1.77 & 0.0452 & 0.137 & 1.34 & 0.0300 & 0.205 & 0.120 & 0.268 & 20.5 \\
\hline TB Upper COMP & 1 & 1 & 12.66 & 0.0571 & 1.72 & 0.0485 & 0.190 & 1.23 & 0.0313 & 0.295 & 0.122 & 0.215 & 63.8 \\
\hline TB Upper COMP & 2 & 1 & 13.42 & 0.0558 & 1.91 & 0.0505 & 0.264 & 1.47 & 0.0333 & 0.349 & 0.118 & 0.286 & 12.4 \\
\hline TB Upper COMP & 3 & 1 & 13.17 & 0.0356 & 1.94 & 0.0460 & 0.122 & 1.41 & 0.0288 & 0.233 & 0.211 & 0.269 & 22.7 \\
\hline TB Upper COMP, Replicate 1 & 4 & 1 & 13.45 & 0.0584 & 1.80 & 0.0465 & 0.119 & 1.33 & 0.0305 & 0.237 & 0.115 & 0.262 & 43.4 \\
\hline TB Upper COMP, Replicate 2 & 4 & 1 & 13.45 & 0.0577 & 2.02 & 0.0436 & 0.138 & 1.34 & 0.0288 & 0.249 & 0.118 & 0.268 & 48.6 \\
\hline TB Upper COMP, Replicate 3 & 4 & 1 & 13.45 & 0.0561 & 1.84 & 0.0519 & 0.136 & 1.46 & 0.0320 & 0.266 & 0.106 & 0.256 & 20.0 \\
\hline TB Upper COMP & 5 & 1 & 14.65 & 0.0255 & 2.39 & 0.0530 & $0: 132$ & 1.56 & 0.0312 & 0.337 & 0.136 & 0.340 & 22.7 \\
\hline TB Lower COMP & 1 & 1 & 13.26 & $0.0145 U$ & 2.12 & 0.0371 & 0.532 & 1.69 & 0.0280 & 0.774 & 0.148 & 0.244 & 11.1 \\
\hline TB Lower COMP & 2 & 1 & 12.88 & 0.0422 & 1.51 & 0.0397 & 0.137 & 1.21 & 0.0267 & 0.350 & 0.092 & 0.214 & 26.8 \\
\hline TB Lower COMP & 3 & 1 & 13.79 & 0.0217 & 2.12 & 0.0498 & 0.136 & 1.61 & 0.0272 & 0.520 & 0.111 & 0.319 & 13.5 \\
\hline TB Lower COMP & 4 & 1 & 12.49 & 0.0210 & 2.05 & 0.0461 & 0.154 & 1.46 & 0.0299 & 0.365 & 0.140 & 0.245 & 33.5 \\
\hline TB Lower COMP & 5 & 1 & 13.61 & $0.0148 U$ & 1.93 & 0.0423 & 0.109 & 1.25 & 0.0271 & 0.329 & 0.110 & 0.241 & 30.9 \\
\hline R-OS & 1 & 1 & 14.02 & 0.0296 & 1.99 & 0.0565 & 0.141 & 1.43 & 0.0307 & 0.238 & 0.124 & 0.231 & 17.4 \\
\hline R-OS & 2 & 1 & 14.51 & 0.0678 & 2.28 & 0.0451 & 0.143 & 1.43 & 0.0238 & 0.184 & 0.100 & 0.252 & 12.8 \\
\hline R-OS & 3 & 1 & 13.34 & 0.0791 & 2.12 & 0.0492 & 0.145 & 1.26 & 0.0329 & 0.233 & 0.112 & 0.237 & 33.8 \\
\hline R-OS & 4 & 1 & 13.97 & 0.0495 & 2.22 & 0.0506 & 0.174 & 1.69 & 0.0405 & 0.317 & 0.123 & 0.309 & 9.65 \\
\hline R.OS & 5 & 1 & 13.36 & 0.0675 & 1.98 & 0.0472 & 0.164 & 1.37 & 0.0337 & 0.343 & 0.104 & 0.251 & 33.8 \\
\hline
\end{tabular}




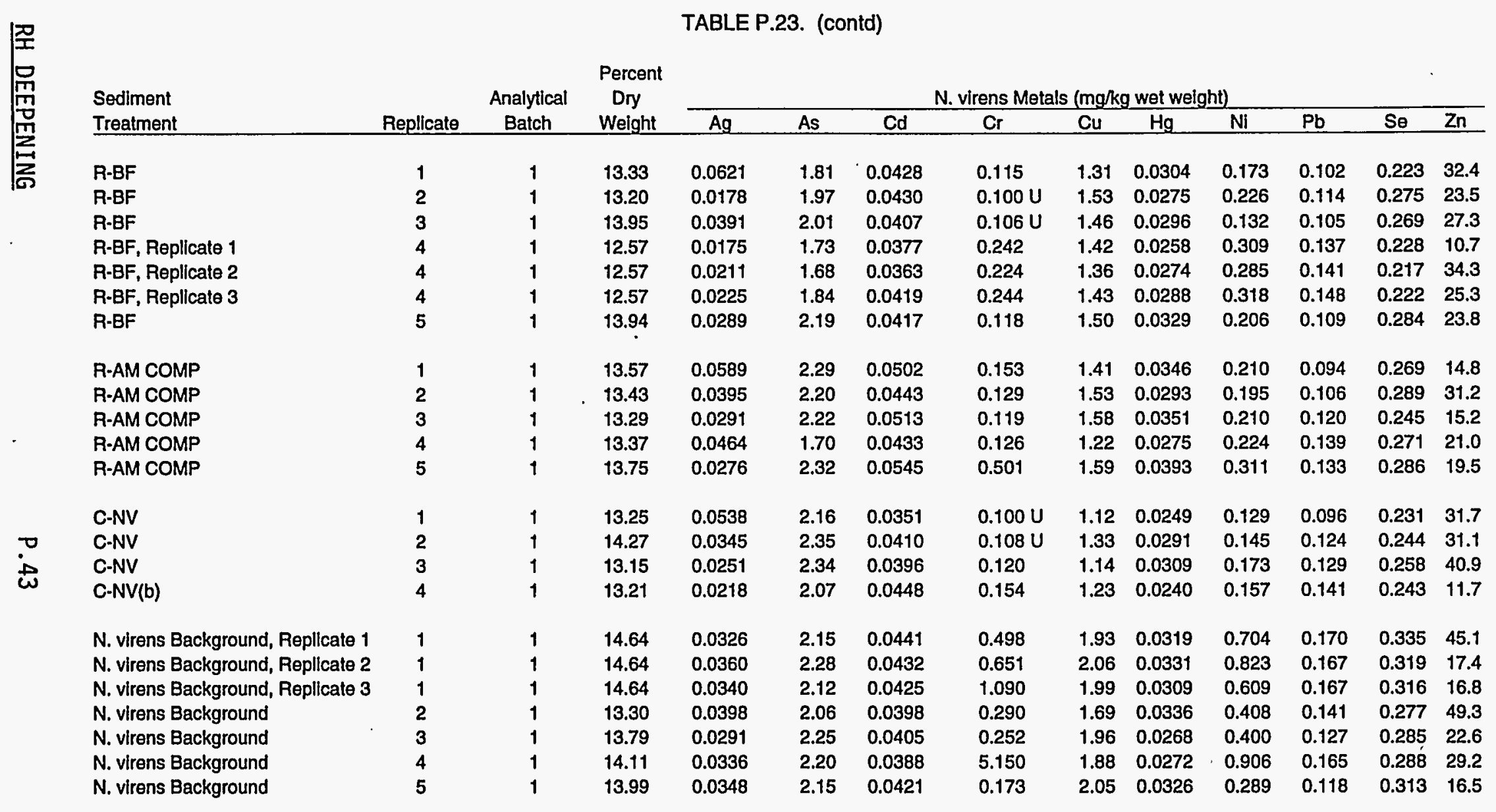

(a) U Undetected at or above detection limit.

(b) Insufficient organisms to test all five replicates. 


\begin{tabular}{|c|c|c|c|c|c|c|c|c|c|c|c|c|}
\hline \multirow{2}{*}{$\begin{array}{l}\text { Sediment } \\
\text { Treatment } \\
\end{array}$} & \multirow[b]{2}{*}{ Replicate } & \multirow{2}{*}{$\begin{array}{c}\text { Analytical } \\
\text { Batch }\end{array}$} & \multicolumn{10}{|c|}{ N. virens Metals (mg $/ \mathrm{kg}$ dry welght) } \\
\hline & & & $\mathrm{Ag}$ & As & Cd & $\mathrm{Cr}$ & $\mathrm{Cu}$ & $\mathrm{Hg}$ & $\mathrm{Ni}$ & $\mathrm{Pb}$ & Se & $\mathrm{Zn}$ \\
\hline Target DL(a) & & & 0.1 & 2.0 & 0.1 & 1.0 & 4.3 & 0.02 & 1.0 & 1.0 & 1.0 & 35 \\
\hline Achieved DL & & & 0.109 & 2.93 & 0.132 & 0.76 & 3.34 & 0.004 & 0.933 & 0.417 & 0.12 & 39.7 \\
\hline SF COMP & 1 & 1 & 0.438 & 14.7 & 0.321 & $0.76 \mathrm{U}(\mathrm{b})$ & 11.9 & 0.189 & 1.14 & 0.696 & 2.06 & 364 \\
\hline SF COMP & 2 & 1 & $0.109 \mathrm{U}$ & 12.7 & 0.323 & $0.76 \mathrm{U}$ & 10.4 & 0.175 & 1.44 & 1.20 & 1.74 & 306 \\
\hline SF COMP & 3 & 1 & 0.413 & 15.2 & 0.330 & 1.49 & 9.28 & 0.200 & 1.30 & 0.973 & 1.84 & 280 \\
\hline SF COMP & 4 & 1 & 0.447 & 14.3 & 0.363 & 1.04 & 10.2 & 0.262 & 1.49 & 0.838 & 1.80 & 207 \\
\hline SFCOMP & 5 & 1 & $0.109 \mathrm{U}$ & 14.4 & 0.319 & 2.69 & 13.2 & 0.237 & 3.13 & 1.43 & 1.96 & 195 \\
\hline SFW COMP & 1 & 1 & 0.386 & 13.5 & 0.326 & 0.95 & 11.8 & 0.231 & 1.79 & 0.831 & 1.79 & 153 \\
\hline SFW COMP & 2 & 1 & $0.109 \mathrm{U}$ & 14.0 & 0.360 & 1.02 & 10.2 & 0.202 & 1.68 & 1.12 & 1.69 & 127 \\
\hline SFW COMP & 3 & 1 & 0.271 & 15.2 & 0.367 & $0.76 \mathrm{U}$ & 10.6 & 0.203 & 1.53 & 0.996 & 2.11 & 171 \\
\hline SFW COMP & 4 & $1 \mathbf{a}$ & 0.267 & 18.1 & 0.321 & 1.28 & 9.97 & 0.238 & 1.34 & 1.15 & 1.76 & 309 \\
\hline SFW COMP & 5 & 1 & 0.513 & 13.2 & 0.360 & 0.97 & 10.5 & 0.210 & 1.78 & 0.977 & 1.86 & 223 \\
\hline UIH COMP & 1 & 1 & 0.146 & 16.3 & 0.350 & $0.76 \mathrm{U}$ & 12.3 & 0.207 & 1.48 & 0.855 & 2.07 & 155 \\
\hline UIH COMP & 2 & 1 & 0.407 & 13.5 & 0.366 & 1.01 & 9.84 & 0.229 & 1.59 & 0.816 & 1.89 & 250 \\
\hline UIH COMP & 3 & 1 & 0.160 & 15.4 & 0.386 & 0.82 & 11.1 & 0.235 & 1.54 & 1.11 & 1.84 & 298 \\
\hline UIH COMP & 4 & 1 & 0.382 & 14.2 & 0.387 & 1.01 & 10.4 & 0.244 & 1.63 & 0.792 & 1.78 & 140 \\
\hline UIH COMP & 5 & 1 & 0.378 & 13.6 & 0.348 & 1.05 & 10.3 & 0.231 & 1.58 & 0.925 & 2.06 & 158 \\
\hline TB Upper COMP & 1 & 1 & 0.451 & 13.6 & 0.383 & 1.50 & 9.73 & 0.247 & 2.33 & 0.965 & 1.70 & 504 \\
\hline TB Upper COMP & 2 & 1 & 0.416 & 14.2 & 0.376 & 1.96 & 11.0 & 0.248 & 2.60 & 0.878 & 2.13 & 92.1 \\
\hline TB Upper COMP & 3 & 1 & 0.270 & 14.7 & 0.349 & 0.92 & 10.7 & 0.219 & 1.77 & 1.60 & 2.04 & 172 \\
\hline TB Upper COMP, Replicate 1 & 4 & 1 & 0.434 & 13.4 & 0.346 & 0.88 & 9.88 & 0.227 & 1.76 & 0.857 & 1.95 & 323 \\
\hline TB Upper COMP, Replicate 2 & 4 & 1 & 0.429 & 15.0 & 0.324 & 1.02 & 9.98 & 0.214 & 1.85 & 0.879 & 1.99 & 361 \\
\hline TB Upper COMP, Replicate 3 & 4 & 1 & 0.417 & 13.7 & 0.386 & 1.01 & 10.9 & 0.238 & 1.98 & 0.791 & 1.90 & 149 \\
\hline TB Upper COMP & 5 & 1 & 0.174 & 16.3 & 0.362 & 0.9 & 10.7 & 0.213 & 2.30 & 0.926 & 2.32 & 155 \\
\hline TB Lower COMP & 1 & 1 & $0.109 \mathrm{U}$ & 16.0 & 0.280 & 4.01 & 12.8 & 0.211 & 5.84 & 1.12 & 1.84 & 83.4 \\
\hline TB Lower COMP & 2 & 1 & 0.328 & 11.7 & 0.308 & 1.06 & 9.39 & 0.207 & 2.72 & 0.714 & 1.66 & 208 \\
\hline TB Lower COMP & 3 & 1 & 0.157 & 15.4 & 0.361 & 0.98 & 11.7 & 0.197 & 3.77 & 0.802 & 2.31 & 98.1 \\
\hline TB Lower COMP & 4 & 1 & 0.168 & 16.4 & 0.369 & 1.23 & 11.7 & 0.239 & 2.92 & 1.12 & 1.96 & 268 \\
\hline TB Lower COMP & 5 & 1 & $0.109 \mathrm{U}$ & 14.2 & 0.311 & 0.8 & 9.20 & 0.199 & 2.42 & 0.806 & 1.77 & 227 \\
\hline
\end{tabular}




\begin{tabular}{|c|c|c|c|c|c|c|c|c|c|c|c|c|c|}
\hline \multirow{5}{*}{ 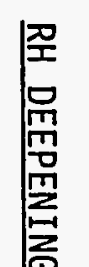 } & \multicolumn{13}{|c|}{ TABLE P.24. (contd) } \\
\hline & \multirow{2}{*}{$\begin{array}{l}\text { Sediment } \\
\text { Treatment }\end{array}$} & \multirow[b]{2}{*}{ Replicate } & \multirow{2}{*}{$\begin{array}{c}\text { Analytical } \\
\text { Batch }\end{array}$} & \multicolumn{10}{|c|}{ N. virens Metals (mg/kg dry weight) } \\
\hline & & & & $\mathrm{Ag}$ & As & $\mathrm{Cd}$ & $\mathrm{Cr}$ & $\mathrm{Cu}$ & $\mathrm{Hg}$ & $\mathrm{Ni}$ & $\mathrm{Pb}$ & Se & $\mathrm{Zn}$ \\
\hline & R-OS & 1 & 1 & 0.211 & 14.2 & 0.403 & 1.00 & 10.2 & 0.219 & 1.70 & 0.884 & 1.65 & 124 \\
\hline & R-OS & 2 & 1 & 0.467 & 15.7 & 0.311 & 0.98 & 9.86 & 0.164 & 1.27 & 0.692 & 1.74 & 88.0 \\
\hline & R-OS & 3 & 1 & 0.593 & 15.9 & 0.369 & 1.08 & 9.41 & 0.247 & 1.75 & 0.836 & 1.78 & 253 \\
\hline & R-OS & 4 & 1 & 0.354 & 15.9 & 0.362 & 1.24 & 12.1 & 0.290 & 2.27 & 0.882 & 2.21 & 69.1 \\
\hline & R-OS & 5 & 1 & 0.505 & 14.8 & 0.353 & 1.22 & 10.3 & 0.252 & 2.57 & 0.781 & 1.88 & 253 \\
\hline & $\mathrm{R}-\mathrm{BF}$ & 1 & 1 & 0.466 & 13.6 & 0.321 & 0.86 & 9.86 & 0.228 & 1.30 & 0.764 & 1.67 & 243 \\
\hline & $\mathrm{R}-\mathrm{BF}$ & 2 & 1 & 0.135 & 14.9 & 0.326 & $0.76 U$ & 11.6 & 0.208 & 1.71 & 0.861 & 2.08 & 178 \\
\hline & R-BF & 3 & 1 & 0.280 & 14.4 & 0.292 & $0.76 U$ & 10.5 & 0.212 & 0.947 & 0.753 & 1.93 & 196 \\
\hline & R-BF, Replicate 1 & 4 & 1 & 0.139 & 13.8 & 0.300 & 1.92 & 11.3 & 0.205 & 2.46 & 1.09 & 1.81 & 85.2 \\
\hline & R-BF, Replicate 2 & 4 & 1 & 0.168 & 13.4 & 0.289 & 1.78 & 10.8 & 0.218 & 2.27 & 1.12 & 1.73 & 273 \\
\hline & R-BF, Replicate 3 & 4 & 1 & 0.179 & 14.6 & 0.333 & 1.94 & 11.4 & 0.229 & 2.53 & 1.18 & 1.77 & 201 \\
\hline & $\mathrm{A} \cdot \mathrm{BF}$ & 5 & 1 & 0.207 & 15.7 & 0.299 & 0.84 & 10.8 & 0.236 & 1.48 & 0.779 & 2.04 & 171 \\
\hline & R-AM COMP & 1 & 1 & 0.434 & 16.9 & 0.370 & 1.12 & 10.4 & 0.255 & 1.55 & 0.694 & 1.98 & 109 \\
\hline & R-AM COMP & 2 & 1 & 0.294 & 16.4 & 0.330 & 0.96 & 11.4 & 0.218 & 1.45 & 0.786 & 2.15 & 232 \\
\hline & R-AM COMP & 3 & 1 & 0.219 & 16.7 & 0.386 & 0.89 & 11.9 & 0.264 & 1.58 & 0.906 & 1.84 & 114 \\
\hline & R-AM COMP & 4 & 1 & 0.347 & 12.71 & 0.324 & 0.95 & 9.16 & 0.206 & 1.68 & 1.04 & 2.03 & 157 \\
\hline G & R-AM COMP & 5 & 1 & 0.201 & 16.9 & 0.396 & 3.64 & 11.6 & 0.286 & 2.26 & 0.964 & 2.08 & 142 \\
\hline & C.NV & 1 & 1 & 0.406 & 16.3 & 0.265 & $0.76 \mathrm{U}$ & 8.48 & 0.188 & 0.973 & 0.723 & 1.74 & 239 \\
\hline & C-NV & 2 & 1 & 0.242 & 16.5 & 0.287 & $0.76 \mathrm{U}$ & 9.32 & 0.204 & 1.02 & 0.870 & 1.71 & 218 \\
\hline & C-NV & 3 & 1 & 0.191 & 17.8 & 0.301 & 0.91 & 8.69 & 0.235 & 1.32 & 0.981 & 1.96 & 311 \\
\hline & $C-N V(c)$ & 4 & 1 & 0.165 & 15.7 & 0.339 & 1.16 & 9.31 & 0.182 & 1.19 & 1.07 & 1.84 & 88.3 \\
\hline & N. virens Background, Replicate 1 & 1 & 1 & 0.223 & 14.7 & 0.301 & 3.40 & 13.2 & 0.218 & 4.81 & 1.16 & 2.29 & 308 \\
\hline & N. virens Background, Replicate 2 & 1 & 1 & 0.246 & 15.6 & 0.295 & 4.44 & 14.1 & 0.226 & 5.62 & 1.14 & 2.18 & 119 \\
\hline & N. virens Background, Replicate 3 & 1 & 1 & 0.232 & 14.5 & 0.290 & 7.44 & 13.6 & 0.211 & 4.16 & 1.14 & 2.16 & 115 \\
\hline & N. virens Background & 2 & 1 & 0.299 & 15.5 & 0.299 & 2.18 & 12.7 & 0.253 & 3.07 & 1.06 & 2.08 & 371 \\
\hline & N. virens Background & 3 & 1 & 0.211 & 16.3 & 0.294 & 1.82 & 14.2 . & 0.194 & 2.90 & 0.921 & 2.07 & 164 \\
\hline & N. virens Background & 4 & $1 a$ & 0.238 & 15.6 & 0.275 & 36.5 & 13.3 & 0.193 & 6.42 & 1.17 & 2.04 & 207 \\
\hline & N. virens Background & 5 & 1 & 0.249 & 15.4 & 0.301 & 1.23 & 14.7 & 0.233 & 2.07 & 0.844 & 2.24 & 118 \\
\hline
\end{tabular}
(a) DL Detection limit.
(b) U Undetected at or above detection limit.
(c) Insufficient organisms to test all five replicates. 


\begin{tabular}{|c|c|c|c|c|c|c|c|c|c|c|c|c|}
\hline \multirow{2}{*}{$\begin{array}{l}\text { Sediment } \\
\text { Treatment }\end{array}$} & \multirow[b]{2}{*}{ Replicate } & \multirow{2}{*}{$\begin{array}{c}\text { Analytical } \\
\text { Batch } \\
\end{array}$} & \multicolumn{10}{|c|}{ N. virens Metals ( $\mathrm{mg} / \mathrm{kg}$ dry weight) } \\
\hline & & & $\mathrm{Ag}$ & As & $\mathrm{Cd}$ & $\mathrm{Cr}$ & $\mathrm{Cu}$ & $\mathrm{Hg}$ & NI & $\mathrm{Pb}$ & Se & $\mathrm{Zn}$ \\
\hline \multicolumn{13}{|l|}{ Method Blanks } \\
\hline Blank-1 & & 1 & 0.219 & 3.07 & $0.132 U(a)$ & $0.758 \mathrm{U}$ & $3.34 \mathrm{U}$ & $0.004 \mathrm{U}$ & $0.933 \mathrm{U}$ & $0.417 U$ & $0.15 U$ & $39.7 \mathrm{U}$ \\
\hline Blank-2 & & 1 & $0.109 \mathrm{U}$ & 7.64 & $0.132 U$ & $0.758 \mathrm{U}$ & $3.34 \mathrm{U}$ & $0.004 U$ & $0.933 U$ & $0.417 \mathrm{U}$ & $0.15 U$ & $39.7 \mathrm{U}$ \\
\hline Blank-3 & & 1 & $0.109 \mathrm{U}$ & 4.59 & $0.132 U$ & $0.758 \mathrm{U}$ & $3.34 \mathrm{U}$ & $0.004 \mathrm{U}$ & $0.933 U$ & $0.417 \mathrm{U}$ & $0.12 U$ & $39.7 \mathrm{U}$ \\
\hline Blank-4 & & $1 a$ & $0.109 \mathrm{U}$ & $2.93 \mathrm{U}$ & $0.132 \mathrm{U}$ & $0.758 \mathrm{U}$ & $3.34 \mathrm{U}$ & NA & $0.933 U$ & $0.417 \mathrm{U}$ & NA & $39.7 \mathrm{U}$ \\
\hline \multicolumn{13}{|l|}{ Matrix Splkes } \\
\hline SF COMP & 5 & 1 & $0.109 \mathrm{U}$ & 14.4 & 0.319 & 2.69 & 13.2 & 0.226 & 3.13 & 1.43 & 1.96 & 195 \\
\hline SF COMP, MS & 5 & 1 & 1.01 & 44.8 & 2.26 & 7.69 & 39.7 & 0.632 & 8.66 & 3.43 & 7.32 & 510 \\
\hline Concentration Recovered & & & 1.01 & 30.4 & 1.94 & 5.00 & 26.5 & 0.406 & 5.53 & 2.00 & 5.36 & 315 \\
\hline Amount Spiked & & & 1.00 & 25.0 & 2.00 & 5.00 & 25.0 & 0.497 & 5.00 & 2.00 & 5.00 & 200 \\
\hline Percent Recovery & & & $101 \%$ & $122 \%$ & $97 \%$ & $100 \%$ & $106 \%$ & $82 \%$ & $111 \%$ & $100 \%$ & $107 \%$ & $158 \%(b)$ \\
\hline TB Upper COMP & 2 & 1 & 0.416 & 14.2 & 0.376 & 1.96 & 11.0 & 0.248 & 2.60 & 0.878 & 2.13 & 92.1 \\
\hline TB Upper COMP, MS & 2 & 1 & 1.23 & 46.1 & 2.34 & 7.05 & 36.7 & 0.756 & 8.05 & 2.67 & 7.36 & 472 \\
\hline Concentration Recovered & & & 0.817 & 31.9 & 1.96 & 5.09 & 25.7 & 0.508 & 5.45 & 1.79 & 5.23 & 380 \\
\hline Amount Spiked & & & 1.00 & 25.0 & 2.00 & 5.00 & 25.0 & 0.498 & 5.00 & 2.00 & 5.00 & 200 \\
\hline Percent Recovery & & & $82 \%$ & $128 \%(b)$ & $98 \%$ & $102 \%$ & $103 \%$ & $102 \%$ & $109 \%$ & $90 \%$ & $105 \%$ & $190 \%$ (b) \\
\hline R-AM COMP & 3 & 1 & 0.219 & 16.7 & 0.386 & 0.894 & 11.9 & 0.264 & 1.58 & 0.906 & 1.84 & 114 \\
\hline R-AM COMP, MS & 3 & 1 & 1.11 & 46.2 & 2.36 & 5.99 & 37.6 & 0.696 & 7.02 & 2.95 & 7.17 & 277 \\
\hline Concentration Recovered & & & 0.894 & 29.5 & 1.97 & 5.10 & 25.7 & 0.432 & 5.44 & 2.04 & 5.33 & 163 \\
\hline Amount Splked & & & 1.00 & 25.0 & 2.00 & 5.00 & 25.0 & 0.498 & 5.00 & 2.00 & 5.00 & 200 \\
\hline Percent Recovery & & & $89 \%$ & $118 \%$ & $98 \%$ & $102 \%$ & $103 \%$ & $87 \%$ & $109 \%$ & $102 \%$ & $107 \%$ & $82 \%$ \\
\hline \multicolumn{13}{|l|}{ Standard Reference Material } \\
\hline $\begin{array}{l}\text { Certified } \\
\text { Value SRM 1566a }\end{array}$ & & & $\begin{array}{r}1.68 \\
+/-0.15\end{array}$ & $\begin{array}{r}14 \\
+/-1.2\end{array}$ & $\begin{array}{r}4.15 \\
+1-0.38\end{array}$ & $\begin{array}{r}1.43 \\
+1-0.46\end{array}$ & $\begin{array}{r}66.3 \\
+/-4.3\end{array}$ & $\begin{array}{r}0.0642 \\
+1-0.0067\end{array}$ & $\begin{array}{r}2.25 \\
+1-0.44\end{array}$ & $\begin{array}{c}0.371 \\
+/-0.014\end{array}$ & $\begin{array}{r}2.21 \\
+/-0.24\end{array}$ & $\begin{array}{r}830 \\
+/-57\end{array}$ \\
\hline SRM 1566a-1 & & 1 & 1.61 & 13.9 & 4.26 & 1.57 & 72.1 & 0.062 & 2.42 & 0.312 & 2.40 & $1130(c)$ \\
\hline SRM 1566a-2 & & 1 & 1.48 & 15.9 & 4.16 & 1.33 & 65.7 & 0.061 & 1.93 & 0.400 & 2.29 & 899 \\
\hline SRM 1566a-3 & & 1 & 1.53 & 15.1 & 4.20 & 1.34 & 71.7 & 0.067 & 2.37 & 0.368 & 2.19 & 941 \\
\hline SRM $1566 \mathrm{a}-4$ & & $1 a$ & 1.54 & 15.7 & 3.92 & 1.01 & 71.7 & NA & 1.97 & 0.363 & NA & 737 \\
\hline
\end{tabular}




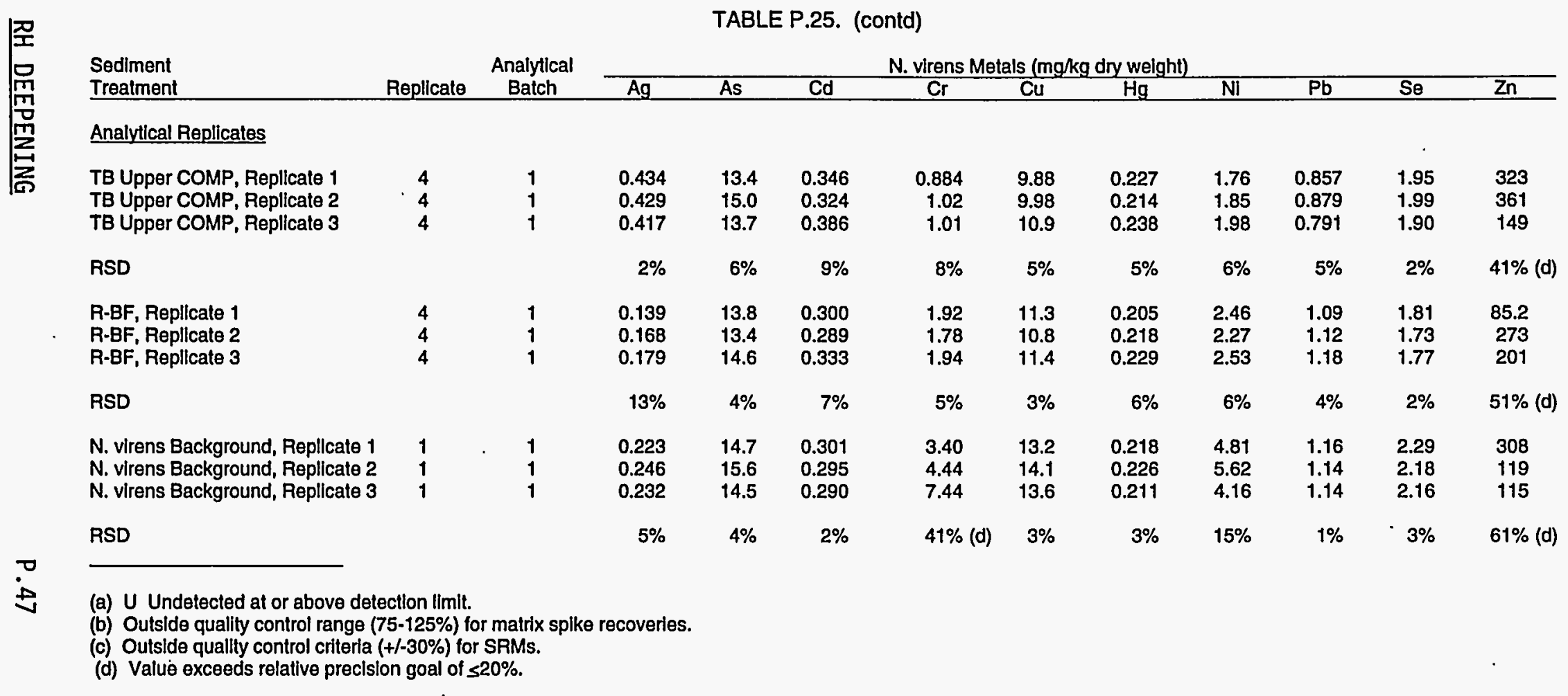




\begin{tabular}{|c|c|c|c|c|c|c|c|c|c|c|}
\hline \multirow[b]{2}{*}{$\begin{array}{l}\text { Sediment } \\
\text { Treatment }\end{array}$} & \multirow[b]{2}{*}{ Replicate } & \multirow[b]{2}{*}{$\begin{array}{c}\text { Analytical } \\
\text { Batch }\end{array}$} & \multirow{2}{*}{$\begin{array}{l}\text { Tripentyltin } \\
\text { (\%) Internal } \\
\text { Standard }\end{array}$} & \multicolumn{3}{|c|}{ (ugg/kg wet weight) } & \multirow{2}{*}{$\begin{array}{l}\text { Percent } \\
\text { Dry } \\
\text { Weight }\end{array}$} & \multicolumn{3}{|c|}{ (ug/kg dry weight) } \\
\hline & & & & $\begin{array}{l}\text { Tri- } \\
\text { Butyltin }\end{array}$ & $\begin{array}{c}\text { Di- } \\
\text { Butyltin }\end{array}$ & $\begin{array}{l}\text { Mono- } \\
\text { Butyltin }\end{array}$ & & $\begin{array}{l}\text { Tri- } \\
\text { Butyltin }\end{array}$ & $\begin{array}{c}\text { Di- } \\
\text { Butyltin }\end{array}$ & $\begin{array}{l}\text { Mono- } \\
\text { Butyltin }\end{array}$ \\
\hline Target DL(a) & & & & 1.00 & 1.00 & 1.00 & $N A(b)$ & NA & NA & NA \\
\hline Achieved DL & & & & 0.48 & 1.39 & 0.39 & NA & NA & NA & NA \\
\hline SF COMP & 1 & 1 & 97 & $0.48 U(c)$ & 1.86 & $0.39 \mathrm{U}$ & 14.09 & $3.41 \mathrm{U}$ & 13.20 & $2.77 \mathrm{U}$ \\
\hline SF COMP & 2 & 3 & 79 & $0.48 \mathrm{U}$ & 2.88 & $0.39 \mathrm{U}$ & 13.61 & $3.53 \mathrm{U}$ & 21.16 & $2.87 \mathrm{U}$ \\
\hline SF COMP & 3 & 1 & 90 & $0.48 \mathrm{U}$ & 1.59 & $0.39 \cup$ & 13.28 & $3.61 \mathrm{U}$ & 11.97 & $2.94 \mathrm{U}$ \\
\hline SF COMP & 4 & 1 & 88 & $0.48 \mathrm{U}$ & 2.23 & $0.39 \mathrm{U}$ & 13.54 & $3.55 \mathrm{U}$ & 16.47 & $2.88 \mathrm{U}$ \\
\hline SFCOMP & 5 & 3 & 101 & 0.70 & 2.23 & $0.39 \mathrm{U}$ & 12.94 & 5.41 & 17.23 & $3.01 \mathrm{U}$ \\
\hline SFW COMP & 1 & 1 & 93 & 0.66 & $1.39 \mathrm{U}$ & $0.39 \mathrm{U}$ & 12.99 & 5.08. & $10.70 \mathrm{U}$ & $3.00 \mathrm{U}$ \\
\hline SFW COMP & 2 & 3 & 96 & $0.48 \mathrm{U}$ & $1.39 \mathrm{U}$ & $0.39 \mathrm{U}$ & 12.32 & $3.90 \mathrm{U}$ & $11.28 \mathrm{U}$ & $3.17 \mathrm{U}$ \\
\hline SFW COMP & 3 & 3 & 96 & $0.48 \mathrm{U}$ & 1.47 & $0.39 \mathrm{U}$ & 13.78 & $3.48 \mathrm{U}$ & 10.67 & $2.83 \mathrm{U}$ \\
\hline SFW COMP & 4 & 1 & 77 & $0.48 U$ & 1.69 & $0.39 \mathrm{U}$ & 13.08 & $3.67 \mathrm{U}$ & 12.92 & $2.98 \mathrm{U}$ \\
\hline SFW COMP & 5 & 2 & 101 & $0.48 U$ & $1.39 \mathrm{U}$ & $0.39 \mathrm{U}$ & 13.95 & $3.44 \mathrm{U}$ & $9.96 \mathrm{U}$ & $2.80 \mathrm{U}$ \\
\hline UIH COMP & 1 & 3 & 83 & $0.48 \mathrm{U}$ & 1.54 & $0.39 U$ & 13.70 & $3.50 \mathrm{U}$ & 11.24 & $2.85 \mathrm{U}$ \\
\hline UIH COMP & 2 & 1 & 97 & $0.48 U$ & 2.24 & $0.39 \mathrm{U}$ & 13.85 & $3.47 \mathrm{U}$ & 16.17 & $2.82 U$ \\
\hline UIH COMP & 3 & 3 & 89 & $0.48 U$ & 6.39 & $0.39 U$ & 13.03 & $3.68 \mathrm{U}$ & 49.04 & $2.99 \mathrm{U}$ \\
\hline UIH COMP & 4 & 1 & 92 & $0.48 \mathrm{U}$ & 1.43 & $0.39 \mathrm{U}$ & 13.21 & $3.63 \mathrm{U}$ & 10.83 & $2.95 \mathrm{U}$ \\
\hline UIH COMP & 5 & 2 & 95 & $0.48 \mathrm{U}$ & 2.09 & $0.39 \mathrm{U}$ & 12.99 & $3.70 \mathrm{U}$ & 16.09 & $3.00 \mathrm{U}$ \\
\hline TB Upper COMP, Replicate 1 & 1 & 1 & 98 & 0.72 & $1.39 \mathrm{U}$ & 1.25 & 12.66 & 5.69 & $10.98 U$ & 9.87 \\
\hline TB Upper COMP, Replicate 2 & 1 & 1 & 102 & $0.48 \mathrm{U}$ & 2.37 & $0.39 U$ & 12.66 & $3.79 \mathrm{U}$ & 18.72 & $3.08 \mathrm{U}$ \\
\hline TB Upper COMP, Replicate 3 & 1 & 1 & 105 & $0.48 \mathrm{U}$ & $1.39 \mathrm{U}$ & $0.39 U$ & 12.66 & $3.79 \mathrm{U}$ & $10.98 U$ & $3.08 \mathrm{U}$ \\
\hline TB Upper COMP & 2 & 1 & 102 & $0.48 U$ & $1.39 \mathrm{U}$ & $0.39 \mathrm{U}$ & 13.42 & $3.58 \mathrm{U}$ & $10.36 \mathrm{U}$ & $2.91 \mathrm{U}$ \\
\hline TB Upper COMP & 3 & 2 & 102 & $0.48 \mathrm{U}$ & $1.39 \mathrm{U}$ & $0.39 \mathrm{U}$ & 13.17 & $3.64 \mathrm{U}$ & $10.55 U$ & $2.96 \mathrm{U}$ \\
\hline TB Upper COMP & 4 & 1 & 81 & $0.48 U$ & $1.39 \mathrm{U}$ & $0.39 \mathrm{U}$ & 13.45 & $3.57 \mathrm{U}$ & $10.33 U$ & $2.90 \mathrm{U}$ \\
\hline TB Upper COMP & 5 & 2 & 104 & $0.48 U$ & $1.39 \mathrm{U}$ & $0.39 \mathrm{U}$ & 14.65 & $3.28 \mathrm{U}$ & $9.49 \mathrm{U}$ & $2.66 U$ \\
\hline TB Lower COMP & 1 & 2 & 105 & $0.48 \mathrm{U}$ & $1.39 \mathrm{U}$ & $0.39 \mathrm{U}$ & 13.26 & $3.62 \mathrm{U}$ & $10.48 \mathrm{U}$ & $2.94 \mathrm{U}$ \\
\hline TB Lower COMP & 2 & 1 & 82 & $0.48 U$ & $1.39 \mathrm{U}$ & $0.39 \mathrm{U}$ & 12.88 & $3.73 \mathrm{U}$ & $10.79 U$ & $3.03 \mathrm{U}$ \\
\hline TB Lower COMP & 3 & 2 & 97 & $0.48 \mathrm{U}$ & 1.71 & $0.39 \mathrm{U}$ & 13.79 & $3.48 \mathrm{U}$ & 12.40 & $2.83 \mathrm{U}$ \\
\hline TB Lower COMP & 4 & 3 & 96 & $0.48 \mathrm{U}$ & $1.39 \mathrm{U}$ & $0.39 \mathrm{U}$ & 12.49 & $3.84 \mathrm{U}$ & $11.13 U$ & $3.12 \mathrm{U}$ \\
\hline TB Lower COMP & 5 & 3 & 97 & $0.48 \mathrm{U}$ & 1.39 & $0.39 \mathrm{U}$ & 13.61 & $3.53 \mathrm{U}$ & 10.21 & $2.87 \mathrm{U}$ \\
\hline
\end{tabular}




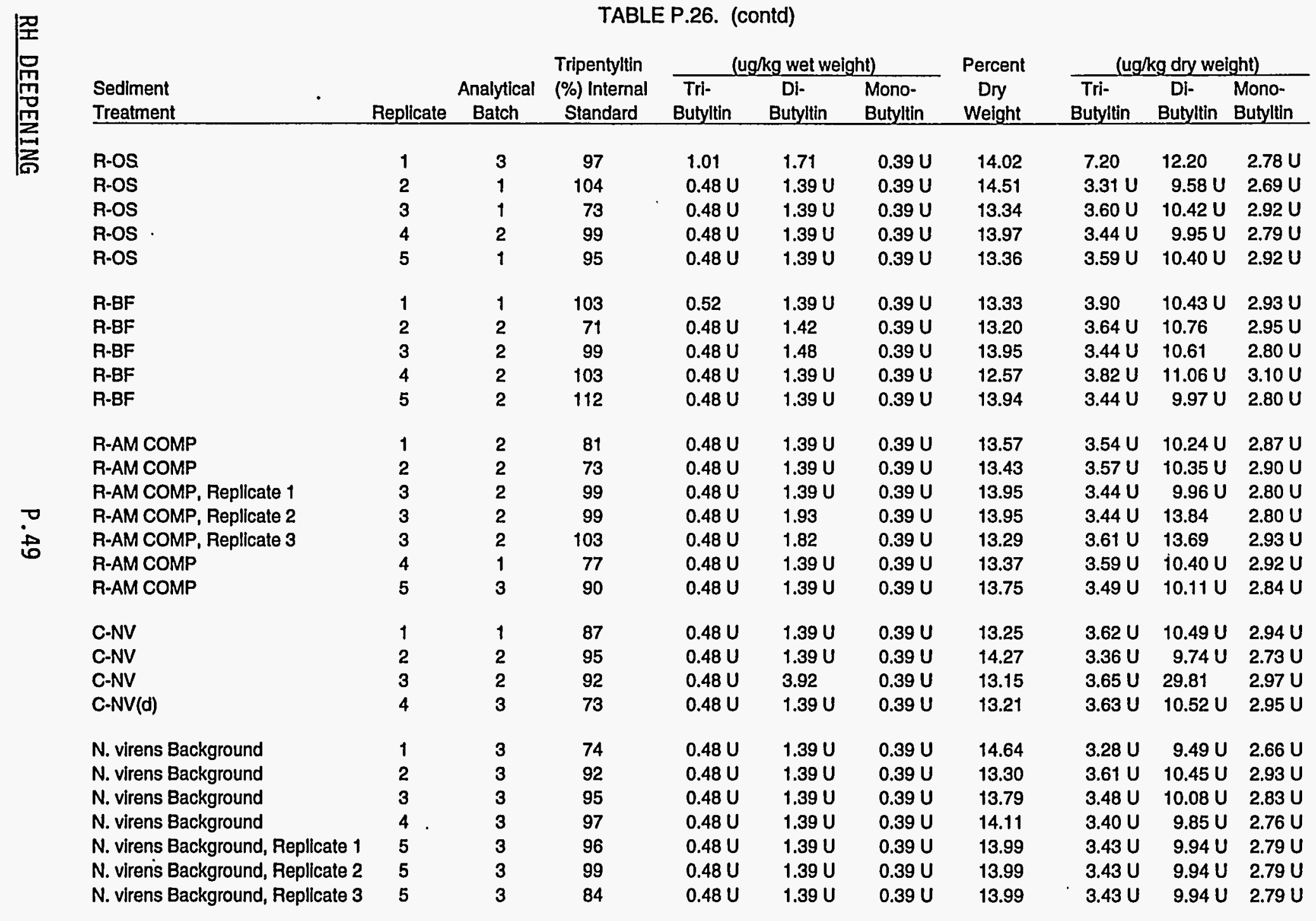
(a) DL Detection limit.
(b) NA Not applicable.
(c) U Undetected at or above detection limit.
(d) Insufficient organisms to test all five replicates. 
TABLE P.27. Quality Control Data for Butyltin Results, Wet Weight, in Tissue N. virens, Richmond Harbor Deepening Project

\begin{tabular}{|c|c|c|c|c|c|c|}
\hline \multirow[b]{2}{*}{$\begin{array}{l}\text { Sediment } \\
\text { Treatment }\end{array}$} & \multirow[b]{2}{*}{ Replicate } & \multirow[b]{2}{*}{$\begin{array}{c}\text { Analytical } \\
\text { Batch }\end{array}$} & \multirow{2}{*}{$\begin{array}{l}\text { Tripentyltin } \\
\% \text { Internal } \\
\text { Standard }\end{array}$} & \multicolumn{3}{|c|}{ (ug/kg wet weight) } \\
\hline & & & & $\begin{array}{l}\text { Tri- } \\
\text { Butyltin }\end{array}$ & $\begin{array}{c}\text { Di- } \\
\text { Butyltin }\end{array}$ & $\begin{array}{l}\text { Mono- } \\
\text { Butyltin }\end{array}$ \\
\hline \multicolumn{7}{|l|}{ Method Blanks } \\
\hline Blank & & 1 & 100 & $0.48 \mathrm{U}(\mathrm{a})$ & $1.39 \mathrm{U}$ & $0.39 \mathrm{U}$ \\
\hline Blank & & 2 & 107 & $0.48 \mathrm{U}$ & $1.39 \mathrm{U}$ & $0.39 \mathrm{U}$ \\
\hline Blank & & 3 & 89 & $0.48 \mathrm{U}$ & $1.39 \mathrm{U}$ & $0.39 \mathrm{U}$ \\
\hline \multicolumn{7}{|l|}{ Matrix Spikes } \\
\hline $\begin{array}{l}\text { TB Upper COMP } \\
\text { TB Upper COMP, MS } \\
\text { Concentration Recovered } \\
\text { Amount Spiked } \\
\text { Percent Recovery }\end{array}$ & $\begin{array}{l}5 \\
5\end{array}$ & $\begin{array}{l}2 \\
2\end{array}$ & $\begin{array}{l}104 \\
107 \\
\text { NA (b) } \\
\text { NA } \\
\text { NA }\end{array}$ & $\begin{array}{l}0.48 U \\
47.5 \\
47.5 \\
49.6 \\
96 \%\end{array}$ & $\begin{array}{l}1.39 U \\
47.4 \\
47.4 \\
49.6 \\
96 \%\end{array}$ & $\begin{array}{l}0.39 \mathrm{U} \\
14.3 \\
14.3 \\
49.6 \\
29 \%\end{array}$ \\
\hline $\begin{array}{l}\text { R-AM COMP } \\
\text { R-AM COMP, MS } \\
\text { Concentration Recovered } \\
\text { Amount Spiked } \\
\text { Percent Recovery }\end{array}$ & $\begin{array}{l}4 \\
4\end{array}$ & $\begin{array}{l}1 \\
1\end{array}$ & $\begin{array}{l}77 \\
91 \\
\text { NA } \\
\text { NA } \\
\text { NA }\end{array}$ & $\begin{array}{c}0.48 \cup \\
55.3 \\
55.3 \\
48.6 \\
114 \%\end{array}$ & $\begin{array}{r}1.39 \mathrm{U} \\
51.0 \\
51.0 \\
48.6 \\
105 \%\end{array}$ & $\begin{array}{l}0.39 \mathrm{U} \\
23.0 \\
23.0 \\
48.6 \\
47 \%\end{array}$ \\
\hline $\begin{array}{l}\text { R-AM COMP } \\
\text { R-AM COMP, MS } \\
\text { Concentration Recovered } \\
\text { Amount Spiked } \\
\text { Percent Recovery }\end{array}$ & $\begin{array}{l}5 \\
5\end{array}$ & $\begin{array}{l}3 \\
3\end{array}$ & $\begin{array}{r}90 \\
113 \\
\text { NA } \\
\text { NA } \\
\text { NA }\end{array}$ & $\begin{array}{r}0.48 \mathrm{U} \\
49.7 \\
49.7 \\
48.5 \\
102 \%\end{array}$ & $\begin{array}{l}1.39 U \\
47.3 \\
47.3 \\
48.5 \\
98 \%\end{array}$ & $\begin{array}{l}0.39 \mathrm{U} \\
21.9 \\
21.9 \\
48.5 \\
45 \%\end{array}$ \\
\hline \multicolumn{7}{|l|}{ Analytical Replicates } \\
\hline $\begin{array}{l}\text { TB Upper COMP, Replicate } 1 \\
\text { TB Upper COMP, Replicate } 2 \\
\text { TB Upper COMP, Replicate } 3 \\
\text { RSD }\end{array}$ & $\begin{array}{l}1 \\
1 \\
1\end{array}$ & $\begin{array}{l}1 \\
1 \\
1\end{array}$ & $\begin{array}{r}98 \\
102 \\
105 \\
\text { NA }\end{array}$ & $\begin{array}{l}0.72 \\
0.48 \mathrm{U} \\
0.48 \mathrm{U} \\
\text { NA }\end{array}$ & $\begin{array}{l}1.39 \mathrm{U} \\
2.37 \\
1.39 \mathrm{U} \\
\text { NA }\end{array}$ & $\begin{array}{l}1.25 \\
0.39 \mathrm{U} \\
0.39 \mathrm{U} \\
\mathrm{NA}\end{array}$ \\
\hline $\begin{array}{l}\text { R-AM COMP, Replicate } 1 \\
\text { R-AM COMP, Replicate } 2 \\
\text { R-AM COMP, Replicate } 3 \\
\text { RSD }\end{array}$ & $\begin{array}{l}3 \\
3 \\
3\end{array}$ & $\begin{array}{l}2 \\
2 \\
2\end{array}$ & $\begin{array}{r}99 \\
99 \\
103 \\
\text { NA }\end{array}$ & $\begin{array}{r}1.31 \\
1.35 \\
1.26 \\
3 \%\end{array}$ & $\begin{array}{l}1.39 \mathrm{U} \\
1.93 \\
1.82 \\
\mathrm{NA}\end{array}$ & $\begin{array}{l}0.39 \mathrm{U} \\
0.39 \mathrm{U} \\
0.39 \mathrm{U} \\
\mathrm{NA}\end{array}$ \\
\hline $\begin{array}{l}\text { N. virens Background, Replicate } 1 \\
\text { N. virens Background, Replicate } 2 \\
\text { N. virens Background, Replicate } 3\end{array}$ & $\begin{array}{l}5 \\
5 \\
5\end{array}$ & $\begin{array}{l}3 \\
3 \\
3\end{array}$ & $\begin{array}{l}96 \\
99 \\
84\end{array}$ & $\begin{array}{l}0.48 U \\
0.48 U \\
0.48 U\end{array}$ & $\begin{array}{l}1.39 U \\
1.39 U \\
1.39 U\end{array}$ & $\begin{array}{l}0.39 U \\
0.39 U \\
0.39 U\end{array}$ \\
\hline RSD & & & NA & NA & NA & NA \\
\hline
\end{tabular}

(a) U Undetected at or above detection limit.

(b) NA Not applicable.

RH DEEPENING 
APPENDIX Q

POTENTIAL EFFECTS OF DISPOSAL OF RICHMOND HARBOR DEEPENING SEDIMENTS AND THE INTENSIVE STUDY OF THE TURNING BASIN SEDIMENTS AT THE BAY FARM BORROW AREA 


\section{APPENDIX Q}

POTENTIAL EFFECTS OF DISPOSAL OF RICHMOND HARBOR DEEPENING SEDIMENTS AND THE INTENSIVE STUDY OF THE TURNING BASIN SEDIMENTS AT THE BAY FARM BORROW AREA

This appendix presents the results of physical/chemical sediment analysis, acute toxicity tests, bioaccumulation tests, statistical comparisons, and a Tier III evaluation of Richmond Harbor Deepening sediments and the Intensive Study of the Turning Basin sediments relative to the Bay Farm Borrow Area reference sediment (R-BF) (Figure Q.1). The Bay Farm Borrow Area could be a potential in-bay dredged material disposal area. All methods and results for sampling, physical descriptions, sediment chemistry, biological testing, and tissue chemistry are contained in Sections 2, 3, and 4 of this report; supporting data are contained in Appendixes A through R. As stated in Section 2.5 of this report, the use of Dunnett's test for statistical comparisons of nonindependent data sets increases the chance of Type II statistical errors in all comparisons, resulting in the identification of a greater number of significant differences than if multiple comparison tests are used.

\section{Q.1 SEDIMENT CHARACTERISTICS}

The five Richmond Harbor Deepening composites are fairly representative of the sediment characteristics of their contributing stations with respect to the sediment parameters that were measured (Tables Q.1 through Q.3). Generally, the Richmond Harbor Deepening sediments had less clay and more sand than the reference sediment R-BF, although UIH COMP and its contributing stations had a grain-size distribution similar to R-BF (Table Q.1). Richmond Harbor Deepening sediments also had less TOC than R-BF sediments. The TVS in UIH COMP and TB Upper COMP was consistently higher than TVS in R-BF; TVS in other composites and contributing stations was similar to or lower than TVS in R-BF. Oil and grease concentrations in Richmond Harbor sediments were similar to or lower than in R-BF; however, TPH was detected at a number of stations in SF, SFW, and UIH COMPS, whereas no TPH was detected in R-BF.

Comparisons of Richmond Harbor Deepening sediment PAHs, pesticides, and PCBs to R-BF are shown in Table Q.2. Concentrations of PAHs were elevated in SF, SFW, and UIH COMPS, their respective stations, or both, relative to R-BF. Concentrations of PAHs were relatively high in both the upper and lower sections of Station TB-4. The other TB stations had very low PAHs in their lower sections ( $>5 \mathrm{ft}$ below mudline). The chlorinated pesticides 4,4'-DDD, 4,4'-DDE, and 4,4'-DDT were considerably elevated in SF, SFW, and UIH COMPs and their respective stations relative to R-BF. Dieldrin was also elevated in SF and SFW 


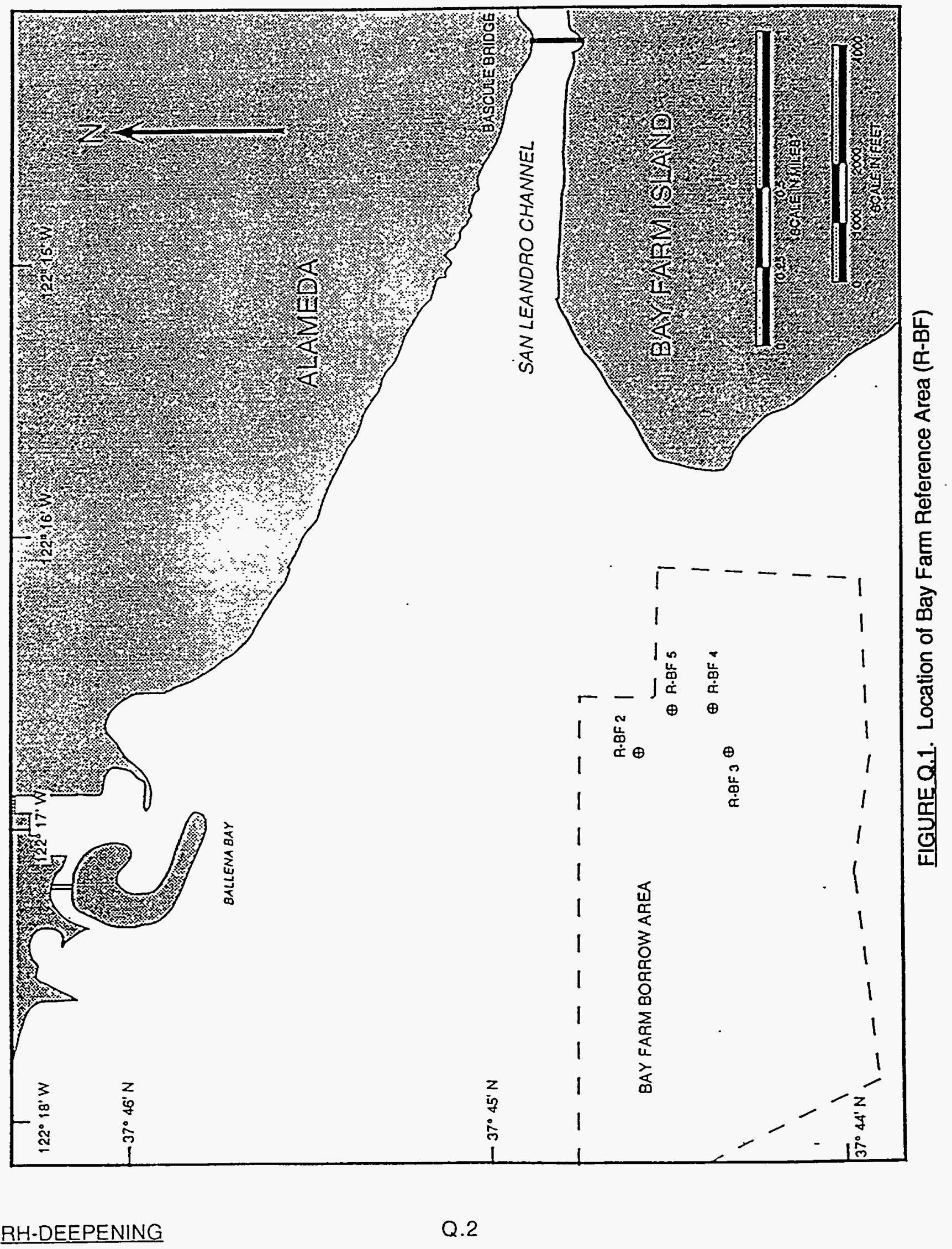


IABLE Q.1. Conventional Sediment Measurement Results for the Richmond Harbor Deepening Project Sediment Treatments

\begin{tabular}{|c|c|c|c|c|c|c|c|c|}
\hline \multirow[b]{2}{*}{$\begin{array}{l}\text { Sediment } \\
\text { Treatment } \\
\end{array}$} & \multicolumn{6}{|c|}{ Percent Dny Weight } & \multicolumn{2}{|c|}{$\mathrm{mg} / \mathrm{kg}$ Dry Weight } \\
\hline & $\begin{array}{c}\text { Gravel } \\
>2000 \mu \mathrm{m}\end{array}$ & $\begin{array}{c}\text { Sand } \\
62.5- \\
2000 \mu \mathrm{m} \\
\end{array}$ & $\begin{array}{c}\text { Silt } \\
3.9- \\
62.5 \mu \mathrm{m} \\
\end{array}$ & $\begin{array}{r}\text { Clay } \\
<3.9 \mu \mathrm{m} \\
\end{array}$ & TOC & TVS & $\begin{array}{c}\mathrm{mg} / \mathrm{kg} \mathrm{Dn} \\
\text { Oil and } \\
\text { Grease }\end{array}$ & Neight \\
\hline R-BF & 0 & 5 & 39 & 56 & 1.24 & 2.34 & 143 & $45 U(a)$ \\
\hline $\begin{array}{l}\text { SF COMP } \\
\text { SF-1 } \\
\text { SF-2 } \\
\text { SF-3 } \\
\text { SF-4 }\end{array}$ & $\begin{array}{l}1 \\
1 \\
6 \\
0 \\
0\end{array}$ & $\begin{array}{r}29 \\
29 \\
18 \\
9 \\
5\end{array}$ & $\begin{array}{l}35 \\
42 \\
34 \\
32 \\
32\end{array}$ & $\begin{array}{l}35 \\
28 \\
42 \\
59 \\
63\end{array}$ & $\begin{array}{l}0.71 \\
0.33 \\
0.98 \\
1.27(b) \\
1.37\end{array}$ & $\begin{array}{l}2.32 \\
2.27 \\
2.62 \\
2.67 \\
2.70\end{array}$ & $\begin{array}{c}29 U \\
36 \\
66 \\
136 \\
98\end{array}$ & $\begin{array}{l}29 U \\
23 U \\
34 \\
67 \\
57\end{array}$ \\
\hline $\begin{array}{l}\text { SFW COMP } \\
\text { SFW COMP(c) } \\
\text { SFW-1 } \\
\text { SFW-2 } \\
\text { SFW-3 } \\
\text { SFW-4 }\end{array}$ & $\begin{array}{l}5 \\
N A(d) \\
13 \\
8 \\
2 \\
3\end{array}$ & $\begin{array}{l}23 \\
\text { NA } \\
35 \\
15 \\
18 \\
27\end{array}$ & $\begin{array}{l}37 \\
\text { NA } \\
21 \\
35 \\
47 \\
45\end{array}$ & $\begin{array}{l}35 \\
\text { NA } \\
31 \\
42 \\
33 \\
25\end{array}$ & $\begin{array}{l}0.76(b) \\
\text { NA } \\
1.00 \\
1.09 \\
0.49 \\
0.32\end{array}$ & $\begin{array}{l}2.26 \\
\text { NA } \\
2.21 \\
2.84 \\
2.32 \\
2.01\end{array}$ & $\begin{array}{c}102(b) \\
232 \\
44 \\
79 \\
117 \\
27\end{array}$ & $\begin{array}{c}68(b) \\
104 \\
35 \\
69 \\
84 \\
22 U\end{array}$ \\
\hline $\begin{array}{l}\text { UIH COMP } \\
\text { UIH-1 } \\
\text { UIH-2 } \\
\text { UIH-3 } \\
\text { UIH-4 } \\
\text { UIH-5 }\end{array}$ & $\begin{array}{l}0 \\
0 \\
0 \\
0 \\
1 \\
0\end{array}$ & $\begin{array}{r}6 \\
5 \\
2 \\
7 \\
13 \\
7\end{array}$ & $\begin{array}{l}33 \\
35 \\
33 \\
35 \\
35 \\
39\end{array}$ & $\begin{array}{l}61 \\
60 \\
65 \\
58 \\
51 \\
54\end{array}$ & $\begin{array}{l}1.23 \\
1.17 \\
1.20 \\
1.12 \\
0.87 \\
0.97\end{array}$ & $\begin{array}{l}2.69 \\
2.80 \\
2.73 \\
2.81 \\
2.83 \\
2.74\end{array}$ & $\begin{array}{r}91 \\
204 \\
97 \\
80 \\
142 \\
139\end{array}$ & $\begin{array}{l}65 \\
75 \\
38 U \\
34 U \\
72 \\
70\end{array}$ \\
\hline $\begin{array}{l}\text { TB Upper COMP } \\
\text { TB-1 Upper } \\
\text { TB-2 Upper } \\
\text { TB-3 Upper } \\
\text { TB-4 Upper } \\
\text { TB-5 Upper } \\
\text { TB-6 Upper } \\
\text { TB-7 Upper } \\
\text { TB-7 Upper(c) }\end{array}$ & $\begin{array}{r}8 \\
22 \\
5 \\
1 \\
0 \\
1 \\
0 \\
0 \\
\mathrm{NA}\end{array}$ & $\begin{array}{r}14 \\
33 \\
20 \\
13 \\
3 \\
7 \\
3 \\
5 \\
\text { NA }\end{array}$ & $\begin{array}{l}45 \\
24 \\
41 \\
48 \\
46 \\
58 \\
49 \\
66 \\
\text { NA }\end{array}$ & $\begin{array}{l}33 \\
21 \\
34 \\
38 \\
51 \\
34 \\
48 \\
29 \\
\text { NA }\end{array}$ & $\begin{array}{l}0.85 \\
0.50 \\
0.73 \\
0.78 \\
1.09 \\
0.79 \\
0.66 \\
0.63 \\
\text { NA }\end{array}$ & $\begin{array}{l}2.48 \\
2.45 \\
3.25 \\
2.47 \\
2.63 \\
2.44 \\
2.43 \\
2.38 \\
\text { NA }\end{array}$ & $\begin{array}{l}47 \\
36 \\
36 \\
28 U \\
169 \\
26 U \\
83 \\
29(b) \\
20 U\end{array}$ & $\begin{array}{l}30 U \\
23 U \\
25 U \\
28 U \\
57 \\
26 U \\
32 \\
25 U(b) \\
20 U\end{array}$ \\
\hline $\begin{array}{l}\text { TB Lower COMP } \\
\text { TB-1 Lower } \\
\text { TB-2 Lower } \\
\text { TB-3 Lower } \\
\text { TB-4 Lower } \\
\text { TB-5 Lower } \\
\text { TB-6 Lower } \\
\text { TB-7 Lower }\end{array}$ & $\begin{array}{l}3(b) \\
9 \\
1 \\
0(b) \\
0 \\
0 \\
0(b) \\
1\end{array}$ & $\begin{array}{l}15(b) \\
53 \\
23 \\
13(b) \\
4 \\
12 \\
7(b) \\
3\end{array}$ & $\begin{array}{l}46(b) \\
23 \\
43 \\
52(b) \\
47 \\
55 \\
50(b) \\
55\end{array}$ & $\begin{array}{l}36(\mathrm{~b}) \\
15 \\
33 \\
36^{(b)} \\
49 \\
33 \\
43^{(b)} \\
41\end{array}$ & $\begin{array}{l}0.69 \\
0.05 \\
0.62 \\
0.70 \\
0.93 \\
0.70 \\
0.55 \\
0.72\end{array}$ & $\begin{array}{l}2.15 \\
1.73 \\
2.08 \\
2.21 \\
2.88 \\
2.27 \\
2.27 \\
2.43\end{array}$ & $\begin{array}{l}35 \\
19 U \\
29 \\
30 \\
58 \\
25 U \\
26 U \\
26 U\end{array}$ & $\begin{array}{l}26 U \\
19 U \\
24 U \\
25 U \\
30 U \\
25 U \\
26 U \\
26 U\end{array}$ \\
\hline $\begin{array}{l}\text { (a) U Undetectec } \\
\text { (b) Value is mean } \\
\text { (c) Sample re-ana } \\
\text { appropriate m } \\
\text { (d) NA Not applic }\end{array}$ & $\begin{array}{l}\text { d at or abov } \\
\text { n of analytic } \\
\text { nalyzed appr } \\
\text { natrix spike } \\
\text { icable. }\end{array}$ & $\begin{array}{l}\text { the detec } \\
\text { replicates } \\
\text { kimately o } \\
\text { ta. }\end{array}$ & $\begin{array}{l}\text { tion limit. } \\
\text { ne month }\end{array}$ & after origir & oil an & ease a & $\mathrm{PH}$ analy & to provide \\
\hline
\end{tabular}

RH-DEEPENING $\quad$ Q.3 


\begin{tabular}{|c|c|c|c|c|c|c|c|c|c|c|c|}
\hline Sediment Treatment & $\begin{array}{l}\text { Total } \\
\text { LPAH } \\
\end{array}$ & $\begin{array}{l}\text { Total } \\
\text { HPAH }\end{array}$ & \multicolumn{2}{|c|}{ 4,4'-DDD } & \multicolumn{2}{|c|}{ 4,4'-DDE } & \multicolumn{2}{|c|}{ 4,4'-DDT } & Dieldrin & \multicolumn{2}{|c|}{ Aroclor-1254 } \\
\hline R-BF & 228 & 1527 & 1.05 & & 1.69 & & 12.1 & & 13.0 & 23.3 & \\
\hline $\begin{array}{l}\text { SF COMP } \\
\text { SF-1 } \\
\text { SF-2 } \\
\text { SF-3(b) } \\
\text { SF-4 }\end{array}$ & $\begin{array}{r}228 \\
79 \\
278 \\
478 \\
480\end{array}$ & $\begin{array}{r}1345 \\
390 \\
1876 \\
3274 \\
3274\end{array}$ & $\begin{array}{l}208 \\
8 \% 8 \\
285 \\
288 \\
288\end{array}$ & $\begin{array}{l}D(a) \\
D \\
D \\
D \\
D\end{array}$ & $\begin{array}{l}342 \\
652 \\
36 \% \\
66.5\end{array}$ & $D$ & $\begin{array}{l}6 \% \\
2 \% \\
36 \% \\
358 \\
137\end{array}$ & D & $\begin{array}{l}140 \\
5.51 \\
25 \% \\
24.1 \\
22.8\end{array}$ & $\begin{array}{l}107 \\
3,6 \\
78 \\
180 \\
198\end{array}$ & \\
\hline $\begin{array}{l}\text { SFW COMP } \\
\text { SFW-1 } \\
\text { SFW-2 } \\
\text { SFW-3 } \\
\text { SFW-4 }\end{array}$ & $\begin{array}{r}389 \\
248 \\
386 \\
28 \% \\
71\end{array}$ & $\begin{array}{r}806 \\
736 \\
3390 \\
1105 \\
396\end{array}$ & $\begin{array}{l}6 \% \\
918 \% \\
6 \% \\
68 \%\end{array}$ & $\begin{array}{l}D \\
D \\
D \\
D \\
D\end{array}$ & $\begin{array}{l}82.0 \\
37 \% \\
3 \% \\
8 \% \\
8 \%\end{array}$ & $D$ & $\begin{array}{l}81 \% \\
62 \\
8 \% \\
56 \% \\
38 \%\end{array}$ & $\begin{array}{l}D \\
D \\
D \\
D\end{array}$ & $\begin{array}{l}662 \\
12.9 \\
17.9 \\
17.5 \\
6.26\end{array}$ & $\begin{array}{l}1 / 5 \\
108 \\
20 \\
3.9 \% \\
20\end{array}$ & $\begin{array}{l}U(b) \\
U\end{array}$ \\
\hline $\begin{array}{l}\text { UIH COMP(b) } \\
\text { UIH-1 } \\
\text { UIH-2 } \\
\text { UIH-3 } \\
\text { UIH-4 } \\
\text { UIH-5 }\end{array}$ & $\begin{array}{l}426 \\
25 \% \\
278 \\
246 \\
227 \\
289\end{array}$ & 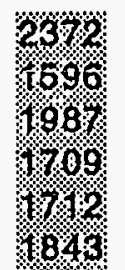 & $\begin{array}{l}1 \% \\
76 \% \\
6 \% \\
6 \% \\
6 \% 8\end{array}$ & $\begin{array}{l}D \\
D \\
D \\
D \\
D \\
D\end{array}$ & 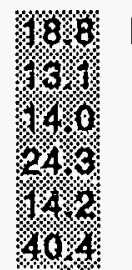 & $D$ & $\begin{array}{l}39 \% \\
49 \% \\
88 \% \\
862 \\
6.2 \\
60 \%\end{array}$ & $\mathrm{D}$ & $\begin{array}{c}9.17 \\
6.46 \\
7.24 \\
10.8 \\
5.47 \\
16.6\end{array}$ & $\begin{array}{r}92 \\
8 \% \\
92.0 \\
6 \% \\
6 \% \\
4 \%\end{array}$ & \\
\hline $\begin{array}{l}\text { TB Upper COMP } \\
\text { TB-1 Upper } \\
\text { TB-2 Upper(b) } \\
\text { TB-3 Upper } \\
\text { TB-4 Upper } \\
\text { TB-5 Upper } \\
\text { TB-6 Upper } \\
\text { TB-7 Upper }\end{array}$ & $\begin{array}{r}115 \\
48 \\
172 \\
161 \\
216 \\
91 \\
13 \\
26\end{array}$ & $\begin{array}{r}820 \\
368 \\
1213 \\
1322 \\
1622 \\
383 \\
18 \\
26\end{array}$ & $\begin{array}{l}1 \% 99 \\
1 \% 9 \\
2 \% 1 \\
1.01 \\
1.00 \\
0.75 \\
0.17 \\
0.16\end{array}$ & $\begin{array}{l}U \\
U\end{array}$ & $\begin{array}{l}0.08 \\
0.08 \\
0.39 \\
0.07 \\
6.16 \\
0.07 \\
0.07 \\
0.07\end{array}$ & $\begin{array}{l}U \\
U \\
U \\
U \\
U \\
U\end{array}$ & $\begin{array}{l}0.73 \\
1.24 \\
2.00 \\
0.50 \\
4.74 \\
6.87 \\
0.48 \\
0.46\end{array}$ & $\begin{array}{l}U \\
U\end{array}$ & $\begin{array}{l}1.06 \\
0.32 U \\
0.57 \\
0.85 \\
2.05 \\
0.62 \\
0.36 U \\
0.34 U\end{array}$ & $\begin{array}{l}20 \\
8.51 \\
20 \\
4.68 \\
46 \% 8 \\
20 \\
20 \\
20 \\
\end{array}$ & $\begin{array}{l}U \\
J(c) \\
U \\
J\end{array}$ \\
\hline
\end{tabular}




\begin{tabular}{|c|c|c|c|c|c|c|c|c|}
\hline & & & 1BLEQ2 & ntd) & & & & \\
\hline Sediment Treatment & $\begin{array}{l}\text { Total } \\
\text { LPAH }\end{array}$ & $\begin{array}{c}\text { Total } \\
\text { HPAH }\end{array}$ & 4,4'-DDD & 4,4'-DDE & 4,4'-DDT & Dieldrin & \multicolumn{2}{|c|}{ Aroclor-1254 } \\
\hline $\begin{array}{l}\text { TB Lower COMP } \\
\text { TB-1 Lower } \\
\text { TB-2 Lower } \\
\text { TB-3 Lower } \\
\text { TB-4 Lower } \\
\text { TB-5 Lower } \\
\text { TB-6 Lower } \\
\text { TB-7 Lower }\end{array}$ & $\begin{array}{r}31 \\
0 \\
13 \\
16 \\
16 \\
260 \\
19 \\
14 \\
28\end{array}$ & $\begin{array}{r}94 \\
2 \\
17 \\
26 \\
2023 \\
25 \\
20 \\
27\end{array}$ & $\begin{array}{c}0.97 \\
0.12 U \\
0.14 U \\
0.16 U \\
2.16 \% \\
0.15 U \\
0.16 U \\
0.16 U\end{array}$ & $\begin{array}{l}0.07 U \\
0.05 U \\
0.06 U \\
0.07 U \\
0.08 U \\
0.06 U \\
0.07 U \\
0.07 U\end{array}$ & $\begin{array}{l}0.47 U \\
0.36 U \\
0.40 U \\
0.46 U \\
18.8 \\
0.43 U \\
0.46 U \\
0.45 U\end{array}$ & $\begin{array}{l}0.36 U \\
0.27 U \\
0.30 U \\
0.34 U \\
1.86 \\
0.32 U \\
0.34 U \\
0.34 U\end{array}$ & $\begin{array}{l}20 \\
20 \\
20 \\
20 \\
5993 \\
20 \\
20 \\
20\end{array}$ & $\begin{array}{l}U \\
U \\
U \\
U \\
U \\
U \\
U\end{array}$ \\
\hline OBM COMP & 8 & 4 & $0.13 \mathrm{U}$ & $0.06 U$ & $0.38 U$ & $0.28 \mathrm{U}$ & 20 & U \\
\hline $\begin{array}{l}\text { (a) D Diluted sample. } \\
\text { (b) U Undetected at } \\
\text { (c) J Detected below }\end{array}$ & $\begin{array}{l}\text { The de } \\
\text { detecti }\end{array}$ & $\begin{array}{l}\text { nit. } \\
\text { ut abov }\end{array}$ & ment dete & limit. & & & & \\
\hline
\end{tabular}




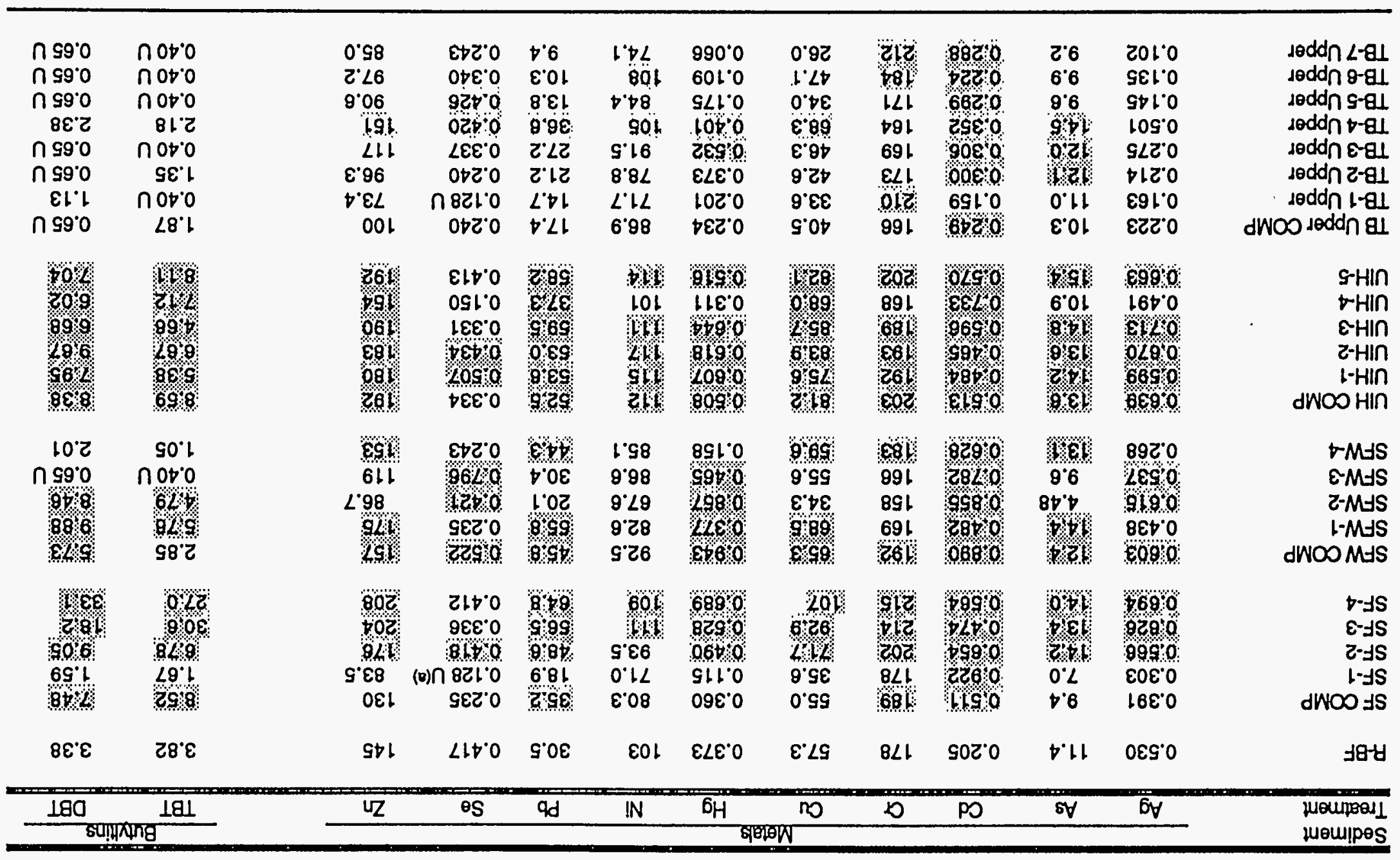

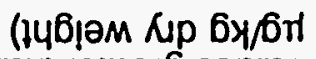

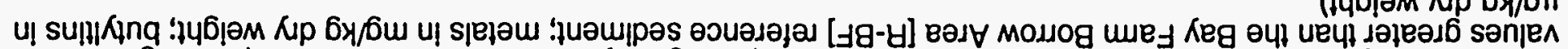

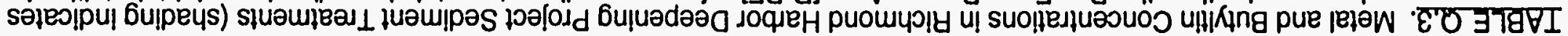




\begin{tabular}{|c|c|c|c|c|c|c|c|c|c|c|c|c|}
\hline \multirow{3}{*}{$\begin{array}{l}\text { Sediment } \\
\text { Treatment }\end{array}$} & \multicolumn{10}{|c|}{ IABLEQ.3. (contd) } & & \\
\hline & & & & & & gtals & & & & & But & \\
\hline & $\mathrm{Ag}$ & As & Cd & $G$ & Cu & $\mathrm{Hg}$ & $\mathrm{Ni}$ & $\mathrm{Pb}$ & Se & $\mathrm{Zn}$ & TBT & DBT \\
\hline TB Lower COMP & 0.158 & 118 & 0.252 & 180 & 39.4 & 0.140 & 90.3 & 9.4 & $0.128 U$ & 91.8 & $0.40 \mathrm{U}$ & $0.65 \mathrm{U}$ \\
\hline TB-1 Lower & 0.128 & 6.7 & 0.100 & 206 & 17.2 & 0.077 & 47.5 & 8.2 & $0.128 U$ & 42.4 & $0.40 \mathrm{U}$ & $0.65 \mathrm{U}$ \\
\hline TB-2 Lower & 0.106 & 11.4 & 0,250 & 201 & 33.5 & 0.073 & 91.5 & 13.7 & 0.346 & 81.0 & $0.40 \mathrm{U}$ & $0.65 \mathrm{U}$ \\
\hline TB-3 Lower & 0.114 & 8.3 & 0260 & 203 & 44.2 & 0.078 & 91.6 & 13.8 & 0.330 & 87.0 & $0.40 \mathrm{U}$ & $0.65 \mathrm{U}$ \\
\hline TB-4 Lower & 0.501 & $13: 8$ & 0.548 & 181 & 65.0 & 0.642 & 98.2 & 40.2 & 0.413 & 155 & $0.40 \mathrm{U}$ & 1.20 \\
\hline TB-5 Lower & 0.115 & 10.3 & 0.281 & 201 & 33.6 & 0.082 & 85.8 & 10.4 & 0.333 & 84.4 & $0.40 \mathrm{U}$ & $0.65 \mathrm{U}$ \\
\hline TB-6 Lower & 0.143 & 10.7 & 0217 & 205 & 47.6 & 0.088 & 101 & 12.7 & 0.240 & 87.1 & $0.40 \mathrm{U}$ & $0.65 \mathrm{U}$ \\
\hline TB-7 Lower & 0.140 & 10.8 & 0.284 & 193 & 44.7 & 0.078 & 105 & 10.4 & 0.273 & 94.5 & $0.40 \mathrm{U}$ & $0.65 U$ \\
\hline OBM COMP & NA(B) & NA & NA & NA & NA & NA & NA & NA & NA & NA & $0.40 \mathrm{U}$ & $0.65 U$ \\
\hline
\end{tabular}

$\stackrel{?}{?}$ 
COMPs and most of their respective stations. The primary source of these pesticides is the former United Heckathom plant on the east shore of Lauritzen Canal (Figure 3.1), which is now a federal Superfund site. The PCB Aroclor 1254 was also elevated in SF, SFW, and UIH COMPs and their respective stations, but was below the method detection limit in all other stations except TB-4 (Upper and Lower).

Metals concentrations were elevated in SF, SFW, and UIH COMPs, their respective stations, or both, relative to R-BF. Butyltin concentrations were low in Richmond Harbor Deepening sediments, except at Stations SF-3 and SF-4 (Table Q.3).

The Intensive Study of the Turning Basin sediments were predominantly fine-grained with a similar composition to the reference sediment R-BF, except for TB-1 Lower, which was predominantly sand and gravel. Sediments from R-BF had higher detectable concentrations of TOC, oil and grease, TPH, PAHs, pesticides, PCBs, six metals, and butyltins than the Turning Basin sediments, with the exception of TB-4 Middle. This test treatment had higher detectable concentrations of PAHs, pesticides, PCBs, 8 of the 10 metals, and TBT than any other sediment treatment. The results of the sediment chemistry analysis for the Tuming Basin sediments are shown in Tables Q.4 through Q.6.

\section{Q.2 DEPOSITED SEDIMENT TOXICITY}

The acute solid-phase tests with Richmond Harbor Deepening sediments showed no acute toxicity to $M$. nasuta when compared with the reference treatment R-BF (Table Q.7). However, the OBM COMP was acutely toxic to N. caecoides relative to R-BF. At this time, no dose response of $N$. caecoides to ammonia is available to determine the contribution of ammonia in sediment to toxicity. The $R$. abronius 10-day test showed statistically significant differences and a $>20 \%$ difference in survival in TB Upper, TB Lower, and OBM COMPs, when compared with the reference R-BF (Table Q.7). The mortality observed in $R$. abronius exposed to TB Lower COMP is greater than can be attributed to ammonia acting alone (see Section 3.4.1, Figure 3.37). However, the low R. abronius survival in TB Upper COMP and OBM COMP could largely be attributed to ammonia. Although the relationship of observed mortality and total ammonia in the interstitial water of TB Upper COMP was below the expected effects range of ammonia as a sole toxicant (Figure 3.37), the mean mortality was affected by one very low replicate (rep $4,45 \%$ sunival). If that replicate were not included in the mean, the response to TB Upper would be within the expected effects range of ammonia.

Solid-phase toxicity tests for the Tuming Basin sediments consisted of three $R$. abronius 10-day tests (Table Q.8). Test results for the static 10-day test with no ammonia manipulation showed that five test treatments were acutely toxic to $R$. abronius when compared with R-BF. 
IABLE Q.4. Conventional Sediment Measurement Results for the Sediment Treatments, Richmond Harbor Deepening Project-Intensive Study of the Turning Basin

\begin{tabular}{|c|c|c|c|c|c|c|c|c|}
\hline \multirow[b]{2}{*}{$\begin{array}{l}\text { Sediment } \\
\text { Treatment }\end{array}$} & \multicolumn{6}{|c|}{ Percent Dry Weight } & \multicolumn{2}{|c|}{$\mathrm{mg} / \mathrm{kg} \mathrm{Dry} \mathrm{Weight}$} \\
\hline & $>2000 \mu \mathrm{m}$ & $\begin{array}{c}62.5- \\
2000 \mu \mathrm{m}\end{array}$ & $\begin{array}{c}3.9- \\
62.5 \mu \mathrm{m}\end{array}$ & & TOC & TVS & $\begin{array}{l}\text { Oil and } \\
\text { Grease }\end{array}$ & TPH \\
\hline R-BF & 0 & 1 & 39 & 60 & 1.4 & 2.3 & 130 & 100 \\
\hline $\begin{array}{l}\text { TB-1 Lower } \\
\text { TB-2 Lower } \\
\text { TB-3 Lower } \\
\text { TB-4 Middle } \\
\text { TB-4 Lower } \\
\text { TB-5 Lower } \\
\text { TB-6 Lower } \\
\text { TB-7 Lower } \\
\text { TB-8 Lower } \\
\text { TB-9 Lower }\end{array}$ & $\begin{array}{r}13 \\
3 \\
1 \\
0(a) \\
0 \\
0 \\
1 \\
1 \\
0 \\
0\end{array}$ & $\begin{array}{r}49 \\
18 \\
15 \\
4(a) \\
10 \\
7 \\
5 \\
7 \\
6 \\
15\end{array}$ & $\begin{array}{r}23 \\
47 \\
50 \\
48(a) \\
44 \\
54 \\
40 \\
53 \\
55 \\
44\end{array}$ & $\begin{array}{r}15 \\
32 \\
34 \\
48(a) \\
46 \\
39 \\
54 \\
39 \\
39 \\
41\end{array}$ & $\begin{array}{l}0.11 \\
0.67 \\
0.67 \\
1.1 \\
0.58 \\
0.90 \\
0.81 \\
0.70 \\
0.76 \\
0.59\end{array}$ & $\begin{array}{l}0.79(a) \\
2.3 \\
2.1 \\
2.6 \\
2.1 \\
2.2 \\
2.6 \\
2.4 \\
2.6 \\
2.1\end{array}$ & $\begin{array}{l}14 \\
50 \\
40 \\
18 U \\
16 U \\
56 \\
17 U \\
15 U \\
43 \\
20\end{array}$ & $\begin{array}{l}9.9 U(\mathrm{~b}) \\
27 \\
16 U \\
18 U \\
16 U \\
58 \\
17 U \\
15 U \\
16 U \\
16 U\end{array}$ \\
\hline OBM COMP & 0 & 18 & 56 & 26 & 0.16 & 1.9 & $11 \mathrm{U}$ & $11 \mathrm{U}$ \\
\hline
\end{tabular}

TABLE Q.5. Detected Total PAHs, Pesticides, and PCBs in Sediment Treatments, Richmond Harbor Deepening Project-Intensive Study of the Turning Basin (values in $\mu \mathrm{g} / \mathrm{kg}$ dry weight)

\begin{tabular}{|c|c|c|c|c|c|c|c|}
\hline $\begin{array}{l}\text { Sediment } \\
\text { Treatment }\end{array}$ & $\begin{array}{c}\text { Total } \\
\text { LPAHs }\end{array}$ & $\begin{array}{c}\text { Total } \\
\text { HPAHs }\end{array}$ & Aldrin & $4,4^{\prime}-\mathrm{DDD}$ & 4,4'-DDE & 4,4'-DDT & $\begin{array}{c}\text { Aroclor } \\
1254\end{array}$ \\
\hline R-BF & 355 & 2116 & 2.15 & 5.19 & 2.61 & $1.19 \cup(a)$ & 46.8 \\
\hline $\begin{array}{l}\text { TB-1 Lower } \\
\text { TB-2 Lower } \\
\text { TB-3 Lower } \\
\text { TB-4 Middle } \\
\text { TB-4 Lower } \\
\text { TB-5 Lower } \\
\text { TB-6 Lower } \\
\text { TB-7 Lower } \\
\text { TB-8 Lower } \\
\text { TB-9 Lower }\end{array}$ & $\begin{array}{r}17 \\
22 \\
38 \\
339 \\
47 \\
51 \\
52 \\
35 \\
38 \\
43\end{array}$ & $\begin{array}{r}37 \\
36 \\
58 \\
2355 \\
66 \\
63 \\
66 \\
69 \\
67 \\
62\end{array}$ & $\begin{array}{l}0.17 U \\
0.66 \\
0.21 U \\
1.15 \\
0.21 U \\
0.22 U \\
1.17 \\
1.69 \\
0.97 \\
0.35 U\end{array}$ & $\begin{array}{c}0.21 U \\
0.17 U \\
0.26 U \\
19.3 \\
0.26 U \\
0.27 U \\
0.29 U \\
0.27 U \\
0.27 U \\
0.43 U\end{array}$ & $\begin{array}{c}0.11 U \\
0.09 \mathrm{U} \\
0.14 \mathrm{U} \\
15.1 \\
0.14 \mathrm{U} \\
0.15 \mathrm{U} \\
0.16 \mathrm{U} \\
0.15 \mathrm{U} \\
0.15 \mathrm{U} \\
0.24 \mathrm{U}\end{array}$ & $\begin{array}{l}0.58 U \\
0.47 U \\
0.74 U \\
9.3 \\
0.72 U \\
0.76 U \\
0.83 U \\
0.77 U \\
0.76 U \\
1.21 U\end{array}$ & $\begin{array}{l}20 U \\
20 U \\
20 U \\
101 \\
20 U \\
20 U \\
20 U \\
20 U \\
20 U \\
20 U\end{array}$ \\
\hline OBM COMP & 29 & 28 & $0.18 U$ & $0.22 \mathrm{U}$ & $0.12 \mathrm{U}$ & $0.63 \mathrm{U}$ & $20 \mathrm{U}$ \\
\hline
\end{tabular}




\begin{tabular}{|c|c|c|c|c|c|c|c|c|c|c|c|c|}
\hline \multirow{2}{*}{$\begin{array}{l}\text { Sediment } \\
\text { Treatment } \\
\end{array}$} & \multicolumn{10}{|c|}{ Metals } & \multicolumn{2}{|c|}{ Butylfins } \\
\hline & $\mathrm{Ag}$ & As & Cd & $\mathrm{Cr}$ & $\mathrm{Cu}$ & $\mathrm{Hg}$ & $\mathrm{Ni}$ & $\mathrm{Pb}$ & $\mathrm{Se}$ & $\mathrm{Zn}$ & TBT & DBT \\
\hline R-BF & 0.44 & 9.4 & 0.14 & 178 & 60.6 & 0.315 & 111 & 35.3 & 0.29 & 158 & 2.27 & 2.11 \\
\hline $\begin{array}{l}\text { TB-1 Lower } \\
\text { TB-2 Lower } \\
\text { TB-3 Lower } \\
\text { TB-4 Middle } \\
\text { TB-4 Lower } \\
\text { TB-5 Lower } \\
\text { TB-6 Lower } \\
\text { TB-7 Lower } \\
\text { TB-8 Lower } \\
\text { TB-9 Lower }\end{array}$ & $\begin{array}{l}0.10 \\
0.11 \\
0.11 \\
0.65 \\
0.11 \\
0.10 \text { (b) } \\
0.12 \\
0.11 \\
0.10 \\
0.10\end{array}$ & $\begin{array}{c}6.07 \\
10.2 \\
9.2 \\
16.5 \\
9.7 \\
10.1 \text { (b) } \\
12.4 \\
9.8 \\
10.7 \\
7.8\end{array}$ & $\begin{array}{l}0.25 \\
0.21 \\
0.20 \\
0.54 \\
0.17 \\
0.21 \text { (b) } \\
0.20 \\
0.20 \\
0.21 \\
0.15\end{array}$ & $\begin{array}{l}231 \\
221 \\
184 \\
182 \\
181 \\
192(b) \\
173 \\
188 \\
182 \\
196\end{array}$ & $\begin{array}{l}20.9 \\
39.8 \\
36.1 \\
74.0 \\
44.3 \\
41.2(b) \\
53.4 \\
42.4 \\
45.8 \\
41.2\end{array}$ & $\begin{array}{l}0.059 \\
0.071 \\
0.058 \\
0.734 \\
0.076 \\
0.058(b) \\
0.037 \\
0.038 \\
0.066 \\
0.068\end{array}$ & $\begin{array}{c}55.3 \\
84.4 \\
85.1 \\
94.6 \\
93.6 \\
97.6(\mathrm{~b}) \\
113 \\
92.7 \\
101 \\
87.9\end{array}$ & $\begin{array}{c}11.1 \\
11.8 \\
9.3 \\
43.9 \\
12.1 \\
10.6(b) \\
8.4 \\
11.1 \\
10.3 \\
14.1\end{array}$ & $\begin{array}{l}0.17 U \\
0.17 U \\
0.17 U \\
0.39 \\
0.17 U \\
0.17 U(b) \\
0.17 U \\
0.19 \\
0.19 \\
0.17 U\end{array}$ & $\begin{array}{c}51.2 \\
88.6 \\
85.4 \\
185 \\
90.7 \\
94.3(b) \\
105 \\
95.8 \\
97.2 \\
82.7\end{array}$ & $\begin{array}{l}0.57 \\
0.53 \\
0.49 \\
3.66 \\
0.61 \\
0.48 \mathrm{U} \\
0.54 \\
0.52 \\
0.48 \mathrm{U} \\
0.48 \mathrm{U}\end{array}$ & $\begin{array}{c}0.56 U(\mathrm{a}) \\
1.05 \\
0.56 U \\
0.82 \\
0.56 U \\
0.76 \\
0.56 U \\
0.56 U \\
0.56 U \\
0.56 U\end{array}$ \\
\hline OBM COMP & 0.11 & 3.28 & 0.56 & 142 & 27.4 & 0.044 & 62.7 & 10.6 & $0.17 \mathrm{U}$ & 68.3 & $0.48 \mathrm{U}$ & $0.56 \mathrm{U}$ \\
\hline $\begin{array}{l}\text { a) U Undete } \\
\text { b) Values is }\end{array}$ & $\begin{array}{l}\text { at or } \\
\text { of } r \epsilon\end{array}$ & $\begin{array}{l}\text { ve de } \\
\text { cate a }\end{array}$ & $\begin{array}{l}\text { tion lin } \\
\text { ysis. }\end{array}$ & & & & & & & & & \\
\hline
\end{tabular}


IABLE Q7 Summary of 10-Day Solid-Phase Toxicity Tests, Richmond Harbor Deepening Project

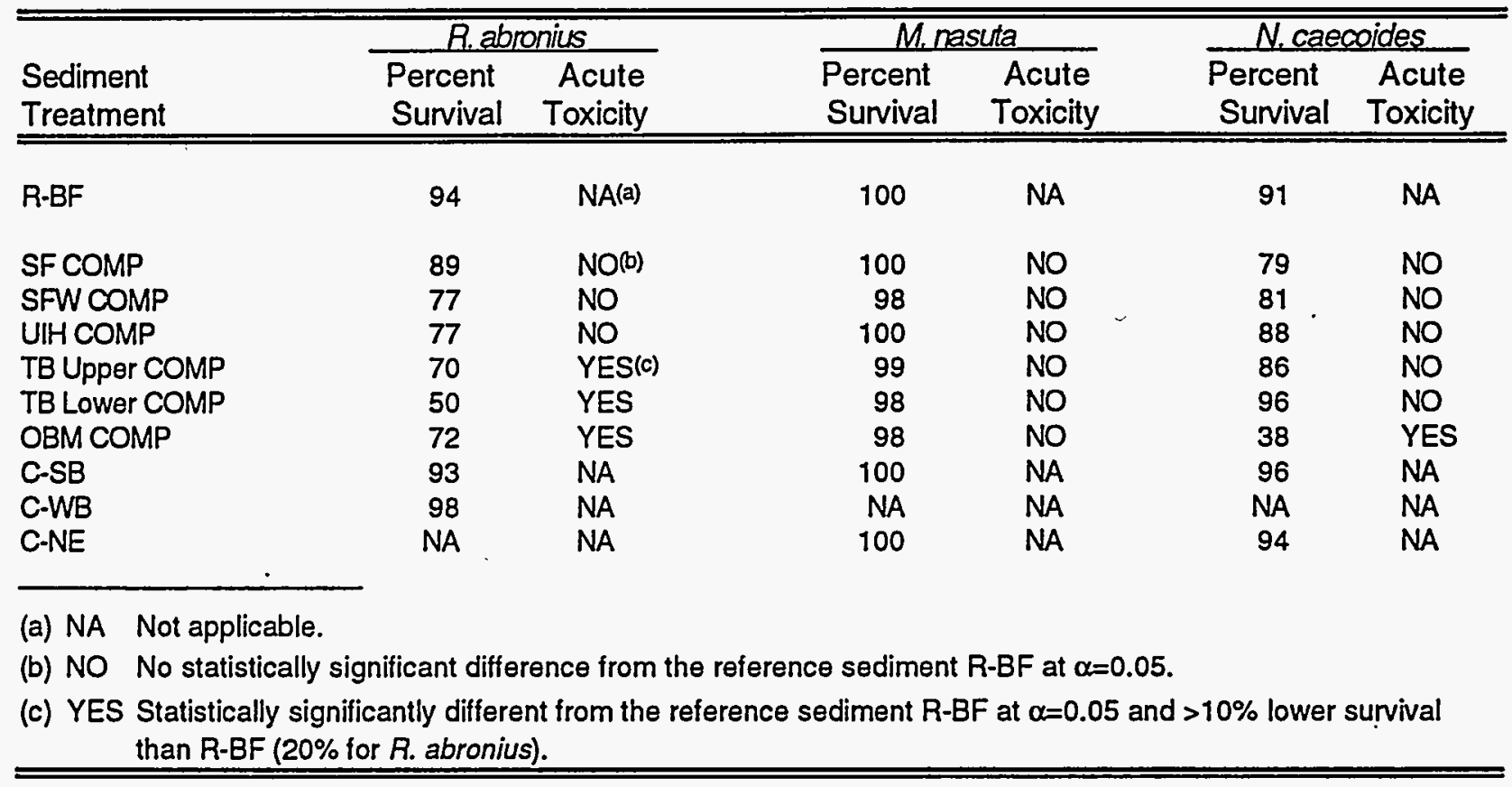

TABLE Q.8. Summary of 10-Day Solid-Phase R. abronius Toxicity Tests, Richmond Harbor Deepening Project-Intensive Study of the Turning Basin

\begin{tabular}{|c|c|c|c|c|c|c|}
\hline \multirow[b]{2}{*}{$\begin{array}{l}\text { Sediment } \\
\text { Treatment } \\
\end{array}$} & \multicolumn{2}{|c|}{ Static } & \multicolumn{2}{|c|}{$\begin{array}{l}\text { Ammonia Reduction } \\
\text { to }<20 \mathrm{mg} / \mathrm{L}\end{array}$} & \multicolumn{2}{|c|}{$\begin{array}{c}\text { Ammonia Reduction } \\
\text { to }<15 \mathrm{ma} / \mathrm{L}\end{array}$} \\
\hline & $\begin{array}{l}\text { Percent } \\
\text { Survival }\end{array}$ & $\begin{array}{c}\text { Acute } \\
\text { Toxicity }\end{array}$ & $\begin{array}{l}\text { Percent } \\
\text { Survival }\end{array}$ & $\begin{array}{c}\text { Acute } \\
\text { Toxicity }\end{array}$ & $\begin{array}{l}\text { Percent } \\
\text { Percent }\end{array}$ & $\begin{array}{l}\text { Acute } \\
\text { Toxicity }\end{array}$ \\
\hline R-BF & 84 & $N A(a)$ & 84 & NA & NA & NA \\
\hline TB-1 Lower & 87 & NO & NA & NA & NA & NA \\
\hline TB-2 Lower & 52 & YES & 79 & NO & NA & NA \\
\hline TB-3 Lower & 25 & YES & 70 & No & 83 & No \\
\hline TB-4 Middle & 82 & NO & 89 & No & NA & NA \\
\hline TB-4 Lower & 76 & NO & 81 & NO & NA & NA \\
\hline TB-5 Lower & 62 & YES & 82 & No & NA & NA \\
\hline TB-6 Lower & 76 & NO & NA & NA & NA & NA \\
\hline TB-7 Lower & 55 & YES & NA & NA & 75 & No \\
\hline TB-8 Lower & 64 & NO & NA & NA & 81 & No \\
\hline TB-9 Lower & 28 & YES & 74 & NO & 80 & NO \\
\hline OBM COMP & 68 & NA & NA & NA & NA & NA \\
\hline C-WB & 98 & NA & 98 & NA & 100 & NA \\
\hline C-SB & 89 & NA & 89 & NA & NA & NA \\
\hline
\end{tabular}


These test treatments were TB-2 Lower, TB-3 Lower, TB-5 Lower, TB-7 Lower, and TB- 9 Lower. When these test treatments were further tested either during the ammonia reduction to $<20 \mathrm{mg} / \mathrm{L}$ test or the ammonia reduction to $<15 \mathrm{mg} / \mathrm{L}$ test, none were acutely toxic to $R$. abronius when compared with the survival of $R$. abronius exposed to the sediments from R-BF.

\section{Q.3 WATER COLUMN EFFECTS}

The evaluation of water column effects does not include comparisons with the reference sediment because the reference sediment is not tested for water column toxicity. The results of the three water column (SPP) toxicity tests conducted with Richmond Harbor Deepening test treatments are presented in Table Q.9. There was no acute toxicity to either the mysid, H. costata, or to the sanddab, C. stigmaeus. T-test results showed that the SPP from SFW, UIH, TB Upper, and TB Lower COMPs significantly affected survival to normal D-cell stage in M. galloprovincialis larvae. The $\mathrm{EC}_{50}$ values for those treatments ranged from $57.6 \% \mathrm{SPP}$ to $80.0 \%$ SPP. Normal development could have been affected by ammonia released from sediment into the SPP (see Section 3.4.7, Figure 3.38). Ammonia concentrations and normal development in $100 \%$ SPP of SFW, UIH, and TB Lower COMPS were within the range of expected effects for ammonia acting alone. However, normal development in TB Upper COMP SPP appeared to be reduced more than would be expected from ammonia only.

\section{Q.4 DEPOSITED SEDIMENT BIOACCUMULATION}

Bioaccumulation of contaminants by the clam, M. nasuta, and the polychaete, $N$. virens, was assessed through a 28-day exposure to Richmond Harbor Deepening composites followed by chemical analysis of tissue samples. The 28-day test methods and results are reported in Sections 2 and 3 and Appendixes $M$ and $N$. Complete tissue chemistry results, QC data, and QAVC summaries are presented in Appendixes $O$ and $P$. The concentrations of contaminants in $M$. nasuta and $N$. virens exposed to the Richmond Harbor sediment treatments were compared with the FDA action limits for contaminants in fish and shellfish (Table Q.10). None of the FDA action limits was exceeded for any of the contaminants.

Contaminant concentrations in $M$. nasuta and $N$. virens exposed to the Richmond Harbor test treatments were statistically compared using Dunnett's Test with concentrations in organisms that were exposed to the reference treatment R-BF. Mean tissue concentrations of metals, butyltins, pesticides, PCBs, PAHs, and phthalate esters in $M$. nasuta and $N$. virens are shown in Tables $Q .11$ and $Q .12$, respectively. Relative to $R-B F$, metals were not bioaccumulated in $M$. nasuta at all, and only slightly in N. virens (Cd in three COMPs, Ni in one COMP, dibutyltin in one COMP). Bioaccumulation of 4,4'-DDD and dieldrin by both $M$. nasuta and $N$. virens 
IABLE Q.9. Summary of Suspended-Particulate-Phase Toxicity Tests, Richmond Harbor Deepening Project (bold type indicates mean survival in 100\% SPP significantly lower than control in 2-sample T-test, $\alpha=0.05$ )

\begin{tabular}{|c|c|c|c|c|c|c|c|c|c|}
\hline \multirow[b]{3}{*}{ Treatment } & \multicolumn{3}{|c|}{ Mysid H. costata } & \multicolumn{3}{|c|}{ Bivalve $M$, galloprovincialis } & \multicolumn{3}{|c|}{ Sanddab C. stiamaeus } \\
\hline & \multicolumn{2}{|c|}{ Mean Survival $(\%)$} & \multirow{2}{*}{$\begin{array}{r}L^{L} C_{50} \text { as } \\
\% \text { SPP }\end{array}$} & \multicolumn{2}{|c|}{ Mean Normal D (\%) } & \multirow{2}{*}{$\begin{array}{l}E C_{50} \text { as } \\
\% S P P\end{array}$} & \multicolumn{2}{|c|}{ Mean Survival (\%) } & \multirow{2}{*}{$\begin{array}{r}L_{50} \text { as } \\
\% \text { SPP }\end{array}$} \\
\hline & $0 \%$ SPP & $100 \%$ SPP & & $0 \%$ SPP & $100 \%$ SPP & & $0 \%$ SPP & $100 \%$ SPP & \\
\hline SF COMP & 94 & 86 & $>100$ & 94 & 96 & $>100$ & 100 & 100 & $>100$ \\
\hline SFW COMP & 98 & 88 & $>100$ & 91 & 26 & 80.0 & 98 & 100 & $>100$ \\
\hline UIH COMP & 100 & 90 & $>100$ & 90 & 0 & 57.6 & 98 . & 98 & $>100$ \\
\hline TB Upper COMP & 96 & 96 & $>100$ & 96 & 17 & 74.8 & 100 & 100 & $>100$ \\
\hline TB Lower COMP & 98 & 94 & $>100$ & 82 & 0 & 69.7 & 98 & 100 & $>100$ \\
\hline OBM COMP & 98 & 96 & $>100$ & 98 & 96 & $>100$ & 100 & 100 & $>100$ \\
\hline
\end{tabular}

TABLE Q.10. Comparison of FDA Action Levels With Contaminant Levels in M. nasuta and $N$. virens Exposed to Richmond Harbor Deepening Project Sediment Treatments

\begin{tabular}{|c|c|c|c|}
\hline \multirow[b]{2}{*}{ Contaminant } & \multirow{2}{*}{$\begin{array}{l}\text { FDA Action Level } \\
\text { (mg/kg wet weight) }\end{array}$} & \multicolumn{2}{|c|}{ Maximum Concentration (mg/kg wet weight) } \\
\hline & & M. nasuta & N. virens \\
\hline Benzene Hexachloride $(\mathrm{BHC})(\mathrm{a})$ & 0.3 & 0.00096 & $U(b)$ \\
\hline Chlordane & 0.3 & $\mathrm{U}$ & $\mathbf{U}$ \\
\hline DDT + DDE & 5.0 & 0.0055 & 0.001038 \\
\hline Dieldrin + Aldrin & 0.3 & 0.00224 & 0.002309 \\
\hline Endrin & 0.3 & $\mathrm{U}$ & U \\
\hline Heptachlor + Heptachlor Epoxide & 0.3 & $\mathrm{U}$ & $U$ \\
\hline Toxaphene & 5.0 & $U$ & $U$ \\
\hline PCBs & 2.0 & 0.00040 & $U$ \\
\hline $\begin{array}{l}\text { (a) Total BHCs (alpha-, beta-, delt } \\
\text { (b) U Undetected at or above de }\end{array}$ & $\begin{array}{l}\text { and gamma-BHC). } \\
\text { stion limit. }\end{array}$ & & \\
\hline
\end{tabular}


TABLE Q.11. Mean Values of Contaminants Detected in Tissues of M. nasuta Exposed to Richmond Harbor Deepening Composites (bold type indicates value is statistlcally significantly greater than R-BF when compared by Dunnett's Test; box indicates value is $>2$ times but $\leq 5$ times R-BF; shaded box indicates value is $>5$ times but s10 times R-BF; shaded double-lined box indicates value is $>10$ times R-BF)

\section{Analyte}

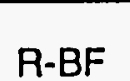

COMP

SFW

UIH

TB Upper

TB Lower

OBM

COMP

C-SB(a)

M. nasuta

$\mathrm{PAHs}$. $\mathrm{g} / \mathrm{kg}$ dn weight

Naphthalene

Acenaphthylene

Acenaphthene

Fluorene

Phenanthrene

Anthracene

Fluoranthene

Pyrene

$\stackrel{\vec{A}}{ }$ Benzo(a)anthracene

Chrysene

Benzo(b)fluoranthene

Benzo(k)fluoranthene

Benzo(a)pyrene

Indeno(1,2,3-cd)pyrene

Benzo(g,h,i)perylene

$\begin{array}{ll}14.6 \mathrm{~B}(\mathrm{~b}) & 11.9 \\ 9.54 \mathrm{U}(\mathrm{d}) & 7.57 \mathrm{U} \\ 9.43 & 7.26\end{array}$

$16.2 \quad 12.7 \mathrm{U}$

11.9

24.0

66.3

32.1

$28.7 \mathrm{~B}$

32.4

71.8

32.7

$43.6^{*}$

34.8

57.5

11.8

27.4

$75.7 *(\bullet)$

131

42.0

45.9

306

113

171

57.4

65.8 $\begin{array}{rr}33.5 & 10.8 \\ 8.79 & 8.02\end{array}$

$5 \% 2$

74.7

562

103

673

782

1665

136

303

107

185

51.2

78.6
$8.02 U$

$7.63 \mathrm{U}$

13.9

12.5

26.8

72.4 *

$1 \%$ ?

$32.1 \mathrm{~B}$

39.2

198

74.7

116

53.1

74.9

\begin{tabular}{llllllllll} 
Diethyl Phthalate & 387 & 288 B & 257 & 235 & 888 & 233 & NA & 188 210 \\
Di-n-butyl Phthalate & 383 & 253 & 358 & 357 & 368 & 256 & NA & 144 U & 207 \\
Butylbenzyl Phthalate & 598 & 575 & $493 *$ & 705 & 694 & 556 & NA & $798 *$ & 204 U \\
Bis(2-ethylhexyl) Phthalate & 902 & 859 & 810 & 906 & 1020 & 757 & NA & 845 & 502 \\
\hline
\end{tabular}

\begin{tabular}{llllllllll} 
Diethyl Phthalate & 387 & $288 \mathrm{~B}$ & 257 & 235 & 888 & 233 & NA & 188 210 \\
Di-n-butyl Phthalate & 383 & 253 & 358 & 357 & 368 & 256 & NA & 144 U & 207 \\
Butylbenzyl Phthalate & 598 & 575 & $493^{*}$ & 705 & 694 & 556 & NA & $798^{*}$ & 204 U \\
Bis(2-ethylhexyl) Phthalate & 902 & 859 & 810 & 906 & 1020 & 757 & NA & 845 & 502 \\
\hline
\end{tabular}

11.9

$7.53 \mathrm{U}$

$7.14 \mathrm{U}$

$12.6 \mathrm{U}$

8.31

20.6

$30.0^{*}$

13.2

$10.9 \mathrm{~B}$

12.7

22.3

13.2

20.8 *

26.0

$54.4 \quad 24.1$

$\begin{array}{lcc}\text { NA(c) } & 10.8 & 9.82 \\ \text { NA } & 5.91 U & 8.56 \\ \text { NA } & 5.99 & 9.61 \\ \text { NA } & 10.0 & 14.1 \mathrm{U} \\ \text { NA } & 9.37 & 23.9\end{array}$

NA $\quad 16.0 \mathrm{U} \quad 23.4$

NA $47.8^{*} \quad 72.8^{*}$

NA $\quad 8.49 \mathrm{U} \quad 46.6^{\circ} \mathrm{B}$

NA $12.3 \mathrm{~B} \quad 13.5 \mathrm{~B}$

NA $\quad 15.1 \quad 23.0 \mathrm{~B}$

NA $24.5^{*} \quad 29.5$ "B

NA $12.3 \quad 25.4$

NA $\quad 18.6^{*}$. 26.2 "B

$\begin{array}{lll}N A & 19.5 \mathrm{U} & 33.7\end{array}$

$\begin{array}{lll}\text { NA } & 46.8 & 29.6\end{array}$

Phthalates. $\mu \mathrm{g} / \mathrm{kg}$ dry weight 
IABLE 0.11. (contd)

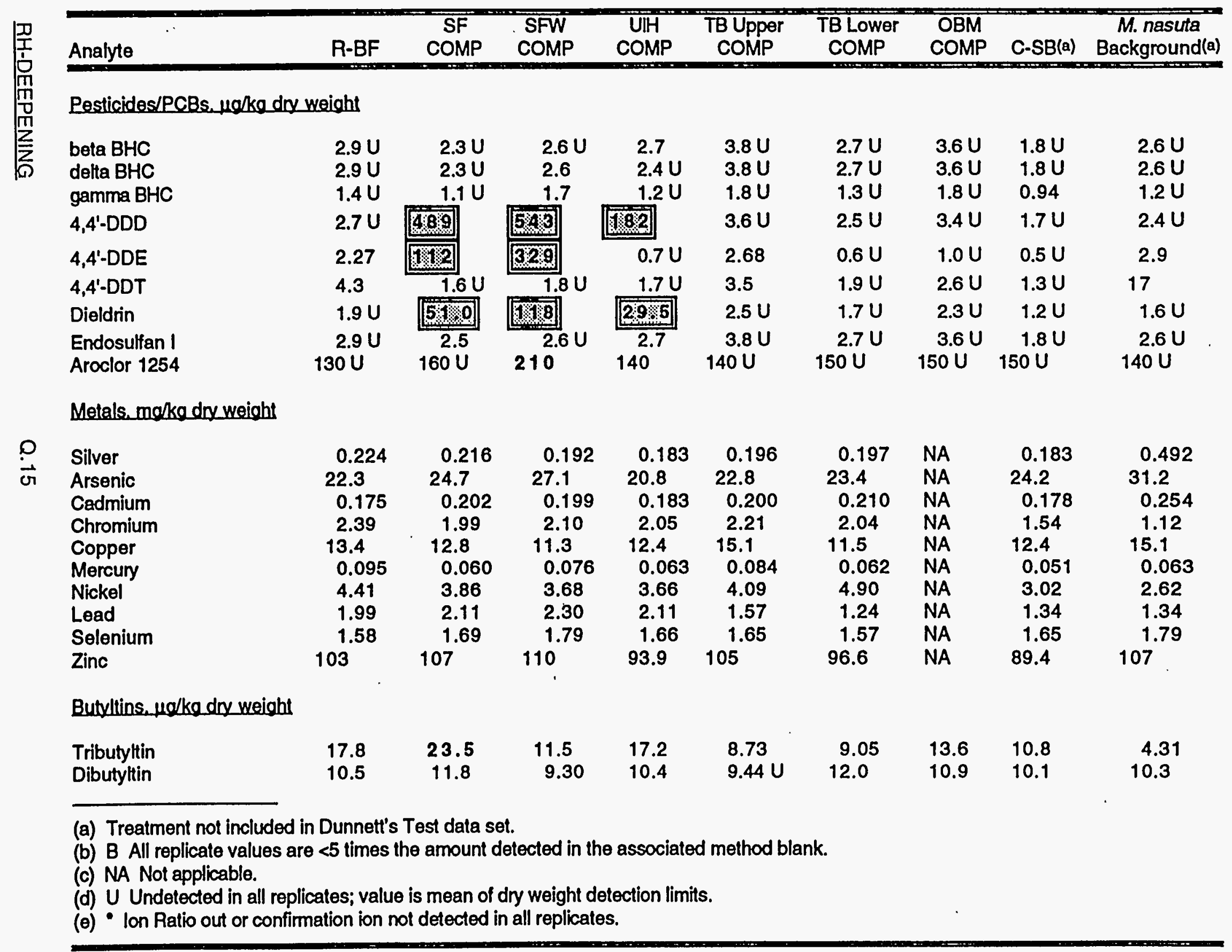




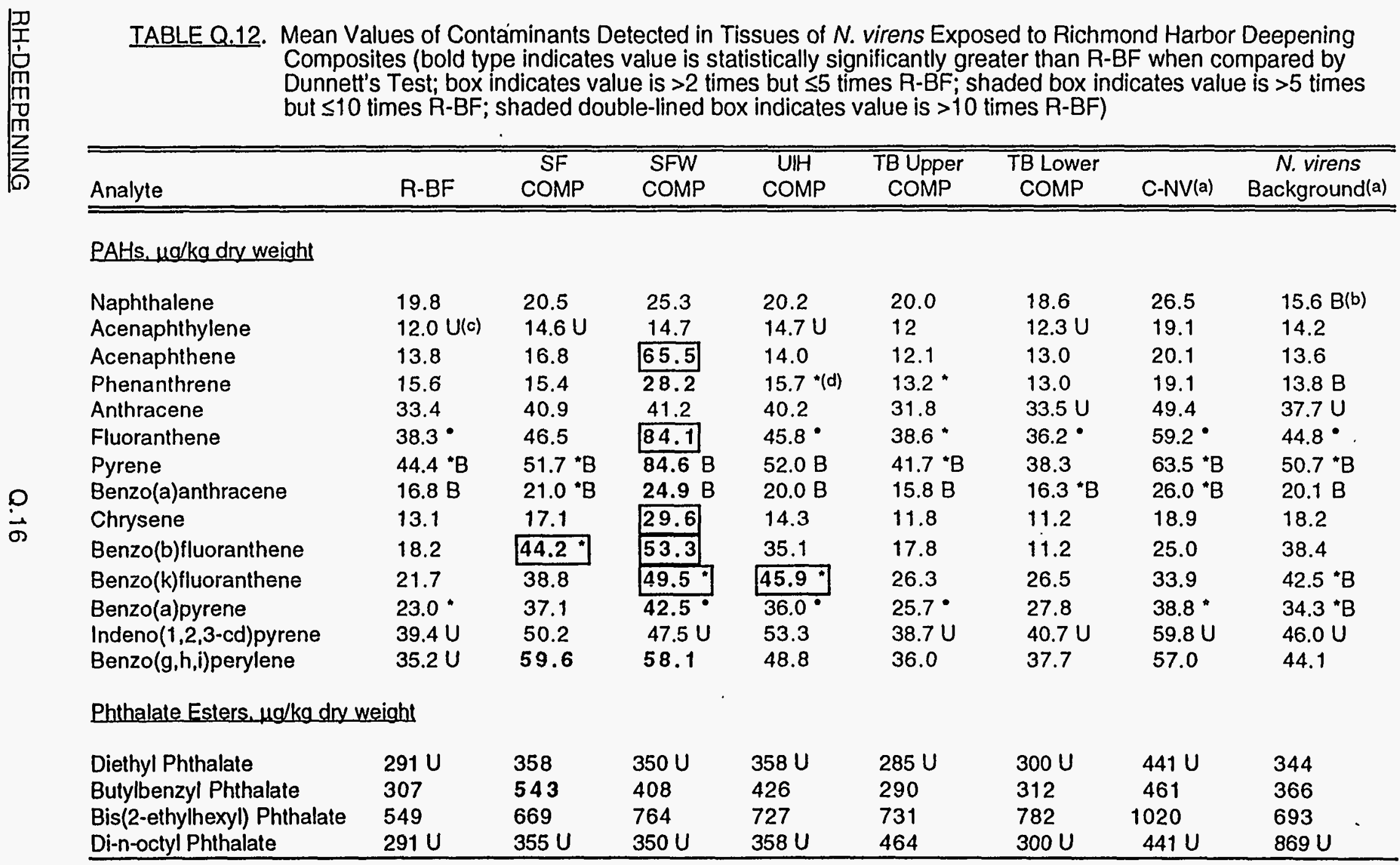




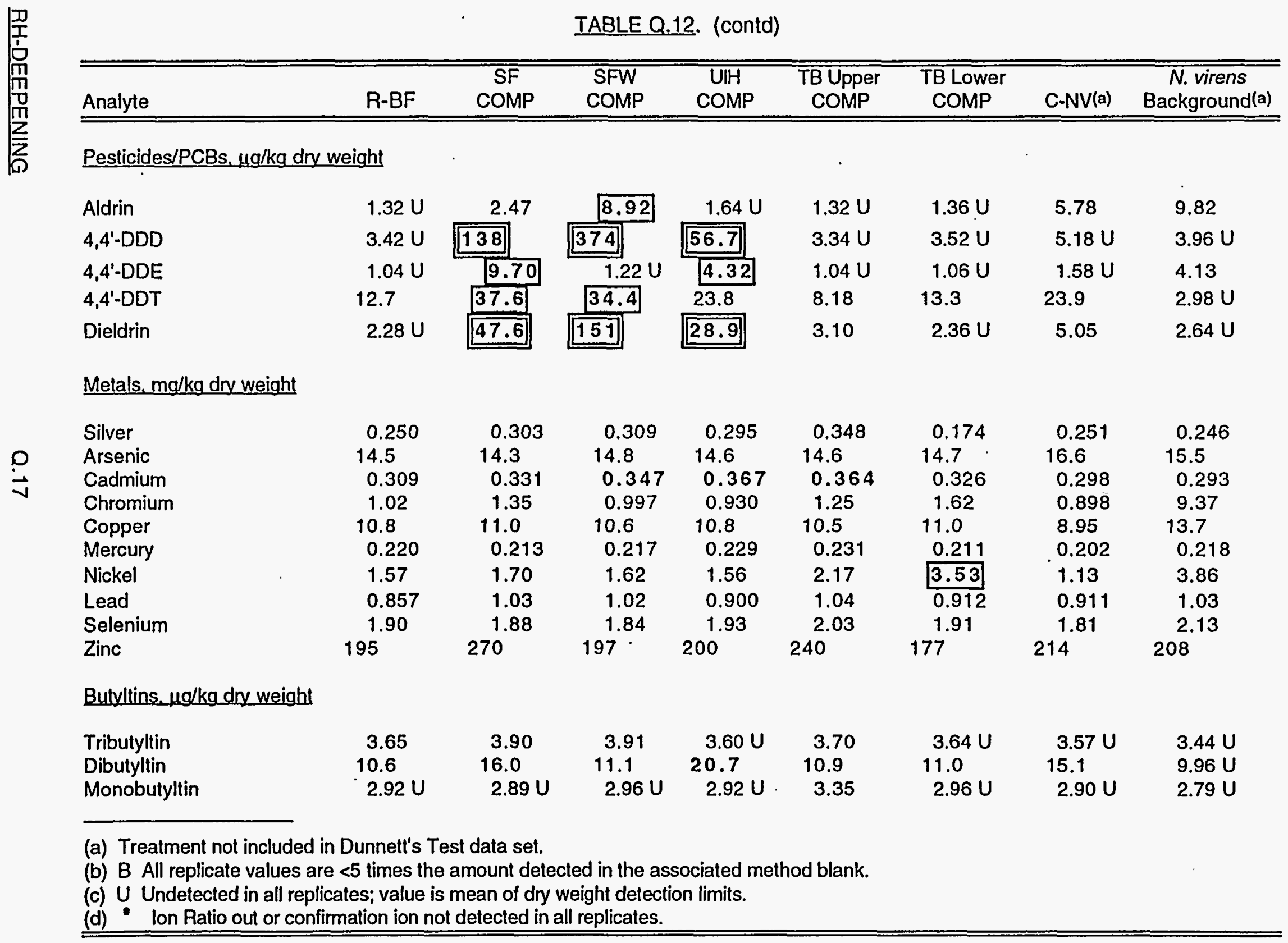


exposed to SF, SFW, and UIH COMPs was both statistically significant and of high magnitude. Significant bioaccumulation of PAHs at moderate to high magnitude occurred in $M$. nasuta and $N$. virens exposed to SFW COMP. Several HPAHs were also bioaccumulated by M. nasuta exposed to SF and UIH Comps.

\section{Q.5 CONCLUSION}

In this appendix, comparisons of Richmond Harbor Deepening dredged material and Intensive Study of the Turning Basin dredged material with the Bay Farm Borrow Area reference are provided to evaluate the acceptability of this sediment for in-bay disposal. For each test treatment, sediment contaminant levels, contribution to acute toxicity, either as water column effect or deposited sediment effect, and potential for bioaccumulation are shown in Table Q.13. The matrix in Figure $Q .2$ is a summary of sediment chemistry, acute toxicity, and bioaccumulation potential for the Richmond Harbor Deepening test treatments relative only to the reference R-BF. This matrix shows the number of contaminants in $M$. nasuta and $N$. virens that were elevated above a range of magnitudes $(2,5$, and 10 times R-BF) and in which cases similar classes of contaminants were accumulated by both species. This summary is intended to assist USACE, EPA, and other resource agencies in evaluating the potential effects of in-bay disposal of dredged material from Richmond Harbor. 


\begin{tabular}{|c|c|c|c|c|c|c|c|c|c|c|c|}
\hline \multirow{2}{*}{$\begin{array}{l}\text { Sediment } \\
\text { Treatment }\end{array}$} & \multirow{2}{*}{$\begin{array}{l}\text { Acute } \\
\text { Toxicity }\end{array}$} & \multicolumn{5}{|c|}{ Mr nesuta Bioaccumulation } & \multicolumn{5}{|c|}{ Nuvirens Bloeccumulation } \\
\hline & & PAH & Pesticides & PCB & Motals & TBT & PAH & Pesticides & PCB & Motals & TBT \\
\hline SF COMP & $-(a)$ & HPAH & DDD,DDE,Diel & $\cdots$ & -. & TBT & HPAH,phth & DDD,DDE,DDT,Diel & $\cdots$ & - & -- \\
\hline SFW COMP & $B(B)$ & LPAH,HPAH & DDD,DDE,Dlel & 1254 & - & - & LPAH,HPAH & Ald,DDD,DDT,Dlel & $\cdots$ & Cd & $\cdots$ \\
\hline UIHCOMP & $\mathbf{B}$ & HPAH & DDD,Diel & - & - & - & HPAH & DDD,DDE,Diel & - & Cd & DBT \\
\hline TB Upper COMP & $B, R(c)$ & -- & - & - & - & - & - & -- & - & $\mathrm{Cd}$ & $\cdots$ \\
\hline TB Lower COMP(d) & $B, R(d)$ & -- & - & - & -- & -- & - & -- & - & $\mathrm{NI}$ & $\cdots$ \\
\hline OBM COMP & $R, N(\theta)$ & NAM & $\cdots$ & $-\infty$ & NA & - & NA & NA & NA & NA & NA \\
\hline \multicolumn{12}{|c|}{$\begin{array}{l}\text { (a) - No statistically significant acute toxicity or bloaccumulation. } \\
\text { (b) B Acutely toxic to M. galloprovincialls in the } 48 \text {-h SPP test. } \\
\text { (c) R Acutely toxtc to } R \text {. abronlus in the 10-day solid-phase test. } \\
\text { (d) Evaluation of } R \text {. abronlus toxicity to TB Lower Comp is based on the results from the Intensive Study of the Turning Basin in October } 1994 . \\
\text { results of this study showed that the nine individual stations making up the TB Lower COMP were not acutely toxic to } R \text {. abronlus. } \\
\text { (e) N Acutely toxlc to N. caecoides in the 10-day solld-phase test. } \\
\text { (f) NA Not Applicable. }\end{array}$} \\
\hline
\end{tabular}




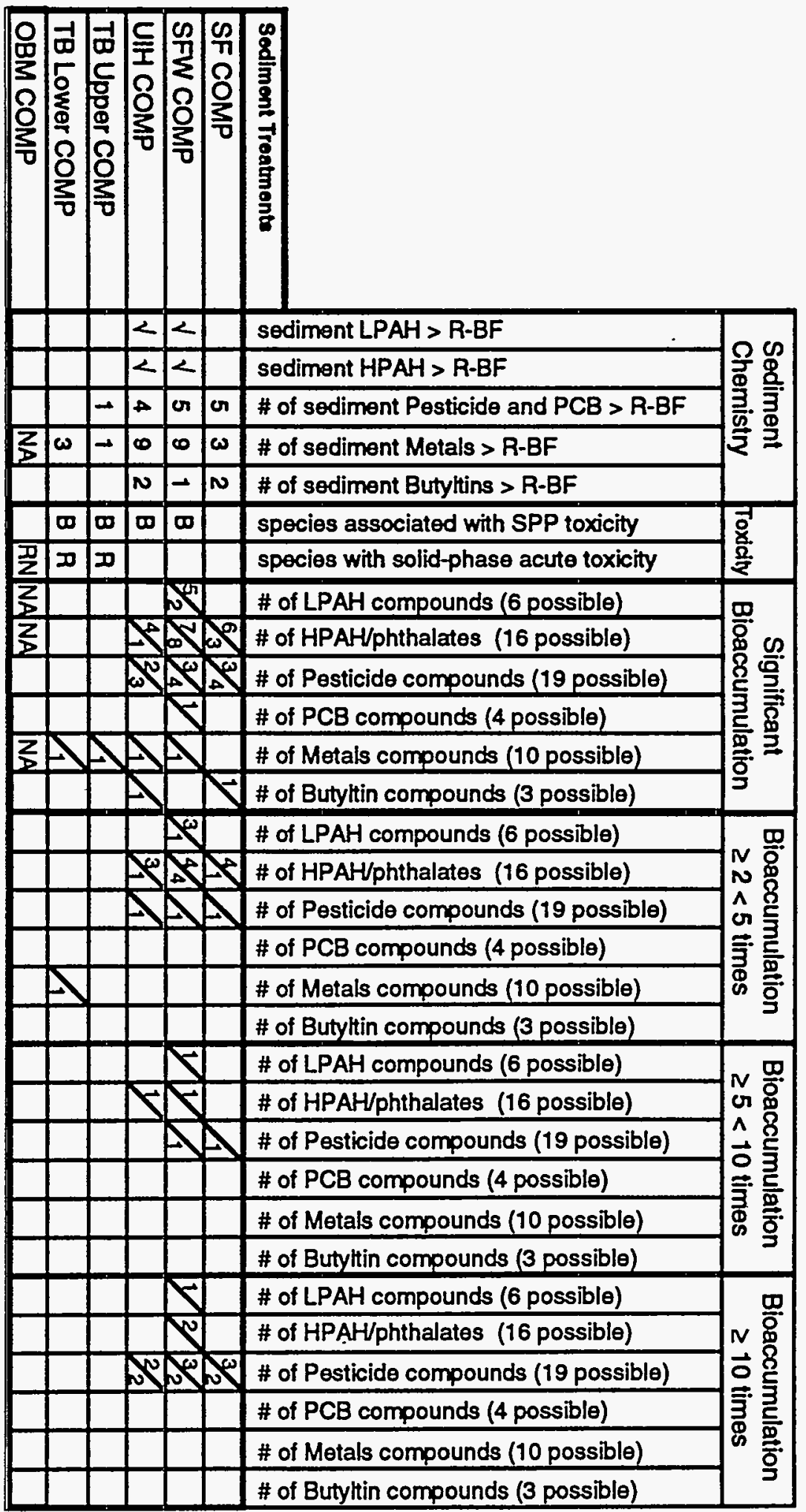




\section{APPENDIXR}

POTENTIAL EFFECTS OF DISPOSAL OF RICHMOND HARBOR DEEPENING AND IURNING BASIN SEDIMENTS AT ALCATRAZ ISLAND DISPOSAL SITE AND AT ALCATRAZ ENVIRONS REFERENCE AREA 


\section{APPENDIX R}

\section{POTENTIAL EFFECTS OF DISPOSAL OF RICHMOND HARBOR DEEPENING AND TURNING BASIN SEDIMENTS AT ALCATRAZ ISLAND DISPOSAL SITE AND AT ALCATRAZ ENVIRONS REFERENCE AREA}

This appendix presents the results of physical/chemical sediment analysis, acute toxicity tests, bioaccumulation tests, statistical comparisons, and a Tier III evaluation of Richmond Harbor Deepening and Intensive Study of the Turning Basin sediments relative to the Alcatraz Environs Reference Area (R-AM) (Figure R.1). The Alcatraz Environs Reference Area is used to evaluate sediment for in-bay disposal at the Alcatraz Island Disposal Site. All methods and results for sampling, physical descriptions, sediment chemistry, biological testing, and tissue chemistry are contained in Sections 2, 3, and 4 of this report; supporting data are contained in Appendixes A through R. As stated in Section 2.5 of this report, the use of Dunnett's test for statistical comparisons of non-independent data sets increases the chance of Type II statistical errors in all comparisons, resulting in the identification of a greater number of significant differences than if a multiple comparison test were used.

\section{R.1 SEDIMENT CHARACTERISTICS}

The five Richmond Harbor Deepening composites were fairly representative of the sediment characteristics of their contributing stations with respect to the sediment parameters that were measured (Tables R.1 through R.3). All of the Richmond Harbor Deepening sediments had much more silt and clay than the reference sediment R-AM, which is almost entirely sand (Table R.1). The other conventional parameters were also considerably higher in most test sediments than in R-AM, which is typical for fine-grained sediment.

Comparisons of Richmond Harbor Deepening sediment PAHs, pesticides, and PCBs with R-AM are shown in Table R.2. Concentrations of PAHs were relatively high in R-AM sediment, indicating possible contamination of the Alcatraz Environs Reference Area from the Alcatraz Island Disposal Site. The PAHs were present in nearly all Richmond Harbor samples, but only five test treatments (all in Santa Fe Channel) had higher PAH concentrations than R-AM. The chlorinated pesticides 4,4'-DDD, 4,4'-DDE, 4,4'-DDT, and dieldrin, were considerably elevated in SF, SFW, and UIH COMPs and their respective stations relative to R-AM. Some of these pesticides were present in TB Upper and Lower COMPs and their contributing stations. The primary source of these pesticides is the former United Heckathom plant on the east shore of Lauritzen Canal (Figure 3.1), which is now a federal Superfund site. PCB Aroclor 1254 was also elevated in SF, SFW, and UIH COMPS and their contributing stations, but was below the method detection limit in all other stations except TB-4 Upper and Lower stations. 


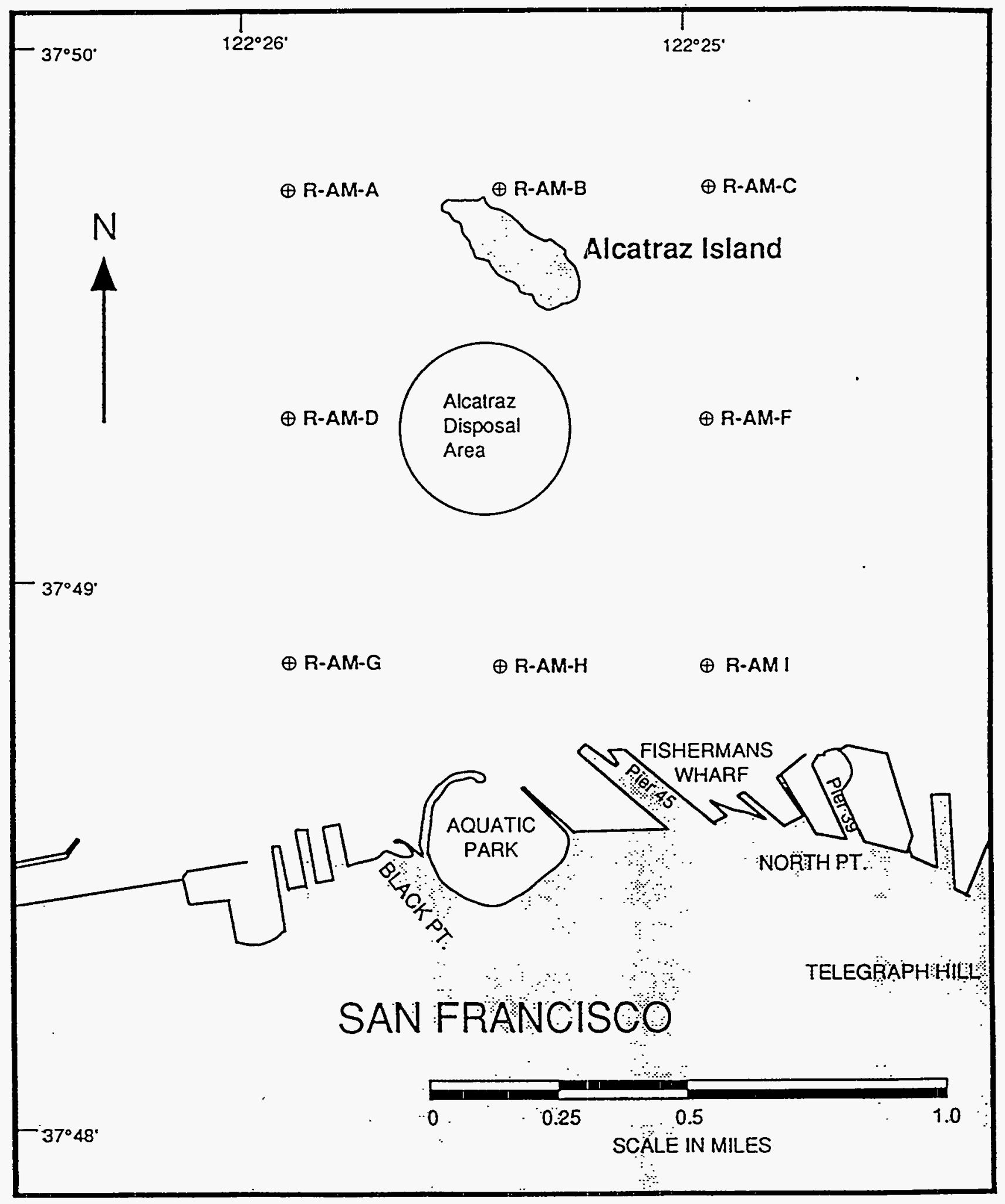

FIGURE R.1. Location of Alcatraz Environs Reference Area (R-AM) 
TABLE R.1. Conventional Sediment Measurement Results for the Richmond Harbor Deepening Project Sediment Treatments

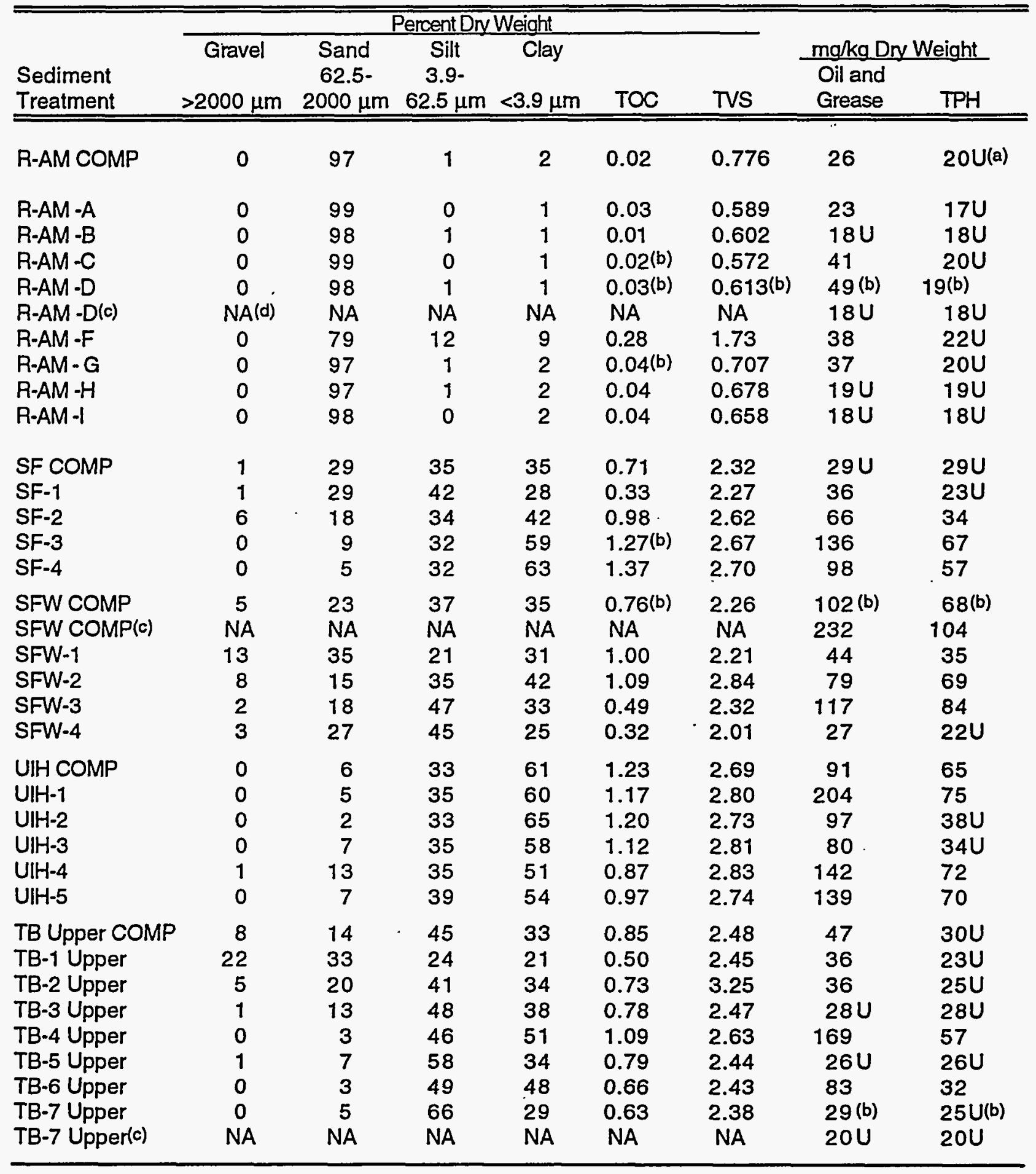


TABLE R.1. (contd)

\begin{tabular}{|c|c|c|c|c|c|c|c|c|}
\hline \multirow[b]{2}{*}{$\begin{array}{l}\text { Sediment } \\
\text { Treatment } \\
\end{array}$} & \multicolumn{6}{|c|}{ Percent Dry Weight } & \multicolumn{2}{|c|}{ mg/kg Dry Weight } \\
\hline & $\begin{array}{c}\text { Gravel } \\
>2000 \mu \mathrm{m}\end{array}$ & $\begin{array}{c}\text { Sand } \\
62.5- \\
2000 \mu \mathrm{m}\end{array}$ & $\begin{array}{c}\text { Silt } \\
3.9- \\
62.5 \mu \mathrm{m} \\
\end{array}$ & $\begin{array}{l}\text { Clay } \\
<3.9 \mu \mathrm{m} \\
\end{array}$ & TOC & TVS & $\begin{array}{c}\text { mg/kg D } \\
\text { Oil and } \\
\text { Grease }\end{array}$ & eight \\
\hline $\begin{array}{l}\text { TB Lower COMP } \\
\text { TB-1 Lower } \\
\text { TB-2 Lower } \\
\text { TB-3 Lower } \\
\text { TB-4 Lower } \\
\text { TB-5 Lower } \\
\text { TB-6 Lower } \\
\text { TB-7 Lower }\end{array}$ & $\begin{array}{l}3 \text { (b) } \\
9 \\
1 \\
0(\text { b) } \\
0 \\
0 \\
0(b) \\
1\end{array}$ & $\begin{array}{l}15(\mathrm{~b}) \\
53 \\
23 \\
13(\mathrm{~b}) \\
4 \\
12 \\
7(\mathrm{~b}) \\
3\end{array}$ & $\begin{array}{l}46(\mathrm{~b}) \\
23 \\
43 \\
52^{(b)} \\
47 \\
55 \\
50(\mathrm{~b}) \\
55\end{array}$ & $\begin{array}{l}36(\mathrm{~b}) \\
15 \\
33 \\
36(\mathrm{~b}) \\
49 \\
33 \\
43(\mathrm{~b}) \\
41\end{array}$ & $\begin{array}{l}0.69 \\
0.05 \\
0.62 \\
0.70 \\
0.93 \\
0.70 \\
0.55 \\
0.72\end{array}$ & $\begin{array}{l}2.15 \\
1.73 \\
2.08 \\
2.21 \\
2.88 \\
2.27 \\
2.27 \\
2.43\end{array}$ & $\begin{array}{l}35 \\
19 U \\
29 \\
30 \\
58 \\
25 U \\
26 U \\
26 U\end{array}$ & $\begin{array}{l}26 U \\
19 U \\
24 U \\
25 U \\
30 U \\
25 U \\
26 U \\
26 U\end{array}$ \\
\hline $\begin{array}{l}\text { (a) U Undetect } \\
\text { (b) Value is mea } \\
\text { (c) Sample rean } \\
\text { appropriate } \\
\text { (d) NA Not appl }\end{array}$ & $\begin{array}{l}\text { at or abov } \\
\text { of analytic } \\
\text { lyzed appro } \\
\text { atrix spike } \\
\text { able. }\end{array}$ & $\begin{array}{l}\text { the detec } \\
\text { I replicates } \\
\text { ximately or } \\
\text { ata. }\end{array}$ & tion limit. & fter origin & oil an & ase a & $\mathrm{PH}$ analy & provic \\
\hline
\end{tabular}

The sediment from R-AM has very low concentrations of most metals and butyltins and all five test treatments had elevated concentrations of metals relative to R-AM (Table R.3). Many metals tend to be associated with the siltclay grain-size fraction, which was predominant in Richmond Harbor sediment but essentially absent in R-AM sediment. Butyltins were exceptionally high in Stations SF-3 and SF-4, located just upchannel from the entrance to Lauritzen Canal (see Figure 3.1).

The sediments from the Intensive Study of the Tuming Basin were predominantly silt and clay except for TB-1 Lower, which was predominantly sand mixed with gravel. The sediment from R-AM was also predominantly sand and had the lowest concentrations of TOC, TVS, oil and grease, and TPH of any sediment treatment (Table R.4). The concentrations of PAHs and aldrin were higher in R-AM sediments than in most of the test treatments. A summary of the organic compounds detected in the test and reference treatment is shown in Table R.5. Seven of the 10 metals that were analyzed were lower in R-AM sediments than in any of the test treatments. Butyltins were not detected in the sediment from R-AM (Table R.6).

\section{R.2 DEPOSITED SEDIMENT TOXICITY}

The acute solid-phase tests with Richmond Harbor Deepening sediments showed no acute toxicity to $M$. nasuta when compared with the reference sediment from R-AM (Table R.7). However, three COMPs were acutely toxic to $N$. caecoides (SF, SFW, and OBM). At this time, 


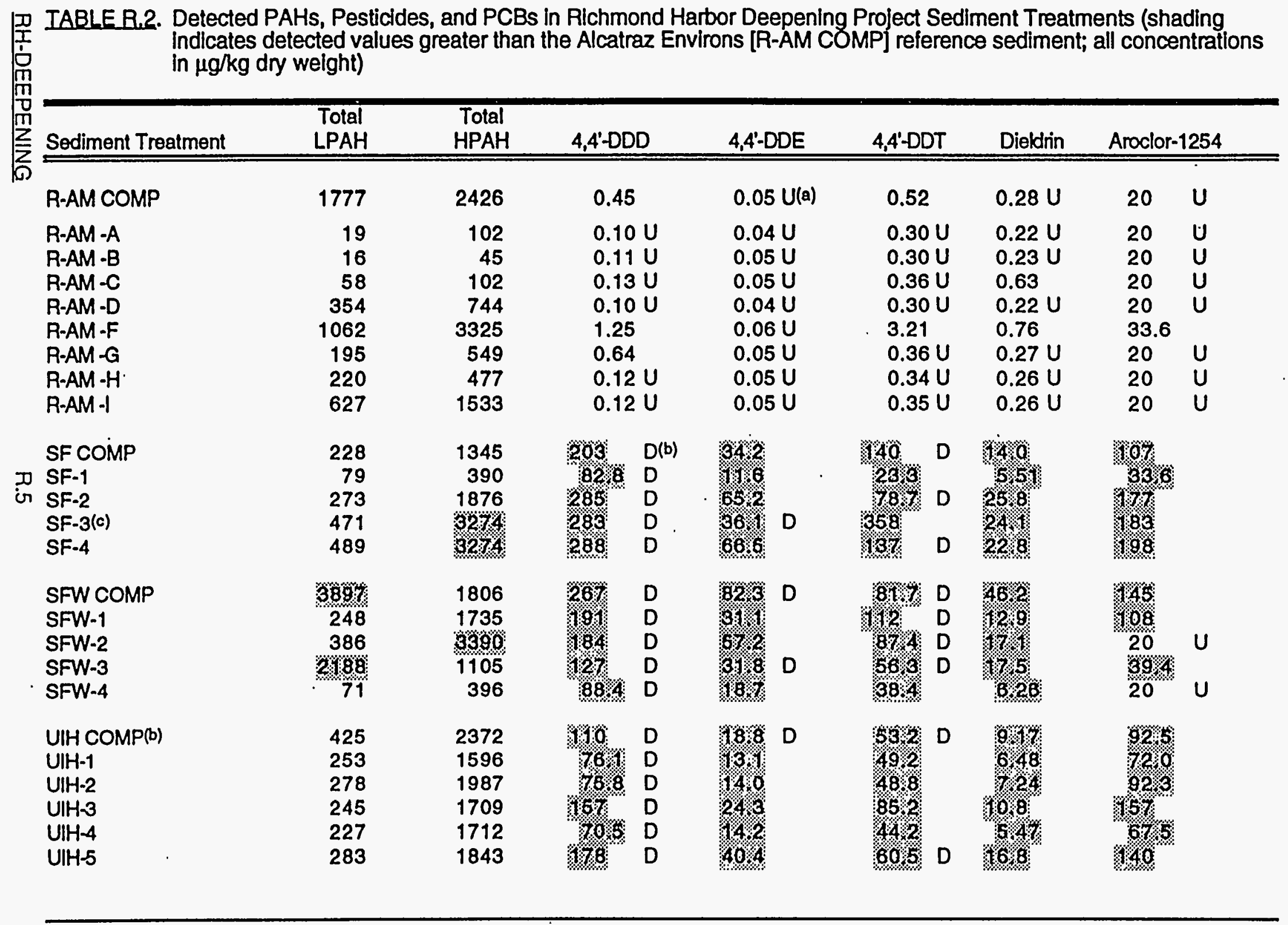




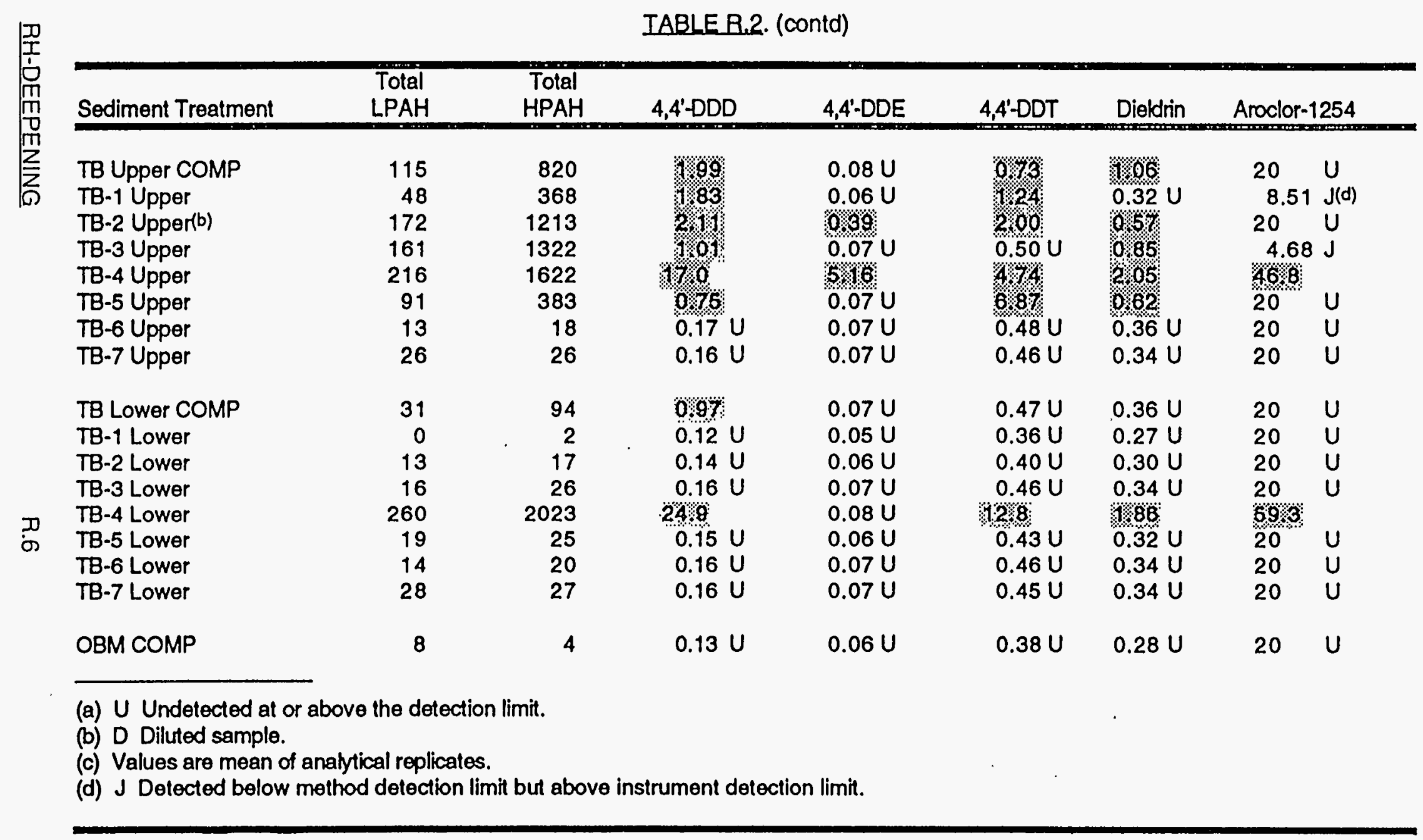




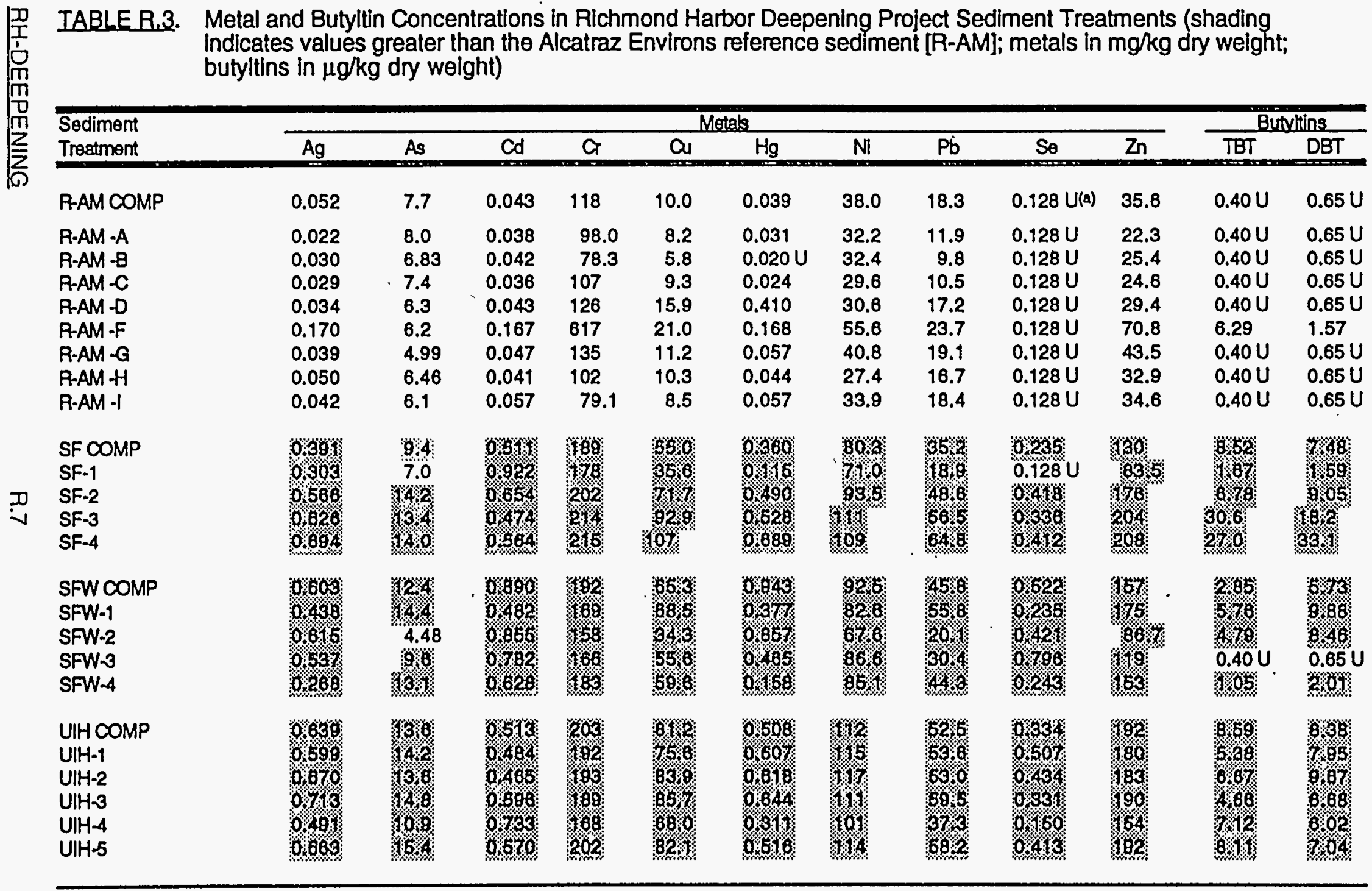




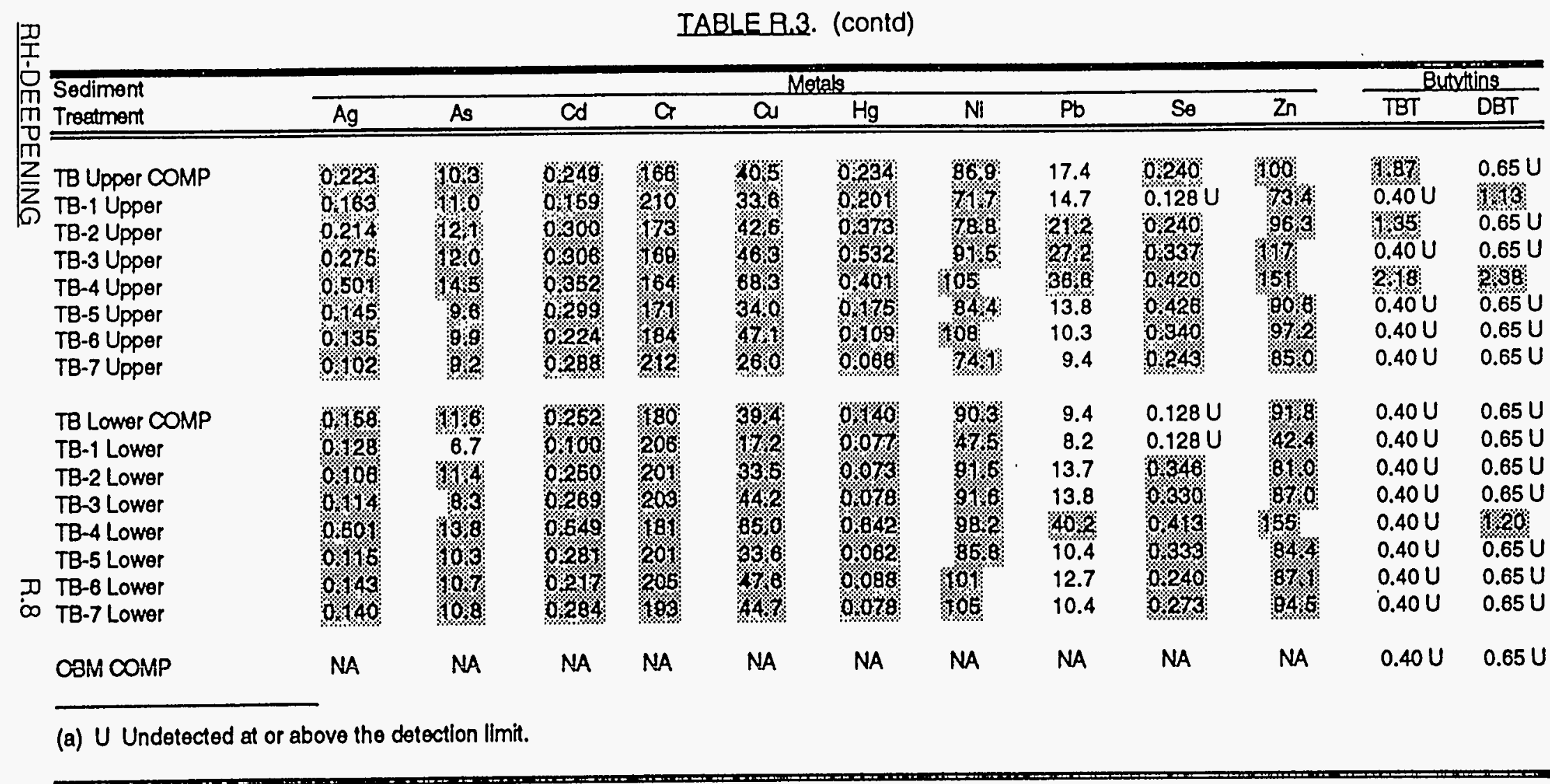


TABLE R.4. Conventional Sediment Measurement Results for the Sediment Treatments, Richmond Harbor Deepening Project-Intensive Study of the Turning Basin

\begin{tabular}{|c|c|c|c|c|c|c|c|c|}
\hline \multirow[b]{2}{*}{$\begin{array}{l}\text { Sediment } \\
\text { Treatment }\end{array}$} & \multicolumn{6}{|c|}{ Percent Dry Weight } & \\
\hline & $\begin{array}{c}\text { Gravel } \\
>2000 \mu \mathrm{m}\end{array}$ & $\begin{array}{c}\text { Sand } \\
62.5- \\
2000 \mu \mathrm{m}\end{array}$ & $\begin{array}{c}\text { Silt } \\
3.9- \\
62.5 \mu \mathrm{m}\end{array}$ & $\begin{array}{l}\text { Clay } \\
<3.9 \mu \mathrm{m}\end{array}$ & TOC & TVS & $\begin{array}{l}\mathrm{mg} / \mathrm{kg} \mathrm{Dn} \\
\text { Oil and } \\
\text { Grease }\end{array}$ & $\begin{array}{c}y \text { Weight } \\
\text { TPH }\end{array}$ \\
\hline R-AM & 0 & 99 & 0 & 1 & 0.104 (a & 0.6 & $10 U(b)$ & $10 U$ \\
\hline $\begin{array}{l}\text { TB-1 Lower } \\
\text { TB-2 Lower } \\
\text { TB-3 Lower } \\
\text { TB-4 Middle } \\
\text { TB-4 Lower } \\
\text { TB-5 Lower } \\
\text { TB-6 Lower } \\
\text { TB-7 Lower } \\
\text { TB-8 Lower } \\
\text { TB-9 Lower }\end{array}$ & $\begin{array}{r}13 \\
3 \\
1 \\
0 \text { (b) } \\
0 \\
0 \\
1 \\
1 \\
0 \\
0\end{array}$ & $\begin{array}{r}49 \\
18 \\
15 \\
4(b) \\
10 \\
7 \\
5 \\
7 \\
6 \\
15\end{array}$ & $\begin{array}{r}23 \\
47 \\
50 \\
48(b) \\
44 \\
54 \\
40 \\
53 \\
55 \\
44\end{array}$ & $\begin{array}{r}15 \\
32 \\
34 \\
48(b) \\
46 \\
39 \\
54 \\
39 \\
39 \\
41\end{array}$ & $\begin{array}{l}0.11 \\
0.67 \\
0.67 \\
1.1 \\
0.58 \\
0.90 \\
0.81 \\
0.70 \\
0.76 \\
0.59\end{array}$ & $\begin{array}{l}0.79(b) \\
2.3 \\
2.1 \\
2.6 \\
2.1 \\
2.2 \\
2.6 \\
2.4 \\
2.6 \\
2.1\end{array}$ & $\begin{array}{l}14 \\
50 \\
40 \\
18 U \\
16 U \\
56 \\
17 U \\
15 U \\
43 \\
20\end{array}$ & $\begin{array}{l}9.9 \mathrm{U} \\
27 \\
16 U \\
18 U \\
16 U \\
58 \\
17 U \\
15 U \\
16 U \\
16 U\end{array}$ \\
\hline OBM COMP & 0 & 18 & 56 & 26 & 0.16 & 2.1 & $11 \mathrm{U}$ & $11 \mathrm{U}$ \\
\hline
\end{tabular}

TABLE R.5. Detected Total PAHs, Pesticides, and PCBs in Sediment Treatments, Richmond Harbor Deepening Project-Intensive Study of the Turning Basin (values in $\mu \mathrm{g} / \mathrm{kg}$ dry weight)

\begin{tabular}{|c|c|c|c|c|c|c|c|}
\hline $\begin{array}{l}\text { Sediment } \\
\text { Treatment }\end{array}$ & $\begin{array}{l}\text { Total } \\
\text { LPAHS }\end{array}$ & $\begin{array}{c}\text { Total } \\
\text { HPAHs }\end{array}$ & Aldrin & 4,4'-DDD & $4,4^{\prime}-\mathrm{DDE}$ & 4,4'-DDT & $\begin{array}{c}\text { Aroctor } \\
1254\end{array}$ \\
\hline R-AM & 538 & 1055 & 1.32 & $0.21 U(a)$ & $0.11 \mathrm{U}$ & $0.58 \mathrm{U}$ & $20 \mathrm{U}$ \\
\hline $\begin{array}{l}\text { TB-1 Lower } \\
\text { TB-2 Lower } \\
\text { TB-3 Lower } \\
\text { TB-4 Middle } \\
\text { TB-4 Lower } \\
\text { TB-5 Lower } \\
\text { TB-6 Lower } \\
\text { TB-7 Lower } \\
\text { TB-8 Lower } \\
\text { TB-9 Lower }\end{array}$ & $\begin{array}{r}17 \\
22 \\
38 \\
339 \\
47 \\
51 \\
52 \\
35 \\
38 \\
43\end{array}$ & $\begin{array}{r}37 \\
36 \\
58 \\
2355 \\
66 \\
63 \\
66 \\
69 \\
67 \\
62\end{array}$ & $\begin{array}{l}0.17 \mathrm{U} \\
0.66 \\
0.21 \mathrm{U} \\
1.15 \\
0.21 \mathrm{U} \\
0.22 \mathrm{U} \\
1.17 \\
1.69 \\
0.97 \\
0.35 \mathrm{U}\end{array}$ & $\begin{array}{c}0.21 U \\
0.17 U \\
0.26 U \\
19.3 \\
0.26 U \\
0.27 U \\
0.29 U \\
0.27 U \\
0.27 U \\
0.43 U\end{array}$ & $\begin{array}{c}0.11 U \\
0.09 U \\
0.14 U \\
15.1 \\
0.14 U \\
0.15 U \\
0.16 U \\
0.15 U \\
0.15 U \\
0.24 U\end{array}$ & $\begin{array}{l}0.58 U \\
0.47 U \\
0.74 U \\
9.3 \\
0.72 U \\
0.76 U \\
0.83 U \\
0.77 U \\
0.76 U \\
1.21 U\end{array}$ & $\begin{array}{l}20 U \\
20 U \\
20 U \\
101 \\
20 U \\
20 U \\
20 U \\
20 U \\
20 U \\
20 U\end{array}$ \\
\hline OBM COMP & 29 & 28 & $0.18 U$ & $0.22 \mathrm{U}$ & $0.12 \mathrm{U}$ & $0.63 \mathrm{U}$ & $20 \mathrm{U}$ \\
\hline
\end{tabular}

RH-DEEPENING 


\begin{tabular}{|c|c|c|c|c|c|c|c|c|c|c|c|c|}
\hline \multirow{2}{*}{$\begin{array}{l}\text { Sediment } \\
\text { Treatment }\end{array}$} & \multicolumn{10}{|c|}{ Metals } & \multicolumn{2}{|c|}{ Butyltins } \\
\hline & $\mathrm{Ag}$ & As & Cd & $\mathrm{Cr}$ & $\mathrm{Cu}$ & $\mathrm{Hg}$ & $\mathrm{Ni}$ & $\mathrm{Pb}$ & $\mathrm{Se}$ & $\mathrm{Zn}$ & TBT & DBT \\
\hline R-AM & 0.026 & 5.88 & 0.015 & 95.4 & 4.30 & 0.049 & 33.6 & 13.9 & $0.17 \cup(a)$ & 32.8 & $0.48 U$ & $0.56 \mathrm{U}$ \\
\hline $\begin{array}{l}\text { TB-1 Lower } \\
\text { TB-2 Lower } \\
\text { TB-3 Lower } \\
\text { TB-4 Middle } \\
\text { TB-4 Lower } \\
\text { TB-5 Lower } \\
\text { TB-6 Lower } \\
\text { TB-7 Lower } \\
\text { TB-8 Lower } \\
\text { TB-9 Lower }\end{array}$ & $\begin{array}{l}0.10 \\
0.11 \\
0.11 \\
0.65 \\
0.11 \\
0.10(b) \\
0.12 \\
0.11 \\
0.10 \\
0.10\end{array}$ & $\begin{array}{c}6.07 \\
10.2 \\
9.2 \\
16.5 \\
9.7 \\
10.1(\mathrm{~b}) \\
12.4 \\
9.8 \\
10.7 \\
7.8\end{array}$ & $\begin{array}{l}0.25 \\
0.21 \\
0.20 \\
0.54 \\
0.17 \\
0.21 \text { (b) } \\
0.20 \\
0.20 \\
0.21 \\
0.15\end{array}$ & $\begin{array}{l}231 \\
221 \\
184 \\
182 \\
181 \\
192(b) \\
173 \\
188 \\
182 \\
196\end{array}$ & $\begin{array}{l}20.9 \\
39.8 \\
36.1 \\
74.0 \\
44.3 \\
41.2(b) \\
53.4 \\
42.4 \\
45.8 \\
41.2\end{array}$ & $\begin{array}{l}0.059 \\
0.071 \\
0.058 \\
0.734 \\
0.076 \\
0.058(\mathrm{~b}) \\
0.037 \\
0.038 \\
0.066 \\
0.068\end{array}$ & $\begin{array}{c}55.3 \\
84.4 \\
85.1 \\
94.6 \\
93.6 \\
97.6(\mathrm{~b}) \\
113 \\
92.7 \\
101 \\
87.9\end{array}$ & $\begin{array}{l}11.1 \\
11.8 \\
9.3 \\
43.9 \\
12.1 \\
10.6(\mathrm{~b}) \\
8.4 \\
11.1 \\
10.3 \\
14.1\end{array}$ & $\begin{array}{l}0.17 U \\
0.17 U \\
0.17 U \\
0.39 \\
0.17 U \\
0.17 U(b) \\
0.17 U \\
0.19 \\
0.19 \\
0.17 U\end{array}$ & $\begin{array}{c}51.2 \\
88.6 \\
85.4 \\
185 \\
90.7 \\
94.3(\mathrm{~b}) \\
105 \\
95.8 \\
97.2 \\
82.7\end{array}$ & $\begin{array}{l}0.57 \\
0.53 \\
0.49 \\
3.66 \\
0.61 \\
0.48 \mathrm{U} \\
0.54 \\
0.52 \\
0.48 \mathrm{U} \\
0.48 \mathrm{U}\end{array}$ & $\begin{array}{l}0.56 U \\
1.05 \\
0.56 U \\
0.82 \\
0.56 U \\
0.76 \\
0.56 U \\
0.56 U \\
0.56 U \\
0.56 U\end{array}$ \\
\hline OBM COMP & 0.11 & 3.28 & 0.56 & 142 & 27.4 & 0.044 & 62.7 & 10.6 & $0.17 \mathrm{U}$ & 68.3 & $0.48 \mathrm{U}$ & $0.56 \mathrm{U}$ \\
\hline
\end{tabular}


TABLE R.7. Summary of 10-day Solid-Phase Toxicity Tests, Richmond Harbor Deepening Project

\begin{tabular}{|c|c|c|c|c|c|c|}
\hline \multirow[b]{2}{*}{$\begin{array}{l}\text { Sediment } \\
\text { Treatment }\end{array}$} & \multicolumn{2}{|c|}{ R. abronius } & \multicolumn{2}{|c|}{ M. nasuta } & \multicolumn{2}{|c|}{ N. caecoides } \\
\hline & $\begin{array}{l}\text { Percent } \\
\text { Survival }\end{array}$ & $\begin{array}{c}\text { Acute } \\
\text { Toxicity }\end{array}$ & $\begin{array}{l}\text { Percent } \\
\text { Survival } \\
\end{array}$ & $\begin{array}{c}\text { Acute } \\
\text { Toxicity } \\
\end{array}$ & $\begin{array}{l}\text { Percent } \\
\text { Survival }\end{array}$ & $\begin{array}{c}\text { Acute } \\
\text { Toxicity }\end{array}$ \\
\hline R-AM & 99 & NA(a) & 100 & NA & 96 & NA \\
\hline $\begin{array}{l}\text { SF COMP } \\
\text { SFW COMP } \\
\text { UIH COMP } \\
\text { TB Upper COMP } \\
\text { TB Lower COMP } \\
\text { OBM COMP }\end{array}$ & $\begin{array}{l}89 \\
77 \\
77 \\
70 \\
50 \\
72\end{array}$ & $\begin{array}{l}\text { NO(b) } \\
\text { YES } \\
\text { YES } \\
\text { YES } \\
\text { YES } \\
\text { YES }\end{array}$ & $\begin{array}{r}100 \\
98 \\
100 \\
99 \\
98 \\
98\end{array}$ & $\begin{array}{l}\text { NO } \\
\text { NO } \\
\text { NO } \\
\text { NO } \\
\text { NO } \\
\text { NO }\end{array}$ & $\begin{array}{l}79 \\
81 \\
88 \\
86 \\
96 \\
38\end{array}$ & $\begin{array}{l}\text { YES(c) } \\
\text { YES } \\
\text { NO } \\
\text { NO } \\
\text { NO } \\
\text { YES }\end{array}$ \\
\hline $\begin{array}{l}\text { C-SB } \\
\text { C-WB } \\
\text { C-NE }\end{array}$ & $\begin{array}{r}93 \\
98 \\
\text { NA }\end{array}$ & $\begin{array}{l}\text { NA } \\
\text { NA } \\
\text { NA }\end{array}$ & $\begin{array}{l}100 \\
N A \\
100\end{array}$ & $\begin{array}{l}N A \\
N A \\
N A\end{array}$ & $\begin{array}{r}96 \\
\text { NA } \\
94\end{array}$ & $\begin{array}{l}N A \\
N A \\
N A\end{array}$ \\
\hline
\end{tabular}

(a) NA Not applicable.

(b) NO No statistically significant difference from the reference sediment R-AM at $\alpha=0.05$.

(c) YES Statistically significantly different from the reference sediment R-AM at $\alpha=0.05$ and $>10 \%$ lower in survival than R-AM (20\% for $R$. abronius).

no dose response of $N$. caecoides to ammonia is available to determine the contribution of ammonia in sediment to toxicity. The $R$. abronius 10-day test showed statistically significant differences and a $>20 \%$ difference in survival in all COMPs except SF COMP when compared with the reference treatment R-AM (Table R.7). The low $R$. abronius survival in SF, SFW, UIH, and possibly TB Upper and OBM COMPs, could be attributed to ammonia; the relationship of observed mortality and total ammonia in the interstitial water of these test treatments was within the expected effects range of ammonia as a sole toxicant (see Section 3.4.1, Figure 3.37). This figure also shows that the mortality observed in OBM and TB Lower COMPS is greater than can be attributed to ammonia; therefore, these COMPs possess some other factor to which R. abronius are sensitive.

To investigate the toxic response of $R$. abronius to the TB Lower COMP, all nine field stations from the TB Lower COMP were tested independently in October 1994. These results are summarized in Table R.8, which shows that for the static test with no ammonia manipulation, eight test treatments, TB-2 Lower, TB-3 Lower, TB-4 Lower, TB-5 Lower, TB-6 Lower, TB-7 Lower, TB-8 Lower and TB-9 Lower were acutely toxic to $R$. abronius when compared with $\mathrm{R}$-AM sediments. These results improved in the ammonia reduction to $<20 \mathrm{mg} / \mathrm{L}$ test where only two test treatments, TB-3 Lower and TB-9 Lower, were acutely toxic relative to R-AM. The 
TABLE R.8. Summary of 10-Day Solid-Phase R. abronius Toxicity Tests, Richmond Harbor Deepening Project-Intensive Study of the Turning Basin

\begin{tabular}{|c|c|c|c|c|c|c|}
\hline \multirow[b]{2}{*}{$\begin{array}{l}\text { Sediment } \\
\text { Treatment }\end{array}$} & \multicolumn{2}{|c|}{ Static } & \multicolumn{2}{|c|}{$\begin{array}{l}\text { Ammonia Reduction } \\
\text { to }<20 \mathrm{mg} / \mathrm{L}\end{array}$} & \multicolumn{2}{|c|}{$\begin{array}{c}\text { Ammonia Reduction } \\
\text { to }<15 \mathrm{mgh}\end{array}$} \\
\hline & $\begin{array}{l}\text { Percent } \\
\text { Survival }\end{array}$ & $\begin{array}{l}\text { Acute } \\
\text { Toxicity }\end{array}$ & $\begin{array}{l}\text { Percent } \\
\text { Survival }\end{array}$ & $\begin{array}{l}\text { Acute } \\
\text { Toxicity } \\
\end{array}$ & $\begin{array}{l}\text { Percent } \\
\text { Percent }\end{array}$ & $\begin{array}{c}\text { Acute } \\
\text { Toxicity }\end{array}$ \\
\hline R-AM & 97 & NA(a) & 97 & NA & NA & NA \\
\hline TB-1 Lower & 87 & NO & NA & NA & NA & NA \\
\hline TB-2 Lower & 52 & YES & 79 & NO & NA & NA \\
\hline TB-3 Lower & 25 & YES & 70 & YES & 83 & NO \\
\hline TB-4 Middle & 82 & NO & 89 & No & NA & NA \\
\hline TB-4 Lower & 76 & YES & 81 & NO & NA & NA \\
\hline TB-5 Lower & 62 & YES & 82 & NO & NA & NA \\
\hline TB-6 Lower & 76 & YES & NA & NA & NA & NA \\
\hline TB-7 Lower & 55 & YES & NA & NA & 75 & YES \\
\hline TB-8 Lower & 64 & YES & NA & NA & 81 & NO \\
\hline TB-9 Lower & 28 & YES & 74 & YES & 80 & NO \\
\hline OBM COMP & 68 & NA & NA & NA & NA & NA \\
\hline$C-W B$ & 98 & NA & 98 & NA & 100 & NA \\
\hline $\mathrm{C}-\mathrm{SB}$ & 89 & NA & 89 & NA & NA & NA \\
\hline
\end{tabular}

results of the ammonia reduction to $<15 \mathrm{mg} / \mathrm{L}$ test showed that only one test treatment, TB-7 Lower, was acutely toxic to $R$. abronius when compared with R-AM sediments.

\section{R.3 WATER COLUMN EFFECTS}

The evaluation of water column effects does not include comparisons with the reference sediment because the reference sediment is not tested for water column toxicity. The results of the three water column (SPP) toxicity tests conducted with Richmond Harbor Deepening test treatments are presented in Table R.9. There was no acute toxicity to either the mysid, $H$. costata, or to the sanddab, C. stigmaeus. T-test results showed that the SPP from SFW, UIH, TB Upper, and TB Lower COMPs significantly affected survival to normal D-cell stage in M. galloprovincialis larvae. The $\mathrm{EC}_{50}$ values for those treatments ranged from $57.6 \%$ SPP to $80.0 \%$ SPP. Normal development could have been affected by ammonia released from sediment into the SPP (see Section 3.4.7, Figure 3.38). Ammonia concentrations and normal development 
TABLE R.9. Summary of Suspended-Particulate-Phase Toxicity Test Results, Richmond Harbor Deepening Project (bold type indicates mean survival in 100\% SPP significantly lower than control in 2-sample T-test, $\alpha=0.05$ )

\begin{tabular}{|c|c|c|c|c|c|c|c|c|c|}
\hline \multirow[b]{3}{*}{ Treatment } & \multicolumn{3}{|c|}{ Musid $H_{1}$ costata } & \multicolumn{3}{|c|}{ Bivalve $M$, galloprovincialis } & \multicolumn{3}{|c|}{ Sanddab $C$. stigmaous } \\
\hline & \multicolumn{2}{|c|}{ Mean Survival $(\%)$} & \multirow{2}{*}{$\begin{array}{r}L_{50} \text { as } \\
\% \text { SPP }\end{array}$} & \multicolumn{2}{|c|}{ Mean Normal D (\%) } & \multirow{2}{*}{$\begin{array}{c}E_{50} \text { as } \\
\% \text { SPP }\end{array}$} & \multicolumn{2}{|c|}{ Mean Survival (\%) } & \multirow{2}{*}{$\begin{array}{r}\mathrm{LC}_{50} \text { as } \\
\% \text { SPP } \\
\end{array}$} \\
\hline & $0 \%$ SPP & $100 \%$ SPP & & $0 \%$ SPP & $100 \%$ SPP & & $0 \%$ SPP & $100 \%$ SPP & \\
\hline SF COMP & 94 & 86 & $>100$ & 94 & 96 & $>100$ & 100 & 100 & $>100$ \\
\hline SFW COMP & 98 & 88 & $>100$ & 91 & 26 & 80.0 & 98 & 100 & $>100$ \\
\hline UIH COMP & 100 & 90 & $>100$ & 90 & 0 & 57.6 & 98 & 98 & $>100$ \\
\hline TB Upper COMP & 96 & 96 & $>100$ & 96 & 17 & 74.8 & 100 & .100 & $>100$ \\
\hline TB Lower COMP & 98 & 94 & $>100$ & 82 & 0 & 69.7 & 98 & 100 & $>100$ \\
\hline OBM COMP & 98 & 96 & $>100$ & 98 & 96 & $>100$ & 100 & 100 & $>100$ \\
\hline
\end{tabular}

in 100\% SPP of SFW, UIH, and TB Lower COMPs were within the range of expected effects for ammonia acting alone. However, normal development in TB Upper COMP SPP appeared to be reduced slightly more than would be expected from ammonia only.

\section{R.4 DEPOSITED SEDIMENT BIOACCUMULATION}

Bioaccumulation of contaminants by the clam, M. nasuta, and the polychaete, $N$. virens, was assessed through a 28-day exposure to Richmond Harbor Deepening composites followed by chemical analysis of tissue samples. The 28-day test methods and results are reported in Sections 2 and 3 and Appendixes $M$ and $N$. Complete tissue chemistry results, $Q C$ data, and QAVC summaries are presented in Appendixes $O$ and $P$. The concentrations of contaminants in $M$. nasuta and $N$. virens exposed to the Richmond Harbor sediment treatments were compared with the FDA action limits for contaminants in fish and shellfish (Table R.10). None of the FDA action limits was exceeded for any of the contaminants.

Contaminant concentrations in $M$. nasuta and $N$. virens exposed to the Richmond Harbor test treatments were statistically compared using Dunnett's Test with concentrations in organisms that were exposed to the reference treatment R-AM. Mean tissue concentrations of PAHS, pesticides, phthalate esters, PCBs, metals, and butyltins in $M$. nasuta and $N$. virens are shown in Table R.11 and Table R.12, respectively. These tables also show the magnitude of contaminant bioaccumulation relative to the reference treatment $R-A M$. Relative to $R-A M$, two metals from each COMP were bioaccumulated in M. nasuta; $\mathrm{Cr}$ and Pb in SF, SFW, and UIH COMPs; $\mathrm{Cr}$ and $\mathrm{Ni}$ in TB Upper and Lower COMPs. Only Ni was accumulated by $N$. virens exposed to TB Lower COMP. None of the metals was more than two times the R-AM tissue value except for the $\mathrm{Ni}$ in $N$. virens, which was 2.1 times the $\mathrm{Ni}$ in $\mathrm{N}$. virens exposed to R-AM. Dibutyltin was accumulated 
TABLE R.10. Comparison of FDA Action Levels With Contaminant Levels in M. nasuta and $N$. virens Exposed to Richmond Harbor Deepening Sediment Treatments

\begin{tabular}{|c|c|c|c|}
\hline \multirow[b]{2}{*}{ Contaminant } & \multirow{2}{*}{$\begin{array}{l}\text { FDA Action Level } \\
\text { (mg/kg wet weight) }\end{array}$} & \multicolumn{2}{|c|}{ Maximum Concentration (mg/kg wet weight) } \\
\hline & & M. nasuta & N. virens \\
\hline Benzene Hexachloride $(\mathrm{BHC})(\mathrm{a})$ & 0.3 & 0.00096 & $U(b)$ \\
\hline Chlordane & 0.3 & $\mathrm{U}$ & $\mathrm{U}$ \\
\hline DDT + DDE & 5.0 & 0.0055 & 0.001038 \\
\hline Dieldrin + Aldrin & 0.3 & 0.00224 & 0.002309 \\
\hline Endrin & 0.3 & $\mathrm{U}$ & $U$ \\
\hline Heptachlor + Heptachlor Epoxide & 0.3 & $U$ & $\mathbf{U}$ \\
\hline Toxaphene & 5.0 & U & $\mathrm{U}$ \\
\hline PCBs & 2.0 & 0.00040 & U \\
\hline $\begin{array}{l}\text { (a) Total BHCs (alpha-, beta-, delta } \\
\text { (b) U Undetected at or above det }\end{array}$ & $\begin{array}{l}\text { nd gamma-BHC). } \\
\text { on limit. }\end{array}$ & & \\
\hline
\end{tabular}

by $N$. virens exposed to UIH COMP, but there was no other instance of butyltin bioaccumulation in either species.

Bioaccumulation of 4,4'-DDD and dieldrin by $M$. nasuta and $N$. virens exposed to SF, SFW, and UIH COMPs was both statistically significant and of high magnitude. Both species accumulated 4,4'-DDE from SF COMP at high magnitudes. M. nasuta also bioaccumulated significant 4,4'-DDE from SFW COMP, and $N$. virens bioaccumulated significant 4,4'-DDE from UIH COMP. Significant bioaccumulation of PAHs at moderate magnitude occurred in M. nasuta and $N$. virens exposed to SFW COMP relative to R-AM. There are few instances of PAH bioaccumulation relative to R-AM despite high concentrations of PAHs in tissues of $M$. nasuta and $N$. virens exposed to SF, SFW, and UIH COMPs. This is because the R-AM sediment had high concentrations of PAHs (Table R.2).

\section{R.5 CONCLUSIONS}

In this appendix, comparisons of Richmond Harbor Deepening dredged material and the Intensive Study of the Tuming Basin dredged material with the Alcatraz Environs Reference Area are provided to evaluate the acceptability of this sediment for in-bay disposal. For each test treatment, sediment contaminant levels, contribution to acute toxicity, either as water column effect or deposited sediment effect, and potential for bioaccumulation are shown in Table R.13 and Figure R.2. The matrix in Figure R.2 is a summary of sediment chemistry, acute toxicity, and bioaccumulation potential for the test treatments from the Deepening Project relative only to the Alcatraz Environs Reference Area, R-AM. For the bioaccumulation potential, the matrix shows the 
TABLE R.11. Mean Values of Contaminants Detected in Tissues of M. nasuta Exposed to Richmond Harbor Deepening Composites (bold type indicates value is statistically significantly greater than R-AM when compared by Dunnett's Test; box indicates value is $>2$ times but $\leq 5$ times $R$-AM; shaded box indicates value is $>5$ times but $\leq 10$ times $R$-AM; shaded double-lined box indicates value is $>10$ times $R$-AM)

S SF SFW UIH TBUpper TB Lower OBM

\section{PAHs, $\mu \mathrm{g} / \mathrm{kg}$ dry weight}

R-AM

COMP

COMP

COMP

COMP

COMP

COMP

$\mathrm{C}-\mathrm{SB}(\mathrm{a})$

Background(a)

Naphthalene

Acenaphthylene

Acenaphthene

Fluorene

Phenanthrene

Anthracene

Fluoranthene

Pyrene

\section{Benzo(a)anthracene}

Chrysene 393

Benzo(b)fluoranthene 276

Benzo(k)fluoranthene

Benzo(a)pyrene

Indeno(1,2,3-cd)pyrene

Benzo(g,h,i)perylene

14.0
13.4
10.4
23.1
149
91.8
578
628
269
393
276
111
252
101
130

$\begin{array}{lr}11.9 & 33.5 \\ 7.57 & \cup(c) \\ 7.26 & 8.79 \\ 12.7 \cup & 54.2 \\ 11.8 & 74.7 \\ 27.4 & 562 \\ 75.7{ }^{\circ}(\theta) & 673 \\ 131 & 732 \\ 42.0 & 165 \\ 45.9 & 136 \\ 306 & 303 \\ 113 & 107 \\ 171 & 185 \\ 57.4 & 51.2 \\ 65.8 & 78.6\end{array}$

10.8

$0.8 \quad 16.8$

$7.63 \mathrm{U}$

13.9

12.5

26.8

$72.4^{\circ}$

170

$32.1 \mathrm{~B}$

39.2

198

74.7

116

53.1

74.9

Phthalales, $\mu \mathrm{g} / \mathrm{kg} \mathrm{dn} / \mathrm{weight}$

Diethyl Phthalate

Di-n-butyl Phthalate

492

Butylbenzyl Phihalate

266

Bis(2-ethylhexyl) Phthalate

$\begin{array}{lllr}288 \text { B } & 257 & 235 & 888 \\ 253 & 358 & 357 & 368 \\ 575 & 493^{\circ} & 705 & 694 \\ 859 & 810 & 906 & 1020\end{array}$

943

906

1020
16.8

11.9

$7.53 \mathrm{U}$

NA(b) $\quad 10.8$

9.82

12.4

$7.14 \mathrm{U}$

$21.3 \mathrm{U}$

$12.6 \mathrm{U}$

14.1

8.31

20.6

$30.0^{*}$

13.2

$10.9 \mathrm{~B}$

12.7

22.3

13.2

$20.8^{*}$

$\begin{array}{lllll}43.5 & 26.0 & \text { NA } & 19.5 \mathrm{U} & 33.7\end{array}$

$\begin{array}{lllll}54.4 & 24.1 & \text { NA } & 46.8 & 29.6\end{array}$

NA $\quad 5.91 \mathrm{U}$

8.56

NA $\quad 5.99$

9.61

NA $\quad 10.0 \quad 14.1 \mathrm{U}$

NA $\quad 9.37 \quad 23.9 \mathrm{~B}$ (d)

NA

NA $\quad 478^{\circ} \quad 72.8^{\circ}$

NA $\quad 8.49 \mathrm{U} \quad 46.6{ }^{*} \mathrm{~B}$

NA $\quad 12.3 \mathrm{~B} \quad 13.5 \mathrm{~B}$

$\begin{array}{lll}\text { NA } & 15.1 & 23.0 \mathrm{~B}\end{array}$

NA $\quad 24.5^{\circ} \quad 29.5^{\circ} \mathrm{B}$

NA $\quad 12.3 \quad 25.4$

NA $\quad 18.6^{\circ} \quad 26.2^{\circ} \mathrm{B}$

NA

46.8

29.6

233
256
556
757

$\begin{array}{lll}\text { NA } & 188 & 210 \\ \text { NA } & 144 \mathrm{U} & 207 \\ \text { NA } & 798^{\circ} & 204 \mathrm{U} \\ \text { NA } & 845^{\circ} & 502\end{array}$


TABLE R.11. (contd)

\begin{tabular}{|c|c|c|c|c|c|c|c|c|c|}
\hline Analyte & R-AM & $\begin{array}{c}\mathrm{SF} \\
\mathrm{COMP}\end{array}$ & $\begin{array}{l}\text { SFW } \\
\text { COMP }\end{array}$ & $\begin{array}{c}\text { UIH } \\
\text { COMP } \\
\end{array}$ & $\begin{array}{l}\text { TB Upper } \\
\text { COMP }\end{array}$ & $\begin{array}{l}\text { TB Lower } \\
\text { COMP }\end{array}$ & $\begin{array}{c}\text { OBM } \\
\text { COMP }\end{array}$ & C-SB(a) & $\begin{array}{c}\text { M. nasuta } \\
\text { Background(a) }\end{array}$ \\
\hline \multicolumn{10}{|c|}{ Pesticides/PCBs. $\mu \mathrm{g} / \mathrm{kg}$ dry weight } \\
\hline $\begin{array}{l}\text { bela } B H C \\
\text { delta } B H C \\
\text { gamma } B H C\end{array}$ & $\begin{array}{l}2.7 U \\
2.7 U \\
1.3 U\end{array}$ & $\begin{array}{l}2.3 \mathrm{U} \\
2.3 \mathrm{U} \\
1.1 \mathrm{U}\end{array}$ & $\begin{array}{l}2.6 \mathrm{U} \\
2.6 \\
1.7\end{array}$ & $\begin{array}{l}2.7 \\
2.4 \mathrm{U} \\
1.2 \mathrm{U} \\
\end{array}$ & $\begin{array}{l}3.8 \mathrm{U} \\
3.8 \mathrm{U} \\
1.8 \mathrm{U}\end{array}$ & $\begin{array}{l}2.7 U \\
2.7 U \\
1.3 U\end{array}$ & $\begin{array}{l}3.6 \mathrm{U} \\
3.6 \mathrm{U} \\
1.8 \mathrm{U}\end{array}$ & $\begin{array}{l}1.8 U \\
1.8 U \\
0.94\end{array}$ & $\begin{array}{l}2.6 U \\
2.6 U \\
1.2 U\end{array}$ \\
\hline $4,4^{\prime}-\mathrm{DDD}$ & $2.5 \mathrm{U}$ & 489 & 543 & 182 & $3.6 \mathrm{U}$ & $2.5 U$ & $3.4 \mathrm{U}$ & $1.7 \mathrm{U}$ & $2.4 U$ \\
\hline $4,4^{\prime}-\mathrm{DDE}$ & 2.06 & 112 & 329 & $0.7 \mathrm{U}$ & 2.68 & $0.6 \mathrm{U}$ & $1.0 \mathrm{U}$ & $0.5 \mathrm{U}$ & 2.9 \\
\hline $4,4^{\prime}-\mathrm{DDT}$ & 5.3 & $1.6 \mathrm{U}$ & $1.8 \mathrm{U}$ & $1.7 \mathrm{U}$ & 3.5 & $1.9 \mathrm{U}$ & $2.6 U$ & $1.3 \mathrm{U}$ & 17 \\
\hline Dieldrin & $1.7 U$ & 51.0 & 118 & 29.5 & $2.5 \mathrm{U}$ & $1.7 U$ & $2.3 \mathrm{U}$ & $1.2 U$ & $1.6 \mathrm{U}$ \\
\hline $\begin{array}{l}\text { Endosulfan I } \\
\text { Aroclor } 1254\end{array}$ & $\begin{array}{c}2.7 U \\
140 U\end{array}$ & $\begin{array}{r}2.5 \\
160 U\end{array}$ & $21.6 U$ & $\begin{array}{l}2.7 \\
140\end{array}$ & $\begin{array}{l}3.8 \mathrm{U} \\
140 \mathrm{U}\end{array}$ & $\begin{array}{c}2.7 \mathrm{U} \\
150 \mathrm{U}\end{array}$ & $\begin{array}{l}3.6 U \\
150 U\end{array}$ & $\begin{array}{c}1.8 \mathrm{U} \\
150 \mathrm{U}\end{array}$ & $\begin{array}{l}2.6 \mathrm{U} \\
140 \mathrm{U}\end{array}$ \\
\hline \multicolumn{10}{|c|}{ Metals. mg/kg dny weight } \\
\hline $\begin{array}{l}\text { Silver } \\
\text { Arsenic } \\
\text { Cadmium } \\
\text { Chromium } \\
\text { Copper } \\
\text { Mercury } \\
\text { Nickel } \\
\text { Lead } \\
\text { Selenium } \\
\text { Zinc }\end{array}$ & $\begin{array}{c}0.241 \\
22.8 \\
0.209 \\
1.50 \\
12.6 \\
0.095 \\
3.22 \\
1.76 \\
1.57 \\
99.0\end{array}$ & $\begin{array}{c}0.216 \\
24.7 \\
0.202 \\
1.99 \\
12.8 \\
0.060 \\
3.86 \\
2.11 \\
1.69 \\
107\end{array}$ & $\begin{array}{c}0.192 \\
27.1 \\
0.199 \\
2.10 \\
11.3 \\
0.076 \\
3.68 \\
2.30 \\
1.79 \\
110\end{array}$ & $\begin{array}{c}0.183 \\
20.8 \\
0.183 \\
2.05 \\
12.4 \\
0.063 \\
3.66 \\
2.11 \\
1.66 \\
93.9\end{array}$ & $\begin{array}{c}0.196 \\
22.8 \\
0.200 \\
2.21 \\
15.1 \\
0.084 \\
4.09 \\
1.57 \\
1.65 \\
105\end{array}$ & $\begin{array}{c}0.197 \\
23.4 \\
0.210 \\
2.04 \\
11.5 \\
0.062 \\
4.90 \\
1.24 \\
1.57 \\
96.6\end{array}$ & $\begin{array}{l}\text { NA } \\
\text { NA } \\
\text { NA } \\
\text { NA } \\
\text { NA } \\
\text { NA } \\
\text { NA } \\
\text { NA } \\
\text { NA } \\
\text { NA }\end{array}$ & $\begin{array}{c}0.183 \\
24.2 \\
0.178 \\
1.54 \\
12.4 \\
0.051 \\
3.02 \\
1.34 \\
1.65 \\
89.4\end{array}$ & $\begin{array}{c}0.492 \\
31.2 \\
0.254 \\
1.12 \\
15.1 \\
0.063 \\
2.62 \\
1.34 \\
1.79 \\
107\end{array}$ \\
\hline \multicolumn{10}{|c|}{ Butyllins, $\mu \mathrm{g} / \mathrm{kg}$ dry weight } \\
\hline $\begin{array}{l}\text { Tributyltin } \\
\text { Dibutyltin }\end{array}$ & $\begin{array}{l}27.6 \\
10.5\end{array}$ & $\begin{array}{l}23.5 \\
11.8\end{array}$ & $\begin{array}{c}11.5 \\
9.30\end{array}$ & $\begin{array}{l}17.2 \\
10.4\end{array}$ & $\begin{array}{l}8.73 \\
9.44 U\end{array}$ & $\begin{array}{l}9.05 \\
12.0\end{array}$ & $\begin{array}{l}13.6 \\
10.9\end{array}$ & $\begin{array}{l}10.8 \\
10.1\end{array}$ & $\begin{array}{c}4.31 \\
10.3\end{array}$ \\
\hline $\begin{array}{l}\text { (a) Treatmen } \\
\text { (b) NA Not a } \\
\text { (c) U Undete } \\
\text { (d) B All repli } \\
\text { (e) Ion ratio }\end{array}$ & $\begin{array}{l}\text { n Dunnett's } \\
\text { cates; value } \\
e<5 \text { times } \\
\text { ation ion ur }\end{array}$ & $\begin{array}{l}\text { Test data se } \\
\text { is mean of } \\
\text { e amount d } \\
\text { letected in }\end{array}$ & $\begin{array}{l}\text { An weight de } \\
\text { etected in th } \\
\text { all replicates. }\end{array}$ & $\begin{array}{l}\text { tection limit } \\
\text { e associate }\end{array}$ & d method bl & & & & \\
\hline
\end{tabular}




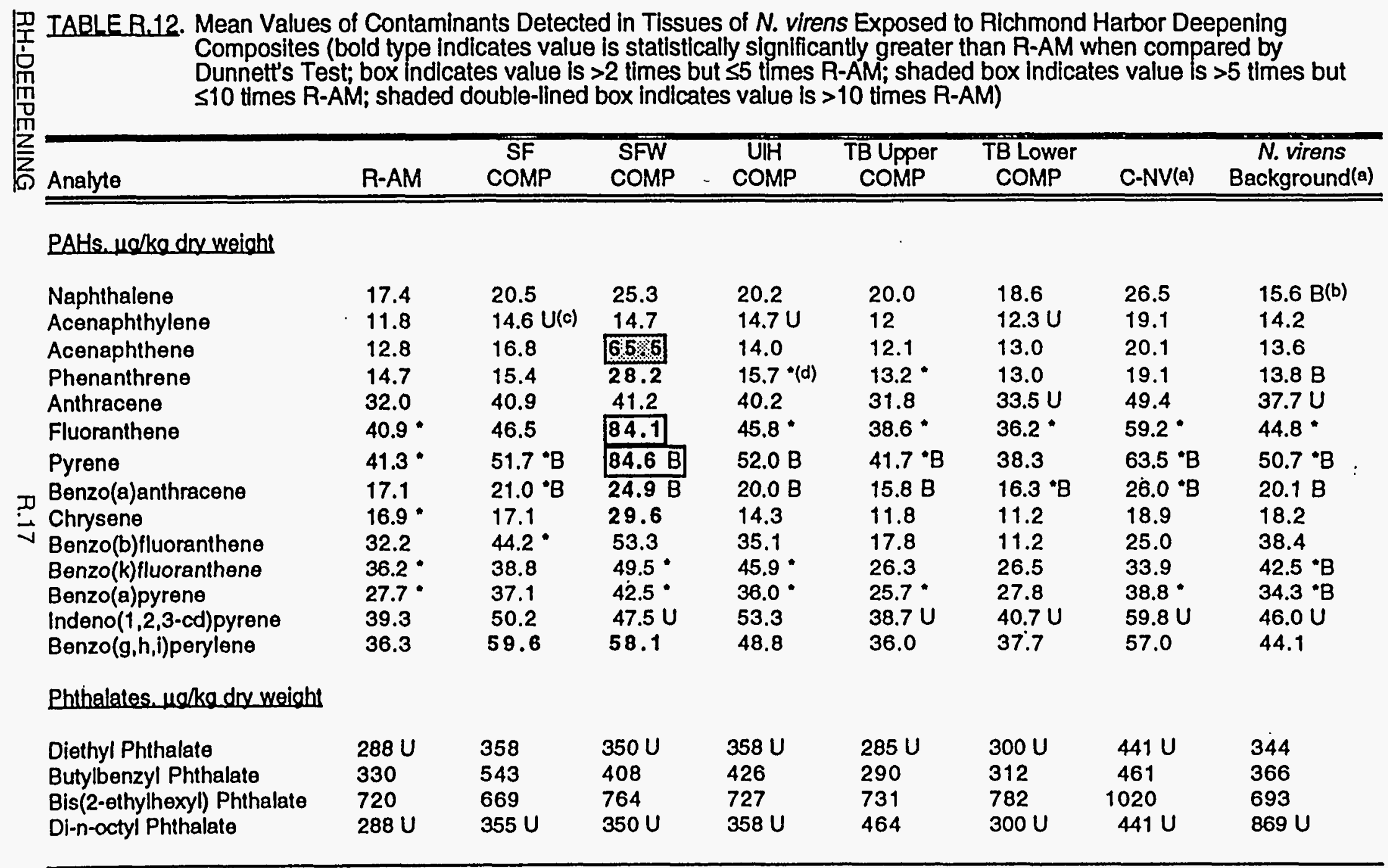




\begin{tabular}{|c|c|c|c|c|c|c|c|c|}
\hline & & & IABLE & 2. (contd) & & & & \\
\hline Analyte & R-AM & $\begin{array}{c}\mathrm{SF} \\
\text { COMP }\end{array}$ & $\begin{array}{l}\text { SFW } \\
\text { COMP }\end{array}$ & $\begin{array}{l}\text { UIH } \\
\text { COMP }\end{array}$ & $\begin{array}{l}\text { TB Upper } \\
\text { COMP }\end{array}$ & $\begin{array}{l}\text { TB Lower } \\
\text { COMP }\end{array}$ & $C-N V(a)$ & $\begin{array}{c}\text { N. virens } \\
\text { Background (a) }\end{array}$ \\
\hline \multicolumn{9}{|c|}{ Pesticides/PCBs $\mu g / k e$ dr wejght } \\
\hline Aldrin & 4.50 & 2.47 & 8.92 & $1.64 \mathrm{U}$ & $1.32 \mathrm{U}$ & $1.36 \mathrm{U}$ & 5.78 & 9.82 \\
\hline $4,4^{\prime}-D D D$ & $3.36 \mathrm{U}$ & 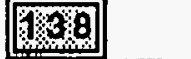 & 378 & $58 \%$ & $3.34 \mathrm{U}$ & $3.52 \mathrm{U}$ & $5.18 \mathrm{U}$ & $3.96 \mathrm{U}$ \\
\hline $4,4^{\prime}-\mathrm{DDE}$ & $1.00 \mathrm{U}$ & $9 \% 7 \%$ & $1.22 \mathrm{U}$ & 4.32 & $1.04 \mathrm{U}$ & $1.06 \mathrm{U}$ & $1.58 \mathrm{U}$ & 4.13 \\
\hline $4,4^{\prime}-\mathrm{DDT}$ & 18.5 & 37.6 & 34.4 & 23.8 & 8.18 & 13.3 & 23.9 & $2.98 \mathrm{U}$ \\
\hline Dieldrin & 3.74 & [4\%606 & 950 & 2809 & 3.10 & $2.36 U$ & 5.05 & $2.64 \mathrm{U}$ \\
\hline \multicolumn{9}{|c|}{ Metals. ma/kg dry weight } \\
\hline Silver & 0.299 & 0.303 & 0.309 & 0.295 & 0.348 & 0.174 & 0.251 & 0.246 \\
\hline Arsenic & 15.9 & 14.3 & 14.8 & 14.6 & 14.6 & 14.7 & 16.6 & 15.5 \\
\hline Cadmium & 0.361 & 0.331 & 0.347 & 0.367 & 0.364 & 0.326 & 0.298 & 0.293 \\
\hline Chromium & 1.51 & 1.35 & 0.997 & 0.930 & 1.25 & 1.62 & 0.898 & 9.37 \\
\hline Copper & 10.9 & 11.0 & 10.6 & 10.8 & 10.5 & 11.0 & 8.95 & 13.7 \\
\hline Mercuny & 0.246 & 0.213 & 0.217 & 0.229 & 0.231 & 0.211 & 0.202 & 0.218 \\
\hline Nickel & 1.70 & 1.70 & 1.62 & 1.56 & 2.17 & 3.53 & 1.13 & 3.86 \\
\hline $\begin{array}{l}\text { Lead } \\
\text { Selenium }\end{array}$ & $\begin{array}{l}0.878 \\
2.02\end{array}$ & $\begin{array}{l}1.03 \\
1.88\end{array}$ & $\begin{array}{l}1.02 \\
1.84\end{array}$ & $\begin{array}{l}0.900 \\
1.93\end{array}$ & $\begin{array}{l}1.04 \\
2.03\end{array}$ & $\begin{array}{l}0.912 \\
1.91\end{array}$ & $\begin{array}{l}0.911 \\
1.81\end{array}$ & $\begin{array}{l}1.03 \\
2.13\end{array}$ \\
\hline Zinc & 151 & 270 & 197 & 200 & 240 & 177 & 214 & 208 \\
\hline \multicolumn{9}{|c|}{ Butyilins, $\mu \alpha / k g$ dn weight } \\
\hline Tributyltin & $3.54 U$ & 3.90 & 3.91 & $3.60 \mathrm{U}$ & 3.70 & $3.64 \mathrm{U}$ & $3.57 U$ & $3.44 \mathrm{U}$ \\
\hline Dibutyltin & 10.7 & 16.0 & 11.1 & 20.7 & 10.9 & 11.0 & 15.1 & $9.96 U$ \\
\hline Monobutyltin & $2.87 U$ & $2.89 \mathrm{U}$ & $2.96 \mathrm{U}$ & $2.92 \mathrm{U}$ & 3.35 & $2.96 \mathrm{U}$ & $2.90 \mathrm{U}$ & $2.79 \mathrm{U}$ \\
\hline \multicolumn{9}{|c|}{$\begin{array}{l}\text { (a) Treatment not included in Dunnett's Test data set. } \\
\text { (b) B All replicate values are <5 times the amount detected in the associated method blank. } \\
\text { (c) U Undetected in all replicates; value is mean of dry weight detection limits. } \\
\text { (d) - Ion ratio out or confirmation ion undetected in all replicates. }\end{array}$} \\
\hline
\end{tabular}




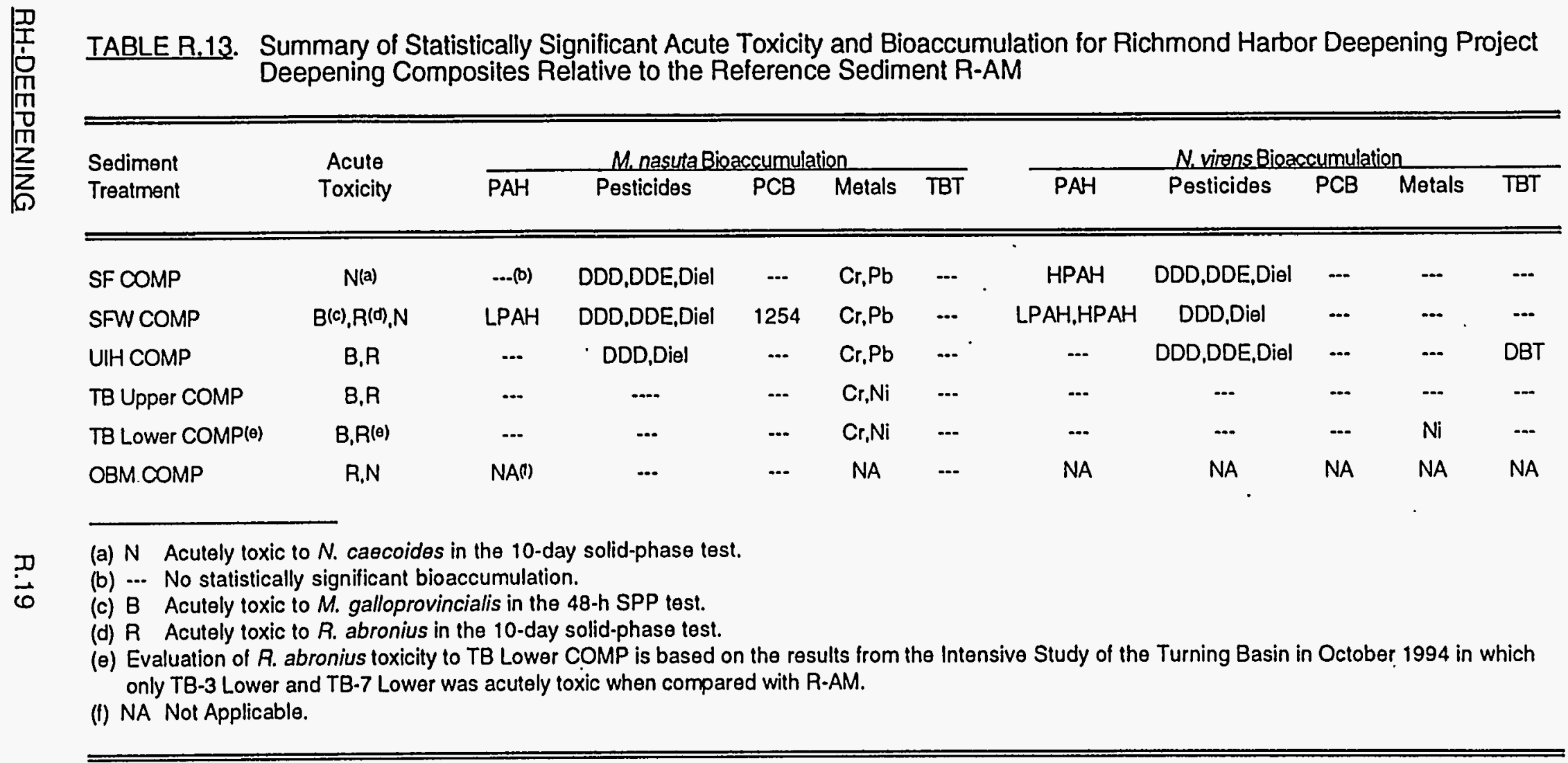




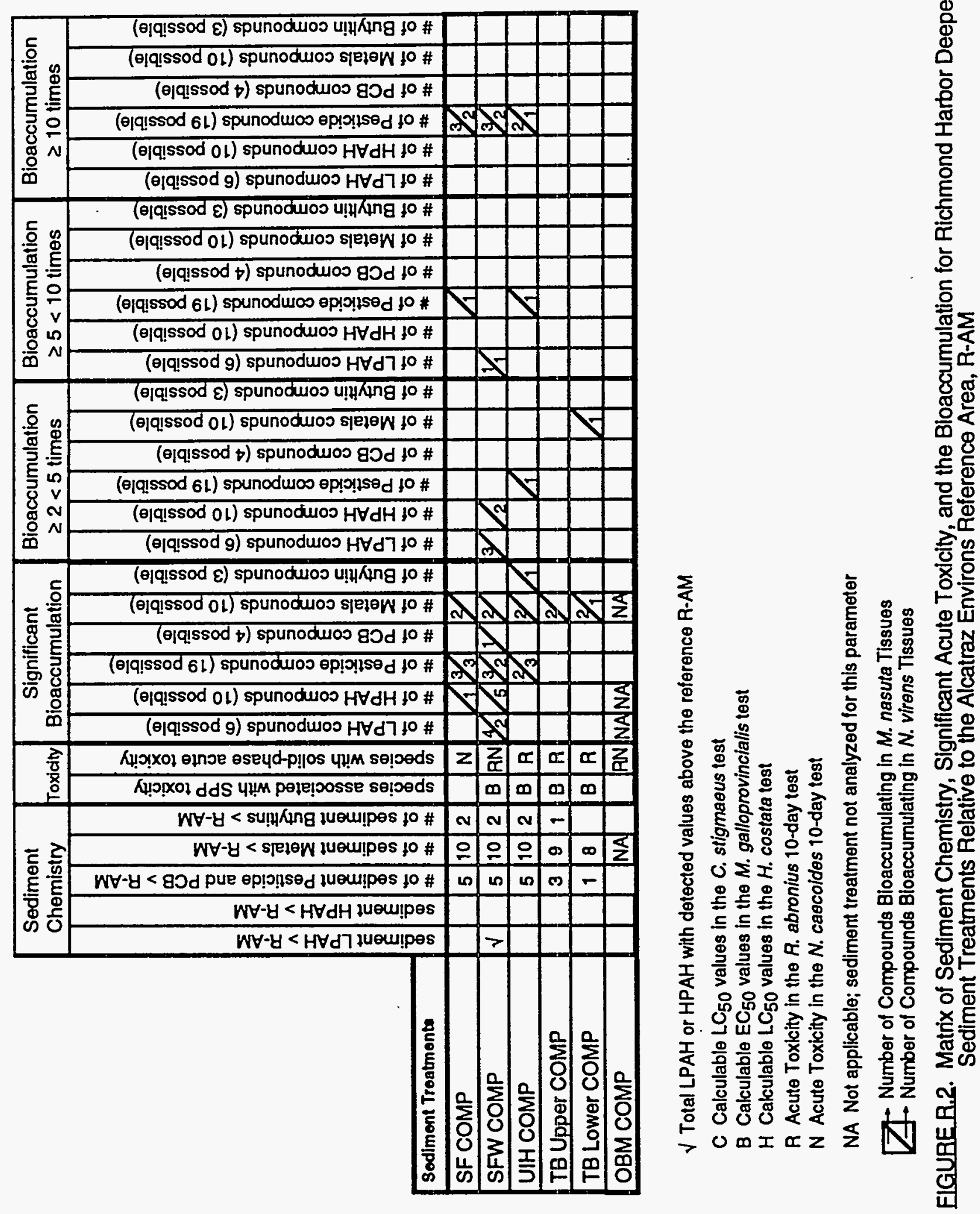


number of contaminants in $M$. nasuta and $N$. virens that were elevated above a range of magnitudes $(2,5$, and 10 times R-AM) and cases in which similar classes of contaminants were accumulated by both species. This summary is intended to assist USACE, EPA, and other resource agencies in evaluating the potential effects of in-bay disposal of dredged material from Richmond Harbor. 


\section{DISTRIBUTION}

No. of

Copies

OFFSITE

2 DOE/Office of Scientific and Technical Information

2 N. Chan/Gene Serex Port of Richmond 1411 Harbour Way South P.O. Box 4046 Richmond, CA 94804

15 R. Chisholm U.S. Army Corps of Engineers San Francisco District 211 Main Street San Francisco, CA 94105

T. Gandesbery California Regional Water Quality Control Board

San Francisco Bay Region

2101 Webster Street, Suite 500

Oakland, CA 94612

J. Harari

U.S. Army Corps of Engineers

San Francisco District

211 Main Street

San Francisco, CA 94105

C. R. Lee

U.S. Army Engineer Waterways

Experiment Station

3909 Halls Ferry Road

Vicksburg, MS 39180-6199

2 B. Ross/Erica Hoffman

U.S. Environmental Protection Agency

Region IX

75 Hawthorne Street

San Francisco, CA 94105-3901
No. of

Copies

ONSITE

DOE Richland Operations Office

P.W. Kruger

A5-54

22 Pacific Northwest Laboratory
B. A. Barbo (2)
L. M. Karle
H. L. Mayhew
N.P Kohn
P. J. White
M. R. Pinza (10)
J. Q. Word (5)
SEQUIM
SEQUIM
SEQUIM
SEQUIM
SEQUIM
SEQUIM
SEQUIM

Routing
R. W. Bryce
R. M. Ecker
S. A. Rawson
R. L. Skaggs
P. C. Hays (last)
K6-96
SEQUIM
K9-34
K9-34
K9-41 